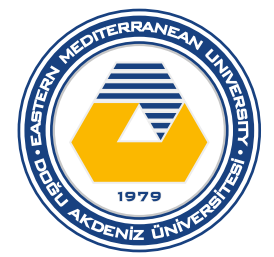

Eastern

Mediterranean

University

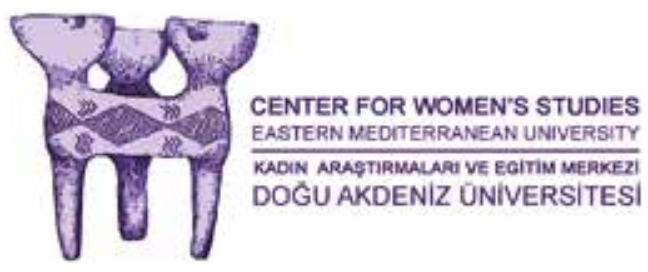

\title{
Proceedings Book
}

\section{$7^{\text {th }}$ International Conference on Gender Studies}
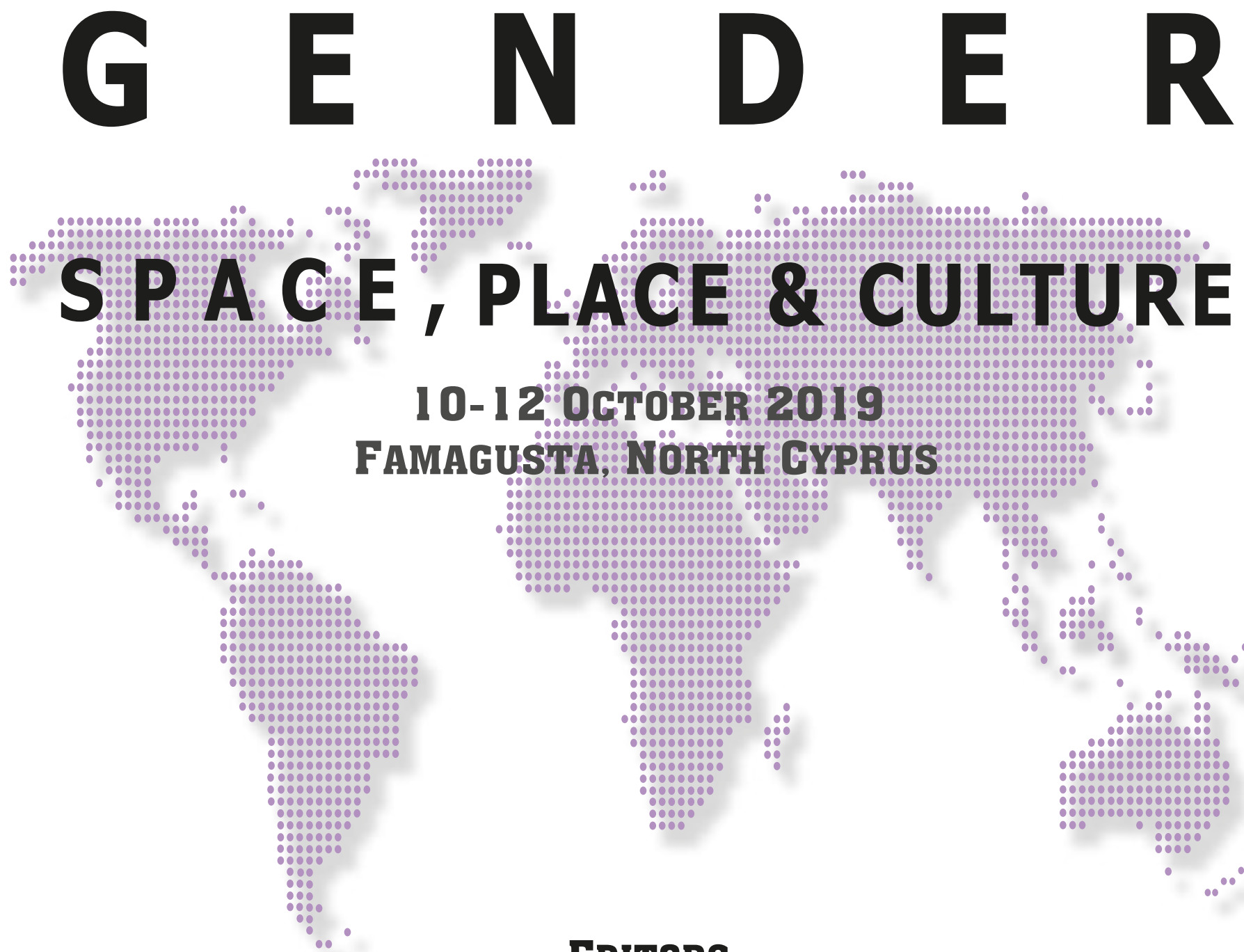

10-12:0GTOBER:201\%

AMAGUSTA:, NORTHEYPRUS

\section{SÜHEYLA ÜÇIŞIK ERBILEN - KAĞAN GÜNÇE}

EDITORS 


\title{
Gender, Space, Place \& Culture
}

\author{
7. International Conference on Gender Studies
}

\author{
Toplumsal Cinsiyet, Yer, Mekân \& Kültür
}

7. Uluslararası Toplumsal Cinsiyet Çalışmaları Konferansı

Conference Proceedings Book

Konferans Bildiri Kitabı

Famagusta, North Cyprus - October 10 - 12, 2019

Gazimağusa, Kuzey Kıbrıs - Ekim 10 - 12, 2019

Printed in North Cyprus by the Eastern Mediterranean University Printinghouse - Doğu Akdeniz Üniversitesi Yayınevi tarafından basılmıştır. 
Editors - Editörler

\title{
Süheyla ÜÇIŞIK ERBILEN - Kağan GÜNÇE
}

\author{
Eastern Mediterranean University - Doğu Akdeniz Üniversitesi \\ Center for Women's Studies - Kadın Araştırmaları ve Eğitimi Merkezi \\ e-ISBN: 978-605-9595-30-8
}


CONTENTS - İÇINDEKİLER

CONTENTS - İÇINDEKILER

INTRODUCTION

ÖNSÖZ

ARTICLES IN ENGLISH - INGILIZCE MAKALELER

Alican ERALP

IS THERE ANY HOME? THE OPPORTUNITIES AND PITFALLS OF PRESENCE IN LGBT + VENUES

Aminu Ahmad HALIRU \& Desy Osondu EZE

SEMIOLOGY AND ARCHITECTURE: THE SEXUAL SEMIOLOGY OF SPACE

Armağan GÜLHAŞ

QUEERING THE FORMAL ARCHITECTURE

Burkay PASIN

PRIVACY, PLEASURE AND HOMOSOCIABILITY: GENDERING OF VICTORIAN TURKISH BATHS

Christiana Ngozi EMENTA

GENDER DISPARITY IN ENROLLMENT AND ACADEMIC PERFORMANCE OF SECONDARY SCHOOL STUDENTS IN COMMERCE IN ANAMBRA STATE, NIGERIA

Demet BAYAR KILIÇARSLAN \& Zeynep ULUDAĞ

URBAN SPATIAL PRACTICES OF THREE GENERATIONS OF WOMEN

95

Duru Başak UĞURLU

BEING A WOMAN IN MASCULINE PLACES: NARGILE CAFE EXPERIENCES OF WOMEN

Elif MADAKBAŞ GÜLENER

PRIVACY AS AN OPTIONAL SUBSET OF THE PRIVATE SPHERE: "HOME” IN IRIS M. YOUNG'S POLITICAL THEORY

Elif ŞEŞEN \& Duygu ÜNALAN

FEMININITY AND MASCULINITY IN TWITTER SHARINGS ABOUT VIOLENCE AGAINST WOMEN IN THE SAMPLE OF SILA AND AHMET KURAL

Emine ATASOYLU \& Işıl Nurdan IŞIK

OCCUPATIONAL SAFETY AND HEALTH LEGISLATION: EMPLOYMENT EQUALITY

CAUSING PROTECTION INEQUALITY OF WOMEN AT WORK

\section{Erzsébet TATAI}

WOMEN'S SPACES IN CONTEMPORARY ART IN CENTRAL EUROPE. CASE STUDY: INSTALLATIONS OF ILONA NÉMETH 
Feyza AK AKYOL

SCHOOL AS A REPRODUCTION PLACE OF GENDER INEQUALITY IN LANGUAGE

Fezarenç VARAN

A COUNTER LANGUAGE: USE OF HUMOUR IN WOMEN'S MARCHES IN TURKEY

Gülșen DİŞLi

AN ANALYSIS OF GENDERING OF SPACE IN HISTORICAL HOSPITALS OF ANATOLIA

Ievgeniia LYSETSKA \& Naciye KUNT

FEMALE TEACHERS' EXPLICIT BELIEFS ABOUT LANGUAGE TEACHING, LEARNING AND RACE

John Peter WAPPA \& Naciye KUNT

GENDER, EQUITY, SOCIAL JUSTICE AND BELIEFS IN FOREIGN LANGUAGE LEARNING: THE CASE OF GRADUATE STUDENTS

Leila SABOKKHIZ \& Canan GÜLCAN

THE EFFECT OF MINIMUM WAGE AND SOCIAL ALLOWANCE POLICIES ON FEMALE EMPLOYMENT IN TURKEY

\section{Müge KATIRCI}

TO ENJOY THE BEST OF TWO SPACES: RECLAIMING OUR BODIES AND KITCHENS WITH HOME-MADE SEX HORMONES

Nagehan VANLIOĞLU YAZICI \& İnci BASA

SOCIO-SPATIAL CONSTRUCTION OF GENDER IN THE CITY, THE CASE OF RIZE, TURKEY

\section{Nezahat DOĞAN}

DOES GENDER EQUALITY IN EDUCATION MATTER FOR AIR POLLUTION IN SUB-

SAHARAN AFRICA?

Nurhan OTO \& Ferhan KUYUCAK ŞENGÜR

GENDER BALANCE FOSTERING IN TURKISH CIVIL AVIATION WITHIN THE CONTEXT OF SUSTAINABLE AVIATION

\section{Özlem ATAY}

PERCEPTIONS OF TURKISH WOMEN IN SENIOR MANAGEMENT ON VALUE BASED MANAGEMENT

Özlem TÖREN \& Evrim TÖREN

EXAMINATION OF HOFSTEDE'S MASCULINITY-FEMININITY DIMENSION IN FOUR POLITICIANS' SPEECHES AT THE G20 SUMMIT IN 2018

\section{Sena IŞIKLAR BENGİ \& A.Yağmur TOPRAKLI}

THE POST OCCUPANCY EVALUATION OF COMFORT CONDITIONS ACCORDING TO GENDER: AHMET HAMDİ AKSEKİ MOSQUE EXAMPLE 
Şenay Sahil ERTAN \& Gözde INAL CAVLAN

INVESTIGATING THE GLASS CEILING PHENOMENON: FROM A SOCIETAL PERSPECTIVE

ARTICLES IN TURKISH - TÜRKÇE MAKALELER

Ayşe Aslı SEZGín \& Tuğba YOLCU

TURKEY ON THE MAP OF GENDER AND THE DIGITAL PARTICIPATION: DIFFERENT DIMENSIONS OF INEQUALITY

Beste ÖZDA $\breve{G}$

GENDER INEQUALITY AND SPACE RELATIONSHIP IN MOVIES: MUSTANG MOVIE REVIEW

Faruk ALAEDDINOĞLU \& Nuray TÜRKER \& Avşin Ayhan KAYA

TURKEY'S PERSPECTIVE OF INTERNATIONAL FEMALE TRAVELERS

Fatma DEMIR

PROMOTING GENDER EQUALITY IN EDUCATION AND THE WORKPLACE

Hakan BİLGEÇ

WOMEN IN BUSINESS LIFE IN THE $20^{\mathrm{TH}}$ CENTURY OTTOMAN EMPIRE: A CASE ANALYSIS

Hiclâl DEMİR

“DARKNESS OF COPY” LOST TIME IN “THE TALE OF COPY”

\section{Hülya BULUT}

HOW CAN THIS HEART FORGET YOU? AN UNBREAKBLE (UNBROKEN) PEN:

HALIDE EDIP ADIVAR

Mürüde ÖZEN SEVİNÇ

MASCULINITY REPRESENTATIONS IN NORTHERN CYPRUS ADVERTISING: 'NEYDI OLACAGI' FIELD STUDY

Nuray TÜRKER \& Sibel AYYILDIZ

GENDER DIFFERENCES IN FOOD CONSUMPTION: A STUDY ON DOMESTIC TOURISTS

\section{Nazime BEYSAN}

THE LANDMARK JUDGEMENT ABOUT DOMESTIC VIOLENCE AGAINST WOMEN: OPUZ V. TURKEY AND LEGAL RESPONSIBILITIES OF STATE

Pakize KUTLU \& Muallâ KÖSEOĞLU

SOCIAL WORK STUDENTS' ATTITUDES TOWARDS LGBTI+ INDIVIDUALS IN TERMS OF SEX: SAMPLE OF TRNC 


\section{Seda AĞIRBAŞ}

NATURE AND WOMEN DESCRIPTIONS IN THE WORKS OF WOMEN PAINTERS OF PRE-RAPHAELITE MOVEMENT

Tuba KORKMAZ

AN INQUIRY ON THE CONCEPT OF MOTHERHOOD: 'MOTHER?' MIXED CERAMIC EXHIBITION EXAMPLE

Tülin URAL

LANDSCAPE AND GENDER IN TURKISH LITERATURE

\section{Ŭ̆urcan TAŞDELEN}

SPACE AND GENDER-ORIENTED DISCOURSE ANALYSIS OF THE TAHSIN YÜCEL'S NOVEL "MUTFAK ÇIKMAZI"

\section{Ulaş GÜNDÜZLER}

CONTRIBUTION OF EU LAW TO GENDER EQUALITY

\section{Zeynep Banu DALAMAN}

THE DEVELOPMENT OF ISLAMIST FEMINISM IN THE MIDDLE EAST: IRAN AND EGYPT CASES

\section{Zeynep Özlem ÜSKÜL ENGIN}

RECOGNIZING THE DATING VIOLENCE: A SOCIOLOGICAL RESEARCH IN LAW SCHOOL

\section{Zübeyde AKSAY}

INDIRECT SEX DISCRIMINATION IN THE WORKING LIFE UNDER THE FRAMEWORK OF THE PRECEDENTS OF THE EUROPEAN COURT OF JUSTICE 724

CALL FOR PAPERS - BİLDİRİ ÇAĞRISI 


\section{INTRODUCTION}

This conference book consists of selected articles from the $7^{\text {th }}$ International Conference on Gender Studies “Gender, Space, Place \& Culture.” The conference held in Famagusta, North Cyprus during October 10-12, 2019 by the Center for Women's Studies of the Eastern Mediterranean University, was the seventh international meeting on gender and women studies. The conference aimed to put forth how various disciplines such as geography, engineering, urban planning, history and sociology view gender, space and culture according to feminist perspectives and the conference brought many scientists, activists, and representatives from various disciplines together. Totally 165 reports were represented in English and Turkish and found the opportunity to be discussed comprehensively by participants from all over the world. Additionally, The conference hosted dear former rector of Istanbul Technical University(19942006) and the first president of European Women Rectors Association, Prof. Dr. Gülsün Sağlamer, and the lecturer from the faculty of language, history, and geography of Ankara University, Doç. Dr. M. Murat Yüceşahin, sharing their knowledge and experiences with the participants of the conference.

Besides oral presentations, there were also panels called Women in Academia, Kadın/Woman 2000 Journal: Gender and International Relations Special Issue, Masculinity in Advertisements, Stories of Women staggering sexist culture in law and the Transformation of Law.

The papers that were presented in the conference were evaluated by the Science Committee in accordance with the academic criterion determined by the Conference Organizing Committee. We would like to thank the members of the EMU-CWS Science Committee for their selfsacrificing work and help to compose this conference book. Although the members of the Science Committee have given many fruitful comments and suggestions about the papers, they 
have not seen them before the book was published. The ideas discussed in the contents of the papers belong to the writers and don't mirror the opinions of the Organizing Committee.

We would like to thanks to all members of the Science Committee and the Board Members of EMU-CWS, Prof. Dr. Fatma Güven Lisaniler, Prof. Dr. Ayşe Işık Gürşimşek, Yrd. Doç. Dr. Nazime Beysan, Yrd. Doç. Dr. Seda Orbay Yücel. On the other hand, we are grateful to our center's Research Assistant Ph.D. C., Bilcan Bladanlı Korkmazel and Student Assistants Gökçe Efe and Ayşegül Bedir for their priceless efforts from the beginning of the organization of the conference, until the publication of this book. Also, we would like to express our heartfelt thanks to all participants that contribute to sharing universal knowledge and development of scientific studies in our conference.

\section{Editors}

Assoc. Prof. Süheyla Üçıșık Erbilen

Eastern Mediterranean University

Center for Women's Studies - Chair

Faculty of Education

Famagusta, TRNC

\author{
Assoc. Prof. Kağan Günçe \\ Eastern Mediterranean University \\ Faculty of Architecture \\ Famagusta, TRNC
}




\section{ÖNSÖZ}

Bu konferans kitabı Toplumsal Cinsiyet, Mekân, Yer \& Kültür temalı 7. Uluslararası Toplumsal Cinsiyet Konferansında sunulan bildirilerden bir seçki sunmaktadır. Doğu Akdeniz Üniversitesi Kadın Araştırmaları ve Eğitim Merkezi (DAÜ-KAEM) tarafından Rauf Raif Denktaş Kongre ve Kültür Merkezi'nde 10-12 Ekim 2019 tarihleri arasında yapılan Konferans, Merkezin Toplumsal Cinsiyet Çalışmaları alanında gerçekleştirdiği 7. Uluslararası buluşmadır.

Konferansın temel amacı coğrafya, mimarlık, kent planlama, tarih ve sosyoloji gibi farklı disiplinlerin toplumsal cinsiyet, mekân, kültür kavramlarına feminist çerçeveden nasıl baktığına dair yeni araştırmaları ortaya koymaktır. Cinsiyet, mekân ve kültür üzerine çalışmalar yapan akademisyenler ve araştırmacılar, cinsiyet, mekân ve kültür arasındaki ilişkiyi, ortak yapılaşmasını sorgulamayı ve ortaya çıkarmayı hedeflemektedirler. 'Sosyal hayat için mekânsal ilişkiler temel taştır' söyleminin esas alan feministler tarafından geliştirilen mekânsal kavramlar ve yaklaşımlar, çeşitli disiplinlere yeni anlayışlar getirmektedir. $\mathrm{Bu}$ yaklaşımla konferansta, cinsiyet, mekân ve kültürün ortak yapılanması üzerinde durularak sosyal bilimlerdeki güncel değişiklikler ve yeni fikirler sunulmuştur.

Farklı ülkelerden bilim insanları, aktivistler, sivil toplum kuruluşlarından çok sayıda temsilcilerin bir araya geldiği ve deneyimlerin paylaşıldığı konferansta İngilizce ve Türkçe olmak üzere 165 bildiri sunulmuştur. Sunulan bildirilerin yanı sıra "Hukukta Cinsiyetçi Kültürü Sarsan Kadın Hikayeleri ve Hukukun Dönüşümü”, “Sinema ve Reklamlarda Erkeklik(ler)”, “Bu Dünyanın Yabancısı olmak", "Women in Academia," "Woman 2000 Gender and International Relations Special Issue” başlıklarını taşıyan beş de panel düzenlenmiştir. Konferansa davetli konuşmacı olarak katılan, İstanbul Teknik Üniversitesi'nin aynı zamanda Türkiye'nin ilk kadın Rektörü (1996-2004) ve Avrupa Kadın Rektörler Derneği’nin (EWORA) ilk başkanı, Prof. Dr. 
Gülsün Sağlamer ile Ankara Üniversitesi Dil ve Tarih Coğrafya Bölümü Öğretim Üyesi Doç. Dr. M. Murat Yüceşahin bilgi ve deneyimlerini katılımcılarla paylaşmışlardır.

Konferansta sunulan çalışmalara ilişkin bildiri özetleri, Konferans Düzenleme Kurulu tarafından belirlenmiş akademik kriterler ışığında farklı bakış açılarına sahip Bilim Kurulu Üyeleri’nin değerlendirmelerine sunulmuştur. Üyeler, özetler hakkında birçok değerli eleştiri ve öneri sunmuşturlar. Konferans kitabı içerisinde yer alan bildiriler, yazarlara ait görüşleri içermekte olup, Konferans'in gerçekleşmesinde yer alan kişi ve komitelerin görüşlerini yansıtmamaktadır. Konferans kitabında sunulan bildirilerin tam metinlerinden oluşan bir seçki yer almaktadir.

Oldukça verimli geçen ve faydalı bir paylaşım ortamı sağlayan, aynı zamanda toplumsal cinsiyet çalışmalarına ivme kazandıran Konferans'ın gerçekleşmesine katkıda bulunan Bilim Kurulu Üyelerine, KAEM Yönetim Kurulu üyeleri Prof. Dr. Fatma Güven Lisaniler, Prof. Dr. Ayşe Işık Gürşimşek, Yrd. Doç. Dr. Nazime Beysan, Yrd. Doç. Dr. Seda Orbay Yücel'e, öte yandan konferansın düzenlenmesindeki her aşamada yoğun bir çaba gösteren Merkez Araştırma Görevlisi Uzm.Bilcan Bladanlı Korkmazel ve Merkez Öğrenci Asistanlarımız Gökçe Efe ve Ayşegül Bedir'e fedakar çalışmalarından ötürü teşekkür ederiz aynı zamanda bizlerle birlikte olarak evrensel bilginin paylaşımında ve gelişimine bilimsel çalışmalarıyla katkıda bulunan bütün katılımcılara en içten teşekkürlerimizi sunarız.

\section{Editörler}

\section{Assoc. Prof. Süheyla Üçışık Erbilen}

Eastern Mediterranean University

Center for Women's Studies - Chair

Faculty of Education

Famagusta, TRNC
Assoc. Prof. Kağan Günçe

Eastern Mediterranean University

Faculty of Architecture

Famagusta, TRNC 


\section{ARTICLES IN ENGLISH - INGGILIZCE MAKALELER}




\title{
IS THERE ANY HOME? THE OPPORTUNITIES AND PITFALLS OF PRESENCE IN LGBT + VENUES
}

\author{
Alican ERALP1
}

\begin{abstract}
Family home might be the first place where LGBT+ individuals intensely experience pressure and various forms of violence. For many LGBT+ subjects, leaving home is a liberating action that opens a way for eliminating domestic violence and offers a resource for establishing/experiencing their identity. Since then, the spaces that queers can be "queer" starts to be formed for the LGBT+s and gay venues (e.g. gay bars) are one of the critical components of this transition. They offer adequate information related to identity diversity, relatively safer zones and a sphere to find oneself or others. It also can enable new forms of relations and a sense of belonging to a place.

However, there is still a risk that these venues can be repressive for several reasons that have similarities to the family home dynamics that put obstacles towards queer liberation. This study focuses on the opportunities and pitfalls of LGBT+ venues by comparison with the experience of the family home. I investigate the possibilities: Do these venues keep individuals away from oppression or do they become places where a different form of oppression emerges by expecting certain performances from their attendees similar to the inside home performance?

Furthermore, I inquiry whether the gay individuals associate these venues with the notion "home", or the people in the community with the notion "family". To be able to acquire these possibilities, the in-depth interviews have been conducted with LGBT+ persons $(n=13)$ who have experienced physical or digitally gay venues.
\end{abstract}

Keywords: LGBTI+ Venues, Gay Scene, Gay Community, Alternative Family, Coming-Out

\footnotetext{
${ }^{1}$ Graduate Student, Galatasaray University, Media and Communication Studies alicaneralp@gmail.com
} 


\section{Introduction}

John D’Emilio (1993) asserts in his article "Capitalism and gay identity" that capitalism has allowed homosexuals to leave the nuclear family, thus they could create an identity. Surely, D'Emilio does not suggest that no person in the past had sexual feelings towards same-sex one. He suggests that capitalism has led homosexuality to emerge as an identity for gays and lesbians to live with. Because homosexuality not only contains "same-sexual intercourse" but also it usually refers to a lifestyle. He indicates that the thing, that we call "homosexuality", has come into existence by crossing through the modern age. In accord with his opinion, the sale and purchase of labor-power give homosexuals a chance to leave home and become freer to identify themselves as gay or lesbian and build a lifestyle that reflects their identity.

Although D'Emilio examines how the change in modes of production provided a sphere to build an identity outside of the heterosexual family home, his article triggered me to follow another inquiry: Drawing upon this article, I deduce that the obstacles to creating an identity in the family home do not or exist to lesser extent outside of the home. Then, the action in the new zone established after immediately leaving the family house is a liberating experience. Is it true?

In this article, I investigated the differences between home and outside in terms of experiencing identity in both spaces, and I explore, if any, the potentials of gays' experience of the outside as a cure to family-related or home-related problems. Even though all sexual identity-based issues do not root in the experience of home and family, it is very usual that the family does not facilitate the transition process to adulthood of gay individuals (Johnston \& Valentine, 1995; D'Augelli et al., 1998; Valentine \& Skelton, 2003). I focused on gay venues as an out-home experience. The reason that I juxtaposed a gay venue with a family home is the opposite perceptions towards the possibilities of two spaces. Weston (1995) reveals that queers feel certain about that they are not the only ones, but others are somewhere not around the home: 
“'There must be not only someone like me but also someone out there somewhere. 'Like' others become spatially located at the very point a person enters the gay imaginary (...) From the start, then, the gay imaginary is spatialized, just as the nation is territorialized." (p. 261262)

The existence of gay venues opens a new door into participating in "gay imaginary". While the family environment does not usually offer support mechanisms, gay venues possess the potential to offer queer individuals a resource for developing an identity. These places might be very effective in finding oneself or others and adequate information about identity, and relatively safer zones. The most important benefit of these venues is that they offer a space where a gay can "be gay", and the gay is certainly sure that these performances are going to be acknowledged. In other words, to complete the identity, it must be "read and accepted" (Valentine \& Skelton, 2003: 854) by others, and gay venues provide a platform for them.

These venues have a constructive and restorative effect, nevertheless, they are not free from societal dynamics. Valentine \& Skelton (2003) properly summarize the opportunities and pitfalls of gay venues:

"On the one hand, it can be a positive, liberating and supportive space that offers a sense of identity, community, and belonging. On the other hand, it can simultaneously be a site of danger where young lesbians and gay men can encounter a range of social risks and be subject to abusive relationships and social exclusion. Vulnerable social groups are not just marginalized/oppressed, but can also marginalize and oppress each other.” (p.863)

I conducted interviews with the aim of comprehension of the complexity of the two atmospheres of home and gay scene: "What did gays experience at home, and what did they find outside?". To be able to understand the diversity of experiences, I conducted in-depth interviews with 13 persons who experienced physically and digitally being in gay venues. This sample consists of an age range from 21 and 40 and the participants live in İstanbul (9) and 
Athens (4). Out of 13, 11 participants describe his sexual orientation as a gay male. Although two of them do not describe themselves as a gay male, they remark that they have been through same-sex experiences according to a societal view. Moreover, this is a space-focused study and their assigned genders by society allow them to enter some gay bars and clubs where lesbians and transgenders cannot do. Thus, I did not hesitate to include them in the study because of their "gay" experience in gay venues.

I conducted this study with gay males, and this is merely due to a factual limitation. Especially in Turkey, gay males are more visible in the gay scene and more numerous. LGBT+ venues are under male-domination. However, this situation is not exclusive to Turkey, this segregation is observable around the world. (Binnie, 1995; Formby, 2017; Browne \& Bakshi, 2011). Groups that live familiar experience under the same roof are not usually together in these places. According to Castells' (1983) controversial argument, males tend to dominate space because this is the way they can release themselves from the social and sexual oppression. $\mathrm{He}$ asserts that women do not need a space for solidarity, and they seek relationships and networks. On the other hand, by virtue of interviews, I learned that some venues do not permit lesbians or transgenders to enter. In brief, these venues are not LGBT+ affirmative in the present study. Therefore, I intentionally use the words "gay venues" or "gay scene" or "gays" despite the fact I have chosen the article's title containing "LGBT+ venues" to be more inclusive for each person who is queer or non-heterosexual. The term 'scene' is usually referred to as commercial 'gay' bars and clubs which are rarely used for 'LGBT' bars and clubs (Formby, 2017: 117). 


\section{Family Relationships and Home Experiences}

One of the remarkable concerns is that the family members are not seen as assistant elements in the course of the transition process when young individuals know themselves and construct an identity. None of the participants attribute a facilitator role to his/her family in sexual orientation related issues. This situation is common for all participants regardless of their coming out to their families. It is evident that it is not possible to pose the question of sexual orientation with their family and try to answer it together. For out ${ }^{1}$ participants, the stages progress in a row by an announcement to the family after self-acceptance. For non-outs, they consider that the transition would most probably be regressed if they informed their families during the self-acceptance period. I asked the latter if they have any intention or plan to come out to the families and none of them indicated any plan or intention of doing that.

Arda, participant aged 25, pointed out: "I'm out to the whole world for ten years, to my father for two years". This statement and others helped me to understand that the identity transition of the participants had been already completed and the role of family was out of service on understanding a gay person's one-self. After the self-acceptance is done, friends are present for validation which gays usually do not receive from the family. This might be the main reason that young queers disclose to a close friend before disclosing to parents and other family members (Rosario, Schrimshaw, \& Hunter, 2009) or that they never disclose to the family.

Interviewer: "Have you ever needed support from your family during all sexual orientation turmoil?"

\footnotetext{
${ }^{1}$ GLAAD, American non-governmental media monitoring organization, suggests that "openly lesbian," "openly gay," "openly bisexual," or simply "out". To explore the "GLAAD Media Reference Guide - Terms To Avoid": https://www.glaad.org/reference/offensive
} 
Samet (30, Istanbul): "It never happened. Because I've already done it in another way with my family of choice. I have very close friends from whom I took all the supports that I need, and with whom I can be totally myself. I describe them as family."

The fact that the participants noted that they have not received any support from the family during the acceptance, disclosure and validation stages of coming out, this does not indicate that the missing support from the family is replaceable. A participant living with HIV+ expressed the lack of family support as an obstacle to go on:

"I'd like to able to speak to them about life that I want to live, my relationships and my health status. I would feel complete, at least I would be a stronger person (...) If I had a different relationship with my parents, I could have told them the sexual harassment. I could tell it only a friend. If they knew it, I absolutely would file a complaint. Those days, I extremely wanted their supports. Extremely."

On the other hand, everything is not perfect for those who are openly gay. It is a complicated question "how much validation" that they feel was given to their identity. Although the participant, named Petros, describes his coming-out moment as a good one, afterward his mother asks him not to wear "very gay", not to draw attention in the neighborhood. Another participant, Sarp also indicates that his mother's behavior changed after the coming out. For instance, she started constantly asking him where he goes or stays over the night while she never did that before.

Along with these sexual orientation-related pressures, Mikhalis, participant aged 26, points out a greater issue about the family ties. He states that he feels the pressure in the family scene, but not only for himself. He exemplifies her mother as another person who is not gay but also tries to fulfill the expected performance at the big family tables. He stated that she does self-censor while she is with her male siblings. The emphasis here is on the family structure which mostly limits its members. However, I do not suggest a pollyannaish view of the family 
institution, which has an inherently restrictive nature. The agent is not a mystery, it is the heteronormative system that limits both. It is likely the most compelling part of these relations that can't be described as the top-down pressure of the persecutor. Oppressed also can be an oppressor.

Fotis, openly gay participant aged 21, declared that he hasn't spotted his feminine-phobic attitude until very recently. He stated that after his coming out to his family, he intensively put effort to look very masculine to avoid the pressure of family gaze. As a result of this problem, he admits now that it becomes a part of his character and he exhibited some discriminatory behaviors to feminine gays in their communications. Another example, Deniz recognized the interiorized oppressor tendency in the family although s/he tries to destruct it with all his/her strength:

“One day, I found a condom in my sister's drawer. Even though I expect her to accept me having sex with men and that I exactly know her having sex with someone... Holding that condom in my hands... A bachelor member of my family is having sex. Maybe I still have something which I could not destroy yet. I quietly put that condom back and I blamed myselffor having this feeling for weeks." (Deniz, aged 25, İstanbul)

Lastly, the experiences of the participants in the family home atmosphere diversify. While a home can be a "neutral" or relatively safer space for some, others attributed it with negative terms like the Sarp's "prison" analogy. However, the distance from the family home is a critical variable that affects the relationship with the family. For instance, Sarp, aged 27, asserts that the relationship with his mother is always better when he is far away from home. Samet also states that it is enough for him: "If they are there and good". 


\section{Gay Venues and Scene}

In the second session of the interviews, the participants expressed their experience of the gay venue and gay scene. We started with their first visit to a gay bar. The words chosen to describe the atmosphere of the venue were "unusual", "different", "new" and so on. For most, gay clubs were not similar to anywhere they have seen before. However, the more complicated side was how they interpret the scene differently even though they have experienced the same places. In parallel to Weston's claim (1991: 403), “bars remain a central symbol of identity, and almost everyone has a story about the first visit to a gay club”. Özgür and Deniz describe their family as "white-middle-class". Their family resources gave them access to these possibilities, and they have already had information about the scene. Both stated that they used this advantage, hence "the image" (a gay scene or kissing gays) did not surprise them. Nevertheless, Samet's experience was different. Although Samet does not have the same kind of family, he also has resources. He has been using the Internet since his childhood. Additionally, he'd made some researches about gay identity and had watched gay porn several times before the first visit. But Samet was very surprised for the first time when he visited the gay bar.

"I entered the venue and saw men kissing. This was the biggest shock of my life (...) I remember that I couldn't understand how they could have kissed. That day when I realized the difference between those that I imagine in my mind and the reality, I said to myself you are nothing'. You are like a militant about gay rights, but you are still afraid of kissing and touching someone. I decided to come out to my friends before I revolutionize in the world" (Samet, aged 30, İstanbul)

In my opinion, for this case, the gay scene has a positive effect on the normalization of the participant's perception of the identity. However, the participants did not describe the general experiences in the gay scene as a positive experience for several reasons. 
The first problem was the "fresh meat" experience of the participants which is prevalent among young gays (Eichler, 2012). A young gay who came to a gar bar for the first time usually feels pressure because he is new in the scene. He draws oppressive attention and feels insecure. Most of the participants stated that they were harassed in their first experiences in gay venues. Although the experiences vary by the venue, the problems commonly encountered by the participants were the disregard of their rejection, and the violation of their bodily integrity.

Although the disturbing experiences related to the harassment have relatively diminished in years, one concern is not changing: Stares. While stares can easily be a sort of harass, some people can interpret it as totally different. In Valentine and Skelton's (2003) interviews, a respondent explains that the gaze made him nervous but happy as well because it made him feel normal. However, stares are very challenging for most of the participants in my study. Regardless of the flirty intents, stares are a very common problem in the gay scene. For instance, Arda stated that he stays away from the gay scene as the stares made him feel alienated in these venues where his "presence was supposed to be normalized".

Another reason to not prefer going to gay venues is music. Jodie Taylor (2012) indicates in her ethnographic account on the role of music in gay venues that these venues help LGBT+ individuals find each other, and music and dance have an important role in accompanying to this socialization. For the participants in this study, music has also a crucial role, but not in a good way: Only one participant indicated that he is satisfied with the music in gay bars. For most of the rest, music is the main reason to not go to gay bars. Can, participant aged 23, explained that he preferred a gay-friendly pub for years rather than a gay bar. He remembers very well the moment when he first stepped into the pub. He narrated that jazz music was playing and it felt him safer than being in a gay bar playing Turkish pop music.

Rivalry and common standards of the scene are troubling issues for participants. Even though the level of oppression is not the same for all participants, they state that they were 
included in a rivalry or observed it. Moreover, there is a body/image hegemony in gay spots that Formby $(2007,116)$ describes as 'off-putting' particularly for gay men.

The aforementioned participant, Can, explains that he was very focused on his look for a certain period because of the impositions of his new friends who desire to get attention in the gay scene. Enes and Özgür declared that they were in a competition related to how a young gay male should look like. Unfortunately, I was told about some experience that can be easily called as "dating violence". Sarp and Deniz explained that they were struggling because of the partners who forced them to adapt to the gay scene where the partners were popular and wanted to show their relationship off. Enes emphasized the class-based side of this rivalry that he experienced in his early ages:

"They competed in spending money. I heard a few times someone asked my friend what he was drinking. 'Ah! Are you drinking beer? I'm drinking vodka.' One night, my friend swiped his mother's necklace to look cooler. "(Enes, aged 24, İstanbul)

The participants compared their physical venue experience to digital one which includes forums, chat sites and applications in smartphones. Between many differences, 'rejection' was a salient factor. Compared to digital experience, being rejected in a gay scene makes attendees feel more depressive. Because the rejection occurs in front of the eyes of other gays. Therefore, in a physical place, the attendee can be shyer on approach to someone he liked. Vasilis, aged 40 , stated that he has dated up a few times with someone from applications who had ignored him in the gay scene or an organization. According to him the reason behind this rejection can be "peer pressure", or image concerns which the person desires to present himself with "hot guys".

Lastly, one of the outside experiences that the participants asserted was the Pride parade as it offers a meeting point for gays. For most participants, the Pride parade evokes strong feelings that strengthen the community ties for LGBT+. However, Sarp and Vasilis explain that 
they felt some pressures in their previous participation in the Parade similar to the pressures they feel in gay spots. Yet they also recognize the identity politics behind these events. Vasilis, an a 40 years old male, declared that he felt excluded in his first parade experience because he did not see any average-looking person around, and there was low-level queer diversity containing only a few women. He depicted the atmosphere as "an endless parade of chiseled naked men". Vasilis concluded that many things have changed in years at least over the diversity issue. Sarp's first parade experience was a more complicated problem:

"It was like... You were in a different group. Especially when you are a teenager, everybody seems heterosexual. You could not succeed to get involved in that world. And now, a new group! New rules! I remember that some dynamics seemed too much for me (...) In the beginning, I was excited, but it looked like it was necessary to feel an affiliation with the group. You have to perform a new role." (Sarp, aged 27, Istanbul)

Sarp explained that this feeling has not disappeared even after participating in the Pride for many times and after gay bar experiences. However, he repeatedly underscored that he has not any problem with being "too much" or extreme. He declared that he does not intend to judge people, the problem for him is the feeling that the others will judge him when he does not adapt to the general scene. Arda also similarly emphasized the feeling that he has to be extreme if he wants to be part of a gay commune.

\section{Conclusion}

Michael Hobbes (2017) questions in his well-elaborated and well-synthesized article in Huffington Post: "Why Didn't Gay Rights Cure Gay Loneliness?"1. This question is a donnee

\footnotetext{
${ }^{1}$ The title of the article has changed to "TOGETHER ALONE: The Epidemic of Gay Loneliness" after a while. To see the unedited version: https://twitter.com/highline/status/837156991877414913 
for this study. Gays left the home, built a new one and some of them can live together as married in those houses. But the "loneliness" could not be fixed so far. And, there are some outputs of this "loneliness". For example, young LGBT+ subjects are at "greater risk for major depression, generalized anxiety disorder, conduct disorder, substance abuse and dependence, multiple disorders, suicidal behaviors, sexual risk-taking, and poor general health maintenance than are their heterosexual peers" (Elizur \& Ziv, 2001:126).

Although gay bar offers a space where LGBT+ "can find information, support and develop a positive sense of self-identification and sexuality" (Valentine and Skelton, 2003: 856), there will be always individuals who cannot afford to be there or adapt to the dominant culture (Binnie, 1995).

This work proves that the "watchful gaze of other household members" (Johnston \& Valentine, 1995:89) in the family house has been transforming into another form in these venues. This can make difficulties for LGBT+ individuals who struggle with anxiety than heterosexuals (King et al., 2008, Timmins, Rimes, \& Rahman, 2019). Even if the authority of parents disappears or reduces to some extent, the opening fills up with the expectation of the general gay scene. This study proves that the new elective communities may exclude some individuals, and that "social pluralism and proliferation of communities do not necessarily guarantee variety or autonomy for all members" (Weeks, 1996: 84).

I have strongly believed that friendship is the key to solve the problems of disadvantaged groups and solidarity can be possible with powerful commune sense. Friendship and solidarity among LGBT + s can be interpreted as another example of "sisterhood" sense in women's movement. Therefore, Peter Nardi's declaration always sounds meaningful: "Not only are friends a form of the family for gay men and lesbians, but friendships are also a political statement. (Nardi, 1992: 108). However, the current participants clearly stated that they have not any strong sense of belonging towards gay venues and the gay community although they do 
not exclude the gay political movement. It is evident that the participants do not associate these venues with a home feeling. Likewise, the participants do not feel closeness with other members of the community just because they live similar sexual orientation-based experiences. The participant, Deniz, has been politically organized for years and actively works in a İstanbulbased LGBT+ organization. He admits that his thoughts on queer politics have changed in years: "I don't have to make friendship with these people (queers) even if we have a genuine partnership over experience. I realized that at this age."

There is a critical point that should not be ignored although these findings are effective in understanding the sense of belonging. In my study, all the participants are graduated or continuing their educations. And, they live in one of the very cosmopolitan cities of their countries like İstanbul or Athens. They have been able to access resources including nonhomophobic friends or gay-friendly places. Additionally, all of them have been using the internet since childhood. Fortunately, their socio-economic status put these individuals in a relatively more advantageous position in this disadvantaged commune. In my opinion, the fact that none of the participants experienced a financial and emotional boycott by their families causes low emotional investment in these venues and people. Valentin and Skelton (2003) question Ulrich Beck's thesis on the declination of class-oriented ties. In contrast to Beck's ideas, the authors reveal that class determinism is still forceful in this field. For instance, the university atmosphere is more tolerant to a young gay from the middle-class yet the places where a young gay, whose working-class family expects him/her to fulfill more macho gender roles, can "be gay" are more limited. The living conditions of gays from the working-class are likely to be harder and more complicated. Therefore, these places might be the sole chance to "be gay" for someone even though it is not for the current participants. With the participants' meaningful contributions, I consider that while examining why some gays do not prefer these venues, it is 
important to try to comprehend why these places are highly important for the gay commune for which class ties are still very decisive:

"When I was an adolescent, I used to hang out in a place named Machine which is too crawling with lubunya ${ }^{1}$. We knew -X- (a gay bar currently working in İstanbul) but did not go there. We used to not like that place. Because my company was very white. I hadn't these kinds of worries at that time (...) Once I got -X-, I noticed that it is a kind of class discrimination that I'm doing. There was no one in Machine who is a construction worker, but you see him in -X-. He does construction works six days of the week in Bağcllar and afterward, he comes there with an evening bus. He enjoys the night until morning and then leaves the venue. He waits for the morning bus for two hours. Because he is also a 'lubunya' and wants to reach the scene, too. But he has just limited opportunities." (Deniz, aged 25, Istanbul)

In conclusion, I am returning to the beginning with the question of "Is there any home?". By following answers, I am partly able to approach the complexity of the family and home issues. In the article focused on transgender murders, Zengin (2015) is certainly sure that "the appeal of the notion (of the family) and the desire forms created by it is never going to stop poking us" (51). In the conclusion of the current inquiry, I come to agree with Zengin's idea. The family and the home are very strong notions than I expected and mostly associated with biological (or assigned) family and its place. The most appropriate matching for the assessment mentioned is Enes' experience. Although he explains that he severely feels the lack of attention and support from his family throughout his life and that he completely found it for a short period in the gay venues, he clearly stated that the notion of family and home can never be replaced with something else.

\footnotetext{
1 "Lubunya" is a term in the Turkish queer-language, roughly equal to the word "queer".
} 
It is seen that the alternative mechanism could not be created which is offering the gays what they expect to get from the family notion. Eleanor Formby (2017) asserts that gay venues are not formed to create LGBTI-affirmative space but are self-created by running from the heteronormative world. She describes this process as a "push than pull effect" (p.132). It is possible that this effect is the main reason for these contradictions. People probably encounter each other incidentally while escaping from somewhere they are not accepted instead of meeting to form a community based on common sharing. Family-based wounds might not be, therefore, bound up.

\section{References}

Binnie, J. (1995). Trading places: consumption, sexuality and the production of queer space. In D. Bell \& G. Valentine (Eds.), Mapping desire: Geographies of sexualities. London: Routledge.

Browne, K., \& Bakshi, L. (2011). We are here to party? Lesbian, gay, bisexual and trans leisurescapes beyond commercial gay scenes. Leisure Studies, 30(2), 179-196. https://doi.org/10.1080/02614367.2010.506651.

Castells, Manuel (1983). The city and the grassroots: a cross-cultural theory of urban social movements. London: Edward Arnold.

D’Augelli, A. R., Hershberger, S. L., \& Pilkington, N. W. (1998). Lesbian, gay, and bisexual youth and their families: Disclosure of sexual orientation and its consequences. American Journal of Orthopsychiatry, 68(3), 361-371. https://doi.org/10.1037/h0080345.

D'Emilio, J. (1993). Capitalism and gay identity. In Abelove, H., Barale, M. A., \& Halperin, D. M. (Eds.). The Lesbian and gay studies reader. New York: Routledge.

Eichler, M. (2012). Consuming my way gay: An autoethnographic account of coming out as consumptive pedagogy. SAGE Open, 2(3), 215824401245757. https://doi.org/10.1177/2158244012457578.

Elizur, Y., \& Ziv, M. (2001). Family Support and Acceptance, Gay Male Identity Formation, and Psychological Adjustment: A Path Model*. Family Process, 40(2), 125-144. https://doi.org/10.1111/j.1545-5300.2001.4020100125.x.

Formby, E. (2017). Exploring LGBT spaces and communities: Contrasting identities, belongings and wellbeing (1st ed.). https://doi.org/10.4324/9781315747798. 
Hobbes, M. (2017) Together alone: The epidemic of gay loneliness. [Online] Available at: https://highline.huffingtonpost.com/articles/en/gay-loneliness/ [accessed 31.10.2016].

Johnston, L., \& Valentine, G. (1995). Wherever I lay my girlfriend, that's my home: the performance and surveillance of lesbian identities in domestic environments. In D. Bell and G. Valentine (eds.), Mapping desire: Geographies of sexualities, London, Routledge.

King, M., Semlyen, J., Tai, S. S., Killaspy, H., Osborn, D., Popelyuk, D., \& Nazareth, I. (2008). A systematic review of mental disorder, suicide, and deliberate self-harm in lesbian, gay and bisexual people. BMC Psychiatry, 8(1), 70. https://doi.org/10.1186/1471-244X-8-70.

Nardi, P. (1992) That's what friends are for: friends as a family in the gay and lesbian community. In Ken Plummer (ed.), Modern homosexualities: fragments of lesbian and gay experience. London: Routledge.

Rosario, M., Schrimshaw, E. W., \& Hunter, J. (2009). Disclosure of sexual orientation and subsequent substance use and abuse among lesbian, gay, and bisexual youths: Critical role of disclosure reactions. Psychology of addictive behaviors: journal of the Society of Psychologists in Addictive Behaviors, 23(1), 175-184. https://doi.org/doi:10.1037/a0014284.

Taylor, J. (2012). Playing it queer: Popular music, identity, and queer world-making. Bern; New York: Peter Lang.

Timmins, L., Rimes, K. A., \& Rahman, Q. (2019). Minority stressors, rumination, and psychological distress in lesbian, gay, and bisexual individuals. Archives of Sexual Behavior. https://doi.org/10.1007/s10508-019-01502-2.

Valentine, G., \& Skelton, T. (2003). Finding oneself, losing oneself: the lesbian and gay "scene" as a paradoxical space. International Journal of Urban and Regional Research, 27(4), 849-866. https://doi.org/10.1111/j.0309-1317.2003.00487.x.

Weeks, J. (1996) The idea of a sexual community. Soundings: A Journal of Politics and Culture, 2: 71-84.

Weston, K. (1991). Families we choose: Lesbians, gays, kinship. New York: Columbia University Press.

Weston, K. (1995). Get thee to a big city: Sexual imaginary and the great gay migration. GLQ: A Journal of Lesbian and Gay Studies, 2(3), 253-277. https://doi.org/10.1215/10642684-2-3$\underline{253}$.

Zengin, A. (2015). Sevginin ölüm dünyası: aile, arkadaşlık ve trans cenazeleri. Kültür ve Siyasette Feminist Yaklaşımlar, 26(3), 38-52. 


\title{
SEMIOLOGY AND ARCHITECTURE: THE SEXUAL SEMIOLOGY OF SPACE
}

\author{
Aminu Ahmad HALIRU ${ }^{1}$ \\ Desy Osondu EZE ${ }^{2}$
}

\begin{abstract}
This study addresses the concept of semiotics in the context of building with a focus on analyzing the phenomenon of aesthetics. The effect of symbolic representations in architecture and the semiotic of architecture in relationship to gender sensitivity form the main objective of the study. Relying on the symbolic nature of architecture as a work of art, an empirical analysis was undertaken of how buildings and other design elements in the built environment can trigger an aesthetic experience including sexuality. The two case studies Ricardo Bio fill Walden 7, Spain and Walking Street Pattaya, Thailand were the public places analyzed.

Here the building form, nature and landscaping, and the color of material finishes have a strong effect on humans where their architectural design coupled with locational site served as a major source of attraction to people. It includes heterosexual and lesbian, gay, bisexual, transgender and (LGBT) communities. Finally, the study concludes that architecture is socially constructed and building could be gendered through its semiotic contents.
\end{abstract}

Keywords: Semiology, Architecture, Space, Gender, Aesthetics

\footnotetext{
${ }^{1}$ Graduate Student, Department of Architecture, Cyprus International University aminuhaliru747@gmail.com

${ }^{2}$ Graduate Student, Department of Architecture, Cyprus International University osondudesy@yahoo.com
} 


\section{Introduction}

Architecture is basically referred to as a product of design and construction however, for anthropologists and critic's it is an expressive subject articulating the paradigm of communication (Bonta, 1979). It is in this approach that Marxists considered tall buildings as expressive of social class in capitalist society and feminists as a representation of gender and class domination by the patriarchy. A building as a symbolic artifact is a well-grounded phenomenon since ancient civilization for example both the Greeks and ancient Romans honored the phallus and worshiped Priapus, the well-endowed god of fertility and built temples and monuments to worship him, utilizing phallic architecture and sculpture (Phallic Architecture, 2014).

Based on the above, a study is carried out in order to explore the semiotic nature of architecture and its role as an aesthetic object in shaping the gender spaces. The main objectives of the study are to: describe the expressive meaning of architecture, explore the sexual semiology of spaces, describe the aesthetic experience in buildings and define the relationship between gender and building. Similarly, the study is expected to answer the questions: How do buildings mean? Are there any relationship between architecture and emotion; in other words, does the built environment affect human sexuality? And Are there any relationship between gender and building?

The study is expected to figure out the role of architecture in bodily pleasure, sexuality and to provide a justification for explaining the rationale behind human's choice of building form, spaces, materiality, color finishes and landscaping in both residential and public places like hotels, bars, clubs, go-go clubs, brothels, etc.

Therefore in the study literature sources such as peer-reviewed journals, books and internet materials will be used and further two 2 case studies will be carried out. The study is structured 
into five chapters: first is the introduction and overview of the research, second is the Extent of the Meaning of Architecture, the Third is the Sexual Semiology of Buildings and Spaces, the fourth is the Discussion and Findings and finally the conclusion.

\section{The Extent of the Meaning of Architecture}

The expressive meanings of the architecture are well documented, there are numerous shreds of evidence on that just as Juan Pablo Bonta notes, architectural history as we know it has been written tacitly adhering to the crudest version of the paradigm of communication (Bonta, 1981), Similarly Umberto Eco shared the same view according to him, "we commonly do experience architecture as communication, even while recognizing its functionality" (Eco, 1997). In this sense, architecture is, therefore, a semiotic work of art and hence interpretational (Figure 1). Thus, this chapter will examine the relationship between architecture and sex and architecture and aesthetic experiences.

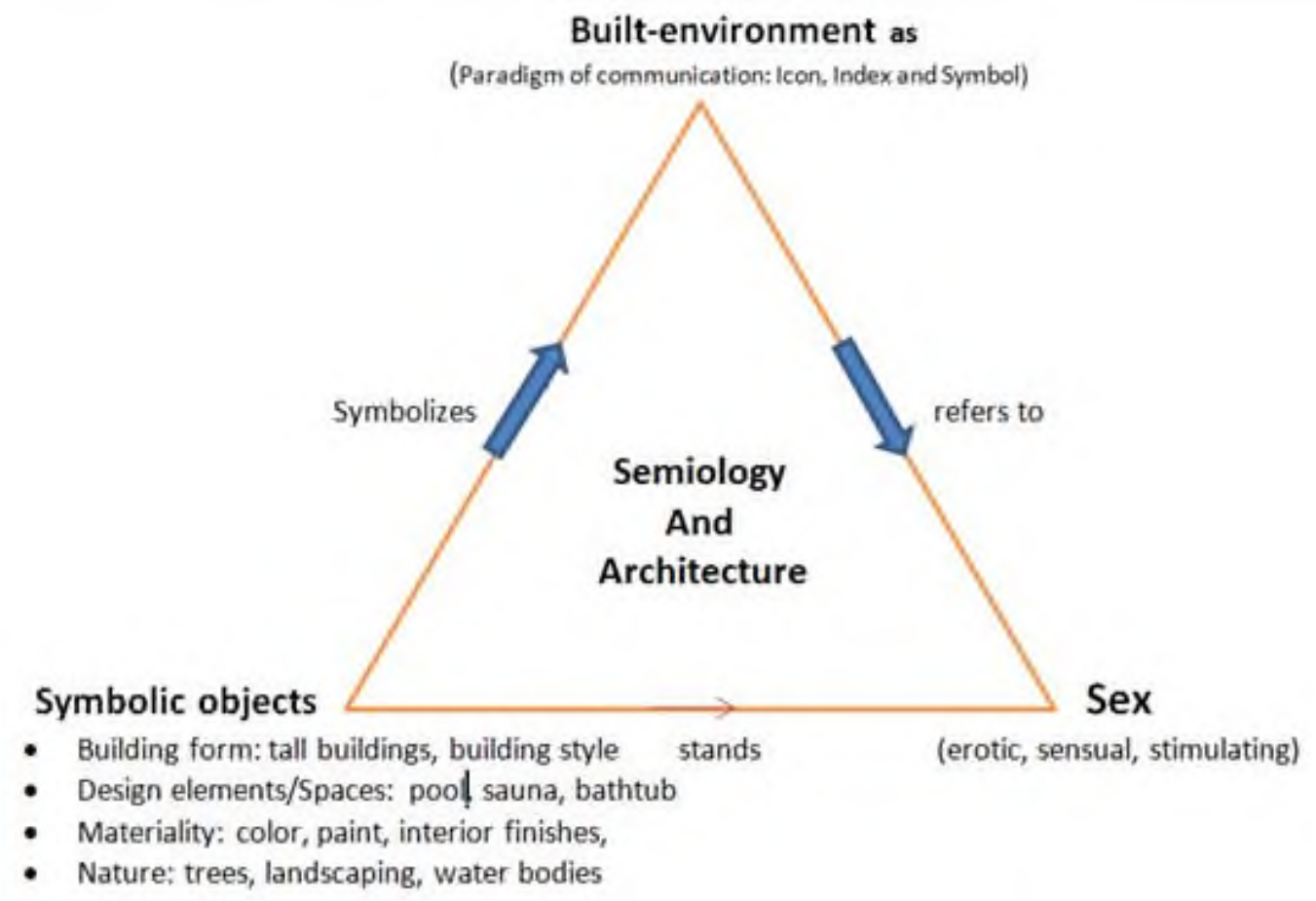

Figure 1: A Semiotic Triangle Adapted from Ogden and Richard Semiotic Triangle (1923) 


\section{Architecture and Sex}

Tall buildings are often referred to as a symbol of masculinity to the extent such iconic buildings have an identity serving as a local source of amusement and inspiration and similarly attract tourists from different cities across the globe as seen in Figures 2,3 and 4. In analyzing their meaning, following the work in The Production of Space by Henri Lefebvre, he noted that buildings of phallic architectural type metaphorically symbolize "force, male fertility, masculine violence" (Lefebvre 1991:287). However, phallic architecture in most cases creating a symbolic representation in building purposefully or not is always a source of amusement and a tourist attraction. Just as the Ypsilanti water tower is now a tourist center so also is the Colonna Mediterranean

Some of the early examples of the relationship between architecture and sex can be found in ancient times where genitalia and human sexuality have a fascination, for example, both the ancient Greeks and ancient Romans honored the phallus and worshiped Priapus, the well-endowed god of fertility and built temples and monuments to worship it, utilizing phallic architecture and sculpture (Phallic Architecture, 2014). In modern time such buildings proliferated and architect often use the forms specifically for inspirational purpose typical example of such phallic buildings includes Ypsilanti Water Tower of Michigan, Torre Agbar of Barcelona Spain, (fig 2), Empire State Building, New York (Figure 3), and the Colonna Mediterranean in Luqua, Malta (fig 4). However, the Colonna Mediterranean monument which was designed and erected by an artist Paul Vella Critien with a conceptual meaning as a "3D Egyptian symbol" an Egyptian obelisk has a contradicting meaning by the public. They see it as a phallic monument, due to its symbolic nature depicted by the architectural features on it, the aesthetic experience shows such, hence been tagged a gender assault that is not acceptable to many. There is such semiotic architecture all over the world which conveys meaning to onlookers that have some sensitivity on gender issues. 

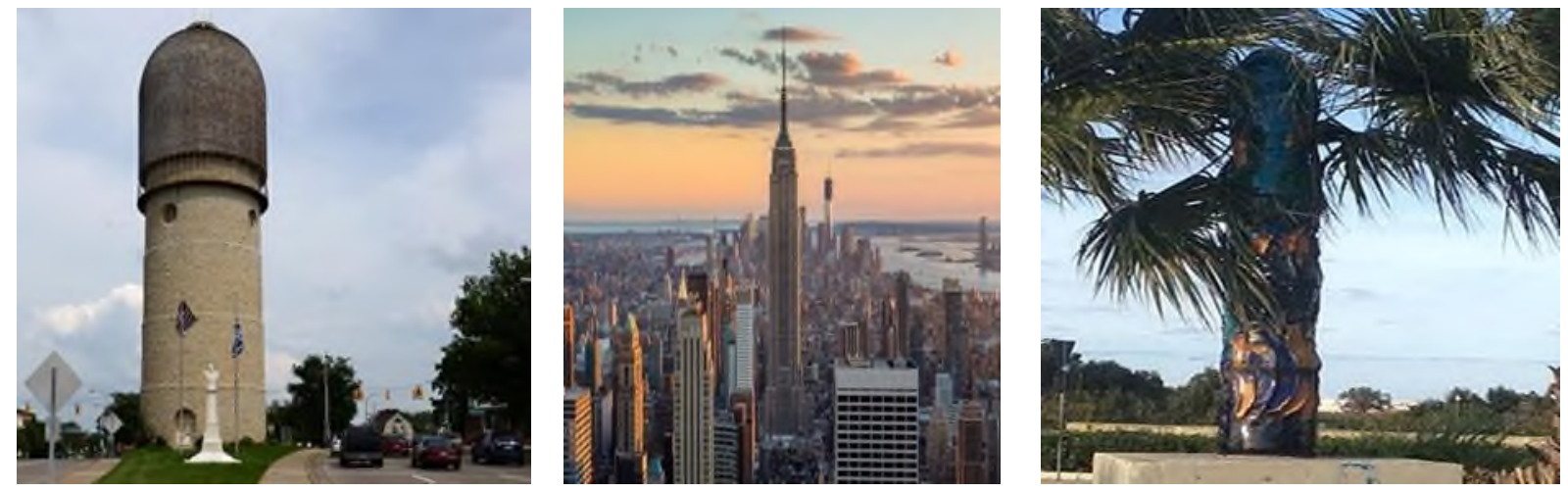

Figure 2: Ypsilanti Water Tower. Figure 3: Empire State Bldg, New York Figure 4:Colonna Mediterranea, Malta

Figure 2: Ypsilanti Water Tower has become a monumental structure attracting people from different, angles built-in 1890, today the tower is Frequently joked about for its phallic shape. (Source: bing.com/images/Ypsilanti Water Tower)

Figure 3: Empire State Building is a notable landmark and one of the American cultural icons Briginshaw (2001) describes the tall building as the symbol of American pride and "The ultimate sign of American phallic power" Wikipedia.org/wiki/Empire_State_Building Retrieved 24th October, 2019)

Figure 4: Colonna Mediterranean popularly known as Luqa monument in Malta, which has created a controversy over its phallic appearance.(Wikipedia.org/wiki/Colonna.Retrieved on 24th October 2019)

Moreover, the effect of the quality of the built environment on sexual arousal cannot be overemphasized. There are lots of shreds of evidence on the role of space in conditioning sexual relations. In the Sex and Building: Modern Architecture and Sexual Revolution (2013), Richard Williams made a discursive analysis of this. According to him any space that places a premium on bodily pleasure might reasonably be described as erotic even if the primary purpose is not sex; sauna is generally erotic in the popular imagination (Figure 5).

Further, in relation to the power of architecture in igniting sensory experiences, Roxanne Mountford opines "space has heuristic power over their inhabitants and spectators by forcing them to change both their behavior" (Mountford, 2001). And Michel Foucault notes "power has its principles not so much in a person as in a certain concerted distribution of bodies, surfaces, light, gazes, in an arrangement whose internal mechanism produces the relation in which 
individuals are caught up" (Foucault, 1990). Therefore, architecture could be said to have a long-standing relationship with sex and thus has a spirit of space and tend to exert inherent power over its occupant.

\section{Architecture and Aesthetic Experiences}

Aesthetic experience has been part of the human phenomenon since ancient times, for example in ancient Greeks, Plato and Aristotle shared the same point of view on aesthetics, both regarded music, poetry, architecture, and drama as fundamental institutions within the body politic. Similarly in medieval times, more widely diffused among medieval thinkers was the Neo-Platonist theory, in which beauty is seen as a kind of divine order conforming to mathematical laws: the laws of number, which are also the laws of harmony, this continue to be dominant view until the early renaissance. And in modern times, Francis Hutcheson was perhaps regarded as the first to place the problem of aesthetic judgment among the central questions of epistemology, in his inquiry: How can we know that something is beautiful? What guides our judgment and what validates it? He concludes: aesthetic judgments are perceptual and take their authority from a sense that is common to all who make them. Immanuel Kant also attempted to describe the imagination as a distinctive faculty, active in the generation of scientific judgment as well as aesthetic pleasure (Scruton and Munro, 2018).

The rise of capitalism and the social class system in the 20th century made a strong impact on our society; people value pleasure, money, and power. Similarly consumption becomes their cultural hallmark, at the level of consumption, people tend to fetishize the built environment; they made their buildings as aesthetics objects in which they derive all sorts of sexual desires and satisfaction (Figure 6). Similarly, they buy commodities neither on the account of their utility nor as status-symbols; but in order to get the experience provided by them, they consume them in order to make their life pleasurable and meaningful. Materials like 
concrete, steel, and glass enable them to build spaces of their choice with the spirit of place. Some of the notable aesthetic modernist architects are Le Corbusier, and Frank Lloyd Wright (Figure 5) and Alvar Aalto as Juhani Pallasmaa argues their architecture is based on a full recognition of the embodied human condition engaging all the human senses (Juhani, 2012).

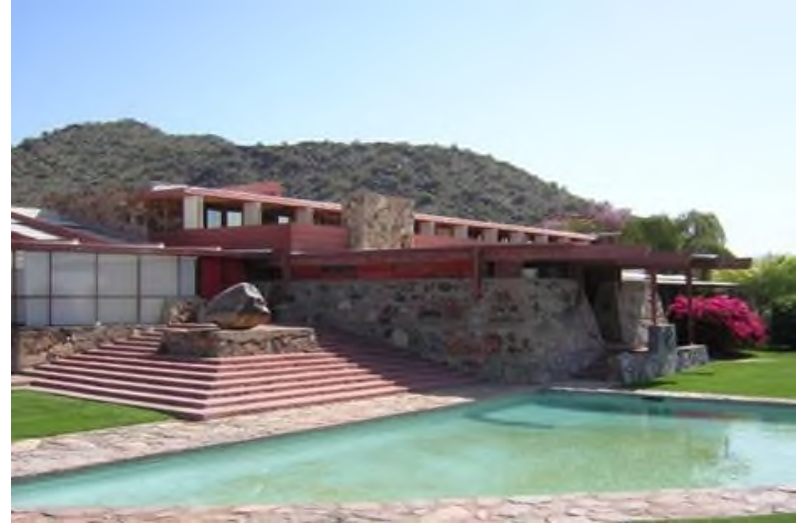

Figure 5: Aesthetic Taliesin Winter Home

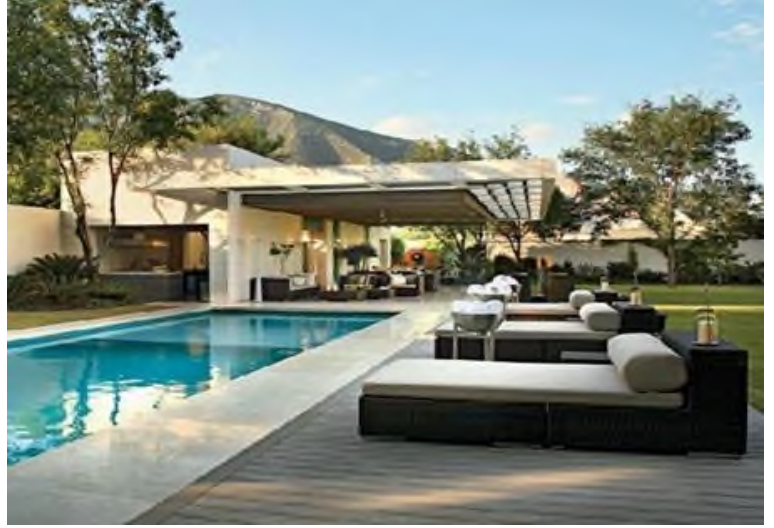

Figure 6: Architecture as Aesthetic Object

Figure 5: A pool and terrace at Taliesin West winter home built by Frank Lloyd Wright for himself. Today the building possesses an almost, prehistoric grandeur (Source: https://en.wikipedia.org/wiki/Taliesin_West)

Figure 6: A modernist residence with an outdoor pool designed for amusement and other bodily pleasure (Source: https://www.homestratosphere.com/swimming-poolideas)

\section{The Sexual Semiology of Building and Spaces}

The preceding sections provide a theoretical background of the symbolic nature of architecture where it exists both as expressive and stimulating through which aesthetician finds all sorts of pleasure and satisfaction. However, this chapter will examine the architecture of two buildings specifically Ricardo Bio fill Walden 7 and Walking Street Pattaya, Thailand to provide a concrete example.

\section{Case study 1: Ricardo Biofill Walden 7}

Walden 7 is a live model of utopian vision of communal space that majorly drew inspiration from science-fiction novel Walden 2 written in 1948 by psychologist B.F Skinnera vision of a utopian society living in which all cultural norms were rejected in favor of a self- 
enforced code of behavior. Although Skinner too sourced his idea from Henry David Thoreau's 1854 work Walden that featured liked-minded of mid-19th-century middle-class life. The current building is 16 story building represented in a vertical labyrinth completed in 1974, attracting a breed of a middle-class community located at the Catalonian region of Spain in the Sant Just Desvern suburban area, designed by Ricardo Biofill.

\section{Architectural Features from case study 1:}

Walden 7 is basically tall building and idiosyncratic in every respect, the building itself was conceptualized through biological analogies in which a 28 -meter square module served as the basic unit of the structure and is organized and stacked up to form a 16-story residential complex. Each floor is in such a way that it shifted slightly from the one below and thereby creating a contrasting light effect and similarly the space created by the incremental displacement allows for a network of walkways and public spaces. The following are some of the architectural features of the building:

- $\quad$ The physical form of the building looks like winding vertical labyrinth consisting of 500 residences of self-sufficient city miniature

- $\quad$ There are 4 internal courtyards that run the full height of the building

- $\quad$ The exterior is coated with red material and the interior with azure sky blue

- $\quad$ Picturesque landscaping with two swimming pools at the rooftop

- $\quad$ There is a basement floor for car parking.

\section{Semiotic Meaning of the Walden 7 Environments}

Apart from the fact that Walden 7 drew its inspiration from mid-19th century utopian vision, the building is tall, coated with exciting colors and also located at the outskirt of the town then in 1975 when it was commissioned giving enough room for eroticism by like-minded bohemians. Therefore, the building is basically an alternative to the normative family 
experience. From the onset, the exterior of the building has a red coating (Figure 6) whereas in the interior has azure sky blue which in accordance with the color psychology is expressive; the red simply signifies lust, excitement, and love and the blue calmness, pleasure, and coziness (Aslam, 2006; Labrecque \& Milne, 2011). In this sense, the colors are used as a stimulant to both draw the attention of passers-by and to conditions the sexual euphoric life in the building. More importantly, there are pot plants, garden furniture, and two swimming pools at the rooftop to allow for a glimpse of the sky above (Figure 7). The rooftop, in fact, turns out to be a nude sunbathing spot with four pools in the center of living space. According to a narration when it was freshly built Walden attracted diverse prostitutes and transsexuals (King, 2016).
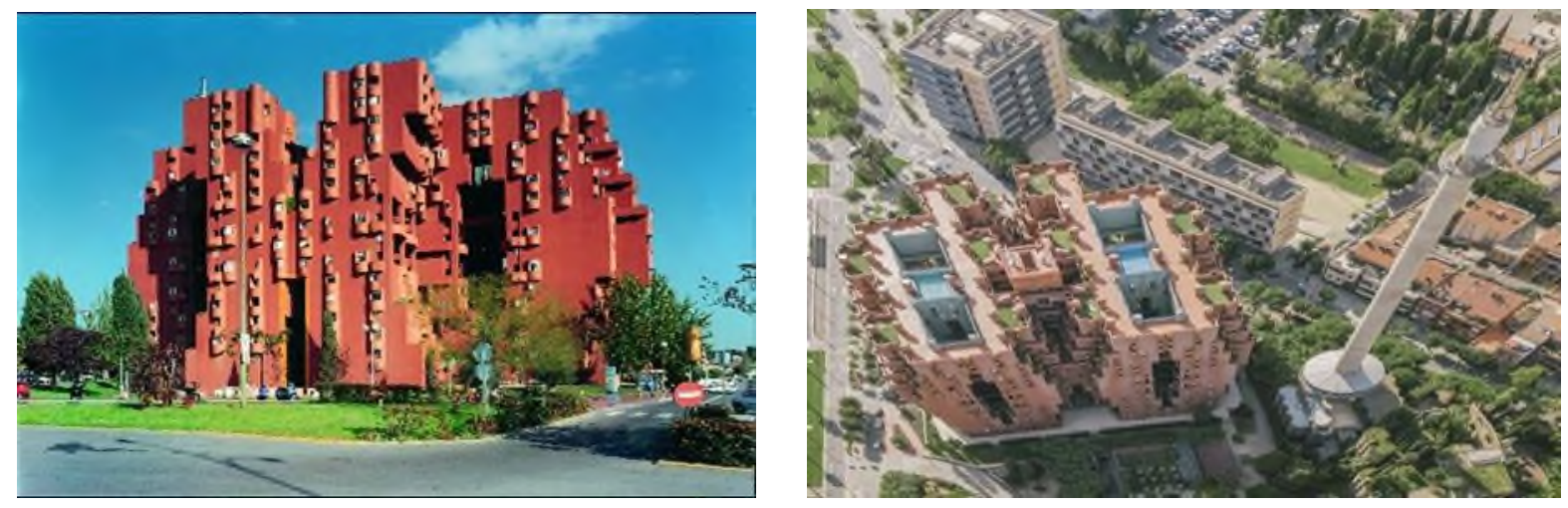

Figure 6: Ricardo Biofill Walden 7 Building Figure 7: An aerial view of Ricardo Biofill

\section{Walden 7}

Figure 6: Exterior view of Ricardo Biofill Walden 7 intentionally painted with red tiles in order to create a striking effect on onlookers (Source: https://frieze.com/article/fortress-solitude)

Figure 7: An aerial view of Walden 7 showing all the 4 full heights the courtyard and two swimming pools at the expense of the sky for eroticism (Source: https://frieze.com/article/fortress-solitude) 


\section{Case study2: Walking Street Pattaya, Thailand}

Perhaps one of the major defining features of any public place is its sociability. Walking Street is a public entertainment, and red-light district, located in the city of Pattaya, Thailand. In addition to a large number of institutions offering sexual entertainment, Walking Street is known for its beer bars, restaurants, sports bars, go-go bars, night clubs, and hotels. Walking Street has a spirit of place and atmospheric tone coupled with beautiful beaches make it a popular tourist site attracting both local and international tourists.

\section{Architectural Features from case study 2}

Walking Street atmospheric tone apart from being perceivable, the red-light district was fashionably designed with various spaces that match the pattern of behavior that people engage in to support both the functional and biological requirements of the space. The following are some of the architectural features of the place.

- Buildings: walking street is an island of love structured with numerous fantastic resort and spa luxury buildings and spaces offering a number of sex-oriented services including dining, massaging and go-go dancing. The hotels are mostly a storey building featuring Le Corbusier concept of communal spaces with number of terraces, rooftop gardens, and exterior glass walls for the visitor to have a look of the outside environment (Figure 8).

- Landscaping: there is a varying number of recreational spaces along the beachfront with beautiful coconut trees, swimming pools and different seating furniture for dining and massage; however, some outdoor gardens are situated at rooftop enjoying beautiful views of the surrounding environment.

- Material finishes: warm material finishes, particularly in the indoor environments, were chosen specifically to create a dramatic and romantic effect this is obvious in most of the beer and go-go bars, restaurants, night club and the building façade along the walking street (Figure 9). 

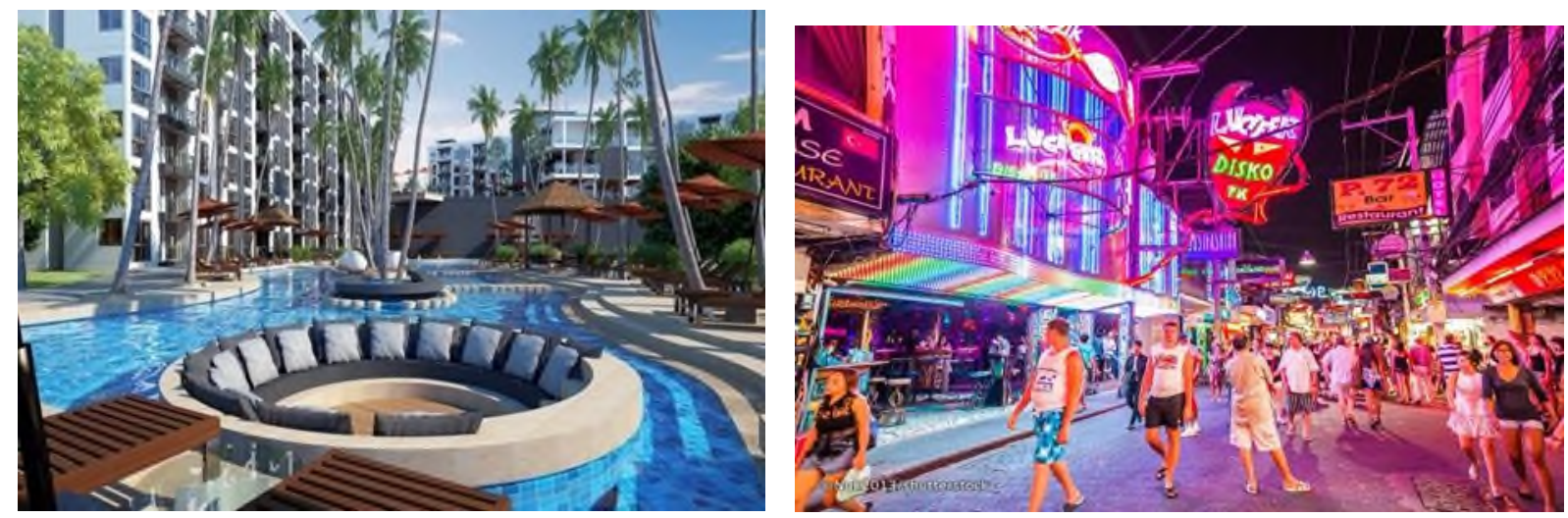

Figure 8: Arcadia Beach Resort, Pattaya Figure 9: A Night View of Walking Street, Pattaya

Figure 8: Arcadia beach resort is selective in material finishes and, design to offer best pleasure and recreation services for, the visitors including massaging, dining and swimming selected for the visitor.

(Source: bing.com/images/walkingstreetpattaya18:10:19)

Figure 9: walking street Pattaya is known for its various sociabilities, such as entertainment, bars, nightclubs, and sex-oriented services. The street is known for its neon signage and also in the interior, particularly in go-go bars colors are decisive.

(Soure:bing.com/images/walkingstreetpattaya18:10:2019)

\section{Discussion and Findings}

In this study, it is clear that there is a strong connection between architecture and human emotion as we can see from the mid-20th-century architecture. Le Corbusier and Frank Lloyd Wright are among the famous aesthetician that design buildings to have a strong effect on the user. This could be seen demonstrably in their Villa Savoye and Fallingwater projects respectively.

Also, material finishes and nature in the form of effective landscaping are among the strong design elements architects use to create a dramatic effect on the people. Further, these elements play a vital role in a sexual relationship, they are among the essential features of the romantic architecture of the 19th century in which nature, unusual colors and geometric building form are used to create an intense emotional feeling. 
Moreover, architecture is also symbolic artifact as noted by feminist, Briginshaw (2001) and Lefebvre (1991) that tall buildings metaphorically symbolize force and male fertility. In this sense, a building represents gender. Similarly, Greek and Roman worshiping of Priapus the well-endowed god of fertility and they built temple and building in the form of phallic form are other examples supporting the gendered nature of building form.

\section{Conclusion}

Architecture as a work of art is a meaningful entity built upon a paradigm of communication, similarly, as an aesthetic object, architecture can be felt by the senses in which its design and internal arrangement of material and spaces could trigger a sensation including sexuality.

Similarly, architecture is a product of social function as it is a common theme in the brutalist design. It gives meaning based on its components and features. Therefore, architecture culturally produces an artifact. In this sense, architecture could be produced to symbolize a particular set of people in line with its culture, location, features around it and design objective. Referring to the case study, Walden 7 for example, when it was freshly built it attracted diverse prostitutes and transsexuals. Further, many public places such as tourist sites, resort and spa hotels, night clubs, among others are designed to give a functional identity to the respective gender group. Finally, there is a strong connection between building and gender, in other words, a building could be gendered.

\section{References}

Aslam, M.M (2006). Are You Selling the Right Colour? A Cross-cultural Review of Colour as a Marketing Cue. Journal of Marketing Communications. 12 (1):15-30. DOI:10.1080/13527260500247827. 
Bonta, J.P. (1979). Architecture and Its Interpretation: A Study of Expressive Systems in Architecture. London: Lund Humphries, 232.

Briginshaw, Valerie (12 October 2001). Dance, Space, and Subjectivity. Palgrave Macmillan. p. 130. ISBN 978-0-333-91973-6. Retrieved: 17 September, 2012.

Eco, U. (1997). Function and Sign: The Semiotics of Architecture in Rethinking Architecture, ed. Neil Leach. London: Routledge, 182.

Foucault, M. (1990). The history of sexuality: An introduction. Vintage.

King, E. (2016). A night at Ricardo Bofill's Barcelona high-rise, Walden 7. In Fortress of Solitude. Retrieved from https://frieze.com/article/fortress-solitude

Labrecque, L.I.; Milne, G.R. (2011). "Exciting red and competent blue: the importance of color in marketing". Journal of the Academy of Marketing Science. 40 (5): 711-727. DOI:10.1007/s11747-010-0245-y.

Lefebvre, H., \& Nicholson-Smith, D. (1991). The production of space (Vol. 142), Blackwell: Oxford.

Mountford, R. (2001). “On Gender and Rhetorical Space. Rhetoric Society Quarterly .31, 41 71.

Munro, T., \& Scruton, R. (2018). Aesthetics. Encyclopedia Britannica. Retrieved from https://www.britannica.com/topic/aesthetics

Ogden, C.K., and Richards, I.A. (1923) The Meaning of Meaning

Pallasmaa, J. (2012). The eyes of the skin: Architecture and the senses. John Wiley \& Sons.

Phallic Architecture. (2014). Wikipedia Encyclopedia. Retrieved from https://en.wikipedia.org/wiki/Phallic_architecture

Williams, R. J. (2013). Sex and Buildings: Modern Architecture and the Sexual Revolution. Reaktion Books. 


\title{
QUEERING THE FORMAL ARCHITECTURE
}

\section{Armağan GÜLHAŞ ${ }^{1}$}

\begin{abstract}
Unlike current architectural discourses, it's known well that, education and practical applications of architecture sustain its formality on space and city. While the formal and functional perception in architecture causes a lack of relationality between the inputs in space, it restrains this relationality to masculine position within a Cartesian duality.

Along with the dualities between form/matter and subject/object; the motivation of creating, designing and organizing establish the problematic of this study. As an alternative way of this heteronormative stance in space, queering the formal architecture creates different passages within architectural education and practices. This move makes it possible to look for the problem by excluding the formal and solution-focused reductionist approach, rather than solving it.

In this way, with the materialization of the formal thought, space gets rid of various abstractions and enters into an ambiguous embodiment. The links that will be established in the triangle of architectural, feminist and queer theory will be providing an alternative view of architecture.
\end{abstract}

Keywords: Queer, Formal Architecture, Problem, Solution

\footnotetext{
${ }^{1}$ Research Assistant, Istanbul Kültür University, Faculty of Architecture, a.gulhas@iku.edu.tr
} 


\section{Introduction}

Problematizing the essentialist concepts and behaviors within normative relations in architecture can be one of the ways of queering architecture. Proposing a queer perspective against solution-focused policies as being the main idea in the study, enables to create motivation for carrying the assumed information and methods from the area of solutions to the area of problems within architecture, being an area of establishing identities. Causing for assumptions to which neutrality and originality are attributed, to undergo deconstruction, creates for a tendency to appear for problematization of assumed solutions. Therefore, the application of a queer perspective in the axis of problem and solution concepts seems to be a way of making it visible. In the study, primarily general information will be given about the concept of queer and its usages and descriptive relations of queer shall be problematization. By passing on to the concept of queering, discussions about architectural acts will be made by using examples that will create opposition with solution-focused strategies of Neufert.

\section{Methodology}

In this study, as being a way of queering the construction forms which I have formally defined within architecture, it will be focused on problematization of solution-focused attitude. As a method, examples from the book of "Architects' Data" which is frequently referred to in the triangle of architectural design-application and training as a source, as being a work of Neufert that has been published in 1936 and which has reached our time by being extended, shall be used in comparison with architectural acts proposing different viewpoints. 


\section{On the Indefinability of Queer}

Generally queer is a concept that has been included in identity policy as having a usage that extends opinion and expression area compressed within dual forms of homosexualityheterosexuality, together with oppositions in relation to a stable communal gender concept. By deeming negative effects created by monolithic structuring of identities as a problem, in the other categories, a search for perspective in which aspects like race and ethnicity have interrelated constitutes a fundamental basis for the queer idea. While there are different queer definitions, as a common definition, by transforming gender, communal gender and normative order of sexuality into a problem, queer which turns identity, community and policy approach upside down, can be defined as a concept that criticizes all types of identity, community and communal gender alternatives believed to have evolved through natural ways. (Jagose, 2010: 121) If queer is defined on commonality of infinite sexual identity, practical, expressive areas, it would be correct to read it as a criticism relating with identity concept and not as a pluralist liberalism: "Because queer is the response given to restrictions caused by emphasizing freedom and identity awareness in lesbian, feminist and gay movements”. (2010: 154)

The reduction of validity of liberal, ethnical and separatist concepts relating to identities through historical progress, has also prepared the ground for queer to come out. In contrast to exclusive tendencies coming out with separate identity categories such as lesbian and gay, ambiguity of queer has come to the forefront. Queer concept, has a placement in architecture, which increases its impact through time. When Betsky defines a venue by using the concept of queer, she mentions about places that are mixtures of human-made/natural spaces and real/imaginative ones. By matching this new alternative queer space with counter architecture, she defines them as free spaces being relieved from classification of buildings and social coding's. (Betsky, 1997: 25). Even though she states that she does not limit queer with spaces 
relating to sexual preferences of people, queer venue examples given by Betsky (gymnasia, Turkish baths, gay bars, etc..) seem to be restrictive in many respects. In this study, relationship of space with queer will not only be evaluated as per the visibility or effectiveness of queer individuals or situations relating with sexual desires in the space, but instead of mentioning what constitutes a queer space, by investigating how they have formed, it will be focused on making this information become useful.

By eliminating the descriptive relationship of space with queer, considering queer with a viewpoint, in fact, overlaps with ambiguity and non-descriptive aspect of queer. Investigating queer in this way, criticizes forms of domination and construction in architecture while encouraging to transform them at the same time.

\section{From Queer X to Queering X}

With the usage of queer in the form of the "Queer X" mold in which it is present as a factor being qualitative and descriptive, I think that a relevant architectural reading will have a solution-focused, stable structure, reducing conceptual ambiguity of queer. For this reason, instead of describing architecture or spaces with queer, queer comes out in front of us as a perspective, to assert queering, as having a usage that is action-focused and which does not restrict its potential.

One of the most important differences that exist conceptually between queer and queering is related to timeliness and completeness. While something that is described as queer, defines a finished-completed time, queering defines the process itself and it's not being completed and that its ending bears ambiguity. The best example that can be given for this is queer space examples of Betsky which I have previously mentioned about. Queering, which we situate opposite to this, is a structure that destroys what exists and hacks it, and it also contains queer in an explicit way. Therefore, for relations, usage of queering instead of queer among the 
concepts and methods bears a critical role in this study which we realize about architecture. While questioning the formal relations and solution-focused structure of architecture, the situation where perspective which emphasizes the problematic aspect with design bears assertion of queering finds its corresponding features.

\section{On the Formality}

While formality is mainly related to material form in architectural hypothesis, with a wide perspective, it defines thought organizations going beyond what is material. Formal perspective corresponds to a system that has the assertion of universality and that basis the applied methods on abstract acceptances. Whether they are practical, theoretical or pedagogical, architectural acts place architecture in an area creating practical/functional/aesthetic solutions to problems as the outcome of formal perspectives. Even though we see oppositions to formal viewpoints from different ways, nowadays we can not observe that this is reflected much on architectural acts. Although architectural design contains a process and socioeconomically and ethical layers being included, formal relations that are tried to be established as based on the final product and particulars defined by it, continue to remain at the forefront. Therefore, materializing formal relations is one of the conditions of queering architecture. Passing from abstract interrelations to the world of material relations and shifting solution-focused organization relating to design to design problem can be one of the first aims. Hence, it can be possible to transform inferences and methods relating to design and space from an abstract/masculine/bodiless world into a conditioning process that embodies and queers.

\section{Formality of Definable Architecture}

Not only in architectural design but also in articulated urban spaces, discussion of 
effectiveness of formal relations and social codes constitute the starting point. Solution focused politics of architecture and design creation, should be seen as an attitude deepening formal relations and social codes. While Agrest mentions about designed and non-designed productions and interrelations, he states that design being created in architecture passes through a normative cultural process as being different from what has not been. By neglecting formal comparisons among different architectural approaches in architecture, he emphasizes the difference between what has been designed and what has not been designed. While he defines the act of design creation as a social practice among approved rules and norms, he states that non-designed productions resolve the limits of architecture. (Agrest, 1974: 48) While the situation of not being designed is quite in contact with queer within venue scale, problematization of designed one shall feed queer thinking practices in relation to the space. By starting from the point emphasized by Agrest, problematization of normative relations in architecture and the essentialist concepts and behaviors, pulls architecture into the queer. Therefore, application of queering, as being an act, in the axis of problem and solution concepts in the plane of architecture, seems to be the way of making it become visible.

\section{On the Problem of Solution-Focused Perspective}

If thinking of a problem in a philosophical plane is defined with a Bergson approach, it will be more related with finding it instead of solving it. A speculative problem will be resolved at the moment when it is correctly revealed. In another way of saying it, if a problem can be expressed, its solution will also be included in it as being covered. (Deleuze, 2014: 55). However, general opinion in empirical area is related with the idea that problem will disappear together with the solution. 
Hence, the questions to be asked could be as: "Do problems exist until their solutions are found? "Does a problem only correspond to lack of knowledge or is it only a pedagogical aspect?"

"However, just as in geometry we imagine the problem solved, so in algebra we operate upon unknown quantities as if they were known: this is how we pursue the hard work of reducing problems to the form of propositions capable of serving as cases of solution. We see this clearly in Descartes. The Cartesian method (the search for the clear and distinct) is a method for solving supposedly given problems, not a method of invention appropriate to the constitution of problems or the understanding of questions. The rules concerning problems and questions have only an expressly secondary and subordinate role. "(Deleuze, 1994: 161)

Thinking act that is perceived as a search for solution relating to the existing problem, constitutes a social and pedagogical prejudice for Deleuze. (Smith, 2006: 146) Since thinking about the problem as constituting an interface on the way to find a solution, creates a priority relationship, it can be considered to be a wrong practice to the attributed values. It is not sufficient to solve a problem with a series of cases being created with an analytical perspective. While the solution corresponds to non-continuity forming in the continuity of the problem, forgetting about the problem that is assumed as being solved, transforms the solution into an abstract generality. (Deleuze, 2017: 221) On the other hand, while being only involved with correctness or wrongness of solutions, the question about how correct the problem is, is not frequently asked. However, it is also required to mention that many of the problems are correlated with solutions in the form of memorizing. According to Deleuze, our belief in that correct and wrong concepts are related to solutions starts from the moment when we are a child 
and it is a communal aspect. These packages in which problems having data are combined with memorized solutions, constitute strategic productions formed to avoid problems to be thought about. For the problems given by teachers, the only thing expected from the student is to solve them. And it is a fact that what corresponds to the solution in this example is equal to memorizing the solution. Therefore, this structure that is created is a kind of slavery that avoids the establishment of creative opinion. Actual freedom is not related to coming up with memorized solutions to a problem having data but it is related to having the competency to determine what the problems are about. (Deleuze, 2014: 55)

Its difference from the solution of problem is that it has a structure that has been determined objectively. (Smith, 2006: 138) In this situation, while solution corresponds to what is pragmatic, problem that is the structure constituting is virtual. Virtuality of problem is related to the structure that continuously changes/produces the solution and itself. Passages between problem and solution and creative transformations, constitute potential areas as being different from problems having data and memorized solutions. The problematic area that can be defined as this kind of a plurality area can also be considered as a deduction that starts from the problem and goes towards accidents and events including the relevant conditions and solutions. (Smith, 2006: 145) Problematiczation does not mean representation of something that previously existed or the creation of what does not exist. It can be considered as acts that include opinions that place a situation in the game of wrong/correct aspects (political, ethical, scientific, etc). (Foucault, 1990: 257)

Way of asking questions gives opinions relating to the problem and subject. The question of "What?", bears hierarchical aspects within itself due to its essence. In return for the hierarchical structure in the questions, Nietsczhe transforms questions into question formats of "Who?" and "Which?". Instead of the question of "What is tragedy?", by asking the question of "Who are Apollo and Dionysos?", and instead of the question of "What is reality?", by asking 
the question of "Who want to have the truth?", he develops his way of thinking. With the changing of questions, while facts turn into interpretations, problem becomes very apparent. (Wasser, 2017: 60) McCormack, mentions about a critical point about how problem is asked. As a problem, he considers terrorism as the subject and he asks this question: "Can terrorism come to an end?". According to McCormack, terrorism is a phenomenon regarding which problem-solving parties, meaning the ruling government will have control. It is observed that asking this question in this way does not cause any threatening particular to arise for none of the subjects (terrorists, terrorized ones, and problem-solving parties/ruling parties). In this context, the problems can never be solved. Hence, each interaction between problem and problem-solving parties cause new problems to be created (2009: 21).

\section{An Experiment on the Formal Architecture: Neufert}

Solution-focused theories are subject to an evolving continuity between the old and the new. While the hierarchical continuity being established closes the paths from the new towards the old one, it enhances correlation with the change factors coming out with time. (Williams, 2000: 206). The purpose in this study that will be realized concerning Neufert is to reach to the questions from answers with a queer perspective and to make the subject become problematic, instead of clearing the given answers and providing new answers.

Architects' Data of Neufert, being a normative architectural structure, has been translated to 17 different languages starting from its first year of the establishment being 1936 until today. While Architects' Data has been divided into 5 sections in its early editions, today it contains 20 sections being extended and developed. Following Neufert the book has also been developed by his son Peter Neufert and a group of architects/engineers and it has been renewed to comply with the new concepts and standards and in the year 2019, its 39th edition has been 
published. This informations bear significant importance in showing the impact area of Neufert and in emphasizing its historical aspect. The book has been compiled about various architectural solutions ranging from human measures to interior space organization and from infrastructure services to daylight and optical issues. Neufert who has made the final big revision of book in the year 1979, 7 years before his death, has brought architectural applications at a point where a situation without standards can not be imagined with the success and popularity he has attained. A short while after its being published, DIN (Deutsches Institut für Normung) standards being used in the book, have begun to be applied in many of the architectural studios, offices, and academic grounds.

In this book he has created for designers, Neufert has also given many proposals about how a design should be like. While this programmatic responsibility loaded on designers contains a human-centered masculine position, it moves within a routine reason and outcome relationship. To explain it with an example, he mentions a designer's learning about appropriate furnishing ways for people to feel comfortable at the venue and for the works to be facilitated. This general and abstract solution relating to design and the single directional relation established with the problem do not reveal what the problem is constituted of. Interventions in policies relating to the design, working principles of designer and the relevant method can also be added. In the calendar recommended relating with planning of design process, he states that starting from the ending of preliminary design, to establish a mental distance between designs and designer, it is required to leave a design space of 3-4 days in between. Mechanical relation form which he tries to establish between design and designer produces receipts as the case with paths followed up during the stage of shaping the structure. On the contrary to these expressions of typification, in between the lines he also mentions ideas that turn mechanical relations upside down. While Neufert states that a human being is not only a biological creature needing a specific area and that his emotions should also be considered, he opens of small holes in the 
mass he has established in a way.

The habit of human-focused solution production in relation to design gets into crisis as the person being the user leaves the equation. As being an example for such a crisis, Bat House Project contest that has been organized in the year 2007, contains extraordinary situations from different respects and thus, it presents an architectural perspective where problem comes before the solutions. When it is requested from architects to construct a home for the bats, changing of scale and users cause for the crisis to occur in relation to the design. Apart from having the practices to create human-centered designs, for many of the designers trying to idealize the people being evaluated, Bat House Project does not allow any other paths than leaving heteronormative practices. Furthermore, two ecologists being bat researchers who were part of the jury of this contest, cause for contest practices of architects to be changed. Discussion of what is best for the bats shows that it is passed on to the process of producing creative problems. (White, 2014: 299) Many problems relating to design, commence negotiation processes relating with bats instead of being limited with a general solution representing the bats (ecologies about the bats). In this way, leaving the heteronormative design approach aside and having a problemfocused thinking strategy, makes both designers and designs gain a queer perspective.

The concept of standardization defines a normalization dimension that is frequently reviewed in architectural expressions. For example, the rules which are specified for bricks, also determine body policy as it is subject to an ideal body form at the same time. (Vossoughian, 2014: 35) Brick standards that are situated with a logic similar to DIN standards of Neufert in paper formats, constitute an important step in relation to structures. Neufert who considers the establishment of a wall within a normative order with the joint thickness has reduced the current format of $12 \mathrm{~cm} \times 25 \mathrm{~cm}$ (width $\mathrm{x}$ length) to $11,5 \mathrm{~cm} \times 24 \mathrm{~cm}$ meters, in a way to conform with the systems being organized on basis of $12.5 \mathrm{~cm}$, being 1/8th in ratio. In this way, when the joint thickness of $1 \mathrm{~cm}$ is added, while dimensions sum up to $25 \mathrm{~cm}$ from width and length, a single 
width dimension will correspond to Neufert measure of $12.5 \mathrm{~cm}$ as including its joint section. This solution brought up by Neufert for establishing bricks can be read as the formation of his world of measures and externalization of conceptual dimensions of structural aspects. What other features does a wall or a column have apart from their functions? These structural elements start the destruction of functional perception as being proportionate to the context and problems they produce. We can search in the structures and expressions of Eisenman about how limitation aspects and political loadings problematize a wall. With a design approach that attaches symbolic values to structural elements besides their function, in situations relating to the articulation of columns within the venue and it's being constructed in very big or small dimensions differentiating it from a classical column, column starts to have internal or external motivation. (Eisenmann, 1999: 212) Another problematic approach that is similar can be read through an architectural project of the recent period. As is different from the normative wall of Neufert having an interval of $12.5 \mathrm{~cm}$, the project of a Mexican architecture office named as "Prison Wall" being aimed to form the border wall considered to be established at the AmericanMexican border, creates a situation where the solution-focused perspective of wall concept is interrupted. Designers approach critically towards the issue of border wall being brought up to the agenda by American president Donald Trump and they reveal this situation with a design where there is a wall established on the side facing Mexico and where the side facing America is a place where immigrants are judged, trained and expelled as constituting a prison, and where it can be climbed on the stairs that are situated and where it can be walked on. In this way, a position is created where it is enabled to talk about problems relating to the establishment of the wall as being outside the scope of a normative and stable wall. The project investigates an assumed wall concept and tries to queering the design.

The conditions under which the solution-focused design policy of Neufert has been shaped brings a different discussion into the agenda. "Rapid design" method of Bauhaus, 
becomes effective in shaping the opinions of Neufert. Rapid design method is an architectural training application aiming for the sector to support rapid production and industrial concepts in the period after the war. In this training, it is expected from students to find rapid solutions for the given architectural problems and to visualize them. Hence, in rapid design method, by using ready plan schemes and sections, it is targeted to create a housing design in a few hours. At the same time, it aims to simulate the pressures confronted by modern period architecture in professional life. The intersection of the path of Neufert with this training method following his graduation bears significant importance creating the foundation of Architects' Data. In conformity with this training system where design is arranged in a hetero-normative and routine way, standardization has become the most important topic for Neufert. According to Vossoughian, acceptance of the idea of gaining time starting with rapid design training and continuing with Neufert, makes the design activities of architect become routine and has caused for vertical design practices to be established. (2014: 49) As is similar to this, we can also observe hegemony of similar techniques and assumed solutions in architectural project contests. The desire to both win the contest and to realize this act without losing much time reduces the chance of contestants to produce creative problems and it causes a solution-focused and empirical approach to come out. The research conducted by Sönmez and Keskin in relation to architectural project contests in Turkey, produces the inventory of gaining schemes of contests. While it is analyzed that in the contests the previously experimented and reliable schemes are gaining, it is emphasized that limited solutions keep on being repeated and that alternatives are not produced. (2017: 8). However, it is required to state that it can be possible to produce alternative solutions by creating the problem and passing on to the problematic area.

Space organizations that are proposed by Neufert and in other solution-focused theories are generally based on dual categories. In space organizations, there are main spatial references and programs such as public-private, open-closed, woman-man, domestic-professional, and 
consumption-production which are dominating. In addition to this, the same dual categories are also seen in relation to the fixtures within the space. Especially separation and representation of women and men as being revealed in housing designs are examples of this. (Vossoughian, 2014: 36). While queer perspective comes up with a perspective in which there are no dual oppositions such as woman-man or interior-exterior as the case in structural proposals, it is also not solely constituted of records of practices that have remained hidden until now or that have been hidden. (Gorny \& Houvel, 2017: 3). Therefore, it is related to transforming both hidden and apparent events relating to the past into problematic forms together with their current reflections and layers. The kitchen which could be an efficient space for problem and solution creation can be evaluated in this respect. While Susan Henderson examines Weimar housing design as being specific to Frankfurt Kitchen, she emphasizes the relationship established between metal surfaces and modular kitchen design having many parts, with the modern appearance of daily life. This Frankfurt Kitchen being structured and fictionalized is the realization of a kitchen functioning as a machine. (1996: 235) The approach relating to Frankfurt Kitchen is also seen in kitchen drawings of Neufert. Due to the reason that excess number of components increases problems relating to kitchen and the solution requests imposed on the architect Neufert has evaluated the most extensive fixture drawings, measures, and workflows comprehensively at the kitchen space. Solutions foreseen by Neufert for the kitchens have been created in relation to body measures as being much more than in the case of other venues. With the impact that it bears variations aiming for more number of functions and usage forms with respect to other venues, all the space has been determined in relation to an ideal female body. Both in the Frankfurt kitchen and in the solutions of Neufert, the woman is seen as a machine belonging to internal space and man is seen as a subject belonging to the external world. As being the case with spatial arrangements, by starting from the point of dual and unjust distributions with respect to spatial aspects, it can be stated that Neufert and Frankfurt Kitchen belong to the Cartesian 
world. While hetero-normative gender policies are materialized with design, femininity remains in the background. Therefore, in the kitchen example, both gender policy and design policy come in front of us. Solutions brought up by these two policies bear similar contexts. Therefore, assumed acts in relation to the kitchen carry out solution-focused strategies and add gender quality to space and a reductionist approach is made in relation to space such as a kitchen in the housing where there is a high level of density with respect to the variety of acts and physical conditions.

\section{Conclusion}

Neufert creates Architects' Data with design-oriented theoretical based approaches and with the practical solutions supporting this theory. Architects' Data which almost contains all types of structures, programs, and structural components, should also be evaluated concerning social and ideological layers being defined in addition to ready solutions he has created for the designer. To express a new view of the problem in a queer way, the order in which the results of the assumed solutions are part of it should be investigated. By using queering as a tactic, this study has revealed problematization and stretching potentials of formal relations and solutionfocused policies within the context of architectural hypothesis and practices.

\section{Acknowledgment}

Participation in this conference was supported by Istanbul Kültür University with $\mathrm{U} 0708 / 53 / 0$.

\section{References}

Agrest, D. \& Léger, J. (1977). Design versus non-design. Communications. 27. 79-102. doi: 10.3406/comm.1977.1410. 
Deleuze, G. (2014). Bergsonculuk. (H. Yücefer, Trans.). İstanbul: Otonom Yayıncilık.

Deleuze, G. (1994). Difference and Repetition. (P. Patton, Trans.). New York: Columbia University Press.

Eisenman, P. (1999) Diagram Diaries, London, Thames and Hudson.

Gorny, R., \& Heuvel, D. (2017). New Figurations in Architecture Theory: From Queer Performance to Becoming Trans. FOOTPRINT, 1-10. doi:10.7480/footprint.11.2.1897

McCormack, B. (2009). The Problem with Problem Solving. Issues in Integrative Studies 27 (2009): 17-34.

Neufert, E., Neufert, P., \& Kister, J. (2014). Yap1 Tasarımı. İstanbul: YEM.

Sheridan, A., \& Kritzman, L. D. (Eds.). (1988). Michel Foucault: politics, philosophy, culture: interviews and other writings 1977-1984. New York: Routledge.

Smith D.W. (2006). 'Axiomatics and Problematics as Two Modes of Formalisation: Deleuze's Epistemology of Mathematics' in Duffy, S. (ed) (2006) Virtual Mathematics: The Logic of

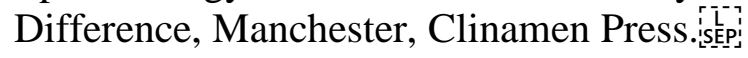

Sönmez, N. O., \& Keskin, O. (2017, March 28). Yarışmalara Katılacaklar İçin Şema

Rehberi. Arkitera. Retrieved from https://www.arkitera.com/gorus/yarismalara-katilacaklaricin-sema-rehberi/

Wasser, A. (2017). How Do We Recognise Problems? Deleuze Studies, Volume 11 Issue 1, Page 48-67. doi:10.3366/dls.2017.0251

White, R. (2014). Gilles Deleuze and the Project of Architecture: An Expressionist DesignResearch Methodology. Doctoral thesis, from https://discovery.ucl.ac.uk/id/eprint/1450434/

Williams, J. (2000). 'Deleuze's Ontology and Creativity: Becoming in Architecture', Pli: The Warwick Journal of Philosophy 9, 200-219.

Vossoughian, N. (2014). Standardization Reconsidered: Normierung in and after Ernst Neufert's Bauentwurfslehre (1936) ). Grey Room. 54. 34-55. doi:10.1162/GREY_a_00125. 


\title{
PRIVACY, PLEASURE AND HOMOSOCIABILITY: GENDERING OF VICTORIAN TURKISH BATHS
}

\author{
Burkay PASÍN 1
}

\begin{abstract}
Under the influence of Orientalist ideology, the British culture incorporated many Eastern forms, one of which is the Turkish bath. During the Turkish Bath Movement in the mid-19th century, more than 600 public bath complexes were built in various regions of the British Isles. The Victorian Turkish baths offered an alternative public environment to the overcrowded working class dwelling and work place.

The gendering of Victorian Turkish baths were threefold. First, as sites for self-governing subjects, personal privacy in the baths was of utmost significance. Second, they had a significant place in sociability among Victorian women, who were able to bypass the masculinized social interactions, especially in the baths located at small spa towns. Third, they provided a variety of safe spaces for queer subjects, distanced from the risks of arrest or assault, ranging from public rooms to individual cubicles where the users meet, cruise, and involve in sexual encounters.

This study concentrates on Victorian Turkish baths that still function as part of larger bath complexes. It follows a case study methodology combined with an archival survey as well as on-site inspections, interviews and questionnaires conducted at these baths. Based on comparative analyses of the data, the study aims to understand how these baths have been gendered throughout their lifetime and how their spatiality conforms to changing gender norms of contemporary British culture.
\end{abstract}

Keywords: Victorian Turkish Bath, Gendering, Privacy, Pleasure, Homosociability

\footnotetext{
${ }^{1}$ Assoc. Prof. Dr., Department of Architecture, Faculty of Fine Arts and Design, Izmir University of Economics, Balçova, İzmir, Turkey, burkay.pasin@ieu.edu.tr
} 


\section{Introduction}

Tradition becomes an ill-defined concept, especially when a unique traditional form of one culture is translated into another. In modernising societies, such a translation shows itself as a mode of (re-)invention of a particular cultural form to generate a common spirit and a suitable historic past for the society. The $19^{\text {th }}$ century Victorian British culture incorporated many Eastern traditional forms which were translated into its modernising society in a myriad of ways. Many of these forms, by means of their sublime aesthetic quality, provided a pleasurable experience and an escape from the detrimental effects of rapid modernisation and industrialisation.

In the middle of the $19^{\text {th }}$ century, the Turkish bath was introduced into the Victorian society and its popularity grew with remarkable speed amongst all sections of the population. Victorian Turkish baths not only provided a pleasurable experience but also functioned as therapeutic centers designating public health and cleanliness. They constituted a hybrid cultural nature associating Eastern habits of bathing with Western, Victorian, and historically Roman, patterns of leisure. The overall success of these baths relied on attracting a broad range of consumers from industrial and commercial classes, who were gathered within the privatised public spaces of the baths.

Tom Crook considers Victorian Turkish baths as schools for moral training of people and examines them as "institutions of active, embodied liberalism: as political spaces where subjects went to practise and enhance their powers of self-government and in so doing embody and perform a clean and respectable lifestyle." (Crook, 2006: 21) For Crook, these baths "allow for an exploration of the material facets of Victorian liberalism, of its spatial and corporeal dimensions" where "personal cleanliness went hand in hand with sober, industrious habits and a conscientious sense of domestic and social responsibility." (Crook, 2006: 21) 
Teresa Breatnach (2004: 163) asserts that "the activity of bathing in the Victorian world can be treated through discourses of improvement and progress, leisure and recreation"constructing alternative habits conforming to accepted morality norms rather than intemperance and filth. Throughout the invention of Victorian Turkish Baths in the British Isles, the Eastern values of cleanliness, pleasure and homosociability seem to have filled the moral gap remaining within the Western norms of health, leisure and privacy. These concerns were paramount to the formation of the baths both as disciplinary institutions and spaces of recreation, where the act of bathing itself is blurred within a public domain of morality and commercialized leisure.

This paper re-visits the Victorian Turkish Bath as an invented tradition. It shows that it aimed at inculcating certain modern values and norms of behaviour such as civility, bodily competence and temperance through dual practices of health and cleanliness, leisure and pleasure, privacy and homosociability. Associating a historical interpretative approach with a case study research, the paper aims to understand how these dualities have been practiced since the mid- $19^{\text {th }}$ century to date and how they are reflected on physical space of the Victorian Turkish bath. In the first section, it provides a theoretical framework for the appropriation of the Victorian Turkish bath tradition in modern Victorian society. In the second section, it briefly presents the historical and social context within which the Victorian Turkish baths were invented. In the following sections, it discusses the dual practices of health and cleanliness, leisure and pleasure, privacy and homosociability consecutively. The paper also aims to reveal whether these dual practices still exist in various surviving Victorian Turkish Bath establishments. 


\section{Theoretical Framework}

In The Invention of Tradition, Eric Hobsbawm and Terence Ranger provide a useful framework to comprehend how the concept of tradition is conceived, constructed and practiced in modern societies. They describe 'Invented Tradition' as "a set of practices, normally governed by overtly or tacitly accepted rules and of a ritual or symbolic nature, which seek to inculcate certain values and norms of behaviour by repetition, which automatically implies continuity with the past" (Hobsbawm and Ranger, 1983: 1). Inventing a tradition is essentially "a process of formalization and ritualization, characterized by reference to the past, if only by imposing repetition" (Hobsbawm and Ranger, 1983: 4).

The invented traditions since the Industrial Revolution have taken three types. The first one is "those establishing or symbolizing social cohesion or the membership of groups, real or artificial communities.” (Hobsbawm and Ranger, 1983: 9) This type is the most prevalent one, embodied in unifying devices and symbols such as national anthem, national flag and national actors. The second type signifies "those establishing or legitimizing institutions, status or relations of authority" (Hobsbawm and Ranger, 1983: 9) organising disciplinary power relations by means of governmental, municipal or religious institutions. The third type includes "those whose main purpose was socialization, the inculcation of beliefs, value systems and conventions of behaviour." (Hobsbawm and Ranger, 1983: 9) In most cases, these three types overlap in order to legitimize certain norms, to generate a common spirit and a suitable historic past for the so-called modern societies.

Victorian Turkish baths exemplify a combination of the second and the third types as they could be considered disciplinary public institutions promoting bodily and mental health. According to Breathnach, "the baths are used as a sign of common progressiveness which is supposedly at the basis of successful empire building in both Eastern and Western contexts" and 
"the bath user is placed at the center of an historical and cultural continuum through an association with powerful empires." (Breatnach, 2004: 170) She asserts that this common progressiveness, power and civilization identified with middle-class is embedded in the use of both oriental and classical styles of architecture and decoration (Breatnach, 2004: 170). They constitute a hybrid cultural nature associating Eastern habits of bathing with Western, Victorian, and historically Roman, patterns of leisure, which can be read in the shaping of both “segregational and recreational, disciplinary and commercial spaces.” (Crook, 2006: 32)

\section{Historical and Social Context}

The Turkish Bath Movement in the British Isles started with the pioneering of David Urquhart in the late 1940s. The movement was supported by various medical practitioners of hydrotherapy such as Dr Richard Barter and Dr J L W Thudichum by means of their lectures appreciating the benefits of hot dry air for the human body. With direct support of Urquhart, Dr Barter established the first Turkish bath in Ireland in 1857, as part his Hydropathic Establishment at St. Ann's Hill in Cork. This was a hot air bath using minimum steam which become a model for the Turkish baths established throughout the country (Figure 1). 

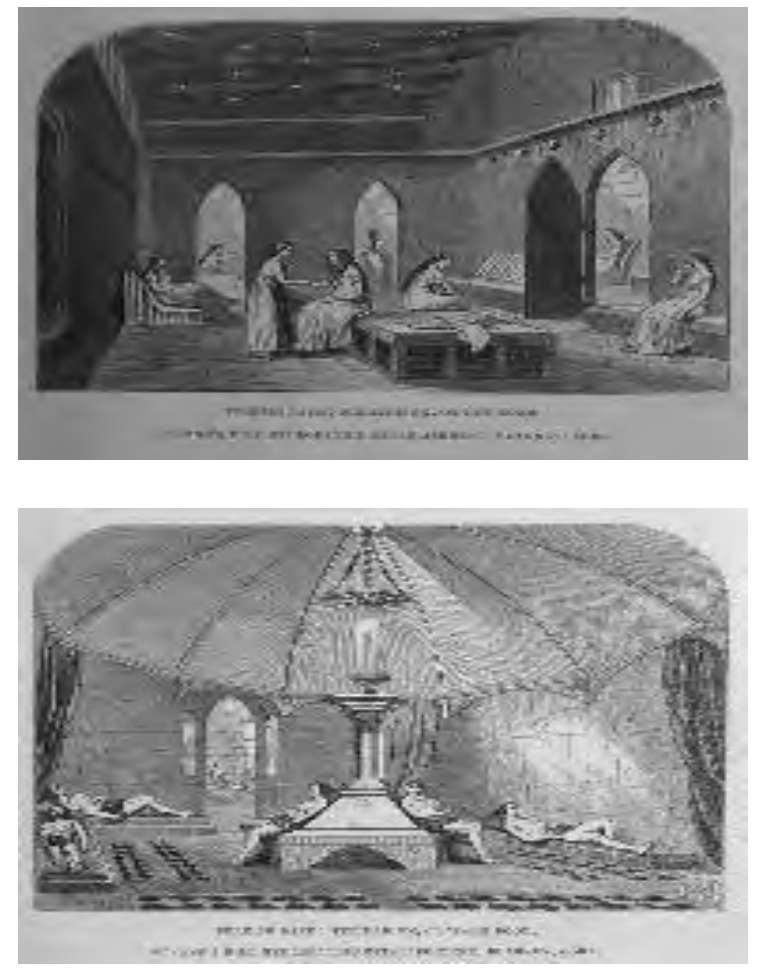

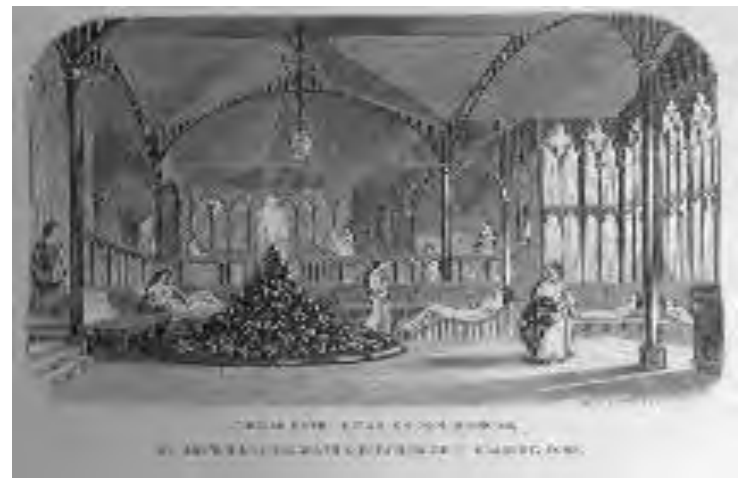

Figure 1. Left: Divan or Cooling Room, Right: Sudatorium or Hot Room,

Bottom Left: Tepidarium or Warm Room (Source: Barter, 1858)

In the following years, the number of public bath complexes increased and the movement spread towards England and Scotland. The members of the Foreign Affairs Committees (FACs) opened more than thirty of the first Victorian Turkish baths in England (Shifrin, 2015: 7), i.e. the first Turkish bath in Manchester by William Potter, Richard Shannon's two Turkish baths in Stephenson Street and in Sunderland, and Charles Bartholomew's Turkish bath in Bristol. The British researcher Malcolm Shifrin has recorded that since 1857 , more than 600 public bath complexes were built in various regions of the British Isles, with various lifespans ranging from a century to a year (2015: 105).

In addition to these entrepreneurial actions, there were social factors effecting Victorian Turkish Baths' rapid spread and popularity among the Victorian society. Until the midnineteenth century, public leisure activities in the British Isles such as bathing, sea-bathing, swimming, dancing, gambling, etc. were largely patronised by wealthy people of aristocracy. Public bathing was seen as part of "formalised daily routines performed by the social elite in the public spaces of communal baths and pump- and assembly-rooms." (Adams, 2015: 1) By 
the $1850 \mathrm{~s}$, the attitudes of upper and middle classes towards leisure and recreation shared a common ground, which can be seen in changing social habits and manners such as "the institution of summer holiday at the seaside, the extension of reading to all classes, drinking in public houses" (Gloag, 1961: 169).

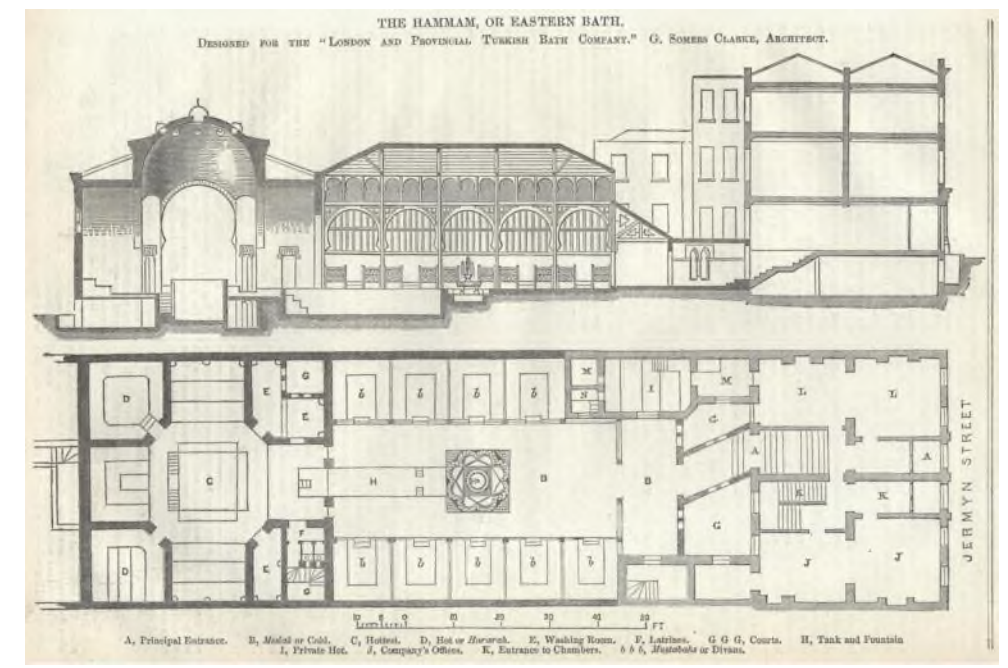

Figure 2. Cross-section and floor plan for the Hammam, the Eastern Bath, designed for the 'London and Provincial Turkish Bath Company'(Source: Urquhart, 1862: 223)

F. M. L. Thompson highlights that "the commercialization of popular entertainment and leisure was a prominent feature of the second half of the century." (Thompson, 1988: 288) As public bathing started to become a popular leisure activity among the middle-class, the idea of personal cleanliness had been associated with the concept of respectability. Within the context of changing social habits of the working class, personal cleanliness had become "a symbol of middle-class status, self-respect, and civility that public baths were seen as the most effective way to improve the health, morality, and social respectability of the urban poor." (Masquelier, 2005: 6) Having connected bodily cleanliness with moral purity, the public baths were believed to "cleanse the social fabric of a society threatened by the poverty, crime, and disorder of burgeoning urban slums...” (Masquelier, 2005: 6) 
The Industrial Revolution had brought about a series of problems threatening public health, such as overcrowding, dirt, and the smoke nuisance, creating unprecedented conditions which made a new movement in favour of cleansing facilities inevitable. This led to an understanding of civility in close association with personal hygiene. Not to offend one's immediate company with unpleasant sights and smells was considered a sign of civility and decency. This brought forward a new ethics of civility based on "receptive mind and sober habits" both in working environment and home life (Crook, 2006: 26). In work place, a clean body was thought to mobilise the practical, hands-on and mechanical intelligence; thus increase efficiency (Crook, 2006: 29). In other public environments, the Victorian Turkish Baths was expected to reinforce the "middle-class belief that cleanliness was central to the fight against both physical and moral decline.” (Breatnach, 2004: 164) Through regular acts of cleansing, as Adeline Masquelier points out, "individuals shape expressions of gender, class, morality, honor, and civility by using the skin, hair and clothing... inscribed with visual statements of social signification.” (Masquelier, 2005: 14). 
In domestic environment, they were believed to have moral contributions such as belonging to home and family life (Crook, 2006: 26).
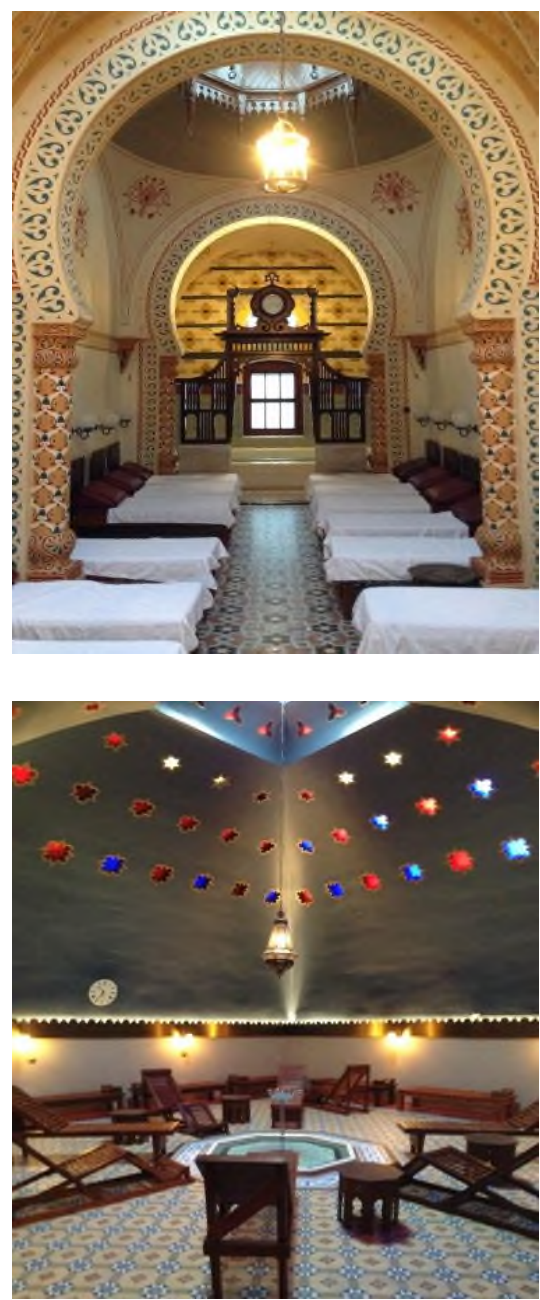

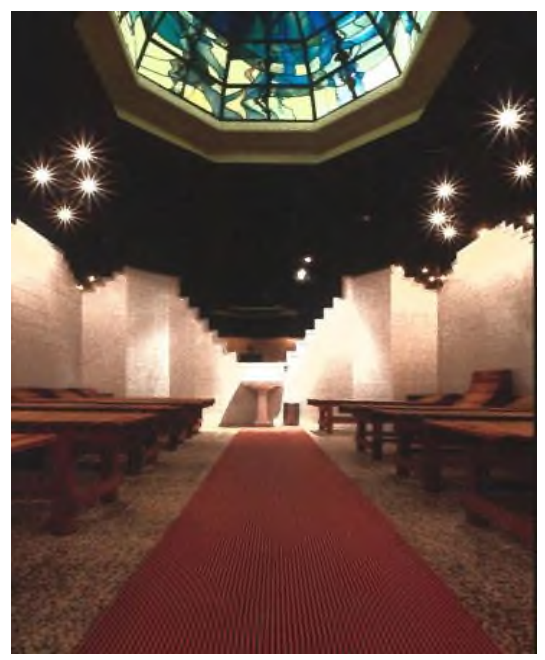

Figure 3. Left: Interior view showing the seats in the frigidarium of Royal Baths at Harrogate, Middle: Interior view showing tepidarium of Western Baths Club,

Right: Interior view of the tepidarium in Arlington Baths Club (Photos by the author)

\section{Health and Cleanliness}

The most triggering factor in the promotion of Victorian Turkish baths was the pursuit of public health and cleanliness for the entire society. The cholera epidemic which occured before the Turkish Bath Movement had led to the stimulation of opening public baths and washhouses by means of regulations of local authorities. The first Baths and Wash-houses Act of 1846 in England and the Towns Improvement Clauses Acts of 1847 and 1854 in Ireland gave a borough or parish, initiative to provide public baths and wash-houses by borrowing money for public washing, bathing and laundry facilities, to make their own bye-laws, and to specify a charge for the use of the facilities provided. According to the act, each adult bather was to be 
supplied with clean water and a clean towel, and give the maximum charge for a warm bath of the lowest class at $2 \mathrm{~d}$ and in the wash-house, each woman was to be provided with a tub and a boiler (Campbell, 1918: 3-4). The Public Health Acts of Scotland in 1867 and in 1897, contained similar regulations for the provision of water for bathing purposes, except for the lowest charge for a bath which often doubled the one in England (Campbell, 1918: 4-5).

Urquhart believed that the existing public baths including individual tubs were inconvenient in terms of ventilation and hygiene. He asserted that the Turkish baths were more hygienic and economic than these baths as they enable the bathing of many people in a single and large hot space. For Dr Barter, the Turkish bath was a significant part of hydropathic treatment against epidemics of deadly diseases like cholera and typhoid. Barter claimed that there was no drug equal to the Turkish bath as a purifier. Gout and rheumatism, and chronic and skin diseases, were not known among the Turks, who were seldom ill, and more long-lived than the Western nations (Barter, 1858: 25). The combination of steam baths to encourage perspiration, cold water baths to close the pores, and sometimes the use of wet bandages and shampooing or massage was believed to expel the poison from the body thereby leaving the patient both well and rested (Breatnach, 2004: 162).

The invention of Victorian Turkish bath put forward the awareness of the individual in relation to his/her body. As Tom Crook highlights, in search for health and cleanliness, the bodily skin became a site for exploration promulgating two new demands: "that washing be regular and applied to all of the body" (Crook, 2007: 561). Crook considers this relation a form of "cubicle space" in which an accentuated sensory intimacy is shaped between individual subjects and their bodies (Crook, 2007: 561), creating a space of self-discipline and self-respect formalised by regular acts of bathing. This cubicle space also extends towards the public environment of the baths controlled by the attendants on the instant of (un)dressing, waiting, walking, swimming, etc. which occur at different places of bath complexes (Crook, 2007: 561), 
and uniformly at different baths accross the British Isles (Crook, 2007: 558). In this context, the Victorian Turkish bath not only functioned for physical cleanliness but also for mental purification and bodily awareness.

In Eastern Muslim geographies, those bathing in accordance with Islamic rules did not need to question the technical aspects regarding the appropriate temperature and humidity levels required for the human body while realizing the weekly bathing ritual. In comparison, the adaptation of the Turkish bath tradition into the Victorian context could be considered the scientification of a traditional form to match long-term expectations of a Western society in terms of health and cleanliness. In search for an empirical basis for the Victorian Turkish bath tradition, the British authorities had to fight with challenges regarding the applicability of the hot air bath as a hydropathic treatment. From their early years, the baths received various objections from the medical authorities, which were mostly based on their promotion "as a therapeutic agent not only as a cleansing agent" (Shifrin, 2015: 94). Some doctors completely forbade their patients to use the baths claiming that they were "injurious to the blood" and "it should be avoided by those with a weak heart", while some doctors allowed their patients to use them "under the supervision of a doctor" (Shifrin, 2015: 95). Another discussion was about the correct temperatures and humidity. While Urquhart and Dr Barter believed in the use of dry hot air, some doctors recommended that "a reasonable amount of humidity was not only desirable, but absolutely essential.” (Shifrin, 2015: 92)

According to Shifrin's records (2015), a considerable number of Victorian Turkish baths were established as part of health hydros such as Swindon Health Hydro, The Royal Turkish Baths at Harrogate and hospitals such as the Newcastle-upon-Tyne Infirmary, Huddersfield and Edinburgh Infirmaries. These complexes not only incorporated the dry hot air bath improved by Dr Barter but a range of supplementary services such as cold water treatments, the cold sheet bath, the sitz bath, the freezing douche, massage and therapy rooms, etc. Relatedly, many 
different subjects of varying professions took part in the accomplishment of the public health and cleanliness service: "patients, medics, masseuses, technicians, wounded soldiers, passing visitors, managers, families, cooks, porters and domestic servants” (Foley, 2014: 15). In this way, the health aspect of the Victorian Turkish baths was highlighted against Eastern type of bathing which was not accepted and applied by all members of the Victorian society.
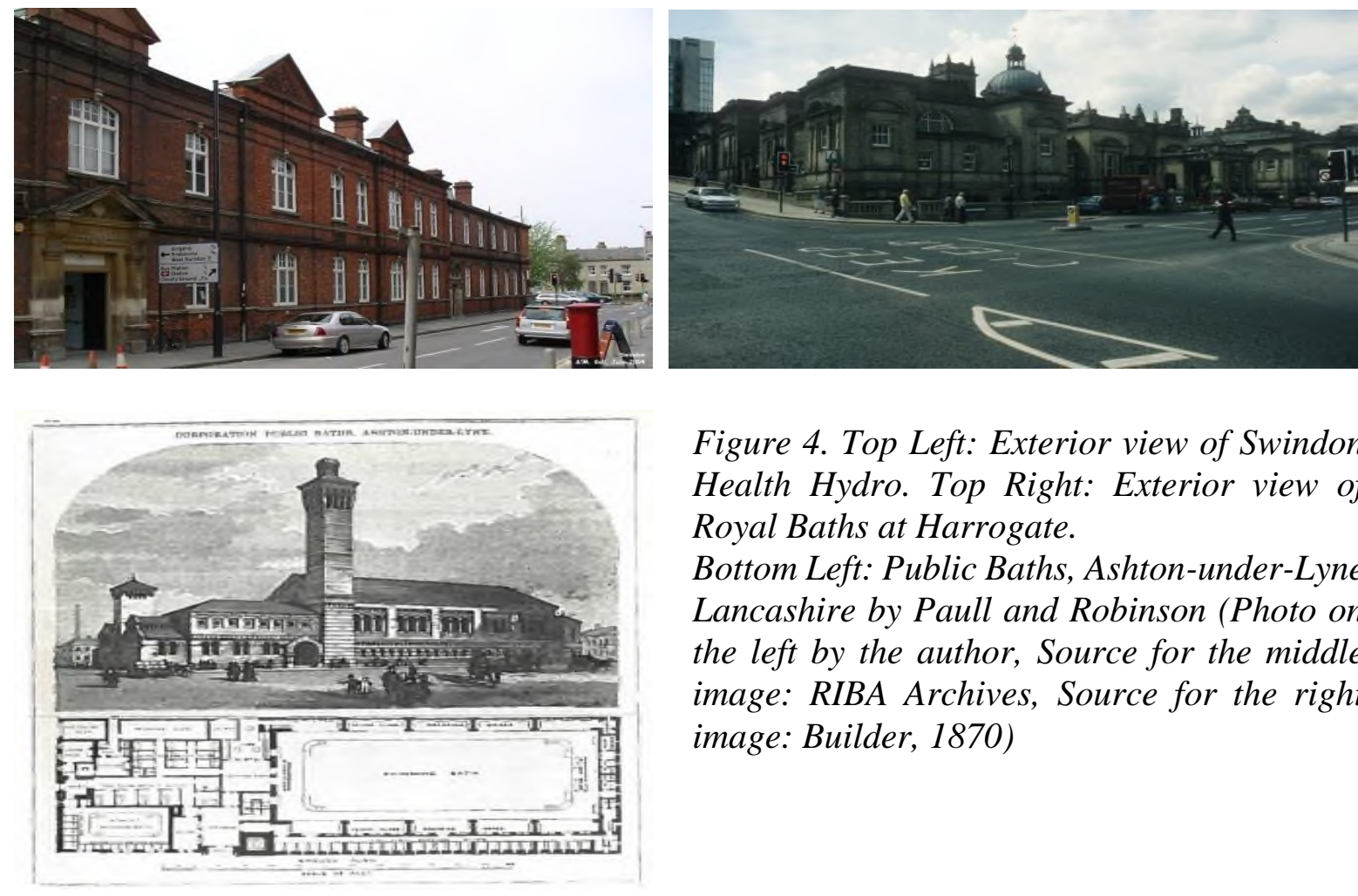

Figure 4. Top Left: Exterior view of Swindon Health Hydro. Top Right: Exterior view of Royal Baths at Harrogate.

Bottom Left: Public Baths, Ashton-under-Lyne Lancashire by Paull and Robinson (Photo on the left by the author, Source for the middle image: RIBA Archives, Source for the right image: Builder, 1870)

\section{Leisure and Pleasure}

One emergent aspect in the daily life of the Victorian society in the mid-19 $9^{\text {th }}$ century was the dissociation of the leisure time and the working time as part of modernization process. However, for the middle-classes, the leisure time did not mean an opportunity for mere pleasure but another occasion for the purification of mind and achievement of moral superiority. Breatnach highlights that "pleasure for pleasure's sake was seen problematic and a threat to social order." She considers the conception of leisure in the mid-19th century as "a fundamental 
anxiety that leisure should not be too pleasurable, but that it must serve other serious purposes... recreation was under legal and philanthropic control bringing alternative activities such as men's clubs, museum visits, etc instead of venues of alcohol" (Breatnach, 2004: 163).

The majority of the British population were unaccustomed to regular bathing in the mid19th century so they were intended to visit the baths for controlled pleasure rather than mere cleaning. As institutions of moral reform playing part in the civilization of the masses, they were alleviating the potentially dangerous social energy immanent within the working class society living in urban areas. (Crook, 2006: 25) In addition to steam room, sauna and hot rooms of varying degrees, the bath complexes also included spaces such as cafe, hairdresser, reading room, billiard room, massage parlour, lecture hall, gymnasium, offering an environment of leisure and pleasure for the working classes.

Urquhart considered the Turkish bath, as not only a place of bathing but also "an instrument for social mixing" in order to "create an intercourse with the lower orders" (Avcioğlu, 2011: 201). He believed that the Turkish bath is a means of cleaning both the body and the mind and should be cheap enough for the poorest working class to be able to benefit from since they had little access to floating water. However, in reality those visiting the baths did not form a singular homogenous group but reflected difference regarding profession and status. Agnes Campbell, in Report on Public Baths and Wash-houses in the United Kingdom, (1918: 28) lists different user groups who regularly used the baths as follows: "tradesmen, artisans, shop assistants, clerks, engineers, apprentices, factory girls, students, seamen, sweeps, mothers with children, carters, labourers, domestic servants, and people of small means who live in apartments..."

Many authorities believed that the baths were places of indolence and luxury at an expense so introducing them to the lower classes would be quite difficult (Shifrin, 2015: 98). This signifies another relation between social class and visual pleasure. The eclectic use of 
classical elements such as Corinthian columns, arched openings, triangular pediments and Eastern motifs such as horse-shoe arches and decorative minarets on the exterior clearly set the baths apart from other buildings surrounding them. The interiors reflected a similar eclecticism with the use of stained glass, arched doorways, tracery, onion domes, patterned tiling, colored plastering and half-moon apertures. The visual richness of the baths both externally and internally assigned a prestigious status to their users.

Breathnach asserts that these "bizarre" interiors which are "eclectic mixtures of oriental decoration and ancient Roman historical tripartite spatial arrangement" were designed to express "middle-class identity" (2004: 165-166). The Victorian Turkish baths contributed to the aesthetic training of its users by providing a high level of visual pleasure in addition to their functional complexity. The Royal Baths in Harrogate, Oriental Baths in London, Victoria Baths in Manchester are some of the examples with neoclassical exteriors and Saracenic interiors, which stand apart from the surrounding buildings attracting the attention of possible customers. 


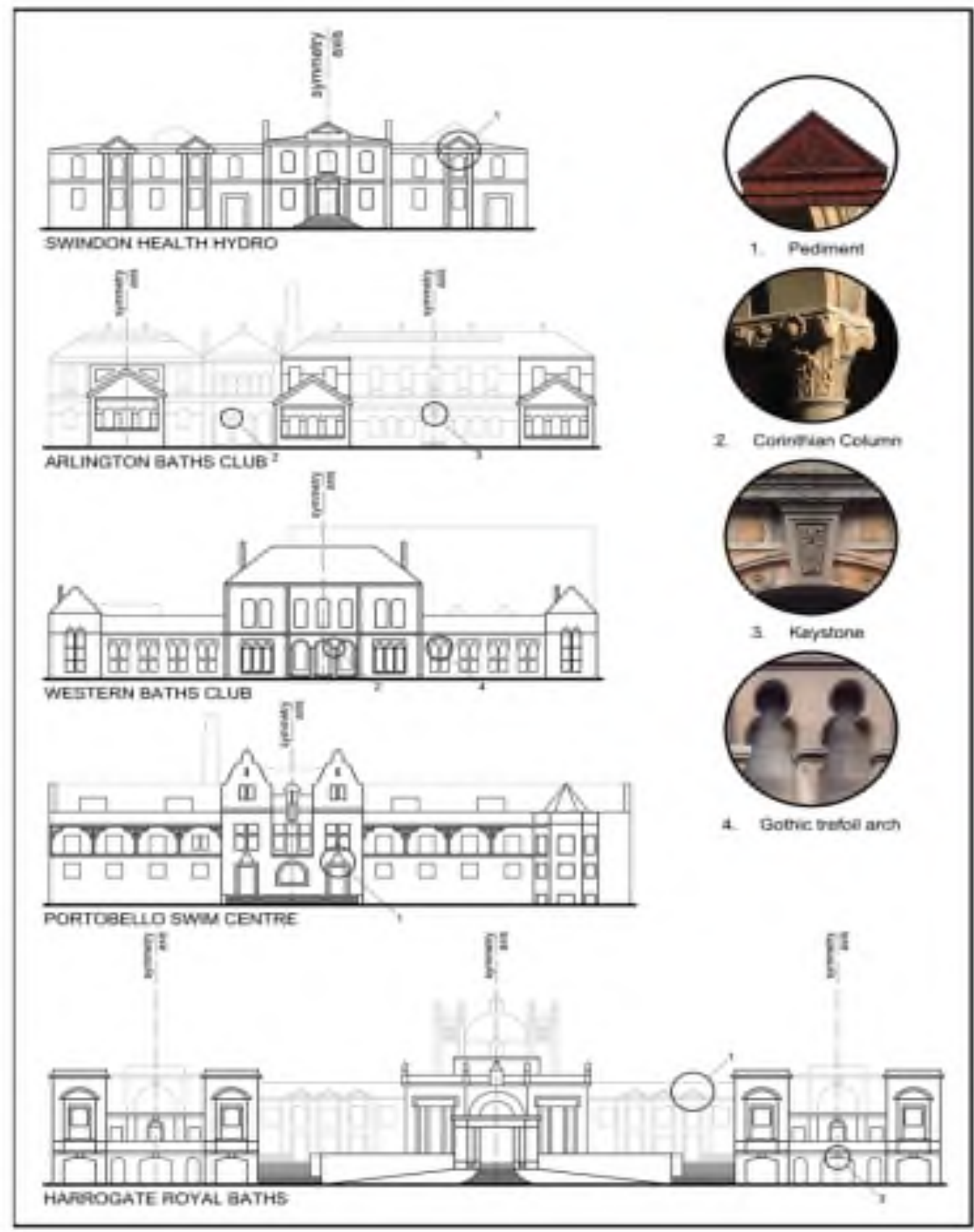

Figure 5. Front elevation drawings of the baths and point details (Drawings by the author) 


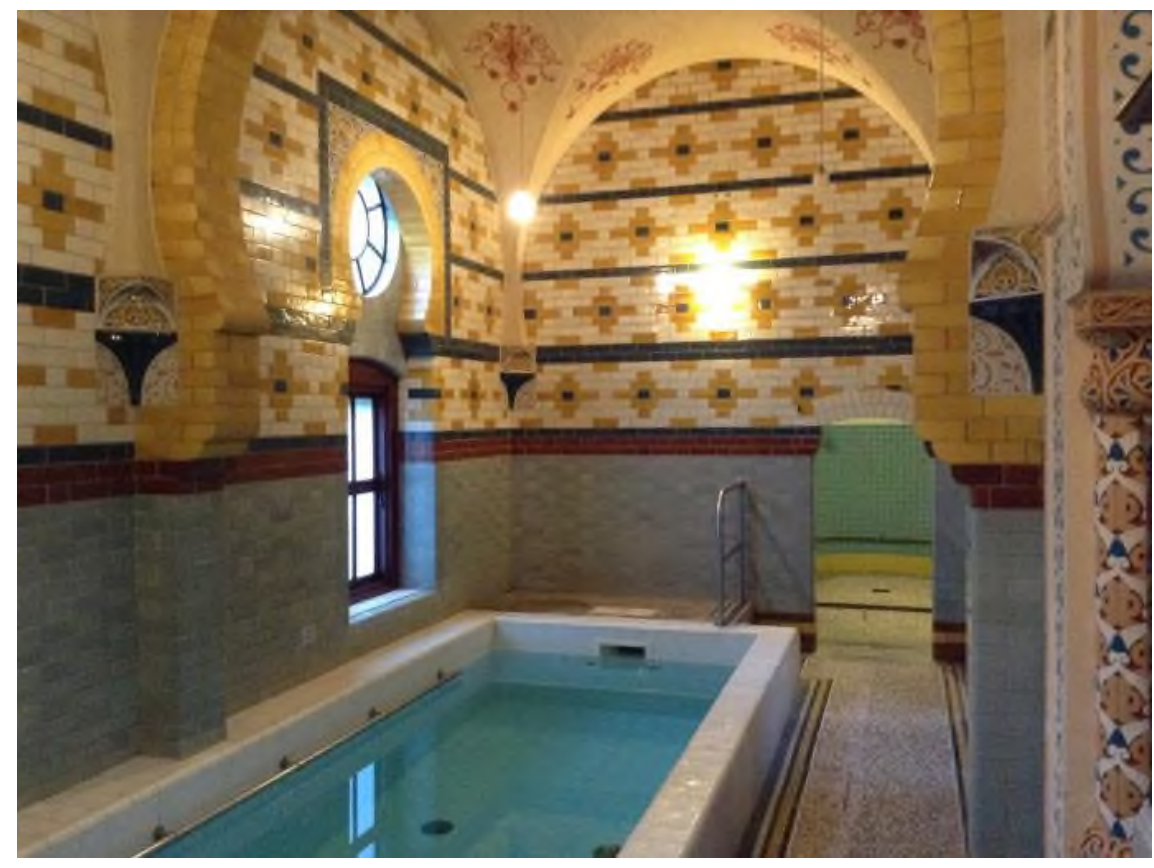

Figure 6. Interior view showing the plunge pool of Harrogate Royal Baths (Photo by the author)

\section{Privacy and Homosociability}

The Victorian Turkish baths created a privatised public environment alternative to the overcrowded working class dwelling and work place. As a disciplinary site to create selfgoverning subjects, personal privacy in the baths was of utmost significance. Except for group activities such as playing billiard, gambling, meetings and special occasions, the users were mostly alone within the private domain of their body and mind and in compliance with personal norms and behaviours of morality.

The baths also had a significant place in sociability among Victorian women. According to Shifrin's records, just over 100 of the baths established in the British Isles provided facilities for women either in the same building with the men's but with separate entrances or in separate sessions on specific days or at stated times (2015: 277-279). Although most of the gendersegregated facilities turned into mixed use in the early $20^{\text {th }}$ century, providing specialised sessions for women still continue in some of the baths, i.e. Western Baths Club and Arlington 
Baths Club in Glasgow, as a mode of positive discrimination to encourage more women users to visit the baths. The sociability among women was enhanced by a series of sports activities one of which was the swimming competition organised by Arlington Ladies Swimming Club. The first competiton was held on 4th November 1875 in various categories such as plunge from diving board, plain swimming, back swimming, side stroke and sculling (Mitchell Library Archives). The competition was repeated annualy until the 1960s when the Arlington Baths started to offer mixed-gender facilities for its users.

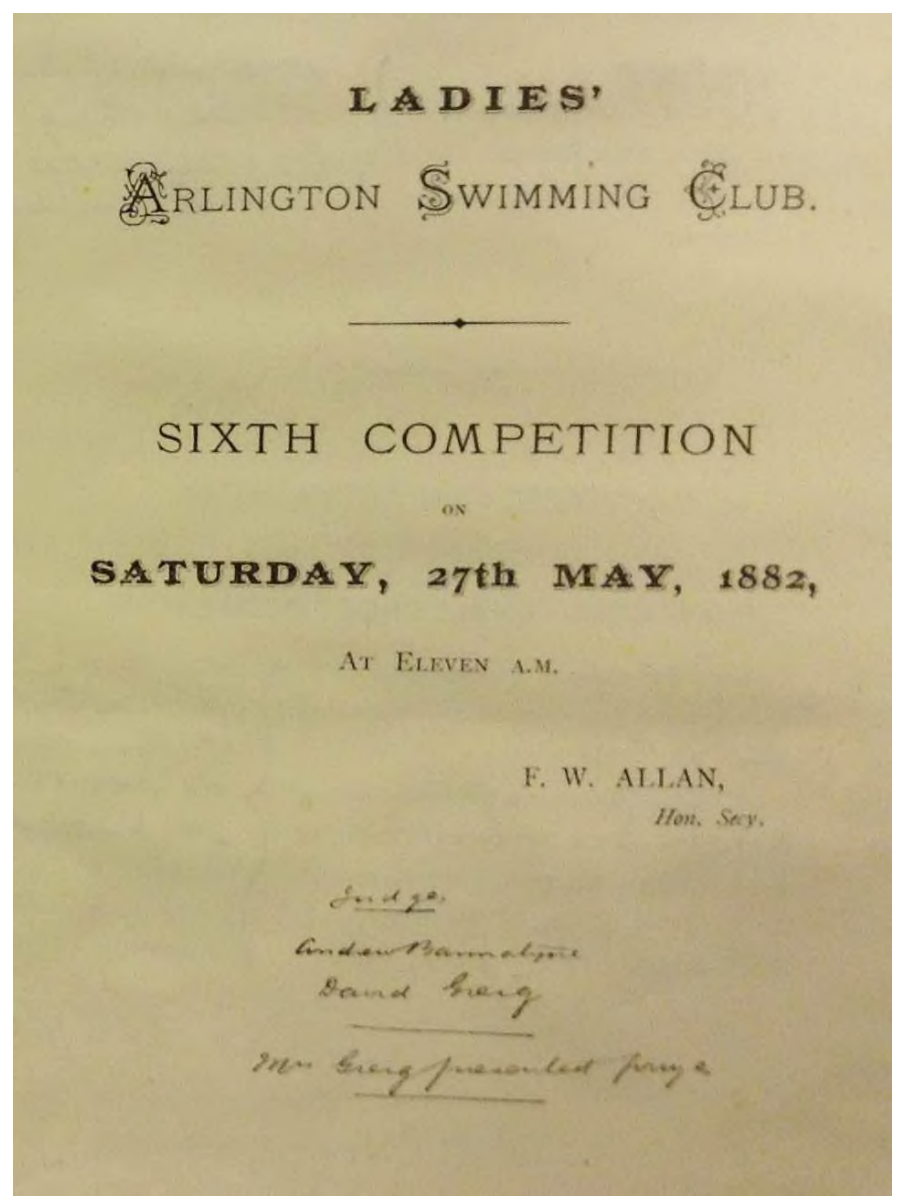

Figure 7. Invitation poster for the ladies' swimming competition at Arlington Swimming Club (Source: Mitchell Library Archives, ref: NRA(S)2900)

Some women were able to bypass the sexualized and masculinized social interactions celebrated by male authors. Especially in baths at small spa towns, women used their elite educations to help facilitate female sociability; they exercised their feminine knowledge of 
medical care, cookery and artistic expression discursively, joining with other women in these activities to create or deepen female social alliance. In this process of female-female interaction, the baths functioned as "crucial geographic sites for female identity creation" (Herbert, 2009: $362)$.

Since their spread in large cities, the Victorian Turkish baths have brought forward certain prejudices, mainly resting upon the fear of homosexual encounters among the users. Members of the leisure class believed that the regular use of the baths would lead to effeminacy and destroy manliness which created the British Empire (Shifrin, 2015: 100). In Vapour and Steam: The Victorian Turkish Bath, Homosocial Health, and Male Bodies on Display (2005), John Potvin treats Urquhart's Jermyn Street Hammam in West end of London as a queer space where "male homosociability was performed and enjoyed" (Potvin, 2005: 319). Accordingly, the interior of the Hammam offered its bathers a sense of refuge, a place of repose, a location to facilitate a sense of interiority; "a ritual withdrawal from the outside forced extraversion of the metropolis, in search of a refuge wherein male homosociability had its own set of rules and roles veiled by the cosmopolitan West End" (Potvin, 2005: 324). While there is no evidence regarding the existence of homosexual activities in Jermyn Street Hammam, Potvin's article provides a thorough understanding of its private interiors where the bourgeoise need to control and regulate the body and bodily pleasures was subverted to a certain degree. 


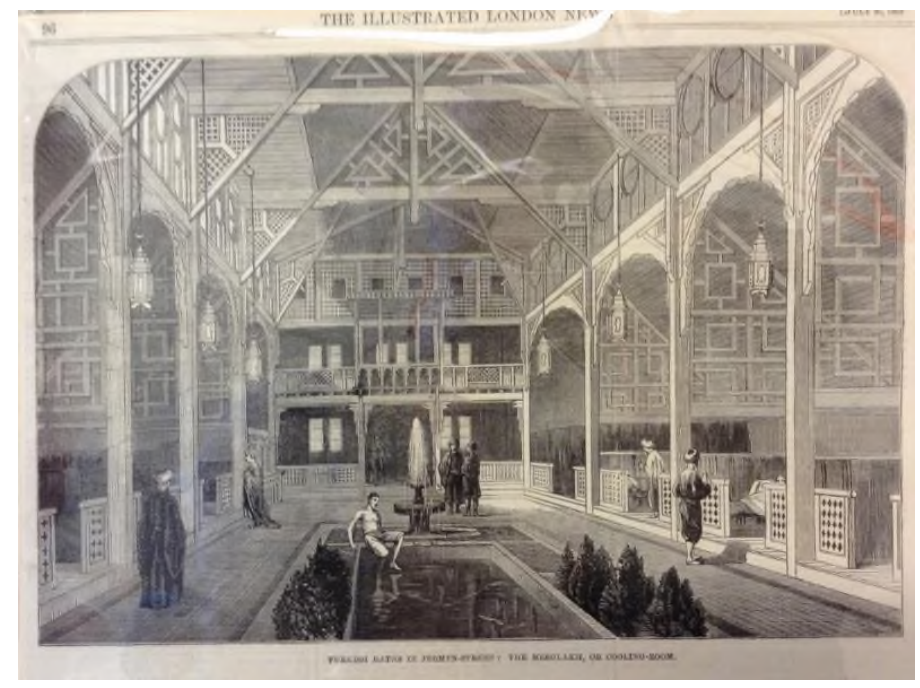

Figure 8. Interior view drawing of Jermyn Street Hamam (Source: London Metropolitan Archives)

Based on personal accounts, Matt Houlbrook concentrates on three Turkish baths in London which were known as homosexual rendezvous: (1) The Savoy from the late nineteenth century, (2) The baths under the Imperial Hotel in Russell Square 1913-1966, and (3) Edgware Road Turkish Baths at Harrow Road 1880-1947 (Houlbrook, 2005: 95-96). Houlbrook argues that homosexual interactions occured in these establishments with regards to "the cultivation of the bodily health and physicality that brought naked male bodies into close proximity" (Houlbrook, 2005: 96). The physical structure of these baths offered their users a variety of spaces ranging from public rooms to individual cubicles where they meet, cruise, and involve in sexual encounters, "creating a distinctive microgeography predicated upon the movement between public and private space" (Houlbrook, 2005: 99). They were drawn by the promise of a safe space distanced from the risks of arrest or assault in the public city.

\section{Conclusion}

This paper has shown that invention of Turkish bath tradition in the mid-19 $9^{\text {th }}$ century was not a straightforward process as it had to cope with certain challenges regarding the modern 
Victorian society while constructing new cultural norms out of an Eastern traditional feature. One can identify from the social history of Victorian Turkish bath, a process of cultural appropriation and assimilation that reflects upon modern norms of personhood. Cleanliness in the baths did not simply signify bodily purification but was rather considered as a means to develop self-respect and self-discipline. Accordingly, its health aspect, both physical and mental, was put forward against its bathing aspect. Leisure time in the baths was controlled by means of various facilities conducted under the supervision of bath attendants in bizarre interiors. In this way, the working classes were to be trained both physically and visually and be increased to middle-class status.

Today, there are only twelve bath complexes remaining in the British Isles, five of which include Turkish baths built in the Victorian era. The aspect of privacy is still a prominent aspect in Victorian Turkish baths as the users prefer visiting the Victorian Turkish bath mostly alone, and engaging in private leisure activities such as swimming, exercising, cleansing, lying down and relaxing in these potentially public spaces. Moreover, the design of a set of rooms of increasing heat with their associated health treatments is still evident in the indigenous settings of the Turkish bath. New associated aspects of health, leisure and privacy can be observed in contemporary spa centers at hotels as part of globalised health tourism networks. In these centers, bathing archetypes of various cultures such as Turkish bath, Russian steam room, Finnish sauna, etc. are associated within a single space where issues of health, leisure and privacy are adapted into consumer culture.

\section{Refferences}

Adams, Jane, M. (2015). Healing with Water: English Spas and the water cure, 1840-1960, UK: Manchester University Press.

Avcıoglu, Nebahat (2011). Turquerie and the Politics of Representation, 1728-1876, England: Ashgate Publishing Limited. 
Barter, Richard (1858). A Lecture on the Improved Turkish Bath Delivered at Bradford, in Descriptive notice of the rise and progress of the Irish Graffenberg, St. Ann's Hill, Blarney, London: Routledge, 1-28.

Breathnach, Teresa (2004). For Health and Pleasure, The Turkish Bath in Victorian Ireland, Victorian Literature and Culture, 03/2004, 32/1, doi: 10.1017/S1060150304000427.

Campbell, Agnes (1918). Report on Public Baths and Wash-houses in the United Kingdom, Edinburgh: The University Press.

Crook, Tom (2006). 'Schools for the moral training of the people: Public Baths, Liberalism and the Promotion of Cleanliness in Victorian Britain, European Review of History, 13: 1, pp. 2147.

Crook, Tom (2007). Power, Privacy and Pleasure: Liberalism and the Modern Cubicle, Cultural Studies, Vol. 21, Nos. 4 _5 July/September 2007, pp. 549-569.

Foley, Ronan (2014). The Roman-Irish Bath: Medical/health history as therapeutic assemblage, Social Science \& Medicine, 04/2014, vol. 106, 10-19.

Gloag, John (1961). "Chapter 7: Comfort and Pleasure", in Victorian Comfort. A Social History of Design from 1830-1900, London: Adam and Charles Black.

Herbert, Amanda E. (2009) Gender and the Spa: Sociability and Self in British Health Spas 1640-1714 Journal of Social History, 43(2), 361-383.

Hobsbawm, Eric (1983) Introduction: Inventing Traditions, in E. Hobsbawm \& T. Ranger (ed.) The Invention of Tradition, (UK: Cambridge University Press): 1-14.

Houlbrook, Matt (2005). Chapter 4: The Baths, Queer London: Perils and Pleasures in the Sexual Metropolis, 1918-1957, Chicago and (London: The University of Chicago Press): 93108.

MacKenzie, John M. (1995) Orientalism: History, Theory and the Arts. Manchester: Manchester UP.

Masquelier, Adeline (2005). Dirt, Undress, and Difference: An Introduction, in A. Masquelier (ed.) Dirt Undress and Difference Critical Perspectives on the Body's Surface, (USA: Indiana University Press): 1-33.

Potvin, John (2005). Vapour and Steam: The Victorian Turkish Bath, Homosocial Health, and Male Bodies on Display, The Journal of Design History, vol. 18, no. 4, pp. 319 -33.

Shifrin, Malcolm. (2015). Victorian Turkish Baths, Swindon: Historic England.

Thompson, F. M. L. (1988). "Chapter 7: Play", in The Rise of Respectable Society: A Social History of Victorian Britain, 1830-1900, London: Fontana Press. 
Gender, Space, Place \& Culture $7^{\text {th }}$ International Conference on Gender Studies e-ISBN: 978-605-9595-30-8 


\title{
GENDER DISPARITY IN ENROLLMENT AND ACADEMIC PERFORMANCE OF SECONDARY SCHOOL STUDENTS IN COMMERCE IN ANAMBRA STATE, NIGERIA
}

\author{
Christiana Ngozi EMENTA ${ }^{1}$
}

\begin{abstract}
The study examined gender disparity in enrollment and academic performance of secondary school students in commerce in Anambra state, Nigeria. Two research questions guided the study while two null hypotheses were formulated and tested at 0.05 level of significance. Expost facto research design was used adopted for the study.

Population of the study was 112, 339 students in six education zones in the state who sat for commerce examination in SSCE from 2013/14 to 2017/18 academic session. Two education zones termed urban and rural were purposively sampled from the six education zones. In the two education zone, 23,016 students registered and sat for commerce. Percentages and Chisquare was used for data analysis. The Senior Secondary Certificate Examination result was used for the study.

Findings of the study revealed that female students enrolled and performed better than males in urban areas while males enrolled and performed better than females in rural area. The study further revealed a significant difference in enrollment pattern and academic performance of students based on gender and location. It was concluded that sensitization and advocacy for female students' enrollment in education in urban areas yields results while enlightenment and sensitization at the rural area is greatly required.

It was recommended among others that the State government should encourage male and female students by awarding scholarships and related incentives to best graduating male and female students in public schools to motivate them towards enrollment and consequent good performance in commerce and other school subjects.
\end{abstract}

Keywords: Gender disparity, enrollment. Academic performance, secondary school students, Commerce.

\footnotetext{
${ }^{1}$ Dr. Nnamdi Azikiwe University, Awka, Anambra State, Nigeria. cn.ementa@ unizik.edu.ng;
} 


\section{Introduction}

Gender is the social, economic, political and cultural attributes associated with being male or female. It relates to socially defined sex, roles, attitudes and values acquired through socialization and ascribed by a given community. Yang (2010) referred to gender as social attributes and opportunities associated with being male and female and the relationships between women and men; boys and girls, as well as the relations between women and those between men. Afonja (2002) viewed it as social constructed concepts based on assumed power and position that group of humans should possess. Similarly, UNICEF (2017) asserted gender as social and cultural constructs which distinguish differences in the attributes of men and women, girls and boys, and accordingly refers to the roles and responsibilities of men and women. Social classification as it concerns gender affects power and position allocation, responsibilities, status and roles. Gender conception within social constructs and contexts brings up concerns on disparity.

Gender disparity is a critical issue all over the world. Little wonder, resolutions of United Nations through United Nations International Children Emergency Fund (UNICEF, 2010) in support of sustainable development goals (SDG, 2015) policy, promotes the development of national capacities to achieve equality for boys and girls through the strengthening of national counterparts in pursuit of development goals and human rights. In many developing countries (Nigeria inclusive), education has been highlighted as a basic human right and an important determinant of a nation's development. Nigeria as a signatory to the pact on world declaration of Education for All (EFA) and her eventual commencement of Universal Basic Education underlines the significance of education for all individual regardless of gender. Gender equality means more than access to schools for boys and girls, it combines the right to education (enrollment) and rights within education (academic performance). The 
right to and within education implies that secondary school children are to enroll and perform at peak in all school subjects (including commerce) they identified to study.

In Nigeria, commerce is one of the business subjects taught at senior secondary school level of education. It is a subject that helps students develop skills, knowledge and understanding related to financial, business, consumer and employment issues. The general objectives of commerce education at this level of education according to Federal Ministry of Education (2007) are to:

- enable students have a broader understanding of the importance of commercial activities;

- enable students cultivate the right attitude to commercial activities;

- provide useful general notion on commercial activities

- develop a habit of wise services offered in commercial institutions.

Commerce is central to human existence (FME, 2007). It develops in individuals the knowledge needed to effectively fit in the community. Fundamental knowledge acquired in commerce education assist persons who wish to pursue their career in non-business areas as well as school drop-outs who wish to venture into other vocations and succeed in their work. In the light of the above understanding, it is expected that students irrespective of their school location enroll for the subject and perform at optimum in internal and external examinations. It is expected that learning experiences offered to children in schools do not discriminate against males and females. There is need to see that both boys and girls are given equal access to education (Ezeudu \& Obi, 2013).

School location means urban-rural environment. The area a school is located affects the academic achievement of the students (Nworgu, Ugwuanyi \& Nworgu, 2013). The performance of students in a school located where there are provisions of amenities like road, 
electricity, viable transportation system, pipe borne water etc, cannot be compared with that of students located where there is paucity of social amenities. Akpan (2009) noted that schools in urban area have electricity, water supply, more teachers, learning facilities and infrastructure. In differentiating urban from rural location, Ezike (2011) stated urban location as those areas with high population density, high variety and beauty while rural areas are those with low population, subsistence mode of life which is monotonous and burdensome. This study will consider school location as a prevailing factor on enrollment and academic performance.

\section{Gender Disparity in Enrollment and Academic Performance in School Subjects}

Numerous studies on gender differences in enrollment and academic performance has been carried out by authors and researchers in various school subjects in Nigeria. Telima (2006) conducted a study on enrollment and academic achievement of secondary school students in physics and found significant difference in enrollment and academic achievement in favour of male students. Aina (2012) found that male students enrolled and performed better than female students in three science subjects; biology, physics, chemistry and mathematics. Filgona and Sababa (2017) revealed low enrollment and poor academic performance of female students in geography. In a 10-year longitudinal study of enrollment of secondary school students in Nigeria, Omoregie and Ihensekhein (2009) recorded that more males enrolled in school than females. Rahji and Fakayode (2012) examined gender gap in enrollment for rural household children in secondary schools and recounted that more boys enrolled than girls, attributing the difference on the ways households perceive male and female children. Nnamani and Oyibe (2016) investigated academic achievement of students in social studies and found that female students achieved better than males. Owosen (2014) assessed enrollment pattern in urban and non-urban school and reported a gap in favour of students in urban location. Ezeudu and Obi 
(2013) carried out a study to ascertain effect of gender and school location on academic achievement of students in Chemistry and reported that male students no matter their location performed better than females, highlighting that students in urban areas do not perform better that rural students. Data from National Bureau of Statistics (2016) revealed gap in enrollment of males and females in secondary schools in Nigeria, with males enrolling more than females. Nevertheless, further study of the report showed that more females enrolled in secondary school than males in Anambra State. This report was however on overall enrollment in secondary school. A study is therefore needed to check enrollment pattern as well as academic performance of students in school subjects especially commerce. This study sought to bridge this gap.

\section{Theoretical Framework}

Certain theories explain human phenomenon as they occur. Theory of gender schema propounded by Bem (1981) tends to describe belief as it regards gender. This theory explains that children learn about what it means to be a male and female from the culture in which they live. According to Bem (1981) children adjust their behaviour to fit in with the gender norms and expectations of their culture. This theory relates to this study as some culture belief that in academic pursuit, male students should tilt towards sciences and engineering while females move towards arts and humanities study. This belief and inclination of a people therefore affects enrollment into selected field or course of study.

Theory of educational productivity is a theory that deals on academic performance. The theory was propounded by Walberg (1981) and posits that psychological characteristics of individual students and their immediate environment influence educational outcomes. The theory identified variables that influence educational outcomes as student ability, prior achievement, motivation, age/developmental level, peer group, quantity and quality of 
instruction, classroom climate, home environment and exposure to mass media outside the school. This theory relates to the study as factors other than one's gender greatly affect the academic achievement of a learner. These factors play a significant role in the academic outcome of students in school subjects.

\section{Statement of the Problem}

Various studies have been conducted to ascertain existence of gender disparity and academic achievement in school subjects. Little has been done with reference to commerce as a school subject. More so, most studies on gender gap and performance placed emphasis on urban areas, giving little or no attention to schools in rural location.

\section{Research Questions}

The following research questions were raised to guide the study:

1. What is the gender enrollment pattern of urban and rural students in Commerce in SSCE from 2013/14 to 2017/18 academic session in Anambra state?

2. What is the academic performance of male and female students in urban and rural location in SSCE in Commerce from 2013/14 to 2017/18 academic session in Anambra state?

\section{Hypotheses}

The following null hypotheses were tested at 0.05 level of significance.

1. There is no significant difference in urban and rural students' enrollment pattern in SSCE in Commerce from 2013/14 to 2017/18 academic session in Anambra state based on gender. 
2. There is no significant difference in urban and rural students' academic performance in Commerce from 2013/14 to 2017/18 academic session in Anambra state based on gender.

\section{Method}

The research design used for this study is ex-post facto design. The population of the study was 112,339 students made up of 47,174 males and 65, 165 female students who sat for SSCE in Commerce in the six education zones in Anambra State from 2013/14 to 2017/18 academic session. Purposive sampling technique was used to select two education zones termed urban and rural zone. 12, 663 students made up of 5378 males and 7, 285 female in urban zone while 10, 353 students made up of 5, 277 male and 5, 076 female in rural zone registered and sat for SSCE in Commerce between 2013/14 and 2017/18 academic session. Data was extracted by the research from the computer processed results of SSCE from Post Primary School Service Commission. It was considered reliable and valid because it is a standard result. Data collected was analyzed using percentage for research questions and non-parametric statistics Chi-Square was used to test the hypotheses. Grading system of A1-F9 was used. Students whose grade was from A1-C6 was regarded as those that passed while those grade ranged from D7-F9 was regarded as students who failed the examination.

\section{Results}

\section{Research Question 1}

What is the gender enrollment pattern of urban and rural students in Commerce in SSCE from 2013/14 to 2017/18 academic session in Anambra state? 
Table 1:Percentage gender enrollment pattern of urban students in Commerce SSCE in Anambra State

\begin{tabular}{|c|c|c|c|c|c|c|c|}
\hline $\begin{array}{c}\text { Academic } \\
\text { Session }\end{array}$ & $\begin{array}{c}\text { Male } \\
\text { Enrolment }\end{array}$ & $\begin{array}{c}\text { Female } \\
\text { Enrolment }\end{array}$ & $\begin{array}{c}\text { Total } \\
\text { Enrolment }\end{array}$ & $\begin{array}{c}\text { Enrolment } \\
\text { difference }\end{array}$ & $\begin{array}{c}\text { \% } \\
\text { Difference } \\
\text { in male }\end{array}$ & $\begin{array}{c}\text { \% } \\
\text { Difference } \\
\text { in female }\end{array}$ & $\begin{array}{c}\text { Percentage } \\
\text { Total }\end{array}$ \\
\hline $2013 / 2014$ & 1030 & 1171 & 2201 & 141 & 47 & 53 & 100 \\
\hline $2014 / 2015$ & 1165 & 1279 & 2444 & 114 & 48 & 52 & 100 \\
\hline $2015 / 2016$ & 1156 & 2315 & 3471 & 1159 & 33 & 67 & 100 \\
\hline $2016 / 2017$ & 976 & 1065 & 2041 & 89 & 48 & 52 & 100 \\
\hline $2017 / 2018$ & 1051 & 1455 & 2506 & 404 & 42 & 58 & 100 \\
\hline Total & 5378 & 7285 & 12663 & 1907 & 42 & 58 & 100 \\
\hline
\end{tabular}

Data in Table 1 show gender enrollment pattern of students in urban location in Commerce in SSCE between 2013/14 to 2017/18 academic session in Anambra state. In the years under review, a total of 12663 students enrolled for SSCE, with male having enrollment of 5378 and female 5285 with an enrollment difference of 1907 in favour of female students.

Specifically, In 2013/14 academic session, out of 2201 students that enrolled for SSCE in Commerce, 1030 (47\%) were male students while 1171 (53\%) were female students. The difference in enrollment shows that 141 more females enrolled than males. For 2014/15 session, 2444 students enrolled, males recorded 1165(48\%) and female students 1279 (52\%) with a difference of 114 in favour of females. In 2015/16 session, a total of 3471 students enrolled, male recording $1156(33 \%)$ and females 2315 (67\%) with difference of 1159 in favour of female students. Out of 2041 students that enrolled in 2016/17 session, male figure stood at 976 (48\%) while female stood at 1065 (52\%) with 89 as the difference in favour of females. Finally, in 2017/18 academic session, 2506 students enrolled, with male students recording 1051 (42\%) and female student 1455 (58\%) with a difference of 404, to the advantage position of female students. 
Table 2: Percentage gender enrollment pattern of rural students in Commerce SSCE in Anambra State

\begin{tabular}{|c|c|c|c|c|c|c|c|}
\hline $\begin{array}{c}\text { Acade mic } \\
\text { Session }\end{array}$ & $\begin{array}{c}\text { Male } \\
\text { Enro lme nt }\end{array}$ & $\begin{array}{c}\text { Female } \\
\text { Enrolment }\end{array}$ & $\begin{array}{c}\text { Total } \\
\text { Enrolment }\end{array}$ & $\begin{array}{c}\text { Enrolment } \\
\text { difference }\end{array}$ & $\begin{array}{c}\text { \% } \\
\text { Difference } \\
\text { in male }\end{array}$ & $\begin{array}{c}\text { \% } \\
\text { Difference } \\
\text { in female }\end{array}$ & $\begin{array}{c}\text { Percentage } \\
\text { Total }\end{array}$ \\
\hline $2013 / 2014$ & 964 & 982 & 1946 & 18 & 50 & 50 & 100 \\
\hline $2014 / 2015$ & 1102 & 976 & 2078 & 126 & 53 & 47 & 100 \\
\hline $2015 / 2016$ & 1121 & 1001 & 2122 & 120 & 53 & 47 & 100 \\
\hline $2016 / 2017$ & 1028 & 1016 & 2044 & 12 & 50 & 50 & 100 \\
\hline $2017 / 2018$ & 1062 & 1101 & 2163 & 39 & 49 & 51 & 100 \\
\hline Total & 5277 & 5076 & 10353 & 201 & 51 & 49 & 100 \\
\hline
\end{tabular}

Data in Table 2 show gender enrollment pattern of students in rural location in Commerce in SSCE between 2013/14 to 2017/18 academic session in Anambra state. In the years under review, a total of 10353 students enrolled for SSCE, with male having enrollment of 5277 and female 5076 with an enrollment difference of 201 to the advantage of female students.

Specifically, In 2013/14 academic session, out of 1946 students that enrolled for SSCE in Commerce, 964 (50\%) were male students while 982 (50\%) were female students. The difference in enrollment shows that 18 more females enrolled than males. For 2014/15 session, 2078 students enrolled, males recorded 1102 (53\%) and female students 976 (47\%) with a difference of 126 in favour of males. In 2015/16 session, a total of 2122 students enrolled, male recording $1121(53 \%)$ and females 1001 (47\%) with difference of 120 in favour of male students. Out of 2044 students that enrolled in 2015/17 session, male figure stood at 1028 (50\%) while female stood at 1016 (50\%) with 12 as the difference in favour of male students. Finally, in 2017/18 academic session, 1062 students enrolled, with male students recording 1062 (49\%) and female students $1101(51 \%)$ with a difference of 39 , to the advantage position of female students. 


\section{Research Question 2}

What is the academic performance of male and female students in urban and rural location in SSCE in Commerce from 2013/14 to 2017/18 academic session in Anambra state?

Table 3: Gender and Academic performance of urban students in Commerce in SSCE in Anambra State

\begin{tabular}{|l|c|c|c|c|c|c|c|c|c|c|c|}
\hline $\begin{array}{l}\text { Academic } \\
\text { session }\end{array}$ & \multicolumn{9}{|c|}{} & \multicolumn{4}{|c|}{} & \multicolumn{4}{|c|}{ \% of Female students academic performance } \\
\hline & Pass & Pass \% & Fail & Fail \% & Total Male & Pass & Pass \% & Fail & Fail \% & Total Female \\
\hline $2013 / 14$ & 932 & $90 \%$ & 98 & $10 \%$ & 1030 & 1007 & $86 \%$ & 164 & $14 \%$ & 1171 \\
\hline $2014 / 15$ & 1102 & $95 \%$ & 63 & $5 \%$ & 1165 & 1176 & $92 \%$ & 103 & $8 \%$ & 1279 \\
\hline $2015 / 16$ & 989 & $86 \%$ & 167 & $14 \%$ & 1156 & 2037 & $88 \%$ & 278 & $12 \%$ & 2315 \\
\hline $2016 / 17$ & 819 & $84 \%$ & 157 & $16 \%$ & 976 & 969 & $91 \%$ & 96 & $9 \%$ & 1065 \\
\hline $2017 / 18$ & 766 & $73 \%$ & 285 & $27 \%$ & 1051 & 1222 & $84 \%$ & 233 & $16 \%$ & 1455 \\
\hline
\end{tabular}

Data in Table 3 shows the percentage of male and female urban students with their academic performance in SSCE in Commerce in Anambra state. In 2013/14 academic session, $90 \%$ of male students passed and $10 \%$ failed while $86 \%$ of female students passed and $14 \%$ failed. For 2014/15 session, 95\% of male students passed and 5\% failed while $92 \%$ of female students passed and $8 \%$ failed. In 2015/16 session, $86 \%$ of male students passed and $14 \%$ failed while $88 \%$ of female students passed and $12 \%$ failed.

In $2016 / 17$ academic session, $84 \%$ of male students passed and $16 \%$ failed while $91 \%$ of female students passed and $9 \%$ failed. Finally in $2017 / 18$ session, $73 \%$ of male students passed and $27 \%$ while $84 \%$ of female students passed and $16 \%$ failed. 
Table 4:Gender and Academic performance of rural students in Commerce in SSCE in Anambra State

\begin{tabular}{|c|c|c|c|c|c|c|c|c|c|c|}
\hline \multirow[t]{2}{*}{$\begin{array}{l}\text { Academic } \\
\text { session }\end{array}$} & \multicolumn{5}{|c|}{$\%$ of Male students academic performance } & \multicolumn{5}{|c|}{$\%$ of Female students academic performance } \\
\hline & Pass & Pass \% & Fail & Fail \% & Total Male & Pass & Pass \% & Fail & Fail \% & Total Female \\
\hline 2013/14 & 906 & $94 \%$ & 58 & $6 \%$ & 964 & 934 & $95 \%$ & 48 & $5 \%$ & 982 \\
\hline $2014 / 15$ & 1039 & $94 \%$ & 63 & $6 \%$ & 1102 & 840 & $86 \%$ & 136 & $14 \%$ & 976 \\
\hline 2015/16 & 998 & $89 \%$ & 123 & $11 \%$ & 1121 & 898 & $90 \%$ & 103 & $10 \%$ & 1001 \\
\hline 2016/17 & 828 & $81 \%$ & 200 & $19 \%$ & 1028 & 808 & $80 \%$ & 208 & $20 \%$ & 1016 \\
\hline $2017 / 18$ & 1024 & $96 \%$ & 38 & $4 \%$ & 1062 & 1002 & $91 \%$ & 99 & $9 \%$ & 1101 \\
\hline
\end{tabular}

Data in Table 4 shows the percentage of male and female urban students with their academic performance in SSCE in Commerce in Anambra state. In 2013/14 academic session, $94 \%$ of male students passed and $6 \%$ failed while $95 \%$ of female students passed and $5 \%$ failed. For $2014 / 15$ session, $94 \%$ of male students passed and $6 \%$ failed while $86 \%$ of female students passed and 14\% failed. In 2015/16 session, $89 \%$ of male students passed and $11 \%$ failed while $90 \%$ of female students passed and $10 \%$ failed.

In $2016 / 17$ academic session, $81 \%$ of male students passed and $19 \%$ failed while $80 \%$ of female students passed and 20\% failed. Finally in 2017/18 session, $96 \%$ of male students passed and $4 \%$ while $91 \%$ of female students passed and $9 \%$ failed.

\section{Hypotheses 1}

There is no significant difference in urban and rural students' enrollment pattern in SSCE in Commerce from 2013/14 to 2017/18 academic session in Anambra state based on gender. 
Table 5:Chi-square analysis of gender and students location enrollment pattern in SSCE

Commerce from 2013/14 -2017/18 academic session in Anambra state

\begin{tabular}{|c|c|c|c|c|c|c|c|c|}
\hline $\begin{array}{c}\text { Academic } \\
\text { session }\end{array}$ & Location & Gender & $\mathbf{N}$ & $\begin{array}{c}\text { Difference in } \\
\text { enrollment }\end{array}$ & $\begin{array}{c}\text { Degree of } \\
\text { freedom }\end{array}$ & $\begin{array}{l}\text { Calculated } \\
\text { Value }\end{array}$ & $\begin{array}{c}\text { Critical } \\
\text { Table } \\
\text { Value }\end{array}$ & Remark \\
\hline \multirow{3}{*}{ 2013/14 } & \multirow{3}{*}{ Urban } & Male & 1030 & \multirow{3}{*}{141} & & & & \\
\hline & & Female & 1171 & & & & & \\
\hline & & Total & 2201 & & & & & \\
\hline \multirow{3}{*}{$2014 / 15$} & \multirow{3}{*}{ Urban } & Male & 1165 & \multirow{3}{*}{114} & & & & \\
\hline & & Female & 1279 & & & & & \\
\hline & & Total & 2444 & & 4 & 187.28 & 9.49 & Significant \\
\hline \multirow{3}{*}{$2015 / 16$} & \multirow{3}{*}{ Urban } & Male & 1156 & \multirow{3}{*}{1159} & & & & \\
\hline & & Female & 2315 & & & & & \\
\hline & & Total & 3471 & & & & & \\
\hline \multirow{3}{*}{$2016 / 17$} & \multirow{3}{*}{ Urban } & Male & 976 & \multirow{3}{*}{89} & & & & \\
\hline & & Female & 1065 & & & & & \\
\hline & & Total & 2041 & & & & & \\
\hline \multirow{3}{*}{$2017 / 18$} & \multirow{3}{*}{ Urban } & Male & 1051 & \multirow{3}{*}{404} & & & & \\
\hline & & Female & 1455 & & & & & \\
\hline & & Total & 2506 & & & & & \\
\hline \multirow{3}{*}{$2013 / 14$} & \multirow{3}{*}{ Rural } & Male & 964 & \multirow{3}{*}{18} & & & & \\
\hline & & Female & 982 & & & & & \\
\hline & & Total & 1946 & & & & & \\
\hline \multirow{3}{*}{$2014 / 15$} & \multirow{3}{*}{ Rural } & Male & 1102 & \multirow{3}{*}{126} & & & & \\
\hline & & Female & 976 & & & & & \\
\hline & & Total & 2078 & & & & & \\
\hline \multirow{3}{*}{$2015 / 16$} & \multirow{3}{*}{ Rural } & Male & 1121 & \multirow{3}{*}{120} & 4 & 11.42 & 9.49 & Significant \\
\hline & & Female & 1001 & & & & & \\
\hline & & Total & 2122 & & & & & \\
\hline \multirow{3}{*}{$2016 / 17$} & \multirow{3}{*}{ Rural } & Male & 1028 & \multirow{3}{*}{12} & & & & \\
\hline & & Female & 1016 & & & & & \\
\hline & & Total & 2044 & & & & & \\
\hline \multirow{3}{*}{$2017 / 18$} & \multirow{3}{*}{ Rural } & Male & 1062 & & & & & \\
\hline & & Female & 1101 & 39 & & & & \\
\hline & & Total & 2163 & & & & & \\
\hline
\end{tabular}

Data in Table 5 reveal five years analysis of significant difference in enrollment pattern of urban and rural students in SSCE in Commerce. In the urban location, the calculated $X^{2}$ value of 187.28 is greater than the critical table value of 9.49. Also, at the rural location, the calculated $\mathrm{X}^{2}$ value of 11.42 is greater than the critical table value of 9.49 . Ho is significant and therefore rejected. This implies that male and female students in urban and rural location differ significantly in enrollment pattern in SSCE in Commerce in Anambra state. 
Table 6: Chi-square analysis of gender and students location on academic performance in SSCE Commerce from 2013/14 -2017/18 academic session in Anambra state

\begin{tabular}{|c|c|c|c|c|c|c|c|c|c|}
\hline \multirow[t]{2}{*}{$\begin{array}{l}\text { Academic } \\
\text { session }\end{array}$} & \multirow[t]{2}{*}{ Location } & \multirow[t]{2}{*}{ Gender } & \multirow[t]{2}{*}{$\mathbf{N}$} & \multicolumn{2}{|c|}{ Academic Performance } & \multirow[t]{2}{*}{$\begin{array}{c}\text { Degree of } \\
\text { freedom }\end{array}$} & \multirow[t]{2}{*}{\begin{tabular}{|c} 
Calculated \\
Value
\end{tabular}} & \multirow[t]{2}{*}{$\begin{array}{c}\text { Critical } \\
\text { Table } \\
\text { Value }\end{array}$} & \multirow[t]{2}{*}{ Remark } \\
\hline & & & & Pass & Failed & & & & \\
\hline \multirow{3}{*}{$2013 / 14$} & \multirow{3}{*}{ Urban } & Male & 1030 & 932 & 98 & \multirow{3}{*}{1} & \multirow{3}{*}{10.56} & \multirow{3}{*}{3.84} & \multirow{3}{*}{ Significant } \\
\hline & & Female & 1171 & 1007 & 164 & & & & \\
\hline & & Total & 2201 & 1939 & 262 & & & & \\
\hline \multirow{3}{*}{$2014 / 15$} & \multirow{3}{*}{ Urban } & Male & 1165 & 1102 & 63 & \multirow{3}{*}{1} & \multirow{3}{*}{6.75} & \multirow{3}{*}{3.84} & \multirow{3}{*}{ Significant } \\
\hline & & Female & 1279 & 1176 & 103 & & & & \\
\hline & & Total & 2444 & 2278 & 166 & & & & \\
\hline \multirow{3}{*}{$2015 / 16$} & \multirow{3}{*}{ Urban } & Male & 1156 & 989 & 167 & \multirow{3}{*}{1} & \multirow{3}{*}{4.09} & \multirow{3}{*}{3.84} & \multirow{3}{*}{ Significant } \\
\hline & & Female & 2315 & 2037 & 278 & & & & \\
\hline & & Total & 3471 & 3026 & 445 & & & & \\
\hline \multirow{3}{*}{$2016 / 17$} & & Male & 976 & 819 & 157 & & & & \\
\hline & Urban & Female & 1065 & 969 & 96 & 1 & 23.46 & 3.84 & Significant \\
\hline & & Total & 2041 & 1788 & 253 & & & & \\
\hline & & Male & 1051 & 766 & 285 & & & & \\
\hline $2017 / 18$ & Urban & Female & 1455 & 1222 & 233 & 1 & 45.88 & 3.84 & Significant \\
\hline & & Total & 2506 & 1988 & 518 & & & & \\
\hline & & Male & 964 & 906 & 56 & & & & \\
\hline $2013 / 14$ & Rural & Female & 982 & 934 & 48 & 1 & 1.72 & 3.84 & Not \\
\hline & & Total & 1946 & 1840 & 106 & & & & \\
\hline & & Male & 1102 & 1039 & 63 & & & & \\
\hline $2014 / 15$ & Rural & Female & 976 & 840 & 136 & 1 & & & \\
\hline & & Total & 2078 & 1879 & 199 & & 54.21 & 3.84 & Significant \\
\hline & & Male & 1121 & 998 & 123 & & & & \\
\hline $2015 / 16$ & Rural & Female & 1001 & 898 & 103 & 1 & & & Not \\
\hline & & Total & 2122 & 1896 & 226 & & 0.2 & 3.84 & Significant \\
\hline & & Male & 1028 & 828 & 200 & & & & \\
\hline $2016 / 17$ & Rural & Female & 1016 & 808 & 208 & 1 & & & Not \\
\hline & & Total & 2044 & 1636 & 408 & & 3.69 & 3.84 & Significant \\
\hline & & Male & 1062 & 1024 & 38 & & & & \\
\hline $2017 / 18$ & Rural & Female & 1101 & 1002 & 99 & 1 & & & \\
\hline & & Total & 2163 & 2026 & 137 & & 26.29 & 3.84 & Significant \\
\hline
\end{tabular}

Data in Table 6 show five years analysis of significant difference in academic performance of urban and rural students in SSCE in Commerce. In the urban location, the calculated $\mathrm{X}^{2}$ value of $10.56,6.75,4.09,23.46$ and 45.88 respectively is greater than the critical table value of 3.84 .

In addition, at the rural location, the calculated $\mathrm{X}^{2}$ value of 54.21 and 26.29 is greater than the critical table value of 3.84 in 2012/13 and 2015/16 academic sessions. Ho is significant in 2014/15 and 2017/18 session and therefore rejected. However, in 2013/14, 2015/16 and 
$2016 / 17$ academic sessions, the calculated $\mathrm{X}^{2}$ value of $1.72,0.20$ and 3.69 respectively is greater than the critical table value of 3.84 . Ho is not significant and therefore not rejected.

This implies that male and female students in urban location differ significantly in their academic performance in SSCE in Commerce in Anambra state but in rural location; male and female students differed significantly in academic performance in some years ( 2 years) and did not differ significantly in other years (3 years).

\section{Discussion of Results}

Gender disparity in enrollment pattern of urban and rural students in SSCE in Commerce for 5 years in Anambra State

There was difference in enrollment pattern with female students having higher enrollment figure in urban location while in rural location, males enrolled more than females. This implies that more females enrolled for Commerce in urban area with its peak in 2015/16 with a difference of 1,159 and the least (89) in 2016/17 session. Nevertheless, in rural area, more males than females enrolled in SSCE in Commerce, its peak was in 2014/15 session with a difference of 126 and the least (12) in 2016/17. Given the trend, on the long run, gender might constitute a great difference in enrollment in SSCE in Commerce. Test of significance revealed enrollment in favour of females in urban location and males in rural location. This finding is in line with Amuda, Durkwa and Apagu (2016), Rahji and Fakayode (2012) who noted more males than females in rural areas enroll in school. The findings however disagree with Benson (2014) who noted that more females than males in Internally Displaced Persons (IDP) camps enroll in secondary schools. The finding also corroborates with Obikezie (1999) who reported that more males enroll in schools than females. This finding could be attributed to role stereotype that males incline towards sciences while females tilt towards humanities; this is 
seen in the wide margin in enrollment in urban areas in Commerce. This also affirms that gender stereotype plays significant role in enrollment in school subjects (Bem, 1981; Ezeudu \& Obi, 2013). Equally, there is significant difference in favour of males in rural areas. In the rural setting, paucity of science teachers, facilities, equipment and materials to conduct practicals in science subjects may have driven male students to enroll in humanity subject like Commerce. Another contributing factor could be poor enrollment of females in schools in rural areas (Owosen, 2014).

Gender disparity in academic performance of urban and rural students in SSCE in Commerce for 5 years in Anambra State

Differences in academic performance reveal that in urban location, male students performed slightly better than female students from 2013/14 to 2014/15 sessions, but from $2015 / 16$ to $2017 / 18$ session ( 3 years), females performed better in progression of $2 \%, 7 \%$ and $11 \%$ difference in the respective years. In rural location, males performed a little better than females in 3 years i.e. 2014/15, 2016/17 and 2017/18 with difference between 1\% and 5\%. Conversely, females performed slightly better than males in two years 2013/14 and 2015/16 academic sessions with difference between $1 \%$ and $8 \%$.

Hypotheses tested revealed that in urban location, there is significant difference in academic performance of female and male students in favour of females. In rural location, there was no significant difference in two years i.e. 2013/14 and 2015/16 session. However, in three years, there was significant difference in favour of males. This finding corroborated with the findings of Epumepu (2014), Ezeudu and Obi (2013) who reported that geographical location does not affect academic achievement of students. The finding disagrees with Nworgu, Ugwuanyi and Nworgu (2013) who reported that male students in urban area perform better than female students, and with Nnamani and Oyibe (2016) that reported significant difference 
in academic performance of male and female students. The finding could be ascribed to the fact that other factors rather than gender and location could contribute to learners' educational productivity (Walberg, 1981). Sensitization and advocacy carried out in urban areas for good academic performance for all students could have been internalized by females which resulted in their good academic standing over males for five consecutive years. However, in rural areas, there may be poor sensitization and advocacy which could make females not understand the importance of excelling in Commerce.

\section{Conclusion}

The findings of the study serve as basis to conclude that there is clear difference in enrollment and academic performance of male and female students in urban and rural location in SSCE in Commerce in Anambra state. This is probably due to gender stereotype as regards enrollment in certain school subjects.

\section{Recommendations}

From the findings and conclusion of the study, the following recommendations abound;

1. Ministry of education in collaboration with Non-governmental advocacy groups should carry out sensitization and enlightenment programmes on the need for male students in urban areas and female students in rural areas to enroll in business subject like Commerce, to boost their interest in pursuing commercial entrepreneurial activities to promote national growth and development.

2. Anambra state government in partnership with Anambra state Chamber of Commerce should encourage male and female students to take up Commerce education by awarding scholarship to best commerce student(s) in public secondary schools to encourage them to pursue advanced careers in commercial endeavours. 
3. Commerce teachers in collaboration with school counsellors should guide and counsel students irrespective of their gender on the need to pursue careers in commercial subjects as to awaken their consciousness and mind in taking up entrepreneurial functions.

4. Parents should be sensitized in Parent Teachers Association (PTA) meeting not to stereotype their children and ward into taking up school subjects believed to be meant for a particular gender as to make room for students to make clear choices in selecting school subjects.

\section{References}

Afonja, S. (2002). Mainstreaming gender into the university curriculum and administration. Paper presented in seminar at the Center for Gender Studies, Olabisi Onabanjo Univeristy, AgoIwoye, Ogun State at the Annual Seminar of Social Science Academy.

Aina, J. K. (2012). Gender inequality in science enrollment and academic performance in Nigeria schools. Retrieved from www.academia.com

Amuda, B. G.; Durkwa, H. \& Apagu, K. B. (2016). Gender difference in enrollment in senior school certificate examination economics among secondary school students in Maiduguri metropolis, Borno State. Nigeria Merit Research Journal of Education and Review, 4(7), 96100.

Bem, S. L. (1981). Gender schema theory: A cognitive account of sex typing. Psychological Review, 88(4), 354-364.

Benson, I. H. (2014). Effects of insurgency on the enrollment of students from the IDP camps in FCT, Abuja. Journal of Higher Education in Nigeria, 5(2), 36-51.

Epumepu, E. A. \& Igbinedion, V. I. (2014). Gender differences in enrollment and academic performance trend in business studies in public junior secondary schools certificate examinations. Nigerian Journal of Business Education, 2(1), 76-84.

Ezeudu, F. O. \& Obi, T. N. (2013). Effect of gender and location of students' achievement in chemistry in secondary schools in Nsukka Local Government Area of Enugu State, Nigeria. Research in Humanities and Social Sciences, 3(15), 50-55.

Federal Ministry of Education (2007). Senior secondary education commerce curriculum for $S S 1$ - 3. Abuja: NERDC Press 
Filigona, J. \& Sababa, L.K. (2017). Effect of gender on senior secondary school students' academic achievement in geography in Ganye educational zone, Nigeria. European Journal of Education Studies, 3(4), 394-410.doi:10.5281/zenodo.400596

National Bureau of Statistics (2016). Statistical report on women and men in Nigeria. Retrieved from http:www.nigeriastat.gov.ng

Nnamani, S. C. \& Oyibe, O. A. (2016). Gender and academic achievement of secondary school students in social studies in Abakaliki Urban of Ebonyi State. British Journal of Education, 4(8), $72-83$.

Nworgu, B. G.; Ugwuanyi, C. S. \& Nworgu, L. N. (2013). School location and gender as factors in senior secondary school students' conceptual understanding of force and motion. International Journal of Education Research and Technology, 4(4), 71 -76.

Obiekezie, N. (1999). Constraints to male enrollments in Anambra State. The Counsellor, 17, (1), 235-241.

Omoregie, N. \& Ihensekhien, O. A. (2009). Persistent gender inequality in Nigerian education. Retrieved from https:/nau.edu $>\mathrm{COE}>$ About $>$ Projects

Owosen, P.J. (2014). A survey of secondary schools enrollment patterns of the urban and nonurban schools in Kwara state. Educational Review, 1(2), 28-35.

Rahji, M. A. Y. \& Fakayode, S. B. (2012). Gender gap and educational development for rural households' children in secondary schools in Oyo State, Nigeria. Journal of Educational Studies, 3(1), 12-19

Telima, A. (2006). Gender differences in enrollment and academic performance in physics among secondary school students. Retrieved from www.researchgate.net

United Nations International Children Education Fund (UNICEF) (2010). About gender equality and UNICEF. Retrieved from www.unicef.org

United Nations International Children Education Fund (UNICEF) (2017). Gender equality: Glossary of terms and concepts. Retrieved from www.unicef.org

United Nations (2015). Sustainable Development Goals. Retrieved from www.un.org

Walberg, H. J. (1981). A psychological theory of educational productivity. In F.H. Farly \& N. Gordon (Eds.), Psychological and Education, 81-110. Chicago: National Society for the Study of Education,

Yang, D. H. (2010). Gender and classroom learning. Psychology in the Schools, 22, 8 - 23. 


\title{
URBAN SPATIAL PRACTICES OF THREE GENERATIONS OF WOMEN
}

\section{Demet BAYAR KILIÇARSLAN ${ }^{1}$ \\ Zeynep ULUDAĞ $\breve{G}^{2}$}

\begin{abstract}
City influences the societies it contains with its socio-cultural structure that changes in time while it is also influenced by this change. The change in social structure transforms the physical environment of the city as well as its sociological environment. Social and physical environment, which are among the key elements of this transformation, change the meaning and use of the public space in that society. The actors who use public space most actively within the spatial motion of daily life are women. In our country, spatial experiences of women related with the urban public space and private space show sharp differences for each generation. When the daily life experiences of women from different generations are assessed, the differences within this context can give us important data to read the urban space, culture, memory and history.
\end{abstract}

The aim of the present study is to comparatively examine the access of urban space and daily life practices of three generations of women from the same ethnic origin in different zones through the sample of Çorum province. It was also aimed to discuss the effects of rural-urban migration, minority status and social gender roles by including these to the phenomenon of "space" and at the same time to create verbal history documentation.

The study was conducted by making use of in-depth interviews with three generations of women and other users who have experienced public space experience with them, and also written and visual resources of urban spaces and history. It was researched to what extent the sociocultural, socio-economic and socio-political structures in different time zones are effective in women's access to urban space and their use of public space and how this interaction changes the space.

Keywords: Women, Public Space, Daily Life Practices, Social Gender

\footnotetext{
${ }^{1}$ Graduate Student, Department of architecture, Gazi University Demetbayar89@ gmail.com

${ }^{2}$ Prof. Dr., Department of architecture, Gazi University Zeynepuludg08@ gmail.com
} 


\section{Introduction}

Since humanity, how people use space has differed according to the effects of environmental, social, religious, cultural, political and economic phenomena. Biological formation and development of human beings have shaped the use of space directly or indirectly. The effects of these phenomena are stronger in women. Throughout history, situations such as political reforms, resistance movements, technological developments and the effects of capitalism have determined the social lives of women and accordingly their use of private and public spaces. Women's use of public spaces is one of the most effective factors influencing their own life standards. "Since women's' relationship with "public" basically means their interaction with the outside world, a woman's experience with the public space starts with her first step outside the house" (Tuncer, 2016: 59). The primary factors influencing this relationship are age, educational status, profession, marital status, and state of disability. In direct or indirect relationship with primary factors, "Class belonging, beliefs, traditions, culture and similar factors determine women's duration and way of public space use" (Cantek et al., 2014: 123-124). The present article examines the relationship of three generations of women from the same ethnic origin who have a mother-daughter relationship and who are still alive with public space within the conditions of the changing world and globalization and their spatial experiences.

\section{Urban Experience of the First Generation Woman}

\section{Urban Identity / Neighborhood Identity}

Starting from the smallest scale, every individual seems to have an abstract identity on the basis of home, street, neighbourhood, city, country and universe. These identities determine our behaviours, rules and social roles in the social life. Use of space is one of the elements of these 
rules and roles. It is an acquisition which is not a law, but it is imprinted in the social memory as "cultural code". Cultural codes present class differences. Harvey (2002:170) associates these differences with space and advocates that "...differences which occur in cities with styles of socializing and various webs arise within processes in which relationships between classes and social differences are produced and maintained and they undergo spatialization”.

The urban experience of first generation woman starts with the migration from rural area to city centre. Migration is a phenomenon which is seen and which continues in every stage of social life, it can occur due to different reasons and it can deeply influence the course and history of societies. The factors which influence migration are primarily economic factors and secondarily political factors. Tümertekin and Özgüç (2009: 296) list the reasons of migration as economic deprivation, social pressures, conflicts, environmental degradation, and the desire to access the social opportunities of the city. The flow of migration generally occurs from the rural area to urban areas. As a result of these migrations, a rural-urban intersection profile located in the boundaries of the city which has the characteristics of rural life culturally and physically but tries to keep up with the city as a new life style can be observed. "People gather in urban spaces in specific neighbourhoods and districts just like plants and animal groups in nature gathering in specific areas and form social and cultural units." (Adaman and Keyder, 2006: 51).

This clustering in Çorum, which is the city the first generation migrated in, can be seen clearly with regard to both denominational differences and unequal income distribution. Tekeli (1978:76) stated in the classification of adaptation phenomena in people's migration process that migration from rural area to urban area is a "radical choice" since both professional and social environment will change.

The urban adventure of the first generation woman, who was previously living in rural area and who was married with four children, started with the migration of the family from 
village to city centre due to concerns for safety as a result of Çorum incidents in 1980s. After migration to the city, she has the identity of neither a city-dweller nor a villager. Environmental, physical and social factors have changed. She is aware that these characteristics she has as an Alawi woman speaking Turkish and her social identity are reasons enough to be the "other". First generation woman G.Y. (75) tells about the process of migration as:

"When we decided to move to Çorum from the village, my husband sold the sheep and goat hastily. With the money that we earned, we built our own slum at a place one of our acquaintances recommended. Later, my husband went to Arabia to work. He sent us money. I became both the mother and the father of the house."

For this reason, the woman adopted her permanent place as the slum neighbourhood formed as a result of migrations with the same reasons, close to the border of city centre. The process of adaptation in this neighbourhood formed by families that migrated mostly due to economic and political reasons at different times started after a certain period of time; however, it is early to say the same thing for the city centre.

\section{"Street" As Space}

The most frequently used public space by women living in slum neighbourhoods is the streets in which the houses are. Cooperation between women is most commonly seen in this generation. The main reason for this is labour organization. Works such as knitting, making bath washcloth from wood moulds, drying vegetable and fruit in summer months, beating wool, washing carpets and making paste are all done in the street and women help each other in these. As can be seen, village practices continue in the city in this generation. In this period, it is not possible for women to come together at home or to meet outdoors. There are no activities as "altın günü" (occasions where women get together for afternoon tea at regular intervals with their friends and/or neighbours) or "five o'clock tea". Meetings are completely based on labour 
and work-force cooperation. In this process, the space shared by women is a place of both production and socialization. A neighbourhood resident S. Ü. (59, Woman) explains one of these labour activities as:

"Only one of us had tandir (oven made in a hole in the earth) in the neighbourhood. We made bread (roll dough bread) there. Everyone had a turn. The others helped the one who had the turn. I mean, it was a collective work. The person who worked was given yanıç (a kind of pastry and flatbread dish) and flaky pastry while going home instead of daily wage."

In this period when women's labour is dominant, the person who manages the house is the first generation woman, that is, the mother. Those who help the mother in managing the house are daughters who correspond to the period called second generation. Second generation actor A. B. (53, Woman) states as the following that they spend their lives doing housework all the time: "There was always work sharing between my mother, my elder sister and me. For example, in the backyard, one of us rubbed clothes; one of us washed and one of us hung. Whatever mum did in the house, we helped her. Men in the house would either go to day labour or to neighbourhood kiraathane (coffee shop) if there was no work."

In this period, there is no social activity that women and men do together or with other families. Men and women spend time in different places during the day. Men are assumed as the head of the family. While men have a social agency and spatial map in which they spend most of their time, women do not have this opportunity. Women go home when it is close to their husbands' returning from work or neighbourhood kiraathane (coffee shop) and the streets get empty. The time allocated to public space has come to an end for women. Housework is next for them.

When asked whether she has another activity in urban space, first generation woman G.Y. (75, female) laughs and says: 
"No, my child, how can I? We had a garden where there were fruit trees, we used to walk around there if my husband was here. When I came here first, I didn't even see the clock tower for a long time. I saw the bazaar, due to necessity, when my husband was in Arabia, that's it. There was no place to go to, or we could not go. We did not leave the doorstep. There would be a change if there was a wedding once in a while. Even the dead would be washed in backyards."

As can be seen, although the city is close to the first generation woman, it is yet far away and even unreachable without a man next to her.

\section{"Home" as Space}

Home is the primary space of first generation woman. This home has two bedrooms, one living room, kitchen, bathroom and toilet. The population (6) in the house and the number of rooms in the house do not match each other and the heating system is stove. For this reason, the inside of the house is restricted with individual freedom. The usage parameters of the house differ in summer months. When it is cold, all the members of the family sleep in the room where the stove is (generally living room). When the man wants to sleep, women bring cold pillows and duvets from the bedroom to make the bed on the floor, the lights are turned off and while mother and father sleep together, girls sleep together and boys sleep together. Due to crowded population of the house and the heating system, all individuals in the house try to use the toilet in minimum period of time. The living space of first generation woman is generally "home" and the place where she spends the most time is the kitchen. Due to physical conditions of the house, time can be spent frequently in the kitchen only in summer months. Since the house is heated by stove, the kitchen is not used unless required in winter months. Thus, preparations are made as practical and fast as possible. The men in the house do not enter the kitchen. Women cook in the cold and wash dishes with cold water in winter. Similarly, the act of "lighting the 
stove" is also the responsibility of women. Wood is carried home from the part called woodshed in the backyard when needed. In the bathroom used, water heating is also done with stove. Shower is settled for specific days. Members of the family take shower in turn when the stove in the bathroom is lit, they get dressed in the cold room quickly and they sit down near the stove in the living room to get dry.

When the elder son of the house gets married, he moves inside the same backyard in a house built by them. The reason for this is again limited financial means and also to form a new labour cooperation between families. In marriages of this generation, there is a tradition for men to live in the same house, or to use the same backyard if they are not living in the same house or to live in close places.

If need be, the woman is restricted from the home space rather than the urban space. The girls in the house are told to go to a room in the house when a male guest comes home and not to leave until the guest leaves. This shows that especially girls are restricted even at home, which is the "most private" place of public space use.

\section{Urban Experience of Second Generation Woman}

\section{Exploring the City- Apartment}

In this period, there was an estrangement from traditional structure in Çorum, which is a small Anatolian city. This estrangement also had an effect on housing culture. It is predominantly observed for capitalist developments and thus developing technologies to influence women's use of indoor and outdoor spaces. With the increasing urbanization, transition to apartment life started. However, the transition period of this family, which had financial difficulty, occurred in a later period. 
The first family member who moved to apartment life is the second generation woman, who is the youngest daughter of the house. The second generation woman tells that they lived for five years after they got married in a building with three floors and garden, with the relatives of her husband and that they decided to move to an apartment when her husband's financial situation was sufficient to move to another house:

"When I was pregnant with my older daughter, my husband went abroad to work. At that time, I was very afraid even to go to grocery store, being pregnant. Thus, I always made and ate the dry legume at home. However, when we moved to apartment and I met my neighbours, I was not afraid anymore."

When the second generation woman entered the apartment life, she gained a new social environment other than her relatives and as a result of this, her spatial map changed. The city centre is no longer far and unreachable; it is now close and easily accessible. The fact that she was free of family and environmental pressure caused the woman to feel free and this in turn enabled her to use the urban space more actively. Apart from these psychological and sociological reasons, the developing neoliberal world economy is now presenting the newest technology to consumption and making household appliances such as washing machine, dishwasher, vacuum cleaner and kitchen robots more accessible and more useful. With the increase in purchasing power of second generation woman, this technology entered her home. The woman began to use heater in apartment life and got rid of lighting the stove. This influenced not only home life but also spatial use. The time spent with lighting stove was eliminated. Technological devices starting to get inside houses caused the time spent in housework and kitchen to get shorter and the time allocated for social life to get longer. 


\section{Activities Between Families and Women}

In this period, more than one family with similar socio-cultural and socio-economic aspects come together and organize activities on holidays. They participate in daily trips to close cities, short summer vacations in North part of the country, spas, and family clubs with their family and children. Second generation woman can go outside to public spaces more easily. However, as long as she is married and her husband is with her.

The husband of second generation woman E.B. $(57$, male) tells the then popular place family clubs as follows when asked:

"If I were to give a rough date range, there were 3-4 different places as family clubs in Çorum between the years 1985 and 2005. Every Saturday evening, we would come as families. There was a different woman singer each week. There used to be holdups as a fence. Single men would be there. They were good and fun times. However, there are no such places today. They have all become wedding halls."

The closing of family clubs and picnic areas open to general public becoming municipalised and some limitations brought caused families who wanted to make maximum use of urban facilities to search for different spaces. New entertainment and picnic areas located outside the city which are used by intellectuals as a second home in Çorum are vineyard houses. These detached houses with a garden, terrace, swimming pool and sport areas, etc. are still an important part of social life. They have replaced the picnic areas families went on holidays or the places where guests were entertained. These vineyard houses are also hobby gardens. In vineyard houses, just like in Anatolian neighbourhoods, families with the same socio-cultural characteristics have gathered in the same areas. For the second generation woman and her family, they are popular places which provide an escape from the exhaustion of the city.

In this generation, relationships between neighbours are weak when compared with the first generation, while they are strong when compared with the third generation. Altın günleri 
(occasions where women get together for afternoon tea at regular intervals with their friends and/or neighbours) and home visits which started in homes when apartment life started left their place to activities conducted in public spaces in time. Women with similar socio-cultural and socio-economic position started to go to spas, entertainment places, restaurants and parks together.

Second generation women who felt that the responsibilities required by the "motherhood" roles attributed to them decreased, even if in part, especially when their children left home stated that the time they allocated to themselves increased because when the number of family members decreased, responsibilities in the house also decreased in general. Lefebvre (1971:73) stated that women had the burden of daily life; women had the power reverse this situation if they wanted; however, they continued to carry this burden. Despite all these thoughts, it is women again who come home before dark, who have to do the housework and who spend too much time in the kitchen.

\section{City Experience of Third Generation Woman}

"Global village" terms of media theorist Marshall McLuhan explain how humans are surrounded by technologies that almost completely take away the effects of space and time and how they are connected to each other (Gibson and Murray, 2016: 313). A rapid increase in technological developments, developed means of mass communication and transportation shortening the distance between countries have changed the daily activities, gender roles and position of women both inside the house and inside the city and also globally. Third generation woman who prefers to reside in a metropolitan city to make use of the range of jobs, education and large opportunities, has been raised in the postmodern world she met while growing up by having new habits of consumption. She uses multi-storey shopping malls, spends time in gyms, participates in art workshops and other activities in her spare time as a hobby. In addition to 
these, she has the habit of consuming ready food outside the house. All this speed of communication and consumption present this generation with very different experiences and opportunities and differentiates her sharply from life practices of other generations about the city. This difference influences both life style and style of thought. "In postmodern capitalism, consumer goods have become a very important area in forming meaning, identity and gender roles.” (Bocock, 1997: 101).

In this generation, although there is a get away from traditional relationship styles, “gendered spaces" still continue to exist. According to Duncan (2005: 2), this differentiation is explained by mind/body dualism, is reflected as public/private area with the reflection of this dualism on the space and it is shaped according to relationship between men and women. Second generation woman's state of having higher education, being active in business life, having trips abroad by herself, being in a public space at night, etc. also support these differences. Third generation woman has higher purchasing power and welfare level and intellectual capacity. Her activity in business life, frequency of travels and activities in public space have made her spatial map very dynamic and variable. Third generation woman has the potential to use urban space more actively. As a result of the increase in technological developments caused by globalization and mass communication tools becoming widespread, the way of using time to cover the space changes and the time and space jam, which is the theory of Harvey is experienced more (Harvey, 1997:270). This situation is more active due to third generation woman's easy access of mass communication tools. Third generation woman spends less time at home and is more present in public space. She prefers dwellings with security, and social activity areas such as swimming pool and sport centre.

"I am married, but I don't have a fixed place. I am studying in Ankara and living in İzir. I make domestic and foreign trips when I get the chance. Sometimes with my husband, sometimes with friends and sometimes alone." (D.B.K., 29, Woman). 
Advocating women's rights and feminist views are most common in the women of this generation. Women studies have begun to be effective academically. Especially the state of her name in urban space is the research area of third generation woman.

\section{Conclusion}

When we analyze the urban space practices of three generations of woman, we come across sharp differences. From the restricted living area of the marginalized woman who tries to adopt to city starting from village life; to the second generation woman who uses urban space more actively than home and street life to the grandchild who discusses the urban limits and questions the place of woman...There is no doubt that when these differences are analyzed, the change in the city, global resistance movements and sociological situations form a basis in women's lives indirectly. Level of education, variables of purchasing power, differences in patriarchal thought, ways of residence structuring and home spaces and even spatial formations which influence the use of home have become determinants in daily life and space uses. In addition, it can be seen that cooperation of women with the same socio-cultural background also eases the access to urban space.

The order that first generation woman is trying to keep up to in the present time is similar to urban behaviour second generation woman enters after marriage. Urban practices of the second generation woman also begin to be similar to the urban practices of third generation woman as day passes. When the three generations of woman are categorized, we can define the first generation woman with passive user identity, the second generation woman with consumer identity and the third generation woman with urban transformer identity. Change continues every day. As globalization advances, the variations in using space also increase; time-space jam is felt more obviously. In addition to all these developments, urban orders in patriarchal 
structure which makes itself felt in this period too is a phenomenon that the third generation woman is aware of and uncomfortable with. In order to be able to observe and compare these differences, making historical readings and making use of comparing the urban behaviours of women from the same generation seems to be one of the most correct options.

\section{References}

Adaman, F., \& Keyder, Ç. (2006). Türkiye'de büyük kentlerin gecekondu ve çöküntü mahallelerinde yaşanan yoksulluk ve sosyal dişlanma [Poverty and social exclusion with the collapse of slums and neighborhoods of big cities in Turkey] ec. europa. eu/employment_social/social_inclusion/docs/2006/study_turkey_tr.pdf.

Bocock, R. (1997). Tüketim [Consumption], (trans İrem Kutluk). Ankara: Dost Bookstore Publishing.

Cantek, F.Ş., Ulutaş, Ç.Ü., Çakmak S. (2014). Evin İçindeki Sokak, sokağın içindeki ev: Kamusal ile özel "ara"sında kalanlar, Kenarın Kitabı, [The street in the house, the house in the street: The public and private, Book of the Edge], (comp. F. Şenol Cantek), Iletişim Publication, Istanbul.

Duncan, N. (Ed.). (1996). BodySpace: Destabilizing geographies of gender and sexuality. Psychology Press.

Gibson, T., \& Murray, S. J. (2012). Global village. Encyclopedia of Media and Communication.

Harvey, D. (2002) Sinıfsal yapı ve mekânsal farklılaşma kuramı [Class structure and spatial differentiation theory] Duru B. and Alkan A. (comp. and trans.), Imge Bookstore Publishing, Ankara, 147-172.

Tuncer, S. (2016). Kadınlar Sokağa Çıkınca: 1950-80 Ankara'sında Kadınların Gündelik Kamusal Mekân Deneyimleri [Women on the Street: Women's Everyday Public Space Experiences in 1950-80 Ankara], Journal of Social History. 269, 57-61.

Tekeli, İ., \& Erder, L. (1978). Yerlesme yapısının uyum süreci olarak iç göçler [Internal migration as the adaptation process of the settlement structure], Hacettepe University Center for Population Studies.

Tümertekin, E., \& Özgüç, N. (1997). Beşeri coğrafya: İnsan, Kültür, Mekân [Human geography: Human, Culture, Place], Çantay Bookstore Publishing.

Lefebvre, H. (1971). Everyday life in the modern world, trans. Sacha Rabinovitch, London: Allen Lane, 39., 73 


\title{
BEING A WOMAN IN MASCULINE PLACES: NARGILE CAFE EXPERIENCES OF WOMEN
}

\section{Duru Başak UĞURLU ${ }^{1}$}

\begin{abstract}
Focusing on how women experience nargile (hookah) cafes which are getting more popular and serving for a dense male socialisation, this study deals with coping tactics and individual performance practises of women in daily life in order to spend their leisure time in nargile cafes against the masculine order of them. Although banality of daily life makes it difficult for us to see, some certain places are socially constructed by gender stratification. As the places are being preferred by same-sex social actors in a broad time, these places become catalyst of homosocial relations between the actors. Beside these places produce and circulate power relations peculiar to men through creating spatial limitations for women.

In this regard homosocial places not only strengthen gendered power relations also turn their male oriented panoptican eyes towards the publicity of women exposing them to act more strategically.

Thus within this study, meaning of being a woman in nargile cafes as masculine places and how women are coping with patriarchal power penetrating into every inches of daily life will be examined.

Based on a qualitative research, this study will be conducted within nargile cafes in Cevizlidere, Balgat and Bahçelievler, Ankara by aiming to use participatory observation, snowball sampling and in-depth interview with both woman nargile smokers and woman nargile makers as a profession.
\end{abstract}

Keywords: Daily life, Gender, Power, Space, Nargile Culture

\footnotetext{
${ }^{1}$ Graduate Student, Hacettepe University, Faculty of Communication, Cultural Studies and Media Departmant, Ankara, Turkey. E-mail: durubasak.ugurlu@gmail.com
} 


\section{Introduction}

Although gender identities are coded as "natural" based on heterosexual matrix in accordance with the needs of Power, they are constantly produced and reproduced within an every particular society through State, Constitutions, Market, Media, Family, School...Rather than being fixed, gender identities are dynamic ones and subject to change in the course of time. Being a woman or being a man involves a process of becoming. This process can be called as gender identity which foregrounds our ideas about who we are in relation to ideal masculinities and femininities and what we can do or we can not do in the gender regime. Raewyn Connell states that these ideas about gender categories are not vaccinated to people in the form of a package of shoulds and shouldn'ts at the beginning of life. They progress and get stricter and detailed involving different patterns of roles, uncertainities, recognitions, disapprovals, tensions in time by leaking into every stages of live not merely at infancy. By the time, patterns of roles by creating gender differences become more complicated and uncertain than actually what they seem on the surface. In other words we can say that it is simply not an issue of wearing blue or pink. Beside, Connell emphasises another point that being a woman or man should not be considered as a consequence of rigid doctrines of power. People themselves also maintain the patterns of gender roles and fulfill the requirements of patriarchal power. By the time there appears a gender order in society, people demand places from this order and acquit themselves related to the impositions of it (Connell, 2009: 5-6). After a while, in foucauldian terms we can say that the gaze of power is imprited on the minds of people. Apart from the discipline practises of authorities, people also interiorize the power, exercise it strongly and turn out to be conductors of it heavily (Powell, 2015: 411). Therefore social actors construct themselves through the gaze of outside and interiorized power within daily life. 
"Because there is neither an 'essence' that gender expresses or externalises nor an objective ideal to which gender aspires, and because gender is not a fact, the various acts of gender create the idea of gender, and without those acts, there would be no gender at all" (Butler, 1988: 521).

Judith Butler foregrounds the idea that gender identity is a cultural construction rather than simply a biological fact. Gender identity is produced by set of acts which organize its consistency. Apart from this set of acts, we can not mention about the social reality of gender identity and its consequences. Existing gender inequalities come to light through performance of the set of practises. To speak more specifically, Butler claims that the concept of performance consisted of ordinary and tedious expressions, practises, plays which became "naturalized" patterns by being repeated constantly. Beside these practises, expressions and plays represent the way of Power speaking to us and they are named as performative actions. At this point, patriarchal power uses the strength of performance in order to shape individuals in the orbit of its aims by trying to control our current performances within daily life. If performance practises are not fulfilled "well", power punishes the individuals by excluding, marginalizing and not recognizing them in society. Another strength of power comes from an ability to turning these performance practises into imposed norms (Butler, 2014: 316). In this sense Butler claims that if an individual performs in accordance with the gendered norms, she/he can take part in society as a subject. Therefore the individual reaches his/her gender and subject identities through performing the imposed set of practises ceaselessly. At the same time these repetitions should be carried out actively and being depended on the repetitions shows the fragile side of patriarchal power and its inconsistency (Butler, 2014: 317).

Within this study, from the eye of daily life I am going to discuss about the meaning of being a woman in masculine places. Finding answers about the issues; how women nargile smokers and makers are being exposed to masculine order of these cafes to smoke their 
favourite nargile or work and how they perform, develop tactics to challenge masculine order of these cafes are going to be my main objectives within this article.

\section{Method}

Firstly, I used participatory observation in nargile cafés by observing any kind of practises taking place in the cafes from the design of cafes to daily dialogues, habits, behaviours, gestures, expressions of women nargile smokers and makers. Second metod was in-depth interviews with women smokers. When I had difficulties to find women nargile makers, I used snow sampling method with the help of women participants. Duration of each interview lasts one hour in total. As to the anonymity of women participants for ethical concerns, I asked them whether I can use their real names or not. Some of them wanted me to share their real names and others did not. At this point for those who did not want to share their real names, we decided to choose random names for this study together. Readers can reach out detailed information about participants below.

Table1: Demographic information of participants.

\begin{tabular}{|c|c|c|c|c|}
\hline Participant & Age & Marital Status & Hometown & Profession \\
\hline Ruya & 24 & Single & Malatya & Student \\
\hline Deniz & 35 & Single & Ankara & Designer \\
\hline Mine & 52 & Married & Ankara & Retired \\
\hline Dilan & 28 & Married & Diyarbakır & Mechanical Engineer \\
\hline Sedef & 21 & Single & Ankara & Nargile maker \\
\hline Betul & 28 & Single & Trabzon & Nargile maker \\
\hline Aynur & 30 & Single & Kayseri & Nargile maker \\
\hline Mavis & 36 & Married & Ankara & Nargile maker \\
\hline Bahar & 33 & Married & Ankara & Survey Engineer \\
\hline
\end{tabular}




\section{Nargile Cafes: "There were so good nargile cafes that I couldn't go... just because I was \\ a woman"}

Nargile is the Turkish word usage of the smoking material. It is also known as shisha, hubble bubble, water pipe, hookah and it is defined as "oriental tobacco pipe with a long tube that draws the smoke through water" ("narghile", n. d.). Nargile material is mainly consisted of four parts which are the flexible pipe (marpuc), the bottle (govde), the pipe bottle (lule), the funnel for the pipe (agizlik). Smoking nargile is considered to be the most highest and delighted form of smoking. There is a quite close relationship between nargile and pleasure. However during my fieldwork, it seemed that male smokers were having more pleasure from the nargile while socialising with their male peers freely compared to

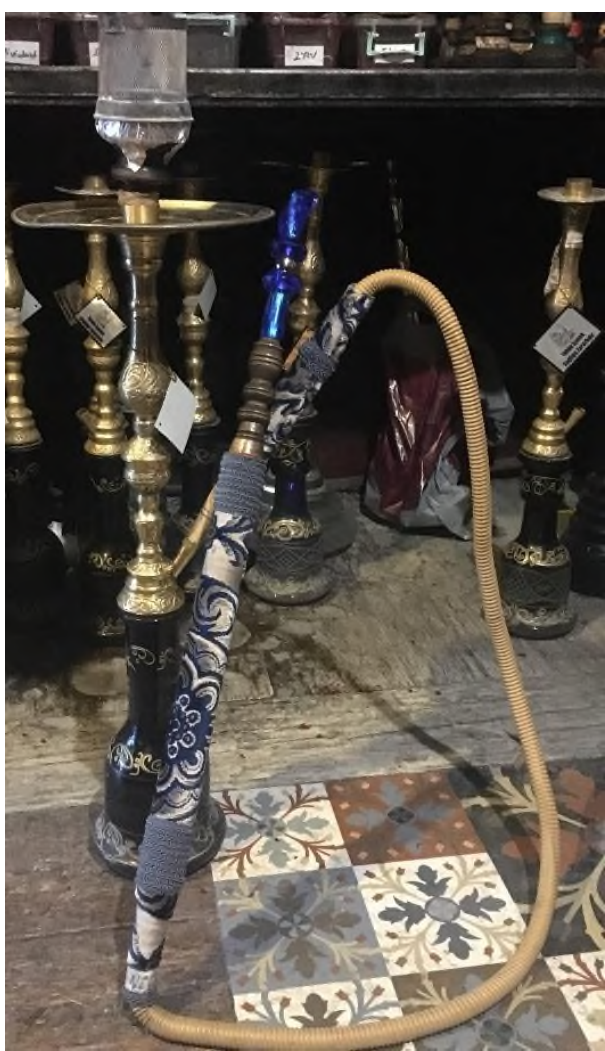

Figure 1

Detail from a nargile (photo: Duru B. Ugurlu).

women. At this point, I want to depict the gendered nature

of these cafes.

Doreen Massey foregrounds inseparable relation between gender and space that; "from, the symbolic meaning of spaces/places and the clearly gendered messages which they transmit, to straightforward exclusion by violence, spaces and places are not only themselves gendered but, in their being so, both reflect and affect the ways in which gender is constructed and understood (Massey, 1994: 179). In my fieldwork Nargile cafes were also surrounded by the gendered messages and apparently designed to enable more agency for only one gender in which there were menus filled by the images of "sexualized" women body and its association with pleasure and nargile, three door toilets of men and one door toilet of women, seating plans 
producing gender hiearchies. We can categorize them into two types; the traditional ones resembling to old Turkish coffehouses and the ones filled with both modern and traditional motifs also divided into two parts, having a diverse menu options and more modern seating plans. Generally these two types of cafés are preffered by both women and men nargile smokers. Although there is a mobility of women in these cafes, there is a highly possibility that one can encounter with the same male smoker five times in a day. However I observed that most of the women were used to prefer these places only once in a day and usually towards the evening through coming up with their male friends, husbands, boyfriends or sitting alone in the isolated parts of the cafes compared to male smokers. As male smokers gather up, they do their daily conversations and spend their time by their male peers till 3 a.m with their laughters. At these time one can almost encounter with one or two women sitting alone and putting on their headphones in the isolated parts. One of the woman smoker, Deniz says that; "Nargile cafes

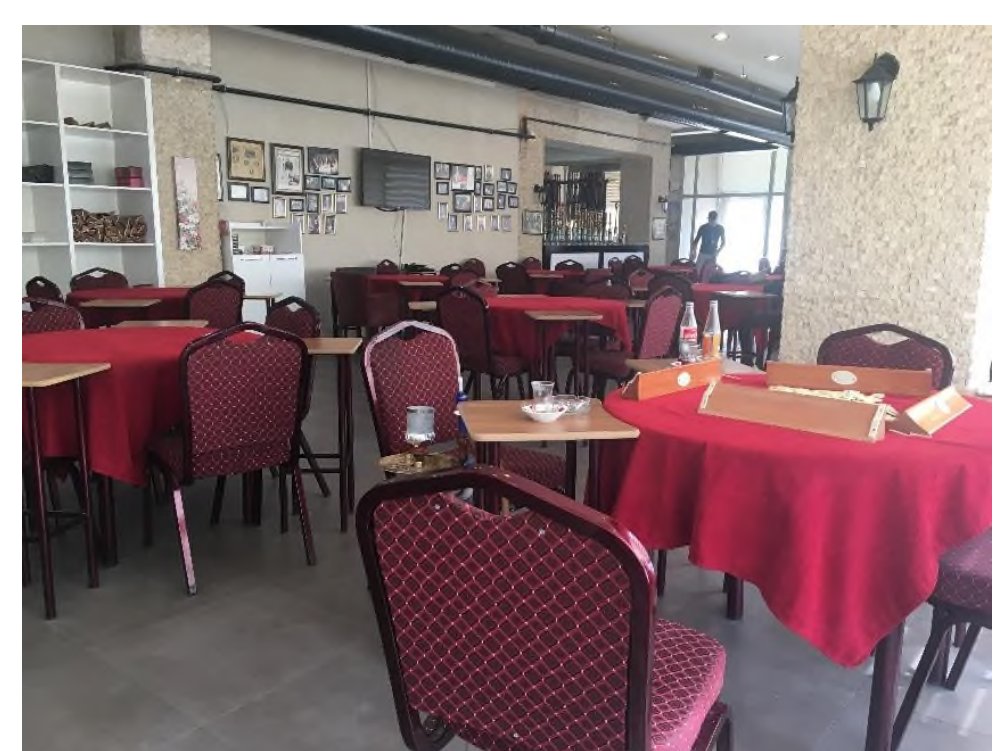

Figure 2 have such an atmosphere that indeed you lose your woman identity unavoidably. As I said before; they do not see you or treat you as a woman" (Deniz, 2019). At this point I will give some details about spatial binaries of these cafes in relation to how woman identity is melted.

A view from traditional nargile café (photo: Duru B. Ugurlu).

Traditional ones are preferred by the male smokers from old generation and filled with the pictures from "the glorious Ottoman past", smoke and dirt. The privilige of being a man enables the mobility of male smokers in these places. They play traditional games, talk about daily agenda of society 
or their personal issues by smoking their traditional nargile, tombeki till morning showing a strong male solidarity. They occupy these places more intensely in the context of both time and mobility in the cafes without any disadvantages. Beside, there is a spesific point about their daily habit; they usually gaze at the door who enters into café by whom, wears what until they decide that the person is proper enough to the manners or in other words constructed "masculine" codes of the cafés. In this respect we can say that patriarchal gaze is on its mission as Mine says her ideas about this situation; "When I come here, I particularly observe that even the personnels of this café too stare in a quite strange way. I do not know what they think; when they see a woman sitting alone and smoking her nargile. They really look differently towards you if you look carefully you can see that the way of dealing with you as a customer even changes if there is not a man with you" (Mine, 2019). While doing my fieldwork, I heard that even if they do not like someone they do not give permission to enter and they make themselves responsible for "guarding the honours of women" . Dominated by the groups of old male smokers, women sit near the windows and accepted only as sisters in a cultural meaning. Otherwise women are not "welcomed well" and their beings are perceived as "desire objects" in the minds of both male smokers and personnels. For example; the metal tongs (marpuc) carries the image of phallus among the male smokers. When they want to exchange their metal tongs, they put it on the table rather than passing it into their mouths. At this point Sedef says that; "male nargile smokers quite often think that; if women smokers put the metal tongs into their mouth, there must be more things which they can do willingly" (Sedef, 2019). 


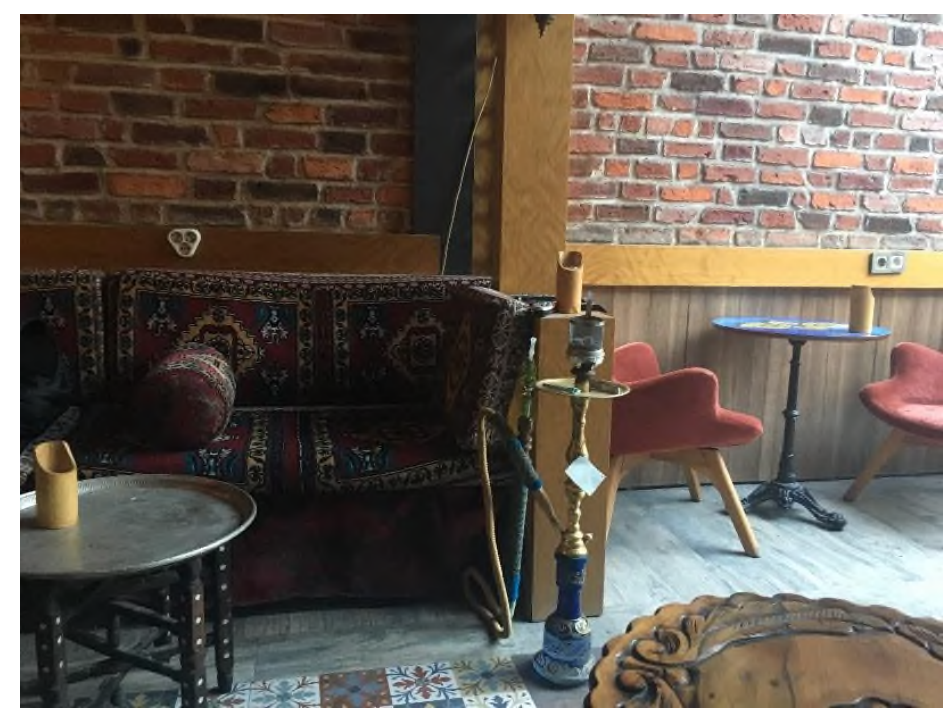

Figure 3

A view from both traditional and modern nargile café (photo: Duru B.

Ugurlu).
Second type of nargile cafes

can be called as both modern and traditional ones divided into two parts as can be seen from the figure. One side is furnished by Turkish traditional sofas and ornamented by the Ottoman architecture. Beside this version of nargile cafes have spesific fields to play traditional games such as rummicubs or card

games. In the traditional part, generally male smokers develop more intimate relations, do their "mannish" conversations and the sofas help male smokers to socialize easily through sitting side by side while limiting the agency of women smokers in this sphere.

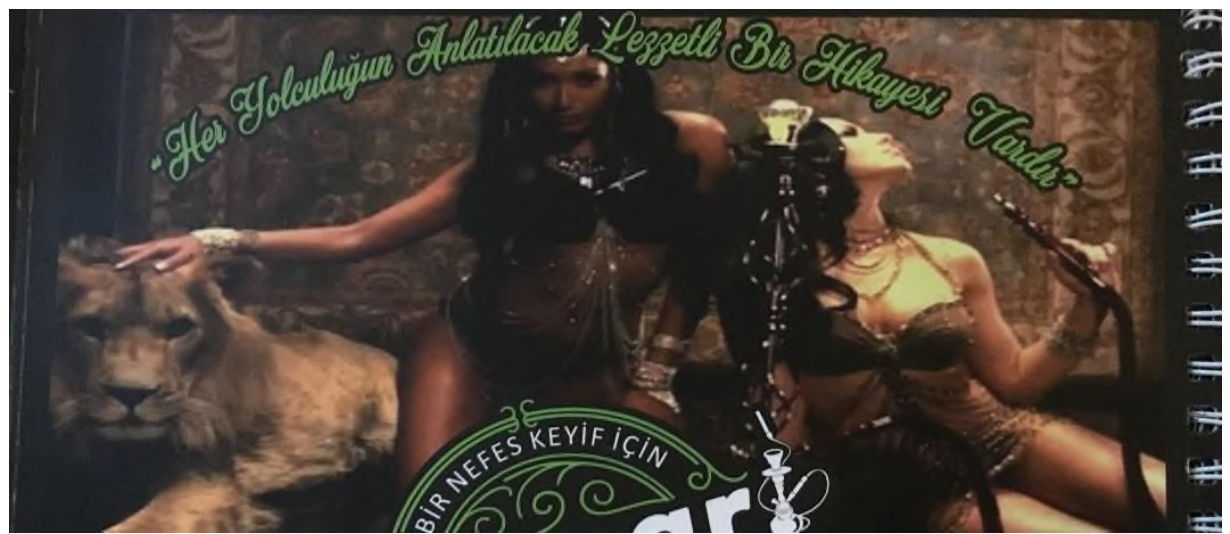

Figure 4

A view from one of the menus associating woman identity with pleasure by saying that; "every journey has a tasteful story to tell” (photo: Duru B. Ugurlu).

As to the other side, we can say that the mobility of women increases in which they can remain distant by the help of chairs compared to the side of sofas. However due to the dense male socialisation increasing towards the inside of the café, women smokers mainly sit near to the entrance door both in daytime and nightime as they want to escape from daily issues of their 
lives through the bubbles of nargile stopping the time for a while. Nargile cafes even create some hesitations among the women smokers. Some of the women generally choose a specific nargile café. The main reason behind this choice is that they fear whether male nargile maker may blend some drugs into the tobacco of nargile or not. Thus with these worries there are some questions to be handled in the minds of women before relieving themselves, as Rüya says "how I should sit and in which position, can I feel comfortable while thinking these? As I came late here, Will they talk behind me ?" In the next chapter we will discuss about how women deal with these questions. In other words how they subvert the patriarchal domain of nargile cafes by which acts in dialogue with the women nargile smokers and makers.

\section{Coping Tactics of Women Nargile Smokers: "It is an issue of eagerness"}

Deniz Kandiyoti states the idea that women are not completely under the domination of male oriented power with the concept patriarchal bargain foregrounding the active position of women in society by playing patriarchal order. Kandiyoti defines this concept as; “...women strategize within a set of concrete constraints that reveal and define the blueprint of what I will term the patriarchal bargain...These patriarchal bargains exert a powerful influence on the shaping of women's gendered subjectivity and determine the nature of gender ideology in different contexts. They also influence both the potential for and specific form of women's active or passive resistance in the face of their oppression" (Kandiyoti, 1988: 275). Although patriarchal power is distributed every inch of daily life there are some gaps in which women can take active role and subvert the male domination. This idea also shows itself in the Nargile cafes. If we come to the question how women experience these cafes, we can say that they play with masculine codes of the cafes and develop coping tactics. Michel de Certeau who stresses the agency of "ordinary" people defines tactic as; "a calculated action determined by the absence of a proper locus. No delimitation of an exteriority, then, provides it with the condition 
necessary for autonomy. The space of a tactic is the space of the other. Thus it must play on and with a terrain imposed and organized by the law of a foreing power" (De Certeau, 1984: 37). In this respect we can assert that women nargile smokers both bargain with patriarchy and develop coping tactics in order to enjoy themselves in the space of the other.

Although women smokers or makers are challenged by masculine atmosphere of the cafes, they prefer these cafe and try to relieve themselves as Aynur says; "When I smoke nargile, I ease myself resting my head and thinking about my decisions of life" (Aynur, 2019) or Deniz says; "I leave the tiredness of day through smoking for hours" (Deniz, 2019). When I asked them what they think about the other women preffering these cafes Bahar says that; " when I look into the women, I see that women mainly sit in silence or talk less as if they should not talk while smoking. They just inhale and exhale the smoke. But when I pay attention to the men I can say that they are more active and social while smoking” (Bahar, 2019).

Based on the fieldwork, I saw that some of the women were changing their paths after realizing that these places were actually nargile cafes filled by smoke and dirtiness. Rahter than turning their ways, as a tactic some of the women were preferring these cafes with their brothers, husbands, male friends or with the group of women in their first experiences as Bahar who started to smoke with her brother says; "if I had not been with my big brother, I would not be able to sit on the sofas directly" (Bahar, 2019). Now she comes up with her husband or Dilan says; "I heard that there is a place making the best nargile of Ankara. Well I do not go there, I only smoke it when there are women." (Dilan, 2019). When I told her that there are some women prefering there. Her answer was that these women are too "easy going". As to the another example, Deniz tells that "I started to come to this cafe with my male friend. When some time passed, a group of male smokers attracted my attention. I wanted to be part of them as they seemed to me quite pleased. One day I told my friend that let's go towards the inside and meet with them. From since then I have become friend with this group and I enjoy a lot 
while smoking with them" (Deniz, 2019). If women are not coming with someone they generally prefer the places near the entrance door as Mine being a nargile smoker for twenty years and everynight sitting near the front door till 3 a.m says that "...I smoke sitting alone, coming there all alone and I have thankfulness for no one" (Mine, 2019). In this sense we can say that some of the women use the advantage of "male privilige" to enter the cafes. Apart from the coming with someone as a tactic, another hesitation lies within the minds of women. Generally women prefer just a one specific nargile café. The reason behind this tactic is that women are afraid of the possibility that male nargile maker can put some drugs into the tobacco. With this reason when they trust a specific café, they frequently prefer the one and some of them bring their own nargile materials. Apart from trusting into the cafes, there is another issue to be handled by women. For example women not only hesitate about the tobacco mixed with drugs but also male nargile makers try to trick them by bringing the wrong nargile tobacco thinking that women somehow can not figure out the original mix or have some biases that women can not smoke the heavy tobaccos. They associate the tobacco taste of women with the "light" versions directly by saying that "lets prepare something sweet and light for you" before hearing the choices of women. However it is about the issue of personal taste rather than gendering the degree of tobacco, Women choose heavy and light ones in accordance with their tastes. Beside they usually smoke heavy ones such as tombeki, cappucino or double apple. In this context we can say there is an issue of women invisibility even leaking into the degree of nargile tobacco.

When the panoptican male eyes are situated towards the women, they begin to think how they should sit and behave, which outfit they should wear, what consequences might appear when they entertain themselves with nargile the same as male smokers do. At this point Rüya says; "well, you are a woman in the end, there will be someone to be interested in you. They will try to communicate with you through nargile after that they will want more" (Rüya, 
2019). In order to prevent "the wishing mores", firstly women pay attention to wear clothes which are "proper" enough. Apart from dressing as they wish, they prefer booth and loose clothes which are not featuring their bodies. Generally women arrive at a consensus that they should behave with a high trust upon themselves. Women smokers say that their stances even say something to male smokers. As Mine says; "if a woman knows how to sit and behave, I have respect for this woman. Even she is respected" (Mine, 2019) and if they look rough and quite, they think that they send a message that "I come here and I do not want to be bothered by someone." In this sense, we can say that message is taken correctly by the male smokers or makers. By this tactic of women, men only come near to women to ask something about the choice of nargile and they are not able to develop further conversations with the women. At this point Mine says; "when they see you lonely playing with phone or computer, they think that they can not chat with this woman. If they want to further conversation with me I pay highly attention to not becoming intimate with them also" (Mine, 2019). Beside she wears a headphone consistently while smoking. However, when some of the women want to socialize with male smokers, they do not scold them. Nevertheles socialisation practises continue with the manners of men. For example; when male smokers start to conversations, they manage the topics of the day mainly focusing on the issues of men. However male smokers ask the ideas of women and listen the topics such as what you think about the women who entered the café now, domestic or girlfriend issues as Deniz says that "you are all the time at the middle of male chat, gradually you are becoming one of them as if leaving aside your woman identity and this makes you comfortable and you are not bothered by someone while smoking. For example; when they see a woman they ask something about her to me. Well I can say something about her appearance such as whether she is beautiful or not. But when I see a man, I can not ask something or express my ideas about the man to male smokers" (Deniz, 2019). We can say that 
women nargile smokers get involved into the socialisation practises of the cafes by only leaving their women identities behind.

\section{Women Nargile Makers: “ He said; could you call the nargile maker? After seeing me that}

\section{I was a woman"}

Nargile maker is coded with a woman name, ayse symbolizing the quality of service and talent of nargile maker in traditional culture (Evren, 1996: 137). This point shows that there is an association between being a woman and service. Although serving personnel is coded as a woman name when we look at the cafes there are usually male nargile makers in practise and compared to male nargile makers, women are quite few in numbers. Beside they are at the centre of male interests as Sedef says; "just because I am a woman, there are such male customers that they come from other cities to smoke my mix of nargile for one day" (Sedef, 2019). Even non smokers want to smoke nargile when they see a woman nargile maker. While trying to reach the women nargile makers, I had some difficulties as well. As a profession, nargile making is associated with male power both physical and mentally on the minds of male customers. When we talked about how they started this job with women nargile makers, the answers were various. Some of them were impressed by the nargile makers, for some of the women, its income was good enough or they had personal issues triggered by men. For example as a woman nargile maker Betul, tells the story of how she started; "I was smoking nargile each day and my boyfriend was not approving this habit. To prevent me from going out every day in other words to lock me in the house, he bought a nargile shaped by an eiffel tower and compelled me to smoke from his gift in the house. When I look at nargile, these memories first come into my mind. Now I think that how lucky I am that I do not smoke nargile in the cafes. But I became a nargile maker" (Betul, 2019). 
Women face up many difficulties such as closing time of the cafes, dense interest of the male smokers, prejudices about the capacity of women in the context of preparing nargile, harsh conditions of the work environment filled by the male dominancy...All of these issues have an impact upon the woman identity in these cafes and urge women to bargain with patriarchy through adopting the masculine codes and improve tactics to prevent the male domination. Firstly some of the women pay attention to their clothes and prefer the loose ones which do not foregrounding their bodies as Aynur says; "to work in these cafes I had to change my whole wardrobe" (Aynur, 2019) or some of the women dress as they wish but they pay attention to their gestures and conversations with male customers. During their working hours, they stay firmly without any mimics and especially when male customers want to get close much and they use harsh gendered slang words. As another tactic some of the women nargile makers wear a wedding ring although they are single to prevent the "excessive" attempts of male customers. Sometimes wearing a wedding ring is not an obstacle for the males even the working with their boyfriends, male customers can insist on bothering women nargile makers.

In their first experiences women try to persuade the male nargile makers also known as masters that they have enough capacity to do this job. One of the challenges was to convice both nargile makers and customers that a woman is capable of making good nargiles even better than male makers as Mavis says; "when I decided to begin, they said; a woman can not be a nargile maker and I got quite pissed of and I said; i can be one of them. Don't decide too early!" (Mavis, 2019). In order to prevent this attitude women develop some tactics by using more energy and time than actually the profession requires. For example, in their first experiences they come quite early to the cafes and they try to taste the all kinds of tobaccos till they feel sick as Sedef says; "when my master told me that if a nargile maker can not smoke an anise tobacco, she or he can not be good at this job. After hearing this sentence I frequently smoked the anise with a dense headache and threw up often while working" (Sedef, 2019). As 
a tactic, after preparing the nargile bench for the heavy day, they try to create new nargile mix using hours to find their own special and tasteful mixes to be written on the minds of customers through their differences apart from the male makers. When the masters decide that they are good enough to stroll around the cafes and take care of the nargiles of customers, this time they become the centre of male customers' interests. For example; sometimes male customers call them to have conversation even if they do not need anything related with nargile. This situation even creates some jealousy among the other personnels. Male personnels come at consensus that all customers want women nargile makers to prepare their nargiles because they are just women ignoring the quality and the taste of nargiles made by women. Even male nargile makers or other male personnels attempt to complain about women to heads of the cafes in order to get rid of women. At that point women use another tactic to defeat these attempts. For example with their own tasteful and different mixes, they create their own group of customers who mainly prefer the cafes to smoke these special mixes. Beside women do not tell the description of those mixes. When they feel threaneted by the male personnels too much, they quit their jobs and take their special group of customers to the other cafes which are their new work places. By this way women try to guarantee their positions and strength their reputation among the other nargile makers. After a while women set up their own nargile benches and create the rules of their own and choosing their team members in the cafes.

\section{Conclusion}

Nargile cafes are becoming more popular socialization places and apparently, these cafes serve for a dense male socialization from both their designs to the practises of cafes. In this paper, I tried to depict the masculine nature of nargile cafes and focuse on active roles of women nargile smokers and makers. Although these cafes are dominated by the groups of men 
or designed to enable more agency to the male individuals there are still some gaps women try to get in with some hesitations on their minds. They experience these cafes with their husbands, male friends or group of women, they pay highly attention to the sitting positions, their dialogues, dressings or stances when they face up with the dense interests of male individuals. Beside, invisibility of woman identity is quite apparent issue as women nargile smokers and makers say; "they do not see you as a woman, your woman identity is melted in such an atmosphere or you can not be a nargile maker because this profession needs male qualifications". Even women smokers are tricked by the male personnels who bring the fake nargile tobacco or dare to put harmful versions of tobacco. Generally, male ones do not see the women's potential of becoming good at nargile making just like anybody regardless of gender discrimination. We can say that the attempts of putting obstacles to women nargile makers or smokers do not work, women use coping tactics through playing with masculine order of the cafes in order to create their own spaces. Some of the women smokers send a message that you should not bother me apart from the things related with nargile with their behaviours, busying with their headphones, dressing loose clothes, bringing their own nargile materials, coming up with their friends or they come alone and adapt "masculine" behaviours. For example, they show a firm look and "masculine" stance and try to socialize with the male smokers and become included to these groups but only with the manners of men. If it is needed, they become the part of gendered daily dialogues of men and use the slang words as men do. By this way women smokers prevent "the extra wills" of the men smokers through becoming like one of them as a tactic. As to the women nargile makers, to put the male ideas behind, they begin to prove themselves and show more efforts than actually what the profession needs. They come to the cafes early, work hard, try to taste every kinds of tobacco whether the tobacoo is heavy or not till them sure that they learn good. Even this attempt might end up with vomitting up. However they continue to spend their time creating new tobacco mixes to show their differences from 
the male makers and by these unique mixes women create their own group of customers. If they feel much bothered by the organized masculine order of the cafes they leave the cafes and open their own nargile benchs. In conclusion we can say that gendered nature of nargile culture and the cafés show the new place experience for the spatial limitations for women. Although women are forced to challenge with the male atmosphere of the cafes, they can create their own spaces to enjoy from this special kind of smoking by following some tactics and acting strategically. Sometimes through leaving their woman identities at the door and becoming like one of the male smokers as they say or sitting in silence and sending message with their stance, looks and busying with themselves while male ones quite actively socialising with their peers. Being a woman in nargile cafes shows that the acts of women are still described but they are open to change by acting strategically as well.

\section{References}

Butler, J. (1988). Performative Acts and Gender Constitution: An Essay in Phenomenology and Feminist Theory. Theatre Journal, 40(4), 519. https://doi.org/10.2307/3207893

Butler, J. (2014). Bela Bedenler (1st ed.). İstanbul: Pinhan Yayincilik.

Connell, R. (2009). Gender (Short Introductions) (2nd ed.). Cambridge: Polity Press.

De Certeau, M. (1984). The Practice of Everday Life (1st ed.). Los Angeles and Berkeley: University of California Press.

Evren, B. (1996). Eski İstanbul'da Kahvehaneler (1st ed.). Milliyet Yayınları.

Kandiyoti, D. (1988). Bargaining with Patriarchy. Gender and Society, 2(3), 274-290.

Retrieved from http://links.jstor.org/sici?sici=0891-

$2432 \% 28198809 \% 292 \% 3 \mathrm{~A} 3 \% 3 \mathrm{C} 274 \% 3 \mathrm{ABWP} \% 3 \mathrm{E} 2.0 . \mathrm{CO} \% 3 \mathrm{~B} 2-\mathrm{W}$

Massey, D. B. (1994). Space, Place, and Gender. (1st ed.). Minneapolis: University of Minnesota Press.

Narghile. (n. d.). In Lexico. Retrieved from https://www.lexico.com/en/definition/narghile

Powell, J. (2015). Foucault, Power and Culture. International Journal of Humanities and Cultural Studies, 1(4), 401-419. Retrieved from https://www.academia.edu/11339833/_Foucault_Power_and_Cul 


\title{
PRIVACY AS AN OPTIONAL SUBSET OF THE PRIVATE SPHERE: "HOME" IN IRIS M. YOUNG'S POLITICAL THEORY \\ Elif MADAKBAŞ GÜLENER ${ }^{1}$
}

\begin{abstract}
There is a considerable literature on home in terms of its relation to women. Some argue that home may have a liberating role while others suggest that home, as a symbol of private sphere, keeps women away from expressing themselves especially in the public sphere.

According to Young, home -by providing safety, individuation, privacy and preservation- is a medium where one can reflect her own identity. Thus, the concept of home should not be abandoned, rather it should be democratized. For this purpose, previous attempts to explain Young's approach to home focus on details of "home" and its way of reflecting democracy and personal identities. Here, I would like to put "home" in the broader picture of Young's political theory.

First of all, I deal with Young's political theory in terms of her "social connection model" and relational approach to concept of power.

Secondly, I deal with transition from "house" to "home" as a missing part in Young's framework and with her reformulation of public and private spheres. Then, I portray her understanding of "private" in formulation of optional subset of private sphere indepted to society.

Finally, I open up a debate whether this optional space can be a space of resistance or it can turn out to be "elitism" if privilege of home owning does not stay in touch with "consciousness raising”.
\end{abstract}

Keywords: Iris M. Young, home, house, private sphere, privacy, social connection model

\footnotetext{
${ }^{1}$ Dr. Uludag University, Department of Political Science and Public Administration emadakbas @ uludag.edu.tr
} 


\section{Introduction}

Iris M. Young's political theory embraces a wide range of issues, including democracy, power and power relations, identities, recognition, and - most notably - justice. Specifically, Young draws on inspiration from critical theory and feminism in order to challenge mainstream theoretical frameworks. One such critique is her perspective on relations inherent to the division between public and private spheres, indebted to the arguments of Jürgen Habermas. It is on this aspect of Young's social theory that this paper will focus. For this purpose, I will begin by briefly mapping out an overall picture of Young's thoughts on politics, within the framework of her "social connection model". I will then locate her reformulation of the public and private spheres at the center of this picture. Finally, I will discuss her approach to home and privacy, and common criticisms of her approach to home.

\section{The "Social Connection Model" in I. M. Young's Political Theory}

Young's example of "Sandy's story" may be sufficient to illustrate her social connection model and political theory. She describes Sandy as a "single mother" with two children, who could not afford to rent a house close to her place of work because of the high rents charged in the area (Young, 2011: 43). Young claims that the proper concept to describe Sandy's situation is injustice, since that situation can be attributed not only to Sandy's individual (in)capacities but also to structures inherent to society. Thus, homelessness should not be labelled as a problem emerging only from the choices and actions of individuals; rather, it is a shared problem contributed to by the choices and actions of all people in society (Young, 2011: 46). Moreover, problems such as homelessness usually result from oppression of some people by others (Young, 2011: 52). At this point, a crucial question is raised: who is "responsible" for Sally's situation? (Young, 2011: 99). Young's answer is rooted in how she interweaves the 
concept of oppression/asymmetry, structure, and responsibility under the rubric of the social connection model.

Power relations take an important part in Young's political theory. According to Young, "for every oppressed group there is a group that is privileged in relation to that group" (Young, 1990: 42). Primarily, injustice is instead a matter of relations between advantageous and disadvantageous groups (Young, 1990: 192). Young describes, for example, "asymmetry between landlords and tenants" (Young, 2011: 51) as one example of a relation between the oppressed (tenant) and the privileged (landlord). This is why power relations are strongly implicated in debates surrounding injustice.

Problems derived from oppressive relations, such as homelessness, cannot be solved at the individual level. As Young explains, "[i]nstitutional and social rules" play a role in contributing to homelessness at structural level (Young, 2011: 55). Whether they are deliberate or not, actions caused by all members of society are all responsible for one's situation of homelessness (Young, 2011: 96). Young describes this as "collective responsibility," a term which addresses the connections between actions rather than individual personal responsibilities (Young, 2011: 9), which might manifest themselves as bringing an accusation against Sally for her homelessness (Young, 2011: 11). Here, as collectivity, responsibility refers to "solidarity" stated as "an ideal, a promise, an engagement" (Young, 2011: 121) and it forms the basis for why Young prefers politics which takes account of ethics (Young, 1987: 57-58). At the same time, "representation of different groups" equally in public life culminates in "effective recognition and representation," allowing groups to gain awareness of the thoughts and feelings of other groups (Young, 1990: 184). The next question, therefore, is: how do they gain awareness?

Gaining awareness may be related to what Young calls "consciousness raising," which she defines as "making the privileged aware of how their habitual actions, reactions, images, 
and stereotypes contribute to oppression." (Young, 1990: 154-155). Additionally, consciousness-raising increases the visibility of disadvantaged groups and provides them with creative ways of articulating their demands through social movements, opening up a place for them to come across privileged groups (Young, 1987: 75). There remains, in light of these observations, a further question: where do different groups encounter and pave themselves a way for awareness?

\section{M. Young's Reformulation of the Concept of Public and Private Spheres}

Jürgen Habermas, studying the emergence of the public sphere and the contribution of the bourgeois class to it, first of all describes how opinions are historically expressed in public debates (Habermas, 1991 [1962]). Habermas then discusses the function of communication in the social sphere through the framework of continental philosophy and pragmatism (Habermas, 1998 [1976]). Finally, he evaluates "communicative action theory," which suggests that when decisions are taken with reference to group discussions, those decisions are congruent with normative principles, and that agreement is reached through dialogue in these situations (Habermas, 1984 [1981], 1987 [1981]). Following the development of the concept of public sphere, heated debates ensued in the related literature (Calhoun, 1992) and Habermas's arguments, including those pertaining to the public sphere, were challenged by many feminists (Meehan, 2013), including Iris M. Young.

Young suggests that Habermas's arguments may be quite fruitful for feminist theory, provided that their shortcomings are remedied. She points out, for example, that his insistence on reason as depending on and reshaped by communication, paves the way for reason to be built from the bottom to up through dialogue (Young, 1987: 68-69). However, she insists that in addition to what people say in dialogue, the way in which they say it is also an indispensable part of communication; she argues, therefore, that Habermas's communicative action theory 
should be enlarged to include feelings and how they are expressed (Young, 1987: 72-73). These observations show that Young seeks to fill in the missing components in Habermas's theoretical framework.

According to Young, the distinction between the public sphere and the private sphere identifies public sphere as neutral and, by doing so, prevents women from entering the public sphere because of the stigmatization of women's issues as emotional/private issues (Young, 1987: 63-64). To overcome this obstacle, Young attributes central importance to the feminist motto of "the personal is political" as a means of bringing neglected feminist issues under discussion in the public sphere, and of breaking the uniformity, imposed in the name of impartiality, currently characterizing the public sphere (Young, 1987: 73-76). Thus, building on feminist critiques of Habermas' arguments, Young expands upon rather than rejecting Habermas. But she does not confine her feminist theory to women's problems; instead Young seeks to extend the scope of feminism to address many other problems arising from power asymmetries.

Young positions feminism under the umbrella of social criticism which combines structural analysis, individual experiences, subjectivity and identity (Young, 2005: 19-20), by examining power relations concerning “caste, class, race, age, ethnicity and, of course, gender" (Young, 2005: 21). As such, the public sphere should be open not only to women, but also to color of people those with a poor economic situation, and many other disadvantaged groups, to express themselves (Young, 1987: 66). According to Young, issues "affect[ing] large number[s] of people" need to be discussed in an "open" and "accessible" public sphere (Young, 1987: 73-74).

The feminist comprehension of "private as political" challenges our attention to two points in the relationship between the private sphere and the public sphere. The first is that no group should be ignored in terms of deliberation on social problems, and the second is that 
problems such as "domestic violence" should not be considered as neglected matters confined to the private sphere (Young, 1987: 74; Young, 1990: 120-121). Domestic violence reflects the asymmetry between men and women and, as long as it is left in the private sphere, the problem will remain invisible, facilitating the one group's ability to exert pressure on the other.

With reference to groups disadvantaged in terms of class, gender, religion, and so on, we may infer that the confinement of oppression-related experiences to the private sphere also disrupts the social connection that Young speaks of. While Habermas suggests that this connection may be provided through communication, for Young people are still interrelated in terms of responsibility even when they do not communicate with each other. Then, it is possible to say that where there is no communication people may not be informed about these oppressions; thus, individuals in society might not be aware of what they should be responsible for, and why.

\section{Home and Privacy from the Viewpoint of I. M. Young}

In her book On Female Body Experience: Throwing Like a Girl and Other Essays, Young is interested in experiences concerning women's daily embodied experiences such as pregnancy, menstruation, having breasts, and so on (Young, 2005). In other works, Young also highlights the fact that, even in daily life, activities are reflections of broader frameworks (such as culture) in the lives of individuals (Young, 1990: 86). Moreover, topics related to the feminist motto "the personal is political," such as dress and advertising tropes, are products of the “politicization of everyday life" (Young, 1990: 87).

Young defines a person's home as "a space in which he or she dwells, carries out everyday activities of caring for self and others, plays, celebrates, plans, and grieves" (Young, 2005: 156). She does not focus attention on the difference between home and house; rather she uses home and house interchangeably (using in the form of "house/home") (Young, 2005: 123- 
154). Building on Young's insistence on "home as a critical value," Cathrine Brun studies the “displacement" and "homemaking" experiences of refugees in Georgia. However, Brun, unlike Young, begins by stating the differences between home and house. She defines home as a sophisticated type of house with "material qualities, symbolic meanings, the occupant's experiences, and their relations with the surroundings of the home." (Brun, 2015: 44). Home can also be located on a spectrum that includes "myself" at one end and "land" at the other end. Concepts such as "room," "house," "village," "municipality," and "province" may also occupy positions between these two ends as signifiers for where we call home (Riukulehto and RinneKoski, 2016: 14; Figure 2-1). For example, feminist Bonnie Honig considers both whole nations and a humble shelter dwelling as potential signifiers for home (Honig, 1996).

Young agrees that people sometimes refer to a large number of places and neighborhoods as home, but in the modern sense home is more like a small apartment. The time spent at home, and therefore the meaning of home, may vary from culture to culture and from person to person. However, the "commodified home" is directly related to "personal identity" in terms of "leisure, pleasure, and consumption" (Young, 2005: 131-132). Addressing these understandings of home, it is possible to talk about four associated values: safety (being protected from outside risks), individuation (having a place for individual belongings and activities), privacy (being free to decide who should be admitted and rejected to the sphere of individuation), and preservation (keeping stories). According to Young, no one should be deprived of these four values (Young, 2005: 151-154). However, at the same time, these values have attracted strong criticism from other feminists.

Alison Weir asserts that many points are missing from Young's above-mentioned four values and she, to correct them, outlines new values. According to Weir, we may not talk about home only as a place safe from outside risks, for example. Instead, home contains "risk of connection". Because of the spirit of connection, individuation should not disregard 
"relation[ality]." Privacy, as a condition promoted by autonomy, must also reckon with its relationality; it is a "freedom as capacity" strongly attached to our relations with others. Finally, for Weir, it is of great importance to make allowance for "transformation" as well as for "preservation" (Weir, 2008: 5). Similar challenges to Young's theories are raised by Honig, who argues that it is not possible to avoid conflict (Honig, 1996: 567), and that, therefore, imagination of a homogenous home is problematic because it may result in people ignoring important differences and conflicts (Honig, 1996: 580). Briefly, both critics highlight the reality of conflict and dangers within the home which should be kept in mind.

I find that Brunt's distinction between home and house (Brun, 2015: 44) makes sense, but I disagree with Weir's critique (Weir, 2008: 5). For example, Weir's point of interest when talking about the "risk of connection" is her claim that Young thinks in a "dichotomic" way. According to Weir, by constantly talking about safety Young fails to draw attention to risks (Weir, 2008: 8-9). This does not seem possible, however, because Young says, above all, that the "dichotomy between reason and desire" draws a line directly between the public and the private sphere, leaving women in the sphere of public (Young, 1987: 63-64). The problem with Weir's critique of Young can also be seen in the point that Young proposes consideration of emotions to balance what she sees as Habermas's excessively normative concept of public space. Furthermore, it is inappropriate to imply that relationality is not sufficiently highlighted in Young's work when she places such significant emphasis on social connection and underlines that our actions are tightly interrelated.

Last but not least, Young states that transformation may only be achieved through "public discussions," "publicizing the harms," and "criticizing powerful agents" (Young, 2011: 149-150). We may add consciousness-raising to this list. What Young wants to achieve by studying Habermas' theory of communicative action is essentially to discover the dynamics of 
change. Young reveals that if the materials and discourses regarding preservation are publicized or discussed among the people sharing the house, transformation will be inevitable.

Following her arguments associated with house/home in On Female Body Experience: Throwing Like A Girl and Other Essays, Young moves her focus to the issue of privacy. For Young, privacy is often understood as the condition of being "left alone in the making of decisions" and of being "protected from access or interference." (Young, 2005: 165-166). Moreover, privacy should not be placed in the same category as the private sphere since the former is related to "autonomy" while the latter is related to "exclusion" (Young, 2005: 152)1. Although privacy is perceived as a psychological and therefore intangible condition, on close examination it is tangible after all. For example, issues relating to privacy, such as memories and special experiences, manifest themselves as material existences, such as diaries or photographs. If someone is homeless or has no space, his or her privacy is diminished since privacy is not only a matter of condition but a matter of place as well (Young, 2005: 165-166). Because of material conditions necessary for home and privacy, being owner of a commodified house/home addresses to be in the position of "privilege" (Young, 2005: 132).

Weir portrays privacy in her new formulation as "relational autonomy, freedom as capacity, to be in relationship one desires, and freedom as expansion of self in relationship" (Weir, 2008). Despite the points I found unfair in Weir's critique of Young, I think the phrase "capacity to be in relationship one desires" is quite useful. Anyone who has attained this capacity and a certain amount of autonomy can be considered an independent person, who can make decisions about her/his own actions. It would therefore be meaningful for an individual

\footnotetext{
${ }^{1}$ Here, Young references Jean L. Cohen for an argument in favor of privacy: "Democracy, Difference and the Right of Privacy," in Democracy and Difference: Contesting the Boundaries of the Political, ed. Seyla Benhabib (Princeton, N.J.: Princeton University Press, 1996).
} 
seeking privacy to have a place that cannot be intervened in and publicized, even when s/he shares a home with others in the private sphere.

\section{Conclusion}

In the sections above, I have tried to explain Young's social connection model with reference to Sandy's story, so as to unpack Young's emphasis on structure, power relations, and responsibility. I have argued, in light of her theories, that those who are more privileged in their relations of power have a responsibility to be aware of the feelings and conditions of the disadvantaged. In other words, knowledge, visibility, and awareness are needed in order to serve this purpose. It can be argued that the social connection is interrupted by a clear-cut distinction between the private and public spheres; in other words, by the dichotomous way of thinking. Young, at this point, discusses the means of transition between these two spheres.

Home is criticized by feminists on the grounds that they identify women with the private sphere and exclude them from the public sphere. Young is aware that there may be harm, risks, and danger for women even at home. However, she decides on "not rejecting but democratizing it [home]" (Young, 2005: 146). However, home may also promote privacy for issues that people do not want to open up to discussion and/or do not want to share with others. Privacy should not be maintained by force, but by the person's own decisions. Thus, it is possible to consider privacy optional under the umbrella of home, as a manifestation of the private sphere.

The ability to have a home and decide the limits of privacy is a privilege. Unless the feelings and needs of the homeless are understood by the privileged, homeless people will remain socially disconnected. The way to see connections is to become conscious, and the way to maintain connections is to realize that we are all responsible. 


\section{References}

Brun, C. (2015). "Home as a Critical Value: From Shelter to Home in Georgia", Refuge: Canada's Journal on Refugees, 31(1), 43-54.

Calhoun, C. (Edt.) (1992). Habermas and The Public Sphere, Cambridge, Massachutts and London: The MIT Press.

Habermas, J. (1998 [1976]). "What is Universal Pragmatics?", On The Pragmatics of Communication, Edt. Maeve Cooke, Cambridge, Massachussets: The MIT Press.

Habermas, J. (1991). The Structural Transformation of the Public Sphere, An Inquiry into a Category of Bourgeouis Society, translated by Thomas Burger with the assistance of Frederick Lawrence, Cambridge: The MIT Press.

Habermas, J. (1987). The Theory of Communicative Action: Lifeworld and System, Volume II, translated by T. McCarthy, Boston: Beacon.

Habermas, Jürgen (1984). The Theory of Communicative Action: Reason and Rationalization of Society, Volume I, translated by T. McCarthy, Boston: Beacon.

Honnig, B. (1994). "Difference, Dilemmas, and the Politics of Home", Social Research, 61(3), pp. 563-597.

Meehan, J. (Edt.) (2013). Feminists Read Habermas: Gendering the Subject of Discourse, Londra ve New York: Routledge.

Riukulehto, S. and Rinne-Koski, K. (2016). A House Made To Be A Home, Cambridge Scholars Publishing.

Weir, A. (2008). "Home and Identity: In Memory of Iris Marion Young”, Hypatia, 23 (3) (In Honor of Iris Marion Young: Theorist and Practitioner), Jul-Sep, pp. 4-21.

Young, I. M. (1987). "Impartiality and the Civic Public: Some Implications of Feminist Critiques of Moral and Political Theory", Feminism as Critique, Edited and Introduced by Seyla Benhabib and Drucilla Cornell, Minneapolis: University of Minnesota Press, pp. 56-76.

Young, I. M. (1990). Justice and Politics of Difference, Princeton/New Jersey: Princeton University Press.

Young, I. M. (2005). On Female Body Experience: "Throwing Like a Girl” and Other Essays, Oxford and New York: Oxford University Press.

Young, I. M. (2011). Responsibility for Justice, Oxford an New York: Oxford University Press. 


\title{
FEMININITY AND MASCULINITY IN TWITTER SHARINGS ABOUT VIOLENCE AGAINST WOMEN IN THE SAMPLE OF SILA AND AHMET KURAL
}

\author{
Elif SESSEN ${ }^{1}$ \\ Duygu ÜNALAN ${ }^{2}$
}

\begin{abstract}
Female and male's form of existence in the society shapes the life of an individual. Biologically being female and male is called natural and innate; on the other hand, femininity and masculinity point to a cultural structuring with the process of socialization. The concept of gender represents female and man's different roles in the society, their social standings, economic and politic power. Gender based work sharing points gender segregation in education, employment, social and political life. Various instruments are used in order to create and continue discrimination. Foremost among these, violence comes first. Socioculturel norm and gender role expectations, which are effective in proceeding women's secondary position and man's violence against women, spread at home, at work and in public areas. The effects of norm and expectations infiltrate our daily lives. Internet and social media which enters our daily lives through technological developments, become basic platform where issues on the social agenda are spreaded, followed and discussed. Initially the happenings which have started as magazine news between singer Sıla Gençoğlu and actor Ahmet Kural at the end of 2018 were discussed, later it became a sample in which social preconceptions of feminity and masculinity roles emerged from obscurity.

The aim of this study is to analyze representations of feminity and masculinity with regards to gender roles in Twitter sharings about happenings between Sila Gençoğlu and Ahmet Kural as a sample of violence against women. In the study, sharings with wearewithyousila, silawearenearyou, sllaisn'talone hashtags have been analyzed through thematic amalysis. In the analysis, gender with femininty and masculinity have been defined as main categories and after that subcategories which have been these categories' indication of representation have been tried to reveal.
\end{abstract}

Keywords: Gender, femininity, masculinity, violence, Sila-Ahmet Kural

\footnotetext{
${ }^{1}$ Assoc. Prof. Dr. Niğde Ömer Halisdemir University, Communication Faculty, Public Relations and Advertising elifsesen@gmail.com

${ }^{2}$ Dr. Niğde Ömer Halisdemir University, Communication Faculty, Journalism duyguunalan85@gmail.com
} 


\section{Introduction}

Female and male's form of existence in the society shapes the life of an individual. Biologically being female and male is called natural and innate; on the other hand, femininity and masculinity point to a cultural structuring with the process of socialization. The concept of gender represents female and man's different roles in the society, their social standings, economic and politic power. Gender based division of labor refers gender segregation in education, employment, social and political life. Various instruments are used in order to create and continue discrimination. Foremost among these, violence comes first. Expectations of socio-cultural norms and gender roles in the persistence of women's secondary status and violence perpetrated by men are spreading at home, at work and in public spaces. The effects of norm and expectations infiltrate our daily lives. Internet and social media which enters our daily lives through technological developments, become basic platform where issues on the social agenda are spreaded, followed and discussed. Initially the happenings which have started as magazine news between singer S1la Gençoğlu and actor Ahmet Kural at the end of 2018 were discussed, later it became a sample in which social preconceptions of feminity and masculinity roles emerged from obscurity. The aim of this study is to analyze representations of feminity and masculinity with regards to gender roles in Twitter sharings about happenings between Sıla Gençoğlu and Ahmet Kural as a sample of violence against women. In the study, sharings with wearewithyoustla, sllawearenearyou, sılaisn'talone hashtags have been analyzed through thematic amalysis. In the analysis, gender with femininty and masculinity have been defined as main categories and after that subcategories which have been these categories' indication of representation have been tried to reveal. 


\section{Gender, Femininity and Masculinity}

Although it is not possible to make a conciliatory and single definition, gender indicates how the differences between men and women in society go beyond the biological and how they are socially created and reproduced. Gender in general is a concept used to point to socially formed roles and learned behavior expectations for men and women. (Ecevit, 2003:83). According to Ökten (2009:303), the distinction between sex and gender defined as cultural construction of female and male body. Simone de Beauvoir's saying 'Not born as a woman, being woman’ on the contrary is valid for men. Because society constructs the identities of men and women. In this respect, gender draws attention to the social aspects of differences between women and men (Tosun, 2006:89). Gender, apart from the inherent differences between men and women, are differences in social life, but how these differences arise and how they relate to innate differences are important controversial issues. Differences that are not innate, then created by society and culture are not universal, are determined within the unique structure of each society. Outhwaite (2003:252) took attention that gender can vary according to cultural values, time and place.

The person completes the gender identity that she gained with birth and with the features she gained as a result of her social life. Thus the person makes his/her own thoughts about himself or herself; in other words, interpretations of gender as male or female distinctive with common values and beliefs. Individuals take on roles appropriate to the identities presented to them. Thus, the identity of the man constitues what he does in the public sphere and the woman's in the domestic sphere. Traditional ideology conveys from generation to generation that family and child come first and foremost for women. For this reason, the works defined as male and female specific are traditionally determined. The idea that working in the public shpere and doing politics are naturally men's work; home and family related works are naturally women's 
work was adopted and implemented by many communities. Gender-based division of labor is determined by society, but biology is the prerequisite and basis for this determination (Savran, 2009:294). The values, roles and patterns imposed on men and women based on gender spread and strengthen hierarchically the idea that men should always be 'above' and 'foremost'.

\section{Violence Against Women}

Violence is the deliberate use of physical pressure or force against another. Violence is a way of imposing the will of the strong on the powerless. While the phenomenon of violence manifests itself in all areas of life, it is the most prevalent violence against women both in the world and in our country. Whether in social or private life, violence against women is described as any form of sex discrimination that causes or may cause physical, sexual, psychological harm and disorder in women, or threatening, coercing or arbitrary deprivation of liberty by the United Nations. Although there are many factors that affect the emergence, repetition, type and severity of violence against women, the main source of violence is mainly gender inequality and the unequal power relationship between men and women resulting from the patriarchal structure of society. Gender-based violence is violence that restricts one's will or freedom, causes psychological or physical harm, adversely affects his or her personality, and distinguishes between men and women (Veur, 2007:43). When it comes to gender-based violence, physical violence often comes to mind, but it is only one form of gender, and there is sexual, psychological, economic and sociocultural violence. Gender-based violence concerns unequal role distributions of femininity and masculinity. Violence against women is largely due to the male-dominated structure of society and is shaped by gender roles. As a result of a maledominated conception of society, men are always entitled to violence and women are obliged to take her share as a subject. 


\section{Violence Against Women in the Media}

Violence that is denied, ignored and normalized by society and even by women who are subjected to violence; it has become a social problem that repeats itself and recreates inequality against women in women-men relations. $\mathrm{n}$ this context, perhaps the biggest problem we face in combating violence against women is the normalization of this violence (Leander, 2002: 18). Almost every day the news of violence against women in newspapers, television or on the internet has made violence against women an ordinary part of daily life and brought about the normalization of violence and the indifference of the society against violence. Media contributes to the inclusion of violence against women. In the news of violence against women, sexist discourse is more secret and insidious. As well as, there are statements condemning violence in news reports with the title like 'The girl who escaped from the house was raped' there are also illusions that affirm the traditional patriarchal social structure. As Fairclough (2010) stated media texts are a useful tool for identifying social processes, movements and differences. It can be said that media texts, including those on social networking sites, constitute a dynamic form of social action. Social networking sites and microblogs, in particular Twitter, provide users with the opportunity for discursive dialogue and a computer-mediated social environment to build social meaning in the communication process. Research (Hermes 2007; Zappavigna 2011) shows that Twitter is an active tool in the creation and transmission of cultural values and ideology. Twitter provides a suitable environment and tool for issues that are influenced by sociocultural values and assumptions, such as gender, representations of femininity and masculinity and violence against women.

\section{Thematic Analysis of Twitter Shares About Sıla-Ahmet Kural}

The aim of this study is to analyze the representations of femininity and masculinity in terms of gender roles in Twitter posts about the experiences of singer Sila Gençoğlu and actor Ahmet 
Kural as an example of violence against women. At the beginning of November 2018, the news that the singer Sıla Gençoğlu (known shortly as Sila) was beaten by the actor Ahmet Kural reflected on the internet and social media platforms. S1la, who filed a complaint with the Istanbul Public Prosecutor's Office on 01 November 2018, ordered a protection order so that Kural could not approach him for 3 months. News on allegations of assault, threats and violence were shared and discussed on all social media platforms, particularly on Twitter. The event, which is an example of violence against women, remained on the agenda due to the fact that the parties became famous, and almost all the details such as courtroom footage, expressions, explanations, videos, and witness statements took place on social media. Initially started as a judicial event, but then the it became a subject of the magazine and in the continuing process with the news like 'Ahmet Kural craved with his family.' 'Reference from Kural's mother.' 'S1la was caugh with a man walking around the ivy.' which are not related the event directly, the event was put in a different frame and can also be read as an example of news that how violence against women has become magazinish. The event took place on Twitter with hashtags such as wearewithyoustla, sllawearenearyou, stlaisn'talone, and comments and shares on the event provide important clues about the cultural reflections of gender in the background of violence against women. Because, the representations of femininity and masculinity reveal social stereotypes and preconceptions. Shares on the subject were examined by thematic analysis method. Thematic analysis is a qualitative method used to identify, analyze and report patterns or themes within a data set (Braun and Clarke, 2006: 79) and can be described as analitik an analytical process focused on coding and theme development "(Lyons and Rohleder, 2014: 96). Thematic analysis contributes to a deeper and broader understanding of the research topic (Marks and Yardley, 2004). A theme is a phrase or sentence that describes what a data unit is about and what it means (Saldana, 2009: 139). Themes are derived from commonly used words, patterns such as repetitive activities, meanings or expressions of emotions (Taylor and 
Bogdan, 1989: 131). Thematic analysis can be applied to identify themes first and to analyze them according to these themes (Fereday and Muir-Cochrane, 2006) or to determine the themes based on the basic categories (Simons, Lathlean and Squire, 2008). In this study, the second method was followed and firstly, women and masculinity and gender were identified as upper categories, and then sub-themes, which are indicative of the representation of these categories, were revealed. In the study, the coding process was done separately by the researchers to determine the themes that were frequently repeated in the shares, and then they were compared and agreed on four themes; 'justification', 'personalization, 'applying stereotypes' and 'highlighting strong woman image'.

\section{Findings and Discussion}

\section{Justification}

In the tweets evaluated under the theme of justification, it is seen that Ahmet Kural's violent action is directly or indirectly supported.

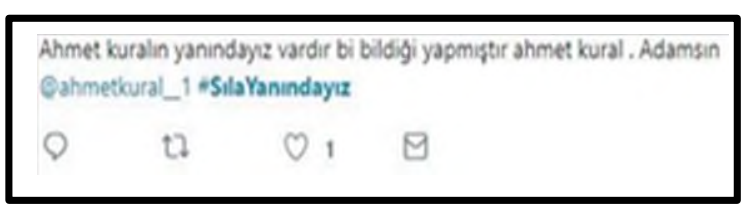

We are with you Ahmet Kural. He knows something and he did. You are a man.

As shown in the above tweet, the action of Ahmet Kural is directly supported. In the tweets examined under the theme of justification, it is seen that there are different approaches to the subject in the tweets considered as indirect support. As can be seen in the examples below, these tweets emphasize that Ahmet Kural had been violent to Sila before, but that Sila was with Kural again and S1la was wrong. Although Ahmet Kural's action is not directly supported, it is argued that S1la deserves what happened to him for reconciling with the rule, and that Sila should also be criticized. 


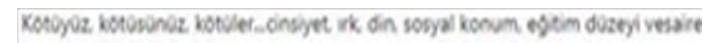

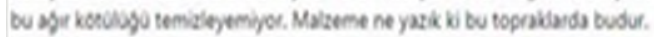

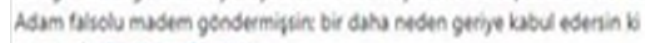
aradas? osiaYalanabegidir

10
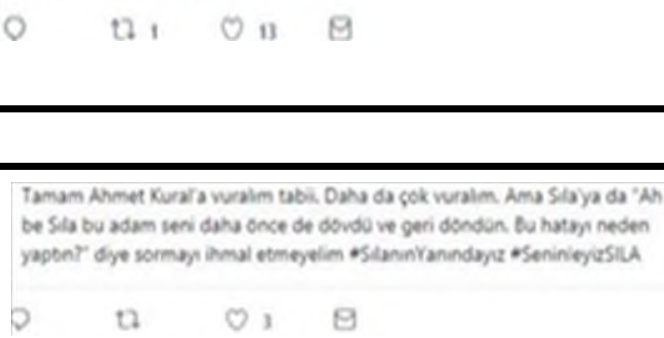

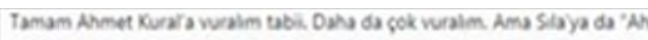
be Sla bu adam revi daha once de dovdo ve geri dondon. bu hatap neden

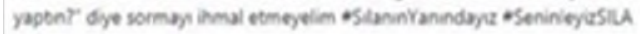
$\begin{array}{llll}0 & 0 & 0 & 0\end{array}$

We are bad, you are bad, they are bad... gender, race, religion, social position, education level cannot clear this heavy evil. Unfortunately this is reality of our lands. He was a wrong man, you left him, why did you accept back?

Ok, we hit Ahmet Kural. We hit more. But forget to ask to Sıla "Sıla, this man hit you before and you turned back. Why did you this fault again?

Another point that draws attention in the tweets examined under the theme of justification is the criticism that there are violent acts against women almost every day in the country, but no one is paying attention to these events, it became agenda because of the famous parties.

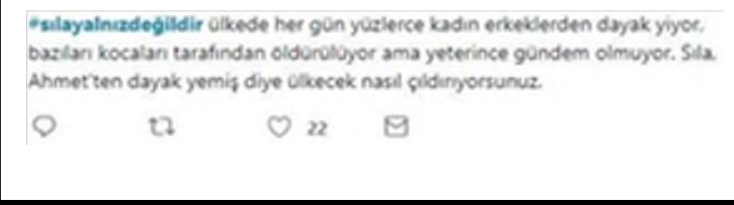

Kadina jiddet kccusunda olanlara goz yumanlar simdi Slann bagana gelenierde

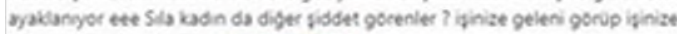
geimegene kor olmunn. iseninlegiasiLA

O $2,0 z$ \&
Hundreds of women get beaten up by men every day in the country, some are killed by their husbands but not enough agenda. You become crazy because Sıla was beaten by Ahmet.

Those who tolerate violence against women now rise in what has happened to Sıla... Sila is a woman but what about the others? You see what you want don't blind what you don't want.

It is also seen in the tweets about the incident that there are ideological criticisms in which there is no sharing of reaction or affirmation to violence.

Tuǵba Ekinci Helal kız sana Stugba_ekinci çok iyi açiklama yaptin.

-SeninleyizSila diyenler Sila guzel bir show yapti buguno kendine kapatt.

Demek ki *ANDINIZ bir işe yaramiyor Ataturkçoler kizlara fena daliyor $\mathcal{U} U$$$
\text { ○ }
$$$$
\text { t2 } 10
$$$$
O_{35}
$$

Tuğba Ekinci, appreciate you, you made very good statement. Those who say 'wearewithyouSıla' Sıla made a nice show. So your swear doesn't work Kemalists are plunging into girls.

As can be seen from the example above, Ahmet Kural was supported indirectly by claiming that S1la was after a show or advertisement, and an ideological criticism was made even though he had nothing to do with the incident. Also slangs like 'plunging into girls' on the 
tweet and smiley emojis can also be interpreted as the person who brought a violent act to a different point, although she herself was a woman who was happy to see another woman being violent and attempting to charge the event to Kemalists in general and to create a perception that all Kemalists were prone to violence.

\section{Personalization}

In the shares made on the Sila-Ahmet Kural incident, it is pointed out that the violence against women is very high in the country. In some shares, it is emphasized that all men are prone to violence in general. At this point, it has seen that, some users are opposed to that generalization at this point, it doesn't matter man or woman, should be evaluated on an individual basis to those prone to violence, that is not true to spread to the general.

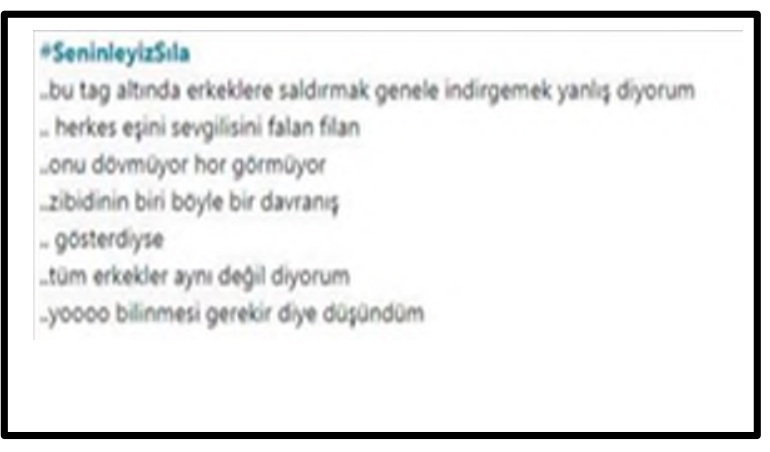

Erkek kadin fark etmez ruh hastası insanlardan uzak durun. -Seninleyizsıla

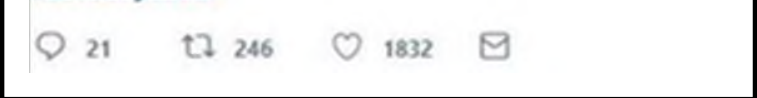

..that's wrong to attack men and generalize it under this tag.

.. everyone doesn't beat his wife or girlfriend.

.. I'm saying that if any one of the crazy showed

such behaviour, not all man are the same.

. I thouaht it should be known.

Men or women; it doesn't matter, stay away from people with mental illness.

From the tweets in the examples, it is noteworthy that the owners of the shares never supported violence and that they were with S1la in the case of S1la-Ahmet Kural. However, as mentioned above, the owners of the shares oppose the spread of violence to all men and emphasize that being prone to violence is a mental disorder and personality disorder. 


\section{Applying Stereotypes}

The tweets examined under the theme of applying stereotypes emphasize the difficulty of being a woman especially in the male-dominated society structure, trying to silence the women who are subjected to violence and motherhood which is the social role of women.

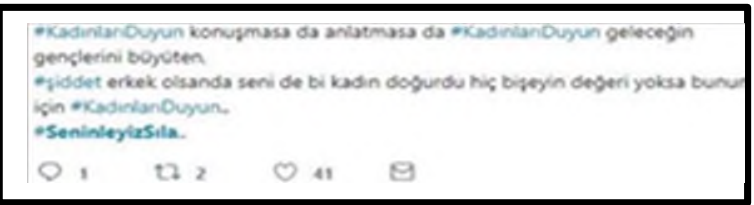

10 sene bilide oldugum biden bav tolat attogricin agnibim. Tehdicen batme polise bawudum darp raporun yok dend. Siddet gordsome inandramadm, if

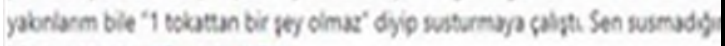

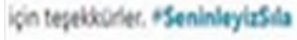

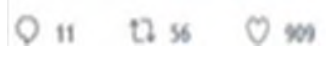

\#HearWomen, if they speak or not, hear women who raise the youth of the future.

\#violence, even though you are a man, a woman gave you birth, because of this \#HearWomen.

Another important point in the tweets examined under the theme is the social roles assigned to women and men. The point that draws attention to the tweets is that the woman is a very "delicate", "fragile" and the man is strong. The strength of women is expressed by comparison with men.

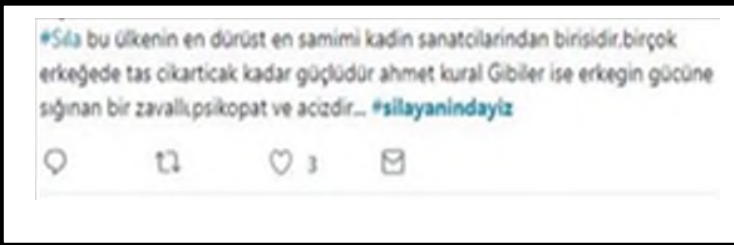

Sevmey bilmijor cogunuz. Evet sonuna kadar guclu ama bir o kadar krilgandir kadinlnotmeden sever? Inctilmeden sevmek ister..Helebi bojle guclu kadinlar yaslanacak bir omuz ister sadece.Geri donmusse ustelik guvenmis_Sevgine_Varigin ivi getir sanmis_. SilaYanundayz
\#Sila is one of the honest and sincere woman singers of our country, and also she is stronger more than many men. Ahmet is a poor man who takes refuge in the power of men, psychopaths and helpless.

At this point, it is noteworthy that the roles assigned to men and women in society are adopted by everyone, whether they are men or women, and that apart from this roles having these characters is perceived as privilege. However, the fact that a woman who has a strong 
character, as seen in the above tweet, is given as much as a man "makes it a secondary position in society. Especially the fact that such an analogy is made by a woman is an indication of the legitimation of social roles.
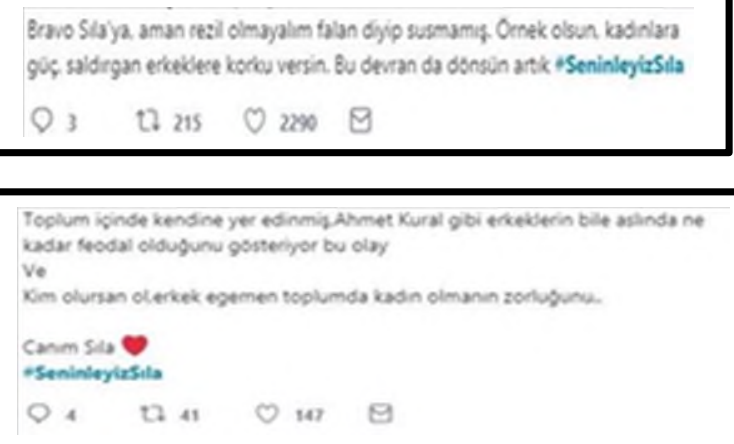

Well done Sıla, she didn't shut up. Be a sample, power for women, fear for agressive men. Let this fate turn.

This event shows how even men like Ahmet Kural who has established a place in society, are actually feudal. And, whoever you are, the difficulty of being a woman in a male-dominated society.

In societies such as our country where the power gap between genders is high, the roles of men and women are clearly defined and it is expected that women will submit to their lives with the logic of don't let it out of this room. When the woman makes her voice, she is either negated, condemned or heroized. In fact, it is usual for a woman not to be silent in the face of her experiences and to seek rights in the face of her experiences, whether she is famous or not. In the tweets, while emphasizing the difficulty of living in male-dominated societies and criticizing this social structure, the roles of women and men are underlined once more.

\section{Highlighting Strong Woman Image}

He stance, actions and actions of a person who has become a society are closely followed by those who love her. Their stance in social or individual events is expected to be an example to society. The fact that Sila did not stop and seek her rights after the violence she was subjected to was reflected in the tweets as a behavior that should set an example to the society.

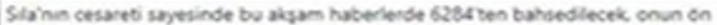

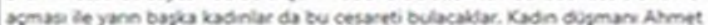

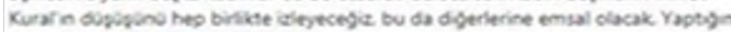

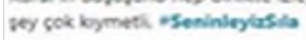

O n ta sis $0 \mathrm{mos}$
Thanks to Sıla's courage, 6284 will be mentioned in the news tonight, thanks to Sila, other women will find courage tomorrow. Together we will watch the fall of the misogynist Ahmet Kural. This will precede the others. What you do is precious. 
It is noteworthy that the "image of a strong woman' of Sila is frequently emphasized in the sharing of events and that this feature is appreciated by the society.

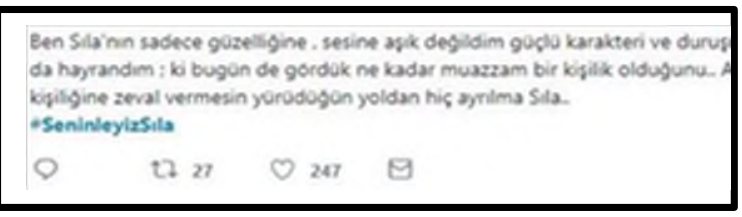

I was not only in love with the beauty and the voice of Sila, but also strong character and stance; and we see today how perfect she is.. God bless your personality, you keep your way

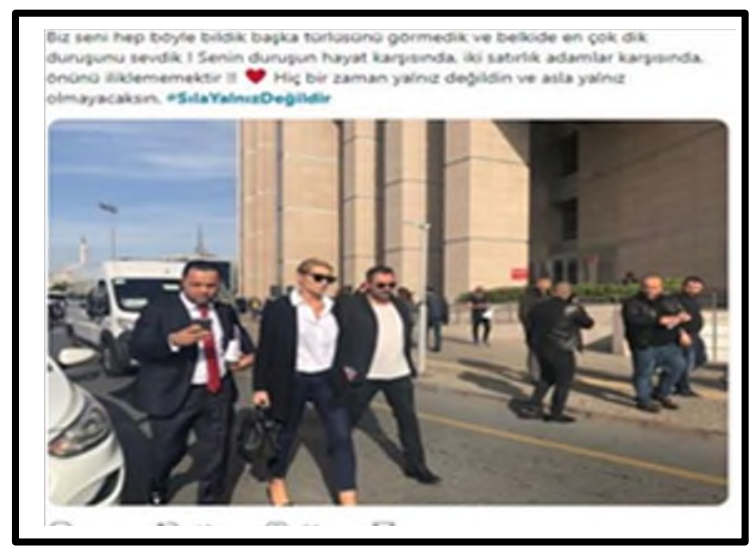

Always we have known you like this, we didn't see it any other way and maybe we liked the upright posture. You stand tall. You are never alone and you won't be alone.

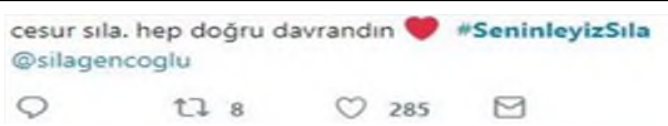

It is understood that it is expected by the society that a person who is socially prominent and is known for her strong stance should not stop in front of violence, and seek her right. However, it is reacted to the violence that Sila is subjected to with a strong emphasis on her strong personality and she is encouraged not to stop in the face of violence.

\section{Conclusion}

In this study, which is aimed to analyze the representations of femininity and masculinity in terms of gender roles in the Twitter shares between the singer S1la Gençoğlu and actor Ahmet Kural as an example of violence against women, the shares related to the event in wearewithyousıla, sllawearenearyou, stlaisn'talone hashtags were examined. A total of 232 tweets were evaluated under four themes: "justification", "personalization", "applying 
stereotypes" and "highlighting strong woman image". In the tweets evaluated under the theme of justification, it is seen that Ahmet Kural's action is directly or indirectly supported. In direct support, Ahmet Kural's behavior is supported by saying we are with you, and in indirect support, it is emphasized that S1la is wrong in this process. Therefore, this emphasis justifies the action of Ahmet Kural. In the shares evaluated under the other three themes, it is seen that there were comments supporting Sila in the event of Sila-Ahmet Kural. In these shares, especially the roles of women and men in the society are emphasized. It is emphasized that women are naive, fragile and men are strong. But this is a result of patriarchal society structure. It is usual for a woman to be strong, such that strength, weakness, naivety, or fragility are not exclusively female or male-specific. The separation of these characteristics inherent in being human according to gender roles is the result of cultural structure. Therefore, emphasizing the roles of femininity and masculinity in a response to violence against women actually brings about the legitimization of these roles, in other words, the patriarchal social structure.

Scope of the study is limited by only one sample and Twitter sharings. Further research on other social media platforms and also analysis of the other parts of the media discourse like news, comments, photographes, etc. in different mass media will be useful.

\section{References}

Braun, V. and Clarke, V. (2006). Using Thematic Analysis in Psychology, Qualitative Research in Psychology, 3(2), 77-101.

Ecevit, Y. (2003). Toplumsal Cinsiyetle Yoksulluk İlişkisi Nasıl Kurulabilir? Bu İlişki Nasıl Çalış1labilir? Cumhuriyet Üniversitesi Tıp Fakültesi Dergisi, 25 (4), 83-88.

Fairclough, N. (2010). Critical Discourse Analysis: The Critical Study of Language. Harlow: Pearson Education.

Fereday, J. and Muir-Cochrane, E. (2006). Demonstrating Rigor Using Thematic Analysis: A Hybrid Approach of Inductive and Deductive Coding and Theme Development, International Journal of Qualitative Methods, 5 (1), 1-11. 
Hermes, J. (2007). Media Representations of Social Structure: Gender. In Media Studies, edited by Eoin Devereux, pp. 191-210. London: Sage.

https://twitter.com/hashtag/s\%C4\%B1layaln\%C4\%B1zde\%C4\%9Fildir?src=hashtag_click. https://twitter.com/hashtag/silaninyanindayiz?src=hashtag_click. https://twitter.com/search?q=\%23seninleyizs\%C4\%B1la\&src=typed_query.

Leander, K. (2002). Preventing Men's Violence Against Women. Acta Psychiatry Scand, 106, 410-431.

Lyons, A. and Rohleder, P (2015). Qualitative Research in Clinical and Health Psychology, United Kingdom: Palgrave Macmillan.

Marks, D. and Yardley, L. (2004). Research Methods for Clinical and Health Psychology, London: Sage.

Outhwaite, W. (2003). The Blackwell Dictionary of Modern Social Thought, USA: Blackwell Publishing.

Saldana, J. (2009). The Coding Manual for Qualitative Researchers, London: Sage.

Savran, G. (2009). Emek Tarih Diyalektik Bir Feminizm İçin, Kanat Kitap, İstanbul.

Simons, L. and Lachlean, J., Squire, C. (2008). Shifting the Focus: Sequential Methods of Analysis with Qualitative Data, Qualitative Health Research, 18, 120-132.

Taylor, S. J. and Bogdan, R. C. (1989). Introduction to Qualitative Research Methods: The Search for Meanings, New York: John Wiley \& Sons.

Tosun, N. B. (2006). Reklam Aracı Olarak Kadın, Kadın Çalışmaları Dergisi, 1 (2), 1-18.

Veur, D. (2007). Gender Matters: A Manual on Addressing Gender-Based Violence Affecting Young People. Budapeshte: Council of Europe.

Zappavigna, M. (2011). Ambient Affiliation: A Linguistic Perspective on Twitter. New Media \& Society 13 (5): 788-806 


\title{
OCCUPATIONAL SAFETY AND HEALTH LEGISLATION: EMPLOYMENT EQUALITY CAUSING PROTECTION INEQUALITY OF WOMEN AT WORK
}

\author{
Emine ATASOYLU1 \\ Işıl Nurdan IŞIK ${ }^{2}$
}

\begin{abstract}
Occupational safety and health (OSH) laws aim to protect all employees, both men and women, from harm at work. In recent years, there has been an increase in women working in traditionally male dominated fields. Occupational hazard exposure limits and preventive measures for these positions were established with a focus on the average male worker, not considering differences in female and male physiology and metabolism. Gender neutral legislation, therefore, does not protect women and men equally. OSH gender-oriented research is scarce. More work is necessary worldwide to understand the problem and provide measures that protect women at work. The goal of this study was to determine OSH related issues of women in North Cyprus and to develop a gender-sensitive OSH management system. Risk assessment was conducted as a pilot study in a hospital, where more women are employed compared to men, using previously validated five step risk assessment instruments. Womenspecific occupational risk factors and other responsibilities were determined by administrating a questionnaire. A model was developed integrating gender specific preventive measures.

North Cyprus workplaces have adopted limited OSH prevention strategies for their workforce due to lack of knowledge and government enforcement. Gender differences aren't considered in these limited preventive measures. The OSH management system model developed for this study will contribute towards building awareness for gender specific preventive needs, with the goal of achieving a work environment where both women and men are protected equally.
\end{abstract}

Keywords: Occupational Safety and Health, Gender Sensitive Risk Assessment, Gender Neutral Legislation, Women at Work, Employment Equality, Protection Inequality

\footnotetext{
${ }^{1}$ Asst. Prof. Dr. Industrial Engineering Department, Eastern Mediterranean University, Gazimağusa, North Cyprus emine.atasoylu@emu.edu.tr

2 Industrial Engineering Department, Eastern Mediterranean University, Gazimağusa, North Cyprus isilnurdan.isik@emu.edu.tr
} 
Occupational safety and health $(\mathrm{OSH})$ regulations aim to protect all employees from harm. This is very clear in OSH laws and other regulations worldwide (OSHA USA; EU directive 89/391/EEC, (1989); Health and safety law 6331 Turkey; (2012), NC OSH LAW 35/2008). Increasingly, women are becoming employed in traditionally male dominated jobs. Additionally, women continue to work in service-oriented fields such as, healthcare and education where the OSH issues are mostly overlooked, and as household workers where OSH issues are not even considered. Women and men differ in their physiology and metabolism (EU-OSHA, 2019). The majority of workplace tools and equipment used in manufacturing such as metal working, construction and agriculture were designed based on the height, strength and dimensions of an average man (ILO 2013; OSHA,1999; ILO, 2009). In most of these places of employment, women have difficulty using these tools (OSHA,1999). The average woman is smaller in stature than the average man. They have a smaller grip, wider hips and narrower shoulders. Studies show that the upper body strength of women is at least 40 percent and as much as 70 percent less than an average man (FReSH, 2017). Lower body strength does not differ as much as the upper body strength but can be 5 to 30 percent less than a male worker doing the same job (FReSH, 2017). All these factors put women at increased risk of injury. Also, women working with dangerous substances such as chemicals used in pesticides and in the cleaning sector (WECF, 2016; Weber, 2016) are not protected as much as their male coworkers since the maximum exposure limits, standards, personal protective equipment (PPE), and preventive measures were established based on the average male employee (WECF,2016; OSH EU 2003; ILO, 2013). This raises the question: "do the current regulations which are gender neutral protect women and men equally? Moreover, are women working in the home environment as household help or in their own homes completely overlooked?" Research in this area is limited, necessitating further investigation in order to better understand the problem, 
and to improve regulations such that there will be equal protection of all employees regardless of gender.

The International Labor Organization (ILO) established guidelines in 2013 recommending that safety professionals include the gender factor in their risk assessments (ILO, 2013). Similarly, the European Agency for Safety and Health at Work (EASHW or OSHA EU) has been trying to raise awareness and recommend a gender sensitive risk assessment (GSRA) in the past two decades (OSHA-EU, 2003). Despite these efforts, it is believed that there is still a great problem for women working in previously male dominated jobs (EU-OSHA, 2013; WHO, 2006; EU-OSHA, 2014). Likewise, OSH issues in jobs traditionally dominated by women were previously overlooked assuming that employment in these areas posed low risk of occupational injury or illness (Weber, 2016). This bias exposes women employees to working conditions that adversely affect both their health and safety (European Risk Observatory Literature review, 2013) . OSH policy should be updated to include all industries where women are employed.

The North Cyprus Occupational Safety and Health law (35/2008) was established in 2008 and has been enforced since 2009. This law, as well as the North Cyprus (NC) labor law, and other regulations, include women specific articles limited to the protection of working women who are pregnant, postpartum or breastfeeding (article 44, 2015 regulation). The aim of this regulation (NC Labor Office, 2015) was to define the OSH related rights for these women and the precautions the employers were required to take for their protection.

Risk assessment and informing women employees of their rights is under the second section of this regulation. According to this section, the employer has to evaluate the nature, degree and duration of the hazard exposure and take OSH preventive measures for pregnant, newly postpartum and breast-feeding women. These may include alteration of working conditions or working hours, and in circumstances where this is not possible, job re-assignment 
as specified under article 7. The hazards that can cause health problems to women or their fetus are categorized and listed as physical, biological and chemical factors in this regulation. Article 8 emphasizes that women in this category providing a medical report documenting their pregnancy or specific health problem cannot be forced to work under conditions where their health and safety or the health and safety of their fetus is at risk. Similarly, if they provide a medical report documenting that night work will affect their health or safety, they can request to work daytime hours and their employer is obligated to accept their request.

\section{Study Goal}

The aim of this study was to start to look at the OSH related issues of women in North Cyprus and develop a gender-sensitive OSH management system. The following hypotheses were generated for this purpose.

H1: Management does not have a gender-sensitive approach for preventing employees from harm (GSRA).

H2: Women take more responsibility outside their job (such as housework or other family responsibilities).

H3: Working conditions, work environment or work tasks are not designed by taking into account gender specific physiological differences.

H4: Women feel more pain in their arms, shoulder, back, and neck compared to men doing the same job.

H5: Men get injured more than women at work.

H6: Women feel more stress, fatigue and burnout as a result of work and home related issues.

H7: Women have more difficulty finding properly fitting PPE (such as masks and gloves). 
H8: Environmental conditions at work more adversely affect the performance of men compared to women.

H9: Women have difficulty taking sick leave for painful menstrual periods, when pregnant or when breastfeeding.

\section{Methods}

A private hospital in Gazimağusa NC was selected for this pilot study. Risk assessment (RA) was conducted by using the classical five step approach, including all employees except medical doctors who were considered more aware of risk as a result of their medical training. The five step RA includes 1) identifying hazards, 2) deciding who is at risk of harm and how they are at risk, 3) evaluating and prioritizing the risks: deciding on the risk level and preventive measures associated with each hazard 4) recording the findings and implementing the decisions/action plan, 5) reviewing the RA periodically and whenever necessary. The fourth and fifth steps were recommendations made to management in this study.

In preparation for this study, a representative of the hospital management team was interviewed to determine whether any procedures were already in place to protect staff from harm, and, if so, whether these included a GSRA. The hospital incident (accident/injury/illness) records were lacking and could not be reviewed and classified based on gender. Hypotheses testing and identification of gender difference in risk were determined using a questionnaire (Appendix A). The questions included: demographic information such as age, gender, weight (BMI), highest level of education, current and past job title, duration of employment, average hours at work per day, nature of work such as average duration standing/sitting per day, number of days working overtime/night shifts, average number of hours of sleep, and the number of 
missed work days in the past year due to health problems, work related injury or illness, or family issues.

The questionnaire was designed using several formats including a 5-point Likert scale, yes/no and narrative responses. The 5-point Likert scale questions addressed safety issues, environmental conditions at work, impact of hazards, availability of suitable PPE, having inappropriate posture, and experiencing pain in the neck, back, shoulders or arms, exposure to violence, experiencing burnout, other responsibilities , and stress due to home responsibilities, work-life balance, A section of the questionnaire with Yes/No type questions was designed for women employees to identify any difficulties they may experience at work due to dysmenorrhea, pregnancy and when breastfeeding. Another section of the questionnaire with Yes/No type questions aimed to determine whether employees ever received OSH training, work varying shifts, consider their daily work breaks to be adequate, and whether they are going home with work clothes. There was also a question to determine the average number of cigarette breaks an employee took per day. Open ended questions were included to determine employee perspective and understanding of potential occupational hazards, preventive measures, whether they felt protected from potential harm, and to gather their concerns and suggestions.

Statistical analysis of questionnaire responses was conducted to find any significant difference between male and female responses, and any significant correlation between only women and only men responses. 


\section{Results}

The hospital has a total of 60 non-physician employees (47 female and 13 male). The questionnaire was distributed to 41 of the 45 employees actively working during this study period. There was a 90\% response rate (31 female and 6 male). Table 1 shows the job distribution of the respondents.

\section{Table 1}

\begin{tabular}{|l|l|}
\hline Job/Job Area/Dept & Number* (\# of male employees) \\
\hline Accounting & 2 \\
\hline Administrative Chief & 1 \\
\hline Cleaning & 4 \\
\hline Esthetician & 1 \\
\hline Information Desk & 5 \\
\hline Kitchen & $2(\mathrm{M}: 1)$ \\
\hline Laboratory & $3(\mathrm{M}: 1)$ \\
\hline Nurse & $7(\mathrm{M}: 1)$ \\
\hline Radiography & 1 \\
\hline Sales Manager & 1 \\
\hline Secretary & 2 \\
\hline Storage & 1 \\
\hline Technician & $5(\mathrm{M}: 3)$ \\
\hline
\end{tabular}

*Two out of the 37 respondents did not report their jobs

\section{Significant Difference between Female and Male Responses}

The only significant difference between female and male responses were that 1) "Male employees experienced more back, shoulder, neck and arm pain" and 2) "Male employees have more missed days of work due to work related illness" with $p<0.05$ (Table 2). 
Table 2

\begin{tabular}{|l|l|l|l|}
\hline Ranks & Gender & $\mathrm{N}$ & Mean Rank \\
\hline \multirow{3}{*}{ Work-related illness } & Male & 4 & 17,50 \\
\cline { 2 - 4 } & Female & 24 & 14,00 \\
\hline $\begin{array}{l}\text { Back, shoulder, arm } \\
\text { pain }\end{array}$ & Male & 6 & 26,08 \\
\cline { 2 - 4 } Test Statistics & Female & 30 & 16,98 \\
\hline & \multicolumn{2}{|l|}{} \\
\hline & Work-related illness & $\begin{array}{l}\text { Back, shoulder, neck, arm } \\
\text { pain }\end{array}$ \\
\hline \multirow{2}{*}{ Chi-Square } & 6,000 & 4,235 \\
\hline df & 1 & 1 \\
\hline Asymp. Sig. &, 014 &, 040 \\
\hline
\end{tabular}

The significant positive and negative correlation between the responses of only female respondents are given in Tables 3 and 4 and those of only male respondents in Tables 5 and 6 .

The answers to the questions related to menstrual period, pregnancy and breastfeeding showed that the majority of female employees are not facing difficulty taking time off during pregnancy or breastfeeding but feel they have a lower performance during their menstrual period (Table 7). 
Table 3

\begin{tabular}{|l|l|l|}
\hline Only women responses -Significant Positive Correlation & $* *$ \\
\hline Number of years at work & finding gloves that fit & $* *$ \\
& working at night & \\
& working different shifts & $*$ \\
\hline Work related injury/illness & difficulty taking leave for menstrual symptoms & $* *$ \\
\hline Lifting & $\begin{array}{l}\text { improper posture, } \\
\text { back, shoulder, neck \& arm pain }\end{array}$ & $* *$ \\
\hline $\begin{array}{l}\text { Menstrual symptoms } \\
\text { performance }\end{array}$ & $\begin{array}{l}\text { suboptimal environmental conditions (heating, } \\
\text { cooling, lighting, ventilation, noise) } \\
\text { back, shoulder, neck \& arm pain }\end{array}$ & $*$ \\
\hline $\begin{array}{l}\text { Doing home responsibilities } \\
\text { alone }\end{array}$ & feeling stressed about home responsibilities & $*$ \\
\hline Working overtime & report a noisy work environment & $*$ \\
\hline
\end{tabular}

**Correlation is significant at the 0.01 level (2-tailed).; *Correlation is significant at the 0.05 level (2-tailed).

\section{Table 4}

\begin{tabular}{|l|l|l|}
\hline \multicolumn{2}{|l|}{ Only women responses- Significant Negative Correlation } & \\
\hline Having OSH training & $\begin{array}{l}\text { work environment adversely } \\
\text { affecting job performance }\end{array}$ & $* *$ \\
\hline Assigned tasks outside of their usual job & report a noisy work environment & $*$ \\
\hline $\begin{array}{l}\text { Work environment adversely affecting work } \\
\text { performance }\end{array}$ & inadequate rest breaks & $* *$ \\
\hline
\end{tabular}

**Correlation is significant at the 0.01 level (2-tailed).; *Correlation is significant at the 0.05 level (2-tailed). 
Table 5

**Correlation is significant at the 0.01 level (2-tailed); *Correlation is significant at the 0.05 level (2-tailed).

\begin{tabular}{|l|l|l|}
\hline \multicolumn{2}{|l|}{ Only men responses -Significant Positive Correlation } & $* *$ \\
\hline Standing & work related illness & \\
\hline Sitting & missed days of work due to illness & $* *$ \\
\hline Going home with work clothes & illness & $* *$ \\
\hline Sleeping enough & finding rest time sufficient & $* *$ \\
\hline Lifting & awkward posture, burnout & $* *$ \\
\hline Improper posture & burnout & $* *$ \\
\hline Back, arm, neck\& shoulder pain & employee given other tasks & $*$ \\
\hline Feeling stress due to home responsibilities & noise & $*$ \\
\hline Feeling stress & ventilation being sufficient & $*$ \\
\hline $\begin{array}{l}\text { Work environment adversely affecting work } \\
\text { performance }\end{array}$ & needing more OSH training & $*$ \\
\hline
\end{tabular}

\section{Table 6}

\begin{tabular}{|c|c|c|}
\hline Only men responses -Negative Positive Correlation \\
\hline Having OSH Training & Work related illness & $* *$ \\
\hline
\end{tabular}

**Correlation is significant at the 0.01 level (2-tailed).

\section{Table 7}

\begin{tabular}{|l|l|l|}
\hline Only for women responses- & No (\%) \\
\hline Question & Yes $(\%)$ & 80 \\
\hline Do you need to take sick leave during your menstrual period? & 20 & 87 \\
\hline $\begin{array}{l}\text { Do you have difficulty in getting permission for leave during } \\
\text { pregnancy or breast feeding? }\end{array}$ & 13 & 60 \\
\hline Do menstrual symptoms affect your work performance? & 40 & 85 \\
\hline Did you work night shifts during your pregnancy? & 15 & 8 \\
\hline
\end{tabular}


Table 8

\begin{tabular}{|l|l|l|}
\hline Percentage of hazards reported by 17 female and 5 male respondents \\
\hline Hazards/health issues & Female \% & Male \% \\
\hline Infectious Diseases & 71 & - \\
\hline Radiation & 6 & 16 \\
\hline Penetrating \& Cutting Tool Injury & 6 & - \\
\hline Back Problems & 18 & - \\
\hline Open Wound Infections & 12 & - \\
\hline Work Stress-Working Conditions & - & 16 \\
\hline No Hazard & 6 & 16 \\
\hline
\end{tabular}

Only eleven of the 31 female respondents and half of the 6 male respondents reported that they smoke. Two of the three smoking male respondents have 5 cigarette breaks and the other 4, where the majority of women smokers (6) are only taking three cigarette breaks in average per day. One of the remaining female smokers reported having 2, two of them 4 and the other two 5 breaks to smoke. 
Table 9

\begin{tabular}{|c|c|c|}
\hline Hypotheses testing results & & \\
\hline Hypotheses & $\begin{array}{l}\text { Supported/ } \\
\text { Not Supported }\end{array}$ & How? \\
\hline $\begin{array}{l}\text { H1: Management does not have a gender- } \\
\text { sensitive approach for preventing } \\
\text { employees from harm (GSRA) }\end{array}$ & Supported & $\begin{array}{l}\text { Employer reported (Also } \\
\text { no documented RA) }\end{array}$ \\
\hline $\begin{array}{l}\text { H2: Women take more responsibilities } \\
\text { outside of their job (such as home related } \\
\text { work or other family issues). }\end{array}$ & Supported & Q12i, g, h \\
\hline $\begin{array}{l}\text { H3: Working conditions, work } \\
\text { environment or work tasks are not } \\
\text { designed by taking into account women's } \\
\text { physiological differences }\end{array}$ & Supported & $\begin{array}{l}\text { Observation } \quad \text { and } \\
\text { employer }\end{array}$ \\
\hline $\begin{array}{l}\text { H4: Women feel more pain in their arms, } \\
\text { shoulder, back, and neck compared to men } \\
\text { doing the same job. }\end{array}$ & Not Supported & $\begin{array}{l}\text { Q12f Men feel more pain } \\
*\end{array}$ \\
\hline $\begin{array}{l}\text { H5: Men get injured more than women at } \\
\text { work. }\end{array}$ & Supported & $\begin{array}{l}\text { Q10 and open-ended } \\
\text { questions }\end{array}$ \\
\hline $\begin{array}{l}\text { H6: Women feel more stress, fatigue and } \\
\text { burnout as a result of a combination of } \\
\text { work and home issues }\end{array}$ & Supported & $\begin{array}{l}\text { Q12-a,g,h,I,k,l } \\
\text { Q14-b,c,d,e,f }\end{array}$ \\
\hline $\begin{array}{l}\text { H7: Women have more difficulty in } \\
\text { finding PPE that properly fits (such as } \\
\text { masks and gloves) }\end{array}$ & Not supported & $\begin{array}{l}\text { Q12-b,c Majority finds } \\
\text { PPE }\end{array}$ \\
\hline $\begin{array}{l}\text { H8: Environmental conditions at work } \\
\text { adversely affect job performance of men } \\
\text { more than women. }\end{array}$ & Supported & Q13, Q12j $\quad \mathrm{p}<0.05$ \\
\hline $\begin{array}{l}\text { H9: Women have difficulty taking leave } \\
\text { during their menstrual period, when } \\
\text { pregnant or when breast feeding }\end{array}$ & Not Supported & Q15 \\
\hline
\end{tabular}

Hypotheses testing results are given in Table 9 where only three was not supported. 


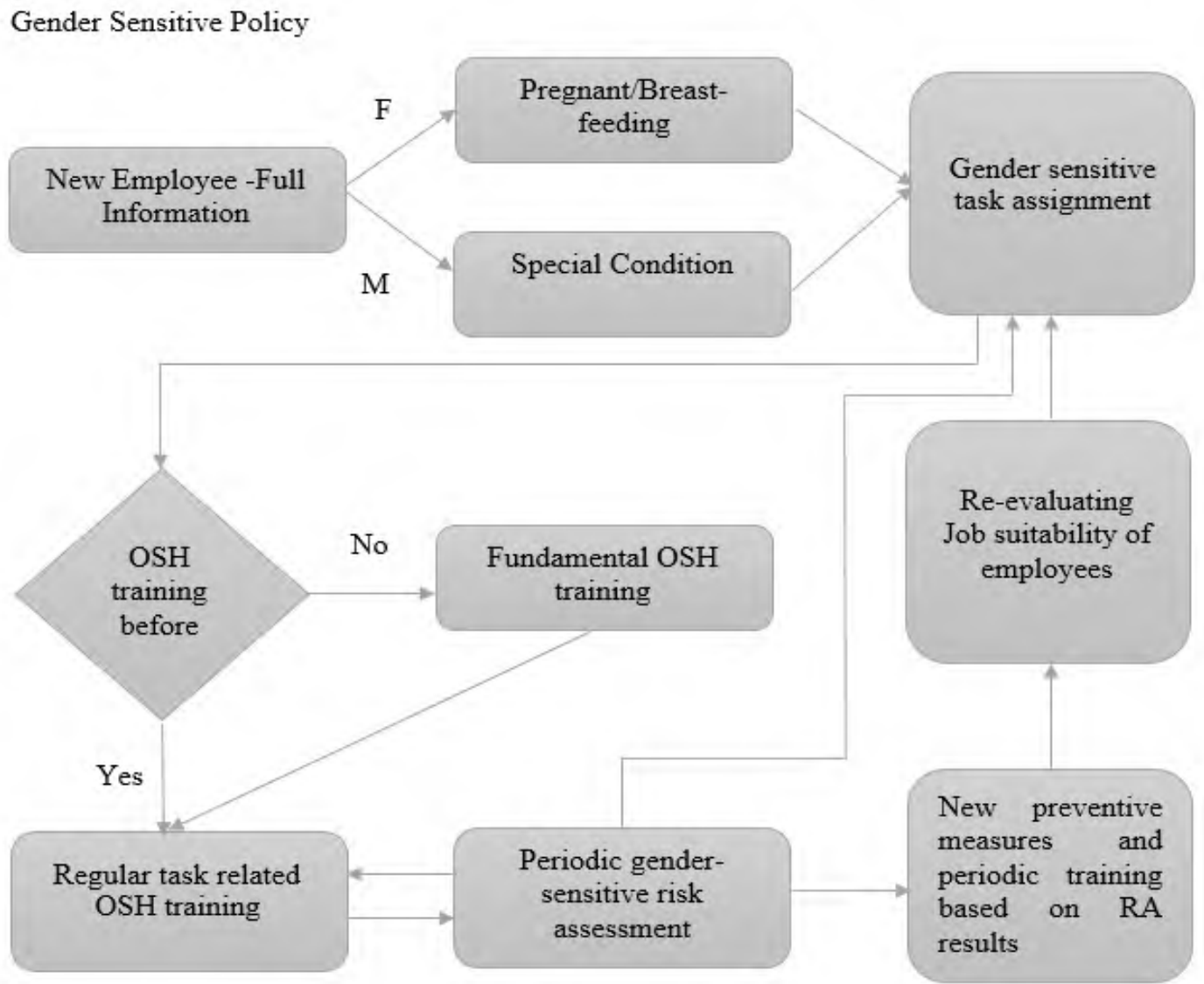

Figure 1: Recommended Gender Sensitive OSH Management System Model

Based on these results, the statistical analyses and hypotheses testing, a Gender Sensitive OSH management system model Figure 1 is recommended. This model includes detailed employee 1) information such as height, weight, previous jobs, diseases, allergies, home issues, after work responsibilities, second paid or unpaid jobs, emotional state, 2) specific needs such as flexible work schedule, working by sitting, number of breaks, psychological support, 3) specific task assignment, OSH training, periodic gender sensitive risk assessment, periodic job suitability evaluation, periodic training program design, periodic OSH training, gender sensitive schedules and preventive measures. 


\section{Study Limitations}

Small scope and sample size with few male workers limits generalizability and gender comparisons. The survey format, self-reported employee opinions, is an inherent limitation of this study. Additionally, there was the misunderstanding of the questions addressing responsibilities outside of work: 'taking home responsibilities alone' or 'work-life balance' may not have been clear to the participants. Here taking home responsibilities alone might have been understood as money issues such as shopping or paying bills, where the intention was to understand responsibilities of child and elder care, as well as cooking and cleaning.

\section{Discussion}

Occupational risk of women is an area of limited research (EU-OSHA,2014; Park et al., 2018; Choi, 2005) and growing interest worldwide. Current OSH guidelines, occupational hazard exposure limits and preventive measures, which are based on an average male worker, do not consider gender differences biology, potentially putting women at increased occupational risk. Additionally, gender differences in sociocultural roles and responsibilities, work-life balance and its impact on occupational risk is gaining increasing attention. This pilot study, based at a hospital in North Cyprus, aimed to understand current OSH practices, working conditions and any gender specific concerns, with the goal of developing a gender sensitive OSH management system. The scope of this study and small sample size limits generalizability and conclusive gender comparisons, however, several important points were identified and worth emphasizing. Discussions with the hospital leadership and observations made by the authors confirmed that, overall, minimal attention is placed on OSH preventive measures, record keeping of occupational incidents (accidents, injuries, illnesses, near misses) is lacking, and gender differences are not considered when designing the work environment and work schedules. Moreover, employee education around occupational safety and risk was lacking. 
Without accurate record keeping it is difficult to definitively ascertain the occupational incidents and measures that need to be taken to prevent injury and illness. Record keeping, risk assessment, as well as OSH training are minimum basic procedures that need to be put in place by all industries. This study also revealed the absence of job descriptions and employees being assigned tasks outside of routine work. This has the potential to increase the risk of occupational injury if the employee hasn't received proper training on these new tasks. Women, who often have additional home responsibilities, such as child or elder care, cooking and cleaning, may have increased stress and less time to rest between work shifts compared to male workers. Stress and fatigue may contribute to increased occupational risk for women. While the majority of women with dysmenorrhea and those that are pregnant or breast feeding don't report difficulty taking time off, some of these women did report difficulty taking time off therefore this group needs more attention. This study raised awareness of these issues and a gender sensitive OSH management model is proposed to include adequate preventive measures for all employees, gender-sensitive risk assessment, periodic training programs, and periodic evaluation of job suitability and task re-assignment. Authors plan to repeat this study in a larger hospital system, as well as test and further develop the proposed gender sensitive OSH management model.

\section{References}

Choi, B. (2005). An international comparison of women's occupational health issues in the Philippines, Thailand, Malaysia, Canada, Hong Kong and Singapure. the CIDA-SEAGEP Study Occupational Medicine, 55, 515-522. doi:10.1093/occmed/kdi147

EU-OSHA. (2003). Gender issues in safety and health at work: A review. Retrieved from https://osha.europa.eu/en/tools-and-publications/publications/reports/209

EU-OSHA. (2013). New risks and trends in the safety and health of women at work. Retrieved from European Risk Observatory Literature Review: https://osha.europa.eu/en/publications/reports/new-risks-and-trends-in-the-safety-and-healthof-women-at-work 
EU-OSHA. (2014). Mainstreaming gender into occupational safety and health practice. Retrieved from https://osha.europa.eu/en/tools-andpublications/publications/reports/mainstreaming-gender-into-occupational-safety-and-healthpractice

EU-OSHA. (2019). Gender and dangerous substances: Promoting safety and inclusivity in the workplace. Retrieved from https://healthy-workplaces.eu/nl/media-centre/news/gender-anddangerous-substances-promoting-safety-and-inclusivity-workplace

European Union Council Directive on Occupational Safety and Health. (1989, June 12). (89/391/EEC). Retrieved from https://eurlex.europa.eu/LexUriServ/LexUriServ.do?uri=OJ:L:1989:183:0001:0008:EN:PDF

Farm and Ranch eXtension in Safety and Health. (2017). FReSH. Women, tools and ergonomics. Community of Practice. Retrieved from http://articles.extension.org/pages/74543/women-tools-and-ergonomics.

ILO. (2009). Providing safe and healthy workplaces for both women and men. Retrieved from https://www.ilo.org/wcmsp5/groups/public/---dgreports/--gender/documents/publication/wcms_105060.pdf

ILO. (2013). 10 Keys for Gender Sensitive OSH Practice - Guidelines for Gender Mainstreaming in Occupational Safety and Health. Retrieved from https://www.ilo.org/wcmsp5/groups/public/---ed_protect/---protrav/---

safework/documents/publication/wcms_324653.pdf

ILO Introductory Report. (2011). Global Trends and Challenges on Occupational Safety and Health. Retrieved from https://www.ilo.org/wcmsp5/groups/public/---ed_protect/---protrav/--safework/documents/publication/wcms_162662.pdf

North Cyprus Labor Office OSH Law. (2008). Retrieved from https://calisma.gov.ct.tr/Portals/33/Mevzuat/352008\%20\%C4\%B0\%C5\%9E\%20SA\%C4\%9ELI\%C4\%9EI\%20VE\%20G\%C3\%9CVENL\% C4\%B0\%C4\%9E\%C4\%B0\%20YASASI.pdf?ver=2016-08-26-094629-347

North Cyprus Labor office regulation for the protection of pregnant, p.-p. a. (2015). Retrieved fromhttps://calisma.gov.ct.tr/Portals/33/Mevzuat/Hamile_emziren_yeni\%20do\%C4\%9Fum\% 20yapm\%C4\%B1\%C5\%9F\%20\%C3\%A7al\%C4\%B1\%C5\%9Fanlar\%20\%20t\%C3\%BCz\%C 3\%BC\%C4\%9F\%C3\%BC.pdf?ver=2016-08-25-160924-933

Occupational safety and health law Turkey (6331). (2012). Retrieved from https://www.ilo.org/wcmsp5/groups/public/---ed_protect/--protrav/ilo_aids/documents/legaldocument/wcms_202369.pdf

OSHA USA Laws and Regulations. (n.d.). Retrieved from https://www.osha.gov/laws-regs

OSHA Women in the Construction Workplace. (1999). Providing Equitable Safety and Health Protection Washington, DC: US Department of Labor,. Retrieved from https://www.osha.gov/doc/accsh/haswicformal.html\#19 
Park, J., Kim, Y., \& Han, B. (2018). Work Sectors for High Risk for Work Related Musculoskeletal Disorders in Korean Men and Women Safety and Health at Work,. 75-78. Retrieved from https://doi.org/10.1016/j.shaw.2017.06.005

Weber, C., \& Henke, N. (2016). Employment trends and their impacts on women's OSH. Federal Institute for Occupational Safety and Health.

WECF women engage for a common future. (2016). Women and Chemicals The impact of hazardous chemicals on women A thought starter based on an experts' workshop. Retrieved from http://www.wecf.eu/english/publications/2016/WomenAndChemicals_WECF.EU.pdf

WHO. (2006). World Health Organization Gender equality, work and health: a review of the evidence,. Retrieved from https://apps.who.int/iris/bitstream/handle/10665/43311/9241593539_eng.pdf?ua=1 


\title{
WOMEN'S SPACES IN CONTEMPORARY ART IN CENTRAL EUROPE. CASE STUDY: INSTALLATIONS OF ILONA NÉMETH
}

Erzsébet TATAI ${ }^{1}$

\begin{abstract}
The number of woman artists has increased in Hungary since 1989, when the political system changed. Many of them even thematise women's use of space in some manner. However, only a few artists ,,contaminated" with feminism have taken a critical stance on the use of space by the genders. This is in spite of the fact that, on a global scale, the dismantling of the dichotomy between public and private spaces has been going on, even by modest estimates, for half a century. By-now-classic examples of this in art are feminist Mierle Laderman Ukeles' performanes, titled Maintenance, and Martha Rosler's works from the 1970s (Semiotics of the Kitchen, Bringing the War Home). Artworks from the last 30 years that problematise women's spaces range from the resolute dismantling of the border between private and public spaces, to representations of the spaces of women's lives, experiences and dreams.

Hungarian-European artist Ilona Németh (born in 1963, Slovakia) raises social issues quite radically - issues such as nationalism, the distance between people, socio-economic changes or feminism. Most of her projects, videos, installations (that is, her whole ouvre) problematise the question of private/public, as well as the different use of space by men and women. My paper will focus on those works of Ilona Németh that reflect in a sophisticated, and indeed critical way on the tradition of gender-specific use of spaces.
\end{abstract}

Keywords: Contemporary Art, Installation, Ilona Németh, Privat/Public, Feminist use of Space

\footnotetext{
${ }^{1}$ Art historian, Senior Research Fellow, Research Center for the Humanities, Institute of Art History Hungary. tatai.erzsebet@btk.mta.hu
} 


\section{Introduction}

Hungarian artist Ilona Németh (born in Slovakia, 1963) became well-known on the international art scene for raising social issues quite radically - Issues such as nationalism, the distance between people, socio-economic changes or feminism. Most of her projects, videos, and installations problematise the question of private/public, as well as the different uses of space by men and women. My paper will focus on the works of Ilona Németh that offer a more and more sophisticated critique on the tradition of gender-specific use of spaces, thereby eroding it. My presentation is thematically arranged and loosely chronological. I do not intend to outline a strictly linear progression, but merely to follow the shifts in Németh's art that are more or less synchronous with certain social changes. Hopefully the presentation will shed light on how her artworks have contributed to feminist discourse.

If Gaytari Chakravorty Spivak is right in saying that every feminist activity includes the deconstruction of the dichotomy between the private and the public (Spivak, 1987: 103), then presumably its inversion is also true: the deconstruction of the dichotomy between private and public benefits feminism. The well-known, ostensibly symmetrical dichotomies that are actually hierarchical (e.g. feminine-masculine, soft-hard, irrelevant-relevant, psychic-social, inner-outer, private-public, personal-political, nature-culture) still stubbornly prevail; bringing them into play can shift some stiff boundaries (Tatai, 2017: 56-72).

Németh creates agonistic spaces in a Chantal Mouffe-ian sense (Mouffe, 2007), as she does not hide the conflicts generated in them; on the contrary, she explores and points out these conflicts. Even when she creates purely "feminine" spaces.

With her first installations, Németh created spaces that archetypically belonged to the so-called feminine sphere. However, in a gender-blind milieu their mere existence generated a discoursive space, where the previously missing feminine - whatever we may think about that 
- became visible, where it was given floor; Németh made discussion possible, which later she herself actually left.

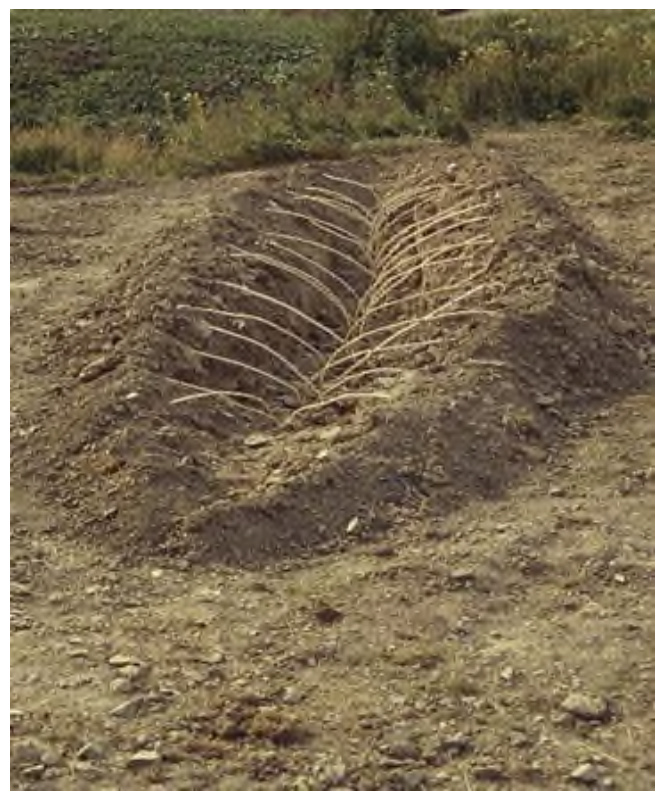

Figure 1: Elementary Object II. 1994, earth, twigs 3x12x2 m (Tatranská Lomnica, Slovakia) Photo: Martin Marenčin.

Her Land Art work in Tatranská Lomnica, Elemental Object II. 1994 (fig. 1), is a wound on the Earth, an aperture between earthen mounds that are covered by twigs which look like ribs - organic associations are guaranteed. Whether we interpret the work mythically, as a modern entrance to the womb of Mother Earth, or simply as a giant vulva made of materials found in nature, Németh as woman artist has definitely brought the feminine into play. It "is an open wound, an incision on the earth, a grave-like pit associated with nature, death, the female genitals, and all the social connotations attached to a woman as a sexual being." - observes an art historian (András, 2013: 188) ${ }^{1}$. Even the title indicates that this is about something primal, basic, essential.

\footnotetext{
${ }^{1}$ Translation modified.
} 


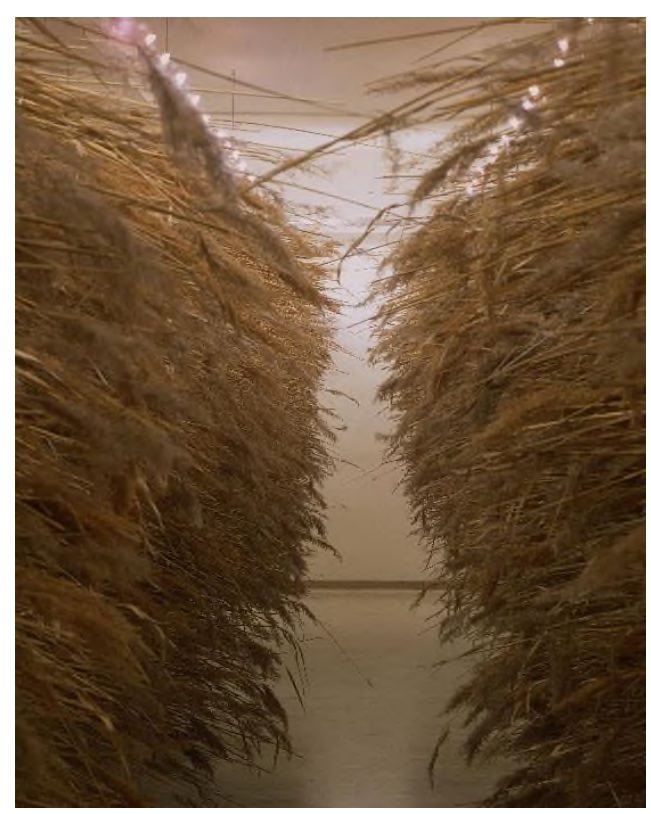

Figure 2: Untitled. 1996, reed, wire, wire netting, 6x12x2,5 m (Bartók 32 Gallery, Budapest) Technician: István Süke. Photo: Martin Marenčin

Just like her Untitled installation of reeds (1996) (fig. 2). Between the 2,5 m high bunches, the artist only left a path so narrow that any visitor who walked along it had to make physical contact with the reeds: the bundles would touch, graze, stroke and prick them whether they liked it or not. The sensuous effect of the vast amount of reed could evoke an allenwrapping sensation and archetypical notions in the sensitive beholder (Tatai, 1997). From a more detached and critical viewpoint, the artist subverted the traditional way we relate to nature. To achieve this, she had to rotate the "forest of reeds" by ninety degrees. By changing the angle of the reeds, Németh questioned the association between nature and the feminine. The artist created a continuity between culture (an art exhibition) and nature (as the exhibition was made of natural materials), which made the space metaphorical. 


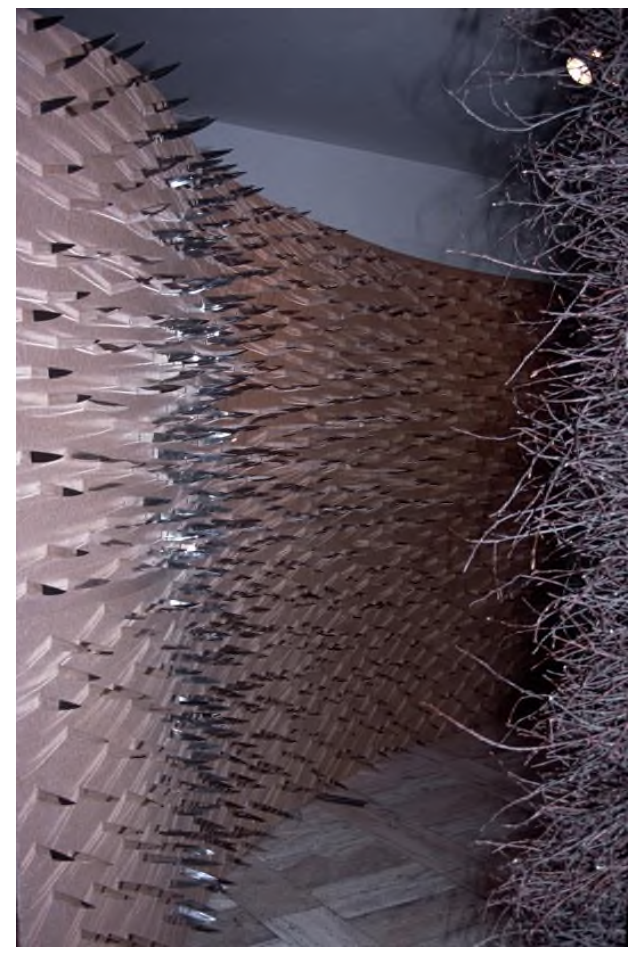

Figure 3: Gate. 1992, fiberboard, iron, 1000 knives, twigs, 2,4x5x1,8 m Zbierka Prvej slovenskej investičnej skupiny, Bratislava. Photo: Marián Ravasz, Ladislav Sternmüller.

The 5-meter-long passage of The Gate (1992) (fig. 3) reinterprets the archetypical topos of passing through difficulties as a trial - think of Ulysses' sailing between the cliffs of Scylla and Charybdis. One side of Németh's installation is covered in brushwood, while on the other side sharp, pointy knives rise toward the person entering the passage. The dangerous tools and the dense, tenderer - though not totally harmless - brushwood are set against each other in a symmetrical arrangement. The artwork naturally represents the polar opposites inherent in human personality ${ }^{1}$, yet at the same time it also recalls all other binaries - including the stereotypical feminine and masculine.

\footnotetext{
${ }^{1}$ As Jana Geržová noted in 1996. (Hushegyi, 2001: 30).
} 


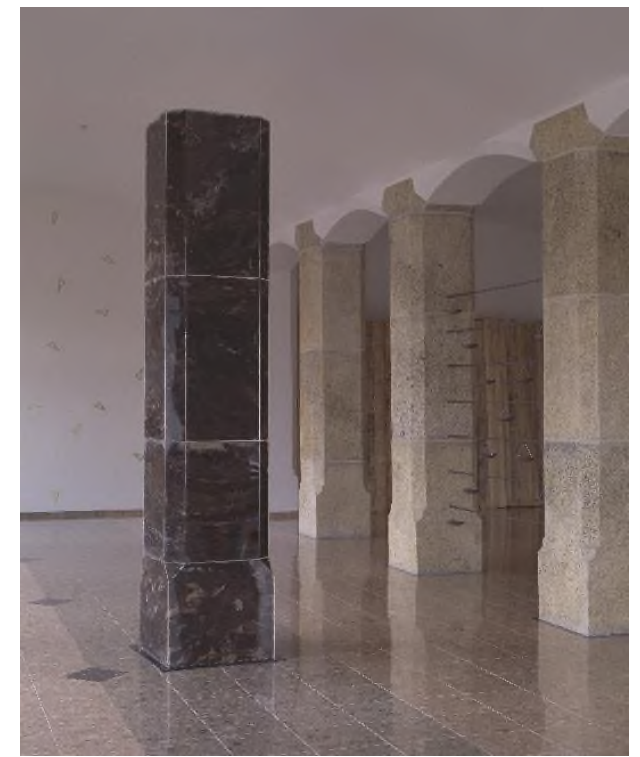

Figure 4: Column. 1995, plexiglass, hair 90x90x $300 \mathrm{~cm}$ (Slovak National Gallery, Bratislava). Považská galéria umenia, Žilina, Slovakia. Photos: Martin Marenčin.

By placing her own pillar (Column, 1995, (fig. 4) in the historicizing, colonnaded hall of the Slovak National Gallery, Németh sharply counterpointed the hierarchy represented by the columns in general. Since ancient times, the column (and the pillar) - being a supportive, decorative and symbolic element of public buildings and palaces - has always symbolised the axis mundi; more specifically, in traditional Christian iconography it has symbolised power, and thus masculinity. Németh's slightly darker column visually fit the room where it was placed, even its blotchy surface resembled marble; on the other hand, its function was different, as it was not a supporter but a container. The pillar-shaped plexiglass container was filled with human hair collected from hairdressers. (Which lent it a marble-like appearance upon compression.) The hair itself also represents power. According to the Bible, Samson lost his power when Delilah cut his hair while he was sleeping. After his hair grew out again, Samson demolished the palace of his captors by breaking its main support columns. (Judges 16). Without going into the details of the long cultural history of hair (Horváth, 2016), I believe it is worth mentioning two things: firstly, to this day, hair is still one of the keys of femininity, 
representing women's power, which some consider threatening; secondly, cut hair is bodily waste and therefore abject (Kristeva, 1990).

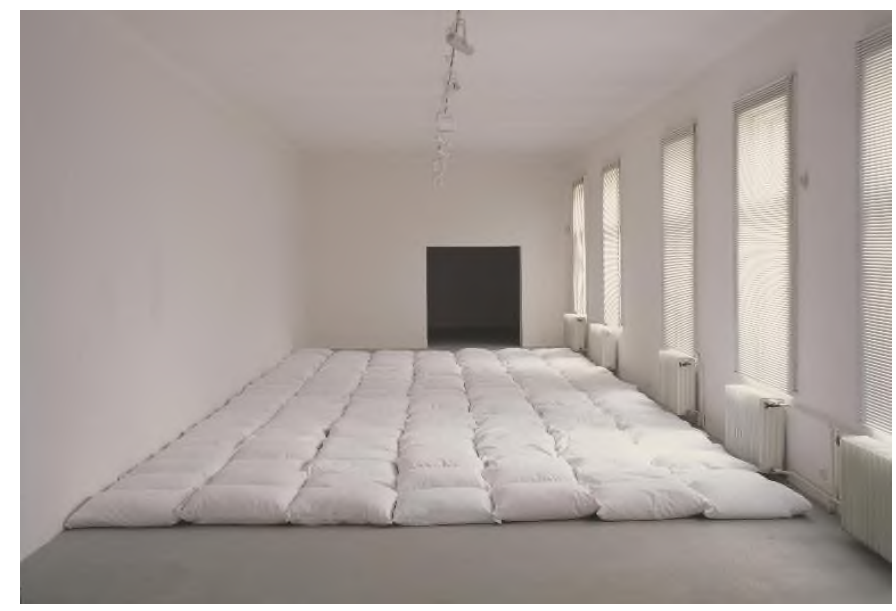

Figure 5: Pillow (Our Dreams)The Floor I. 1996, site specific installation, pillows, 5,2x 11,2 $m$ (Museum of Art / Považská galéria umenia, Žilina, Slovakia) Photo: Martin Marenčin.

In her later series called Floor works (1996-2002), the artist abandoned natural materials and started using ready-made objects and artificial materials. One example of this was when she covered the floor of a gallery with snow-white pillows (Hushegyi, G., Kišová, K., 1998), so that visitors had to trample on them (Floor I., 1996) (fig. 5).

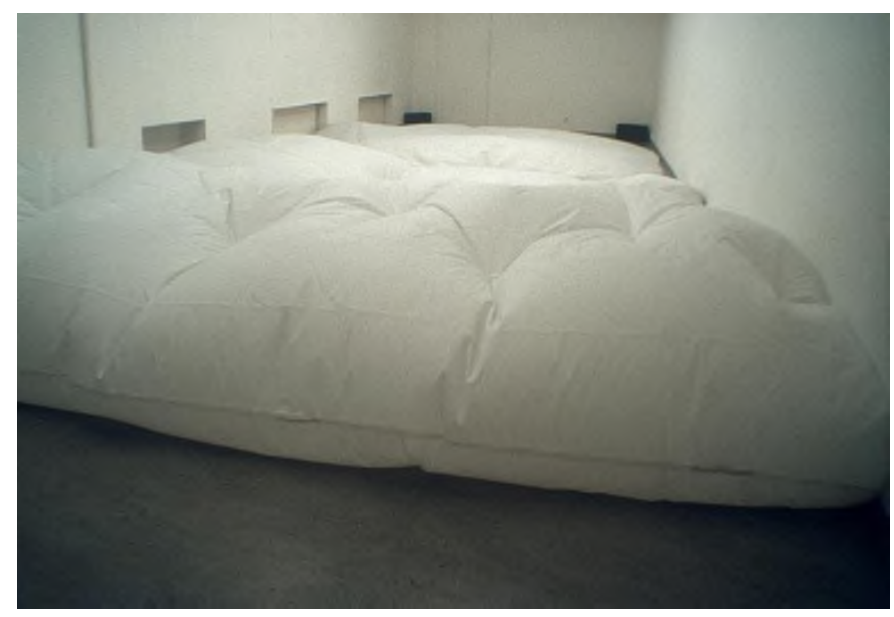

Figure 6: Breathing Floor. The Floor III. 1998, interactive installation, pillows, ventillator, electronics, 7,5x11,5 m. Slovenská národná galéria, Bratislava. Photos: Miklós Sulyok, Tibor Somogyi. 
Breathing Floor (Floor III., 1998) (fig. 6) was an interactive artwork: the gigantic pillowcases lying on the floor alternately became inflated and deflated as if they were animated by the presence of the entering visitor; as if they were the metaphor of the sentient, living subaltern. (Spivak, 1988)

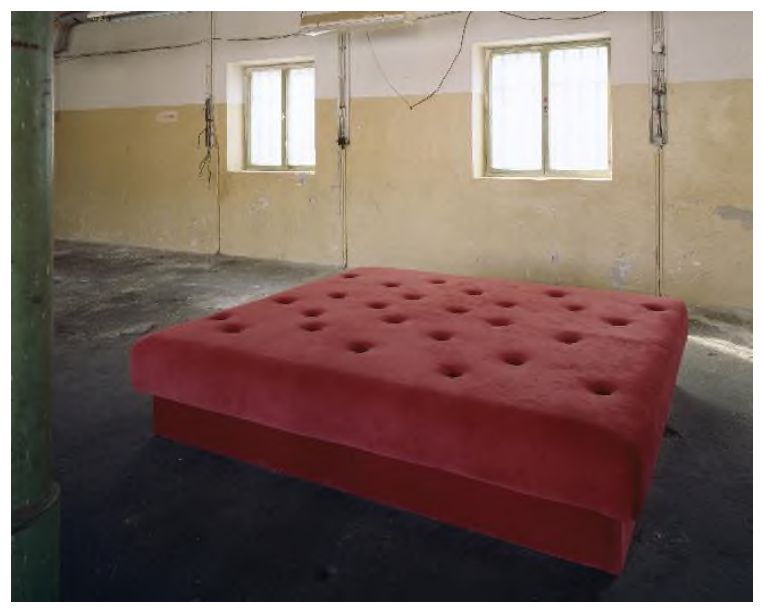

Figure 7: Polyfunctional Woman. 1996, sound installation, bed, velvet upholstery, audio equipment, 200x260x45 cm. Ludwig Museum - Museum of Contemporary Art, Budapest. Photo: Martin Marenčin

Two of Németh's ready-mades are explicitly feminist. Polifunctional Woman (1996) is a double bed covered with red velvet, with numerous holes in it housing hidden speakers (fig. 7). If one lies on the bed and puts his ear over the holes, one can listen to women's voices whispering, moaning, whimpering, sighing etc. No matter how feminine the connotations that come to mind at first sight, the ironic title and the eavesdropping position subvert this - once again questioning the sexual role of women as accepting, erotic beings. It's worth noting that the artist once again appeals to all the senses: hearing, movement and touch force sight into a background role (Peić, 2013: 128); this object is special because the bed "speaks" to us, shifting the masculine gaze out of its central role and extending traditionally "feminine" spaces, thereby liberating the feminine. 


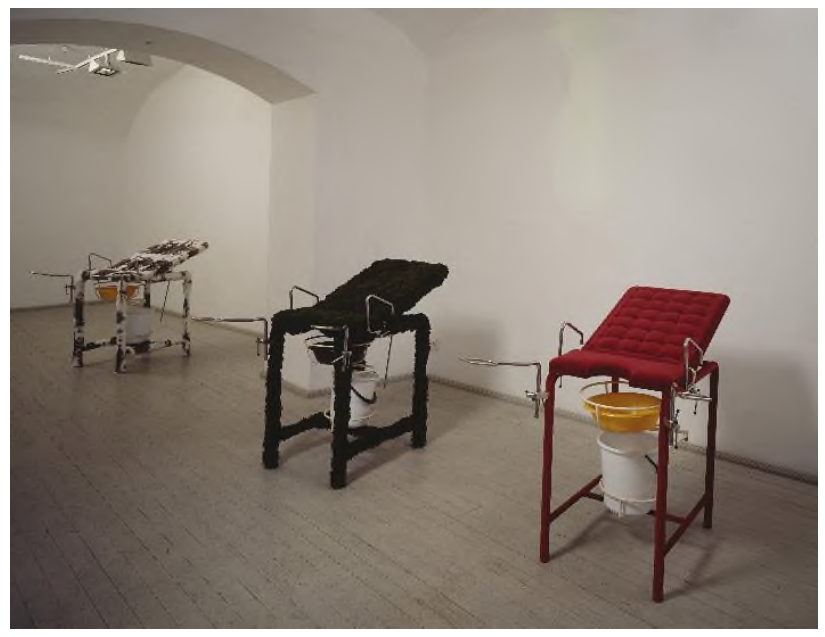

Figure 8: Private Gynecological Ambulance I. - III. 1997, installation: metal examining chair, velvet, rabbit fur, moss, $72 \times 112 \times 112 \mathrm{~cm}$. Ludwig Museum - Museum of Contemporary Art, Budapest. Photo: Martin Marenčin.

Private Surgery (1997) consists of three modified ready-mades: the artist shockingly exhibited $^{1}$ gynecological examining chairs covered with different materials (fig. 8). One would be hard put to find more intimate objects - objects that also represent vulnerability to the medical gaze. The connotations of the three different covers evoke the stereotypical roles or functions of women: the red velvet recalls the erotic lover, the rabbit fur - due to the animal's prolification - recalls the mother, and the moss recalls the faithful companion (wife). Thereby they point out that even in modern societies women are still defined by and positioned according to their bodies and sexuality. Modifying the objects (with their sensual conceptualism) and the strong contrast between private and public (all the sharper because the large windows of the gallery faced a downtown street) challenge the role issues.

\footnotetext{
${ }^{1}$ Stúdió Gallery, Budapest. (Tatai, 1997 b: 13).
} 


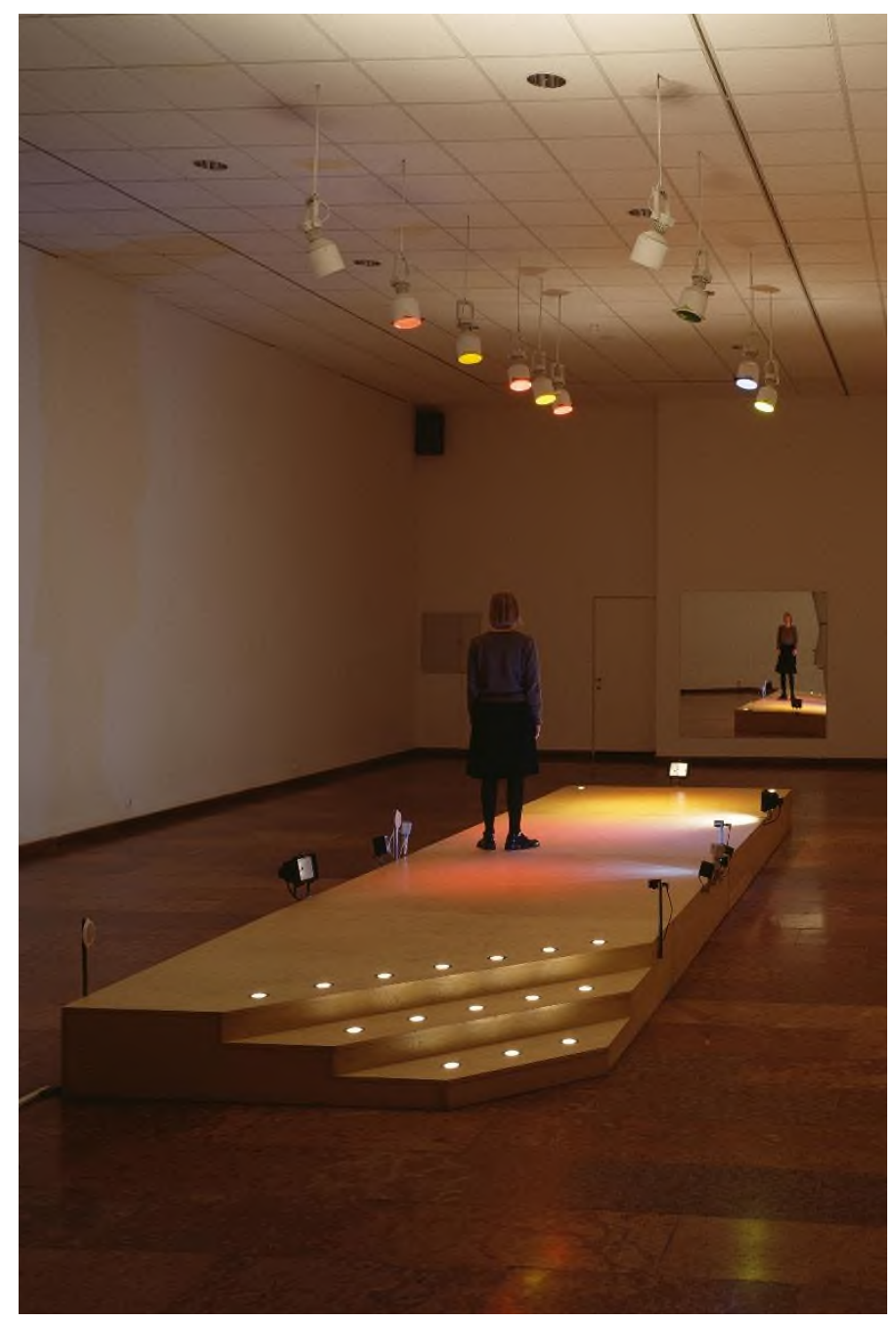

Figure 9: Exhibition room. The Floor IV. 1998, wood, reflectors, electronics, sensors, light effects, mirror, $200 \times 800 \times 50 \mathrm{~cm}$. (The 2005 version is the property of the Galéria Jána Koniarka, Trnava) Photo: Mária Baloghová, Lajos Kalmár.

At the turn of the Millennium the artist made the politics of private and public spaces her main explicit topic: she interpreted her installation entitled Exhibition room /Runway (1998) as a continuation of her Floor series by giving it the subtitle Floor IV. (fig. 9) The work seems like a simple platform until a visitor steps on it, rousing its electronics and turning it into a stage surrounded by flashing, colourful lights accompanied by a storm of applause and the clicking of cameras. In a mirror on the wall the surprised visitor comes face to face with her or his transfiguration. For a short time, (s)he is transformed from spectator to actor by the technology- 
aided formalities of stardom in that public space. Of course, it's the visitor's decision whether or not to enter the game.

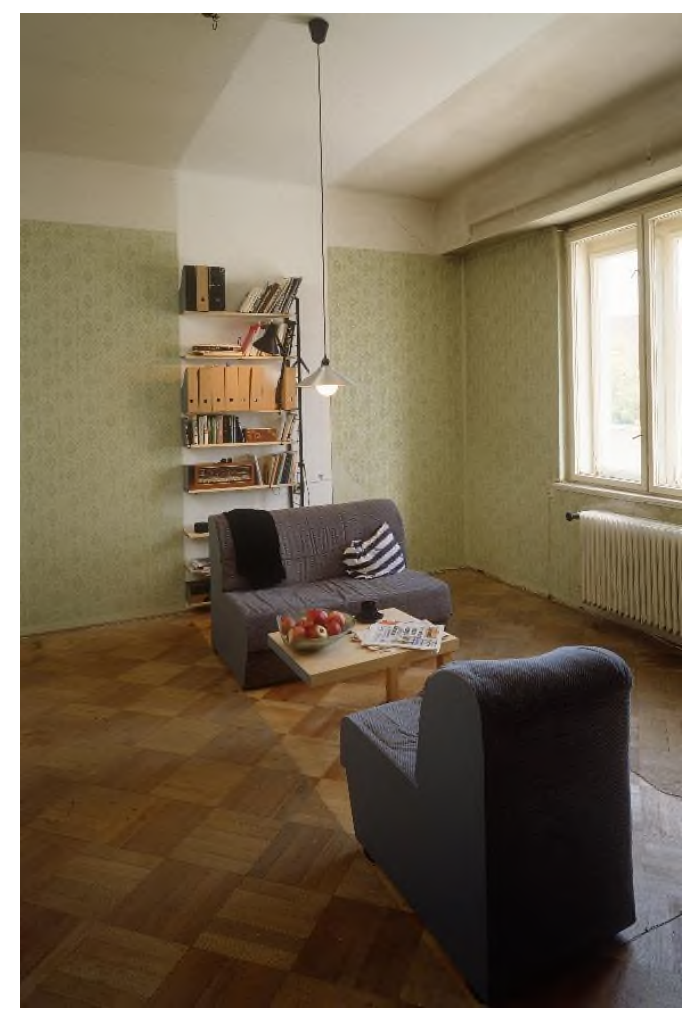

Figure 10: Part. 2000, interactive sound installation, furniture, various objects, sensors. $3 x$ 1,2 x 5 m, Property: Linea Collection, Bratislava. Photo: Martin Marenčin

With her installations The Part (2000) and Invitation for a visit (2001), Németh completely abolishes the border between public and private. The Part is a living room cut precisely in half - with its furniture, sounds and lights activated by the movement of the visitors. The Part (fig. 10) is also a work that surprises the visitor: a private apartment placed in a public space makes one feel a bit uneasy. The meaning of the precise cut is not quite clear. It might recall the nightmare of divorce, or perhaps merely an absence, and the uncertainty caused by that absence, while everything is very tidy and cosy in that Part. Perfect, as if nothing had happened, except that the other Part is missing. 
The installation in the Czech and Slovakian pavilion of the Venice Biennale in $2001^{1}$, Invitation for a visit, seems to be an extension of The Part as it is also an apartment, only larger and complete. But these are not the only differences: in this installation, Németh turned her own home inside out - the rooms, re-created with their exact measures, became external spaces. Besides the metaphoric advantages, this reversal also came with the practical benefit that visitors could look at the apartment from a central podium, walking high above the construction. (Thus continuing the "floor" theme, as the subtitle was: Floor VI.) Therefore, Invitation turns things inside out in two senses: topographically and metaphorically. The inner, the hidden, the personal was totally exposed to one of the largest audiences of the art world. (This exposure was also visually emphasized by the easy entry and the top-down view.) The space of Németh's private life became utterly public in a public space. It was open and investigable; one could freely walk through it, or even settle down in it - for the duration of an exhibition visit (Hushegyi, 2008: 15-29).

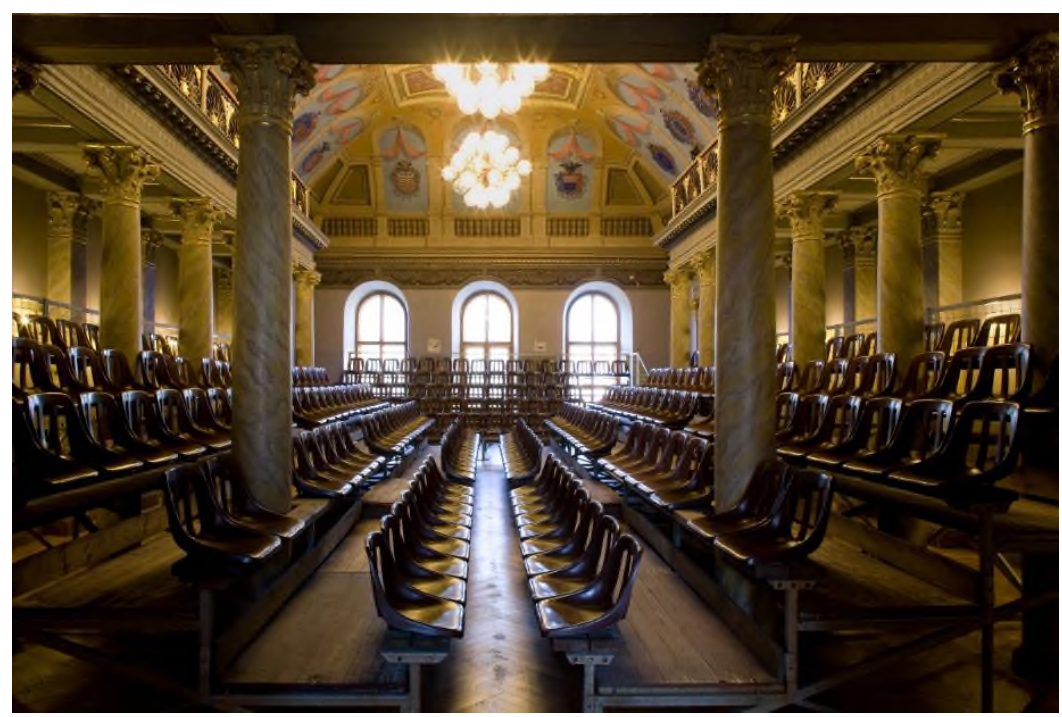

Figure 11: Invitation for a visit / Public Privacy. The Floor VI. (49 th Venice Biennale, with Jiri Surưvka, architect Marian Ravasz) 2000-2001, Mücsarnok, Budapest, 2002, furniture objects, ready-mades, various objects, electronics, $35 \times 528 \times 968 \mathrm{~cm}$. Photo: Marián Ravasz

\footnotetext{
${ }^{1}$ With the Czech artist Jiři Surůvka.
} 
The intensity of the artist's intent of realising (representing) complete permeability between private and public is evidenced by the fact that when she later exhibited this work in Budapest (Kunsthalle, 2002), this time without Surůvka's pictures, she gave it the title: Public privacy. (fig. 11) Németh's most sophisticated, and perhaps most feminist (Baglyas, 2013: 55) work so far is Non identical Space, an exhibition that was held in the East-Slovakian Gallery ${ }^{1}$ (Košice, Slovakia, 2012).

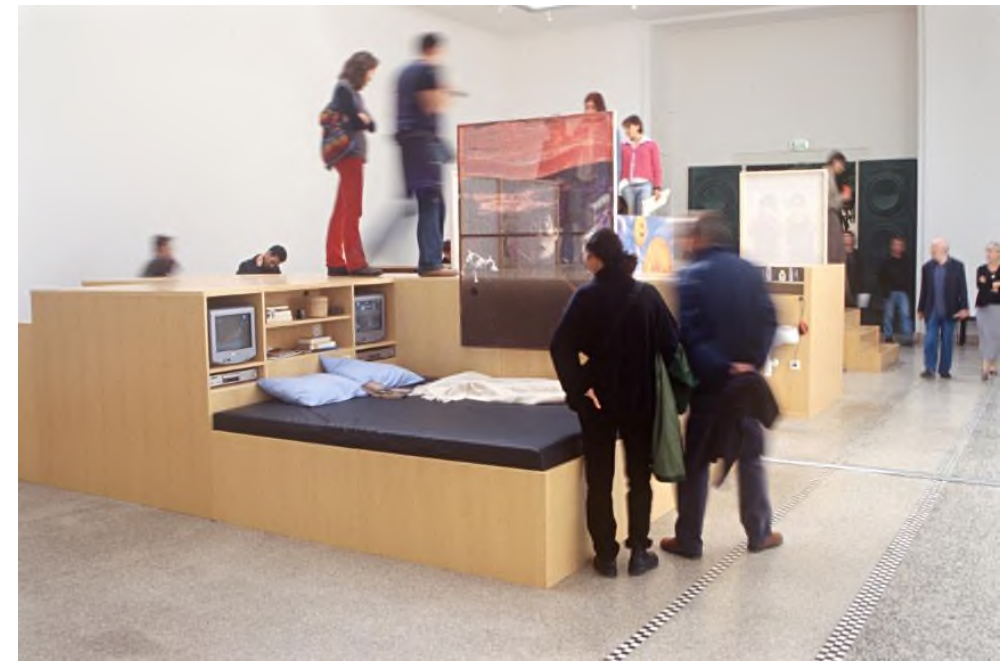

Figure 12: Grandstand 1. (Greetings from Košice to Bruce Neumann.) 2012, site specific installation, steel construction, wood, seats. Photo: József Rosta.

Its central element was an enormous installation titled Grandstand I. Greetings from Košice to Bruce Nauman (fig. 12), which filled the former County Hall's ceremonial hall (Hushegyi, 2013) - a room otherwise not used for exhibitions so completely that only a narrow passageway was left between the individual grandstands. Removed from their original function, two six-tiered grandstands stood facing each other, with a third one placed at right angles to them. No room was left for either a stage or an arena, the spectators (audience) who sat there could only look at each other.

\footnotetext{
${ }^{1}$ This was the second version of the exhibition Dilemma (Budapest, 2011) and of the Identity of Space (Brno, 2012).
} 
This huge construction forced all other works out to the edges of the room, including a three-channel video installation titled 8 men (fig. 13), in which three Hungarian women - all of them coming from different generations, but living in the same village in Slovakia - tell their stories, of how they lost their men.

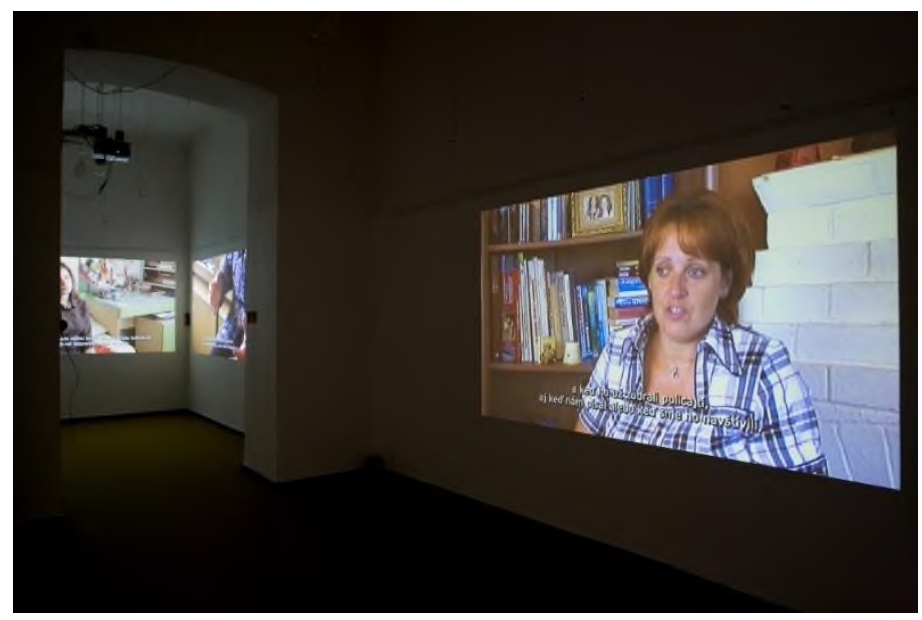

Figure 13: 8 Men: Timea (2009, 15'14'), Gizella (2012, 12'35”), Flóra (2012, 5'14”), video editor: Csaba Czibula, Juraj Szaszák - XL PIXEL media studio Košice; Mirka Gáberová, Ivan Svoboda Photo: József Rosta, Richard Köhler

Another installation focuses on the video interview titled Zsófia Meller, which was made with philosopher Ágnes Heller (fig. 14).

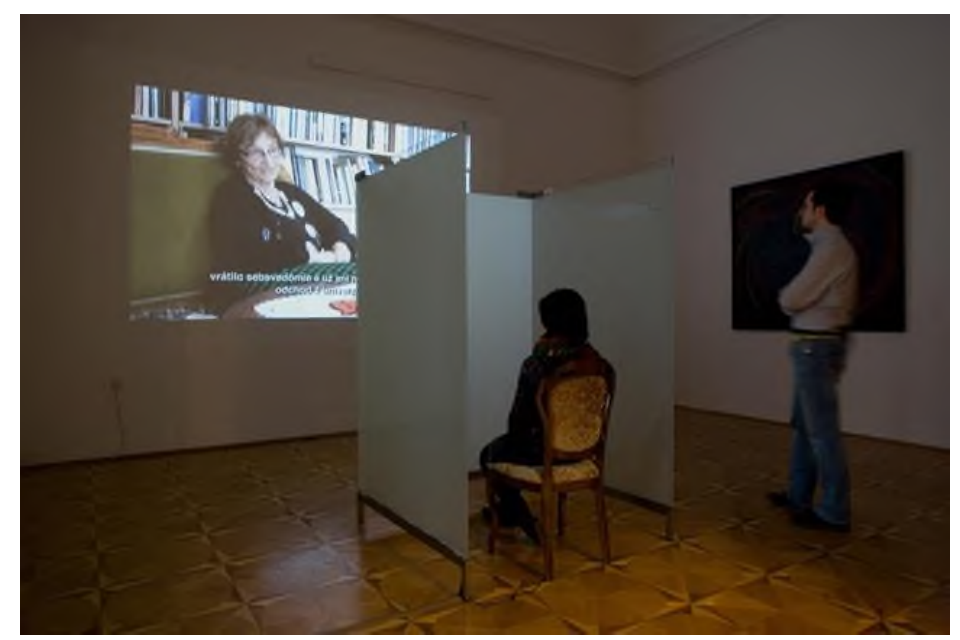

Figure 14: Zsófia Meller (dialogue with Ágnes Heller, 10'30”). 2012, interactive installation with Dóra Rudas, AttilaHegyi, Mira Gáberová, Ivan Svoboda. Photo: József Rosta. 
In the late $19^{\text {th }}$ century, Zsófia Meller, the grandmother of the philosopher, was the first woman student of Germanistics at Vienna University. The installation reproduces a situation that today seems absurd, but at that time was humiliating: Zsófia Meller had to attend lectures at Vienna University while hidden behind some folding screens, so as not to disturb male students. In her installation, the artist placed a chair in front of the projected video interview and surrounded it on three sides with a folding screen made of intelligent glass. Whenever a visitor sat down on the chair, the glass became opaque and (s)he could not watch the video. (They could still listen to it, though, as long as they understood Hungarian.) In a way, this reenactment is an inversion of the original situation, since the visitor sitting behind the folding screen can clearly be seen; yet it is also a perfect mirror, when we consider the feelings of vulnerability and powerlessness. In the interview Heller speaks about her youth and her family members, ambitious women who were her role models, who affirmed the mind of the eager schoolgirl. Though it may be unintentional, Heller gives us a feminist historical narrative.

The grandstands could recall the auditoria of universities, if they were not so separated from the other artworks. And why did these constructions have to be so huge? Since they are obviously not functional (the grandstands cannot be used for watching anything, neither university lectures or performances, films or a circus show), they are just an exhibited artwork, like the other installations. The context, the frame of interpretation is given by the feminist videos and objects - but without any content, yet. However, its dimensions and altered functionality are puzzling: what is this, then? The idea of the tiered podiums facing each other comes from a small drawing of Bruce Nauman. Ilona Németh writes: „... with the help of the drawing I came to understand a situation when the heart of the 'matter' is lost; everything is given, the opportunity, the space, the circumstances, but we can't use, utilize them. So content 
- in a general sense - is absent." (András, 2013: 182) ${ }^{1}$ These constructions, constituents of prominent spaces of masculinity, which tower over the visitors' heads densely, in an overwhelmingly breathtaking manner, leaving no room for anything, were regarded by Edit András as the frame of interpretation in a Derridaean sense. In this arrangement, Grandstand I. also invokes the absence: “...there is no audience, but there is nothing in the center either, there is nothing to see, except for the wound, the loss, the absence itself." - she writes. (András, 2013: 188) The absence can also be the signifier of the missing womanliness. But even if it is, her interpretation s still valid (András, 2013: 189): "From a feminist perspective, the institutional critique formulated by a female artist is rooted in the very opening of the wound, if only for a brief moment, through a symbolic act that holds subversive power in itself."

\section{References}

András, E. (2013). One must keep open the wound. Institutional critique from the sideline, from a woman's perspective. In András, E. (Ed.). Dilemma. Three Central-European Versions of Ilona Németh's exhibition. Németh Ilona kiállitásának három közép-európai változata. Tri strednoeurópske varianty výstavy Ilony Németh. Bratislava: Kalligram. 181-190.

Baglyas, E. (2013). Double vision. In András, E. (Ed.). Dilemma. Three Central-European Versions of Ilona Németh's exhibition. Németh Ilona kiállitásának három közép-európai változata. Tri strednoeurópske varianty výstavy Ilony Németh. Bratislava: Kalligram. 54-55.

Horváth, Zs. K. (2016). A bundátlan Vénusz. 1-4. A szem. From http://aszem.info/2016/11/aaabundatlan-venusz-1-resz/; $\quad$ http://aszem.info/2016/11/aaa-bundatlan-venusz-2-resz; /http://aszem.info/2016/11/aaa-bundatlan-venusz-3-resz; /http://aszem.info/2016/11/aaabundatlan-venusz-4-resz/.

Hushegyi, G., Kišová, K. (Eds). (1998). Ilona Németh. Instalacie - Installations - Installációk. Bratislava: Soros Center for Contemporary Arts - Slovakia.

Hushegyi G. (2001). Ilona Németh. Bratislava: Kalligram.

\footnotetext{
${ }^{1}$ Translation modified.

2 Translation modified.
} 
Hushegyi, G. (2008). Németh. Bratislava: Kalligram.

Hushegyi, G. (2013) Cordon, neo-normalistion, social art. In András, E. (Ed.). Dilemma. Three Central-European Versions of Ilona Németh's exhibition. Németh Ilona kiállitásának három közép-európai változata. Tri strednoeurópske varianty výstavy Ilony Németh. Bratislava: Kalligram. 15-31.

Kristeva, J. (1991). Approche de l'abjection. In Pouvoirs de l'horreurs. Essai sur l'abjection. Paris: Éditions du Seuil. 9-39.

Mouffe, Ch. (2007, Summer). Artistic Activism and Agonistic Spaces. Art \& Research - A Journal of Ideas, Contexts and Methods. 1(2), from http://www.artandresearch.org.uk/v1n2/mouffe.html

Peić, B. (2013). On freedom. In András, E. (Ed.). Dilemma. Three Central-European Versions of Ilona Németh's exhibition. Németh Ilona kiállitásának három közép-európai változata. Tri strednoeurópske varianty výstavy Ilony Németh. Bratislava: Kalligram. 123-134.

Spivak, G. Ch. (1987). Explanation and Culture: Marginalia. In In other worlds. Essays in cultural politics. New York and London: Routledge. 103-117.

Spivak, G. Ch. (1988). Can the subaltern speak? In C. Nelson and L. Grossberg (Eds.) Marxism and the Interpretation of Culture. Basingstoke: Macmillan Education. 271-313.

Tatai, E. (1997). Németh Ilona. In Tatai E. (Ed.). A Bartók 32 Galéria kiállításai 1996-1997. Exhibition Catalogue. Budapest, Bartók 32 Gallery, 1997.

Tatai, E. (1997) b. Magánrendelö. Németh Ilona kiállítása. [Private Surgery. Exhibition of Ilona Németh] Balkon, 1997/6. 13.

Tatai, E. (2017, June). Women's Space in Hungarian Contemporary Art. Using of space in two public art projets of Ágnes Eperjesi and in painting of Márta Czene. TNTeF, 7(1), 56-72, 203. http://tntefjournal.hu/vol7/iss1/tatai.pdf., http://tntefjournal.hu/vol7/iss1/abstracts.pdf. 


\title{
SCHOOL AS A REPRODUCTION PLACE OF GENDER INEQUALITY IN LANGUAGE ${ }^{I}$
}

Feyza AK AKYOL ${ }^{2}$

\begin{abstract}
Gender equality refers to the equal visibility, empowerment, responsibility and participation of women and men in all areas of public and private life. It also refers to equality in the distribution of resources between men and women. Cultural norms, the way we are cultivated, and social prejudices are so unconscious that we sometimes reproduce discrimination without being aware of it. The language we use also causes this inequality to be reproduced without being aware of it.

When the child perceives himself as a masculine or feminine, it first occurs visually. After this process, he starts to perceive his sexual identity behaviorally. In other words, the fact that the child recognizes his identity as a sex is also reflected in his behaviors. Shortly after the children realize that there are two groups of people, male and female, they are able to comprehend in which of these groups they are involved, and finally code the behaviors, that fit the male and female sexes, to their cognitive structures. At this stage, however, the environment in which the child lives (family, parents, places, schools, tools, etc.) has undeniable contributions in determining and reinforcing the gender.

In this study, which deals with the question of how the school contributes to the reproduction of gender inequality in language, with its structure, actors, processes and everyday life, the structures of primary and secondary education will be explained in the concepts of habitus and symbolic violence by Pierre Bourdieu.
\end{abstract}

Keywords: Gender Inequality, Language, School, Habitus, Symbolic Violence

\footnotetext{
${ }^{1}$ This research (18.502.001) is supported by Galatasaray University Scientific Research Projects.

${ }^{2}$ Assoc. Prof. Dr. Galatasaray University, Department of Sociology, Çırağan cad. No:36 Ortaköy İstanbul Turkey, feyzaak@gmail.com
} 


\section{Introduction}

Education plays an important role in the socialization process of individuals and mediates the reproduction of culture and social structure. Education mostly takes place at school, includes also the transmit of some properties from the family. Educational background can be promoted through the school as institutional structure and can be reproduced.

The relationship between education inequality and social factors has been the subject of researches in countries such as the United States, Britain and France since the 1950s and 1960s. The result of these researches is that the social inequalities have been reproduced through education. Pierre Bourdieu and Jean-Claude Passeron (1964, 1970), Basil Bernstein (1975) found that the differences and similarities arising from the social class were conveyed in the same way to the schools, as Christian Baudelot ve Roger Establet (1971) emphasized that capitalist school couldn't give necessary conceptual framework to students in order to make them understand social conflict and differences and Samuel Bowles and Herbert Gintis (1976) also emphasized that there is a relationship between labor position and cultural transmission. In mixed education systems, girls and boys receive education that is considered equal, but is it really equal? Despite the better success of girls in school (in terms of average length of study, average level of diplomas, success rate in exams), they are still underrepresented in the prestigious jobs. Subsequently, women encounter more difficulties in their career path: they are more often than men facing unemployment, precarious work, forced part-time work and often less well paid. Therefore school is a place of primary socialization in the construction of inequalities between girls and boys (Duru Bellat, 1995): on the one hand, because it conveys and transmits to children codes related to the roles and expectations of the school institution in the behavior and skills of girls and boys; on the other hand, because at the same time as he 
discovers the school institution and learns the "occupation" of a pupil, the young child constructs his sexual identity and affirms his belonging to one sex group.

\section{The Subject and the Methodology of the Research}

The research titled as "School as a reproduction place of gender inequality in language" is based on the results of field studies conducted between October 2018 and June 2019. The research was designed to determine the attitudes of children about being boy or girl during their education, as well as in-school and out-of-school. In the scope of research, in-depth interviews with 30 children from the secondary school have been carried out in Istanbul provincial borders. The interviewed girls and boys who are between 10-14 years old continue all to public education institutions.

This paper deals with the question of how the school contributes to the reproduction of gender inequality in language, with its structure, actors, processes and everyday life. Through the help of the data obtained from research, we will try to demonstrate how the cultural gender biased codes come transmitted to children at school and how they affect their perception of world.

Gender equality refers to the equal visibility, empowerment, responsibility and participation of women and men in all areas of public and private life. It also refers to equality in the distribution of resources between men and women. Cultural norms, the way we are cultivated and social prejudices are so unconscious that we sometimes reproduce discrimination without being aware of it. The language we use also causes this inequality to be reproduced without being aware of it.

When the child perceives himself as a masculine or feminine, it first occurs visually. After this process, he/she starts to perceive his/her sexual identity behaviorally. In other words, the fact that the child recognizes his/her identity as a sex is also reflected in his/her behaviors. 
Shortly after the children realize that there are two groups of people, male and female, they are able to comprehend in which of these groups they are involved, and finally code the behaviors, that fit the male and female sexes, to their cognitive structures. At this stage, however, the environment in which the child lives (family, parents, places, schools, tools, etc.) has undeniable contributions in determining and reinforcing the gender.

Gender stereotyping in schools reinforces particular ideas about what is expected and acceptable behavior from women and men: such as that women are weak and emotional, while men are strong and brave. A significant portion of teachers report that sexism is an everyday occurrence in the classroom, and that small, seemingly insignificant events together create an environment in which pupils of both sexes come to see each other as different.

\section{Experiences of Sexism in College}

Gender stereotypes disqualify women or girls, as show 3 testimonials of the boys interviewed about professions:

"Secretary is for women because there are women who talk a lot on the phone" (12 years old boy)

"Interior designer, its masculine ... ah, it's for decoration, so it's for girls" (10 years old boy) "Sportsman, it depends, there are girls in sports, those who are pretty, and there are sports of boy,

Its better, it's faster, you get bored less. "(14 years old boy)

As a teenager, male identity is shaped by peer groups. This is how it will operate on the pejoration of the feminine (not being a girl,) and on being a real guy in front of the boys group. The socialization of boys draws two distinct groups: those who succeed in showing their 
strength, in being the strongest, the most virile; and others who risk to be downgraded to the category of sub-men, "queers" (Ayral 2011).

At the same time, the identity of young girls will be built by renouncing the expectations of school competition to fit the criteria of seduction and will change according to the eyes of boys. A girl, 14 years old says:

"I have great grades in college, I dress in fashion like my girlfriends, but boys, they do not even look at me ... All my girlfriends who are not so good, they don't have problem finding someone." (14 years old girl)

To be a girl means to be pretty, and attentive to others.

“When I don't feel as good as enough, with dirty hairs or some buttons on the face I don't come to school" (13 years old girl)

Baudelot and Establet (2002) point to two distinct models of school success closely linked to gender socialization and the relation to knowledge. One is effective in the short term, the other is revealed during the school trajectory. Indeed, girls seem better prepared to integrate into the social world of kindergarten and primary school which, in the early years, is perceived as an extension of family life. On the other hand, boys are more likely to win in the academic competition which intensifies with the level of studies. Indeed, they have often had the opportunity to confront each other in sports competitions, or in fights, which demand and prepare for the implementation of some aggressive and conflicting form of self-esteem. A masculine culture develops during the schooling of boys. This concept refers to the culture of struggle in all aspects of life, both personal and professional. This culture would be less internalized and valued by girls, who would rather develop a spirit of mutual aid and respect for others. 
The school path of girls and boys is then guided by the adoption of sex roles that renew the social relations of sex. In line with this work, de Boissieu (2009) proposes a new concept: "the school gender", which covers "the differentiated ways of being in school, a kind of school habitus, and the way in which pupils incorporate » According to this author, the school gender thus refers to the construction of a pupil-girl or pupil-boy identity, largely influenced by gender socialization and the development of sexual identity in progress.

It turns out that children make a very strong link between maturity and work in a mixed way. Proposals for answers expressing the wish to work with people of the same sex are described as "childish" for some girls. A girl protests:

"We are no longer in kindergarten, we have passed: I am going to put myself with a girl, oh, I prefer to put myself with a boy". (11 years old girl)

For another girl:

"It is rather according to the school results of the people that we will work now". (12 years old girl)

In the class too, we observe that boys exercise dominance: they occupy the "sound space" (Mosconi, 1989, 1994, Zaïdman, 1996) of the classroom. They intervene much more, and especially spontaneously, without having invited by the teacher, either in the main communication network (concerning knowledge and learning), if they have the opportunities, or they are in the network (they "get noticed" by their indiscipline). They do not hesitate to interrupt girls and prevent them to speak and their place in the classroom by various means (interruptions, mockery, derision, aggressive, sexist remarks). 
"Most of the time girls talk, but they talk empty. The class is listening to me with my simple comment" (12 years old boy)

"Four girls and two boys were candidates for class presidency. But I have been chosen because I know how to speak. (13 years old boy)

"I'm a little quiet and shy. Every time I take speech in a lesson, there's a loud man interrupting. And the teacher interrupts and listens to him." (13 years old girl)

\section{The Attraction of Cultural Capital}

According to Bourdieu (1979), habitus is the "the scheme of productive trends" that is acquired without being consciousness during the first childhood and thus displays continuity. These trends produce people's practices, improvisations, attitudes or physical movements. The objective existence conditions that each individual embodied in his/her own body during his/her own socialization process, constitute a permanent and transmittable habitus for that individual (Bourdieu, 1984). As the founding structure of the individual's encounter with the social world and socialization within the social world, the habitus presents the individual a whole of possible actions if it is in harmony with the objective conditions that produce itself. The individual will never have any difficulty when there are objective conditions suitable to his/her habitus. In this sense, habitus is the set of familiarities of individuals towards actions. While the trends adapt to the limitations that emerge from the social environment, habitus differs acoording to social roots. Forms of speech, bodily movements, perceptions of beauty or individual identity, all of them differs according to class roots. For instance, when compared to working class members, middle class feels more confident about public speaking or official situations and this can be an important asset in the economic area. Thus, the concept of habitus of Bourdieu has a central place in the analysis of different forms of reproduction of its social inequality (Meder, M. \& Çeğin, G. 2011). 
When having habitus, the competition among three capitals (economic, social, cultural) mentioned by Bourdieu is important. Cultural capital can be obtained both through transmissions from family and through formal education. The members belong to upper socioeconomic class in the society maintain their power by using the mobility and learning methods of capital. Bourdieu (1984) conceptualize cultural capital in three forms as "embodied", "objectified" and "institutionalized" cultural capital. While "embodied" cultural capital include choices and behaviors, "objectified" cultural capital include transmission of cultural elements (such as paintings, music, reading books); but in order for this transmission to be internalized, it must be transformed into a form of embodiment, in other words, must be reflected in behaviors. "Institutionalized" cultural capital includes the institutionalization of the form of embodiment, ie, the documents acquired through education (such as diplomas, certificates). According to Bourdieu cultural capital is concerned with the sum of skills and abilities possesed and transmitted from privileged groups in society. Thus, cultural capital obtained through education serves to reproduce social inequalities.

According to Bourdieu (1994) families tend to sustain their social beings with all their strength and privileges through reproductive strategies, fertility strategies, marital strategies, economic strategies and most importantly through educational strategies. Because cultural capital is relatively heavier than economic capital and is more diverse compared to other strategies, families invest more in school education. Stakeholders aiming for direct transfer of economic capital are relatively less efficient and less profitable.

In the scope of research, it is seen that particularly the children who belong to parents in upper socio-economic class are equipped with the cultural capital of linguistic and cultural skills necessary for their acceptance in friend groups at school. Social class, beyond gender, shapes the attachment and conformity to gendered stereotypes of gendered behaviors: Gender postures become markers of social hierarchy. Any attitude or dress that is not in keeping with 
the desired image of the school or institution justifies sanctioning or reframing the least legitimate students in the categorization hierarchy.

\section{Weight of the Symbolic Violence}

The education system distinguishes those who have cultural capital from those who are deprived of this capital through inheritance. Because differences in talent cannot be separated from social differences based on inherited cultural capital, thus retains the old social differences (Bourdieu, 1994). At this point, symbolic capital concept comes into play. Since symbolic capital that exists in a field is determined by the advantageous class, every step taken in order to have the symbolic capital requires imitation of the practices of this class and in this way the system, especially the education system, is reproduced. In this sense, education has an important role in the point of reproduction and legitimization. The role of education also can be summarized as follows; through family education, the habitus that the family has acquired from the existing system reaches the individual and the individual completes the education life with this habitus which is also the basis of school experience. Both the knowledge obtained from the habitus through his/her family and education guides the individual's after-school experiences. This habitus which will be transmitted to his/her child when she/he begin to work consists largely of experiences gained through the family and educational institutions. Individuals who cannot be well educated or never be educated will always have a secondary position in the economic sense, because they cannot have advantageous class practices and general symbolic capital. Thus, education that shapes cultural capital through symbolic violence in favor of advantageous class contributes to the determination of economic capital.

Symbolic violence is neither an influence process nor a wide manipulation. It is a collective belief that helps to preserve social hierarchies. Language is the most important means of internalizing symbolic violence. Research on discriminations in education and on the contributions of ethnic gaps and families (Bernstein, 1975; Hoff, 2003) suggest that language 
used at home is the most important factor causing the educational gap. Parents of lower socioeconomic class are less able to speak and read with their children than upper socio-economic parents. The differences in the attitudes of the parents directly affect children's vocabulary.

Compared with upper socio-economic status parents, lower socio-economic status parents are using a harder, more authoritarian form of child rearing, which indicates the lack of reasoning with their children about the consequences of physical punishment and behavior. Such child rearing practices are linked to the less-competent social and emotional development of children and adolescents (Hoff, 2003). According to theory, the characteristics of parents' job-profession can affect children through home learning environment, and the parents who have lower cognitive skills are less cognitively encourage home learning environment (Menaghan ve Parcel, 1991).

While the children in lower socio-economic status who participated to the research say that the time they share with their parents is limited, they are unaware of what they can do in this regard. They were asked what they have done with their parents when they have leisure time and have opportunities, and most of them answered such as, "we watch TV", "we watch competition programs", "we go to the shopping center". When the same questions were asked to children in upper socio-economic status, answers such as "we go to theater", "we read book", "we visit museum" or "we eat out and we chat" were gotten. Moreover, the vocabulary that children of different socio-economic classes differs in terms of slang use or sexist elements.

The findings of this research supports the argument that the education is influential in the understanding of social realities of children and that the education shape their perceptions and by this way, legitimize and reproduce the social and gender inequalities. This way of thinking and perception internalized by the children is not limited to educational subjects and this can be understood from the overlapping of interpretations about the whole life and education. 
The main interest of this research lies in highlighting the complex links between gender socialization, a vector of social inequalities, and the establishment of differentiated school experiences. Thus, we can affirm the existence of a gender that would have a direct and unidirectional effect on the orientation and educational pathways of girls and boys. This multifaceted, sometimes conflictual, influence is mediated by the activity of the young child, who, from an early age, appropriates these different stereotypes during his identity construction, and more particularly during the development of his sexual identity. Thus, from the early ages, through the differentiated representations of the education system, girls and boys, in a relation to the specific school, are intimately linked to the gender of the child, to the gender roles conveyed by the socialization of the gender and the construction of gender identity at work during this period of development

\section{Conclusion}

These results show the importance of the relationship to the gender that the child will develop in his living environments. From an early age, the child seeks to understand his membership of a sex group and the roles that are attached to it, this activity of meaning is not reduced to a mere internalization of stereotypes, because it uses different socialization processes. In this way, the importance of a pedagogy fostering a "culture of equality for girls and boys" can also be seen in secondary school, for example by promoting the access of children of both sexes to discovery and the practice of activities (play, sports, etc.) usually aimed at girls or boys. Today this overlap makes the social roles of students effective which are shaped in the process of education in maintaining the continuity of social inequalities.

Sexual stereotypes thus present a double threat: they can become discriminatory (they result in treating or judging people in a less favorable way according to their gender), they are 
prescriptive (they function as norms) and descriptive (they show everyone the behavior to adopt). The school, by its current missions, is not a simple place of transmission of knowledge, it is also a place of learning of sexual behaviors fixed in the representations that our society makes of the role of each according to its sex: The school also learns to be a woman or a man. This value system is part of the hidden curriculum that children integrate without being part of an explicit pedagogical project

So, the model of sex ratio that is implemented in the school system is a model similar to that which exists in the rest of society and it's hard to say that the school is ahead of the family or business. At the same time, this model has all the ambiguity of social sex relations in the society: they are still massively unequal but there are evolutions, transformations and some advances. Some girls, some boys transgress stereotypes, girls do choice of so-called "nontraditional" sectors; of even some boys resist the pressures very strong that push them towards scientific or technical orientations and choose literary orientations. But we are far still a true egalitarian education between girls and boys

\section{References}

Ayral S. (2011). La Fabrique des garçons : sanctions et genre au collège, Paris : PUF.

Baudelot, C. \& Establet, R. (1971). L'école capitaliste en France, Paris: Maspero

Baudelot, C. \& Establet, R. (2002). Allez les filles ! Paris : Le Seuil

Becker, G. S. (1975). Human capital. New York: National Bureau of Economic Research.

Bernstein, B. (1975). Langage et classes sociales. Les codes socio-linguistique et contrôle social, Paris: Edition de Minuit.

Boissieu de, C. (2009). Sexes et genres à l'école maternelle : Un essai de modélisation du concept de genre scolaire. Recherches et éducations, 2, 23-43.

Bourdieu, P. (1979a). Les trois états du capital culturel. Actes de la recherche en sciences sociales, Volume 30, Numéro 1, 3-6 
Bourdieu, P. (1984). Questions de sociologie. Paris: Minuit

Bourdieu, P. (1994) Raisons pratiques: sur la théorie de l'action, Paris: Seuil.

Bourdieu, P. \& Passeron, J-C. (1964). Les Héritiers. Les étudiants et la culture, Paris: Edition de Minuit.

Bourdieu, P. \& Passeron, J-C. (1970). La Reproduction: Éléments d'une théorie du système d'enseignement, Paris: Edition de Minuit.

Bowles, S. \& Gintis. H.(1976). Schooling in Capitalist America: Education Reform and the Contradictions of Economic Life. New York: Basic Books.

Duru-Bellat Marie (1995). Garçons et filles à l'école de la différence. Paris : La Découverte.

Hoff, E. (2003). The specificity of environmental influence: Socioeconomic status affects early vocabulary development via maternal speech, Child Development, 74, 1368-1378.

Meder, M. \& Çeğin, G. (2011). Bourdieu 'eü Okumak: Post-Pozitivist Bir Sosyolojinin İmkânı Üzerine, Gaziantep Üniversitesi Sosyal Bilimler Dergisi), 10(1), 233 - 256.

Menaghan, E. G. \& Parcel, T. L. (1991). Social sources of change in children's home environments: The effects of parental occupational experiences and family conditions, Journal of Marriage and the Family, 57, 69-94.

Mosconi, N. (1989). La Mixité dans l'enseignement secondaire: un faux-semblant?, Paris, PUF

Zaidman, C. (1996). La Mixité à l'école primaire, Paris, L'Harmattan. 


\title{
A COUNTER LANGUAGE: USE OF HUMOUR IN WOMEN'S MARCHES IN TURKEY
}

\author{
Fezarenç VARAN ${ }^{1}$
}

\begin{abstract}
Varan argues that the use of humour as a tool of protestation is a hooksian way of creating a place and a language of resistance. It is a direct example of a person placing her/himself on the margin and creating a counter language against the oppression. It is the anti-depressant and a place of possibilities, therefore it holds the potential of recovery and healing. Humour is a place where mockery, irony and sarcasm creates a milieu of ridicule, which unarms the classical political subject and undermine the colonial, oppressor, sexist rhetoric. Along with the global movements since 1990's, Women's Marches are such critical protests that the protestors are using humour and mockery in their banners and slogans to create places of discussion and resistance where women-humour relationship is a margin-center relationship. Three different strategies are explained in the paper, which are used in the banners.

One of the strategies used in the protests is the embracement of the humiliation words or words having sexist references in order to undermine the sexist values of them and to unarm the sexist rhetoric.

Another strategy is that talking about women's sexuality and women's biology in order to normalize them, where speaking about them is not welcomed in the current sexist culture. An additional strategy used in the marches is mocking about the acts that mostly performed by women and creating a place where we can discuss the gender-related actions.
\end{abstract}

Keywords: Humour; Social Movements; Women's Marches; Feminism; Gender

\footnotetext{
${ }^{1}$ Istanbul Technical University, Department of Architecture. fezarenc@gmail.com
} 


\section{Introduction}

After the 1990's, humour has been an important, non-traditional element in protests around the world (Deren, 2014). The use of humour and irony created a passive way of act in such a way that it unarms the classical political subject and creates a sympathy for the protestors. It is the powerless power (Critchley, 2007) where the creation of new possibilities of resistance is possible in a hooksian perspective. This article focuses on the analysis of humour used as a way of protesting in terms of bell hooks' theory of politics of location and Critchley's suggestions on humour based on Freud as a way of resistance by giving the examples of humour used in Women's Marches in the public sphere.

\section{How to Create a Counter Language?}

According to bell hooks (2000), by moving out and changing our location, we are moving in shifting relations of power, gender, race and class. While we confront the continuously changing lifestyles and perspectives, we face different nexuses. It is critical in hooks' writings that in this process of motion, how one is positioning her/himself is crucial for the reason that this positioning is a political gesture. Since the relations are changing in terms of power, gender, race and class, the relationship and the identity of the oppressor and the oppressed are also changing. One can act in the dominant way of the oppressor and adopt the language and the perspective of the totalitarian practices or one can response to this situation standing up against the colonizing mentality by creating a place of resistance and a counter language to transform the current milieu. She emphasizes that this choice is vital and creating this opposition is possible by placing ourselves on the margin rather than the center. 
Margin is a place, which is located on the outside of the center but still a part of the whole, in terms of hooks (2000). She defines margin as a place of possibilities, as a place that embracing diversities therefore it creates an environment where people are able to create alternatives of lives and languages, a place of resistance. In this place of resistance, it is possible to create alternative ways of acting against the oppression. In hooks' point of view, taking a stand and resisting is crucial to those who are suffering from political abuse, colonization and domination in everyday life.

The core method of the hooks' theory of margin and center relies on the principle of one's locating her/himself on the margin rather than the center (2000). hooks is taking a stand against the oppression, colonization mentality and she finds the solution in a space that the resistance is possible: on the margin. She describes margin as a place of possibilities rather than the place of the oppressor: center. The center is not a place that different identities, perspectives and languages are welcomed since it stands for the place of oppressors and colonizers who have the power of domination and suppression. She finds the solution; not using the ways of the center but by creating anti-colonial ways of transforming the society's structure.

In the article "From Margin to Center", hooks focuses on the language as a place of struggle (2000). She describes this struggle by giving examples from her childhood and adulthood years. She emphasizes that using the language of the oppressor -which is free from diversities- enables us to get into university, go to job interviews, to have a career and makes us adapted to the colonizing system and being assimilated by it. The public speech that people use in the academy or in business is a common language, which is purified from the multiplicity of society. This common language is the mainstream voice of the oppressor. The use of this common, whitewashed and purified language is also a way of sustaining the colonization and the oppression. Therefore, the use of private and personal expressions in public speech is not 
welcomed by the oppressor. Language is a place that we should question ourselves whether we choose to use the oppressor's language or the language of the resistance. hooks believes that creating a counter language is possible, where the language is not limiting, dominating or holding us back. She suggests that revolting against the oppressor's language can be achieved by using our own voices, scents and motives of our culture. By not speaking the oppressor's language, one is inviting the audience to meet on the margin rather than the center.

I argue that one of the powerful ways of creating this counter language deriving from the multiplicity rather than the oppressor's colonizing mentality, is using humour as in the way of Simon Critchley suggests in his theory of politics of resistance (2007). To describe how humour can be used as a counter language; first I will explain the nature of humour by using Freud's terms and then I will base using humour in Critchley's politics of resistance through this perspective.

\section{Humour as an Anti-Depressant}

According to Freud (cited in Critchley, 2007), there is there two main responses to depression, an emotional struggle, which is created by the tension between ego and super-ego. First response is mania, and the other is melancholia which are pathologic emotional responses and opposite appearances of the same complex. Freud suggests that there is an alternate, third response to depression, which is the use of humour. Where in the case of melancholia, super ego oppresses ego. On the contrary, mania is the epiphany that person is in full denial of the current situation of her/himself. In response to these two emotional states, Freud suggest that humour might be a healthier response to depression, an anti-depressant (1985). While using humour, super-ego does not oppress ego, but person keeps a distance between ego and super ego in order to take her/himself lightly. In this case, the person is in a more realistic and 
conscious state where the person is not in denial like in the case of mania or in deep grief like in the other case, melancholia. Now, the person is able to make fun of her/himself in a gentle and clear way. In his book Infinitely Demanding, Critchley argues that humour is a way of act which reminds people their modesty and human nature by this Freudian perspective (2007).

Humour is a good example of hooks' counter voice which comes out of a struggle in the language. To create a language against the colonizing oppressor's, or in the way of Critchley uses, against the classical political subject; using humour is a modest way of acting rather than the dominant way. Humour is opposing the oppressor's language. As Critchley suggests, the classical political subject is male-dominant and lacking humour. It uses a tragic, heroic, promethean language which is violent, vindictive, very serious and naturally oppressive, therefore it creates a political culture which is lacking humour and fun. Using humour creates a distance between the dominant political rhetoric and the person, and it allows person to perceive the situation in a more modest way (2007). I suggest that this distance directly positions oneself on the margin since this distancing creates a space where there are more creativity and possibility since humour puts us in a lighter and humane way of thinking rather than the oppressor's tragic-heroic way (Critchley, 2007). According to Critchley (2007), "humour is a powerless power" which is a comic self-aware, passive act rather than the oppressor's language. It is an alternative response, unlike the melancholic response similar to serious, heroic, tragic political subject's, or unlike mania where the person is in a denial of the situation. Humour works as an anti-depressant against the oppression in Freudian terms and is offering new ways of resistance as Critchley suggests. With the use of humour, people are invited to the action with the creation of sympathy, laughter and joy in a modest, not tragic way. Humour works as a bonding element without the concern of being extremists, being heroic and tragic. Along with the fun elements of humour, it disarms the oppressors' sexist rhetoric and 
physical power in a more passive way. The sexist language and the physical power loses its power in the presence of humour, since there is nothing to interfere with physical power or violence.

I argue that the use of humour in public sphere is a place where we can position ourselves on the margin, produce a counter language and speaking with our voices as a hooksian way of resistance.

\section{Humour and Women}

Women were kept out from many areas of humour in public sphere until the recent past (Shifman \& Lemish, 2010). There still is a common belief that men are funnier than women, women are not capable of making humour or cannot be comedians, where we can still observe that most of the comedians are men. On the contrary, and despite this gender asymmetry, we can observe that women are entering more and more in the fields of humour and the belief that women are not funny is being broken. From the historical point of view and for a global comparison; just after the second wave feminism, the women stand-up shows became places of expressing the social change of empowering women in US (Lavin, 2004). In this growing feminist culture in comedy, comedians started to talk, joke and mock about everyday sexism and gender inequality in their stand-up shows. According to Nancy Walker, this creation of humour by women comedians created a place of discussion in a sexist environment where women were supposed to appraise humour created by men (1988). Women's humour was also different mainly with its subjects and themes but also with the form of it, where women had different relationships with decision-making processes, authority and the changing social environment rather than men's relationship (Walker, 1988). In a hooksian perspective, these comedians were positioning themselves on the margin in terms of their relationship with sexist 
power relations where they were creating their own culture of mockery instead of sustaining the existing humour culture. By doing that, they were creating hooksian places of discussion and resistance.

As a local comparison, the relationship of women and humour in Turkey is not the same with US. The mainstream mediums of humour are different then US, where in Turkey, humour magazines were one of the popular and important mediums of humour in the same period, 1980's. After the 1980's and the late emergence of the second wave feminism in Turkey, there were few women in humour. A caricaturist who has worked in many humour magazines, Kemal Kenan Ergen, explains the environment at the magazine's office as follows:

We used to work in one room, all of us. That was the system, initiated by Oğuz Aral in Girgır. We had to come to the magazine office certain days of the week and stay awake the whole night. Because there were very few women writers and we were 25 men, it was mostly a fun men's chitchat (interviewed by Ĕgilmezler, 2014).

Many writers and illustrators in humour magazines as well as the comedians in Turkish $\mathrm{TV}$, cabarets and theatres were defining the humour as a rebellious act, an expression of resistance, an opposition and a critical act by its nature (Eğilmezler, 2014). Despite this milieu of contrariety against the oppression, most of these comedians and caricaturists were men. From 1980 's to today's world, the gender gap in the sectors of comedy and humour is getting smaller however still women comedians are facing with prejudices because of their sexes and the legacy of the past culture where women supposed to admire men's jokes, where there was this belief that women cannot be funny.

In these manners, the relationship of women and humour is a direct, critical margincenter relationship by its nature where one's positioning him/herself is crucial. The use of humour in public sphere by women is an act of creating an area of resistance against the sexist 
oppression in and out of the comedy. Therefore, Women's Marches are critical spaces in this context for creating humour. This article focuses on humour practiced in public space, specifically in Women's March in Turkey.

\section{Humour in Women's Marches}

Starting from the 1990's, using humour has been one of the typical behaviours in the global protests (Deren, 2014). Along with the global movements like Occupy Wall Street in US, Otpor in Serbia, Zapatistas in Mexico and Gezi in Turkey, Women's Marches are also places where people are using humour, creativity and fun elements as ways of protesting. The protestors are using mockery, irony and sarcasm in their banners, slogans and graffitis for making fun of the sexist and oppressive power relations, and they are creating new ways of resistance to transform the current milieu with the help of humorous language.

One of the strategies that the protestors using is embracing the words which are used as humiliation or have sexist references and undermining the sexist values of them and even assigning them positive meanings. As an example, by owning and using the words like 'slut', 'whore', 'strumpet', the protestors are disarming these words from their sexist references where they are no longer functioning as humiliation tools. Banners ${ }^{1}$ like 'We Are Lilith's Sluts'2 or 'Whore' ${ }^{3}$ with an arrow on the banner which is pointing the protestor are specific examples of protestors using this strategy of disarming current sexist rhetoric.

\footnotetext{
${ }^{1}$ All of the banners are translated by the author.

2Original banner "Lilith'in Sürtükleriyiz" is available at https://bianet.org/biamag/print/195524-pankartlarimizinfeminizmle-alakasi-var-hem-de-cok/ (Date accessed October 2019).

3 Original banner "Orospu" is available at https://www.gazeteduvar.com.tr/forum/2019/03/28/kadincinayetlerinde-orospu-panik-savunmalar-ve-omer-arbek-uzerine/ (Date accessed October 2019).
} 
The same strategy is also used with the words, which are commonly used in sexist contexts. By using the words like 'chaste' and 'namus' 1 in absurd ways in banners, the protestors are creating a language without using the narrow sexist contexts of these words. For instance, in the banners 'Right When I'm About To Be Chaste, I Cannot Stop Laughing'2 or 'Honour? I Can't Stop Staining It!' ${ }^{3}$ there is a plot twist where these strong words suddenly lose their serious, sexist contexts. In accordance with Critchley's suggestions, there is a huge distance between these serious, tragic, humour-lacking notions and this culture of fun and laughter, which the protestors are creating. They become pointless and useless with the help of absurdity, where the tools/words of controlling women sexuality are no longer functioning.

Another strategy is the use of words/images/phrases, which are not appropriate for women to use in public sphere. Where talking about women sexuality, menstrual cycle and women biology openly is not appropriate in Turkish culture, using these taboo words in banners and graffitis in humorous ways are passive yet effective ways of creating a counter language and normalizing women's body and sexuality. In the banners 'Minimum Three Orgasms a Week'4, 'We Want Vibrator, Not Dictator' ${ }^{5}$ and 'Love Nature, Touch Clitoris' ${ }^{\prime 6}$, along with the political and environmentalist statements, there is again a plot twist where the protestors are using taboo

\footnotetext{
${ }^{1}$ The word 'namus' in Turkish can be translated as 'honour' yet 'namus' is usually associated with the women's virginity or women's sexual acts according to the social ethical norms in Turkey.

${ }^{2}$ Original banner "Tam İffetli Olucam, Bi Gülme Geliyor!” is available at http://bianet.org/bianet/print/161886kadikoy-de-tacize-karsi-ses-cikardilar/ (Date accessed October 2019).

${ }^{3}$ Original banner "Namus mu? Kirletmeden duramam!" is available at https://onedio.com/haber/8-mart-dunyakadinlar-gunu-gece-yuruyusunde-kadinlardan-37-pankart-689149/ (Date accessed October 2019).

${ }^{4}$ Original banner "Haftada En Az 3 Orgazm" is available at http://sendika63.org/2018/03/orgazmli-vibratorlusurtuklu-8-mart-sulandiriliyor-mu-ebru-pektas-ileri-haber-480149/ (Date accessed October 2019).

${ }^{5}$ It is ironic that this banner was made news with the headline "Immoral Banner from Radicals in Women's March". Original banner "Diktatör Değil Vibratör İstiyoruz" is available at https://www.superhaber.tv/kadinyuruyusunde-radikallerden-ahlaksiz-pankart-haber-181083/ (Date accessed October 2019).

6 Original banner "Yeşili Sev Klitorisi Okşa" is available at https://m.bianet.org/biamag/toplumsalcinsiyet/195524-pankartlarimizin-feminizmle-alakasi-var-hem-de-cok/ (Date accessed October 2019).
} 
words in Turkish culture. This openly use of 'vibrator' and 'clitoris' is creating a space where we can openly talk about women sexuality and normalize it.

An additional strategy is that making fun of the acts, which are mostly associated with women like doing housework, doing the dishes, waxing, make up etc. In the banners 'Let the Martians Do the Dishes', 'Let the House Get Messy', 'Your Father Can Wax, We Are Doing Self-Defence, ${ }^{3}$, the protestors are creating places of discussion and resistance with the use of mockery and irony. This space of resistance is not aggressive yet joyous, fun and inviting where the protestors are creating a bonding and sympathetic environment.

I believe that these strategies are creating a place of possibilities where one can speak their own voice. These are very distinctive examples of where the creation of a counter language against the oppressor comes out with the use of humour creatively as a powerless power. It comes out from the margin, where protestors speak and create their own voice.

\section{Conclusion}

In these examples, we can see the use of creative, passive and humorous ways of protesting, which are actual examples of resisting the oppression. By the use of humour, people are invited to the action without concern of being extremists. Humour also works as a bonding element with the creation of sympathy and laughter. And beyond the fun elements of humour,

\footnotetext{
${ }^{1}$ Original banner "Ev İşlerini Marslılar Yapsın" is available on http://www.milliyet.com.tr/samsun-da-dunyakadinlar-gunu-yuruyusu-samsun-yerelfotogaleri-13733703/ . (Date accessed October 2019).

${ }^{2}$ This banner is funnier in Turkish where the protestor is using slang language. Original banner "Birak Evi Bok Götürsün" is available http://www.sosyalistfeministkolektif.org/feminist-politika/buelten-mutfak-cad-lar/birakinevi-bok-gotursun/ . (Date accessed October 2019).

${ }^{3}$ Original banner "Ağdayı Baban Yapsın Biz Özsavunma Yapıyoz" is available on https://onedio.com/haber/8mart-dunya-kadinlar-gunu-gece-yuruyusunde-kadinlardan-37-pankart-689149/. (Date accessed October 2019).
} 
the use of it as a counter language disarms the oppressors sexist rhetoric, and physical power. We can see that police violence loses its point where there is nothing to suppress with physical interference, and also the sexist language loses its point where its words are losing their bases. Humour is a hooksian example of resistence where she defends in her theory of margin and center. It is the place of possibilities and a counter language. The use of humour as protestation in these movements is only possible by protestors locating themselves on the margin. These movements are hooksian places of resistance, where diversities are welcomed and where people can speak up for themselves, who are suffering from oppression and colonization. Humour, is a place where the oppressor's language is not welcomed in the global social movements. The use of mockery, irony and sarcasm becomes the antidepressant of the oppression in a Freudian way, therefore it holds the possibility of recovery and healing, rather than the classical political subject, which is tragic, heroic, and lacking humour.

\section{References}

Deren Van Het Hof, S. (2014). 'Political Potential of Sarcasm: Cynicism in Civil Resentment'. In Yalçıntaş, A. (Ed.) Creativity and Humour in Occupy Movements: Intellectual Disobedience in Turkey and Beyond. London: Palgrave Macmillan.

Eğilmezler Boylan, M. (2015). Humorists' Narratives On Social Role of Humor In Turkey In a Historical Perspective (Doctoral dissertation). Middle East Technical University, Ankara, Turkey.

hooks, b. (2000). Choosing the Margin as a Space of Radical Openness. J. Rendell (Ed), Gender Space Architecture: An Interdisciplinary Introduction. London: Routhledge.

Critchley, S. (2007). Infinitely Demanding: Ethics of Commitment, Politics of Resistance. London: Verso.

Freud, S. (1985). 'Humour', Art and literature, ed. A Dickson. London: Penguin.

Lavin, S. (2004). Women and comedy in solo performance: Phyllis Diller, Lily Tomlin and Roseanne. New York: Routledge.

Shifman, L., Lemish, D. (2010). Between Feminism And Fun(Ny)Mism. Information, Communication \& Society, 13:6, 870-891, doi: 10.1080/13691180903490560 
W, Nancy. (1988). A Very Serious Thing: Women's Humor and American Culture. Minneapolis: University of Minnesota Press.

Yalcintas, A. (2014). 'Intellectual Disobedience in Turkey'. In A. Yalcintas (Ed.) Creativity and Humour in Occupy Movements: Intellectual Disobedience in Turkey and Beyond, pp. 629, London: Palgrave Macmillan. 


\title{
AN ANALYSIS OF GENDERING OF SPACE IN HISTORICAL HOSPITALS OF ANATOLIA
}

\author{
Gülşen DİŞLi' ${ }^{1}$
}

\begin{abstract}
Medical ethics, clinical practices, as well as privacy considerations affected the gender-space relationship in spaces of healing. Researchers to date have been analysed the historical hospitals of Anatolia in terms of their architecture, planning, art history, history of medicine, and even in terms of their functional systems, but not yet regarding their gendered space segregation. There are also limited studies related to the gender, religion, and secularism in historical hospitals outside of Anatolia. Hence, in this paper, historical hospitals of Anatolia have been chosen as case studies and analysed from the point of gendered perspective including how privacy, religion, culture, and gender issues shaped their architecture and planning. In Ottoman Empire, it is known that among the palace elites, there was limited access of women patients to the male doctors, but documented evidence of female attendants being employed in Ottoman hospitals belongs to later periods. In Ottoman dynasty there were also female patrons constructed hospitals for women and for the general public, demonstrating the power and status of women in the Ottoman palace. In addition, based on travellers' accounts, old drawings, gravures, and archival resources, it is understood that there were separate units for women in Anatolian historical hospital. Those units included the patients' rooms, wards, latrines, and even courtyards.

The research showed that in Anatolian hospitals as the spaces for physical healing and medical training, gendered-space segregation have been acknowledged, at least to some extent in some certain space arrangements.
\end{abstract}

Keywords: Gendered Space, Gendered Architecture, Segregation, Historic Hospitals, Anatolia

\footnotetext{
1 Assoc. Prof. Dr., Necmettin Erbakan University, Faculty of Engineering \& Architecture, Department of Architecture, Koycegiz Campus, Konya, Turkey, disli001@umn.edu

209
} 


\section{Introduction}

Historical hospitals in Anatolia were places of healing for all kind of patients and were spaces of education for medicine students. Specialists in historic hospitals have studied the issue mostly through the architectural, art history, or historical approach (Cantay, 1992; Terzioğlu, 1999; Y1lmaz, 2007; Kahya ve Erdemir, 2000; Bolak, 1950; Kılıç, 2012). There are also detailed studies related to their functional systems such as heating, waste and clean water, refrigeration, ventilation, and illumination systems (Disli, 2018: 174-185; Disli \& Ozcan, 2016: 183-200; Dişli, 2015: 253-276; Disli, 2014: 45-51; Disli \& Ozcan, 2014: 169-177; Ozcan \& Disli, 2014: 1015-1021). Yet, despite their obvious significance, gender studies, gendered architecture, and gendering of space in historic hospital buildings remain a relatively neglected area of research. Similarly, Green $(2003,358)$ asserts that in Islamic world, gender and women issues in history of medicine have hardly figured. Hence, this study looks at whether gender segregation has been applied during medical practices, namely between patient and healer relations, and whether gender was an important factor in architectural space organization of historic hospitals in Anatolia, especially in Seljuk and Ottoman periods. Such a study, evaluating the historic hospitals within gender and space perspective, is important to help address the gap in literature by reporting results of archival, and historic research, as well as by means of travellers' accounts, and case study evaluations.

Miri Shefer-Mossensohn (2011: 281-312), a prominent scholar in Muslim medicine, health, and wellbeing, in her article examines the very relations between patient and healer in Ottoman imperial harem from the gender point of view. Her research reveals that Ottoman elite women in harem had limited access to treatment by male physicians. Outside the palace on the other hand, gender aspects of healing were less concerned by non-elite Ottomans (SheferMossensohn, 2011:308). Yet, chief male physicians could treat the female patients in harem, 
but with a thin cover over them, escorted by a concubine/cariye (Bayat, 1999: 7). Dengiz's (2001) unpublished master's thesis also provides important knowledge on the field of gendered space in built environment, especially in Ottoman house architecture. The study deals with the boundaries of the house and its relation with the body and gaze of the women.

Historic hospitals were generally built by the sultans, their wifes, daughters, or by rich people in order to serve for the homeless, poor, lonely patients, merchants, and travellers. In history, the hospitals constructed by women builders are as follows (Kadığlu \& Kadığlu, 2008: 89-104); Kayseri Gevher Nesibe Hospital (1205-6), Divriği Turan Melek Hospital (1228), Amasya Amber bin Abdullah Hospital (1308-9), Manisa Hafsa Sultan Hospital (1539), İstanbul Haseki Sultan Hospital (1550-57), İstanbul Atik Valide Hospital (1579), and Bezm-i Alem Valide Sultan Hospital (1843). As understood from the Archives of Topkap1 Palace Museum, b. 4172, f. 5b dated May 1705; Imperial women of the palace not only funded for the construction of new hospitals but also funded hospices, and donated money and utensils such as blanket, and fur for the sick palace servants (Shefer, 2005: 339-340). Yet, in old times, in Anatolia, it was common to look after the patients at their homes. Only the insane and the patients with plague were generally hospitalized, and the rest were looked after at their homes by their mothers, wives, sisters, or servants or a physician was called to home instead of treatment at the hospital (Altıntaş, 2015: 42-43). For instance, according to an archival register (Konya Şer'i Sicili) dated 1614, in Konya Hospital, it was come into question to heal an insane women at the hospital, but her son decided to take care of her mother at home instead of in the hospital (Altıntaş, 2015: 42-43).

Colored illustrations of Cerrahiyyet'ül Haniyye written by Şerefeddin Sabuncuoğlu, a famous surgeon in the $15^{\text {th }}$ century, also verify this situation that, only a few female patients were illustrated in this book compared to the male patients (Uzel, 1992). Similarly, in another 
book called as Tashrih Badan al-Insan written ca. in 1390 in Iran by Mansur b. Muhammad b. Ahmad, a pregnant women miniature was depicted (Bayat, 2006: 3) (Figure 1).
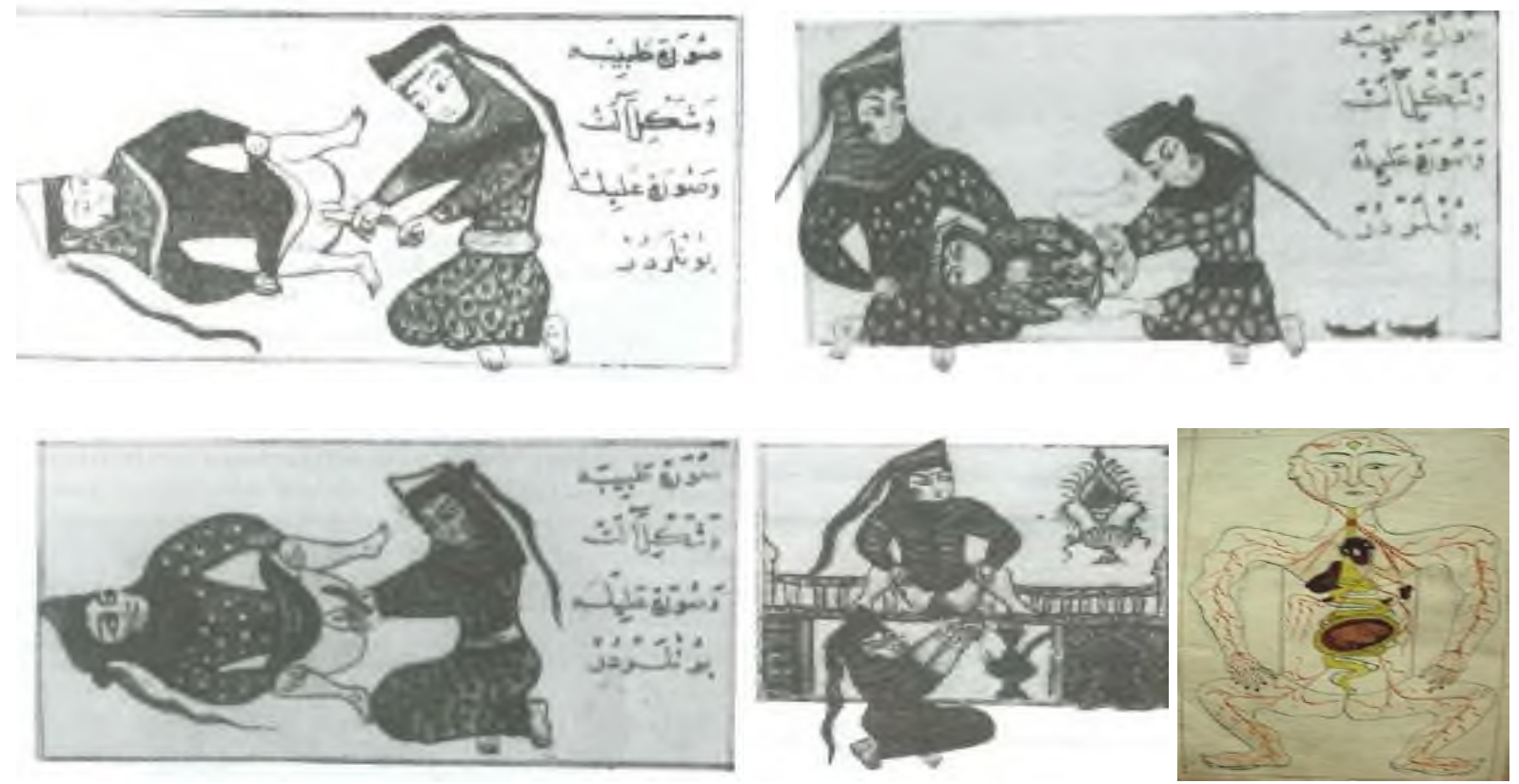

Figure 1: Examples from illustrations of female patients in the book Cerrahiyyet'ül Haniyye \& depiction of a pregnant women (Source: Uzel, 1992: 300-302, 309; Bayat, 2006: 3).

\section{Gendered Space Analysis in Historic Hospitals of Anatolia}

When waqf deeds/documents of Seljuk and Ottoman period hospitals of Anatolia have been examined in detail, the picture that emerges reveals that these documents do not stress, even comment on any kind of gender discrimination of patients admitted into the hospitals during medical practices. Yet, hospital officers mentioned in those waqf deeds give some information about the gender segregation in medical treatments. For instance, both male and female nurses were counted among the officers working under the order of physicians, among them female nurses were called as Nigehban-ı Hastegan, and male nurses were called as bimarcl/bimaran/bimardar, and even during examination of female corpses female servants were allocated (Çetin 2006; Köker, 1991: 23-47; Köker, 1991: 27; Yıldırım, 2010: 24). However, in Ottoman hospitals, moral code of the society necessitated the segregation of the 
sexes, such that especially, treatment of female patients by male doctors was considered indecent by deontologists (Shefer-Mossensohn, 2003: 131-2), or a Muslim doctor was preferred for the treatment of females (Karaaslan, 2012: 538). Dols (1981: 3, 11) similarly states that, considering the special status of Muslim women in Islamic societies, their families generally take care for mentally ill women patients at home, unless they did not cause serious danger, and when hospitalized there were separate wards for male and female patients. He explaines the very reasons of this situation with Qur'an and Islamic law (Dols, 1981: 11). From the accounts of Bobovi, a servant in Topkap 1 Palace in the $17^{\text {th }}$ century, it is understood that, male patients, on the other hand, could be treated by old female healers called as anne (Shefer-Mossensohn, 2003:131-2). Similarly, during the realm of Bayezid II, in Palace School Hospital (Enderun), three old women were allocated to care for young male patients (Kays11, 2006: 22-23) (Figure 2). However, in archival registers of Topkapı Palace, among chief physicians of Baslala Tower, female physicians were not mentioned (Bayat, 1999: 7).
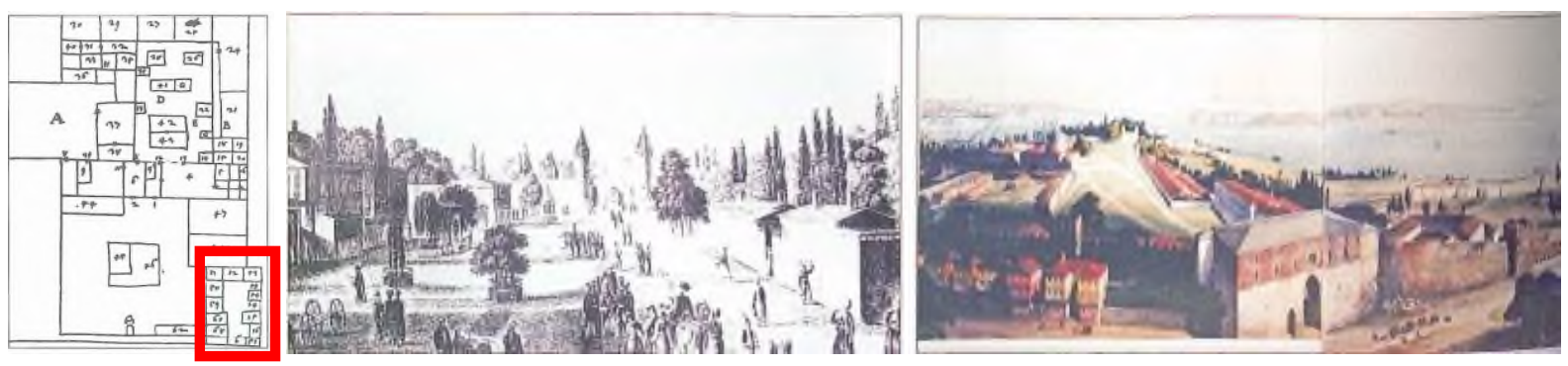

Figure 2: Plan drawing of Topkap Palace including Enderun Hospital (left), drawn by Bobovio in his book dated 1665. 50: Enderun Hospital, 51: Space for the administrative staff of the hospital, 52: Space for the old female nurses called as analar 53: Hospital belonging to Has Oda, 54 Hospital belonging to treasure house, 60: Entrance, 68: The bath of Enderun Hospital, and Enderun Hospital in Topkapı Palace (center-right), drawn by Melling and Fossati, respectively (Source: Terzioğlu, 1992: 177; Kılıç, 2015: 284).

In early Islam, on the other hand, during the Prophet's period women physicians/ healers were so common. For instance, Şifa binti Abdullah el-Kureyşiyye (620-640) had learned some treatment methods, especially treatment of skin disorders and had tought it to Hafsa Hatun, wife 
of the Prophet (Ağırakça, 2004: 79). Esma binti Umeys, Halide binti Enes, Şifa binti Abudallah, and Ümmü Sinan were among the other known female healers in that period. Similarly, Rufeyde el-Ensariyye is known to be the first female physician founding clearing field hospital in history of medicine (Terzioğlu, 1992: 163). In early Islam, during the Prophet's period, Umm Qatiya or Umm Sulaym were the other female healers providing medical care to his male companions, demonstrating the "medical contact between men and women in case of necessity" (Pormann, 2017: 658). In addition to female healers there were also female nurses, Rubeyye binti Muavvız, Leyla el-Gıfariyye, and Ümmü Umara being only some of them (Ağırakça, 2004: 79-80). In al-Dimnah Hospital dated $9^{\text {th }}$ century near to Great Mosque in Sudan, it is also known that Sudanese women served as nurses (Terzioğlu, 1970: 140). Kaysıl1 (2006: 51) claims that Turkish women started to work in hospitals only with the beginning of Balkan Wars, and it is considered to be the establishment of nursing profession of women in Turkey. Safiye Ali was the first Turkish women physician with medical training completed in Germany, and after graduation she opened her clinic in Istanbul in 1922 (Arda, 2009: 11). Before the beginning of the $20^{\text {th }}$ century there were traditional women healers, but they were started to be accepted to enter medicine schools not earlier than that date in Anatolia (Karaaslan, 2012: 538; Arda, 2009: 11). However, it is known that a famous female hernia surgeon called as "Küpeli Kızı Saliha Hatun" based in Uskudar, served both for male and female patients outside of hospitals even in 1621-25 (Çetin, 2006: 67; Taneli \& Şahin 2013: 98, 149). Similarly, in the $17^{\text {th }}$ century, in Anatolia there were also female vaccinators travelling around and variolate small kids (Kahya, 2000: 272) and in Anatolian Selçuk period, there was a women association called as Anadolu Bacılarl/Bacıyan-ı Rum founded as part of Ahi Community, and they also served for taking care of homeless and travellers (Sar1 ve Akgün, 2008: 1-24). As Y1ldırım (2010: 73, 76) stated, Ottomans inherited vaccination from Seljuks and vaccination 
was generally done by specialized women, since treatment of girls by male vaccinators was considered indecent.

Miri Shefer-Mossensohn (2003: 132) claims that, in historic hospitals of Ottomans, male and female patients could have different and/or special spaces/buildings for treatment. Accounts of Evliya Celebi, old drawings, and miniatures also suggest this situation. From those primary sources, segregation of spaces according to gender in historic hospitals of Anatolia has been acknowledged especially in patients' rooms, wards, hamams, and in service spaces such as toilets, and even in courtyards. Patients' rooms in historic hospitals were generally arranged as separate wards for male, female and non-muslim patients (Disli, 2014: 28). For instance, from the accounts of Evliya Celebi and by means of old drawings, it is possible to reveal that in Fatih Hospital in Istanbul, in Hafsa Sultan Hospital in Manisa and in Kalavun Hospital in Cairo, there were separate spaces for male and female patients (Kahraman and Dağlı, 2003: 276). As an instance, in old plan drawing dated 1911 in archives of Directorate General of Foundations (DGF) belonging to Hafsa Sultan Hospital, it is clear that different wards were allocated for different sexes (Figure 3). In this old drawing, two toilets, a fountain, a room for the warden, and a shared area for women have been identified in detail, and the ward on the left side of the entrance was specified to be women's ward/nisa koğuşu. Similarly, there were there more wards allocated for women built adjacent to the wall of women's courtyard. It is also known that in 1916 just before the closure of the hospital, one of the six wardens of the building was female (Altan, 2008: 61). From the accounts of Y1ldırım (2010: 67) related to Üsküdar Miskinler Tekkesi $\left(16^{\text {th }} \mathrm{cc}\right.$.) in Istanbul, it is also possible to get information about the furniture design of separate wards and cloths of male and female patients. For instance, in Miskinler Tekkesi, bed sheets were in blue color for women patients, and they wore baggy pants made of woven cloth. 


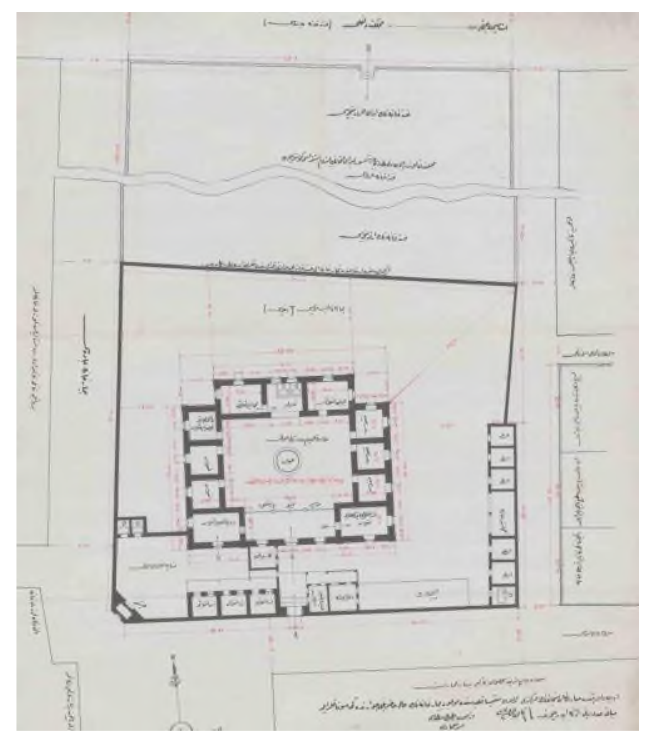

Figure 3. Plan drawing of Hafsa Sultan Hospital, dated 1911 (Source: Archives of DGF).

Similarly, Evliya Celebi describes the Fatih Hospital in Istanbul as a seventy-room, eighty-dome building with a separate hospital in a corner near the main building, dedicated solely for women and non-Muslim patients (Kahraman and Dağl1, 2003: 276).

Tschanz (2017: 441) similarly, claims that bimaristans were either served for men or women, or for both sexes, but in separate wings with duplicate facilities. Based on an old drawing dated 1826-27 by the French architect Pascal Costre, such a division can be clearly identified in Kalavun Maristan in Cairo, in which patients' rooms were separated according to their gender (Figure 4) (Terzioğlu, 1992: 168-170). Özdemir (2012: 49), likewise, states that in Seljuk period hospitals, the physicians visited and treated the male and female patients staying in different rooms/wards separated according to type of their illnesses in early mornings. To him (201: 86), in Amasya, Amber bin Abdullah Hospital a similar situation could have been applied, such that the building might have been planned in a symmetrical manner from the beginning in order for the treatment of male and female patients in the same building but in different separated wings located on the east and west side of the courtyard. Similarly, Bursa Hospital was enlarged in 1879 by the governor of the time Ahmet Vefik Pasha, thus it had the capacity to hospitalize 45 
male and 15 female patients. Later in 1913, separate wards were reserved for male and female patients, the east wing belonging to the women (Erer, 2010: 247-248) (Figure 5).
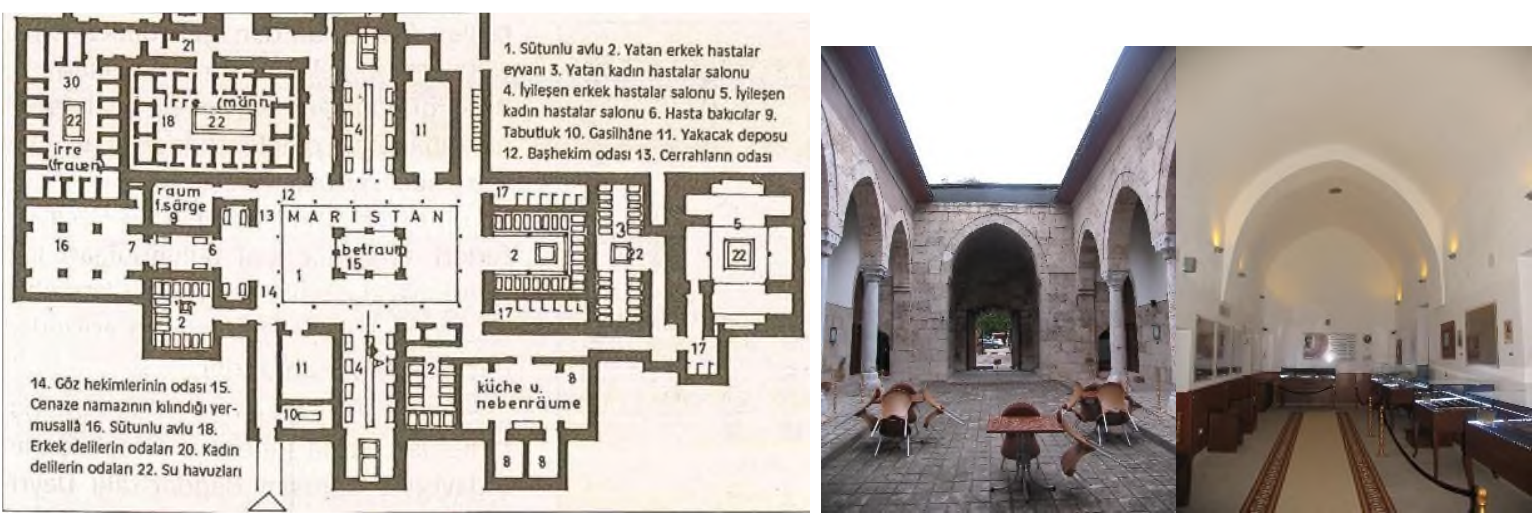

Figure 4. Plan drawing of Kalavun Maristan in Cairo (left) (Source: Terzioğlu, 1992: 168), (center-right) a view from the courtyard and one of the wings of Amasya Amber bin Abdullah Hospital (Source: Archives of the Author, 2011).

Besides different wards, different barracks were also observable for male and female patients in hospitals. For instance in 1910, a temporary cholera hospital was established in Demirkap1, Gülhane with six temporary barracks, one of which was allocated only for female patients. (Yıldırım, 2010: 95). In Cemil Pasha Zeynep-Kâmil Hospital, on the other hand, instead of different barracks, different compartments for male and female patients were reserved on different floors. Treatment and operation rooms of male patients were planned at downstairs, and infectious diseases wards, operation room and surgery ward for female patients were located at the upper floor (Y1ldırım, 2010: 263-264). 

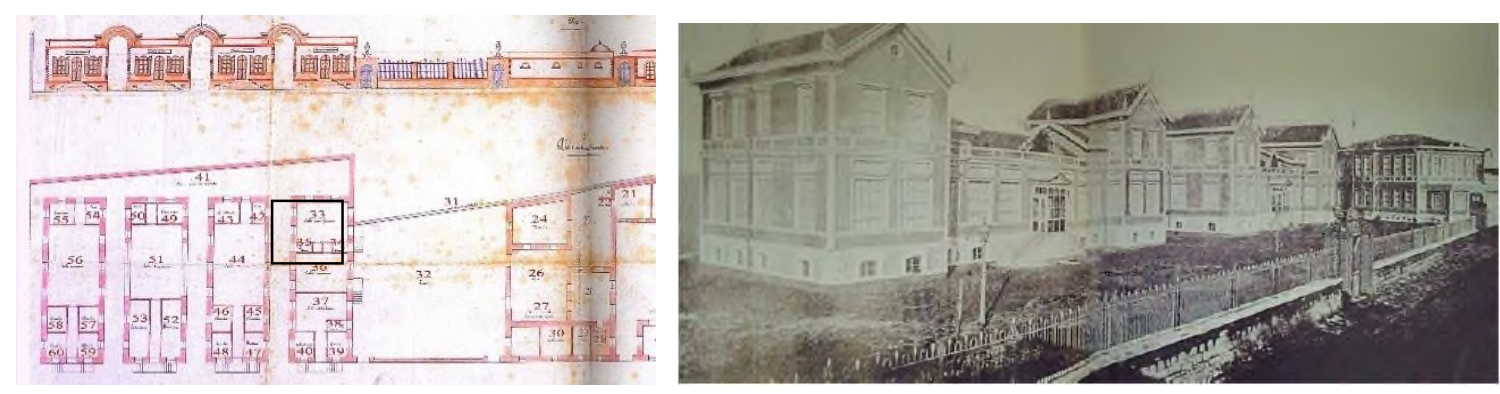

Figure 5: The Municipality Hospital in Baghdad, number 33 is women's ward (left), \&Ahmet Vefik Pasha/Bursa Government Hospital (right) (Source: Yllmaz, 2007: 2; Erer, 2010: 248).

In some other cases, gender division is applied on the whole hospital building, instead of creating different rooms, wings, wards, and courtyards for different sexes inside the same building. As an instance, in Ottoman Turkish Dictionary of Develioğlu, hospitals that served for the birth of poor women were called as darülvilade and clinics for gynaecological diseases were named as nisaiyye (Devellioğlu, 1997: 168, 840). Similarly, hospital of concubines in Topkap1 Palace (Cariyeler Hastanesi) was built in 1665 just for women living in the Palace. It had different sections such as wards, bath, laundry, kitchen, and gasilhane (Figure 6). It is also known that, in Eski Saray, similarly, there was a hospital just for concubines, with a developed women health organization, namely all the healers were women and organized in a hierarchical manner (K1lıç, 2015: 288-289). There are also historic hospitals in Anatolia which were first constructed for both sexes but later turned into a women hospital, partially or totally. For instance, though not built just for male of female patients at the beginning, in Atik Valide Hospital, guest house/ tabhane section of the mosque complex was allocated for women in 1899 (Dişli, 2016: 269; Saygılıgil-Gündüz, 1999: 30). Hospital and guest house sections were adjacent to each other with a bath, kitchen and a depot in between (Sayg1ligil-Gündüz, 1999: 129-133). In addition, during the epidemic cholera in 1910, separate quarantine parts, kitchen, operation rooms, laboratuary and policlinics were built for male and female patients in the hospital (Y1ldırım, 1994: 195). The Hospital was started to be used just for women in 1843 and 
only women patients were treated there (Taneli and Şahin, 2013: 17, 46) (Figure 7). Similarly, in the Almshouse/ Darülâceze dated 1896, two separate hospitals were constructed for different sexes (Y1ldirım, 2010: 257).

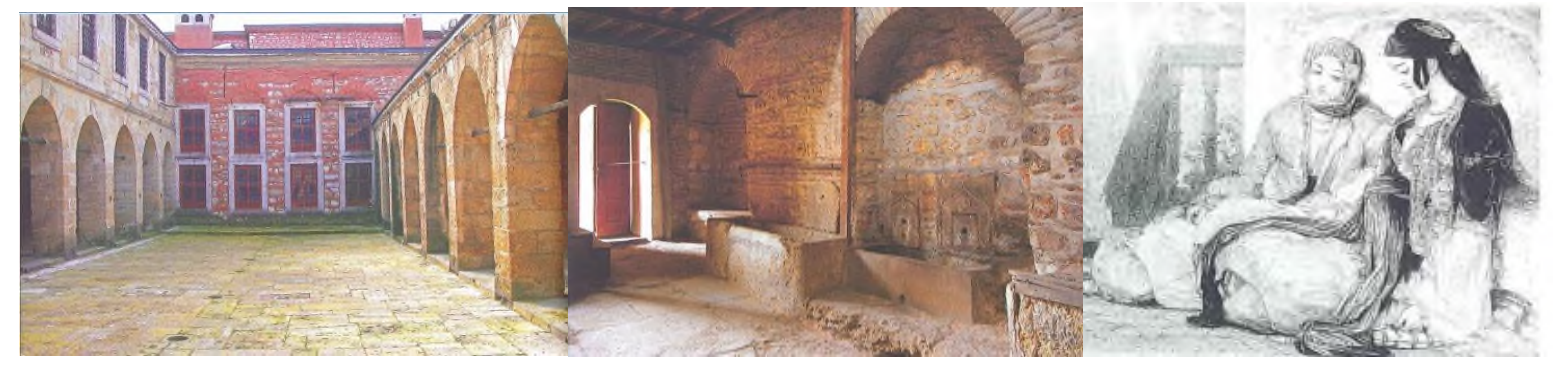

Figure 6: Courtyard of concubine hospital (left), gasilhane and laundry sections of concubine hospital (center), concubines in an old drawing (rigth) (Source: Kllıç, 2015: 290, 294, 296).

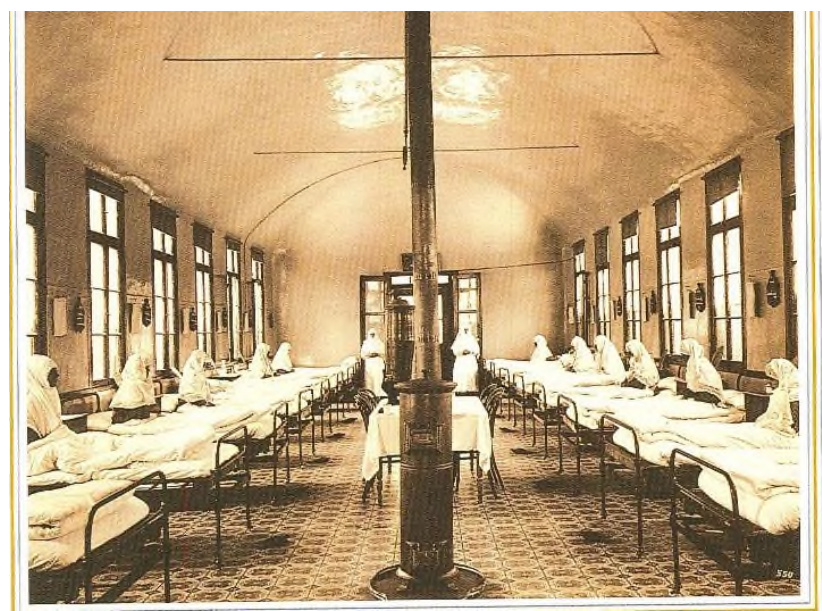

Figure 7: The ward of tuberculosis of Haseki Hospital of Women (Source: Yllmaz, 2007: 2).

Baths as cleaning spaces for patients, medicine students, or servants of the hospitals were the other parts of historic hospitals that acknowledge gendered segregation. They have been observed as part of both Seljuk and Ottoman period hospitals. For instance, Süleymaniye Hospital, Atik Valide Hospital, Haseki Hospital, and Sultan I. Ahmed Hospital have baths inside the hospital building (Figure 8). All these baths are single baths, allocated just for males or females in certain times of the day or week. Similarly, in Gevher Nesibe Sultan Hospital and Sivas I. İzzettin Keykavus Hospital of Seljuk period, there are baths located inside the 
hospitals (Dişli, 2014: 37). Dinç (2015: 209) also mentions about the existence of a bath section until 1920s, in which there were separate parts for male and female users, for the cleaning of the bodies and clothes of the users in Fatih Hospital. In addition, illustrations on transfer of patients to the hospitals show that, female patients could be transferred either on the shoulders of possibly their relatives or on the stretcher by male nurses/relatives (Figure 9).
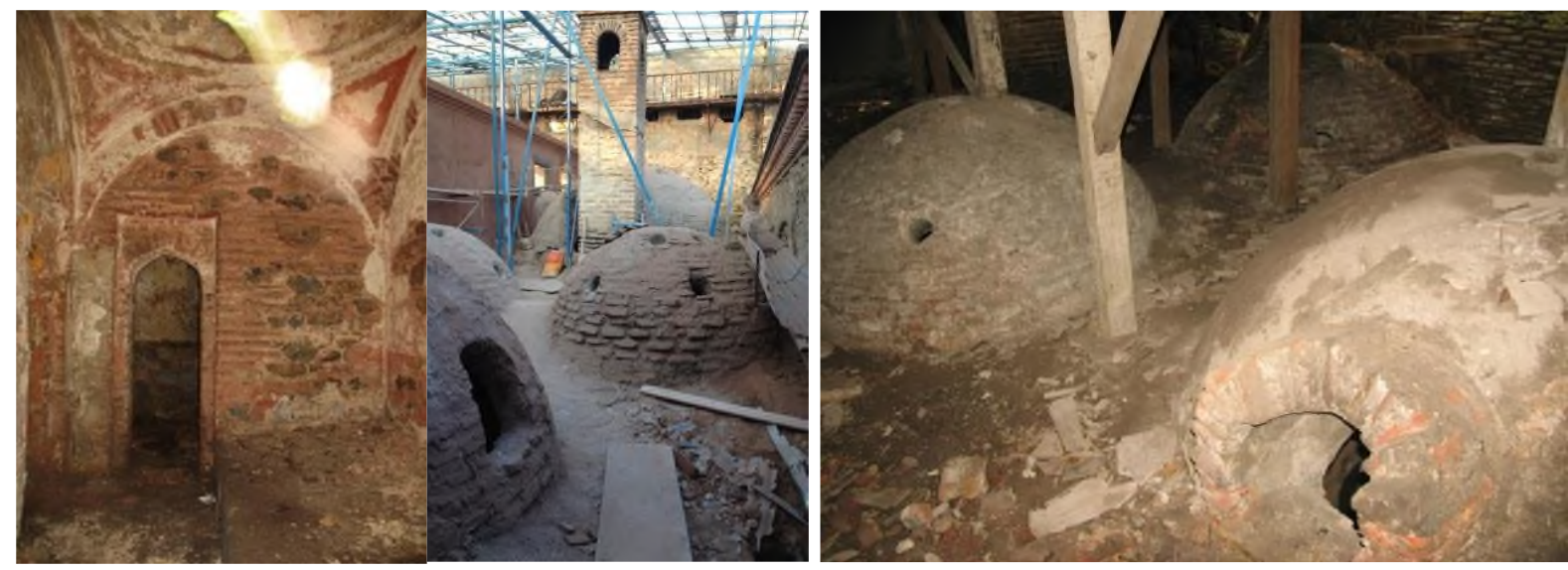

Figure 8: The bath of Atik Valide Hospital (Source: Archives of the author, 2014).

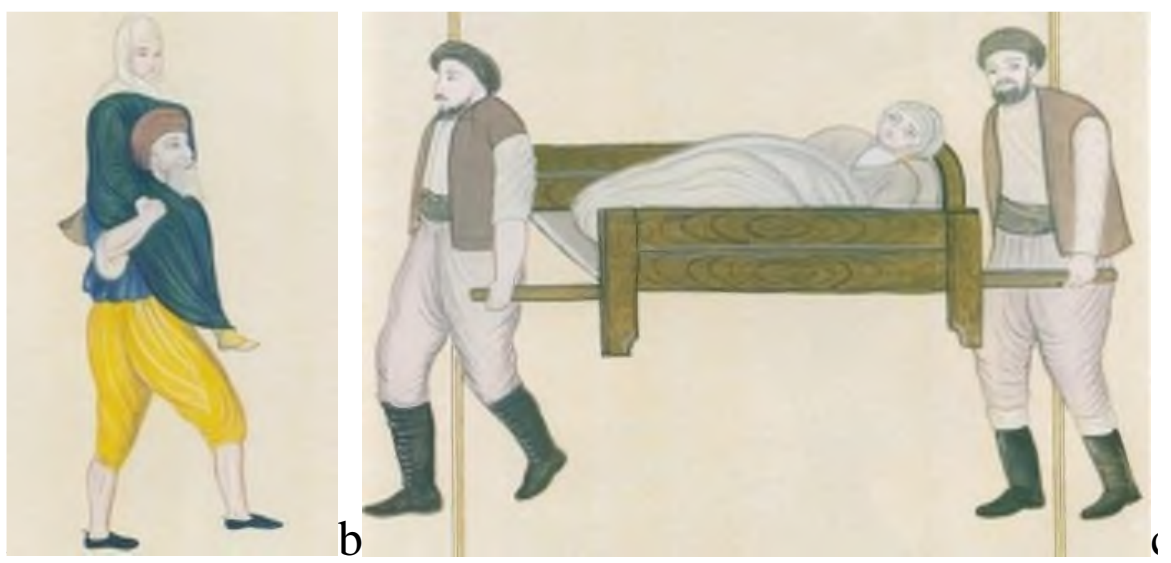

Figure 9: Illustrations showing transfer of female patients to the hospital: transfer on the shoulders (left) and transfer on the stretcher (right) (Source: Erke, 2002: 158-159).

\section{Conclusion}

This paper discusses gendered space divisions in historical hospitals in Anatolia, and examines how medical ethics, clinical practices, as well as privacy considerations affected the 
gender-space relationship in those spaces of healing, thus offers a perspective so far little studied. Primary conclusions of the study are outlined as follows:

- Both in Ottoman and Seljuk period hospitals in Anatolia, when first constructed, different parts such as patients' rooms and wards were observable both for different sexes, but especially in late Ottoman period in the $19^{\text {th }}$ century, hospitals were constructed just for male or female patients.

- In addition to separate wards and rooms, in some cases different floors and barracks were allocated for different sexes.

- Cariyeler Hastanesi/hospital for concubines, darülvilade, nisa hastanesi/women's hospital, nisaiyye were some common terms used for the definition of treatment spaces serving just for female patients.

- The baths in hospitals are moslty single baths, which can be explained as their dual usage by male and female users in different parts of the day or week. Only in Fatih Hospital, the bath is mentioned to have separate parts for male/ felame patients/users.

- The toilets, patients' rooms/wards in hospitals could be identified to some extent, which support the gender segregation, as in Amasya Amber bin Abdullah Hospital, Süleymaniye Hospital, Fatih Hospital, and Hafsa Sultan Hospital.

- In Muslim society, moral code necessitated the segregation of the sexes, or else it was common to look after the patients at their homes or a physician was called for the treatment of the patient at home. Hospitals were instead healing places for the poor, homeless, travellers, strangers, merchants, and for the patients with serious diseases.

- Even at the beginning of early Islam women were mentioned among the traditional healers of the patients, but they were geneally performing this duty out of hospitals. Yet, in archival registers, female nurses, called as Nigehban-ı Hastegan, were mentioned in order to look after female patients inside the hospitals, and treatment of female patients by male doctors was considered indecent by deontologists.

- Especially in Ottoman Palace there were female patrons built hospitals for women and for the general public, but elite women in the harem had limited access of healing by male physicians compared to the non-elite Ottomans.

- Old miniatures and illustrations, though rather rare in number, support that female patients were generally treated by women healers.

- It was at the first half of the $20^{\text {th }}$ century that medical training of female students were observable in Turkey in medicine schools.

\section{References}

Ağırakça, A. (2004). İslam Tıp Tarihi, Başlangıçtan VII.-XIII. Yüzyıla Kadar. İstanbul: Nobel Tip Kitabevi. 
Altan, S. (2008). Geçmişten Günümüze Manisa Hafsa Sultan Bimar-hanesi: 1539-2008. In Amasya Uluslararası Anadolu-Türk Darüşşifaları ve Sabuncuoğlu Kongresi, Kadıŏlu, S., Kadıoğlu, F. G. \& Uzel, İ. (Eds.), (pp. 57-62). Ankara: Anıt Matbaa.

Altıntaş, A. (2015). Anadolu Selçukluları ve Osmanlı'da Tıp ve Darüşşifalar. In Anadolu Selçuklu ve Osmanlı Şefkat Abideleri Şifahaneler, Kılıç, A. (Ed.), 2. Edition (pp. 21-60). İstanbul: Bilnet Publishing House.

Altıntaş, A. (2015). Konya Darüşşifası (Selçuklular ve Osmanlılar Döneminde). In Anadolu Selçuklu ve Osmanlı Şefkat Abideleri Şifahaneler, Kılıç, A. (Ed.), 2. Edition (pp. 137-143). İstanbul: Bilnet Publishing House.

Amasya, Bursa, Edirne, İstanbul, Kayseri, Manisa, Sivas ve Tokat illerindeki darüşşifalara ait vakfiye, fotoğraf, teknik çizim ve idari raporlar dizini (2012). Ankara, Vakıflar Genel Müdürlüğü Arşivi.

Arda, B. (2009). Anatolia; the Cradle of Modern Medicine. Ankara Üniversitesi Tip Fakültesi Mecmuas1, 62(1), 8-12.

Bayat, A. H. (2006, December). Turkish Medical History of Seljuk Era. Foundation for Science, Technology and Civilisation, FSTC Limited, 2-14.

Bayat, A. H. (1999). Osmanlı Devletinde Hekimbaşılık Kurumu Ve Hekimbaşılar. Ankara: Atatürk Kültür Merkezi Yayınları.

Bolak, O. (1950). Hastanelerimiz. İstanbul: İstanbul Matbaacılık.

Cantay, G. (1992). Anadolu Selçuklu ve Osmanlı Darüşşifaları. Ankara: Atatürk Kültür, Dil ve Tarih Yüksek Kurumu Atatürk Kültür Merkezi Yayını.

Çetin, O. (2006). İlk Osmanlı Hastanesi, Bursa Yıldırım Darüşşifası (Bursa Mahkeme Sicillerine Göre). İstanbul: Göz Nurunu Koruma Vakfı Yayınları.

Dengiz, E. B. (2001). Boundaries of Gendered Space: Traditional Turkish House. Unpublished master's thesis, Bilkent University, Ankara.

Devellioğlu, F. (2004). Osmanlıca Türkçe Ansiklopedik Lugat. Ankara: Aydın Kitabevi.

Dinç, G. (2015). Fatih Darüşşifası. In Anadolu Selçuklu ve Osmanlı Şefkat Abideleri Şifahaneler, Kılıç, A. (Ed.), 2. Edition (pp. 205-215). İstanbul: Bilnet Publishing House.

Disli, G. (2018). Analysis of ancient ventilation and illumination practices in Anatolian Seljuk and Ottoman hospitals and suggestions for their conservation measures. International Journal of Heritage Architecture, 2(1): 174-185.

Dişli, G. \& Özcan, Z. (2016). An Evaluation of Heating Technology in Anatolian Seljuk Period Hospitals (Darüşşifa). Metu Journal of Faculty of Architecture, 33(2): 183-200. 
Dişli, G. (2015). Planning of functional spaces in Ottoman Period hospitals (darüşşifa) of Anatolia. Al-Masaq: Journal of the Medieval Mediterranean, 27(3): 253-276.

Dişli, G. (2014). Anadolu Selçuklu ve Osmanlı Darüşşifalarında İşlevsel Sistemlerin ve Koruma Ölçütlerinin İrdelenmesi. Unpublished doctoral dissertation, Gazi University, Ankara.

Disli, G. \& Ozcan, Z. (2014). Waste and clean water systems in Anatolian Seljuk and Ottoman Period hospitals. International Journal of Academic Research, 6(3):169-177.

Disli, G. (2014). Sustainability of Historic Building Systems: Anatolian Seljuk and Ottoman Hospitals. APT Bulletin: Journal of Preservation Technology, 45(4): 45-51.

Dols, M. W. (1987). Insanity \& Its Treatment in Islamic Society. Medical History, 31:1-14.

Erer, S. (2010). Osmanlılar Döneminde Bursa'da Yaptırılan Hastaneler. U.Ü. Fen-Edebiyat Fakültesi Sosyal Bilimler Dergisi, 19(2): 241-252.

Erke, Ü. \& Sarı, N. (Eds.) (2002). Turkish Medical History through Miniature Pictures Exhibiton. In 38th International Congress on History of Medicine. İstanbul: Nobel Publishing.

Green, M. H. (2003). History of Science. In Encyclopedia of Women and Islamic Cultures Vol. 1, Methodologies, Paradigms and Sources, Joseph, S. (Ed.), (pp. 358-361). Leiden: Brill.

Kadıŏ̆lu, F. G. \& Kadıŏlu, S. (2008). Adı Darüşşifalara Ad Olan Kadınlar. In Amasya Uluslararası Anadolu-Türk Darüşşifaları ve Sabuncuoğlu Kongresi, Kadıoğlu, S., Kadıoğlu, F. G. \& Uzel, İ. (Eds.), (pp. 89-104). Ankara: Anit Matbaa.

Kahraman, S. A. \& Dağl1, Y. (Ed.) (2003). Günümüz Türkçesiyle Evliya Çelebi Seyahatnamesi 1 (1). İstanbul: Yapı Kredi Yayınları.

Kahya E. \& Erdemir, A. D. (2000). Bilimin Işığında Osmanlıdan Cumhuriyete Tıp ve Sağlık Kurumları. Ankara: Türkiye Diyanet Vakfı Yayınları.

Kaysili, B. (2006). Tanzimat'tan Cumhuriyet'e Türkiye'de Saglik Egitimi Üzerine Bir Arastirma (1839-1938). Unpublished master's thesis, Selcuk University, Konya.

Karaslan, A. (2012). Health Facilities in Bosnia-Herzogevina In The Light Of Ottoman Documents. IBAC, 2: 534-541.

Kılıç, A. (Ed.) (2012). Anadolu Selçuklu ve Osmanlı Şefkat Abideleri Şifahaneler. İstanbul: Medicalpark.

Köker, A. H. (1991). Selçuklu ve Osmanlı Devirlerinde Tıp Öğretimi ve Eğitimi. In Selçuklular Devrinde Kültür ve Medeniyet, Gevher Nesibe Sultan Adına Düzenlenen Selçuklu Gevher Nesibe Sultan Tıp Fakültesi Kongresi, (pp. 23-47), Kayseri.

Ozcan, Z. \& Disli, G. (2014). Refrigeration Technology in Anatolian Seljuk and Ottoman Period Hospitals. Gazi University Journal of Science (GUJ Sci), 27(3): 1015-1021. 
Özdemir, C. (2012). Amasya Darüşşifası ve Cerrah Sabuncuoğlu Şerafeddin. Amasya: Amasya Valiliği.

Pormann, P. E. (2017, October). Female Patients, Patrons and Practitioners in the Medieval Islamic World. Aspetar, Sports Medicine Journal, 656-660.

Sarı, N. \& Akgün, B. (2008). Türk Tarihinde Psikiyatri Hastasına Kısa Bakış. In İ.Ü. Cerrahpaşa Tıp Fakültesi Sürekli Tıp Eğitimi Etkinlikleri 1, Türkiye'de Sık Karşılaş1lan Psikiyatrik Hastalıklar Sempozyum Dizisi 62 (pp. 1-24). Istanbul: Istanbul University.

Saygılıgil-Gündüz, F. (1999). Osmanlı Devletinde İstanbul'da Kadınlara Hizmet İçin Açılan Hastahane ve Klinikler. Unpublished master's thesis, İstanbul Üniversitesi, İstanbul.

Shefer-Mossensohn, M. (2011). A Sick Sultana in the Ottoman Imperial Palace: Male Doctors, Female Healers and Female Patients in the Early Modern Period. Journal of Women of the Middle East and the Islamic World, 9: 281-312.

Shefer, M. (2005). Old Patterns, New Meaning: The 1845 Hospital of Bezm-i Alem in Istanbul. Dynamis. Acta Hisp. Med. Sci. Hist. Illus., 25, 329-350.

Shefer-Mossensohn, M. (2003). Charity and Hospitality: Hospitals in the Ottoman Empire in the Early Modern Period. In Poverty and Charity in Middle Eastern Contexts, Bonner, M., Ener, M. \& Singer, A. (Eds.), (pp. 121-143). New York: State University of New York Press.

Taneli, B. \& Şahin, H. (Eds.) (2013). Cumhuriyetten Önce ve Sonra Ülkemizde Hastaneler, Çocuk Hastaneleri ve Tıp Eğitimi. İzmir: Ege Üniversitesi.

Terzioğlu, A. (1999). Osmanlı'da Hastaneler, Eczacılık, Tababet ve Bunların Dünya Çapında Etkileri. İstanbul: Kültür Bakanlığı Yayınları.

Terzioğlu, A. (1992). Bimaristan. In Türkiye Diyanet Vakfi İslâm Ansiklopedisi, Vol. 6, (pp. 163-175). İstanbul: Türkiye Diyanet Vakfı Yayınları.

Terzioğlu, A. (1970). Orta çağ İslâm-Türk Hastaneleri ve Avrupa'ya Tesirleri, Belleten, XXXIV/2: 121-149.

Tschanz, D. W. (2017, October). Bimaristans and the Rise of Modern Healthcare Systems, Aspetar, Sports Medicine Journal, 438-443.

Uzel, İ. (1992). Cerrahiyyet'ül Haniyye I. Ankara: Türk Tarih Kurumu Yayınları.

Y1ldırım, N. (2010). A History of Healthcare in Istanbul. İstanbul: Düzey Publishing.

Yıldırım, N. (1994). Toptaşı Bimarhanesi. In Dünden Bugüne İstanbul Ansiklopedisi Vol. VII. Tekeli, İ. (Ed.). İstanbul: Kültür Bakanlığı ve Tarih Vakfı Yayınları.

Y1lmaz, Ö. F. (Ed.) (2007). Last Period Ottoman Hospitals. Istanbul: Çamlıca Publishing. 


\title{
FEMALE TEACHERS' EXPLICIT BELIEFS ABOUT LANGUAGE TEACHING, LEARNING AND RACE
}

\section{Ievgeniia LYSETSKA ${ }^{1}$ \\ Naciye KUNT ${ }^{2}$}

\begin{abstract}
Abstaract
The beliefs play a major role in the teaching practice; the beliefs are fundamentally developed in our subconsciousness and are proved to be resistant to change. The beliefs could be classified as institutional and personal, explicit and implicit (Fives, \& Buehl, 2012). The teachers' believes play the prominent role in the teaching and learning processes in the classroom. Teachers construct the goals, curriculum and shape objectives according to their beliefs; the beliefs dictate the methods used during the pedagogical practice. The teachers rely on their previous experiences that frame their assumptions and expectations of the students' learning proficiency level. Unfortunately, there are still prejudices regarding the race in our society, and the teachers are not exceptions. It is essential to indicate racism and increase awareness of the white privilege, expand critical thinking and bring the social justice into the classroom. These changes in beliefs also have influence on the learning outcomes improvement, safe space in the classroom that encourages the dialogue and hearing out all students' voices. The values of teachers and their individual beliefs are viewed important in shaping the goals, curriculum, objectives, and instructional methods (Yero, 2002).

The participants of the present study are experienced female teachers in the context of Turkish Republic of the Northern Cyprus. In order to collect information regarding explicit beliefs, the short self-reported survey was implemented. After the self-reported survey the teachers were interviewed. The findings show that the teachers declare positive attitudes regarding inclusion of students of various origins. Nevertheless, the results of the study reflect that some teachers support stereotypes regarding some races and modify tasks for different races differently.
\end{abstract}

Keywords: Language Teaching, Female Teachers, Stereotypes, Northern Cyprus

\footnotetext{
${ }^{1} \mathrm{PhD}$ Candidate in Eastern Mediterranean University, English Language Teaching Department, Faculty of Education, Famagusta, North Cyprus, lysjane@ukr.net,

${ }^{2}$ Assoc. Prof. Dr. Instructor in Eastern Mediterranean University, English Language Teaching Department,Faculty of Education,Famagusta,North Cyprus, naciye.kunt@emu.edu.tr,
} 


\section{Introduction}

The beliefs are very deeply settled down in our subconsciousness and are resistant to change, they can be institutional and personal, explicit and implicit. The teachers' believes play the prominent role in the teaching and learning processes in the classroom; they shape the goals, curriculum, objectives and dictate the methods used. The teachers rely on their previous experiences that form their expectations of the students' learning proficiency level. The beliefs of teachers have extensive impact on actions and instructional judgements (Gayl, 2010). Unfortunately, there are still prejudices regarding the race in our society, and the teachers are not exceptions. It is essential to indicate racism and increase awareness of the white privilege, expand critical thinking and bring the social justice into the classroom. It is essential for teachers to receive the education on cultural diversity, to become aware of cultural differences and raise the commitment to social justice that leads to change in beliefs and personal preferences. These changes in beliefs also have influence on the learning outcomes improvement, safe space in the classroom that encourages the dialogue and hearing out all students' voices.

\section{Literature review}

\section{Beliefs}

The review of literature regarding teacher beliefs suggested by Fives and Buehl (2012) concludes that several definitions of beliefs exist (Hermans, van Braak, \& van Keer, 2008; Kagan, 1992; McAlpine, Eriks-Brophy, \& Crago, 1996; Pajares, 1992; Richardson, 1996; Thompson, 1992). It has been revealed that there is no agreement about the nature of teacher's beliefs (Fives \& Buehl, 2012). It has been attempted to unite multiple definitions in order to produce one definition that could be used in the research (Pajares, 1992). Pajares (1992) 
suggested a broad definition and underlined the subtle shade of meaning incorporated in some other terms as images, theories, attitude, perceptions and values. The teacher cognition (what teacher knows, thinks and believes) is seen as cognitive aspect in teaching that cannot be observed (Borg, 2003). The educational belief research shows the widespread terms, such as perceptions, expectations, beliefs, theories, characteristics, sense of efficacy, attitudes, values, thought processes, and sense of efficacy (Smith, Skarbeck, \& Hurst, 2005). The literature on beliefs also suggests such terminology as opinions, personal theories, rules of practices, judgments, implicit an explicit theories, perceptions, and practical principles (Pajares, 1992). The research conducted on teacher beliefs includes the beliefs about students, self, teaching approach, the context, teaching practices, and content or knowledge (Fives \& Buehl, 2012). The research depicts that teacher beliefs can be classified as implicit and explicit; the beliefs are resistant to change in time, the connection between the beliefs and knowledge, the beliefs can be contextual and general, the beliefs can be individual or exist within larger systems (Fives \& Buehl, 2012). The teachers have both individual and personal beliefs that are creating for the action base in the classroom activity; these two types of beliefs may not always be in consonance. The previous research has shown that the gap between teachers beliefs and actual practice occurs (Yuan, 2017). The values of teachers and their individual beliefs are viewed important in shaping the goals, curriculum, objectives, and instructional methods (Yero, 2002). The assumed mismatch in individual and professional beliefs together with the public characteristics of the profession is seen as unique quality of teacher beliefs. The literature suggests that teachers very often rely on their existing experience, and if the expectations about students cannot be adjusted in the existing framework, the disconsolance may lead to lowered expectations and decline in the proficiency performance (van der Bergh et al., 2010). The teachers' expectations regarding the students' performance may be dictated by students' belonging to the particular group or race. 
Race

In spite of claims to be color blind, the actions that depict racist behavior still remain (Bonilla-Silva, 2003). Despite the ideological protests against the prejudice, the racism still takes place. The fact that racism still exists despite all objections cannot be easily explained by arguments about represses, dysconscious, or unconscious beliefs, but it can be expressed by imbalance in mental beliefs and perceptual or bodily actions (Lewis, 2018). It is claimed that white teachers capture 'tools of whiteness' that have performative, emotional and ideological qualities. These tools apart from resisting in critical-race consciousness shield white privilege from being ruined by racial difference experiences (Picower, 2009). The power and authority positions in the society lead to construction of white race identities among the teachers (Solomona et al., 2005).

One of the central contributors in teacher education is Paulo Freire. The theory of critical consciousness is often used in the research in the theoretical parts and in data analysis. The author claims the critical consciousness development results the overcome of naïve magical forms of consciousness (Freire, 1973). Ricardo E. Gonsalves (2007) develops Freire's approach and argues that critical consciousness helps to overcome the 'hysterical blindness' in multicultural courses. The author claims that unspoken beliefs are been unconscious and correspond to racial stereotypes. The dysfunctional consciousness is the type of consciousness that automatically adjusts to social and racial norms in the society. Dysfunctional consciousness is shielded by different psychological defenses, such as hysterical blindness. The term 'hysterical blindness' stands for resistance to any knowledge that can question the most basic beliefs, assumptions, and images that create the self.

The study of whiteness is interested in the ways in which white privilege and whiteness has come to be institutionalized and focuses on the underlining factors that lead to its continued dominance (Giroux, 1992; Giroux \& McLaren, 1994; Leonardo, 2002; Levine-Rasky, 2000; 
Rodriguez, 2000; Rodrigues, \& Vilaverde, 2000). W. E. B. DuBois (1973) and Frederick Douglas have influenced the emergence of the notion of whiteness. The revival of this notion has been conducted by Ruth Frackenberg (1993) and Richard Dyer (1988). It is claimed that white studies lead to questioning the whiteness as invisible, inevitable and colorless form. In the field of teacher education, the study of whiteness pursues teachers and pre service teachers to analyze their understanding of their racial identity, ideologies they have, examination of the effect of the ideologies on their teaching practice and the interactions with students (Tatum, 1992; Sleeter, 1993; Roman, 1993). The study of whiteness inquires teachers to question the links between education, power and race and it instructs the connections to oppression. It is essential for the personal attitudes and understandings to be analyzed by the teachers to realize the ways the racial acknowledgement and social positioning is related to the actual practices

and interactions with students (Lewis, 2018). The research shows that teachers lack knowledge how racism functions and lack background to effectively teach students from various backgrounds (Amos, 2016; Picower, 2009; Shim, 2018; Sleeter, 2008; Sue, 2011).

The significance of this study is the valuable insight of the teaching practices and perceptions of experienced in-service English teachers about stereotypes, discrimination and racism. There was no previous research conducted on teachers' explicit beliefs regarding English language teaching, learning and race in the context of Turkish Republic of Northern Cyprus. The results presented are the part of the larger study conducted in 2018.

\section{Research questions}

1. Do the in-service teachers express the positive beliefs about representatives from different race among their students?

2. Are there any racial stereotypes expressed by in-service teachers? 


\section{Participants}

The teaching has been reportedly described as prevailing female occupation (Bullogh, 2015; Ingersoll et al., 2018; Schmude \& Jakisch, 2019). The participants are experienced inservice female teachers in a university in Turkish Republic of Northern Cyprus. The participation was on voluntarily basis and teachers signed the consent forms. The participants were aware that they can withdraw from the research at any point.

\section{Method}

A self-report questionnaire survey was used to obtain the information regarding teachers' explicit beliefs. The questionnaire was developed, piloted, and used by Reeves (2006). The questionnaire had minor changes: the minority students from the initial questionnaire were changed into students of African and Asian origin. The questionnaire was applied after singing the consent forms and directly before the interview questions. The semi-structured interviews were 12-21 minutes long; they were audio recorded and the written notes were made for easier transcribing.

\section{Data analysis}

The answers of questionnaires were counted manually and classified. The interview recordings have been transcribed. The interview texts have been coded according to the topics and classified in discourses.

\section{Results of the study}

The general positive explicit beliefs in the results of the questionnaire coincided with the previous studies conducted for mainstream teachers from secondary and middle schools in 
United States (Harrison \& Lakin, 2018) and in secondary schools (Reeves, 2006). Reeves (2006) also concluded that some teachers tend to provide more time for minority students. The teachers questioned the use of the second language in classroom; these results coincide with the previous study conducted by Reeves (2006) and Harrison and Lakin (2018). The number of participants who received the training is considerably lower comparing to the previous studies. The tendency to simplify the material and to modify the assignments also coincides with the previous studies. Just like in previous studies (Harrison \& Lakin, 2018; Reeves, 2006) not all the teachers speak other second language apart from English. Unlike the previous study the number of native English speaking teachers is much smaller. The participants use broader definition of discrimination in general and confuse racism with attitudes to cultural diversity. Only one teacher could give the most precise definition. These results show the need in the awareness of the racism and the need in familiarity with the term racism (Picower, 2009). One of the teachers describes the power relations and the superiority issues. Racial acknowledgement and social positioning plays important role in the teaching practice and interaction with students (Lewis, 2018). One of the teachers suggested for the discriminated person to change so the discriminating community would accept the individual. It can be described as blaming the individual for being discriminated (Vossoughi \& Rodela, 2018). Only two teachers were familiar with the term and could give the example of positive discrimination, yet, they could not provide any example of positive discrimination in education. The results of these findings coincide with the research conducted by Jara-Labarthé, Browitt, Nakata and Puebla (2018). Despite perceiving racism as extremely negative phenomenon, some teachers yet expressed some prejudices in their teaching practice, while one teacher claimed that she doesn't know any stereotypes at all and believes that there is no racism in her country. The research shows that most of the teachers rely on their previous experience. The teacher explicit beliefs express the importance of education, upbringing, personal values and principles. 


\section{Conclusions}

Generally the female in-service teachers claim to be against racism and express the positive attitudes towards inclusion of students of African and Asian origin into their class. Yet, some teachers support stereotypes, prohibit native language use in classroom, simplify and modify tasks for the representatives of different races. The research shows that most of the teachers rely on their previous experience. The teachers' explicit beliefs indicate the importance of education, upbringing, personal values and principles. The research showed the unawareness of some teachers of terminology, nature of stereotypes and absence of necessary training for the majority of teachers. The training is required to raise the awareness of power relations in society, nature of racism and white privilege, need to familiarize teachers with the terminology and encourage self-reflection. The teacher education is necessary to prepare teachers for a community, where they teach and help teachers identify the students' needs for more effective teaching practice (Picower \& Marshall, 2017).

The present study is only about explicit beliefs; the recommendation for the further studies is to include the explicit beliefs and enlarge the number of participants. This research was conducted only with experienced in-service teachers; the further study may be conducted about novice and preservice teachers' beliefs and attitudes.

\section{References}

Amos, Y. T. (2016). Voices of teacher candidates of color on white race evasion: 'I worried about my safety!'. International Journal of Qualitative Studies in Education, 29(8), 1002-1015.

Bonilla-Silva, E. (2003). Racism without Racists: Color-blind racism and the persistence of racial inequality in the United States. Lanham, MD: Rowman \& Littlefield.

Borg, S. (2003). Teacher cognition in language teaching: A review of research on what language teachers think, know, believe, and do. Language Teaching, 36(2), 81-109. 
Bullough, R. V. (2015). Differences? Similarities? Male teacher, female teacher: An instrumental case study of teaching in a Head Start classroom. Teaching and Teacher Education, 47, 13-21. doi:10.1016/j.tate.2014.12.001

DuBois, W. E. B. (1973). The education of Black people: Ten critiques, 1906-1960. Amherst: University of Massachusetts Press.

Dyer, R. (1988). White. Screen, 29, 45-64.

Frankenberg, R. (1993). White women, race matters: The social construction of whiteness. Minnesota: University of Minnesota Press.

Freire, P. (1973). Education for Critical Consciousness. New York: Continuum.

Fives, H., \& Buehl, M. M. (2012). Spring cleaning for the "messy construct of teachers' beliefs: What are they? Which have been examined? What can they tell us. APA Educational Psychology Handbook, 2, 471-499.

Gay1, G. (2010). Acting on beliefs in teacher education for cultural diversity. Journal of Teacher Education, 61(1), 143-152. doi:10.1177/0022487109347320

Giroux, H. A. (1992). Resisting difference: Cultural studies and the discourse of critical pedagogy. In L. Grossberg, C. Nelson, \& P. Treichler (Eds.), Cultural Studies (199-212). New York, Routledge.

Giroux, H. A., \& McLaren, P. (1994). Between borders: Pedagogy and the politics of cultural studies. New York: Routledge.

Gonsalves, R. E. (2007). Hysterical blindness and the ideology of denial: Preservice teachers' resistance to multicultural education. In L. I. Bartolomé (Ed.), Ideologies in education: Unmasking the trap of teacher neutrality (pp. 3-27). New York: Peter Lang.

Harrison, J., \& Joni Lakin, J. (2018). Mainstream teachers' implicit beliefs about English language learners: An implicit association test study of teacher beliefs. Journal of Language, Identity \& Education, 17(2), 85-102. doi:10.1080/15348458.2017.1397520

Herman, R., van Braak, J., \& van Keer, H. (2008). Development of the beliefs about primary education scale: Distinguishing a developmental and transmissive dimension. Teaching and Teacher Education, 24(1), 127-139.

Ingersoll, R. M., Merrill, E., Stuckey, D., \& Collins, G. (2018). Seven trends: The transformation of the teaching force - Updated October 2018. CPRE Research Reports. Retrieved from https://repository.upenn.edu/cpre_researchreports/108

Jara-Labarthé, V., Browitt, J., Nakata, N. M., \& Puebla, C. C. (2018). Positive discrimination and discourse: A methodological approach for studying Australian and Chilean indigenous educational experiences. Interciencia English, 43(9), 664-671. 
Kagan, D. (1992). Implication of research on teacher belief. Educational Psychologist, 27(1), 65-90.

Leonardo, Z. (2002). The souls of white folk: Critical pedagogy, whiteness studies, and globalization discourse. Race Ethnicity and Education, 5(1), 29-50.

Levine-Rasky, C. (2000). The practice of whiteness amongst teacher candidates. International Studies in Sociology of Education, 10(3), 263-284.

Lewis, T. E. (2018). But I'm not a racist! Phenomenology, racism, and the body schema in white, pre-service teacher education. Race Ethnicity and Education, 21(1), 118-131. doi:10.1080/13613324.2016.1195354

McAlpine, A., Eriks-Brophy, A., \& Crago, M. (1996). Teaching beliefs in Mohawk classrooms:Issues of language and culture. Anthropology \& Education Quarterly, 27(3), 390413.

Pajares, M. F. (1992). Teachers' beliefs and educational research: Cleaning up a messy construct. Review of Educational Research, 62(3), 307-332.

Picower, B. (2009). The unexamined whiteness of teaching: How white teachers maintain and enact dominant racial ideologies. Race, Ethnicity, and Education, 8(2), 197-215.

Picower, B., \& Marshall, A. M. (2017). Run like hell to look before you leap: Teacher educators' responses to preparing teachers for diversity and social justice in the wake of edTPA. In J.H. Carter, \& H.A. Lochte (Ed.), Teacher Performance Assessment and Accountability Reforms (pp. 189 -212). New York: McMillan.

Reeves, J. (2006). Secondary teacher attitudes toward including English language learners in mainstream classrooms. The Journal of Educational Research, 99, 131-142. doi:10.3200/JOER.99.3.131-143

Richardson, V. (1996). The role of attitudes and beliefs in learning to teach. Handbook of Research on Teacher Education, 2, 102-119.

Rodriguez, N. M. (2000). Projects of whiteness in a critical pedagogy. In N. M. Rodriguez, \& L. E. Villaverde (Eds.), Dismantling white privilege: Pedagogy, politics and whiteness (pp. 124). New York: Peter Lang.

Rodriguez, N. M. \& Villaverde, L. E. (2000). Dismantling white privilege: Pedagogy, politics and whiteness. New York: Peter Lang.

Roman, L. G. (1993). White is a color! White defensiveness, postmodernism and, anti-racism pedagogy. In C. McCarty, \& W. Crichlow (Eds.), Race, identity and representation in education, (pp. 71-88). New York: Routledge.

Shim, J. M. (2018). Co-existence of race-evasiveness and race-visibility identifications: Complexifying one white male teachers' racial knowledge. Teaching and Teacher Education, 70, 132-14. doi:10.1016/j.tate.2017.11.019 
Schmude, J., Jakisch, S. (2019). Feminization of teaching: Female teachers at primary and lower secondary schools in Baden-Württemberg, Germany: From its beginnings to the present. In H. Jahnke, C. Kramer, \& P. Meusburger (Eds.), Geographies of Schooling (pp. 333349). Cham: Springer.

Sleeter, C. E. (1993). How white teachers construct race. In C. McCarty \& W. Crichlow (Eds.), Race, identity and representation in education (pp. 157-171). New York: Routledge.

Sleeter, C. E. (2008). Preparing white teachers for diverse students. In M. Cochran-Smith, S. Feiman-Nemser, \& D. J. McIntyre (Ed.), Handbook of research on teacher education: Enduring questions in changing contexts (pp. 559-582). New York, NY: Routledge.

Smith, R. L., Hurst, J., \& Skarbek, D. (2005). The passion of teaching: Dispositions in the schools. Maryland: R\&L Education.

Solomona, P. R., Portelli, J. P., Daniel, B., \& Campbell, A. (2005). The discourse of denial: How white teacher candidates construct race, racism and 'white privilege'. Race Ethnicity and Education, 8(2), 147-169. doi:10.1080/13613320500110519

Sue, C. A. (2011). Race blindness in Mexico: Implications for teacher education inthe United States. Race, Ethnicity and Education, 14(4), 537-559.

Tatum, B. (1992). Talking about race, learning about racism: The application of racial identity development in the classroom. Harvard Educational Review, 62(1), 1-24.

Thompson, A. G. (1992). Teachers' beliefs and conceptions: A synthesis of the research. London: Macmillan Publishing Co Inc.

Van den Bergh, L., Denessen, E., Hornstra, L., \& Voeten, M. (2010). The implicit prejudiced attitudes of teachers: Relations to teacher expectations and the ethnic achievement gap. American Educational Research Journal, 47(2), 487-527.

Vossoughi, S., \& Rodela, K. (2018). Rewriting race, class, and the "culture of poverty:" Ethnographic Work by Eleanor Leacock, 1959-1980. Diaspora, Indigenous, and Minority Education, 21, 169-179. doi:10.1080/15595692.2017.1421534

Yero, J. L. (2002). Teaching in mind: How teacher thinking shapes education. Hamilton: MindFlight Publishing.

Yuan, E. R. (2017). Exploring university-based teacher educators' teaching beliefs and practice: A Hong Kong study. Teaching in Higher Education, 22(3), 259-273. doi:10.1080/13562517.2016.1248393 


\title{
GENDER, EQUITY, SOCIAL JUSTICE AND BELIEFS IN FOREIGN LANGUAGE LEARNING: THE CASE OF GRADUATE STUDENTS
}

\author{
John Peter WAPPA ${ }^{1}$ \\ Naciye KUNT ${ }^{2}$
}

\begin{abstract}
The study investigated the gender equity and social justice beliefs among the female graduate students of communication and television Department at an English medium university in Cyprus (pseudonym). The study investigated PhD female students on gender equity and social justice beliefs through interview are from different nationalities. Qualitative approach was adopted for the analysis of the data. The general beliefs among the students according to the findings is that of them been aimful in their study. Their instructors are generally believed to be successful, their classes are under control, and their relationship with their students are cordial. Then, the female gender enjoys equity and social justice, and are not under any kind of treat from the lecturers. The instructors' gender is no hindrance to their academic pursuit, and some students passively prefer the female teachers.
\end{abstract}

Keywords: Gender Equity, Social Justice, Beliefs, Second Language Learning

\footnotetext{
${ }^{1}$ PhD. C. Department of English Language Teaching, Faculty of Education Eastern Mediterranean University, Cyprus wappajp@gmail.com

2 Assoc. Prof. Dr. Department of English Language Teaching, Faculty of Education Eastern Mediterranean University, Cyprus naciye.kunt@emu.edu.tr
} 


\section{Introduction}

English, according to Hall (2016) is no longer considered as a luxury rather, it is considered as part of basic universal education that people have clamoured to have. The place of gender, equity and social justice in schools and in the classroom in particular starts with the teacher education programs as teachers are trained on how to be effective in handling all categories of learners despite their diverse cultures, races and origin. They should equally be able to teach the gender roles selflessly without their personal thought tempering with it (Daniel \& Koss, 2016; Faust, 2016).

Social justice involves critical analysis, social and environmental realities of injustices that temper with effective teaching, learning, and curriculum. Women are always segregated against in spaces such as public transport, academic institutions, even lines in buffets, seating areas in public functions or concert (Faust, 2016; Halli, 2016; Kapur, 2016), and no questions were raised on such segregations. Kapur proposes the positioning of sensitization "as a learning outcome of English language class empowers learners to become critical users of language" as it helps in understanding gender construction through language use (Kapur, 2016: 180).

\section{Gender Beliefs, Equity and Social Justice in Education}

Gendered workplace norms and policies limit men's and women's change to develop egalitarian relationships at home (Pedulla \& Théband, 2015). They further state that despite the fact that women are much in the labour force of recent, still the number of men out numbered them even in the female-dominated occupations. Whenever the issue of equity comes up, what always comes to mind is the need for equal treatment for all gender. Gender relations and identities are constructed through cultures, lifestyle, also values and languages. Concerning education and training, gender differences feature in both attaining and choosing courses of 
study in schools (Kapur, 2016). People learned cultural heritage as stereotype early in life, such that people develop an implicit gender stereotypes, which spontaneously link men and women with stereotype traits, abilities, and roles, even when they reject these traditional beliefs. Rudman and Phelan (2010) investigated old women who had their patterns of beliefs changed overtime as they become established in masculine domains. Gender is "is primarily an identity or role that is taught at childhood and enacted in family relations" (Ridgeway \& Correll, 2004: 510).

Social justice makes available opportunities for persons or groups to develop and exploit their potentials to the fullest irrespective of their gender, class, race or origin. The inclusion of social justice in ELT will help in many ways to eliminate gender biasness from the curriculum and challenge its existence in the society (Daniel \& Koss, 2016; Kapur, 2016). Social justice education, according to Ayers et al., (2009) in Sleeter, Montecinos, and Jiménez (2016) relays on three main principles: equity as it relates to principle of fairness; activation, the principle of agency; then social literacy, which is the principle of relevance.

Education is a means of awakening social justice to make effective change in "policy, curriculum, instruction, learning, and assessment" (Kapur, 2016: 180). The issue of social justice within TESOL, and its global context continued to increase. TESOL prepares diverse people to be able to communicate with one another in one language -English, as well as targeting the elimination of discrimination of all sorts. TESOL is very much concerned in using education to promote equity, self-determination, reflect gender, sexual orientation, ethnicity, race, privilege, migration, colonization, and imperialism (Chang, 2018; Coney, 2016). TESOL education increased the level of awareness on cultural norms in ELT with the connection between gender, social identity and English language acquisition. Language learners should be empowered through classroom discussion because it fosters awareness of social justice that 
include such as gender discrimination perpetuated in different racial, cultural, and sociocultural contexts (Daniel \& Koss, 2016).

\section{Studies on Gender Beliefs and Social Justice}

With all effort of ingenuities to improve gender equity across STEM fields, the representation of women in the undergraduate engineering programs is low. Blair, Miller, Ong, and Zastavker (2017) adopted feminist post-structural epistemology and discursive methodology, and they discovered predominant faculty members to make meaning of students' gender expressions and to construct teacher identities. The first is what they called gender blindness, the most common position, and then finally, the prevalent discursive position is gender intervention. Meanwhile, Robinson, Shakeshaft, Grogan and Newcomb (2017) concentrated on the differences that gender makes among school leadership, ranging from difference in career paths, personal life, as well as characteristics of workplace. They reported that women generally have more chances of heading a district with a larger number of homeless and disable students. Nevertheless, women are still highly underrepresented while women of colour are rare.

In addition, English helps the female folks to overcome iniquitous gender roles, as they access new linguistic and social space to develop their aspirations. They belief, using English as a more gender-neutral medium is closely tied with tangible promise of permanently exiting from one social identity and entry into another (Rudman \& Phelan, 2010). Considering the study on gender in education, to the best of our knowledge, no research has investigated the gender, equity, social justice and beliefs among graduate students. That is why this study is timely. 


\section{The Study}

This study looks at gender, equity, social justice and beliefs in the learning of the FSL. It examined student-teacher relationship as it affects gender, determine the nature of gender equity and social justice beliefs, and identify the nature of students' reaction to the place of gender in the teaching pedagogy. This will give answers to questions such as how is the studentteacher relationship in the Department of Communication and Television? What is nature of gender equity and social justice beliefs in the Department of Communication and Television? Then, what is the students' reaction to the place of gender in the teaching pedagogy in the Department of Communication and Television?

The study will be valuable to the stakeholders in the educational sector and to curriculum developers to always consider the position of gender as to promote equity and social justice in schools, and be reflected in the school curriculum. The students and the teachers in any institution of learning will equally benefit from it.

\section{Method}

\section{Participants}

The study was conducted during the 2018/2019 fall semester with six $\mathrm{PhD}$ female students of different nationalities from Department of Communication and Television in English Medium University in Cyprus (pseudonym). The participants were randomly selected from different backgrounds: Turkish-Cypriote, Nigeria, Iran and Pakistan showing the diverse nature of the department and the school at large. Pseudonyms names were used for anonymity. 
Table 1: Participants' demographic information

\begin{tabular}{lll}
\hline Participants & Age & Nationality \\
\hline Asli & 28 & Turkish-Cypriot \\
Basak & 44 & Turkish-Cypriot \\
Vic & 33 & Nigeria \\
Elaheh & 35 & Iran \\
Eleni & 28 & Turkish-Cypriot \\
Azra & 33 & Pakistan \\
\hline
\end{tabular}

\section{Procedure}

Qualitative approach is adopted for the study because it is a more suitable method for the study as it will be able to explore the in depth perspectives of the participants. This is to get objective data for the issue been studied. The instrument used for collecting data for this study was a semi-structured interview, basic demographic information of the participants and openended questions aimed at unravelling the participants' beliefs about gender equity and social justice. The participants were made to understand that the interview was being recorded which they accepted but with the assurance that every information obtained was mainly for academic purpose and would be treated with utmost confidentiality. The study adopted a discursive method of data analysis. Qualitative method of research was used to investigate the subjective opinions, experience and beliefs of the individual participant.

\section{Results and discussion}

The findings of the study on gender, equity, social justice and beliefs reflected the in depth perspectives of the participants. The findings of the study were thematised and discussed, showing their opinions, experiences and beliefs on gender equity and social justice. The results are discussed under several themes as identified from the interviews. 


\section{Studying at the university}

The students believe their study at the university is fruitful and hope to fulfil their dreams. They believe it is an empowering experience, democratic, educationally beneficial, and enlightening as well. It is described as aimful and interesting, and they get more than they had expected. This is reflected in the responses of all the participants and was equally noted from the researchers' informal discussions. Azra and Vic like all other students say they really love their experience of studying in a multi-national and multi-cultural environment. They appreciated their being in the university, which they described as full of hope and determination; believing to get well equipped academically at the end of their studies. .

They equally believe that they would be able to achieve their aim of coming to school. Their study at the university will equip them to be better citizens. They are all ready to learn as the university gives them what is required. As Basak stated "...I want to learn.... lot about research methods and applications in different fields as well as in communication, which will help me proceed with my thesis later on." She sees course work as a simplified means to her thesis. So as to start it with less stress. While Vic says “...from my courses, I would say my challenges have always been research and application of theories. I hope that by the end of my study here, I am going to be grounded in both mass communication research and mass media theories."

Generally, they are aiming at learning more about processing of information as well as considering new ways of learning to process more than just learning data. They will be able to learn more and be able to expand their learning processes. The students have their target for enrolling in the programme and choosing that particular. 


\section{The Instructors' Role and Class Achievement}

The instructors served as good examples to their students, this received $100 \%$ confirmation from the participants. It was also observed to have reflected in the researchers' field notes and class observations. Their worth of experience played a great deal in the class which the students admired. Their style and approach are highly commendable by their students; the researchers noticed this during the class observations. The instructors never imposed their ideas or views on them. Open discussion and sharing of different ideas by the students was encouraged by the instructors. The instructors were said to have achieved much because they were able to get the attention of their students. They are comfortable in the instructors' classes. In the words of Vic, “...the teachers have also achieved... much in areas of engaging the students. There is never a boring class because like the teachers, the students also contribute in the class. They have succeeded in communicating well with the students."

The instructors most times are successful in their teaching because they consider their students' capacity in their teaching paradigm; even if there are some weak areas, such are negligible. They know much details and very knowledgeable in their fields. The instructors are teaching with good illustrations and proper guides. They get their students into critical thinking. In a conversation with Basak, she says:

... you attended some of our classes....In my research method or theory's course, $\mathrm{PhD}$ course instructor would get us to do the presentations and we have a nice flow. If we're not sure of something we can turn and ask the instructor and she will help or clarify or give example to simplify it...that makes it's really enjoyable classroom discussions.

They play their roles as instructors in an exemplary way which is well exhibited. Elaheh says: ....For example, in one of my classes, we had this discussion over certain critical theory point of view of a new social media use between people. I think, the way our instructor pointed out 
and guided the whole discussion was exceptional, and it was a good example of how the whole taught needs to be directed.

A popular view and general experience of the studednts on their instructors' practical approach to issues, Eleni says "I had one course about arts history, and I was researching about art fields; my instructor during the class gave us some suggestions about good books which explain all these things...." They appreciate such teaching approach, because they have only three hours in a week for the class which is not enough. With such support from the instructors, they go extra mile to equip themselves with some extra information.

\section{Student-Teacher Relationship}

From the interview, $100 \%$ of the participants state that the relationship between the students and their instructors is very cordial. They described it as friendly, fantastic, very good etc; this is independent of any gender relation. The instructors are said to be very accommodating, easy going and eager to help their students where the need be. There exist relationship between them as Vic said, “...is very cordial. It's great actually. My lecturers are fantastic. We've a great relationship". So also with Asli who described their relationship with their instructors by saying:

...I think, they're friendly...although they're really busy, there's always...time to answer our questions too...I think...as $\mathrm{PhD}$ students, our relationship is beyond the class material...they don't see us as students only, they see us as future public intellectuals or future academicians. They treat us that way, not just students. I know that when I need a help with my...course, or if I need a career advice, they will be...more than happy to help.

Nevertheless, they try to give a definition for the kind of relationship or friendship that should exist between the instructors and the students. Friendly should mean just be accommodative and willing to help, respect and guide the students when the need arises. 
Because they believe that if it is friendly as in 'friend', then there would be problem for both the instructors and the students in achieving their objectives. It should be a controlled kind of friendship aimed at a target of academic achievement.

\section{The Level of Struggles among the Students}

With all the good and friendly environment given to the students, there are students who survive by struggling, this view is expressed by $50 \%$ of the participants. Such struggles include cultural, language, academic, gender struggles etc. The class is described as a multicultural; so, cultural tolerance is highly accommodated despite the diversity. This was equally noted during the class visitations. They experience a kind of cultural and gender struggles occasionally among the students in the class. This is a clear signal of gender discrimination, and when asked if there was differences in the ways male and female students are treated in class, Elaheh stated that all are treated equally. Basak says “... with different cultures, there's struggle between men and women, male and female students... when an issue of gender studies comes up or gender discussion comes up, you can see how emotional they get...but at the end of the day, it get resolved. I mean, it's not a big problem, but you can see that there is great gender discrimination in some cultures, and that is also reflected of course in the classroom."

Some students struggle with limited knowledge of the course as their degrees were in other fields. They struggle to survive the course. In addition, there are those students who have little concern for their academics, the lazy students who either come late to class or do not come at all, they also struggle. Those who do not have reserve line between their relationships with the instructors struggle too. In relation to the relationship with teachers, when they lose to maintain the status quo with the teachers, either they get too friendly or they get too offended. Meanwhile, some have language challenges because their understanding of the English language is not much as expressed by $33.3 \%$ of the participants; such struggle to catch up with 
the class, and it can have negative effects on their academics. Sometimes, the instructors have to either look for more ways of presenting the information to them or say it in another language they understand. Language barrier is a serious issue in the class. In Basak's words on some categories of struggling students:

Mostly, I mean the first... struggle is we've many students who are not from the field ...they are not familiar with the subject at all, unlike me, I've some background at least, ... and the second one is language of course. Many people struggle with the language, the academic language, listening or writing. I don't think they benefit much from the classes.

Repeating same information, Vic says:

... English is the language of instruction here, the people who don't really grasp the English language seem to struggle because I've observed that, when you mention some words, like today in class, someone used the word pistol, and a...student was like 'what's a pistol?' and someone said 'gun', and she said 'ah!' So, people like that struggle...they've to pause and ask... so the lecturer has to use another English word...

\section{Equal Social Justice}

All the research participants stressed the importance of equal social justice for all the gender. Equal treatment should be accorded all no matter the person's race, culture or nationality. No one is allowed to enjoy any extra privilege above others. Some believe they all receive equal attention, while about $50 \%$ believe that equal social justice does not exist in its entirety. It is highly controlled but the traditional society still harbours inequity and injustice according to Eleni, “....if you look at it in the general mass as the whole Cyprus, I will say there are some inequality still...because we've lots of areas which still...have old traditional thinking that the wife should be at home or should look after the kids, the modern generation has rejected 
the old ways". Elaheh says, though there is equal social justice but that does not exist in its entirety, it is highly controlled:

...there is always this preference, in both male and female subjects...but it is about how to control these preferences. How to learn to control them.... Not let them surface in the public domain, right!...to be honest, not all of us are successful in that manner, sometimes they surface and re-surface in our social interaction with each other. That's where the problem actually appears and that's where we see in social context that even teachers are not exceptions. That you see in classroom for example...that teachers favour male students, female students and that can lead to certain problem....

All the genders enjoy equity and social justice, as discrimination has no space in the classroom; this is the general belief of the participants. Mutual respect is required for all genders, cultures, and race. Though all receive same justice because no one is placed on band because of his/her gender. However, there is fear of over neutrality that can lead to become feminist which is another issue of one-sided protection. She further says:

In my department to be honest, they're trying their best, most of the times to handle it with care. Because they're trying to base this notion of equality. It's in their...ideological...concept to handle it with care as with the idea of racism, as well as regarding gender equality. I do believe that, sometimes this issue falls a little bit too much into either side. You know the danger that we face....You know this concept that we have, in order to prevent been racists, sometimes we fall on been not too much racists.... We want to be gender equal, but we sometimes have this danger of being not too much...we end up been too much feminists. So that's the danger we face and sometimes that happens but I say, in most of the parts, they try their best to be equal and you can see that in this department. 


\section{Favouritism and Differences in Gender Treatment}

Relating to the treatment accorded different genders by the instructors; $100 \%$ of the participants said they have received equal treatment from their instructors not minding their gender differences. So also the issue of favouritism is absent as all students enjoy equal treatment. No one enjoys a particular privilege or opportunity because of his/her gender. While there seem to be some issues, where the males are favoured as expressed by $16.6 \%$ of the participants, but most of them do not want to talk about it. For instance, the appointment of research assistants, more men seem to be appointed than the women as depicted in the conversations with Vic, who says “....But that again, I notice that we have more male research assistants than female assistants in the department....I think, it favours the male more." In responding to the same question, Basak says she is not aware and cannot talk about it because she has not been involved “....I know a lot of gossip going round, that it's not equal, but I cannot look from that window...I trust...the administration of this department, and I do believe that they have a good criterion of selection, and since I don't know, since I haven't been involved in that...I mean, I'm not the right person to answer that."

They are all treated well, not just as basic students but also as sort of future colleagues, future public intellectuals, future academicians etc. Therefore, equal chances are given to them all, so same justice to all the gender, race and nationalities. They attend to students' needs equally. The idea of gender equity and social justice is very much present as deduced from the discussion with the participants. Nobody's gender gave or denied him/her employment or had made easy or tough their $\mathrm{PhD}$ programme. Though they may not like to voice out some issues, in their separate conversations, the participants on the presence or the absence of social justice, the following statements emerged from Basak and Elaheh respectively: ....I don't know. I haven't seen an absent of gender equity in terms of students or in terms of instructors...I never heard someone wasn't employed because he...is a man or a woman....A 
female $\mathrm{PhD}$ student gets easier her $\mathrm{PhD}$ because she's a woman and the man had to struggle more, not because of gender, no. I can't give you evidence for both, in order to do that I would be more involved in the department which I'm not.

...well there is obviously some happenings you can't deny it but no I can't deny it. I can't pin point anything to you... and say well this was the case...no I can't say it like that. But obviously, there were cases.... They try their best to avoid it and to control it as much as possible. She further says:

...you know generally speaking, we're living in a part of the world which is more...in favour of men. You know, and you can feel it in the culture generally...but in this department, can we intentionally put that burden on their shoulder? No. I'm definitely against it. We can't do, no. Invariably, there are certain issues which people, especially the students may be aware of, but do not want to point out. Consider the statements by the participants above. There are issues that people are rising eye-brow over but they seem to be managed well to avoid popping up in the public domain, and so, they are well controlled and managed.

\section{Gender Category of Preferred Teacher}

Reflecting on the discussion with the participants, $100 \%$ of them said that their teachers' gender as far as they are concern is not an issue in selecting who are to be their instructors for various courses, not even for thesis supervision. Neither the male nor the female instructors are preferred in no way by the students, rather the teacher who has a rich academic profile. A person who has distinguished himself/herself in an academic area. Even when choosing a thesis supervisor, what they consider as criteria for that are the instructors' areas of specialization, academic achievement, such as publications, and the ability to give students attention and prompt feedback. Some believe that being of the same gender with the supervisor gives a better 
chance for mutual understanding, to be of like minds, but that can only be the last option. Their general concern is self-improvement and development academically. When asked of the gender they would have preferred their instructors to be, Basak says:

I don't care. I don't choose my teachers according to gender. I choose my teachers according to the...information and the lecture and instructions I get.....Gender is not an issue. I look at publications, supervision ... practices. I mean, as per supervisor who really takes care of student and gives feedback. Is better to say 'ok, you're a $\mathrm{PhD}$ student, you've to do it yourself, you can meet me once in a while and you contact me.' That would be the criteria, weather its male or female that is not an issue for me.

While Elaheh says, she prefers genderless people. Those who are not interested in their gender identity. "My preference is genderless people ... if they can leave their gender preferences at the door and come to the class." However, in some sort of way, $33.3 \%$ of the participants may prefer female instructors as supervisors, just as Asli said “...been more likeminded and have a better relationship, maybe I would say I prefer...female, but only for that, but it doesn't have to be that way, but it is just may be." While Azra believes that female instructors are more lenient and more knowledgeable, “...I really observe like females have better...approach to the subject and have more detailed knowledge. I may say like...they're more lenient...more cooperative somehow." However, never in a way did they declare the female instructors to be their selected course instructors or thesis supervisors. Generally, the participants are not interested in the gender of the instructors that will teach or supervise them.

\section{Conclusion}

Conclusively therefore, the students believe their study at the university is aimful and appreciative. The instructors on the other hand are successful in their work and are in good 
control of their classes making the students relax and study with ease. They equally maintain a cordial relationship with their instructors. Meanwhile, as everyone enjoys equal social justice, there are unvoiced issues hidden in some quarters and are being managed. Though they all enjoy equal favour, some seem to enjoy more. There are some elements of gender discrimination but not too glaring. Then serious categories of struggles in the class. Lastly, the instructors are judged not by their gender but by their academic wealth of experience and achievements. This study haven considered the students' perspectives on gender, equity, social justice and beliefs, it therefore recommends that certain areas have not been covered by the current study and therefore recommend that a study of this nature can be conducted on the teachers too. There can also be a comparative study of this kind on the academic community and the host community of institutions.

\section{References}

Blair, E.E., and Miller, R.B., Ong, M., and Zastavker, Y. V. (2017).Undergraduate STEM Instructors' Teacher Identities and Discourses on Student Gender Expression and Equity, Journal of Engineering Education, 106(1), 14-43, DOI 10.1002/jee.20157.

Chang, B. (2018). Social Justice, in J.I. Liontas (ed.) The TESOL Encyclopedia of English Language Teaching. John Wiley \& Sons, Inc. DOI: 10.1002/9781118784235.eelt0137.

Daniel, M. C. and Koss, M. (2016). Exploring Perceptions of Gender Roles in English Language Teaching in C. Hasting and L. Jacobs (eds) Social Justice in English Language Teaching, USA, tesolpress.

Faust, H.J. (2016). Understanding Privilege: Considering for Teaching and Teacher Training Towards Social Justice, in C. Hastings and L. Jacob (eds) Social Justice in English Language Teaching, USA, tesolpress.

Hall, C. (2016). A Short Introduction so Social Justice and ELT, in C. Hastings and L. Jacob (eds) Social Justice in English Language Teaching, USA, tesolpress.

Kapur, K. (2016). Gender Sensitization as a Learning Outcome in C. Hastings and L. Jacob (eds) Social Justice in English Language Teaching, USA, tesolpress. 
Pedulla, D. S. and Thébaudb, S. (2015). Can We Finish the Revolution? Gender, Work-Family Ideals, and Institutional Constraint, American Sociological Review, 80(1), 116-139, DOI: $10.1177 / 0003122414564008$

Robinson, K., Shakeshaft, K. C., Grogan, M., and Newcomb, W.S. (2017). Necessary but not Sufficient: The Continuing Inequality between Men and Women in Educational Leadership, Findings from the AASA Mid-Decade Survey, Frontiers in Education, 2(12),1-12. doi:10.3389/feduc.2017.00012.

Rudman, L.A. and Phelan, J. E. (2010). The Effect of Priming Gender Roles on Women's Implicit Gender Beliefs and Career Aspirations, Social Psychology, 41(3),192-202. DOI: $10.1027 / 1864-9335 / \mathrm{a} 000027$

Sleeter, C., Montecinos,C. , and Jiménez, F.(2016). Preparing Teachers for Social Justice in the Context of Education Policies that Deepen Class Segregation in Schools: The Case of Chile in J. Lampert and B. Burnett (eds.) Teacher Education for High Poverty Schools, Education, Equity, Economy 2, DOI 10.1007/978-3-319-22059-8.

Ridgeway, C.L., \& Correll, S.J. (2004). Unpacking the gender system. A theoretical perspective on gender beliefs and social relations. Gender and Society, 18(4), 510-531. http://dx.doi.org/10.1177/0891243204265269

Ayers, W., Quinn, T., \& Stovall, D. (Eds.). (2009). Handbook of social justice in education. New York: Routledge. 


\title{
THE EFFECT OF MINIMUM WAGE AND SOCIAL ALLOWANCE POLICIES ON FEMALE EMPLOYMENT IN TURKEY
}

\author{
Leila SABOKKHIZ ${ }^{1}$ \\ Canan GÜLCAN ${ }^{2}$
}

\begin{abstract}
This paper attempts to analyze the effect of the minimum wage and social allowance policies on female employment in Turkey between the years 1994-2018. Turkey has one of the lowest female employment rates at $28 \%$ compared with OECD 64\%. The findings of the previous studies on the effect of minimum wage on female employment show that it can be positive or negative depending on the economic, political, cultural factors and especially the accompanying social policies.

Current study will empirically investigate the effect of minimum wage on female employment and social policies; birth, breastfeeding, kindergarten allowances and availability of part time jobs. The data obtained from World Bank, ILO and OECD for the period of 1994-2018. According to the empirical findings of the study, there is no relationship between minimum wage or the social policies and the female employment in Turkey over the investigated period.
\end{abstract}

Keywords: Minimum Wage, Female Employment, Social policies, Turkey

Jel Code: J3, J30, J31.J21

\footnotetext{
${ }^{1} \mathrm{PhD}$ candidate, Eastern Mediterranean University, Faculty of Business and Economic, Department of Economics, Famagusta-North Cyprus, leilassn@gmail.com.

${ }^{2} \mathrm{PhD}$ candidate, Eastern Mediterranean University, Faculty of Business and Economic, Department of Economics, Famagusta-North Cyprus. canangulcan81@ hotmail.com.
} 


\section{Introduction}

The effect of minimum wage (MW) on employment is one of the topics that the studies achieved different results through their studies. The findings of the previous studies on the effect of MW on employment show that the effect of MW policies varies according to the economic and social structures of every country (Broecke et al, 2017).

Investigating the relationship between MW and female employment is crucial to understand the role of economic and social policies in the level of female employment. Turkey is the country with the lowest female employment level (28\%) among OECD countries (OECD average \%64) (WB, 2018). This is why this study uses Turkey as a case study in the investigation of this relationship. There are a lot of determinants of female employment. This study limits its investigation on the government policies and aim to understand whether government policies (MW and social policies) foster or hinder female employment for the period 1994 to 2018 in Turkey.

\section{Background information on Minimum Wage and Social Policies in Turkey}

\section{Minimum Wage}

The MW is supposed to provide an appropriate standard of living for workers and reduce poverty and inequality. It should facilitate the conditions of employees to be fairer and organized in the most general sense (Gerek, 1999: 9-11).

In Turkey between the years 1988-1999, the minimum wage changed 12 times and doubling in nominal value in most cases. The initial decrease in the female employment rate in Turkey was massively based on the urbanization of the workforce after the 1950s. Before then, nearly all of the women in rural areas were employed in agriculture. For rural women household duties and work in agriculture were easier to be considered employed (Ozturk, 2007). But when women 
move to cities, they cannot find a place for themselves in the labor force of urban Turkey (Dayioglu, 1998; Ozar, 1996)

The level of MW in Turkey determined by a Government commission including members of business, labor organiations and government representatives (Fikret ,A.,\& Burcay ,B.2016). The number of MW workers from official statistics is not available in Turkey, while employee to evade taxes and social security report their incomes at lower levels. Indeed, in 2012, the Minister of Finance declared that about $45 \%$ of MW workers in the reports were receiving the MW (Fikret et al., 2016)

"Turkey has poverty among the working population. According to TurkStat (2011), 15\% of employed individuals were below the absolute poverty threshold of 825 TL ( $€ 382$ at the average exchange rate in 2009) for a household with four members in 2009 (note that 2009 is the latest year for which this figure was calculated)” (Fikret ,A.,\& Burcay ,B.(2016- P.1) pa The minimum wage was raised by $30 \%$ in Turkey in January 2016 , which represents the $22 \%$ inflation rate in 2015 but youth and women were paid less than MW in 2015(Fikret ,A.,\& Burcay ,B.2016). The studies on the effect of MWs on the Turkish labor market are limited and the findings are controversial.

\section{Related Social Policies and Laws}

Social policies are other terms that protect workers against risk and insecurity, like from job loss, health problems or disability that can be used to promote the position of women on the labor market by providing equal opportunities to women.

The Family Law of Turkey accepted husbands as the head of the family before 2002. This situation has been replaced expressig that both wife and husband have the equal management for the administration of families (Oktay \& Menteşe, 2002). In 2011, it has been decided that 
female workers should not be employed for a total period of 16 weeks, 8 weeks before birth and 8 week after birth (Clauses of Labor Law no 4857). Since 2012 it has been accepted that, female workers cannot be forced to work at night from the date they are confirmed by the medical report that they are pregnant. Those who have given birth also cannot be employed at night within the first year of delivery.

Moreover, pregnant or breastfeeding women cannot be employed for more than 7.5 hours per day. Pregnant employees are paid during their pregnancy for periodic checks. Also the right of mother to have 6 months unpaid leave after childbirth stated in 5th paragraph of Labor Law Article 74 will also be granted to one of the married couple.

Additionally, in the same year, a new policy has made a nursing room must in establishments where 100-150 women are hired. The nursing room can be inside or outside, but not within the 250 meters of the workplace. For companies with over 150 women workers, it is compulsory for the employer to establish aday care center (Article 13" issued in the official journal No. 28737, dated 16th August 2013).

In 2016, a right for breastfeeding was provided for women who have a baby less than a year old.

Accordingly, female employees shall be allowed a total of 3 hours for first 6 months, and one and a half for the second 6 months were approved.Also, it has been allowed that one of the working parents can work as a part time until the child begins to school (Article 13 of Labor Law No. 4857). In addition with the Provisional Article 5 which is appended to Unemployment Insurance Law No. 4447, these unpaid leave periods will be paid by employer, and insurance premiums and wages for off-hours will be covered by the state through Unemployment Insurance Fund.

"After the maternity leave, working women,(or the male or female adopter of a child under three years of age), may work half time up to two months on first childbirth, four months on 
second and six months for the third child" (Article 22 of Law on Amending Income Tax Law and Some Other Laws No,6663).

\section{Literature Review}

\section{MW and Female Employment}

The MW has different effect, negatively, positively or no effect on economic growth, balance of payment, distribution of income, employment and unemployment that depends on the degree of the development of the countries (Günsoy \& Tekeli, 2013). The most controversial effects of the MW are seen in the labour market.

Neo-classical economists argue that the minimum wage negatively affects employment and leads the workers who would like to work on fewer wages to become unemployed. Kramarz and Philippon (2001), Partridge and Partridge (1999) found negative relationship between minimum-wage and employment level.

In a Monopsonistic labor market model a MW set above the monopsony wage level will increase employment. Depending on the monopsony wage level, employment may decrease (Suryahadi et al.,2003: 29; McConnell et al., 2003: 412-414; Biçerli, 2011: 400-401; Neumark and Wascher, 2008:50-53).Card and Krueger (1994), Neumark, Cunnigham and Siga (2006) are supporters of this view in literature. Card and Krueger (1994)found that in the MW case the estimated labor demand curve may not be that much elastic.

Günsoy and Tekeli (2013) find no significant effect of MW on female employment. The low-skilled workers mostly employ in the informal sector in Turkey, Pelek in 2011, finds a positive effect of minimum wages on informal work for the low-skilled and, to a lesser extent, for medium-skilled young workers. (Broecke et al., 2017). 
Numerous studies in the literature focus on the effects of MW on female employment. However the studies on female employment show that besides economic factors, political, cultural and social factors are also important factors that affect the female employment (Günsoy \& Tekeli, 2013). In addition the studies on female labour force participation suggest gender wage gap, gender gap in education, long working hours, high informality rates, economic crises, lack of childcare opportunities, housework, childcare and elderly care, urbanization and marital status as important female labour force participation determinants (WB \& DPT, 2009).

Even so, Surya Hadiet et al. (2003) found a negative effect of MW on urban female employment in Indonesia. Montenegro and Pages (2003) examined the effect of the increase in MW in China, and found that it increased female employment but decreased employment among young and qualified employees (Montenegro \& Pages, 2003).

In Turkey, the female employment rate decline in the second half of the 20th century, followed by a slight increase after 2004. Toksoz argue that "The emergence of a labour supply that is sufficient to meet the demand for women's labour, and working conditions for women, is closely related to the way the patriarchal and capitalist systems operate" (Toksöz, 2016: p$65)$.

In Turkish labor market, part-time workers be paid 3 times more than full-time employees. Most of these workers are university graduated and 31 percent among of them are college-educated women according the survey Turkish Household Labor Force in 1988 (Ozturk, 2007). During the domination of agricultural production and employment, women usually worked as unpaid family workers in small agricultural activities.

\section{3-b- Social policy and Female Employment}

Social policies tend to strengthen female workers and facilitate the equality on female labor market. Although related regulations to female workers help to safeguard women's family 
responsibilities and increase their physical security, these policies can raise the cost to firms of employing women. "There is a wide-spread popular belief that unemployment can be reduced by reducing the number of hours worked per person. However, if restrictions on hours make labor less attractive to employers, they will substitute to other inputs, and there will also be a scale effect reducing use of all inputs" (Hunt, 1999: p-1).

If maternity policies are financed by firms, firms' demand for workers shifts leftward (Ruhm, 1998a). On the supply side, the workers will accept a lower wage for a given quantity of labor supplied (Summers, 1989). Therefore, the labor supply curve of shifts on the right. These shifts in labor demand and supply decline the female's relative wages. If leave benefits are financed mostly by the government, then the shift of the demand curve will be modest (Van der Meulen Rodgers, 1999). Waldfogel (1998) found that maternity leave policy help women to remain in the labor force and continue working with their former employer after childbirth. A negative relationship between fertility and women's employment was revealed (e.g., Lehrer \& Nerlove, 1986; Brewster \& Rindfuss, 2000). In overall, women workers prefer to have fewer children, and those with more children their labor participation rate decrease. The authors (Brewster and Rindfuss 2000; Ahn and Mira 2002) discovered that in OECD countries, negative correlation between total fertility and females' labour force participation (FLFP) before the 1980s and after that it shift positively (Günsoy \& Tekeli, 2013).

Child benefits may reduce labour supply through an income effect (Cahuc et al., 2014) and women with children tend to be more responsive to such transfers (Blundell, 1995). In fact, evidence from other countries suggests that there can be large negative effects of child benefits on female labour supply, which tend to be greater for women with lower skills (Jaumotte, 2003; Milligan \& Stabile 2009.Gonzalez (2013) analyses the fertility and labor supply effects of a large universal in Spain in 2007. She finds a negative labor force participation effect a year after birth, which however disappears by the time for the second child. 
According to the UNDP the statistics show, only six countries female employment remains lower than in Turkey (namely Jordan, Egypt, Morocco, Yemen, Oman and Saudi Arabia) (UNDP, 2007: 339-41). These statistics indicate Turkey as an Islamic country in the same culture as Arab countries with large Muslim populations. This survey would confirm the significance of religion as a cultural variable in female employment (Tzannatos, 1999) and it prove as a significant factor in society and politics in Turkey during the last few decades ( Buğra, \& Yakut-Cakar, 2010).

In Turkey, the employment policies have increased informal jobs and support the belief woman as homemakers and caregivers (Cosar-Yegenoglu, 2011).The related social policies to the female employment mainly instead of providing flexible forms of employment for women they tend to reverse the decreasing fertility and design to encourage women to continue childcare. Infant care services are insufficient and costly and the regulations of part-time labor raise costs for employers so under these conditions (low demand for female workers) the women confine itself to leave the labor market (Toksöz, 2016).

Usually governments have four policy goals; stable price level, full employment, balanced trade with low budget deficit and high economic growth. The government changes the interest rate by using monetary policy to influence the rate of inflation. Inflation can have different effect on female employment. In one hand, high inflation increases the cost of living, so females (as an added worker) decide to participate in labor force to help their family financially but this relationship can only exist in the short run. On the other hand, uncertainty which is the result of inflation, cause business failures. Due to a fall in demand, employment decreases and employers reduce their cost by employing part time workers only, thus female employment decreases in this situation.

Economists found that the poorest countries have the lowest participation rates, while the richest European countries have the highest participation rates. These correlations explain 
the U-shape, which show that in early stages of economic growth, female labor force participation tends to fall, and as a country advances in economic development it grows systematically.

In sum, it is theoretically difficult to predict the earnings effects of the MW on different groups of workers. All of these claims and theories show the true complexity of modeling of female employment as the labor market. The present paper primarily estimates the effect of minimum wage on female employment in Turkey using the data from World Bank, ILO and TUIK for the period 1994-2018. Regard to the aim of the study that is investigating the relationship between government policies and female employment we regressed female employment on minimum wage and social policies. Considering the relationship between macroeconomic performance and the employment level of a country, besides minimum wage and social policies as government policies, we chose inflation rate and the growth rate of the gross national income per capita as explanatory variables to capture economic fluctuations. First 2002 then 2005 year dummy variable used to capture the effect of social policies since social policies introduced in 2002. Since at the first date of applying the social policy the result is not clear so we chose also 2005 to see if the policies had any effects or not.

\section{Investigation the relationship of MW and social policies with Female Employment}

\section{Econometrics Analysis}

The data used in the study encompasses 25 observations starting from 1994 to 2018. In the study, five variables were used including female employment rate, real minimum wage, inflation rate, national income, and social policies ( 0 for before 2002, 1 for after 2002) as a dummy variable started from 2002 . For second time ( 0 for before 2005,1 for after 2005). The 
data was obtained from both World Bank and Turkish Statistical Institute (TSI) database and they were evaluated using Eviews 9 software.

\section{Methodology}

In the current study, we planned to investigate the effects of social policies and the minimum wage on female employment rate in Turkey using data from periods 1994 to 2018. Since we wanted to check the effects of government policies on female employment rate, we only added the variables including minimum wage, inflation, gross national income, and social policies dummy variable. For the purpose of the study, regression analysis was applied using eviews 9. The model specification for the study is as below;

Model 1:

$\mathrm{LFER}=\beta 0+\beta 1 \mathrm{LRMW}+\beta 2 \mathrm{LINF}+\beta 3 \mathrm{LGNI}+\beta 4 \mathrm{SP} 2002+\mu \mathrm{t}$ Model 2:

LFER $=\beta 0+\beta 1$ LRMW $+\beta 2 \mathrm{LINF}+\beta 3 \mathrm{LGNI}+\beta 4 \mathrm{SP} 2005+\mu \mathrm{t}$

Where;

LFER= Female Employment Rate

LRMW (Real Minimum Wage)

LINF ( Inflation)

LGNI ( Gross National Income per capita)

SP2002 (Social Policy as a Dummy Variable; “0” before 2002, “1” after 2002)

SP2005 (Social Policy as a Dummy Variable; "0" before 2005, “1” after 2005)

$\mu \mathrm{t}$ (error term).

\section{Econometrics Procedure}

For the best regression model, it is needed to check R2 of the model, existence of serial correlation in the residuals, existence of the heteroskedasticity in the residuals, and normal distribution of residuals. Accordingly, in order to check the suitability of the model, LM test, Breush Pagan Test, and Jarque Bera were applied, respectively. Finally, regression analysis was presented to forecast the model.

As a first step, we tested the serial correlation in the model. Serial correlation can be defined as the relationship between a variable and its lagg over time (Durbin \& Watson, 1951). In order 
to check the existence of serial correlation in the data, we employed Breusch-Godfrey LM test, and the results were shown in Table 1 as below. Accordingly, the findings of Breush-Godfrey serial correlation test indicated that there was no serial correlation in the residuals for dummy used after 2002 with a 0.2134 probability, and dummy used after 2005 with a 0.2013 probability. Additionally, we checked it with correlogram, and the results were also showed that there was no serial correlation in the residuals as shown in Table 2. These results pointed out that the model we tested was suitable to regress.

Table 1 Breusch- Godfrey Serial Correlation LM Test, Breusch Pagan Test, and Normality Test (Dummy used after 2002 and 2005)

\begin{tabular}{|c|c|c|c|}
\hline \multicolumn{4}{|c|}{ Jarque-Godfrey LM Test(Dummy used after 2002) } \\
\hline F-statistic & 1.094352 & Prob. & 0.4633 \\
\hline Obs R-squared & 15.53578 & Prob. Chi-Square & 0.2134 \\
\hline \multicolumn{4}{|c|}{ Breush Pagan Test for Heteroskedasticity (Dummy used after 2002) } \\
\hline F-statistic & 0.394947 & Prob. & 0.8098 \\
\hline Obs R-squared & 1.830173 & Prob. Chi-Square & 0.7670 \\
\hline \multicolumn{4}{|c|}{ Normality Test (Dummy used after 2002) } \\
\hline Jarque Bera & 2.254140 & Prob. & 0.323981 \\
\hline \multicolumn{4}{|c|}{ Jarque-Godfrey LM Test (Dummy used after 2005) } \\
\hline F-statistic & 1.754854 & Prob. & 0.2013 \\
\hline Obs R-squared & 4.079213 & Prob. Chi-Square & 0.1301 \\
\hline \multicolumn{4}{|c|}{ Breush Pagan Test for Heteroskedasticity (Dummy used after 2005) } \\
\hline F-statistic & 2.331696 & Prob. & 0.0910 \\
\hline Obs R-squared & 7.950740 & Prob. Chi-Square & 0.0934 \\
\hline \multicolumn{4}{|c|}{ Normality Test (Dummy used after 2005) } \\
\hline Jarque Bera & 1.927262 & Prob. & 0.3815 \\
\hline
\end{tabular}


Table 2 Correlogram (Dummy used after 2002 and 2005)

Dummy used after 2002

Dummy used after 2005

\begin{tabular}{|l|l|l|l|l|l|l|l|l|l|l|}
\hline \multicolumn{4}{|l}{ Dummy used after 2002 } & \multicolumn{4}{l|}{ Dummy used after 2005 } \\
\hline Lag & AC & PAC & Q-stat & Prob. & Lag & AC & PAC & Q-stat & Prob. \\
\hline 1 & 0.355 & 0.355 & 3.5414 & $\mathbf{0 . 0 6 0}$ & 1 & 0.382 & 0.382 & 4.1120 & $\mathbf{0 . 0 4 3}$ \\
\hline 2 & 0.044 & -0.093 & 3.5993 & $\mathbf{0 . 1 6 5}$ & 2 & 0.058 & -0.103 & 4.2112 & $\mathbf{0 . 1 2 2}$ \\
\hline 3 & -0.082 & -0.077 & 3.8068 & $\mathbf{0 . 2 8 3}$ & 3 & - & -0.171 & 4.9915 & $\mathbf{0 . 1 7 2}$ \\
\hline 4 & -0.185 & -0.143 & 4.9042 & $\mathbf{0 . 2 9 7}$ & 4 & - & -.0161 & 7.2260 & $\mathbf{0 . 1 2 4}$ \\
\hline 5 & -0.166 & -0.061 & 5.8294 & $\mathbf{0 . 3 2 3}$ & 5 & - & -0.034 & 8.4195 & $\mathbf{0 . 1 3 5}$ \\
\hline 6 & -0.123 & -0.062 & 6.3704 & $\mathbf{0 . 3 8 3}$ & 6 & - & -0.284 & 11.417 & $\mathbf{0 . 0 7 6}$ \\
\hline 7 & 0.021 & 0.071 & 6.3868 & $\mathbf{0 . 4 9 5}$ & 7 & - & -0.044 & 12.435 & $\mathbf{0 . 0 8 7}$ \\
\hline 8 & 0.016 & -0.062 & 6.3967 & $\mathbf{0 . 6 0 3}$ & 8 & - & -0.047 & 12.504 & $\mathbf{0 . 1 3 0}$ \\
\hline 9 & -0.103 & -0.153 & 6.8434 & $\mathbf{0 . 6 5 3}$ & 9 & - & -0.187 & 12.630 & $\mathbf{0 . 1 8 0}$ \\
\hline 10 & 0.034 & 0.112 & 6.8958 & $\mathbf{0 . 7 3 5}$ & 10 & - & -0.234 & 13.003 & $\mathbf{0 . 2 2 4}$ \\
\hline 11 & -0.153 & -0.255 & 8.0292 & $\mathbf{0 . 7 1 1}$ & 11 & 0.013 & 0.009 & 13.010 & $\mathbf{0 . 2 9 3}$ \\
\hline 12 & -0.211 & -0.117 & 10.351 & $\mathbf{0 . 5 8 5}$ & 12 & 0.214 & 0.099 & 15.383 & $\mathbf{0 . 2 2 1}$ \\
\hline
\end{tabular}

However, serial correlation testing is not enough to check the suitability of the model, therefore we continued with normality test to check whether residuals were normally distributed or not. The findings of Jarque Bera normality test shown in Table 1 indicated that residuals were normally distributed with 0.3239 (after 2002) and 0.3815 (after 2005) probabilities. Since the probability of the test is higher than 0.05 significance levels, we cannot reject the null hypothesis indicating that "residuals normally distributed". As a next step, we checked the heteroscedasticity of the series with Breusch Pagan Test. The findings showed that we cannot reject the null hypothesis "Series are homoscedastic" with probabilities 0.7670 (after 2002) and 0.0934 (after 2005). These results pointed out that the model we tested was suitable to regress. 
Table 3 Regression Analysis (Dummy used after 2002 and 2005)

\begin{tabular}{|c|c|c|c|c|}
\hline \multicolumn{5}{|c|}{ Dummy used after 2002} \\
\hline Variables & Coefficient & Std.Error & T-statistic & Probability \\
\hline $\mathrm{C}$ & -2.426443 & 0.920327 & -2.636502 & $0.0158 * *$ \\
\hline $\log$ GNIpc & 0.698859 & 0.166894 & 4.187446 & $0.0005 * * *$ \\
\hline $\operatorname{logINF}$ & 0.1222926 & 0.036477 & 3.369915 & $0.0030 * * *$ \\
\hline $\log \mathrm{RMW}$ & -0.161845 & 0.174366 & -0.928192 & 0.3644 \\
\hline $\mathrm{SP}$ & -0.050957 & 0.068443 & -0.744518 & 0.4652 \\
\hline F Prob. & 0.000010 & & & \\
\hline $\mathrm{R}^{2}$ & 0.745498 & & & \\
\hline
\end{tabular}

\begin{tabular}{|c|c|c|c|c|}
\hline \multicolumn{5}{|c|}{ Dummy used after 2005} \\
\hline Variables & Coefficient & Std.Error & T-statistic & Probability \\
\hline $\mathrm{C}$ & -2.842668 & 1.050779 & -2.705295 & $0.0136 * *$ \\
\hline $\log G N I p c$ & 0.733034 & 0.184936 & 3.963725 & $0.0008 * * *$ \\
\hline $\log \mathrm{INF}$ & 0.133315 & 0.028065 & 4.750217 & $0.0001 * * *$ \\
\hline $\log \mathrm{RMW}$ & -0.157115 & 0.174392 & -0.900931 & 0.3783 \\
\hline $\mathrm{SP}$ & -0.042959 & 0.065716 & -0.653710 & 0.5207 \\
\hline F Prob. & 14.52488 & & & \\
\hline $\mathrm{R}^{2}$ & 0.743916 & & & \\
\hline
\end{tabular}

*** denotes significance at 0.01

** denotes significance at 0.05

* denotes significance at 0.10

After checking the suitability of the model, we regressed the model and findings were shown in Table 3. According to the results, we only found that gross national income per capita and inflation were statistically significant for both after 2002 and 2005. However, both real minimum wage and social policies applied after 2002 and 2005 were not statistically significant. These findings for 1 st model which includes social policies after 2002 indicate that gross national income has a positive effect on female employment rate with a probability of 0.0005 ( $\mathrm{p}<0.01)$. Accordingly $1 \%$ change in gross national income, will lead to an increase by $69 \%$ in female employment rate. Similarly we found that inflation has a positive effect on female employment with a probability of $0.003(\mathrm{P}<0.05)$. This result indicated that a $1 \%$ 
change in inflation will lead to $12 \%$ change in female employment rate. The effects of real minimum wage and social policies applied after 2002 on female employment rate were negative, however they are insignificant with probabilities $0.3644(\mathrm{p}>0.01,0.05,0.1)$ and $0.4652(\mathrm{p}>0.01,0.05,0.1)$, respectively. Overall, R-square of $74 \%$ indicates that $74 \%$ of the data fit the regression model.

The results for 2 nd model which includes social policies used after 2005 were same with 2002, we only found that gross national income per capita and inflation were statistically significant. Similarly, both real minimum wage and social policies applied after 2005 have a negative relationship female employment rate but were not statistically significant. According to the results of the regression gross national income has a positive effect on female employment rate with a probability of $0.0008(\mathrm{p}<0.01)$. Accordingly $1 \%$ change in gross national income, will lead to an increase by $73 \%$ in female employment rate. Similarly we found that inflation has a positive effect on female employment with a probability of 0.0001 (P $<0.05)$. This result indicated that a $1 \%$ change in inflation will lead to $13 \%$ change in female employment rate. The effects of real minimum wage and social policies applied after 2005 on female employment rate were negative same as 2002, however they are insignificant with probabilities $0.5207(\mathrm{p}>0.01,0.05,0.1)$ and $0.3783(\mathrm{p}>0.01,0.05,0.1)$, respectively. Overall, R-square of $74 \%$ indicates that $74 \%$ of the data fit the regression model.

\section{Conclusion}

Our empirical findings show that there is no statistically significant relationship between the minimum wage and female employment in Turkey. These findings are consistent with the findings of Card (1992), Korkmaz and Çoban (2006), Güven et al. (2009); Günsoy and Tekeli (2013) in that the minimum wage does not produce any significant effects on female 
employment. We can also conclude that government policy doesn't hinder or foster female employment in Turkey. So minimum wage and social policy allowance are not effective on female employment in Turkey.

The findings of the study will be more conclusive with extended data set and inclusion of variables measuring the effect of social policies.

\section{References}

Ahn, N., \& Mira, P. (2002). A note on the changing relationship between fertility and female employment rates in developed countries. Journal of population Economics, 15(4), 667-682.

Biçerli, M K. (2011). ÇalismaEkonomisi, Beta BasimYayinDagitim A.S, Gözdengeçirilmis 6. Baski

Blundell, R. (1995). The Impact of Taxation on Labour Force Participation and Labour Supply (OECD Jobs Study Working Papers). doi:10.1787/576638686128

Brewster, K. L., \& Rindfuss, R. R. (2000). Fertility and women's employment in industrialized nations. Annual review of sociology, 26(1), 271-296.

Broecke, S., Forti, A., \& Vandeweyer, M. (2017). The effect of minimum wages on employment in emerging economies: A survey and meta-analysis. Oxford Development Studies, 45(3), 366391.

Buğra, A., \& Yakut-Cakar, B. (2010). Structural change, the social policy environment and female employment in Turkey. Development and change, 41(3), 517-538.

Cahuc, P., Carcillo, S., \& Zylberberg, A. (2014). Labor economics. MIT Press.

Card, D. (1992). Do minimum wages reduce employment? A case study of California, 198789. ILR Review, 46(1), 38-54.

Card, D. (1992). Using regional variation in wages to measure the effects of the federal minimum wage. ILR Review, 46(1), 22-37.

Card, David, and Alan B. Krueger. 1994. "MinimumWages and Employment: A Case Study of the Fast-Food Industry in New Jersey and Pennsylvania."American Economic Review. Vol. 84, No. 5 (December), pp. 772-93.

Cosar, Simten/Yegenoglu, Mesut (2011): New Grounds for Patriarchy in Turkey?

Gender Policy in the Age of AKP. In: South European Society and Politics 16(4),555-573. 
Dayioglu, M. (1998), "Labor Market Participation of Women in Turkey"in F. Acar and A. Ayata (eds.), Women's Identities and Roles in the Course of Change: Central Asia, East and Central Europe and Turkey, Duke University Press.

Fikret ,A.,\& Burcay ,B.(2016). Increase of minimum wage in Turkey and its potential impacts: ESPN Flash Report 2016/21.http://ec.europa.eu/social/main.jsp?catId=1135\&langId=en

Gerek, S. (1999). Türkiye'deAsgariÜcretlerveEnflasyon 1977-1999, AnadoluÜniversitesiYayınları, No: 1094, Eskişehir.

González, L. (2013). The effect of a universal child benefit on conceptions, abortions, and early maternal labor supply. American Economic Journal: Economic Policy, 5(3), 160-88.

Günsoy, G., \& Tekeli, S. (2013). Time series analysis for effect of the minimum wage on female employment in Turkey. International Journal of Business and Social Science, 4(6).

Güven, A., Ş. Mollavelioğluve B. Ç. Dalgıç (2009). “AsgariÜcretİstihdamıArttırırmı? (19692008) TürkiyeÖrneği”,Econ Anadolu 2009: AnadoluUluslararasıIlktisatKongresi, 17-19 Haziran 2009, s. 1-24.

Hunt, Jennifer. 1999. "Has Work-Sharing Worked in Germany?" Quarterly Journal of Economics 114(1):117-148.

Jaumotte, F. (2003). Female labour force participation: past trends and main determinants in OECD countries.

Korkmaz, A., \& Çoban, O. (2006). Emek Piyasasında Asgari Ücret, øşsizlik ve Enflasyon

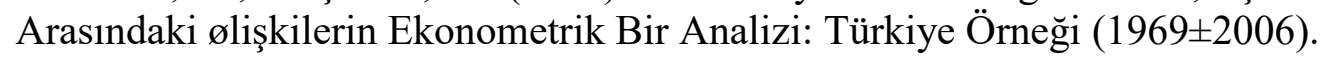

Kramarz, F., \& Philippon, T. (2001). The impact of differential payroll tax subsidies on minimum wage employment. Journal of Public Economics, 82(1), 115-146.

Lehrer, E., \& Nerlove, M. (1986). Female labor force behavior and fertility in the United States. Annual Review of sociology, 12(1), 181-204.

McConnell, C. R.,Stanley L. Brue ve David A. Macpherson (2003). ContemporarayLaborEconomics, McGraw-HillIrwin, Sixth Edition, Boston.

Milligan, K., \& Stabile, M. (2011). Do child tax benefits affect the well-being of children? Evidence from Canadian child benefit expansions. American Economic Journal: Economic Policy, 3(3), 175-205.

Montenegro, C.E. ve C. Pages (2003). "WhoBenefitsfromLabor Market Regulations? Chile 1960-1998”, NBER WorkingPaper, No. 9850, s. 77-110.

Neumark, D. ve W. Cunningham ve L. Siga, (2006). "TheEffects of the Minimum Wage in Brazil on the Distribution of FamilyIncomes: 1996-2001", Journal of Development Economics, 80 (2006), s. 136-159. 
Neumark, D. ve W.L. Wascher (2008). MinumumWages, Massachusetts Institute of Technology, ISBN978-0-262-14102-4, http://www.google.com.tr/books

Oktay, E.Y., \& Menteşe, B. (2002). Türkiye'de 2002 Y1lından İtibaren Kadın İstihdamına Yönelik Uygulanan Sosyal Politikalar.

Ozar, S. (1996).The Employment Aspects of the Informal Sector. In Tuncer Bulutay

Ozturk, O.D. (2007). Employment effects of minimum wages in inflexible labor markets. Available at SSRN 1113175

Partridge, M. D., \& Partridge, J. S. (1999). Do minimum wage hikes raise US long term unemployment? Evidence using state minimum wage rates. Regional Studies, 33(8), 713-726.

Pelek, S. (2011). The employment effect of the minimum wage on youth labour market in Turkey: A regional panel data analysis. Paper presented at the 2011 IIPPE Annual Conference, Istanbul, Turkey.

Ruhm, Christopher. 1998. "The Economic Consequences of Parental Leave Mandates: Lessons from Europe.” Quarterly Journal of Economics 113 (1): 285-317

Summers, Lawrence. 1989. "Some Simple Economics of Mandated Benefits." American Economic Review 79(2): 177-183

Suryahadi, A., W. Widyanti, D. Perwirave S. Sumarto (2003). "Minimum WagePolicyandItsImpact on Employment in the Urban FormalSector", Bulletin of IndonesianEconomicStudies, Vol. 39, No: 1, s.29-50.

Toksöz, G. (2016). Transition from 'Woman'to 'Family', An Analysis of AKP Era Employment Policies from a Gender Perspective. Journal für Entwicklungspolitik, 32(1/2), 6483.

Tzannatos, Zafiris. 1999. "Women and Labor Market Changes in the Global Economy: Growth Helps,

Van der Meulen Rodgers, Y. (1999). Protecting women and promoting equality in the labor market: Theory and evidence. World Bank, Development Research Group, Poverty Reduction and Economic Management Network.

Waldfogel, Jane. 1998. "Understanding the>Family Gap' in Pay for Women with Children." 


\title{
TO ENJOY THE BEST OF TWO SPACES: RECLAIMING OUR BODIES AND KITCHENS WITH HOME-MADE SEX HORMONES
}

Müge KATIRCI ${ }^{1}$

\begin{abstract}
One of the major issues that transgender individuals and other subjectivities who demand body adaptation confront is the procedure of taking hormones during the process of gender affirmation because of both the legal control of the state, and the economic control of pharmaceutical corporations. Considering difficulties on healthcare access, and economic struggle of queers; biohacking comes to light in order to produce and obtain sex hormones. In the cis-patriarchal world, biohacking mostly targets cisgender men, however biohacking also makes it possible to deviate cisgendered understanding. Researches on home-made sex hormones lead us to possibility on reclaiming our bodies as our very intimate spaces within tight budgets. Besides, making sex hormones with affordable and basic recipes in the house, and particularly in the kitchen leaves a door open to deconstruct the heteropatriarchal meaning of these spaces where cisgender women are confined, and it reveals a new image of the space where a transgender woman makes her own sex hormones as if she is cooking for dinner. The study focuses on the potential of home-made sex hormones on body-politics through the deconstruction of the conventional kitchen. The in-depth interviews with four participants who experience hormone therapy for body adaptation have been conducted during the research process in order to center their experiences.
\end{abstract}

Keywords: Biohacking, Transgender Subjectivity, Body Adaptation, Home-Made Sex Hormones, Kitchen, Economic Struggle

\footnotetext{
${ }^{1}$ Graduate Student in Gender and Women's Studies, Middle East Technical University, Gender and Women's Studies IIBF TURKEY mugekatirci@gmail.com
} 


\section{Introduction}

The geographer Linda McDowell (1999) claims that the concept of body has found a narrow space as regards to other categories of spaces since the body hasn't seen as a place by a major part of scholars in this field. However, over the last decades, the scope of research on body in academia enlarged, and discussions in this field helps to reveal the exercise of power over body. Within the perspective of Enlightenment legacy and rationalism, body has been considered as a unity of flesh and blood, and it is separated from the mind. Moreover, the mind has been exalted over the body. However, the power maintains its power through social body (Foucault, 1980).

In capitalist societies, the form of citizenship has shifted from the juridical model of rights and citizenship to biopolitical (Miller, 2007). Biopolitics provides a set of mechanisms to power in order to maintain its formed institutions through social body (Foucault, 1980). Since the power assigns sex for each body, sexual minorities are exposed the regulations of the power while they might take very little initiative. Rather than speak on sexual minorities as a whole, I intend to focus on people who wants and needs to body adaptation.

The inspiring idea which led me to work on body adaptation issue comes from a new study in United States of America. A group of biohackers have prototyped a urine hormone extraction protocol, revealed an open source on their work, and they created a speculative fiction film in which trans-femmes making their hormones in the kitchen in order to bring body and gender politics up for discussion (Maggic, 2015). In this short fiction movie, the artists starts with talking over challenges to provide and use estrogen as trans-femmes. And later, they imagine how it would be if they could synthesise estrogen with low-budget, easily found materials in their kitchens by developing a system of "do it yourself" (DIY) protocols (Maggic, 2017). 
The challenges of body-adaptation process do not pertain to United States. Also in Turkey, research to date, and expressions of subjects have brought out the the problems during their hormone therapy for transgenders. Therefore, I aim to discuss the idea of biohackers in USA within the Turkish context, and I planned carry out the work through two spaces: first, bodies in adaptation as a space where is defined, regulated, and controlled; and second, the kitchen where cisgender women are confined, and where trans women are excluded since their gender has been questioned within traditional understanding. To deliberate the issue I have decided to conduct in-depth interview with people who has experience on body adaptation in order to center their experience by following feminist methodology. At the beginning of this research I had planned to meet with transgender people, and particularly trans women, since the research focuses on estrogen usage. However, over the course of field work, I have met people who are both subjects of the issue, and also describe their gender identity out of the gender binary. With the respect of their declaration, I am going to speak on my work as a major issue of people who want and need body adaptation through hormone therapy because of the fact that all transgender people do not want or need body adaptation, or all people who want and need hormone-therapy are not transgenders.

In the part of field study, I completed in-depth interviews with four people. Three of them had or/and have hormone therapy with estrogen and testosterone blocker during their body adaptation process. On the other hand one of the participants is having hormone therapy with testosterone. Even though this research focuses on hormone therapy process with estrogen, I count him in, since he is medical staff and has knowledge to discuss deeply.

My main purpose to conduct this research is raising the topic of difficulties during hormone-therapy in cissexist society, and reconsider them as urgent issues for queer people. I also aim to investigate participants' opinions on hormone-making by DIY methods in return for the difficulties that they experience and whether they regards to DIY protocols as liberatory 
methods. And lastly, I look over their connection with kitchen, and question whether the fictional idea of biohackers could deconstruct the traditional position of the kitchen.

\section{Bodies in Adaptation as a Political Space}

The understanding which puts forward the binary between the body and mind tells that mind decides and body materializes (or in other word, embodies). From this point of view, initiative and control over civilians' bodies has been systematically given to power which is the mind of the society throughout the history of rationalism (Grosz, 1992). Nevertheless, the discourse of the power has been shifted along with the capitalist structure. In order to continuity of the population, and hence the embodiment of the power, power maintain its regulations based on the politics of make live or let die, instead of take life or let live (Foucault, 1976). Nonetheless, the life of people from certain identities is not valuable. Such approach has been particularly crystallized for sexual minorities. Women, bisexuals, transgenders, lesbians, gays, queers and so forth are exposed to vulnerable position before the power and its current sexual politics. In case of sexual health of individuals who experience body adaptation process, the deprivation of rights comes into focus.

From the clear classification on gender identities, trans subjects are addressed as patients based on particularly medical discourse, yet being transgender is an identity to whom both legal and medical rights are given with the perspective which sees transgenders as people who needs to be healed. Even so, to accord a set of rights does not procure the status of equal citizenship because government is liable to ensure transgenders being enjoyed their rights (Uygur, 2015: 126). Subjects who demand to enjoy their rights for body adaptation express many obstacles and challenges in course of practice of law, and related procedure. To procure sex hormones, the process of taking sex hormones, and the health of body which takes sex hormones are several of fundamental and major issues in this field. 
According to reports on statistics which are annually published by "Republic of Turkey Ministry of Health" (n.d.), the usage of sex hormones increases constantly over the years. I had to delimit the time period from the year 2003 to 2017 because the oldest report on the statistics of sex hormone usage in Turkey is from the year 2003. It doesn't exist any distinction between the consumers of the drugs as cisgender or transgender under the title of sex hormone usage. It also contains the consumption for birth control or prostate disease along with body adaptation. Related to this research the critical point is that the data have been reached through General Directorate for Pharmacy. Hence the data does not only indicate the drugs which are prescribed by doctors but also the amount of drug which are bought from the pharmacy without any prescription. The importance of this point comes from the fact that many people in body adaptation directly buy the drug from pharmacy without passing through medical examination, or prescription. On the following sentences, I am going to enlighten the reasons of such condition.

How does the process of taking sex hormones proceed for an individual in bodily gender adaptation while there is a constant increase on hormone consumption in Turkey then? In what ways this individual can provide sex hormone? In practical terms there are two ways to undergo hormone therapy. First, the individual who asks for bodily adaptation can take legal action on the matter, and take hormone therapy under the supervision of medic with the guidance of the court. Secondly, the individual can demand the hormone therapy drug from pharmacies without any guidance or prescription. However in both ways there are certain challenges which root in the lack of policies and LGBT+ phobia. Challenges in this field varies in many context such as physical, economic, social and so forth as follows;

The constraint on service in hospitals because of the fact that the process of sex hormone therapy in hospitals has to proceed in training and research hospitals which are few and not in every city. This leads to a mass in appointment schedule, and very long waiting process for 
people. In case of working system in hospitals, another major issue is discriminatory behaviors and attitudes of medical staffs. Ceyda, participant from Ankara, tells that they left the hospital at the first appointment because of the fact that they called them to doctor's room with assigned name not with the social name within all other patients. They also add that these kind of discriminatory protocols caused the most effective obstacle to prolong to their process of hormone therapy. At the end, Ceyda states this attitude as the politics for intimidation.

Economic challenges forms a major part of the issue for taking hormone therapy for transgender people since poverty concentrates among transgender subjects as is the case with other sexual minorities ( Lambdaİstanbul LGBTT Dayanışma Derneği, 2010). Hence, the sale of sex hormones drugs over high price leads a great difficulty for transgenders. In addition to this, health insurance, even the individual has it, does not cover sex hormone drugs unless the person is cisgender. However, I was already aware of many of these problems before starting to this research, I learned another which surprise me during one of the interviews. During the interview with Deniz, participant from İstanbul, she mentions that she is having difficult time to find a pharmacy where sells testosterone blocker since it is mostly withdrew from the market. When I asked her opinion for the reason to withdraw of the drug, she answers;

“ There isn't, I mean. Because being transgender isn't something important. Probably that is why. (Laughs)".

Usage of sex hormone does not pertain to transgenders on the other hand. Therefore, when I asked the situation for women with pink id cards, Deniz explains that estrogen supplement can be found in the market but not testosterone blockers what women with pink id card do not need. At this point, I would like to remark that testosterone blockers are used by trans women and also by elderlies. Herein, it is possible to realize the political approach of the power against another vulnerable category of the society. 
The field study that we conduct with participants demonstrates that taking hormone therapy requires towering financial strength for transgenders. Either with seeking medical guidance or buying directly from pharmacy with the information about drug's name, the dose, and the usage procedure based on experience sharing among transgenders, it requires to budget a robust part of the income. Deniz expresses that the changes on bodily change also causes the cost for new clothes and care products. At some point she says, with the cost of all expenses she had to decide whether she would starve or she would buy hormone therapy drugs. Also Ceyda tell that they had to budget 400 liras for hormone therapy while they were earning 1750 liras, and they only had 50 liras to do the month including their fare to work.

The pressure over the subjects having bodily adaptation is not only economical. Supplying hormone therapy drugs with queer subjects whether they have health insurance or not exposes them to feeling of discrimination as they experience in many sites of society while women with pink id cards can provide it without any fee through their health insurance. Beren, participant from Eskişehir, tells that she completed her body adaptation process with the financial support of her family, and did not have great difficulties as other participants had/has. Even though she had robust financial strength to cover the cost of her hormone therapy, she expresses her discomfort because of the discriminatory policies.

The relationship with medical staff and pharmacists varies with regards to experiences of each subject. The subject who wants to enter in the process of hormone therapy might have decided on doctor, or pharmacy based on the informations through experiment sharing among transgender subjects. Besides, the subjects might develop survival strategies in daily life while they provide the hormone therapy drug. Deniz details about her little pharmacy tour in İstanbul to buy the drugs. She expresses that if there are five men in the pharmacy she moves forward to find another one with the concern of any transphobic and discriminatory behaviour, but if 
women works in the pharmacy then she enters to buy. In other words, in the process of hormone therapy, subjects might have to be on alert in daily life.

In return for all of these challenges, is there any alternative way to have hormone therapy by eliminating transphobic and financially compelling procedures which gives very little initiative to the subjects? In order to seek the answer of this question, I direct my focus towards the work of Mary Maggic and a group of biohackers who discuss on homemaking sex hormone. Biohacking basically refers to manipulating the biology through medical, biomolecular, and technological innovations by do it yourself protocols (Malationo, 2017: 2). In mainstream understanding, we became familiar with the concept while biohacking generally targets bourgeois cisgender men in order to make men more masculine, more muscular, sexually more charged, and so forth (Maletino, 2017:4). Yet it is possible for us to discuss the concept of biohacking as a tool for speak on gender equality, and moreover to generate new methods for provide gender equality.

One of the strong examples of this idea is a method for abortion in the history. certain feminist groups in United States in 1970s attempted to develop their own reproduction means in order to liberate themselves. Carol Downer who refused the the governance of neither the state nor the doctor in reproduction as a feminist has built own device for the practice of menstrual extraction to regulate her reproductivity by own (Murphy, 2012: 158). She built the device for abortion with very basic, and cheap equipment which are easily found at grocery, hardware, and pet stores. The practice has been heard and learnt by experience sharing among women. She also obtained the patent of the device in order to pursue women's movement without any intervention by institutional agents because of the fact that these agents producing, marketing, selling, and distributing their own devices thereby regulating reproductive; and hence women's or transmen's bodies in high prices. 
Besides, hormone therapy drugs have been another turning point for the issues of body. The advances on the production of synthetic hormones rendered the body more manipulative. They become a manipulative attack to cisgenderism, and opens a way to fight against construction of sex as oppositions. moreover, they provide to transgender subjects a concordant body. However, it is well known that hormone therapy drugs are highly expensive and very regulated to enjoy this right. Lately, I have encountered with a project of producing own synthesis of estrogen, which is released with the name "Open Source Estrogen” (Maggic: 2015). The project is conducted but still driven in ongoing process by a group of queers. As the earlier example on menstrual extraction does, this project also has been started with the discussions on the politics of estrogen. Hence the executives of this project address the subjects of the issue in regards to challenge the regulations on our hormones, in a wider scope on our bodies. They provide a low budget practice to produce estrogen as former project on menstrual extraction also did since it is well known that women and queers do not possess the economic means as much as cis men have. Hence with the inspiration of the project of Mary Maggic and their other biohacker friends, I develop the idea with the participants of this research within the context of Turkey by discussions in interviews. Rather than speak on the outcomes of hormone extraction protocol for usage, we have focused on the video that same biohackers fictioned. On the video, we see trans-femme actresses when they synthesized their estrogen in the kitchen, and at the and we witness to their enjoyment based on the satisfaction of having full initiative over their bodies. On the other hand, any of the participants embraces the method properly when I question their opinions on making hormones with DIY protocols as a futuristic idea. Deniz tells that this is extremely dangerous and it shouldn't be followed by anyone. Ongoing dialogues between Deniz and me, shows that she refused the method since she thinks that the process of producing a drug is highly complicated as much that we can not understand with our current knowledge. However, at the and of the fictional video that we watched during the interview she tells that 
she should keep listen her sisters who hasn't medical education but a large scaled hormone therapy experience. She refers to her confidence to her sisters as long as the recommendations on hormone-therapy drugs are from the market of course. But, one of the major aims of Mary Maggic and their biohacker friends is demystification over biology, and drug making.

Sinan, participant who is medical staff, warns about the lack of regular tests, and doctor's supervision in the process of hormone therapy. Otherwise, he says, it has a risk of death in long term usage. The dilemma at this point is, the important part of estrogen takers in queer community provides the hormone therapy drugs directly from pharmacies without any supervision of doctors. Ceyda points out exactly this issue and tells that they are already very concerned about current situation, and adds that making hormone at home causes the less control than ever, and hence it may put the life and health of people in adaptation process into jeopardy. Nevertheless both Sinan and Ceyda leaves a door half-open at some point. They tell that if the project is executed in safe labs -according to Ceyda, if it is sterile, also in kitchenand leads to reduction of the costs then it is valuable to think over. Similarly during the drug crisis for AIDS, the drugs were overpriced. With the increase of new researches on the cure for AIDS lead to price reduction over the ones in the market (Luccini et al., 2003).

According to Ceyda, the reliability over the projects and and DIY protocols are not enough per se. It also requires to inform the subjects who experience these protocols properly. Because, both Ceyda and Deniz mention that there are many transgenders who can not afford the hormone therapy and seek alternative ways with hearsay methods such as drinking sage tea or consuming soy products, and some of them might be ready to seek another way without proper information or safety in order to take hormone therapy because of their vulnerable position on this issue. In other words, they say, there are some people who jump in to these protocols without guidance and become exposed to risks over health. 
Beren, on the other hand, rather than underline the risks on health, she tells that these kind of alternative methods do not liberate queers but do lead them to be out of right to health more than today. Beren also says that she does not want to hormone therapy issue as another site that she labour while this is already her right to have as much as cisgender women.

\section{Kitchen: Does It Change Hands?}

The kitchen has been planned as a secondary space to discuss with the intervention of queers making hormone therapy drugs. I approached to this spatial area as a site of confinement for cisgender women, and a site of exclusion and discrimination for trans women. When I framed the secondary part of the research, I had pictured the trans-femmes to synthesize estrogen to deconstruct both the traditional regard to kitchen, and the assignment of mind and science to men (particularly to cisgender men). However the participants who takes hormone therapy with estrogen discuss the definitions, norms, and performativity when we talk about gender identity. Each of them share the process of questioning gender binary, and identification on gender within themselves and their circles. Therefore their expressions about relation with kitchen are not for neither strengthen their gender identity nor changing the existing cissexist understanding in a decontructive manner, but only reveals their personal bond with the space. Ceyda who loves to spend time in kitchen does not build a relationship with the kitchen room as somewhere they develop their gender identity, but they exemplifiy the various actions that they can in the kitchen non-concerning the gender identity. On the other hand, Beren revealed her weak bond with kitchen as saying;

"To make something in the kitchen you need to have time and need to be psychologically fine. There is some time when you have no energy to go bathroom, and then, to crown it all, you go to kitchen and making hormones?" 


\section{Conclusion}

The field study has shown that the reducement on the prices of hormone therapy drugs is essential and urgent for subjects who experience body adaptation. However, to go out of the frame of institutionalized, and legal medical field does not lead to way for liberation, on the contrary it exposes the subjects who demand body adaptation through hormone therapy to endanger their health and life. Hence it also reinforces their vulnerable status within the society. Nevertheless, as some of the participants do, I hold the project on making own hormone therapy drugs in high regard for the efforts of executives of the project and its prospective effects on drug price. In addition to this, I also support the project within the context of concerning the demystification of technology and science. However it requires a serious effort to learn properly and to synthesize for the subjects at least at the beginning while their agenda is mostly covered with struggle in daily life. Therefore, the fundamental demand should be implementation of the rights through existing and promising institutions in order to ensure equal citizenship, and moreover positive discrimination should be practising in qualifying conditions in order to overcome poverty and social exclusion.

In this research, I had to opportunity to meet with people whom I am very thankful. Yet, in this research all of the participants are from metropolitans, and three of them have activist background. All of the participants have a friend circle who has been the similar experiences to share, and to guide them during their hormone therapy. Hence I am still wondering whether the transgender people from small towns without any guidance of a friend from similar subjectivities. In a digital age, with the robust network among transgender community such question remains without any projected opinion for me. To further studies, I recommend that the scope of participants should be enlarged, and it should be contains the subjects with the background from a different social, economic, geographical categories. 


\section{References}

Foucault, M., \& Gordon, C. (1980). Power/knowledge: Selected interviews and other writings, 1972-1977. New York: Pantheon Books.

Foucault, M. (2003). Lecture 11, 17 March 1976, 239-264 in Society Must Be Defended: Lectures at the College de France. New York: Picador Press.

Grosz, E. (1992). Bodies and cities in Sexuality and Space. ed. by Beatriz Colomina, Princeton: Princeton Architectural Press, pp. 241-255

Lambdaİstanbul LGBTT Dayanışma Derneği, (2010) İt iti 1sırmaz, İstanbul: Punto Bask1

Luccini et al. (2003), Decrease in prices of Antriretroviral drugs for developing countries: from political "philanthrophy" to regulated markets? Retrieved from http://apps.who.int/medicinedocs/documents/s18253en/s18253en.pdf

Maggic, M. (2015). Open source estrogen (2015). Retrieved from http://maggic.ooo/OpenSource-Estrogen-2015

Maggic, M. (2017) Housewives making drugs (2017). Retrieved from http://maggic.ooo/Housewives-Making-Drugs-2017

Malationo, H. (2017), Biohacking gender, Angelaki, 22:2, 179- 190,

DOI: $10.1080 / 0969725 X .2017 .1322836$

McDowell, L. (1999). Gender, identity and place: Understanding feminist geographies. Minneapolis: University of Minnesota Press.

Miller, R. A. (2007). The Limits of bodily integrity: Abortion, adultery, and rape legislation in comparative perspective. Boston: Ashgate Publishing

Murphy, M. (2012). Seizing the means of reproduction: Entanglements offeminism, health, and technoscience. London: Duke University Press

Republic of Turkey Ministry of Health. (n.d.), Retrieved from https://www.saglik.gov.tr/TR,11588/istatistik-yilliklari.html

Uygur, G. (2015). Toplumsal cinsiyet ve adalet: Hukuk adaletsizdir. Ankara Barosu Dergisi, 2015 (4). 121-132. 


\title{
SOCIO-SPATIAL CONSTRUCTION OF GENDER IN THE CITY, THE CASE OF RIZE, TURKEY ${ }^{1}$
}

\author{
Nagehan VANLIOĞLU YAZICI ${ }^{2}$ \\ İnci $\mathbf{B A S A}^{3}$
}

\begin{abstract}
This study is placed theoretically in intersecting fields of space and gender theories. With respect to Lefebvre's (1991) claim that "(social) space, is a (social) product" (p. 31), it is possible to state that the social relationships and routines of everyday life construct the space. Regarding this understanding, in this study the discursive relationship between gender and space is investigated. The study uses the pioneering works in both gender and space studies to lay out a theoretical framework and superimposes them on the concept of everyday life. It examines the experiences of women in the city, as one of the main subjects of gendered space; analyses their priorities, problems, workspaces, leisure time qualities, and cultural activities. It also focuses on the representation of woman in urban space, the barriers of gender, and the dichotomies faced by women due to the gendered space. After observing the discursive relationship between gender and space, the study investigates a case study; Rize, Turkey. By doing so, it aims to bring a new focus to existing studies made in the field while working on the image of women in the multi-layered socio-political structure of Turkey.
\end{abstract}

Keywords: Public Space, City, Gender, Women's Studies, Discourse

\footnotetext{
${ }^{1}$ This paper is based on unpublished master's thesis, titled 'Gender Discourse And Public Space: Socio-Spatial Construction of Gender in the City, the Case of Rize, Turkey' (2019). Which was completed at the Middle East Technical University.

${ }^{2}$ M.Arch. Middle East Technical Univesity, Ankara, Turkey, vanlioglunagehan@ gmail.com

${ }^{3}$ Prof. Dr. Middle East Technical Univesity, Faculty of Architecture Ankara, Turkey basa@metu.edu.tr
} 


\section{Introduction}

The 1960s were years marked by rapid transformation in social comprehensions. Some of the previously unquestionable issues were moved to the centre of public debate for the first time. A great number of common societal issues have begun to be discussed. This situation led to provide a social sphere with general freedom for critiques of the "others."

Since then, a variety of movements concerning different groups of people who were termed as minorities started to rise. In this societal atmosphere, people were also protesting for women's rights, for students' rights, and against war. The voice of the others started to be heard more, especially in universities as a matter of course. New departments were established, and studies on minority problems were led up. The academia recognized the existence of gender stratification, especially in the social sciences, with contributions such as analyses of gender issues.

Space was also another important topic in those years. In the early 1970s, geographers sought after different meanings of space. Henri Lefebvre (1991), an eminent philosopher and sociologist, stated that "(social) space is a (social) product." (p. 31) Within the framework of sociological consciousness, this approach to space opened fresh venues for social-sciencebased architectural studies. It was comprehended that architecture has vigorous connections with everyday life. As Diana Agrest (1991) claims:

Ideology is no more than the social production of meaning. Thus, all cultural production, such as architecture, when articulated at the economic and political levels, manifests the ways in which ideology is produced as part of a given social structure. (Accordingly, architecture itself must be approached as a particular form of cultural production as a specific kind of overdetermined practice. 
Within such an understanding, the relationship between space and gender is accepted as a non-negligible social issue. This way, an academic and societal focus was started in conformity with the problematic nature of this relation, and as a result, gender showed up as a strong concept in the spatial arguments.

Besides subjects such as migration, travel, borders, boundaries, place, and non-place, scholars who work in a variety of fields conducted studies concerning women in place. They touched on the issues of people who do not have a place and termed it as "displaced," especially focusing on women. These studies have continued until this day. By focusing on the problems in these fields, gender is accepted as a culturally-formed and spatially-positioned social performance.

Michel de Certeau (1984) says: "space is a practical place. Thus, the street geometrically defined by urban planning is transformed into a "space" by walkers." (p. 117) This sentence simply and perfectly summarises the production of public space by the user. Its production by its users' practice is actually what makes space political. Considering space as a political and strategic production, Lefebvre (1976) states, "Space is not a scientific object removed from ideology or politics. It has always been political and strategic.” (p. 31) According to him, space has its own ideology as a social product on the grounds that it appears to be homogeneous and exists in its objectivity.

This article focuses on the relationship between gender and space, with the understanding that space is a social product rather than a tectonic object. Also, it mainly focuses on women as one of the main subjects of gender theory. By doing so, the article attempts to create a background on the intersecting fields of gender and space theories; after that, with a case study, the article aims to render this problematic issue in a tangible environment. 


\section{The Construction of Gendered Space}

Before analysing a case study, mentioning significant points of this relationship and understanding the construction of the space under the domination of patriarchy are crucial. As mentioned above, this relationship is handled in many different ways from different fields of science and art.

The first concern that produces a gendered space is the representation and misrepresentation of women in the social sphere. Foucault argues about power relations that “our bodies, our lives, our day-to-day existences . . . between every point of a social body, between a man and a woman, between the members of a family, between a master and his pupil, between everyone who knows and everyone who does not, there exist relations of power." The social power arising from social acts is not rigid either. Obviously, it's created by representation. Within this understanding, it is not wrong to conclude that misrepresenting and excluding women from the social sphere and space withdraws women from power relations, which is an essential part of being in a social structure and also without access to this power, women continue to be excluded from the social space; this recreates and feeds gendered space structures.

Simon de Beauvoir (1989), the very influential intellectual concerning gender issues, states in her ground-breaking work of gender theory, namely The Second Sex, that:

In actuality the relation of the two sexes is not quite like that of two electrical poles, for man represents both the positive and the neutral, as is indicated by the common use of man to designate human beings in general; whereas woman represents only the negative, defined by limiting criteria, without reciprocity (p. 27).

In addition, this situation reveals another important issue of feminist geography, public and private space distinction. The distinction between public and private space is another 
crucial matter when it comes to the intangible captivity of women in their daily life and city. This division is rooted in the human body and self and can be seen in power relations, political issues, and popular discourses even though it is produced spatially. The ideology of separate spheres comprises the field of man-made public construction and the private space of its subproduction, and it also refers to women and men. In this context, ideology is both capitalist and patriarchal. By reproducing repeatedly, the public/private distinction is often used to build, control, and discipline the gender and sexual differences and protect heterosexist power formations. Additionally, this distinction determines how the genders should act in both spaces and also gives fewer rights to women than to men, by separating, in particular, the areas of work and leisure for women and men. By drawing the boundaries of the distribution of labour, it generally excludes women from the public sphere by confining them to the private space and home. However, in a patriarchal context, women have stereotypically determined home responsibilities. Gender performances tie them into the responsibility of caring for, cleaning, and organizing the home. This condition removes their right to decide things about themselves and their environment. Therefore, in a patriarchal system, the so-called women-related home belongs man. According to Nancy Duncan (1996);

Paradoxically the home which is usually thought to be gendered feminine has also traditionally been subject to the patriarchal authority of the husband and father.

'A man's home is his castle' — this familiar expression reveals the important historical link between masculinity, patriarchal autonomy and its spatial expression in the form of private property (p.131).

The body is an essential part of the gender and space relationship discussions due to its resemblance to inside and outside, core and shell as self and body. It is an essential instrument in the process of space production and a basic agent in space perception. According to gender 
theory the body is an essential part of woman's embodiment, existence, and identity. Also, public space and the users of public space can be seen as a vast collective body. The bodies play an important part in the creating a general social perception and the perception of the public space; therefore, the public body space is accordingly rendered as a failure, when the woman's body is misrepresented.

\section{The Case Study: Rize}

According to Lefebvre, "Every society - and hence ever mode of production . . . produces a space, its own space.” Following Lefebvre's terms, concentrating on a case study becomes essential to better comprehend and demonstrate social sphere production and social space. By doing this analysis, this work utilised semi-structured interviews, which were conducted with 20 women living in the city of Rize. Participants were selected from different age groups: 5 participants between the ages of 18 and 25, 4 participants between the ages of 25 and 35, 7 participants between the ages of 35 and 45, 5 participants between the ages of 45 and 55, and 5 participants over the age of 55. The interview questions were structured to analyse city perception, day-to-day city experience, feeling of security and fear, social life, and public and private space activities. The study aims to map the existing urban formations and perceptions by analysing the results of the interview.

Moreover, specific observations were made in the city, and gender densities are examined in different time periods in areas determined on maps. At these observation sites, the locations where social events and activities frequently happen in the city centre have been chosen. These selected sites were observed at noon and in the evening hours. By taking the averages from the observation results, maps of population distribution have been developed. 


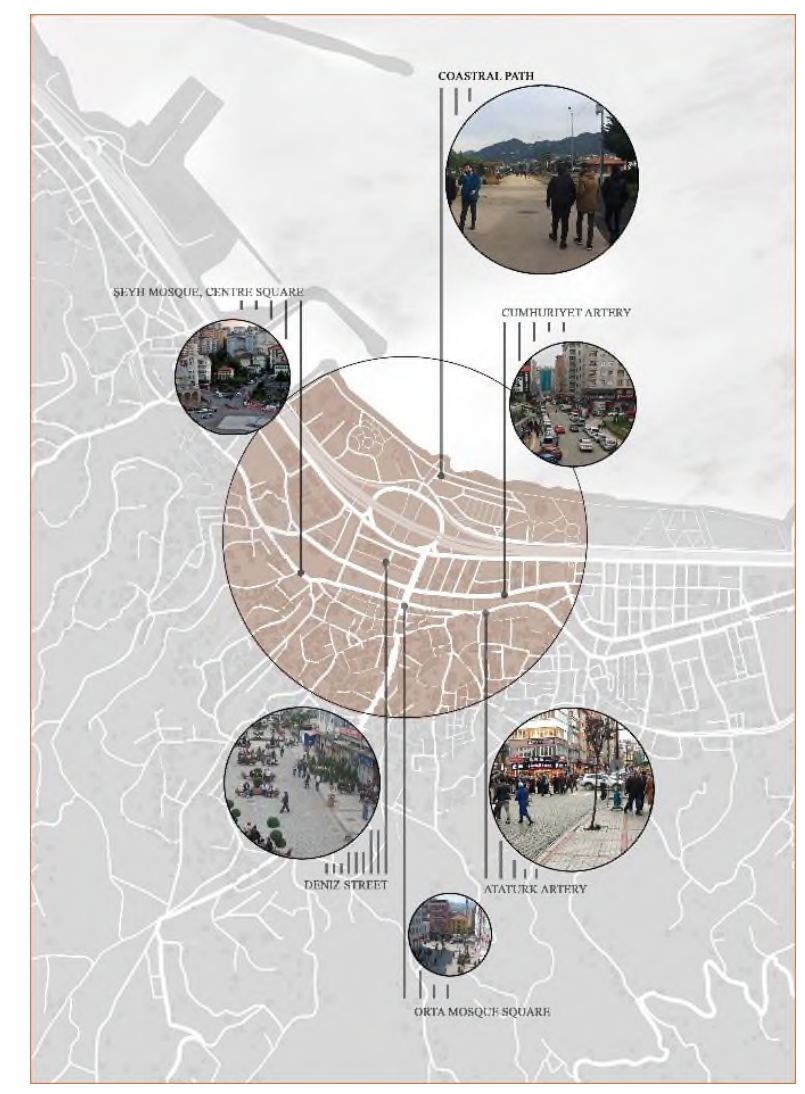

Figure 1: Observation Places

In the first and second questions of the interview, the respondents were asked to present their city and, in particular, the locations to go to the city and the locations to go to the city centre. All the respondents who mentioned the natural beauties of the city by mentioning its plateaus, mountains, and the sea found hard to answer when questioned about locations to go to the city centre. They stated that there were not too many options.

-In the city centre, Rize Castle, there is not anywhere else.

-Hmm... In the city center, let me think... A place to go specially... Maybe Rize Castle could be. And that is it.

-This is a hard question... Maybe the places on the mountain tops. There are not so many places near to city centre, unfortunately. 
Also, more than half of the respondents said they do not prefer to be in the centre in their daily life, except for their working life. A municipal worker stated;

-If I am not working, I try to keep it as low as possible, so maybe once a week or so.

In this respect, it would be precise to say that women did not develop an urban belonging link with the city centre. Participants were also asked which portion of their home they liked to spend most of their time. Although the responses were variable, they were gathered around the dining room, balcony, and kitchen. Then, when asked where they spent more time at home, apart from one single woman over 30 years of age, they all replied the kitchen. It would be precise to say that many women under 30 live with their family, and a woman owns the kitchen again. A housewife said;

-Home? I don't know, everywhere... I like my home. Most of my time goes by in the kitchen. But I prefer to sit on the balcony nowadays, in the summer time.

Another two different women at work from 8 am to $5 \mathrm{pm}$;

-Since I am a working woman, I can be in any part of the house. Since women get stuck with everything related to cleaning, I can be in any part.

-It wouldn't be wrong to say, I can't get out of the kitchen. After 5 pm, I enter the kitchen; when I leave, it is $9 \mathrm{pm}$.

As mentioned earlier, traditional patriarchal and heterosexist power structures are protected by public / private duality. This duality is used to control, regulate, discipline, restrict, exclude, and suppress genders. This situation not only excludes the woman from the social space and associates it with the home, but also limits all genders to prevent them from finding their own identities in the city. The women of Rize discover themselves willingly or unwillingly, in this duality, in the situation established for them by the patriarchy. As a consequence of this situation, women are excluded from the urban public space and forced to be in charge of domestic responsibilities such as cooking, cleaning, and organising. To 
demonstrate, when questioned whether they can do sports, they say they don't, not having time for it due to working and doing all the housework.

-No. I'd love to do sports, but I can't ... because I have two daughters. In the winter it is challenging when they are there. their school is open. You see... when you have a job, are a woman and are a housewife, some things are difficult. Honestly, we cannot make time for ourselves. I did sports for a while, but I couldn't continue.

When the participants were asked if there was an area they were afraid to go to, they said that they were not usually afraid. According to the answers, it would not be wrong to state that the feeling of security stems from the fact that Rize is a small city, where, as they say, "everybody knows each other." Although this is the general belief of women who have been living in the city for a long time, the following shows the city's map of fear (insecure places) for women according to at least one participant.

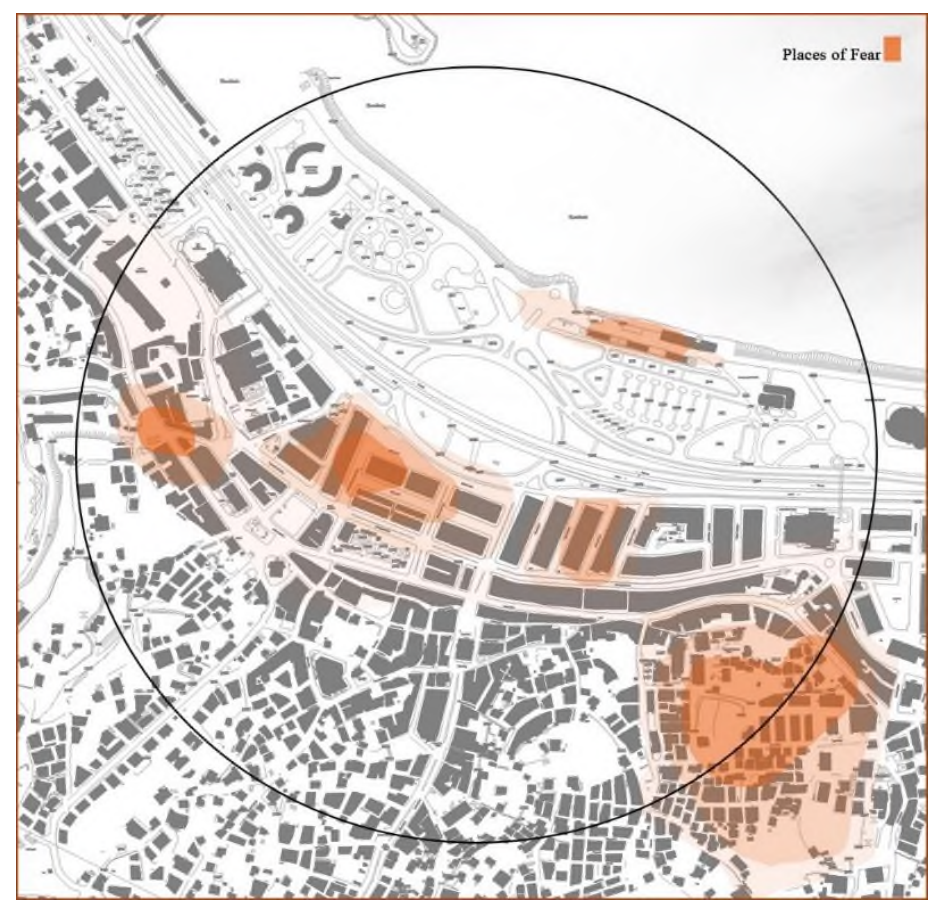

Figure 2: Map of Fear 
There is a misunderstanding that many women who participated in the survey generally stated that they are safe in the city, except in some small unsafe areas; however, they do their daily activities in the city at noon or in the evening, never mentioning other periods. For example, 9 and 11 a.m. were mentioned only once by two different women. In addition, these women stated these times as the most recent hours. Apart from them, no other participant said they went out relatively late. According to the results, it would be reasonable to say that women in this city do not prefer to be out at night. In women's perception, they may face problems such as harassment or theft at night, but they always think they are safe during the day. This shows how women were indirectly excluded from the city at night in the context of the patriarchal structure.

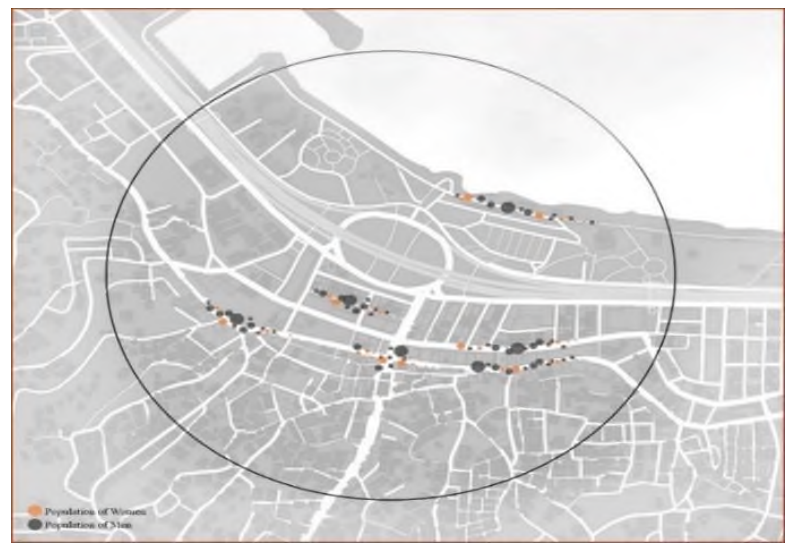

Figure 3:Population distribution at 14.00 pm

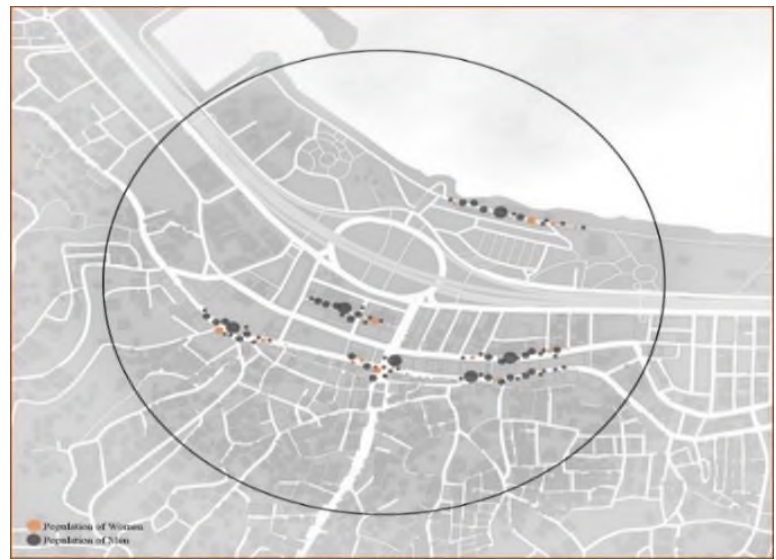

Figure 4:Population distribution at $20.00 \mathrm{pm}$ 
The maps below show the outcomes of the observations produced at 2 p.m. and 8 p.m. for three days in separate places. When the time distribution of the sexes on the maps is examined, the proportion of women in the maps decreases.

8 p.m. is seen as $41 \%$ when the density of men decreased by $21 \%$. Some participants also stated this situation about not being in late night in the city centre;

-Since I do not stay outside at nights, I don't know insecure places. But, not for ourselves but for our children, the surroundings of the schools, hmm... Deniz Avenue and Kahvehane being there, I don't like it. I don't like these kinds of stuff.

-Like 4 -5 p.m. I would not like to go at night, it is not so safe. I want to be at home at night. On the safety of the city, another woman stated;

-To be honest, there is not much... In that aspect, Rize is a safe city. But there is a place, I went through this before. The riverside under the Engindere bridge...Of course, a woman does not have to go there. But I was there to go to a plantation and pick some flowers... I saw some people who were drinking, and I was disturbed by their looks at me. Except that...aha maybe this...yes... The back alleys of Tophane ... I can say I feel anxious to go there even in the mornings. Yes, I am a teacher, I live in the city centre, I have lived in this city for so long but... I can't say that I know every place of it. I heard a lot of complains from my students about the region that the school is located in, the back alleys of Tophane Neighbourhood, we talked, there is certainly a problem there.

"Of course, a woman does not have to go there." This answer shows how the patriarchal structure dominates the gendered roles and the limits of the city. Even she believes there are places in the city that women should avoid. Besides, after this question, many women stated the discomfort they experienced because of the "staring" acts in the city.

-To be honest, every street that is not main, irritates me, you know the surface streets in Çarş1 region. 
-What do you think is behind that?

-No, I think the reason behind that is there are a lot of small coffeehouses and there are always men who sit in front of them... Old men...Here everyone looks at each other, not just those old men but while I was passing, them looking at me all together irritates me especially in the evening hours.

In order to comprehend the times during which they worked in the town, the participants were asked to answer the following query: are there any activities that Rize does not provide, in your view? About $81 \%$ of participants felt that Rize's activities were not sufficient, particularly the alternatives accessible to women.

-I mean since we cannot look at it as so much developed (as city), we don't have many choices, whatever there is. We have to go with what there is. We don't have the chance to choose. We can't choose. When you look at the art aspect, there is not an artistic situation; there is no theatre, there is not a place to tour, shopping malls are so few, we behave accordingly. Are there any outfits or accessories you don't prefer to wear or use in Rize? 77\% of participants replied that they had some clothes or accessories they didn't prefer to wear or use in Rize.

-Aaa...If it is possible, I prefer clothes that are not too revealing according to the standards of the city. Too revealing could be a mini skirt, eee... cleavage, plunging gown... I mean I prefer dressing conservatively as much as possible.

- I wear tights in Ankara. Or I don't wear the shirts that I wear in Ankara, here. I mean I don't wear skirts anyway, but I would not prefer Rize if I would.

These are a strict illustration of how essential it is for an individual to have the right to decide to accept himself and be one's self. Thus, women have another limitation in these examples through their bodies. To accomplish their daily activities, they should choose a proper mode of dress. Regarding the body as a fundamental part of existence, the complication of the body 
issues is quite broad. Another participant says again about her daughters and her own clothing by referring to the act of "staring";

-I don't like to wear revealing things because men stare at you. Everything is so restrictive. Of course, I am not for revealing clothes but when my children wear those kinds of things, they are annoyed by the stares, so I don't want them to wear things like that.

In this example, the term "revealing clothes" is essential again. Even a T-shirt can be called as "revealing clothes," and interestingly, not only by men but also by women. In the borders of Rize, Mothers warn their daughters not to wear clothes like that in public space. In addition, when mothers were asked where they didn't prefer their kids to go, $66 \%$ said there was no specific area they didn't want their children to go, $22 \%$ said they didn't want them to be in some areas late at night, and $12 \%$ said they didn't want their children to go to the coast alone. The mentioned regions are also rendered on the fear map above.

All the responses stand out that the city of Rize is an introverted and conservative town, with its own invisible rules engendered by its culture. The research respondents had a wide variety of time lived in Rize. Some were comparatively new to the town. However, most of them had long lived in this town, some even residing here from birth. Because Rize has a comparatively fresh university, respondents were asked if in the latest years they had noticed any changes in Rize and if so, what those changes were. The responses were mostly positive about the university. While the participants talked about the increase in activities and places to go, some of the participants talked about the change of culture. They noted that the patriarchal structure had started to soften with the newcomers to the city. 


\section{Result of Interviews and Conclusion}

The relationship between space and gender evitable. Limitations of one's ability are determined by space; thus, it also forms one's identity. In a manner, the human self becomes one with space. Following Virginia Woolf's words; the woman must have her own space, or, in other words, "a room of her own." to learn, to develop, and to advance. The place of women, her own room must be provided to embrace her own identity that is ignored by the patriarchal city.

While focusing on the case study, it is possible to observe this clearly, tangibly in a small and inward-looking city like Rize; public space is produced by people in that space, and this public space shapes people's perception in it. The more introverted a city's social structure, the more gender understanding develops in line with its own balance of power in the city.

Observations and the results of interviews show that Rize is a city under the effect of present gender roles, which also reproduce these roles continually in its cultural and political atmosphere. To better understand these reproductive processes, women's city experiences would be examined through their answers as their perceptions are significant in this study.

Even though women who live in Rize love their city, they state the lack of opportunities. They specify many reasons behind this deprivation; however, they do not relate them with patriarchy, which is the actual obstacle. To accommodate themselves to ideals and norms in society, and even to ensure their security, women change the way that they behave in their daily lives. For instance, for these women, there is no city after 9 p.m. Women withdraw from the public space as necessary accordingly to their perceived duty and roles, under a patriarchal domain which is supported by a neoconservative perception. Family and home are vital parameters in the socio-political conjecture, and women who connect themselves with these parameters, maintain their excluded position in the public space. 
This situation, while reinforcing unwanted women's image in the public sphere, is also the reason behind the visible or invisible barriers for women in the public space. Man dominated public space escalates this situation by having veiled entrance requirements for women to enter and use the space. Notably, women made changes that are considered appropriate in the perceptions of a patriarchal structure, even censure their clothing and bodies, and interiorize a perpetual concern regarding disapproval.

It is possible to see that with the University and new populations in the city, perceptions that cause a gendered structure and exclude women from the public space and the power relations underlying this, started to break down while creating little fractions in the conservative structure. Even though there is a wide range of scholarly works regarding gender studies, there are relatively few studies on gender in space theory. The studies on the relationship between gender and space are more restricted, especially in countries such as Turkey and cities such as Rize, which has a different perspective of women's situation and an utterly particular process of women's movement. It is vital to conduct studies from a spatial viewpoint, especially in such geographies that create social inequities regarding gender issues.

\section{References}

Agrest, D. (1991). Architecture from without: theoretical framings for a critical practice. Cambridge, MA: MIT Press.

Baydar, G. (2012). Sexualised productions of space. Gender, Place \& Culture, 19(6), 699-706. doi: 10.1080/0966369x.2012.675472

Beauvoir, S. de. (1989). The second sex. (H. M. Parshley, Ed.). South Yarra, Vic.: Louis Braille Productions.

Bondi, L. (1998). Gender, Class, And Urban Space: Public And Private Space In Contemporary Urban Landscapes. Urban Geography, 19(2), 160-185. doi: 10.2747/0272-3638.19.2.160

Butler, J. (1988). Performative Acts and Gender Constitution: An Essay in Phenomenology and Feminist Theory. Theatre Journal, 40(4), 519. 
Butler, J. (2015). Bodies that matter: on the discursive limits of "sex". London: Routledge.

Colomina, B. (Ed.). (1996). Sexuality and Space. New York (US): Princeton Architectural Press.

De Certeau, M. (1984). The practice of everyday life. Berkeley, CA: University of California Press.

Duncan, N. (1996). Bodyspace: destabilising geographies of gender and sexuality. London: Routledge.

Foucault, M. (2010). The Archaeology of Knowledge. London: Routledge.

Grosz, E. (2003). Bodies-Cities. In A. Jones (Ed.), The feminism and visual culture reader. London: Routledge.

Kandiyoti, D. (1996). Gendering the Middle East: emerging perspectives. New York: Syracuse University Press.

Lefebvre, H. (1976). Reflections on the Politics of Space. (M. Enders, Trans.) Antipode. 8. 3037.

Lefebvre, H. (1991). The production of space. Blackwell, Oxford.

Madanipour, A. (2014). Public and Private Spaces of the City. Abingdon, Oxon: Taylor and Francis.

McDowell, L. (2007). Gender, identity and place: understanding feminist geographies. Minneapolis: Univ. of Minnesota Press.

Rendell, J. (2007). Gender space architecture: an interdisciplinary introduction. London: Routledge.

Vanlıoğlu Yazıcı, N. (2019). Gender Discourse and Public Space: Socio-Spatial Construction of Gender in the City, the Case of Rize, Turkey. Unpublished master's thesis, Middle East Technical University, Ankara.

Woolf, V. (1991). A room of one's own. Orlando: Harcourt, Inc. 


\title{
DOES GENDER EQUALITY IN EDUCATION MATTER FOR AIR POLLUTION IN SUB-SAHARAN AFRICA?
}

\author{
Nezahat DOĞAN 1
}

\begin{abstract}
This study provides a macrolevel framework for gender issues and its link to energy policies and environmental quality, in line with the sustainable development goals (SDG). It examines the relationship between air pollution, gender equality in education, energy consumption and income of the Sub-Saharan Africa for the years between 1972 and 2014 by using cointegration analysis and autoregressive distributed lag (ARDL) method. Estimation results of the study is consistent with Environmental Kuznet Curve (EKC) hypothesis in both short run and long run and shows that gender equality in education has negatively related with air pollution in SubSaharan Africa. Therefore, as a policy recommendation, gender equality should be considered as a part of energy and environment policies.
\end{abstract}

Keywords: CO2 Emissions, Gender Equality, SDG, Sub-Saharan Africa

Jel Codes: J16, Q53, Q01, N57

\footnotetext{
${ }^{1}$ Assoc. Prof. Dr. Final International University, Department of International Finance Kyrenia North Cyprus, nezahat.dogan@final.edu.tr
} 


\section{Introduction}

The Sustainable Development Goals (SDG) setting some global objectives for 15 years from 2016 to 2030 have adopted by United Nations to improve the life of both current and future generations as a development agenda and replacement of Millennium Development Goals (MDGs). It provides some common standards and targets related to economic, social and environmental issues that affect all population and the planet. Achieving gender equality and empower all women and girls (goal 5) and taking urgent action to combat climate change and its impacts (goal 13) are only 2 of 17 objectives $^{1}$ mentioned in SDG 2018. The aim of this paper is to address gender equality and environmental problems in terms with the context of SDG in sub-Saharan Africa ${ }^{2}$ and to examine the role of gender equality with its education dimension in air pollution in the region. The United Nations Economic Commission for Africa (UNECA) report (2015) written about implementing MDGs mentions that in term of goal7 of MDGs (ensuring environmental sustainability), carbon dioxide emissions have increased in most of the regions except Africa between 1990-2010 years. However, the proportion of the land area covered by forest has reduced by $3.1 \%$ in sub-Saharan Africa, while it was $1 \%$ globally. It shows that deforestation discharging carbon dioxide into the atmosphere was higher in the region than other parts of the world.

In line with these, This study is looking for the answer of following questions; i) Does income per capita has a positive impact in $\mathrm{CO} 2$ emission of sub-Saharan Africa?, ii) Does $\mathrm{CO} 2$ emission start decreasing when income per capita reaches a certain point?, iii) Does higher level

\footnotetext{
1 Available at: https://unstats.un.org/sdgs/files/report/2018/TheSustainableDevelopmentGoalsReport2018.pdf

2 Angola, Benin, Botswana, Burkina Faso, Burundi, Cabo Verde, Cameroon, Central African Republic, Chad, Comoros, Congo, Dem. Rep., Congo, Rep., Cote Ivoire, Equatorial Guinea, Eritrea, Ethiopia, Gabon, Gambia, The, Ghana, Guinea, Guinea-Bissau, Kenya, Lesotho, Liberia, Madagascar, Malawi, Mali, Mauritania, Mauritius, Mozambique, Namibia, Niger, Nigeria, Rwanda, Sao Tome And Principe, Senegal, Seychelles, Sierra Leone, Somalia, South Africa, South Sudan, Sudan, Swaziland, Tanzania, Togo, Uganda, Zambia, Zimbabwe
} 
of energy consumption of sub-Saharan Africa lead higher CO2 emission, iv) Does gender equality in education has positive impact on $\mathrm{CO} 2$ emission?

\section{Literature Review}

Though sub-Saharan Africa shows grate effort on gender equality progress and limiting greenhouse gas (GHG) emissions regarding with MDG7, she has a higher fertility rates rather than other parts of the world without increase in economic growth over the years from 1960 to 2015 (World Bank, 2016). According to Amegah and Mensah (2017), rapid increase in the population of sub-Saharan Africa (625 million) leads rising in vehicle ownership and using more solid fuels for transportation, heating and cooling purposes, that result in higher $\mathrm{CO} 2$ emission and health problems in turn. However, almost half of this population is at below age 15 , that is seen a sign of potential for future economic growth in the region. This rapid increase in population without an adequate planning results in higher pressure on need for industrialization and improved infrastructure. In turn, adverse effects of industrialization in subSaharan Africa may bring negative outcomes for carrying capacity of its environment in the long term. This cycle can be explained by Environmental Kuznet Curve (EKC) hypothesis that shows relationship between economic growth and environmental pollution. According to the Grossman and Krueger (1991), the relationship between environmental degradation level and economic growth is like inverted $U$ shape curve. However, the relationship between these variables with a specific subject related to gender within the EKC framework has not evaluated in the literature. In this regard, this study will be a pioneer study showing the link between gender equality and $\mathrm{CO} 2$ emission by using gender embedded EKC hypothesis.

Women and environment or pollution studies are limited in general, but it is much more lesser for the case of sub-Saharan Africa. One of the pioneer report was written by World Bank 
Group in 1994 about population, agriculture and environment nexus in sub-Saharan Africa. Growth in population, decrease in agricultural performance and environmental degradation were defined as three basic concern in the region. One of the key action plans suggested by World Bank to promote environmental friendly development was improving women's productivity through education training policies. Very recently published study by Amegah and Mensah (2017) outlined the urban air pollution in sub-Saharan Africa within the international policy actions including SDG by associating pollution with its impacts on health. They mentioned that the cost of air pollution could be as high as $2.7 \%$ of national income of subSaharan Africa.

As a result, all the studies in the literature regarding air pollution consider the gender as a biological difference within the framework of household roles, without considering its educational dimension. The present study revisits the relationship between growth, energy consumption and pollution nexus in the sub-Saharan Africa and contributes the existing literature in several ways. First, this study provides new evidence to the existing investigations by considering the female education in sub-Saharan Africa. The results address the importance of the female education for the air pollution with regards to SDGs. Second, instead of focusing the gender and energy link in micro level, this study analyses the gender related pollution issue from macro level. Therefore, the results of this study will be interesting for both national and international policy makers, interest groups, and researchers.

\section{Data and Methodology}

According to EKC hypothesis, environmental pollution is the function of the economic growth indicating with income per capita. This study takes gender parity in 
education as an indicator of gender equality into account and following function given below is employed;

$C O 2=f(G D P P C, G D P P C 2, E, G P I)$

$\mathrm{CO} 2$ refers the carbon dioxide emission which is stemming from the burning of fossil fuels. GDPPC is the gross domestic product per capita in US dollar. E indicate primary energy consumption, and GPI is the gender parity index that shows the ratio of girls to boys enrolled at primary and secondary levels. All data are is gathered from World Bank development indicators database for the years between 1972- 2014. In order to test the relationship between $\mathrm{CO} 2$ emission and economic growth, the model is estimated as below;

$$
\mathrm{LCO}_{t}=\mu+\alpha_{1} L G D P P C_{t}+\alpha_{2} L G D P P C 2_{t}+\alpha_{3} L E_{t}+\alpha_{4} L G P I_{t}+\varepsilon_{t}
$$

Here, $\mathrm{L}$ indicates natural logarithms, $\mu$ is the intercept, $\alpha$ is the parameters in estimation, $\varepsilon$ is the error term and $\mathrm{t}$ is the time. LGDPPC2 is calculated as $(L(G D P P C))^{2}$.

\section{Unit Root Tests}

Augmented Dickey Fuller (ADF) and Phillips-Perron (PP) tests, which are most wellknown and widely used unit root tests, are conducted to check stationarity of the variables used in this study. They test the null of unit root (denoted as I (1)) against the stationarity of the data (denoted as I (0)). Table 1 reports the unit root test results. According to results of the unit root tests, non-stationarity is detected in their levels, but null hypothesis of a unit root (no stationarity) is rejected when data is in their first differences.

\section{Cointegration Tests}

Table 2 reports the associated bound test results with the critical values calculated for $5 \%$ level. According to the results, there is no cointegration for the model without deterministic 
trend, while all calculated F statistics are higher than the upper bound for the models with deterministic trends. Hence, we can conclude that there is cointegration among variables only if we can consider the deterministic trend in our estimations. Therefore, in all estimations, trend is added to the regressions in line with the bound test results.

\section{Empirical Results}

\section{ARDL Model and Estimation Results}

Table 3 reports the ARDL estimation results of level equation with constant and trend. Estimated long run coefficients of energy consumption and gender parity are highly significant at $1 \%$ level, while the coefficients of income per capita is significant at $5 \%$. The coefficients also indicate elasticities of the variables. LGDPPC as a measure of income per capita has a positive significant impact $(0.55$ with $\mathrm{p}<0.05)$ on $\mathrm{CO} 2$ emission of sub-Saharan Africa, which estimates that a $10 \%$ increase in income per capita leads $5.5 \%$ rise in $\mathrm{CO} 2$ emission level of the region. LGDPPC2 as a measure of higher level of income has negative significant impact (0.039 with $\mathrm{p}<0.05)$ on $\mathrm{CO} 2$ emission of the region. This can be interpreted as $10 \%$ increase in higher level of income per capita will decrease the pollution level by $0.39 \%$. The results are consistent with the inverted U shaped EKC hypothesis discussed in section 3 due to having positive sign of LGDPPC and negative sign of LGDPPC2. This means that a growth will lead higher pollution at its initial levels, but then, it will cause a positive impact on air pollution in line with EKC hypothesis. This result agrees with other studies testing the EKC hypothesis for the sub-Saharan Africa (Kivyiro and Arminen, 2014; Shahbaz et al, 2015; Boutabba, Diaw and Lessoua, 2018).

Another indicator used as a function of $\mathrm{CO} 2$ emission is energy consumption. The results show that $1 \%$ increase in energy consumption rises the pollution level by $2.5 \%$ 
$(\mathrm{p}<0.001)$. Therefore, in line with the estimation results, sub-Saharan Africa should promote the energy saving production strategies to improve the air quality while growing.

As an indicator of gender equality, gender gap in education has a negative significant sign, which indicates that $1 \%$ increase in gender parity in education will decrease $\mathrm{CO} 2$ emission by $3.51 \%$. GPI is the gender parity index is defined as the ratio of girls to boys enrolled at primary and secondary levels. From the definition of the variable, one can conclude that any increase in female education at primary and secondary level will have positive impact on $\mathrm{CO} 2$ emission level of the region. This variable was the main concern of the paper and estimation result support that of having more female in education will improve the environmental quality in the region. However, this study does not explain the reasons for the relationship between female education and $\mathrm{CO} 2$ emission more specifically. As it is mentioned at the introduction, the main focus of the paper is providing the macroeconomic view to the gender in education into pollution and energy policies in regards to SDGs. From this point of view, we can conclude that environmental quality will be improved through integration of gender considerations in environment policies and women's contribution to the energy sector, when gender inequality in education is removed. From the estimation results, female share in education elasticity of $\mathrm{CO} 2$ emission in sub-Saharan Africa is highly elastic with the value of 3.51. The finding of positive influence of education on environment is supported by the other studies (Holmes, 2003; Dias et al., 2004; Asadullah and Rahman, 2009) as well, that are not directly focusing on the women education. The results also support the finding of Economic and Social Research Council (ESCR) survey (2011) based on 22000 people. They found that "the more educated people with degrees are $25 \%$ more likely than people with no education to adopt proenvironmental behaviors" and "women are more likely than men to adopt pro-environmental behaviors". These results suggest that girls' skills in climate, environment and energy solutions can be possible through their education. Positive impact of the female education can be 
explained by different arguments. For example, more educated women's willingness to behave environmentally friendly will be higher than uneducated women due to their increased sensitivity or awareness gained through education. When assumed that access to employment opportunities of educated women become easier with education, their willingness to pay more for environmentally friendly products is expected to be higher. Because of the roles assigned to women within the households, knowledge and information regarding the environment is transferred into future generations as well. Table 4 reports the short run coefficients derived from equation 5. The short run coefficients are also consistent with inverted $\mathrm{U}$ shaped EKC hypothesis. The sign of energy consumption is again positive and highly significant in short run as it is in long run. The short run coefficient of female share in education is parallel with the long run test results, which affects $\mathrm{CO} 2$ emission in a positive way by decreasing its level. As a result, we can conclude that both in short run and long run, higher female share in education leads lower level of $\mathrm{CO} 2$ emission, which improves air quality. The coefficient of lagged ECT is negative, as a proof of convergence and is highly significant at $1 \%$ level. Its value is -0.74 which means that the speed of adjustment to equilibrium after a shock is approximately $74 \%$. In another word, $74 \%$ of the disequilibria from a shock occurred in last term converge back to the long run equilibrium in the current term.

\section{Conclusion}

This paper investigates the long run relationship between $\mathrm{CO} 2$ emission, as a measure of the air pollution, and female education in sub-Saharan Africa, in line with the sustainable development goals (SDG). Energy consumption and economic development are also considered as a function of $\mathrm{CO} 2$ emission level of the region. The outcome of this paper implies that the variables used in the study has a long run relationship and the results are consistent with 
EKC hypothesis for the region in both short run and long run. Most importantly, estimation results show that female education has highly significant positive impact on decreasing $\mathrm{CO} 2$ emission. However, the study does not focus on the differences within the region and evaluate sub-Saharan as a whole one single region. Differences within the region can be the concern of another study.

From this point of view, all the goals of SDGs are equally important for sustainable development of sub-Saharan Africa. All policy makers should pay a special attention on environmental issues with their solutions embedded into gender equality. All stakeholders including governments should monitor progress on equal opportunities in education and develop some appropriate strategies to gain from its reflection on all other socio economic and environmental issues. All gender and environmental issues should be integrated into all aspects starting from planning to implementing. Policy makers, starting from local governors to international organizations should support the girls' education and train people effectively to address the link between growth, environmental awareness and gender equality.

\section{Tables and Figures}

Table 1. Unit Root Test Results

\begin{tabular}{|c|c|c|c|c|c|}
\hline \multirow[b]{3}{*}{$\mathrm{ADF}$} & \multirow{4}{*}{$\begin{array}{l}\text { Variables } \\
\text { LCO } 2\end{array}$} & \multicolumn{2}{|l|}{ Level } & \multicolumn{2}{|c|}{ First differences } \\
\hline & & & Intercept & & \\
\hline & & Intercept & trend & Intercept & Intercept \& trend \\
\hline & & $-2.088024(0)$ & $-3.044739(0)$ & $-6.877945 * * *(0)$ & $-6.814338 * * *(0)$ \\
\hline & LGDPPC & $-1.997093(1)$ & $-2.620852(1)$ & $-3.932974 * *$ & $-3.962434 * *$ \\
\hline & LGDPPC2 & $-1.716362(1)$ & $-2.341161(1)$ & $-4.020982 * * *(0)$ & $-4.005381 * *$ \\
\hline & LE & $-1.782782(0)$ & $-1.986991(0)$ & $-7.398085 * * *(0)$ & $-7.380393 * * *(0)$ \\
\hline & LGPI & $-1.059430(0)$ & $-2.786875(0)$ & $-7.537337 * * *(0)$ & $-7.525602 * * *(0)$ \\
\hline$\overline{\mathrm{PP}}$ & LCO2 & -2.364257 & -3.127023 & -6.865731*** & $-6.802301 * * *$ \\
\hline & LGDP & -1.444783 & -1.943347 & $-3.932974 * * *$ & $-4.028120 *$ \\
\hline & LGDPPC2 & -1.208458 & -1.815193 & $-4.068304 * * *$ & $-4.049163 * *$ \\
\hline & LE & -1.828136 & -1.968616 & $-7.355251 * * *$ & $-7.338545^{* * *}$ \\
\hline & LGPI & -1.211734 & -1.211734 & $-7.759365 * * *$ & $-7.782321 * * *$ \\
\hline
\end{tabular}


Table 2. Bound Test Results at \%5 level

\begin{tabular}{|c|c|c|c|}
\hline $\mathrm{k}=4$ & & $\begin{array}{l}\text { Lower } \\
\mathrm{I}(0)\end{array}$ & $\begin{array}{c}\text { BoundUpper Bound } \\
\text { I(1) }\end{array}$ \\
\hline $\mathrm{F}_{\mathrm{iii}}$ (Unrestricted intercept and no trend) & 1.587137 & 2.86 & 4.01 \\
\hline $\mathrm{F}_{\mathrm{iv}}$ (Unrestricted intercept and restricted trend) & 4.434074 & 3.05 & 3.97 \\
\hline $\mathrm{F}_{\mathrm{v}}$ (Unrestricted intercept and unrestricted trend) & 5.228673 & 3.47 & 4.57 \\
\hline
\end{tabular}

Table 3. ARDL Level Equation with Constant and Trend

Dependent Variable: LCO2

\begin{tabular}{lllll}
\hline \hline Variable & Coefficient & Std. Error & t-Statistic & Prob. \\
\hline \hline LGDPPC & 0.554641 & 0.234458 & 2.365634 & 0.0231 \\
LGDPPC2 & -0.039601 & 0.016946 & -2.336908 & 0.0247 \\
LE & 2.577137 & 0.293529 & 8.779828 & 0.0000 \\
LGPI & -3.514879 & 0.627118 & -5.604815 & 0.0000 \\
C & -19.92949 & 1.778624 & -11.20500 & 0.0000 \\
\hline
\end{tabular}

Table 4. Estimation Results of ECM

Dependent Variable: DLCO2

\begin{tabular}{|c|c|c|c|c|}
\hline Variable & Coefficient & Std. Error & t-Statistic & Prob. \\
\hline $\begin{array}{l}\text { DLGDPPC } \\
\end{array}$ & 0.876632 & 0.433035 & 2.024390 & 0.0502 \\
\hline DLGDPPC2 & -0.058713 & 0.033840 & -1.735036 & 0.0911 \\
\hline DLE & 1.970309 & 0.327518 & 6.015884 & 0.0000 \\
\hline DLGPI & -1.697063 & 0.503950 & -3.367525 & 0.0018 \\
\hline $\mathrm{C}$ & 0.011466 & 0.005575 & 2.056771 & 0.0468 \\
\hline ECT(-1) & -0.741933 & 0.140670 & -5.274279 & 0.0000 \\
\hline \multicolumn{5}{|c|}{ 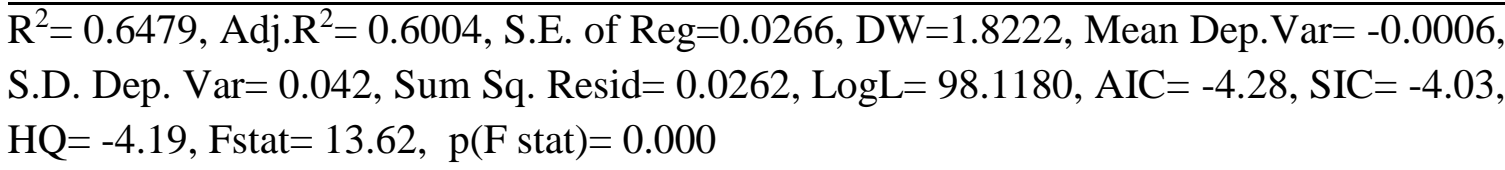 } \\
\hline
\end{tabular}




\section{References}

Amegah, A.K., Omisore, A.G. (2018), "Attaining sustainable development goals in subSaharan Africa; The need to address environmental challenges ", Environmental Development, 25, pp. 138-145, https://doi.org/10.1016/j.envdev.2017.09.002

Asadullah, M. \& Rahman, S. (2009), "Farm productivity and efficiency in rural Bangladesh: the role of education revisited", Applied Economics, Vol. 41, pp. 17-33.

Boutabba, M.A., Diaw, D., Lessoua, A., (2018), "Environment-energy-growth nexus in SubSaharan Africa: The role of intermediate goods", International Economics, pp.1-14.

Dias, R., Mattos, C. and Balestieri, J. (2004) "Energy education: breaking up the rational energy use barriers", Energy Policy, Vol. 32, pp. 1339-1347.

Ding, W., Wang, L., Chen, B., Xu, L., Li, H. (2014), "Impacts of renewable energy on gender in rural communities of nort-west China", Renewable Energy, Vol 69, pp. 180-189.

Economic and Social Research Council (ESRC). "When it comes to the environment, education affects our actions." ScienceDaily. ScienceDaily, 21 March 2011, Available at: www.sciencedaily.com/releases/2011/03/110321093843.htm

Ellegård, K., Palm, J., (2015), "Who is behaving? Consequences for energy policy of concept confusion”, Energies, Vol. 8, pp. 7618-7637.

Grossman, G. M. and Krueger, A. B., (1991), “Environmental Impacts of a North American Free Trade Agreement", National Bureau of Economic Research Working Paper 3914, NBER, Cambridge MA.

Holmes, C. (2003), "The influence of protected area outreach on conservation attitudes and resource use patterns: a case study from Western Tanzania", Oryx, Vol. 37, pp. 305-315.

Kivyiro, P., Arminen, H. (2014), "Carbon dioxide emissions, energy consumption, economic growth, and foreign direct investment: Causality analysis for Sub-Saharan Africa”, Energy, Vol. 74, pp. 595-606, https://doi.org/10.1016/j.energy.2014.07.025

Migheli, M. (2018), “ Brown parents, green dads: gender, children and environmental taxes”, Journal of Cleaner Production, Vol. 180, pp. 183-197.

Parikh, J.K. (1995), “Gender issues in energy policy”, Energy Policy, Vol. 23, No. 9, pp. 745754

Park, H.C., Heo, E., (2007), "The direct and indirect household energy requirements in the Republic of Korea from 1980-2000 an input-output analysis.”, Energy Policy, Vol. 35, pp. 2839-2851.

Permana, A.S., Aziz, N.A., Siong, H.C. (2015), “ Is mom energy efficient? A study of gender, household energy consumption and family decision making in Indonesia", Energy Research and Social Science, Vol. 6, pp. 78-86 
Pesaran, M.H., Shin, Y., and Smith, R.J. (2001), "Bounds testing approaches to the analysis of level relationships", Journal of Applied Econometrics, Vol 16, pp 289-326.

Ryan, S.E., (2014), "Rethinking gender and identity in energy studies", Energy Research and Social Science, Vol. 1, pp. 96-105.

Shahbaz, M., Solarin, S.a., Sbia, R., Bibi, S. (2015), "Does energy intensity contribute to CO2 emissions? A trivariate analysis in selected African countries", Ecological Indicators, Vol. 50, pp. 215-224.

United Nations Educational, Scientific and Cultural Organization (UNESCO) (2015), "Education for all: 2000-2015: Achievements and challenges". Available at: http://unesdoc.unesco.org/images/0023/002322/232205e.pdf (Accessed 11 July 2018).

World Bank Group, 1994, "Fighting the population/agriculture/environmental nexus in subSaharan Africa", Africa region, No. 28. Available at: http://documents.worldbank.org/curated/en/773441468008707071/pdf/multi0page.pdf (Accessed 21 July 2018)

World Bank Group, 2016. Data; Sub-Saharan Africa. Available at: http://data.worldbank.org/region/sub-saharan-africa (Accessed 12 July 2018) 


\title{
GENDER BALANCE FOSTERING IN TURKISH CIVIL AVIATION WITHIN THE CONTEXT OF SUSTAINABLE AVIATION
}

\author{
Nurhan OTO ${ }^{1}$ \\ Ferhan KUYUCAK ŞENGÜR ${ }^{2}$
}

\begin{abstract}
One of the main Sustainable Development Goals of the United Nations is "Achieve Gender Equality and Empower All Women and Girls". In support of this goal, International Civil Aviation Organization (ICAO) has initiated the "Gender Equality Program Promoting the Participation of Women in the Global Aviation Sector" program and declared a commitment to enhancing gender equality by 2030, at all professional and higher levels of employment in the global aviation sector. In parallel to those developments, in 2018, "Instruction for Gender Balance Fostering in Turkish Civil Aviation" was drawn up by the Directorate General of Turkish Civil Aviation (DGCA). The Gender Balance Fostering Commission has been established to encourage, in particular, women towards education and training in fields related to aviation and to determine the procedures and principles regarding works and operations.

The purpose of this study is to investigate the Gender Balance status of Women Aviator in the Turkish Civil Aviation (TCA) and to evaluate the relationship between Gender Balance and Sustainable Aviation. To manage this aim, exploratory research was been designed. According to the results, within the TCA, the percentage of women has historically been low and the sector has been male-dominant. On the other hand, there has been an increase in the number of women in the industry. Women will comprise a significant component of future growth in the aviation industry. Gender Balance improvement will key to Sustainable Turkish Aviation.
\end{abstract}

Keywords: Aviation Sustainability, Gender Equality, Gender Balance, Women in Aviation, Aviatrix, Woman Aviator.

\footnotetext{
${ }^{1}$ Dr. Deputy Head Manager of Esenboğa Airport- DGSAA, The Gender Balance Improvement Advisory Board Member of the DGCA, Environmental Social Sciences (PhD) nurhan.oto@ hotmail.com

${ }^{2}$ Prof. Dr. Eskişehir Technical University Faculty of Aeronautics and Astronautics Aviation Management, the Gender Balance Improvement Commission Member of the DGCA. fkuyucak@eskiehir.edu.tr
} 


\section{Introduction}

A number of studies have shown that "Sustainable Development" is impossible without women's empowerment and gender equality. Consequently, it is asserted that "Gender Equality" is both a human rights issue and a precondition for, and indicator of, Sustainable Development (Bayeh, 2019). How can we have a more gender-balanced and equitable world and workplace?

If women were in more productive and decision-making roles, the world could be moving faster and more assuredly towards sustainability in the economic, social and environmental sense (Stevens, 2010). Aviation is a key component and driver of global business and economy (ATAG, 2019) It is supporting 65.5 million jobs and \$2.7 trillion in global GDP. Global air transport is expected to grow by around 5\% annually until 2030 (EC, 2019). Global aviation is a driver of Sustainable Development, bringing together people, businesses and communities and supporting trade and tourism (ATAG, 2019). Historically, the aviation and aerospace industry has been dominated by men. Despite various efforts, little progress has been made over the past decade in advancing the aviation Gender Balance.

In the book of "Absent Aviators: Gender Issues in Aviation", the editors, Bridges et.al, highlight that the role of women in aviation is conspicuously absent from the history books (Bridges, Smith, \& Mills, 2014). Accordingly, the scientific literature on Turkish woman aviators is very limited (Kuyucak, 2019). The purpose of this study is to investigate the Gender Balance status of Women Aviator in the Turkish Civil Aviation (TCA) and to evaluate the relationship between Gender Balance and Sustainable Aviation. To manage this aim, exploratory research was been designed and data obtained with techniques including literature review, document and media review, and case studies. This study focused on the UN Sustainable Development's goals (SDGs) and approach to Gender Balance issues within the context of Turkish Aviation. 


\section{Literature Review}

\section{Conceptual Background}

The most known definition of "sustainable development" came from a report entitled "Our Common Future" published in 1987 by the UN World Commission on Environment and Development;

"Sustainable development is economic, social and environmental development that ensures human well-being and dignity, ecological integrity, gender equality and social justice, now and in the future"

Oto explained that the aviation industry and all its relevant institutions have been adopting more holistic sustainability approaches. By doing so, they aim at achieving the full integration of economic viability, operational efficiency, livability, natural resource conservation and social responsibility. (Oto, 2011). Stevens explained the three pillars of Sustainable Development are also relevant to discussions of Gender Equality (Stevens, 2010).

UN defines the concept of "Gender Equality" as accessing equal rights, responsibilities and opportunities between women and men, girls and boys. What's actually meant by Gender Equality is equal possibilities for accessing those rights rather than pure numerical equality (Kuyucak Şengür, 2019). Gender Equality is a necessary foundation for a peaceful, prosperous and sustainable world (UN, 2019). According to the World Economic Forum (WEF), Gender Equality is not just a concern of half of the world's population. It is a human right, a concern for us all because no society can develop economically, politically, or socially when half of its population is marginalized (WEF, 2015). Therefore, it would be more meaningful to talk about "Gender Balance" (Kuyucak Şengür, 2019). OECD explained that, the term "Gender Balance" used in refers to "an equitable distribution of life's opportunities and resources between women and men, and/or the equal representation of women and men" (OECD, 2008). According to the 
Turkish DGCA, Gender Balance is both genders participating in all public and private areas of life in a balanced manner and having balanced visibility in such areas (SHGM, 2019).

\section{Women in Aviation}

Collier mentioned the first recorded use of the term aviator (aviateur in French) was in 1887, as a variation of "aviation". The term aviatrix (aviatrice in French), now archaic, was formerly used for a female aviator. These terms have been using more in the early days of aviation (P. F. Collier and Son, 1905).

Today, aviation is expanding globally and so is the number of women working as pilots, air traffic controllers, engineers and managers. Kuyucak (2010) argued, women notably contributed to aviation from the first powered flight in 1903 until today (Kuyucak, 2010, p. 21). Aviation is a male-dominated industry, and male-centric attitudes affect the beliefs and actions of aviators (Robertson, 2014, p. 29). Women often had to work hard to prove themselves as capable as men in the field. The following is just a small sampling of the contributions women have made to the field of aviation (Ninety-Nines, 2019).

The first machine-powered flight occurred by Wright Brothers on December 17, 1903 (Burman, 2000). Their sister Katharine Wright is in remembering with the financial and moral support provided to them (WAI, 2019). Aida de Acosta is the first woman to solo in a motorized aircraft in 1903. Mlle P. Van Pottelsberghe flew as the first woman passenger in July 1908 (Ninety-Nines, 2019).

Starting in 1906, Emma Lilian Todd began designing her own airplane. Todd's first plane flew in 1910 (WAI, 2019). Raymonde de Laroche was the first woman to receive a pilot's license, in 1910. Şevket Belkis flew as First Turkish Woman passenger in 1913 (Arit, F., 1967, pp. 7-9), (Kuyucak, 2010, pp. 7-9). Katherine Stinson was the first woman to own a flying school in 1913. Amelia Earhart, during the 1920s and 1930s, was the first woman to solo across 
the Atlantic Ocean (Ninety-Nines, 2019). Helen Richey became the first woman to fly a commercial airliner in 1934. She quit that job in ten months because the all-male pilots union would not admit her (Air Electro, 2019).

Because flying was considered dangerous, many manufacturers in the 1920s hired women as sales representatives and flight demonstrators. The reasoning was that if a woman could fly an airplane, it really could not be that difficult or dangerous (Air Electro, 2019). During the first Women's Air Derby in 1929, women flying the race faced "threats of sabotage and headlines that read, 'Race Should Be Stopped (Ninety-Nines, 2019). After the race, women kept in contact with each other and talked about forming an organization of women pilots; "The Ninety-Nines" (Ninety-Nines, 2019).

Yazıc1 implied that in the Turkish War of Independence with their heroism, courage and sacrifice Turkish woman had created an epical milieu. One of the fields Turkish women were involved in, was aviation (Yazıc1, 2005). Kuyucak says that, when we look at world and Turkish history, we see those female aviators are quite active in aviation compared to other fields (Kuyucak Şengür, 2019). At a time when flying was considered largely a male-only domain, Turkish women aviators were prominent, particularly during the 1930s, Bedriye Tahir Gökmen was the first Turkish woman to earn a pilot license in 1933 (SHGM, 2019). Sabiha Gökçen was the first woman to combat pilot in 1936 (Guinness World Records, 2019).

According to the Federal Aviation Administration (FAA) records, World War II was very beneficial to the movement of women into aviation fields. At the beginning of 1943, 31.3\% of the aviation workforce was women. The history of aviation during these years is immense (Ninety-Nines, 2019).

Women entered the ranks of air traffic controllers in large numbers to replace men who joined the war effort. Since then, historians have long tried to identify the "first" female 
controller. There is some evidence that Mary Gilmore became the first CAA tower operator specialist in September 1941 (FAA, 2019).

Turkey's first air traffic controller was Nazmiye Göyük in the 1950s (SHGM, 2019).

The first woman to fly faster than the speed of sound was Jacqueline Cochran in 1953.

There are four female pilots to "have flown supersonic" for the first time across Turkey in 1996, Tuğba Aydı, Ayşe Ebru Toka, Leyal Semerci, Hürriyet Munanoğlu (SHGM, 2019). The First Turkish Aviatrixes are seen in Table 1 below.

Table 1. First Turkish Aviatrixes List (30 January 2019)

\begin{tabular}{|c|c|c|c|c|c|}
\hline 1.Belkıs ŞEVKET & $\begin{array}{l}\text { First woman } \\
\text { passenger to } \\
\text { fly }\end{array}$ & 913 & $\begin{array}{l}\text { Nazmiye } \\
\text { GÖYÜK }\end{array}$ & $\begin{array}{l}\text { First Air Traffic } \\
\text { Controller }\end{array}$ & 956 \\
\hline $\begin{array}{l}\text { 2.Bedriye Tahir } \\
\text { GÖKMEN }\end{array}$ & $\begin{array}{l}\text { First woman } \\
\text { pilot }\end{array}$ & 933 & $\begin{array}{l}\text { Leman } \\
\text { BOZKURT } \\
\text { ALTINCEKİC }\end{array}$ & First Jet Pilot & 958 \\
\hline 3.Yıldız UÇMAN & $\begin{array}{l}\text { First woman } \\
\text { parachute }\end{array}$ & 935 & Şenay GÜNAY & First Jet Fighter Pilot & 960 \\
\hline $\begin{array}{l}\text { 4.Sabiha } \\
\text { GÖKÇEN }\end{array}$ & $\begin{array}{l}\text { First woman } \\
\text { fighter pilot }\end{array}$ & 936 & $\begin{array}{l}\text { Dilhan EZER } \\
\text { ERYURT }\end{array}$ & $\begin{array}{l}\text { First woman aviator, } \\
\text { occupied NASA }\end{array}$ & 961 \\
\hline 5.Naciye TOROS & $\begin{array}{l}\text { First woman } \\
\text { glider pilot. }\end{array}$ & 936 & $\begin{array}{l}\text { Leman } \\
\text { ALDAK }\end{array}$ & $\begin{array}{l}\text { First Master's degree } \\
\text { Aircraft Engineer }\end{array}$ & 961 \\
\hline $\begin{array}{l}\text { 6.Eribe KARTAL } \\
\text { HÜRKUŞ }\end{array}$ & $\begin{array}{l}\text { First Martyred } \\
\text { Aviatrix }\end{array}$ & 936 & $\begin{array}{l}\text { Türkan } \\
\text { DEMİREL }\end{array}$ & First Flight Doctor & 964 \\
\hline $\begin{array}{l}\text { 7. Edibe SUBAŞI } \\
\text { KUTUCUOGLLU }\end{array}$ & $\begin{array}{l}\text { First woman } \\
\text { acrobatic pilot }\end{array}$ & 937 & $\begin{array}{l}\text { Melahat } \\
\text { MORÇÖL }\end{array}$ & First Licensed Pilot & 958 \\
\hline 8.Adile TUĞRUL & $\begin{array}{l}\text { First Cabin } \\
\text { Crew/Hostess }\end{array}$ & 948 & Ayfer GÖK & $\begin{array}{l}\text { First Martyred jet fighter } \\
\text { pilot }\end{array}$ & 001 \\
\hline
\end{tabular}

Source: (SHGM, 2019)

Today, women are in all positions within the aviation job spectrum, but they are still less likely to be in the workforce than men in aviation are.

Hart (2018) mentioned that, as women continue to strive toward the glass ceiling of inequality at the workplace to shatter it, instructional designers must continue to identify opportunities to remove gender barriers from technical documents (Hart, 2018, p. 2). In his research, FAA technical training documents had examined. In the documents, 987 occasions of 
male nouns and pronouns were identified while 733 occasions of female nouns and pronouns were noted (Hart, 2018, p. 7).

Gender stereotypes and attitudes occur within mixed-gender career fields (Robertson, 2014, p. 3). The long-time stereotype of airline pilots is that they are male. Walton and Politano explained that studies examining aviation accidents have not found differences in accident rates by gender, although there may be gender differences in the types of accident (Walton, 2016).

\section{UN Sustainable Development Goals}

The 2030 Agenda (35-page, five sections) for Sustainable Development, adopted by all UN Member States in 2015. At its heart are the 17 Sustainable Development Goals - SDGs (169 targets, 231 indicators), which are an urgent call for action by all countries-developed and developing-in a global partnership. They recognize that ending poverty must go hand-in-hand with strategies that build economic growth and address a range of social needs including education, health, social protection, and job opportunities while tackling climate change and environmental protection (UN, 2019). See below, Figure 1, symbols of SDGs.

\section{Figure 5 Symbols of SDGs}
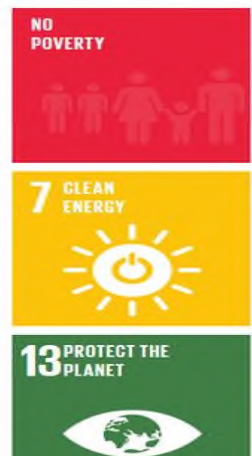
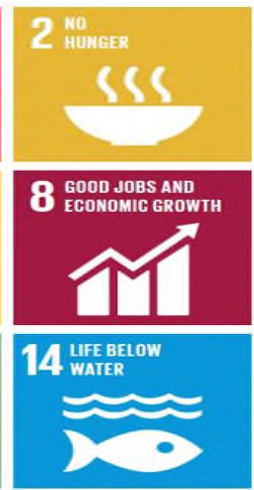
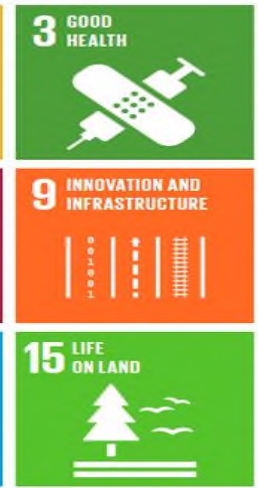
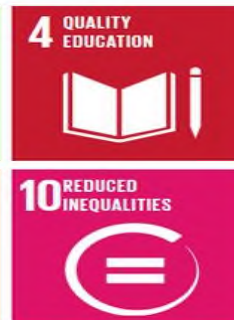

16.jugtige and

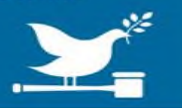

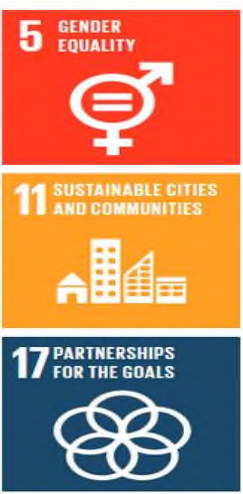

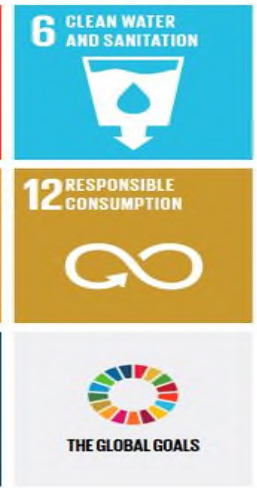

Source: (UN, 2019).

This was the most inclusive process the world has ever seen to determine a genderresponsive global policy. 


\section{ICAO and UN Sustainable Development Goals}

ICAO is a specialized UN agency with a unique mandate to support the sustainable growth of international civil aviation transport. ICAO develops policies and international Standards and Recommended Practices (SARPs) in support of a safe, efficient, secure, economically sustainable and environmentally responsible civil aviation sector (UN, 2017).

Achieving 2030 Agenda for Sustainable Development and its SDGs will rely on advances and innovations in sustainable transport, including aviation.

In 2016, ICAO's 39 ${ }^{\text {th }}$ General Assembly unanimously adopted Resolution A39-25 on "Aviation's Contribution towards UN 2030 Agenda for Sustainable Development". In doing so, all 192 Member States recognized the essential role of aviation in achieving 2030 Agenda and the fundamental interlinkages between SDGs, ICAO's Business Plan and its 5 Strategic Objectives and "No Country Left behind (NCLB)" initiative (UN, 2017).

ICAO has identified the linkages between its 5 Strategic Objectives and 15 out of 17 UN SDGs. ICAO's work on the Environmental Strategic Objective contributes to 14 out of the 17 SDGs, including SDG7 on renewable energy, SDG9 on resilience and SDG13 on climate change. ICAO's Aviation Safety Strategic Objective - which links to 11 out of 17 SDGs, 20172019 ICAO Global Aviation Safety Plan (GASP) outlines the key activities and global targets driving collaborative international air safety improvements worldwide. Air Navigation capacity and efficiency are closely linked to 11 out of 17 SDGs.

Economic Development of Air Transport; ICAO as a custodial agency for Goal 9 target 9.1.2 works closely with the UN and its agencies as well as OECD.

The aviation sector is supporting UN Women's Empowerment Principles, which offer guidance for business on how to empower women in the workplace, marketplace and community. ATAG implied that air transport is an essential component of a broader mobility strategy to help achieve the UNs 2030 Agenda for SD (ATAG, 2019). 


\section{SDG5; "Gender Equality and empower all women and girls" and Aviation}

SDGs, which have captured Gender Equality issues with over 40 gender-related targets, represent a new way of addressing some of the greatest challenges facing women. The universality of the agenda is key, as gender inequality is a global problem (ONU MULHERES, 2017). Gender Equality as a stand-alone goal (SDG5), with related targets under a number of other Goals. It has 9 Targets and 14 Indicators. Gender Equality is understood as central and contributes to the achievement of other objectives: stimulate growth and reduce poverty, reduce inequities-contribute to child development.

From the SDG5, relevant targets are; 5.1) End all forms of discrimination against all women and girls everywhere. 5.2) eliminate all forms of violence against all women and girls in the public and private spheres, including trafficking and sexual and other types of exploitation. 5.5) Ensure women's full and effective participation and equal opportunities for leadership at all levels of decision-making in political, economic and public life. From the SDGs: aviation-relevant indicators, 5.5.2) Proportion of women in managerial positions (ATAG, 2019).

To achieve UN SDG5 in support of Resolution A39-30 "ICAO Gender Equality Programme Promoting the Participation of Women in the Global Aviation Sector", and its commitment to enhancing GE by 2030, at all professional and higher levels of employment in the global aviation sector, a new initiative on "Air Transport Gender Equality" was developed by ICAO in 2017 (ICAO, 2019).

The Programme aims to facilitate and coordinate targeted programmes and projects to enable and make regular reports on progress towards the SDG5 of Gender Equality by 2030, especially in professional and higher levels of employment, within ICAO, and within States and the global aviation sector. 
It has four main objectives for effective implementation: (i) Build capacity and enhance awareness for Gender Equality, (ii) Enhance gender representation, (iii) Increase awareness and accountability, and (iv) further engagement with external partners (DGCA 56, 2019).

It includes the establishment of gender indicators through the collection of statistics provided as a voluntary base from States, ICAO is consulting with ILO, UNESCO and UN Women on this new statistical form.

ICAO’s first female Secretary General, Liu said that;

"...the percentage of women serving as airline CEOs is currently fewer than 5\%. When one considers how important leadership examples are as role models for future generations, it is especially vital that greater gender equality in aviation be pro-actively pursued and expedited by all stakeholders in the global aviation community. This is a responsibility shared between governments, industry partners and ICAO" (Airport Review, 2017).

It's stated that ICAO is working with the Member States, aviation industry partners and professional associations, academia, and UN to facilitate equal STEM education access to girls and boys as well as career development opportunities for women working in aviation through professional assignments at ICAO (UN, 2017). The principles are also embedded in the Next Generation of Aviation Professionals (NGAP) Programme. ICAO also hosts networking and advocacy events aimed at raising awareness for gender in aviation and the advancement of women within the global aviation community (UN, 2017).

ICAO focused on, half of the world's population has made up of women - therefore the attraction and retention of more women with sought-after aviation technical and policy qualifications and experience. Relevant opportunities need to be created at the State, regional and international level in order for more women to seek out, and to be given, chances to pursue a career in the aviation sector and, similarly, to advance their career on an equal footing with their male counterparts (ICAO, 2019). 
According to the forecasts; by the year 2036, 620,000 new pilots will be needed to fly the world's 100-seat-and-larger aircraft. There will be 600,000 new airline technicians required around the world by 2036, and to support this growing industry, additional 60,000 managers will be needed (ICAO, 2019).

Women make up $41 \%$ of all aviation employees in Europe, but a much lower percentage in technical roles aviation is working to achieve GB across the sector (ATAG, 2019). It is interesting to note that almost $80 \%$ of flight attendants are female, whereas only $5 \%$ of pilots are women (DGCA 56, 2019).

Almost $10 \%$ of women are on top management positions among 500 member airports of ACI Europe (ACI, 2019). This is not yet sufficient but it is already encouraging to see how the airport industry is actively becoming more inclusive (ACI, 2019).

It seeks to mobilise men and boys to promote GE and help to build a more balanced society (ACI, 2019). DGCA mentioned that ICAO and the International Aviation Women's Association (IAWA) collaborate on a sponsorship programme, with the goal of providing development opportunities to qualified female aviation professionals, from different regions (DGCA 56, 2019).

Therefore, for consistency in sustainability, it is evident that the policy and principle of Gender Equality and the engagement of women in aviation should be bestowed with equal opportunities (DGCA 56, 2019).

ACI implied that five stakeholder organizations in the aviation and aerospace industry will launch a global study -“Soaring through the Glass Ceiling"- to identify and promote means by which the aviation and aerospace industry can more effectively recruit and advance women into leadership roles (ACI Aero, 2018).

These efforts contribute to SDG5 by promoting equal leadership opportunities for women and encouraging their full participation in aviation. 


\section{Gender Balance Fostering Efforts in the Turkish Civil Aviation}

Turkey, which is the $17^{\text {th }}$ biggest economy in the world. The workforce participation rate of women is $34.4 \%$ and $71.7 \%$ for men (TurkStat Labour Statistics 2019). According to the Gender Gap Index of World Economic Forum (WEF); Turkey, is the $131^{\text {st }}$ country out of 144 countries (UNFPA TR, 2019).

Kuyucak Şengür argued that the gender imbalance we mentioned above is an undeniable fact in aviation as well. Fostering Gender Balance in a global industry with such a high impact on economic and social life is also a vital necessity (Kuyucak Şengür, 2019). The general director of TCA, Mr Kesici also indicated that a disproportionate breakdown is predominant between women-men employees across the TCA industry and that these figures clearly reveal why more systematic efforts should be made to develop "Gender Balance" in TCA.

To overcome this imbalance a series of efforts has been started. The first official effort was The Instruction on Development of Gender Balance in Turkish Civil Aviation (SHT-TCD) which was drawn up on Law 5431 on Organization and Duties of Directorate General of Turkish Civil Aviation (DGCA), Turkish Prime Ministry Circular on Increasing Women Employment and Ensuring Gender Equality, "ICAO Gender Equality Programme" and "UN SDGs Goal 5: Ensuring Gender Equality and Empowerment of All Women and Young Girls" initiatives (SHGM, 2019).

Following this, the Gender Balance Fostering Commission (GBFC) was established, in order to ensure Gender Balance among employees in TCA sector, to provide equality of opportunity for the genders in the selection of aviation professions and to encourage women to participate in education and training in aviation-related areas. DGCA - Gender Balance Fostering Advisory Board (GBFAB) was formed of the members selected from among the representatives of aviation authorities and sector (SHGM, 2019). 
The Commission, in accordance with the objective specified in the Instruction, identifies the framework for intellectual, cultural and social activities and principles and goals of such activities. The activities within the scope of the $8^{\text {th }}$ of March Women of Aviation Worldwide Week /Day are been addressed and carried within this scope.

The symposium on "Development of Gender Balance in Aviation" was organized by GBFC for the "March 8, International Women's Day" was held under the motto of "Let Women Soar!", "Women of Aviation Flying Supersonic"1 and "Flying in their Careers"2 gather at the symposium, with the aim of fostering Gender Balance in aviation on March 8, 2018, in Ankara.

On April 26, 2018, a symposium themed "Women in Air and Space" was also been organized under the Eurasia Airshow in Antalya (Kuyucak Şengür, 2019).

In the meetings of DGCA-GBFC; the entire week of March, which includes 8 March, was recognized as "Women of Aviation Worldwide Week" in TCA as it coincides with Women of Aviation Day on March $8^{\text {th }}$. Moreover, the theme of the GBFC activities in 2019 was determined as "Women in Airport" (Kuyucak Şengür, 2019).

There are also international efforts of the Commission. The secretary of GBFC represented the GBFC and TCA organizations at the ICAO's $1^{\text {st }}$ Global Aviation Gender Summit was held in Cape Town, on 08-10 August 2018, and made a presentation on the activities of Turkey.

Another milestone of the gender balance fostering efforts was the "Registry of First Aviatrixes". According to SHT-TCD Article 12, the Commission keeps a register in order to ensure recognition of the first or leading women, who flew or contributed to the flight of an

\footnotetext{
${ }^{1}$ Moderator: T.TUGLUER, Senior Consultant at STM-SSM panellists: A. E. TOKA, L.SEMERCI, B.SAHINKAYA, Captain Pilots, and M.ER, Pilot

${ }^{2}$ Moderator: Prof. Dr. F.KUYUCAK SENGUR, C.CELEBIOGLU, Chairperson of the Board of Directors, Dr. N. OTO, Deputy Head Manager of Esenboğa Airport.(DGSAA), B.TOPEL, Manager at TAI, and. G.B. DOGAN, Head of Air Navigation Department at DGCA
} 
aircraft, significantly contributed to the development of aviation, pioneered and raised awareness in the subject. (SHGM, 2019). According to SHT-TCD Article 13, the First Aviatrixes list was announced on 30 January 2019. (see Table 1.)

\section{Key Results}

In this study, to evaluate TCA women status the needed sector data had been collected by DGCA at the beginning of 2019. Data from 28 different stakeholder organizations (Government Agencies, Airlines, Airports, Manufacturers, i.e.) obtained from DGCA by email, analyzed and listed in Table 2. below.

Table 2. The Gender Balance Status of Women Aviator in TCA(first quarter of 2019)

\begin{tabular}{|l|l|l|l|l|l|}
\hline Women employees by occupations & total & male & ratio\% & female & ratio\% \\
\hline Board Member & 125 & 105 & 84,00 & 10 & 8,00 \\
\hline Work Management (Chief/Lieder) & 5299 & 3963 & 74,79 & 1336 & 25,21 \\
\hline Operation Management(Director/Manager) & 2060 & 1702 & 82,62 & 358 & 17,38 \\
\hline C $^{+}$Level (General Directory.) & 193 & 171 & 88,60 & 22 & 11,40 \\
\hline Starting Level & 91423 & 66998 & 73,28 & 24425 & 26,72 \\
\hline Total & $\mathbf{9 9 0 8 6}$ & $\mathbf{7 2 9 3 4}$ & $\mathbf{7 3 , 6 1}$ & $\mathbf{2 6 1 5 2}$ & $\mathbf{2 6 , 3 9}$ \\
\hline Women employees by job & & & & & \\
\hline Engineer & 11117 & 8527 & 76,70 & 2590 & 23,30 \\
\hline Pilot & 7091 & 6790 & 95,76 & 301 & 4,24 \\
\hline Cabin Crew & 14785 & 4728 & 31,98 & 10057 & 68,02 \\
\hline Air Traffic Controller & 1597 & 1035 & 64,81 & 562 & 35,19 \\
\hline Maintenance Technician & 10078 & 9291 & 92,19 & 787 & 7,81 \\
\hline Operation & 671 & 440 & 65,57 & 231 & 34,43 \\
\hline Other & 53336 & 41347 & 77,52 & 11989 & 22,48 \\
\hline Total & $\mathbf{9 9 0 8 6}$ & $\mathbf{7 2 9 3 4}$ & $\mathbf{7 3 , 6 1}$ & $\mathbf{2 6 1 5 2}$ & $\mathbf{2 6 , 3 9}$ \\
\hline
\end{tabular}

Source: Compiled by the authors.

According to Table 2; the percentage of women employees; Percentage of Women of Aviation across the Industry $26.39 \%$ to $73.64 \%$, In cargo airlines $12 \%-15 \%$, In large-sized MRO organizations 5\%-15\%, In design/manufacturing-focused aviation organizations which support predominantly our national defence aviation $8 \%-25 \%$. Percentages of women employees by occupations; Engineer 23.30\%, Pilot 4.24\%, Cabin Crew 68.2\%, Maintenance 
Technician $7.81 \%$.Women account $26.39 \%$ of the national workforce, but only $4.40 \%$ of airline pilots are women.

It is seen that, within TCA, the percentage of women has historically been low and the sector has been male-domain.

\section{Discussion and Recommendations}

In this study, it was explored that the possible link between advances in achieving Turkish aviation Gender Balance and advances in achieving sustainable development goals. It was also questioned that the lack of progress on Gender Balance in aviation may be at the heart of the failure to advance on sustainable development of aviation in Turkey.

To achieve Sustainable Aviation in Turkey; that have to bear in mind the global agenda for Sustainable Development launched by the UN in 2015. TCA already has a great contribution to sustainable development, however, the sector can also be a pioneer for other industries in building a gender-balanced sustainable future. Women shape the future of the global aviation industry. The Gender Balance improvement will be a key to Sustainable TCA. As stated by Gazi Mustafa Kemal Atatürk,

"If a society fails to walk arm in arm with all its women and men towards the same target,

it is not technically possible and scientifically probable for such country to develop".

For this reason, to promote gender diversity at all levels in TCA is important and the efforts of the Commission are valuable. For accelerating women's participation and professional growth in TCA, there seem to be very positive developments in Turkey in order to improve this balance. To move the industry forward; more women in senior roles is needed. This is not a women's problem this is a problem for all of us. Essentially, there is no "woman aviator" it is "aviator"! We will achieve real equality and equilibrium when we do not need to mention this (Kuyucak Şengür, 2019). 
This study contributes to the literature by focusing on the current situation of women in the TCA within the context of sustainable development. It has also social contributions. Focusing on women aviators can inspire young girls. It helps young women see that they can actually follow their aviation or aerospace dreams because they see the face of a woman trailblazer. In future research, linkages between the 2030 Agenda, gender balance and aviation; barriers and opportunities for gender balance in leadership positions, and partnerships for gender balance in TCA could be examined.

\section{References}

ACI. (2019, 03 07).Yes, they can: Women leading European airports.Retrieved from http://www.airport-business.com

ACI Aero. (2018, 9 13).Soaring through the glass ceiling:five aviation aerospace stakeholders launch a global study on women in leadership. Retrieved from https://aci.aero/news/2018/09/13/

Air Electro.(2019, 10 29).Women's equality day the most influential women of aviation.Retrieved from http://www.airelectro.com/blog/industry/womens-equality-day-themost-influential-women-of-aviation/

Airport Review.(2017, 03 08).International women's day-gender equality targets.Retrieved from www.internationalairportreview.com

Arıt,F.(1967).Havalarda ilk Türk kadınları.İstanbul:Baha Matbaası.

ATAG.(2019, 05 22). SDG 5:Gender Equality:Aviation:Benefits Beyond Borders.Retrieved from https://aviationbenefits.org

Bayeh,E.(2019, 10 28).The role of empowering women and achieving gender equality in the sustainable development of Ethiopia.Retrieved from https://www.researchgate.net

Bridges,D.,S.J.,\&Mills,A.J.(2014).Absent Aviators:Gender Issues in Aviation. Farnham:Ashgate Publishing Limited.

Burman,B.(2000).Racing bodies:dress and pioneer women aviators.Women's History Review, 9:2, 299-326.

Collier P.F. \& Son.(1905).Aeronautics in 1904.Collier's Self-Indexing Annual, p. p. 6. New York. (2013 digital)

DGCA56.(2019).Retrieved from https://www.dgca56.com.np/papers/dp/56-12b-1-DPBangladesh-Theme-Topic-DGCA-57-Rev3-Aug\%206-2019.pdf 
EC.(2019, 06 2019).Mobility and Transport.Retrieved from https://ec.europa.eu

FAA.(2019, 10 26).The First Women Controllers.Retrieved from https://www.faa.gov Guinness World Records.(1936).First female combat pilot|.Retrieved from https://www.guinnessworldrecords.com/world-records/first-female-combatpilot?fb_comment_id=847048878660727_1953127661386171

Hart,W.(2018).Isolation and Onboarding:Gender Bias in Aviation Training Documents.Minnesota State University,Mankato, p. 19.

ICAO.(2019, 05 22).The Air Transport Gender Equality Initiative.Retrieved from https://www.icao.int

Kuyucak,F.(2010).Türk Havacılığında Kadın. 21. Yüzyılın Eşiğinde Kadınlar(pp.21-25). İzmir: Dokuz Eylül Üniversitesi Fen-Edebiyat Fakültesi.

Kuyucak,F.(2019).Let Women Soar! Efforts to Develop Gender Equality in Civil Aviation. pp.volume 13,1ssues 91.

Ninety-Nines.(2019, 10 26).Women Involved in Aviation.Retrieved from https://www.ninetynines.org

OECD.(2008, 10 26).Gender and Sustainable Development.Paris:OECD Publications. Retrieved from https://uweboard.files.wordpress.com/2014/08/gender-and-sustainabledevelopment.pdf

ONU MULHERES.(2017, 03 10).Gender Equality and Empowerment of Women and Girls. Africa.

Oto,N.(2011).Education for Sustainable Airports.Procedia-Social and Behavioral Sciences CYICER2012,pp.Volume 47,2012,Pages 1164-1173.

Robertson,O.(2014).Gender and Crew Resource Management:A Pheniomenological Qualitative Study(The Degree Doctor of Management).The University of Phoenix.

SHGM.(2019, 05 23).Instruction for Gender balance Fostering.Retrieved from http://web.shgm.gov.tr

Stevens,C.(2010, 04 03).Are Women the Key to Sustainable Development?Retrieved from http://www.bu.edu

UN.(2017).ICAO.Retrieved from UN System SDGs Action Database: https://sustainabledevelopment.un.org/content/unsurvey/organization.html?org=ICAO

UN.(2019, 05 23).17 Goals to Transform Our World.Retrieved from https://www.un.org/sustainabledevelopment/

UN.(2019, 05 23).Goal 5:Achieve gender equality and empower all women and girls. Retrieved from www.un.org 
UNFPA TR.(2019, 06 13).Gender Equality- Situation in Turkey.Retrieved from https://turkey.unfpa.org/topics/gender-equality-6

WAI.(2019, 10 29).100 Most Influential Women in the Aviation and Aerospace Industry. Retrieved from https://www.wai.org/pioneers/100womenscript

Walton,P.P.(2016).Characteristics of General Aviation Accidents Involving Male and Female Pilots. Aviation Psychology and Applied Human Factors,6,pp.39-44.

WEF.(2015, 03 10).Why gender equality is key to sustainable development.Retrieved from https://www.weforum.org/agenda/2015/03/why-gender-equality-is-integral-to-sustainabledevelopment/

Yazıc1,S.(2005).Sabiha Gökçen and women pilots in Turkey.İzmir:Dokuz Eylül Üniversitesi /Atatürk İlkeleri ve İnkılap Tarihi Enstitüsü. 


\title{
PERCEPTIONS OF TURKISH WOMEN IN SENIOR MANAGEMENT ON VALUE BASED MANAGEMENT ${ }^{1}$
}

\author{
Özlem ATAY²
}

\begin{abstract}
The main aim of the study is to examine perceptions of Turkish women in senior management at the level of General Manager/Assistant General Manager on Value Based Management (VBM). VBM is an approach and also a philosophy that enables and supports leaders of an organization to create a meaningful environment and help the workers find meaning in their work in relation to others. Thus the stakeholders feel more connected to be part of the organization as a living body and a community. The paper is based on an ongoing project which has been supported by the Ankara University Scientific Research Projects Office (BAP), Turkey. The paper consists of two parts. The first part puts forward a conceptual framework and the second part describes a field research. In the light of the literature review "respect for" the six core values which are human dignity, justice, trust, diversity, environmental concern, and sustainability has been determined. The scope of the research is the top 500 Turkish Industrial Enterprises which is determined by the Istanbul Chamber of Industry every year. Concurrent nested mixed method is used to analyse the top 500 Turkish Industrial enterprise high level women managers' perceptions on VBM. For data entry the package software of IBM SPSS Statistics 25 is used. Data is converted into the package software of IBM SPSS Statistics 25(sav.) and Excel format (xls). Following the data entry through statistical methods (NVIVO8, AMOS23) and using the package software of IBM SPSS Statistics 25, statistical tables are drawn. Then, final reports on the data about validity and reliability analysis and its results is prepared. As a conclusion, the perceptions of women senior managers' on VBM is discussed.
\end{abstract}

Keywords: Value Based Management, Human Dignity, Justice, Trust, Diversity, Environmental Concern, Sustainability, Turkish Female Top Managers

\footnotetext{
${ }^{1}$ The research is supported by the Ankara University Scientific Research Projects Office (BAP), Turkey. "Ankara University Ethic Board Approval" for the research questionnaire has been taken.

${ }^{2}$ Prof. Dr., Ankara University Faculty of Political Sciences, Department of Management, Ankara-Turkey, ozkanli@ politics.ankara.edu.tr, ORCID ID: 0000-0002-2563-825X
} 


\section{Introduction}

The main aim of the study is to examine the perceptions of Turkish women in senior management at the level of General Manager/Assistant General Manager on Value Based Management (VBM). Accordingly, a literature review was made, and the values constituting the conceptual framework of the research were determined. VBM is an approach and also a philosophy that enables and supports leaders of an organization to create a meaningful environment and help the workers find meaning in their work in relation to others. Thus the stakeholders feel more connected to be part of the organization as a living body and a community. The paper is based on an ongoing project which has been supported by the Ankara University Scientific Research Projects Office (BAP), Turkey. ${ }^{1}$ The main aim of VBM in this research is to support the organizational culture with a value-based approach and to assist in a transformation that takes diversity into account. The paper consists of two parts. The first part puts forward a conceptual framework and the second part describes a field research. In the light of the literature review and concurrent nested mixed method results "respect for" the six core values which are human dignity, justice, trust, diversity, environmental concern and sustainability has been determined. Ankara University Ethic Board Approval for the research questionnaire has been taken.

VBM literature consists of some different definitions. Mostly the definitions of value and VBM differ according to the organizational culture (Wyk, 2008). The value of an organization is determined by its discounted future cash flows. Value is created only when companies invest capital at returns that exceed the cost of that capital. VBM extends these concepts by focusing on how companies use them to make both major strategic and every day operating decisions. Properly executed, it is an approach to management that aligns an

\footnotetext{
${ }^{3}$ I would like to thank Prof. Dr. Mualla Selçuk, Dr. Sinem Uğurlu, Nazmi Karyağdı for the valuable contributions I have received from them.
} 
organization's overall aspirations, analytical techniques, and management processes to focus management decision making on the key drivers of value. VBM is not a staff-driven exercise. It focuses on better decision making at all levels in an organization. It recognizes that top-down command-and-control structures cannot work well, especially in large multi-business corporations. Instead, it calls on managers to use value-based performance metrics for making better decisions. When VBM is implemented well, it brings tremendous benefit. It is like restructuring to achieve maximum value on a continuing basis. It has high impact, often realized in improved economic performance. The focus of VBM should be on the why and how of changing corporate culture (Copeland, T., T. Koller and J. Murrin, 1994).

Stakeholders play a very significant role in the organizational culture. Organizations exist to create value for all stakeholders. Stakeholders include customers, owners, managers, employees, suppliers and society in general. Organizations determine the degree to which they will prioritize the interests of each stakeholder group and will therefore balance performance goals accordingly. Values depend on the stakeholders, however, examples might be: Markets and owners expect that economic value be created; customers may expect to obtain desired goods and services on time and at competitive prices; employees may expect a substantive and meaningful job with commensurate compensation; suppliers may expect to be paid on time; society may expect that their environment will be improved (Sumantra, G., C. A. Bartlett and P. Moran, 1999).Organizations have to change constantly in order to meet expectations. VBM focus the efforts of people in the organization on driving to achieve what's important in a holistic manner. For example; satisfied customers, correctly assigned resources, growing profits, streamlined processes that deliver, business facts to manage the business, motivated and accountable people, waste eliminated...etc. Disciplined application of defined measurements and goals is critical to accomplishment of the desired values/goals (Sharman, P.A., 1999). 
Some researchers (Sharman, P.A., 1999) consider VBM not only as a matter of creating values but as a discipline that focuses on the management of the organization holistically. It emphasizes the creation of value as defined by its stakeholders and priorities defined by management. It focuses on the deployment of strategy and value creation by managing processes, activities, jobs, and compensation and organization structure.

The relatively scarce academic research examining the use of VBM has mainly compared the success of firms having adopted VBM to those that have not (Wallace, 1997; Kleiman, 1999). In the other areas of management accounting, evidence shows the divergent use of management accounting methods, such as ABC and Balanced Scorecard (Gossein, 1997; Kaplan and Norton, 2001; Malmi, 2001). Thus one may expect that companies could vary with respect to their VBM use as well. Such variation has even been acknowledged in the normative VBM literature (Martin and Petty, 2000; p.p. 228-229), though the precise nature of these differences remains unexplored.

Ittner and Larcker(2001), building on normative VBM literature, suggest that VBM consists of the following six basic steps:

1. Choosing specific internal objectives that lead to shareholder value enhancement;

2. Selecting strategies and organizational designs consistent with the achievement of the chosen objectives;

3. Identifying the specific performance variables, or "value drivers", that actually creates value in the business given the organization's strategies and organizational design;

4. Developing action plans, selecting performance measures, and setting targets based on the priorities identified in the value driver analysis;

5. Evaluating the success of action plans and conducting organizational and managerial performance evaluation;

6. Assessing the ongoing validity of the organization's internal objectives, strategies, plans, and control systems in light of current results, and modifying them as required. 
The literature contains prescriptions on the design of a management control system, including objectives, performance evaluation, target setting and rewards. Moreover, a number of examples have been presented to illustrate how the adoption of VBM should impact on decision making, both at strategic and operational levels. (See e.g. Martin and Petty, 2000).

Yet there is a need to uncover the philosophy behind any implementation. VBM is an approach and also a philosophy that enables and supports the leaders of an organization to create a meaningful environment and help the workers find meaning in their work in relation to others. Thus the stakeholders feel more connected to be part of the organization as a living body and a community (http://www.lucintel.com/value_based_management.aspx)

It is important to note VBM differs from a profit-focused way of managing business. Specifically, VBM means that the decisions that you make today are not simply driven by shortterm profit. Instead, we consider the longer-term effects that the decisions will have on organizational sustainability and profitability. VBM asks people within a organization to think like owners and to make decisions that will ultimately benefit the owners. Managers and executives must constantly look for investment and growth opportunities that will create valueand use the organization's capital in ways that ensure long-term, sustainable success ( http://flevy.com/blog/what-is-value-based-management-vbm/).

\section{Field Research}

After completing the conceptual framework data is collected by a questionnaire. The questionnaire includes two groups of questions: qualitative and quantitative. Ankara University Ethic Board Approval for the research questionnaire has been taken.

The questionnaire is developed in three stages. In the first stage, 2500 senior executives who are KALDER (Turkish Quality Association) members representing the target audience in VBM were asked the question "What does VBM mean to you and your organisation?" via e-mail. 
Unfortunately only eight of the members gave a respond ${ }^{1}$. Even this low response rate shows that there is a deep concern to oppose any kind of instrumentalization of human individual and work life.

The reasons of this low response rate might be their unfamiliarity with the concept of VBM, lack of time or their work overload. However these eight feedbacks profoundly changed the perspective of the research and provided very valuable information to develop an attitude scale assessing the concept of VBM. The detailed compositions written by the eight top executives who responded to the e-mail were analysed through content analysis.

Before moving to the process of developing an attitude scale brief analysis of the feedbacks were very helpful. The feedbacks generally illustrate the current problems at workplace under three categories and present VBM as a way to overcome these problems. The categories are; being undercapitalized, bad market condition and unqualified people. When it comes to the meaning of VBM there is no single regulatory, accepted body of definition or meaning in the essays. Some consider VBM as an alternative business model, one of them sees it as a system of global management, and another one defines it as a faith-based approach.

These eight responses have been an important aspect of the development of the research question: How is VBM expressed in the work culture and in the daily life of the organization? In the light of these eight feedbacks, a draft scale depending on related values has been developed. Dimensions of the scale have been designed by "respect for" the twelve values. Twelve concepts which expresses sub-dimension of VBM were set forward with the help of content analysis and literature review.

\footnotetext{
${ }^{1}$ I would like to thank Alpay E. İĞNEK, Prof. Dr. Aysun YILMAZLAR, Bülent ÖZDOĞAN, İrfan ONAY, Önder KIRATLILAR, Remzi ACAR, Taner ALGIN, Y1lmaz BAYRAKTAR for the valuable comments I have received from them.
} 
As a second step this draft of attitude scale has been sent to the experts in the fields of theology, management and statistics. This research is an example of a new and an uncommon collaboration of these three fields in Turkey. By coming into a closer dialogue around this theme of VBM a real encounter has been experienced.

The received interdisciplinary feedbacks and suggestions helped to create a draft version of the survey questionnaire and the scale. ${ }^{1}$

With the help of expert views and feedback acquired from the KALDER members twelve values which has been set forward before were turned into six main values regarding these could be more inclusive.

At the latest version of the questionnaire six values below were determined:

- Human Dignity

- Justice

- Trust

- Diversity

- Environmental Concern

- Sustainability

After this stage, in the light of literature and expert views semi-structured "VBM Executives Questionnaire" which includes six main values with their sub-dimensions has been developed. Six business executives who are randomly selected from the top 500 Turkish Industrial Enterprises were interviewed face to face. In line with the data acquired from structured interviews and expert views a questionnaire has been constituted. The questionnaire included structured interview questions. Structured interview questions are one of the most common data collection techniques as it enables some advantages such as in the qualitative researches,

\footnotetext{
${ }^{1}$ I would like to thank Ass. Prof. Dr. Ömer Kutlu and Lecturer PhD. Özge Altıntaş for their assistance to finalize the survey questionnaire and statistical evaluation.
} 
considering the advantages of the findings obtained by one method in the questionnaire form that can be explained and grounded by another method. It can allow different perspectives and in-depth examination of the subject area (Berg, 2008).

This questionnaire was finalized using the opinions of a total of ten experts; one business, one finance, two theology, two social psychology, one psychometry, three assessment and evaluation experts. Then, the structured questionnaire developed is used at the field research In all interviews conducted within the scope of this research, it is necessary to briefly inform the participants, assure that the information obtained from interviews would be used only in the scope of this research and obtain permission beforehand (Bogdan and Biklen, 2007).

In all interviews conducted within the scope of this research, the participants were briefly informed about the research. Informed volunteer consent form was given by assuring that the information obtained from the interviews would be used only in the scope of this research and in a reliable manner.

The data is collected during February- December 2018. The scope of the research is the top 500 Turkish Industrial Enterprises which is determined by the İstanbul Chamber of Industry in 2016. ${ }^{1}$ There are a lot of researches about the top 500 Turkish Industrial Enterprises managers in Turkey (for example: Özkanlı, 1995; Özkanlı and Eke, 1996).

Field application of the survey is conducted via e-mail, telephone interview and in person. In this study, pollsters who have worked in similar researches were assigned. A fullday training was provided to prepare the pollsters for the field research. A guideline is prepared including the issues to be considered in practice and given to the pollsters. In line with the timetable prepared, the researchers met with the managers in the regions where they were responsible.

\footnotetext{
${ }^{1}$ For company names and information, see; http://www.iso500.org.tr/
} 
In the initial stage of the data collection process, 481 enterprises whose information was published from the top 500 enterprises announced by Istanbul Chamber of Industry were brought together. It is seen that among the 481 enterprises whose name and identification information are accessible in this list of 500 enterprises, some of them are different companies of the same holding. Therefore, enterprises with the same management are excluded from the list. As a result of these arrangements, the contact information of the top managers of 467 enterprises was reached. Then the managers or executive assistants of these enterprises were reached via e-mail. The sudden changes in meetings due to the workloads of the managers of the related enterprises caused the cancellation of appointment or e-mail return in some meetings. Business managers who could not participate in the study justified this with the intensity of work. Questionnaires are delivered to senior executive managers of businesses and some of the forms are filled in face to face meetings while majority of them are filled through reminder phone calls. At the end of field research in total 92 business managers are interviewed which constitutes $18.4 \%$ of the universe. The contact information of the executive assistants were reached and questionnaires were sent to them via e-mail and face-to-face interviews were requested via telephone. The questionnaires were filled face to face with the managers who accepted the interview. Other managers agreed to answer the questionnaire via telephone or email.

Concurrent nested mixed method (for detailed information: Greswell and Plano, 2011) is used to analyse the top 500 Turkish Industrial enterprise high level women managers' perceptions on VBM. Qualitative data is analysed by a descriptive content analysis method (Creswell, 2016). Induction method is also used at the research (Yin, 2011). For data entry the package software of IBM SPSS Statistics 25 is used. Data is converted into the package Software of IBM SPSS Statistics 25(sav.) and Excel format (xls). Following the data entry through statistical methods (NVIVO8, AMOS23) and using the package software of IBM SPSS 
Statistics 25, statistical tables are drawn (IBM, 2015). Open coding has been done (Patton, 2014). NVIVO8 programme is used for coding. The coding has been controlled manually. Then, final reports on the data about validity and reliability analysis and its results is prepared.

\section{Results}

The summary of the research results are shown by the tables below. Distribution of the senior executives interviewed according to their characteristics is given in the Table 1:

Table 1. Distribution by Manager Characteristics

\begin{tabular}{|c|c|c|}
\hline$(\mathrm{n}=92) *$ & Number & Percent \\
\hline \multicolumn{3}{|l|}{ Sex } \\
\hline Male & 70 & 76,1 \\
\hline Female & 22 & 23,9 \\
\hline \multicolumn{3}{|l|}{ Education Level } \\
\hline Doctorate & 1 & 1,1 \\
\hline Bachelor's Degree & 85 & 93,4 \\
\hline Master's Degree & 5 & 5,5 \\
\hline \multicolumn{3}{|l|}{ Job } \\
\hline Regional Director & 3 & 3,3 \\
\hline External Affairs & 3 & 3,3 \\
\hline Other & 26 & 28,3 \\
\hline Factory Manager & 3 & 3,3 \\
\hline General Manager & 4 & 4,3 \\
\hline Administrative Affairs & 3 & 3,3 \\
\hline Human Resources & 41 & 44,6 \\
\hline Purchasing & 4 & 4,3 \\
\hline Production & 5 & 5,4 \\
\hline \multicolumn{3}{|l|}{ Working Years } \\
\hline 1-5 Years & 34 & 37,0 \\
\hline 6-10 Years & 31 & 33,7 \\
\hline 11-15 Years & 19 & 20,7 \\
\hline 15 Years more & 8 & 8,7 \\
\hline
\end{tabular}

*Because the participants did not answer to some questions, the total number is not 92.

When Table 1 is examined, the characteristics of the managers participating in the research are given. Accordingly, $76.1 \%$ of the managers participating the research is male and $23.9 \%$ is female. While the education level of $1.1 \%$ of the managers is doctorate, $93.4 \%$ is 
bachelor's degree and 5.5\% is master's degree. When the distribution of jobs are examined, the majority is Human Resources with $44.6 \%$ and the other with $28.3 \%$. While $37 \%$ of the managers' working years are in the range of $1-5$ years, $33.7 \%$ are $6-10$ years, $20.7 \%$ are $11-15$ years and $8.7 \%$ are 15 years.

\section{Graph 1. Sex}

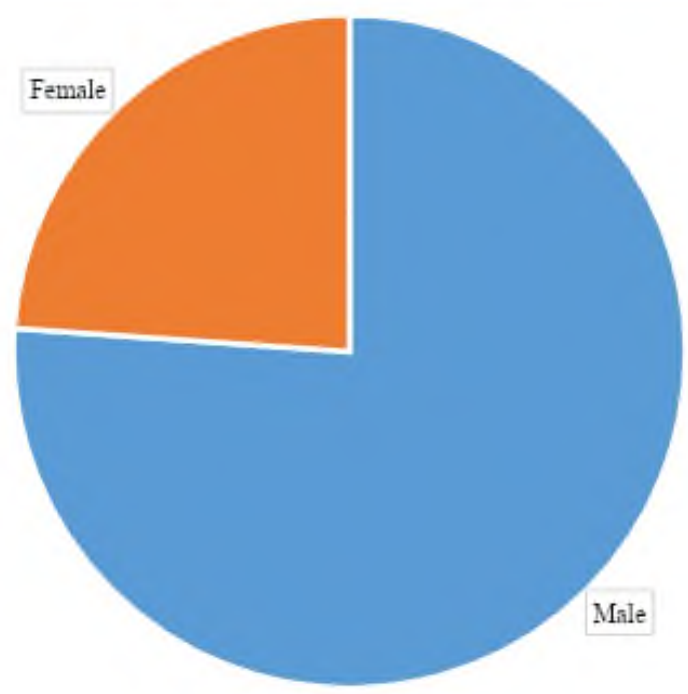

Graph 1 also shows that $76.1 \%$ of the managers participating the research is male and $23.9 \%$ is female. 
Table 2. Investigation of Employee Dignity Perspective and Application Differences According to Manager Characteristics.

\begin{tabular}{lcccccc}
\hline & \multicolumn{3}{c}{ Human Dignity Perspective } & \multicolumn{3}{c}{ Human Dignity Application } \\
& Av. & St. Dev. & Av. & St. Dev. & \\
\hline Sex & & & & & & \\
Male & 4,71 & 0,72 & $\mathrm{p}=0,240$ & 4,59 & 0,74 & $\mathrm{p}=0,191$ \\
Female & 4,75 & 0,32 & & 4,51 & 0,54 & \\
\hline Education Level & & & & & & \\
Bachelor's Degree & 4,71 & 0,67 & $\mathrm{p}=0,999$ & 4,56 & 0,72 & $\mathrm{p}=0,454$ \\
Master's Degree/Doctorate & 4,79 & 0,34 & & 4,83 & 0,20 & \\
\hline Working Years & & & & & & \\
1.1-5 Years & 4,71 & 0,40 & & 4,55 & 0,50 & \\
2.6-10 Years & 4,75 & 0,73 & $\mathrm{p}=0,247$ & 4,64 & 0,76 & $\mathrm{p}=0,551$ \\
3.11-15 Years & 4,88 & 0,21 & $\mathrm{n}=0,64$ & 0,40 & \\
4.15 Years More & 4,23 & 1,41 & & 4,25 & 1,45 & \\
\hline
\end{tabular}

As a result of the Mann-Whitney $U$ test, there was no statistically significant difference in terms of Employee Dignity Perspective and Employee Dignity Application scores between the gender and education levels of the managers.

As a result of the Kruskal-Wallis test, there was no statistically significant difference in terms of Employee Dignity Perspective scores and Employee Dignity Application scores between the managers' working years groups.

There was no significant difference in terms of employees' dignity value perspectives between gender, education level and working year criteria. This also applies to employee dignity application scores. 
Table 3. Investigation of Justice Perspectives and Application Differences According to Manager Characteristics

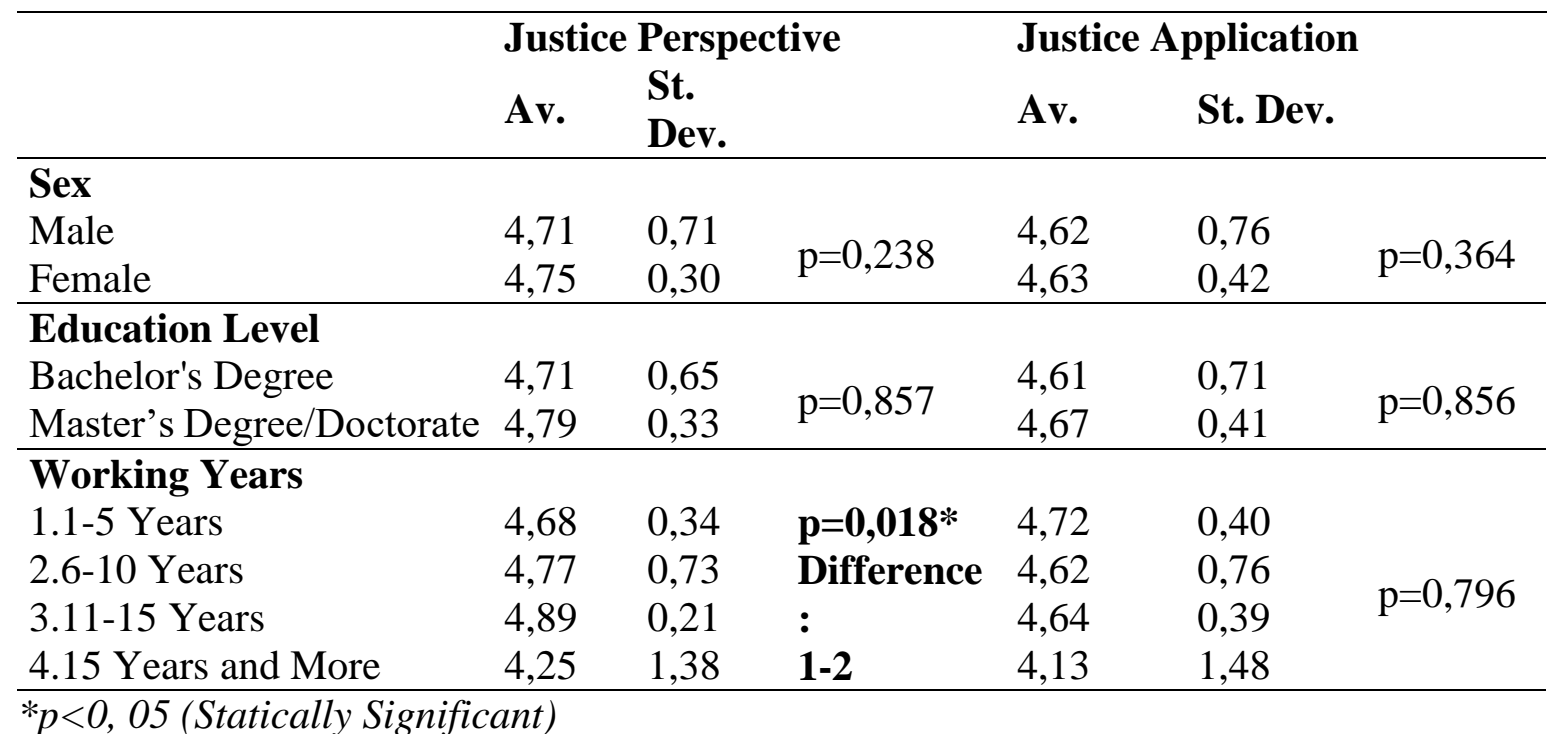

$* p<0,05$ (Statically Significant)

As a result of the Mann-Whitney U test, there was no statistically significant difference in terms of Justice Perspective scores and Justice Application scores between the gender and education levels of the managers.

Table 4. Investigation of Trust Perspectives and Application Differences According to Manager Characteristics.

\begin{tabular}{lcccccc}
\hline & \multicolumn{3}{c}{ Trust Perspective } & \multicolumn{3}{c}{ Trust Application } \\
& Av. & St. Dev. & Av. & St. Dev. & \\
\hline Sex & & & & & & \\
Male & 4,73 & 0,73 & $\mathrm{p}=0,061$ & 4,55 & 0,76 & $\mathrm{p}=0,209$ \\
Female & 4,68 & 0,38 & & 4,82 & 0,34 & \\
\hline Education Level & & & & & & \\
Bachelor's Degree & 4,71 & 0,69 & $\mathrm{p}=0,263$ & 4,62 & 0,72 & $\mathrm{p}=0,493$ \\
Master's Degree/Doctorate & 4,77 & 0,23 & & 4,72 & 0,25 & \\
\hline Working Years & & & & & & \\
1.1-5 Years & 4,77 & 0,34 & & 4,71 & 0,54 & \\
2.6-10 Years & 4,73 & 0,76 & $\mathrm{p}=0,380$ & 4,67 & 0,64 & $\mathrm{p}=0,384$ \\
3.11-15 Years & 4,83 & 0,36 & $\mathrm{4}, 53$ & 0,56 & \\
4.15 Years and More & 4,18 & 1,42 & & 4,25 & 1,43 & \\
\hline
\end{tabular}


As a result of the Mann Whitney U Analysis, there was no statistically significant difference between the managers' gender and education levels in terms of Trust Perspective scores and Trust Application scores.

As a result of the Kruskal Wallis analysis, there was no statistically significant difference between the managers' working years groups in terms of Employee Trust Perspective scores and Trust Application scores.

Table 5. Investigation of Diversity Perspectives and Application Differences According to Manager Characteristics.

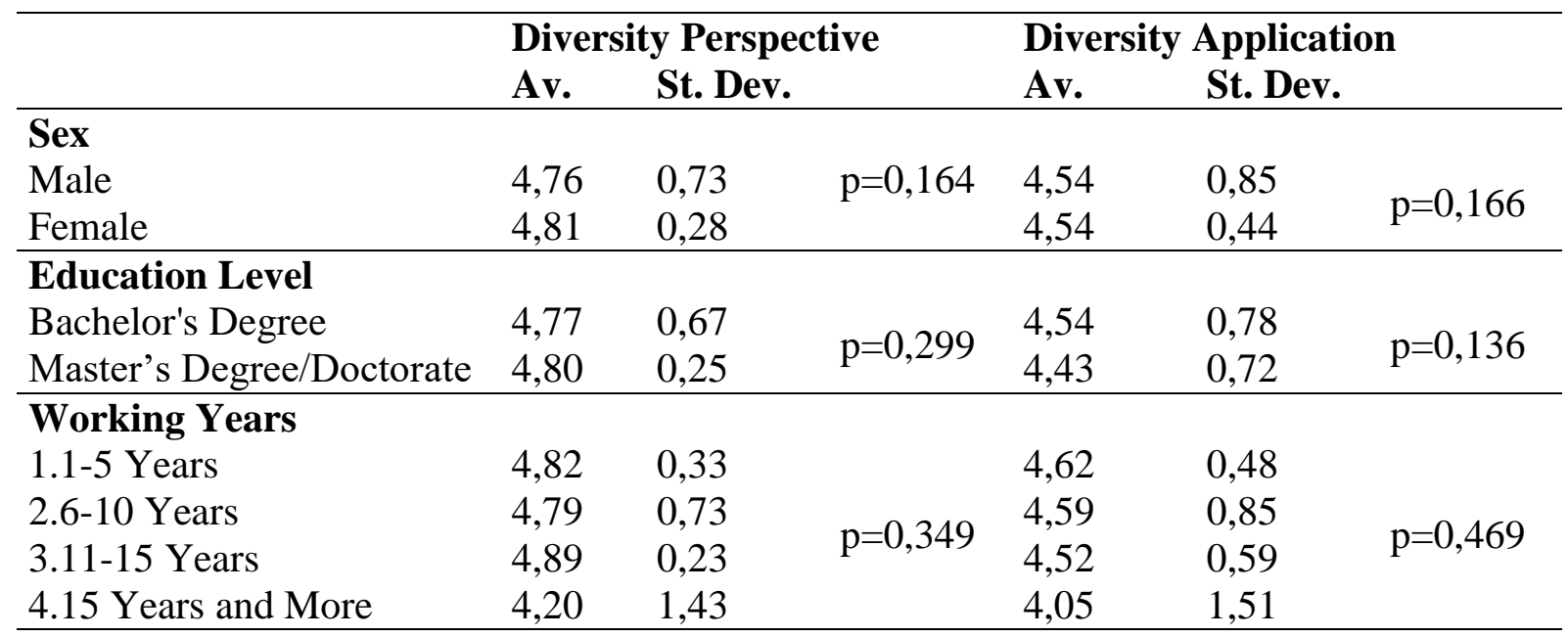

As a result of Mann Whitney U Analysis, there was no statistically significant difference between the managers' gender and education levels in terms of Pluralism Perspective scores and Pluralism Application scores.

As a result of the Kruskal Wallis analysis, there was no statistically significant difference between the managers' working year groups in terms of Employee Pluralism Perspective scores and Pluralism Application scores. 
Table 6. Investigation of Contribution to Life Quality Perspectives and Application Differences According to Manager Characteristics.

\begin{tabular}{|c|c|c|c|c|c|c|}
\hline & \multicolumn{3}{|c|}{$\begin{array}{l}\text { Contribution to Life Quality } \\
\text { Perspective }\end{array}$} & \multicolumn{3}{|c|}{$\begin{array}{l}\text { Contribution to Life Quality } \\
\text { Application }\end{array}$} \\
\hline & Av. & St. Dev. & & Av. & St. Dev. & \\
\hline Sex & & & & & & \multirow{3}{*}{$\mathrm{p}=0,318$} \\
\hline Male & 4,67 & 0,76 & \multirow{2}{*}{$\mathrm{p}=0,162$} & 4,45 & 0,90 & \\
\hline Female & 4,70 & 0,34 & & 4,53 & 0,51 & \\
\hline \multicolumn{7}{|l|}{ Education Level } \\
\hline Bachelor's Degree & 4,67 & 0,70 & \multirow{2}{*}{$\mathrm{p}=0,701$} & 4,43 & 0,84 & \multirow{2}{*}{$\mathrm{p}=0,149$} \\
\hline Master's Degree/Doctorate & 4,75 & 0,32 & & 4,92 & 0,13 & \\
\hline \multicolumn{7}{|l|}{ Working Years } \\
\hline 1.1-5 Years & 4,68 & 0,45 & \multirow{4}{*}{$\begin{array}{l}\mathrm{p}=0,047 * \\
\text { Diff: } \\
2-4\end{array}$} & 4,42 & 0,69 & \multirow{4}{*}{$\mathrm{p}=0,245$} \\
\hline 2.6-10 Years & 4,77 & 0,75 & & 4,61 & 0,84 & \\
\hline 3.11-15 Years & 4,78 & 0,31 & & 4,45 & 0,61 & \\
\hline 4.15 Years and More & 4,09 & 1,38 & & 4,19 & 1,50 & \\
\hline
\end{tabular}

As a result of the Mann Whitney U Analysis, there was no statistically significant difference between managers' gender and education levels in terms of Contribution to Life Quality Perspective and Contribution to Life Quality Application scores.

As a result of the Kruskal Wallis analysis, there was a statistically significant difference between the managers' working year groups in terms of Contribution to Quality of Life. According to this, the Contribution to Life Quality Perspective scores of managers whose working year group is 6-10 years are significantly higher than those who's working year is over 15 years. 
Table 7. Investigation of Continuous Development Perspectives and Application Differences According to Manager Characteristics.

\begin{tabular}{|c|c|c|c|c|c|c|}
\hline & \multicolumn{2}{|c|}{$\begin{array}{l}\text { Continuous } \\
\text { Perspective }\end{array}$} & Development & \multicolumn{2}{|c|}{$\begin{array}{l}\text { Continuous } \\
\text { Application }\end{array}$} & Development \\
\hline & Av. & St. Dev. & & Av. & St. Dev. & \\
\hline Sex & & & \multirow{3}{*}{$\mathrm{p}=0,403$} & & & \multirow{3}{*}{$\mathrm{p}=0,625$} \\
\hline Male & 4,71 & 0,73 & & 4,55 & 0,73 & \\
\hline Female & 4,78 & 0,32 & & 4,59 & 0,43 & \\
\hline Education Level & & & & & & \\
\hline Bachelor's Degree & 4,72 & 0,68 & \multirow{2}{*}{$\mathrm{p}=0,209$} & 4,55 & 0,69 & \multirow{2}{*}{$\mathrm{p}=0,612$} \\
\hline Master's Degree/Doctorate & 4,72 & 0,31 & & 4,70 & 0,39 & \\
\hline Working Years & & & & & & \\
\hline 1.1-5 Years & 4,75 & 0,32 & \multirow{4}{*}{$\mathrm{p}=0,120$} & 4,65 & 0,39 & \multirow{4}{*}{$\mathrm{p}=0,996$} \\
\hline 2.6-10 Years & 4,76 & 0,75 & & 4,55 & 0,75 & \\
\hline 3.11-15 Years & 4,89 & 0,23 & & 4,56 & 0,51 & \\
\hline 4.15 Years and More & 4,10 & 1,43 & & 4,23 & 1,39 & \\
\hline
\end{tabular}

As a result of the Mann Whitney U Analysis, there was no statistically significant difference between the managers' gender and education levels in terms of Continuous Development Perspective Scores and Continuous Development Application scores.

As a result of the Kruskal Wallis analysis, there was no statistically significant difference between the managers' working year groups in terms of Employee Continuous Development Perspective Scores and Continuous Development Application scores.

Table 8.Investigation of the Relationship between Value Based Management Application Status and Manager Gender in the Organization.

\begin{tabular}{|c|c|c|c|c|c|c|c|}
\hline & & & $\begin{array}{l}\text { Sex } \\
\text { Male }\end{array}$ & Female & Total & $\begin{array}{l}\text { Fisher's } \\
\text { Exact }\end{array}$ & $\mathbf{p}$ \\
\hline \multirow{4}{*}{ Application } & \multirow{3}{*}{ Yes } & Number & 62 & 20 & 82 & \multirow{4}{*}{0,653} & \multirow{4}{*}{0,675} \\
\hline & & Percent & 89,9 & 95,2 & 91,1 & & \\
\hline & & Number & 7 & 1 & 8 & & \\
\hline & Partially & Percent & 10,1 & 4,8 & 8,9 & & \\
\hline \multirow{2}{*}{ Total } & & Number & 69 & 21 & 90 & & \\
\hline & & Percent & 100,0 & 100,0 & 100,0 & & \\
\hline
\end{tabular}

Fisher's Exact Analysis was used because the expected value assumption of the Chi Square analysis was not provided and the table was $2 \times 2$. 
While the percentage of enterprises applying value based management is $89.9 \%$ in the organizations with male managers, the same rate was $95.2 \%$ for the female managers. As a result of Fisher's Exact analysis, there is no statistically significant relationship between manager gender and value-based management practice in the organization.

The fact that men and women have similar perspectives and the number of respondents who answered "yes" being many can be evaluated positively. This result can be accepted as a promising development in Turkey.

Table 9. Investigation of the Relationship between the Observed Problems in Other Institutions Adopting VBM Approach and Executive Gender in the Sector.

\begin{tabular}{|c|c|c|c|c|c|c|c|}
\hline & & & $\begin{array}{l}\text { Sex } \\
\text { Male }\end{array}$ & Female & Total & Chi-Square & $\mathbf{p}$ \\
\hline \multirow{4}{*}{$\begin{array}{l}\text { Observed } \\
\text { Problem }\end{array}$} & \multirow{2}{*}{ Yes } & Number & 27 & 3 & 30 & \multirow{4}{*}{4,736} & \multirow{4}{*}{$0,030^{*}$} \\
\hline & & Percent & 38,6 & 13,6 & 32,6 & & \\
\hline & \multirow{2}{*}{ No } & Number & 43 & 19 & 62 & & \\
\hline & & Percent & 61,4 & 86,4 & 67,4 & & \\
\hline \multirow{2}{*}{ Total } & & Number & 70 & 22 & 92 & & \\
\hline & & Percent & 100,0 & 100,0 & 100,0 & & \\
\hline
\end{tabular}

$*_{p}<0,05$ (Statically Significant)

While $38.6 \%$ of the male respondents observed problems in other institutions that adopted the VBM approach in the sector, the same rate was $13.6 \%$ for the female respondents. As a result of the chi-square analysis, there is a statistically significant relationship between executive gender and observing problems in other institutions that adopt VBM approach in the sector. Accordingly, for men the rate of those who have problems in other institutions that have adopted the VBM approach in the sector is significantly higher than that of women. 
Table 10. Investigation of the Relationship between the Frequency of the Vision Update and the Gender of the Managers in the Organization.

\begin{tabular}{|c|c|c|c|c|c|c|c|}
\hline & & & $\begin{array}{l}\text { Sex } \\
\text { Male }\end{array}$ & Female & Total & Chi-Square & $\mathbf{p}$ \\
\hline \multirow{6}{*}{$\begin{array}{l}\text { Frequency } \\
\text { of the } \\
\text { Vision } \\
\text { Update }\end{array}$} & \multirow{2}{*}{ Never } & Number & 13 & 6 & 19 & \multirow{6}{*}{0,957} & \multirow{6}{*}{0,620} \\
\hline & & Percent & 22,0 & 33,3 & 24,7 & & \\
\hline & 12 Voars & Number & 33 & 9 & 42 & & \\
\hline & 1-3 Years & Percent & 55,9 & 50,0 & 54,5 & & \\
\hline & 4 years and & Number & 13 & 3 & 16 & & \\
\hline & more & Percent & 22,0 & 16,7 & 20,8 & & \\
\hline \multirow{2}{*}{ Total } & & Number & 59 & 18 & 77 & & \\
\hline & & Percent & 100,0 & 100,0 & 100,0 & & \\
\hline
\end{tabular}

While $22 \%$ of the organizations with male managers did not update their visions at all, the same ratio was $33.3 \%$ for the organizations with female managers. As a result of Chi-square analysis, there was no statistically significant relationship between executive gender and frequency of vision update.

Table 11. Investigation of the Relationship between the Mission Update Frequency and the Gender of the Managers in the Organization

\begin{tabular}{llllllll}
\hline & & & $\begin{array}{l}\text { Sex } \\
\text { Male }\end{array}$ & Female & Total & \multirow{2}{*}{ Chi-Square $\mathbf{p}$} \\
\hline \multirow{2}{*}{ Mission } & \multirow{2}{*}{ Never } & Number & 12 & 5 & 17 & \\
Update & $\mathbf{1 - 3}$ Years & Percent & 20,3 & 26,3 & 21,8 & & \\
Frequency & & Number & 33 & 11 & 44 & 0,682 & \multirow{2}{*}{0,711} \\
& $\mathbf{4}$ years & Percent & 55,9 & 57,9 & 56,4 & & \\
& more & Number & 14 & 3 & 17 & \\
Total & & Percent & 23,7 & 15,8 & 21,8 & \\
& & Number & 59 & 19 & 78 & \\
\hline
\end{tabular}

While $20.3 \%$ of the organizations with male managers did not update their visions at all, the same percentage was $26.3 \%$ for the organizations with female managers. As a result of 
the Chi-square analysis, there was no statistically significant relationship between manager gender and mission update frequency.

Table 12. Investigation of the Relationship between the Value Update Frequency and the Gender of the Managers in the Organization

\begin{tabular}{|c|c|c|c|c|c|c|c|c|}
\hline & & & & $\begin{array}{l}\text { Sex } \\
\text { Male }\end{array}$ & Female & Total & $\begin{array}{l}\text { Chi- } \\
\text { Square }\end{array}$ & $\mathbf{p}$ \\
\hline \multirow{6}{*}{$\begin{array}{l}\text { Value } \\
\text { Frequency }\end{array}$} & \multirow{6}{*}{ Update } & \multirow{2}{*}{ Never } & Number & 13 & 7 & 20 & \multirow{6}{*}{0,559} & \multirow{6}{*}{0,756} \\
\hline & & & Percent & 29,5 & 36,8 & 31,7 & & \\
\hline & & \multirow{2}{*}{ 1-3 Years } & Number & 23 & 8 & 31 & & \\
\hline & & & Percent & 52,3 & 42,1 & 49,2 & & \\
\hline & & \multirow{2}{*}{$\begin{array}{l}4 \text { years and } \\
\text { more }\end{array}$} & Number & 8 & 4 & 12 & & \\
\hline & & & Percent & 18,2 & 21,1 & 19,0 & & \\
\hline \multirow{2}{*}{ Total } & & & Number & 44 & 19 & 63 & & \\
\hline & & & Percent & 100,0 & 100,0 & 100,0 & & \\
\hline
\end{tabular}

While $29.5 \%$ of the organizations with male managers did not update their values at all, the same percentage was $26.3 \%$ for the organizations with female managers. As a result of Chisquare analysis, there was no statistically significant relationship between manager gender and frequency of value update.

The main query at the beginning of the research used to make a comparison on gender perception regarding VBM. In the light of the research data there seems to be no significant difference related to the issue. This can be considered a sign of hope for the practical aspect of VBM in Turkish enterprises on the one hand and for the future of gender studies on the other hand. As a conclusion, the perceptions of women senior managers' on VBM is discussed at the study. In accordance with the final report, data and problems observed during implementation gender perspective for the women senior managers is provided. Comparative cultural analysis of women senior managers' perceptions on VBM from different countries is planned for future studies. 


\section{References}

Berg, B.L. (2008). Qualitative Research Methods for the Social Sciences, $7^{\text {th }}$ Edition, USA.

Bogdan, R.C. and S.K. Biklen. (2006). Qualitative Research for Education: An Introduction to Theories and Methods, $5^{\text {th }}$ Edition, USA: Pearson Publishing Company.

Copeland, T., T. Koller and J. Murrin. (1994). Valuation: Measuring and Managing the Value of Companies, Second Edition, New York: John Wiley and Sons, USA.

Creswell, J. W. (2016). Nitel Araştırma Yöntemleri (Qualitative Research Methods) (Eds., Mesut Bütün and Selçuk Beşir Demir). Ankara: Siyasal Publication Company.

Creswell, J. W. and Plano C., V. L. (2011). Designing and Conducting Mixed Methods Research, 2nd Edition. Thousand Oaks, CA: Sage Publishing Company.

Gossein, M. (1997). "The effect of strategy and organizational structure on the adoption and implementation of activity-based costing", Acc. Organ. Society, 22, p.p. 105-122.

Retrieved May 06, 2019, http://www.lucintel.com/value_based_management.aspx

Retrieved May 06, 2019, from http://flevy.com/blog/what-is-value-based-management-vbm/

Retrieved May 06, 2019, https://www-01.ibm.com/support/docview.wss?uid=swg27043942 \#relnotes $\mathrm{S}$ ystem

Ittner, C.D. and D.F. Larcker (2001). "Assessing empirical research in managerial accounting: a value based management perspective", J.Acc.Econ. 32, p.p. 349-410.

Kaplan, R.S. and Norton, D.P. (2001). The Strategy Focused Organization. Boston: Harvard Business School Press, MA, USA.

Kleiman, R. (1999). "Some evidence on Economic Value Added (EVA) companies", J. Appl. Corp. Finance, 12, p.p.80-91.

Malmi, T.and S.Ikaheimo (2001). "Value Based Management Practices- Some Evidence from the Field", Management Accounting Research, Volume: 14, Issue: 3, September, p.p. 235-254.

Martin, J.D. and J.W. Petty (2000). Value Based Management: The Corporate Response to the Shareholder Revolution. Boston: Harvard Business School Press, USA.

Özkanl1, Ö. and A. E. Eke. (1996). "Ülkemiz Büyük Sanayi Işsletmelerinde Performans Değerleme Yöntemlerinin Uygulanma Düzeyi (The performance evaluation practices of the top 500 Turkish Industrial Enterprises)", IV. Ulusal Yönetim ve Organizasyon Kongresi Proceedings Book, Middle East Technical University, Ankara, 29-31 May 1996, 250-260.

Özkanlı, Ö. (1995). Personel Politikalarının Belirlenmesinde Performans Değerlemenin Yeri ve Ülkemiz Büyük Sanayi Issletmelerindeki Uygulama(The importance of performance evaluation in determination of the personnel policies- A research on the top 500 Turkish 
Industrial Enterprises), Unpublished PhD Dissertation, Ankara University Social Sciences Institute, Ankara.

Patton, M. Q. (2014). Nitel Araştırma ve Değerlendirme Yöntemleri (Qualitative Research and Evaluation Methods) (Eds., Mesut Bütün and Selçuk Beşir Demir). Ankara: PEGEM Academy.

Sharman, P.A. (1999). Value Based Management, Focused Management Information Inc., August, Rev.4, www.FocusedManagement.com.

Sumantra, G., C. A. Bartlett and P. Moran. (1999). "A New Manifesto for Management", Sloan Management Review, Spring, Vol.40, Number: 3

Wallace, J.S. (1997). "Adopting residual income-based compensation plans: do you get what you pay for?" J. Acc Econ., 24, p.p. 275-300.

Wyk, L.V. (2008). "The concept of Value Based Management and its application in developing value maximizing strategies at Anglo Platinum", Third International Platinum Conference "Platinum in Transformation", The Southern African Institute of Mining and Metallurgy.

Yin, R. K. (2011). Applications of case study research. California: Sage Publishing Company. 


\title{
EXAMINATION OF HOFSTEDE'S MASCULINITY-FEMININITY DIMENSION IN FOUR POLITICIANS' SPEECHES AT THE G20 SUMMIT IN 2018
}

\author{
Özlem TÖREN ${ }^{1}$ \\ Evrim TÖREN ${ }^{2}$
}

\begin{abstract}
Culture shapes worldviews, social rules, use of language, interactions among individuals, and both interpersonal and intercultural dynamics of human population. It is not possible to speak of people without referring to their culture in the society. Based on Hall's high-context and lowcontext cultures, the study examines the speeches of Donald J. Trump, Theresa M. May, Mark Rutte and Sebastian Pinera at the G20 summit in 2018 through content analysis in SPSS 22.0 software.

While doing content analysis, the study takes into consideration Hofstede's masculinityfemininity dimension in order to examine dominant values and themes of both masculine and feminine cultures uttered by four politicians from different cultures.

In this regard, the aim is to discuss not only the degree to dominant values, but also demonstrate prominent themes articulated in the speeches of four politicians.

The research findings confirm that there is an impact of masculinity-femininity dimension on themes and politicians. Thus, the study ensures that contextual meanings can be understood truly by focusing on the influences of masculinity-femininity dimension which reflects the cultural values in a speech.
\end{abstract}

Keywords: Culture, Masculinity, Femininity, G20, Politicians.

${ }^{1}$ Ph.D Candidate, Faculty of Communication and Media Studies, Eastern Mediterranean University, ozlemtorenemu@gmail.com;

${ }^{2}$ Ph.D Candidate, Faculty of Business and Economics Eastern Mediterranean University evrim.toren@emu.edu.tr; 


\section{Introduction}

Culture refers to the beliefs, rules, techniques, organizations and artifacts which describe the distinctive features of human populations. It specifies worldviews, social rules, use of language, interactions among individuals, material wealth, etc. (Rathje, 2009). There are two experts who examine the culture in the wide literature. One of them is called the Dutch social psychologist Geert Hofstede who provides 6 dimensions of national cultures which are values of countries in the world. Another expert is called Edward T. Hall who provides the characteristics of high-context cultures and low-context cultures in the world. The six dimensions that Hofstede (2001) provides are power distance, uncertainty avoidance, individualism vs. collectivism, masculinity vs. femininity, long-term vs. short-term orientation, and indulgence vs. restraint. Power distance is associated with accepting unequal distribution of power in the society. There are large-power distance societies or small-power distance societies. Uncertainty avoidance refers to the situations in which people feel themselves threatened by inexactness. There are both high-uncertainty avoidance nations and lowuncertainty-avoidance nations. Individualism vs. collectivism is one of the value dimensions. Individualistic cultures are defined as a group of human populations which look after only themselves. On the other hand, the collectivist cultures give a group priority over each individual in it. When the masculinity vs. femininity dimension are considered, Hofstede (2001) argues that the important values in masculine cultures are assertiveness, acquisition of money, status, achievement, etc. whereas the prominent values in feminine cultures are friendship, quality of life, environmental sensitivity, fairness, justice, etc. In this respect, competition, success and assertiveness are influential in masculine societies whereas quality of life is associated with the sign of achievement in feminine societies. Long-term orientation is concerned with the future because it deals with the change. On the other hand, short-term orientation focuses on the present and past due to the moral standards. The last dimension is 
called restraint vs. indulgence. People control gratifications and pursue social norms in restrained societies whereas people benefit from free gratifications for fun in indulgence societies (Hofstede, 2001). In the literature, there are studies which appreciate Hofstede's six dimensions due to their favorable and useful outcomes while understanding the characteristics of different cultures in the world (Sondergaard, 1994; Kirkman et al., 2006; Merkin et al., 2014). However, there are some studies criticizing Hofstede's masculinity vs. femininity dimension when they take into account gender equality from the feminist point of view. While evaluating masculine cultures and feminine cultures according to Hofstede's identification, these studies claim that Hofstede identifies gender roles rigidly by fostering stereotypes for the masculinity vs. femininity dimension. For example men are associated with being confident, decisive, determined and tough whereas women are supposed to be sensitive, caring, emotional and having concern for others. According to the feminist perspective, these articulations are associated with stereotypes which are fixed ideas about masculine and feminine cultures (Dorfman and Howell, 1988; Clungston, Howell, and Dorfman, 2000; Cross and Madson, 1997; Vitell, Paolillo and Thomas, 2003; Dwyer, Mesak and Hsu, 2005; Jeknic, 2014). Therefore, these studies claim that there are generalizations for the characteristics of cultural aspects in terms of masculinity and femininity.

When the ways of interacting with people from other cultures are taken into account, there are two important issues. Hall (1976) emphasizes that high-context cultures are classified as societies using non-verbal methods to promote logical knowledge in dialogues through an effective facial expression, eye contact and intonation. Thus, high-context cultures prefer to use implicit messages and cultural cues. People who live in high-context cultures mostly support each other because relationships and group ties are important to them. On the other hand, lowcontext cultures do not benefit from contextual elements while interacting with others. People 
who belong to low-context cultures involve in a direct and explicit approach. In this regard, low-context cultures are individualistic because they firstly prefer to look after themselves. Thus, the state of being free public attention and personal space are very important in lowcontext cultures (Hall, 1976).

In line with the articulations above, culture affects the way people have a particular belief or idea about something and speak to others in their lives. People's speeches act as the mirrors of their culture due to the impact of culture on the negotiating style (Salacuse, 1998; Giri, 2006; Jie, 2015). When people come together, their aim is to get contact with each other. Therefore, they use language to articulate or exchange their ideas and feelings. In the cultural system of a specific society, every speech is under the influence of cultural values and norms. Although every person has her/his own style of speaking, people sharing the same cultural aspects reveal a lot of similarities in the speech styles. In other words, these similarities emerge from their cultures. In this regard, the study examines the speeches of four politicians who are Donald J. Trump, Theresa M. May, Mark Rutte and Sebastian Pinera at G20 summit held in Argentina in 2018. The G20 (or group of twenty) is an international summit for the governments and central bank governors from 19 countries and the European Union (EU). It was founded in 1999 to maintain policy coordination, sustain stability and growth, and promote international structure in the world. This summit is very important because the G20 economies are influential in the world economy when their characteristics are taken into consideration in terms of trade, economic and financial growth and area in the world (Narlikar and Tussie, 2004).

The analyses are done through content analysis in SPSS 22.0 software in this study. While doing the content analysis, the study takes into consideration Hofstede's masculinity vs. femininity dimension in order to examine dominant values and themes of both masculine and 
feminine cultures uttered by four politicians from different cultures. According to Hofstede (2001), the US scores 62 on masculinity whereas the UK scores 66 on this dimension. The Netherlands scores 14 on masculinity whereas Chile scores 28 on masculinity. In this regard, the UK and the US are defined as masculine cultures whereas the Netherlands and Chile are specified as feminine cultures. Therefore, the aim is to discuss not only the degree to dominant values, but also demonstrate prominent themes articulated in the speeches of four politicians. The study is organized as follows: Section 2 fundamentally introduces a theoretical framework. Section 3 specifies methodology. Section 4 is devoted to the presentation of the results of content analysis. Section 5 summarizes the basic findings and insights of the study.

\section{Theoretical Framework}

The theoretical framework is based on Hall's (1976) high-context cultures and lowcontext cultures. It is important to note that characteristics of high-context cultures and lowcontext cultures should be understood truly in order to promote favorable intercultural communication which is a particular way of communication while disseminating information across different cultures. Since the study examines the speeches of the presidents Donald J. Trump and Sebastian Pinera, and the prime ministers Theresa M. May and Mark Rutte at the G20 summit in Argentina in 2018, the way of articulating speeches of four politicians are examined according to the characteristics of their cultures proposed by Hall (1976). In this regard, the countries such as the US, the UK and Netherlands are the countries specified as lowcontext cultures whereas Chile is identified as a high-context culture according to Hall's (1976) emphases on high-context cultures and low-context cultures. The aim is to show how these politicians reflect either direct or indirect communication style while they are talking about certain topics according to their cultural values at the G20 summit in 2018. 


\section{Methodology}

Content analysis is a technique which is used to examine a set of data systematically. (Neuendorf, 2002). This study employs a content analysis because it quickly provides a beneficial technique in a quantitative research through computer calculations in SPSS 22.0 software. The quantitative content analysis is done after obtaining the data set including the politicians, countries, gender of the politicians, Hofstede's masculinity vs. femininity dimension, and topics according to the speeches of four politicians. They are entered to the SPSS 22.0 software. Content analysis is done through cross tabulation in order to show the distribution of utterances by the politicians, utterances according to the gender of politicians, Hofstede's masculinity vs. femininity dimension, and topics of four politicians in their speeches. Then, the independent-samples T test is applied to show the impact of the Hofstede's masculinity vs. femininity dimension on topics of speeches and politicians.

\section{Findings}

In this section of the study, the analyses based on the frequencies and percentages of the utterances by the politicians, utterances according to the gender of politicians, Hofstede's value dimension (masculinity vs. femininity), and topics of four politicians' speeches are discussed in order to evaluate Hofstede's masculinity vs. femininity dimension in four different speeches at the G20 summit in 2018. Then, the impact of the Hofstede's masculinity vs. femininity dimension on topics of speeches and politicians are tested through independent-samples $\mathrm{T}$ test. Table 1. Shows the frequencies and percentages of utterances belonging to the politicians of different countries at the G20 summit in 2018. 
Table 1. Utterances of the Politicians

\begin{tabular}{llll}
\hline Politicians & Country & Frequency & Percent \\
\hline Donald D. Trump & The US & 67 & 32.1 \\
Theresa M. May & The UK & 34 & 16.3 \\
Mark Rutte & Netherlands & 61 & 29.2 \\
Sebastian Pinera & Chile & 47 & 22.5 \\
\hline
\end{tabular}

The sum total of the politicians' utterances is 209 in Table 1. This table presents that Trump speaks out $32.1 \%$ of the utterances in this summit held in Argentina. His utterances have the highest percentage among the politicians. The lowest percentage belongs to Pinera who is the president of Chile. Table 2. Below illustrates the frequencies and percentages of utterances in the four speeches according to the gender of the politicians.

Table 2. Utterances according to gender

\begin{tabular}{lll}
\hline Gender & Frequency & Percent \\
\hline Female & 34 & 16.3 \\
Male & 175 & 83.7 \\
\hline
\end{tabular}

The female politician, who is May speaks out directly and expressively $16.3 \%$ of the utterances as a prime minister of the UK which is a low-context culture at the G20 summit in 2018. The male politicians who are Trump, Rutte, and Pinera speak out $83.7 \%$ of the utterances in the summit. Trump directly articulates his ideas as a president of the US which is an example of the low-context cultures. Rutte also speaks out explicitly as the prime minister of the Netherlands because this country is one of the low-context cultures. On the other hand, Pinera who is the president of Chile utters his messages implicitly due to the characteristics of the highcontext culture. Table 3. Presents frequencies and percentages of Hofstede's value dimension based on masculinity vs. femininity. 


\section{Table 3. Value Dimension}

\begin{tabular}{lll}
\hline Value Dimension of Hofstede & Frequency & Percent \\
\hline Femininity & 108 & 51.7 \\
Masculinity & 101 & 48.3 \\
\hline
\end{tabular}

Table 3 shows that $51.7 \%$ of the utterances belongs to the femininity whereas $48.3 \%$ of the utterances is associated with the masculinity. This study takes into consideration not only the speeches of politicians from the feminine cultures such as the Netherlands and Chile, but also the speeches of politicians from the masculine cultures like the US and the UK. Thus, Table 3. shows that the politicians of the Netherlands and Chile speak out more than the politicians of the US. and the UK. Due to Hofstede's emphases on masculinity vs. femininity dimension, it is important to note that speeches of Rutte and Pinera from feminine cultures reveal distinctive topics which distinguish them from the speeches of Trump and May who are from masculine cultures. Table 4. Presents the percentages of topics that Trump speak out at the G20 summit in 2018. As it is seen in the Table 4, there are certain topics uttered by the president of the US in his speech in Argentina. 
Table 4. Topics of Trump's Speech at the G20

\begin{tabular}{ll}
\hline Topics & Percent \\
\hline Money & 1.5 \\
Assertiveness & 3 \\
Success & 6 \\
Power & 7.5 \\
Competition & 4.5 \\
Economic Integration & 20.9 \\
Trade & 10.4 \\
Dominance and Hierarchy & 1.5 \\
Wealth & 6 \\
Trade Restriction & 3 \\
Tariff & 1.5 \\
Economic Growth & 4.5 \\
Job Opportunities & 10.4 \\
Economic and Financial Crises & 1.5 \\
Goods and Services & 3 \\
Development & 9 \\
Technology & 5.8 \\
\hline
\end{tabular}

When the topics of Trump's speech at the G20 summit are taken into consideration, the highest percentage belongs to the economic integration which is $20.9 \%$ of Trump's utterances. When Trump came to the stage for his speech, he was not alone in this summit. He shared the platform with the president of the Mexican States and the Prime Minister of Canada. As the president of the masculine culture, Trump is in an attempt to articulate the importance of economic integration which is necessary to be powerful in the world. In this regard, he mostly talks about the United States-Mexico-Canada Agreement (USMCA) which is signed in 2018. For Trump, this economic integration promotes environmental and labor regulations, and incentives for economic development. As it is seen in Table 4., trade and job opportunities are topics of Trump's speech. Their percentage is $10.4 \%$. The percentage of development as a topic in Trump's speech is $9 \%$. Trump also talks about issues based on having the power in the world. The percentage of this topic is $7.5 \%$. When other topics are taken into account, they are also consistent with the characteristics of masculinity because Hofstede (2001) defines masculinity 
as a value dimension which is associated success, material wealth, and having or showing a confident and forceful personality in the society. Thus, Trump's utterances are associated with the characteristics of masculinity. Table 5. Shows the percentages of topics which are mentioned by May at the G20 summit in 2018. May, who is the prime minister of the UK reflects the values of masculinity in her speech.

Table 5. Topics of May's Speech at the G20

\begin{tabular}{ll}
\hline Topics & Percent \\
\hline Success & 2.9 \\
Economic Integration & 5.9 \\
Trade & 20.6 \\
Wealth & 2.9 \\
Environmental Sensitivity & 2.9 \\
Health & 2.9 \\
Economic Growth & 11.8 \\
Laws, Rules and Regulations & 2.9 \\
Goods and Services & 5.9 \\
Partnership and Investment & 17.9 \\
Population & 2.9 \\
Production & 8.8 \\
Modernization & 2.9 \\
Development & 8.8 \\
\hline
\end{tabular}

Table 5 presents that the highest percentage belongs to the utterances which are about trade in May's speech. The percentage of this topic is $20.6 \%$. Since material wealth, acquisition of money, power and achievement are important values in a masculine culture according to Hofstede (2001), it is important to note that May prefers to indicate the importance of buying and selling goods and services in a global environment in her speech. Then, she speaks about the necessity of partnership and investment. $17.9 \%$ of her utterances is based on partnership and investment. $11.8 \%$ of May's speech belongs to the topic called economic growth whereas both production and development have $8.8 \%$ of May's utterances. Other topics, which are economic integration, goods and services, wealth, success, modernization, etc. uttered by May are also 
compatible with the masculinity because masculine cultures care about these issues in their societies according to Hofstede (2001). Table 6. Illustrates the percentages of topics uttered by Rutte who is the prime minister of the Netherlands.

Table 6. Topics of Rutte's Speech at the G20

\begin{tabular}{ll}
\hline & \\
Topics & Percent \\
\hline Success & 1.6 \\
Economic Integration & 1.6 \\
Trade & 4.9 \\
Environmental Sensitivity & 4.9 \\
Gender Equality & 1.6 \\
Support and Caring & 9.6 \\
Collaboration & 4.9 \\
Relationship Oriented Leadership & 1.6 \\
Women's Issues & 1.6 \\
Violence Against Women & 1.6 \\
Fairness & 6.6 \\
Economic Growth & 8.2 \\
Job Opportunities & 1.6 \\
Modernization & 1.6 \\
Human Rights & 1.6 \\
Economic and Financial Crises & 1.6 \\
Development & 9.1 \\
Laws, Rules and Regulations & 1.6 \\
Good and Services & 3.3 \\
Technology & 3.3 \\
Partnership & 1.6 \\
Population & 1.6 \\
Security & 1.6 \\
Energy & 1.6 \\
Global Governance & 1.6 \\
Innovation and Knowledge & 3.3 \\
Terrorism & 4.9 \\
Financial and Economic Policies & 1.6 \\
Social Division vs. Collectivism & 1.6 \\
Protectionism & 3.3 \\
Multilateralism & 1.6 \\
Production & 1.6 \\
Issues of Young & \\
Governmental Org. & and \\
\hline
\end{tabular}


Rutte, who is the prime minister of a feminine culture talks about distinctive issues in his speech (See Table 6). The title of his speech called "Eyes forward: what the world wants (and needs)." demonstrates that Rutte is a member of a feminine culture defending cooperation, caring, and concern for others. When the topics of Rutte's speech are taken into account, it is observed that the highest percentage belongs to the topic called development that has $9.1 \%$ of his total utterances. Rutte states that there should be fair and sustainable development for the well-being of nations in the world. He also talks about support and caring as a topic which is $8.6 \%$ of the speech. For example, Rutte states that there is no country which can resolve problems alone. Thus, he indicates that there should be a common approach for international cooperation. $8.2 \%$ of Rutte's speech is based economic growth. Rutte prefers to indicate the importance of sustainable economic growth that benefits everyone. When fairness is taken into consideration as a topic in Rutte's speech, the results show that $6.6 \%$ of the speech is based on this topic. Rutte emphasizes that fair commitments are necessary to promote opportunities in the world. The prime minister of the Netherlands also talks about trade which has the $4.9 \%$ of his utterances. For Rutte, trade is necessary for growth, but fair trade is necessary for development. Thus, he asserts that there should be equal economic growth and prosperity for all nations in the global environment. When other topics are considered in Table 6., it is important to note that there are interesting topics in Rutte's speech that Trump and May do not mention them in their speeches. For example, the topics, which distinguish Rutte from Trump and May are human rights, gender equality, violence against women, women's issues, global governance, social division, security, terrorism, etc. In this regard, the study shows that Rutte's speech is consistent with Hofstede's (2001) views on femininity. Table 7. Presents the percentages of topics which are provided by Pinera at the G20 summit in 2018. 
Table 7. Topics of Pinera's Speech at the G20

\begin{tabular}{ll}
\hline Topics & Percent \\
\hline Trade & 10.6 \\
Environmental Sensitivity & 2.1 \\
Justice & 10.6 \\
Gender Equality & 4.3 \\
Support and Caring & 2.1 \\
Relationship-Oriented Leadership & 2.1 \\
Women's Issues & 4.3 \\
Violence Against Women & 4.3 \\
Discrimination Against Women & 2.1 \\
Health & 2.1 \\
Education & 2.1 \\
Fairness & 4.3 \\
Tariff & 6.4 \\
Economic Growth & 2.1 \\
Job Opportunities & 4.3 \\
Modernization & 4.3 \\
Conflict Resolution & 4.3 \\
Democracy & 2.1 \\
Human Rights & 6.4 \\
Economic and Financial Crises & 2.1 \\
Freedom & 4.3 \\
Development & 6.4 \\
Violence Against Children & 2.1 \\
Laws, Rules and Regulations & 4.3 \\
\hline
\end{tabular}

As it is stated before, Chile is one of the feminine cultures in the world. Therefore, Pinera's articulations are consistent with the features of femininity proposed by Hofstede (2001). Table 7. Presents that both trade and justice are topics having the highest percentage which is $10.6 \%$ of Pinera's utterances. While talking about trade and justice in the summit, Pinera emphasizes that there should be free trade for equal salaries and great opportunities in order to modernize and strengthen the world. It is also important to note that development, human rights, and tariff are the topics having $6.4 \%$ of his speech. Moreover, gender equality, women's issues, violence against women, fairness, job opportunities, modernization, and conflict resolutions are topics having $4.3 \%$ of Pinera's utterances at the G20 summit (See Table 
7). These topics are compatible with the characteristics of a feminine culture because collectivism, concern for others, caring, modesty, etc. are prominent values of femininity.

Due to the characteristics of masculinity vs. femininity dimension proposed by Hofstede (2001), the hypotheses to be tested through independent-samples T test in SPSS 22.00 software are:

a) There is an impact of Hofstede's masculinity vs. femininity dimension on topics of speeches which belong to the four politicians.

b) There is an impact of Hofstede's masculinity vs. femininity dimension on politicians.

When independent-samples T test is run for 209 data in SPSS 22.0 software, results of the independent-samples $\mathrm{T}$ test are presented in Table 8.

Table 8. Results of Independent-Samples T Test

\begin{tabular}{lll}
\hline Variables & T-Statistics & Sig. (2 Tailed) \\
\hline Topics of Speeches & 4.031 & 0.000 \\
Politicians & 31.129 & 0.000 \\
\hline
\end{tabular}

This table presents effects of Hofstede's masculinity vs. femininity dimension on topics of speeches and politicians by providing both t statistics and $\mathrm{p}$ values. The lower $\mathrm{p}$-values (Sig. (2 Tailed)) make a greater conclusion of the right and consistent hypotheses at the 95\% significance level. In this respect, there is a statistically significant relationship between Hofstede's masculinity vs. femininity dimension and topics of speeches because $\mathrm{p}$ value is equal to 0.000. Lastly, there is also a statistically significant relationship between Hofstede's masculinity vs. femininity dimension and politicians because $p$ value is equal to 0.000 (See Table 8). 


\section{Conclusion}

According to Hall's (1976) emphases on high-context and low-context cultures, the study examines the speeches of Donal J. Trump, Theresa M. May, Mark Rutte, and Sebastian Pinera at G20 summit in 2018 through content analysis in SPSS 22.0 software. While analyzing speeches of these four politicians through content analysis, the study also takes into consideration Hofstede's (2001) masculinity vs. femininity dimension in order to examine dominant values and themes of masculine and feminine cultures uttered by four politicians from different cultures in their speeches at the G20 summit. The results obtained from independentsamples $t$ test confirm that there is a statistically significant relationship between Hofstede's masculinity vs. femininity dimension and topics of speeches. It is also observed that there is a statistically significant relationship between Hofstede's masculinity vs. femininity dimension and politicians. Therefore, politicians' value dimensions such as masculinity and femininity affect topics of their speeches at the G20 in 2018. Additionally, politicians from low-context cultures such as Trump, May and Rutte use a direct and explicit approach. However, Pinera uses an implicit approach while articulating his ideas.

Although the results are consistent with the masculinity vs. femininity dimension proposed by Hofstede, it is important to note that Hofstede's ideas on masculine and feminine cultures should be taken into account carefully because his emphases are prone to create fixed ideas (stereotypes) about genders and cultural aspects of nations. In other words, a person within a culture may not share the same perspective as the majority of people in the society.

\section{References}

Clugston, M., Howell, J. P., \& Dorfman, P. W. (2000). Does Cultural Socialization Predict Multiple Bases and of commitment?. Journal of management, 26(1), 5-30.

Cross, S. E., \& Madson, L. (1997). Models of The Self: Self-Constructs and Gender. Psychological Bulletin, 122(1), 5. 
Dorfman, P. W., \& Howell, J. P. (1988). Dimensions of national culture and effective Leadership Patterns: Hofstede Revisited. Advances In international Comparative management, 3(1), 127-150.

Dwyer, S., Mesak, H., \& Hsu, M. (2005). An Exploratory Examination of The Influence of National Culture on Cross-National Product Diffusion. Journal of International Marketing, 13(2), 1-27.

Giri, V. N. (2006). Culture and Communication Style. The Review of Communication, 6(1-2), 124-130.

Hall, E. T. (1976). The Anthropology of Space: An Organizing Model. Environmental Psychology. New York: Rinehart \& Winston.

Hofstede, G. (2001) Cultures Consequences: Comparing Values, Behaviors, Institutions and Organizations Across Nations. Thousand Oaks, London, New Delhi: Sage Publications.

Jeknić, R. (2014). Gender Equality, Young Women and Culture in the Context of the "Masculinity/Femininity" as A Dimension in Geert Hofstede's Model of "National Culture". Zbornik radova Pravnog fakulteta u Splitu, 51(3), 681-696.

Jie, Z. (2015). Language Mirrors Culture With Speech Styles. Sino-US English Teaching, 12(6), 464-470.

Kirkman, B. L., K. B. Lowe, \& C. B. Gibson. (2006). A quarter century of Culture's Consequences: A review of empirical research incorporating Hofstede's cultural values framework. Journal of International Business Studies, 37(3), 285-320.

Merkin, R., Taras, V., \& Steel, P. (2014). State of the Art Themes in Cross-Cultural Communication Research: A systematic and Meta-analytic Review. International Journal of Intercultural Relations, 38, 1-23.

Narlikar, A., \& Tussie, D. (2004). The G20 at the Cancun Ministerial: Developing Countries and Their Evolving Coalitions in the WTO. World Economy, 27(7), 947-966.

Neuendorf, K. A. (2002). The Content Analysis Guidebook. California: Sage Publications.

Rathje, S. (2009). The Definition of Culture: An Application Oriented Tool. Intercultural Journal, 35, 119-149.

Salacuse, J. W. (1998). Ten Ways That Culture Affects Negotiating Style: Some Survey Results. Negotiation Journal, 14(3), 221-240.

Søndergaard, M. (1994). Hofstede's Consequences: A Study of Reviews, Citations and Replications. Organization Studies, 15(3), 447-456.

Vitell, S. J., Paolillo, J. G., \& Thomas, J. L. (2003). The Perceived Role of Ethics and Social Responsibility: A Study of Marketing Professionals. Business Ethics Quarterly, 13(1), 63-86. 


\title{
THE POST OCCUPANCY EVALUATION OF COMFORT CONDITIONS ACCORDING TO GENDER: AHMET HAMDİ AKSEKI MOSQUE EXAMPLE
}

\author{
Sena IŞIKLAR BENGi ${ }^{1}$ \\ A. Yağmur TOPRAKLI
}

\begin{abstract}
Mosques are defined as religious buildings and researchers from different sciences, such as architects, art historians and theologians, are of interest. The spatial and psychological characteristics of worship areas such as the interaction between the users, providing enough space for the worshiping behavior and other potential uses may be the subject of the academic studies of the mosques in the field of architecture. Mosques are the basic place of worship of the community in Islam, however, the mosque community is mostly composed of male users. Female users are uncomfortable with male dominated use and the comfort conditions of places reserved for women who are trying to raise awareness in order to improve this situation. However, sufficient academic studies have not been reached in Turkey for female oriented design for mosques. In these conditions, the necessity of evaluating the comfort conditions of mosques according to gender comes to the agenda. A field study was conducted with the Ankara Ahmet Hamdi Akseki Mosque users in Ankara. The comfort conditions of the mosque were examined according to gender. Thus, the trust and safety perception of the individuals in different profiles, the deficiencies of the mosque in the worship part of the mosque were identified. Due to the data obtained, the psychological and physical qualities of mosques affecting the users were determined. As a result of the study, it was seen that the mosques should provide the necessary physiological and psychological conditions appropriate to the needs of female users. With this study, it is aimed to provide the user satisfaction, to obtain structures in which function and space conditions will overlap, to increase the comfort conditions of places of worship and to contribute to the typologies of mosques in the future.
\end{abstract}

Keywords: User Satisfaction, Gender Satisfaction, Post Occupancy Evaluation, Place of Worship, Mosque.

${ }^{1} \mathrm{PhD}$ Candidate, Gazi University Faculty of Architecture Department of Architecture, Ankara TURKEY sena.isiklar@gmail.com

${ }^{2}$ Dr. Gazi University Faculty of Architecture Department of Architecture, Ankara TURKEY toprakli@gazi.edu.tr 


\section{Mosques, the Places of Worship}

Mosque, which are Muslims' places of worship; is an issue that is under the close interest of architects, art historians and theologians and has been dealt with by both art and religious sciences. The word mosque was derived from French mosque and from Italian moschea, which was ultimately from Arabic مَسْجِد (masjid, literally "place of prostration") ("mosque" at www.etymonline.com). According to Turkish Linguistic Society, "cami" the Turkish equivalent of mosque refers to the place where Muslims gather to worship; gathering, bringing together, keeping together (Url-1). The etymological origin of the word is Arabic; "bringing the things that are spread away together, collecting, combining, wearing clothes.

Mosques are places where spiritual functions such as preaching, sermon, prayer of mawlid or hatim, teaching religious sciences, collective prayer, and places where bodily worship come to the forefront (Yaşar and Tutkun, 2007). In this respect, mosques generally consist of a large prayer room, a small room for the imam (prayer leader) and a place for hatip (orator, preacher). In many cases, these components are formed in the large space without any division. As a supporting function, there are ablutions and toilets for men and women (Kurniawan, 2011). In large mosques, units such as the harim, harem, nave, the last congregation place (narthex), minarets, fountains, muvakkithane, rooms of imams and muezzins and musallataşı (coffin rest) are included (Hasol, 2010: 105). In addition to religious uses, mosques accommodate social and cultural activities. For the residential, social and educational functions, housing, multi-purpose halls, open spaces, grocery and library units can also be embedded to the main function. Thus, the active use of the mosques is provided not only during prayer times but also at other times of the day and the users are encouraged to use the place for different reasons. 
In the current practices, the actors who commission mosques are formed by associations and the local community. However, perhaps as this situation must have been seen as a wrong practice, it has created a movement in the architectural community and the bureaucracy of the Directorate of Religious Affairs (Atl1, 2016). Works on improving mosques, eliminating disruptions and increasing user participation have started. Especially in recent years, the number of studies on the mosque has increased. However, the lack of research on the suitability of mosques to the present conditions and the relationship with their users is noteworthy (Y1ldiz \& Toprakl1, 2018).

When the relationship between the mosque and its users is examined; while mosques are intended to be used by everyone; it is seen that the user mass is mostly composed of men. This situation has been criticized by women and the desire for improvement has been expressed. With this desire, as of October 2017, women launched the "Women in Mosques" campaign. Within the scope of this campaign, women have come together in the mosque and discussed the problems and inequalities they have been seeing in mosques. Major complaints have been the reservation of small and unequal places for women; use of dirty, dusty rooms, places even used as a pantry and storage rooms for women; the use of screen-curtain to keep them away from the congregation; the restriction of access to mosques for disabled and elderly women, and the stairs that children and elderly people cannot use; the insufficiency or pollution of ablution rooms, the fact that they were not resistant to climatic conditions and that women could not feel themselves belonging to mosques. They also reported that they had seen interventions to restrict their worship by the male community (Url-2). Accordingly, the campaign team, which completed its first year, held a meeting on September $29^{\text {th }} 2018$. The women who talked about their experiences discussed the mosque issue with the campaign; stated that they have been doing a solution-oriented study with the aim of improving mosques. In this direction, although there is no physical improvement in mosques yet, the 
Directorate of Religious Affairs has committed to the improvement through a commission established (Url-3).

\section{Post Occupancy Evaluation Method}

User behaviour in buildings is the subject of scientific studies. The effects of spatial features on users' movements, emotions and perceptions have been proven by previous studies. For this reason, it is important to meet the needs and activities of the user with the built environment. Users prefer to be in places where they can feel secure, satisfy their sense of belonging, where hygienic conditions, optimum solution of heat, ventilation and light elements are provided, places which have no odour or noise problem, and are accessible. In addition, the fact that the place which can accommodate different uses and provide ergonomic comfort is one of the important criteria in choosing it.

Reason for ignoring user needs is qualitative characteristics that make measurement and transferability problematic. An assessment-oriented approach is required to address this problem and to determine the effects of the building on users (Watson, Evans, Karvonen, Whitney, 2016). One of these approaches is called "Post Occupancy Evaluation" (POE). Post Occupancy Evaluation was introduced in the 1960s in the UK in response to problems between users and building performance. Firstly, the relationship between the building and the progress towards the recovery or re-socialization of the residents was observed in institutional care facilities such as mental hospitals, nursing homes and correctional facilities (Preiser, 1995). The POE assesses how well buildings meet the needs of users. It involves the systematic evaluation of the building, which is in use, from the point of view of its inhabitants (Turpin-Brooks and Viccars, 2006). It focuses on customer satisfaction and functional "compliance" assessment (Zimmerman \& Martin, 2001). 
Zimmerman and Martin (2001) argue that POE is a recurrent process. It provides a knowledge base that can be used to improve gaps in existing buildings or to create a programming base for future buildings. According to Preiser (1995), the benefits of Post Occupancy Evaluation are seen in three stages:

- Short-term benefits: Providing user feedback on problems in buildings and identifying appropriate solutions.

- Medium-term benefits: The contribution of positive and negative lessons learned in the next building design to the design strategy development.

- Long-term benefits: The creation of databases is the creation of planning and design criteria for certain types of buildings (Preiser, 1995).

Turkey has a limited number of studies related to the POE method. In the international literature, mosques are considered as one of the less studied buildings typology. In this context, POE method was applied for a mosque in order to eliminate the lack of literature. The assessment system has been designed considering the complaints of women among the mosque users about the comfort conditions.

\section{Post Occupancy Evaluation of Ankara Ahmet Hamdi Akseki Mosque}
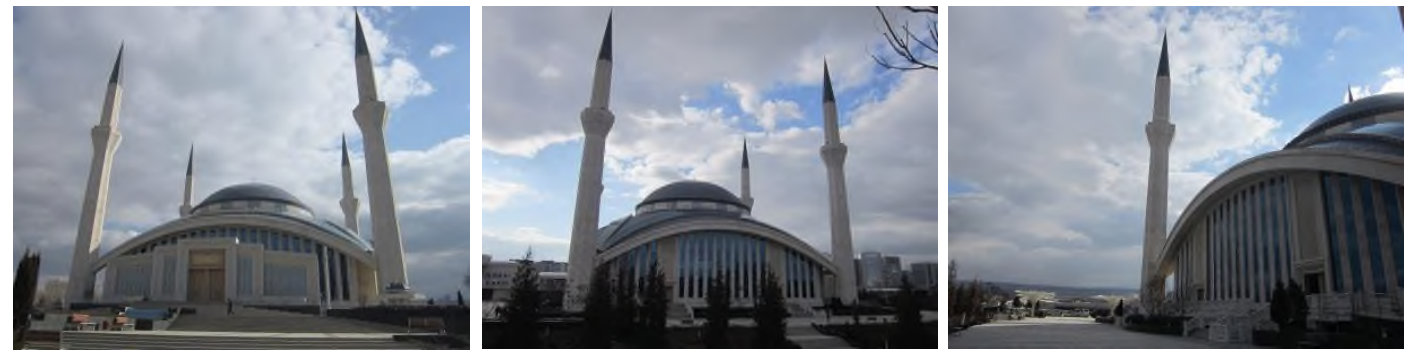

Figure 1:Ahmet Hamdi Akseki Mosque (Photo by Sena Işılklar Bengi)

Within the scope of the study the comfort assessments of male and female users of Ahmet Hamdi Akseki Mosque, located in Ankara, was evaluated. The mosque, which is located at the junction of Eskişehir highway and Bilkent road, next to the Directorate of Religious Affairs, has been in service since 2013. It was built in honour of former Director of 
Religious Affairs Ahmet Hamdi Akseki (1882-1947). Due to its location, it is used by the state protocol rather than by local inhabitants.

The mosque consists of $80.000 \mathrm{~m}^{2}$ closed area, $20.618 \mathrm{~m}^{2}$ courtyard and $11.087 \mathrm{~m}^{2}$ landscape area. There is an underground parking for 1860 cars, storage areas, radio and TV studios, a gas station, $\mathrm{WC}$ and ablution place included in the mosque complex. The mosque has a capacity of 6000 people during normal times and 30.000 people during funeral prayers. Ankara Ahmet Hamdi Akseki Mosque is a project designed in neo-classical style with an emphasis on architectural, interior and landscape details. Circulation details, outdoor furniture, visual elements such as calligraphy and stained glass, disability access, ecological interventions such as storage of rain water, elements such as lighting and acoustics were brought up to attention in the design of the mosque (Url-4). Due to its location, it is used by the state protocol rather than by local community.

\section{Method of Study}

A field study was conducted within the context of Post-Occupancy Evaluation (POE) method in order to evaluate the spatial relationship of Ahmet Hamdi Akseki Mosque with its user. Questions were asked about to TC Directorate of Religious Affairs personnel who use the mosque in order to understand the physical and psychological effects of the Ahmet Hamdi Akseki Mosque. The questionnaire consists of 139 participants aged 20-60; 93.5\% are male and $6.5 \%$ are female. The questions consisted of the scoring system; It is designed to measure the safety and security and comfort of Harim. The evaluation of the comfort conditions of the mosque is discussed with the point of view of women and men. The deficiencies and the satisfaction of the mosque satisfaction were obtained through the SPSS program chi-square test. The chi-square test used in the evaluation of the data is the statistical test used to measure the 
nonparametric values. In the interpretation of the chi-square test, the Pearson Chi-Square value obtained from the test describes the significance between the compared data.

$\mathrm{P}$ values obtained in the study findings (Pearson Chi-Square);

- Statistical significance: $0.01<=\mathrm{p}<0.05$

- High level of statistical significance: $0.001<=\mathrm{p}<0.01$

- Very high statistical significance: $\mathrm{p}<0.001$

- Significance trend (borderline significance): $0.05<=\mathrm{p}<0.10$

- (no statistically significant difference: $p>0.10$ (Kul, 2014) was evaluated as. It was aimed to reveal the usage of the mosque by means of the findings and to determine the deficiencies of the mosque according to the opinion of different genders.

\section{Evaluation Findings of the Ahmet Hamdi Akseki Mosque by Gender}

\section{Findings on Trust and Security}

The following criteria are used for measuring the safety and security perceptions.

- Measures taken for falls and gliding in mosques

- The feeling that the mosque is safe against earthquakes

- Easy evacuation of the mosque in fire

- Prevention of incidents and persons interrupting worship

- Keeping things safe during events such as theft 
Table 1.Gender based tables of trust and safety

\begin{tabular}{|c|c|c|c|c|c|c|c|c|c|c|c|}
\hline & & & $\begin{array}{l}\text { Very } \\
\text { bad }\end{array}$ & $\mathrm{Bad}$ & $\begin{array}{l}\text { Middle } \\
\text { level }\end{array}$ & Good & $\begin{array}{l}\text { Very } \\
\text { good }\end{array}$ & $\begin{array}{l}\text { Chi- } \\
\text { square } \\
\text { test }\end{array}$ & Value & df & $\begin{array}{l}\text { Asymptot } \\
\text { ic } \\
\text { Significa } \\
\text { nce (2- } \\
\text { sided) }\end{array}$ \\
\hline \multirow{6}{*}{ 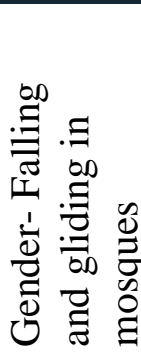 } & \multirow[t]{2}{*}{ Woman } & $\mathrm{n}$ & 0 & 0 & 1 & 6 & 2 & $\mathrm{P}$ & $2,816^{\mathrm{a}}$ & 4 &, 589 \\
\hline & & $\%$ & $0,0 \%$ & $0,0 \%$ & $11,1 \%$ & $66,7 \%$ & $22,2 \%$ & $\begin{array}{l}\text { Likeliho } \\
\text { od Ratio }\end{array}$ & 3,165 & 4 &, 531 \\
\hline & \multirow{2}{*}{ Man } & $\mathrm{n}$ & 2 & 5 & 20 & 51 & 52 & & & & \\
\hline & & $\%$ & $1,5 \%$ & $3,8 \%$ & $15,4 \%$ & $39,2 \%$ & $40,0 \%$ & & & & \\
\hline & \multirow{2}{*}{ Total } & $\mathrm{n}$ & 2 & 5 & 21 & 57 & 54 & & & & \\
\hline & & $\%$ & $1,4 \%$ & $3,6 \%$ & $15,1 \%$ & $41,0 \%$ & $38,8 \%$ & & & & \\
\hline \multirow{6}{*}{ 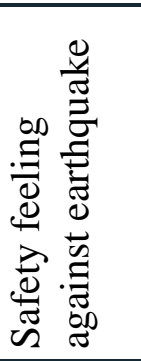 } & \multirow[t]{2}{*}{ Woman } & $\mathrm{n}$ & 1 & 0 & 4 & 1 & \multicolumn{2}{|c|}{$3 \mathrm{P}$} & $10,571^{\mathrm{a}}$ & 4 & ,032 \\
\hline & & $\%$ & $\begin{array}{r}11,1 \\
\%\end{array}$ & $0,0 \%$ & $44,4 \%$ & $11,1 \%$ & \multicolumn{2}{|c|}{$\begin{aligned} & 33,3 \% \text { Likeliho } \\
& \text { od Ratio }\end{aligned}$} & 7,733 & 4 &, 102 \\
\hline & \multirow[t]{2}{*}{ Man } & $\mathrm{n}$ & 1 & 6 & 27 & 51 & 45 & & & & \\
\hline & & $\%$ & $0,8 \%$ & $4,6 \%$ & $20,8 \%$ & $39,2 \%$ & $34,6 \%$ & & & & \\
\hline & \multirow[t]{2}{*}{ Total } & $\mathrm{n}$ & 2 & 6 & 31 & 52 & 48 & & & & \\
\hline & & $\%$ & $1,4 \%$ & $4,3 \%$ & $22,3 \%$ & $37,4 \%$ & $34,5 \%$ & & & & \\
\hline \multirow{6}{*}{ 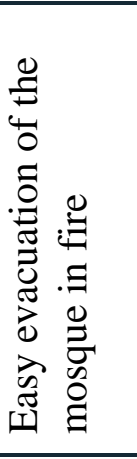 } & \multirow[t]{2}{*}{ Woman } & $\mathrm{n}$ & 0 & 2 & 2 & 2 & 3 & $\mathrm{P}$ & $3,125^{\mathrm{a}}$ & 4 & ,537 \\
\hline & & $\%$ & $\begin{array}{r}0,0 \\
\%\end{array}$ & $\begin{array}{r}22,2 \\
\%\end{array}$ & $22,2 \%$ & $22,2 \%$ & $33,3 \%$ & $\begin{array}{l}\text { Likeliho } \\
\text { od Ratio }\end{array}$ & 2,610 & 4 &, 625 \\
\hline & \multirow[t]{2}{*}{ Man } & $\mathrm{n}$ & 3 & 9 & 30 & 46 & 42 & & & & \\
\hline & & $\%$ & $\begin{array}{r}2,3 \\
\%\end{array}$ & $6,9 \%$ & $23,1 \%$ & $35,4 \%$ & $32,3 \%$ & & & & \\
\hline & \multirow[t]{2}{*}{ Total } & $\mathrm{n}$ & 3 & 11 & 32 & 48 & 45 & & & & \\
\hline & & $\%$ & $\begin{array}{r}2,2 \\
\%\end{array}$ & $7,9 \%$ & $23,0 \%$ & $34,5 \%$ & $32,4 \%$ & & & & \\
\hline \multirow{6}{*}{ 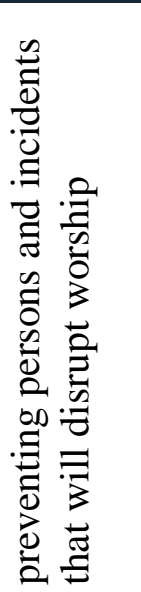 } & \multirow[t]{2}{*}{ Woman } & $\mathrm{n}$ & 0 & 1 & 4 & 2 & 2 & $\mathrm{P}$ & $3,375^{\mathrm{a}}$ & 4 & ,497 \\
\hline & & $\%$ & $\begin{array}{r}0, \\
0 \\
\%\end{array}$ & $\begin{array}{r}11,1 \\
\%\end{array}$ & $44,4 \%$ & $22,2 \%$ & $22,2 \%$ & $\begin{array}{l}\text { Likeliho } \\
\text { od Ratio }\end{array}$ & 3,346 & 4 & ,502 \\
\hline & \multirow[t]{2}{*}{ Man } & $\mathrm{n}$ & 5 & 6 & 30 & 49 & 40 & & & & \\
\hline & & $\%$ & $\begin{array}{r}3, \\
8 \\
\%\end{array}$ & $4,6 \%$ & $23,1 \%$ & $37,7 \%$ & $30,8 \%$ & & & & \\
\hline & \multirow[t]{2}{*}{ Total } & $\mathrm{n}$ & 5 & 7 & 34 & 51 & 42 & & & & \\
\hline & & $\%$ & $\begin{array}{r}3, \\
6 \\
\%\end{array}$ & $5,0 \%$ & $24,5 \%$ & $36,7 \%$ & $30,2 \%$ & & & & \\
\hline
\end{tabular}


Table 1.Continues...

\begin{tabular}{|c|c|c|c|c|c|c|c|c|c|c|c|c|}
\hline & & \multicolumn{3}{|c|}{ Very bac } & $\mathrm{Bad}$ & $\begin{array}{l}\text { Middle } \\
\text { level }\end{array}$ & Good & $\begin{array}{l}\text { Very } \\
\text { good }\end{array}$ & $\begin{array}{l}\text { Chi- } \\
\text { square } \\
\text { test }\end{array}$ & Value & $\mathrm{df}$ & $\begin{array}{l}\text { Asymptotic } \\
\text { Significanc } \\
\text { e (2-sided) }\end{array}$ \\
\hline.$\equiv$ & & Woman & $\bar{n}$ & 0 & 0 & 2 & 6 & 1 & $\mathrm{P}$ & $5,910^{\mathrm{a}}$ & 4 & 206 \\
\hline 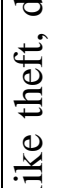 & & & $\%$ & $0,0 \%$ & $0,0 \%$ & $22,2 \%$ & $66,7 \%$ & $11,1 \%$ & $\begin{array}{l}\text { Likelihoo } \\
\text { d Ratio }\end{array}$ & 6,753 & 4 & 150 \\
\hline $\begin{array}{l}\infty \\
0\end{array}$ & & Man & $\mathrm{n}$ & 5 & 16 & 33 & 39 & 37 & & & & \\
\hline $\bar{z}$ & & & $\%$ & $3,8 \%$ & $12,3 \%$ & $25,4 \%$ & $30,0 \%$ & $28,5 \%$ & & & & \\
\hline$\stackrel{\oplus}{\pi}$ & 0 & Total & $\mathrm{n}$ & 5 & 16 & 35 & 45 & 38 & & & & \\
\hline$\stackrel{\infty}{=}$ & $\begin{array}{l}\ddot{z} \\
0 \\
0 \\
3\end{array}$ & & $\%$ & $3,6 \%$ & $11,5 \%$ & $25,2 \%$ & $32,4 \%$ & $27,3 \%$ & & & & \\
\hline
\end{tabular}

The responses were grouped by gender. There is no significant difference according to the chisquare test results. Although not meaningful;

- Measures taken for falls and slippage within the mosque; $22,2 \%$ of those who rated it as very good were women; $40,00 \%$ were men; $0 \%$ of those who rated very badly were women and $1,5 \%$ were men,

- For the feeling of being safe against earthquakes; 33,3\% of women who rated it as; very good 'were female; $11,1 \%$ of the women who evaluated as, very bad 'were women;

- For easy evacuation of the mosque in fire; $33,3 \%$ of the women who rated as; very good 'were female; $32,3 \%$ were male; $0 \%$ of those who rated very badly were women and $2,3 \%$ were men,

- $22,2 \%$ of the people who described the very good as the ones to prevent the incidents and individuals to interfere with the worship were women and $30,8 \%$ were men; $0 \%$ of those who rated very badly were women, and 3,8\% of them were men, 
- In order to ensure that the goods are safe against theft during the worship, $11,1 \%$ of the people who describe it as very good are women and $28,5 \%$ are men; while $0 \%$ of women who evaluated as very bad were women and $3,8 \%$ of them were men.

\section{Findings about Harim Comfort}
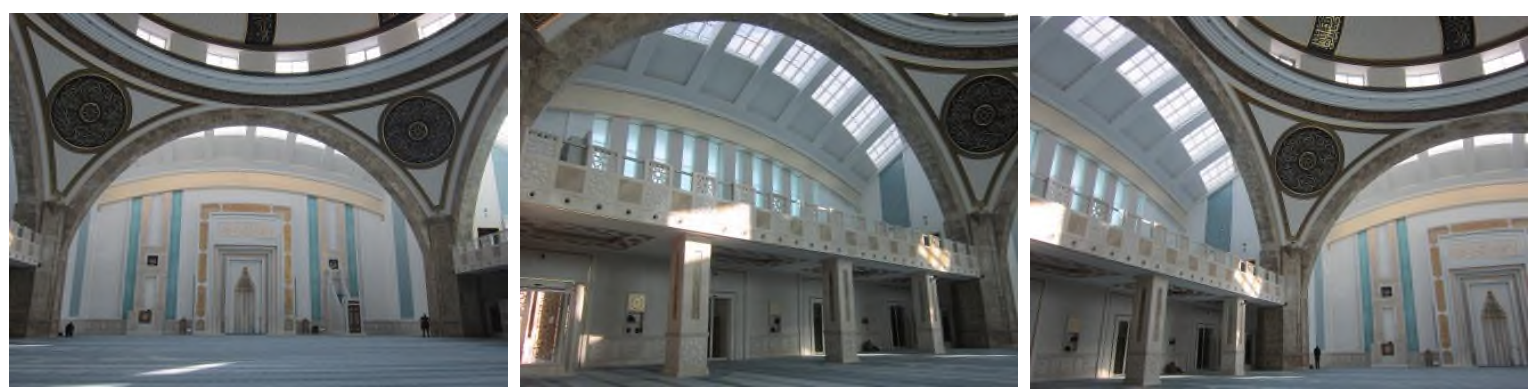

Figure 2: Images of Harim (Photo by Sena Işılklar Bengi)

The part allocated for the prayer of the congregation is called "harim". In this section, to measure the degree of comfort of the harim of Ahmet Hamdi Akseki Mosque;

- Sufficiency of daylight of harim

- Qualification of natural ventilation

- Cooling during summer months

- Warm-up in winter months

- Adequacy of lighting required for worship

- Prevention of external noise

- The wisdom of the Imam in worship

- The muezzin can be seen during the conversation

- Adequacy of shoe count

- Prevention of odor in shoes

- Prevention of odor in carpets

- Cleaning of carpets, prayer rugs, prayer beads 
- Qualification criteria of ramps such as ramps and elevators required for the access of disabled people were directed to the users on the scale between 1 and 5 . The answers were grouped by gender.

Table 2. Elements of harim comfort, which is no significant difference depending on gender

\begin{tabular}{|c|c|c|c|c|c|c|c|c|c|c|c|}
\hline & & & $\begin{array}{l}\text { Very } \\
\text { bad }\end{array}$ & $\mathrm{Bad}$ & $\begin{array}{l}\text { Middle } \\
\text { level }\end{array}$ & Good & $\begin{array}{l}\text { Very } \\
\text { good }\end{array}$ & $\begin{array}{c}\text { Chi-square } \\
\text { test }\end{array}$ & Value & $\mathrm{df}$ & $\begin{array}{c}\text { Asymptotic } \\
\text { Significance } \\
\text { (2-sided) }\end{array}$ \\
\hline \multirow{6}{*}{ 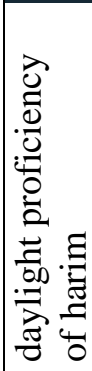 } & \multirow[t]{2}{*}{ Woman } & $\mathrm{n}$ & 0 & 0 & 1 & 5 & 3 & $\mathrm{P}$ & \begin{tabular}{|r|}
1,98 \\
$8^{\mathrm{a}}$ \\
\end{tabular} & 4 &, 738 \\
\hline & & $\%$ & $0,0 \%$ & $0,0 \%$ & $11,1 \%$ & $55,6 \%$ & $33,3 \%$ & $\begin{array}{l}\text { Likelihood } \\
\text { Ratio }\end{array}$ & $\begin{array}{r}2,21 \\
8 \\
\end{array}$ & 4 & ,696 \\
\hline & \multirow{2}{*}{ Man } & $\mathrm{n}$ & 3 & 2 & 15 & 44 & 66 & & & & \\
\hline & & $\%$ & $2,3 \%$ & $1,5 \%$ & $11,5 \%$ & $33,8 \%$ & $50,8 \%$ & & & & \\
\hline & \multirow{2}{*}{ Total } & $\mathrm{n}$ & 3 & 2 & 16 & 49 & 69 & & & & \\
\hline & & $\%$ & $2,2 \%$ & $1,4 \%$ & $11,5 \%$ & $35,3 \%$ & $49,6 \%$ & & & & \\
\hline \multirow{6}{*}{ 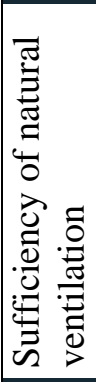 } & \multirow[t]{2}{*}{ Woman } & $\mathrm{n}$ & 1 & 0 & 1 & 5 & 2 & $\mathrm{P}$ & $\begin{array}{r}5,02 \\
4^{\mathrm{a}}\end{array}$ & 4 & ,285 \\
\hline & & $\%$ & $11,1 \%$ & $0,0 \%$ & $11,1 \%$ & $55,6 \%$ & $22,2 \%$ & $\begin{array}{l}\text { Likelihood } \\
\text { Ratio }\end{array}$ & $\begin{array}{r}4,52 \\
7\end{array}$ & 4 & ,339 \\
\hline & \multirow{2}{*}{ Man } & $\mathrm{n}$ & 3 & 5 & 18 & 43 & 61 & & & & \\
\hline & & $\%$ & $2,3 \%$ & $3,8 \%$ & $13,8 \%$ & $33,1 \%$ & $46,9 \%$ & & & & \\
\hline & \multirow{2}{*}{ Total } & $\mathrm{n}$ & 4 & 5 & 19 & 48 & 63 & & & & \\
\hline & & $\%$ & $2,9 \%$ & $3,6 \%$ & $13,7 \%$ & $34,5 \%$ & $45,3 \%$ & & & & \\
\hline \multirow{6}{*}{ 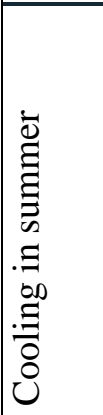 } & \multirow[t]{2}{*}{ Woman } & $\mathrm{n}$ & 1 & 0 & 1 & 5 & 2 & $\mathrm{P}$ & $\begin{array}{r}5,40 \\
6^{\mathrm{a}}\end{array}$ & 4 & ,248 \\
\hline & & $\%$ & $11,1 \%$ & $0,0 \%$ & $11,1 \%$ & $55,6 \%$ & $22,2 \%$ & $\begin{array}{l}\text { Likelihood } \\
\text { Ratio }\end{array}$ & $\begin{array}{r}5,23 \\
1\end{array}$ & 4 & ,264 \\
\hline & \multirow[t]{2}{*}{ Man } & $\mathrm{n}$ & 5 & 6 & 27 & 34 & 58 & & & & \\
\hline & & & $3,8 \%$ & $4,6 \%$ & $20,8 \%$ & $26,2 \%$ & $44,6 \%$ & & & & \\
\hline & \multirow[t]{2}{*}{ Total } & $\mathrm{n}$ & 6 & 6 & 28 & 39 & 60 & & & & \\
\hline & & $\%$ & $4,3 \%$ & $4,3 \%$ & $20,1 \%$ & $28,1 \%$ & $43,2 \%$ & & & & \\
\hline
\end{tabular}


Table 2. Continues (a)

\begin{tabular}{|c|c|c|c|c|c|c|c|c|c|c|c|}
\hline & & & Very bad & $\mathrm{Bad}$ & $\begin{array}{c}\text { Middle } \\
\text { level }\end{array}$ & Good & $\begin{array}{l}\text { Very } \\
\text { good }\end{array}$ & $\begin{array}{c}\text { Chi-square } \\
\text { test }\end{array}$ & Value & df & $\begin{array}{c}\text { Asymptotic } \\
\text { Significance } \\
\text { (2-sided) }\end{array}$ \\
\hline \multirow{6}{*}{ 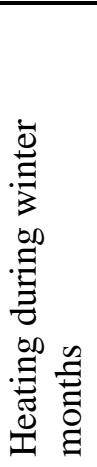 } & \multirow[t]{2}{*}{ Woman } & $\mathrm{n}$ & 0 & 1 & 0 & 3 & 5 & $\mathrm{P}$ & \begin{tabular}{|r|}
2,57 \\
$9^{\mathrm{a}}$ \\
\end{tabular} & 4 &, 631 \\
\hline & & $\%$ & $0,0 \%$ & $\begin{array}{r}11,1 \\
\%\end{array}$ & $0,0 \%$ & $\begin{array}{r}33,3 \\
\% \\
\end{array}$ & $55,6 \%$ & $\begin{array}{l}\text { Likelihood } \\
\text { Ratio }\end{array}$ & $\begin{array}{r}3,64 \\
1 \\
\end{array}$ & 4 & , 457 \\
\hline & \multirow[t]{2}{*}{ Man } & $\mathrm{n}$ & 5 & 5 & 16 & 37 & 67 & & & & \\
\hline & & $\%$ & $3,8 \%$ & $\begin{array}{r}3,8 \\
\%\end{array}$ & $12,3 \%$ & $\begin{array}{r}28,5 \\
\%\end{array}$ & $51,5 \%$ & & & & \\
\hline & \multirow{2}{*}{ Total } & $\mathrm{n}$ & 5 & 6 & 16 & 40 & 72 & & & & \\
\hline & & $\%$ & $3,6 \%$ & $\begin{array}{r}4,3 \\
\%\end{array}$ & $11,5 \%$ & $\begin{array}{r}28,8 \\
\%\end{array}$ & $51,8 \%$ & & & & \\
\hline \multirow{6}{*}{ 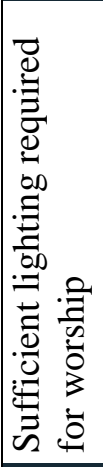 } & \multirow{2}{*}{ Woman } & $\mathrm{n}$ & 0 & 0 & 1 & 4 & 4 & $\mathrm{P}$ & $\begin{array}{r}1,87 \\
5^{\mathrm{a}}\end{array}$ & 4 & ,759 \\
\hline & & $\%$ & $\begin{array}{r}0,0 \\
\%\end{array}$ & $\begin{array}{r}0,0 \\
\%\end{array}$ & $11,1 \%$ & $\begin{array}{r}44,4 \\
\%\end{array}$ & $44,4 \%$ & $\begin{array}{l}\text { Likelihood } \\
\text { Ratio }\end{array}$ & $\begin{array}{r}2,02 \\
5\end{array}$ & 4 & ,731 \\
\hline & \multirow{2}{*}{ Man } & $\mathrm{n}$ & 2 & 2 & 9 & 35 & 82 & & & & \\
\hline & & $\%$ & $\begin{array}{r}1,5 \\
\%\end{array}$ & $\begin{array}{r}1,5 \\
\%\end{array}$ & $6,9 \%$ & $\begin{array}{r}26,9 \\
\%\end{array}$ & $63,1 \%$ & & & & \\
\hline & \multirow{2}{*}{ Total } & $\mathrm{n}$ & 2 & 2 & 10 & 39 & 86 & & & & \\
\hline & & $\%$ & $\begin{array}{r}1,4 \\
\%\end{array}$ & $\begin{array}{r}1,4 \\
\%\end{array}$ & $7,2 \%$ & $\begin{array}{r}28,1 \\
\%\end{array}$ & $61,9 \%$ & & & & \\
\hline \multirow{6}{*}{ 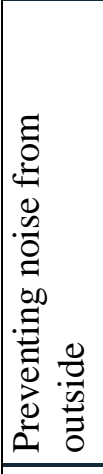 } & \multirow[t]{2}{*}{ Woman } & $\mathrm{n}$ & 0 & 0 & 2 & 4 & 3 & $\mathrm{P}$ & $\begin{array}{r}2,58 \\
1^{\mathrm{a}}\end{array}$ & 4 & ,630 \\
\hline & & $\%$ & $\begin{array}{r}0,0 \\
\%\end{array}$ & $\begin{array}{r}0,0 \\
\%\end{array}$ & $22,2 \%$ & $\begin{array}{r}44,4 \\
\%\end{array}$ & $33,3 \%$ & $\begin{array}{l}\text { Likelihood } \\
\text { Ratio }\end{array}$ & $\begin{array}{r}2,46 \\
4\end{array}$ & 4 & 651 \\
\hline & \multirow[t]{2}{*}{ Man } & $\mathrm{n}$ & 1 & 1 & 12 & 44 & 72 & & & & \\
\hline & & $\%$ & $\begin{array}{r}0,8 \\
\%\end{array}$ & $\begin{array}{r}0,8 \\
\%\end{array}$ & $9,2 \%$ & $\begin{array}{r}33,8 \\
\%\end{array}$ & $55,4 \%$ & & & & \\
\hline & \multirow{2}{*}{ Total } & $\mathrm{n}$ & 1 & 1 & 14 & 48 & 75 & & & & \\
\hline & & $\%$ & $\begin{array}{r}0,7 \\
\%\end{array}$ & $\begin{array}{r}0,7 \\
\%\end{array}$ & $10,1 \%$ & $\begin{array}{r}34,5 \\
\%\end{array}$ & $54,0 \%$ & & & & \\
\hline \multirow{6}{*}{ 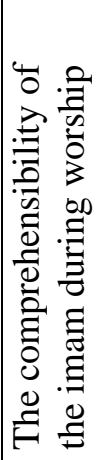 } & \multirow[t]{2}{*}{ Woman } & $\mathrm{n}$ & 0 & 0 & 3 & 5 & 1 & $\mathrm{P}$ & $\begin{array}{r}6,00 \\
0^{\mathrm{a}}\end{array}$ & 4 & ,199 \\
\hline & & $\%$ & $\begin{array}{r}0,0 \\
\%\end{array}$ & $\begin{array}{r}0,0 \\
\%\end{array}$ & $33,3 \%$ & $\begin{array}{r}55,6 \\
\% \\
\end{array}$ & $11,1 \%$ & $\begin{array}{l}\text { Likelihood } \\
\text { Ratio }\end{array}$ & $\begin{array}{r}6,83 \\
3\end{array}$ & 4 &, 145 \\
\hline & \multirow{2}{*}{ Man } & $\mathrm{n}$ & 2 & 5 & 19 & 43 & 61 & & & & \\
\hline & & $\%$ & $\begin{array}{r}1,5 \\
\%\end{array}$ & $\begin{array}{r}3,8 \\
\%\end{array}$ & $14,6 \%$ & $\begin{array}{r}33,1 \\
\%\end{array}$ & $46,9 \%$ & & & & \\
\hline & \multirow{2}{*}{ Total } & $\mathrm{n}$ & 2 & 5 & 22 & 48 & 62 & & & & \\
\hline & & $\%$ & $\begin{array}{r}1,4 \\
\%\end{array}$ & $\begin{array}{r}3,6 \\
\%\end{array}$ & $15,8 \%$ & $\begin{array}{r}34,5 \\
\%\end{array}$ & $44,6 \%$ & & & & \\
\hline
\end{tabular}


Table 2. Continues (b)

\begin{tabular}{|c|c|c|c|c|c|c|c|c|c|c|c|}
\hline & & & $\begin{array}{l}\text { Very } \\
\text { bad }\end{array}$ & $\mathrm{Bad}$ & $\begin{array}{c}\text { Middle } \\
\text { level }\end{array}$ & Good & $\begin{array}{l}\text { Very } \\
\text { good }\end{array}$ & Chi-square test & Value & df & \begin{tabular}{|c|} 
Asymptotic \\
Significance \\
(2-sided) \\
\end{tabular} \\
\hline \multirow{6}{*}{ 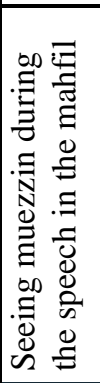 } & \multirow[t]{2}{*}{ Woman } & $\mathrm{n}$ & 0 & 2 & 1 & 5 & 1 & $\mathrm{P}$ & \begin{tabular}{|r|}
5,26 \\
$5^{\mathrm{a}}$ \\
\end{tabular} & 4 & ,261 \\
\hline & & $\%$ & $0,0 \%$ & $\begin{array}{r}22,2 \\
\%\end{array}$ & $11,1 \%$ & $55,6 \%$ & $11,1 \%$ & Likelihood Ratio & $\begin{array}{r}5,10 \\
3\end{array}$ & 4 & ,277 \\
\hline & \multirow[t]{2}{*}{ Man } & $\mathrm{n}$ & 4 & 9 & 29 & 47 & 41 & & & & \\
\hline & & $\%$ & $3,1 \%$ & $6,9 \%$ & $22,3 \%$ & $36,2 \%$ & $31,5 \%$ & & & & \\
\hline & \multirow[t]{2}{*}{ Total } & $\mathrm{n}$ & 4 & 11 & 30 & 52 & 42 & & & & \\
\hline & & $\%$ & $2,9 \%$ & $7,9 \%$ & $21,6 \%$ & $37,4 \%$ & $30,2 \%$ & & & & \\
\hline \multirow{6}{*}{ 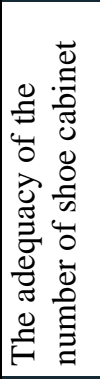 } & \multirow[t]{2}{*}{ Woman } & $\mathrm{n}$ & 0 & 2 & 3 & 3 & 1 & $\mathrm{P}$ & $\begin{array}{r}5,09 \\
5^{\mathrm{a}}\end{array}$ & 4 & ,278 \\
\hline & & $\%$ & $0,0 \%$ & $\begin{array}{r}22,2 \\
\%\end{array}$ & $33,3 \%$ & $33,3 \%$ & $11,1 \%$ & Likelihood Ratio & $\begin{array}{r}4,78 \\
5\end{array}$ & 4 &, 310 \\
\hline & \multirow[t]{2}{*}{ Man } & $\mathrm{n}$ & 6 & 9 & 23 & 55 & 37 & & & & \\
\hline & & $\%$ & $4,6 \%$ & $6,9 \%$ & $17,7 \%$ & $42,3 \%$ & $28,5 \%$ & & & & \\
\hline & \multirow[t]{2}{*}{ Total } & $\mathrm{n}$ & 6 & 11 & 26 & 58 & 38 & & & & \\
\hline & & $\%$ & $4,3 \%$ & $7,9 \%$ & $18,7 \%$ & $41,7 \%$ & $27,3 \%$ & & & & \\
\hline \multirow{6}{*}{ 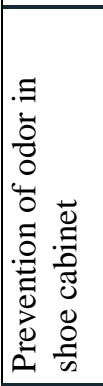 } & \multirow[t]{2}{*}{ Woman } & $\mathrm{n}$ & 1 & 0 & 2 & 3 & 3 & $\mathrm{P}$ & $\begin{array}{r}2,07 \\
9 \mathrm{a}\end{array}$ & 4 & ,721 \\
\hline & & $\%$ & $11,1 \%$ & $0,0 \%$ & $22,2 \%$ & $33,3 \%$ & $33,3 \%$ & Likelihood Ratio & $\begin{array}{r}2,19 \\
5\end{array}$ & 4 &, 700 \\
\hline & \multirow[t]{2}{*}{ Man } & $\mathrm{n}$ & 5 & 6 & 22 & 62 & 35 & & & & \\
\hline & & $\%$ & $3,8 \%$ & $4,6 \%$ & $16,9 \%$ & $47,7 \%$ & $26,9 \%$ & & & & \\
\hline & \multirow[t]{2}{*}{ Total } & $\mathrm{n}$ & 6 & 6 & 24 & 65 & 38 & & & & \\
\hline & & $\%$ & $4,3 \%$ & $4,3 \%$ & $17,3 \%$ & $46,8 \%$ & $27,3 \%$ & & & & \\
\hline
\end{tabular}

Although there is no significant difference according to chi-square test results;

- To take daylight of harim; 33,3\% of the women who rated it as very good were women;

$0 \%$ of those who rated very badly were women and $2,3 \%$ were men,

- For natural ventilation; $22,2 \%$ of the people who rated it as very good were female; $46,9 \%$ were male; $11,1 \%$ of women who rated them as very bad are women and $2,3 \%$ of them are men,

- For cooling in summer; $22,2 \%$ of the people who rated it as very good were women, $44,6 \%$ were men; $11,1 \%$ of the women who rated them as very bad are women and $3,8 \%$ of them are men,

- For heating in winter; 55,6\% of the people who rated as; very good were women; 55,6\% were men; $0 \%$ of those who rated very bad were women and $3,8 \%$ were men, 
- In order to provide adequate lighting for worship; $44.4 \%$ of the people who rated it as very good were women; $0 \%$ of those who rated very bad were women and $1.5 \%$ of them were men,

- To prevent noise from outside; $33,3 \%$ of females and 55,4\% males; $0 \%$ of women who evaluated as very bad are women and $0,8 \%$ of them are men,

- For the comprehensibility of the Imam's words during worship; $11,1 \%$ of those who rated it as very good were female; $46,9 \%$ were male; $0 \%$ of those who rated very bad were women and $1,5 \%$ of them were men,

- In order for the muezzin to be seen during the conversation in the courtroom; of the $11,1 \%$ of the women, $31,5 \%$ of the men; $0 \%$ of those who rated very bad were women, $3,1 \%$ were men,

- For the sufficiency of items such as carpets, prayer rugs, prayer beads; $33,3 \%$ of the people who rated it as very good were women; $11,1 \%$ of women who rated them as very bad are women and $2,3 \%$ of them are men,

- For the adequacy of shoe count; $11,1 \%$ of the people who rated it as very good were women; $11,1 \%$ of the women who evaluated as very bad are women and $4.6 \%$ of them are men,

- To prevent odor in footwear; $33,3 \%$ of females and $26,9 \%$ males; and $11,1 \%$ of the cases evaluated as very bad were female and $3,8 \%$ were male.

A significant difference was found between the questions asked about the comfort of the Harim according to the gender of the following questions.

- Prevention of odor in carpets

- Cleaning of items

- Ramp for access of disabled people, solution of units such as elevator 
Table 3. Elements of harim comfort, which is a significant difference depending on gender

\begin{tabular}{|c|c|c|c|c|c|c|c|c|c|c|c|c|}
\hline \multirow{6}{*}{ 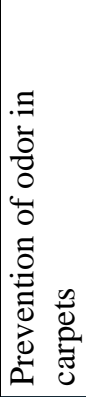 } & \multirow[t]{2}{*}{ Woman } & $\mathrm{n}$ & 2 & 0 & 2 & 1 & 4 & $\mathrm{P}$ & $\begin{array}{r}11,34 \\
6^{\mathrm{a}}\end{array}$ & 4 & & ,023 \\
\hline & & $\%$ & $22,2 \%$ & $0,0 \%$ & $22,2 \%$ & $11,1 \%$ & $44,4 \%$ & Likelihood & 7,448 & 4 & & ,114 \\
\hline & \multirow[t]{2}{*}{ Man } & $\mathrm{n}$ & 3 & 2 & 26 & 51 & 48 & & & & & \\
\hline & & $\%$ & $2,3 \%$ & $1,5 \%$ & $20,0 \%$ & $39,2 \%$ & $36,9 \%$ & & & & & \\
\hline & \multirow[t]{2}{*}{ Total } & $\mathrm{n}$ & 5 & 2 & 28 & 52 & 52 & & & & & \\
\hline & & $\%$ & $3,6 \%$ & $1,4 \%$ & $20,1 \%$ & $37,4 \%$ & $37,4 \%$ & & & & & \\
\hline \multirow{6}{*}{ 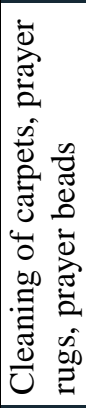 } & \multirow[t]{2}{*}{ Woman } & $\mathrm{n}$ & 1 & 1 & 1 & 3 & 3 & $\mathrm{P}$ & $\begin{array}{r}16,40 \\
6^{\mathrm{a}}\end{array}$ & 4 & & ,003 \\
\hline & & $\%$ & $11,1 \%$ & $\begin{array}{r}11,1 \\
\%\end{array}$ & $11,1 \%$ & $33,3 \%$ & $33,3 \%$ & $\begin{array}{l}\text { Likelihood } \\
\text { Ratio }\end{array}$ & 6,983 & 4 & & , 137 \\
\hline & \multirow[t]{2}{*}{ Man } & $\mathrm{n}$ & 0 & 4 & 24 & 46 & 56 & & & & & \\
\hline & & $\%$ & $0,0 \%$ & $3,1 \%$ & $18,5 \%$ & $35,4 \%$ & $43,1 \%$ & & & & & \\
\hline & \multirow[t]{2}{*}{ Total } & $\mathrm{n}$ & 1 & 5 & 25 & 49 & 59 & & & & & \\
\hline & & $\%$ & $0,7 \%$ & $3,6 \%$ & $18,0 \%$ & $35,3 \%$ & $42,4 \%$ & & & & & \\
\hline \multirow{6}{*}{ 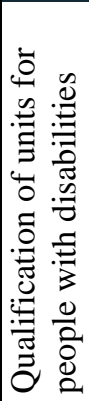 } & \multirow[t]{2}{*}{ Woman } & $\mathrm{n}$ & 0 & 2 & 0 & 4 & 3 & $\mathrm{P}$ & $\begin{array}{r}14,85 \\
3^{\mathrm{a}}\end{array}$ & & 4 & ,005 \\
\hline & & $\%$ & $0,0 \%$ & $\begin{array}{r}22,2 \\
\%\end{array}$ & $0,0 \%$ & $44,4 \%$ & $33,3 \%$ & $\begin{array}{l}\text { Likelihood } \\
\text { Ratio }\end{array}$ & 9,449 & & 4 & ,051 \\
\hline & \multirow[t]{2}{*}{ Man } & $\mathrm{n}$ & 3 & 2 & 19 & 42 & 64 & & & & & \\
\hline & & $\%$ & $2,3 \%$ & $1,5 \%$ & $14,6 \%$ & $32,3 \%$ & $49,2 \%$ & & & & & \\
\hline & \multirow[t]{2}{*}{ Total } & $\mathrm{n}$ & 3 & 4 & 19 & 46 & 67 & & & & & \\
\hline & & $\%$ & $2,2 \%$ & $2,9 \%$ & $13,7 \%$ & $33,1 \%$ & $48,2 \%$ & & & & & \\
\hline
\end{tabular}

According to the chi-square test results, the significant differences are below:

A statistically significant difference was found in the cross-section between the prevention of odor in carpets, and in the chi-square $(0,023)$. Of the $44.4 \%$ of the women, $36,9 \%$ were male; $22,2 \%$ of the participants evaluated as very bad, and $2,3 \%$ of them were males.

A high level of statistical significance was found in the chi-square $(0,003)$ in the cross between gender and the cleaning of items such as carpets, prayer rugs, and prayer beads. This shows that there is a significant difference in the opinions of male and female participants. According to the data, of the $33.3 \%$ of the women, $43.1 \%$ were male; $11.1 \%$ of the participants evaluated as very bad are female, and $0 \%$ of them were males.

A high level of statistical significance was found in the chi-square value (0.005) in the crossing made on the adequacy of the units such as the elevator and the ramp required for the 
access of the disabled people. Of the $33.3 \%$ of the women, $49.2 \%$ were male; $0 \%$ of the participants evaluated as very bad are female, and $2.3 \%$ of them were males.

\section{Evaluation and Conclusion}

Mosques are places that tell the cultural values of society and embrace every individual of the society. For this reason, they should not only be considered as a built element in the city, but it should be emphasized that they gain meaning with the activities of their users. Activities within the space will be provided to the extent that the users are satisfied with the place of worship.

Ensuring the comfort conditions of the users from each individual profile is one of the important factors that increase the active use of the space. In the use of mosques, there are complaints that the needs of women are ignored because the majority of the users are men. Female users expressed their spatial dissatisfaction in mosques. In this study, spatial comfort of each individual at Ahmet Hamdi Akseki Mosque was examined by using POE method. The personnel of the Directorate of Religious Affairs were asked questions to measure the safety, security and comfort of the harim. Thus, comfort conditions were evaluated with respect to the opinions of the male and female users. The views of the mosque users regarding comfort were mostly good and very good. Positive views maybe viewed as the consequence of the fact that the mosque was designed elaborately considering its close location to governmental structures and therefore the possibility of being used by the state protocol. According to the test conducted on the answers, the difference between the opinions of men and women in most of the answers occurred by chance. There was a statistically significant difference in the questions about the prevention of odour in carpets, cleaning of items such as carpets, prayer rugs, prayer beads and the provision of units such as ramps and elevators required for access of disabled people. In this case, it is not appropriate to make a clear comparison with respect to the comfort 
conditions of the spaces reserved for the male and female users in the mosque. After this exploratory study, the analysis of the different mosques will be added to the evaluation pool with the building examinations and then the assessment of dissatisfaction with comfort conditions by gender will make sense.

In an important symbolic structure such as the mosque, the satisfaction of each individual in the space is important. In this respect, the provision of comfort conditions will increase the frequency of individuals to use the mosque, and support maintaining the mosque as a place which lives, offers culture and ensures the transfer of social values. It is anticipated that with its evaluation method this study would be a starting points for renovations in existing mosques and initiatives to develop design strategies for future mosques.

\section{References}

Atlı, M. (2016). Türkiye'de cami mimarlığı tartışması nerelerde tıkanıyor? Kubbeyi yere ve/veya Çamlıca Tepesi'ne koymak, (inside) İnşaat Ya Resulullah. İletişim.

Güzer, C.A. (2009). Modernizmin Gelenekle Uzlaşma Çabası Olarak Cami Mimarlı̆̆ı. Mimarlık, 348: 21-23.

Hasol, D. (2010). Ansiklopedik Mimarlık Sözlüğü, 11th Edition, İstanbul: Yem: 105.

Kul, S. (2014). İstatistik sonuçlarının yorumu: p değeri ve güven aralığı nedir?. Bulletin of Pleura/Plevra, 8(1).

Kurniawan, H. (2011). Familiarity in Designing a Mosque: A Practice of Universal Design. UIA 2011 Tokyo World Congress Programme Work Programme - Architecture for All Regions I, II, III \& IV

Longhurst, C,E. (2012). Theology of a Mosque: The Sacred Inspiring Form, Function and Design in Islamic Architecture, Lonaard Magazine, 8 (2): 2045 - 8150

Preiser, W.F.E. (1995) "Post-occupancy evaluation: how to make buildings work better", Facilities, Vol. 13 Issue: 11, pp.19-28, https://doi.org/10.1108/02632779510097787

Turpin-Brooks,S., Viccars, G. (2006). The development of robust methods of post occupancy evaluation. Facilities.24(5-6): 177-196.

Watson, K., Evans, J., Karvonen, A., Whitney, T. (2016). Capturing the social value of buildings: The promise of Social Return on Investment (SROI). Building and Environment, 103:289, 301. 
Yaşar, Y., Tutkun, M. (2007). Çağdaş Cami Mimarisinde Tasarımsal Arayışlar http://www.boyutpedia.com/1620/67712/cagdas-cami-mimarisinde-tasarimsal-arayislar Date of access: 22.10.2018

Yıldız, S., Topraklı, A.Y. (2018). Ankara camilerinde bakım kolaylığı algısının cami görevlileri açısından ilçelere göre analizi, Akademik Sosyal Araştırmalar Dergisi, 67. 483-492

Zimmerman, A., Martin, M. (2001) Post-occupancy evaluation: benefits and barriers, Building Research \& Information, 29:2, 168-174, DOI: 10.1080/09613210010016857

(Url-1):

http://www.tdk.gov.tr/index.php?option=com_gts\&arama=gts\&guid=TDK.GTS.5c653afa729 ec3.23507874 Date of access: 14.02.2019

(Url-2): http://kadinlarcamilerde.com Date of access:25.12.2018.

(Url-3): $\quad$ http://www.sivilsayfalar.org/2018/10/08/camide-kadin-meselesi-gundemlesirkengecen-bir-yil/ Date of access:25.12.2018.

(Url-4): http://www.dshv.org.tr/eser.php?id=3 Date of access: 25.10.2018. 


\title{
INVESTIGATING THE GLASS CEILING PHENOMENON: FROM A SOCIETAL PERSPECTIVE
}

\author{
Şenay Sahil ERTAN ${ }^{1}$ \\ Gözde INAL CAVLAN²
}

\begin{abstract}
Glass ceiling includes an unfavourable content itself which demonstrates the negative effect that suppress' the career advancement of women. Thus, it prevents women from promotion, improvement and holds them away from advanced responsibilities in the organization. Furthermore, glass ceiling phenomenon restrains women (and any other minority groups) from being in the higher positions and only promoting men for the senior positions due to the stereotypical attitudes in the organization.

According to social role theory, women face stereotyping perceptions because of their multiple social roles. The social role theory examines the causes of sex differences and similarities in social behaviours. It also argues that, gender division of labour leads to the gender stereotypes which characterizes a society (Eagly, 1987). The acceptable reason of glass ceiling for women in leadership positions produces comes from role of inconsistency. The role of incongruity for women in leadership positions arising from glass ceiling creates prejudices that produce barriers for promotion and their effectiveness at top management positions. In most cultures, women are perceived as family care takers, obedient and hence, contradictory with the leadership roles. In general, based on the social role theory, this paper is based on an extant review of literature to explain the glass ceiling phenomenon from a societal view.
\end{abstract}

Keywords: Societal Perspective, Glass Ceiling, Social Role Theory.

${ }^{1} \mathrm{PhD}$. C. European Leadership University Faculty of Economics and Administrative Sciences, Department of Business Administration sahil@elu.edu.tr

${ }^{2}$ Assoc. Prof. Dr. European University of Lefke Faculty of Economics and Administrative Sciences Department of Business Administration ginal@eul.edu.tr 


\section{Introduction}

It is a known fact that over the past years, the contribution of women in global work force has expanded (Kiaye and Singh, 2013); and the trend has been moving towards their fair representation regarding their role in economic terms, especially in Asian countries. Instead of traditional occupations such as teaching and nursing, their representations in occupations traditionally assigned to men are increasing (Kiaye \& Singh, 2013). Various factors can lead to this growing number of women in work force. First of all, women have an easier access to education now more than ever, and once the level of education is higher, enrolment rises in diverse sectors (Acker, 2009; Kiaye \& Singh, 2013). Secondly, with quota system and policy reforms, governments promote the participation of females in every occupational area. As a result of these factors, there are more employment opportunities for women at entry and midlevel positions (Kiaye \& Singh, 2013).

However, the misrepresentation of women at upper positions has been observed in countless studies (Acker, 2009; Catalyst, 2014; Choi \& Park, 2014; Glass \& Cook, 2016; Hoobler, Wayne, \& Lemmon, 2009; Kiaye \& Singh, 2013; Sabharwal, 2013). There is a term for this under-representation which is referred as "Glass Ceiling" (Acker, 2009; Choi \& Park, 2014; Glass \& Cook, 2016; Hoobler, Wayne, \& Lemmon, 2009; Kiaye \& Singh, 2013; Morrison, 1980; Sabharwal, 2013). The term was originally created in the 1980s by Ann Morrison. As specified by Morrison (1980), glass ceiling implies blockages or barriers so invisible that they create obstacles for females and other minority groups as they try to rise to the upper management positions. Afterwards, the Wall Street Journal reporters made the term "glass ceiling" mainstream in 1986.

Although various factors can be linked with this misrepresentation regarding the top management positions, we believe that societal barriers are considered as a primary reason. Glass ceiling impacts the agenda for economic development as well as constituting a threat to 
reaching the objectives in terms of gender equity which is a problem in organizations and in society at all levels. In this context, pointing out the social issues that prevent women from partaking at the upper level echelon seems to be the main problem. Hence, the aim of this paper is to examine the obstacles which prevent women to step up the organizational ladder considering the glass ceiling phenomenon in the epistemological sense.

Our secondary aim is to present insights regarding the societal barriers hindering females from reaching equality with men in higher positions. Social Role Theory underpinning societal barriers is also examined. In the conclusion section, the study aims to propose possible future empirical studies on glass ceiling phenomenon analysing societal barriers.

\section{Glass Ceiling Phenomenon}

A highly-discussed issue is the reason for the inconsistencies between the numbers of women and men in senior positions in organizations. Some refer to a "glass ceiling", a term popularized in the 1980s which, as stated by Morrison and Von Glinow in 1990, was used to define a wall so transparent and so substantial that it blocks females (Morrison et al., 1992), as well as other minority groups (Powell, 2000) from progressing to upper executive positions just because of their race and/or gender. It was 1986 when the term "glass ceiling" was first used in a Wall Street Journal article (Hymowitz \& Schellhardt, 1986). It was written to define the developmental obstacles for disadvantaged racial minority groups such as women, and since then, its focus area has been extended to include not only the upper management positions but all the promotional opportunities. In 1999, Powell stated that even for women who are educated and have the required experience, there is still a glass ceiling. 
Table 1: Categorized Societal Barriers

\begin{tabular}{|c|}
\hline Societal Barriers \\
\hline Social Norms and Stereotypes \\
National Cultures \\
Gender and Different Leadership Style \\
Supply Barrier \\
Tokenism \\
\hline
\end{tabular}

\section{Social Role Theory}

Social role theory and social stereotypes have a significant role in restarining the advancement of women. Singh and Terjesen (2008, p. 56) claimed that the presence of the glass ceiling was preferable to gendered social systems where work was "designed by men and for men" and where patriarchy described work roles in terms of gender, has resulted in stereotyping and gender discrimination. In an environment where the promotional systems run in a gender biased way, it is anticipated that career paths cannot be broken. Such systems work to exclude women since they take maternity leave or work part-time or they may just have to relocate due to their spouses' career moves, structuring the glass ceiling (Singh \& Terjesen, 2008). Singh and Terjesen explained further that women's family responsibilities are the factors that hindered or were perceived to hinder their organizational commitment and consequently leading to lack of involvement in corporate networks which commonly provide access to influential people. Around mid-career, when a male counterpart is stepping up the corporate ladder, the female may have to, in most cases, take career breaks to raise a family or attend to family needs: these breaks that really can block women from being considered as a potential corporate candidate (April et al., 2007; Mooney \& Ryan, 2009). Hoobler et al. (2009) argued that the glass ceiling in gender specific roles (the breadwinner versus the homemaker) associated with men and women, respectively, formed their behavioral expectations and beliefs regarding their abilities 
and capabilities. This view is in harmony with social role theorists since they claim that women are not associated with executive effectiveness because of their nurturing, communal and supportive nature. As this type of nature is considered as not consistent with top executive profundity, it results in subconscious gender specific stereotyping. Hoobler et al. (2009, p. 939) says that stereotyping women with being kind and caring whereas seeing men as tough and achievement-oriented has been labeled "think leader, think male". Social role theorists associate females with being more of caregivers and hence, less engaged in their careers: a situation incongruent with leadership and less prospects for promotion structuring the glass ceiling (Hoobler et al., 2009). However, Lewis (2001 cited in Hoobler et al., 2009), opposes the claim that women are primarily caregivers. Instead, he says that women in professional life who focus more on their careers are less likely to start a family and those who do start a family are inclined to have fewer children. As mentioned by Harris (2010), women are at greater risk than men of suffering from high stress levels and get exhausted because of the different roles they play. This makes women their own worst enemies. Nevertheless, Byron (2005 cited in Hoobler et al., 2009) is determined that men and women experienced equivalent levels in terms of carrier interfering with family and family interfering with carrier. Although the findings of Byron offer a new dimension to social roles, the other studies cited reveal that gender stereotyping has a negative impact on the career prospects of women.

\section{Societal Barriers}

Societal barriers can be examined through the following factors: social norms and stereotypes, national cultures, gender and different leadership style, supply barrier and tokenism. 


\section{Social Norms and Stereotypes}

Social norms condition women such that it becomes impossible to unite their house and work roles in life (Jain \& Mukherji, 2010). The evidences show that the model of an efficient executive is linked with masculinity and accordingly, male executive perspective is more operative than women's which does not accept the female leaders' mental model. (Jain \& Mukherji, 2010). It surely exposes the gender stereotype observed in the organizations. The patriarchal culture convinced people that men are better for higher positions than women so strongly that this perception constantly blocks easy access to higher positions for women (AlManasra, 2013). A woman has to fight against the informal culture, social norms and traditions in order to advance in her career. Nevertheless, these structured beliefs may be corrected by utilizing various programs for enhancing awareness (Bombuwela \& Chamaru, 2013). In addition, in Islamic traditions such as Iran, women are excluded due to the stereotypical perception that they are excessively emotional (Ghorbani \& Tung, 2007).

\section{National Cultures}

Further clarifications for the glass ceiling women face in organisations as they try to make progress particularly include the notion of culture. The national culture profoundly influences the models that people look up to before taking an action for their organisations and the ideas that are assigned through them (Hofstede \& Hofstede, 2005). A subjective entity is built by organisations since employers create an atmosphere unique to the organisation based on their own perception of culture (Trompenaars \& Hampden-Turner, 1998). Due to this, the organisational cultures are also influenced by the culture of the country in which they reside; they are described by the cultural features of their human resources, which is defined in different ways than cultures in general. 
Concurrently, due to the connections between organisational and social culture, individuals within the organisation might choose to act with the belief that women desiring a career are in a way violating cultural standards (Eagly \& Karau, 2002; Heilman, 2001). This may be especially relevant for women who are also mothers, since it has been taught that women who bear features solely related with their gender, like motherhood, are considered in a less favorable way than their male counterparts or even than their female counterparts who do not have to look after some dependent children (Heilman \& Okimoto, 2007). However, organisations which request long hours for work are especially challenging in means of managing work and motherhood simultaneously meaning that a woman should create the balance between work and family as well as other personal responsibilities (Lewis, 2001; Hayman, 2005). Also, women might encounter harrassment biased by gender within the organisation since they might be considered as getting away from their traditional female roles (Leskinen et al., 2015). Leskinen and Cortina (2014) noted five possible ways of gender harassment; including sexist comments, infantilization, gender policing, crude behaviour, and policing of work and life boundaries. This last category primarly influences mothers.

\section{Gender and Different Leadership Styles}

There is a continuing discussion, in the past decades, regarding the particular leadership styles female and male executives utilize. Society assumes that men and women are dissimilar in their personalities, desires, behaviours, and needs. Mostly, different skills linked to the gender of an individual can be identified. The typical male stereotype may be defined as independent, objective, and aggressive whereas the typical female stereotype may be defined as sensitive, kind, and passive. Can it be foreseen that those stereotypes impact the leadership style and behaviour of both genders? A study conducted by Bartol, Martin, and Kromkowski (2003) 
found some support for the view claiming both organizational and gender requirements impact the behaviour of female executives who act in higher positions in organizations.

\section{Supply Barrier}

The Supply Barrier is the secondary type of social barrier. It is associated with opportunities, achievements, levels of education, and work force engagement of women (Clevenger and Singh, 2013). The Supply Barrier implies the lack of qualified women and minority groups due to the inequities in the country's education system. Even if the corporations may not be able to start a movement to reform the education system, they may still be supportive by taking part in attempts including research, school-to-work programs, internships and they may also provide scholarships (U.S. Glass Ceiling Commission, 1995). The supply barrier is so strong that it doesn't just keep competent applicants from reaching an executive position; it also keeps them from even getting into the building of an organisation. The Pipeline Theory states that there is a large supply of women devoting a long time in the back expecting to be promoted to a CEO position (Miller, 2009). Nevertheless, there have been some achievements for women in terms of the supply barrier. As specified by a report by the White House, women have made progress in educational accomplishments and work force participation (United States Department of Commerce Economics and Statistics Administrations and the Executive Office of the President Office of Management and Budget for the Council on Women and Girls, 2011).

\section{Tokenism}

Tokenism theory has been commonly used as a societal barrier for women employed in untraditional or patriarchal occupations (Forkuor et al., 2019). Laws (1975) first popularized the notion by analysing the particular issues facing women entering a male-dominated environment. Laws emphasized the marginal status of a token as a participant who is permitted 
to join due to ownership of recruitments for group entry but is not permitted to participate fully due to absence of pre-requisites for individuals in that situation (gender, race, ethnicity). Tokenism indicates that 'an individual whose social category in specific situations is underrepresented will have to deal with adverse experiences such as enhanced visibility and social isolation' (Lupton, 2000, p. 483). Studies examined token woman soldiers, cadets, researchers, doctors, managers, professors and students of engineering. Other studies concentrated on token man nurses, educators of elementary college, flight attendants, and baby care and clerical employees (Cognard-Black, 2004). In the police force, several writers investigated tokenism (Gustafson, 2008). It is an evolving worldwide phenomenon that a growing number of women take on managerial-level duties right up to corporate boardrooms. While at the entrance stage in organizations there are a big number of women, these figures decrease significantly as women climb the ladder. 2005 Catalyst Census of Women's Board of Directors of the Fortune 500 businesses disclosed that while women accounted for $46.4 \%$ of the workforce, $14.7 \%$ came to boardrooms and only $1.6 \%$ came to the top as CEOs. The incidence of token representation has been demonstrated by literature over the years (Arfken et al, 2004).

\section{Conclusion}

In this paper, societal barriers originated from social role theory have been analyzed through under several factors such as social norms and stereotypes, national cultures, gender and different leadership style, supply barrier and tokenism. There are limited studies examining glass ceiling concept relating to societal barriers in northern Cyprus context. Therefore, we encourage future researchers to conduct empirical studies more on this topic. Future studies can be conducted on women who encounter societal barriers when advancing in their careers. Studies on women (and minority groups) in the tourism, financial and academic sectors can be conducted. 


\section{References}

Acker, J. (2009): From glass ceiling to inequality regimes, Sociologie du travail, 5 (1), pp. 199217.

Al-Manasra, E.A., 2013. What Are the" Glass Ceiling" Barriers Effects on Women Career Progress in Jordan?. International Journal of Business and Management, 8(6), p.40-46.

Arfken, D. E., Bellar, S. L., \& Helms, M. M. (2004). The ultimate glass ceiling revisited: The presence of women on corporate boards. Journal of Business ethics, 50(2), 177-186.

Bartol, K. M., Martin, D. C., \& Kromkowski, J. A. (2003). Leadership and the glass ceiling: Gender and ethnic group influences on leader behaviors at middle and executive managerial levels. The Journal of Leadership and Organizational Studies, 9(3), 8-18.

Bombuwela, P. and Alwis, A.A., 2013. Effects of Glass Ceiling on Women Career Development in Private Sector Organizations-Case of Sri Lanka.Journal of Competitiveness, 5(2), pp.3-19.

Catalyst. 2014. Women on boards. http://www.catalyst.org/knowledge/women-boards. Accessed January 6, 2016.

Choi, S., \& Park, C. (2014): Glass Ceiling in Korean Civil Service: Analyzing Barriers to Women's Career Advancement in the Korean Government, Public Personnel Management, 43(1), pp. 118-139.

Clevenger, L., \& Singh, N. (2013). Exploring barriers that lead to the glass ceiling effect for women in the US hospitality industry. Journal of Human Resources in Hospitality \& Tourism, 12(4), 376-399.

Cognard-Black, A. J. (2004). Will they stay, or will they go? Sex-atypical work among token men who teach. Sociological Quarterly, 45(1), 113-139.

Eagly, A.H. and Karau, S.J. (2002), "Role congruity theory of prejudice toward female leaders", Psychological Review, Vol. 109 No. 3, pp. 573-598.

Forkuor, J. B., Buari, M. A., \& Aheto, C. K. A. (2019). Breaking Barriers: The Experiences of Women in Male Dominated Informal Sector Occupations in Urban Ghana. Gender Issues, 119.

Ghorbani, M. and Tung, R.L., 2007. Behind the veil: an exploratory study of the myths and realities of women in the Iranian workforce. Human Resource Management Journal, 17(4), pp.376-392.

Glass, C., \& Cook, A. (2016): Leading at the top: Understanding women's challenges above the glass ceiling, The Leadership Quarterly, 2(7), pp. 51-63.

Gustafson, J. L. (2008). Tokenism in policing: An empirical test of Kanter's hypothesis. Journal of Criminal Justice, 36(1), 1-10. 
Hayman, J. (2005), "Psychometric assessment of an instrument designed to measure work life balance", Research and Practice in Human Resource Management, Vol. 13 No. 1, pp. 85-91.

Heilman, M.E. (2001), “Description and prescription: how gender stereotypes prevent women's ascent up the organizational ladder", Journal of Social Issues, Vol. 57 No. 4, pp. 657-674.

Heilman, M.E. and Okimoto, T.G. (2007), "Why are women penalized for success at male tasks?: the implied communality deficit", Journal of Applied Psychology, Vol. 92 No. 1, pp. 81-92.

Hofstede, G. and Hofstede, G.J. (2005), Cultures and Organizations: Software of the Mind Intercultural Cooperation and Its Importance for Survival, 2nd ed., McGraw Hill, Verlag.

Hoobler, J. M., Wayne, S. J., \& Lemmon, G. (2009). Bosses' perceptions of family-work conflict and women's promotability: Glass ceiling effects. Academy of Management Journal, 52, pp. 939-957.

Jain, N. and Mukherji, S., 2010. The Perception of' Glass Ceiling'in Indian Organizations: An Exploratory Study. South Asian Journal of Management,17(1), p.23-42.

Kiaye, R., \& Singh, A. (2013): The glass ceiling: a perspective of women working in Durban, Gender in Management: An International Journal, 28(1), pp. 28-42.

Laws, J. L. (1975). The psychology of tokenism: An analysis. Sex roles, 1(1), 51-67.

Leskinen, E.A. and Cortina, L.M. (2014), "Dimensions of disrespect: mapping and measuring gender harassment in organizations", Psychology of Women Quarterly, Vol. 38 No. 1, pp. 107123.

Leskinen, E.A., Rabelo, V.C. and Cortina, L.M. (2015), "Gender stereotyping and harassment: a 'catch-22' for women in the workplace”, Psychology, Public Policy and Law, Vol. 21 No. 2, pp. 192-204.

Lewis, S. (2001), "Restructuring workplace cultures: the ultimate work-family challenge?", Women in Management Review, Vol. 16 No. 1, pp. 21-29.

Lupton, B. (2000). Maintaining masculinity: men who do 'women's work'. British journal of management, 11, 33-48.

Morrison, A. M., \& Von Glinow, M. A. (1990). Women and minorities in management. American Psychologist, 4, pp. 200-208.

Morrison, L. V. (1980). On the analysis of megalithic lunar sightlines in Scotland. Journal for the History of Astronomy Supplement, 11, S65.

Sabharwal, M. (2013): From Glass Ceiling to Glass Cliff: Women in Senior Executive Service Journal of Public Administration Research and Theory, 25 (2), pp. 399-426.

Sabharwal, M. (2013): From Glass Ceiling to Glass Cliff: Women in Senior Executive Service Journal of Public Administration Research and Theory, 25 (2), pp. 399-426. 
Trompenaars, F. and Hampden-Turner, C. (1998), Riding the Waves of Culture: Understanding Cultural Diversity in Global Business, 2nd ed., McGraw Hill, New York.

U.S. Federal Glass Ceiling Commission. (1995, November). A solid investment: Making full use of the nation's human capital. Recommendations of the Federal Glass Ceiling Commission Washington, D.C. Retrieved from http://digitalcommons. ilr.cornell.edu/cgi/viewcontent.cgi? article $=1117 \&$ context=key_workplace. 


\section{ARTICLES IN TURKISH - TÜRKÇE MAKALELER}




\title{
TURKEY ON THE MAP OF GENDER AND THE DIGITAL PARTICIPATION: DIFFERENT DIMENSIONS OF INEQUALITY
}

\author{
Ayşe Aslı SEZGín ${ }^{1}$ \\ Tuğba YOLCU ${ }^{2}$
}

\begin{abstract}
The International Telecommunications Union (ITU), which operates as an agency of the United Nations specializing in information and communication technologies, has mapped the activities of gender and digital participation across different continents and presented them to the world. This realization purpose of the study is to discuss the reason for the remarkable size of the position of Turkey.

In many countries around the "Digital Participation and Gender" in spite of the realization of projects of different scope, any activity from Turkey could not find a place on this map.

In this paper, aimed primarily gender equality and the digital divide in Turkey, participation in discussions of digital assessed under social conditions, then randomly selected characteristics of activities in adjacent areas, was analyzed by descriptive analysis method.

Lastly, future studies and gender equality in Turkey to make a contribution to the literature on the subject and suggestions for activities that can be performed on digital inclusion is presented.
\end{abstract}

Keywords: Gender, Gender Equality, Digital Division, Digital Divide, Digital Participation

\footnotetext{
${ }^{1}$ Assoc. Prof. Dr. Osmaniye Korkut Ata University, Faculty of Economics and Administrative Sciences aaslisezgin@gmail.com

${ }^{2}$ Dr. Lect. Osmaniye Korkut Ata University, Faculty of Economics and Administrative Sciences tugbayolcu@hotmail.com
} 


\section{TOPLUMSAL CINSIYYT VE DİJITAL KATILIM HARITASINDA TÜRKİYE: EŞITTSIZLİĞIN FARKLI BOYUTU}

\section{$\ddot{O}_{z e t}$}

Birleşmiş Milletler'in bilgi ve iletişim teknolojileri konusunda uzmanlaşmış ajansı olarak çalışmalarını sürdüren International Telecommunications Union (ITU) farklı kıtalar boyunca gerçekleştirilen toplumsal cinsiyet ve dijital katılıma ilişkin faaliyetleri haritalandırarak, tüm dünyanın bilgisine sunmuştur. Bu çalışmanın gerçekleştirilme amacl, söz konusu haritada Türkiye'nin konumunun dikkat çekici boyutta olmasının sebeplerini tartışmaya açmaktır. Çevresindeki birçok ülkede "Dijital Katılım ve Toplumsal Cinsiyet" konusunda farkl kapsamlarda projeler gerçekleştirilmesine rağmen, Türkiye'den herhangi bir hareketlilik bu haritada yer bulamamıştır. Çalışmada, bu amaçla öncelikle Türkiye'de toplumsal cinsiyet eşitliği ve dijital katılım, dijital bölünme tartışmaları toplumsal koşullar kapsamında değerlendirilmiş, ardından yakın bölgelerdeki rastlantısal olarak seçilen faaliyetlerin özellikleri, betimsel analiz yöntemiyle incelenmiştir. Son olarak, gelecek dönem çalışmalara ve konuyla ilgili alan yazına katkı sağlamak amacıyla Türkiye’de toplumsal cinsiyet eşitliği ve dijital katılım konusunda gerçekleştirilebilecek faaliyetlere ilişkin öneriler sunulmuştur.

Anahtarkelimeler: Toplumsal Cinsiyet, Toplumsal Cinsiyet Eşitliği, Dijital Bölünme, Dijital Uçurum, Dijital Katılım

\section{Giriş}

Toplumsal ilişkilere ve bu toplumsal ilişkilerin yaşandığı kültürel ortama dair önemli bulgular içeren toplumsal cinsiyet kavramı, son yıllarda teknolojik gelişmelere de bağlı olarak farklı içerikteki araştırmalara konu olmaktadır. Toplumsal cinsiyet konusu kapsamındaki “eşitsizlik" vurgusu da yine bu yeni bakış açılarında sıkça karşımıza çıkmaktadır. Ayrımcılık, önyargılar-kalıp yargılar bu eşitsizlikle birlikte günümüzde varlığını halen sürdürmektedir. Özellikle toplumsal yaşamın farklı bir boyutuyla devam ettiği dijital çağda kadın ve erkeğe yönelik yorumlamalarda bu kez dijital eşitsizliği vurgulayan değerlendirmeler dikkat çekmektedir. 
Yaşam mekânlarının kentlere kayması, geleneksel aile yapısındaki değişim, zamanla kadının üstlendiği rollerde de değişiklik yaşanmasına neden olmuştur. Her toplumsal değişime bağl1 olarak farklılık gösteren ve zamanın etkileriyle de yeniden tanımlanan toplumsal cinsiyet kavramı, Türkiye'de siyasi, sosyal, ekonomik etkenlere bağlı olarak dönüşüm geçirmiştir. Bu dönüşüme rağmen, eleştirel bakış açısı kadın-erkek arasındaki eşitsizliği vurgulamaya devam etmektedir. Eğitim, sağlık, çalışma ortamı, siyasi ortam başlıkları altında kadının konumu ayrı ayrı değerlendirildiğinde bu eşitsizliği ön plana çıkartan uygulamalar dikkat çekmektedir.

1990’larla beraber toplumsal cinsiyet konusundaki eşitsizlikler, teknolojik gelişmelere bağlı olarak farklı başlıklar altında değerlendirilmeye başlamıştır. Kadın ve erkeğin yeni teknolojilere erişimi ve bu teknolojileri kullanma yeterliliği konusundaki yaklaşımlar, yaşanan eşitsizliği açıklayan önemli bir konudur. Bu çalışmada da kavramsal temel üzerinde toplumsal cinsiyet, toplumsal cinsiyet eşitsizliği konuları incelendikten sonra dijital katılım ve dijital katılım tartışmalarındaki eşitsizlik yine toplumsal cinsiyet başlı̆ğ ile ilişkilendirilerek değerlendirilmiştir. Özellikle kadının konumuna dikkat çekmek isterken, Türkiye'de son yıllarda kadın nüfusunun artışına yönelik de bir bilginin dikkate alınması gerekir. Suriye İç Savaşı sonrası yaşanan göçle birlikte Türkiye'de artan kadın nüfusunun ve bu nüfusun dijital katılım konusunda yaşadığı eşitsizliğin etkisi teknoloji kullanımına ilişkin verilerde de göze çarpmaktadır.

\section{Toplumsal Cinsiyet Eşitliği-Eşitsizliği}

Toplumsal cinsiyet, kişisel yaşamın, toplumsal ilişkilerin ve kültürün yorumlanmasında önemli bir konuma sahip olmuştur. Bu kavram aynı zamanda çok fazla ön yargı, mit ve yanlış anlaşılmalarla da değerlendirmiştir. Birçok farklı bakış açışı, kadınların ve erkeklerin psikolojik 
olarak zıt olduklarını savunurken, bazı bakış açılarına göre de erkeklerin kadınlara göre daha zeki oldukları vurgulanmaktadır (Connell, 2009). Bu değerlendirmeler, toplumsal cinsiyet konusunda kadın ve erkeğe yönelik toplumsal rollerin algılanmasındaki eşitsizliği ön plana çıkartmaktadır.

Toplumsal cinsiyete yönelik farklı değerlendirmelerden biri de Butler (2004) tarafından yapılmıştır. Kadın ve erkeğin biyolojik ve toplumsal ayrımına dikkat çekerek yapılan bir tanımlama yerine Butler, toplumsal cinsiyetin iktidar ile ilişkisine odaklanır (Butler, 2009). Kadın ve erkeğin biyolojik cinsiyetler olarak tanımlanmasının dışında, toplumsal cinsiyetin belirlenmesinde toplumsal, kültürel etkenler de önemli bir role sahiptir. Toplumdan topluma farklılık gösteren bir yaklaşımla toplumsal cinsiyet, tarihsel olarak da değişebilmektedir. Konum ve kimlik konusunda bir değerlendirmeyi içeren toplumsal cinsiyet, bu şekliyle güç ilişkilerine yönelik bir yorumlamaya da sahip olmaktadır. Toplumsal cinsiyet vasıtasıyla kadın ve erkeğin toplumsal statü ve rolleri konusunda da bir konum belirlenebilmektedir (Ökten, 2009).

Eşitsizlik konusunda toplumsal cinsiyet ile ilgili araştırmalarda ayrımcılık, önyargılar ön plana çıkmaktadır. Stereotipleşmiş, kalıplaşmış önyargılar kişisel deneyimlerle başlayarak zaman içinde toplumun geneline yayılabilmektedir. Bazı toplumlarda özellikle kadınlara yönelik bu önyargılarda, kişisel düşüncelerin önemli etkisi bulunmaktadır. Önyargılar neticesinde genelleştirme yapılarak, bireysel farklılıklar dikkate alınmamaktadır. Ayrımcılığın da doğmasına sebep olan önyargılar, bazı toplumlarda kadınlara yönelik davranışlarda da gözlenebilmektedir (Vatandaş, 2007). 
Cinsiyet rollerinin biyolojik farklılıklar yerine kültürel bazı etkenlerle yorumlanıp değerlendirilmesi neticesinde kadının ve erkeğin toplum içindeki rolleri de belirlenmektedir. Başta ailenin ve ardından da eğitimin, toplumsal çevrenin etkisiyle kız ve erkek çocuklar kimliklerini kazanma sürecine girmektedir. Ancak zaman içinde küreselleşmenin de etkisiyle kadın ve erkeğe yüklenen rollerde değişim gözlenmektedir (Günay ve Bener, 2011).

Türkiye'de de neoliberal değişimle birlikte toplumsal süreçte ailenin yapılanması ve bu yeni aile modeli içerisinde kadının üstlendiği roller ve konumu farklılık göstermiştir. Ancak, toplumsal cinsiyet kavramının ataerkil bir yaklaşımla değerlendirildiği Türkiye'de, toplumsal cinsiyet eşitsizliği konusu yaşanan değişim ve dönüşüme rağmen tartışılmaya devam eden bir başl1k olmuştur.

\section{Türkiye'de Toplumsal Cinsiyet Eşitliği-Eşitsizliği}

Küreselleşme ve kentleşmenin etkisi Türkiye'de de kentte yaşayan ailelerin yapılanmasında farklılıklar oluşmasına neden olmuştur. Çekirdek aile yapısı, geleneksel görev dağılımında, kadın ve erkeğin rollerinde değişimi yansıtmaktadır. Çalışma yaşamına katılan kentli kadının aile içindeki rolü, modern ve demokratik aile yapısına geçişi hızlandırmıştır (Günay ve Bener, 2011). Ancak bu değişim ve dönüşüm toplumsal yapının da etkisiyle tam bir eşitlikten söz edilmesi için yeterli olamamıştır.

Dünya Ekonomik Forumu'nun (WEF) her yıl açıkladı̆̆ı Küresel Cinsiyet Eşitsizliği Raporu'nda siyaset, ekonomi ve eğitim gibi bazı alanlarda kadın haklarının durumuna ilişkin bir değerlendirme yapılmaktadır. Forum'un yayınladığı raporun, toplumsal cinsiyet eşitsizliği konusundaki sonuçlarında, 2018 yılı için kadınlara yönelik değerlendirmede olumsuz bir tablo dikkat çekmektedir. Ücret eşitsizliği, kamu kurumlarındaki cam tavan sendromu, eğitime 
erişimdeki eşitsizlik, sağlık alanında yaşanan sıkıntılar gibi bazı başlıklar, bu olumsuz durumun temel maddeleri olarak belirtilebilir (BBC Türkçe, 2018).

Söz konusu raporda Türkiye 2018 yılı verilerine göre 149 ülke arasında cinsiyet eşitsizliğinde 130. sırada yer alıyor. Cinsiyet eşitsizliğii, eğitim, sağlı, siyaset ve iş yaşamı başlıkları bulunan raporda cinsiyet eşitliği konusunda İzlanda, Norveç ve İsveç 1 tam puanla ilk sırada yer alırken, Suriye, Irak, Pakistan ve Yemen ise son siradaki ülkeler olarak Türkiye'nin ardından geliyor. Raporda dikkat çeken bir diğer konu da Türkiye'nin 2006 yılından bu yana 25 sıra birden gerilemiş olmasıdır (Bianet, 2018).

İslamiyet öncesinde, İslamiyet'in kabulüyle ve Cumhuriyet döneminde Türk toplumunda kadın, farklı konumlandırmalara sahip olmuştur. Türkiye'de kadınların toplumsal cinsiyet eşitsizliği konusunda yaşadıkları sorunların kaynağında da geçmişten gelen toplumsal yapıya özgü faktörlerin etkisi bulunmaktadır. Geleneksel Türk aile yapısı, erkeğin toplumsal konumu bu faktörler arasında ilk sırada değerlendirilebilir. Türk aile yapısının zaman içinde çekirdek aile yapısına dönüşmesi neticesinde dahi geleneksellik ve ataerkillik özellikleri korunmaya devam etmektedir. Modernleşme, Batı'nın etkisi aile yapısında görülmeye başlasa da geçmişten devralınan miras, kadının toplumsal konumunda belirleyici olmaya devam etmektedir. Kadın Türkiye'de “dişilik” temsilini sürdürmektedir (Bingöl, 2014).

\section{Dijitalleșen Katılım Süreci}

Katılma basit bir meraktan yoğun bir eyleme kadar olan birçok davranış kalıbını içine alır. Özellikle toplumsal alanın biçimlenmesinde önemli bir yeri olan siyasal alanda siyasal katılmanın önemli bir yeri vardır. Siyasal katılma, siyasal sistem karşısındaki siyasal toplumun üyesi olan vatandaşların tutumlarını ve davranışlarını belirleyen bir kavramdır (Kapani, 2011). 
Siyasal katılmanın en önemli aracı seçimlerdir. Ancak katılım seçimlerle sınırlı değildir. Dolayısı ile katılmanın özellikle gelişen ve değişen teknoloji ile birlikte farklı boyutları da önemli bir hal almıştır. İletişim olanaklarındaki gelişmeler sosyal hareketler içinde yer alan sosyal katılımın dönüşmesini, dolayısı ile siyasetin alanının genişlemesini sağlamıştır (Tilly, 2008).

Katılma demokrasinin vazgeçilmez unsurlarından biridir. Demokrasi “ortak kararların alınmasına eşit katılım” şeklinde tanımlandığında, demokrasinin iki temel ilkesi halk denetimi ve siyasal eşitlik olarak belirlenebilir (Beetham, 2008). Son yıllarda üzerinde konuşulan bir katılım türü, post modern katılım başka bir ifade ile dijital katılımdır. Post modern katılım ya da dijital katılım siyasal toplumun üyelerinin internet üzerindeki siyasal etkinliklerini ifade etmektedir (Griffin, 2005). Bu katılım türü bir taraftan internet ortamını diğer taraftan ise sivil toplumu içermektedir. Katılımın internet boyutu özellikle internet üzerinden siyasal ve sosyal etkinliklere katılmak şeklinde kendini göstermektedir (Erdoğan, 2013). Teknolojinin her alana hükmettiği günümüzde, dijital katılım demokrasilerde önemli bir yer almıştır. Ancak dijital katılım üzerindeki tartışmalarda ortak bir noktada fikir birliğine varılamamaktadır.

Dijital katılımın, katılım imkanlarını iki yönden, karar alıcılar ve vatandaşlar açısından, arttırdığı görülmektedir. Bu imkân karar alıcılar ve vatandaşlar yönü ile çift yönlü bir ilişkiyi ortaya koymaktadır. Birincisi karar vericilerin alacakları kararlardan vatandaşlar çok kısa zamanda haberdar olabilir. Diğeri ise vatandaşlar alınan veya alınacak olan kararlara karşı hızlı bir şekilde görüş bildirebilir (Işıklı, 2018).

Dijital eşitsizliğin yol açtığı dijital uçurum, teknoloji araçlarına erişim olanağından ziyade daha derin bir alanı ifade etmektedir. Dijital uçurum mevcut eşitsizlikleri daha derinleştirebilme yeteneğinin bulunması ile ona ayrı bir önem katmaktadır (Öztürk, 2005). Mevcut eşitsizlikleri derinleştirmesi açısından dijital eşitsizliğin ekonomik eşitsizlik, kullanma 
eşitsizliği ve katılım eşitsizliği şeklinde üç boyutu bulunmaktadır. Ekonomik eşitsizlik, eşitsizliğin en yalın hali olup teknolojiye sahip olmadaki ekonomik gücü ifade ederken, teknoloji okuryazarlığı ise kullanım eşitsizliğini ifade etmektedir. Katılım eşitsizliği ise bilgi teknolojilerinin üretimine ve hizmetlerin gelişimine katılmadaki orantısızlığı açıklayan bir kavramdır (Çapar ve Vural, 2013). Özellikle gelişmekte olan ülkelerde bilgi yoksulluğu olarak adlandırılan yeni bir yoksulluk türünü de beraberinde getirmektedir (Öztürk, 2005).

Tüm bu tartışmalar 1şığında dijital katılım, dijital eşitsizlik ve dijital uçurum kavramları ile yakından ilişkilidir. Katılım imkanlarının teknolojiye erişim imkânı ile paralellik göstermesi sosyoekonomik koşullarla yakından alakalıdır. Teknolojiye erişim mekânsal ve bireysel olarak farklılık göstermektedir. Mekânsal olarak kırsal alan ve kentler ile gelişmiş ve gelişmemiş ya da gelişmekte olan bölgeler arasındaki farklılığı yansıtırken bireysel olarak ise cinsiyet, yaş eğitim gibi faktörler arasındaki farklılığı yansıtmaktadır. Bu farklılık dijital bölünmeyi de beraberinde getirmektedir.

\section{Türkiye'de Dijital Katılım Tartışmaları}

Türkiye'de internetin tarihine baktığımızda ilk olarak 1986 yılında Türkiye Üniversiteler ve Araştırma Kurumları Ağı'ndan bahsedilebilir. 1991 yılında ilk internet servis sağlayıcı TR.NET olarak dağıtıma başlamıştır. 1996 yılında Türkiye'nin ilk internet altyapısı olan TURNET oluşturulmuştur. 1997 yılında Ulusal Akademik Ağ (ULAKNET) oluşturulmuş ve 2000'li yıllara kadar Türkiye'de internet özellikle üniversitelerde kullanılarak internet altyapısı kurulmuştur (Çubukçu ve Bayzan, 2013).

Türkiye'de ICT Development Index'e göre 2000 yılında internet kullanımı \%3 seviyelerinde iken 2017 yılına kadar internet kullanımı tüm bireyler içinde \%64,7 yükselmiştir. Bunlar içinde erkeklerin oranı \%72,8, kadınların oranı ise \%56,6 olarak tespit edilmiştir (www.itu.int,2019). Ancak günümüz teknoloji çağında bu oran yetersiz kalmaktadır. Özellikle 
katılım imkanlarının dijitalleşmesi bu alanda yetersiz bir katılım düzeyini de beraberinde getirmektedir.

Katılımın dijitalleşmesi ile birlikte ortaya çıkan e-katılımın aktörleri yurttaşlar, politikacılar ve devlet kurumları olarak belirtilmiştir. E-katılım aktivitelerinde ise; e-oylama, çevirimiçi siyasal söylem, e-aktivizm, e-danışma ve e-dilekçe yer almaktadır (Saebo, Rose ve Flak, 2008). Aktörler ile birlikte farklılaşan aktiviteler farklı bir ilişki ağını da beraberinde getirmiştir. Tek yönlü ilişki ağ1 dijitalleşme ile birlikte çift yönlü bir ilişki ağ oluşmaya başlamıştır.

$\mathrm{Bu}$ ilişki ağı Türkiye için değerlendirildiğinde toplumsal katmanlar arasındaki sosyoekonomik uçurum ile birlikte tezatlıkları da beraberinde getirmektedir. Bir yandan kamu kurumları dijital katılımı gerçekleştirerek e-devlet sürecine girmekte bir yandan ise hala okuma yazma bilmeyen bir kesim varlığını sürdürmektedir. TUİK verilerine göre okuma yazma bilmeyen yaklaşık 2 milyon kişi bulunmaktadır. Ayrıca e-devlet uygulamalarına erişim için temel şart olan internete erişim ise hanelerde \%72,9 iken bilgisayar kullanımı \%59,6 düzeyindedir (TÜİK, 2019). Bilgiye erişim konusunda ise TÜİK 2012 verilerine göre yüksek öğretim düzeyinde eğitime sahip olanlar bireyler internet \%71,0 ile ilk sırada yer almaktadır. Bu oran herhangi bir okul okumayan bireylerde ise \%13,3'e düşmektedir (TÜİK, 2019a).

Cinsiyet açısından bu durum değerlendirildiğinde kadınların erkeklere oranla daha az internet ve bilgisayara eriştikleri ortaya çıkmaktadır. 2018 yılı itibari ile kadınların internet kullanımı \%65,5 iken erkeklerin \%80,4'tür (TÜİK, 2019b). Bu durum birçok ülkede olduğu gibi Türkiye açısından da cinsiyetler arası dijital bölünmenin yaşandığını göstermektedir. 


\section{Türkiye’de Dijital Bölünme ve Toplumsal Cinsiyet Tartışmaları}

Bilgi ve iletişim teknolojilerindeki gelişmelere bağlı olarak kullanılan bilgi toplumu kavramı içinde, her şeyin dijitalleşmesinden, dijital araçların ve uygulamaların hayatın her alanına hâkim olmasından söz edilmeye başlamıştır. Bu ortamda bilgiye erişme, bilgiyi kullanma ve gerektiği şekillerde bilgiyi üretme noktasında bireylerin dijital teknolojileri kullanabilecek yeterlilikte olması beklenmektedir. Dijital olanakların kullanımına ilişkin birçok farklı etkenle birlikte (yaş, ekonomik gelir seviyesi, eğitim, meslek, yaşanılan coğrafi konum gibi) cinsiyet de önemli bir faktör olarak değerlendirilmektedir. Konuyla ilgili Türkiye'deki istatistikler ${ }^{1}$ incelendiğinde kadınların özellikle bölgelere göre erkeklere oranla dezavantajlı durumda oldukları dikkat çekmektedir. Bu sonuçlar neticesinde de tartışmalar dijital bölünme, dijital katılım ve dijital eşitsizlik kavramları çerçevesinde şekillenmektedir (Dinç, 2017). Bu çalışmanın daha önceki bölümlerinde dijital eşitsizlik, dijital katılım kavramlarıyla ilgili tartışmalara yer verilmiş, bu bölümde ise dijital bölünme kavramı özellikle toplumsal cinsiyetle olan ilişskisi çerçevesinde değerlendirilmiştir.

Zamanla internet kullanımının toplumsal yaşamın geneline yayılması ve internetin birincil bilgi kaynağı haline gelmesi neticesinde, dijital bölünme yalnızca bilgisayara erişimde yaşanan boşluğu değil, aynı zamanda internet erişimindeki boşlukları da belirtmek için kullanılmıştır. Dijital bölünme konusunda yapılan ilk araştırmalardaki fiziksel erişim problemleriyle ilgili değerlendirmeler de zamanla daha geniş bir açıdan ele alınmaya başlamıştır. Sosyolojik, psikolojik ve kültürel geçmiş dijital bölünmeyle ilişkilendirilmiştir (Van Deursen ve Van Dijk, 2011).

Bu çalışmanın konusu kapsamında incelendiğinde dijital bölünmeyle ilgili toplumsal şartlara bağlı olarak birçok farklı faktörün dikkate alınması gerekir. Toplumsal cinsiyet de 
toplumdan topluma ve aynı toplum içerisinde değişiklik gösteren yapısıyla, dijital bölünmenin de kimi zaman kaynağı olarak değerlendirilmelidir. Buna karşın bazı çalışmalarda dijital bölünmenin kaynağı olarak toplumsal cinsiyetin gösterilmesi noktasında farklı görüşler de savunulmaktadır. Örneğin Cooper (2006), konuyla ilgili son 20 yılda yapılmış olan çalışmalar incelendiğinde, bilgisayar ve bilgisayar destekli yazılım yardımıyla öğrenim konusunda kadınların, erkeklere göre dezavantajlı olduğu sonucunun savunulduğunu belirtir. Ancak bu tip yargıların cinsiyete ilişkin klişe değerlendirmeler olduğunu, bu kalıp yargıların dijital bölünme ile ilişkilendirildiğini vurgular. Buna karşın bilgisayar kullanımındaki sorunların her toplumdan, her yaştan ve her cinsten insanın yaşayabileceği sorunlar olarak değerlendirilmesi gerektiğini belirtir.

Türkiye'de cinsiyet etkeni çerçevesinde dijital teknolojileri kullanma konusunda yapılan araştırmaların sayısal verileri incelendiğinde cinsler arasındaki farklılık göze çarpmaktadır². Dinç (2017), kadınların dijital olanaklara uyum sürecini Türkiye örneği üzerinden incelediği araştırmasında, TÜİK'in 2017 yılı istatistikleri çerçevesinde Türkiye'de kadınların internet kullanımlarına yönelik bazı değerlendirmelerde bulunmuştur. Buna göre Türkiye'de kadınlar yaşanılan bölge, işgücüne katılım gibi bazı özelliklerin etkisiyle dijital teknolojilerden yararlanabilmektedir. Bunun yanı sıra dijital teknolojilere uyum sağlayamayan kadınlar da bulunmaktadır.

\section{Yöntem}

Çalışmada, Birleşmiş Milletler’ in bilgi ve iletişim teknolojileri konusunda uzmanlaşmış ajansı olarak çalışmalarını sürdüren International Telecommunications Union'ın (ITU) farklı kıtalar boyunca gerçekleştirdiği toplumsal cinsiyet ve dijital katılıma ilişkin faaliyetlerinin yer aldığı harita (Resim 1) kapsamındaki inceleme, betimsel analiz yöntemi vasıtasıyla 
gerçekleştirilmiştir. Bu doğrultuda yakın bölgelerdeki rastlantısal olarak seçilen faaliyetlerin özellikleri dikkate alınmıştır. Bu kapsamda, çalışmanın kuramsal temeline dayanarak araştırma cümleleri ve bu cümlelere bağlı olarak temalar tespit edilmiştir (Tablo 1).

Yapılan araştırmadaki sonuçların betimsel bulgularla analiz edilmesi, yorumlanması amacını taşıyan betimsel analiz yöntemi, nitel araştırma yöntemleri arasında değerlendirilmektedir. Yukarıda da bahsedilen temalar doğrultusunda bulguların kategorilendirilmesini ve analiz edilmesini amaçlayan betimsel analiz yöntemi, yorumlamalarda literatürden destek alınmasını gerekli kılmaktadır (Yıldırım ve Şimşek, 2008). Bu çalışmada da gerçekleştirilen analiz esnasında çalışmanın kuramsal temelini de oluşturan literatürden destek alınmıştır.

Tablo 1. Araştırma cümleleri ve temalar (bknz notlar)

\section{Tartışma ve Bulgular}

\section{Girls in Tech Armenia}

Yeni teknolojilerle şekillenen toplum yaşamında, cinsiyet eşitsizliğine son vermek amacıyla Ermenistan'da kurulan, kâr amacı gütmeyen bir oluşum olan Girls in Tech Armenia, 2007 y1lından bu yana faaliyetlerini sürdürmektedir. Özellikle bilim, teknoloji, mühendislik ve matematik alanlarındaki yenilikçi yaklaşımı bünyesinde toplayan STEM yaklaşımı gibi dijital çağda bilim ve teknoloji okuryazarlığı konusunda yetkin bireyler yetiştirmeyi amaçlayan (Uğraş, 2007) alanlarda kadınların kariyerlerini sürdürmeyi amaçlayan bu oluşum teknoloji konusunda tutkulu kadınları güçlendirmeyi hedeflemektedir. Bu tutkuyu yaşatabilmek için de Girls in Tech Armenia kadınların ihtiyaç duydukları erişimi sağlamaya çalışmaktadır. 
Araştırma cümlesi (A) kapsamındaki temalar çerçevesinde değerlendirildiğinde özellikle "kadın-kız-katılım" temalarının ağırlıklı olarak vurgulandığı proje web sayfasında ayrıca Kariyer Koordinasyon Girişimleri, A $\breve{g}$ Etkinlikleri, Programlama Kursları başlıkları altında kadınlara sunulan ve teknolojik katılımı destekleyen etkinliklere yer verilmiştir.

Sovyetler sonrasında Ermenistan'da sosyal gelişim konusu çelişkilerle dolu bir süreç olarak tanımlanmıştır. Özellikle sosyal, politik ve ekonomik alanlardaki belirsizlikler bu çelişkilerin yaşanmasına neden olmuştur. Böyle bir ortamda bireyler sayısız değişimle başa çıkmanın yollarını aramışlardır. Sivil toplum oluşumları da bu arayış içerisinde 1990'larla birlikte ortaya çıkmıştır. Demokrasinin toplum yaşamına yerleşmesine katkı sağlaması, uluslararası küresel bir diyaloğun parçası olmak için önemli bir gelişme olması, Ermenistan'da sivil toplum oluşumunun önemini arttırmaktadır. Ermenistan'da 1999'da 2500'den fazla sivil toplum kuruluşunun üçte ikisinden fazlasının kadınlar tarafından yönetilmesi de dikkat çekmektedir (Ishkanian, 2000).

1990 sonrasında Ermenistan'da yaşanan dönüşüm demokrasi fikrine doğru güçlü bir atılım olarak değerlendirilmektedir. Otoriter hükümet modelinin ardından sivil toplumun güç kazandığ1 yeni bir modele geçilmiştir. Ancak bu yeni model ve demokratikleşme süreci yavaş ilerlemektedir. Sosyal reformlara ihtiyaç duyulan Ermenistan'da sosyal yaşam, ekonomik gelişim ve eğitim sistemi konularında özellikle kadınların etkisini arttıracak projelere ihtiyaç duyulmaktadır (Babayan, 2001).Kız çocukları başta olmak üzere tüm kadınların teknolojik gelişmelere uyum sağlaması noktasında faaliyetler sürdüren, etkinlikler ve eğitimler planlayan Girls in Tech Armenia, belirtilen temaların hemen hemen tamamına yer vermektedir. 


\section{Syrian Telecentre Project}

Türkiye'nin güneyinde, Suriye'de gerçekleştirilmiş olan Syrian Telecentre Project, Birleşmiş Milletler'in bilgi ve iletişim teknolojileri konusunda uzmanlaşmış ajansı olarak çalışmalarını sürdüren International Telecommunications Union (ITU) tarafından farklı kıtalar boyunca gerçekleştirilen toplumsal cinsiyet ve dijital katılıma ilişkin faaliyetleri belirttiği haritasında yer almaktadır. 2015 yılında gerçekleştirilen bu proje yine Birleşmiş Milletler desteğine sahiptir.

Arap Bölgesi’ndeki kızları güçlendirmek amacı taşıdığını belirten proje, Suriye'deki Salameih bölgesinden15 kız öğrencinin tasarım, grafik tasarım, ürün tasarımı, fotoğrafçılık uygulamaları ve görsel sanatlar gibi konularda eğitim alması amacını taşımaktadır. Araştırma cümlesi (A) altındaki temalarla doğrudan alakalı bir içeriğe sahip olan proje özellikle "kızlar" vurgusunu yapmış ve onları bir toplumdaki potansiyel enerji kaynakları olarak betimlemiştir. Teknolojideki gelişmeler karşısında özellikle kızların kendilerini güçlü hissetmeleri ve kariyerlerini bu doğrultuda yönetmeleri için bilgi ve iletişim teknolojileri konusunda eğitim almaları gerektiğinin farkına varılmasıyla projenin gerçekleştirildiği vurgulanmıştır. Bu eğitim Suriye'de, Uluslararası Girls in ICT Day Etkinlikleri kapsamında gerçekleştirilmiştir.

Mart 2011'de başlayan İç Savaş sonrası toplumsal görünümünün büyük oranda değiştiği Suriye'nin teknolojik gelişmeler konusunda da bu savaşın etkisiyle dijital anlamda eşitsizlik yaşadığı, bu eşitsizliğin özellikle kadınları etkisi altına aldığı belirtilebilir. Birleşmiş Milletler' in kendi desteğiyle Suriyeli kadınlara yönelik bu eğitim projesine haritada yer vermesi ilgi çekici fakat anlaşılabilirdir. Savaş ortamında dahi Birleşmiş Milletler tarafından özellikle Suriyeli kadınların ve genç kızların, teknolojik gelişmeler karşısında kayıtsız kalmaması adına bu proje gerçekleştirilmiştir. "Kızlar için Grafik Tasarım İlhamı” başlığını taşıyan proje 
kapsamındaki etkinlikte, kızların teknolojik gelişmelere bağlı olarak bir gelecek hayali kurabilmeleri, bilgi ve iletişim teknolojilerini kullanmaları konusunda cesaretlendirilmeleri, medya vasıtasıyla öğrenme konusunda yetkinlik kazanmaları amaçlanmıştır. "Kız, dijital firsat, teknoloji, proje, eğitim, iletişim teknolojisi” temaları projede dikkat çekmektedir.

Toplumsal normlar ve gelenekler kadınların Suriye toplumundaki yaşamları üzerinde önemli bir etkiye sahiptir. Yasalar yerine din, kadınların toplum yaşamındaki konumlarını belirlemede önemli bir etkiye sahiptir. Sosyal normlar etnik kökene, kırsal ve kentsel alanlara göre değişiklik gösterse de bu normların genel doğası, kadınları genellikle ikinci plana koymaktadır. Kadınlar aileleri için ya onur ya da utanç kaynağı olmaktadır. Kadınlara yönelik en büyük baskı aile ortamında gerçekleşmektedir. Çoğu zaman erkekler karşısında sosyal şiddete maruz kalan kadınlara yönelik ayrımcılık birçok alanda karşımıza çıkmaktadır (Habib, 2018).

Suriye toplumunda kadının konumuna ilişkin yukarıda aktarılan bilgilerin 2011 sonrasında çok daha farklı boyutları ile incelendiği gözlenmektedir. Bu kez sığınmacı konumunda Suriyeli kadınların, göç etmek zorunda kaldıkları ülkelerde yaşadıkları problemler araştırma konusu olmuştur. Özelikle ailelerinden kopan, eşlerini savaşta kaybeden kadınlar ve kız çocukları sığınmacı oldukları ülkelerde, kendi toplumlarında yaşadıkları problemlerin daha ağır boyutunu tecrübe etmek zorunda kalmıştır. Ancak diğer taraftan özellikle sivil toplumun desteğiyle Suriyeli kadınlara yönelik projeler, onları toplumsal hayata kazandırmaya ve başarılı olmaya teşvik edecek eğitim programları, başta Türkiye gibi birçok ülkede hayata geçirilmeye çalışılmıştır. Bu projelerin başarıları göreceli bir şekilde değerlendirilmekle birlikte, dikkatleri Suriyeli kadın sığınmacılara çektiği de bir gerçektir. Bu çalışmada incelenen ve haritada Türkiye'nin güneyinde yer verilen Birlemiş Milletler destekli dijital katılıma yönelik proje de 
yine sonuçları nezdinde tartışmaya açık bir proje olmakla birlikte, eleştirel bakış açısıyla değinilmesi gereken bir diğer nokta da projenin konusunun, söz konusu Suriyeli kadınlar kapsamında önceliğinin bulunup bulunmadığı noktasında olmalıdır.

\section{Rails Girls Bucharest}

International Telecommunications Union (ITU) tarafindan yayınlanan toplumsal cinsiyet ve dijital katılıma ilişkin haritada yer alan bir diğer etkinlik, bu kez Türkiye'nin kuzeyindeki Romanya'da gerçekleştirilmiştir. Rails Girls Bucharest başlıklı proje, web teknolojileri konusunda kendisini geliştirmek isteyen kadınlar için ücretsiz olarak gerçekleştirilen bir dizi etkinliği içermektedir.

Geleneksel ve ataerkil kültür Romanya'da derin köklere sahiptir. Ayrıca 1990’lı yıllarda başlayan ekonomik sıkıntılar da eşitlikçi uygulamaların önünde önemli bir engel olmuştur. Romanya'da kadın ve erkeklerin çoğunluğunun karşısına, toplumsal cinsiyet eşitliğinden çok daha acil sorunlar çıkmıştır. Bununla birlikte 21. yüzyılın başlarında ise Romanya'da yaşanan ekonomik büyüme, liberal yönetim anlayışı toplumsal cinsiyet konusunun tartışılmasına uygun zemini yaratmaya başlamıştır. Romanya'da kadınlara yönelik mevcut tutumu şekillendiren Ortodoks Kilisesi, siyasi partiler, feminist örgütler ve medya, siyasi ve sosyal arenada yaşanmaya başlayan toplumsal cinsiyet tartışmalarında da önemli birer taraf konumundadır (Oprica, 2008).

Rails Girls projesi Romanya'da gerçekleştirilen dış kaynaklı bir proje özelliğindedir. Romanya'da kadınların teknolojik alanda kariyer planları yapmalarını teşvik eden proje, dünyanın birçok farklı ülkesinde gerçekleştirilmektedir. Nepal, Vietnam, Ukrayna gibi ülkelerin dikkat çektiği etkinlik takviminde, proje ekibi uygulamaların öncelikli bölgelerde 
gerçekleştirilmesi amacını taşımaktadır. Romanya'nın sosyo-ekonomik özellikleri de dikkate alındığında bu öncelikli bölgeler içinde değerlendirildiği tespiti yapılabilir. Tıpkı Suriye'de olduğu gibi Romanya'da da kadınların ve kız çocuklarının teknolojik gelişmelere uyumu noktasında desteğe ihtiyaç duyduğu anlaşılmaktadır.

\section{Code it Like a Girl}

Çalışmada tespit edilen “Türkiye'nin kuzeybatısı ve batısında yer alan ülkelerde (Romanya ve Yunanistan) kadınlara ve kız çocuklarına yönelik dijital katılımı destekleyen çalışmalar gerçekleştirilmektedir” araştırma cümlesi (B) kapsamında, International Telecommunications Union (ITU) tarafindan yayınlanan toplumsal cinsiyet ve dijital katılıma ilişkin haritada yer alan bir diğer etkinlik Yunanistan' da gerçekleştirilmiştir.

Code it Like a Girl başlıklı proje, kadınların hayallerini takip etmeleri için onlara ilham vermeyi amaçlamaktadır. Teknoloji haberlerine, dünyanın farklı bölgelerindeki insanların hikayelerine, feminizm hakkındaki makalelere yer verilen proje web sayfasında, dijital medyada içerik yaratılması konusunda kadınlara yol gösterilmesi amaçlanmaktadır.

2009'da Yunanistan, İkinci Dünya Savaşı’ndan bu yana en büyük ekonomik krizlerden birini yaşamaya başladı. Mart 2010'da Yunan Hükümeti, borçlanma gerekliliklerini yerine getirmek için özellikle vergi sisteminde ve kamu sektöründe bazı düzenlemeler yapılması yoluna gitti. İşten çıkartmalar, büyük şirketlerin kapanması gibi ekonomik durgunluğa yol açan bazı gelişmeler yaşandı. Kriz derinleştikçe, uygulanan politikalar da sorgulanmaya başladı. Bu krizden kadınlar da yoğun şekilde etkilendi. Emeklilik kesintileri 75 yaş üstü insanların yoksulluk riskini arttırdı. 65 yaş üstü kadınların \%30’u 2010'da yoksulluk ve dışlanma riski altına girdi. Özellikle kadınlara yönelik ayrımcılık vakaları artmaya başladı. Hamilelik ve 
annelik ihtiyaçlarıyla ilgili özel istihdam gereklilikleri bu dışlanmanın yaşanmasında etkili oldu (Davaki, 2013).

Code it Like a Girl, bu krizin ardından tamamen ulusal bir girişimle gerçekleştirilen bir projedir. "Kodlayın kız gibi” sloganındaki cinsiyetçi söylem tartışmaya açık olmakla birlikte, bu proje kadınlara teknoloji dünyasında kariyer sahibi olmaya yönelik birtakım etkinlikler düzenlemektedir.

\section{Sonuç}

Türkiye'de son yıllarda dijital çağa uyum konusunda kamu ve özel sektörde birtakım girişimlerde bulunulmaktadır ${ }^{3}$. Bilgi ve iletişim teknolojilerinin gündelik hayata girmesi ve her geçen gün gelişmesi bu uyum politikalarını gerekli kılmaktadır. Sivil toplumun da yine dijital çağa geçiş ve uyum konusunda projeler hayata geçirdiği bilinmektedir. Toplumsal cinsiyet konusunun bu projeler kapsamındaki konumu ayrı bir çalışma konusu olarak, gelecek dönem çalışmalarda yer verilebilecek önemli bir başlık olarak değerlendirilebilir. Ancak burada kısaca değinmek gerekirse, Türkiye'de toplumsal cinsiyet kavramı çerçevesinde, çalışmada incelenen ve farklı ülkelerde gerçekleştirilen projelere benzer girişimlerin ${ }^{5}$ bulunduğunu söylemek doğru olacaktır. Ancak yine eleştirel bir bakış açısı ile değerlendirildiğinde, bu projelerin duyurulması ve daha geniş kesimlere hitap etmesi noktasında etkin bir politikaya ihtiyaç duyulduğu gözlenmektedir.

Birleşmiş Milletler'in bilgi ve iletişim teknolojileri konusunda uzmanlaşmış ajansı olarak çalışmalarını sürdüren International Telecommunications Union (ITU) farklı kıtalar boyunca gerçekleştirilen toplumsal cinsiyet ve dijital katılıma ilişkin faaliyetleri ile ilgili haritada Türkiye'den hiçbir etkinliğin yer almaması oldukça dikkat çekicidir. Bu noktada da 
yapılması gerekenler için ayrı bir yol haritasına ihtiyaç duyulduğu düşünülmektedir. Ayrıca, çalışma boyunca incelenen ve farklı ülkelerde gerçekleştirilen projeler dikkate alındığında, bu projelerin daha çok genç kadın girişimciler tarafından gerçekleştirildiği gözlenmiştir. $\mathrm{Bu}$ noktada özellikle genç kadınların ülkemizde de teşvik edilmesi, bu konuda aldıkları eğitimin kalitesinin yeterli olması gerektiği düşünülmektedir.

\section{Notlar:}

1. TÜİK tarafından 2018 yılında yapılan Bölgeler ve Cinsiyete Göre Bilgisayar Kullanımı Araştırması'na göre, 2018 yılında Batı Marmara Bölgesi'nde kadınların bilgisayar kullanım oranı \%47,8 iken, Ortadoğu Anadolu'da bu oran \%35,6, Güneydoğu Anadolu'da ise \%29,7'dir. Aynı araştırmada erkeklerin Batı Marmara Bölgesi'nde bilgisayar kullanım oranı \%67,1 iken, Ortadoğu Anadolu'da bu oran \%61,6, Güneydoğu Anadolu'da ise \%57,1'dir.

2. IAB (Interactive Advertising Bureau) Türkiye ve Gemius'un 8 Mart Dünya Kadınlar Günü dolayısıyla yaptığı ve "Türk Kadınının Dijital Haritası" başlıklı çalışmada, kadınların internette geçirdikleri süre ve kullanım alışkanlıklarına dair rakamlar açıklanmıştır (IAB, 2019). Diğer bir araştırma da We Are Social ve Hootsuit tarafından her yıl hazırlanan, internet ve sosyal medya istatistiklerini içeren "Digital 2019 in Turkey" ismiyle yayınlanmıştır. Bu araştırma sonuçlarına göre de Türkiye'de Facebook, Instagram, Twitter gibi sosyal medya ağlarının kullanıcıları büyük oranda erkeklerdir (We Are Social, 2019).

3. “Türkiye'nin ilk ve tek dijital kadın zirvesi” sloganı ile gerçekleştirilen Dijital Topuklar Zirvesi, dijital gelişmeleri kadınlar özelinde ayrıntılı olarak incelemeyi hedeflemektedir. Sosyal medya aracılığıyla kadın girişimcilerin bu girişimlerini genişletebilmeleri için onlara yol göstermeyi hedefleyen \#SheMeansBusiness projesi; yine aynı amacı taşıyan ve sosyal medya kullanımı konusunda kadınları aydınlatmayı amaçlayan "Işste Dijital Kadınlar" projesi, Türkiye Ulusal Ajansı tarafından desteklenen iş dünyasına yeni atılan, kendi işini yapmak isteyen kadınlara güç kazandırmayı amaçlayan EmpowerWOMENt projesi.

\section{Tablo 1. Araştırma cümleleri ve temalar}

\section{Araştırma Cümlesi}

\section{Temalar}

Türkiye'nin kuzeydoğusu ve güneyinde yer alan Kadın, kız, dijital firsat, teknoloji,

A ülkelerde (Ermenistan ve Suriye) kadınlara ve kız proje, eğitim, bilgi toplumu, çocuklarına yönelik dijital katılımı destekleyen iletişim teknolojisi, katılım. çalışmalar gerçekleştirilmektedir.

Türkiye'nin kuzeybatısı ve batısında yer alan Kı, kadın, dijital medya, tasarım,

B ülkelerde (Romanya ve Yunanistan) kadınlara ve kız kodlama, atölye çalışması.

çocuklarına yönelik dijital katılımı destekleyen

çalışmalar gerçekleştirilmektedir. 


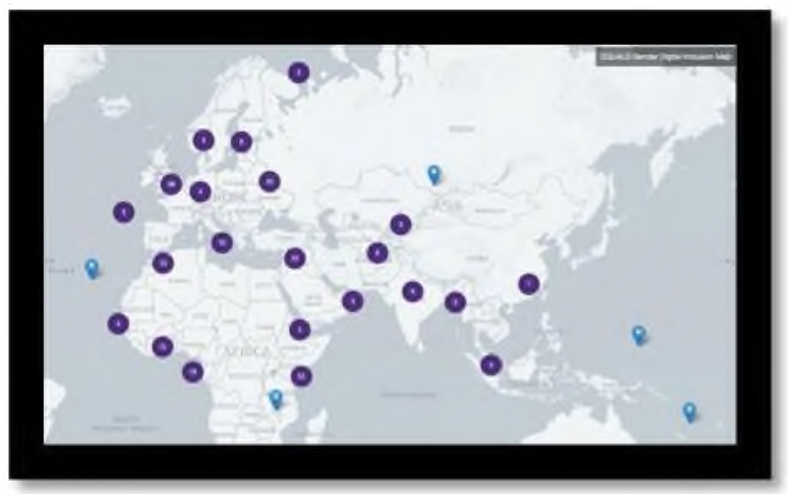

Resim 1. Toplumsal cinsiyet ve dijital katılım haritası

Kaynak:https://www.itu.int/en/action/gendeequality/SiteAssets/Pages/equalsGDImap/map.ht $\underline{\mathrm{ml}}$

\section{Kaynaklar}

Babayan, S. (2001). The reconstruction of society's gender culture through higher education in Armenia. International Journal of Sociology and Social Policy, 21(1/2): 57-67.

BBC Türkçe, Küresel cinsiyet eşitsizliğini tamamen gidermek için 200 y1l gerekiyor. Erişim: https://www.bbc.com/turkce/haberler-dunya-46619022, 03.06.2019.

Beetham, D. (2008). Demokrasi ve Insan Hakları, Çev. B. Canatan, Ankara, Liberte Yayınları.

Bianet (2018). Türkiye toplumsal cinsiyet eşitliğinde 19 ülkeyi geride bıraktı. Erişim: https://m.bianet.org/bianet/toplumsal-cinsiyet/203672-turkiye-toplumsal-cinsiyet-esitliginde19-ulkeyi-geride-birakti, 03.06.2019.

Bingöl, O. (2014). Toplumsal cinsiyet olgusu ve Türkiye'de kadınlık. KMÜ Sosyal ve Ekonomik Arastırmalar Dergisi, 16 (1): 108-114.

Bora, A. (2012). Toplumsal cinsiyete dayalı ayrımcılık. Ayrımcılık: Çok Boyutlu Yaklaşımlar. Der: Kenan Çayır ve Müge Ayan Ceyhan, İstanbul Bilgi Üniversitesi Yayınları.

Butler, J. (2004). Undoing Gender. Routledge.

Butler, J. (2009). Toplumsal cinsiyet düzenlemeleri. Cogito, 58: 73-92.

Code it Like a Girl (2014). Erişim: http://codeitlikeagirl.com/about/, 30.07.2019.

Connell, R. (2009). Gender. UK:Polity Press.

Cooper, J. (2006). The digital divide: The special case of gender. Journal of Computer Assisted Learning, 22(5): 320-334. 
CNNTÜRK, (2019). BTK'den Türkiye'nin dijital dönüşümü için yol haritası. Erişim: https://www.cnnturk.com/ekonomi/btkden-turkiyenin-dijital-donusumu-icin-yol-haritasi, 30.07.2019.

Çapar, F. ve Vural, Ö. F. (2013). "E-devletleşme önündeki engel: Diijital eşitsizlik”. International Journal of Human Sciences, 10(1): 1674-1692.

Çubukçu A. ve Bayzan Ş. (2013). Türkiye'de dijital vatandaşlık algısı ve bu algıyı internetin bilinçli, güvenli ve etkin kullanımı ile artırma yöntemleri. Middle Eastern \& African Journal of Educational Research, 5: 148-174.

Davaki, K. (2013). The policy on gender equality in Greece (In) European Parliament's Committee on Women's Rights and Gender Equality. Erişim: http://www.europarl.europa.eu/RegData/etudes/note/join/2013/493028/IPOLFEMM_NT\%282013\%29493028_EN.pdf, 30.07.2019.

Dinç, S. (2017). Kadınların dijital olanaklara uyumu: Türkiye örneği. Süleyman Demirel Üniversitesi İktisadi ve İdari Bilimler Fakültesi Dergisi, 22: 1761-1783.

Erdoğan, E. (2013). Türkiye'de Gençlerin Siyasal ve Sivil Katılımı, SAGE Yayıncılık, Ankara.

Girls in Tech Armenia (2019). Erişim: https://armenia.girlsintech.org/ 29.07.2019.

Griffin, C. (2005). Challenging assumptions about youth political participation: critical insights from great britain, (In) Revisiting Youth Political Participation, Ed. J. F., Strasbourg, Council of Europe, 145-154.

Günay, G. ve Bener, Ö. (2011). Kadınların toplumsal cinsiyet rolleri çerçevesinde aile içi yaşamı algılama biçimleri. Türkiye Sosyal Araştırmalar Dergisi, 15 (3): 157-171.

Habib, N. (2018). Gender role changes and their impacts on Syrian women refugees in Berlin in light of the Syrian crisis (No. SP VI 2018-101). WZB Discussion Paper.

Hürriyet (2019). Dijital Türkiye için bağlanabilirlik ve yapay zeka kritik önemde. Erişim: http://www.hurriyet.com.tr/teknoloji/dijital-turkiye-icin-baglanabilirlik-ve-yapay-zeka-kritikonemde-41099740, 30.07.2019.

IAB, (2019). Türk Kadınının Dijital Haritası, Erişim: https://www.webtekno.com/turkkadinlarinin-dijital-haritasi-belli-oldu-h64537.html, 06.06.2019.

Ishkanian, A. (2000). Gender and NGOs in Post-Soviet Armenia. Anthropology of East Europe Review, 18(2): 17-21.

Işıklı Ş. (2018). Dijital vatandaşlık: katılımcı demokrasi kuramına aktüel bir katkı. Uluslararası Bilişim, Teknoloji ve Felsefe Dergisi, 1: 143-161.

ITU, (2019). Gender digital inclusion map. Erişim: https://www.itu.int/en/action/genderequality/SiteAssets/Pages/equalsGDImap/map.html, 06.06.2019.

Kapani, M. (2011). Politika Bilimine Giriş, Bilgi Yayınları, İstanbul. 
Oprica, V. (2008). Gender equality and conflicting attitudes toward women in post-communist Romania. Human Rights Review, 9(1): 29-40.

Ökten, Ş. (2009). Toplumsal cinsiyet ve iktidar: Güneydoğu Anadolu Bölgesi'nin toplumsal cinsiyet düzeni. Uluslararası Sosyal Araştırmalar Dergisi, 2(8): 302-312.

Öztürk, L. (2005). Türkiye'de dijital eşitsizlik: tübitak-bilten anketleri üzerine bir değerlendirme. Erciyes Üniversitesi İktisadi ve İdari Bilimler Fakültesi Dergisi, 24: 111-131.

Rails Girls Bucharest (2014). Erişim: http://railsgirls.com/bucharest.html, 29.07.2019.

Saebo O., Rose, J., ve Skiftenes Flak, L. (2008). The shape of eParticipation: Characterizing an emerging research area. Government Information Quarterly, 25(3): 400-428.

Syrian Telecentre Project (2015). Erişim: https://www.itu.int/en/ITU-D/DigitalInclusion/Women-and-Girls/Girls-in-ICT-Portal/Pages/events/2015/Arab-States/Syrian-ArabRepublic-2015.aspx, 29.07.2019

Tilly, C., (2008). Toplumsal Hareketler. Çev. O. Düz, İstanbul, Babil Yayınları.

TÜİK (2018). İstatistiki bölge birimleri sınıflaması düzey 1'e ve cinsiyete göre bireylerin bilgisayar kullanım oranı. Erişim: http://tuik.gov.tr/PreTablo.do?alt_id=1028, 05.06.2019.

TÜIKK (2019). Okuryazarlik ve cinsiyete göre nüfus 2008-2018, http://www.tuik.gov.tr/PreTablo.do?alt_id=1018

TÜIKK (2019a). Eğitim durumuna göre bilgiye erişim kaynakları, http://www.tuik.gov.tr/PreTablo.do?alt_id=1018

TÜİK (2019b). Bilgi Toplumu İstatistikleri, http://www.tuik.gov.tr/PreTablo.do?alt_id=1028

Uğraş, M. (2017). Okul öncesi öğretmenlerinin STEM uygulamalarına yönelik görüşleri. Ĕ̆itimde Yeni Yaklaşımlar Dergisi, 1(1): 39-54.

Van Deursen, A. ve Van Dijk, J. (2011). Internet skills and the digital divide. New media \& Society, 13(6): 893-911.

Vatandaş, C. (2007). Toplumsal cinsiyet ve cinsiyet rollerinin algılanışı. Sosyoloji Konferanslarl, (35): 29-56.

We Are Social, (2019). Digital in 2019. Erişim: https://wearesocial.com/global-digital-report2019, 06.06.2019.

Yıldırım, A. ve Şimşek, H. (2008). Sosyal Bilimlerde Nitel Araştırma Yöntemleri. Ankara: Seçkin Yayıncılık. 


\title{
GENDER INEQUALITY AND SPACE RELATIONSHIP IN MOVIES: MUSTANG MOVIE REVIEW
}

\section{Beste ÖZDAĞ $\breve{1}^{1}$}

\begin{abstract}
Mustang film directed by Deniz Gamze Ergüven. Film tells the story of the growth of five sisters. The film is very important in that it demonstrates how the dominant gender-based ethics in society transforms the female body into an object of fear. While the bodies of five teenage daughters are imprisoned for fear because of this fear, the story of the house depicted as the nest in in the majority narratives is transformed into prison, violence, oppression, harassment. In this study, it will be focused on the analysis of selected scenes of how to use the spaces in the representation of womanhood and masculinity with the close reading.
\end{abstract}

Keywords; Film, Masculinity, Space, Female Representation, Gender

\footnotetext{
${ }^{1}$ MA. Eastern Mediterranean University, Faculty of Communication, besteozdagg@ hotmail.com
} 


\section{FILMLERDEKI TOPLUMSAL CINSIYYT EŞITTSIZLİĞí VE MEKÂN ILIŞKİSİ: MUSTANG FILM INCELEMESI}

\section{$\ddot{O} z e t$}

Deniz Gamze Ergüven'in yönetmenliğini yaptı̆̆ Mustang filmi, beş kı kardeşin büyüme hikayesini anlatmaktadır. Toplumda hâkim toplumsal cinsiyet odaklı ahlak anlayışının kadın bedenini bir korku nesnesine nasıl dönüştürdüğünü göstermesi açısından film oldukça önemlidir.

Çocuk denecek yaşlardaki beş ergen genç kızın bedenleri bu korku sebebiyle eve hapsedilirken, çoğunluk anlatılarda 'yuva' olarak resmedilen 'ev'in bir hapishaneye, şiddetin, baskının, tacizin hüküm sürdüğü bir mekâna nasıl dönüştüğünü ele alınmaktadır.

Bu çalışmada yapılan yakın okuma ile kadınlı̆̆ın ve erkekliğin temsilinde mekânların nasıl kullanıldı̆̆ına seçilen sahnelerin analizi yapılarak odaklanılacaktır.

Anahtarkelimeler; Film, Erkeklik Temsili, Mekân, Kadın Temsili

\section{“Hakkında En Ufak Bir Kuşku Olsaydı İmkânı Yok Evlenemezdin Yavrum”}

Mustang ${ }^{1}, 10$ 'lu yaşlardaki beş kız kardeşin (Sonay, Selma, Ece, Nur ve Lale) yaşam mücadelesini anlatır. Çocuklar babaanne ve dayı ile Karadeniz'in bir köyünde yaşam sürerken, bu kız çocuklarının büyümesinin gerginliğine dayanamayan ebeveynler, yaşamı onlar için bir hapishaneye dönüştürür.

Film küçük bir kız kadına sarılırken açılır. Hüzünlü bir durum olduğu bellidir, çocuğun üzerinde okul kıyafetleri, elinde kitaplar. Kitap arasından bir kâğıt çıkartır, kâğıtta kadının ismi ve adresi bulunmaktadır. Film, daha sonra, olayları başlatacak sahneye geçer; küçük kız diğer kardeşlerinin yanına gider ve hep birlikte denize girerler. Kızlı-erkekli şakalaşıp oynarlar. Petek hanımın (komşuları) kızları denizde erkeklerin omuzlarında görmesi ile başlar bütün kâbus.

\footnotetext{
${ }^{1}$ Filmin yönetmeni Deniz Gamze Ergüven'dir. Ergüven, 1978 tarihinde Ankara'da doğup, Fıransa'da büyümüştür. 2002 de Fransa'nın en iyi sinema okullarından olan La Femis’te yönetmenlik üzerine eğitim aldı. Aynı zamanda Bir Damla su, Mon Trajet Prefere, Ondes film adları italik kısa filmlerini ve Liberabes Belgesel Filmini çekti. Deniz Gamze Ergüvenin, Mastang filmi, ilk uzun metrajlı filmi olmasına rağmen birçok ödülün de sahibidir.
} 
Kadın, çocukları babaannelerine şikâyet eder. Babaanne çocukları hırpalarken "el âleme rezil ettiniz bizi”, "Torunların kendilerini erkeklerin ensesinde tatmin ediyor dedi!" şeklinde konuşmalar yapar.

''Hakkında en ufak bir kuşku olsaydı imkânı yok evlenemezdin yavrum' diyor babaanne, kızlık zarı kontrolü dönüşü çocuklara. Evlenmeden kadının bekaretini kaybetmesinin toplum tarafından affedilemez bir şey olduğunu vurguluyor film bize. Bununla da kalmıyor, Selma evleniyor, evlendiği gece erkeğin anne/babası çarşaf istiyor. Damat telaşlı, çarşafa bakınıyor, kan yok. Doğruca hastaneye gidiliyor, çünkü bekaret önemli! Bekâretin, toplumsal cinsiyet rollerinin önemli olduğu ailede, ensest ilişki-taciz normal.

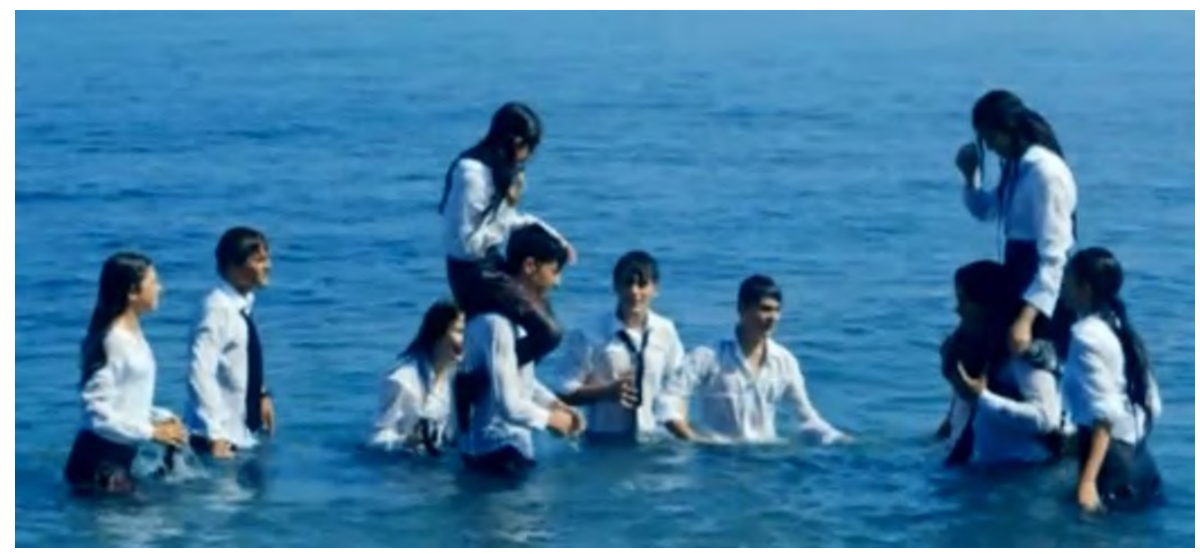

Fotoğraf $1^{1}$

\section{Basmakalıp Kadınlar}

En temele inip, okullarda kullanılan kıyafetlere bakacak olursak, tekdüze insan yaratma modelinin eğitim sisteminde başlamış olduğunu görmüş oluruz.

Ardiç'in de dediği gibi 'Eşitlik sağlıyoruz' palavranızın altında, 'biz herkesi tornadan çıkmış gibi, birörnek yetiştirmek istiyoruz hevesi yatıyor. Aykırı görüş, çatlak ses istemiyorsunuz, büyükleri olarak siz her şeyi çocuklardan daha iyi bilir ve onların yerine de düşünürsünüz. Buna 'faşizan' yaklaşım denir (Ardiç, 2002). Eğitim sisteminin en başında bir örnek insan modeli

\footnotetext{
${ }^{1}$ Sonay, Selma, Ece, Nur ve Lale arkadaşlarıyla denizde oynadıkları o sahne, filmin 3:31. Dakikasında çekilmiştir. (Ergüven, 2015)
} 
yaratmaya başlıyorlar. Aykırı sesleri birer birer bastırıp tek düze insan yaratarak kendi istedikleri gibi bir düzende yaşamaya zorluyorlar çocukları. Baskıcı düzenden zevk alıyorlar adeta.

Babaanne de eğitim sisteminin dayattığg düşünceyi benimsemiş, toplumsal baskılar ağır basmış olacak ki torunlarının yırtık pantolonlarını, baskılı tişörtlerini, makyaj malzemelerini, sakızları, telefonları, bilgisayarları toplar ve bir dolaba kilitler. Leyla'nın da filmde dediği gibi ‘'ahlakımızı bozabilecek her şey yasaklandı.' Kadın süslü olamaz, sakız çiğneyemez ve farklı elbiseler giyemez algısı oluşturuldu, basmakalıp kadınlar getirildi. Film bu düşüncenin baskın olduğunu desteklemek için, yemek sahnesinde arkadan bize, televizyonda Bülenç Arınç'1n Temmuz 2014'de yaptığı, ' 'kadın iffetli olacak, mahrem namahrem bilecek, herkesin içinde kahkaha atmayacak, bütün hareketlerinde cazibedar olmayacak ve iffetini koruyacak." konuşmasını dinlettirerek, sadece izlediğimiz bölgede değil toplumumuzda algının böyle olduğunu, bu şekilde vurgulamıştır.

“Ev bir anda içinden çıkamadığımız bir ev kadını fabrikası haline geldi”’ Önce hamur açmayı öğrendiler arkasından ince uzun, kalem gibi sarma sarmayı. Kadının rolü olduğuna inanılan roller öğretilmeye başlandı teker teker. Giydikleri renkli kıyafetler kalktı daha düz ve daha uzun kapalı elbiseler dikildi ve hepsine aynısı giydirildi. Bütün kadınlar aynıymış gibi. Ki zaten filmde de öyle, köydeki bütün kadınlar aynı, hiçbir aşırılık yok, küçücük bir renk farkı yok. Kadınlarda kahverengi, siyah, gri tonları ağırlıkta kullanılmış ve hepsine uzun basmakalıp elbiseler giydirilmiştir.

Filmde geçen bir diyalog bu düşünceyi pekiştirmemizi sağlıyor, Selma doktorla olan konuşmasını kız kardeşlerine anlatırken “kadının neye benzediğini senden öğrenmeyeceğim dedi, sonuçta haksız değil yani, hepimiz aynıyı'" der. Ailenin, içerisinde bulundukları toplumsal çevrenin ve aldıkları eğitimin de etkisiyle, kız ve erkek çocuklar cinsiyetlerine uygun roller kazanmakta ve toplumsal cinsiyet kimliğini edinmektedirler. Böylece kadınlar için ev 
işleri ile ilgilenip çocuk bakma gibi roller ortaya çıkarken erkekte evi geçindirme rolünün aktif olduğunu görüyoruz. (Zeynep ve Hasan 2012), Toplum kadını, aynılık duygusunu kabullenmesi gerektiğine itmiş ve kadınlar da bunu kabul etmiştir.

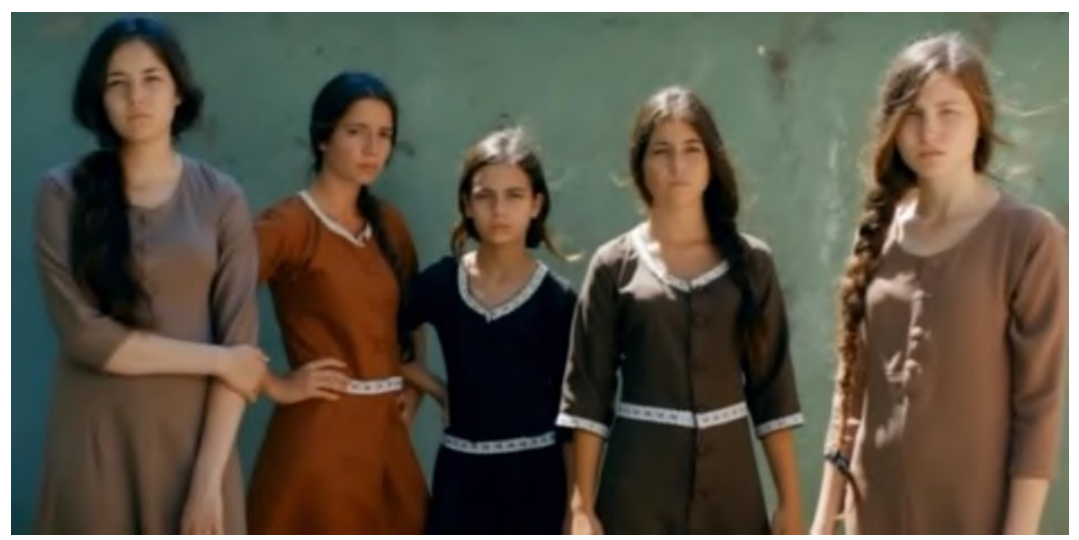

Fotoğraf $2^{1}$

\section{Aile İçi Taciz-Tecavüz, Ensest İlişkiler}

Bir gece Leyla kapı arasında amcasını görür, amcası karanlıkta yürür ve yan odaya geçer, kemer sesi ve ani bir korkma sesi duyarız. Bu ses, inleme sesiyle devam eder. Başka bir sahnede ise amca, Lale uyurken yan odadan çıkar, mutfağa girer. Lale sese uyanıp kalktığında mutfakta, babaannesinin amcasina; "Ne oluyor...? Ne oluyor...? Ne yapıyorsun?!"

‘ Buna artık bir son ver! Buna bir son ver. Anladın mı!’ dediğini duyarız. Lale yukarı ablasının yanına çıktığında ablası çarşafı temizlemektedir. Oda karanlık ve kadraj açısından dolayı çarşafta neyi temizlemeye çalıştığını göstermez bize yönetmen, panikle lekeyi saklar ve yatar pozisyon alır Nur.

Ortada ensest bir ilişki söz konusudur. Toplumumuzda yaşanan çoğu ensest ilişkide ya da aile içi taciz-tecavüzlerde, mağdurların ifadelerine bakıldığında, ailenin aslında bunu bildiği

\footnotetext{
${ }^{1}$ Selma, Ece, Lale, Nur, Sonay filmin 34:08 dakikası (Ergüven, 2015)
} 
ama sakladığı gözlemlenmektedir. Filmin bu sahnesinde yönetmen bize, toplumda olan durumu babaannenin üzerinden, 'bildiği halde sessiz kalan' olarak anlatmak istemiştir. Amcanın çocuklara uyguladığı taciz-tecavüz sahnesinde izleyiciye bunu açık açık göstermeyerek (taciz mi ediyor yoksa tecavüz mü ediyor bilmiyoruz) toplumda yaşanan bu tür aile içi taciz-tecavüz olaylarında medyadaki 'suskunluk sarmalı' teorisi vurgulamıştır. Suskunluk sarmalında kitle iletişim araçlarına örnek vermemiz gerekirse, egemen düşünceyi daha çok aktarırken azınlığa çok az yer vererek egemen düşünceye sahip kitlelerin çoğalmasına, azınlığın daha da azalmasına sebep olur. (Dural \& Coşkun, 2010) Azınlıkta olan insanlar bir süre sonra kendi düşüncelerinde kimsenin olmadığını görerek, seslerini hiç çıkartmamaya ve susmaya başlarlar. Tacizin medyada gösterilmemesi, tacize uğrayan insanların yavaş yavaş susmasına ve artık seslerini çıkartmamalarına sebep olmuştur.

\section{'Bugün Oğlumuzu Evlendirdik Çarşafı Göremedik...',}

TDK'da gelenek kelimesi iki anlamla açıklanmıştır. Birincisi, öteden beri yapılagelen şeyler, alışkanlıklar anlamında kullanılırken diğeri ise geçmiş ile olan bağlantı anlamında kullanılmaktadır.

Bir toplumda çok eskilerden kalmış ve kuşaklar arası aktarımı olan, günümüze uzanan kültürel adetlerdir. Her toplumun adetleri ve o adetlerin anlamları farklılık göstermektedir. Türk kültürünün de belli başlı gelenekleri vardır; bunlara örnek olarak, evlenecek olana ya da askere gidecek olana kına yakmak, geline yüz görümlüğü takmak, kırmızı kuşak bağlamak, gerdek gecesi çarşafın gösterilmesi ya da adak adamak gibi değişik adetler yer almaktadır.

Selma ile Sonay’ın kına gecesinin yapılması, düğ̈̈n öncesi ellerine kına yakılması kadının kedisini eşine adaması anlamında yapılan bir gelenektir. Düğünlerinde Selma ile Sonay’ın gelinliklerine bağlanan kırmızı kuşak, kadının bekaretinin olduğunu sembolize eder. Düğünden sonra Osman'ın babası kapıyı tıklatır ve 
‘'Osman bekliyoruz oğlum?’' diyerek çarşafı ister. Osman yatakta bir süre aranır, çarşafın sağına soluna bakar, annesi içeriden,

“oğlum, Osman çarşafı verir misin?”, diye baskı yapmaya devam ederler. Osman eşine kanın nerede olduğunu ve ailesine ne diyeceğini sorar panikle,

Selma 'valla bakireyim" diyerek cevap verse de soluğu hastanede alırlar. Osman'ın annesi personele, 'bugün oğlumuzu evlendirdik çarşafı göremedik' derken aslında olayın toplumda ne kadar normal olduğunun da vurgusunu yapmaktadır. Personel önce kadına daha sonra babanın belindeki silaha vurgu yaparak bize 'at avrat silah' üçlemesini hatırlatır.

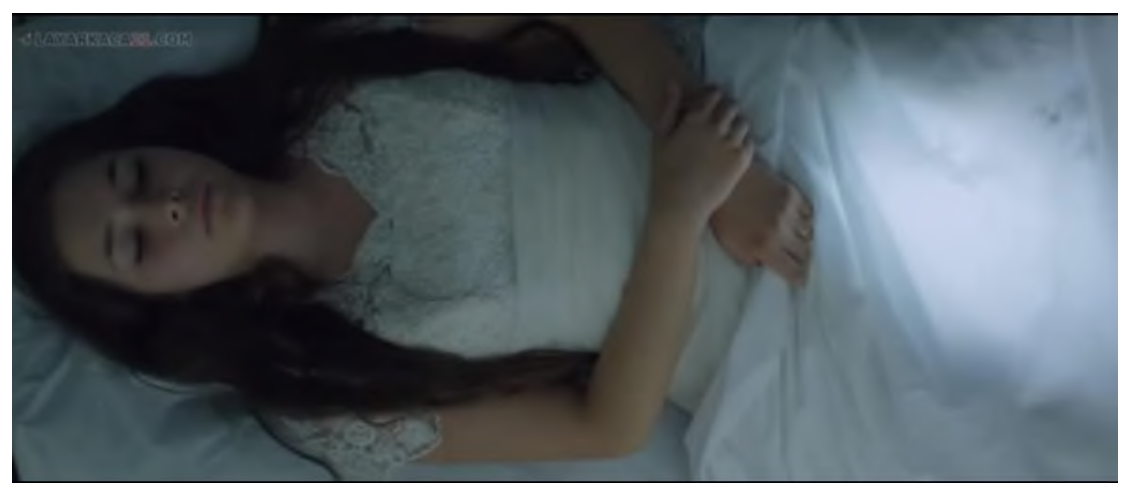

Fotoğraf $3^{1}$

Selma’nın doktor kontrolü sahnesinde, Selma yatağa yatar ve doktor ile birkaç diyalog kurar. Kamera tam tepeden Selma’yı bel plan almıştır. Ortalama iki dakika süren bu sahnede, sanki Selma mezardaymış gibi üzerindeki beyaz ise kefeni simgeler. Kasıtlı olarak rahatsız eden, izleyiciyi bunaltan bir sahne kullanılmıştır. Bu da Selma'nın ruh halini bize yansıtma şeklidir. Toplumsal baskıların bireylerdeki ruhsal sıkışmalara sebep olmasını yansıtır.

\footnotetext{
1 (0:48:47) Selma'nın doktor kontrolündeki bu plan 1 dakika 27saniye sürmektedir. (Ergüven, 2015)
} 


\section{İçlerinden Geldiği Gibi}

Mustang İngilizce bir kelime olup, Türkçesi “yabani at” anlamına gelmektedir. Yönetmen filmin ismini beş kız kardeş ile özdeşleştirmiş. Filmin başından beri asi, burunlarının dikine giden, ehlileştirilemeyen kız çocukları görüyoruz, yönetmen bize filmin ismiyle zaten büyük bir spoiler veriyor. Hem karakterleri ile hem de beşinin de beline kadar uzanan saçları ile yabani atı temsil ediyorlar.

Kapalı tekdüze giydirilen kıyafetleri yırtıp yırtmaç yapıyorlar, yasaklanan sakızı marmelat ile elde edip çiğnemeye devam ediyorlar ya da en küçük kardeşin maça olan ilgisi. Toplumda futbol erkekleri ilgilendiren bir spor dalı gibi algılanıyor. Küçük kız futbola ilgi duyuyor filmde ve amcasından Süper Lig'in çeyrek finalin maçına gitmek için izin istiyor fakat amcası "senin yerin statlarda erkeklerin yanı değil'" diyerek geri çeviriyor isteği. Statlar erkeklere verilen bir yermiş gibi bir algı olduğunu vurgularken film, çocukların kaçıp maça gidişiyle aslında orası sadece erkeklerin değil, kadınlarında gidebildiği bir yer mesajını çok güzel veriyor.

Sonay her şeye rağmen evden kaçıyor erkek arkadaşıyla gezip eve gizli gizli giriyor, evlendirmek istedikleri çocukla evlenmek yerine istediği kişiyle evlenmeyi seçiyor ya da Lale bir şekilde araba sürmeyi öğreniyor. Kendisi mücadele ediyor, inanıyor ve başarıyor. Selma düğün günü Lale ile birlikte evden kaçıp İstanbul'a gidiyor, kurtuluyor. Ehlileştirilemiyor yabani at gibi özgürlüklerine koşuyorlar.

Başka bir sahnede ise kardeşler odada birbirleriyle şakalaşır, ayakları bacakları iç içe geçmiş bir şekilde yatarlar kahkaha atarlar. $\mathrm{Bu}$ sahne köşe yazarları tarafından, 'kadını nesneleştiren bir sahne' olarak fazlaca eleştiri almıştır. Biz bu sahneye baktığımızda yönetmenin arada kalmışlığını da biraz hissederek, beş kız kardeşin hala çocuk olduğunu ve büyümediklerini, birlikte oyun oynayıp eğlendiklerini, masumluklarını doğallıklarını görürüz. Yabanilikleri toplumdan gelen baskılara, olmadıkları kalıba sokmaya çalışanlara karşıdır. 
Genel olarak baktığımız zaman, film bize beş kız kardeşin toplumsal baskılara karşı sergiledikleri direnci anlatmaktadır. Çocuklar yabani at misali, toplum onları ehlileştirmeye çalışıyor, ama onlar asıl olmaları gerektiği gibi, içlerinden geldiği gibi davranıyorlar.

\section{“Yuva'” Olarak Anlatılan 'Evin'” Hapishaneye Dönüşümü}

Toplumsal cinsiyet rollerinde, kadın ve erkek kimlikleri açısından simgesel olarak anlamlandırdıkları incelendiğinde, “ev içi” dış mekân ile ev içi arasında bir ara mekân olan, demir parmaklıklı bahçe ve kamusal alan olan 'dış mekânlar”' incelendiğinde, “ev içi'” kadın mekânı, “güvenli alan’ gibi gösterilirken, erkeklerin alanının kısıtlanmadığı vurgulanmıştır. Filmin çoğunluğu ev içerisinde geçmektedir.

Literatüre baktığımız zaman, kadın kimliği, ev içerisindeki ailenin bütünlüğünü ve devamlılığını koruma sorumluluğunu kocasından devralma yönü başta olmak üzere farklı biçimlerde de karşımıza çıkar. Kadının evdeki işlevi, ev dışından aileye gelebilecek tehlikeler karşısında erkeğe yardım etmek, kocasının ya da ev içindeki erkeğin evden uzak kaldığı zaman dilimlerinde iffet ve namusu aile bütünlüğ̈̈n̈̈ koruyan olarak gösterilir. (ÖLÇER, 2003). Filme döndüğümüzde babaanne olan kadının görevi, beş kız kardeşin namusunu korumak ve onların iffeti zedelenmeden evlendirmektir. 


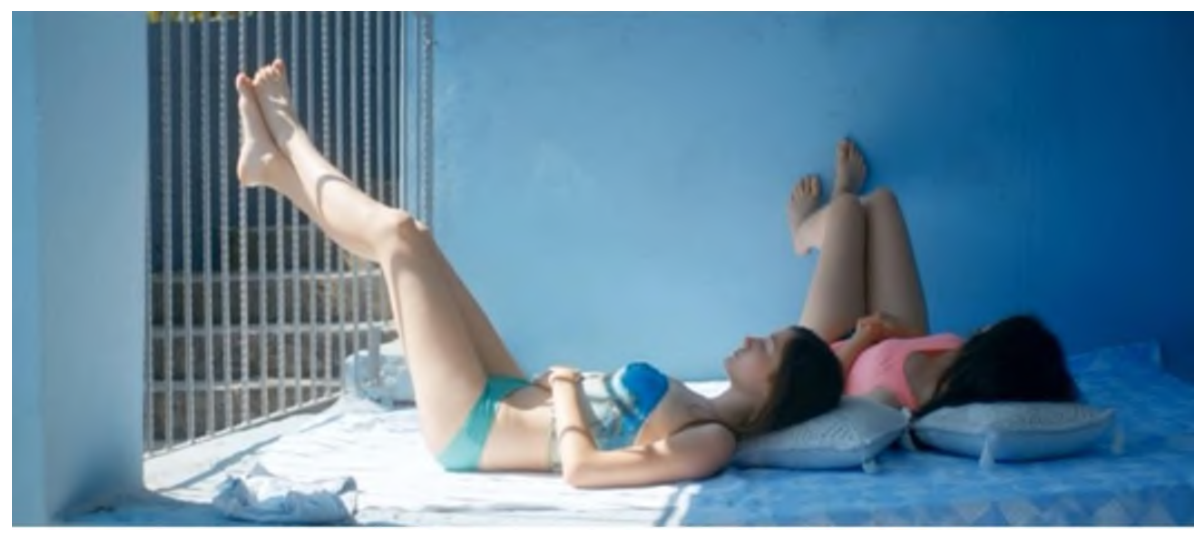

Fotoğraf $4^{1}$

\section{İçeri ile Dışarı Arasındaki}

Ara mekân ya da eşik mekân karşımıza çok sık çıkmayan bir kavram olsa da kamusal alan ile özel alanın arasında kalan ayrı bir yer, ayrı bir alan olarak ele anılır. Bu mekânlar ev içi ve dış dünya arasındaki yerler olarak nitelendirilir (Ölçer Özünel, 2006). Bu ara mekânlar bazen pencere bazen bahçe bazen ise veranda olarak görülebilir ve bu alanlar bir geçiş işlevi görebilir (Yetkiner, 2014). Bizim filmimizde yer alan ara mekânlar, pencere ve evin bahçesi olacaktır.

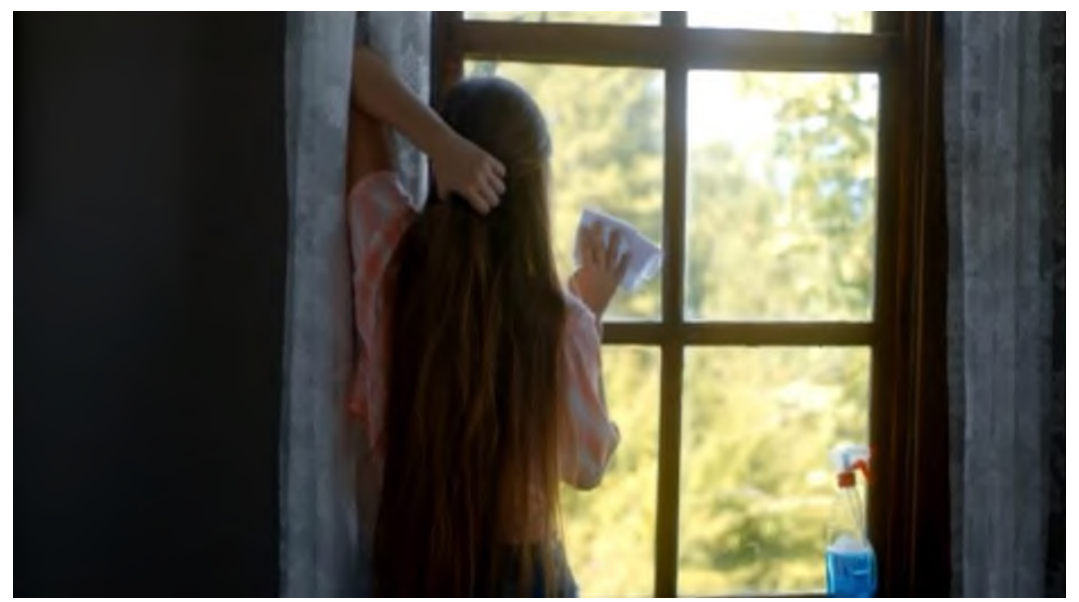

Fotoğraf $5^{2}$

${ }^{1}(0: 34: 44)$ Sonay ve Selma verandada demir parmaklıkların önünde güneşlenmektedirler.

2 (0:16:50) Sonay pencere önünde erkek arkadaşıyla bakışırken çekilen bir fotoğraf karesi. (Ergüven, 2015) 
Filmde çocukları çoğunlukla pencere önünde dışarı gözetleyen, izleyen olarak görürüz. Yanında erkek olmadan, çoğunlukla bu ya eş ya da amca olan erkek, dışarıya çıkamayan ve dışarısı ile bağını pencere önünde sürdürebilen bireyleri görmekteyiz. Bu pencere onlar için bazen evden kaçış, özgürlük bazen umut olarak bize yansıtılmaktadır. Sonay sevdiği kişi ile uzun uzun pencere önünde bakışır, Ece gece evden kaçıp başkalarıyla buluşmak için yine pencereyi kullanır. En küçük kardeş olan Lale için pencere daha çok özgürlük arayışına çıkan bir ara mekândır. Çünkü Lale çoğu zaman araba kullanmayı öğrenebilmek için pencereden kaçar. Daha sonra camlara demir parmaklıklar takılır. "Görsel bir motif olarak "demir parmaklıkların ardında olmak", tüm yan anlamlarıyla birlikte (kıstırılmışlık, kapatılmışlık, çaresizlik vs.) dış dünyaya ait, ya da belki dışarıdaki hayatın da bir tür "içeridelik" olduğunu imleyen bir öğe olarak kullanılır’' (Uzunali, 2015).

Görkem’in mekân araştırmasında vurguladığı “demir parmaklıkların ardında olmak” gibi, yönetmen filmdeki karakterleri, kıyafetleri dikilirken, gelinlikleri giydirilirken genellikle demirli pencere önüne konumlandırmış. Demir parmaklıkları olan pencereleri devamlı göstererek onların tutsaklığını, çaresizliğini anlatan bir motif kullanmıştır.

\section{Sonuç}

Kadını ön planda tutan nadir filmlerden bir tanesi olmakla birlikte, Türkiye'deki toplumsal baskılara, çocuk gelinlere, okutulmayan kız çocuklarına ve aile içi taciz-tecavüzün bastırılmasına büyük derecede ayna tutan, yönetmenin hayatından ve çevresinde yaşananlardan alıntıladığı, toplumda çocukların çocuk olarak değil de inatla kadın olarak gösterildiğini vurgulayan bir filmdir. Kadın ve erkeğe dayatılan toplumsal cinsiyet normlarını her firsatta bize gösterse de karakterlerin “topluma aykırı davranışları”, ile asıl gerçeği sorgulamamıza da yardımcı olmaktadır. 
Filmin çekim açılarına baktığımız zaman, genellikle yakın plan tercih edilip aktüel kamera kullanımı söz konusu olmuştur. Bu da film ile izleyiciyi özdeşleştirmeyi hedefleyen çekim yöntemidir. Kamera ‘erkeğin gözü’ olarak kullanılmamış, genellikle beş kız kardeşi takibe alan, izleyiciyi onların hayatını gözetleyen konumuna koymaktadır. Tekrar filmdeki mekânlara bakacak olursak, kadınlar çoğunlukla ev içi mekânlarda, yemek yaparken veya temizlik yaparken gösterilirken, kaçarak da olsa ev dışına çıktıklarını. Lale'nin maç sevgisi ile stada kaçmaları ya da araba sürmeyi öğrenmek için kamyona binip kamyon sürmesi yani sadece erkeklere ait gibi gösterilen kamusal alanda da bulunabileceklerini bizlere göstererek, kadın mekânlarının sadece ev olmadığını, kadınların aslında her yerde olabileceklerini vurgulamış oluyor.

Çoğunlukla demir parmaklıkları göstererek karakterlerin iç dünyalarındaki sıkışmışlık, esir olmuşluk, çaresizlik hislerini izleyiciye yansıtmıştır. Genel olarak filme bakacak olursak, dayatılan baskıyı kabul eden ile kabul etmeyen çocukların sonunun farklı olduğunu, görücü usulü evlenip, pasif kalan bireyin mutsuzluğu ile karşı çıkıp evden kaçarak hapishane hayatına son veren bireylerin yaşadığı özgürlük hazzını görmekteyiz.

\section{Kaynaklar}

Ardiç, E. (2002). Efendiler Buna Reform Denir.

Dural, A., \& Çoşkun, L. (2010). Medya, Görüngünün Dişavurumu. Trakya Üniversitesi Sosyal Bilimler Dergisi, 24-25.

Ergüven, D. G. (Yöneten). (2015). Mustang [Sinema Filmi]. https://www.youtube.com/watch?v=hPppc2VGn8Q adresinden alınd 1

Gürkan, H., \& Arus, Z. (2012). Toplumsal Cinsiyet Ve Sinemaya Yansimasi: Yeniden Çekimler Araciliğiyla Japon Ve Amerikan Sinemalarinda Kadinin Temsiline Bir Bakiş. Selçuk Ünv. İletişim Fakültesi Akademik Dergi, 206-217.

Ölçer Özünel, E. (2006). Masal Mekânında Kadın Olmak. Ankara: Geleneksel Yayıncılık.

Ölçer, E. (2003, Haziran). Türkiye Masallarinda Toplumsal Cinsiyet Ve Mekân İlişskisi. Ankara. 10 5, 2019 tarihinde http://hdl.handle.net/11693/29269 adresinden alınd1 
Uzunali, G. (2015). Zeki Demirkubuz Sinemasında Mekân Kullanımı. Hacettepe Üniversitesi Sosyal Bilimler Enstitüsü. Ankara. HÜAES: http://hdl.handle.net/11655/1526 adresinden alınd1.

www.biyografi.net.tr. (tarih yok). $11 \quad 2018$ tarihinde biyografi: https://www.biyografi.net.tr/deniz-gamze-erguven-kimdir/ adresinden alınd1

Yetkiner, B. (2014). Mine Filminde Yeni Bir Hayata Geçişte Ara Mekân'in Temsili. 2. Gümüşhane: Gümüşhane Üniversitesi İletişim Fakültesi Elektronik Dergisi. 


\title{
TURKEY'S PERSPECTIVE OF INTERNATIONAL FEMALE TRAVELERS
}

\author{
Faruk ALAEDDINOĞLU ${ }^{1}$ \\ Nuray TÜRKER ${ }^{2}$ \\ Avşin Ayhan KAYA ${ }^{3}$
}

\begin{abstract}
The social, cultural, economic and environmental factors that people live in make them different from each other, which in return cause differences in their behaviors. One of the factors that people have different preferences is the gender factor. The subject of female travelers, which has started with modern tourism, and has become increasingly popular recently, has become a subject that scientists are increasingly interested in. As for the academic level, considering female travelers on sectoral basis, tourism businesses and tourism destinations in a larger scale have made many differences.
\end{abstract}

To study female travelers in many different points of the world, a study on GGT (Girlfriend Getaway Tourism) has been done. Within the scope of this study, answers to the questions of the development of the female travelers in the world and why the trend has increased have been examined. Furthermore, the study examined whether if there are destinations or if there are practices of this tourism in Turkey; and if it is not found, then reasons and applicability of not having it are highlighted. As Turkey is a diverse country with international standards in tourism, female travelers' tourism is an alternative tourism in Turkey which can be applied in many tourism destinations in Turkey. The fact that women's status in societies has changed all over the world and they can freely decide on their vacations, has made women an important customer in many markets. This is a development that bonds women to a society rather than separates them from it, and shows that women are in a good position of the community. Adapting to this type of tourism, which is constantly evolving and increasing day by day, needs significant efforts to be open to innovations. Thus, all positive new approaches to tourism experienced professionals in Turkey are of great importance as they will contribute to the tourism sector such introducing the necessary arrangements to spread the tourism of female travelers. The research showed that female travelers have become increasingly common throughout the world while female travelers phenomena in Turkey has not been researched enough. Tourism businesses don't enter such new trends in Turkey, but international tour companies in Turkish market, especially in Istanbul, understand the need to include such a new program.

Keywords: Female Travelers, Special Interest Tourism, Niche Market, Accommodation Business

\footnotetext{
${ }^{1}$ Prof. Dr. Van YuzuncuY1l University, The Faculty of Literature, Department of Geography, Van, Turkey alaeddinoglu@yyu.edu.tr

${ }^{2}$ Assoc. Prof. Dr., Faculty of Economics and Administrative Sciences, Karabuk University, Karabuk, Turkey nturker@karabuk.edu.tr

${ }^{3}$ Graduate Student, Van Yuzuncu Yil University, School of Tourism and Hotel Management, Van,Turkey avsinayhan@gmail.com
} 


\section{DÜNYADA KADIN KADINA SEYAHAT VE TÜRKIYY'YE YANSIMALARI}

\section{$\ddot{O} z e t$}

Özel ilgi turizminde yaşanan gelişmeler, değişen talep ve beklentiler turizm sektörünün tamamında yeni yaklaşımları zorunlu kılmıştır. Zira insanların içinde yaşadı̆̆̆, sosyal, kültürel, ekonomik ve çevresel faktörler onları birbirinden farklı kılmakta dolayısıyla davranışlarında da farklılıklar meydana getirmektedir. Insanların farkl tercihlere sahip olmalarında belirleyici değişkenlerden bir tanesi de cinsiyet faktörüdür. Özellikle modern turizmle başlayan ve günümüzde sayıları giderek artan kadın gezginler konusu bilim insanlarının üzerinde giderek daha fazla araştırma yaptıkları bir konu haline gelmiştir. Akademik düzeyde olduğu gibi sektörel bazda da kadın gezginler dikkate alınmış ve bu konuda turizm işletmeleri ve daha büyük ölçekte turizme konu olan destinasyonlar birçok farklıliğa gitmişlerdir.

Bu bă̆lamda çalışmada ilk olarak Dünyanın birçok farklı noktasında gelişim gösteren kadın kadına seyahat konusu GGT (Girlfriend Getaway Tourism) incelenmiştir. Söz konusu inceleme kapsamında kadın kadına seyahatin dünya da ki gelişimi ve trendin neden arttı̆ sorularına cevaplar aranmıştır. Ayrıca, çalışmada Türkiye de bulunan destinasyonlarda veya seyahat işletmelerinde bu konu ile ilgili uygulamalar olup olmadiğl, uygulanmıyorsa nedenleri ve uygulanabilirliği üzerinde de durulmuştur. Zira Türkiye turizm konusunda çok çeşitliliğe ve uluslararası standartlara sahip bir ülkedir. Bu nedenle kadın kadına turizmin, Türkiye'nin birçok turizm destinasyonunda uygulanabilecek alternatif bir turizm çeşidi olacağı söylenebilir. Kadınların toplumdaki statülerinin tüm dünyada değişmesi ve özgürce seyahat kararı alabilmeleri kadınları birçok pazarda odak noktası haline getirmiştir. Bu durum kadınları toplumdan ayrıştıran değil daha çok birleştiren ve kadınların iyi bir konumda olduklarını gösteren bir gelişmedir. Sürekli gelişim gösteren ve her geçen gün artan bu turizm çeşidine uyum sağlamak aynı zamanda yeniliklere açık olma noktasında da önemli katkılar sunmaktadır. Dolayısıyla, turizmde yaşanan bütün olumlu yeni yaklaşımlar Türkiye turizmi açısından büyük önem arz ettiği gibi, kadın kadına seyahat turizminin de yaygınlaşması için gerekli sektörel düzenlemelerin yapılması Türkiye turizmine katkı sunacaktır.

Yapılan araştırmalar neticesinde kadın kadına seyahatin dünya genelinde giderek yaygınlaştı̆̆ oysa Türkiye'de bu konuda henüz yeterli çalışmanın yapılmadı̆̆ görülmüştür. Türkiye'deki turizm işletmeleri söz konusu trend konusunda her hangi bir yapılanmaya gitmedikleri ancak uluslararası tur şirketlerinin Türkiye pazarını ve özelde de İstanbul'u yeni yeni programlarına dahil ettikleri anlaşılmaktadır.

Anahtar Sözcükler: Kadın Turistler, Özel İlgi Turizmi, Niş Pazar, Konaklama İşletmeleri,

\section{Giriş}

Geçmişten günümüze sosyal, ekonomik, kültürel ve politik yaşamın içinde yer alan kadınlar, bazı dönemlerde yaşamın ve yaratılan düzenin bizzat belirleyicisi olmuşlardır. Ancak 
bölgeden bölgeye ve zamana göre değişen bu durum birçok gelgitler yaşasa da çoğunlukla kadınların lehine gelişmelerle sonuçlanmıştır. Diğer bir ifadeyle kadınlara yüklenen anlamlar değişmiş ve varoluştan günümüze temel haklar konusunda önemli gelişmeler sağlanmıştır. Şüphesiz bu iyileşmelerin birçok nedeni olsa da en önemlisi kadınların tarihin her döneminde var olmak için verdikleri mücadelelerdir. Bununla birlikte kadınların hak ve özgürlükler noktasında en önemli kazanımları sanayi ve modern çağın yarattığı yeni dünya düzeninde olmuştur. Bu yeni süreç, kadınların yeni talep ve beklentilerle ortaya çıkmasına, eşit ve adil bir dünya yaratılmasına fırsat sunmuştur. Bu nedenledir ki, birçok sektör kadınları desteklemiş ve çoğu zaman da araştırmaya konu etmiştir.

Turizm sektörü de insanların kişisel talep ve beklentilerine önem veren bir sektör olduğundan, yeniliklere de açıktır. Bu yenilikleri takip eden işletmeler sürekli bir gelişim göstererek çağın gerisinde kalmamaktadırlar. $\mathrm{Bu}$ nedenle kadınların toplumun temel yapı taşlarından biri olduğu gerçeğinin farkında olan işletmeler kadınlara yönelik farklılaştırmalara yönelmişlerdir. Bu farklılıklardan bir tanesi de girlfriend getaways yani kadın kadına seyahattir. Günden güne artış gösteren bu trend, kişisel zevk ve isteklere saygılı olmanın yolunun aynı zamanda farklılıklara saygı göstermekten geçmekte olduğunu göstermektedir. Kadınların toplumdaki statülerinde meydana gelen maddi manevi her değişim onları turistik faaliyetlere daha da bağımlı hale getirmektedir. Çalışma hayatında aktif yer alan veya kadınların kişisel özgürlüğüne önem veren kişiler farklı ihtiyaçlarla farklı turizm alternatiflerine yönelmektedirler. Bu bağlamda çalışmada dünyanın farklı yerlerinde gerçekleştirilen turizm faaliyeti olan kadın kadına seyahat bir diğer adıyla kız kıza seyahat incelenmiş ve Türkiye’ye olan etkileri üzerinde araştırmalar yapılmıştır. 


\section{Literatür Araştırması}

\section{Geçmişten Günümüze Dünya'da Kadın Kadına seyahat}

Kadınlara yönelik ayrımcılık uygarlık tarihi kadar eskidir. Kadınlar geçmişten günümüze kadar dünyanın farklı yerlerinde de olsa sömürüye, şiddete, ötekileştirilmeye, taciz ve tecavüze maruz bırakılmışlardır. Kadının yeri sürekli olarak ev yani özel alan olarak konumlandırılmış, kadınların kamusal alanda ki varlığı kabul görmemiştir. Ancak, 18. ve 19. Yüzyıllar arasında sanayi devriminin gerçekleşmesi için yalnızca erkek gücü üretime katılımı yeterli olmamış ve kadın-çocuk iş gücünden faydalanılmaya başlanmıştır. Bu başlangıç kadınlar ve erkekler arasında ki eşitliği tam anlamıyla yaratamasa da kadını özel alanla sınırlı tutmaktan çıkarmış, kamusal alana yönlendirmiştir. Bu dönemde kadın erkek arasında eşit iş gücü düşük (farklı) maaş uygulamaları kadınları bir başkaldırıya itmiş ve böylelikle kadın mücadelesi gündeme gelmeye başlamıştır. Bu süreç yalnızca kadınların iş hayatında var olmasının önünü açmamış aynı zamanda sosyal, kültürel, politik ve eğlenceye dönük alanlarda da kendine has yaklaşımların gelişmesine neden olmuştur. Bu alanlardan biri de turizm sektörüdür.

Çağdaş Batı toplumlarında, turizm günden güne daha fazla kadının boş zaman geçirdiği önemli bir sektör olarak tanımlanmaktadır (Ürdün ve Gibson'dan aktaran Heather vd. 2012: 40). Kadınların çalışma hayatında aktif yer almaya başlamasıyla ortaya çıkan seyahat etme ve tatil ihtiyacı turizm sektöründe yeni bir pazarın açılmasında neden olmuştur. Kadınların, kadın kadına seyahat etme arzularına yanıt veren bu pazar girlfriend getaways adını taşımaktadır. Kadın kadına kaçamak olarak adlandırılan girlfriend getaways'i Balneg kadınların birlikte gerçekleştirdikleri günden güne artış gösteren bir turizm trendi olarak tanımlamaktadır”(Balneg 2010' dan aktaran Heather vd. 2012:38). Kadın kadına seyahat turizm endüstrisinde 2000'li yıllarda ortaya çıkmış ve popülerlik kazanmaya başlamıştır (Mirehie vd. 2018: 2). Bu turizm pazarı aynı zamanda, günümüzde popülerlik göstermeye başlayan aynı cinsiyetten oluşan kişilerin grup seyahatlerini (Burns 2014'den aktaran Khoo-Lattimore vd. 2018: 2), özellikle de 
başka kadınlarla seyahat eden kadınları hedef alan bir pazardır (Bond 2017'den aktaran KhooLattimore vd. 2018: 2 ) . Bu pazar turizm sektöründe günden güne önem kazanmakta ve dikkat çekmektedir. Girlfriend getaway hemen hemen her turistik destinasyonda gerçekleştirilebilecek faaliyetleri içeriyor olsa da özelinde kadın temalı olduğu için önem arz etmektedir. Bu durum kadınların turizm sektörü için ne denli önemli olduğunun göstergesidir.

\section{Kadın Kadına Seyahat'in Özellikleri}

Kadın gezginlerin motivasyonları üzerine yapılan araştırmalar birçok niş pazarı ortaya çıkarmıştır (Khoo-Lattimore vd. 2018: 8). Kadın kadına gerçekleştirilen seyahatler ihtiyaçlara göre farklı değişkenlere dayanmaktadır. Bu seyahatler arkadaşlıkların sürdürülmesi amacıyla, kadınların yaşamlarında bir noktadan başka bir noktaya geçmelerinde veya özel gün kutlamalarında gerçekleştirdikleri bir turizm faaliyeti olarak örneklenebilir (Heather vd. 2012: 38). Kadınların farklı talep ve beklentileri girlfriend getaway turistik faaliyetinin içeriğini etkilemektedir. Bu etkinliğin gerçekleştirilebilmesi için en az iki kadının olması gerekmektedir. Kadın kadına seyahatler kadın aile üyeleri, arkadaşlar, akrabalar, spor takımları üyeleri veya diğer kadın tanıdıklar ile birlikte özgürlük, rahatlama veya eğlence amacıyla gerçekleştirilebilmektedir (Gibson vd. 2012'den aktaran Mirehie vd. 2018: 4). Yorio kadınların gerçekleştirdikleri bu turistik faaliyetlerin etkilerini şu başlıklar altında toplamaktadır:

- Arkadaşlar sizi sağlıklı tutar.

- Kaybettiğiniz benliğinizi yeniden bulabilirsiniz.

- Hayatınızda ki dönüm noktalarını ölümsüzleştirebilirsiniz.

- Yeni deneyimler sizi daha da yakınlaştırır.

- Sizin için ücretsiz bir terapi olabilir.

- Yeni geleneklere ihtiyacinız olabilir.

- Daha fazla sevgi ile evinize dönebilirsiniz (Yorio,2010:1)

Gibson ve Yiannakis (2002) turistlerin tarzlarının veya rollerinin çeşitli sosyo-psikolojik gereksinimlerle ve farklı yaşam evreleri ile bağlantılı olduğunu ifade etmiştir (Gibson vd. 'den aktaran Gibson vd. 2012:38). Kadın kadına seyahatin de bu motivasyonlara bağlı olarak 
değişkenlik gösterdiği söylenebilir. Sosyal yaşamlarında ki durumları, iş yaşantısında ki konumları, yaşları vb. değişkenler kadın kadına seyahatin içeriğini etkilemektedir. Kadın kadına seyahat AAA Worldwide Travel'a göre 6 milyar dolarlık bir pazardır ve yalnızca kadın gruplarına hizmet veren şirketler 2001 'den bu yana yüzde 230 oranında artış kaydetmiştir (Yorio, 2010:1). Bu turizm’den gelir sağlayan ülkeler için önemli bir orandır.

\section{Kadın Kadına Seyahat'in Dünyadaki Örnekleri}

Girlfriend getaway dünyanın birçok yerinde gerçekleştirilen veya gerçekleştirilebilecek çok kapsamlı bir turizm etkinliğidir. Kadınların talep ve beklentilerine göre değişkenlik gösteren bir içeriğe sahip olan GGT, esnek yapısından dolayı turizm sektörü için önemli bir pazardır. Dünya genelinde birçok otel, tur ve gemi şirketlerinin bu kapsamda turistik faaliyetler gerçekleştirdikleri görülmektedir.

\section{Oteller}

Loews World's Largest Girlfriends Getaway, Miami Beach: Kadın kadına seyahatte otelin sunduğu hizmetler yoga, kokteyl, disko, havuz başında seçkin tatlı ve içecek ikramları, Miami de ki bazı gece kulüplerine VIP giriş (www.loewshotels.com [03.10.2019]).

Beaches Turks \& Caicos Resort Villages\&Spa: Kokteyl partisi, gün batımında yelken turu, plaj yogası, dans dersleri, ateş başında eğlence imkanı sunmaktadır (Yorio, 2010).

Grand Wailea Resort Hotel and Spa, Hawaii: Spa, Humuhumunukunukuapua'da dört çeşit akşam yemeği, misafirlerin tercih ettiği bir gece için şarap tadımı, bir milyon dolarlık değerli pırlanta ve nadir bulunan değerli taşlardan yapılan atölyeler (www.fivestaralliance.com[03.10.2019]). 


\section{Tur Şirketleri}

- Travels Girl Getaways

- A world to Travel

- The Girls Trip

- Girl Time Getaways

- Travel Right

- Cruise West Chester

- Southern Living

\section{Gemi Turlart}

- Celebrity Cruises: Bizimle ne kadar uzaklaşırsanız, kız arkadaşlarınızla o kadar yakınlaşırsınız. Ödüllü gemilerimizle dünyanın dört bir yanındaki 280'den fazla destinasyona yelken açıyor ve 160 geceden fazla konaklama imkanı sunuyoruz. Bir hafta sonu kaçamağı için kız arkadaşlarınızla örneğin Karayiplere kaçın, Akdeniz'de şaraplarınızı yudumlayın, Alaska'nın engebeli doğal güzelliklerini içinize çekin. Kadın kadına bir kaçamak için sizleri nereye götürebileceğimiz konusunda bir sınırımız yok (www.celebritycruises.com[01.09.2019]).

- Holland America Cruise: 3 günlük kız kıza seyahat içermektedir. İçeriğinde Sailaway’e kaçış, Oprah Magazin direktörü Oprah Winfrey ile sohbet, Adam Glassman ile seyahat esnasında nasıl giyinilmesi gerektiğine yönelik bir çalışma yer almaktadır (www.hollanda merica.com [28.08.2019]).

- Cruise Westchester: Mevsime göre değişkenlik gösteren seçeneklere sahiptir. Bu seçenekler Karayipler, Meksika Rivierası, Alaska, Avrupa ve Güney Amerika gibi destinasyonlardır. Kendinizi şımartmak için spa’yı ziyaret edip aroma terapi, İsveç masajı, deniz yosunu yüz masajı gibi egzotik şeyler deneyebilirsiniz. Alışverişsiz yapamayanlardansanız denizde alışveriş yapabilirsiniz. Kadın kadına sahne şovlarına, tiyatrolara, kumarhanelere ve barlara gidip eğlenebilir, dinlenmeyi tercih ediyorsanız da kütüphanede kitap okuyabilirsiniz (http://www.cruisewestchester.com[03.09.2019]).

\section{Kadın Kadına Seyahat'in Türkiye Örnekleri}

Travels Girls Gateaways kadın kadına seyahat turlarına her geçen gün yenisini eklemektedir. Şirket Ekim ayında Türkiye'ye bir tur düzenlemeyi planlamaktadır. Tur'un içeriği şunlardan oluşmaktadır: 8 gece 7 gün konaklama, İstanbul ve Kapadokya gezisi, 5 yıldızlı otel konaklaması, Sultanahmet Camii, Ayasofya Müzesi, Yerebatan Sarnıcı ve Topkapı 
Sarayı'nı keşfederek tam gün rehberli İstanbul turu, bir nehir gezisinde şehri sudan görüntüleme, geleneksel bir Türk hamamı, Kapalıçarşı'da mağaza gezisi, Ürgüp, Paşabağları, Devrent Vadisi, Aşk Vadisi ve Uçhisar Kalesi gibi Kapadokya'nın ünlü turistik mekânlarına rehberli turlar, gündoğumunda ise sıcak hava balonu yolculuğu (isteğe bağlı) (getaways.wearetravelgirls.com [03.10.2019]).

My Girlfriend Guide Zürih 2015 yılında İstanbul'a kadın kadına tur düzenlemiştir. Tur, tarihi İstanbul gezisi, Türk Hava Yolları ile business class uçuş, baklava yemek, lüks otel konaklaması ve alışveriş yapmayı içermektedir. (myfriendguide.com [03.10.2019]).

Girl on Travel'ın İstanbul'a gerçekleştirdiği turun içeriği, Sultanahmet Camii, Ayasofya Müzesi ve Kapalıçarşı ziyareti, Türk mutfağı deneyimleme, Türk hamamında rahatlama, Bosphorus'da gece turu ve dans gösterisi, Topkapı Sarayı gezisinden oluşturmaktadır (www.girlsontravel.co.uk [03.10.2019]).

\section{Metodoloji}

Araştırmanın konusu genellikle metropol kentlerde ve turistik cazibe merkezlerinde gelişen kadın kadına seyahat olmuştur. Bu bağlamda konu ile ilgili literatür incelenmiş ve ilgili bilimsel çalışmaların sınırlı olduğu gözlemlenmiştir. Bu nedenle konu ile ilgili bilgi edinmek adına başka yollara başvurulmuştur. Söz konusu alanda faaliyet gösteren otel ve tur şirketlerinin kendi internet sitelerinden bilgiler derlenmiş ve kadın kadına seyahat konusunun Türkiye yansımalarının yol açacağı etkiler SWOT analizi ile incelenmiştir.

\section{Kadın Kadına Seyahat Konusunun Türkiye Yansımalarının SWOT Analizi}

Kadın kadına seyahatin Türkiye'ye yansımaları konusunda geç̧ekleştirilen Swot analizi sonucunda aşağıdaki bilgiler bir araya getirilmiştir. 


\section{Güçlü Yanlar}

- Türkiye turizm çeşitliliği anlamında zengin bir potansiyele sahiptir.

- Misafirperver bir ülkedir.

- Kadınlar için geniş alışveriş imkanları sunmaktadır.

- Kadın kadına seyahat henüz Türkiye'de yaygın olmamasından ötürü güncelliğini korumaktadir.

\section{Zaylf Yanlar}

- Türkiye kimi kesimlerce Ortadoğu ülkesi olarak görülmektedir.

- Ülkeye yalnız başına seyahat eden bazı kadın turistlerin yaşadıkları talihsizlikler kötü imaj yaratmaktadir.

- Kadın kadına seyahat, henüz Türk seyahat acenteları tarafından gerçekleştirilmemektedir.

- Literatürde Türkiye'den başka ülkelere profesyonel olarak gerçekleştirilen kadın kadına seyahatlere rastlanmamıştır.

- Türkiye'de bilinirliğinin az olması.

\section{Firsatlar}

- Türkiye'de bu turizm çeşidinin yaygınlaştırılması turizmden daha fazla ekonomik kazanç elde edilmesine neden olacaktır.

- Kadınlar konusunda turizmde hep geri planda olduğu düşünülen ülkemizin konu ile ilgili yaratılan imaj değişecektir.

- Kadın kadına seyahatin Türkiye'de artış göstermesi turizm anlamında yeni bir niş pazar oluşturacaktır.

- Şu an bu konseptte özellikle İstanbul'a turlar düzenleniyor olması bir firsattır.

- Lüks turizm çeşidi olarak görülmesinden ötürü önemli döviz getirici etkisi olacaktır.

\section{Tehditler}

- Ülkemizde gerçekleştirilecek kadın kadına seyahatler ne yazık ki bazı bölgeler için henüz tam anlamda güvenilirlik sağlamamaktadır.

- Henüz Türk tur şirketlerince bu faaliyetlerin yapılmıyor olması.

- Türkiye'nin belirli illeriyle sinırlı olması.

- Türkiye'de kadınların turizm sektöründe henüz tam anlamıyla niş bir pazar olarak görülmemesi.

\section{Sonuç}

Kadın kadına seyahat faaliyeti turizm için yeni bir niş pazardır. Bu pazarı kendileri için firsata çeviren otel ve tur şirketlerinin sayısı her geçen gün artış göstermektedir. Bu artış turizm 
pazarlamasında önemli bir değişken olan cinsiyet faktörünün önemini ortaya koymuş bu nedenle de yeniliklerin takipçisi olan tur şirketleri ve oteller bu durumu kendileri için fursata çevirmişlerdir. Kadınların yalnız başına seyahatlerinde gözlemlenen artış turizm sektörünü bu alanda özel çalışmalar yapmaya itmiştir. Kadınların yıllarca yalnızca özel alanın bir objesi olarak görülmesi ve sosyal alanda varlığının kabul görmemesi fikrinin yıkılması kadınları turizm sektöründe pazar belirleyici bir konuma getirmiştir.

Kadınların yaşlarına ve içerisinde bulundukları sosyal statüye göre değişen kadın kadına seyahat etme arzuları kadın kadına seyahat faaliyetinin ilerleyen zamanlarda kendi içinde de bölüneceğinin sinyallerini vermektedir. Ev veya iş yaşantısından bunalan kadınlar kendilerini daha iyi anlayacaklarını düşündükleri kadın arkadaşlarıyla seyahat etmenin mutluluk verdiğini ifade etmektedirler. Evli kadınlar ise kadın kadına çıktıkları seyahatlerin sonucunda evlerine döndüklerinde eşlerine ve çocuklarına daha fazla sevgi gösterdiklerini ifade etmişlerdir. Erken yaşta seyahat deneyimi elde etmek isteyen küçük kadınlar ise özgür olmanın tadına bu yolla vardıklarını belirtmişlerdir. Görüldüğü üzere kadınların birbirleri üzerinde terapi etkisi bulunmaktadır. Kadınların alışverişe ve rahatlama faaliyetlerine ne kadar düşkün oldukları birçok toplumun inandığı bir gerçektir. Bu bağlamda kadın kadına seyahat kadınlara bütün bu istediklerini bir arada yapma firsatı tanımaktadır.

Turizm canlılığı ve çeşitliliği bakımından Türkiye ile denk birçok ülkede gerçekleştirilen bu turizm faaliyeti ne yazık ki ülkemizde gereken değeri görmemektedir. 2000 yıllarında ortaya çıkan bu trendin ülkemizde henüz çok yaygın olmaması üzerinde durulması gereken bir konudur. Türkiye'de başarısı dünya çapında bilinen tur şirketleri ve oteller olmasına rağmen kadınlara özel bu pazara yeterince önem verilmemektedir. Yabancı tur şirketleri ülkemizde turlar düzenlemekte dolayısıyla bu durum ülkeye ekonomik anlamda bir fayda sağlamamaktadır. Bu pazarın pastasında büyük dilim yabancı tur şirketlerine düşmektedir. Öte yandan yapılan incelemeler sonucu Türkiye çıkışı kadın kadına seyahat turlarının düzenlendiği 
bilgisine de ulaşılamamıştır. Bu durum ülkemizde turizm sektöründe kadınların henüz hak ettikleri değere ulaşamadıklarını göstermektedir. Bireysel olarak veya gruplar halinde kadın kadına seyahat edilse de profesyonel anlamda ülkemizden başka ülkelere bu tür seyahatler gerçekleştirilmemektedir. Türkiye turistik faaliyetler bakımından oldukça zengin bir ülkedir. $\mathrm{Bu}$ nedenle her geçen gün artış gösteren kadın kadına seyahat'in ülkemizin bütün turistik destinasyonlarına yayılmasını sağlamak önemli sosyo-ekonomik kazançlar sağlayacaktır. Konu ile ilgili Türkiye menşeli tur şirketlerine ve otellere büyük görev düşmektedir.

\section{Kaynaklar}

Heather J. G., Berdychevsky L., Heather L. Bell (2012). Girlfriend getaways over the life course: change and continuity. Annals of Leisure Research. 15(1), 38-40

https://www.loewshotels.com/blog/loews-miami-girlfriends-getaway/ https://www.girlsontravel.co.uk/istanbul-citybreak-grouptour-women-2.html

Mirehie M., Heather J G., Khoo-LattimoreC., Girish P. (2018). An exploratory study of hospitality needs and preferences of U.S. Girlfriend Getaways. Journal Of Hospitality Marketing \& Management.27 (7), 2-4

https://getaways.wearetravelgirls.com/turkey-2019/

https://www.celebritycruises.com/groups-and-events/special-occasion-cruises/girls-getaway

Khoo-Lattimore C., Girish P., Disegna M. (2018). Me, My Girls and the Ideal Hotel: Segmenting Motivations of the Girlfriend Getaway. Market using Fuzzy $C$-Medoids for Fuzzy Data. Sf.2-8

https://mygirlfriendguide.com/2015/07/13/girlfriend-getaway-istanbul/

https://www.hollandamerica.com/en_US/cruise-ships/ms-nieuw-statendam/girls-getaway.html

Yorio, N. (2010). Doctor's Orders: Escape on a Girlfriend Getaway! 7 Ways Taking off With Your Girls Helps Your Body, Mind, Sanity, Marriage... Everything. Redbook. 215(2), 1

http://www.cruisewestchester.com/resource-center/cruise-related-articles/groups-or-specialoccasions/girlfriend-getaways.aspx https://www.fivestaralliance.com/maui-hi/hawaii-escapes-girlfriend-getaway-at-the-grandwailea-resort 


\title{
PROMOTING GENDER EQUALITY IN EDUCATION AND THE WORKPLACE
}

\section{Fatma DEMIR ${ }^{1}$}

\begin{abstract}
Gender equality is access to resources and opportunities, regardless of sex, including gender equality, economic participation and decision-making, equal valuation of different behaviour, aspirations and needs, encouraging and equal assessment of the needs of women and men in education and workplace definable.

There are many international initiatives promoting gender equality in education and the workplace. Many policy resolutions, shaped by international initiatives such as the UN Global Compact, UN Women, Women's Empowerment Principles (WEPs), are supported through participants and practices. Initiatives promoting gender equality in education and the workplace; It can be strengthened by promoting lifelong learning and equal opportunities for all, by empowering all women and girls, and by ensuring that girls and boys, women and men have access to and complete education at the same time, and are equally established in education and workplace. As a matter of fact, all these efforts can be permanent with the production and implementation and sustainability of gender equality projects.

In this context, this study examines international initiatives supporting gender equality and projects to promote gender equality in practice.
\end{abstract}

Keywords: Gender Equality, Education, Workplace, Global Priorities

\footnotetext{
${ }^{1}$ Asst.Prof.Dr.-Girne American University, Kyrenia, Noth Cyprus, demiroffice@ gmail.com
} 


\section{EĞITIMDE VE İŞYERINDE TOPLUMSAL CINSIYYET EŞITTLİĞININ DESTEKLENMESI}

$\ddot{O}_{z e t}$

Toplumsal cinsiyet eşitliği, ekonomik katılım ve karar alma dâhil olmak üzere cinsiyetten bağımsız olarak kaynaklara ve firsatlara eşit erişsimin kolaylaştırıldığı, cinsiyete bakılmaksızın, farklı davranış, özlem ve ihtiyaçlara eşit değer verme, kadınların ve erkeklerin ihtiyaçlarının eğitim ve işyerinde teşvik edilmesi ve eşit olarak değerlendirilmesi durumu olarak tanımlanabilir. Eğitimde ve işyerinde toplumsal cinsiyet eşitliğini destekleyen pek çok uluslararası girişim söz konusudur. BM Küresel İlkeler Sözleşmesi (UN Global Compact), BM Kadınları (UN Women), Kadının Güçlenmesi Prensipleri (WEPs) gibi uluslararası girişimlerle şekillenen birçok politika kararı, katılımcılar ve uygulamaları aracılığıyla desteklenmektedir. Eğitimde ve işyerinde toplumsal cinsiyet eşitliğini destekleyen girişimler; yaşam boyu öğrenmeyi ve herkes için firsat eşitliğinin teşvik edilmesiyle, tüm kadınların ve kızların güçlendirilmesiyle, kız ve erkek çocuklarının, kadın ve erkeklerin eğitime erişip onları tamamlamalarının yanında aynı zamanda eğitim ve işyerinde eşit olarak tesis edilmesiyle güçlendirilebilir. Nitekim tüm bu çabalar toplumsal cinsiyet eşitliği projelerinin üretilmesi ve uygulanması ve sürdürülebilmesi ile kalıcı olabilir. Bu bağlamda, bu çalışmada, toplumsal cinsiyet eşitliğini destekleyen uluslararası girişimler ve bunları uygulamada da hayata geçirmeye dönük toplumsal cinsiyet eşitliğini teşvik etmeye dönük projeler incelenmektedir.

Anahtar Sözcükler: Toplumsal Cinsiyet Eşitliği, Eğitim, İsyeri, Küresel Öncelikler

\section{Giriş}

Çağdaş yaşam koşulları, kadın ve erkeklerin, toplumları daha güçlü ve mutlu hale getirmek için eşit haklarla yaşamın her alanına katılmalarını gerektirir. Toplumsal cinsiyet eşitliği, sadece kadınlar için olumlu bir yaklaşım değil, toplumun tümüne fayda sağlar. Kadınlara eşit hakların verilmediği bir ortamda, toplumun yarısı yerinden edilmiştir. Nitekim kadınların güçlenmesi yalnızca kadınlarla değil aynı zamanda tüm toplumla da ilişkili bir durumdur. Bu nedenle toplumsal cinsiyet eşitliği oluşturmak, tüm bireylerde toplumsal cinsiyet eşitliği bilincini geliştirerek farkındalıklar yaratmakla söz konusu olabilir. 
Toplumsal cinsiyet eşitliği aynı zamanda bir kalkınma aracı olarak da önemlidir ve ekonomide akılcılıktır: üç yolla ekonomik etkinliği artırabilir ve diğer kalkınma sonuçlarını iyileştirebilir. Birincisi, kadınların eğitime, ekonomik firsatlara ve üretken girdilere erkeklerle aynı düzeyde erişebilmesini önleyen engelleri kaldırmak birçok verimlilik kazanımları sunabilir. İkincisi, kadınların mutlak ve göreli statülerinin iyileştirilmesi, çocuklara yönelik olanlar da dâhil olmak üzere birçok diğer kalkınma sonucunu besler. Üçüncüsü, kadınlar ve erkeklerin sosyal ve siyasi açıdan aktif hale gelmek, kararlar almak ve politikaları şekillendirmek için eşit şansa sahip oldukları bir oyun alanı yaratmaktır (WB, 2012: 3).

Cinsiyete dayalı iş bölümü, kadınlarla erkekleri farklılaştırmakla kalmaz, aynı zamanda toplumsal kaynaklara erişimlerini de etkiler ve eşitsiz kılar. Bu eşitsizlik, cinsiyete dayalı çeşitli ayrımcılık ve engellemelerle güçlenir; sadece kadınların değil, bütün toplumun ekonomik, siyasal, kültürel gelişmesi önünde ciddi bir engel haline gelir(Özaydınlık, 2014: 94). Bu nedenle kadınların ve kızların ihtiyaçlarının karşılanmasını hızlandırmak, kadınların yaşamın her alanına katılımını desteklemek, kadınların ekonomik olarak güçlenmesine katkıda bulunmak; istihdam ve meslek açısından ayrımcılığın ortadan kaldırılmasına destek olmak; işyerinde, pazarda ve toplumda kadınları güçlendirmek; barışçıl, müreffeh ve sürdürülebilir bir yaşam bilinci kazandırmakla toplumsal cinsiyet eşitliği mümkün olabilir. Toplumsal cinsiyet eşitliği aynı zamanda kadın ve kız çocuklarının eğitime, sağlık hizmetlerine, iyi işlere eşit erişimlerinin sağlamasıyla; 2030 Sürdürülebilir Kalkınma Hedeflerine uygun olarak kadınlar ve erkekler için eşit vatandaşlar olarak eşit firsatlar, seçimler, yetenekler, güç ve bilgiden yararlanmalarını teşvik etmekle mümkün olabilir. Sürdürülebilir Kalkınma Hedefleri ${ }^{1}$, diğer bir deyişle küresel hedefler, yoksulluğu ortadan kaldırmak, tüm insanların barış ve refah içinde yaşamasını

\footnotetext{
${ }^{1}$ The Sustainable Development Goals (SDGs) are a collection of 17 global goals set by the United Nations General Assembly in 2015 for the year 2030. The SDGs are part of Resolution 70/1 of the United Nations General Assembly, the 2030 Agenda
} 
sağlamak, iklim değişikliği, ekonomik eşitsizlik, yenilikçilik, sürdürülebilir tüketim, barış ve adalet gibi yeni alanları içeren evrensel eylem çağrısıdır. Aşağıda Sürdürülebilir Kalkınma Hedeflerini oluşturan, "Kadın ile erkeğin eşitliği săglanmalı, tüm kadınlar ve kızların toplumdaki konumu güçlendirilmelidir." Anlayışını taşıyan toplumsal cinsiyet eşitliği hedefi yanında birbirini bütünleyen 17 hedef yer almaktadır.

\begin{tabular}{|c|c|c|}
\hline 1 & Fakirliğe son & Fakirliğin her yerdeki her türlü şekli son bulmalıdır. \\
\hline 2 & Açlığa son & $\begin{array}{l}\text { Açlık sonlandırılmalı, gida güvenliği sağlanmalı, beslenme } \\
\text { iyileştirilmeli ve sürdürülebilir tarım desteklenmelidir. }\end{array}$ \\
\hline 3 & İyi sağlık durumu & $\begin{array}{l}\text { İnsanların sağlıklı olması sağlanmalı ve her yaşta sağlıklı olmak } \\
\text { desteklenmelidir. }\end{array}$ \\
\hline 4 & Kaliteli eğitim & $\begin{array}{l}\text { Tüm insanları kapsayan, eşit ve kaliteli eğitim sağlanmalı ve } \\
\text { herkes için hayatları boyunca öğrenme firsatları } \\
\text { desteklenmelidir. }\end{array}$ \\
\hline 5 & Toplumsal cinsiyet eşitliği & $\begin{array}{l}\text { Kadın ile erkeğin eşitliği sağlanmalı, tüm kadınlar ve kızların } \\
\text { toplumdaki konumu güçlendirilmelidir. }\end{array}$ \\
\hline 6 & Temiz su ve hijyen: & $\begin{array}{l}\text { Herkes için su ve hijyen mevcut ve sürdürülebilir bir şekilde } \\
\text { sağlanmalıdır. }\end{array}$ \\
\hline 7 & $\begin{array}{l}\text { Yenilenebilir ve uygun } \\
\text { fiyatlı enerji }\end{array}$ & $\begin{array}{l}\text { Herkesin uygun fiyatlı, güvenilir, sürdürülebilir ve modern } \\
\text { enerjiye erişimi sağlanmalıdır. }\end{array}$ \\
\hline 8 & İyi işler ve güçlü ekonomiler & $\begin{array}{l}\text { Kesintisiz, herkesi kapsayan ve sürdürülebilir ekonomik büyüme } \\
\text { ile herkes için tam zamanlı, üretken ve hoş bir iş ortamı } \\
\text { sağlanmalıdır. }\end{array}$ \\
\hline 9 & Yenilikçilik ve iyi altyapı & $\begin{array}{l}\text { Sağlam bir altyapı inşa edilmeli, herkesi kapsayan ve } \\
\text { sürdürülebilir bir sanayileşme süreci yaşanmalı, yenilikçilik } \\
\text { teşvik edilmelidir. }\end{array}$ \\
\hline 10 & Eşitsizliklerin azaltılması & Ülke içi ve ülkeler arası eşitsizlik azaltılmalıdır. \\
\hline 11 & $\begin{array}{l}\text { Sürdürülebilir şehirler ve } \\
\text { topluluklar }\end{array}$ & $\begin{array}{l}\text { Şehirler ve yerleşim yerleri herkesi kapsayan, güvenli, sağlam ve } \\
\text { sürdürülebilir şekilde inşa edilmelidir. }\end{array}$ \\
\hline 12 & $\begin{array}{l}\text { Kaynakların sorumlu bir } \\
\text { biçimde kullanılması }\end{array}$ & Tüketim ve üretimin sürdürülebilir olması sağlanmalıdır. \\
\hline 13 & $\begin{array}{l}\text { İklim konusunda faaliyete } \\
\text { geçme }\end{array}$ & $\begin{array}{l}\text { İklim değişikliği ve bunun etkileriyle savaşmak için acil olarak } \\
\text { harekete geçilmelidir. }\end{array}$ \\
\hline 14 & Sürdürülebilir okyanuslar & $\begin{array}{l}\text { Okyanuslar, denizler ve deniz kaynakları sürdürülebilir gelişme } \\
\text { için korunmalı ve sürdürülebilir şekilde kullanılmalıdır. }\end{array}$ \\
\hline 15 & $\begin{array}{l}\text { Sürdürülebilir toprak } \\
\text { kullanımı }\end{array}$ & $\begin{array}{l}\text { Toprak ekosistemleri korunmalı, yeniden inşa edilmeli ve } \\
\text { bunların sürdürülebilir şekilde kullanımı desteklenmeli, ormanlar } \\
\text { sürdürülebilir biçimde yönetilmeli, çölleşmeye karşı savaş1lmalı } \\
\text { ve toprak erozyonu ile biyoçeşitlilik kaybı durdurulup geri } \\
\text { kazanımlar sağlanmalıdır. }\end{array}$ \\
\hline 16 & Barış ve adalet & $\begin{array}{l}\text { Sürdürülebilir gelişme için barışçl ve herkesi kapsayan } \\
\text { toplumların inşa edilmesi desteklenmeli, herkesin adalete erişimi }\end{array}$ \\
\hline
\end{tabular}




\begin{tabular}{|l|l|l|}
\hline & & $\begin{array}{l}\text { sağlanmalı ve her alanda verimli, hesap verebilen ve herkesi } \\
\text { kapsayan kurumlar oluşturulmalıdır. }\end{array}$ \\
\hline 17 & $\begin{array}{l}\text { Sürdürülebilir kalkınma } \\
\text { için ortaklıklar }\end{array}$ & $\begin{array}{l}\text { Uygulama yöntemleri güçlendirilmeli ve sürdürülebilir gelişme } \\
\text { için global ortaklık yeniden canlandırılmalıdır. }\end{array}$ \\
\hline
\end{tabular}

Sürdürülebilir kalkınma hedefleri, kadınlar ve erkekler eşit vatandaşlar olarak eşit firsatlardan, yeteneklerini geliştirecek güçten ve bilgiden faydalanırsa hayata geçebilir. Cinsiyete dayalı her türlü ayrımcılık, insan haklarının ihlali olduğu gibi 2030 Sürdürülebilir Kalkınma Gündemi ve 17 Sürdürülebilir Kalkınma Hedefine ulaşılmasında önemli bir engel de teşkil etmektedir. Eşitsizlikleri en aza indirmek ve toplumsal cinsiyet eşitliği sağlamak için şunlar yapılabilir:

Kadınlar ve kızlarla konuşmak: Her alanda henüz cinsiyet eşitliği elde etmememizin temel nedeni, kadınların ve kızların seslerinin küresel ve ulusal karar alma süreçlerinden çok fazla dışlanmalarıdır.

Kızların cep telefonu kullanmasına izin vermek: Hindistan'daki kızların çoğunluğu, altyapıyla ilgili zorluklar ve ekonomik nedenlerden dolayı telefonlar ve bilgisayarlar gibi temel teknolojiyi kullanamıyorlar.

Çocuk evliliğini ve cinsel tacizi durdurmak: Kızların eğitimi tamamlayabilmelerini istiyorsak, çocuk evliliğini sonlandırmalıyız. Ayrıca kızların cinsel tacizini ciddiye almalıyız. Eğitimi toplumsal cinsiyete duyarlı hale getirmek: Eğitime erişimin arttırılmasında çok ilerleme kaydedilmesine karşın, ders kitaplarının pozitif kalıpları teşvik etmesini sağlamak da dâhil olmak üzere eğitim sisteminin cinsiyet duyarlılığını artırmada ilerleme kaydedilmişstir.

Kızların ve ebeveynlerinin hayattan beklentilerini arttırmak: Kızlara hayallerini genişleten imajlar ve rol modeller vermeliyiz.

Anneleri güçlendirmek: Anneler hayatlarında seçim yapmak için eğitilip yetkilendirildiklerinde kızlarının okula gitmesini sağlarlar. 
Kadınların işine uygun değer vermek: Ücretsiz kadınlar ve kızlar, küresel ekonominin temelini oluşturur. Bu gerçeğin medyada, özel sektörde ve topluluklarda daha fazla vurgulanmas1 gerekmektedir.

Kadınları iktidara getirmek: Bir kadının başarısına yönelik birçok sistemik engelin üstesinden gelmenin kanıtlanmış bir yolu, kadınların güçlendirilmiş değişim aracıları olarak yerel, bölgesel ve ulusal mevzuata katılımı arttırmıştır.

Kadınları geleneksel olmayan mesleklere teşvik etmek: Kadınları geleneksel olmayan işlerde desteklemek, yaşamlarında uzun süren değişiklik yapmakla kalmamakta, aynı zamanda sosyal tabuların kırılmasına da yardımcı olmaktadır.

Şiddeti durdurmak: BM, küresel olarak, her üç kadından birinin yaşamı boyunca şiddete maruz kalacağını, çoğu zaman mevcut veya eski bir eş tarafından uygulanan kadına yönelik şiddete maruz kalacağını tespit etti.

\section{Eğitimde Toplumsal Cinsiyet Eşitliği}

Toplumsal cinsiyet kavramı, hem kadınların hem de erkeklerin özellikleri, yetenekleri ve muhtemel davranışları (kadınlık ve erkeklik) ile ilgili beklentileri içerir. Bu kavram, ortak uygulamaların cinsiyetler arasındaki uyuşmazlıkları nasıl meşrulaştırdığını analiz etmede yararlıdır(UNICEF, 2017: 2). Eğitimde toplumsal cinsiyet eşitliği politika ve uygulamalarında da bu gerçek göz önüne alınmalıdır. Çünkü toplumsal cinsiyet eşitliğinin sağlanması insan haklarının korunması, demokrasinin işleyiş̧i, hukukun üstünlüğüne saygı ve ekonomik büyüme ve sürdürülebilirlik için çok önemlidir (CE, 2015:3). Nitekim toplumsal cinsiyet eşitliğinin en önemli uygulama alanlarından biri olan eğitim, bilinçli yaklaşımlarla bireylerin yaşamlarında kendi deneyimleri yoluyla olumlu sonuçları yaratmada etkin bir rol üstlenmektedir. $\mathrm{Bu}$ bağlamda okullarda toplumsal cinsiyet eşitliğini teşvik etmenin çeşitli yolları hayata geçirilebilir. Bunlar: 
Karakter özelliklerini cinsiyetten ayırmak: Eğer öğrencilere "erkeklerin duyarlı olabileceğini”" ve "kızların baskın olabileceğini” öğretirsek, hala kadınsı bir özellik olarak duyarlılı̆̆ı ve erkeksi bir özellik olarak baskınlığı sunmaya devam ediyoruz. Bu terimleri cinsiyetten ayırmamız ve öğrencilere karmaşık bir özellik yapısına sahip bir birey olarak yargılamayı öğretmemiz gerekir. Cinsiyet normlarının onaylanmasını önlemek için kullandığınız dilde özen gösterin. Hassasiyet gibi özellikleri içermek için erkeklik tanımlarını açmaya ve hâkimiyet gibi özellikleri içerecek şekilde kadınlık tanımlarını genişletmeye çalışın. Ayrıca, ikili ve transseksüel kimlikleri ortaya çıkaran tanımlara yer açın.

İyi niyetli cinsiyetçilik gibi örtülü önyargıları vurgulamak: Öğrenciler etrafa bakabilir ve "Burada herhangi bir toplumsal cinsiyet önyargııı görmüyorum” diye düşünebilirler. Bunun sebebi çoğumuzun yalnızca düşmanca cinsiyetçiliğin nasıl çalıştığı ve düşmanca cinsiyetçiliğin eğitimsiz olduğudur. Cinsiyet yanlılığının bir başka şekli, hayırsever cinsiyetçilik, oyunda daha sık görülür. Yardımsever cinsiyetçilik, kurbanı "yağlayarak” çalışan ve böylece kurbanı kendi baskısına zorlayan cinsiyetçiliktir. Çoğu zaman failleri, yaptıklarını bile bilmiyorlar. Bir kız öğrencinin öğrenci meclisinde liderlik pozisyonu için çalıştığı ancak mükemmel bir sekreterlik yapacağı söylendiğinde, “erkeklerden hiçbiri işi doğru yapamaz”, yani bu iyi bir cinsiyetçiliktir. İstenmeyen toplumsal cinsiyet rollerini olumlu bir 1ş1kta döndürerek pekiştiriyor. Öğrencilere bu gibi durumları tanımayı ve bunlarla başa çıkmayı öğretelim.

Toplumsal cinsiyet eşitliğini destekleyen öğretim materyalleri kullanmak: Ders kitaplarında ve diğer öğretim materyallerinde cinsiyet eğilimi gerçek bir sorundur. Bazı UNSECO çalışmaları, bu metinlerin çoğunun "kadınları temsil etmeyen, kadınlar hakkında basmakalıp ya da kadınlarla ilgili rahatsız edici yorumlar içerdiğini” ortaya koymuştur. Araştırma, öğretim materyallerindeki nitelendirmeler genellikle “erkek çoğunluğu gösterdiğini” ortaya koymaktadır. Alternatif olarak, öğretim materyallerindeki cinsiyet önyargısı, örneğin ders 
kitaplarının görüntüleri yalnızca öğretmen ve hemşire olarak kadınlara gösteriliyorsa, erkeklerin rollerinin daraltılmasina neden olabilir.

Dilin gücünü vurgulamak: Öğrencilere, duyduklarında veya gördüklerinde dilde cinsiyet yanlılı̆̆ı tanımalarını öğretin. Örneğin, neden “Bir erkek ol” ifadesinden kaçınmayı bu kadar tartışmasız bir şekilde duyuyor, içselleştiriyor ve kabul ediyoruz? Bu üç basit kelimeyle, erkeklerin geleneksel erkeklik kavrayışları etrafında kendi değerlerini nasıl biçimlendirmeleri gerektiği konusundaki fikirlerinden, "Kadın ol” ifadesinin dikkat çeken yokluğuna kadar pek çok şey var. Cinsiyet yanlılığı gündelik dilimize yerleşerek ve bu cümlelerin kullanılmaya devam edilmesiyle önyargıları nasıl sürdürüldüğünü ortaya koymaktadır.

Rahatsız edici durumlarla baş etmek için sözcükler öğretmek: Öğrencilere cinsiyet yanlılığ1 durumlarını anlamalarında yardımcı olmak. Öğrencilerin genellikle rahatsız edici olan durumlarla başa çıkabilmek için sözlüğe ihtiyacı vardır ve biz de onlara bu sözcükleri hatırlatmakta rol oynayabiliriz. Bu kelime içeriğe bağlı olarak belirlenir genel bir cevap olabilir. Örneğin, bir erkek öğrencinin yeterince güçlü veya hızlı olmadığı için alay edildiğinde beden eğitimi dersinde "Kendimi ne kadar hızlı koştuğuma göre tanımlamıyorum" diyebilir. Bir kız otomatik olarak "sekreter türü" olarak kullanılırsa öğrenci konseyinde "Kendimi bu şekilde tanımlamıyorum; kendimi lider olarak görüyorum" diyebilir. Dolayısıyla onlara kelime hazinesi oluşturmaları için yardım edelim.

Kültürel farklılıklara duyarlı olmak: Araştırmalar, ebeveynlerin kızlarına veya oğullarına doğdukları anda farklı davranmaya başladığını, ağlayan kızları ağlayan erkeklerden daha fazla rahatlatmaya başladığını ve cinsiyetlerine bağlı olarak veya bebeklerle oynadıkları için küçük kız çocukları övdüğünü ya da erkek çocukların bebeklerle oynamasında rahatsız olduklarını gösteriyor. Erkek ve kız çocuklarına kim olmak istediğine karar verme şansı verelim. 


\section{İșyerinde Toplumsal Cinsiyet Eșitliği}

İşyerinde toplumsal cinsiyet eşitliği, insanların cinsiyetten bağımsız olarak aynı ödüllere, kaynaklara ve firsatlara erişip bunları kullanabildiklerinde elde edilebilir. Nitekim işyerinde toplumsal cinsiyet eşitliğinin amac1, kadınlar ve erkekler için geniş çapta eşit firsatlar ve sonuçlar elde ederken, herkes için tamamen aynı olan sonuçlar değil, kadınlar ve erkekler için geniş ölçüde eşit sonuçlar etmek olmalıdır.

İşyerinde toplumsal cinsiyet eşitliğinden yoksun yasalar ve politikalarla ortaya çıkan toplumsal cinsiyet eşitsizliği, kadınların varlıklara ve hizmetlere, kredi veya iş firsatlarına erişme yeteneklerini sınırlayarak ekonomik büyümeyi daha da engellemektedir (EBRD, 2015: 8). Dolayısıyla, işyerinde toplumsal cinsiyet eşitliğini desteklemek için adil bir çalışma ortamı teşvik etmenin yanı sıra, genel olarak iş verimliliğinin mümkün olduğunca yüksek olmasının koşulları oluşturulmalıdır. Toplumsal cinsiyet eşitliğine yapılan bu yatırımlar doğal olarak ülke ekonomisinin büyümesine katkı sağlayacaktır.

Toplumsal cinsiyet eşitliği uygulayan bir şirket, kadın ve erkeklere aynı şekilde davranır. İşyerinde toplumsal cinsiyet eşitliğini sağlamanın temel koşulu, kadın ve erkeklerin eşit muamele görmeleridir: Bunlar: Karşllaştırılabilir roller ve eşit ücret; ihtiyaçların eşit olarak değerlendirilmesi; ilerleme ve kariyer gelişimi için eşit fırsatlar; çalışanlar, erkek veya kadın oldukları için herhangi bir ayrımcılığa maruz kalmamaları gibi bir dizi birbiriyle bağlantılı konuları içermektedir. Nitekim toplumsal cinsiyet eşitliğinin güçlendirilmesine yardımcı olmak için şunlar yapılabilir:

1. Farkındalığı artırmak ve adil davranışları teşvik etmek için eğitim vermek

2. Çocuk bakım tesisleri, aile dostu politikalar ve çocuk bakımı sağlamak

3. Hem şirket içi hem de medya kanalları aracılı̆̆ıyla şirketteki/işyerindeki başarılı kadınlara 1şık tutmak ve üst düzey kadınlardan mentor olarak hareket etmelerini istemek 
4. Adil ücret ve iş-yaşam dengesi politikaları oluşturmak ve yöneticilerin bunları tam olarak desteklemesini sağlamak

Günümüzün dinamik iş ortamlarında, toplumsal cinsiyet eşitliğini sağlamak, herhangi bir kuruluşun rekabet edebilirliği ve büyümesi için temel faktör olarak kabul edilmektedir. Kapsayıcı ve dinamik bir ekonomi yaratmak için herkesin eşit firsatlara sahip olması sağlanmalıdır. Kadınlar genel olarak işgücünün ayrılmaz bir parçası olarak bütünleştirilmezse, küresel sorunların üstesinden gelmek, yeni fursatları değerlendirmek için gerekli olan becerileri, fikirleri, etkili karar verme gücünü ve küresel bakış açısını da kaybetmek hiç de zor olmayacaktır. Toplumsal cinsiyet eşitliği, yoksulluğu azaltma, iyi yönetişim oluşturma ve sürdürülebilir kalkınmayı teşvik etme zorluğunun üstesinden gelmenin de bir önkoşuldur.

\section{Cinsiyetlerine bakılmaksızın çalışanlara liderlik rollerini üstlenmeleri için fırsatlar}

yaratılması işyerinde toplumsal cinsiyet eşitliğini desteklemenin önemli yollarında biridir. Dünya Ekonomik Forumu'nun, 2017-Küresel Cinsiyet Açı̆̆ı Raporu’na göre, kadınların analiz edilen her sektördeki liderlerin \% 50' sinden daha azını temsil ettiğini belirtiyor. Enerji, Madencilik ve İmalat gibi bazı endüstrilerde, kadınların liderlik temsiliyeti dünya genelinde sadece \% 20'ye düşüyor (WEF, 2017). Kadınların liderlik rollerinde daha iyi temsil edilmesiyle, işyerinde daha fazla sayıda kadın istihdam edileceği için işyerinde toplumsal cinsiyet eşitliğini arttırmaktadır.

Eşit işe eşit ücret yaklaşımı bir organizasyonda göz önünde bulundurulması gereken önemli bir unsurdur. Ücret, iş rolüne bağlı olmalı ve şeffaflığı artırmak ve ayrımcı ücret oranı sorunlarını ortadan kaldırmak için düzenli bir ödeme yapısının uygulamaya konması gerekmektedir. Tamamıyla, herhangi bir yanlış anlaşılmadan kaçınmak için ücretlendirme ile ilgili kararların çalışanlara bildirilmesi gerekir. 
İssyaşam dengesini önemsemek toplumsal cinsiyet eşitliğini desteklemek için önemli yollardan biridir. Uluslararası Çalışma Örgütü (ILO) raporuna göre, kadınlar ücretsiz bakım çalışmalarının toplam saatinin yüzde 76,2'sini erkeklerin üç katından daha fazla yapıyor. Çalışan annelerin stresini hafifletmek ve kariyer hedeflerine ulaşmalarını sağlamak için, babalara çocuk bakım izni vermeleri gerekir, çünkü bu annelerin sadece kariyerlerine odaklanmalarına izin vermekle kalmaz, babaların da çocuğun yetiştirilmesine katılımını sağlar. Nitekim iş-yaşam dengesi, sağlıklı bir çalışma ortamının hayati bir unsuru olarak kabul edilir, uygun bir iş-yaşam dengesinin korunması, işyerinde stres seviyelerinin en aza indirilmesine de yardımc1 olur.

Taciz ve işyerinde suça karşı sıkı ve etkili politikalar gelişstirmek işverenin sorumluluğundadır. İşverenler, bu gibi durumlarda suçluların cezalandırıldığından emin olmak için derhal hareket etmeli ve mağdura yardımcı olmak için gerekli önlemleri almalıdır. İşverenler, gelecekte bu tür vakaları/yeltenmeleri önlemek için işyerinde önlem almalıdır. İşyerinde bu tür faaliyetlere karşı duyarsızlık, örgüt içinde gerçekleşen toplumsal cinsiyet eşitsizliğinin açık bir göstergesidir. İşverenler, yöneticiler ve ekip liderlerinin geniş ve açık fikirli bir politikaya sahip olmaları, işyerinde toplumsal cinsiyet eşitliğini sağlamanın önemli yollarından bir diğeridir. İşletme içindeki bölümlerin çoğunun cinsiyet önyargılı olması durumunda, şirketin uzun vadede büyümesini kesinlikle olumsuz etkileyecektir. Çalışanlar, işverenin kişisel favorilerine göre değil, yeteneklerine ve performanslarına göre değerlendirilmelidir. Bunlar, işverenlerin işyerinde toplumsal cinsiyet eşitliğini teşvik ederken göz önünde bulundurması gereken kilit noktalardan bazılarıdır.

Esnek çalışma koşulları ile tam zamanlı ya da yarı zamanlı politikalar uygulanması toplumsal cinsiyet eşitliğinin desteklenmesine katkı sağlayacaktır. Kadın ve erkeğin yüzyıllardır omuz omuza çalışmasına rağmen cinsiyete dayalı iş bölümü sonucu kadın ev işleri ve bakım işlerini üstlenmekte, erkek emek piyasalarında çalışmaktadır (Tilev, 2018:123). 
Bununla birlikte günümüzde kadınlar da işgücü piyasasında yerini almıştır. Ancak geleneksel rollerin sadece kadına yüklenmesi (çocuk bakımı gibi) kadınların iş yaşamı ve kariyer gelişimlerini çoğu zaman olumsuz etkileyebilmektedir. Özellikle kadınların doğum ve çocukların anne bakımına doğrudan ihtiyacı olduğu ilk yıllarında esnek çalışma koşullarıyla desteklenmesi önemlidir. Aynı zamanda erkeklerin de benzer koşullardan yararlanması ve çocuk bakımının bir parçası olarak yerini alması ve tıpkı kadın gibi erkeğin de söz konusu ebeveynlik sorumluklarını yerine getirmelerine destek olunmalıdır. Böylece çocuk bakımı sadece kadınlara yüklenmemiş ve kadınların çalışma yaşamına katılımı desteklenmiş ve kariyer gelişimleri de dikkate alınmış olacaktır.

Işsyerinde toplumsal cinsiyet eşitliğini güçlendirmek için işyerini kadın ve erkekler için konforlu hale getirmek yöneticilerin nasıl yönetileceği konusunda eğitilmiş olmasını gerekir. İşyerinde toplumsal cinsiyet eşitliğini tesis edilmesi ya da bozulması yöneticilerin eğitimiyle doğrudan ilişkilidir. Çalışanların performansının ödüllendirilmesi ve herkese geri bildirim verilmesi gerekir. Her yöneticinin eğitilmesi sağlanmalı ve bu eğitimler yenilenmelidir. Böylece şirket toplumsal cinsiyet eşitliğine duyarlı ve verimli yapılara dönüşebilir.

\section{Toplumsal Cinsiyet Eşitliğini Destekleyen Uluslararası Girişimler}

\section{BM Küresel ilkeler sözleşmesi (UN Global Compact)}

BM Küresel İlkeler Sözleşmesi ${ }^{1}$, dünya çapındaki işletmeleri sürdürülebilir ve sosyal açıdan sorumlu politikalar benimsemeleri ve uygulamalarını rapor etmeleri konusunda teşvik etmek için bağlayıcı olmayan ilkeler bütünüdür. BM Küresel İlkeler Sözleşmesi, sürekli rekabet içindeki iş dünyasına ortak bir kalkınma kültürü oluşturmak üzere sürdürülebilirlik, sosyal sorumluluk ve yolsuzluğa karşı mücadele konusunda evrensel ilkeler öneren yenilikçi bir

\footnotetext{
${ }^{1}$ UN Global Compact: 26 Temmuz 2000, New York City, USA
} 
kurumsal sorumluluk yaklaşımıdır. 2000 yılından bu yana 160'dan fazla ülkeden 9.000'in üzerinde kurumsal katılımcı ve paydaşın imzasıyla dünyanın en büyük gönüllü kurumsal sorumluluk girişimi olan Küresel İlkeler Sözleşmesi insan hakları, çalışma, çevre ve yolsuzlukla mücadele ana başlıkları altında 10 evrensel ilke belirlemiştir. Toplumsal cinsiyet eşitliği noktasında "İstihdam ve meslek açısından ayrımcılığın ortadan kaldırılması, işyerinde ve toplumda kadınları güçlendirmek" ön plana çıkmaktadır.

\section{Kadının Güçlenmesi Prensipleri (Women Empowerment Principles-WEPs)}

Kadının Güçlenmesi Prensipleri (WEPs) bir UN Women ve UN Global Compact ortak inisiyatifidir. Kadının Güçlenmesi Prensipleri, işyerinde ve toplumda kadınların nasıl güçlendirileceğine dair rehberlik eden bir dizi iş ilkesidir. Kadının Güçlenmesi Prensiplerinin geliştirilmesi, Mart 2009'da başlayan ve Mart 2010'da Uluslararası Kadınlar Günü'nde başlatılmasıyla sonuçlanan uluslararası birçok paydaşlı danışma sürecini içermiştir. Bugüne kadar dünya genelinde toplam 1.400'den fazla firmanın imzaladığı Kadının Güçlenmesi Prensiplerini, Türkiye'den ise 150 'den fazla firma desteklemektedir. Kadının Güçlenmesi Prensipleri başlıkları şunlardır:

1.Cinsiyet Eşitliği için Üst Düzey Kurumsal Liderlik Sağlanması

2.Tüm Kadın ve Erkeklere İşte Adil Davranılması, İnsan Haklarına ve Ayrım Yapmama İlkesine Sayg1 Gösterilmesi, Bu İlkelerin Desteklenmesi

3.Tüm Kadın ve Erkeklere Sağlık, Güvenlik ve Refah Sağlanması

4.Kadınların Eğitim, Kurs ve Profesyonel Gelişim İmkânlarıyla Desteklenmesi

5.Kadınları Güçlendiren Girişimci Gelişimi, Tedarik Zinciri ve Pazarlama Yöntemlerinin Uygulanmas1

6.Toplumsal İnisiyatifler ve Destekler Aracılığıyla Eşitliğin Teşvik Edilmesi 
7.Cinsiyet Eşitliğinin Sağlanması için Gelişimin Ölçülmesi ve Halka Açık Raporlanmas1

\section{BM Kadınları (UN WOMEN)}

BM Kadınları, kadın ve kız çocuklarının ihtiyaçlarının karşılanmasını hızlandırmak, toplumsal cinsiyet eşitliğini sağlamak, kadınların yaşamın her alanına katılımını desteklemek, kadınların ekonomik güçlenmesine katkı sağlamak üzere, toplumsal cinsiyet eşitliğine ve kadınların güçlendirilmesine adanmış BM kuruluşudur.

BM Kadınları'nın ana rolleri şunlardır: Kadının Statüsü Komisyonu gibi hükümetler arası organları politika oluşturma, küresel standartlar ve normlar konusunda desteklemek; üye devletlerin bu standartları uygulamalarına yardımcı olmak, talep eden ülkelere uygun teknik ve finansal destek sağlamak için hazır kalmak ve sivil toplum ile etkin ortaklıklar kurmak için hazır olmaktır. Aynı zamanda sistem genelinde kaydedilen ilerlemenin düzenli izlenmesi de dâhil olmak üzere BM sistemini toplumsal cinsiyet eşitliği konusundaki taahhütlerinden sorumlu tutmak da BM Kadınları'nın ana rollerindendir.

\section{HeForShe}

HeForShe-BM Toplumsal Cinsiyet Eşitliği ve Kadının Güçlendirilmesi Birimince başlatılan bir girişimdir. Girişimin özünü, "Herkesin özgür olduğuna ve eşit olduğuna inanan milyonlarca kişiden biriyim; eşitliğin tüm faydalarını içimizden her birine sunmak için cinsiyet önyargısı, ayrımcılık ve şiddete karşı harekete geçeceğim ” anlayışı oluşturmaktadır.

HeForShe-Kampanyanın genel hedefi, kadınlara karşı her türlü ayrımcılığı, kadınlara karşı her türlü şiddeti ortadan kaldırmakta her yaştan bireylerin sahip olduğu sorumluluk hakkında farkındalık yaratmak ve harekete geçilmesini sağlamaktır. Diğer hedefler arasında şunlar sayılabilir: 
1.UN Women: BM kuruluşları ve ülke ofisleri tarafından erkeklerin toplumsal cinsiyet eşitliğini desteklemeye tam katılımı için sürdürülebilir ve dönüştürücü programlar geliştirilmesini sağlamak.

2.Resmi kurumlar: Erkek örgütleri ve diğer sivil toplum kuruluşlarıyla, üniversite ve yüksekokullarla işbirliği yaparak kendi toplulukları içinde HeForShe etkinlikleri ve kampanyaları yaratmak ve tanitmak.

3.Her yaştan kadına uygulanan şiddete ve cinsiyet tabanlı ayrımcılığa karsı harekete geçmeleri için insanlara ilham vermek.

4.Dünya çapında kadınlara uygulanan şiddete ve cinsiyet tabanlı ayrımcılığa karsı harekete geçen erkeklerin rol modelleri olarak öne çıkarılacağı bir platform yaratmak.

\section{Toplumsal Cinsiyet Eşitliğini Destekleyen Projeler}

\section{‘Ülkem İçin Toplumsal Cinsiyet Eşitliğini Destekliyorum’ Projesi ${ }^{1}$}

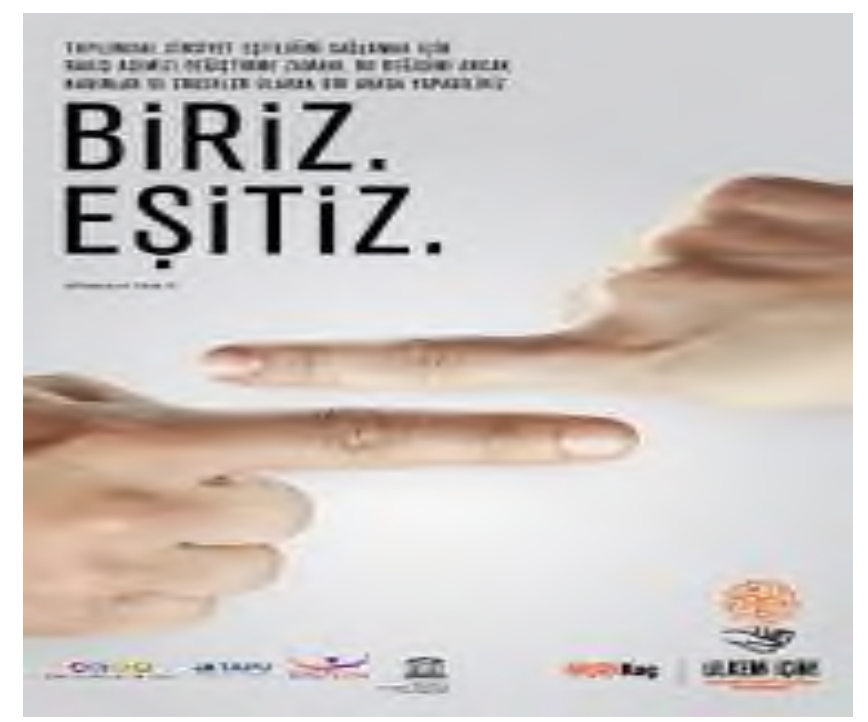

Koç Grup çalışanları ve bayileri, 2006'dan bu yana yürütülen Ülkem İçin Projesi’nde aktif görev almıştır. Proje kapsamında Koç Holding, Anne Çocuk Eğitim Vakfı (AÇEV),

\footnotetext{
1 Koç Grup ‘Ülkem İçin Toplumsal Cinsiyet Eşitliğini Destekliyorum’ Projesi verilerinden derlenmiştir.
} 
Türkiye Aile Sağlığı ve Planlaması Vakfı (TAP Vakfı) ve Koç Üniversitesi Kadın Araştırmaları Merkezi (Koç-KAM) ile Birleşmiş Milletler Eğitim, Bilim ve Kültür Örgütü (UNESCO) ile işbirliği yapmıştır. Bu işbirliği kapsamında hayata geçen farkındalık seminerleri 81 ili temsil eden ve projenin gönüllü elçileri olan Koç Grup bayileri ile bölge müdürlerinin öncülüğünde devam etmiştir. Bugüne kadar gerçekleşen eğitimler ile 84 bin kişiye ulaşılmıştır.

\section{'Çocuk Gelinler’ Projesi'}

Sabancı Vakfı’nın desteklediği ‘Çocuk Gelinler! Projesi Uçan Süpürge Kadın İletişim ve Araştırma Derneği tarafından yürütülmüştür. Projeye ilişkin bilgiler aşağıda verilmiştir.

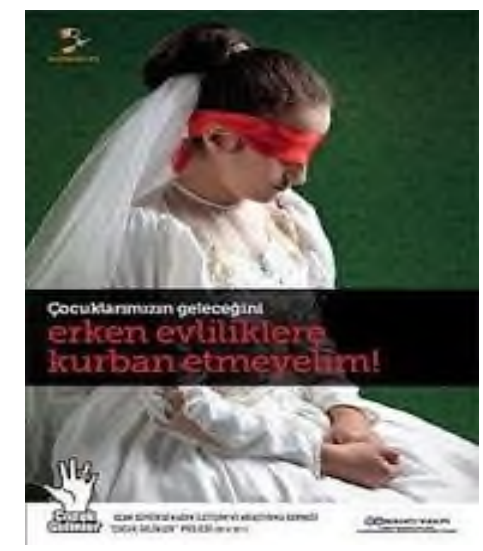

Amacı: Erken çocuk evlilikleri konusunda farkındalık yaratmak Bölge: 54 il

Hibe tutar1: $268.000 \mathrm{TL}$

Proje süresi: 15 Nisan 2010 - 15 Ekim 2011

Durum: Tamamlandı

Proje y1lı: 2010

Mevcut Durum: Çoğu "zorla" gerçekleşen erken evlilikler, önemli bir sorun odağı. Sebepleri kadar sonuçları da karmaşık ve çok yönlü olan bu sorun, tüm dünyada olduğu gibi Türkiye'de de her yıl binlerce kız çocuğu ve kadını mağdur ediyor.

\section{Proje Sonuçları:}

1.Ziyaret edilen 54 ilde 20.000 kişiye film gösterimi gerçekleştirildi.

2.Film gösterimlerinden sonra toplumsal cinsiyet ve erken evliliklerle ilgili katılımcilarla söyleşiler yapıldı.

3.Ziyaret edilen illerde yerel yöneticiler ve STK'larla da görüşmeler yapıldı. Bu kapsamda 123 STK ve 199 yerel yönetici ile görüşüldü.

4.7 basın mensubu ve TBMM Kadın- Erkek Fırsat Eşitliği Komisyonu Başkanı Güldal Akşit katılımıla basın toplantısı yapıld1.

\footnotetext{
${ }^{1}$ Sabancı Vakfi ‘Çocuk Gelinler’ Projesi verilerinden derlenmiştir.
} 
5.Şarkıcı Burhan Şeşen kampanyayı desteklemek için bir şarkı besteledi.

6.Ziyaret edilen 10 ilde katılımcılarla 32 soruluk anketler ve görüşmeler yapıldı ve "erken evlilik haritası" raporu hazırlandı.

7.30 dakikalık bir belgesel film hazırland1.

8.54 ilde yapılan görüşme ve toplantıların sonucunu anlatan "Küçük Yaşta Evlilik Büyük Geliyor: Çocuk Gelinler" isimli proje kitabı basıldı.

9.İmza kampanyası, internet ve sosyal medya siteleri aracılığıyla yaygınlaştırılarak 8 Mart 2012'de TBMM'ye iletilmek üzere uzatıld1.

10.Çocuk evlilikleri hakkında yeterli nitel ve nicel verinin bulunmaması konusunda kamu kurumlarında farkındalık yaratıldı; ülke genelini temsil edebilecek çok kapsamlı bir araştırma için Başbakanlık Kadının Statüsü Genel Müdürlüğü ve Devlet Planlama Teşkilatı ile görüşmeler başlatıldı.

11.Kültür Bakanlı̆̆ı'nın katkısı ve Milli Eğitim Bakanlığı işbirliğiyle Ankara'nın bütün ilçelerinde önceden belirlenmiş ilköğretim okulları ve liselerde film gösterimleri ve seminerler düzenlemeye başladı.

\section{'Kız Kardeşler Laboratuvarı’ Projesi ${ }^{1}$}

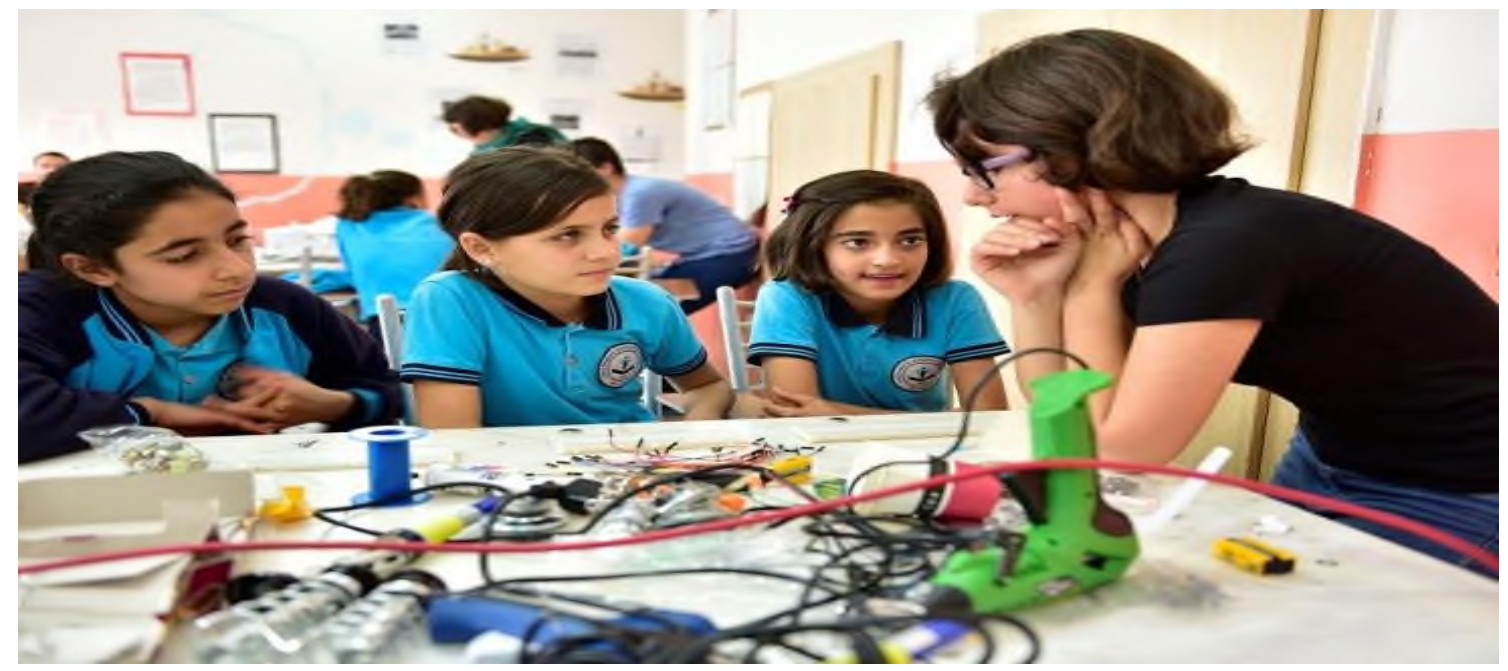

Amacı: Mardin'de okuyan kız öğrencilerin bilim ve teknoloji atölyeleri ile güçlendirilmesi

Bölge: Mardin

Hibe tutar1: $99.838 \mathrm{TL}$

Proje ortağı: Kersnikova Enstitüsü

Proje süresi: 2 Ekim 2017 - 28 Eylül 2018

Durumu: Tamamland 1

Proje y1lı: 2017

\footnotetext{
${ }^{1}$ Sabancı Vakfı, 'Kız Kardeşler Laboratuvarı’ Projesi verilerinden derlenmiştir.
} 
Mevcut Durum: Türkiye'de fen bilimleri ile ilgili meslekleri seçen kadınların oranı erkeklere göre düşüktür. Mardin'de ise genç kızların bilim ve teknoloji ile temas ettikleri ortamlar yok denecek kadar azdır. Dolayısıyla Mardin'de kız öğrencileri için bilim ve teknoloji ile buluşturacak ortamlar yaratılması gerekmektedir.

Projenin Hedefledikleri: Mardin'de bulunan liselerden gelen 28 kız öğrenciyle 3 gün süren bilim ve teknoloji atölyesi gerçekleştirilmesi planlanmıştır. Aralarından seçilen 10 lise öğrencisi İstanbul Makerhane'de 4 günlük bir eğitici eğitimine katılacak. Eğitici eğitimine katılan kızlar, Mardin'de ortaokulda öğrenim gören $32 \mathrm{kız}$ öğrenciyle bilim ve teknoloji atölyesi gerçekleştirecek. Rol model bir bilim kadının katılımıyla projenin uygulanacağı okulda bir konferans gerçekleştirilecek.

Proje Sonuçları: Mardin'in 4 ilçesindeki liselerden gelen 33 kız öğrenci ile 3 gün süren bilimteknoloji atölyesi gerçekleştirildi. Atölyeye katılanlar arasından seçilen 11 öğrenci, İstanbul’a gelerek Robert Kolej'de kız kardeşlerine öğretebilecekleri konuları içeren 4 günlük eğitmen eğitimi atölyesine katıldı. Eğitmen eğitimi alan öğrenciler, Mardin’de 33 ortaokullu kız öğrenci ile birlikte bilim ve teknoloji atölyesi gerçekleştirdi. İstanbul ve Mardin'de yapılan atölyelerin içeriklerini anlatan videolar ve bir kitapçık hazırlandı. NASA Astrofizik Komitesi Başkanı Prof. Feryal Özel, Mardin’de “Astronomide Yeni Ufuklar” başlıklı söyleşi gerçekleştirdi. Söyleşiye 400 kişi katıldı. 


\section{'Nar Taneleri' Projesi ${ }^{1}$}
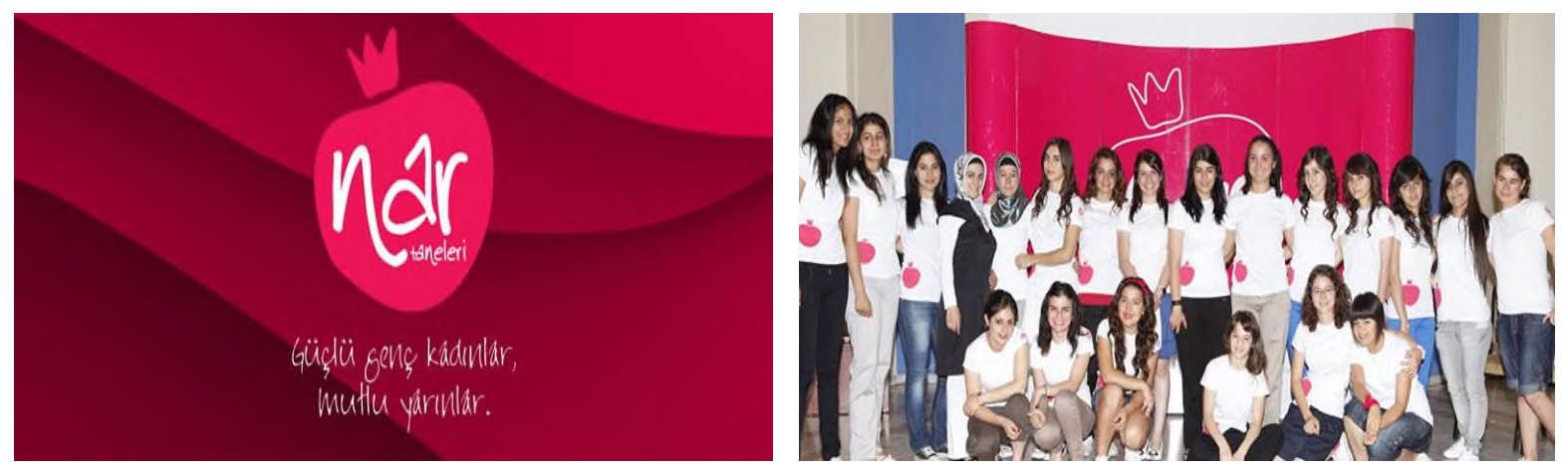

Nar Taneleri - Güçlü Kadınlar Mutlu Yarınlar projesi; toplumda sosyal ve ekonomik dışlanmaya maruz kalan ‘Çocuk Hizmetleri Genel Müdürlüğü’ yetiştirme yurtlarında yetişmiş, 18-24 yaş arası lise ve üniversite mezunu genç kadınların; eğitime devam etmelerinin teşvik edilmesini, kişisel gelişimlerini ve iş arama becerilerini geliştirerek iş gücü piyasasına hazırlanmaları amaçlanmıştır. Nar Taneleri, özel sektör tarafından "yetiştirme yurtlarında" uygulanan kadın odaklı ilk proje olmuştur. Ayrıca Birleşmiş Milletler tarafından örnek proje seçilen Nar Taneleri, birçok ulusal ve uluslararası ödüle de layık görülmüştür. İlk 5 yıl (20092014) yetiştirme yurtlarında yetişen 160 genç kadına kişisel gelişimden, akademik başarı desteğine, yükseköğrenime hazırlıktan meslek seçimi danışmanlığına kadar pek çok alanda eğitimler sunuldu ve genç kadınlar bir monitörlük programıyla desteklenmiştir. 2014-2016 yılları arasındaki ikinci dönemde ise Çocuk Hizmetleri Genel Müdürlüğüne bağlı yurtlarda (sevgi ve çocuk evlerinde) görev yapan 370 bakım personeli, sosyal hizmet uzmanı, psikolog ve öğretmenleri kapsayan bir çalışma yapılmıştır. Çocukların yetiştirilmesinde kişisel bilgi ve yetkinliklerinin artırılması ve 18 yaş altı çocukların yetiştirilmesinde güçlendirme yaklaşımı ile eğitici eğitimleri yaparak Nar Taneleri projesini, sürdürülebilir bir programa dönüştürülmüştür. Eğitmenler eğitilmiş ve süreç yurtlardaki paydaşlara devredilmiştir.

\footnotetext{
${ }^{1}$ Boyner Grup 'Nar Taneleri’ Projesi verilerinden derlenmiştir.
} 
Proje katılımcıları, paydaşları, eğitim personeli, Çocuk Hizmetleri Genel Müdürlüğü çalışanları ile birlikte projeye katılan ve etki alanında olan 69 ilde yaklaşı 40.000 kişi bulunuyor. Proje dâhilinde çalışmalara katılan genç kadınlardan \%88 istihdama katılmış, proje süresince eğitimine devam eden sayısı \%15'e kadar yükselmiştir.

\section{‘'́yi İşler’ Projesi' ${ }^{1}$}
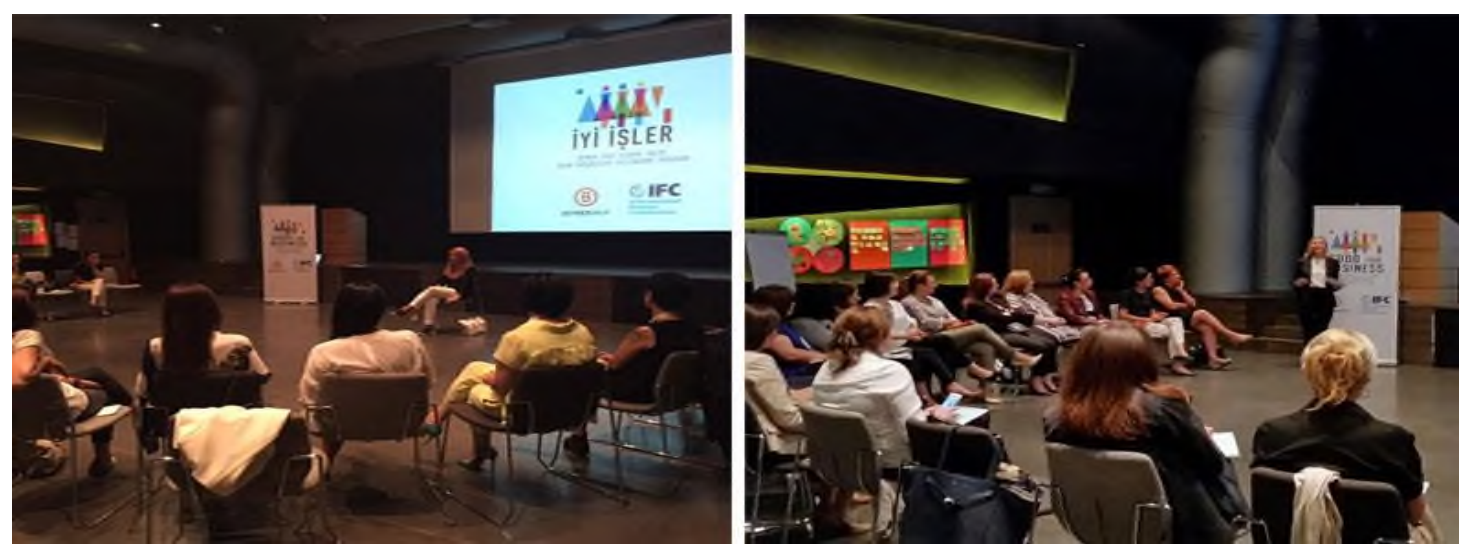

Boyner Grup tarafından 2015 yılında başlatılan ve "İYİ İŞLER” adı verilen Kurumsal Sosyal Sorumluluk (KSS) projesi Boyner Grup tedarik zincirinde yer alan kadın girişimcilere yönelik bir eğitim ve gelişim programı tasarlanmıştır. İyi İşler ile Türkiye'de ve dünyada ilk defa özel sektörde faaliyet gösteren bir şirket, kendi tedarikçi ağında yer alan kadın girişimcilerin ihtiyaçlarını destekleyecek bir kapasite geliştirme programı kurmuştur. "İyi İşler"in eğitim ve gelişim programı Boyner Grup ve Uluslararası Finans Kurumu (IFC) tarafından ortaklaşa hazırlanmıştır. Programın içeriği kadınların taleplerine uygun olarak kadın girişimcilerin sosyal becerileri, iş becerileri ve finansal becerilerini geliştirecek şekilde tasarlanmıştır ve 12 hafta süren bir program ile hayata geçirilmiştir.

Boyner Grup’taki özel markaların üretimini yapan toplam 400’e yakın tedarikçi söz konusudur. Tedarik ağında yer alan kadın girişimci oranı ise yalnızca \%15. Boyner Grup

\footnotetext{
${ }^{1}$ Boyner Grup ‘İyi İşler’ Projesi verilerinden derlenmiştir.
} 
tarafından bu kadınları işlerinin başında tutmak, işlerini büyütmelerini sağlamak ve yeni kadınları da cesaretlendirmek hedefiyle ön planda alınmıştır. Programın ilk döneminde bu tedarikçilerden 25 kadın girişimci 12 hafta süren eğitimlere katılmıştır. Kadın girişimcilerin kapasitelerini artırarak büyümeleri için tasarlanan edilen eğitim programı oldukça başarılı olmuştur. Projenin ikinci döneminde (2018), KAGIDER işbirliği ile yeni kadın tedarikçileri de programa dâhil ederek kadın girişimciliğinin güçlenmesini desteklemeye devam edilmektedir. “İyi İşler” 2016’da New York’ta gerçekleştirilen “Birleşmiş Milletler Kadınların Güçlenmesi Prensipleri Toplantısı'nda da örnek program olarak dünyaya anlatıldı.

\section{Mart Kampanyalari ${ }^{1}$}

Boyner Grubu'nun 2009 yılından bu yana her yıl 8 Mart Dünya Kadınlar Günü’nde toplumsal cinsiyet eşitliğini gündeme taşıyacak bir kampanyayla, değerleri ve cinsiyet eşitliğine bakış açısı paylaşılmıştır. Bu ilanlarla toplumsal cinsiyet eşitliği konusu işveren yaklaşımıyla gündeme taşınmış ve iş dünyasından ve toplumun tüm kesimlerinden kadınların eşitlik ve özgürlük taleplerine destek vermek amaçlanmıştır.

İlanlar aracılığıyla kadın-erkek eşitliğine ilişkin oluşturulması gereken destekleyici politika ve uygulamalara dikkat çekiyor, bu alanda toplumsal gündem oluşturma çabaları destekleniyor. Tepe yönetimi başta olmak üzere tüm yöneticiler bu konuda kamuoyunda farkındalık yaratmaya ve kadın haklarına özel platformların gerçekleştirdiği etkinlik ve konferanslara katılmaya teşvik ediliyor. Dünya Kadınlar Günü’ne özel iç ve dış iletişimin yanı sıra, üniversite ve sivil toplum paydaşları ile bir araya gelinen platformlarda çalışmalar ve topluma vermek istenen mesajlar paylaşılıyor. Küresel platformlarda aktif varlık göstererek çalışmalar sadece ülke içerindeki paydaşlar ile sınırlamıyor, yurt dışına da taşıyor.

\footnotetext{
${ }^{1}$ Boyner Grup ‘8 Mart Kampanyaları' verilerinden derlenmiştir.
} 

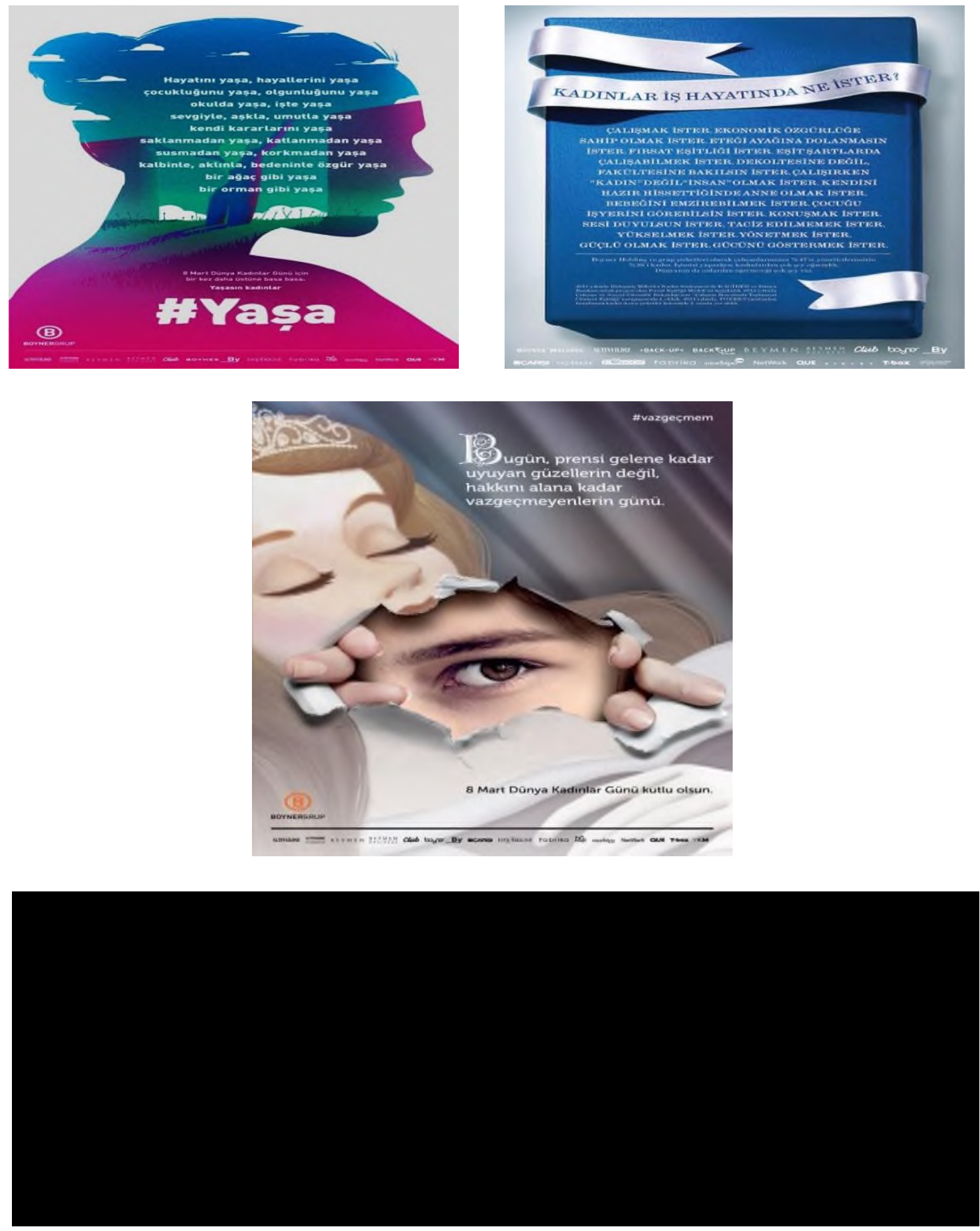


\section{Sonuçlar}

Cinsiyet eşitliği sadece temel bir insan hakkı değil aynı zamanda barışçı1, müreffeh ve sürdürülebilir bir dünya için gerekli bir temeldir. Kadın ve kız çocuklarının eğitime eşit erişim, sağlık hizmeti, iyi iş ve siyasi ve ekonomik karar alma süreçlerinde temsil edilmesi, sürdürülebilir ekonomileri besleyecek ve toplumlara ve insanlığa büyük ölçüde fayda sağlayacaktır. Nitekim kadınların yeterince özgürleşmediği ve güçlenmediği bir dünyada kalkınma da mümkün olmayacaktır.

Toplumsal cinsiyet eşitliğine dair politika kararlarının uygulama örneklerine bakıldığında, öncelikli olarak, toplumsal cinsiyet eşitliğine dair bilinç oluşturma çabaları dikkat çekmektedir. Toplumsal cinsiyet eşitliği bilinci oluşturma çabaları sadece kadınları değil, toplumun tüm kesimlerini içermekte ve özellikle erkeklerin toplumsal cinsiyet eşitliğine dair bilinçlendirilmesi (HeForShe girişiminde olduğu gibi), konuyu sadece kadınların değil tüm toplumun meselesi haline getirmek açısından etkili bir yaklaşımdır.

Çocuk gelinlerin önlenmesine ilişkin bilinçlendirme projeleri; ders araç gereçlerinde kullanılan toplumsal cinsiyet eşitsizliği oluşturan unsurların bilinçli olarak denetlenmesi ve giderilmesi, toplumsal cinsiyet eşitliğine duyarlılığın artmasına ve bu tür yaklaşımların çoğalmasına yardımcı olacaktır. Nitekim uluslararası girişimler ve uygulamalarına ilişkin çabaların yanında, toplumsal cinsiyet eşitliği bilincinin oluşması ailede başlayan, toplumda desteklenen politika ve uygulamaların kültürel örneklerinin bireye aktarılması ile mümkün olabilir.

Toplumsal cinsiyet eşitliği ve kadının güçlenmesi için uluslararası girişimler ve oluşturulan ağlar, katılımın özendirilesi ve kurumsal yapılarla ve yöneticilerin bu tür çalışmaları gerçekleştireceğine dair taahhütleri içermesi sürecin hızlanması ve farkındalığın artması için önemlidir. Uluslararası girişimler (BM Küresel İlkeler Sözleşmesi gibi) ve bunları destekleyen 9,946 şirket, 162 ülke, dünyada ve Türkiye'de kurumsal sorumluluk yapılanmalarıyla birlikte, 
iş yaşamında kadının desteklenmesine ilişkin uygulamaların artmasında pozitif etki sağladığı görülmektedir.

İşyerinde toplumsal cinsiyet eşitliği öncelikli olarak işverenin sorumluluğunda olmalıdır. Nitekim toplumun her kesiminde, özellikle eğitim ve işyerinde cinsiyet eşitliğine duyarlı yöneticiler ve kurumsal kültürün geliştirilmesi bu konuda yol almaya katkı sağlayacaktır.

Kadınların başarısındaki birçok sistemik engelin üstesinden gelinmesinin önemli yollarından biri, kadınların yerel, bölgesel ve ulusal mevzuata katılımının güçlendirilerek değişim ajanları olarak arttırılmasıdır. Toplumsal cinsiyet eşitliğinin güçlendirilmesinde, çarpan etkisi büyük projeler çok daha etkili olacaktır. Bu nedenle, toplumsal cinsiyet eşitliğine dair çabalar, projelerle uygulamaya geçirilmeli; projeler, sorunlardan doğrudan ve de dolaylı olarak etkilenen tüm tarafları içine alan bir yaklaşım taşımalıdır.

\section{Kaynaklar}

CE (2015). Gender Equality Strategy 2014-2017, Council of Europe: February 2014, Reprinted at the Council of Europe: June 2015

EBRD (2015). Strategy for the Promotion of Gender Equality 2016-2020 Making Business Transformative: Creating Opportunities for All. European Bank for Reconstruction and Development

Özaydınlık, K. (2014). Toplumsal Cinsiyet Temelinde Türkiye'de Kadın ve Eğitim. Sosyal Politika Çalışmaları Dergisi, Sayı 33, Temmuz-Aralık 2014. Ss. 93-112 ISSN: 2148-9424

Tilev, F.(2018). Esnek Çalışma ve Kadın İstihdamı. Fırat Üniversitesi İIBF Uluslararası İktisadi ve İdari Bilimler Dergisi Cilt:2,Sayı:2,2018 121, s. 123

UN (2010). The World's Women 2010: Trends and Statistics, Department of Economic and Social Affairs. New York: United Nations.

UN (2019) [Online]. UN Global Compact: https://www.unglobalcompact.org

UN (2019) [Online]. UN Women: https://www. https://www.unwomen.org

UN (2019) [Online]. Women Principles: https://www.unglobalcompact.org/engage-locally/manage/engagement/womensempowerment-principles 
WB (2012). Gender and Development. The World Bank Development Report 2012. Washington, DC 20433, USA

WEF (2017). The Global Gender Report. Report, ISBN 978-1-944835-12-5 


\title{
WOMEN IN BUSINESS LIFE IN THE $20^{\mathrm{TH}}$ CENTURY OTTOMAN EMPIRE: A CASE ANALYSIS
}

\section{Hakan BİLGEÇ ${ }^{1}$}

\begin{abstract}
Despite the need for women in economic life and as a result of which women are encouraged to enter work life in the $20^{\text {th }}$ century Ottoman Empire, women have faced many discrimination and problems due to gender perception. These issues should be examined separately in terms of women who are working in companies and women who are the founder of the companies. In the scope of this review, the two companies operating in the relevant period provide us with striking data. The first company is the "Dersaâdet Telefon Anonim Şirket-i Osmâniyesi" which was established with foreign capital. This company has hired seven Muslim women for the first time as employee. Our second example is "Hanımlara Mahsus Eşya Pazarı Anonim Şirketi" which was founded by Ottoman women. Although all of the founders of this company were women, in later time they could not take part in the management of their own company. In our paper, by these two companies, the obstacles imposed on women in economic life in the $20^{\text {th }}$ century Ottoman Empire will be examined under equality right (as a human right) and companies law.
\end{abstract}

Keywords: Business Life, Ottoman Empire, Gender, Woman, Equality Right, Companies Law.

\footnotetext{
${ }^{1}$ Asst. Prof. Dr. Faculty of Law Eastern Mediterranean University, hakan.bilgec@emu.edu.tr; ORCID: 0000-00017951-0756
} 


\section{YÜZYIL OSMANLI IMPARATORLUĞU ÇALIŞMA HAYATINDA KADIN: BİR VAKA ANALIZİ}

\section{$\ddot{O} z e t$}

20. yüzyıl Osmanlı Impratorluğu ekonomik hayatında kadınlara duyulan ihtiyaç ve bunun sonucunda kadınların çalışma hayatına girmesinin teşvikine rağmen, bu dönemde kadınlar toplumsal cinsiyet algısı dolayısıyla birçok ayrımcılı̆̆a uğramış ve sorunlarla yüz yüze kalmışlardır. Söz konusu sorunları, şirketlerde çalışan pozisyonunda bulunan kadınlar ve şirket kurucusu konumunda olan kadınlar bakımından ayrı ayrı incelemek gerekir.

Bu incelemeler kapsamında ilgili dönemde faaliyet gösteren iki şirket bizlere çarpıcı veriler sunmaktadır. Şirketlerden ilki, yabancı sermayeli "Dersaâdet Telefon Anonim Şirket-i Osmâniyesi” dir. Bu şirket bir ilke imza atarak yedi müslümna kadını işe almıştır. İkinci örnek ise bizzat kadınlar tarafından kurulan "Hanımlara Mahsus Eşya Pazarı Anonim Şirketi”dir. Anılan şirketin ise, kurucularının tamamı kadın olmasına rağmen, dönemin koşulları nedeniyle ilerleyen zamanlarda kadınlar kendi kurdukları şirketin yönetimde yer alamamışlardır.

Çalışmamızda bu iki şirkette yaşanan çarpıcı olaylar gözönünde tutularak Osmanlı'nın son dönemindeki toplumsal cinsiyet anlayışının ekonomik yaşamda kadınlara getirdiği engeller bir insan hakkı olarak eşitlik hakkı ve şirketler hukuku bakış açılarılyla incelenecektir.

Anahtar Kelimeler: Çalışma Hayatı, Osmanlı İmpratorluğu, Toplumsal Cinsiyet, Kadın, Eşitlik Hakkı, Sirketler Hukuku.

\section{Giriș}

Türk tarihinde kadın eski zamanlardan beri çalışma hayatının içinde olmuştur. Ancak, İslamiyet'in kabulünden sonraki dönemde kadınların çalıştığı alanlar kamusal alandan uzaklaşmıştır. Osmanlı İmparatorluğu'nda da tanzimat dönemine kadar kadının çalışma hayatının kamusal alandan önemli ölçüde ayrıştı̆̆ı gözlenmektedir. Tanzimat Fermanı ile birlikte ise devlet politikası olarak “yüzünü batıya çeviren” Osmanlı İmparatorluğu, batılılaşma hamleleri kapsamında eğitim, sağlık, güvenlik gibi alanlarda yeniliklere başlamıştır. $\mathrm{Bu}$ dönemde özellikle kız çocuklarının erkekler tarafından eğitilmesine karşı çıkan muhafazakar toplum yapısı nedeniyle kadınlar kamusal alanda öğretmen olarak faaliyet göstermeye 
başlamışlardır. Daha sonraki süreçte kadınlar, hastabakıcılık, ebelik, kolculuk ve gardiyanlık da yapmaya başlamışlardır.

Osmanlı İmpratorluğu'nda kadınların, özellikle de müslüman kadınların kamu hizmeti niteliğindeki işlerde çalışmaya başlamaları II. Meşrutiyet'in ilânından sonraki sürece rastlar. Batılı devletler tarafindan “hasta adam” olarak nitelendirilen Osmanlı İmparotorluğu'nun adeta ölüm döşeğinde olduğu bu dönemin, kadınların çalışma hayatına katıldığı bir dönem olabilmesi (Göle, 2016: 70) birden çok toplumsal olayın birlikte gerçeklemesinin sonucudur. Bunlardan ilki şüphesiz II. Meşrutiyet'in ilânından sonra ülke yönetiminin İttihad ve Terakki Cemiyeti'ne geçmesi ve bu Cemiyetin kadınlara yönelik bakış açısıdır. II. Meşrutiyet ile gerçekleşen siyasi devrim, toplumsal hayata da yansıtılmak istenmiş ve kadınların geleneksel yaşam biçimini bırakarak toplumsal yaşama katılmaları arzu edilmiştir (Göle, 2016: 77). İkinci önemli olgu ise 1908 yılında II. Meşrutiyet'in ilânından yalnızca üç sene sonra başlayan ve 1911-1923 yılları arasında neredeyse kesintisiz on iki yıl boyunca devam eden savaşlar dönemidir. Trablusgarp Savaşı ile başlayan savaşlar dönemi, Balkan Savaşları, I. Dünya Savaşı ve Kurtuluş Savaşı takip etmiştir. Belirtmek gerekir ki, söz konusu durumların ortaya çıkışı kadınların çalışma hayatına doğrudan katılmalarına yetmemiş, bu konuda ciddi mücadele vermelerini de gerektirmiştir.

Çalışmamızda, Osmanlı İmparatorluğu'nun savaşlar dönemi olarak adlandırdığımız döneminde kadınların çalışma hayatına katılmaları bakımından sembolik önem taşıyan iki vaka üzerinde durulacaktır. Bunlardan ilki, müslüman kadınların çalışan olarak "Dersaâdet Telefon Anonim Şirket-i Osmâniyesi”ne katılım süreçleri; ikinci ise Osmanlı İmparatorluğu'nda kadınlar tarafından kurulan bir şirket olan “Hanımlara Mahsus Eşya Pazarı Osmanlı Anonim Şirketi”nin serüvenidir. 


\section{Savaşın Toplumsal Cinsiyet Üzerine Etkileri}

\section{Savaşa Katılan Sanayileşmiş Ülkelerde}

Savaş dönemlerinde ülkelerin toplumsal cinsiyet algıları önemli ölçüde değişime uğrar. Bunun en somut örneği o ana kadar Dünya tarihinde eşi görülmemiş bir şekilde katılan ülkeler bakımından topyekün savaşa dönüşen I. Dünya Savaşı esnasında gözlemlenmiştir.

Savaşları sona erdirecek savaş olarak lanse edilen ve çok kısa bir süre içerisinde tamamlanacağı öngörülen I. Dünya Savaşı, 28 Haziran 1914 tarihinde Avusturya-Macaristan İmpartorluğu veliaht prensi Franz Ferdinand'ın Saraybosna'da bir genç bir Sırp milliyetçisi Gavrilo Princip tarafından öldürülmesiyle başlamış ve beş kıtaya yayılan savaş aralıksız dört yıl boyunca devam etmiştir. I. Dünya Savaşı, savaşları sona erdiren bir savaş olamamış, ancak bu savaş imparatorlukların tarih sahnesinden büyük ölçüde silinmesine yol açmıştır. Savaş sonunda Osmanlı İmparatorluğu ve Avusturya-Macaristan İmparatorluğu dağılmış, savaş devam ederken Rusya'da çarlık rejimi sona erdirilmiştir.

İngiltere, Fransa, Almanya gibi endüstri devrimini gerçekleştiren ve sanayileşen devletlerin bu kadar uzun süren bir savaşa girmesi ve ülkede erkek nüfusu zorunlu olarak savaş alanına kaydırmaları bu ülkeleri işgücü bakımından ciddi bir ihtiyaçla karşı karşıya bırakmıştır. Söz konusu işgücü ihtiyacı büyük ölçüde kadınlar tarafından tamamlanmıștır. Savaş döneminde kadınlar "savaş zamanı işleri” ve "barış zamanı işleri” olmak üzere iki ana grupta faaliyet göstermişlerdir. Savaş zamanı işleri, doğrudan savaş ile ilgili olan işler olup, cephane üretimi, savaş alanlarında hemşirelik, hasta bakıcılık gibi işler bu grupta sayılabilir. Barış zamanı işleri ise savaştan büyük ölçüde bağımsız olan, bu işgücünde çalışanlar erkekler savaşır halde oldukları için işgücüne ihtiyaç duyulan işlerdir. Savaş zamanı işleri, savaşın bitmesi ile tasfiye edildiğinden, bu grupta çalışan kadınların çoğu savaş sonunda işsiz kalmışlardır. Barış zamanı işlerinde durum farklı olmakla birlikte sonuç aynıdır. Bu işler, savaş sonrası devam etmiş lakin, ülkeler istidam politikası olarak savaştan dönen erkeklere öncelik vermiş, 
kadınların ise çoğu işlerinden çıkarılmışlardır. Çalışmaya devam edebilen az sayıdaki kadına ise, savaş döneminde aldıkları ücretlerden daha azı teklif edilmiş, aynı işi yapan erkekler ve kadınlar arasında erkekler lehine farklı ücret uygulamasına gidilmiştir. Zira, toplumsal algı erkeğin bir aile geçindirmekle yükümlü olması ve dolayısıyla da kadınlardan daha yüksek ücret alması gerektiği yönündedir.

\section{Osmanlı İmparatorluğu'nda}

Osmanlı İmpartorluğu'nda ise süreç, savaşa katılan endüstrileşmiş ülkelerden farklı şekillenmiştir. Öncelikle belirtmeliyiz ki, Osmanlı İmparatorluğu savaş döneminde endüstri devrimini tam olarak gerçekleştirememiş, ekonomisi tarıma dayalı olan bir devlettir. Ayrıca, savaş döneminde tüm erkekler değil, sadece müslüman erkekler silah altına alınmıştır. Gayrimüslim olarak nitelendirilen müslüman olmayan erkeklerse orduya katılmamışlardır. Bunun nedeni, İmparatorluğun Balkan Savaşları'nda yaşanan tecrübeler nedeniyle gayrimüslim erkeklere silah teslim etmekten duyduğu çekincedir. Dolayısıyla göçlerin etkisi ayrı tutulursa savaş süresince gayrimüslim erkeklerin çalıştıkları alanlarda işgücü ihtiyacı doğmamıştır. Müslüman erkeklerin silah altına alınması ise, müslüman kadınların ekonomik açıdan büyük ölçüde zor durumda kalmalarına neden olmuştur. Bunun da etkisi ile müslüman kadınlar kamusal alanda çalışma konusunda istekli olmak durumunda kalmışlardır. Müslüman kadınların bu istekleri, toplum tarafından ise kolay kabul görmemiştir.

Dönemin öncülerinden Emine Seniye Ali Hanım'ın şu sözleri II. Meşrutiyet'in ilân edildiği dönemde kadınların toplumsal statülerinin ve ekonomik durumlarının anlaşılabilmesi bakımından oldukça önemlidir:

“Kadınlar havasız, kötü kokulu vapur mevkilerine hapse tıkılırcasına kapatılmadan seyahat edebilsin, vapurlardan çıkarken, tramvaylara binerken kadınlara öncelik tanınsın, alışveriş için sabahın erken saatinde yola koyulanların akşama kadar sadece simit, peynirle karın doyurmak 
zorunda kalmaması için, hizmetlileri kadınlardan oluşan lokantalar açılsın, millet bahçelerinde kadınlara seyrek kafeslerle bölünmüş bir yer ayrllsın, tiyatrolar, tarihi ve ahlaki nitelikli oyunları kadınlar için de gösterime koysun, yoksul kadınlar orada burada süreneceğine yardımsever hanımların kuracă̆ kurumlar aracılı̆̆ ile ticarete atılabisin." (Tümer Erdem/Yiğit’ten, 2010: 108).

Söz konusu dönemde kadınların kamusal alanda çalışabilmelerinin, ekonomik durumlarını iyileştirmenin yanı sıra diğer kadınlar bakımından yararlı olacağı Emine Seniye Hanım'ın çalışanları kadınlardan oluşan lokantalarda, kadınların rahatça yemek yiyebileceğine ilişkin sözlerinden anlaşılmaktadır.

Savaş döneminde Osmanlı İmparatorluğu'nda boşalan devlet kadrolarının kadınlarla tamamlanmasına çok sıcak bakıldığı söylenemez. Bu dönemde kadınlar Maliye Nezareti ve İstanbul Postanesi’nde görev alabilmişlerdir. Öte yandan, Osmanlı Bankası ve Dersaâdet Telefon Anonim Şirket-i Osmâniyesi ile kadınlar kamu hizmeti ile uğraşan özel sektör kuruluşlarında görev alabilme olanağı bulmuşlardır.

Diğer ülkelerden farklı olarak değinilmesi gereken bir diğer husus ile Osmanlı İmparatorluğu'nda savaşlar döneminde kamusal alanda çalışmaya başlayan kadınların adeta bu durumu kazanılmış hakka dönüştürmüş olmalarıdır. Başka bir deyişle, kadınların kamusal alanda çalışmaları savaş süresi ile sınır kalmamıştır. Bu yönü nedeniyle Ahmed Emin Yalman, Osmanlı İmparatorluğu'nun savaşın kaybedenlerinden olmasına karşın, kadınlarının savaşın kazananlarından sayılması gerektiği görüşündedir (Yalman, 1930: 235-238). Türk öğretisinde de I. Dünya Savaşı'nın Osmanlı kadınını kölelikten kurtadığı da belirtilmektedir (Abadan Unat, 1990: 1; Tekeli, 1982: 198-199). 


\section{Dersaâdet Telefon Anonim Şirket-i Osmâniyesi’nin Müslüman Kadın Çalışanları}

\section{İşe Alınış Süreci}

Telefon, Osmanlı İmparatorluğu'nda ilk olarak 1881 y1lında İstanbul'da kullanılmaya başlanmıştır. Bir noktadan diğerine çekilen hatlar üzerinden iletişim olanağı veren telefonlar beş yıl boyunca devletin kullanımında kalmış ancak 1886 yılında dönemin padişahı II. Abdülhamid tarafından yasaklanmıştır. Yasak, II. Meşrutiyet'e kadar devam etmiş; II. Meşrutiyet'in ilânından sonra 10 Mayıs 1909 günü İstanbul Sirkeci'de kurulan elli hatlık bir santral ile İstanbul yeniden telefona kavuşmuştur (Karakışla, 2014: 21). Telefon kısa sürede büyük ilgi görmüş ve bunun üzerine "Posta ve Telgraf ve Telefon Nezareti" tarafindan İstanbul'un tamamında faaliyet gösterecek bir telefon sistemi kurulması için çalışmalara başlanmıştır. Bu arayışlar doğrultusunda 1909 y1lında "Meclis-i Mebusan" ve "Meclis-i Ayân" tarafından kabul edilen ve Padişah V. Mehmed Reşad'ın onayı ile keşinleşerek yayınlanan tek maddelik bir kanun ile imtiyaz verilmesi kararlaştırılmıştır (Tan, 1967: 300).

İmtiyaz, Amerikan Western Electric Company, İngiliz British Insulated Helsby Cables Limited Company ve Fransı Compagnie Française pour l'Exploitation des Procédés Thompson Huston şirketleri tarafindan kurulan konsorsiyuma verilmiş olup, daha sonra National Telephone Company Limited de bu konsorsiyuma dahil olmuştur. Verilen imtiyaz uyarınca İstanbul'da otuz yıl süreyle telefon hizmetini yürütmek üzere Dersaâdet Telefon Anonim Şirket-i Osmâniyesi adında bir şirket kurulmuştur (Tan, 1967: 300). Şirketin sermayesinin yüzde altmışı İngilizlere, yüzde yirmi beşi Fransızlara, yüzde yedisi Amerikalı'lara, kalanı da “diğer”lerine ait olup merkezi de İstanbul'dadır (Tan, 1967: 301).

O dönemde Avrupa'da telefon santrallerinde kadınların çalışması adeta bir gelenek halini almış olduğundan, altyapısını iki yıl içinde tamamlayan Dersaâdet Telefon Anonim Şirket-i Osmâniyesi 1913 yılında santrallerde çalışacak kadın memur arayışına girmiş ve bu amaçla gazete ve dergilere ilanlar vermiştir. Şirketin ilân verdiği dergilerden birisi de Kadınlar 
Dünyası Dergisi olmuştur. Kadınlar Dünyası, 17 Nisan 1913 ve 21 Mayıs 1921 tarihleri arasında önce gündelik, yüzüncü sayısından itibaren de haftalık olarak toplam iki yüz sekiz sayı yayınlanan ve Müdafaa-i Hukuk Nisvan Cemiyeti'nin yayın organı niteliğinde gösterilen dönemin en önemli kadın dergisidir (Çakır, 2011: 133, Karakışla, 2014: 12, dn. 1; Baysal, 2017: 345). Derginin yazarları müslüman kadınlara kamusal alanda çalışma olanağı sağlayacağını düşündükleri bu ilândan büyük heyecan duymuş ancak ilân derginin okuyucularında aynı etkiyi yaratmamış ve müslüman kadınlar arasından ilâna başvuran olmamıştır. Bunun üzerine derginin yazarlarından Emine Seniye Ali şu ağır sözlerle kadınları eleştirmiştir:

“...Erkeklerimizde olduğu gibi, yalnız söz söylemeyi biliyormuşuz, faaliyet bizde dahi yokmuş. Maksadlarımız, gayelerimiz, şöyle olacak, böyle olacak, bu türlü yapacağız demekten ibaretmiş. (...) darılmayalım ama bizde âsâr-ı hayât (yaşam belirtisi) olarak görünen yalnızca çene var." (Ali: 2).

İlânın derginin okuyucularda beklenen etkiyi yaratmaması üzerine, dergi yönetiminin de 1srarı ve müslüman kadınlara örnek olması amacıyla Osmanlı Müdafa-i Hukuk Nisvan Cemiyeti üyelerinden Ayşe Bedra Osman dört kadınla birlikte Dersaâdet Telefon Anonim Şirket-i Osmâniyesi'ne ilk başvuru yapmaya karar vermişlerdir (Karakışla, 2014: 29-31). Başvuru yapacakları doğru yeri uzun uğraşlar sonunda bulan kadınların başvuru süreçleri bekledikleri gibi gitmemiş, karşılarına çıkan şirket tercümanı Sürenyan (Sir Noyan) Efendi, Fransızca ve Rumca bilmeyen kadınların bu işe başvuramayacaklarını hakaretvari bir şekilde belirterek başvuruları almayı reddetmiştir. Sürenyan Efendi'nin Ayşe Bedra Osman ve arkadaşlarına karşı sergilediği tutumun altında müslüman kadınların telefon başında elverişli iş göremeyecekleri düşüncesinin yattığı da belirtilmektedir (Karakışla, 2014: 33). Ancak kadınlar, başvuru konusunda kararlı bir duruş sergilemişler ve şirket başvuruları almak durumunda kalmıştır. Başvuruların sonuçlandırılması ise bir yıl sürmüştür. Bu süreçte müslüman kadınların 
işe alınması için Müdafaa-i Hukuk Nisvan Cemiyeti de etkin çaba göstermiştir (Göle, 2016: 71).

Ayşe Bedra Osman, 9 Mayıs 1913 tarihinde Kadınlar Dünyası'nda Dersaâdet Telefon Anonim Şirket-i Osmâniyesi ve Nafıa Nazırlığı'na hitaben, Sürenyan Efendi'nin tavırlarını anlatan açık bir mektup yayınlamıştır. Bu mektuba her iki muhatabın da herhangi bir yanıt gelmeyince Kadınlar Dünyası ısrarlı bir şekilde konunun üzerine giderek Nafia Nazırlığı'ndan şirketin imtiyaz sözleşmesinde santral memurlarının Fransızca ve Rumca bilmeleri gerektiği yönünde bir madde olup olmadığını açıklamasını istemişlerdir. Dergide, 1900'lü yılların başında etkili olan milliyetçilik akımının da etkisiyle şirketin bu taleplerinin Türk kadınlarında “acı hisler” uyandırdığını belirtilmiştir (Çakır, 2011: 379).

Halbuki hassasiyetler bir kenara bırakılırsa 1913 y1lında İstanbul'daki kozmopolit yapıda, telefon santrallerinde görev yapacak kişilerin o dönem İstanbul'da en çok konuşulan yabancı dil konumundaki Fransızca'ya hakim olmalarının aranması eleştirilmemelidir. Buna karşın Rumca bakımından aynı şeyleri ifade etmek mümkün değildir. Nitekim, Karakışla da, Rumca bilme şartının Sürenyan Efendi tarafından "uydurulduğu” düşüncesindedir (Karakışla, 2014: 55)

Kadınlar Dünyası'nın konu ile ısrarlı yayınları dönemin büyük yayın organlarında çok fazla dikkate alınmamıştır. Fakat, Abdullah Cevdet'in, sahibi olduğu İçtihad dergisinde Kadınlar Dünyası Dergisi’nin başyazarı Ulviye Mevlan'ın “İzahat Bekleriz, Özür Temenni Ederiz” başlıklı yazısına (12 Mayıs 1913) verdiği cevap (15 Mayıs 1913) sürecin seyrinde önemli bir dönüm noktası olmuştur. Abdullah Cevdet cevabında dört noktaya dikkat çekmiştir:

1. Özür "temennisindeyiz" yerine "azmindeyiz" ifadesi kullanılmadıkça hiçbir şey elde edilmeyeceği,

2. Hak haktır, verilmeyince alınır düsturuyla hareket edilmesi gerektiğgi, 
3. Şirketin santral memurlarının Fransızca bilmesi istemesinin yukarıda belirttiğimiz gerekçelerle haklı bir talep olduğu,

4. İstenilen özrün elde edilebilmesi için greve gidilmesinin doğru olacağı, ancak Kadınlar Dünyası'nın toplumda bu etkiye sahip olmadığı.

Hemen belirtelim ki, Abdullah Cevdet'in grev kavramını, bu kavramların henüz tam olarak dile yerleşmediğinden hareketle yanlış kullandığı kabul edilerek, grev çağrısı aslında boykot çağrısı olarak anlaşılmalıdır (Karakışla, 2014: 41).

Kadınlar Dünyası, Abdullah Cevdet'in özellikle Kadınlar Dünyası'nın toplumda boykota neden olacak etkisinin bulunmadığı görüşüne içerlemiş bir şekilde 19 Mayıs 1913 tarihinde yeni bir başyazı yayınlamış ve yazıda

“... bir de bize grev silahı tarif olunuyor, tekrar adab-ı milliyemiz ve terbiye-i içtimaiyemiz düşünülmeden ifrat (aşırılık) yolu gösteriliyor. (...) Biz kadınlar hukukumuzu kendimiz, bizzat kendi ictihadımızla müdafaa edebiliriz.”

ifadelerine ye verilmiştir.

Adeta dergiler arası bir atışmaya dönen bu yazılarda sürekli olarak grev (boykot) kelimesinin geçmesi Dersaâdet Telefon Anonim Şirket-i Osmâniyesi'nde ciddi bir endişeye neden olmuş, şirket faaliyete geçmeden önce olası bir müslüman boykotunu önlemek amacıya müslüman kadınları işe almaya karar vermiş ve bu amaçla Kadınlar Dünyası Dergisine bir temsilci göndererek hem özürlerini hem de çalışacak kadınların seçim sürecinde aracılık yapmaları isteğini iletmiştir. Şirketin bu geri adımının hemen arkasından Nafia Nezareti de Kadınlar Dünyası'na bir mektup göndererek müslüman kadınların işe alınmaları konusunda herhangi bir ayrımcılık yapılmayacağı konusunda bilgi vermiştir.

Müslüman kadınların işe kabulü, Ayşe Bedra Osman'ın şirkete başvuruda bulunuşun birinci yıl dönümünde gerçeklemiştir (Karakışla, 2014: 86). İşe alınan yedi müslüman kadından (Ayşe Bedra Osman, Hamiyet Derviş, Bedia Muvahhit, Mediha Enver, Refika Mustafa, Semiha 
Hikmet, Nezihe Mustafa) biri olan Ayşe Bedra Osman’a müfettişlik pozisyonu verilmiş (Çakır, 2011: 378) ve müslüman kadınların işe alınması Kadınlar Dünyası'nın 17 Nisan 1914 tarihli sayısının kapağında Ayşe Bedra Osman'ın fotoğrafına yer verilerek duyurulmuştur. Aynı zaman diliminde şirkette işe alınan gayrimüslim kadınların sayısı ise yüz yirmidir. Yedi müslüman kadının işe alınış sürecinde yaklaşık iki yüz müslüman kadının başvuruları ise dil engeli nedeniyle reddedilmiştir (Karakışla, 2014: 85). İşe alınan yedi müslüman kadından biri de, daha sonra ilk müslüman kadın tiyatro sanatçılardan biri olarak tarihe adını yazdıracak olan Bedia Muvahhit'tir. Kadınlar Dünyası, işe alınan müslüman ve gayrimüslim kadın sayıları arasındaki bu orantısızlığı "islam kadınlarına karşı bir taassub” olarak nitelemiştir (Çakır, 2011: 379'dan).

Müslüman kadınların işe alınmaları Servet-i Fünûn ve Fransız I'llustration dergileri ile muhabiri Müdafaa-i Hukuk Nisvan Cemiyeti üyelerinden Odette Feldmann olan Berliner Tageblatt'ta da haber olmuştur (Çakır, 2011: 380-382; Karakışla, 2014: 95-97).

Dersaâdet Telefon Anonim Şirket-i Osmâniyesi'nde çalışacak kadınlar için yabanc1 dil koşulunun aranması nedeniyle şirkete kabul edilen müslüman kadınlar iyi eğitim görmüş ve dönemin koşullarına göre ekonomik durumu iyi olan ailelerden gelmişlerdir. Dolayısıyla müslüman kadınlar için Dersaâdet Telefon Anonim Şirket-i Osmâniyesi’nde çalışmak, geçim kaygısından ziyade, müslüman kadınların kamusal alana çıkmaları bakımından bir sembol niteliğindedir. Kadınlar Dünyası'nın süreçteki rolü, kadının toplumsal yaşamda anne ve eş rolünün dışında farklı bir statü kazanma taleplerine ilişkin en etkin rolün basın tarafından üstlenildiği şeklinde yorumlanmaktadır (Baysal, 2017: 345).

Şirketin işe alma sürecindeki bu tavrı esasında hukuka da uygun değildi. O dönemde yürürlükte olan 1909 yılında değişikliğe uğrayan Kanun-i Esasi'nin 17. maddesine göre Osmanlı toplumunun tamamı mensup oldukları dine veya etnik kökene bakılmaksızın eşit konumdalard1. 
"Osmanlıların kâffesi huzuru kanunda ve ahvali diniye ve mezhebiyeden maada memleketin hukuk ve vezaifinde mütesavidir" (Kanun-i Esasi m. 17).

Dolayısyla sadece müslüman oldukları gerekçesiyle kadınların işe alınmaması, yerlerine müslüman olmayan kadınların seçilmesi eşitlik ilkesine de aykırıydı. Esasında gayrimüslüm azınlıkların haklarını teminat alma amacıyla getirilen bu düzenleme Dersaâdet Telefon Anonim Şirket-i Osmâniyesi vakasında tam tersi şekilde işlev göstermeliydi. Bu noktada şirketin, sözleşme özgürlüğü kapsamında, akdedeceği hizmet sözleşmelerinin tarafını serbestçe seçebilme hakkına sahip olduğu kabul edilmekle birlikte, kanımızca bu hakkın eşitlik ilkesi göz önünde tutularak kullanılması daha uygun olurdu.

\section{Kadınların Çalışma Koşulları}

Dersaâdet Telefon Anonim Şirket-i Osmâniyesi’nde kadınların çalışma koşullarına ilişkin temel kaynak, şirket tarafından yayınlanan Telefon Kitabı'dır. Ayrıca şirket, o dönem koşullarına göre oldukça modern olarak inşaa ettiği tesislerini kamuyouna sergileyebilmekte adına rehber eşliğinde turlar da düzenlemiştir. Dolayısyla çalışma koşulları yerinde de gözlemlenebilmiştir.

Şirkette santral memurları kadınlardan oluşmakta ve Muhavere Salonu adı verilen salonda görev yapmaktadırlar. Müslüman kadınlar kullandıkları yeldirme ve başörtüleri ile gayrimüslim kadınlardan ayırt edilebilmekte; peçe ise kullanılmamaktadır. Kadınlar, çalışma saatleri içinde yemeklerini de şirkette yerler ve bu yemeklerin hazırlanması ve yenmesi için kadınlara ayrı salonlar oluşturulmuştur. Yemek salonlarında porselen yemek takımlarının kullanılması, dönem koşullarına göre şirketin kadın çalışanlarına verdiği değerin bir yansıması niteliğindedir (Baysal, 2017: 356). Öğle yemeği araları kırk beş dakikadır, ayrıca kadınların on beş dakikalık çay molası alma hakları da vardır. Haftalık toplam çalışma süreleri ise kırk sekiz saattir. Şirkette kadın çalışanlar, erkek çalışanlarla bir arada bulunamazlar, yemek ve dinlenme 
salonları ile tuvaletleri ayrıdır. İşyerini terk saatleri de farklılaştırılarak kadın ve erkek çalışanların karşılaşması engellenmiştir (Erdem/Yiğit, s. 115).

Dersaâdet Telefon Anonim Şirket-i Osmâniyesi’nde kadınlar ve erkekler arasında ücret konusunda farklı1ık olup olmadığına ilişkin bir kaynak bulunamamıştır. Lakin, şirkette kadınlar ile erkeklerin görev alanları ayrı olduğu için eşit ücret almamaları şaşırtıcı değildir.

Öğretide Dersaâdet Telefon Anonim Şirket-i Osmâniyesi’nde çalışan müslüman kadınların, çarşafa benzer, göğüs kısmında kırmızı kumaş parçası olan aynı tip kıyafet giydikleri belirtilmiş olmakla birlikte (Erdem/Yiğit, s. 115), Karakışla'nın kitabında yer alan fotoğraflar incelendiğinde böyle bir uygulama olmadığı anlaşılmaktadır. Kanımızca Dersaâdet Telefon Anonim Şirket-i Osmâniyesi’nde çalışan kadınlar ile İstanbul Postanesinde çalışan kadınlar birbirine karıştırılmıştır. Nitekim Karakışla da söz konusu kıyafetin İstanbul Postanesinde kullanıldığını belirtmektedir (Karakışla, 2014: 103-104). Üniforma benzeri kıyafet nedeniyle kadınlar sokakta muhafazakar kesimin saldırılarına da maruz kalmış, hatta bazı kadınların kıyafetleri dahi yırtılmıştır (Kaplan, 1998: 31).

Yeri gelmişken belirtelim ki, bir devlet kuruluşu olan İstanbul Postanesinin istihdam politikası, yönetimde bulunan İttihad ve Terakki'nin de etkisiyle Dersaâdet Telefon Anonim Şirket-i Osmâniyesi ile taban tabana zıttır. İstanbul Postanesinde çalışan doksan kadının seksen beşi müslümandır. Ayrıca dil şartı aranmadığı için, bu kadınlar toplumun farklı kesimlerinden gelebilmektedir. İstanbul Postanesinde erkekler ve kadınlar arasında maaş farkı da bulunmamaktadir. 


\section{Hanımlara Mahsus Eşya Pazarı Osmanlı Anonim Şirketi Kuruluşunda Karşılaşılan Sorunlar}

Hanımlara Mahsus Eşya Pazarı Osmanlı Anonim Şirketi'nin kuruluşu ve kuruluşundan sonra karşılaşılan sorunlar da kadınlar çalışma hayatındaki konumları bakımından sembol niteliğindeki örneklerden biridir. Dersaâdet Telefon Anonim Şirket-i Osmâniyesi'ne ilişkin incelememizden farklı olarak kadınlar bu şirkette sadece çalışan konumunda değil aynı zamanda şirketin kurucuları konumundadırlar.

Belirtmek gerekir ki, söz konusu şirket Osmanlı dönemindeki ilk kadın girişimi değildir. II. Meşrutiyet döneminde Fatma Nüzhet Hanım öncülüğünde kurulan Haymana Siyah Kehribar Madeni Işletme Şirket-i Milliyesi ve Fatma Nefise Hanım'ın kurduğu Iş̧ Yurdu kadınların önceki girşimlerine örnek olarak gösterilebilir (Okay, 1999: 12).

Hanımlara Mahsus Eşya Pazarı Osmanlı Anonim Şirketi, İttihat ve Terakki yönetiminin milli ekonomi ve kadınların iş hayatında yer alma girişimlerinin bir sonucu olarak Birinci Dünya Savaşı'nın sonuna yaklaşıldığı dönemde Sultan V. Mehmed Reşad'ın 07 Nisan 1917 tarihli iradesine uygun olarak 18 Ekim 1917 tarihinde kurulmuştur.

Merkezi İstanbul'da bulunan şirketin kurucuları, Fatma Hasene Hanım, Fatma Zehra Hanım ve Ayșe İzzet Hanım'dır. Şirkette müdür, muhasebeci, kapıcı, kadın terzisi ve hamallar dışındaki tüm görevlilerin kadınlardan oluşması öngörülmüştür (Akyıldız, 2018: 176-177).

Şirketin yönetimi, genel kurul tarafindan seçilecek 5-7 kişiden oluşan idare meclisi (yönetim kurulu) tarafından gerçekleştirilecektir. İlk idare meclisi beş y1l görev yapmak üzere kurucular tarafından belirlenmiştir. İdare meclisine üye olabilmek için kırk, genel kurula katılabilmek için ise en az yirmi adet paya sahip olunması zorunludur.

Şirketin sermayesi 30.000 lira olup, her biri 5 lira değerini haiz 6.000 paya bölünmüştür. Esas sözleşmeye göre payların üçte biri, muvazzaf veya emekli subay ailelerine; üçte biri, Eşya- 
yı Askeriyye Ticaret Şirketi'ne, üçte biri de çalışan ve emekli memurlara satılacak; belirlenen gruplar tarafından satın alınmayan paylar ise piyasada satışa sunulacaktır.

Hanımlara Mahsus Eşya Pazarı Osmanlı Anonim Şirketi'nin kadınların çalışma hayatındaki yerleri bakımından önemli bir örnek olmasının nedeni, gerçekleşmesi neredeyse kesin olan, payların satışa sunulması ile bunlardan bazılarının erkekler tarafından satın alınması olasılığı idi. Söz konusu olasılığın gerçekleşmesi, şirketin genel kurulunda kadınlar ve erkeklerin bir arada bulunmasına neden olacaktı. Pay sahibi olan erkeklerin idare meclisine seçilmeleri halinde aynı durum, burada da gündeme gelecekti.

Kadın ve erkeklerin şirkette bir arada bulunma ihtimalleri şirketin kuruluşu sırasında çok önemli bir sorun hale gelmiş ve bu konu "Şûra-yı Devlet Maliye Nafia Dairesi”ne kadar taşınmıştır (Akyıldız, 2018: 177). Şûra-yı Devlet Maliye ve Nafia Dairesi tartışmalarında sorunun çözümü için payların sadece kadınlar tarafından alınabileceğine ilişkin düzenleme yapılması ileri sürülmüş, ancak bu görüş biri ekonomik biri hukuki olmak üzere iki gerekçeyle reddedilmiştir. Ekonomik gerekçe, payların sadece kadınlara özgülenmesi halinde, yeterli sermayenin sağlanamayacağı endişesidir. Hukuki gerekçe ise mülk edinme ve tasarruf konularında kadınlar ve erkeklerin eşit oldukları ve böyle bir düzenlemenin eşitlik ilkesine aykırı olacağı düşüncesidir (Akyıldız, 2018: 177). Bununla birlikte tartışmalar sırasında ileri sürülen öneriler de şu şekilde özetlemek mümkündür:

- Üyelerden İhsan Bey, genel kurul ve idare meclisinde kadınların ve erkeklerin bir arada bulunması "ahkâm ve âdâb-1 milliyyeye mugayir" olduğunu belirterek şirket esas sözleşmesine konulacak bir hükümle genel kurul ve idare meclisinin asaleten veya vekalaten sadece kadınlardan yahut sadece erkeklerden oluşması gerektiğini ileri sürmüştür. 
Anonim şirket genel kurullarına temsilen katılım mümkündür. Ancak, idare meclislerine bizzat katılım esastır. Dolayısıyla, İhsan Bey tarafından ileri sürülen bu görüş sadece kadın - erkek eşitliği bakımından değil, ticaret hukukunun temel ilkeleri karşısında isabetli değildir.

- Edhem Bey ise, tesettüre uygun olmak ve oturacakları yerler ayrı olmak kaydıyla kadınların erkeklerle bir arada bulunmalarında sakınca olmadığı görüşündedir.

- Başkan Nazif Bey ve üyelerden Şadan, Serçiven ve İstefenaki beylerden oluşan çoğunluk görüşü ise genel kurul ve idare meclisinin oluşum şeklinin zabıtaya ait idari bir keyfiyet olduğu gerekçesiyle şirket esas sözleşmesinde buna ilişkin bir hüküm konmasına gerek olmadığı yönündedir.

Şûra-yı Devlet Maliye ve Nafia Dairesi’nin bu görüşü üzerine konu “Şûra-yı Devlet Genel Kurulu" na da taşınmış ve burada da hararetli tartışmalara neden olmuştur. Üyelerden Mustafa Efendi, kadınlar ve erkeklerin ticaret amacıyla da olsa birarada bulunmalarının "hem şer'an, hem hikmet-i içtimaiyye nokta-i nazarından" yasak olduğunu belirtmiştir. Ancak genel kurulun çoğunluk görüşü, kadınların şirket kurması ya da kurulan şirketten pay almalarının erkeklerle ihtilat etmek anlamına gelmeyeceğinden hareketle, bu konuya ilişkin yapılan itirazları reddetmek ya da kabul etmek için görüş bildirmeye gerek olmadığı yönünde şekillenmiştir. Şûra-yı Devlet Genel Kurulu, kadınlar ve erkeklerin bir arada bulunma ihtimallerinin hukuki veya şer’i değil; inzibatı bir mesele olduğunu belirterek, Şûra-yı Devlet Maliye ve Nafia Dairesi'nin kararına paralel olarak, kadınlar ve erkeklerin zabıta tarafından kendileri için ayrılan yerlere oturarak toplantılara katılabilicekleri kararına varmıştır (Akyıldız, 2018: 179).

\section{Tasfiyesi}

Kuruluşu takip eden faaliyet yılında şirket, beklenenin üzerinde bir ekonomik başarı sergileyerek 80.000 liralık işlem hacmine ulaşır ve 30.000 lira olan sermayesini Sultan'ın da onayı ile 100.000 liraya arttırır. Ancak sonraki yıllarda savaşın ekonomik etkileri de gerekçe 
gösterilerek şirketim, Eşya-yı Askeriye Anonim Şirketi ile birleşmesi gündeme getirilir. Yukarıda da belirtildiği gibi Eşya-yı Askeriye Anonim Şirketi, Hanımlara Mahsus Eşya Pazarı Osmanlı Anonim Şirketi’nin paylarının üçte birinin elinde bulundurduğu için iki şirket arasında zaten organik bir bağ söz konusudur (Akyıldız, 2018: 181).

6 Şubat 1921 tarihinde her iki şirketin genel kurulları olağanüstü toplanarak iki şirketin de tasfiye edilerek Şark Eşya Pazarı Osmanlı Anonim Şirketi adını alacak yeni bir şirket çatısı altında birleşmesine karar verirler (yeni kuruluş yoluyla birleşme).

Hanımlara Mahsus Eşya Pazarı Osmanlı Anonim Şirketi’nin birleşmeye ilişkin genel kurul kararından anlaşıldığı kadarıyla 1921 yılında şirketin idare meclisi başkanvekili Mehmet Neşet Paşa'dır. Bu bilgi, şirketin yönetimin erkeklere geçtiğini göstergesidir. Sultan Mehmet Vahideddin'in 8 Ağustos 1921 tarihli iradesiyle resmen kurulan Şark Eşya Pazarı Osmanlı Anonim Şirketi'nin ilk idare meclisi, Suphi Ziya Bey, Kemal Ömer, İpekçi İsmail Efendi, İbrahim Hakkı Paşa, Mehmet Neşet Paşa, Abdullah Bey ve Mehmet Esat Bey’den oluşur. İdare meclisinin bu yapısı, yeni kurulan şirketin yönetiminde kadınlara söz hakkı tanınmadığının somut belgesi niteliğindedir. Kuruluş amaçlarından biri kadınların iş hayatında yer almalarını sağlamak olan Hanımlara Mahsus Eşya Pazarı Osmanlı Anonim Şirketi bu amacını gerçekleştirmekte istenen başarıyı ne yazık ki sağlayamamış, gösterdiği ekonomik başarıya rağmen tasfiye edilerek yönetimi sadece erkeklere bırakılan bir şirkete dönüşmüştür.

\section{Sonuç}

Yalnızca 23 yıl süren Osmanlı İmparatorluğu'nun 20. yüzyıl serüveni kadınların toplumsal hayatta varolmaları ve özellikle çalışma hayatında yer almaları bakımından önemli gelişmelere sahne olmuştur. Çalışmamız kapsamında bu gelişmelere örnek olarak iki vaka incelenmiştir. 
İncelediğimiz ilk vaka Dersaâdet Telefon Anonim Şirket-i Osmâniyesi’nin kadınları işe alış sürecidir. Osmanlı İmparatorluğu'nda kadınların, sadece cinsiyete bağlı olarak değil, dine bağlı olarak da toplumsal hayatta yer alma çabalarının önüne çıkarılan engelleri ve bu engellerin ortadan kaldırılmasında basının da gücünü ortaya koyması bakımından bu vaka çarpıcıdır.

İnceleme kapsamımıza aldığımız ikinci vaka ise kadınların ticaret hayatında yönetici pozisyonlarına ulaşmada yaşadıkları zorluklara ilişkin önemli bir tarihsel örnektir. Esasında kadınların ticaret hayatında yaşadığı zorluklar günümüzde de tam olarak ortadan kaldırılmış değildir. Özellikle "cam tavan sendromu” olarak adlandırılan kadınların üst düzey yönetici pozisyonuna ulaşmalarını engelleyen davranışsal ve kurumsal önyargılar varlığını devam ettirmektedir (Songur, 2019: s. 417-422). Hanımlara Mahsus Eşya Pazarı Osmanlı Anonim Şirketinin kuruluş aşamasında Şûra-yı Devlet Maliye ve Nafia Dairesi ve Şûra-yı Devlet Genel Kurulu'nda yaşanan tartışmalar kadınların, toplumsal cinsiyet algısı nedeniyle yaşadıkları zorlukları çok açık bir şekilde ortaya koymaktadır. Hanımlara Mahsus Eşya Pazarı Osmanlı Anonim Şirketi'nin bu tartışmalara rağmen kuruluşunu tamamlamış olsa da, kısa sayılabilecek bir süre içinde birleşme yoluyla sona ermesi ve birleşme sonucunda yeni kurulan Şark Eşya Pazarı Osmanlı Anonim Şirketi’nin yönetiminde kadınlara yer verilmemesi de bu önyargıların ne derece etkili olduğunu kanıtlar niteliktedir.

\section{Kaynaklar}

Abadan Unat, N. Women in Turkish Society, Leiden 1990.

Akyıldız, A. Anka'nın Sonbaharı, 2. Baskı, İstanbul 2018.

Ali, E. S. "Faâliyet", Kadınlar Dünyası, No: 14, s. 2.

Baysal, H. 'Osmanlı'da Kadın Memureler İçin Motivasyon Uygulamaları: Bank-ı Osmani-i Şahane, Dersaadet Telefon Anonim Şirketi Osmaniyesi ve Kadın Birinci İş̧i Taburu Üzerine Bir İnceleme" Süleyman Demirel Üniversitesi Sosyal Bilimler Enstitüsü Dergisi, 2017/4, S. 29, s. 340-366.

Çakır, S. Osmanlı Kadın Hareketi, 3. Baskı, İstanbul 2011. 
Göle, N. Modern Mahrem, 13. Bask1, İstanbul 2016.

Kaplan, L. Cemiyetlerde ve Siyâsi Teşkilâtlarda Türk Kadını, Ankara 1998.

Karakışla, Y. S. Osmanlı Kadın Telefon Memureleri, İstanbul 2014.

Okay, Cü. "Meşrutiyet Döneminde Bir Kadın Şirketi: Hanımlara Mahsus Eşya Pazarı A.Ş.” Tarih ve Toplum Mart 1999, S. 183, s. 12.

Songur, D. G. "Toplumsal Cinsiyet Eşitliği Perspektifinden Ticaret Hukuku ve Uygulamasına Genel Bakış”, Hukuk ve Toplumsal Cinsiyet Çalışmaları (Ed.: Uygur, Gülriz/Özdemir, Nadire), 2. Bask1, Ankara 2019, s. 413-432.

Tan, T. "Osmanlı İmparatorluğunda Yabancılara Verilmiş Kamu Hizmet İmtiyazları", Ankara Üniversitesi Siyasal Bilgiler Fakültesi (SBF) Dergisi 1967, C. XXII, S. 2, s. 285-326.

Tekeli, Ş. Kadınlar ve Siyasal Toplumsal Hayat, İstanbul 1982.

Tümer Erdem Y./ Yiğit H. Bacıyân-1 Rûmdan Günümüze Türk Kadının İktisadî Hayattaki Yeri, İstanbul 2010.

Yalman, A. E. Turkey in the World War, New Heaven 1930. 


\title{
"DARKNESS OF COPY" LOST TIME IN "THE TALE OF COPY"
}

\section{Hiclâl DEMİR ${ }^{1}$}

\begin{abstract}
"The Tale of Copy" is the first story in Murathan Mungan's book In Front of Mountain Kaf. Events in the story; from social life to politics, from woman/man roles to architectural degeneration is handled in a broad perspective. Comparisons such as individual-society, female-male, Istanbul-Mardin, life-death are examined through the metaphor of copy which continues throughout the story. In the early 1970s, a young and talented painter candidate, Faris, went to Istanbul and started to the academy, but could not fulfill his dreams and he returned to Mardin. The fact that he could not find Mardin as in his childhood and the disappointment he caused was the theme of his story. When Faris returned to Mardin, he continued to paint but was alienated himself. He begins to question his life, in mansion of his grandfather Hact Faris, namesake with him, by examining the copy of grandfather and taking refuge in the darkness of a copy. In the story, the comparison of lack of perspective "copy" reproductions with "picture" was carried to a wider plane, and the comparison of "dogmatism" /"originality" was made. Faris wanted to take modern painting education in Istanbul, in order not to draw in-depth, non-dimensional replicas. Returning to Mardin and leaving his paintings aside; his grandfather's attempt to make a copy similar to the one he drew, marks the vicious circle he has entered. Faris meets Ceyla who is also from Mardin like him in the Academy. In this study, the examination of "copy" of Faris and Ceyla will analyzed in the plane of these terms: individual/society, female/male roles and Mardin,
\end{abstract}

Keywords: Copy, Picture, “The Tale Of Copy”, In Front Of Mountain Kaf, Murathan Mungan.

\footnotetext{
${ }^{1}$ Dr. Lect- Hitit University, Arts and Sciences Faculty hiclaldemir@yahoo.com;
} 


\section{"SURETIN KARANLIĞI" "SURET MASALI"NDA YITIKK ZAMAN}

$\ddot{O} z e t$

"Suret Masalı", Murathan Mungan'ın Kaf Dağının Önü adlı kitabında yer alan ilk öyküdür. Öyküde olaylar; toplumsal yaşamdan siyasete, kadın/erkek rollerinden mimari yozlaşmaya geniş bir perspektifte ele alınır. Birey-toplum, kadın-erkek, İstanbul-Mardin, yaşam-ölüm gibi karşılaştırmalar öykü boyunca devam eden "suret" metaforu ile irdelenir. Genç ve yetenekli bir ressam adayı olan Faris 'in 1970'li yılların başında İstanbul'a gidip Akademi'ye başlaması, hayallerini gerçekleştiremeyip geri döndüğ̈̈ Mardin'i çocukluğundaki gibi bulamaması ve bunun yarattığı hayal kırıklı̆̆l, öykünün ana izleğidir. Faris, Mardin'e döndüğünde de resim yapmaya devam eder, ancak kendisine yabancılaşmıştır. İsmini taşıdı̆̆ı dedesi Hacı Faris’in konă̆ında onun çizdiği sureti inceleyip "bir suretin karanlı̆̆ına sı̆̆ın[arak]” yaşamını sorgulamaya başlar.

Öyküde, perspektiften yoksun "suret”" çoğaltmacılı̆̆ ile "resim” karşılaştırması daha geniş bir düzleme taşınmış, “dogmatiklik”/“özgünlük” mukayesesi yapılmıştır. Faris; derinliği olmayan, boyutsuz "suret”"ler çizmemek için İstanbul'da modern resim eğitimi almak istemiştir. Mardin'e geri dönüşü ve yaptı̆̆ resimleri bir tarafa bırakarak dedesinin çizdiği suretin benzerini yapmaya çalışması, içine girdiği kısırdöngüyü imler.

Bu çalışmada, Faris ve Akademi'de tanıştığı Ceyla'nın "suret” ile imtihanı; birey/toplum, kadın/erkek rolleri ve Mardin düzleminde incelenmektedir.

Anahtar Kelimeler: Suret, Resim, "Suret Masalı”, Kaf Dağının Önü, Murathan Mungan.

"Ben bir suretin karanlı̆̆ına sığındım. Ya sizler ne yaptınız?”

Murathan Mungan - "Suret Masalı"

\section{Giriş}

"Suret” kelimesi; "biçim, görünüş, tarz, yol” gibi anlamların yanı sıra "resim”, "yazı veya resim kopyası" anlamlarına da gelmektedir. Murathan Mungan'ın eserlerinde sik kullandığı "suret” sözcüğü; onun yaşadığı toplumun sosyokültürel yapısını, değer yargılarını değerlendirirken kullandığı metaforlardan biridir. Bir yazısında, çocukluğu boyunca en çok 
merak ettiği yüzün dinî tasvirlerde her zaman bir peçe ile örtülü olan Hz. Muhammed'in yüzü olduğunu söyler ve şöyle devam eder: "Sanırım bütün yazarlığım ve bütün masallarım bu peçeyi (ve her peçeyi) açmak üzere kuruldu. Zaten bir suret toplumunda bundan daha anlaşılabilir ne olabilir ki?” (Mungan, 1995: 115) Mungan'ın burada sözünü ettiği “her peçeyi kaldırmak” imgesi, içinde yaşadığı topluma yönelik bir eleştiri de içermektedir. Geçen zamana, değişen koşullara ve edinilen birikime rağmen benzer davranış kalıplarının çoğaltılması, düşünce biçimlerinin kopyalanması ve özgün olamama, yazarın "suret toplumu” olarak nitelediği toplumun temel özellikleridir. Bu düşüncelerle metafor olarak kullandığg "suret" kelimesi, Kaf Dă̆ının Önü adlı kitabındaki ilk öykünün adını oluşturur.

“Suret Masalı”nda Murathan Mungan’ın yaşamına dair ayrıntılar dikkat çeker. Yazarın "Bu kitaptaki ben, doğrudan benim. Anlattıklarım bütünüyle yaşamımdan alınmadır. (...) Hiçbir yalana, süslemeye, değiştirmeye, kurmaca olaya, hayal gücü ürünü olan bir sahneye yer vermedim” (Mungan, 2016a: 84) dediği Paranın Cinleri ve yaşamöyküsel bir roman olarak nitelediği Harita Metod Defteri adlı eserleri okunduğunda “Suret Masalı"ndaki otobiyografik ögeler bariz bir şekilde görülür. "Suret Masalı” bu iki otobiyografik eserden önce yazılmış ve Mungan'ın çocukluğuna dair bazı ayrıntılar, öykünün kahramanı Faris’te vücut bulmuştur. ${ }^{1}$ Nitekim Paranın Cinleri’nde yazar, öykünün kahramanı Faris’e kendi çocukluğundan bazı sahneleri ödünç verdiğini belirtir. ${ }^{2}$ Kahramanın adı da Mungan'ın büyük dedesi Faris Çelebi'den gelmektedir. Yazar bu tercihin sebebini şöyle açıklar: "Bir yazar olarak bu, benim hayatımda yeri, anısı, yankısı olan insanların hatırasına yaktığım bir mum yerine geçer” (Mungan, 2016b: 251). Yine “Suret Masalı”nın kahramanlarından Ceyla da -gerçek yaşamdayazarın kendinden bir yaş büyük halasının kızının ismidir (Mungan, 2016a: 48). Mungan, eserlerindeki bu tür otobiyografik unsurları, (o zamanlar) henüz tamamlayamadığı

\footnotetext{
${ }^{1}$ Öykünün sonunda “Kasım 1980, 1981/1982” tarihleri yer almaktadır.
}

2 Paranın Cinleri, s. 17, 29, 89. 
yaşamöyküsel romanından diğer çalışmalar için zaman zaman "tırtıklamak zorunda kaldı[ğg1]" malzeme olarak niteler (Mungan, 2016a: 85). Diğer yandan “Suret Masalı"ndaki ana mekânlardan birinin Mungan'ın çocukluğunun ve ilk gençliğinin geçtiği Mardin olmas1, öyküdeki otobiyografik unsurları arttırmaktadır.

“Suret Masalı”nın kahramanı Faris, 70’li yılların başında resim eğitimi almak için Mardin'den İstanbul'a gider. Akademi, onun "resim dâhisi olma" hayallerini gerçekleştirebilmesi için önemli bir basamaktır. Doğuştan gelen yeteneğiyle çok güzel bozkır resimleri çizen Faris'in en büyük korkusu "bozkır ressamı olarak kalmak" ve "imzasının hep güneş ve buğday rengiyle birlikte anılması"dır (Mungan, 2011: 17). "Bir sanatçı için, en öldürücü benzerliğin sanatı ile hayatı arasındaki benzerlik olduğunu” düşünür (2011: 19). Akademi ve İstanbul, onun sıkıştığı bu dünyadan çıkması için birer anahtar olacaktır. Başlangıçta zekâ ve yeteneğiyle herkesin dikkatini çeken Faris, "bozkır ressamı” olma korkusu ile soyut resme, grafiğe, kolaja merak sarar. Ceyla ile de Akademi'de tanışırlar. İnsanlardan uzak duran, acımasız görünen Ceyla, sadece güzelliğiyle değil zekâ ve yeteneğiyle de Faris’i etkiler. Bir ortak noktaları da Mardin'dir. Ceyla küçük yaşta oradan ayrılmış, bir daha dönmemiştir. Faris ise yaşadığı hayal kırıklıkları sonucu tekrar memleketine, Mardin’e dönecektir.

Öyküde Faris ve Ceyla, farklı geçmişlere sahip olmalarına rağmen “suret toplumu”nda yaşamanın zorluklarıyla mücadele eden iki karakter olarak sunulur. Metafor olarak kullanılan “suret” kelimesi burada, "kopyası”, “benzeri” anlamlarında olup özgünlükten uzak, var olan kuralları sorgulamayan ezber görüntülere, fikirlere ve yaşamlara işaret etmektedir. $\mathrm{Bu}$ çalışmada suretin izleri, Faris ve Ceyla'nın yaşamları üzerinden takip edilecek; toplum/birey, toplumsal cinsiyet algısı ve kent kültürü bağlamında incelenecektir. 


\section{"Suret Toplumu” ve Birey}

Öyküde Faris, hayallerine ulaşamamış, yenik bir insan olarak döner Mardin’e. Hayatla bağları zayıflamış; aldığı eğitim, girdiği ortamlar, okuduğu kitaplar onu mutlu bir insan yapamamıştır. Geçmişini, ideallerini gözden geçirdiği bu son durakta Faris'in ilk sorguladığı, birey ve toplum ilişkisidir. O da -pek çok yaşıtı gibi- 70'li yılların öğrenci hareketlerine dâhil olmuş, haksızlığın kader olmadığı, sevgi dolu, aydınlık bir toplum hayal etmiştir. Ancak bu ideallerle yola çıkan bireyin "karakalabalıklar" olarak nitelediği toplum tarafından sindirildiğini tecrübe eder. Toplum, kara delik gibi bireyi içine alıp onu kendine benzetmiştir. "Değiştirmeye, dönüştürmeye çalıştığımız dünya bizi teslim aldı sonunda" der (2011: 12). Toplumla kaynaşmak için atılan adımlar, ona ters düşmemek için gösterilen çaba ve duyulan saygı maalesef- karşılık bulmamıştır. Birey, her şeyden bu "karakalabalık" için vazgeçmişken toplum sonunda bireyi kendine benzetmiş ve ideallerine ulaşamayan birey, yalnızlık ve hayal kırıklığı ile baş başa kalmıştır. Bundan sonra Faris için seçilebilecek iki yol vardır: Ya toplumun onayladı̆̆ı "onursuz" bir yaşamı sürdürecek ya da toplumdan soyutlanıp yalnızlığa mahkûm olacaktır. Faris'in çocukluğu ve ilk gençliğinin geçtiği Mardin'e dönme sebeplerinden biri, toplumu değiştirme/dönüştürme mücadelesinde yaşadığı hayal kırıklığıdır.

Öyküde, bireyi yok sayan toplumsal yapıya yönelik keskin eleştiriler devam eder. Kişilerin tek tek bireysel gelişimi toplumu ayağa kaldırmaya yetmemiş, tam tersi bireyi derin çelişkilere ve yalnızlığa mahkûm etmiştir. Faris, geldiği noktada “Öyleyse niçin okuduk bunca şeyi?” diye sorar. "Bunca umutsuzluğa, bunca yenikliğe, bunca intihara, ölüme, yıkıma değer miydi?” (2011: 12) Bu bilinç seviyesine ulaşan kişinin “onaylanmaların kolaycı rahatlığı”na kaçması da artık mümkün değildir. Çelişkiler içinde kıvranan Faris, her geçen gün kişiliğinin parçalanıp içinden birçok insanın çıktığını düşünür. Üstelik bu insanlar birbirini sevmeyen, birbiriyle geçinemeyen insanlardır. Suret çoğaltmacılığı burada da kendini göstermiş; toplum, sorgulayan bireyi dışlayıp kişinin iç dünyasında derin çelişkiler yaşamasına sebep olmuştur. 
Faris, sadece değiştirmek istediği toplumun değil aynı düşünceleri savunduğu arkadaşlarının da dogmatik tavırlarına maruz kalır. Henüz okulu bitirmeden açtı̆̆ 1 ilk resim sergisinde yanında onu destekleyen hiç kimseyi bulamaz. Gelenler, sergisini alaycı bakışlarla gezerler. Sergi açacak kadar kendine güvenen Faris, eleştirileri göğüsleyecek kadar güçlü değildir henüz. Ancak bu alaycı bakışların altında, gelen kitlenin kendi eksiklikleri ve başarısızlıkları yatmaktadır: "Hayatları boyu hiçbir şeye emek katmamış, hiçbir güzellik üretmemiş bu yağmacı kalabalık, şimdi karşısına geçmiş, ellerindeki cigaralardan uzun soluklu dumanlar çekerek onu beğenmiyorlar. Hiçbir şeyi beğenmiyorlar. (...) Başkalarının yıkımlarıyla, başarısızlıklarıyla besleniyorlar” (2011: 25). Bir yandan da etrafa sahte gülücükler dağıtan bu kalabalık, Faris'in insan ilişkilerindeki samimiyeti sorgulamasına sebep olur: "Herkes çirkin, küçük maskeler taşıyor yüzünde” (2011: 26). Yüzlerdeki bu maskeler, suret çoğaltmacıllığının da bir örneğidir. Desteklemek, yapıcı eleştiri yöneltmek yerine övgü ile yergi arasına sıkışmış, yaratıcılıktan uzak bu kişiler, yetersizliklerini başkalarının başarısızlığıyla normalleştirme yolunu seçmişlerdir. Faris bu durumu "Duvarlardaki resimlerden daha çok boya var bu yüzlerde, bu maskelerde" sözleriyle somutlaştırır (2011: 26).

Bireyin çelişkilerden arınıp huzuru bulmasının yolu, sorgulamamaktan geçer. Sorgusuz yaşamak, herkesin beğendiğini beğenmek, onlar gibi düşünmek, onlar gibi yaşamak onaylanmanın rahatlığını getirecektir. Çelişkileriyle baş edemeyen Faris, "silik yurttaşların memleketi” olarak nitelediği memleketine dönmeye karar verir. Çocukluğunun ve ilk gençliğinin geçtiği bu şehirde yaşam ümidine dair bir şeyler arar. Memleketindeki insanlar gibi düşünüp onlar gibi yaşarsa çelişkilerinin ve hayal kırıklıklarının sona ereceğini düşünür.

\section{Toplumsal Cinsiyet: Kadınlık/ Erkeklik Rolleri}

Öyküde "suret toplumu”nun eleştirilen bir yönü de kadına ve erkeğe toplumun yüklediği rollerdir. "Cinsiyet" kavramının yalnızca biyolojik özelliklere dikkat çekmesi, sosyolojik 
araştırmalarda "toplumsal cinsiyet" kavramının kullanılmasını zorunlu kılmıştır. Feminist aktivist Kamla Bhasin’e göre toplumsal cinsiyet, kadınlık ve erkekliğin yalnızca biyolojik değil toplumsal kategoriler/yapılar olduğunu açıklayan bir kavramdır (Bhasin, 2003: 58-59). “Toplumsal cinsiyet”, kadın ve erkeğin sosyokültürel açıdan tanımlanmasını ve toplumların onlara verdiği toplumsal rolleri ifade etmektedir (2003: 7). Micheal S. Kimmel de erkekliğin içsel bir özün dışavurumu olmayıp toplumsal olarak inşa edildiğini belirtir (akt. Arslan, 2018: 29). Ülkemizde toplumsal cinsiyet alanındaki çalışmalarıyla tanınan Serpil Sancar ise toplumsal cinsiyet kavramının, cinsler arasındaki eşitsiz ilişkilerin toplumsal bağlamlarına dikkat çekerek cinsiyetin sadece biyolojik bir özellik olarak algılanmasını reddettiğini söyler (Sancar, 2011: 176). Bir başka ifadeyle, kadınlık ve erkeklik rolleri biyolojik ve değiştirilemez değildir. Aksine, bu roller toplumsal ve kültürel etkenler sonucu şekillenmektedir ve değişkendir.

“Suret Masalı”nda toplumsal cinsiyet algısı, Ceyla'nın yaşadıkları üzerinden onun anlatımıyla eleştirilir. Ceyla, dünyayı değiştirmek idealiyle dâhil olduğu devrimci harekette toplumun nasıl bir suret çoğaltıcısı olduğunu mücadelenin her aşamasında görür. Sınıf farkının olmadığı, eşitliğe dayalı, ilerici bir düzen savunulurken örgüt içinde yerleşik algılar ve davranış kalıpları aynen devam ettirilir. Bu süreçte Ceyla, bir kadın olarak her türlü erkek şiddetine maruz kalır. Örneğin güzelliğinden dolayı devrimci hareketle bir türlü bağdaştırılamaz. Kendini çirkinleştirmek için kirli parkalar, büyük postallar, eprimiş kazaklar giyer ancak hiçbiri yetmez. Diğer yandan, küçük burjuva bir aileden geldiği için kendisine hiçbir zaman tam olarak güvenilmez. Örgütün önemli sırları kendisiyle paylaşılmaz. Sınıf alışkanlıklarını kırmak için kendisine çöpleri toplamak gibi en basit işler verilir. Varlı̆̆ı, öğrenci temsilciliği sırasında oy istemek, miting kortejinde yanlarında yürümek gibi durumlar söz konusu olduğunda önemsenir. Kısaca, eşitlik idealiyle yola çıkan devrimci hareketin her aşamasında ataerkil yapının izleri hüküm sürmektedir. Ceyla, bu durumu şu sözlerle eleştirir: "Bu memlekette her şey erkeklerin tekelinde. Her şey erkekliğin. Ve ne kadar olağan bir şeymiş gibi yaşıyoruz bu gerçeği””. 
Hâlbuki "kadın meselesini çözememiş bir sosyalizm yenilmeye mahkûm”dur. Bu durumda Ceyla'ya göre asıl atılması gereken slogan “Kahrolsun erkeklerin demokrasisi! Kahrolsun Fallokrasi!" (Mungan, 2011: 29) olmalidır.

Değiştirmeye çalıştıkları dünyanın temel ilişki biçimlerinin aynen devam ettiğini gören Ceyla, derin bir hayal kırıklığı yaşar. Suret kopyacılığı; ilerici, eşitlikçi olduğunu iddia eden bir hareketin içinde de devam etmekte, erkekler öğrenilmiş davranış biçimlerinin tekrarından öteye gidememektedir. Ceyla bu yapının hâlâ devam ettiğini Faris’e şu cümlelerle ifade eder: “Git bak üniversite kantinlerine, derneklere, lokallere 'Devrimci' namı altında nasıl bir suretin çoğaltmacılığının yapıldığını gör. Herkes nasıl da birbirine benziyor” (2011: 35).

Ceyla’nın yaşadıkları, birbirine benzemenin “erdem” kabul edildiği bir toplumda kökten değişiklik yapmanın zorluğunu gözler önüne serer. Devrim düşüncesiyle bağdaşmayan bu toplumsal yapıda verilen mücadelenin eğretiliği ise minyatür/resim karşılaştırması ile gözler önüne serilir. Bilindiği gibi minyatür; 1şık-gölge, perspektif, renk değerleri gibi ögelere dayanan Batı resim geleneğinden farklıdır. Minyatürlerde nesneler gibi canlılar da doğadan soyutlanarak gerçek görünümlerinden çok farklı birer dekoratif ögeye dönüştürülebilir. İki boyutlu bir kalıba dönüşen insan figürü, çevresindeki nesnelerle orantılı olmayabilir (Renda, 1997: 1262). Ceyla bu mücadeledeki uyumsuzluğu, ideal olan ile var olanın bir türlü birbiriyle uyuşmamasını şu sözlerle anlatır: "Görmüyor musun iğreti minyatürler gibiyiz, kaba saba, boyutsuz figürler gibi yerleştirildik devrim manzarasına. Oysa suretimiz bile perspektiften yoksun bu manzarada" (Mungan, 2011: 35).

Davanın bu kadar dışında tutulan Ceyla'nın polis tarafından ilk içeri alınanlardan olması tezat gibi görünmektedir. O bunu, sıkı devrimci olmasına değil, güzel olmasına bağlar. Kendisinin bu mücadelede yer almasına anlam verilememiştir. Daha sonra gelen işkence süreci de erkeklik hâllerini çok trajik bir şekilde gözler önüne serer. Kantin masalarında gerçek devrimcilerin hiçbir şart altında konuşmayacağı üzerine nutuklar atılır, işkenceye direnebilmek 
için “mertlik, dürüstlük, erkeklik” gerektiği vurgulanırken sonuçta en çok erkekler çözülmüştür. En ufak bir tartışmada kendilerini fiziki güçleriyle savunan erkekler, içeride bu haklarından mahrum kalmışlar, kendilerini savunmanın başka bir yolunu öğrenmedikleri için de daha kolay çözülmüşlerdir. Sonuçta "Kendilerini ve imgelerini savunmak için gerekli olan bütün silahları ellerinden alınmıştı[r]” (2011: 61-62). Oysa Ceyla, devrimciliğini kanıtlayacak tek şey olarak gördüğü işkenceden hiç çözülmeden çıkar. Üstelik bunu sadece çıktıktan sonra “aynada kendi yüzüne bakabilmek” için yapmıştır.

Ceyla'nın içeride konuşmaması, kadına cinsiyetçi bir gözle bakan erkek egemen anlayışı rahatsız eder. Örgüte dair çok az şey bilmesine rağmen konuşmayıp direnmesi, işkence yapan eril gücü şaşırtmış, örgütün üst düzey elemanları bile çözülmüşken bir kızın direnmesini kabul etmek istememişlerdir. Çünkü o, polislerin gözünde de küçük burjuva kızıdır. Yaşadığı olaylar Ceyla’nın erkeklik rollerini sorgulamasına sebep olur. İşkenceye dayanabilmek için “erkek” olmak gerektiği düşüncesi yerle bir olmuştur. Gelenekçi yapı yine kendini kopyalamış ancak sonuç beklendiği gibi olmamış; Ceyla çözülmemiştir.

İçeriden çıktıktan sonra devrimci harekete, insanlara, aydınlatmaya çalıştıkları halka inancını kaybeden Ceyla, yaşadıklarını düşündüğünde kendini ihanete uğramış hisseder: “Kimseyi bağışlamıyordum. Herkes çoğaltılmış bir suçluluğun başka bir parçasıydı bana göre. Sesini çıkarmayan, hiçbir şey için sesini çıkarmayan, suskun kalan herkes elektrik akımıydı, coptu, işkenceydi” (2011: 36).

Diğer yandan Ceyla, kadının dirayetini, gücünü, koşullara uyum çabasını gördüğünde ülkede bir kadın meselesi olmadığını düşünür. Asıl mesele, erkeklik meselesidir. Erkek, toplumun kendisine dayattığı kalıp rollerin içinde kıvranmaktadır. Kadına yönelik cinsiyetçi bakışı, kadın-erkek ilişkilerinde tökezlemesine; zorluklarla mücadelede fiziki güç dışında başka bir uzlaşma yolu öğrenmemesi, güçlükler karşısında çaresiz kalmasına sebep olmaktadır. Ceyla, kadınların iyi-kötü bir denge kurup hayatlarını sürdürdüklerini düşünür ve şöyle devam eder: 
"Ya erkekler? Onlar ne kadar zavallı, ne kadar çaresiz, ne kadar korunmaya muhtaçlar. Bomboş bir böbürlenmeyle geçiyor bütün hayatları (...) Erkek olmak uğruna neler yitirdiklerinin farkında bile olmadan ölüp gidiyorlar” (2011: 31).

\section{Mardin: Özgünlüğünü Yitiren Şehir}

Öyküde suret çoğaltmacılığının bir tezahürü de Faris'in çocukluk ve ilk gençliğinin geçtiği Mardin şehrinin değişiminde görülür. Murathan Mungan'ın çocukluğunun da geçtiği Mardin, öyküde, birbirinin kopyası binalarla özgünlüğünü yitiren bir mekân olarak değerlendirilir.

Kevin Lynch “Çevrenin İmgesi” başlıklı yazısında kenti, mimari bir esere benzetmiştir. Aralarındaki fark, kentin ölçeğinin daha büyük olması ve uzun zaman içinde algılanabilmesidir. Kentte her zaman gözün görebileceği, kulağın işitebileceğinden fazlası, keşfedilmeyi bekleyen bir dekor ya da manzara vardır. Kentte yaşayan her insanın kentin bazı kısımlarıyla uzun süren bir ilişkisi olmuştur ve ona ilişkin imgesini bu anılar şekillendirir. ${ }^{1}$ Murathan Mungan'ın da Mardin'le derin bir ilişkisi vardır. "Benim için sızılı çağrışım” (Mungan, 2016a: 9) dediği Mardin'e şiir, öykü ve tiyatrolarında sık sık yer vermiştir. Mungan'ın tutku derecesinde sevdiği bu kent, otobiyografik unsurların yoğun olduğu "Suret Masalı"nda yalnızca mekân olarak yer almaz. Mardin'in o eşsiz mimarisinin geçmiş ile şimdiki hâlinin karşılaştırıldığı öyküde, kent kültürüne dair belgesel nitelikte değerlendirmeler de yapılmıştır.

İstanbul'da mesleki anlamda dilediği başarıyı yakalayamayan, insan ilişkilerinde de çıkmaza giren Faris, bir kriz geçirir. Hastane sürecinden sonra, inancını kaybettiği hayata tutunabilmek için son ümidi, çocukluğudur. Çocukluğunun güzel günlerine sığınıp yaralarını

\footnotetext{
${ }^{1}$ https://proje6kentselmetraj.files.wordpress.com/2012/02/kevinlynch_kentimgesi_ch2-3.pdf, s.1. 
sarmak için Mardin'e döner. Dedesinin konağına yerleşen Faris’i burada da hayal kırıklıkları beklemektedir.

Faris, küçük yaşlardan itibaren yaşadığı kente dair önyargılar biriktirmiş, İstanbul'u kendisi için kurtuluş olarak görmüştür: "Mardin'deyken orayı küçümserdim, insanlarını sevmezdim, hepsi yalan söylerdi. Sürekli büyük kent hayalleri kurardım. (...) Bir gün buradan, bu boğucu ilişkilerden, akrep korkusundan her şeyden kurtulacağımı düşünürdüm” (Mungan, 2011: 44). Faris'in İstanbul hayali kurmasının bir nedeni de annesinin İstanbullu olmasıdır. Annesinin gizli gizli sıla özlemi çekmesi ve Mardin'de gurbet hayatı yaşaması, Faris’in İstanbul hayallerini büyütür. Edibe Hanım için mazi olan İstanbul, Faris’in geleceğini inşa etmek istediği yerdir: "Onun sürgün edildiği İstanbul, belki de benim düşlerimi gerçekleştirdiğim anayurdum olacaktı" (2011: 49). Faris bu düşüncelerle kentten ayrılıp İstanbul'a gitse de Mardin peşini bırakmaz. Hiç istemediği hâlde sürekli bozkırı, Mardin'in dümdüz ovalarını, mor dövmeli kadın yüzlerini çizmeye devam eder. Diğer yandan, İstanbul'da kendisine sürekli Mardin ile ilgili sorular sorulur. Böylece kurtulmak istediği șehir, Faris için övünme vesilesi olmaya başlar. Peki bu çelişkili durumun suçlusu kimdir? Faris, Mardin'in seçkin bir ailesinin çocuğu olarak büyük şehirlerdeki gibi görkemli bir hayat yaşamış; şehrini tanıyıp kültürel değerlerine sahip çıkması gerektiğini kimse kendisine söylememiştir. Mardin'deki kiliseler, Artuklu camileri, gümüş işçiliği, kemerler ve abbaraların ne kadar değerli olduğunu İstanbul'a gidince çevresinin bu kente ilgisiyle fark eder. Suret toplumunun öğrettiği yaşam biçimi kopyalanarak devam etmiş, Faris, kendisine “öğretilen bir hayatı” yaşamıştır. Farklı bir bakış açısıyla hem kendi kültürünü hem de modern dünyayı kucaklayan bir yaşam biçimi yeni nesle aktarılamamıştır.

Faris, incinmiş ruhunu çocukluğunun anılarıyla sarmak ve şehriyle barışmak ümidiyle döner Mardin'e. Ancak Mardin, çocukluğunun ve ilk gençliğinin Mardin'i değildir artık. Kentin mimarisi hoyratça tahrip edilmiş, eski evlerin birçoğu yıkılmıştır. Bu taş evlerin tarihî değeri anlaşılınca ev sahipleri yıkamadıkları evlerin avlularına betondan odalar yapmaya 
başlamışlardır. Avluların kapatılmasıyla değişen kent mimarisini Faris şöyle eleştirir: “Çocukluğumun avlularıydı bunlar. Bir tarihin dinlendiği, soluk aldığı, uzun, geniş, taş düzlüklerdi. (...) Söyleyin n'olur avlulara ne yaptılar? Niye kestiler bu avluya düşen güneşin cömert aydınlığını? Avludaki saksılar bu yüzden mi kurudu? Çiçeklerin boynu bu yüzden mi kırık böyle? (...) Söyleyin avlulara ne yaptılar?” (2011: 56-57)

Şehrin yeni mahallerine ise sıcağa, soğuğa, güneşe, yağmura dayanmayan avlusuz, ayvansız, kubbesiz evler yapılmaktadır. Suret kopyacılığının bir örneği de burada görülür. Şehrin tarihî dokusu gözetilmeden yapılan estetikten uzak bir örnek binalar, kentin özgün mimarisiyle asla bağdaşmaz. Faris bu evleri "İklimi unutan, tarihi unutan, insanı unutan evler" (2011: 57) olarak niteler. Belli bir projeyle her şehre birbirinin aynı evler yapmak, öncelikle binlerce yıllık tarihe haksızlıktır. Kentin geçmişini, iklimini, insanların ihtiyaçlarını gözetmeden yapılan bu evler, mimari bütünlüğe de büyük zarar vermektedir. Faris kentteki bu değişim içinde geçmişini, çocukluğunu, anılarını bulamaz. Üstelik çocukluğunun geçtiği evin yerine bir otel yapılmıştır. Bu hayal kırıklığıyla odasına kapanır ve evleri, sokaklarıyla bütün Mardin'in resimlerini yapmaya başlar. Bir zamanlar yapmak istemediği bozkır resimleridir bunlar. İşte o zaman Mardin'in ruhunda derin izler bıraktığını, bunu inkâr etmenin hiç de gerekmediğini idrak eder. "Bozkırda yaşamak da bir yaşama biçimi”dir ve bunu reddetmek yerine onunla bütünleşmeye çalışmak kişiyi daha huzurlu kılacaktır. Ancak tüm bu git-gelleri, çalkantıları, inkâr ve kabulleri yaşadıktan sonra ruhundaki parçalanmayı onarması mümkün değildir. Yıllardır kaçtığı suretle yüzleşir. Bir deriye kendine/dedesine benzeyen bir suret çizer ve o soruyu sorar: “Ben bir suretin karanlığına sığındım. Ya sizler ne yaptınız?” (2011: 70). 


\section{Sonuç}

“Suret Masalı” Murathan Mungan'1n, birey/toplum, toplumsal cinsiyet, kent kültürü gibi konuları geniş bir perspektiften sorguladığı girift öykülerinden biridir. Bu farklı izlekleri yazar, metafor olarak kullandığı "suret" üst başlığında incelemiştir. "Suret" kelimesinin "kopyasını çıkarma, benzerini yapma” anlamından yola çıkan yazar, sözcügün "bir örneklik, özgünlükten uzak olma" yan anlamlarıyla toplumsal yapıyı, kadın/erkek rollerini ve kent mimarisini irdelemiştir.

Öyküde, bozkır ressamı olmamak için Mardin'den ayrılan Faris'in İstanbul'da suret çoğaltmacılığının her hâliyle karşılaşıp tekrar Mardin’e dönmesi konu edilmiştir. Faris, toplumu değiştirme idealini gerçekleştirememiş, tam tersi, topluma uymaya zorlanmıştır. Hayal kırıklığı ile Mardin'e döndüğünde çocukluğunun eski evlerinin tek tek betonlaştırıldığını görür. Tutunacağı son kale de elinden alınmıştır. Adını taşıdığı dedesinin konağına kapanır. Öykünün diğer kahramanı Ceyla, devrimci hareketin içinde bir kadın olarak erkek egemen anlayışın her türlü şiddetine maruz kalır. Dava içinde ve yakalandıktan sonraki işkence günlerinde, aslında toplumdaki hiçbir önyargıyı yıkamadıklarını görmüş, zihinlerdeki kalıplaşmış "erkeklik" kavramının en ufak bir zorlukta yerle bir olduğuna şahit olmuştur.

Faris ve Ceyla'nın yaşadıkları, öyküde minyatür/resim farkıyla sembolize edilir. Toplumsal kalıplar ve öğrenilmiş davranış biçimleri içinde sıkışan bireyin durumu; iki boyutlu perspektifsiz figürler gibidir. Kişi, toplumsal yapıya boyun eğdiği müddetçe sıkıntısız yaşayacaktır. Ancak kalıplara sığdırılmış, öğrenmeye, ilerlemeye kapalı bu yaşam kabul edilemez. Değişimin gerçekleşebilmesi için mücadeleci, çok boyutlu düşünebilen, onurlu bireyler yetiştirmek zorunludur. 
Öyküde suret çoğaltmacılığının kişinin yaşantısının her anında görülebileceği vurgulanmaktadır. Bireyden başlayıp topluma uzanan bu çizgide değişim olmadı̆̆ı müddetçe benzer şeyleri gelecek kuşaklar da aynı şekilde yaşayacaktır. Kadına ve erkeğe yüklenen toplumsal roller sorgulanıp eşitlik sağlanmadıkça özgür bireylerin yetiştirilmesi mümkün olmayacaktır. Öğrenilmiş yaşamların, kalıp bilgilerin, bildik tutum ve davranışların eleştirel gözle irdelenmesi toplumun üzerindeki o "peçe”yi kaldıracaktır. "Suret toplumu” olmaktan da ancak bu şekilde kurtulmak mümkün olur.

\section{Kaynaklar}

Arslan, A. D. (2018). “Murathan Mungan'ın öykülerinde hegemonik erkekliğin tezahür alanı olarak beden: ‘Ökkeş ile Cengâver' ve ‘Ensar ile Civan’ örnekleri’. Monograf, 10: 24-46.

Bhasin, K. (2003). Toplumsal Cinsiyet. Erişim Adresi: https://docplayer.biz.tr/4690201Toplumsal-cinsiyet-kamla-bhasin.html. (4.10.2019)

Lynch, K. “Çevrenin İmgesi”. Erişim Adresi:

https://proje6kentselmetraj.files.wordpress.com/2012/02/kevinlynch_kentimgesi_ch2-3.pdf.

Mungan, M. (1995). Murathan '95. İstanbul: Metis Yayınları.

Mungan, M. (2011). Kaf dă̆ının önü. İstanbul: Metis Yayınları.

Mungan, M. (2016a). Paranın cinleri. İstanbul: Metis Yayınları.

Mungan, M. (2016b). Harita metod defteri. İstanbul: Metis Yayınları.

Renda, G. (1997). “Minyatür”. Eczacıbaşı Sanat Ansiklopedisi. C.2. İstanbul: Yapı-Endüstri Merkezi Yayınları.

Sancar, S. (2011). Erkeklik: Imkânsız iktidar. İstanbul: Metis Yayınları. 


\title{
HOW CAN THIS HEART FORGET YOU? AN UNBREAKBLE (UNBROKEN) PEN: HALIDE EDIP ADIVAR
}

\author{
Hülya BULUT ${ }^{1}$
}

\begin{abstract}
Halide Edip Adivar, who lived between 1882 to1964, is one of the most important pens of Turkish literature \& literature sociology. On the one hand, the writer was mentioned as one of the names of the National Struggle Literature because of her contributions to the War of Independence, on the other hand she was an exile forced to leave the country because of her dissenting attitude after the proclamation of the Republic.

Besides living with Adnan Advvar 14 years in different countries like France, England and United States of America and conducting seminars about women rights she also followed Turkish politics very closely and had conflicts with Atatürk. Atatük declared her as a traitor and supporter of mandate in his Great Speech (NUTUK) which he hold in Turkish Grand National Assembly 15 - 20 October 1927 for parliamentarians. In similar years she was heavily criticized by names like Orhon Seyfi Orhon and Mahmut Esat Bozkurt.

Despite her dissident discourse \& views she returned to her country in 1939. 3 years later her Sinekli Bakkal Novel (The Clown and His Daughter) wons CHP novel reward. Bringing up an award winning work to agenda is an important canonization activity for both raising the prestige of the author and increasing the sales of the work. It is very remarkable that such an excluded author is rewarded for her work quite outside of the Revolutionary Canon.

In addition to being Inönü's reconciliation gift, it is necessary to attribute another meanings to this award. Why Halide Edip was is broght up again? Why was writer, whose name was also taken in the high school text books, not completely forgotten but kept in minds in the boundries of national literatur in next years? This presentation will open the discussion of Halide Edip's perception to the present day in the context of canon (espicially a woman writer) and social memory.
\end{abstract}

Keywords: Halide Edip Adıvar, Woman Writer, Canonization, Memory.

\footnotetext{
${ }^{1}$ Dr. Boğaziçi University, Etiler-İstanbul, hulyab@ boun.edu.tr
} 


\section{BU KALP SENI UNUTUR MU? KIRIL(A)MAYAN BİR KALEM: HALIDE EDİP ADIVAR}

\section{$\ddot{O} z e t$}

1882-1964 yılları arasında yaşamış olan Halide Edip Adıvar, Türkçe Edebiyatın ve edebiyat sosyolojinin oldukça önemli kalemlerinden birisidir. Yazar, bir taraftan Kurtuluş Savaşı'na katkıları dolayısıyla Mili Mücadele edebiyatına dâhil bir isim olarak anılırken, diğer taraftan Cumhuriyet'in ilanından sonraki muhalif tavrlyla ülkeyi terk etmek zorunda kalan bir “sürgün”dür. Adnan Adıvar’la birlikte 14 yll boyunca Fransa, Ingiltere, Amerika gibi farklı ülkelerde yaşayan ve bu ülkelerde bir taraftan kadın haklarıyla ilgili çeşitli seminerler düzenlerken diğer taraftan Türkiye siyasetini yakından takipeden, Atatürk'le fikir ayrılıkları yaşar. Atatürk, 15-20 Ekim 1927 tarihleri arasında TBMM salonunda milletvekillerine hitaben okuduğu Nutuk'unda Halide Edip'i mandacı ve vatan haini ilan eder. Yazar, benzer yıllarda Orhon Seyfi Orhon, Mahmut Esat Bozkurt gibi isimlerin ă̆ır eleştirilerine maruz kalır.

Halide Edip Adıvar, bütün muhalif söylem ve görüşlerine rağmen 1939 yılında ülkeye geri döner. Üç yıl sonra Sinekli Bakkal romanı CHP Roman Mükâfatını kazanır. Ödülü kazanan eserlerin gündeme taşınması, hem yazarların prestijlerini yükseltmek hem de eserin satışlarını artırmak noktasında önemli bir kanonlaştırma faaliyetidir. Böylesi dışlanmış bir yazarın İnklap Kanonu'nun oldukça dışındaki eserinin ödüllendirilmesi oldukça dikkate değer bir noktadır. Bu ödüle İnönü'nün barlşma hediyesi olmasının dışında da anlamlar atfetmek gerekecektir. Halide Edip neden tekrar gündeme getirilir. Sonraki ylllarda lise öğrencileri için hazırlanan ders kitaplarına da adı alınan yazar neden bütünüyle unutulmamış, ama akıllardaki yeri Milli Edebiyat sinırları içinde tutulmuştur. Bu çalışma, kanon ve toplumsal hafiza bağlamında Halide Edip algısının günümüze kadarki serüvenini tartışmaya açacaktır.

Anahtar Kelimeler: Kadın Yazar, Halide Edip Adıvar. Edebi Roman, kanonlaştırma 


\section{Giriş}

Berna Moran, Türk Romanına Eleştirel Bir Bakış 1 adlı eserinin "Sinekli Bakkal"1 incelediği bölümünde Halide Edip'in ilk romanlar. ${ }^{1}$ olarak bilinen Raik'in Annesi (1909), Seviye Talip (1910), Handan, (1912) vb. eserlerinde kahramanların "yaşadıkları toplum çevresinden soyutlanmış izlenimi verecek kadar bireysel hayatlarının” merkeze alındığından bahseder. Yazarın bahsi geçen eserlerini bireysel, psikolojik aşk romanları olarak değerlendirir. (Moran, 2005: 153-177) Romanlarda, (örneğin Handan ya da Seviye Talip) merkezdeki kadına, onun zekâsına ve eğitimine âşık ya da hayran erkekler vardır. Sosyoekonomik durumları oldukça iyi olan ailelerin kızlarıdır bu karakterler, hayatlarının merkezine aşkı, bireysel mutluluklarını alırlar, bu durum topluma bir başkaldırıdır da. Seviye Talip’te "Aşk en yüksek nikâhtır. İki kişiyi ondan başka bir şey bağlayamaz... fikriyle sivrilen Seviye tipiyle, dönemi için hiç de sıradan olmayan bir perspektif açmıştır. (Yaraman, 2001: 70) $\mathrm{Bu}$ olağanın, alışılmışın dışına çıkmak için İstanbul'dan da uzaklaşılır; örneğin yine Handan'da kahramanlar bir dönem Londra'da yaşarlar, böylelikle kadın-erkek arkadaşlığı, ilişkilere dair fikirlerin paylaşımı daha kolay olacaktır.

Halide Edip'in ilk dönem romanlarının yayınlanma tarihleri II. Meşrutiyet'in hemen sonrasına 1910'lu yıllara denk gelir. Eserler, “Bir kadın yazarın aynı anda kadın ve yazar olarak kendini tanımlama mücadelesidir." (Adak: 2004:162) Bu yıllarda basında kadın hakları konusundaki tartışmalar sırasında Halide Edip gerek Tanin, Hanımlara Mahsus Gazete, Yeni Местиа gibi dergilerde tefrika ettiği romanlarıyla gerekse yine bu dergilerdeki köşe yazılarıyla “ideal kadın” meselesini tartışmaya başlar. Takvimler 1920’li yılların başlarını gösterdiğinde ise Ankara'ya gider. Bu dönemde yazdığg eserlerinde örneğin Dağa Çıkan Kurt adlı öykü

\footnotetext{
${ }^{1}$ Yazarın 5 Ekim 1899-26 Temmuz 1900 yılları arasında Hanımlara Mahsus Gazete'de tefrika edilen Çingene Kızı adlı romanı Halide Edip'in eserleri arasında anılmaz. Bu "unutulma"nın sebebi, romanın tamamlanmamış olmasıyla ilişkilendirilebilir.

${ }^{2}$ Yazarın 1963 yılında 79 yaşındayken kaleme aldığı Çaresaz adlı romanında da benzer meseleleri kaleme aldığı görülecektir.
} 
kitabında ama özellikle de Ateşten Gömlek'te kadın hakları ya da bireysel aşktan bahsetmez Halide Edip; bu konuların yerini vatan, toplum aşkı ve savaşa karşı topyekün bir mücadele örneği olacak konular almaya başlar. Berna Moran merkezinde kadın kimliğinin yer almasından, kadına hayran ve âşık erkelerin varlığının devam etmesinden dolayı Ateşten Gömlek'i de yazarın ilk romanları bağlamında değerlendirir. Oysa Ateşten Gömlek ${ }^{\mathbf{1}}$ edebiyat tarihinde kendine yer bulan Halide Edip Adıvar için birinci dönem romanlarının çok daha ötesinde bir yerlerde durmaktadır. Roman, yazarın edebiyat tarihinin dışında, tarihin tozlu raflarında kalmaması için bir kurtarıcı, yalnız yazarı kurtaran bir eser değil, Milli Edebiyat söyleminin de başucu kitabı, feneri gibidir adeta. Üstelik, Adıvar ilk dönem romanlarıyla değil; Nükhet Sirman'ın "Kadınların Milliyeti” adlı makalesinde de vurguladığı gibi “özellikle Ateşten Gömlek (1922) ve Vurun Kahpeye ${ }^{2}$ (1923) romanlarıyla hatırlanmaktadır.” (Sirman, 2002: 241) Romanlar bireysel aşktan toplumsal aşka evrilmiştir; kadınlar romanların sonunda yasak ilişkilerin çıkmazıyla intihar eden ya da ölümcül hastalıklara yakalanan kimlikler değil vatanı için mücadele ederken şehit düşmeyi göze alan, isteyen kişilere dönüşmeye başlarlar. Peki neden?

\footnotetext{
1 Ateşten Gömlek'te mesele işgal ve işgalin ülkede yarattı̆̆ korkunç manzara ve Türk'ün zaferidir. Roman, İzmir'in işgali sırasında eşi ve oğlunu kaybeden, kendi eli de feci şekilde yanan Ayşe'nin İstanbul'da oldukça bohem bir hayat yaşayan akrabası Peyami’nin yanına gelişi, İhsan'la birlikte ona mücadele ruhu aşılaması ve birlikte Anadolu'ya geçerek Milli Mücadele'ye katılmalarını konu edinir. Olayların büyük bir kısmı yaşanmış ve bitmiştir; okur süreci, Peyami’nin hatıra defteri aracılığıyla öğrenecektir. Ayşe'nin yanık eli, ele duyulan saygı ve eli iyileştirme çabaları, İzmir yangını ve kurtuluş mücadelesi bağlamında simgesel ve önemli bir örnek olarak eserde yer alır. Roman, Kurtuluş Savaşı'nı ele alan ilk eser olması bağlamında da dikkat çekicidir.

${ }^{2}$ Yazar, 1923 yılında Akşam'da tefrika edilen Vurun Kahpeye romanında, yobaz-aydın çatışmasına yer vererek sekülerizmin önemini dolayısıyla da merkeze Cumhuriyet'in kuruluş anlatısını yerleştiren eserler kaleme almaya başlar. Romanda, eserin ana kahramanı olan öğretmen Aliye Anadolu’nun küçük bir köyüne tayin edilir. Köyde hem çocuklara ders verir, hem de Milli Mücadeleyi destekler; köylüyü de mücadeleye destek olmaları yönünde cesaretlendirir. Halkın bilinçlenmesini istemeyen, düşmanla işbirliği yaparak kendilerine çıkar sağlayan birtakım yobaz köylü (özellikle de köyün imamı) tarafından iftiraya uğrar, tutsak edilir. Romanın sonunda Kuvayı Milliye kuvvetleri köye ulaşmış olsa da Aliye'nin canını kurtaramayacaklardır.
} 


\section{Kahraman Kadından Sürgün Kadına}

Halide Edip Adıvar 1922 yılında İkdam Gazetesi'nde tefrika edilen ve 1918-1922 yıllarını merkeze alan Ateşten Gömlek'i yazdığı Kurtuluş Savaşı yıllarında Ankara'ya kaçmış kendisini ikinci kez sığınmacı olarak gören bir kadındır. ${ }^{1}$ Daha önce İstanbul'da yazan-anlatan binlerce insana hitaben Sultanahmet Mitingi'nde ${ }^{2}$ konuşan, Sabiha Sertel'in anılarında; “... kürsüde siyah çarşaf içinde vakarla ayakta duruyor, kürsünün üzerine siyah bir bayrak gerilmiş. Ayyıldızın altında 'Ya İstiklal, Ya Ölüm' yazıyor”' (Sertel, 1978: 27) diyerek bahsettiği Halide Edip doğduğu şehrin, İstanbul'un mekânsal olarak çok da uzağında olmayan ama kimsenin Milli Mücadele’ye kadar pek de önemsemediği Ankara'sında kendisini sığınmacı olarak hissedecektir. Bu durum uzun sürmez, Ankara'dan Eskişehir'e de geçerek Hilal-i Ahmer Cemiyeti hastanesinde gönüllü hemşirelik yapar. Atatürk'ün bizzat teşvikiyle kurulan Tetkiki Mezalim Komisyonu'nda yer alarak Yunan işgali sırasında Batı Anadolu'da yaşanan olumsuz manzaralara dair izlenimlerin raporların hazırlanmasında katkıda bulunur. Böylelikle Anadolu'yu da tanımaya ve "sı̆ğınmacı" kimliğinden uzaklaşmaya başlar, bu süreçte hem bireysel hem toplumsal kimliğini inşa edecektir. Yazar Cumhuriyet'in kurucu kadroları arasında yer alır, İstanbul'dan mental olarak da uzaklaşır, Ankara’yı bir başkent olarak idealize etmeye başlar, Anadolu'nun köylü kadınlarını yücelterek yeni bir yurttaş kimliğini oluşturmaya çalışır. Yine 1920’li yılların başında, politikanın da içinde kadınlara siyasal hakların çok yakın bir tarihte verileceğinin altını çizer. "Bizde kadınların hakk-1 intihabları olmasına ne İngiltere'de ne de hatta Amerika'da olduğu kadar bile itiraz olmayacaktır... bizim erkeklerde

\footnotetext{
${ }^{1}$ Ayşe Durakbaşa, 1908 Devrimi’nden sonra Mısır’a çocuklarıyla birlikte kaçmak zorunda kaldığında bu duyguyu ilk kez hissettiğinden bahseder. (134)

'İzmir'in 15 Mayıs 1919 yılındaki işgali karşısındaki aktif konumu, Türk Ocağı tarafından düzenlenen üç mitingde (Fatih-Kadıköy ve özellikle Sultanahmet) konuşmacı olarak yer alması, İstanbul'daki Divan-1 Harb tarafından gıyabındaki idam hükmünün verilmesi ve Anadolu'ya kaçışıyla Milli Mücadele'nin en önemli destekçilerinden birisi olur. Birinci İnönü Zaferi’nden sonra ilk kez cepheye giden Adıvar, Eskişehir'deki hastanede hastabakıcılık yapar, bir yıl sonra kendisine “onbaşılık” rütbesi verilir. Rütbesi, daha sonra "başçavuşluk”a yükseltilecektir.
} 
kadınları kıskaçlık yok. Yani bir kadın kabiliyetini göstermiş olabilirse onu pekala kabul ediyorlar.” (Yaraman, 2001: 148)

Politikanın bu kadar içinde olan ve Cumhuriyet'in temel taşlarından sayılan Halide Edip, Cumhuriyet'in ilanından hemen sonra eşi Adnan Adıvar'ın kurucuları arasında bulunduğu Terakkiperver Cumhuriyet Fırkası'nın kapatılmasıyla ülkeden uzaklaşmak zorunda kalacaktır; yazar 1924-1939 yılları arasında ülkeyi terk etmek zorunda kalan "bir muhalif”tir. Kâzım Karabekir, Adnan Adıvar gibi isimleri de içinde barındıran Terakkiperver Cumhuriyet Fırkası, cumhurbaşkanının yetkilerinin sınırlandırılması, ülkede liberalizmin uygulanması vb. talepler sebebiyle kapatılır ve Parti içindeki 29 milletvekilinden altısı idam edilir. Süreç içinde Adıvar'lar dört yıl İngiltere'de ikamet ederler; bu sırada Halide Edip iki cilt hâlinde İngilizce olarak anılarını yayımlar. Süreci Ayşe Durakbaşa şöyle özetler: "Yeni Türkiye’nin yönetici kadrolarından elenmiş olmasını reddediyor ve Batı dünyası için Yeni Türkiye'yi tanımlamayı, tasvir etmeyi üstlenen bir yazar olarak, modern Türkiye ile ilgili Batılıların mutlak kaynak gösterdikleri otoriteler arasına giriyor.” (175) Anılarını İngilizce olarak yazması Kurtuluş mücadelesini, Kuvayi Milliye ruhunu öncelikli olarak dünyaya duyurmak isteyen önder bir kadın kimliğiyle var olmasına da sebep olarak gösterilebilir. Halide Edip, Batı basınında milletini dolayısıyla kendisini de tanıtmaya devam ediyorken ülke içinde onunla ilgili hem kadın hem erkek cephelerinden gelen olumsuz görüşlerin sayısı oldukça fazladır. Buna sebep olarak da Atatürk'ün Cumhuriyet Halk Fırkası İkinci Kongresi’nde (15-20 Ekim 1927), altı gün boyunca 36 saat 31dakika sürecek Nutuk'unda kendisini mandacı olarak suçlaması gösterilebilir. "Mustafa Kemal Nutuk'u okurken mandaya artık yeni bir siyasi anlam kazandırılmıştı. Artık manda bir çözüm arayışı değil, bir teslimiyet olarak tanımlanıyordu. 1919 yılında (Halide Edib'in) Mustafa Kemal'e yazdığı ünlü mektup tarihi sürecinden kopartıldığında bir ihanet belgesi gibi algılandı, bugün de bazı çevreler tarafindan böyle algılanıyor." (Çalışlar, 2001: 346) Halide Edip Mustafa Kemal'e The Times aracılı̆̆ıyla sert bir 
yanıt verir. "Bildirgeyi imzalayan ve savunanlardan biri olduğum doğrudur. Ama şu anda Gazi Paşa'nın yardımcısı olanlardan birçoğu da buna taraftardı. Aynı zamanda Gazi Paşa'nın son nutkunda ima ettiği gibi buna karşı çıktığı da doğru değildir. Wilson Cemiyeti'nin bildirisini, Türk sorununun kan dökülmeden çözümü olarak düşündüğü Türkiye'de ve özellikle Erzurum'da iyi bilinen bir husustur. Ancak Mustafa Kemal Paşa, tarihe ve siyasi olaylara istediği rengi verecek konumda olduğu için, Türkiye'den iddiasını düzeltecek bir ses çıkmayacaktır." (346) Mustafa Kemal'in öfkeli sesine karşılık Halide Edip'in öfkeli yanıtı çerçevesinde Türkiye'deki birçok köşe yazarı Adıvar'ı acımasızca eleştirmeye başlar. Örneğin Orhon Seyfi Orhon şöyle yazar: “... İstiklal harbine asker oldu, çavuş rütbesinden fazla rütbe vermediler. Kadın oldu solda sıfır bıraktılar. İttihat ve Terakki devrinde çınlayan şöhretinin milli harekette zirveye çıkacağını zannediyordu. Heyhat, siyasette bir nefer, kadınlıkta bir acuze muamelesi gördü. Bütün bu hissizlik ve haksızlıklara isyan ederek hışımla Ankara'dan kaçtı. Haftalarca, aylarca hatta senelerce bir davet bekledi. Küçük bir davet! Bunu da göremeyince hıçkırıklarla kabaran göğsü boşaldı. Şimdi kaleminin ucundan mürekkep siyah gözyaşları gibi akıyor, artık neler yazmayacak, neler söylemeyecek... Bu yarı kadın yarı erkek acayip mahlûk, işte bu yüzden 50 yaşının buhranlarını siyasi hezeyanlar halinde Londra' da geçirmektedir!..." (Orhan Seyfi, 25 Temmuz 1928, aktaran Çalışlar, 2010: 360) Adıvar'ı sadece erkekler değil kadın yazarlar da eleştirirler. Münevver Ayaşlı meseleyi en başa döndürerek yazarın Milli Mücadele yıllarındaki tavrını, giyimini dahi küçümseyecektir: "Bütün bir millet, ölüm kalım mücadelesi veriyordu. Türk milleti en güç, en ulvi devrimi yaşıyordu. Millet öyle bir dram içindeyken kafası acaib sargılar ile sarılmış, ayağında pantolon, beygirin yuları bir elinde, öbür elinde kırbaç, Halide Hanım poz poz resimler çektiriyor, yok Halide Onbaşı, yok Halide Çavuş gibi manasız ciddiyetle telif edilmeyecek hallerdi bunlar.” (Ayaşl1, 1973: 83) Müfide Ferit Tek Pervaneler adlı romanında doğrudan Halide Edip Adıvar'ı hedef almaz belki ama eserdeki özellikle Nesime karakteri (aldığı eğitim bağlamında) Adıvar’ı çağrıştırır. 20. yüzyılın ilk 
çeyreğinde İstanbul'da Bizans Koleji'inde ${ }^{1}$ okuyan Leman ve Nesime'nin tek amac1 Amerika'ya gidip ömürlerinin sonuna kadar orada yaşayabilmektir. Kolejde açıkça Hıristiyanlık ve Amerikan mandası propagandası yapıldığını vurgulayan anlatıcı bu kolejden mezun olacak Nesime için, “Hele bir Columbia Üniversitesi’ne gidebilsin, şahadetnamesini alsın, konferansçı olsun, gerisi kolay!” der. Kolejin diğer kızları da ülkenin savaş ve yokluk içinde olmasını umursamayan, nankör ve haris tiplerdir (109).

Tüm bu muhalif söylem ve öfkeli görüşlere rağmen Halide Edip Adıvar, Atatürk'ün vefatından sonra 1939 yılında ülkeye geri döner. Üstelik 1935 yılında İngiltere'deyken The Clown and His Daughter (Soytarl ve Kızı) başlığıyla Londra' da yayımlanan hemen sonrasında Sinekli Bakkal ${ }^{2}$ adıyla Haber'de tefrika edilmeye başlanan romanı 1942 yılında CHP Roman Mükâfatını kazanır.

\section{Sürgün Kadından Yeniden Kahramanlığa}

Selçuk Çıkla, “Türk Edebiyatında Kanon ve İnkılâp Kanonu” adlı Ülkü’de yayımlanan makalesinde "CHP roman mükâfatını kazandıktan sonra Sinekli Bakkal ve eserin müellifi Halide Edip tekrar $(a b c ̧)$ günün meselesi oldu” ifadelerine dikkat çeker. Roman, ödül aldığ1 1940’lı yıllarda 33 baskı yapar. Aslında yazar Türk basınında yazmaya devam etmektedir; örneğin 1936-1937 yılları arasında Yedigün'de tefrika edilmiş olan Yolpalas Cinayeti adlı romanı ve yine tefrikası Yedigün'de 1937 yılında yapılan ve ilk tefrikada "Maskeli Ruhlar" başlığıyla yayımlanan Maske ve Ruh adlı tiyatro oyununu (ilk baskısı 1945 yılında Türkiye'de

\footnotetext{
${ }^{1}$ İnci Engünün, romanın sonunda yer alan "Pervaneler" adlı yazısında, kolejin hem kuruluşu hem de anlattığı bazı şahısları bakımından Amerikan Koleji'ni hatırlattı̆̆ını vurgular.

${ }^{2}$ Romanda, anlatının ana kahramanı Rabia'nın sesinin güzelliğini ve ezber kabiliyetini fark eden Dede'nin küçük kızı hafız yapmaya karar vermesi, 15 yıldır İstanbul'da yaşayan İtalyan Peregrini'nin Rabia'nın sesine ve Kur'an okumasına duyduğu hayranlık, Dede ve Peregrini'nin Doğu-Batı meselesi üzerine tartışmaları, zengin ve alafranga Türklerin çevresinde yaşayan Peregrini'nin din değiştirip Rabia'yla evlenmesi, aradaki kültür farklılı̆̆ının fark edilmesine rağmen romanın sonundaki umut vb. meseleler Sinekli Bakkal'ın İnkılâp Kanonu'nun oldukça dışında bir roman olduğunun örnekleridir.
} 
yapılacak; Mask or Souls adıyla İngilizce baskısı da 1953'te gerçekleşecektir) ile en azından okurun zihinlerinden çok uzak değildir. Fakat burada kast edilen elbette edebiyat dünyasının dikkatini çekmesi ve muhtemel popülerliğinin tekrar gündeme gelecek olmasıdır.

Ahmet Hamdi Tanpınar, Edebiyat Üzerine Makaleler'in "Sinekli Bakkal"1 incelediği bölümünde, roman hakkındaki olumlu görüşlerini "son devir Türk romanındaki bir merhale" (Tanpınar, 1992: 512) olarak belirttikten sonra çok önemli bir noktaya dikkat çeker. "Sinekli Bakkal'ın bir hususiyeti de kitabın Garp âleminde uyandırdığı büyük ve heyecanlı kabuldür. Unutulmamalı ki romanını daha evvel bir kere de İngilizcede yazmış olan Halide Edib Hanım, aramızda bir Garb diliyle ibda yapan ilk muharrirdir. Bu itibarla Sinekli Bakkal'ın garplılaşma tarihimizde mühim addedilecek bir mevkii vardır.” (512) Yazarla ilgili önceki olumsuz söylem ve düşüncelerin bir tarafa bırakılıp yazara ve eserine bu kadar ilgi gösterilmesinin altını özellikle çizmek gerekir. Yapıt her ne kadar içerdiği mistisizm, tefekkür, Doğulu değerlerin önemi vb. meseleler bağlamında Cumhuriyet ideolojisinin merkezinde yer alamayacak olsa da, daha önce İngilizce yazılması, yapıta Batılılaşma tarihinin bir adımı olarak yaklaşılmasını sağlar. Romanın katıldığı yarışma sırasında üçe kalan diğer iki eser, Yakup Kadri Karaosmanoğlu'nun Yaban'1, Abdülhak Şinası Hisar'ın Fahim Bey ve Biz'idir. İlk oylamada Yaban 30, Sinekli Bakkal 28, Fahim Bey ve Biz 19 oy alır. İkinci oylamada Sinekli Bakkal öne geçerek 9 oyla (Yaban 8, Fahim Bey ve Biz 6 oy) birinciliği kazanır. İpek Çalışlar’ın aktardığına göre, Akşam Gazetesi, haberi “Büyük Sanat Olayı” başlığıyla duyurur: "1931 senesi... New York’ta meşhur Columbia Üniversitesi'nde zeki bakışlı bir kadın, misafir profesör olarak ders veriyor... Anlattığı mevzu 'Yakın Şarkta fikir hareketleri' O kürsüden indiği zaman, kendisini dinleyenlerden biri yanındakine soruyor: 'Ne milletten' ‘Türk!' Türk ha... Bir Türk kadını!... Evet, bu Türk kadını üstad Halide Edib'den başka kimse değildi.” (420) Yine Çalışlar'ın aktardığına göre Yücel Dergisi ödül sonrası neredeyse bütün sayısını Halide Edip'e ayırır. Samet Ağaoğlu, "Şimdi derhal itiraf edeyim ki ben de jüri azası olsaydım belki de reyimi bu 
esere verecektim... Halide Edib yalnız bir romancı değil, bizzat bir roman kahramanıdır ve bu kahraman kendi kendisini yaratmıştır. (abç) Elbette böyle manevi bir mükâfata böyle bir eser layıktır." (421) der. Gerçekten de Halide Edip bir roman kahramanı gibidir. Nice badireler atlatmış, ülkede kalsa belki de idam edilecek bir yazar, yurt dışında kendisini var etmeyi sürdürüp bir Türk kadını olarak takdir görmektedir. Bu takdir ülkeye dönüşüyle yurt içinde de görünür olmaya başlamıştır, üstelik Sinekli Bakkal gibi bir romanla. Eserin ana teması zorbalık ve sömürü düzeni yerine özgürlüğü ve adaleti değil, bireyi mutlu yapacağına inandı̆̆ı iç huzurunu koyan (Moran, 2005: 165) mistisizmin önemi ve güzelliğidir. Mahalleyi sıcak ilişkilerin, sevginin dostluğun olduğu bir alan olarak tanımlayan bir roman birincilik ödülüne lay1k görülmüştür. ${ }^{1}$

Halide Edip bu eserle “ilk kez Abdurrahman Nisari’nin 1955 yllında okutulmaya başlanan Metinlerle Türk Edebiyatı kitabında da yer alır. Yazardan, 'o zamana kadar alışılmamış bir söz dizimi ve sade bir dille yazdığı hikâye ve romanlarıyla yenilik hareketinin tutulmasında büyük emeği geçmiş bir yazar' olarak bahsedilir. Sonraki yıllarda yayımlanan edebiyat ders kitaplarında da bu esere büyük çoğunlukla yer verilir. (Baki, 201: 81)² 1950'li yıllarda Halide Edip'i Demokrat Parti milletvekili olarak görürüz. Bu yıllarda yayımladığı Döner Ayna (1954), Akile Hanım Sokă̆ (1958), Kerim Usta’nın Oğlu (1958), Sevda Sokağı Komedyası (1959) gibi romanlarında merkeze aşkı alarak değiş̧en İstanbul'u, özellikle yine kadın karakterler üzerinden, anlatır. 1963 yılında yani vefatından bir yıl önce kaleme aldığı Çaresaz'da da mesele değişmeyecektir. Bu dönem romanları da tıpkı ilk dönem romanlarında olduğu gibi arka planda kalmaktadır. Dolayısıyla yazar, sınırlı-seçme eserleriyle gündeme

\footnotetext{
${ }^{1}$ Türkçede en çok baskı yapan romanlardan biri olmasına da dikkat çeken Fethi Naci roman hakkında 1976 yılında (ki 34. baskısını yapmıştır) "mistik düşünceleri yeni ve olumu bir şeymiş gibi ileri sürme, kötü bir Türkçe... Sinekli Bakkal, sıradan bir roman; bilmem kaç baskı yapmasına bunca şişirilmesine rağmen." (30) diyerek eserle ilgili olumsuz görüşlerini dile getirir.

${ }^{2}$ Roman, Mor Salkımlı Ev'le birlikte MEB’in orta öğretim öğrencileri için hazırladığı 2005 yılında tavsiye edilmeye başlanan, 2018 yılında yürürlükten kaldırılan 100 Temel Eser listesi içinde de yer alır.
} 
getirilir. Bu bağlamda, bir Halide Edip Adıvar kimliği çizilip kamusal alanda görünür kılınmaya çalış1lırken ülkeye dönüşüyle birlikte ödül aldığ1 Sinekli Bakkal da yazarın dönüm noktası olarak okunabilir. Eserin tarihsel bağlamda "daha geride kalmış" Halide Edip'in tekrar hatırlanmasına aracı olduğu ve bu aracılık vasfiyla bir Halide Edip seçimine gidildiğine tanık oluruz. Roman, Batıya kendisini kabul ettirmiş bir yazarın kendi ülkesinde de tekrar kabulünün bir işareti gibidir adeta, her ne kadar dönemin zihniyetine uygun olarak yazılmış olmasa da Milli Mücadele romanlarının gündeme gelebilmesi için bir anahtar gibidir.

\section{Sonuç Yerine}

Halide Edip Adıvar'ın zorlu yaşam koşulları içinde (hem kadın-hem entelektüel, zaman zaman da muhalif) Milli Mücadele Dönemi’ni anlattı̆̆ Sinekli Bakkal ve Ateşten Gömlek ${ }^{1}$ yazarın toplumsal hafıza içinde diri tutulmasını sağlayan (görsel hafıza içinde de var olan²) eserleri arasında yer alır. Bu iki romanla birlikte Adıvar'ın yurt dışındaki başarıları göz önünde bulundurularak Sinekli Bakkal da 1950'li yıllardan itibaren lise edebiyat kitaplarına dâhil olur ve bir geçmiş inşası sürecinin önemli kaynakları arasında bulunur. Jan Assman Kültürel Bellek'te, "Bellek denince insanın aklına genellikle bir iç olgu gelir ve bunun mekânı bireyin beynidir, yani belleğin beyin fizyolojisiyle, nöroloji ve psikolojiyle ilgili olduğu düşünülür, ama tarihsel kültür bilimi ile bir ilgisi yoktur. Oysa bu belleğin neler içerdiğini, bu içeriklerin organize edilişini ve ne kadar süre ile muhafaza edileceğini, bireyin kapasitesi ve yöneliminden çok, dış koşullar yani toplumsal ve kültürel çerçevenin koşulları belirler.” (24) der. Bu diş koşullara bakıldığında entelektüel kadın imgesi, Cumhuriyet tarihi reformlarının ve

\footnotetext{
1 Eserler, Abdurrahman Nisari'nin Metinlerle Türk Edebiyatı 3 adlı kitabında ve 1960'lı yılların lise ders kitaplarında yer alacaktır.

${ }^{2}$ Vurun Kahpeye, 1949-1964 ve 1973 yıllarında üç kez sinemaya uyarlanır. Ateşten Gömlek ilk 1950 y1lında sinemaya uyarlanmıştır. Roman daha sonra 1987 yılında TRT'de dört bölümlük bir sinema filmi olarak Ateşten Günler adıyla izleyiciye sunulur. Sinekli Bakkal da 1967 yılında sinemaya uyarlanacaktır. Roman, 2007 yılında bir TV Dizisi olarak da seyirci karşısına çıkar.
} 
oluşturulmaya çalışılan Türk kimliğinin tamamlayıcı bir parçasıdır; dolayısıyla da oldukça merkezi bir konuma sahiptir. Bu bağlamda da Halide Edip yok sayılamayacak kadar merkezdeki bir kadındır aslında. Yazar sadece köşe yazılarıyla kalsaydı belki unutulabilirdi, anılarını kaleme almasaydı da unutulabilirdi belki. Bu anılarda, özellikle Türkün Ateşle İmtihanı'nda kendini ulusla özdeşleştiren bir kimlik olarak görürüz yazarı, özel hayatı yok denecek kadar azdır, sonraki sürgün yıllarından bahsetmez; ${ }^{1}$ anıların Türkçe çevirisi bir kurtuluş-kuruluş $^{2}$ anlatısı olarak kaleme alınır. Tüm bu metinlerin ötesinde roman gibi kurmaca bir kanal aracılığıyla okurlara seslenir; dolayısıyla Cumhuriyet ideolojisinin ondan vazgeçmesi pek de mümkün değildir. Gregory Jusdanis Gecikmiş Modernlik ve Estetik Kültür'de “Millet inşa etmek, kolektif anılar uydurmayı, etnik farklılıkların homojenleştirilmesini ve muhayyel bir cemaat ideolojisini yurttaşlara benimsetmeyi gerektirir." (Jusdanis, 1998: 53) "Edebiyat kolektif kimliğin aynası olarak hizmet verir ve aynı zamanda onun hikâyesini anlatır" (68) der. Bu hikâyeyi anlatan erkek yazarlardan birisinin örneğin Aka Gündüz gibi bir ismin ya da özellikle tarihi romanlarıyla tanınan Nizamettin Nazif Tepedelenlioğlu'nun unutulması mümkündür; çünkü bu isimlerin yerine konabilecek Yakup Kadri Karaosmanoğlu, Reşat Nuri Güntekin gibi yazarlar mevcuttur. Ama tarihten Halide Edip’i özellikle de Milli Mücadele Dönemi'ni anlattığı Ateşten Gömlek ve Vurun Kahpeye gibi romanlarını çektiğinizde bu kadar çok türde eser veren, otobiyografisini bildiğimiz, toplumun yurt dışındaki ilk kadın temsilcilerinden olan başka bir yazara ulaşmak pek de mümkün gözükmemektedir. Dolayısıyla da yazar ve eserleri “sınırlı” bir şekilde sonraki kuşaklara aktarılmaya çalışılır. Halide Edip’e özellikle sürgün yıllarında eleştiri oklarını çeviren edebiyatçılar unutulurken ya da kanonun tek bir alanında (örneğin şiir ama günümüzde şiir kitaplarının yeni baskıları yapılmaz bile) adları

\footnotetext{
${ }^{1}$ İngiltere ve İngilizlerle ilgili anılarını da Türkiye’ye döndükten hemen sonra Akşam'da Haziran-Ağustos 1939 tarihleri arasında kaleme alacaktır.

${ }^{2}$ The Turkish Ordeal, Türkün Ateşle Imtihanı başlı̆̆ıyla 1962 yılında, özellikle Atatürk'le ilgili olumsuz yargıların büyük bir kısmı yazar tarafından esere dâhil edilmeyerek Türkçeye aktarılmıştır.
} 
anılırken Adıvar, yapıtlarıyla ölümsüzler arasına girmeyi başarmıştır. Bu ölümsüzlük, maalesef, hem onun yaşamının belli bir kısmını hem de roman kahramanlarının "uysal" ve "yararlı" olanlarına sağlanmış bir hak olarak kalır.

\section{Kaynaklar}

Adak, H. (2004), Kadınlar Dile Düşünce: Edebiyat ve Toplumsal Cinsiyet, (der. S. Irzık-J. Parla), İstanbul: İletişim Yayınları, 161-178.

Ayaşl1, M. (1973), İşittiklerim... Gördüklerim... Bildiklerim..., İstanbul: Atlas Kitabevi, 1973.

Baki, E. (2010), Ulusun İnşası ve Resmi Edebiyat Kanonu, İstanbul: Libra Kitap.

Çalışlar, İ. (2010), Biyografisine Sığmayan Kadın, Halide Edib, İstanbul: Everest Yayınları.

Çıkla, S. (2007), “Türk Edebiyatında Kanon ve İnkılâp Kanonu”, Muhafazakâr Düşünce, 4 (1314), 47-67.

Durakbaşa, A. (2007), Halide Edib Türk Modernleşmesi ve Feminizm, İstanbul: İletişim Yayınlar1.

Jusdanis, G. (1998), Gecikmiş Modernlik ve Estetik Kültür, İstanbul: Metis Yayınları.

Lekesiz, Ö. (1997), Şirazeden Şirazeye, İstanbul: Timaş Yayınları.

Moran, B. (2005), Türk Romanına Eleştirel Bir Bakış 1, İstanbul: İletişim Yayınları.

Naci, F. (2010) Yüz Yılın 100 Türk Romanı. İstanbul: Türkiye İş Bankası Kültür Yayınları.

Sertel, S. (2015), Roman Gibi, İstanbul: Can Yayınları.

Sirman, n. (2002), “Kadınların Milliyeti”, Modern Türkiye'de Siyasi Düşünce Milliyetçilik, (4), 225-244.

Tanpınar, A.H.(1992), Edebiyat Üzerine Makaleler, İstanbul: Dergâh Yayınları.

Tek, M. F. (2002), Pervaneler, İstanbul: Kaknüs Yayınları.

Yaraman, A. (2001), Resmi Tarihten Kadın Tarihine Elinin Hamuruyla Özgürlük, İstanbul: Bağlam Yayınları. 


\title{
MASCULINITY REPRESENTATIONS IN NORTHERN CYPRUS ADVERTISING: 'NEYDI OLACAGI' FIELD STUDY
}

\section{Mürüde ÖZEN SEVİNÇ${ }^{1}$}

\begin{abstract}
Abstaract
Advertisements play an important role in spreading and re-building gender roles as well as spreading consumer culture. Advertisements have major role on consumer's behaviour and also advertisements are among the major sources of revenue for the media. As it is known, media tools are very effective in shaping the social structure. Hence, consumers learn about gender roles from the media and behave as they learn from the media. Today, undoubtedly, one of the most widely used media tools is social media. For this reason, many brands, corporations or businesses have moved their ads from traditional media to digital media tools. In this context, the aim of this study is to analyze how to represent masculinity in popular advertising and how it is transmitted to consumers. 'Neydi Olacă̆g' is the Facebook page which creates advertisiments for Cyprus brands. Mostly 'Neydi Olacă̆l creates humorous viral advertising which is include Cypriot culture in their advertisements. Therefore, two advertisements on this page - 'World is reversed: shopping, World is reversed: Valentines Day - will be critically analyzed.
\end{abstract}

Keywords: Masculinity, Advertisements, North Cyprus, Social Media, Gender Inequality

${ }^{1}$ PhD. C. Communican and Media Studies, Eastern Mediterranean University, e.murudeozen29@gmail.com 


\section{REKLAMLARDA ERKEKLIK TEMSILLERİ: NEYDİ OLACAĞI ÇALIŞMASI}

$\ddot{O z e t}$

Tüketim kültürünün yayllmasında önemli bir yere sahip olan reklamlar, ayn zamanda toplumsal cinsiyet rollerinin yansilttlmasinda ve yeniden inşasinda da önemli rol oynamaktadir. Kitlelerin, tüketim alışkanlıklarını yönlendirmeye çalışan reklamlar medyanın önemli gelir kaynakları arasında yer almaktadır. Bilindiği üzere toplumsal yapının şekillenmesinde medya araçları oldukça etkili olmaktadır. Kitlelerin, toplumsal cinsiyet rollerini medyadan ögrrenmeleri ve ona göre davranmaları mümkündür. Günümüzde en çok kullanılan medya araçlarından bir tanesi şüphesiz ki sosyal medyadir. Bu sebeple birçok marka, kurum veya işletme, reklamların geleneksel medya araçlarından dijital medya araçlarına kaydırmıştır. Kuzey Kıbrıs'ta ise yapılan araştırmalar sonucunda en çok kullanılan sosyal medya ağının Facebook olduğu bilinmektedir. Bu bağlamda çalışmanın amact; popüler reklamlarda erkekliğin nasıl temsil edildiği ve tüketiciye nasıl aktarıldığını incelemektir. Buna göre, Kıbrıs kültürü ile reklamları entegre etmiş olup, çoğunlukla mizah içerikli viral reklam içerikleri oluşturan Neydi olacağı isimli Facebook sayfasının 'Dünya tersine dönse: Alş̧veriş've 'Dünya tersine dönse: Sevgililer günü' isimli reklamları eleştirel olarak incelenecektir.

Anahtar Kelimeler: Erkeklik temsili, Reklamlar, Kuzey Kıbrls, Sosyal Medya, Toplumsal cinsiyet eşitsizliği

\section{Giriş}

Kuzey Kıbrıs’ta dijital reklam sektörü son yıllarda gelişmeye başlamıştır. Özellikle sosyal medyada yayınlanan viral reklamlar bir çok kişi tarafından izlenip, paylaşılmaktadır. Bu yüzden reklamlarda kullanılan temsiller toplumsal cinsiyetin inşasında önemli rol oynamaktadır. Kuzey Kıbrıs gelişmekte olan bir ülke olmasına rağmen reklamlarda kullanılan kadın ve erkeklik temsillerinde genel geçer bir temsiliyetin olduğu söylenebilir.

Son yıllarda başlayan ve Kuzey Kıbrıs'ta sadece üç şirketin uyguladığı viral reklam teknikleri, Kuzey Kıbrıs halkı tarafından çok fazla beğenilmiş ve milyonlarca izlenmeye ulaşmıştır. Bu duruma; senaryo, yaratıcılık vb birçok şey etki ederken, en önemli etkenlerden 
biri, reklamcıların Kıbrıs kültürünü kullanmaları olmuştur. Kuzey Kıbrıs halkı, son yıllarda kendi kültürlerinin yok olması korkusu içerisinde yaşamaktadırlar. Bu durum da Kıbrıs lehçesini, geleneklerini ve göreneklerini kullanan reklam şirketleri için çok büyük bir avantaj olmuştur.

Reklamların, toplumsal cinsiyet alanında önemli yere sahip olduğu bilinmektedir. Sadece tüketim alışkanlığını değil, bunun yanında kadınlara ve erkeklere toplum tarafından atfedilen rolleri de yaymaktadırlar. Genel olarak reklamlarda kadınların kullanılma sebebi tüketicinin ilgisini çekmek veya onları ikna etmek olarak kullanılır (Dumanlı, 2011). Rollere bakıldığında ise, bugüne kadar kadınlar, genelde ev işleri veya çocuklar ile ilgilenen, erkekler ise eve para getirmek veya fiziksel güç isteyen bir takım işler yaparken görülürken günümüzde kadın iş hayatına, erkek ise ev içinde gösterilmeye başlamıştır (Tosun \& Ülker, 2018). Reklamların, toplum üzerinde bir hayli etkisi olduğundan dolayı, alt metinde anlattıkları da çok önemlidir. Bu nedenden dolayı sadece ürün veya hizmeti satma amacının yanında toplum yapılanmasını da önemsemelidirler.

\section{Neydi Olacağı Haber Bülteni Nasıl Ortaya Çıktı?}

Neydi olacağı haber bülteni Kuzey Kıbrıs’ta bulunan ve yukarıda bahsedilen 3 reklam şirketinden bu işe giren ilk şirkettir. "Neydi olacağı haber bülteninin kurucusu olan Mehmet Ekin Vaiz mizah yapmaya lise yıllarında Ziligurti isimli mizah dergisiyle başlamıştır. Daha sonra radyoda zorunlu seçmeli ve televizyonda hellimli demokrasi programlarıyla kariyerine devam etmiştir (Gürkan, 2018). Hellimli demokrasi programını devam ettirmek için mali destek amacıyla başladığı (Öze \& Ulaş, 2018) Neydi olacağı haber bülteni ilk başlarda Facebook üzerinden siyasi mizah ağırlıklı haber bültenleri yapmaktaydı. Daha sonra ürün yerleştirme olarak reklam almaya başlamış ve son olarak yerel dili (Kıbrıs lehçesi) kullanarak kısa parodiler şeklinde viral reklamlar oluşturmuşlardır (Özen \& Kaya, 2019). Şu anki eşi Gülşen Erçin ile iş 
ortaklığını sürdüren Mehmet Ekin Vaiz, hikaye ağırlıklı parodilerde oynattıkları karakterleri aileden, komşularından veya halkın içinden seçmektedirler (Gürkan, 2018).

Bir konferansta konuşma yapan Vaiz’e (2017) göre reklamcılığın temel kuralının hedef kitlenin ilgisini çekebilecek reklamlar tasarlamak olduğunu söylemiştir. Bunun dışında reklamda önemli olanın hedef kitlenin ilgisini çekmek olduğunu ve sürekli değişen gündeme göre reklamın yapılması gerektiğini belirtmiştir (Ciu.edu.tr, 2017 ).

\section{Hegemonik Erkeklik}

Erkeklik çalışmaları, 1990'lı yıllara kadar ağırlıklı olarak kadın çalışmalarının gölgesinde kalmıştır. 90'lı yıllarda Connell'in yanısıra bir çok önemli isim de bu alana önemli katkı koymuşlardır. Bu yıllara gelene kadar toplumsal cinsiyet çalışmaları denildiğinde ataerkil toplum içerisinde kadın sorunları ele alınıp, daha çok kadın bedeninin metalaşması ile ilgili çalışmalar akla gelmekteydi. Erkeklik uzun bir süre Kadınlık çalışmalarının gerisinde kalsa da Horzum'a (2018) göre, bu çalışmaların temeli Erkek Özgürlük Hareketi’ne dayanmaktadır. 1970’li yılların başında Kadın Özgürlük Hareketi'nden sonra ortaya çıkmıştır. Erkek özgürlük hareketi "eril cinsiyet rollerini düzeltip iyileştirmeyi amaçladığını ve bunun da erkeklere, iktidara ve değişime dair ilgi çekici siyasal tartışmaları" ortaya çıkardığı söylenmektedir (Horzum ,2018, s. 78).

"Erkeklik, bir biyolojik cinsiyet olarak erkeğin toplumsal yaşamda nasıl düşünüp, duyup, davranacağını belirleyen, ondan salt erkek olduğu için beklenen rolleri ve tutumları içeren bir pratikler toplamıdır" (Tokdoğan, 2013, s. 8). Farklı bir deyişle erkek ve erkeklil arasında fark vardır. Biyolojik olarak eril veya dişil bir birey olurken, toplumun da kişilerden beklediği bir takım roller vardır işte bu rollere göre erkeklik veya kadınlık tanımları yapılabilmektedir. 
Connell'e göre, bir kültürde veya yapıda genellikle farklı erkeklik biçimleri bir arada ve birbirine alternatif yaşam biçimleri olmaktan çok, karşılıklı hiyerarşi ve mücadele gibi ilişki biçimleri içerisinde varlık gösterir. Ancak çoğunlukla bu erkeklik biçimlerinden birisi diğerleri üzerinde egemenlik kuran, baskın bir yapıya sahiptir. Connell, bu baskın erkeklik biçimini "hegemonik erkeklik" olarak adlandırmaktadır (Oktan, 2008, s. 155).

Connel, hegomonik erkekliği, kazanılmış bir güç, diğerlerine karşı toplumsal bir üstünlük olarak görmektedir. Bu güç ve üstünlük toplum ve kültür tarafından verilmektedir. Dolayısıyla eril tahakküm sadece kadına değil erkeğin erkeğe de uyguladığı bir hegemonyadır.

\section{Reklam Analizleri}

Analiz edilen ilk reklam filmi 12 Şubat 2019 tarihinde paylaşılan 'Dünya tersine dönsesevgililer günü’ adlı reklam filmidir. Reklam filmi, Neydi Olacağının Facabook sayfasından yayınlanmış 1.4 Milyon görüntülenme 18 bin beğeni, 1023 yorum almış ve 13.078 paylaşım yapılmıştır. Reklam filminde üç çift, altı karakter bulunmaktadır ve bu karakterler mizahi bir anlatımla izleyiciyle buluşmaktadır. Ekranda görülen ilk çift Nermin-Necati, sonra Pervin-Çetin ve daha sonra ise Ruhsan- Mehmet çifti'nin arabada giderken kurdukları diyaloglar üzerinden sevgililer günü için kadın ve erkek temsillerinin tepkileri anlatılmaktadır fakat kadın temsillerini erkekler, erkek temsillerini ise kadınlar canlandırmaktadır.

Reklam filmi Necati karakterinin “sevgililer gününde napacayık?’ sorusuyla başlamaktadır. Bu soruyla bir erkek olarak sevgililer gününde özel bir beklentisinin olduğunu anlatmak istemektedir. Bunun üzerine eşi rolundeki Nermin ise "Ne demek napacayık?" sorusuyla sevgililer gününün özel bir gün olmayıp sıradan bir gün olduğunu vurgulamaktadır. Diğer çiftlerde de benzer durumlar yaşanmaktadır. Mehmet karakteri sevgililer gününde ne yapacaklarını eşi Ruhsan’a sorduğunda aldığı cevap “'seni Fenerin maçına götüreyim mi??” olmaktadır. Pervin ve Çetin karakterinde de durum yine aynıdır. Çetin karakteri eşi Pervin'e 
“ben senin için sürpriz hazırladım o gece özel olsun diye’ derken, Pervin karakteri “İnanma bunlara, bunlar hep para tuzağı, kapitalizmin oyunlarına gelme'" diyerek eşiyle aynı görüşte olmadığını belirtmektedir. Tüm bu söylemlerle kadınların sevgililer günü gibi günlerde özel bir beklenti içerisinde oldukları, erkeklerin ise bu gibi günlere önem vermedikleri anlatılmak istenmiştir. İlerleyen diyaloglarda, Necati karakteri eşinin ona karşı ilgisiz olduğundan, sevgililer günü için işyerinde herkesin özel bir planı olduğundan ve kendilerinin bir programları olmadığından bahsetmektedir. Bunun üzerine Nermin " ben seninnan bir ömür geçirecem, bir güne odaklanma"' diyerek eşi Necati’yi sevgililer gününün özel bir gün olmadığına ikna etmeye çalışmaktadır. Burada da yine anlatılmak istenen, kadınların özel günlerde,özel bir program bekledikleri, herkesin özel bir planı varsa onların da mutlaka olması gerektiği savunan karakterler olduğunu ve başkalarına özenen kişiliklere sahip olduğuklarıdır. Erkeklik temsilinde ise sevgililer gününün özel bir gün olmadığı ve özel bir gün olmadığı için kutlanmaya değer görülmediği anlatılmak istenmiştir.

Bunun dışında Necati karakterinin sevgililer gününü kutlamadıkları için eşine söylenmesinin üzerine Nermin karakteri “'senin aybaşın mı geliyor?’ sorusuyla kadınların genelde gergin olduğu zamanlar erkekler tarafından özel döneminde olmakla suçlanmakta olduğuna gönderme yapılmaktadır.

Bunların dışında üç çiftte de arabayı kullananların kadın olduğunu görmekteyiz fakat buna rağmen yine erkeklerin kadınlara “'yavaş sür da vuracan”, “'kedi basıyon”, “'yavaş da vuruyon kamyona" “bu arabayı kötü süren” gibi söylemleri kalıplaşmış bir söylem olan 'kadınların iyi araba kullanamadıklarına' gönderme yaparak bir kez daha hegemonik erkekliği inşa etmektedir.

İkinci reklam filmi ‘Dünya Tersine Dönse- Alışveriş’ ise 721 bin görüntülenme, 12 bin beğeni, 520 yorum ve 2.6 bin paylaşıma sahiptir. Bu reklam filmi de yine aynı şekilde kadınların erkekleri, erkeklerin de kadınları temsil ettiği bir reklam filmidir. Aynı karakterler bu reklam 
filminde de bulunmaktadır ve yine mizahi anlatımla izleyiciyle buluşmaktadırlar. Bu reklam filminde de erkek karakterlerin alışverişe gitmek istemesi, kadın karakterlerin de onları alışverişe götürmek istememesi üzerine kurulmuş diyaloglar üzerinden kadın ve erkek temsilleri anlatılmaktadır.

İlk sahnede görülen Pervin ve Çetin karakterlerinin diyaloğu Çetin'in 'Perviiiiin, iki gözüm” diye eşine seslenmesiyle başlamaktadır. Bunun üzerine Pervin'in cevabı "Gene nesden?', olur. Burada, kadınların her zaman erkeklerden bir şeyler istediği, erkeklerin de bu gibi isteklerden bıktığır izleyiciye anlatılmaktadır. Diğer iki çiftte de durum aynıdır; kadın temsilini canlandıran erkekler giyecek bir şeylerinin kalmadıklarını ve alışverişe gitmek istediklerini söylerken erkek temsilini canlandıran kadınlardan gelen tepkiler şu şekildedir; “buhranlar geçirdin bana alışverişte", "10 tane beyaz gömleğin, 20 tane siyah gömleğin var”, “dolaplara sığman”. Bu gibi söylemlerle kadınların sürekli tüketen, sadece ihtiyaçları doğrultusunda değil, gereksiz yere alışveriş yapan karakterler olduğu gösterilmektedir. Bunun dışında Mehmet karakterinin eşinin söylediklerine alınmasıyla "vazgeçtim istemem” sözünün üzerine eşi Ruhsan "sonra cır cır cır yeyesin kafamı” söylemi ile, erkeklerin kadınları sürekli söylenen bireyler olarak gördüklerini anlatmaktadır. Nermin ve Necati karakteri ise ekranda ilk göründüklerinde Necatinin "gene yağmur başladı, ma Londra mı be burası?” söyleminin üzerine eşi Nermin' in “Havaya olsun trip atma yahu” söylemi erkeklere göre kadınların gerekli gereksiz bir çok şeye trip attığını anlatmaktadır.

İki reklam filminde de erkekler genel olarak, kadınlara göre daha mantıklı karakterler olarak gösterilmiştir. Alışveriş reklamında “euro kaç oldu haberin var mı?”, sevgililer günü reklamında ise "bir çiçek, bir çukulet kaç paradır?" gibi söylemler, rasyonel olmayı sadece erkek özelliği gibi aktarmıştır.

Bunun dışında genellikle arabaları erkeklerin kullandığını, fakat roller değiștiğinden dolayı, reklam filminde arabaları kadınların kullandığı izleyiciye aktarılmaktadır. Buna rağmen 
incelenen reklam filmlerinde, 3 çiftin erkekleri de, kendi toplumsal cinsiyetlerine geri dönüp "yavaş da vuruyon" "kedi basıyon" "kamyona vuruyon" gibi söylemlerle kadınlara müdahale etmektedirler. Bura da yine kadınların iyi araba kullanamadıkları, erkeklerin çoğu konuda olduğu gibi araba kullanma konusunda da kadınlardan iyi olduğu, arabayı kadın kullansa da erkeğin mutlaka müdahale etmesi gerektiği izleyiciye aktarılmaktadır.

İki reklam filmi de karakterleri komik durumda sunmaktadır fakat kadın temsillerini daha da komik durumda sunmaktadır. Bu da yine toplum içerisinde erkekleri kadınlara göre daha çok yüceltmektedir.

\section{Sonuç}

Sonuç olarak reklam filmlerinde kadın ve erkek kullanımı eşittir çünkü bir kadın ve bir erkeğin diyalogları üzerinden erkeklerin kadınları, kadınların da erkekleri temsil ettiği anlatılmaktadır. Genel olarak iki reklam filmi de erkekleri kaba, düşüncesiz ve hegemonik olarak göstermektedir. Bunun yanında ataerkil toplum normlarını taşıdıklarını da çeşitli söylemlerle görebilmekteyiz. Örneğin yemeği kadının yapması, alışverişi erkeğin yapması, "evin reisinin" erkek olması, bir şey yapılacağında erkeğe sorulması, erkeğin otoriter olması çeşitli söylemlerler izleyiciye aktarılmaktadır. Gürbüz'e (2016) göre Hegemonik erkeklik kültürel bir yapılanmadır. İdeal bir erkekte bulunması gereken özellikler, kültüre ait iktidar kurumları tarafından belirlenir (s.139). Analiz edilen iki reklam filmi de Kıbrıs kültürünü içeren, izleyiciye kültürle yaklaşan reklam filmleridir. $\mathrm{Bu}$ bağlamda ataerkil toplum yapılanmasını bu tarz reklam filmleriyle yeniden inşa etmiş olmaktadırlar.

\section{Kaynaklar}

Ciu.edu.tr. (2017, Ocak 4). Nisan 16, 2019 tarihinde UKÜ'de Kıbrıs'ta Reklamcılığın Geleceği Konuşuldu : http://www.ciu.edu.tr/tr/haberler/ukude-kibrista-reklamciligin-gelecegikonusuldu adresinden alındı 
Dumanlı, D. (2011). Reklamlarda Toplumal Cinsiyet Kavramı ve Kadın İmgesinin Kullanımı; Bir İçerik Analizi . Yalova Ssoyal Bilgiler Dergisi, 132-149.

Gürbüz, N. E. (2016 ). Korkuyorum Anne'de Hegemonik Erkekliğin Yapısökümü . ilef dergisi, 125-142.

Gürkan, N. (2018, eylül 3). Neydi Olacağı dedi fenemon oldu. Nisan 18, 2019 tarihinde

Havadis Kıbrıs: http://www.havadiskibris.com/neydi-olacag1-dedi-fenomen-oldu adresinden alınd1

Horzum, Ş. (2018). Erkek ve Erkeklik Çalışmaları: Sorunsaldan Kuramsala. Amasya Üniversitesi Sosyal Bilimler Dergisi , 75-101.

Oktan, A. (2008). Türk Sinemadında Hegomonik Erkeklikten Erkeklik Krizine: Yazı Tura ve Erkeklik Bunalımının Sınırları. 152-166.

Öze, N., \& Ulaş, S. (2018). Viral Videolar Üzerinden Markaların Sosyal Medya Ortamlarında Konumlandırılması:Neydi Olacağı- Çekemeyenler Çatlasın Örneği. Current Debates in Public Relations \&Communication Studies, 28, 85-96.

Özen, M., \& Kaya, A. K. (2019). Viral Reklamların Kültüre Entegrasyonu:Neydi Olacağı Alan Çalışması. X.Kıbrıs Araştırmaları Kongresi. Gazimağusa: Doğu Akdeniz Üniversiesi.

Tokdoğan, N. (2013). Milliyetçili, Militarizm ve Toplumsal Cinsiyet İlişkisini Nefes Filmi Üzerinden Okumak.

Tosun, N. B., \& Ülker, Y. (2018). Kadınların, Televizyon Reklamlarında Erkek İmgesi Kullanımına Yönelik Tutumlarında Demografik Özelliklerinin Rolü. Akdeniz İletişim Dergisi, 225-244. 


\title{
GENDER DIFFERENCES IN FOOD CONSUMPTION: A STUDY ON DOMESTIC TOURISTS
}

\author{
Nuray TÜRKER ${ }^{1}$ \\ Sibel AYYILDIZ ${ }^{2}$
}

\begin{abstract}
The main aim of this study is to determine the food and beverage preferences of domestic tourists depending on their gender. An empirical study was carried out in Safranbolu, the most important cultural tourism destination of the Western Black Sea region, in order to determine the differences in the food and beverage consumption between males and females. In this context, data were collected from 210 participants using a structured questionnaire. The results of the research show that there are significant statistical differences between male and female tourists in terms of food and beverage consumption. In this context, during their trip female tourists consume vegetables, salads, pastries, pies, pancakes as it is in their daily routine lives. However, males mainly prefer to eat meat products (kebab, döner, or grill etc.). Similarly, male tourists prefer to eat at fast food, kebab or pide restaurants, or restaurants where alcoholic beverages are served, or roadside restaurants, while female tourists choose restaurants where well-known chefs work or the restaurants in the hotel they overnight.
\end{abstract}

Keywords: Gender, Food Consumption, Domestic Tourists, Vacation.

\footnotetext{
${ }^{1}$ Assoc. Prof. Dr. Karabuk University Safranbolu Faculty of Tourism nturker@karabuk.edu.tr; ${ }^{2}$ Lect. Karabük Universty, Faculty of Tourism sibelayyildiz@karabuk.edu.tr;
} 


\section{GIDA TÜKETIMINDE CINSIYYET FARKLILIKLARI: YERLİ TURISTLER ÜZERINE BİR ÇALIŞMA}

\section{$\ddot{O} z e t$}

Bu çalışmanın temel amacı cinsiyet faktörü bağlamında yerli turistlerin yiyecek-içecek tercihlerinin belirlenmesidir. Kadın ve erkekler arasındaki turistik yiyecek-içecek tüketim farklılıklarını belirlemek amacıyla Batı Karadeniz'in en önemli kültür turizmi destinasyonu olan Safranbolu'da ampirik bir çalışma gerçekleştirilmiştir. Bu kapsamda; yapısal bir anket formu kullanılarak ankete katılan 210 kişiden veri toplanmıştır. Araştırma sonuçları, kadın ve erkek turistler arasında yiyecek-içecek tüketimi açısından önemli istatistiki farklar olduğunu ortaya koymaktadır. Bu bağlamda, kadın turistler seyahatleri sırasında da günlük rutin yaşamlarında olduğu gibi sebze, salata, hamur işi, börek, gözleme ağırlıklı beslenmeyi; erkekler ise et ürünleri odaklı (kebap, döner, ızgara v.b.) beslenmeyi tercih etmektedirler. Benzer şekilde, erkek turistler yemek yemek için fast food restoranları, kebapçı ve pidecileri, alkol de alınabilen restoranlar ile yol kenarındaki dinlenme tesislerini tercih ederken kadın tüketiciler erkeklere kıyasla tanınmış şeflerin çalıştı̆̆ restoranlarda ve gecelenen oteldeki restoranlarda yemek yemeyi tercih etmektedirler

Anahtar Kelimeler: Toplumsal Cinsiyet, Gıda Tüketimi, Yerli Turistler, Yolculuk

\section{Giriş}

Beslenme fiziksel ihtiyaçları karşılamanın da ötesinde toplumların kültürel yapılarına ve özelliklerine göre farklılık gösteren kültürel bir olgu olup kadın ve erkekler arasında beslenme biçimleri bakımından farklılıklar bulunmaktadır. Bu farklılığı çeşitli sosyolojik faktörlerle, cinsiyet kimliği, yaş, gelir durumu v.b. bireysel faktörlerle açıklamak mümkündür. Cinsiyetler bakımından ortaya çıkan beslenme farklılıkları, bireylerin çeşitli amaçlarla yaptıkları seyahatlerde de kendini göstermektedir.

Turistik deneyimin önemli bir kısmını oluşturan yiyecek-içecek tüketiminin destinasyon üzerindeki etkileri son zamanlarda araştırmacıların ilgisini çeken bir konu haline gelmiştir. Araştırmalar (Bessiere, 1998; Cohen \& Avieli, 2004; Hall \& Mitchell, 2001; Hall \& Sharples, 2003; Hjalager \& Richards, 2002; Long, 2004), turistlerin yiyecek-içeceklere karşı olan ilgi ve 
tercihlerinin destinasyon seçimini etkilediğini ortaya koymaktadır. Turistlerin seyahatleri sırasında tükettikleri yiyecek ve içecekler için yaptıkları harcamalar, toplam seyahat harcamalarının üçte birini oluşturmaktadır (Hall \& Sharples, 2003; Telfer \& Wall, 2000). Quan \& Wang (2004: 299), toplam turist harcamalarının \% 25'inin gıda harcamalarından oluştuğunu belirtmektedir.

Yiyecek-içecek tüketimi, turistik gelir elde etmenin de ötesinde turist deneyiminin önemli bir parçası olup seyahat memnuniyetini etkilemektedir. Kivela \& Crotts'a (2006: 357) göre turistler için yiyecek ve içecek tüketimi yalnızca beslenme ihtiyacını karşılamak anlamına gelmemekte, yerel veya bölgesel yiyecek ve içecekler, şarap v.b. aynı zamanda destinasyonun kültürü hakkında bilgi edinmeyi sağlamaktadır. Mak, Lumbers ve Eves'e göre (2012a) yemek fizyolojik, kültürel, sosyolojik ve psikolojik boyutları olan bir olgudur. Fizyolojik boyut yemeğin açlığı giderme fonksiyonu ile ilgilidir. Kültürel, sosyolojik ve psikolojik boyut ise yemekten zevk alma, kendini iyi hissetme ve öğrenme gibi ihtiyaçları karşılamaktadır. Dolayısıyla, yiyecek ve içecekler sadece gastronomik amaçla seyahat edenler için değil tüm turistler için farklı kültürleri tanımada önemli bir araçtır. Bu bağlamda turistlerin seyahat sırasındaki yiyecek-içecek tüketim tercihlerinin belirlenmesi; turist memnuniyetinin sağlanmasında, destinasyonun pazarlanmasında, destinasyondaki ve turistik tesislerdeki gıda arzında önemli bir husustur.

Kadın ve erkek turistlerin yiyecek-içecek tercihlerinin belirlenmesini amaçlayan bu çalışmada; (1) ilgili alanyazından elde edilen bilgiler ve bu konuda yapılan çalışmalar ile (2) Safranbolu'yu ziyaret eden turistler üzerine yapılan ampirik bir çalışmanın sonuçlarına yer verilmiştir. 


\section{Literatür}

Yiyecek-içecek tüketimi kültürel, sosyal, psikolojik boyutları olan karmaşık bir karar verme sürecidir. İnsanların yiyecek-içecek tüketimini etkileyen pek çok faktör bulunbtadır. $\mathrm{Bu}$ faktörleri birey, yiyecek ve çevre olmak üzere temelde üç kategoride incelemek mümkündür. Yiyecekle ilgili faktörler yiyeceğin tadı, görünüşü, yapısı gibi özellikleri ile ilgili iken çevresel faktörler kültürel, sosyal, ekonomik ve fiziksel unsurları içermektedir. Bireyle ilgili faktörler ise bireyin yiyecek-içecek tüketimini doğrudan etkileyen sosyo-kültürel, fizyolojik ve psikolojik hususlardır (Mak v.d., 2012b). Mak v.d (2012b) insanların yiyecek tercihlerini etkileyen hususları turist, destinasyonda sunulan yiyecek ve destinasyonun çevresi olmak üzere üç başlıkta incelemektedir. Destinasyonda sunulan yiyecek; yiyeceğin içeriği, pişirme metodları ve duyusal özellikleri ile ilgilidir. Destinasyon çevresi ise destinasyonun gastronomik imaj1/kimliği, pazarlama iletişimi, hizmet sağlayıcıları ve hizmet çatısı ile ilişkilidir.

İlgili alanyazında yapılan çalışmalar (Nield v.d., 2000; Kim v.d., 2009; Ryu and Jang, 2006; Torres, 2002; Chang v.d., 2011; Kivela ve Crotts, 2006; Long, 2004; Chang v.d., 2010) turistlerin yiyecek-içecek tüketiminin (1) kültürel ve dini faktörler, (2) sosyo-demografik faktörler, (3) kişisel özellikler örn; yiyecek neofobisi, (4) geçmiş tecrübeler ve (5) motivasyonel faktörler gibi hususlardan etkilenebileceğini ortaya koymaktadır.

İnsanların tutum ve davranışlarının ve yiyecek - içecek tüketiminde insanlar arasındaki farklılıkların açıklanmasında önemli bir olgu olarak görülen sosyo-demografik faktörler, gastronomi ile ilgili olarak yürütülen çalışmalarda sıklıkla kullanılmaktadır. Araştırmalar, yiyecek-içecek seçiminde ve yeme davranışında cinsiyetin önemli bir faktör olduğunu ortaya koymaktadır. Nitekim, demografik değişkenler ile yiyecek ilişkisini ortaya koymak amacıyla yapılan araştırmalar (Kim v.d., 2007; Mak v.d., 2012b; Kim, vd. 2009) yiyecek-içecek tüketiminin cinsiyetlere göre farklılaştığını göstermektedir. 
Araştırmalar, erkeklerin daha çok yüksek enerji veren besinler tükettiklerini ve bu enerjinin genellikle hayvansal gıdalardan sağlandığını; erkeklerin beslenmesinin et, ekmek ve alkol ağırlıklı olduğunu, erkeklerin daha çok yağlı besin tükettiğini ortaya koymaktadır. Diğer yandan, kadınlar ise daha çok sebze ve meyve tüketmektedir. Benzer şekilde, kadınların beslenme ve sağlıklı besinler tüketme ile ilgili konularda erkeklere kıyasla daha duyarlı ve daha bilgili oldukları belirlenmiştir (Missagia, v.d., 2013). Wadolowska v.d. (2008) de yapmış olduğu araştırmasında kadınların sağlıkla ilgili konulara, diyetlerine ve beslenme ile ilgili bilgi edinmeye önem verdiklerini ortaya koymuştur.

Erkekler daha çok yağdan zengin et ürünlerini tercih ederken; kadınlar ise sağlıklı ve düşük kalorili gıdaları tüketmektedirler. Araştırmalar, kadınların erkeklere kıyasla yiyecekiçecek fiyatlarına daha duyarlı olduklarını, yeni ve farklı meyve ve sebzeleri denemeye daha çok istekli olduklarını ortaya koymaktadır (Jaison, 2015). Nitekim; Tuorila v.d.'nin, (2001) araştırması da kadınların erkeklere kıyasla daha az neofobik (yeni şeylere karşı duyulan korku) olduklarını belirlemiştir. Flynn v.d. (1994), yiyecek-içecek satın alırken kadınların daha çok güvenilir yiyecek seçtiklerini, yiyeceklerin fiyatlarına dikkat ettiklerini, erkeklerin ise yiyeceğin tadına önem verdiklerini belirtmektedirler.

Rozin'in (2006) çalışması ise ABD'li kadınların kilo alma endişesinin, et tüketiminden kaçınma ve düşük kalorili yiyecek tüketme eğiliminin yüksek olduğunu ortaya koymuştur. Girgin'in (2018: 800) yapmış olduğu araştırmada ise insanların yerel gıda tercihlerinde etkili olan “Kültürel Deneyim”, “Heyecan”, “Kişilerarası İlişki”, "Duyusal Çekicilik” ve "Sağlık Kaygısı" faktörlerini, kadınların erkeklere göre daha çok göz önünde bulundurdukları tespit edilmiştir.

Kim, Eves ve Scarles'in (2009) çalışması turistlerin yiyecek-içecek tüketimlerinin cinsiyet ile ilişkili olduğunu ortaya koymaktadır. Araştırmada, kadınların erkeklere kıyasla yerel yemekleri tüketmeye daha istekli oldukları sonucuna ulaşılmıştır. Şarap turistleri üzerinde 
Alebaki ve Iakovidou (2011) tarafından yapılan bir araştırma cinsiyet farklılıklarının içecek tüketimini etkilediğini; Avrupa'da şarap turistlerinin erkeklerden, Amerika'da ise kadınlardan oluştuğunu ortaya koymuştur.

Nisari (2018) turistlerin yerel yemek motivasyonlarını belirlemek amacıyla Çeşme'de yaptığı araştırmada; kadın turistlerin erkeklere kıyasla yerel yiyecekleri daha sağlıklı olarak değerlendirdiklerini, yerel yiyeceklerin kültürel anlamda önemli katkı sağladığına inandıklarını, kadınların duyusal anlamda yerel yiyeceklerden daha fazla şey beklediklerini ortaya koymuştur. Quan ve Wang (2004) turistlerin yiyecek tüketim davranışlarının günlük yaşamlarından farklı, olabileceğini belirtmektedir. Mak ve diğerlerine göre (2012a; 2012b) seyahat sırasında yiyecek ve içecek tüketimi gündelik yaşamın tersi, gündelik yaşamın uzantısı ya da sembolik olabilir. Turistlerin yiyecek ve içecek tüketimini gündelik yaşamlarının bir uzantısı olarak görmeleri yemeğin açlığg giderme amacıyla tüketildiğini, yiyecek ve içecek tüketiminin gündelik yaşamın tersi olarak algılanması durumunda ise yiyeceklerin destinasyonun kültürü hakkında bilgi edinmek amacıyla tüketildiğini göstermektedir.

Tatil sırasında alışılmışın dışında yemek yeme turistlerin ilgisini çekmektedir. Çünkü dışarıda yemek yemek bazıları için sadece ihtiyacı karşılamak iken, diğerleri için zevk almak, paylaşmak ve hiç denemedikleri şeyler hakkında bilgi edinmek için bir fırsat olabilir (Martinez, 2015: 12).

\section{Yöntem}

Turistlerin seyahat sirasında tükettikleri yiyecek ve içeceklerin cinsiyetlere göre farklılık gösterip göstermediğinin belirlenmesi amacıyla yapılan bu çalışma, Batı Karadeniz Bölümünün en önemli kültür turizmi destinasyonu olan Safranbolu'da yürütülmüştür. Bir UNESCO Dünya Miras Kenti olan Safranbolu'yu yılda bir milyon civarında yerli ve yabancı turist ziyaret etmektedir. 
Yapısal bir anket formunun kullanıldığı araştırma Nisan-Haziran 2019 tarihleri arasında Safranbolu'da turistik faaliyetin en yoğun olduğu Çarşı bölgesinde gerçekleştirilmiştir. Araştırmada kullanılan anket formu üç kısımdan oluşmaktadır. Beş sorudan oluşan anketin ilk kısmında turistlerin seyahatleri sırasında tükettikleri yiyecekler (en çok ya da en az tükettikleri yiyecekler) ve yiyecek-içecek işletme seçimleri ile ilgili sorular bulunmaktadır. Toplamda 26 önermeden oluşan ikinci bölümde ise turistlerin seyahat sırasında tercih ettikleri yiyecek ve içecekler ile ilgili sorulara yer verilmiştir. Anketin ikinci kısımdaki sorular 5'li Likert ölçeğinde (1= Hiç katılmıyorum, 5= Tümüyle katılıyorum) hazırlanmıştır. Üçüncü kısım ise katılımcıların demografik özelliklerinin belirlenmesine yönelik sorulardan oluşmaktadır.

Olasılıklı olmayan örnekleme yönteminin kullanıldığı araştırmada veriler kolayda örnekleme metoduyla toplanmıştır. Araştırma yüz yüze olarak gerçekleştirilmiş olup geçerli kabul edilen 210 anket formuna ulaşılmış ve veriler Sosyal Bilimler için kullanılan istatistik programı ile analiz edilmiştir. Araştırmada tanımlayıcı istatistikler (frekans analizi, aritmetik ortalama, çapraz tablolar-crosstabs-) ile cinsiyetler arasındaki farklılığın belirlenmesinde Bağımsız Örneklem t-testi ve ki-kare analizi kullanılmıştır.

Araştırmanın temel sorusu "yerli turistlerin seyahat sırasında tükettikleri yiyecek ve içecekler cinsiyetlerine göre farklılık göstermektedir" olarak kurgulanmıştır.

\section{Bulgular}

$\mathrm{Bu}$ bölümde sunulan bulgular üç başlık altında incelenmiştir. İlk kısımda demografik bilgilere, ikinci kısımda ziyaretçilerin tatil sırasında tükettikleri yiyecek ve içecekler ile restoran seçimlerine, üçüncü kısımda ise tatil sırasındaki yiyecek-içecek tercihlerine yer verilmiştir. Araştırmada kullanılan ölçeğin güvenilirlik analizleri Tablo 1'de verilmektedir. 
Tablo 1. Güvenilirlik Analizi Sonuçları

\begin{tabular}{|l|l|}
\hline İfade Sayısı & $\begin{array}{l}\text { Cronbach's } \\
\text { Alpha }\end{array}$ \\
\hline 26 &, 701 \\
\hline
\end{tabular}

Ankette kullanılan ölçeğin güvenilirliği Cronbach’s Alpha (a) ile ölçülmüştür. 26 ifadeden oluşan ölçeğin Cronbach Alpha değerinin 0,701 olduğu saptanmıştır. Bu durum ölçeğin güvenilir olduğunu göstermektedir (Büyüköztürk v.d., 2017).

Ayrıca verilerin normal dağılıp dağılmadığını ve parametrik test koşullarını sağlayıp sağlamadığını belirlemek için çarpıklık ve basıklık analizi yapılmıştır. Sonuçlar, aşağıdaki tabloda verilmektedir:

Tablo 2. Çarpıklık-Basıklık katsayıları

\begin{tabular}{|l|l|l|l|l|l|l|l|l|l|}
\hline Ölçek Adı & $\mathbf{n}$ & Min & Max & Ort. & Ss & Statistic & $\begin{array}{l}\text { Standart } \\
\text { Hata }\end{array}$ & Statistic & $\begin{array}{l}\text { Standart } \\
\text { Hata }\end{array}$ \\
\hline $\begin{array}{l}\text { Yiyecek- } \\
\text { içecek } \\
\text { Tüketim } \\
\text { Tercihleri }\end{array}$ & 210 & 2,56 & 4,48 & 3,4847 &, 34374 &, 109 &, 168 &, 484 &, 334 \\
\hline
\end{tabular}

Çarpıklık ve basıklık katsayıları; 0,109 ve 0,484aralığında gözlenmiştir. Bu bağlamda Skewness ve Kurtosis değerlerinin (-+) 1 aralığında olması parametrik testlerin yapılabileceğini göstermektedir (Büyüköztürk v.d., 2017). 


\section{Demografik Bilgiler}

Araştırmaya katılan kişilerin demografik özellikleri aşağıda verilmektedir.

Tablo 3. Katılımcıların Demografik Özellikleri $(n=210)$

\begin{tabular}{|c|c|c|c|c|c|}
\hline Cinsiyet & $\mathbf{n}$ & $\%$ & Aylık Gelir & $\mathbf{n}$ & $\%$ \\
\hline Kadin & 100 & 47,6 & 2000 TL'den az & 115 & 54,8 \\
\hline Erkek & 110 & 52,4 & 2001-3000 TL & 32 & 15,2 \\
\hline Yaş & & & $3001-4000 \mathrm{TL}$ & 30 & 14,3 \\
\hline 18 ve alt 1 & 7 & 3,5 & $4001-5000 \mathrm{TL}$ & 9 & 4,3 \\
\hline $19-30$ & 127 & 60,3 & 5001 TL ve üzeri & 24 & 11,4 \\
\hline $31-40$ & 40 & 19 & Yaşanılan Şehir & & \\
\hline $41-49$ & 20 & 9,7 & Ankara & 26 & 12,4 \\
\hline 50 ve üstü & 16 & 6,5 & İstanbul & 38 & 18,1 \\
\hline Medeni Durum & & & Kastamonu & 12 & 5,7 \\
\hline Evli & 92 & 43,8 & Kocaeli & 8 & 3,8 \\
\hline Bekar & 118 & 56,2 & Zonguldak & 11 & 5,2 \\
\hline Meslek & & & Bartın & 12 & 5,7 \\
\hline İşsiz & 9 & 4,3 & Karabük & 25 & 11,9 \\
\hline $\begin{array}{l}\text { Profesyonel işler } \\
\text { (doktorluk, avukatlik v.b.) }\end{array}$ & 6 & 2,9 & Diğer (diğer iller) & 86 & 37,3 \\
\hline Emekli & 8 & 3,8 & Eğitim Durumu & & \\
\hline Akademik/Eğitimci & 17 & 8,1 & İlköğretim & 13 & 6,2 \\
\hline Teknik işler/Mühendislik & 6 & 2,9 & Ortaöğretim & 13 & 6,2 \\
\hline Öğrenci & 68 & 32,4 & Lise & 46 & 21,9 \\
\hline İşçi & 7 & 3,3 & Önlisans/Lisans & 122 & 58,1 \\
\hline Devlet memuru & 28 & 13,3 & Lisansüstü & 16 & 7,6 \\
\hline Ev hanımı & 24 & 11,4 & & & \\
\hline Serbest Meslek & 22 & 10,5 & & & \\
\hline Esnaf & 15 & 7,1 & & & \\
\hline
\end{tabular}

Katılımcıların demografik özellikleri ile ilgili olarak aşağıdaki bulgulara ulaşılmıştır.

- Araştırmaya katılanların \% 52,4'ü erkek, \% 47,6'sı ise kadındır.

- $\% 43,8$ 'i evli, \% 56,2'si ise bekardır.

- Cevaplayıcıların yaşlarına göre dağılımları incelendiğinde \% 3,5'inin 18 yaş ve altı, \% 60,3'ünün 19-30 yaş aralığında, \% 19'unun 31-40 yaşları arasında, \% 9,7'sinin 41-49 yaş aralığında ve \% 16'sının ise 50 yaş ve üzerinde olduğu görülmektedir. Bu durum, katılımcıların 2/3'ünün genç bireylerden oluştuğunu göstermektedir. 
- Katılımcıların \% 32,4’ü öğrenci, \% 13,3’ü devlet memuru, \% 11,4’ü ev hanımı, \%10, 5'i serbest meslek sahibi, \% 8,1'i akademisyen/eğitimci ve \% 7,1'i ise esnaftır. Katılımcıların 1/3'ünün kenti ziyaret eden öğrencilerden oluştuğu görülmektedir.

- Katılımcıların aylık gelirleri dikkate alındığında \%54,8'inin asgari ücretin de altında bir gelire sahip olduğu (2000 TL'den az, bu durumun ağırlıklı olarak öğrenci olan ziyaretçilerden kaynaklandığı tahmin edilmektedir), \% 15,2'sinin 2001-3000 TL arasında, \% 14,3'ünün 3001-4000 TL arasında ve \% 11,4'ünün ise 5001 TL ve üzerinde aylık gelire sahip olduğu belirlenmiştir.

- Katılımciların \% 12,4'ü Ankara'da, \% 18,1'i İstanbul'da, \% 5,7'si Kastamonu'da, \% 3,8'i Kocaeli'nde, \% 5,2'si Zonguldak'ta, \% 5,7'si Bartın'da ,\% 11,9'u Karabük'te yaşamaktadır. Katılımcıların \% 37,3'ü ise Türkiye'nin diğer illerinde ikamet etmektedirler. Bu durum ziyaretçilerin ağırlıklı olarak Ankara, İstanbul gibi metropol kentlerden geldiğini ayrıca Karabük'e yakın illerde (Kastamonu, Bartın, Zonguldak) ikamet eden turistlerden oluştuğunu göstermektedir.

- Katılımcıların \% 58,1'i Önlisans/Lisans, \% 21,9’u Lise, \% 12,4'ü Ortaöğretim ve \% 7,6's1 ise Lisansüstü programlardan mezundur. Bu durum kat1lımc1ların 2/3'ünden fazlasının üniversite ve lisansüstü eğitim derecesine sahip olduklarını göstermektedir.

\section{Ziyaretçilerin tïkettikleri yiyecek ve içecekler ve restoran tercihleri}

Bu bölümünde katılımcıların seyahat sırasında en çok ya da en az tükettikleri yiyecek ve içecekler, seyahat sırasında tercih edilen yiyecek içecek işletmesinin türü ve restoran seçiminde dikkate aldıkları faktörlerle ilgili bulgular sunulmuştur. 
Tablo 4. Seyahat Sırasında En Çok Tercih Edilen Yiyecek İçecek İşletmeleri

\begin{tabular}{|l|l|l|l|l|l|l|}
\hline \multirow{2}{*}{ Yiyecek İçecek İşletme Türü } & \multicolumn{2}{l|}{ Kadın } & \multicolumn{2}{l|}{ Erkek } & \multicolumn{2}{l|}{ Toplam } \\
\cline { 2 - 7 } & $\mathbf{n}$ & $\mathbf{\%}$ & $\mathbf{N}$ & $\mathbf{\%}$ & $\mathbf{n}$ & $\mathbf{\%}$ \\
\hline Fast food restoranlar & 28 & 37,8 & 46 & 62,2 & 74 & 100 \\
\hline Kebapçı ve pideciler & 47 & 41,9 & 65 & 58,1 & 112 & 100 \\
\hline Tanınmış şeflerin çalıştığı restoranlar & 14 & 51,8 & 13 & 48,2 & 27 & 100 \\
\hline Yöresel yemeklerin üretildiği yerler & 61 & 48,8 & 64 & 51,2 & 125 & 100 \\
\hline Kaldığım otelde üretilen yemekler & 44 & 55 & 36 & 45 & 80 & 100 \\
\hline Balık restoranları & 23 & 45,1 & 28 & 54,9 & 51 & 100 \\
\hline Alkol tüketilebilen restoranlar & 13 & 31,7 & 28 & 68,3 & 41 & 100 \\
\hline Vejetaryen/Vegan restoranlar & 11 & 100 & - & - & 11 & 100 \\
\hline Yol kenarındaki dinlenme tesisleri & 18 & 40,1 & 26 & 59,9 & 44 & 100 \\
\hline $\begin{array}{l}\text { Herhangi bir yerde yerim, hiç ayrım } \\
\text { yapmam }\end{array}$ & 23 & 47,9 & 25 & 52,1 & 48 & 100 \\
\hline
\end{tabular}

Katılımcıların seyahatleri sırasında sırasıyla en çok yöresel yemeklerin üretildiği yerleri, kebapçı ve pidecileri ve konaklanan oteldeki restoranları tercih ettikleri belirlenmiştir. Bulgular, kadınların erkeklere kıyasla daha çok tanınmış şeflerin çalıştığı restoranları $(\% 51,8)$ tercih ettiklerini göstermektedir. Bu durum, kadınların otel konforunun dışına çıkmak istemedikleri şeklinde yorumlanabilir. Erkekler ise kadınlara kıyasla alkol tüketilebilen restoranları $(\% 68,3)$, fast food restoranlarını $(\% 62,2)$, yol kenarındaki dinlenme tesislerini $(\% 59,9)$, kebapçı ve pidecileri $(\% 58,1)$ daha çok tercih etmektedirler. Erkeklerin tatil sırasında da et ağırlıklı restoranları tercih ettikleri görülmektedir. 
Tablo 5. Seyahat Sırasında Yiyecek İçecek İşletmesi Seçerken Dikkate Alınan Faktörler

\begin{tabular}{|l|l|l|l|l|l|l|}
\hline \multirow{2}{*}{ Yiyecek İçecek İşletmesi Seçim Faktörleri } & \multicolumn{2}{l|}{ Kadın } & \multicolumn{2}{l|}{ Erkek } & \multicolumn{2}{l|}{ Toplam } \\
\cline { 2 - 7 } & $\mathbf{n}$ & $\mathbf{\%}$ & $\mathbf{N}$ & $\mathbf{\%}$ & $\mathbf{n}$ & $\%$ \\
\hline $\begin{array}{l}\text { Sosyal medyada insanların paylaştığı yiyecek } \\
\text { içecek deneyimleri ve yorumları }\end{array}$ & 36 & 57,1 & 27 & 42,9 & 63 & 100 \\
\hline $\begin{array}{l}\text { İnternette yer alan seyahat sayfalarındaki } \\
\text { işletme puanlarına göre }\end{array}$ & 31 & 52,5 & 28 & 47,5 & 59 & 100 \\
\hline Yöresel yemeklerin sunulup sunulmadığı & 40 & 42,1 & 55 & 57,9 & 95 & 100 \\
\hline Dişarıdan güzel görünmesi & 34 & 47,9 & 37 & 52,1 & 71 & 100 \\
\hline Müşterisi kalabalık olan işletmeler & 28 & 41,8 & 39 & 58,2 & 67 & 100 \\
\hline Hiç araştırma yapmam, anlık karar verim & 25 & 45,5 & 30 & 54,5 & 55 & 100 \\
\hline Aile, arkadaş ve tanıdıklarımın tavsiyesi & 61 & 47,7 & 67 & 52,3 & 128 & 100 \\
\hline Yemek yazarlarının/bloglarının tavsiyesi & 16 & 64 & 9 & 36 & 25 & 100 \\
\hline
\end{tabular}

Katılımcıların seyahat sırasında yiyecek içecek işletmesi seçerken dikkat ettikleri hususlar incelendiğinde; katılımcıların sırasıyla aile, arkadaş ve tanıdıklarının tavsiyesini, restoranda yöresel yiyecek ve içecek sunulup sunulmadığını ve restoranın dışarıdan güzel görünüp görünmediğini dikkate aldıkları belirlenmiştir. Bununla birlikte, kadınların restoran seçiminde erkeklere kıyasla yemek yazarlarının/bloglarının tavsiyesi (\%64) ile sosyal medyada insanların paylaştığı yiyecek içecek deneyimleri ve yorumlarını dikkate aldıkları $(\% 57,1)$ görülmektedir. $\mathrm{Bu}$ durum kadınların restoran seçiminde daha çok sosyal medyadan etkilendiklerini göstermektedir.

Erkeklerin ise; restoran seçiminde müşterinin kalabalık olduğu restoranları $(\% 58,2)$ tercih ettikleri ve işletmede yöresel yemek sunulmasına $(\% 57,9)$ daha çok önem verdikleri belirlenmiştir. Ayrıca, erkekler misafirler seyahat öncesinde destinasyonda bulunan restoranlarla ilgili herhangi bir araştırma yapmamaktadırlar. $\mathrm{Bu}$ sonuçlardan hareketle kadınların seyahat sırasında yiyecek içecek işletmesi seçerken erkeklere göre daha planlı hareket ettikleri, seyahate çıkmadan destinasyondaki yiyecek-içecek işletmeleri ile ilgili bilgi topladıkları görülmektedir. Bu bulgular ilgili literatürden (Missagia v.d., 2013; Wadolowska v.d., 2008) elde edilen sonuçlarla örtüşmektedir. 
Tablo 6. Seyahat Sırasında En Çok Tüketilen Yiyecekler

\begin{tabular}{|c|c|c|c|c|c|c|}
\hline \multirow{2}{*}{$\begin{array}{l}\text { Seyahat Sırasında En Çok } \\
\text { Tüketilen Yiyecekler }\end{array}$} & \multicolumn{2}{|c|}{ Kadın } & \multicolumn{2}{|c|}{ Erkek } & \multicolumn{2}{|c|}{ Toplam } \\
\hline & $\mathbf{n}$ & $\%$ & $\mathbf{N}$ & $\%$ & $\mathbf{n}$ & $\%$ \\
\hline Fast Food & 32 & 45,1 & 39 & 54,9 & 71 & 100 \\
\hline Pide & 41 & 49,4 & 42 & 50,6 & 83 & 100 \\
\hline Izgara Et Ürünleri & 38 & 38,8 & 60 & 61,2 & 98 & 100 \\
\hline Kebaplar & 34 & 35,4 & 62 & 64,6 & 96 & 100 \\
\hline Döner & 26 & 31,7 & 56 & 68,3 & 82 & 100 \\
\hline Hamur İşleri ve Börek, Gözleme & 43 & 58,1 & 31 & 41,9 & 74 & 100 \\
\hline Sebze Yemekleri & 32 & 58,2 & 23 & 41,8 & 55 & 100 \\
\hline Salata Türleri & 29 & 58 & 21 & 42 & 50 & 100 \\
\hline Zeytinyağl1lar, Mezeler, Dolmalar & 27 & 50 & 27 & 50 & 54 & 100 \\
\hline Hamur Tatlıları & 12 & 44,4 & 15 & 55,6 & 27 & 100 \\
\hline Sütlü Tatlılar & 24 & 50 & 24 & 50 & 48 & 100 \\
\hline Meyveler & 26 & 56,5 & 20 & 43,5 & 46 & 100 \\
\hline
\end{tabular}

Tablo 6 incelendiğinde; katılımcıların sırasıyla en çok ızgara et ürünleri, kebablar, pide, döner, hamur işi ve fast food yiyecekler tükettikleri belirlenmiştir. Bulgular, seyahat sırasında tercih edilen yiyeceklerin günlük yaşamda tüketilen yiyeceklerden çok da farklılaşmadığını göstermektedir. Bununla birlikte; erkeklerle kıyaslandığında kadın ziyaretçilerin seyahatlerinde en çok sebze yemeklerini (\% 58,2), hamur işlerini, börek ve gözlemeyi (\% 58,1) ve salataları (\% 58) tercih ettikleri saptanmıştır.

Erkek ziyaretçilerin ise seyahatlerinde en çok döner (\% 68,3), kebap $(\% 64,6)$ ve 1zgara et ürünlerini $(\%$ 61,2) tercih ettiği tespit edilmiştir. Bu yiyecekleri hamur tatlıları $(\% 55,6)$ ve fast food (\% 54,9) yiyecekler takip etmektedir (Tablo 4). 
Araştırmadan elde edilen bulgular ilgili alanyazından elde edilen sonuçlarla da örtüşmektedir. Tarihsel süreç açısından incelendiğinde, et tüketimi erkeksi bir davranış olarak algılanırken, sebze tüketimi de kadına atfedilen bir davranıştır. Toplumsal cinsiyet rolleri açısından değerlendirildiğinde; kadınların erkeklere oranla daha az et tükettiği belirlenmiştir (Sezgin ve Ayyıldız, 2019: 514). Nitekim, İngiltere'de 2003 yılında yapılan bir araştırma, erkeklerin kadınlardan daha fazla et ve daha az meyve ve sebze tükettiğini ortaya koymaktadır (Chapman, 2015: 11).

Tablo 7. Seyahat Surasında En az Tüketilen Yiyecekler

\begin{tabular}{|l|l|l|l|l|l|l|}
\hline \multirow{2}{*}{$\begin{array}{l}\text { Seyahat Sırasında En } \\
\text { Tüketilen Yiyecekler }\end{array}$} & \multicolumn{2}{l|}{ Kadın } & \multicolumn{2}{l|}{ Erkek } & \multicolumn{2}{l|}{ Toplam } \\
\cline { 2 - 7 } & n & \% & n & \% & n & $\%$ \\
\hline Fast Food & 46 & 52,8 & 41 & 47,2 & 87 & 100 \\
\hline Pideler & 7 & 53,8 & 6 & 46,2 & 13 & 100 \\
\hline Izgara Et Ürünleri & 20 & 57,1 & 15 & 42,9 & 35 & 100 \\
\hline Kebablar & 21 & 77,7 & 6 & 22,3 & 27 & 100 \\
\hline Döner & 22 & 59,5 & 15 & 40,5 & 37 & 100 \\
\hline Hamur İşleri, Börek, Gözleme & 26 & 51 & 25 & 49 & 51 & 100 \\
\hline Sebze Yemekleri & 40 & 41,2 & 57 & 58,8 & 97 & 100 \\
\hline Salata Türleri & 32 & 33,7 & 63 & 66,3 & 95 & 100 \\
\hline Zeytinyağlılar, Mezeler, Dolmalar & 25 & 40,3 & 37 & 59,7 & 62 & 100 \\
\hline Hamut Tatlıları & 33 & 57,9 & 24 & 42,1 & 57 & 100 \\
\hline Sütlü Tatlılar & 17 & 38,6 & 27 & 61,4 & 44 & 100 \\
\hline Meyveler & 13 & 26,5 & 36 & 73,5 & 49 & 100 \\
\hline
\end{tabular}

Katılımcıların seyahat sırasında en az tükettiği yiyecekler sırasıyla; sebze yemekleri, salata çeşitleri ile fast food yiyeceklerdir. Fast food yiyecekler ile ilgili frekansın yüksek olması kadınların bu tür yiyeceklere karşı olan olumsuz tutumundan kaynaklanmaktadır. Seyahat sırasında kadınların en az tükettiği yiyecekler; sırasıyla, kebaplar $(\% 77,7)$, döner $(\% 59,5)$ ve 1zgara et ürünleridir $(\% 57,1)$. Erkek katılımcılar ise; seyahatlerinde meyve $(\% 73,5)$, salata $(\% 66,3)$, sütlü tatlılar $(\% 61,4)$ ile zeytinyağl1lar-mezeler-dolmalar $(\% 59,7)$ tüketmemektedirler. Kadınların et tüketmek istememeleri daha hafif ve sağlıklı beslenmek istekleriyle ilgili olabilir. Benzer bulgulara Rozin'in (2006) çalışmasında da ulaşılmıştır. 
Tablo 8. Cinsiyetlere Göre Beslenme Biçimi

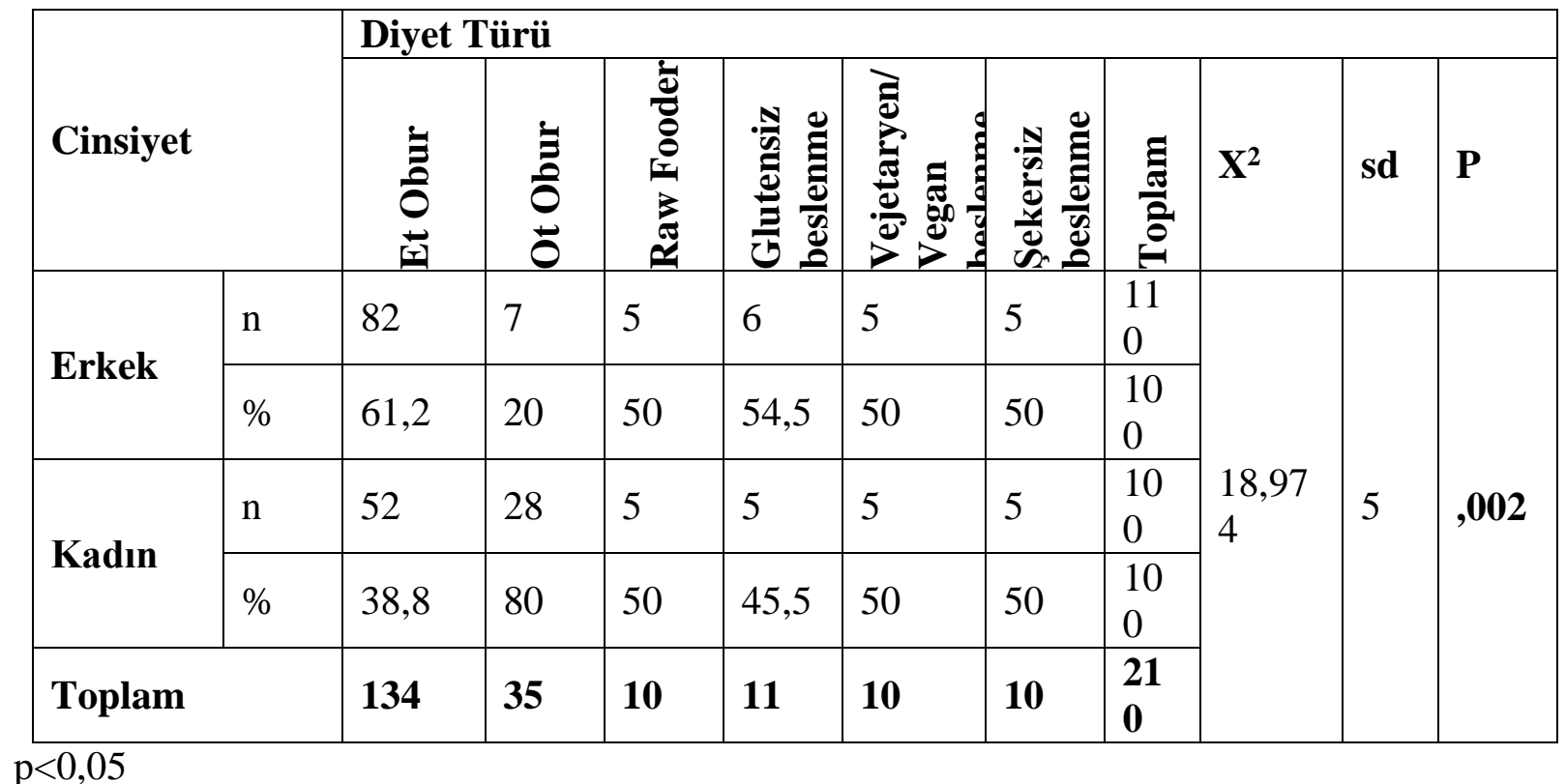

Tablo 8 incelendiğinde; erkeklerin \%61,2'sinin, kadınların ise \%38,8'inin kendilerini et obur olarak tanımladıkları görülmektedir. Benzer şekilde kadınların \% 80'i, erkeklerin ise \%20'si kendisini ot obur olarak tanımlamıştır. İlgili alanyazında da benzer sonuçlara ulaşılmış olup erkeklerin daha çok et tüketmeyi, kadınların ise sebze ağırlıklı beslenmeyi tercih ettikleri görülmektedir. 


\section{Ziyaretçilerin Seyahat Strasında Yiyecek ve İçecek Tüketim Tercihleri ve Cinsiyetler}

\section{Arasındaki Farklılıklar}

Tablo 9, katılımcıların seyahatleri sırasındaki yiyecek ve içecek tüketim tercihlerini göstermektedir.

Tablo 9. Ziyaretçilerin Seyahat Sırasında Yiyecek ve İçecek Tüketim Tercihleri

\begin{tabular}{|c|c|c|c|}
\hline $\begin{array}{l}\text { İfade } \\
\text { No }\end{array}$ & $\begin{array}{l}\text { SEYAHATIM SIRASINDA } \\
\begin{array}{l}\text { 1: Hiç katılmiyorum 2: Katılmıyorum } \\
\text { 3: Ne katılmıyorum ne de katılıyorum 4: Katılıyorum 5: Tümüyle } \\
\text { katılıyorum }\end{array}\end{array}$ & Ort. & S.S. \\
\hline 1 & Yöresel yiyecek ve içecekleri tüketmek benim için önemlidir. & 3,985 & ,8937 \\
\hline 2 & $\begin{array}{l}\text { Tükettiğim yiyecek ve içeceklerin güvenilir gıda olması benim için } \\
\text { önemlidir. }\end{array}$ & 4,423 & ,6961 \\
\hline 3 & Daha az kalorili yiyecek ve içecekleri tercih ederim. & 3,309 & 1,1300 \\
\hline 4 & Fast food restoranlarına sıklıkla giderim & 2,671 & 1,2647 \\
\hline 5 & $\begin{array}{l}\text { Tükettiğim yiyecek ve içeceklerin hijyenik üretilmesine dikkat } \\
\text { ederim. }\end{array}$ & 4,395 & ,8190 \\
\hline 6 & Organik yiyecekler tüketmeyi tercih ederim & 3,823 & 9939 \\
\hline 7 & Tükettiğim yiyecek ve içeceklerin sağlıklı olmasına dikkat ederim. & 4,000 & 9831 \\
\hline 8 & Vejeteryan yiyecek ve içecekler tüketirim. & 2,376 & 1,1476 \\
\hline 9 & ek ve içecekler tük & 2,114 & 1,1265 \\
\hline 10 & e kebap tüketirim & 3,881 & 1,0849 \\
\hline 11 & Yiyecek ve içeceklerin fiyatları $\mathrm{b}$ & 3,919 & 1,0062 \\
\hline 12 & Diyetime (kolestrol ve diyabet gibi l & 3,261 & 1,2229 \\
\hline 13 & Kilo aldırıcı yiyecek ve içecekler tük & 3,133 & 1,1825 \\
\hline 14 & Tükettiğim yiyecek ve içeceklerin besin değerlerine dikkat ederim. & 3,181 & 1,1639 \\
\hline 15 & Hamur işi yemekler yemeyi severim. & 3,357 & 1,0853 \\
\hline 16 & Alkol & 3,123 & 1,0910 \\
\hline 17 & Lezzetti yemekler tüketmeyi isterim. & 4,547 & ,6187 \\
\hline 18 & Daha çok yemek yiyiyorum & 3,595 & 1,1166 \\
\hline 19 & Yemek yemek benim için bir keyiftir. & 4,100 & ,9042 \\
\hline 20 & Yemek yemek benim için bir sosyalleşm & 3,185 & 1,1233 \\
\hline 21 & Fiziksel bir ihtiyaç olduğu için & 3,052 & 1,1248 \\
\hline 22 & $\begin{array}{l}\text { Yemek yediğim yerde yiyeceğin sunumu ve servisi benim için } \\
\text { önemlidir. }\end{array}$ & 4,085 & ,9343 \\
\hline 23 & Sebze ve meyve tüketmeye özen gösteririm & 3,704 & 1,0753 \\
\hline 24 & $\begin{array}{l}\text { Farklı ve daha önce tatmadığım yiyecek ve içecekleri } \\
\text { deneyimlemek isterim }\end{array}$ & 3,947 & 1,0223 \\
\hline 25 & $\begin{array}{l}\text { Destinasyon seçimimde bölgenin mutfak kültürü benim için çok } \\
\text { önemlidir. }\end{array}$ & 3,733 & 1,0284 \\
\hline 26 & Çocukların isteklerine göre yiyecek tüketiriz. & 2,490 & 1,1625 \\
\hline
\end{tabular}


Tablo 9 incelendiğinde; katılımc1ların lezzetti yemekler tüketmek istedikleri $(\bar{x}=4,547)$, yiyecek ve içeceklerin güvenilir gida olmasına $(\bar{x}=4,423)$, hijyenik bir biçimde üretilmesine $(\bar{x}$ $=4,395)$ önem verdikleri, yiyecek ve içeceklerin sağlıklı olmasına dikkat ettikleri $(\bar{x}=4,000)$, yemek yemeyi bir keyif olarak gördükleri $(\bar{x}=4,100)$ ve yiyeceğin sunumu ve servisine önem verdikleri $(\bar{x}=4,085)$ belirlenmiştir. Bu durum hem kadın hem de erkekler için güvenilir ve hijyenik gıda tüketiminin önemli olduğuna işaret etmektedir. Ayrıca, yiyecek-içecek tüketiminde lezzet her iki cins için de önemli bir faktördür.

Ankete katılanların en az katıldığı ifadeler dikkate alındığında turistlerin fast food restoranlara siklıkla gitmedikleri $(\bar{x}=2,671)$, yiyecek tüketiminde çocukların isteklerini çok da dikkate almadıkları $(\bar{x}=2,490)$, vejeteryan $(\bar{x}=2,376)$ ve vegan $(\bar{x}=2,114)$ yiyecek ve içecek tüketmedikleri görülmektedir.

Tablo 10. Cinsiyetler Arasındaki Yiyecek ve İçecek Tüketim Farklılıkları

\begin{tabular}{|l|l|l|l|l|l|}
\hline Cinsiyet & $\mathbf{N}$ & Ortalama & ss & $\mathbf{T}$ & $\mathbf{p}$ \\
\hline Erkek & 110 & 3,4283 &, 33880 & $-2,524$ & $\mathbf{0 , 0 1 2}$ \\
\hline Kadın & 100 & 3,5467 &, 34007 & & \\
\hline
\end{tabular}

$\mathrm{p}<0,05$

Araştırmada; katılımcıların seyahat sırasında tükettikleri yiyecek içeceklerin cinsiyete göre farklılık gösterip göstermediğini belirlemek için Bağımsız Örneklem t Testi yapılmış ve kadınlarla erkekler arasında yiyecek ve içecek tüketiminde istatistiksel olarak anlamlı farklılık olduğu tespit edilmiştir. Bu farklılığın hangi ifadelerden kaynaklandığını belirlemek amacıyla yapılan Bağımsız Örneklem t Testi sonuçları aşağıda verilmektedir. 
Tablo 11. İfadelere göre Cinsiyetler Arasındaki Yiyecek ve İçecek Tüketim Farklılıkları

\begin{tabular}{|c|c|c|c|c|c|c|c|}
\hline $\begin{array}{l}\text { İfade } \\
\text { No }\end{array}$ & $\begin{array}{l}\text { Turistlerin Seyahat } \\
\text { sırasındaki yiyecek tüketim } \\
\text { eğilimleri }\end{array}$ & $\begin{array}{l}\text { Cinsiye } \\
\mathbf{t}\end{array}$ & $\mathbf{n}$ & Ort. & S.S. & $\mathbf{t}$ & $\mathbf{p}$ \\
\hline \multirow{2}{*}{3} & \multirow{2}{*}{$\begin{array}{l}\text { Daha az kalorili yiyecek ve } \\
\text { içecekleri tercih ederim }\end{array}$} & Erkek & 110 & 4,520 & ,6587 & \multirow{2}{*}{$-2,481$} & \multirow{2}{*}{, 014} \\
\hline & & Kadın & 100 & 3,127 & 1,0930 & & \\
\hline \multirow{2}{*}{8} & \multirow{2}{*}{$\begin{array}{l}\text { Vejetaryen yiyecek ve } \\
\text { içecekler tüketirim }\end{array}$} & Erkek & 110 & 2,100 & 8980 & \multirow{2}{*}{$-3,707$} & \multirow{2}{*}{, 000} \\
\hline & & Kadın & 100 & 2,680 & 1,3094 & & \\
\hline \multirow{2}{*}{10} & \multirow{2}{*}{ Et ürünleri ve kebap tüketirim } & Erkek & 110 & 4,181 & ,9003 & \multirow{2}{*}{4,341} & \multirow{2}{*}{,001 } \\
\hline & & Kadın & 100 & 3,550 & 1,1752 & & \\
\hline \multirow[b]{2}{*}{13} & \multirow{2}{*}{$\begin{array}{l}\text { Kilo aldırıcı yiyecek ve } \\
\text { içecekler tüketmemeye dikkat } \\
\text { ederim }\end{array}$} & Erkek & 110 & 2,954 & 1,1682 & \multirow[b]{2}{*}{$-2,322$} & \multirow[b]{2}{*}{, 021} \\
\hline & & Kadın & 100 & 3,330 & 1,1725 & & \\
\hline \multirow[b]{2}{*}{14} & \multirow{2}{*}{$\begin{array}{l}\text { Tükettiğim yiyecek ve } \\
\text { içeceklerin besin değerlerine } \\
\text { dikkat ederim }\end{array}$} & Erkek & 110 & 3,000 & 1,0836 & \multirow[b]{2}{*}{$-2,376$} & \multirow[b]{2}{*}{,018 } \\
\hline & & Kadın & 100 & 3,380 & 1,2208 & & \\
\hline \multirow{2}{*}{16} & \multirow{2}{*}{ Alkollü içki tüketmeyi severim } & Erkek & 110 & 3,380 & 1,0346 & \multirow{2}{*}{3,321} & \multirow{2}{*}{,001 } \\
\hline & & Kadın & 100 & 2,890 & 1,0989 & & \\
\hline \multirow[b]{2}{*}{23} & \multirow{2}{*}{$\begin{array}{l}\text { Sebze ve meyve tüketmeye } \\
\text { özen gösteririm. }\end{array}$} & Erkek & 110 & 3,536 & 1,0724 & \multirow[b]{2}{*}{$-2,407$} & \multirow[b]{2}{*}{,017 } \\
\hline & & Kadın & 100 & 3,890 & 1,0530 & & \\
\hline
\end{tabular}

Kadın ve erkek turistlerin seyahat sırasındaki yiyecek ve içecek tüketimleri ve tercihleri farklılık göstermektedir. Bu farklılıklar kadınların erkeklere kıyasla daha çok vejetaryen yiyecek ve içecekler tüketmelerinden $(\mathrm{p}=0,000)$, daha düşük kalorili yiyecek ve içecekleri tercih etmelerinden ( $p=0,014)$, kilo aldırıcı yiyecek ve içecekleri tüketmemeye özen göstermelerinden $(p=0,021)$, tükettikleri yiyecek ve içeceklerin besin değerlerine dikkat etmelerinden $(p=0,018)$ ve seyahat sırasında sebze ve meyve tüketmeye özen göstermelerinden $(p=0,017)$ kaynaklanmaktadır. Bu durumda kadınların seyahat sırasında da erkeklere kıyasla yüksek kalorili ve kilo aldırıcı gıdalardan uzak durdukları, sebze ve meyve tüketmeyi tercih ettikleri söylenebilir. Benzer şekilde; erkeklerin kadınlara kıyasla seyahat sırasında daha çok et ürünleri ve kebap tüketmeyi tercih ettikleri $(\mathrm{p}=0,001)$ ve seyahat sırasında alkollü içki tüketmeyi 
sevdikleri $(\mathrm{p}=0,001)$ görülmektedir. Nitekim, erkeklerin yiyecek-içecek işletmesi seçiminde alkol tüketilebilen restoranları tercih etmeleri bu durumu doğrulamaktadır (Bkz. Tablo 4).

\section{Sonuç}

Tatil sırasında yiyecek-içecek seçiminin ve tüketiminin cinsiyetlere göre farklılaşıp farklılaşmadığını belirlemek amacıyla Safranbolu'yu ziyaret eden 210 yerli turist üzerinde yapılan bu araştırmada aşağıdaki sonuçlara ulaşılmıştır.

- Araştırmaya katılanların yarıya yakını evlidir.

- 2/3'ü 19-30 yaş aralığında olup genç ve yetişkin bireylerden oluşmaktadır.

- $1 / 3$ 'ü Safranbolu'yu ziyaret eden öğrencilerden oluşmaktadır.

- Katılımcıların yarısının aylık gelirleri asgari ücretin altındadır. Bu durum katılımcıların önemli bir kısmının öğrenci olmasına bağlanmaktadır.

- Katılımcılar, ağırlıklı olarak Ankara, İstanbul gibi metropol kentlerden ve Karabük'e yakın olan Kastamonu, Bartın, Zonguldak, Kocaeli gibi illerden gelmektedir.

- Katılımcıların 2/3'ünden fazlası lisans ve lisansüstü eğitim derecesine sahiptir.

- Hem kadın hem de erkek turistler seyahat sırasında daha çok yöresel yemeklerin üretildiği yerlerde yemek yemek istemektedirler.

- Erkekler tatil sırasında yemek yemek için alkol tüketilebilen restoranları, fast food restoranları, yol kenarındaki dinlenme tesisleri ile kebapçı ve pidecileri tercih etmektedirler.

- Kadınlar ise erkeklere kıyasla konaklanan otellerdeki restoranlar ile tanınmış şeflerin çalıştığı restoranlarda yemek yemeyi daha çok tercih etmektedirler.

- Hem erkek hem de kadın katılımcılar için restoran seçiminde aile, arkadaş ve tanıdıkların tavsiyeleri ile restoranda yöresel yiyecek ve içecek sunulup sunulmadığı 
önemli bir etkendir. $\mathrm{Bu}$ durum, turistlerin seyahat sırasında yöresel mutfakları deneyimlemeye önem verdiğini göstermektedir.

- Kadınlar, restoran seçiminde sosyal medyada yer alan paylaşımlardan, yemek yazarlarından ve yemekle ilgili bloglardan daha çok etkilenmektedirler. Kadınlar, seyahatten önce destinasyonda sunulan yiyecek-içecek hizmetleri ile ilgili internetten bilgi toplamakta ve restoran seçiminde daha planlı hareket etmektedirler. Bu sonuçlar Kim v.d. 'nin (2007) sonuçları ile örtüşmektedir.

- Restoranın kalabalık müşterisinin olması erkeklerin yiyecek içecek işletmesi seçiminde en çok dikkat ettikleri faktörlerdir. Hatta erkekler restoran seçimine daha çok anlık karar vermektedirler.

- Seyahat sırasında günlük alışkanlıkları da olduğu üzere erkekler; en çok döner, kebap, 1zgara et, fast food ve hamur tatlıları; kadınlar ise sebze yemekleri, salatalar, hamur işleri, gözleme ve börekler ile meyve tüketmektedir. Sonuçlar ilgili alanyazın (Sezgin \& Ayyıldız, 2019; Chapman, 2015) ile örtüşmektedir. Cohen \& Avieli (2004) insanların günlük yaşamda kazandıkları alışkanlıkların ve gösterdikleri davranışların tatil süresince de devam etiğini belirtmektedir. Dolayısıyla bu araştırmada da ortaya konduğu üzere; kadın ve erkek turistlerin tatil sırasındaki yiyecek-içecek tüketimleri günlük yaşamlarından pek de farklılaşmamaktadır.

- Günlük yaşamda da olduğu gibi seyahat sırasında da kadınlar daha çok sebze ağırlıklı, erkekler ise daha çok et ağırlıklı beslenmektedirler.

- Hem kadınlar hem de erkekler için seyahat sırasında yiyecek ve içecek seçiminde ya da tüketiminde yemeğin lezzeti en önemli faktördür. Bununla birlikte; gıdanın hijyenik ve güvenilir olması da çok önemlidir. Kadın ve erkekler yemeği bir keyif olarak görmektedirler. Nitekim; Cohen ve Avieli (2004: 760) turistlerin yeni deneyimler ve elde edilecek hazlar konusunda bir taraftan heyecanlanırken, diğer yandan da 
destinasyonda özellikle güvenli, yenilebilir ve lezzetli yiyeceklerin bulunması gibi konularda endişe duyduklarını belirtmektedir. $\mathrm{Bu}$ araştırmadan elde edilen sonuçlar ilgili literatür ile benzerlik göstermektedir.

- Seyahat sırasında yiyecek içecek seçimi ve tüketimi bakımından kadın ve erkekler arasında belirgin farklılıklar vardır.

- Kadınlar, seyahat sırasında da yüksek kalorili ve kilo aldırıcı gıdalardan uzak durmaktadırlar. Kadınlar tatil sırasında da daha çok vejetaryen yiyecek ve içecek ile sebze ve meyve tüketmektedirler. Bu sonuç ilgili alanyazından (Rozin, 2006) elde edilen sonuçlar ile benzerlik göstermektedir.

- Erkekler ise seyahat sırasında kadınlara kıyasla daha çok et ürünleri, kebap ve alkollü içki tüketmektedir.

$\mathrm{Bu}$ araştırmanın sonuçları, turistik destinasyonlarda faaliyet gösteren yiyecek-içecek işletmelerinin turistlerin yiyecek-içecek tüketimleri arasındaki farklılıkları dikkate almaları bakımından önem taşımaktadır. Turistik bir destinasyonda faaliyet gösteren konaklama ve yiyecek-içecek işletmeleri gıda üretiminde cinsiyetler arasındaki yiyecek-içecek tüketme farklılıklarını dikkate almalıdırlar. Bu durum, turistlerin beklentilerini karşılamak ve müşteri memnuniyeti yaratmak açısından önem taşımaktadır.

Yiyecek ve içecekler, bir destinasyon değerini ve rekabetçiliğini artırmakta, olumlu bir imaj yaratılmasına, markalanmasına katkı sağlamaktadır. Zira, pek çok popüler turizm destinasyonunda yöresel, etnik ve egzotik yiyecekler, lüks otellerdeki ünlü restoranlar, ünlü şeflerin yaptıkları yemekler ile Michelin yıldızlı restoranlar önemli bir tanıtım ve pazarlama aracı olarak sunulmaktadır (Cohen \& Avieli, 2004).

Günümüz turisti destinasyonun tüm kültürel öğelerini deneyimlemek istemektedir. Zira yiyecek-içecek tüketimi beslenmenin de ötesinde kültürel bir olgudur. Bu açıdan, bir turizm destinasyonu, destinasyonda faaliyet gösteren yiyecek-içecek işletmeleri, konaklama tesisleri 
v.b. destinasyonda sunulan yerel yiyecekleri, yerel lezzetleri, damak tadını, farklı turist tüketim motivasyonlarına göre sundukları hizmetleri ön plana çıkaran bir tanıtım ve pazarlama anlayışı gütmelidir.

\section{Kaynaklar}

Alebaki, M., \& Iakovidou, O. (2011). Market segmentation in wine tourism: a comparison of approaches. Tourismos: An International Multidisciplinary Journal of Tourism, 6(1),123-140.

Bessière, J. (1998). Local development and heritage: traditional food and cuisine as tourist attractions in rural areas. Sociologia ruralis, 38(1), 21-34.

Büyüköztürk, Ş., Çakmak, E. K., Akgün, Ö. E., Karadeniz, Ş.ve Demirel, F. (2017). Bilimsel Araştırma Yöntemleri. Ankara: Pegem.

Chang, R.C.Y., Kivela, J., Mak, A.H.N. (2011). Attributes that influence the evaluation of travel dining experience: when East meets West. Tourism Management, 32 (2), 307-316.

Chang, R.C.Y., Kivela, J., Mak, A.H.N. (2010). Food preferences of Chinese tourists. Annals of Tourism Research, 37 (4), 989-1011.

Chapman, S. (2015). Young South African vegetarians: constructing identities and negotiating Relationships. Unpublished Doctorate Thesis, South Africa.

Cohen, E. \& Avieli, N. (2004). Food in tourısm. Annals of Tourism Research, 31(4), 755-778.

Flynn, J., Slovic, P., Mertz, C.K. (1994). Gender, race and perception of environmental health risks. Risk Analysis, 14 (6), 1101-1108.

Girgin, G. K. (2018). Yerel gıdaların tüketilmesine yönelik turist motivasyonlarının ölçülmesi: Antalya'da bir uygulama. Atatürk Üniversitesi Sosyal Bilimler Enstitüsü Dergisi, 793-810.

Hall, C. M., Mitchell, R., \& Sharples, L. (2004). Consuming places: the role of food, wine and tourism in regional development. In Food tourism around the world (pp. 37-71). Routledge.

Hall, C. M., \& Sharples, L. (2004). The consumption of experiences or the experience of consumption? An introduction to the tourism of taste. In Food tourism around the world (pp. 13-36). Routledge.

Hjalager, A. M., \& Richards, G. (2002). Still undigested: research issues in tourism and gastronomy. Tourism and gastronomy, 224.

Jaison, G. (2015). Food Tourism and Consumer Behavior. ELK Asia Pacific Journals, Special Issue.

Kim Y. G.,Eves A., \& Scarles C. (2009). Building a Model of Local Food Consumption on Trips and Holidays: A Grounded Theory Approach. International Journal of Hospitality Management, 28, 423-431. 
Kim, D. Y., Lehto, X. Y., \& Morrison, A. M. (2007). Gender differences in online travel information search: Implications for marketing communications on the internet. Tourism management, 28(2), 423-433.

Kivela, J., \& Crotts, J. C. (2006). Tourism and gastronomy: Gastronomy's influence on how tourists experience a destination. Journal of Hospitality \& Tourism Research, 30(3), 354-377.

Kivela, J., Crotts, J.C. (2009). Understanding travelers' experiences of gastronomy through etymology and narration. Journal of Hospitality and Tourism Research, 33 (2), 161-192.

Long, L.M. (2004). Culinary Tourism. Kentucky:The University Press of Kentucky.

Mak A. H. N.,Lumbers M., \& Eves A. (2012a). Globalisation and Food Consumption in Tourism. Annals of Tourism Research, 39(1), 171-196.

Mak, A. H., Lumbers, M., Eves, A., \& Chang, R. C. (2012b). Factors İnfluencing Tourist Food Consumption. International Journal of Hospitality Management, 31(3), 928-936.

Martinez, A. F. G. (2015). Food in tourism: Exploring inherent influential factors in food decision processes of travelers. Unpublished Doctorate Thesis, Oklahoma State University, Stillwater.

Missagia, S.V., Oliveira, S.R. ve Rezende, D.C. (2013). Beauty and the Beast: Gender Differences in Food-Related Behavior. Revista Brasileira de Marketing, 12(1), 149-165.

Nield, K., Kozak, M., LeGrys, G. (2000). The role of food service in tourist satisfaction. International Journal of Hospitality Management, 19, 375-384.

Nisari, M.A. (2018). Ziyaretçilerin Yerel Yemek Tüketim Motivasyonlarının Analizi: Çeşme Örneği. Yayımlamamış Yüksek Lisans Tezi, İzmir Kâtip Çelebi Üniversitesi, İzmir.

Quan, S., \& Wang, N. (2004). Towards a structural model of the tourist experience: An illustration from food experiences in tourism. Tourism management, 25(3), 297-305.

Rozin, P., Vollmecke, T.A. (1986). Food likes and dislikes. Annual Review of Nutrition, 6, 433456.

Ryu, K., Jang, S. (2006). Intention to experience local cuisine in a travel destination: the modified theory of reasoned action. Journal of Hospitality and Tourism Research, 30 (4), 507516.

Sezgin, A. C. ve Ayyıldız, S. (2019). Gastronomi alanında vejetaryen/vegan yaklaşımı; Giresun yöre mutfağının vejetaryen mutfak kapsamında incelenmesi. İçinde. E. İnanır, O.

Köse, Y. Ulutürk (Ed) Siyasi, sosyal ve kültürel yönleriyle Türkiye ve Rusya, (s.505-533). Ankara: Berikan Yayınevi.

Telfer, D. J., \& Wall, G. (2000). Strengthening backward economic linkages: Local food purchasing by three Indonesian hotels. Tourism Geographies, 2(4), 421-447. 
Torres, R. (2002). Toward a better understanding of tourism and agriculture linkages in the Yucatan: tourist food consumption and preferences. Tourism Geographies, 4 (3), 282-306.

Tuorila, Lahteenmaki, L., Pohjalainen, L., \& Lotti, L. (2001). Food neophobia among the Finns and related responses to familiar and unfamiliar foods. Food Quality and Preference 12(1), 2937.

Wadolowska, L., Babicz-Zielinska, E., Czarnocinska, J. (2008). Food choice models and their relation with food preferences and eating frequency in the Polish population. Food Policy, 33, $122-134$. 


\title{
THE LANDMARK JUDGEMENT ABOUT DOMESTIC VIOLENCE AGAINST WOMEN: OPUZ V. TURKEY AND LEGAL RESPONSIBILITIES OF STATE
}

\author{
Nazime BEYSAN 1
}

\begin{abstract}
The European Court of Human Rights has made some significant decisions in relation to gender-based violence. The most significant one is the judgement about the case called Opuz v.Turkey (2009). The European Court of Human Rights ruled that Turkey had failed to protect applicant Nahide Opuz and her mother againts grave instances of domestic violence and even found that the situation amounted to gender-based discrimination. The European Court of Human Rights, in a very extensive judgment, dealt in detail with the applicant's claim that the authorities had failed to offer sufficient protection against domestic violence. The great importance of this judgement can be found in Court's elaborate acknowledgement of the seriousness and viciousness of the crime of domestic violence. State obligations are spelt out in detail and the Court significantly recognised that violence against women is a form of unequal treatment. So Opuz v. Turkey case has significant implications for the way in which authorities tackle domestic violence. The most important international legal document about domestic violence is Istanbul Convention of the Council of Europe.

On the base of this Convention legal responsibilities of states (prohibition, prevention, punishment and indemnification) are defined similar to The Opuz v.Turkey decision of Court.
\end{abstract}

Keywords: Opuz v. Turkey, Domestic Violance, Due Diligence, Violence Against Women

\footnotetext{
${ }^{1}$ Asst. Prof. Dr. Eastern Mediterranean University, Faculty of Law, North Cyprus, nazime.beysan@emu.edu.tr
} 


\section{KADINA KARŞI EV İÇİ ŞİDET KONUSUNDA BİR DÖNÜM NOKTASI: OPUZ v. TÜRKIYYE KARARI VE DEVLETIN HUKUKI YÜKÜMLÜLÜKLERİ}

\section{$\ddot{O}_{z e t}$}

Avrupa İnsan Hakları Mahkemesi, toplumsal cinsiyete dayalı şiddetle ilgili önemli kararlar vermiştir. Bu kararlardan en önemlisi Opuz v. Türkiye (2009) davası hakkında verdiği kararldır. Avrupa Insan Haklarl Mahkemesi söz konusu kararında, Türkiye Devleti’nin başvurucu Nahide Opuz ve annesini maruz kaldıkları ölümcül derecedeki ev içi şiddetten koruyamadığına ve bu durumun da cinsiyete dayalı ayrımcılık teşkil ettiğine hükmetmiştir. Bu kararın en önemli özelliği, Mahkeme'nin ev içi şiddetin ciddi bir suç olduğunu detaylı bir biçimde temellendirmesidir. Kararda, devletin ev içi şiddet konusundaki yükümlülükleri detaylı bir biçimde belirtilmiş; ayrıca, Mahkeme kadına kart şiddetin eşitliğe aykırı bir muamele olduğunu önemle vurgulamıştır. Bu özellikleri nedeniyle Opuz Davası'nın, devletlerin ev içi şiddet sorununu nasıl ele almaları gerektiği konusunda önemli sonuçlarl vardır. Ev içi şiddetle ilgili en önemli uluslar arası hukuki düzenleme kısaca Istanbul Sözleşmesi olarak da ifade edilen, Kadınlara Yönelik Şiddet ve Ev İçi Şiddetin Önlenmesi ve Bunlarla Mücadeleye Dair Avrupa Konseyi Sözleşmesi'dir (2011). Bu Sözleşme çerçevesinde devletlerin hukuki yükümlülükleri de(önlemek, korumak, kovuşturmak ve cezalandırmak) Avrupa Insan Hakları Mahkemesi'nin Opuz Kararı'na benzer biçimde tanımlanmıştır.

Anahtar Kelimeler: Opuz v. Türkiye, Ev Iç̧i Şiddet, Devletin Özen Yükümlülüğü, Kadına Karşı Şiddet

\section{Devletin Özen Yükümlülüğü...}

Kadına karşı ev içi şiddet, hukuk sistemlerinin göz ardı edemeyeceği kamusal niteliği olan bir sorundur. Bir insan hakları ihlali, ayrımcılık biçimi ve toplumsal cinsiyet eşitliğinin sağlanmasının önündeki en önemli engellerden biridir.( Uygur, 2015: 196 vd.)

Kadına karşı ev içi şiddet, diğer şiddet türlerinden farklı özellikler taşıması nedeniyle devlet tarafından farklı önleme, koruma ve müdahale mekanizmaları geliştirilmesi gereken bir suç tipidir. Bu şiddet türünün küresel ölçekteki yaygınlığı ve çoğunlukla hukuk sistemlerinin sorunu 
çözmekte yetersiz kalmalarından dolayı konu uluslararası normlarla düzenlenmiş, devletlerin bu konudaki sorumluluğu tanınmış ve uluslararası mahkemeler tarafından devletlerin özen yükümlülüğü doğrultusunda ölçütler geliştirilmiştir. (Sever, 2012: 20)

"Devlet, kural olarak kamu görevlilerinin ya da daha genel bir ifadeyle kamu gücünü kullanan bu nedenle kendisine sorumluluk atfedilebilecek kişilerin neden olduğu zararları tazminle yükümlüdür. $\mathrm{Bu}$ nedenle kamu gücünü kullanmayan kimselerin neden olduğu zararlardan veya özel alanda “devlet dışı aktörlerin” neden olduğu zararlardan devletin sorumlu tutulması mümkün değildir. Bu kuralın tek istisnası, devletin bu zararın oluşmasını önlemek konusunda gerekli özeni göstermemesi ve gerekli tedbirleri almaması halidir. $\mathrm{Bu}$ durumda devletin “özen yükümlülüğünden” kaynaklanan sorumluluğu söz konusudur. Buna göre devlet ve kamu otoritesi, icrai veya ihmali bir eylem neticesinde, bir suçun işleneceğilişlenebileceği veya bir hakkın ihlal edileceğiledilebileceği bilgisine sahipse ve bu öngörülebilir sonucun önlenmesi için gerekli imkânlara sahip olmasına rağmen bunu önlemiyorsa, bundan doğacak zararlardan sanki bu zararlara doğrudan kendisi neden olmuş gibi sorumludur”. (Doğan, 2016: 92)

Bu konuda bilinen ilk örnek, yani özen yükümlülüğü kavramının insan hakları alanında kullanımına ilişkin ilk önemli örnek Inter Amerikan İnsan Hakları Mahkemesi’nin 1988 yılında verdiği Velasquez Rodriguez v. Honduras kararıdır. Kararda devletin sorumluluğunun doğrudan eylemin kendisinden değil, devletin gerekli özeni göstermemesinden (due diligence) kaynaklandığı belirtilmiştir. Bu, gerekli özeni gösterme yükümlülüğü, daha sonraki uluslararası belgelere ve mahkeme kararlarına da yansımıştır. (Güregey, Dericiler, 2019:238; Doğan,2016:101)

Devletin özen yükümlülüğünden kaynaklanan sorumluluğu kavramının kadının insan haklarının korunması amacıyla kullanılması ise oldukça yeni bir gelişmedir. Kadının insan hakları açısından özen yükümlülüğü kavramı, kadına karşı işlenen şiddet eylemlerinin sonuçları 
ile bu sonuçların önlenmesinde devletin yükümlülüklerini gereği gibi yerine getirip getirmediğini değerlendirmemizi sağlayan bir ölçüt olarak kullanılmaktadır. Devlet dış1 aktörlerin yol açtığı zararlardan devletin sorumlu tutulmasını sağlayabilme özelliğinden dolayı, özellikle kadına yönelik ev içi şiddet eylemlerinden doğan zararlardan devletin sorumlu tutulup tutulmayacağının belirlenmesinde önemli bir araçtır. (Doğan, 2016: 93)

Özen yükümlülüğ̈̈ kavramı aracılığıyla, kamusal-özel alan ayrımı ile hep ikinci plana itilen kadının, insan haklarının hayata geçirilmesi ve şiddetten korunması amacıyla, her bir somut olay için ulusal hukukta şiddetten korunmaya ilişkin önlemlerinin bulunup bulunmadığ1, bunların etkili ve elverişli olup olmadığı ve de şiddeti önleme amacıyla uygulanıp uygulanmadığı değerlendirilmektedir.(Manjoo, 2013: 263)

Devletin kadına yönelik şiddet konusundaki özen yükümlülüğü, “devletin bireysel özen yükümlülüğü” ve “devletin sistematik genel yükümlülüğü” olarak iki kategoride incelenebilir. $\mathrm{Bu}$ bağlamda devlet bir yandan genel olarak şiddetin kökenini oluşturan sebeplere ve bunun sonuçlarıyla mücadeleye ilişkin etkili ve iyi işleyen bir yapının kurulmasını sağlamak diğer yandan da her bir şiddet mağduruna etkili bir koruma, önleme, tazmin hizmeti sunmak, failleri de caydırıcı bir biçimde cezalandırmak ile yükümlüdür. (Manjoo, 2013: 262, 244-245)

Devletin bireysel özen yükümlülüğü; her bir kadına ilişkin olarak şiddetin önlenmesi, kadının şiddete karşı korunması, faillerin cezalandırılması ve mağdur için alternatif çözüm yolları bulunması hususlarını içerir. Bu yükümlülük her bir kadının ihtiyaçlarını karşılama konusunda, kadının ihtiyaçlarına göre değişecek birtakım esnek müdahaleleri kapsar. Devlet her bir kadına, karşı işlenebilecek şiddet eylemiyle ilgili özen yükümlülüğünü, şiddete karşı danışma ve yardım hatları kurarak, tedavi ve bakım hizmeti vererek, psikolojik destek ve hukuki yardım hizmetleri sunarak, mağdur için barınma hizmeti sağlayıp, failler hakkında uzaklaştırma kararı alarak ve benzeri yollarla yerine getirir. (Manjoo, 2013: 262; Doğan, 2016:100) 
Devlet sistematik genel özen yükümlülüğünü ise; kadınları şiddete karşı koruma, şiddeti önleme, failleri cezalandırma ve mağdurun zararını tazmin etme konusunda bütüncül, kapsayıcı ve sürdürülebilir bir yapı kurmak suretiyle yerine getirir. Bir başka ifadeyle pratikte her bir somut olayda işleyebilen makul ve etkili bir sistem oluşturmak yoluyla yerine getirir. Bu bağlamda devlet özen yükümlülüğünü, gerekli yasal düzenlemeleri yaparak, eylem planları yürürlüğe koyarak, toplumsal cinsiyet eşitliği konusunda farkındalık yaratmak için kampanyalar düzenleyerek, uzmanları eğiterek, ev içi şiddet konusunda yükümlülüklerini yerine getirmeyen görevlileri ve şiddet uygulayan gerçek failleri cezalandırarak ifa eder. Bunun yanında devletin genel ve sistematik özen yükümlülüğü, tüm toplumun toplumsal cinsiyet eşitliğinin sağlanması ve ayrımcılığın önlenmesi konusunda bir dönüşüm sürecine tabi tutulması görevini de içerir. (Manjoo, 2013: 262; Doğan, 2016:100)

İlk kez CEDAW komitesinin 19 numaralı tavsiye kararında, CEDAW kapsamındaki ayrımcılık yasağının sadece kamu görevlilerinin eylemlerinden kaynaklanan haller ile sınırlı olmadığı, devletin herhangi bir kişi, kurum veya kuruluş tarafından yürütülen ayrımcılığa karşı da gerekli tedbirleri almasının zorunlu olduğu belirtilmiştir. Bununla beraber devletin uluslararası hukuka ve insan hakları sözleşmelerine uygun olarak özel alanda işlenen şiddet eylemleri konusunda da şiddeti önlemek, şiddet eylemlerini soruşturmak, failleri cezalandırmak ve mağdurun zararını tazmin etmek ile yükümlü olduğu, bu yükümlülüğünü yerine getirme konusunda gerekli özeni göstermeyen devletin ise bu eylemlerden sorumlu tutulabileceği belirtilerek “kadına yönelik şiddet konusunda devletin özen yükümlülüğ̈̈” kavramına ilk atfı yapmıştır. Daha sonra ise Birleşmiş Milletler'in “Kadınlara Yönelik Şiddetin Bertaraf Edilmesi Sözleşmesi” (1993) ile 1995 tarihli Pekin Deklerasyonu'nda da tekrarlanmıştır. Bölgesel düzeyde ise Kadına Yönelik Şiddetin Önlenmesi, Cezalandırılması ve Ortadan Kaldırılmasına ilişkin Amerika Kıtası Sözleşmesi (The Convention of Belem do Para) (1994) kadına yönelik şiddetin önlenmesi, soruşturulması ve faillerin cezalandırılması konusunda taraf devletlerin 
gerekli özeni göstermekle yükümlü olduğunu belirtilmektedir. Benzer bir düzenleme de Kadınlara Yönelik Şiddet ve Ev İçi Şiddetin Önlenmesi ve Bunlarla Mücadeleye Dair Avrupa Konseyi Sözleşmesi'nin 5. maddesinde de yer almaktadır. Öyle ki Sözleşme, hem kamu hem de özel hukuk gerçek ve tüzel kişilerinin kadına yönelik şiddet eylemlerinden dolayı taraf devletleri sorumlu tutmaktadır. (Doğan, 2016: 96 vd.) bu doğrultuda madde 5\1 devletin kendi yetkililerinin, görevlilerinin, temsilcilerinin, kurumlarının veya devlet adına hareket eden diğer kişilerin kadına yönelik şiddet anlamına gelen fiillerden kaçınmalarını sağlama yükümlülüğü; madde $5 \backslash 2$ ise taraf devletlerin devlet dışı aktörler tarafından işlenen fiilleri titizlikle ele alması yükümlülügünü ortaya koymaktadır. Dolayısıyla bu madde uyarınca taraf devletler, devlet dış1 aktörlerce yani özel hukuk kişilerince gerçekleştirilen ve sözleşmenin kapsamı dahilindeki şiddet eylemlerinin önlenmesi, soruşturulması, cezalandırılması ve tazmin edilmesi konusunda azami dikkat ve özenin sarf edilmesi için gerekli hukuki ve diğer önlemleri alacaklardır. Sözleşmedeki yükümlülükler, sözleşme kapsamında şiddet olarak kabul edilen eylemlerin işlenmesini önlemeye, koruma ve destek sağlamaya, şiddet eylemlerini etkili bir biçimde soruşturarak faillerin cezalandırılmasına, mağdurun zararlarının tazmin edilmesine ilişkin yükümlülükler olarak sınıflandırılabilir. Ayrıca sözleşme taraf devletleri yalnızca kendi vatandaşlarına yönelik şiddet eylemlerinden değil, sığınmacı, mülteci ve hukuki durumu ne olursa olsun göçmen kadınlara yönelik şiddetten de sorumlu tutmaktadır. (Detaylı bilgi için bkz. Bakırc1, 2015: $133 \mathrm{vd)}$

$\mathrm{Bu}$ tür uluslararası düzenlemelerde vurgulanan en önemli konu, ev içi şiddetin önlenebilmesi için devlet müdahalesinin gerekliliği ve kadının korunmasına yönelik önlemlerin kapsamının genişletilmesi ve etkililiğinin sağlanması ihtiyacıdır.

Kadınlara Yönelik Şiddet ve Ev İçi Şiddetin Önlenmesi ve Bunlarla Mücadeleye Dair Avrupa Konseyi Sözleşmesi oluşturulmadan önce, kadına karşı ev içi şiddet konusunda devletin pozitif yükümlülüklerinin kapsamına ilişkin Avrupa İnsan Hakları Mahkemesi (AHİM) yerleşik 
bir içtihat oluşturmaya başlamıştı. Öyle ki Avrupa Konseyi Sözleşmesi’nin içeriğinin de aslında kadına karşı şiddet ve ev içi şiddet konusunda AİHM'in oluşturmaya başladığı içtihadın temel ilkelerinin bir yansıması olduğu görülmektedir.

AİHM, ihlal kararı vermemekle birlikte özel kişilerin eylemlerinden dolayı devletin sorumlu olabileceğini ilk olarak 1998 yılında Osman v. Birleşik Krallık davasında tanımış; daha sonra 2003 yılında M.C. v. Bulgaristan davasında da bu ölçütleri geliştirerek, kişinin yaşam hakkının gerçek ve acil bir risk altında olması durumunda devletin bu riski ortadan kaldırma yükümlülügünden bahsetmiştir. M.C. davasında tecavüze uğrayan bir kadın, adli makamlara başvurmuşsa da soruşturmanın devamı için çaba harcamamış, bu olayda mahkeme kadının içinde bulunduğu koşulları dikkate alarak, o tarihte hala olayın etkisinde ve korkmuş olduğu gerekçesiyle devletin, kadının çabası olmamasına rağmen, gerekli önlemleri almadığı için sorumlu tutulması gerektiğini belirtmiştir. Avrupa İnsan Hakları Sözleşmesi (AİHS) m.3 ve 8'in ihlal edildiğine karar vermiş, 14. madde yönünden inceleme gereği duymamıştır. (Sever, 2012:33).

AİHM'in AİHS'i yaşayan bir metin olarak ele alarak içtihadını geliştirmesi sonucunda verdiği iki önemli karar daha vardır. Bunlardan ilki Bevacqua v. Bulgaristan kararıdır. Bevacqua, eski eşi tarafından defalarca şiddete maruz kalmış ve şikâyetine rağmen son olayda savcılık hafif yaralanma olduğu için kovuşturmaya gerek olmadığına karar vermiştir. Mahkeme 8. maddede yer alan özel hayatın korunmasına ilişkin hükmün ihlal edildiğine karar vermiştir. 2002 tarihli tavsiye kararı, 2006 tarihli BM raporları, Inter Amerikan İnsan Hakları Mahkemesi'nin ilgili kararlarına atıf yaparak, devletin ev içi şiddeti önlemek için gerekli özeni gösterme yükümlülügünü değerlendirmiştir. Mahkeme 8 . maddedeki özel hayata sayg1 hakkının, devlete müdahale etmemek biçiminde negatif bir yükümlülük değil, aynı zamanda bireyler arasında özel alanda gerçekleşen ilişsilere ilişkin önlemler alma şeklinde pozitif yükümlülükleri de içeren bir hak olarak yorumlamıştır. (Sever, 2012: 33-34). 


\section{Opuz v.Türkiye Kararı...}

AHIM'in, kadına karşı ev içi şiddet ile ilgili içtihadına yön veren ilke karar ise 2009 tarihli Opuz v. Türkiye kararıdır. AHİM'in Türkiye aleyhine ihlal kararı verdiği Opuz kararı, Türkiye'deki kadına yönelik şiddet sorununu açıkça ortaya koymuş olmasının yanında kadına karşı ev içi şiddetin hukuki nitelendirilmesi ve devletlerin yükümlülüğü bakımından yeni ölçütler getirdiğgi için de önemli bir karardır. Öyle ki Opuz Kararı kadına karşı şiddette devletin sorumluluğu bağlamında bir dönüm noktası olmuştur. (Sever, 2012: 19)

Bu karada AİHM, içtihadında ilk kez toplumsal cinsiyete dayalı şiddete karşı devletin gerekli tepkiyi vermemesinin ve etkili bir koruma sunmamasının ayrımcılık teşkil ettiği ve durumun da AİHS'in 14. maddesine aykırı olduğu hususu karara bağlanmıştır. Kararda ev içi şiddetin kişisel bir konu olmadığ koruma mekanizması kurmasını gerekli kılan bir konu olduğunu belirtmiştir. Ayrıca karada, davacı Nahide Opuz ile annesinin Hüseyin Opuz'un şiddet eylemlerine karşı polis ve cumhuriyet savcılığına yaptıkları müracaatlarda, bu makamların özen yükümlülügünü yerine getirip getirmediği hususu, AİHM'in başta Osman v. Birleşik Krallık ve Bevacqua v. Bulgaristan kararları 1şı̆̆ında tartış1lmıştır.(Doğan 2016: 107)

Bevacqua kararının, Opuz kararından bir adım geri sayılmasının iki nedeni vardır: İlki, AİHM'in ulusal makamların hafif yaralanma olması nedeniyle olayı kovuşturmamalarını AİHS'in ihlali olarak yorumlamaması ve bu tür düzenlemeleri ülkelerin takdirinde kabul etmesidir. İkinci olarak ise AİHM bu kararında ayrımcılık yasağına ilişkin 14. maddeye aykırılık görmemiş ve sadece 8. madde bakımından ihlal kararı vermiştir. Oysa Bulgaristan ceza hukuku bakımından bu tür düzenlemelerin pratikteki sonucu ayrımcılıktır, kadınlar çok ağır yaralanmalar dışındaki yaralanmalarda korumasız kalarak, eşitsiz konumlarının daha kötü duruma gelmesine neden olmaktadır. (Sever, 2012: 34) 
Opuz Davasına konu olan olayda, başvurucu Nahide Opuz, 10 Nisan 1995 de başlayıp, 29 Ekim 2001 tarihine kadar devam eden süreçte, kocası Hüseyin Opuz’un 5 kez saldırısına uğramış ardından 11 Mart 2002 tarihinde Nahide Opuz'un annesi, Hüseyin Opuz tarafindan öldürülmüştür. Nahide Opuz kocası Hüseyin Opuz'dan defalarca şiddet görmüş, boşanma kararı alma evresinde bu şiddet annesine de yansıyarak, bıçaklama, arabayla ezme de dahil olmak üzere yedi şiddet olayı adli makamlara da yansımıştır. Olaylar sırasında Nahide Opuz'un annesi hayatının tehlikede olduğunu savcılığa bildirmişse de, yaptığı başvuruloar sonuçsuz kalmıştır. Dosyadan, Hüseyin Opuz hakkında özellikle ölümle tehdit, ağır müessir fiil, öldürmeye teşebbüs gibi bir dizi suçtan dolayı başlatılan ceza soruşturmaları, Nahide Opuz ve annesinin ya şikâyetlerini geri çekmesi, ya ifadelerini değiştirmeleri ya da yeterli delil olmadığı için Hüseyin Opuz serbest bırakılmasıyla sonuçlanmıştır. Ancak başvurucunun kocası hakkında iki olaydan dolayı ceza davası açılmış, birinden para cezasına çevrilen 3 ay hapis cezası, diğerinden de para cezasına mahkûm edilmiştir. Ev içi şiddete ilişkin adli bir profile sahip olduğu yerel makamlarca da bilinen Hüseyin Opuz, nihayetinde 2002 y1lında başvurucunun ortak yaşadığı evden kaçması için yardım etmeye çalışan annesini silahla öldürmüştür. $\mathrm{Bu}$ süreçte Nahide Opuz’un kendisini ve annesini korumak için yaptığı başvurular sonuçsuz kalmıştır. Cezaevine konan Hüseyin Opuz uzun süre tutuklu olarak yargılanmasının ardından 26 Mart 2008 tarihinde 15 yıl 10 ay hapis cezasına çarptırılmış ve tutuklu bulunduğu süre dikkate alınarak serbest bırakılmıştır. Salıverilmesinin ardından Hüseyin Opuz, Nahide Opuz’u kendisi ile tekrar birlikte olması için tehdit etmeye devam etmiştir. Bu dava AHIM'de 15 Temmuz 2002 tarihinde açılmış olup, Nahide Opuz'un koruma altına alınması ve kendisine yönelik tehditlerin önlenmesi, nihai, kararın verildiği 9 Eylül 2009 tarihinden ancak kısa bir süre önce AİHM'in ısrarlı talepleri ve Adalet Bakanlığı'nın müdahalesi ile 21 Kasım 2008 tarihinde gerçekleşebilmiştir. (Doğan, 2016:107; Sever, 2012:34; Köksal, 2018:65-66) 
AHIM, Opuz Davasında, polisin kendisine yapılan koruma başvurularında adeta bir arabulucu gibi davranıp, kadınları evlerine gönderip kocaları ile barışmaya davet etmesi ve şikâyetlerinden vazgeçirmeye çalışması ya da şiddet konusunu aile içi bir mesele olarak görüp, müdahale etmek istememesi sebebiyle kadının şiddetten korunmasını amaç edinen kanunların uygulanmasında ciddi sorunlar bulunduğunu, bunun da hak ihlallerine yol açtığını belirtmiştir. AİHM ayrıca Hüseyin Opuz hakkındaki ceza yargılamasının 6 yıldan fazla sürmesi, koruma ve tedbir başvurularında bu başvuruların sanki boşanma davalarına yönelik bir tedbirmiş gibi algılanarak duruşma için uzun süreler verilmesini, şiddet faillerinin caydırıcı bir cezaya çarptırılmayıp cezaların namus gerekçesiyle haksız tahrik indirimine tabi tutulması gerçeği karşısında, ev içi şiddet fiillerinden temel olarak kadınların olumsuz etkilendiğini ve yargı organlarının pasif davranmasının da şiddetin işlenmesi için uygun bir ortam hazırladığını belirtmiştir. (Opuz v. Turkey para.92,96,102,151, 195, 196, 198)

AİHM'in 2009 tarihinde verdiği opuz kararı, kadına karş1 şiddetle mücadelede etkili bir koruma mekanizmasının kurulmadığı, etkili bir soruşturmanın yürütülmediği, kadının şiddetten korunması noktasında ayrımcılığa tabi tutulduğu iddiasıyla yapılan başvurularda AİHM'in taraf devletlerin özen yükümlülügünü yerine getirip getirmediğini belirlemek üzere sıklıkla uyguladığı bir içtihat haline gelmiştir.

Türkiye savunmasında Nahide Opuz ve annesinin yaşadıkları şiddet olaylarında yürütülen adli takibat sırasında ya şikâyetlerinden vazgeçtikleri veya ifadelerini değiştirdikleri gerekçesiyle özel hayata müdahale edemeyeceğini belirtmiştir. Bu olayı diğerlerinden farklı kılan; başvurucu Nahide Opuz'un yaşadığı şiddete karşı yasal yollara başvurmamış veya etkili olarak işletilmesi için gerekli çabayı göstermemiş olmasıdır. O dönemde yürürlükte olan ceza yasasına göre, 10 günden az iş göremezlik raporu alacak biçimdeki yaralamaların şikâyete tabi suç olması, şikâyet geri çekildiğinde davanın görülmesine devam edilmemiştir. Bununla birlikte bu olayların yayıldığı zaman diliminde Ailenin Korunmasına Dair Kanun yürürlüğe girmiş, ama 
bu kanun uyarınca da herhangi bir önlem alınmamıştır. Opuz kararında AİHM taraf devletlerin bu tür suçlarda yapacağı düzenlemeler bakımından ölçütler geliştirmiş ve Türkiye'deki ceza yasasını değerlendirirken bu ölçütlerin dikkate alınmadığını belirtmiştir. Bu bağlamda AİHM, Bevacqua Kararından farklı olarak, bu tür suçların şikâyete bağlı olmasının AİHS’e aykırılık anlamına gelebileceği yorumunu yapmıştır. Ayrıca AİHM, bu tür durumlarda devletin yeterli koruma sağlayamamasının ayrımcılık anlamına geldiğini ve bu denli ağır ve sürekli bir şiddetin özel kişilerce yapılsa dahi işkence yasağı kapsamında değerlendirilebileceğine karar vermiştir. (Opuz v. Turkey para 160 vd; Sever 2012.34-35)

$\mathrm{Bu}$ bulgu ve delilere uygun olarak da mahkeme, her ne kadar kasitlı olmasa da yargı makamlarının genel olarak kadına yönelik şiddet konusunda gereken hassasiyeti göstermeyip kayıtsız kalmasını sanıkların şiddet eylemlerinin caydırıcı bir yaptırıma tabi tutulmamasını göz önüne alarak Nahide Opuz ve annesinin toplumsal cinsiyete dayalı şiddete ve dolayısıyla şiddetten korunma noktasında ayrımcılığa tabi tutulduğunu tespit etmiş ve yaşananların AİHS'in yaşam hakkına ilişkin 2. maddesine, işkence yasağına ilişkin 3. maddesine ve ayrımcılık yasağına ilişkin 14. maddesine aykırı olduğu hususunu karara bağlamıştır. (Opuz v. Turkey para.200-202)

\section{Yaşam Hakkı...}

AİHS'in 2. maddesinde düzenlenen yaşam hakkını garanti altına alma konusunda devletin pozitif ödevlerini yerine getirmediği iddiası söz konusu olduğunda; yerel makamların kişilerin yaşamlarının üçüncü kişilerin suç fiilleri ile gerçek ve yakın bir tehdit altında bulunduğunu bildiği veya bilmesi gerektiği; bu tehlikeyi bertaraf etmek için yetkileri dâhilindeki önlemleri almadığının ortaya konulması gerekmektedir. Opuz Davasında Nahide Opuz ve annesine yönelik sistematik ve giderek artan bir şiddet uygulandığı ve bu tehdidin devam eden bir tehdit olduğu tespit edilmiştir. Bu tehdidin kolluk makamları tarafından 
bilinmekte olduğu, savcılığa da bu kapsamda başvurulmuş olduğu, dolayısıyla saldırı riskinin öngörülebilir olduğuna kanaat getirilmiştir. Bunun ardından AHİM, yetkili makamların öngörülebilen bu riske karşı uygun tedbirleri alıp almadıkları hakkında bir değerlendirmede bulunmuştur. Özellikle bu noktada aile içi şiddet mağdurlarının somut olayda şikâyetlerini geri çekmelerine bağlanan hukuki sonuçlar ve şikayetlerin geri çekilmesinin gerekçeleri üzerinde durulmuştur. Somut olayda mevcut şiddet ortamına ve ateşli silah kullanımı ve ölüm tehditlerinden haberdar edilmelerine rağmen, devlet makamlarının aile meselesi olarak gördükleri bu duruma müdahale etmekten kaçınmak amacıyla Hüseyin aleyhine başlatılan cezai işlemlere devam edilmemesi yönünde çok sayıda karar verilmesi ile bu kararlara neden olan yasal düzenlemelerin devletin kişileri ev içi şiddetten koruma konusundaki pozitif yükümlülükleri ile uyuşmadığı vurgulanmıştır.

Opuz kararını daha önceki AİHM kararlarından ayıran nokta, ulusal mahkemelerin kadına karşı şiddet bakımından suç şikâyete bağlı olsa bile kovuşturup kovuşturmama konusunda karar verirken dikkate alınması gereken aşağıdaki gibi unsurları içeren bir liste sunmasidir: (Sever, 2012:37)

-suçun ciddiyeti

-mağdurun yaralarının fiziksel ve psikolojik olması

-davalının silah kullanıp kullanmadığı

-davalının saldırıdan bu yana tehditlerde bulunup bulunmadı̆̆

-davalının saldırıyı planlayıp planlamadı̆̆ı,

-hanede yaşayan çocuklar üzerindeki psikolojik etkisi,

-davalının tekrar saldırıda bulunma ihtimali

-mağdur veya dahil olan veya olabilecek olan diğer kişilerin sağlı̆̆ ve güvenliğine yönelik devam etmekte olan tehdit. 
-mağdurun davalıyla halihazır ilişkisi, kovuşturmaya mağdurun isteğinin aksine devam edilmesinin bu ilişki üzerindeki etkisi;

-ilişkinin evveliyatı, özellikle geçmişte de şiddet uygulanıp uygulanmadığ

-davalının adli sicili, özellikle geçmişte şiddet uygulamış olup olmadığı.(Opuz v. Turkey, para138)

Bu listeden hareketle mahkeme, "Bu uygulamadan, suç ne kadar büyükse ya da başka suçların işlenmesi riski ne kadar yüksekse, kamu yararı açısından kovuşturmanın devam etmesinin, mağdurlar şikâyetlerini geri çekse dahi, o derece önemli olduğu" sonucuna varmıştır.(Opuz v. Turkey, para139) Buna göre Opuz davasında olduğu gibi bu listede yer alan unsurların olayda gerçekleşmesine rağmen, suçun kovuşturulmamasına yol açacak bir yasa ve uygulama AİHS'in ihlali anlamına gelecektir. Ayrıca AİHM'in de vurguladığı gibi Opuz kararındaki şiddet olayları devam ederken 4320 sayılı yasa yürürlüğe girmiş olmasına rağmen etkili biçimde işletilmemiştir. Bu olaylar sırasında şikâyetlerin geri çekilmesine rağmen savcılık 4320 sayılı yasanın uygulanmasını sağlama olanağına sahipti. .(Opuz v. Turkey, para148) Ayrıca AİHM kararda Hüseyin Opuz’a karşı verilen tedbir ve mahkumiyet kararlarının bu kişi üzerinde hiçbir önleyici ve caydırıcı etkisi olmadığı üzerinde de durulmuştur. Nahide Opuz ve annesinin maruz kaldığı şiddetin son bulmadığı ve yetkili makamların hareketsiz kalmaya devam ettikleri ve Nahide ve annesinin fiziki bütünlüklerini ciddi biçimde tehdit eden eski eşin saldırılarına karşı koruyacak etkili koruma tedbirlerini alma yükümlülüklerini yerine getirmedikleri vurgulanmıştır.

AİHM şikâyetin geri çekilmesi örneğindeki gibi rıza sorununu değerlendirirken, şiddet gören kadının psikolojik durumunu, şiddetin özelliklerini, ayrıca bu kadınların sosyo-ekonomik koşulları nedeniyle savunmasız olduklarını dikkate almış; devletlerin bu tip suçları düzenlerken elbette takdir yetkileri olmakla birlikte bu düzenlemelere AİHS bağlamında bir sınır getirmiş olmaktadır. (Sever, 2012:38) 


\section{İşkence Yasă̆ı}

Toplumsal cinsiyete dayalı şiddetin farklı türleri vardır. Bununla birlikte hukuki olarak tanımlarken tüm şiddet türlerini, tek bir başlık altında inceleyip, bunlara benzer hukuki sonuçlar bağlamak gerekmemektedir. Meyersfeld ev içi şiddeti ikiye ayırmaktadır: Kötü muamele (hakaret, sövme, aşağılama, küçük düşürme, itme, tokatlama vs) ve özel işkence (yumruklama, tekmeleme, yaralama, tecavüz vb) Özel işkence kapsamındaki şiddet diğer şiddet türlerinden farklı olarak, genellikle mağdurun aciz hale gelmesine neden olur. Fiziksel şiddet, ekonomik bağımlılık, psikolojik kontrol, tehdit ve korkutmak gibi araçlarla mağdur genelde bu şiddetten kaçamaz hale gelir. Özel işkence, tekrar eden, sistematik olma, güç kontrolünü içeren ve nitelikli bir şiddet içerir. Bu tür şiddetin sürekli ve sistematik olması, bu şiddetin mağdur üzerinde anlık değil, geniş zamana yayılan biçimde etki etmesine ve şiddete maruz kalması yanında sürekli bir şiddet tehlikesi altında yaşamasına neden olur. Özel işkencenin güç kontrolünü içermesi ise, ilişkideki güç dengesizliği sonucunda, mağdurun şiddet sonucunda aciz hale gelmesine neden olur. Bu nedenle de şiddet gören kadınlar çoğu zaman bu döngüden çıkamazlar. Şiddeti işkence haline döndüren diğer bir unsur da, şiddetin derecesidir. Ev içi şiddetin bu hali, kemik kırma, bıçakla yaralama, yüzde tahribat, tecavüz vb yoğun bir şiddet içermesi nedeniyle mağduru bakımından güçsüzleştirici ve yıkıcı bir ortam oluşturur.(Mayersfeld, 2004: 390) Vurgulamak gerekir ki bu ikili ayrımla, kötü muamelenin daha az önemli olduğu ya da göz ardı edilebileceği sonucu çıkmaz. İkincinin başka türden yaptırımları ve önlemleri gerektirdiği vurgulanmak istenmektedir. (Sever, 2012:39)

Bu tür şiddetin “özel işkence” olarak, değerlendirilmesinin pratikteki ve kadına karşı ev içi şiddetin önlenmesi bakımından sonucu; işkence yasağına ilişkin uluslararası normların uygulanmasıdır. Her ne kadar uzun süre uluslararası hukukta özel kişilerin faaliyetleri nedeniyle doğan zararlar özel alana ilişkin ve uluslararası hukukun süjesi olarak devletlerle ilişkili görülmemişse de, bu durum değişmeye başlamıştır. Yukarıda ifade edilen türden bir şiddete 
maruz kalan kadın ile kamusal bir alanda (cezaevi) şiddete maruz kalan kadın arasında korumanın niteliği, kapsamı ve devletin bu şiddet bakımından konumunun farklılaşmasını gerektirecek bir durum yoktur. Özel işkencenin üç özelliği nedeniyle diğer işkence türlerine tanınan korumadan ve devletin sorumluluğundan yararlanması gerekir: özel işkence kamusal işkence gibi yoğun bir şiddeti ifade eder. Mağdurun izole edilmesine neden olur. İşkence görenin ötekileştirilmesine, ona ayrımcılık yapılmasını içerir. (Mayersfeld, 2004:401)

İşkence suçunun ortaya çıkışı özellikle mahkûm, tutuklu veya gözaltına alınan kişilere uygulanan şiddetin önlenmesi için olmuştur. Ancak zamanla suç tipi genişlemeye uğramış, ve doğrudan devlet tarafından işlenmese de kamu görevlisinin rızası, bilgisi dahilinde işlenmiş olması da tanım içinde yer almış; hatta devletin varlığını bildiği ancak önlemek için yeterince çaba harcamadığı durumların da bu kapsam içinde değerlendirilmesi gerektiği savunulmuştur. (Sever, 2012: 40)

Bu bakımdan, kadına karşı ev içi şiddetin bir özel işkence türü haline gelebilmesinin temel koşulu, ev içi şiddetin önlenmesi bakımından devletlerin yükümlülüklerinin tanınması ve devletlerin bu yükümlülükleri yerine getirmemesi durumunda söz konusu şiddetin adeta devletin gözetiminde gerçekleşen bir hal alacağının kabul edilmesidir. AHİM Opuz Kararında, daha önceki kararlarına atıfla devletin sorumluluğunun kapsamını geniş yorumlayarak, “devletlerin, kendi yargı yetkileri dâhilindeki bireylerin, bireyler tarafından uygulananlarda dahil olmak üzere işkence, insanlık dışı, küçültücü muameleye maruz bırakılmamaları temin etmek için gerekli tedbirleri almaları gerekir”. (Opuz v. Turkey, para159) Bu nedenle AHİM'in Opuz Kararı, ev içi şiddette devletin sorumluluğu bağlamında bir dönüm noktasıdır. $\mathrm{Bu}$ yaklaşım aslında sorumluluk hukukunun geleneksel yaklaşımından ayrılarak, devletin doğrudan faili olmadığı ve o anda müdahale etmesi dahi mümkün olmayabilecek bir eylemden dolayı ve 
daha geniş bir çerçeve dâhilinde tekrarlanan, dozu yüksek şiddeti engellemeye yönelik etkin mekanizmalara sahip olmamasından ötürü sorumlu tutulmaktadır. (Sever, 2012: 41)

\section{Ayrımcılık Yasağı}

Opuz kararının diğer bir dikkat çekici yanı, kadına karşı ev içi şiddeti ayrımcılık yasağına ilişkin 14. madde bakımından da incelemesi ve bu maddenin de ihlal edildiğine karar vermesidir. Belirtmek gerekir ki kadına karşı her türlü şiddet ve devletin bu şiddete yeterli

müdahalede bulunmadığı her durum 14. maddeye aykırılık oluşturmayacaktır. (Örneğin 2010 tarihli bir başka kararında kadına karşı ev içi şiddet ve yetersiz devlet müdahalesi nedeniyle 2, 3 ve 8 den ihlal kararı vermişse de, Opuz davasından farklı olarak mahkemelerin pasif tutumu ve polisin meseleyi aile içi mesele olarak görme gibi unsurlar bulunmadığı için ayrımcılık olmadığı için 14. maddenin ihlal edilmediğine karar vermiştir.) (Sever, 2012:35)

Opuz kararında AİHM, kadınların o ülkede cinsiyetleri nedeniyle ayrımcılı̆̆a uğradığının tespiti konusunda geliştirdiği kriterler ile TC'deki durumu değerlendirmiştir: AİHM'e göre istatistikler tek başına ayrımcılığı tespit etmek konusunda yeterli delil oluşturmamakla birlikte, bir ülkede örneğin kadınlar ve erkeklerin durumuyla ilgili bir eşitsizliği tespit eden verilerin olması durumunda, bu verilerin ayrımcılık anlamına gelmediğini ispat etmek devlete düşecektir; aksi halde ispatı zaten zor olan dolaylı ayrımcılı̆̆ın ispatı imkânsız hale gelecektir.(Opuz v. Turkey, para180)

AİHM, ayrıca Türkiye'de kadına karşı şiddet konusunda ayrımcılık bulunduğu değerlendirmesi için Türkiye'deki çeşitli kuruluşların (Mor Çatı, Diyarbakır Barosu, Uluslar arası Af Örgütü vb) rapor, inceleme ve saha çalışmalarını dikkate alarak, kararında ayrıntılı biçimde bunlara yer vermiş ve bu raporları ayrımcılığa ilişkin bir gösterge olarak kabul etmiştir. $\mathrm{Bu}$ raporlardan hareketle, kadınların başvurduğu polislerin, meseleyi aile içi mesele olarak gördükleri ve kadınlara bu yönde telkinde bulunarak kimi zaman hiç müdahale etmedikleri ve 
benzer biçimde yargının da kadına karşı şiddette ayrımcı pasif tutum sergilediği, Ailenim Korunması Hakkındaki Kanunun uygulanmasında da önemli sorunlar yaşandığı vurgulanmıştır.(Opuz v. Turkey, para91-106, 194-196)

AİHM, yaptığı değerlendirmede ev içi şiddetin esas olarak kadınları etkilediği ve Devlet makamlarının genel ve ayrımcı pasifliklerinin ev içi şiddeti teşvik eden bir atmosfer yarattığı sonucuna varmıştır. Dolayısıyla Nahide Opuz ve annesine karşı gösterilen şiddetin, toplumsal cinsiyete dayalı bir şiddet olarak değerlendirilmesi ve kadına yönelik bir ayrımcılık biçimi oluşturduğunun kabul edilmesi gerektiği vurgulanmıştır.

\section{Sonuç Yerine}

Ayırt edici özellikleri nedeniyle kadına yönelik ev içi şiddetin önlenmesi için farklı koruma mekanizmalarının geliştirilmesi ve işletilmesi bir gerekliliktir. Bu mekanizmaların oluşturulabilmesi için her şeyden önce toplumsal cinsiyete duyarlı bir perspektif geliştirilerek, bu şiddetin altında yatan asıl faktörün erkek egemen toplumdaki eşitsiz güç ilişkilerinin olduğunun görülmesi gereklidir. Ev içi şiddet konusunda devletin rolü, diğer şiddet türlerinde olduğu gibi ceza hukuku aracılığıyla cezalandırma tehdidinin ötesinde olmak zorundadır. Ev içi şiddetin önlenmesi için devlet, kadının şiddete uğramasını engelleyecek önlemleri almanın yanı sıra, şiddete uğradığında ve şiddetten kaçtığında güvenliğini sağlamak üzere kadının korunmasını içeren önlemler almalı, hayatını sürdürebileceği maddi ve fiziki koşulların oluşturulması için gerekli önlemleri almalıdır. Sığınma evleri ve koruma tedbirleri bu noktada çok önemlidir.

Devletin özel alanda meydana gelen ev içi şiddet vakalarına kayıtsız kalması halinde; kişilerin sebep olduğu bu eylem devlet tarafindan meşrulaştırılan veya mazur görülen bir eyleme dönüşmekte dolayısıyla devletin sorumluluğunu gerektiren bir hal almaktadır. Aynı durum devletin kadına yönelik şiddetle mücadele konusunda gösterdiği siyasi irade ve 
kararlılığın, pratiğe dönüştürülemediği, siyasi iradedeki kararlılığın kamu gücünü kullanan kamu görevlileri tarafından desteklenmediği hallerde de söz konusudur. Her iki durumda da devlet, "devlet dışı aktörlerin" neden olduğu bu eylemlere toleranslı davrandığı, bu eylemleri meşrulaştırdığı ve özen yükümlülüğünü yerine getirmediği için sorumludur.(Doğan, 2016:116) Özen yükümlülüğü standardı, her şeyden önce kamusal-özel alan ayrımına karşı çıkması sebebiyle, kadına karşı şiddetin temelinde yatan ve ataerkil kültürden beslenen normlara karşı mücadeleyi kolaylaştıran bir niteliğe sahiptir. Özen yükümlülüğü bağlamında, her bir kadının insan haklarından ve temel hak ve özgürlüklerden erkeklerle eşit bir biçimde yararlanması ilkesini hayata geçirilebilmesi için, şiddetle mücadele amacıyla kurulan sistemin bütüncül, sistematik ve sürdürülebilir olması ve ayrıca uygulamada etkili bir biçimde işletilmesi zorunludur. Bu amaçla tüm toplumun, toplumsal cinsiyet eşitliğinin sağlanması ve ayrımcılığın önlenmesi konusunda bir dönüşüm sürecine tabi tutulması, şiddete neden olan ve ataerkil düşünceden beslenen yaygın düşünce kalıplarına ve geleneklere karşı çıkılması gereklidir. (Doğan, 2016:117)

\section{Kaynaklar}

Bakırc1, Kadriye (2015). “İstanbul Sözleşmesi”, Ankara Barosu Dergisi, C. 4, 133-204.

Doğan, Recep (2016). "Kadının Şiddete Karşı Korunmasında Devletin Özen Yükümlülüğü ve Uluslarars1 Standartlar”, Ankara Barosu Dergisi, C.2, 90-121.

Gürgey, Fatma İrem Çağlar \& Dericiler, Özge Yücel (2019). "Uluslarası İnsan Hakları Hukukunda Özen Yükümlülüğünün Dönüşümünün Bir Örneği Olarak CEDAW Komitesinin 35 Say1lı Tavsiye Kararı", Ankara Barosu Dergisi, C. 1, 232-266.

Köksal, Tuğçe Duygu (2018). "Kadına Karşı Şiddet ve Aile İçi Şiddet Vakalarında Devletin Pozitif Yükümlülükleri Üzerine Örnekler”, İsanbul Barosu Kadın Hakları Merkezi 8 Mart 2018 Özel Sayısı, 64-71.

Manjoo, Rashida (2013). "State Responsibility to act with Due Diligence in the Elemination of Violence against Women”, International Human Rights Law Review, C. 2, 240-265.

Meyersfeld, Bonita C. (2004). "Reconceptualizing Domestic Violence in International Law", Albany Law Review, C. 67, 371-426. 
Sever, D. Çiğdem (2012). "Kadına Karşı Ev İçi Şiddette Devletin Sorumluluğu ve Avrupa İnsan Hakları Mahkemesi'nin Opuz v. Türkiye Kararı”, Atılım Sosyal Bilimler Dergisi, C. 1 S. 2, 1946.

Uygur, Gülriz (2015). "İstanbul Sözleşmesi Işı̆̆ında Ailenin Korunması ve Kadına Karş1 Şiddetin Önlenmesine Dair Kanun'un Temel Yaklaşımı”, Şiddetin Cinsiyetli Yüzleri, der. Betül Yarar, İstanbul Bilgi Üniversitesi Yayınları, 193-210. 


\title{
SOCIAL WORK STUDENTS' ATTITUDES TOWARDS LGBTI+ INDIVIDUALS IN TERMS OF SEX: SAMPLE OF TRNC
}

\author{
Pakize KUTLU ${ }^{1}$ \\ Muallâ KÖSEOĞLU ${ }^{2}$
}

\begin{abstract}
The present study was conducted to determine social work students' who study in social work programmes in Turkish Republic of Northern Cyprus (TRNC), attitudes towards LGBTI+ individuals. One part of the research that is considered in this paper was focused on students' sex and their attitudes towards LGBTI+ individuals.

The study was consisted of 241 social work students who were studying at the 1st, $2 \mathrm{nd}$, 3rd and 4th grades of the European University of Lefke (EUL) and Near East University (NEU). The questionnaire consisted of two parts inwhich the first one had questions about sociodemographical feautures and the second one had a scale called "Hudson and Ricketts Homophobia Scale (HRHS)". This scale was developed by Hudson and Ricketts (1980) and it was adapted to Turkish language by Sakall and Ugurlu in 2001. Data collection upon completing of questionnaires was taken place in EUL and NEU among 241 social work students. The data were coded via SPSS version 20 and all missing data were excluded. Then data were analyzed and frequency tables was used for descriptive characteristics, while, Kolmogorov-Smirnov, Shapiro-Wilk and Mann-Whitney $U$ tests were used for advanced statistical anayses.

According to the results, it was determined that homophobia levels of the students differ according to sex. The Mann Whitney U test results showed that women's homophobia levels are lower than men's. When the literature was reviewed, it was also observed that women mostly make less negative statements about LGBTI + individuals comparing to men.
\end{abstract}

Keywords: Social Work, Attitudes towards LGBTI + Individuals, Homophobia

\footnotetext{
${ }^{1}$ Lect. Health and Social Sciences, University of Cyprus pkutlu8@gmail.com;

${ }^{2}$ Asst.Prof.Dr.- Faculty of Communication Sciences, New Media \& Journalism Department, European University of Lefke mkoseoglu@eul.edu.tr;
} 


\section{KKTC ÜNIVERSITELERININ SOSYAL HİZMT BÖLÜMLERINDE OKUYAN ÖĞRENCILERIN LGBTI+ BİREYLERE YÖNELIK TUTUMLARI: CINSIYYET ÜZERINNDEN BİR DEĞERLENDİRME}

\section{$\ddot{\text { Ozet }}$}

Araştırma, KKTC'de sosyal hizmet lisans programına devameden ögrencilerin LGBTI+ bireylere yönelik tutumlarının cinsiyet üzerinden değerlendirilmesi amacıyla yapılmıştır. Araştırmanin örneklemini, Lefke Avrupa Üniversitesi ve Yakın Doğu Üniversitesi’nde ögrrenim gören 1., 2., 3. ve 4. Sinıf toplam 241 sosyal hizmet bölümü öğrencisi oluşturmaktadır. Çalışmada veri toplamak amacıyla anket formu kullanılmıştır. Kullanılan anket formu iki bölümden oluşmaktadır. Birinci bölümde ögrencilerin sosyodemografik özelliklerini belirlemek için bazl sorulara yer verilmiştir. İkinci bölümde ise, Hudson ve Ricketts tarafindan geliştirilen ve Türkçe diline uyarlama çalışması 2001 yılında Sakallı ve Uğurlu tarafindan yapılan Hudson ve Ricketts Homofobi Ölçeği kullanılmıştır. Verilerin analizi, SPSS programı ile yapılmış olup araştırmada frekans dağılımı, Kolmogorov-Smirnov ve Shapiro-Wilk testleri ile Mann-Whitney Uve Kruskal Wallis testleri kullanılmıştır.

Elde edilen sonuçlara göre, cinsiyetin homofobik tutum geliştirmede önemli bir etkisi olduğu sonucuna ulaşılmıştır. Mann Whitney U test sonuçlarına bakıldığg zaman kadınların homofobi düzeylerinin erkeklere göre daha düşük olduğu görülmektedir. Literatür tarandığl zaman da genellikle kadınların erkeklere göre LGBTI+ bireylere yönelik daha az negatif söylemlerde bulunduğu görülmüş̧ür.

Anahtar Kelimeler: Sosyal Hizmet, LGBTI+ Bireylere Yönelik Tutum, Homofobi

\section{Giriş}

Sosyal Hizmet Uzmanları Uluslararası Federasyonu (IFSW, 2014) tanımına göre sosyal hizmet, sosyal değişim ve gelişmeyi, sosyal uyumu, insanların güçlenmesi ve özgürleşmesini teşvik eden uygulama temelli bir meslek ve akademik bir disiplindir. Sosyal adalet, insan hakları, ortak sorumluluk ve farklılıklara saygı, sosyal hizmetin esasları arasındadır. Sosyal hizmet alanında istenilen hedeflere ulaşılmada, sosyal hizmet uzmanlarının üstlenmiş oldukları rol ve sorumlulukları büyük önem taşımaktadır. Sosyal hizmet uzmanları, mesleki eğitim sürecinde kazandıkları bilgiyle birlikte işlerini oldukça özveriyle yapmak durumundadır çünkü hizmet sundukları kitleler hassas ya da kırılgan bireylerden oluşmaktadır. Sosyal hizmet uzmanları mesleklerini yasalardan güç alarak ve uygulamalarını da resmi politikalar doğrultusunda gerçekleştirmektedir (Danış, 2007). Sosyal hizmet mesleği toplumun 
dezavantajı bireylerine, sosyal adaletsizliğe ve baskıya maruz kalan, ayrımcı ve dişlayıcı tutum ile karşılaşan bireylere ve gruplara öncelik tanımaktadır. Çocuklar, yoksullar, yaşlılar, özel gereksinimli bireyler, LGBTI+ bireyler toplumun dezavantajlı grupları arasında gösterilmektedir (Selcik ve Güzel, 2016). Sosyal adaleti temel alan bir meslek grubu olarak sosyal hizmetin toplumsal cinsiyet eşitsizliklerine karşı mücadele etmesi ve bu yönde çözüm önerileri sunması gerekmektedir. Sosyal hizmet eğitimi ve uygulamalarına geç girmiş olan toplumun dezavantajlı gruplarından birisi de lezbiyen, gey, biseksüel, transseksüel, intersekseksüel, interseks ve queer (LGBTI+) bireylerdir.

Toplumlarda LGBTI+ bireylere yönelik farklı tepkiler ve yaklaşımlar söz konusu olsa da bazı toplumlar heteroseksüel olmayan cinsel yönelimlere karşı hoşgörü ve anlayış içindedir (Güney vd., 2004). Bazı toplumlarda ise heteroseksist anlayışın kabul görmesiyle homofobik tutumun güçlü olmasına bağlı olarak LGBTI+ bireylerin toplumdan yavaş yavaş izole oldukları görülmektedir. $\mathrm{Bu}$ bağlamda sosyal hizmet, çeşitli nedenler doğrultusunda ayrımcılıkla karşılaşan, ötekileştirilen ve güçlenme gereksinimi olan bireylere, gruplara psiko-sosyal destek sağlama ve geliştirme sorumluluğunu taşıyan, bunu mesleğin değeri olarak benimseyen bir alan olarak öne çıkmaktadır (Duyan vd., 2011). Bu nedenle, sosyal hizmet uzmanlarının LGBTI+ bireylere yönelik kişisel tutum ve davranışlarının farkında olmaları önemlidir. Alanda görev alacak sosyal hizmet uzmanlarının toplumsal cinsiyet, cinsel yönelim ve cinsiyet kimliği ile ilgili kişisel duygu, düşünce, tutum ve davranışlarının sosyal hizmetin mesleki değerleriyle çelişmemesi gerekmektedir.

Bireylerin sorunlarının çeşitliliğinden dolayı çeşitli müdahale düzeylerinde farklılaşan rol ve görevleri olan sosyal hizmet uzmanlarının, LGBTI+ bireylerle çalışmalarının mesleğin değer sisteminin sağladığı tutum ve bakış açısı nedeniyle önemli bir yardım ve destek etkisi yarattığı bilinmektedir. Ancak, sosyal hizmet uzmanlarının homofobik tutumlarının varlığı, müracaatçı sistemi içinde sağlıklı bir yardım bağı ve destek ilişkisinin kurulmasını 
engelleyecektir. Bu sebeple, sosyal hizmet uzmanlarının müracaatçı ya da meslektaşlarına karşı cinsiyetlerinden veya cinsel yönelimlerinden kaynaklı bir ayrım yapmak bir yana, var olan negatif ayrımcılığa karşı durmak, önlemek ve ayrımcılıkla karşılaşan bireylere destek olmak öncelikli görevleri arasında bulunmaktadır (IFSW, 2002). Dolayısıyla, mesleğe hazırlanan gençlerin farkındalığını artırmaya ilişkin çalışmalar çoğaltılarak, özellikle lisans eğitim programlarının gözden geçirilmesi yararlı olacaktır. Sosyal hizmet lisans ve önlisans programlarına devam eden öğrencilerin bazı sosyal hizmet uygulamalarında ve eğitim programlarında LGBTI+ bireylerle/müracaatçılarla karşılaşmalarına rağmen birçoğunun LGBTI+ bireylere yönelik olumsuz yaklaşımlarının olabileceği öngörülebilmekte ve bunun mesleğin gücünü etkileyeceğinden kaygı duyulmaktadır. Bu nedenle, Kuzey Kıbrıs Türk Cumhuriyeti'nde (KKTC) yer alan üniversitelerin sosyal hizmet bölümlerinde öğrenim gören öğrencilerin homofobik tutumlarına bakılmış ve cinsiyetin homofobik tutum geliştirmede önemli bir etken olduğu saptanmıştır.

\section{İnşa Edilen Erkeklik (Masculinity) ve Homofobi}

Toplumlarda heteroseksüelliğin yaygın olarak bireylere benimsetilmesi farklı cinsiyet kimliği ve cinsel yönelimi olan kişilerin görmezden gelinmelerine, temel hak ve özgürlüklerinden kısıtlanmalarına neden olmaktadır. Toplumsal normlar ve sosyal denetleme mekânizmaları ile birçok LGBTI+ bireyin insan hakları ihlaline maruz bırakıldığı, ayrımcı ve dışlayıcı bir biçimde toplumda yaşamaya sürüklendiği görülmektedir (Öztunalı Kayır, 2015). LGBTI+ bireylere yönelik temelde en yaygın olarak görülen tutumun ise homofobi olduğu görülmektedir. Homofobi kavramı, heteroseksüellik dışında farklı cinsel yönelimleri olan kişilere karşı duyulan olumsuz duygu ve düşüncelere bağlı tutum ve davranışların tamamı olarak nitelendirilmektedir. Kısaca LGBTI+ bireylere yönelik toplumda var olan nefret içerikli tutum ve davranışlar olarak tanımlanmaktadır (Biçmen ve Bekiroğulları, 2014). Homofobi kelimesi ilk olarak Weinberg tarafından 1972 yılında kullanılmaya başlanmıştır. Eşcinsellik 
anlamında kullanılan "homo" ile korku anlamını ifade eden "fobi” kelimelerinin birleşmesiyle oluşan kavram, eşcinsel bireylere yönelik korkuyu ifade etmektedir.

Erkeklik kavramı ise toplumsal, kültürel ve tarihsel koşulların bir ürünü; yani toplumsal bir inşadır. Zamana ve topluma bağlı olarak değişiklikler göstermektedir (Kimmel, 1997: 225). Bem (1974), erkeklik ve kadınlığın sosyalleşme süreci içerisinde gözlemleme, kategorileştirme ve ödül ya da cezalarla birlikte cinsiyet tipleştirme süreciyle birlikte içselleştirildiğini ifade etmektedir. Ayrıca, erkeklerin, erkekliklerini göstermek için daha baskıcı toplumsal normlarla yüzleştiğini ve erkeklik göstergesi olarak heteroseksüelliğin öne çıkarılıp eşcinselliğin aşağılandığı bir cinsiyet tipi ortaya çıtı̆̆gnı belirtmektedir (Bem, 1974: 157). Gilmore (1991) ise erkeklerin çocukluktan itibaren, erkek olmak, erkekliğini kanıtlamak için sürekli olarak toplum tarafından onaylanmış cinsiyet davranışları ile test edildiğini ve böylece erkekliğin biyolojik olmaktan çıkarak sosyal bir inşaya dönüştüğünü ifade etmektedir (Gilmore, 1991: 150-151). Yine Gilmore (1991), erkeklerin onlara atfedilen dölleyici, koruyucu ve geçindirici rollerle birlikte heteroseksüelliğin de dikte edildiği bir erkekliği benimsediğini söylemektedir.

Genel geçer bir erkeklik tanımlamasının mümkün olmamasına rağmen her toplumda erkek olmanın en önemli göstergelerinden biri kuşkusuz ki heteroseksüelliktir. Connell (2005) hegomonik erkeklik kavramını öne sürerek erkekler arasında varolan hiyerarşiye dikkati çekmekte ve bu hiyerarşik yapı içinde en alt düzeyde heteroseksüel olmayan erkekler olduğunu ifade etmektedir. Connell (2005), hegeomonik erkeklik içinde feminenliği çağrıştıran hiçbir özelliğin kabul edilmediğini ve eşcinsel erkeklerin ötekileştirilirek erkeklik piramitindeki en alt basamağa konumlandırıldığını savunmaktadır (Connell, 2005; 77-78). Bu bağlamda, güçlü erkekliğin temelini heteroseksüelliğin oluşturduğu ve bunu ispat etme biçimlerinden birisi olarak da heteroseksüel olmayan erkeklere karşı homofobik tutumların geliştirildiği hatta bazı durumlarda toplumsal cinsiyete dayalı şiddet ya da nefret suçlarının ortaya çıktığ görülmektedir. 


\section{Yöntem}

$\mathrm{Bu}$ çalışma Kuzey Kıbrıs Türk Cumhuriyeti (KKTC) üniversitelerinin Sosyal Hizmet bölümlerinde öğrenim gören öğrencilerin LGBTI+ bireylere yönelik tutumlarının cinsiyet üzerinden değerlendirilmesi amacıyla yapılmış tanımlayıcı bir çalışmadır. Araştırma modeli olarak tarama modeli kullanılmıştır. Araştırma evrenini KKTC'de yer alan üniversitelerin Sosyal Hizmet bölümlerinde öğrenim gören öğrenciler oluşturmaktadır. Araştırmanın örneklemini ise, sosyal hizmet lisans eğitimine 1. 2. 3. ve 4. sınıf öğrencileri oluşturmaktadır. Araştırmaya toplam 241 kişi katılmıştır.

Öğrencilerin LGBTI+ bireylere yönelik tutumlarının cinsiyet üzerinden belirlenmesinde, sosyo-demografik özelliklere ait soru formu ve Hudson ve Ricketts Homofobi Ölçeği olmak üzere 2 bölümden oluşan bir anket formu kullanılmıştır. Anket formunun sosyo-demografik özellikler bölümünde; araştırmaya dahil edilen öğrencilerin yaş, cinsiyet, cinsel yönelim, uyruk, medeni durum, öğrenim gördükleri sınıf gibi tanıtıcı özelliklerini içeren sorular yer almaktadır. Araştırmaya katılan öğrencilerin LGBTI+ bireylere yönelik tutumlarının belirlenmesinde orjinali 1980 yılında Hudson ve Ricketts tarafından geliştirilen ve Türkçe diline uyarlama çalışması 2001 yılında Sakallı ve Uğurlu tarafından yapılan Hudson ve Ricketts Homofobi Ölçeği kullanılmıştır. Hudson ve Ricketts Homofobi Ölçeği, "Hiç katılmıyorum=1 puan”, "Oldukça katılmıyorum=2 puan”, "Biraz katılmıyorum=3 puan”, "Biraz katılıyorum=4 puan”, “Oldukça katılıyorum=5 puan" ve "Çok katılıyorum=6 puan" şeklinde altılı derecelendirme kullanılarak yanıtlanan 24 maddeden oluşan bir ölçme aracıdır. Ölçekte bulunan 5-6-8-10-1113-17-18-23 ve 24 numaralı maddeler "Hiç katılmıyorum=6 puan" ve "Çok katılıyorum=1 puan” olacak şekilde ters puanlanmaktadır. Katılımcıların ölçekten alabilecekleri en düşük puan 24, en yüksek puan ise 144'tür. Hudson ve Ricketts Homofobi Ölçeğinden alınacak olan puanın yüksek olması, katılımcının LGBTI+ bireylere yönelik tutumlarının olumsuz olduğunu göstermektedir. 
Araştırma bulgularında değinilen istatistiksel analizler Statistical Package for Social Sciences (SPSS) yazılımı kullanılarak gerçekleştirilmiştir.

Öğrencilerin sosyodemografik özelliklerinin dağılımının saptanması için frekans analizi uygulanmıştır. Öğrencilerin Hudson ve Ricketts Homofobi Ölçeği'ndeki önermelerden ve ölçek genelinden aldıkları puanlara ait betimleyici istatistikler (ortalama, std. sapma) verilmiştir. Öğrencilerin bazı özelliklerine göre Hudson ve Ricketts Homofobi Ölçeği puanlarının karşılaştırmak için kullanılan hipotez testlerine ölçek puanlarının normal dağılıma uyumuna bakılarak karar verilmiştir. Normal dağılıma uyum Kolmogorov Smirnov ve Shapiro-Wilk testleri kullanılarak incelenmiş ve öğrencilerin Hudson ve Ricketts Homofobi Ölçeği puanlarının normal dağılıma uyumlu olmadığı belirlenmiştir. Buna göre öğrencilerin cinsiyetine, uyruğuna, medeni durumuna, göre Hudson ve Ricketts Homofobi Ölçeği puanlarının karşılaştırılmasında Mann-Whitney U testi kullanılmıştır. Öğrencilerin yaşlarına, aile yapısına ve sınıflarına göre Hudson ve Ricketts Homofobi Ölçeği puanlarının karşılaştırılmasında Kruskal-Wallis testi uygulanmıştır.

\section{Bulgular}

Araştırmanın bulguları değerlendirildiğinde, öncelikle Tablo-1'de katılımcıların sosyo demografik özelliklerinin yer aldığg görülmektedir.

Tablo-1 incelendiğinde, araştırma kapsamına alınan öğrencilerin \%51,04’ünün 20-21 yaş, \%37,34'ünün 22 yaş ve üzeri, \%11,62'sinin ise 18-19 yaş arasında olduğu görülmektedir. Katılımcılardan \%55,19’u kadın, \%44,81'i ise erkektir. Kat1lımc1ların \%89,63'ünün TC uyruklu, \%10,37'sinin KKTC uyruklu olduğu görülmektedir. Öğrencilerin medeni durumu incelendiğinde, \%75,10'unun bekar, \%23,65'inin ilişkisi olan ve yalnızca \%1,24'ünün evli olduğu tespit edilmiştir.

Aile yapıları açısından değerlendirildiğinde, \%70,54'ünün çekirdek aile yapısı, $\% 24,07$ 'sinin geniş aile yapısı, \%5,39'unun ise tek ebeveynli bir aile yapısına sahip olduğu 
görülmektedir. Lisans eğitimine devam eden katılımcıların, \%34,02'sinin IV. Sınıf, \%29,88'inin III. Sınıf, \%23,65'inin II. Sinıf ve \%12,45'inin I. Sınıfa devam etmekte olan öğrencilerden oluştuğu görülmüştür.

Tablo 1. Öğrencilerin sosyodemografik özelliklerinin dağılımı $(n=241)$

\begin{tabular}{lrr}
\hline & Sayı (n) & Yüzde (\%) \\
\hline Yaş grubu & 28 & 11,62 \\
18-19 yaş & 123 & 51,04 \\
$20-21$ yaş & 90 & 37,34 \\
22 yaş ve üzeri & & \\
\hline Cinsiyet & 133 & 55,19 \\
Kadın & 108 & 44,81 \\
Erkek & & \\
\hline Uyruk & 25 & 10,37 \\
KKTC & 216 & 89,63 \\
TC & & \\
\hline Medeni durum & 181 & 75,10 \\
Bekar & 57 & 23,65 \\
İlişkisi var & 3 & 1,24 \\
Evli & & \\
Aile yapısı & 170 & 70,54 \\
Çekirdek & 13 & 5,39 \\
Tek ebeveynli & 58 & 24,07 \\
Geniș & & \\
\hline Sinıf & 30 & 12,45 \\
I. Sınıf & 57 & 23,65 \\
II. Sınıf & 72 & 29,88 \\
III. Sınıf & 82 & 34,02 \\
IV. Sınıf & & \\
\hline Cinsel yönelim & 235 & 0,83 \\
Heteroseksüel & 4 & \\
Eşcinsel & 2 & \\
Biseksüel & & \\
\hline
\end{tabular}

Tablo-2'de ise öğrencilerin cinsiyetlerine göre Hudson ve Ricketts Homofobi Ölçeği’nden almış oldukları puanlar yer almaktadır. Bu bulgu değerlendirildiğinde, cinsiyetlere göre Hudson ve Ricketts Homofobi Ölçeği toplam puanları arasında istatistiksel olarak anlamlı fark olduğu tespit edildiği görülmüştür $(\mathrm{p}<0,05)$. Erkek öğrencilerin $(\bar{x}=87,69 \pm 24,83)$ Hudson ve Ricketts 
Homofobi Ölçeği toplam puanları, kadın öğrencilerin $(\bar{x}=66,61 \pm 22,05)$ ölçekten almış oldukları toplam puandan istatistiksel olarak anlamlı düzeyde yüksek bulunmuştur.

Tablo 2. Öğrencilerin cinsiyetlerine göre Hudson ve Ricketts Homofobi Ölçeği toplam puanlarının karşılaştırılması $(n=241)$

\begin{tabular}{cccccccc}
\hline Cinsiyet & $\mathbf{n}$ & $\overline{\boldsymbol{x}}$ & $\mathbf{s}$ & $\mathbf{M}$ & $\mathbf{S O}$ & $\mathbf{Z}$ & $\mathbf{p}$ \\
\hline Kadın & 133 & 66,61 & 22,05 & 65,00 & 95,76 & \multirow{2}{*}{$-6,239$} & \multirow{2}{*}{$0,000^{*}$} \\
Erkek & 108 & 87,69 & 24,83 & 85,00 & 152,09 & & \\
\hline
\end{tabular}
$*_{p}<0,05$

Elde edilen bulgular incelendiğinde öğrencilerin homofobi düzeylerinin cinsiyete göre farklılaştığı görülmüştür. Tabloda sunulan Mann Whitney U test sonuçları, kadınların homofobi düzeylerinin erkeklerinkine göre daha düşük olduğunu göstermektedir. Literatür geneline bakıldığı zaman da LGBTI+ bireylere yönelik yapılan söylemlerde kadınların çoğunlukla erkeklerden daha az olumsuz açıklamalarda bulundukları gözlenmiştir. Kadınların LGBTI+ bireylere yönelik bakış açıları erkek bireylere göre olumlu ve yapıcı olduğu gözlenmiştir. Bu da kadınların erkeklere göre daha düşük homofobi düzeylerine sahip oldukları yönündeki bulguyu tutarlı kılmaktadır. Erkeklerin toplumsal cinsiyet rollerinin dışında farklı davranışlar gösteren bireylere karşı olumsuz tutumlar beslediği literatür taramalarında gözlenmiştir. Bununla birlikte, erkeklerin yüksek düzeydeki homofobi tutumları hegemonik erkeklikle de açıklanmaktadır. Hegemonik erkeklik, ataerkil düzenin içinde var olan erkeklik biçiminin diğer erkeklik biçimleri üzerinde hegemonya oluşturması ve ötekileştirmesini ifade etmektedir (Akca ve Ergül, 2014). Hegemonik erkeklik, kadın ve erkek rollerinin karşılıklı ilişkisini ve biçimini tanımlayan erkeklerarası ilişkilerin ana temelini oluşturmaktadır. Bu noktada, erkekler arasında da bir hiyerarşinin olduğunu belirten Connell, bu hiyerarşik yapı içinde en alt düzeyde heteroseksüel olmayan erkekler olduğunu ifade etmekte ve bu erkeklerin ötekileştirildiğini belirtmektedir (Connell, 1998). Bu bağlamda, güçlü erkekliğin temelinin heteroseksüellik 
olduğu ve bunu ispat etme biçimlerinden birisi olarak da heteroseksüel olmayan erkeklere karş1 homofobik tutumların geliştirildiği görülmektedir.

Tablo-3 incelendiğinde, araştırmaya dahil olan öğrencilerin yaş gruplarına göre Hudson ve Ricketts Homofobi Ölçeği toplam puanları arasında istatistiksel olarak anlamlı fark olmadığı tespit edilmiştir ( $\mathrm{p}>0,05)$. 18-19 ve 20-21 yaş arası yaş grubuna mensup öğrencilerin ölçek genel puanları, 22 yaş ve üzeri yaş grubuna mensup öğrencilerin puanlarından daha yüksek hesaplanmasına karşın aralarındaki fark istatistiksel olarak anlamlı düzeyde değildir.

Tablo 3. Öğrencilerin yaş gruplarına göre Hudson ve Ricketts Homofobi Ölçeği toplam puanlarının karşılaştırılması $(\mathbf{n}=\mathbf{2 4 1})$

\begin{tabular}{lccccccc}
\hline \multicolumn{1}{c}{ Yaş grubu } & $\mathbf{n}$ & $\overline{\boldsymbol{x}}$ & $\mathbf{S}$ & $\mathbf{M}$ & $\mathbf{S O}$ & $\mathbf{X}^{\mathbf{2}}$ & $\mathbf{p}$ \\
\hline 18-19 yaş & 28 & 76,82 & 26,97 & 84,00 & 125,34 & 1,509 & 0,470 \\
20-21 yaş & 123 & 77,71 & 25,65 & 77,00 & 125,24 & & \\
22 yaş ve üzeri & 90 & 73,57 & 25,04 & 72,00 & 113,86 & & \\
\hline
\end{tabular}

Tablo-4 incelendiğinde, araştırmaya dahil olan öğrencilerin uyruklarına göre Hudson ve Ricketts Homofobi Ölçeğinden almış oldukları puanlar arasında istatistiksel olarak anlamlı fark olmadığ1 görülmüştür $(\mathrm{p}>0,05)$. TC ve KKTC uyruklu öğrencilerin ölçek genelinden almış oldukları puanlar benzerdir. Ataerkil yapının Türkiye'de daha yoğun görüldüğü düşüncesinin de burada doğrulanmadığı görülmektedir. KKTC uyruklu öğrencilerin ölçekten almış oldukları puan ortalamasının azımsanmayacak düzeyde olması, Kuzey Kıbrıs'ta da aterkillik ve bağlamında gelişen hegomonik erkekliğin ileri düzeyde olduğuna işaret etmektedir.

Tablo 4. Öğrencilerin uyruklarına göre Hudson ve Ricketts Homofobi Ölçeği toplam puanlarının karşılaştırılması $(n=\mathbf{2 4 1})$

\begin{tabular}{cccccccc}
\hline Uyruk & $\mathbf{n}$ & $\overline{\boldsymbol{x}}$ & $\mathbf{S}$ & $\mathbf{M}$ & $\mathbf{S O}$ & $\mathbf{Z}$ & $\mathbf{p}$ \\
\hline KKTC & 25 & 69,64 & 25,43 & 71,00 & 105,66 & $-1,162$ & 0,245 \\
TC & 216 & 76,80 & 25,51 & 74,50 & 122,78 & & \\
\hline
\end{tabular}


Tablo-5 incelendiğinde, katlımcıların medeni durumlarına göre Hudson ve Ricketts Homofobi Ölçeğinden aldıkları puanlar arasında istatistiksel olarak anlmalı fark bulunamamıştır $(\mathrm{p}>0,05)$. Evli/ ilişkisi olan katılımcıların ölçek genelinden almış oldukları puan ortalaması, bekar katılımcıların puan ortalamasından daha yüksek hesaplanmasına karşın aralarındaki fark istatistiksel olarak anlamlı düzeyde değildir.

Tablo 5. Öğrencilerin medeni durumlarına göre Hudson ve Ricketts Homofobi Ölçeği toplam puanlarının karşılaştırılması $(n=241)$

\begin{tabular}{cccccccc}
\hline Medeni durum & $\mathbf{n}$ & $\overline{\boldsymbol{x}}$ & $\mathbf{S}$ & $\mathbf{M}$ & SO & $\mathbf{Z}$ & $\mathbf{p}$ \\
\hline Bekar & 181 & 77,60 & 24,48 & 76,00 & 125,94 & \multirow{2}{*}{0,912} & 0,056 \\
İlişkisi var/Evli & 60 & 71,40 & 28,24 & 66,00 & 106,09 & & \\
\hline
\end{tabular}

Tablo-6 incelendiğinde, araştırmaya dahil olan öğrencilerin aile yapılarına göre Hudson ve Ricketts Homofobi Ölçeği puanları arasında istatistiksel olarak anlamlı fark olmadığı görülmüştür ( $p>0,05)$. Tek ebeveynli ailede yaşamış öğrencilerin ölçek genelinden almış oldukları puan ortalaması, çekirdek ve geniş ailede yaşamış öğrencilerin puan ortalamasından daha yüksek bulunmasına karşın aralarındaki fark istatistiksel olarak anlamlı düzeyde değildir. 
Tablo 6. Öğrencilerin aile yapılarına göre Hudson ve Ricketts Homofobi Ölçeği toplam puanlarının karşılaştırılması $(n=241)$

\begin{tabular}{cccccccc}
\hline Aile yapısı & $\mathbf{n}$ & $\overline{\boldsymbol{x}}$ & $\mathbf{S}$ & $\mathbf{M}$ & $\mathbf{S O}$ & $\mathbf{Z}$ & $\mathbf{p}$ \\
\hline Çekirdek & 170 & 76,27 & 25,25 & 76,00 & 122,00 & 0,124 & 0,940 \\
Tek ebeveynli & 13 & 77,15 & 27,81 & 71,00 & 119,85 & & \\
Geniş & 58 & 75,19 & 26,35 & 71,50 & 118,33 & & \\
\hline
\end{tabular}

Tablo-7, incelendiğinde, araştırma kapsamına alınan öğrencilerin sınıflarına göre Hudson ve Ricketts Homofobi Ölçeği puanları arasında istatistiksel olarak anlamlı fark olduğu saptanmıştır $(\mathrm{p}<0,05)$. I. sınıf olan öğrencilerin $(\bar{x}=82,80 \pm 28,06)$ ölçek genelinden aldıkları puanlar, IV . sınıf olan öğrencilerin $(\bar{x}=69,17 \pm 24,12)$ puanlarından istatistiksel olarak anlamlı düzeyde yüksek bulunmuştur. Literatürde yapılan gözlem sonucunda da sınıf düzeyi arttıkça LGBTI+ bireylere yönelik tutumlarının olumlu yönde arttığı ve homofobi düzeylerinin de düştüğü gözlenmiştir. Eğitim seviyesinde yaşanan artışın LGBTI+ bireylere yönelik tutumu olumlu yönde etkilediği gözlenmiştir.

Tablo 7. Öğrencilerin sınıflarına göre Hudson ve Ricketts Homofobi Ölçeği toplam puanlarının karşılaştırılması $(n=241)$

\begin{tabular}{ccccccccc}
\hline Sinıf & $\mathbf{n}$ & $\overline{\boldsymbol{x}}$ & $\mathbf{S}$ & $\mathbf{M}$ & $\mathbf{S O}$ & $\mathbf{Z}$ & $\mathbf{p}$ & Fark \\
\hline I. Sinıf & 30 & 82,80 & 28,06 & 85,00 & 139,37 & 10,045 & $0,018^{*}$ & $1-4$ \\
II. Sinıf & 57 & 79,12 & 27,95 & 76,00 & 126,84 & & & \\
III. Sinıf & 72 & 78,67 & 22,72 & 79,00 & 130,56 & & & \\
IV. Sinıf & 82 & 69,17 & 24,12 & 66,00 & 101,82 & & & \\
\hline
\end{tabular}
$* p<0,05$

Elde edilen bulgular incelendiğinde, araştırma kapsamına alınan 1.,2.,3. ve 4. Sınıf sosyal hizmet öğrencilerinin, homofobi düzeyinin sınıf atlandıkça azaldığının görülmesidir. Birçok araştırmada yaş ve sınıf düzeyi arttıkça azalması beklenen homofobi düzeyinin bu çalışmada da benzer bir sonucu verdiği ortaya çıkmıştır. Literatür taramasında da benzer 
sonuçların olduğu görülmektedir. Sakallı-Uğurlu tarafından aktarılan, Göregenli ve Erel'in, yaptıkları araştırmada, bireylerin yaşlarının arttıkça ve üst sınıflara geçtikçe, homofobi düzeylerinin azaldığı öne sürülmektedir (Sakallı-Uğurlu, 2006). Bu bağlamda, alınan eğitim doğrultusunda öğrencilerin önemli ölçüde farkındalık kazandığı ve LGBTI+ bireylere yönelik homofobik tutumlarının azaldığı ortaya çıkmaktadır.

\section{Sonuç}

Yapılan araştırmada, KKTC üniversitelerinde sosyal hizmet lisans eğitimine devam eden öğrencilerin, LGBTI+ bireylere yönelik tutumları ölçülerek cinsiyet üzerinden etkisi olup olmadığına bakılmıştır. Araştırma sonucunda cinsiyetin homofobik tutum üzerinde etkisi olduğu sonucuna ulaşılmıştır. Kadın ve erkek öğrenciler karşılaştırıldığı zaman, erkek öğrencilerin homofobik tutum ölçeğinden aldıkları puanın, kadın öğrencilere kıyasla daha yüksek olduğu görülmüştür. Literatür tarandığı zaman yapılan araştırmalar da bu bulguyu desteklemektedir. Şah'ın 2009 yılında Ankara ve İstanbul'da yaşayan üniversite öğrencileri ve mezunları arasından toplam 362 kişi ile gerçekleştirdiği bir araştırmada, homofobi düzeyinin cinsiyetle ilişkili olduğu gözlenmiştir. Aynı araştırmada, erkeklerin homofobi düzeylerinin kadınlarınkine göre daha yüksek olduğu ve eşcinsellik, biseksüellik ve transseksüellik ile alakalı yapılan tanımlamalarda, erkeklerin olumsuz açıklamalarının kadınlara göre daha fazla olduğu saptanmıştır. Bu bulguyu destekleyen bir diğer araştırma ise 2006 yılında Anadolu bölgesinde bulunan iki farklı üniversitede öğrenim gören 168 kadın ve 147 erkek öğrenci ile gerçekleştirilmiştir. Türkiye'de üniversite öğrencilerinin lezbiyen ve gey erkeklere karşı tutumlarının değerlendirildiği araştırmada, kadın öğrencilerin erkeklere göre eşcinselliğe daha olumlu baktığı bulunmuş ancak LGBTI+ bireylere yönelik yaklaşımın yine de geleneksel toplumsal cinsiyet rolleri etkisinde kaldığı ifade edilmiştir (Gelbal ve Duyan, 2006). Çırakoğlu'nun (2006), 334 üniversite öğrencisi ile gerçekleştirdiği bir diğer araştırmada, kadın bireylerin erkeklere göre eşcinsel ve biseksüel bireylere yönelik daha olumlu tutumlar 
sergilediği saptanmıştır. Uluslararası alanyazın tarandığında, Harbaugh ve Lindsey tarafından 2015 yılında Northeastern Üniversitesi'nde 194 lisans öğrencisi ile yürütülen araştırma, bireylerin kendi cinsiyetlerinden olan eşcinsel bireylere karşı daha olumsuz tutum ve davranışlar beslediklerini, bununla birlikte de erkeklerin, kadınlara oranla kendi cinsiyetinden eşcinsellere karşı daha fazla olumsuz tutuma sahip olduklarını göstermiştir. KKTC'de yürütülen bu araştırmada da, ulaşılan erkek öğrencilerin yüksek düzeydeki homofobi tutumlarının, literatürde yer alan diğer çalışmalarla paralellik gösterdiği gözlenmektedir.

Sosyal hizmet uzmanlarının, müracaatçı grubun kim veya kimlerden oluştuğuyla ilgilenmeksizin psikososyal destek sağlamaları gerekmektedir. Birçok ders kitabı ve sosyal hizmet eğitimlerinde de sosyal hizmet uzmanlarının müracaatçı olarak başvuran kişilerin din, dil, ırk, cinsiyet, cinsel yönelim ve yaş ayrımı yapmaksızın destek vermesi gerektiği savunulmaktadır. İkinci olarak sosyal adaleti ve insan haklarını savunmayı benimseyen sosyal hizmet mesleğinin, öğrencilere, , müracaatçılara, uygulamacılara ve topluma homofobik olmayan bir bakış açısı kazandırması önem teşkil etmektedir. Bu bulguda öne çıkan sorun, sosyal hizmet eğitimi alan öğrencilerin belli bir kısmının mesleğin temel ilkesine aykırı bir görüşü benimsemeleridir. Sosyal hizmet eğitiminde yer alan eksikliklerin saptanması ve düzeltilmesi için gerekli adımların atılması, meslek elemanı yetiştirilmesi noktasında hayati öneme sahiptir. Krieglstein (2003) ve Snively ve diğerlerinin (2004) yapmış oldukları bir diğer araştırmada, sosyal hizmet öğrencilerinin yüksek düzeyde heteroseksist tutuma sahip oldukları ve homofobik tutumlar sergiledikleri gözlenmektedir (Akt:Tucker ve Tripodi, 2006). KKTC'de yürütülmüş olan bu araştırmada da benzer sonuçlar ortaya çıktığı görülmektedir. Öğrenciler sosyal hizmet eğitimleri sırasında LGBTI+ bireylerle ilgili mesleki uygulamalar konusunda yeterince yer verilmediği ve var olan önyargıyı azaltmak için bir çaba gösterilmediği görülmektedir. Toplumda LGBTI+ bireylere yönelik alg1 ve tutumun olumsuz bir hal almasının temel nedenleri arasında toplumsal cinsiyete dayalı değerler, normlar, kurallar ve ataerkil 
yapının etkisiyle oluşan heteroseksist algının aktarılmasıdır. Aktarılan bu algının üniversite eğitimi alan öğrencileri de doğrudan etkilediğini söylemek mümkündür. Savunuculuk ve adalet rollerini temel alan bilgi ve hizmet üreten sosyal hizmet mesleğinin, LGBTI+ bireylere yönelik de bilgi ve hizmet modelleri sunması gerekmektedir. Bununla birlikte, cinsiyet kimliği ve cinsel yönelim eşitsizliklerini azaltarak, LGBTI+ bireylerin bire bir yaşamış oldukları sorunlara müdahale edecek bir sosyal hizmet yaklaşımının devreye sokulması bu konuda atılacak önemli bir adım olacaktır.

Sonuç olarak, araştırmada elde edilen bulguların sosyal hizmet eğitim programlarının geliştirilmesine yönelik farkındalık kazandırması öngörülmektedir. Her türlü ayrımcılığın karşısında olması gereken sosyal hizmet eğitimi alan öğrencilerin farkındalık düzeylerini mümkün olduğunca geliştirmek önem teşkil etmektedir. Bunun için sosyal hizmet eğitimi müfredatlarına LGBTI+ bireylerin spesifik olarak içinde yer aldığı toplumsal cinsiyet eşitliği dersi mutlaka eklenmelidir. Bunun yanında, sosyal hizmet eğitim müfredatlarında yer alan kuram ve etik derslerinde öğrencilere özellikle insan hakları, farklılıklara saygı ve kendi kaderini belirleme hakkı gibi insani ve mesleki değerlere ilişkin bilgilerin ve farkındalıkların aktarılmasıdır. Üniversite ortamında, dersler dışında öğrencilerin konuyla ilişkili farkındalık düzeylerini artırıcı etkinlikler (film/belgesel gösterimleri, söyleşi, seminer, atölye çalışmaları vb.) düzenlenmesi de öneriler arasında yer almaktadır. Elbette ki yalnızca üniversite ortamında veya eğitim programlarında gerçekleştirilen yapılandırmalar heteroseksist ataerkil sistemle mücadelede yeterli olmayacaktır. Toplumdaki farkındalığı artırmak için çeşitli kamu spotları, bilgilendirme afişleri eğitimlerinin düzenlenmesi önerilmektedir. Bununla birlikte, ancak kullanılan dilden medyaya, siyasetten sanat ve spora kadar her alanda makro düzeyde bir mücadele gerçekleştirerek LGBTI+ bireylerin eşit hak ve özgürlüklere ulaşması mümkün olacaktır. Bu noktada da, savunuculuk rolü gereği sosyal hizmet uzmanlarının bu mücadelede 
yer alarak lobicilik çalışmaları yapması ve sosyal politikaların oluşturulmasında aktif olması arzulanmaktadır.

\section{Kaynaklar}

Akca, E. B. ve Ergül, S. (2014). Televizyon dizilerinde erkeklik temsili: Kuzey güney dizisinde hegemonik erkeklik ve farklı erkekliklerin mücadelesi. Global Media Journal: Turkish Edition, 4(8).

Bem, S. L. (1974). The measurement of psychological androgyny. Journal of Consulting and Clinical Psychology, 42(2), 155-162.

Biçmen, Z. ve Bekiroğulları, Z. (2014). Social problems of LGBT people in Turkey. ProcedioSocial and Behavioral Sciences, 113, 204-233.

Connell, R.W. (2005). Masculinities (Second Edition). USA: University of California Press.

Çırakoğlu, O. C. (2006). Perception of homosexuality among Turkish university students: The role of labels, gender, and prior contact. The Journal of Social Psychology, 146(3), 293-305.

Danış, M. Z. (2007). Sosyal hizmet mesleği ve disiplininde sosyal politikanın yeri ve önemi. Toplum ve Sosyal Hizmet Dergisi, 2(18), 51-64.

Duyan, V., Tuncay, T., Sevin, Ç. ve Erbay, E. (2011). Sosyal hizmet öğrencilerinin eşcinselliğe yönelik tutumları: Bir atölye eğitiminin etkileri. Toplum ve Sosyal Hizmet, 22(2), 7-18.

Gelbal, S. ve Duyan, V. (2006). Attitudes of university students toward lesbians and gay men in Turkey. Sex Roles, 55(7-8), 573-579.

Gilmore, D. (1991). Manhood in the Making: Cultural Concepts of Masculinity.USA: Yale University Press.

Güney, N., Karg1, E. ve Çorbacı-Oruç, A. (2004). Üniversite öğrencilerinin eşcinsellik konusundaki görüşlerinin incelenmesi. Turkish Journal of HIV/AIDS, 7, 131-137.

Harbaugh, E. ve Lindsey, E. W. (2015). Attitudes toward homosexuality among young adults: Connections to gender role identity, gender-typed activities, and religiosity. Journal of Homosexuality, 62(8), 1098-1125.

IFSW. (2014). Global agenda for social work and social development. First Report, 3-16. International Federation of Social Workers. (2002). Draft document: Ethics in social work statement of principles. Geneva: IFSW General Meeting.

Kimmel, M. S. (1997). Masculinity as homophobia: Fear, shame and silence in the construction of gender identity. In M. M. Gergen \& S. N. Davis (Eds.), Toward a new psychology of gender (pp. 223-242). 
Öztunalı Kayır, G. (2015). Sosyolojik değerlendirme: Lgbt bireyler açısından cinsiyet kimlikleri meselesi. Eğitim Bilim Toplum, 13(51), 73-97.

Sakallı, N. ve Uğurlu, O. (2006). Eşcinsellere ilişkin tutumlar: Türkiye'de yapılan görgül çalışmalar. Türk Psikoloji Yazlları, 9(17), 53-69.

Selcik, O. ve Güzel, B. (2016). Sosyal hizmet mesleğinin çalışma alanı ve sosyal hizmet uygulamasının Türkiye ölçeğinde değerlendirilmesi. Journal of International Social Research, 9(46).

Şah, U. (2009). Türkiye'deki Gençlerin Cinsel Yönelimlere İlişkin Sosyal Temsilleri Ve Homofobi, Yüksek Lisans Tezi, Ankara Üniversitesi Sosyal Bilimler Enstitüsü.

Tucker, E. W. ve Potocky-Tripodi, M. (2006). Changing heterosexuals' attitudes toward homosexuals: A systematic review of the empirical literature. Research on Social Work Practice, 16(2), 176-190. 


\title{
NATURE AND WOMEN DESCRIPTIONS IN THE WORKS OF WOMEN PAINTERS OF PRE-RAPHAELITE MOVEMENT
}

\author{
Seda AĞIRBAŞ ${ }^{1}$
}

\begin{abstract}
The aim of this study, which is the nature-woman descriptions in the works of women painters, is the position of women painters who took part in the development of this movement that emerged in 19th century Victoria England.

In the first part of the research, the development of Pre-Raphaelite movement, the male artists gathered around the stream and the female artists participating in the period of the period will be explained. In the second part, woman painters such as Elizabeth Siddal, Emma Sandys, Lucy Madox Brown will be evaluated in the context of the nature-woman relationship. This study will focus on two different perspectives. The works of women artists will be compared with the works of the male artists in the current, and the approach of women to the women's theme will be discussed.

As a result, in the Victorian period where the strict and traditional attitude was adopted, the social rights and freedoms of women painters who rebelled against authority will be exhibited in line with their artistic approaches.
\end{abstract}

Keywords: Pre-Raphaelite Brotherhood, Woman Painters, Women and Nature.

\footnotetext{
${ }^{1}$ Dr. Lect. Ege University, Bergama Vocational School sedaagirbas@gmail.com;
} 


\section{ÖN RAFAELLOCULUK AKIMI (PRE-RAPHAELITE BROTHERHOOD) KADIN RESSAMLARIN ESERLERINDE DOĞA-KADIN BETIMLEMELERİ}

\section{$\ddot{O}_{z e t}$}

Ön Rafaelloculuk akımı kadın ressamlarının eserlerinde doğa-kadın betimlemeleri başlıklı bu çalışmanın amacı, 19. Yüzyıl Victoria İniltere 'sinde ortaya çıkan bu hareketin gelişiminde yer alan kadın ressamların konumuna değinmektir.

Araştırmamın ilk bölümünde Ön Raffaelloculuk hareketinin gelişimi, akımın çevresinde toplanan erkek sanatçılar ve ardından dönem dönem akıma katılan kadın sanatçılar anlatılacaktır. İkinci bölümünde ise Elizabeth Siddal, Emma Sandys, Lucy Madox Brown gibi kadın ressamların eserlerinde doğa-kadın ilişkisi bă̆lamında kadın betimlemeleri değgerlendirilecektir.

Bu çalışmada farklı iki bakış açısı üzerinde durulacaktır. Kadın sanatçıların yapıtları, akımın içinde yer alan erkek sanatçıların eserleriyle karşılaştırılacak, bir diğer açıdan sanatçı olarak kadınların kadın temasına yaklaşımları ele alınacaktır.

Sonuçta katı ve geleneksel tutumun benimsendiği Victoria döneminde otoriteye başkaldıran kadın ressamların sahip oldukları sosyal hak ve özgürlükleri, paralelinde ortaya koydukları sanatsal yaklaşımları sergilenecektir.

Anahtar Kelimeler: Ön Rafaelloculuk Akımı, kadın ressamlar, kadın ve doğa.

\section{Giriş}

Viktorya dönemi, İngiltere'nin Kraliçe Viktorya tarafından yönetildiği 1837'den 1901'e kadar olan dönemi kapsamaktadır. 19. yüzyılda gittikçe büyüyen İmparatorluk, yüzyılın ilk yarısında taç giyen Viktorya ile hem ekonomik hem de kültürel alanda büyük değişimleri gerçekleştirmiştir. İngiltere bu yüzyılda, hızlı sanayileşme sonucu köyden kente göç, işsizlik, yeni sınıfların ortaya çıkması, salgın hastalıklar ve genç ölümler gibi toplumsal sorunlarla uğraşmıştır. Büyüyen ekonomi karşısında ortaya çıkan bir takım adaletsizlikler, sınıf ayrımı ve eşitsizlikler özellikle toplum yapısında meydana gelen değişimleri önemli ölçüde etkilemiştir. İşçi ve aristokrat sınıf arasındaki uçurum gitgide büyümüş ve kentlerde yoksullaşan halkın yaşamı kötüleşmiştir (Tanilli, 1999: 20-22). 
Çalışma alanları olarak fabrika ve maden ocaklarının tehlikeli ve sağlıksız oluşu, çalışma saatleri veya ücretlerin yetersizliği ve kuralların olmayışı işçileri olumsuz yönde etkilemiştir. Halkın reform istemesi üzerine birtakım yasalar çıkarılmıştır. Böylece madenlerde ve fabrikalarda çocukların çalıştırılması durdurulmuş, işçi çalışma saatleri ve iş güvenliğiyle ilgili düzenlemeler getirilmiştir (Mitchell, 2009: 40-41).

Kadınlar açısından da bazı değişikliklerin olduğu bu dönemde, yapabilecekleri meslekleri sınırlı olan kadınların bir kısmı genelde evde çocuk bakımı ve ev işleri yaparken bir kısmı da öğretmenlik ve hemşirelikle uğraşmıştır. Bu dönemde kadınların oy kullanamama gibi siyasi haklardan yoksun olmalarının yanı sıra evlenme ve boşanma konularında da çok az hak ve özgürlüğe sahip oldukları görülür; ancak yüzyılın sonuna doğru çıkarılan bir yasayla mülkiyet hakkı kazanırlar (Shanley, 1989: 8).

Bu yüzyılda sosyal, ekonomik ve kültürel değişimler, İngiltere toplumu üzerinde önemli izler bırakmıştır. Ekonomik büyüme sonucunda yükselen yaşam standardı eğitim alanında da kendini göstermeye başlamıştır. 19. yüzyıl İngiltere'sinde kızların eğitim ve öğretimlerine daha az önem verilmiştir. İyi bir eş ve anne olmak üzerine aldıkları terbiyeyle birlikte mesleki eğitimlerini evde almak zorunda kalmışlardır. İşçi sınıfındaki kızlar ise kardeşleriyle ilgilenerek veya kazanç getiren çamaşır yıkama ve dikiş dikme gibi işlerle uğraşarak ailelerine yardım etmişlerdir. Ancak bazı hakların kazanılması sonucunda orta sınıf ailelerin kızları da okulda öğrenim görme firsatı yakalamıştır. Aileler kız çocuklarını evden uzaktaki büyük okullara göndermekten hoşlanmadıkları için yakın çevredeki küçük özel okullara ya da evlerinde ders veren kadınlara göndermişlerdir. Bunun yanı sıra güçleri yettiği oranda, kızlarının kendi evlerinde özel öğretmen tarafından eğitim almasını sağlamışlardır (Mitchell, 2009: 183).

Genel eğitimle paralel sanat eğitiminde, Viktorya dönemi kadınlarının çok da elverişli olmasa da bazı koşullara sahip oldukları görülmektedir. Aileler, özel öğretmen tutarak kızlarına müzik ve resim dersi aldırırlar, erkek çocukları aile içi eğitimini tamamladıktan sonra sanat 
eğitimlerine devam ederler, yetenekli olanları Kraliyet Akademisi'ne kabul edilirler. Kızlar, erkekler kadar şanslı olamasalar da 19. yüzyılın ortalarına doğru önce temel sonra yüksek düzeyde sanat eğitimi alma imkanı bulmuşlar, kadınlar için sanat eğitimi veren Female School of Art gibi okullarda ise orta sınıf ailelerin kızları resim öğrenimi görmeye başlamıştır (Arslan Sevin, 2002: 522).

Tutucu ve sert bir politika izleyen Kraliçe Viktorya döneminde İngiltere'de sanatsal alanda kadınların varlıklarını kanıtlamaları zor olmuştur. Bu zorlukların başında erkek egemen sanat anlayışı gelmektedir. O zamanlar sadece erkek çocuklarının girebildiği Kraliyet Akademisi yalnızca İngiltere'de değil tüm Avrupa'da sanat konusunda en büyük otoritelerden biridir. Gerek sanatsal çalışmalar gerek sanat piyasası erkeklerin hâkimiyetindedir. Kuruluşunda Angelica Kauffmann ve Mary Moser gibi sanatçıların imzaları olmasına rağmen 19. yüzyılın ikinci yarısına kadar kadın sanatçılar Akademi’ye kabul edilmemiştir. Aynı dönemde feminist yaklaşımlarıyla kamuoyunu etkileyen Barbara Bodichon ve arkadaşları sayesinde sanat okulları açllır. Slade School of Art, Birmingham School of Art gibi sanat okullarına girebilen kadınlar yerli usta ve ünlü ressamlardan ders alıp Kraliyet Akademisi (Royal Academy), The British Institution, The Old Watercolor Society, The New Watercolor Society, The Society of British Artist, New English Art Club ve The National Institution gibi Londra'nın belli başlı sanat galerinde sergiler açmışlardır (Günay Topallı, 2001: 72-73).

Söz konusu dönemde, sanat çalışmalarını gerçekleştirirken birtakım engellerle karşılaşan kadınların sanat eğitimini aldıkları okullarda kadın veya erkek çıplak modelden çalışmaları asla kabul edilemezdi. Kadın sanatçı, figürlü resimlerini ancak vücut hatlarını örten giysilerle yapmak zorunda kalmıştır. Dolayısıyla figür yönünden aldıkları desen eğitimi yetersiz olduğu için dikiş-nakış ve illüstrasyon gibi yaratıcılık istemeyen çalışmalara yönlendirilmişlerdir. Erkek sanatçılar büyük boyutlu yağlıboya tablo çalıştıkları halde kadınlar; kara kalem, suluboya ve tebeşir gibi malzemelerle küçük boyutlu çalışmalar yapmışlardır. 
İngiltere'de kadınların tek başlarına açık alanlarda çalışmaları da hoş karşılanmamıştır. Dar korseleri ve etekleriyle dağlarda veya tepelerde çalışmaları resim aletlerini bir yerden başka bir yere taşımaları pratik açıdan karşılaştıkları zorluklar arasındadır (Marsh and Gerrish Nunn, 1999: 11-12).

\section{Bölüm}

19. Yüzyıl İngiliz resim sanatının Kraliyet Akademisi'nin kurallarıyla biçimlendiği bilinmektedir. Öncelikle Neoklasik döneme ve tarihi konulara, portrelere, manzara resimleriyle, günlük yaşam konulu resimlere yer veren İngiliz ressamlardan 1848 yılında William Holman Hunt, John Everett Millais, Dante Gabriel Rossetti, Luke Fildes, Lord Leighton önderliğinde Ön Raffaellocular (Pre-Raphaelite Brotherhood) akımını meydana getirmişlerdir. Viktorya dönemi tutuculuğunu ve bütün alışılagelmiş edebi ve sanat kavramlarını alt üst eden yaklaşımıyla tepki gören Ön Raffaellocular, canlı ve parlak renkleri tercih etmişler; konularını genellikle Kutsal Kitap'tan, tarihten, edebiyattan ve çağdaş yaşamdan seçmişlerdir. Ressamlar tarihi konulu resimlerinde Kutsal Topraklarda araştırmalar yapmışlar, portre türü resimlerinde akraba ve dostlarını model olarak kullanarak gerçekçi bir yaklaşımla eserlerini sergilemişlerdir (Rona, 1997: 1407).

Akademik sanatın geleneksel kurallarına başkaldırı olarak sanatın bir tür ahlaki amaca hizmet etmesi gerektiğini savunan sanatçılar ciddi ve önemli temalar üzerinde çalışırken figür ve nesneleri doğrudan doğadan çalışmayı ve seçilen konuyu gerçekçi bir şekilde verebilmeyi amaçlamıştır. Açık havada ve doğrudan doğa içinde modellerini çalışırken gerçekçi nesnelere de sembolik anlamlar yüklemişlerdir. $\mathrm{Bu}$ nedenle seçtikleri konuları farklı bir tarzda betimledikleri için eleştirilere maruz kalmışlardır. Ön Raffaelloculuk hareketinin en büyük destekçilerinden John Ruskin de doğaya bağlılık öğretisiyle yapıtlarda doğal ve gerçek 
nesnelerin, en küçük ayrıntıların hem gerçeğe uygun bir biçimde hem de simgesel bir anlam ifade edecek şekilde resmedileceğine inanmaktadır (Yaşdağ, 2017: 174-175).

Ön Raffaellocular 1849 yılında tartışıp geliştirdikleri simgesel gerçekliğin örneklerini sergilemeye başlarlar. Örneğin John Everett Millais'in Ísabella adlı eseri (Res. 1) sanatçının canlı modelden çalıştığı, sembolik anlamların yüklendiği, fresko tekniğine benzer etkiyi yansıtan ünlü bir yapıtıdır. Beyaz bir zemin üzerine saydam boyalarla ve sulu boyayla çalışılmış parlak canlı renklere sahiptir. Millais'in İsabella'nın saç modeli ve elbisesini tarihi bir kıyafet albümünden kopya ettiği bilinmektedir. Romantik tarihi konulu bu eserin esin kaynağı John Keats'in bir şiiridir (Hunt, 1905: 374). Bütün resim bu trajik öyküye ilişkin simgelerle doludur. Kısa bir süre sonra İsabella'nın ağabeyi tarafından başı kesilecek olan sevgilisi Lorenzo, İsabella’ya kesik bir başı anımsatan yarım bir kan portakalı sunmaktadır, önlerindeki mayolika tabak, Davud ve Golyat'ın baş kesme sahnesiyle resimlenmiştir, masaya dökülmüş tuz ise dökülecek kanı simgelemektedir (İnankur, 1989: 52).

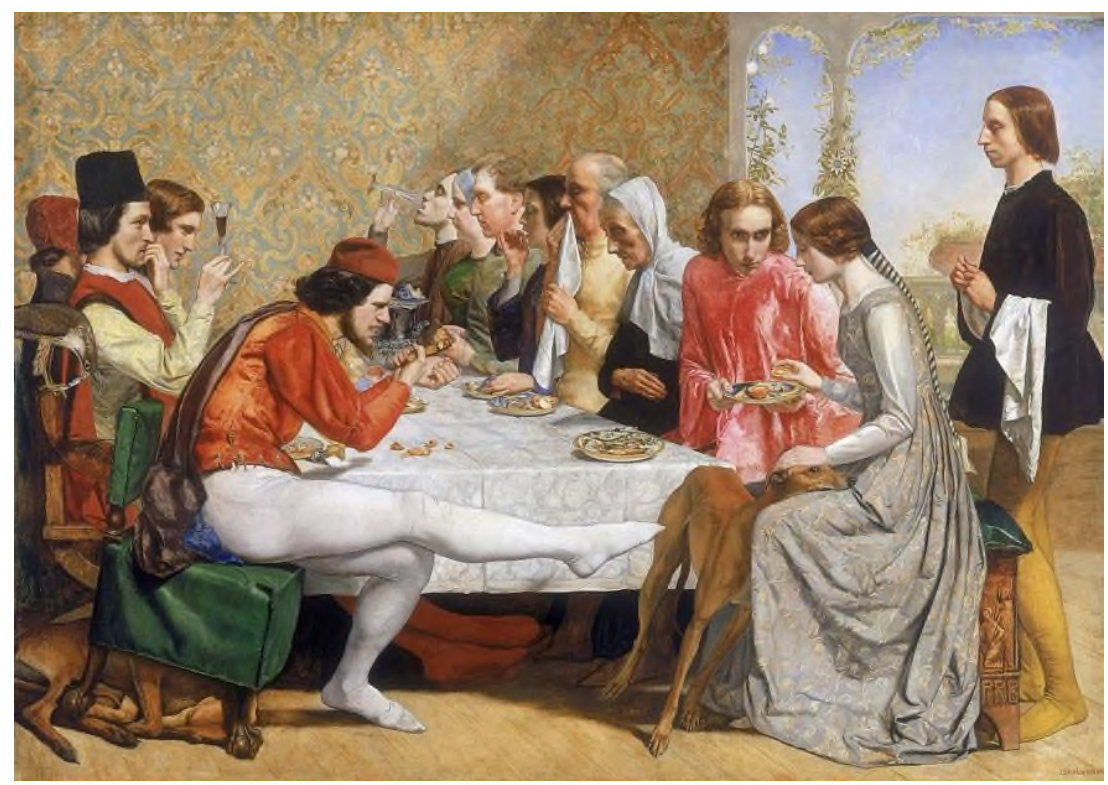

Resim 1: John Everett Millais'in Ísabella

Dante Gabriel Rosetti Meryem'e Müjde Ecce Anna Domini! (Res. 2) adlı tablosuyla Erken Rönesans dönemi dinsel konulu resimlerinden birini betimlemiştir. İnce, uzun ve dar 
biçimiyle Gotik bir panoyu anımsatan resme yer yer kırmızı, mavi ve altın renklerinin parlaklık verdiği beyazlık hakimdir. Bu renklerin tümü de Meryem ve onun doğumuyla ilişkilidir. Güvercin ve zambak da simgeseldir. İkonografik anlatımı ilginç olan resimde, Müjde $e^{l}$ sahnelerinde genellikle kitap okuyan Meryem, burada yatağında henüz uykudan uyandırılmış bir konumda tasvir edilmiştir. Müjde meleği Gabriel (Cebrail) in de ayaklarından alevler çıkmasına karşın kanatları yoktur. Rosetti bu eserde yüzyıllardır yinelenen tüm anlamını yitirmiş domestik ayrıntıları ve hareketleri bir yana bırakıp ilahi atmosferi yansıtmaya çalışmıştır (İnankur, 1989: 54).

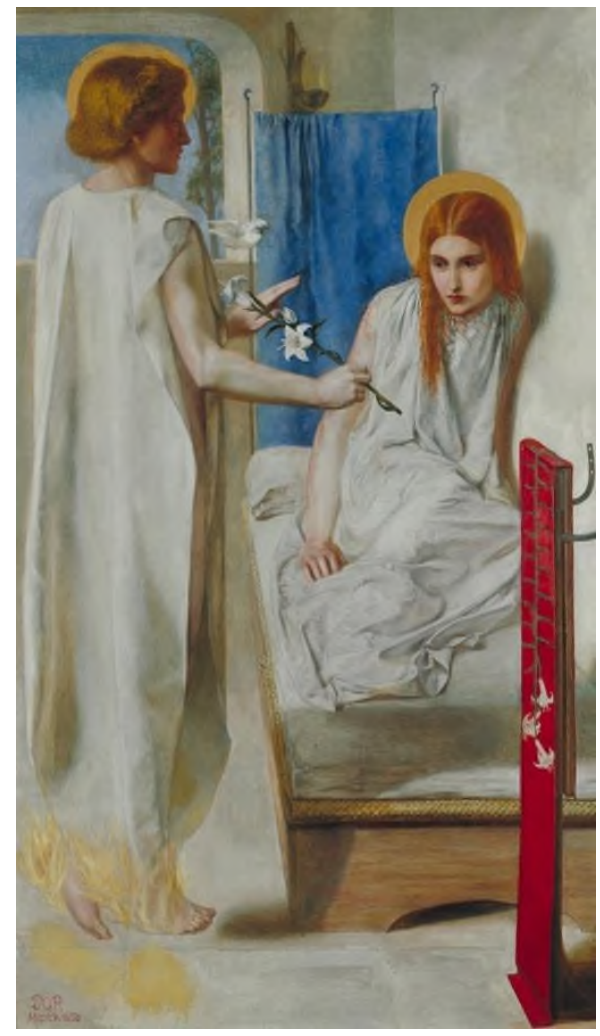

Resim 2: Dante Gabriel Rosetti Meryem'e Müjde Ecce Anna Domini!

Manzaraların, tarihi, dini ve edebi konuların yanı sıra çağdaş yaşam sahneleri de Ön Raffaellocuların işlediği temalar arasında yerini almıştır. William Holman Hunt Uyanan Vicdan

\footnotetext{
${ }^{1}$ Müjde sahneleri, .......Batı Sanatında İkonografi...
} 
(Res. 3) tablosunda o yıllarda büyük kentlerin sorunlarından biri olan düşmüş kadın ve fuhuş konusuna eğilmiştir. İş bulma umuduyla köyden kente göç eden ancak sonunda çaresiz kalıp hayatını fahişelik yaparak kazanan genç kızlar o dönemde büyük sanayi kentlerinin en önemli sorunlarından biridir ve bu tür kadınlar dönemin pek çok yazarına esin kaynağı olmuştur. Nitekim Hunt'un bu eserindeki esin kaynağı da Charles Dickens'in David Copperfield adlı romanıdır. Hunt bu romandaki kötü yola düşmüş Emily’den etkilenmiştir. Tabloda sevgilisinin kucağında otururken birden onun söylediği bir şarkının etkisiyle çocukluk yuvasını anımsayan ve büyük bir pişmanlık duyan genç bir kadın tasvir edilmiştir (Hunt, 1905: 428-431).

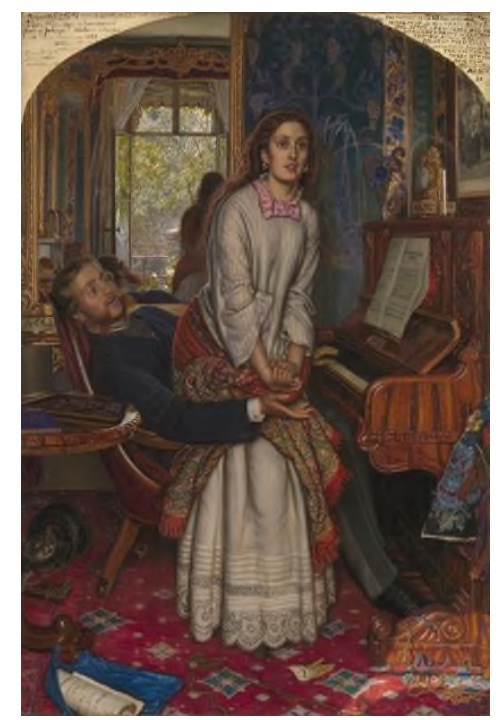

Resim 3: William Holman Hunt Uyanan Vicdan

Kadın günahkâr yaşamı terkedip yeniden iyi bir yola dönme kararıyla erkeğin kucağından fırlamaktadır. Hunt, resmini inandırıcı kılmak için bu tür gizli buluşmaları için kullanılan bir oda kiralamıştır. Oda, yepyeni, cilalı ve gösterişli ancak adi eşyalarla döşelidir. Ressam, adamla kadının gayrimeşruluğunu, kadını elinde bir nişan yüzüğünün bulunmayışı ve adamın yere atılmış kirli eldiveniyle vurgulamaktadır. Bu eldiven bir gün terkedilecek metresin sonunun fahişelik olacağını ima etmektedir. Odadaki hemen her eşya simgesel özellikler taşır. 
Piyanonun üzerindeki ve yerlere saçılmış notalar masumiyeti sembolize ederken, kızın içine düştügü ağ, piyanonun üzerindeki vazoda bulunan kahkaha çiçeği, cam fanusun içindeki yarı çıplak kadın heykelciği ve halının üzerindeki birbirine dolanmış ipliklerle simgelenmiştir. Piyanonun üzerindeki resimde İncil'deki Günahkar Kadın öyküsü betimlenir. Pencereden görülen manzara aynada bir yansıma olarak gösterilmiş olup kadının kaybolan saflığını temsil eder. Bütün bu olumsuz işaretlere karşın sağ köşedeki 1ş1k demeti ve baştan çıkaran erkeği temsil eden kedinin yakalamaya çalıştığı kuşun odadan kaçması kadın için de bir kurtuluş şansının olduğunu gösterir (İnankur, 1993: 243-244).

Ön Raffaellocular 1855-60 yıllarından sonra farklı bir üslup geliştirerek Sembolistleri etkilemişlerdir. Bir önceki sembolik gerçeklikten farklı olarak resimde öykü ya da öykücülük en aza indirgenmiş hatta tümüyle ortadan kaldırılmıştır. Ayrıntılı bir gerçekçilik yerine atmosferi, renk ve biçim olarak izleyiciyi etkileyen örnekler sergilenmiştir. Ön Raffaellocu ressamlar dönemin din, edebiyat sosyal ve politik yaşamındaki değişikliklere bağlı olan konuları seçmişler ve semboller aracılığıyla izleyiciye aktarmışlardır (Rona, 1997: 1408).

\section{Bölüm}

Viktorya döneminde sanat eğitimi alan kadınların çoğunun bir ressamın kızı, kardeşi ya da eşi olduğu bilinmektedir. Ayrıca söz konusu kadın sanatçılar, 19. Yüzyıl İngiltere'sinde önemli eserler üretmişler; Henrietta Word, Jessie ve Emma Landseer, Rosa Brett, Elizabeth Siddal, Emily Osborne, Rose Barton, Sophie Anderson, Elizabeth Thompson gibi birçok kadın sanatçı döneme damgasını vurmuştur (Arslan Sevin, 2002: 525). 
Pamela Gerrish Nunn’a göre Ön Raffaelloculuk hareketi kadın ve erkeğin karşılıklı bir alışveriş ilişkisi içinde her iki cinsiyetin birbirini beslediği bir sanat düşüncesine sahiptir. Modellerini genelde aile fertleri, çevresindeki dostlar ve güzellikleriyle öne çıkan kadınlardan seçmişlerdir. Şair Christina Rosetti (1830-1894) ressam Dante Gabriel ve yazar William Michael'ın küçük kardeşidir. Christina Rosetti (1830-1894), ağabey Dante Gabriel'in 1840 ve 1850'lerdeki Bakire Meryem 'in Gençkızlığ (Res. 4) modellik yapmıştır (Yaşdağ, 2017: 178).

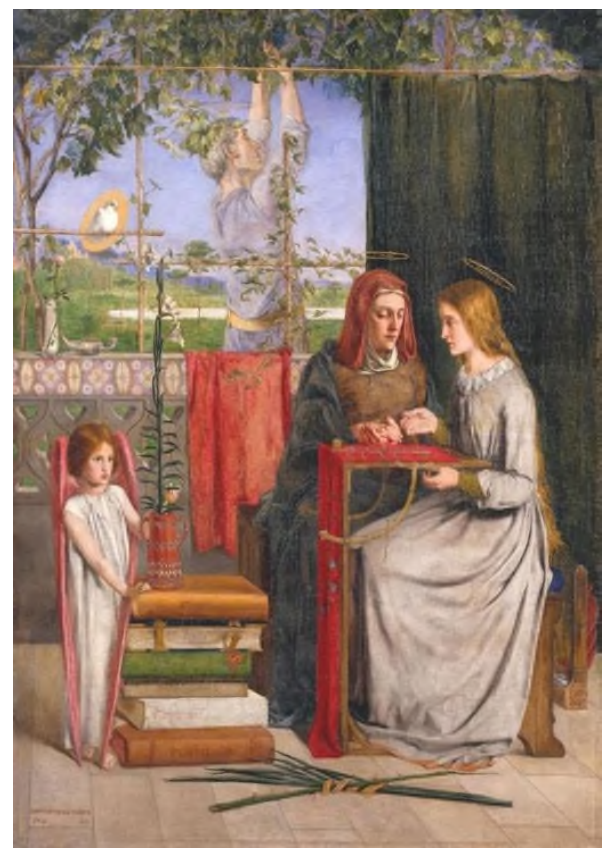

Resim 4: Dante Gabriel Rossetti, Bakire Meryem ’in Gençkızlı̆̆

Ön Raffaellocuların sanatında fark edilen, gözle görülen bir motif olan kadın figürü manzara, portrecilik, tarihsel ve günlük yaşam konulu tür resimlerine rağmen genellikle sade yalın yüzleriyle- resimlerde en sık rastlanan betimlemelerdir. Spesifik feminen bir bakış tarzını yansıtan resimlerde özellikle her şeyden çok kadınlar tasvir edilmiştir (Gerrish Nunn, 1987: 2021).

Ön Raffaellocu resmin güzel ama bilinmeyen kadınları erkekler tarafindan keşfedilmiştir. Kelimenin tam anlamıyla kadın modellerini sokaklardan alıp, hatta efsanevi ikonlara dönüştürüp, tuval üzerinde ölümsüzleştirmişlerdir. Profesyonel ilişkilerinin dışında 
onlarla birlikte olmuşlardır. Bu durumda dolaylı olarak kadınların üretici değil, sanat objesi olduğu; Ön Raffaellocu resmin içeriğini oluşturduğu ancak yaratıcıları olmadığı görülmektedir. Oysa 19. yüzyıl sanat tarihi ve biyografisindeki ilgili araştırmalar, hem Ön Raffaellocu oluşumun anlaşılması için önemli olan alanların, hem de birçok diğer bilgi alanlarında olduğu gibi kadın isimlerinin ve kazanımlarının olduğunu gösterir. Ama Ön Raffellocu tarzda ressam olan bazı kadınların kaybedilmesi veya baskılanması nedeniyle topluluğa katkılarının fiilen gözden kaybolduğu anlaşılmıştır. 1850’li yılların başlarında yetenek vaat eden kadın ressamlar, topluluğun genç erkek ressamlarından çok farklı bir konumdaydılar. Onların üretme azmi ve istekleri pratik, sosyal ve ideolojik düşüncelerle sınırlıydı aynı zamanda spesifik engeller ve dışlanmalarla karşı karşıyaydı. Kadınların, Ön Raffaelloculuk hareketinin başladığı dönemde sanattaki konumu, bu nedenle yasal statü, eşitlik, eğitim ve istihdam içeren "kadın sorununa" kapsamlı geçmişine karşı bir mücadele olarak görülmektedir (Gerrish Nunn, 1989: 153).

İlk aşamada sanat eğitimi, resim eğitimi almak isteyen kızı için para harcasın ya da harcamasın genellikle karar verme yetkisini elinde bulunduran babanın söz sahibi olduğu ailenin tutumlarına göre saptanmıştı. Kızların edebi kültür ve matematik becerisi gibi temel eğitimi alması çoğunlukla ebeveynlerin sorumluluğuydu. Ayrıca genellikle ahlaki ve dini öğretimin yanı sıra, kıyafet dikip onarmak, günlük ev idaresi gibi eğitimi de vermekle mükelleftiler. Başta müzik ve Fransızca olmak üzere diğer dersler uzman öğretmenlerden alınıyordu. Kadınlar için mevcut olan sanat eğitiminden en yaygın olanı, öğrencilere evde eğitim veren ve kızlar için çok da profesyonel olmayan amatör bir seviyeye getirecek olan yerel bir çizim ustasının yani illüstratörün olmasıydı (Mitchell, 2009: 184).

Ön Raffaellocu tarzda eser veren kadın sanatçılar hem akademik tür resminin dışına çıkabiliyor hem de teknik detay ve içerikleriyle çalışmalarını ciddiye alan bir kesimle de bağlantı içinde olabiliyorlardı. Bu dönemde Ön Raffaellocular manzara resmine, yenilenmiş dinsel konulara ve modern edebiyat çevrelerinin yeni ilhamlarına önem veriyorlardı. 
Emma Sandys ailesinin desteğiyle erkek kardeşiyle birlikte eğitim almak üzere sanat okuluna gönderildi. Sandys'in diğer eserleri, ilk olarak yanlışlıkla The Lady Shalott olarak adlandırılan Baloya Hazırlık'tır. (Res. 5). 1885 y1lında Elaine (Res. 6) ve Viola (Res. 7) adlı portreleri sergilemiştir.

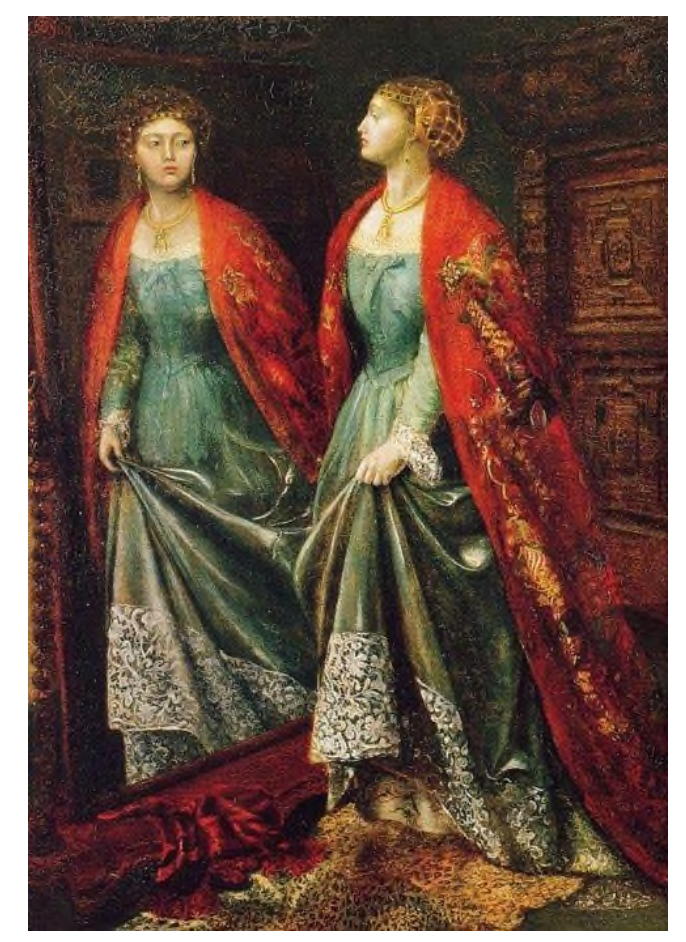

Resim 5: Emma Sandys , Baloya Hazırlık

Bunlar orta boy yağlıboya baş figürlerdir. Emma Sandys bir portre ressamı olarak beceri kazanmış, özellikle tebeşir ve yağlıboya kullandığı çocukların portrelerini yapmakta uzmanlaşmıştır. Ne yazık ki, Sandys hakkında daha ünlü kardeşi Frederick ile karşılaştırıldığında çok az şey biliniyor. Baloya Hazırlık adlı tablosu daha çok ayna resmine iyi bir örnektir. 


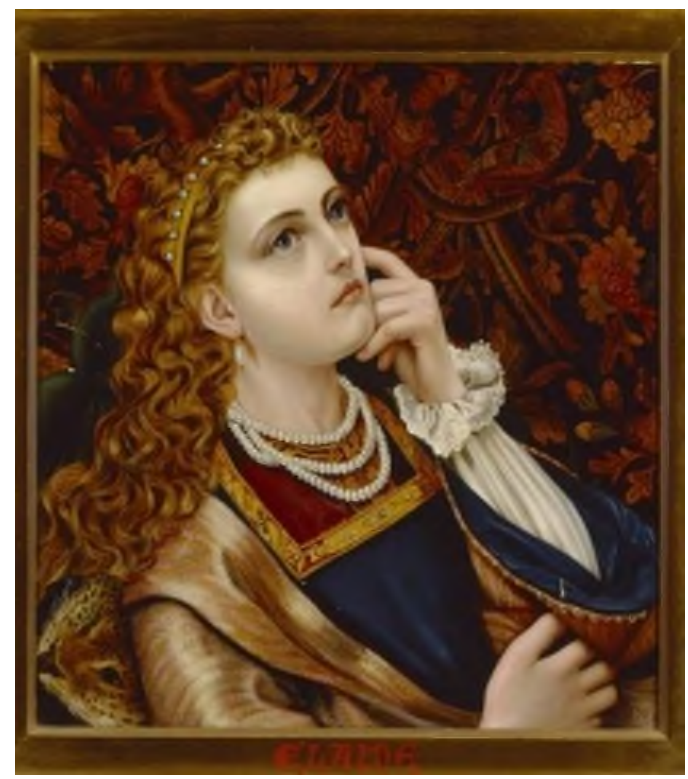

Resim 6: Emma Sandys, Elaine

Baloya Hazırlık resmindeki moda unsurlarına ek olarak, yine Viola'ya ve Elaine'e bakarsak, Sandys'in sık sık kıyafetlerinde ve mücevherlerinde görkemli ayrıntıları kullandığını görebiliriz: saçlarında ve boynunda inciler, mücevher tonlarında kumaşlar, bağcıklı kenarları vb. Elaine'de Sandys, Lancelot'a aşık olan “Astolat'ın zambaklı hizmetçisi” nin öyküsünü bir Arthur efsanesinden ilham alarak betimler. Ne yazık ki Elaine için karşılıksız bir aşktır. Çalışmaları kesinlikle Ortaçağ etkili bir Ön Raffaellocu tarzı yansıtmaktadır (Gray, 2009: 231).

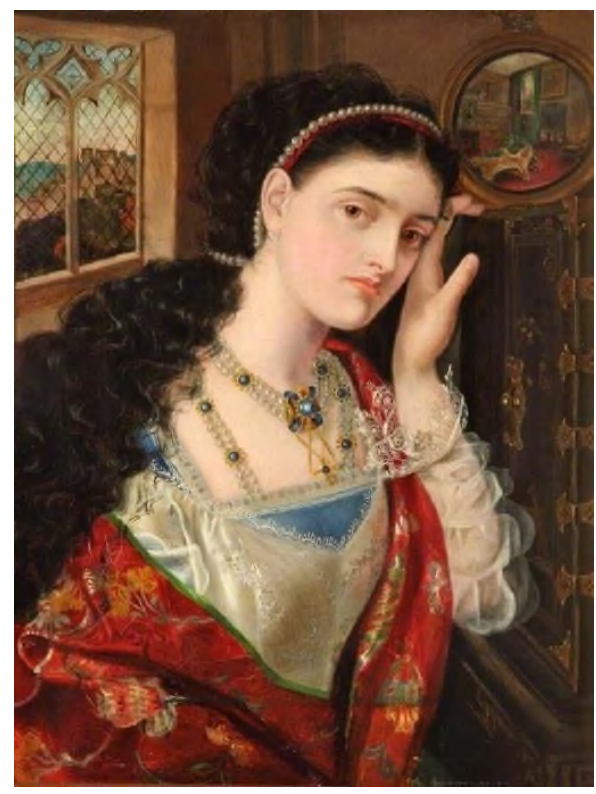

Resim 7: Emma Sandys, Viola 
Ön Raffaellocu kadın ressamlarından biyografi yazarı ve model olan Lucy Madox, ressam Ford Madox Brown kızıdır, yazar ve sanat eleştirmeni William Michael Rossetti’nin de eşidir. 1868'de resim yapmaya başladı ve üvey kız kardeşi Catherine ile birlikte, babaları ressam Ford Madox'un atölyesinde asistan olarak çalıştılar ve ona modellik yaptılar. Aynı stüdyoda, Georgiana Burne-Jones, Thomas Seddon'ın kız kardeşi ve Marie Spartali Stillman'ın kardeşi gibi diğer kadın sanatçılar da dersler aldı. Başta suluboya olmak üzere çalışmaları 1869'dan 1872'ye kadar Dudley Müzesi ve Sanat Galerisi'nde, 1870’de de Düet (Res. 8) resmi Kraliyet Akademisi'nde sergilenmiştir (Chapman-Stabler, 2003: 85).

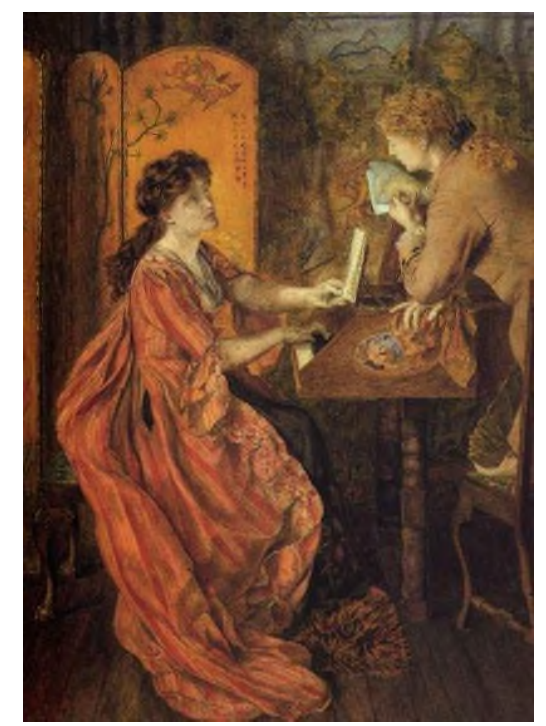

Resim 9: Lucy Madox Brown, Düet

Lucy Madox’un, Margaret Roper Babası Sir Thomas More’un Kellesini Kurtarırken (Res. 9) adlı tablosu 1534 yılında gerçekleşen tarihsel bir olaya gönderme yapmaktadır. Sekizinci Henry’nin eşinden ayrılışını reddeden Papalığa karşı takındığı tutumunu susarak protesto eden Thomas More'un kellesinin kesilmesinin ardından kızı Margaret'in babasının kellesini Londra köprüsünden kurtararak kendi ölümünde birlikte gömülmeyi vasiyet etmesini konu almaktadır. Ulusal değerleri, Thomas More'un cesaretini ve kadının sadakatinin altını çizmesi bakımından Ön Raffaelloculara uygun bir konu olmasına rağmen sertliği ve kesik başı göstermesi yüzünden eleştirilmiştir (Bölüktaş, 2018: 13). 


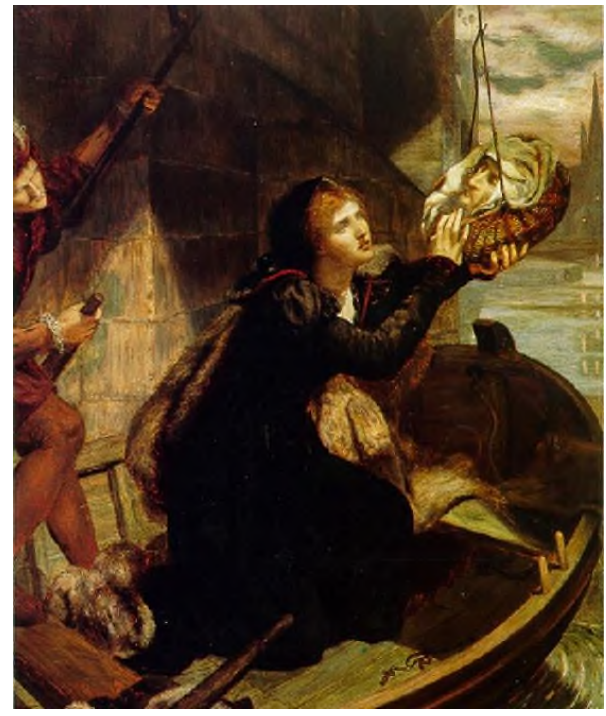

Resim 9: Lucy Madox Brown, Margaret Roper Babası Sir Thomas More'un Kellesini Kurtarirken

Marie Spartali Stillman (1844-1927) Lucy Madox Brown ile birlikte babası Ford Madox’tan resim dersleri almış, Ön Raffaelloculara hem modellik yapmış hem de yüzden fazla eser meydana getirmiştir. Patronlar tarafından sevilen dekoratif kadın portreleri dışında tarihsel ve edebi konulara eğilmiştir. Dante Verona'da (Res. 10) adlı tablosu 1888 y1lında New Galeri'de Rosetti'nin bir şiiriyle birlikte sergilenmiştir. Tablo, Romeo ve Juliet'in şehri olan Verona'ya göç etmiş, etrafı genç güzel kızlarla çevrili Dante'yi hayali bir Ortaçağ bahçesinde çeşmeler ve ağaçlarla betimlemektedir.

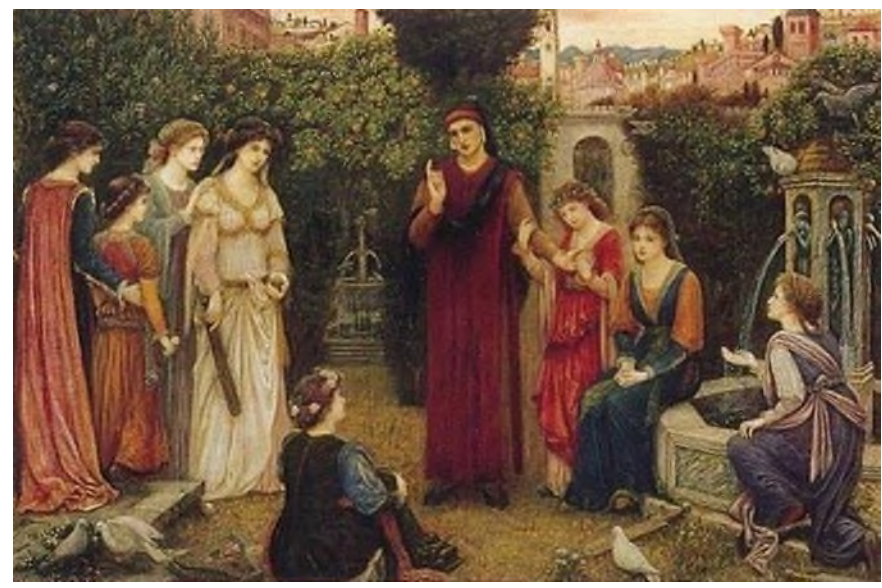

Resim 10: Marie Spartali Stillman, Dante Verona'da 
Stillmann'ın ayrıca kadın portrelerinde ne kadar başarılı olduğu görülmektedir. Sanatçının meşhur tablosu Aşk Mesajı (Res. 11) teknik olarak Rönesans etkilerini yansıtır (Marsh-Gerrish Nunn, 1989: 100-104).

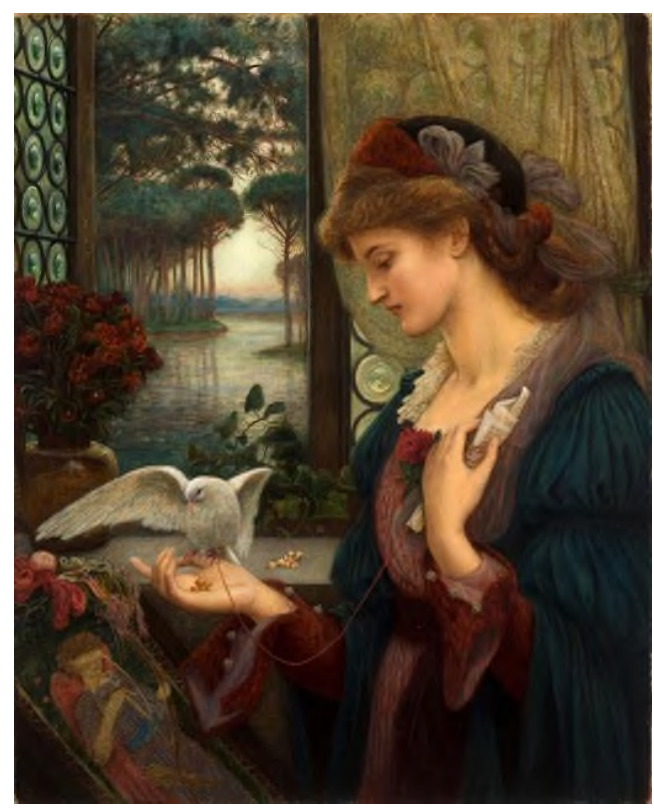

Resim 11: Marie Spartali Stillman Aşk Mesajı

1880’lerden sonra kadın Ön Raffaelloculuğun etkileri Evelyn de Morgan (1855-1919), ve Eleanor Fortescue Brickdale (1872-1945) gibi kadın sanatçılarda görülmektedir. Evelyn de Morgan 15 yaşından itibaren Kensington ve Slade School gibi okullarda eğitim görmüş, çalışmalarıyla birçok ödül kazanmıştır. Seramik sanatçısı William de Morgan ile evlenmiştir. Sanatçı güçlü bir feministti ve 1889 tarihli Kadın İstihdamına İlişkin Deklarasyona imza atmıştır. Zamanın diğer birçok kadın sanatçısı gibi, Londra'daki Grosvenor, Dudley ve Yeni Galerilerde sergilenen Kraliyet Akademisi'ni boykot etmiştir. Floransa'da gerçekleştirdiği Flora (Res. 12) adlı çalışmasında estetik olarak Sandro Boticelli’nin Illkbahar Alegorisi 147782, Uffizi Galerisi, Floransa (Res. 13) ve Venüs'ün Doğuşu, 1485-86, Uffizi Galerisi, Floransa (Res. 14) eserlerinin etkisi altında kaldığ görülmektedir. İlkbahar ve Venüs'ün niteliklerinin sentezini yaparken bu eserlere açıkça gönderme yapmaktadır. 


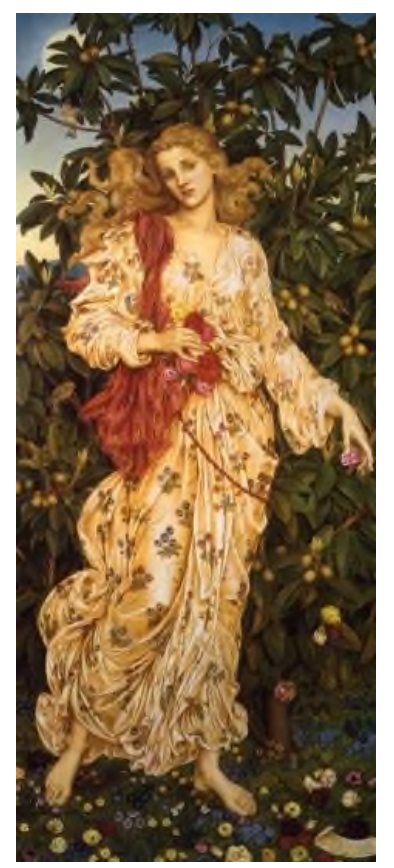

Resim 12: Evelyn de Morgan, Flora

De Morgan'a ait 1894 tarihli yağlıboya tabloda Flora, baharla ilişkilendirilmiş, Roma Çiçek tanrıçasıdır ve küçük ölümlü bir figürdür. Renkli hercai menekşe ile kaplı, üzeri parlak altın varakla süslü kıvrımlı beyaz bir elbiseyle resmedilmiştir. Boynundaki şalı, altın renkte bir kırlangıç deseni ile kırmızı renklidir. Arka plandaki ağaç, dekoratif olmasına karşın adeta soluk yeşil yapraklarla süslenmiştir, bu ilkbaharda meyve veren bir Nespolo ağacıdır. Tanrıça, ilkbaharda meyve veren nescola veya yenidünya ağacının önünde tasvir edilmiştir. Giysisi Floransa çiçekleriyle desenlidir. Bazı çiçekler ellerinden düşerken bazıları da ayaklarının önünde dağınık şekilde uzanır. Ağacın üzerinde yaprakların arasında da küçük kuşlar görülebilmektedir. Bu resim Evelyn De Morgan'ın kış aylarında çalıştığı Floransa'da tamamlanmıştır. Maneviyatın, mitolojik, İncil ve edebi temaların sergilendiği resimlerinde yaşam ve ölüm; aydınlık ve karanlık gibi dualiteler veya metaforlar; savaş alegorileri ve kadınların rolü de belirgin bir şekilde hissedilmektedir. 


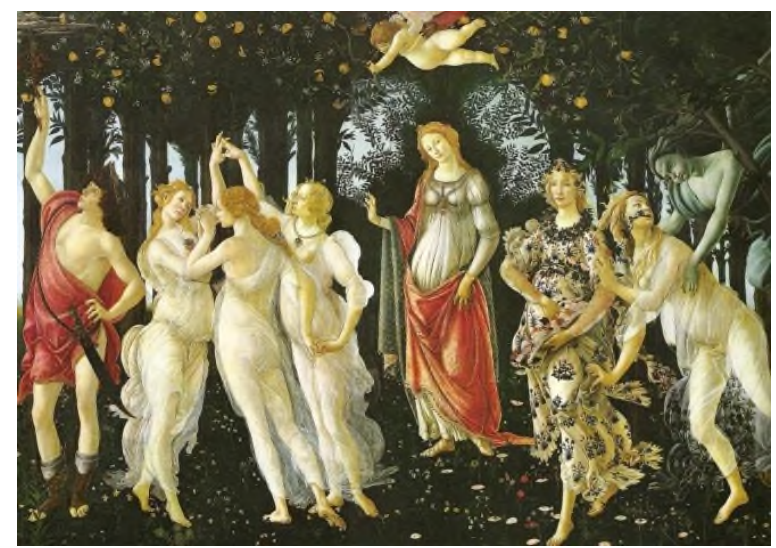

Resim 13: Sandro Boticelli, Illkbahar Alegorisi

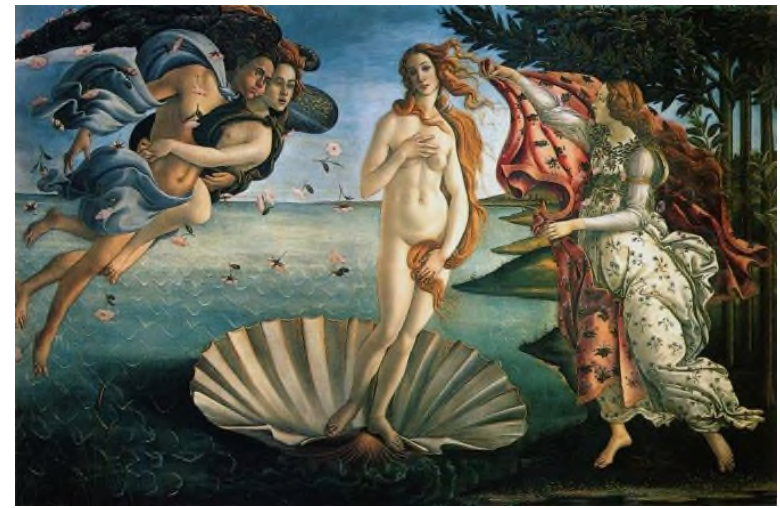

Resim 14: Sandro Boticelli, Venüs'ün Doğuşu

Detaylara bakıldığında gökyüzünde resmin üst tarafında ay, kuş ve meyveler; orta kesimde Flora'nın eli ve tuttuğu pembe bir gül, sağ altta İtalyanca bir rulo ve alt kesimde ayaklarıyla üzerinde durduğu çiçeklenmiş toprak parçası.

(kaynak:http://www.victorianweb.org/painting/demorgan/paintings/5.html)

1880'lerin sonlarında Eveleyn De Morgan tarafindan yapılan Clytie (Res. 15), sanatçının belki de en muhteşem yapıtıdır. De Morgan'ın resmi çarpıcı ancak çiçekli güzellik henüz kasvetli öykünün altındadır. Güzel bir su perisi olan Clytie güneş tanrısı Apollon'a aşık olur. Fakat Apollon onun sevgisine karşılık vermez. Kırgın ve reddedilmiş olan Clytie hareket edemez duruma gelir ve bir süre sonra Apollon'a olan aşkı bir saplantrya dönüşür. Clytie ise 
aşkından çılgına dönmüştür. Apollon ona artık görünmemektedir. Gökyüzünde Güneş’i arar durur.. Gördügü zaman takip etmiş kafastyla. Dokuz gün hiçbir şey yememiş, içmemiş ve devamlı ağlamış. En sonunda gövdesi solgun bir ota dönüşmüş başı ise pırıl pırıl parlayan bir çiçeğe. Devamlı Güneş'e çevirmiş başını ve ona bakıp durmuş. İste bu yüzden Günebakan derler Clytie’nin dönüştüğü bitkiye.' (Ovid,Metamorphoses IV:256-273).

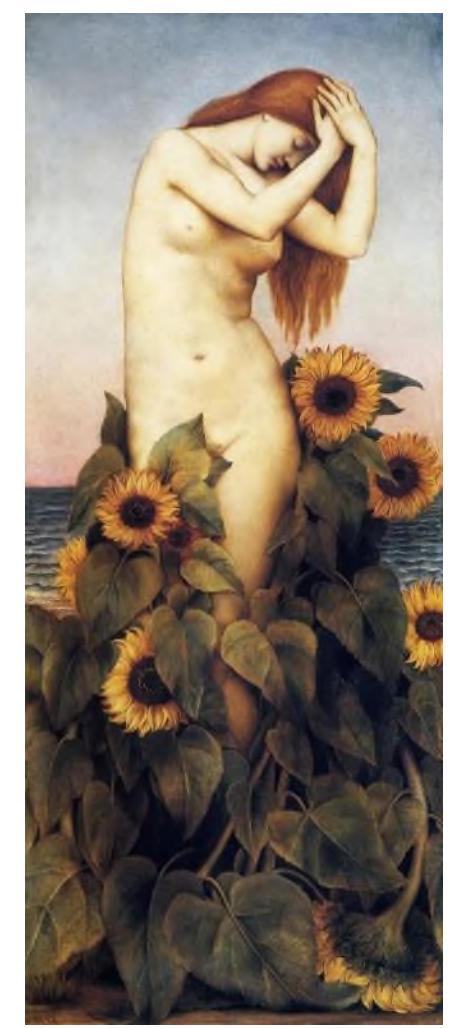

Resim 15: Eveleyn De Morgan, Clytie

Eleanor Fortescue Brickdale Crysral Palace School of Art ve 1897-1900 tarihleri arasında Royal Academy'de eğitim görmüştür. The Little Foot Page adlı (Res. 16) eseri İskoç baladlarında zalim sevgilisinin peşinden yalın ayak koşan Burd Helen'in hikayesinden esinlenerek yapılmıştır. Bu sahnede Helen fark edilmemek için saçlarını keserken resmedilmiştir. Bu resim De Morgan'ın Flora'sı ile birlikte Ön Raffaellocu kadın ressamların eşit şartlarda eğitim gördükleri takdirde nasıl şaheserler yaratabileceklerinin kanıtıdır (Bölüktaş, 2018: 14). 


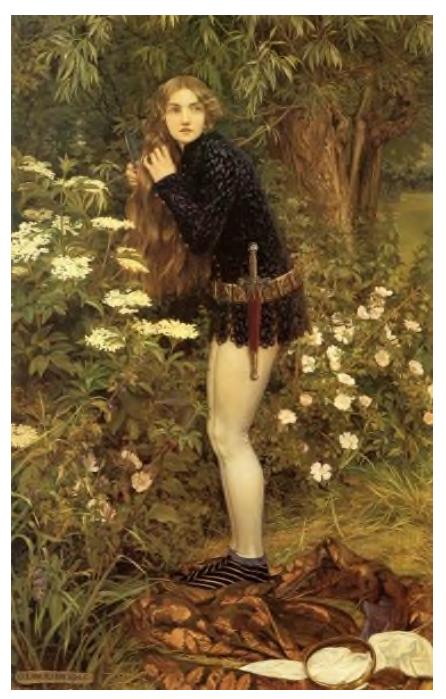

Resim 16: Eleanor Fortescue Brickdale, The Little Foot Page

The Little Foot Page - Burd Helen adlı resim, i "Çocuk Suları" veya "Perd Helen'in Thomas Percy’nin 1765 tarihli Eski İngiliz Şiirindeki “Çocuk Suları” olarak adlandırılan geleneksel bir halk şarkısından detaylar göstermektedir. Ballad, kalpsiz sevgilisi Child Waters'ın çocuğunu taşıyan Ellen'ın sadakatini anlatıyor. Ellen'ın ona şövalye eğitimi alan bir çocuk gibi hizmet etmesinde ısrar ediyor. Bu yüzden erkek kılığına giriyor. Uzun güzel saçlarını kesmek üzeredir, böylece bir erkek çocuk olarak görülebiliyor. Elbisesi ve pelerini ön planda atılmaktadır.

Ön Raffaellocular modellerini genelde aile fertleri, çevresindeki dostlar ve güzellikleriyle öne çıkan kadınlardan seçmişlerdir. Modellerin Ön Raffaellocu ressamlarla olan aşk ve arkadaşlık ilişkileri kimi zaman kadınların toplumsal sınıflar içinde yükselmelerine yardımcı olsa da kimi zaman trajik sonlarını hazırlamıştır. Bu modellerden en tanınmışı ve aynı zamanda resim eğitimi alan yetenekli Elizabeth Siddal'dır (Marsh- Gerrish Nunn, 1989:65). Siddal'ın Ön-Rafaelloculuk tarzındaki ilk üretimi, taze bir yaklaşım ve yaratıcı özgünlügüyle beğeni kazandı. Resimlerinde figürler sert ve anatomik olarak tuhaf olup çizim tekniği de oldukça ilkel görünmektedir. Bununla birlikte, konuları iddialı bir şekilde edebi ve şiirseldir. 
1853'ün başlarında şair Tennyson'dan Rossetti'nin Kraliyet Akademisi'ne göndermesini umduğu bir konuda Lady Shalott'u (Res. 17) çalışır.

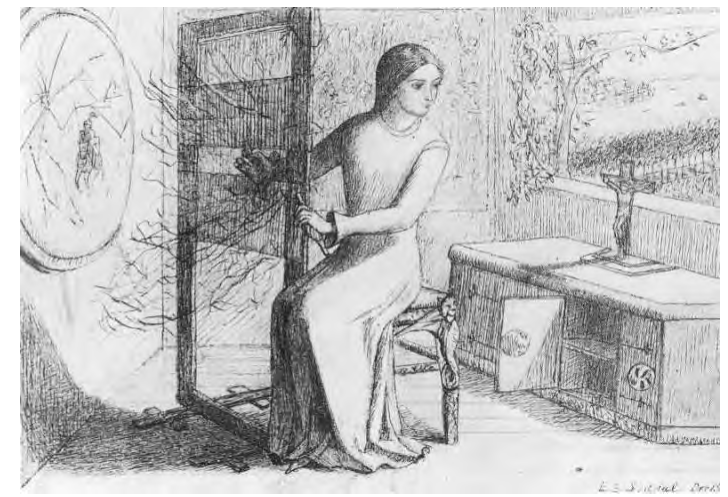

Resim 17: Elizabeth Siddal, Lady Shalott.

Wordsworth'un sadeliğe övgü konulu şiirinin suluboya çalışmasında, bir İskoç baladından ${ }^{1}$ esinlendiği Yas Tutan Kadınlar ${ }^{`}$ da (Res. 18) dağlar arasında bir kilisede yas tutan genç bir kızı resmeder (Marsh-Gerrish Nunn, 1989: 67).

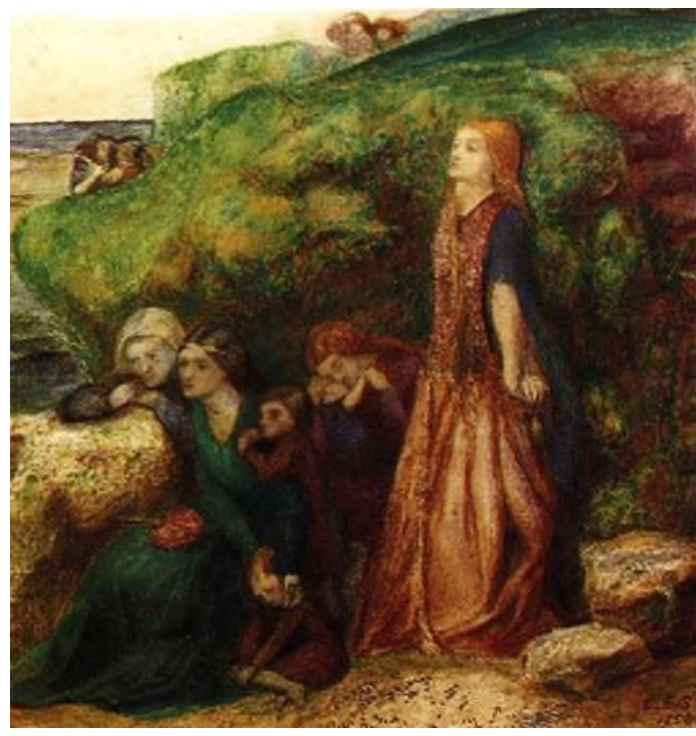

Resim 18: Elizabeth Siddal, Yas Tutan Kadınlar

${ }^{1}$ Elizabet Siddal'ın 1856 tarihli The Ladies' Lament (Yas Tutan Kadınlar)'ı eski bir İskoç baladından esinlenilerek yapılmıştır. İskoçya Kralı, ülkedeki en iyi denizci olan Sir Patrick Spens'den, kızını geri almak için Norveç'e yelken açmasını ister. Ama dönüşünde, gemi büyük bir firtınada kaybolur ve kral, mürettebatı ve her şey yok olur. İskoçya'da bekleyen eşleri ve aileleri, geminin yelkenini boşta görünce neler olduğunu anlar. Siddall da bu anı vurgular. Sağdaki figür kendi portresi gibi görünüyor. 
Siddal, 1854 yılının baharında, William Allingham tarafindan düzenlenen bir balad (halk öyküleri) kitabına bir dizi resim hazırlamıştır. Kitabın iki bölümünde Siddal'a ait çizimler yer almıştır. Diğer erken çalışmalarda, aynı tarihte Howitt tarafından ele alınan düşmüş kadın temasının bir versiyonu olan Browning'in dramatik şiirinden Pippa ve Hayat Kadınları (Res. 19) ile Müzik Dinleyen Aşıklar (Res. 20) olarak bilinen orijinal bir kompozisyonu yapmıştır. Bu eserdeki erkek figürü de Rosetti'nin bir portresidir. Tüm çizim, sanatçının ve aşıklarının yaratıcı bir temsili olarak okunabilir. Muhtemelen arka plan manzarası Siddal ve Rosetti'nin yaz başlarında bir araya geldiği Fairlight ile Hastings arasındaki uçurumdaki Aşıklar Koltuğu olarak bilinen romantik noktadan ilham almış. Müzik Dinleyen Aşıklar'da müzik yapan oryantal kızlar belki de aşk şarkısını temsil ederler ve aşk muhtemelen çiftin yanında ayakta duran küçük, çocuksu aşk tanrısının yani Eros’un kimliğiyle tasvir edilmektedir. Siddal'ın çalışmalarının karakteristik bir özelliği olan kavramsal karmaşıklık ve saf, naif kullanımın bu birleşimi, Ön Rafelloculuk coşkusunu incelemiş olduğu sanat eğitiminin bir kısmında görülmektedir. Resimlerinde William Blake etkileri ve geç Ortaçağ el yazmalarının yankıları görülmektedir (Marsh-Gerrish Nunn, 1989: 68-69).

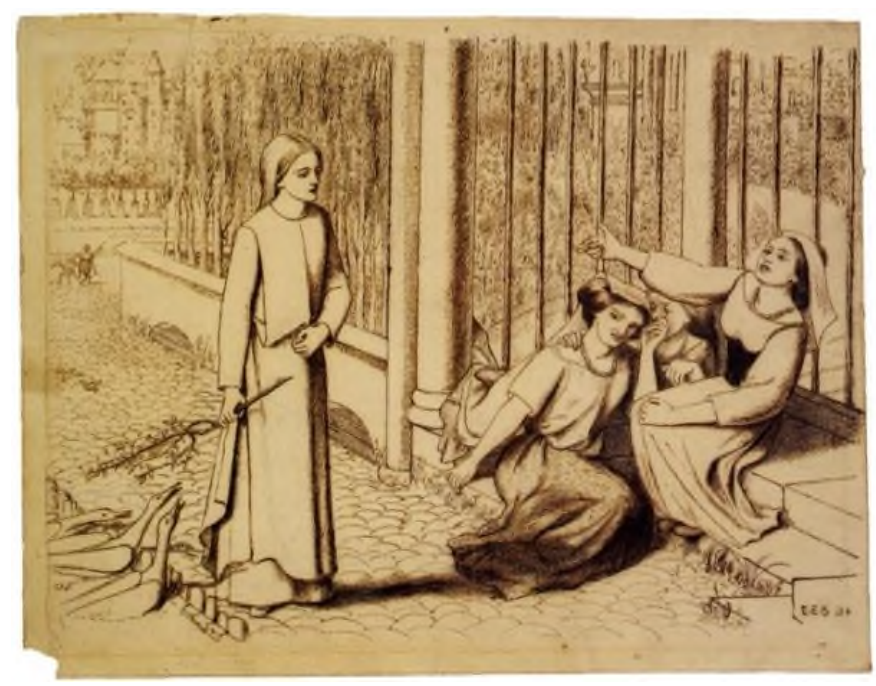

Resim 19: Elizabeth Siddal, Pippa ve Hayat Kadınları 


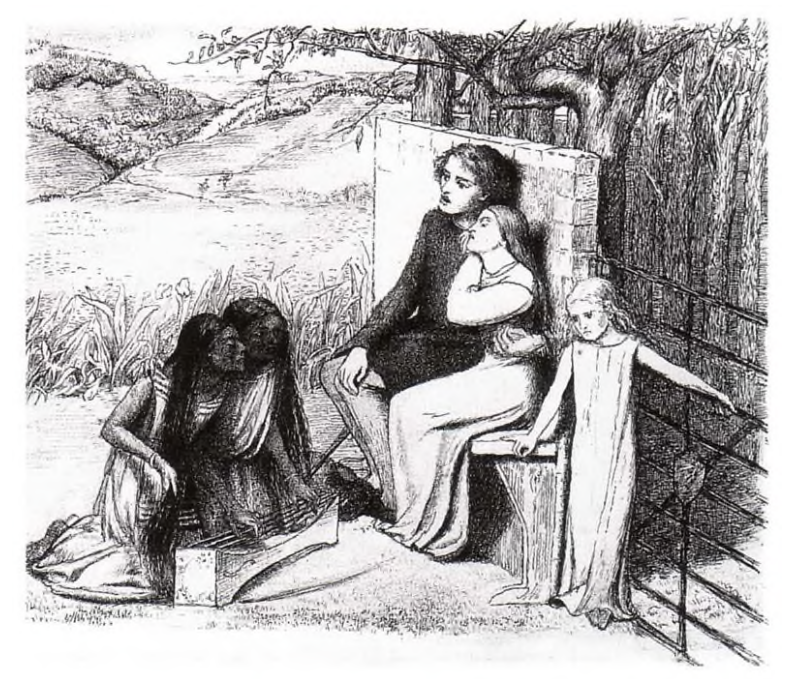

Resim 20: Elizabeth Siddal, Müzik Dinleyen Aşıklar

Atölye mekânı ya da kendi materyallerini karşılayamayan Siddal'ın çalışmaları, uygulamada olmasa bile genel olarak küçük ve temada geleneksel kaldı. Bu sirada Siddal erken İtalyan sanatında ve aynı zamanda 1850'lerde Anglo Katoliklerin ruhunda yeniden canlanan İsa’nın Yaşamı konulu bir dizi dinsel konulu çalışmalara yönlenmiştir. Bu konular arasında, İsa’nın Doğumu, Meleklerle Meryem ve Çocuk İsa diğer pek çok doğum sahnelerinin eskizlerini suluboya olarak çalışmıştır. 1857 yılında aralarında Rahip Saunders adlı yapıtının bulunduğu bir dizi resim de yapmıştır. Siddal'ın Rahip Saunders (Res. 21) adlı çalışması bu bağlamda eski İngiliz folklorik şiirine atıfta bulunurken diğer taraftan sevgiliye duyulan arzuyu dışa vurmaktadır. Viktoryen geleneklere ters bir biçimde Siddal, Margaret'i Saunders'a kendisini öpmesi için yalvarırken resmetmiş, aşkına duyulan sadakatten çok aşka duyulan sadakat ön plana çıkmıştır. Özellikle başının üstündeki sögüt ağacı kederi simgelemektedir. Bu örneklerde görüldüğü üzere Stillman, Blunden, Siddal ve Boyce edebi metinleri diğer erkek Pre-Rafaelitler gibi ele almış fakat farklı ve özgün biçimde yorumlamışlardır (Bölüktaş, 2018: $15-16)$. 


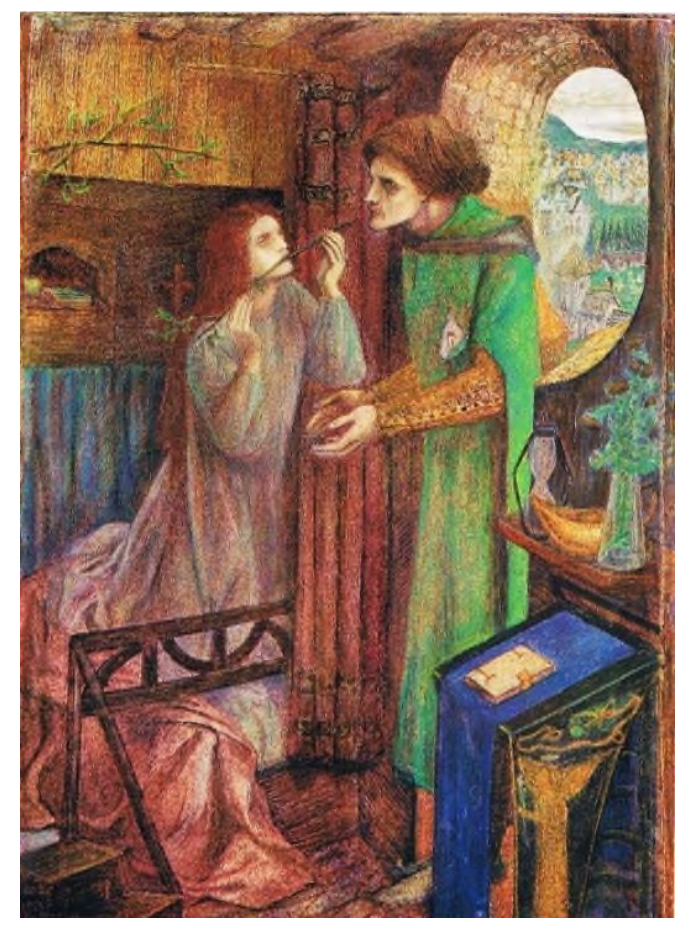

Resim 21: Elizabeth Siddal, Rahip Saunders

Doğa ve manzara resmi Viktorya Dönemi İngiliz sanat eleştirmenleri için ayrıcalıklı bir konuma sahiptir. Hareketin amaçları arasında doğadan gerçekçi bir üslupla çalışmak yer almaktadır. Doğaya yönelinmesi hususunu destekleyenlerin başında John Ruskin gelmektedir (Ruskin, 1848: 123-125).

19. Yüzyılda akademideki kadın ressamlar arasında manzara, yerleşik bir konuydu. Yüzyılın ortalarına kadar onların yapmış olduğu bu resimler görünümm şeklinde temsilden çok bir izlenim olarak ele alınmaktadır. Rosa Brett, Barbara Leigh Smith Bodichon, Joanna Boyce ve Anna Blunden gibi kadın ressamlar ise bu tarz resme özgün bir nesnellik ve maddesel olgunluk kazandırmışlardır. Bazı eleştirmenler Ön Raffaellocuların doğa resimlerinde pozitivist ve ampirik bakış açıları olduğunu belirtmişler ve doğanın bir bilimsel araştırma gibi doğrudan gözlemlenmesini erkeksilik ile özdeşleştirerek kadınların resimlerini yersiz bulmuşlardır. Kadın ressamlar çiçekleri resmetmişler ama "çiçek ressamı" olmayı reddetmişlerdir (Gerrish Nunn, 1987: 187). 
Barbara Leigh Smith Bodichon, Viktorya kadın hareketinin en sıradışı ve etkili lideriydi. Son derece yetenekli, enerjik ve özgün, feminist, hukuk reformcusu, ressam, gazeteci, George Eliot'un yakın arkadaşı ve Florence Nightingale'nin kuzeni idi. Bir ressam olarak, Bodichon, Raffaello öncesi kadın sanatçılar arasında hayati bir figür olarak tanınmaktadır. Bir feminist olarak evli kadınların yasal statüsü, çalışma hakkı, oy kullanma ve eğitim hakkı konularında dört büyük kampanya başlatmıştır. Yazar ve ressam olarak Bodichon kadını tüm ruh hallerinde yeniden canlandırmış ve onu kadın eşitliği mücadelesi bağlamına sıkıca yerleştirmiştir (Hirsh, 2002: 53-58).

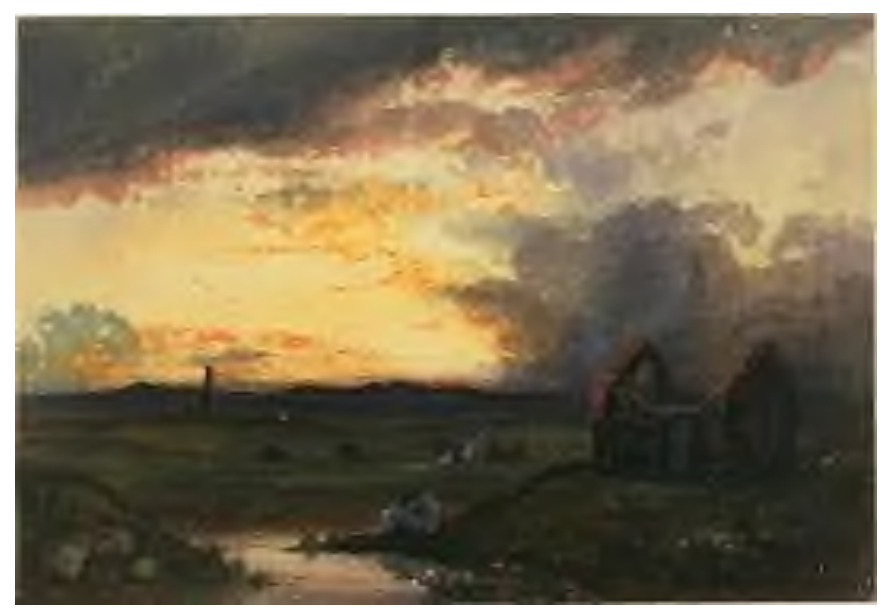

Resim 22: Barbara Leigh Smith Bodichon, Hayallerden Kaçış: Irlanda

Bodichon'un bilinen en erken resmi bugün Whitworth Gallery'de bulunan Hayallerden Kaçış: Irlanda 1846, (Res. 22) dır. Bu çalışma, hem sulu boya ressamlığı yeteneğini hem de günün meselelerine olan ilgisini göstermektedir, çünkü 1845-1851 yılları arasında İrlanda açlık ve kıtlıkla mücadele etmektedir. İnsanların çoğunun Amerika veya Avustralya’ya göç etmesine sebep olan patates kıtlığı felakete yol açmıştır. Tasvir edilen manzara, İrlanda'nın batısının terk edilmiş kır evleri ve yıkık bir manastırla birlikte hayali bir görüntüsüdür. Gökyüzündeki gemilerin hayalet direkleri muhtemelen İrlanda'dan uzaktaki ıssız figürü alacak ve güvenlik açısından kıtlığa değecek olanları ifade eder. Bodichon'un hem sosyo-politik durumu tanımasını hem de resim yapma becerisini birleştiren bu suluboya, Hollandalı manzara 
ressamlarının üslubunu yansıtır. Anna Mary Howitt'le buluştuktan sonra, Ön Raffaellocu tarzın, özellikle de tercih ettiği manzara türünde görülebileceği gibi ayrıntıya gösterilen dikkatli savunucusu olur (Bölüktaş, 2018: 17).

$\mathrm{Bu}$ kadın sanatçıların en gözdelerinden biri de Joanna Mary Boyce idi. Londra ve Paris'teki sanat okullarında eğitim almış ve Henry Tanworth Wells ile evlenmeden önce İtalya'yı gezen sanatçı, sergilenen çalışmalarıyla mükemmel övgüler almış. Elgiva (Res. 23), kraliyet mücadelesinde bir piyon olarak feda edilen bir Anglo-Sakson kraliçesidir. Resimlerinde sadelik ve doğruluk, renklerin parlaklığı ve heykelimsi duruşlar söz konusudur.

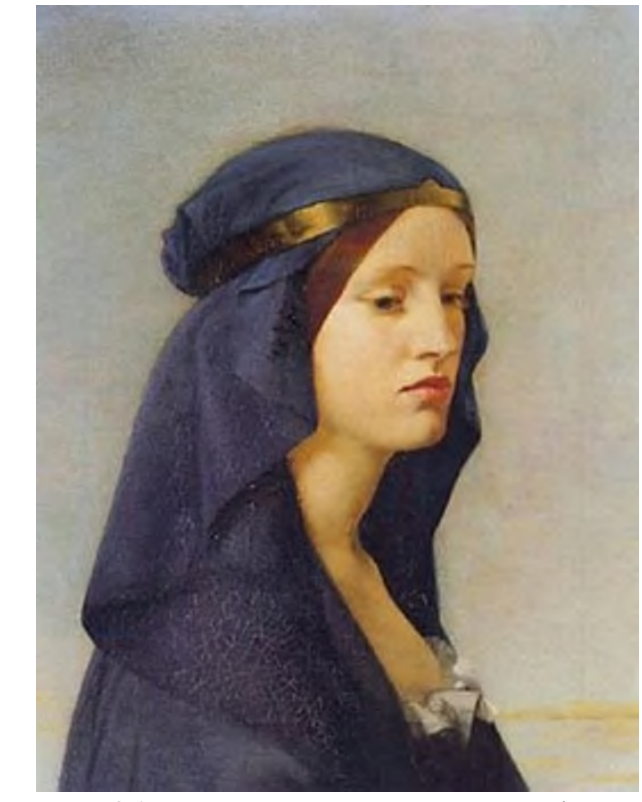

Resim 23: Joanna Mary Boyce, Elgiva

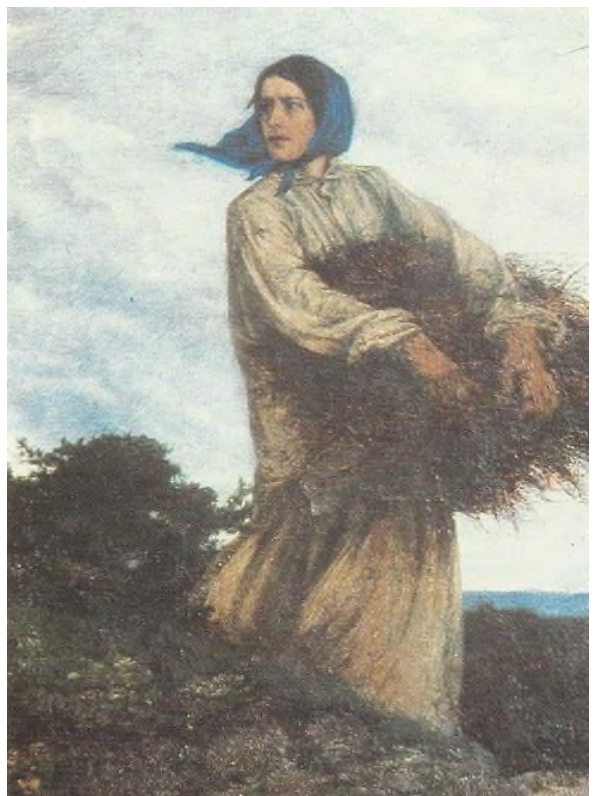

Resim 24: Joanna Mary Boyce, Çalı Toplayıcı

1850'lerde Boyce, çalışan kadınların ve hizmetçilerin resimlerine odaklanmıştır. Boyce'un - Çalı Toplayıcı (Res. 24) bunlardan biridir. Resim, Barbizon ekolü ve Fransız realistleriyle bir bağlantıyı düşündürmektedir. Çünkü Boyce Fransa'da bir dönem bulunmuştur. Boyce'un bu resimlerinde güçlü kadınları, katı bedenleri ve güçlü kollarıyla çalışan kadınları gerçekçi bir şekilde tasvir ettiği görülür (Gerrish Nunn, 1987:146-147).

Erken dönemde aktif ya da dramatik ilişki içindeki hem erkekleri hem kadınları içeren manzara ve figür resimleri Ön-Raffaelist resimler içinler genel bir malzemeyken sonraki dönemlerde 
hissi niyet dereceleriyle resmedilmiş ideal, alegorik ya da dekoratif kadın figürleri ve yüzleri William Rossetti'nin tam olarak yerleştirdiği gibi çiçek süslemeli kafalar - Ön-Rafaelloculuğun önemli bir özelliği haline gelmiştir. Kadınların eserleri bazı erkeklerinki kadar nadiren ifadesiz olsa da Ön-Raffaelit sanatta kadın sunumuna olan bu odaklanma iki yönlüydü. Bir yandan kadın figürleri ve grupları geleneksel olarak kadın sanatçılara verilen kısıtlı şartlar kapsamında ve genellikle kumaşlarla kaplıyken görgü kuralları sebebiyle dışlanmıyorlardı. Hangi özelliklere sahip olurlarsa olsun Rossetti'nin eserlerindeki 'bedensel güzelliğin imgeleri' gibi bu tür resimler geç Viktorya döneminde cinselliğin dile getirilişinin bir eseri ve katkısıdır. Ancak dikkatle incelendiğinde başarılı kadın ressamların eserlerinde detayları gerçekçi bir dille ifade ettikleri gözlenmektedir. Romantik bir ortaçağdan ya da genellikle Ön Raffaellocularla ilişkilendirdiğimiz kadınların duygusal görüntülerinden uzak olmayan figürlerdir (Cassou, 2006: 44-46).

Eleanor Fortescue Brickdale'in renkli illüstrasyonu olan Süt Sağmaktan Gelen Çiftçi Kızlar (Res. 25), Palgrave'nin 1919 yılında yayınlanan Altın Şarkılar ve Lirik kitabından Milton'ın L'Allegro (Allegro) adlı şiirinin de konusudur. Günlük yaşamdan bir sahneyi içermektedir. John Everett Millais'in Çiftçi Kızlar (Res. 26) çalışması da yine aynı dönemde betimlenen günlük yaşam sahnelerinden biridir. Brickdale'in süt sağmaktan gelen çitçi kızlarında kırsal manzarada iki kız figürü yer alırken Millais'in çiftçi kızında bir figür ve yine kırsal manzara içinde üstlerindeki kıyafetleriyle ellerinde tuttukları süt güğümleri oldukça doğal bir betimlemeyle karşılaşmaktayız. Ancak Brickdale'in figürleri köyden kişiler gibi oldukça gerçekçi işlenirken Millais'in modelinin adeta bu resim için poz verdiği anlaşılmaktadır (Gerrish Nunn, 2001: 71). 

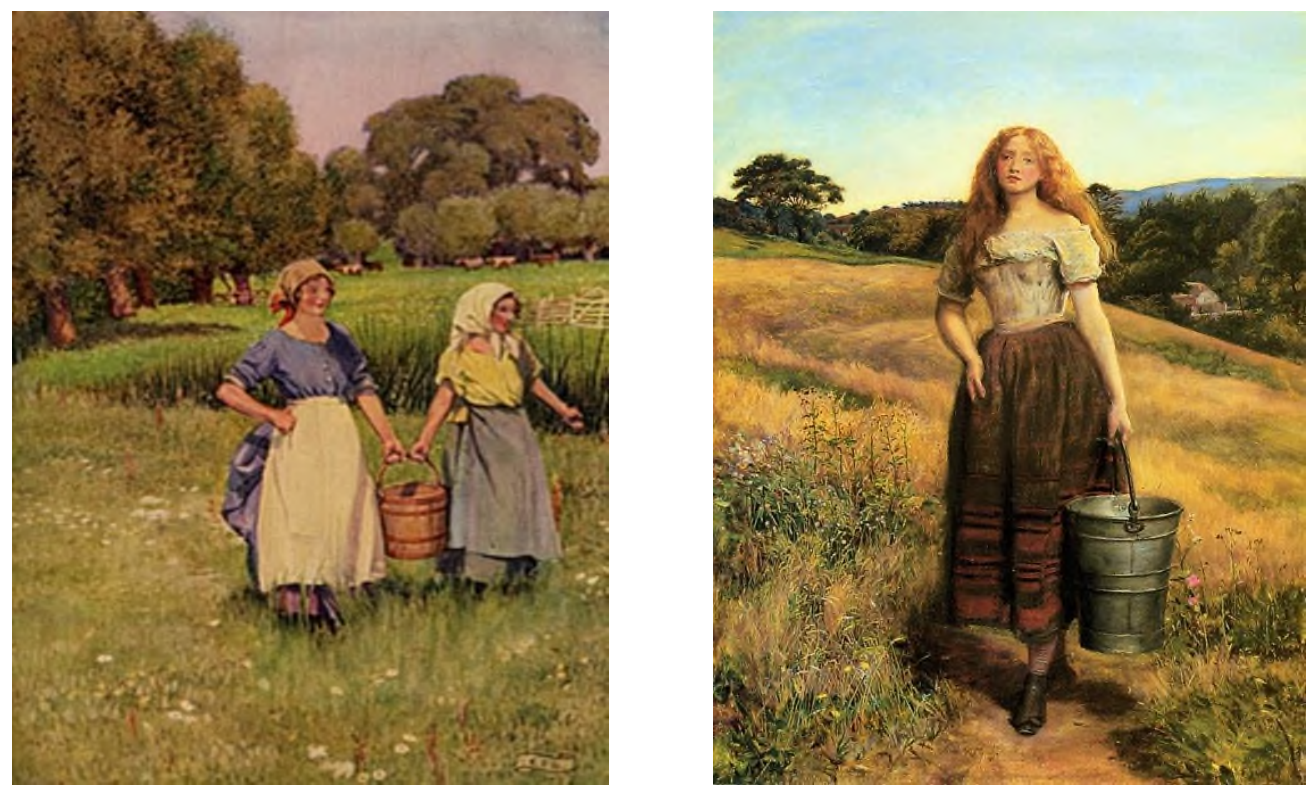

Resim 25: Eleanor Fortescue Brickdale Süt Sağmaktan Gelen Çiftçi Kızlar Resim 26: John Everett Millais, Çiftçi Kızlar

Bir portre ressamı olarak beceri kazanmış olan Emma Sandys'in, çok sayıda kadın portresi yaptığg bilinmektedir. Bunlardan biri Viola'nın portresidir ki (Res. 27) ve Dante Gabriel Rosetti’nin Monna Vanna'sı (Res. 28) ve diğer kadın portreleriyle kıyaslandığında, Sandys'in sık sık kıyafetlerinde ve mücevherlerinde görkemli ayrıntıları kullandığını görebiliriz: saçlarında ve boynunda inciler, mücevher tonlarında kumaşlar, bağcıklı kenarları vb. Sandys'in çalışmaları kesinlikle Ortaçağ etkili bir Ön Raffaellocu tarzı yansıtmaktadır. Rosetti'nin de Monna Vanna portrelerindeki kadınların gerçekçi detaylarla işlendiği anlaşılmaktadır. Monna Vanna adlı portre eseri 1860'ların ortalarında sanatçının ürettiği güzel ve sansasyonel kadınların bir dizi dekoratif resimlerinden biridir. Omuzlarından aşağıya dökülen kumral saçlarındaki spiral inci toka ve kırmızı mercan kolye Rossetti'nin kadın resimlerinde sıkça ortaya çıkar. Kolların genişçe birleşme hareketi, omzundaki yeşil rozetler ve çiçek küpeler ile birlikte resmin dairesel kompozisyonunu vurgulamaya yardımcı olurlar (Campbell Orr, 1995: 120). 


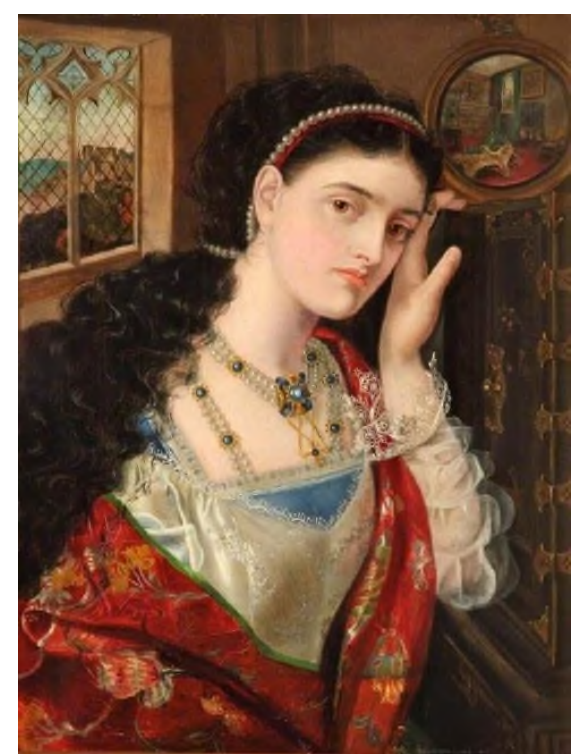

Resim 27. Emma Sandys, Viola

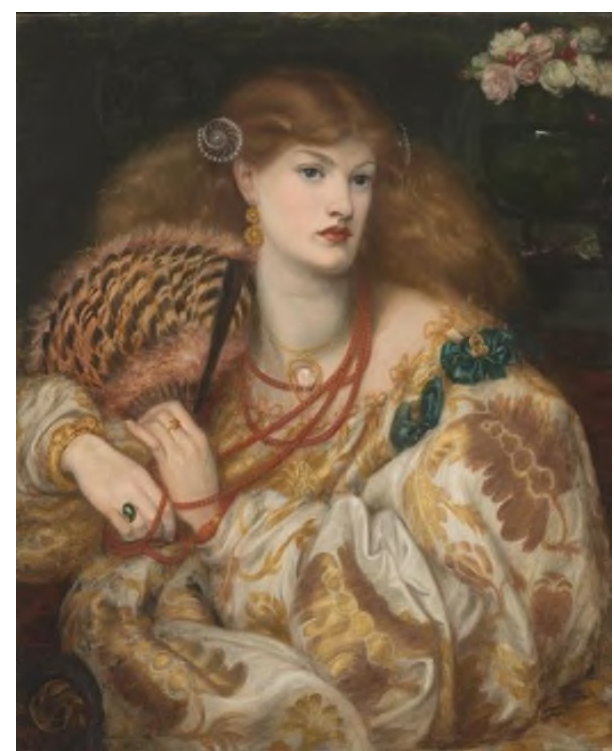

Resim 28: Dante Gabriel Rosetti, Monna Vanna

Ön Raffaellocu ressamlar tarafından resimlenen bu modeller iri gözlere ve geniş göz kapaklarına sahip; uzun boyunlu, kalın ve gür saçlıdırlar. Genellikle çoğu fakir ve eğitimsiz, orta sınıftan olan bu kadınlar, bir süre sonra üst sınıf sanat camiasının ve edebi şahsiyetlerin ve de Ön Raffaellocu ressamların eşleri ve sevgilileri olarak önemli bireyler haline gelirler. $\mathrm{Bu}$ kadınların görünüşlerine bakıldığında oldukça değişkendir, kesin bir güzellik ideali söz konusu değildir. Siddal ateşli kızıl saçlı ve soluk tenlidir ve diğerlerinden daha sade bir yüze sahip olduğu düşünülse de, resimlerde hüzünlü ve son derece durgun betimlenir. Bu durum da onun cazibesini arttırırken bir taraftan miskin bir duruş ve ifade verir. Elizabeth Siddal'ın aksine, Jane Morris siyah saçlı ve kalın kaşlı esmer güzelliği temsil eder. Rossetti’nin eserlerine sayısız kez modellik yapmıştır. Muhteşem bir yüz ve güçlü ifadeye sahip olmasına rağmen, fotoğraflarda görünüşüyle gizemli sessiz bir havası vardır. Ustaca bir masumiyet ve davetkar havasıyla çekicidir. Sandys gibi dönemin pek çok kadın ressamı Ön Raffaellocu erkek ressamlardan ders aldıkları gibi onlar da benzer konularda eser üretmiştir. Kadın yüzlerine baktığımızda kadın modellerin yalın, durgun iri gözler ve geniş göz kaplarına sahip olduğunu; giysilerin ve arka planda kullanılan nesnelerin verilişinde sembolik anlamlarla birlikte gerçekçi bir üslubu yansıttıklarına tanık oluruz (Marsh-Gerrish Nunn, 1989: 90). 

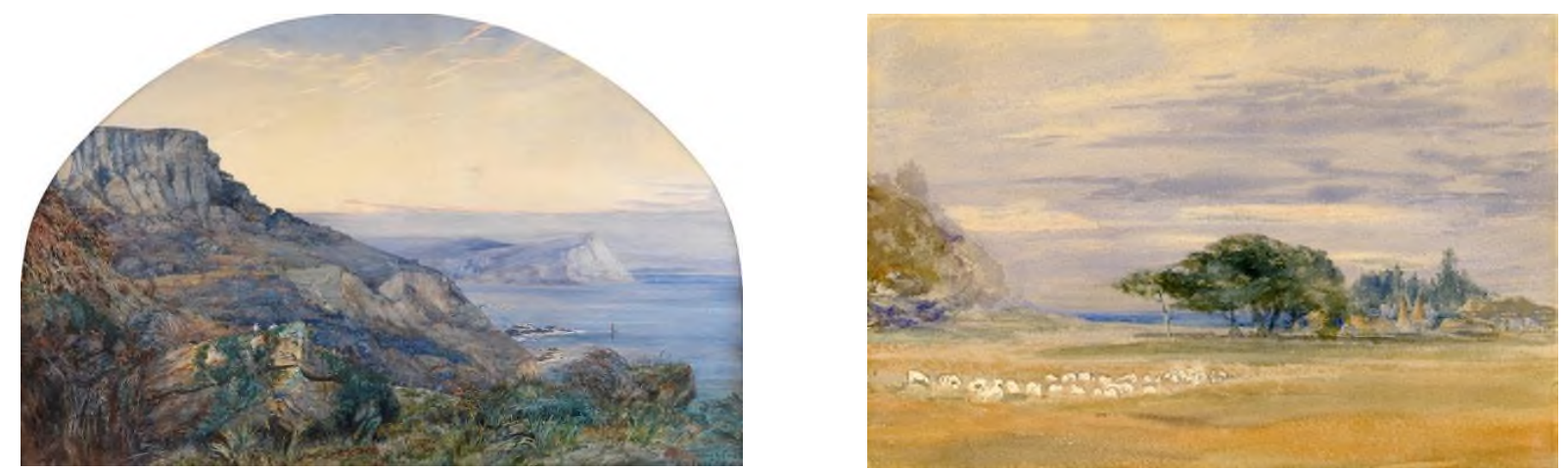

Resim 29:Barbara Bodichon, Ventnor'da Wight Adası Resim 30: Barbara Bodichon, Kuzularla Deniz Kenarında Bir Yer

Doğa ve manzara çalışmalarında da aynı etkilere sahip dönemin ve akımın gerek erkek gerek kadın ressamların birbirine benzer aynı teknik ve üslupla başarılı örnekler sergilediği anlaşılmaktadır. Barbara Bodichon, Ventnor'da Wight Adası (Res. 29) ve Kuzularla Deniz Kenarında Bir Yer (Res. 30) ile William Holman Hunt'un Asparagus Adası (Res. 31) ve Fairlight Tepeleri (Res. 32) doğa manzaraları 19. Yüzyılda İngiliz sanatçılar ve kadın ressamlar arasında yerleşik bir konuydu. Yüzyılın ortalarına kadar onların yapmış olduğu bu resimler görünüm şeklinde temsilden çok bir izlenim olarak ele alınmaktadır. Rosa Brett, Barbara Leigh Smith Bodichon, Joanna Boyce ve Anna Blunden gibi kadın ressamlar ise bu tarz resme özgün bir nesnellik ve maddesel olgunluk kazandırmışlardır. Bazı eleştirmenler Ön Raffaellocuların doğa resimlerinde pozitivist ve ampirik bakış açıları olduğunu belirtmişler ve doğanın bir bilimsel araştırma gibi doğrudan gözlemlenmesini erkeksilik ile özdeşleştirerek kadınların resimlerini yersiz bulmuşlardır (Marsh-Gerrish Nunn, 1989: 155-160).
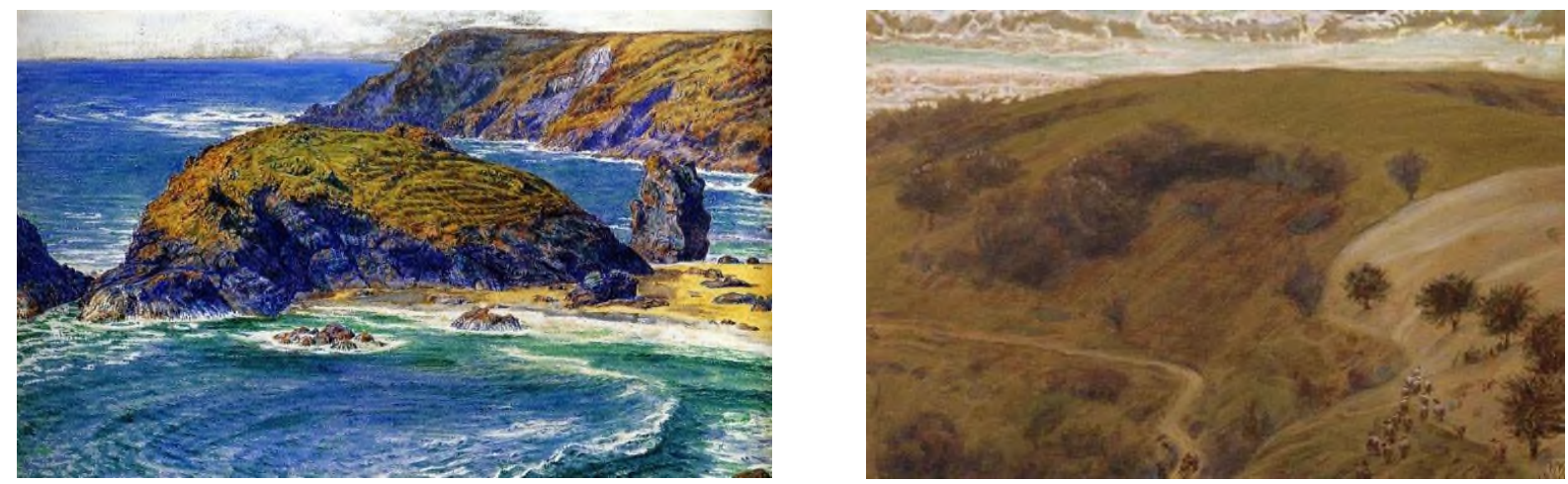

Resim 31: William Holman Hunt Asparagus Adast Resim 32: William Holman Hunt, Fairlight Tepeleri 


\section{Sonuç}

$\mathrm{Bu}$ çalışmada yer alan sanatçıların yaşamları ve eserleri ile ilgili erişilebilir bulgular diğerlerinden daha az gözle görünür şekilde tasvir edilmesine rağmen kadın sanatçıların ÖnRafelloculuğa nasıl karşılık verdikleri, kariyerlerinin ve şöhretlerinin nasıl şekillendiği, kabul edildiği yollar ve ürettikleri resim türleri bakımından bazı genel ifadelerde bulunulabilir. 1850lerin başlarında Ön-Rafaellocular girişiminin Anna Howitt ve Joanna Mary Boyce gibi eğitimli sanatçıları, tazeliği ve yaratıcılığı, ciddiyeti ve idealizm duygusu ile nasıl cezbettiğini görüyoruz. Bu sanatçılar erkekler ile yarım yamalak bir anlaşma ile başarılı ve yenilikçi ressamlar olarak gelişmiştir - ya da gelişiyor gibi görünmüştür. Ailevi şartları resmi eğitim almasını engelleyen Siddal gibi bir sanatçı için Ön-Rafaelloculuk ve onun sosyal çevresi bireysel cesaret ve eserlerinin sade niteliğine bir yanıt vermiştir. Brett ve Blunden gibi nispeten kısıtlanmış ve dar görüşlü çevrelerdeki diğer sanatçılar sanatın kuşatabilecekleri yönlerine değer veren amaçları - ahlaki ve dini temalar, manzaralar ve hassaslık - ile bu tarza sempati ile karşılık vermiştir. Bu sanatçılar bu akımın fikirlerinde kendi sanat uygulamalarını geliştirme dürtüsünü bulmuşlar.

Bu erken dönemde Ön-Rafaelloculuk aslında kadınlara karşı genellikle arkadaşça olarak tanımlanabilir. Kardeşliğin genç erkekleri ne kadınlara ne de sanata karşı tavırlarında sonradan öyle olmuş olsalar da - karşıt değildi. Ayrıca, Ön-Rafaelloculuğun çoğu ailelerindeki kadınları çizmeye ve sergilemeye teşvik ettiği de bilinmektedir. Kısacası çok fazla çıkarımda bulunmamak gerekse de Ön-Rafaellocu hareket kendini kadınlara karşı düşman ya da kibirli olarak göstermemiş ya da ortaya çıkmamıştır.

Sanatçılar 1860'ların sonunda ve 1870'lerde kariyerlerine başladığında ÖnRafaelloculuk İngiliz sanatının oturmuş bir gerçeği haline gelmiştir. Lucy ve Catherine Madox Brown babalarından Emma Sanyds erkek kardeşinden öğrenmiştir. Kadın sanatçıları cesaretlendirme konusunda her zaman cömert olan - Ford Madox Brown'un çocuğu olarak 
Marie Spartali klana katılmıştır. Evelyn De Morgan Pickering'in de amcası vasıtasıyla bir aile bağı vardır ancak Slade Okulu'ndan ayrıldıktan sonra Ön-Rafaelloculuğa giden yolunu kendisi bağımsızca bulmuş gibi görünmektedir. Bu dönemde de Ön-Rafaelloculuk sanatçılara doğruluk kriterini oluşturmak yerine hayal gücü ve ifadeyi teşvik eden bir resim tarzı sunmuştur. Ancak kadınlar Ön-Rafaelloculukta çalışılacak nispeten cana yakın sanatsal bir çevre bulduysa da istisnalar da olmuştur. William Holman Hunt'ın kız kardeşinin çabasını önemsememesine ve Rossetti'nin dişiliğiyle ile ilgili geleneksel görüşleri hayal kırıklığına uğrayarak ifade etmesine neden olarak zaman içerisinde kaybolmuştu. Bazı sanat derneklerine katılmaları ya da sergi açmaları için kadınların asla davet edilmediği gibi durumlarla karşılaşmışlardır. Yanı sıra başka zorluklarla da yüz yüze gelen kadınların 19. yüzyıl İngiltere'sinin burjuvazi kültüründe sanat uygulamasında karşılaştıkları engeller $\quad$ söz konusu olmuştur. Bu bazıları için geçerli olmamış, örneğin Boyce genellikle hor görülmektense övülen bir sanatçı olarak hayranlık görmüştür - ancak bunun çalışmalarında sınırlı etkisi olmuş gibidir, çizim ya da kompozisyon alışkanlıkları nispeten değişmeden kalmıştır.

Ön-Rafaelloculukta figür konusu ile ilgili bir sorun mevcuttur. Erken dönemde aktif ya da dramatik ilişki içindeki hem erkekleri hem kadınları içeren manzara ve figür resimleri ÖnRafaelist resimler içinler genel bir malzemeyken sonraki dönemlerde ideal, alegorik ya da dekoratif kadın figürleri ve yüzleri - William Rossetti'nin tam olarak yerleştirdiği gibi çiçek süslemeli kafalar - Ön-Rafaelloculuğun önemli bir özelliği haline gelmiştir. Sandys, Spartali, Madox Brown ve Birckdale bu usulde eserler üretirken Pickering'in eserleri nispeten modern tarzda tam boy kadın figürü içeriyordu. Kadınların eserleri bazı erkeklerinki kadar nadiren ifadesiz olsa da Ön-Rafaelit sanatta kadın sunumuna olan bu odaklanma iki yönlüydü. Bir yandan kadın figürleri ve grupları geleneksel olarak kadın sanatçılara verilen özne şartları (savaşların ve gemi enkazlarının aksine) kapsamındayken ve genellikle kumaşlarla kaplıyken görgü kuralları sebebiyle dışlanmıyorlardı. Fakat kadınlığın izleyicinin memnuniyetine yönelik 
albenili ya da ilgi uyandıran bir görüntü içinde temsili bu eserler erkek müşterilere satıldığı için kadın ya da erkek sanatçılar için farklı bir uygulamaydı. Diğer hangi özelliklere sahip olurlarsa olsun Rossetti'nin eserlerindeki 'bedensel güzelliğin imgeleri’ gibi bu tür resimler 1899'da tasvir edilene tam uyarak geç Viktorya döneminde cinselliğin dile getirilişinin bir eseri ve katkısıdır.

Belirli bir ölçüye kadar Sanat ve El Sanatları Akımının yükselişi kadın sanatçıları olumsuz etkilemişti. Toplum bir taraftan uygulamalı sanatların yeniden değerlendirmesinde daha fazla kadının sanat uygulamasına katılmasını ve erkeklerle bu onuru paylaşmasını mümkün kılmış, diğer taraftan kafa ve el, eril ve dişil arasındaki ayrım 'güzel sanatlar' uygulamasını temel olarak erkek uygulayıcılara ayırarak kadınları 'dekoratif sanat' köşesi içinde tutmaya eğilimliydi. Sonuç olarak Ön-Rafaelloculuk bir hareket olarak hiçbir kadını erken Millais, Rossetti, Madox Brown ya da Burne-Jones'un yanı sıra saygınlık konumuna yükseltmemiştir.

Kadın ressamların dışında model olarak Ön Raffaelloculuk hareketi içinde beliren kadınlar ressamlar için önem arz ediyordu. Bunlar, Ön Raffaellocu Kadın Ressamları Kardeşliği, Ön Raffaellocu Erkek ressamları Kardeşliği için model olarak kullanılan ve bunlarla ilişkili olan kadınlardır. Bu kadınlar çekici oldukları için Ön Raffaellocu erkek ressamalr tarafından kabul edilip seçildiler. Genellikle çoğu fakir ve eğitimsiz, orta sınıfta yer alan bu kadınlar, bir süre sonra üst sınıf sanat camiasının ve edebi şahsiyetlerin yanı sıra Ön Raffaellocu ressamların eşleri ve sevgilileri olarak önemli bireyler haline geldiler.

Her ne kadar feminist bir bakış açısı yalnızca fiziksel değerlerine odaklandığını iddia edebilse de, bunun ötesinde resimlerde bu kadınların gücü, tarihi ve gizliliği belirgin bir şekilde görülmektedir. Sanat aracılığgyla, günlük Viktorya yaşamlarında olacağından daha yüksek bir konuma getirilmişlerdir. Görüldüğü üzere kadın figürünün, Ön Raffaellocu kadın ressamların eserlerinde hem mental hem de fiziksel olarak güçlü olduğu, resmedilen keder ve acı olsa bile 
karakterlerin daha soylu, iradeli ve dayanıklı olduğu anlaşılmıştır. Ve erkek ressamların öteki tasvirleri, kadınların kadınlarından farklı olduğu tespit edilmiştir.

\section{Kaynaklar}

Campbell Orr, C. (1995). Women in the Victorian Art World, Manchester: Manchester University Press. p. 120.

Carpenter, W. M. (2010). Health, medicine, and society in Victorian England. London: Greenwood Publishing.

Cassou, J. (2006). Sembolizm Sanat Ansiklopedisi. (çev. İnce Ö., Usmanbaş, İ.).İstanbul: Remzi Kitabevi A.Ş.

Gerrish Nunn, P. (1987). Victorian women artists. London: The Women's Press Limited.

Gerrish Nunn, P. (2001). We are not a muse. Women artists and the Russell-Cotes collection. (Ed. Mark Bills). Art in the age of Queen Victoria. Bournemouth: Russell-Cotes Art Gallery and Museum Press, pp. 68-87.

Gray, S. (2009). Emma Sandys. Dictionary of British Women Artists: London: The Lutterworth, p. 231.

Günay Topallı, E. (2001). 19. Yüzyılda Osmanlı İmparatorluğu'nda çalışan İngiliz Oryantalist ressamlar. Yayınlanmamış doktora tezi, İstanbul Üniversitesi, İstanbul.

İnankur, Z. (1993). Pre-Rafaelit resim akımında ikonografi. Sanat Tarihinde İkonografik Araştırmalar Güner İnal'a Armağan. Ankara: Hacettepe Üniversitesi.

İnankur, Z. (1989). Pre-Raphaelite Kardeşliği. Sanat Tarihinde Doğu'dan Batıya Ünsal Yücel Anısina Sempozyum Bildirileri. İstanbul: Güzel Sanatlar Matbaası.

Kiriş, H. (2007). Sembolist resimde tenebrizm ve ölüm konusuna bakış. Yayınlanmamış yüksek lisans tezi. Mimar Sinan Güzel Sanatlar Üniversitesi, İstanbul.

Marsh, J., Gerrish Nunn, P. (1989). Women artists and the Pre-Raphaelite movement. London: Virago Press.

Mitchell, S. (2009). Daily life in Victorian England. London: The Greenwood Press.

Rona, Z. (1997). Ön Raffaellocular. Eczacıbaşı Sanat Ansiklopedisi, C. 3, İstanbul: YEM Yayınları.

Sevin, N.A. (2002). 19. Yüzyılda Yakındoğu'ya giden İngiliz kadın sanatçılar. Uluslararası Sanat Tarihi Sempozyumu Bildirileri Gönül Öney'e Armağan. İzmir: Ege Üniversitesi 
Shanley, M. L. (1989). Feminism marriage and the law in Victorian England. New Jersey: Princeton University Press.

Tanilli, S. (1999). Yüzyılların gerçeği ve mirası, 19. Yüzyıl: İlerlemeler ve çelişmeler. İstanbul: Adam Yayınları.

Yaşdağ, M. (2013). Pre-Rafelit dönemi resimlerinde sembolizm. Yayınlanmamış doktora tezi, Ankara Üniversitesi, Ankara.

Hirsh, P. (November 2002). Barbara Leight Bodichon-Feminist, artist and rebel. Woman's Art Journal 22(2): 44-58.

Plasa, C. (1992, Autumn-Winter). Cracked from side to side: Sexual politics in "The Lady of Shalott". Victorian Poetry, 30: 247-263.

Siddal, B. L. (2012, Autumn). The sad, short life of Elizabeth Siddal pre-Raphaelite model and artist. Pre-Raphaelite Society Review. www.pre-raphaelitesociety.org

Bölüktaş, C. (2018). Pre-Rafaelit kadın ressamlar ve ilham perileri. 12 Nisan 2019, http//www. academia.edu.tr

\section{Görsel Kaynakçası}

http://www.artcyclopedia.com/artists/brown_lucy_madox.html https://www.delart.org/collections/british-pre-raphaelites/ https://www.delart.org/exhibits/politics-and-paint-barbara-bodichon/ http://www.liverpoolmuseums.org.uk/ladylever/exhibitions/eleanor/ http://www.victorianweb.org 


\title{
AN INQUIRY ON THE CONCEPT OF MOTHERHOOD: 'MOTHER?' MIXED CERAMIC EXHIBITION EXAMPLE
}

\section{Tuba KORKMAZ ${ }^{1}$}

\begin{abstract}
Motherhood, which has various meanings throughout history, is generally seen as a concept conjoined to being a woman, even in different cultures. The masculine perspective in the political, social and economic processes through the role and identity of being a mother, ignores the feelings and moods produced by women on the concept of motherhood, and shapes the social structure especially through the media by means of the codes they create with the list of what should be.

A mixed ceramic exhibition, titled 'Mother?', was held on 24-30 May 2019 at Çanakkale State Fine Arts Gallery in order to be aware of this situation and to reconsider. Masculine perspective was disabled by inviting especially female ceramic artists to the exhibition. Ceramic material was particularly restricted in the exhibiton. Because throughout history, the first owner of terracotta work from different cultures is usually women. When this business became a craft that could be turned into money, it was taken from the production of women by men. Therefore, ceramic material has a special meaning. 47 female ceramic artists from Turkey participated in the exhibition, their ideas and emotions on the subject of motherhood shaped with ceramic materials were exhibited regardless of whether they had the experience of being a mother or not. In the catalog, the thoughts of the artists about their work or independently about motherhood are also written.

This exhibition bringing together ceramic artists as an activity of Çanakkale Onsekiz Mart University Women's Studies Application and Research Center aims to provide artistic, cultural and social interaction and to reflect on the concept of motherhood. Thanks to this written study on the exhibition, the sub-text, philosophical foundations and results of an inquiry created in the field of plastic arts will be recorded.
\end{abstract}

Keywords: Ceramic, Woman, Mother, Exhibition, Art

\footnotetext{
${ }^{1}$ Dr. Lect. Çanakkale Onsekiz Mart University, tubakorkmaz@ comu.edu.tr;
} 


\section{ANNELIK KAVRAMI ÜZERINE BİR SORGULAMA: ‘ANNE?' KARMA SERAMİK SERGISİ ÖRNEĞİ}

$\ddot{O} z$

Tarih boyunca çeşitli anlamlar yüklenmiş 'annelik' farklı kültürlerde de olsa genellikle kadın olma haline yapışık bir kavram olarak görülmektedir. Anne olma rolü ve kimliği üzerinden siyasi, sosyal ve ekonomik süreçlerdeki eril bakış açısı kadınların 'annelik' kavramı üzerine ürettikleri duygu ve ruh durumunu çoğunlukla yok sayarak, olmast gerekenler listesi ile oluşturdukları kodlarla özellikle medya üzerinden toplumsal yapıya yön vermektedir.

Bu durumun farkında olmak ve üzerine tekrar düşünmek üzere 24-30 Mayls 2019 tarihleri arasında Çanakkale Devlet Güzel Sanatlar Galerisi'nde 'Anne?’ başlıklı bir Karma Seramik Sergisi gerçekleştirilmiştir. Sergiye özellikle kadın seramik sanatçıları davet edilerek eril bakış açısı devre dışı bırakılmıştır. Sergide özellikle seramik malzeme sınırlaması getirilmiştir. Çünkü tarih boyunca farklı kültürlerde pişmiş toprakla yapılan her türlü işin ilk sahibi genellikle kadınlardır. Bu iş, paraya döndürülebilir bir zanaat halini aldığında erkeklerin eline geçerek kadın üretiminden çıkartılmıştır. Bu sebeple seramik malzeme özel bir anlam içermektedir. Sergiye Türkiye'den toplam 47 kadın seramik sanatçısı katılmış, sanatçıların anne olma deneyimi yaşayıp yaşamadığı gözetilmeksizin bir kavram olarak annelik mevzu üzerine fikirlerinin ve duygularının seramik malzeme ile şekil bulmuş halleri sergilenmiştir. Çıkarılan katalogda sanatçıların çalışmalarılla ilgili ya da bağımsız olarak annelik üzerine düşüncelerine de yazılı olarak yer verilmiştir.

Çanakkale Onsekiz Mart Üniversitesi Kadın Çalışmaları Uygulama ve Araştırma Merkezi etkinliği olarak seramik sanatçılarını bir araya getiren bu sergiyi düzenleyerek sanatsal, kültürel ve sosyal etkileşimi sağlamak ve annelik kavramı üzerine düşündürmek amaçlanmıştır. Sergiye dair yapılan bu yazılı çalışma sayesinde de plastik sanatlar alanında oluşturulmuş bir sorgulamanın alt metni, felsefi temelleri ve sonuçları kayıt altına alınmış olacaktır.

Anahtar Kelimeler: Seramik, Kadın, Anne, Sergi, Sanat 
IIster erkek olalım, ister kadın, öteki cinsiyet her zaman kadın cinsiyetidir.

(Schaeffer, 2015;173)

\section{Toplumsal Cinsiyet Rollerinde Kadın ve Annelik}

Varoluş en temelde doğum ile başlıyorsa, varlık üzerine konuştuğumuzda doğum, doğurganlık ve annelik konuları da tartışılmaya başlanır. En basit tanımıyla 'anne' doğuran kadındır. Varlığımızın temel noktası, başlangıç yerimizdir.

Bugün kadını algılayışımızda, toplumda kadının yeri bakımından en önemli ayrımlardan birine sebep olan 'annelik' her haliyle bir tür yargı nesnesi olmuştur. En önce 'anne olmak' ya da 'olmamak' veya 'olmamayı tercih etmek' birkaç farklı bakış açısıyla toplumsal anlamda kadının yerini belirleyen bir pozisyondur. Anne olanlar ve olmayanlar arasındaki hiyerarşi hem toplum hem de kadınlar tarafindan tekrar tekrar üretilmektedir. Annelik kurgusunun hâlâ kadınları kategorize eden ve anne olmayı tercih etmeyenler kadar edenlerin de üzerinde baskı yaratan bir içeriği var. "İdeal anne" söylemiyle birçok ikilik yaratıliyor ve bu ikilikler tüm kadınları etkiliyor.' (Sever, 2015;72). Anne olanların olmayanlara karşı geliştirdiği 'eksiklik' söylemi ve anne olmayanların da annelere karşı sunduğu 'modern, kariyerine düşkün kadın imajı karşılıklı olarak birbirini besleyen ve her iki tarafından da baskıcı ve eril sistemin destekçisi bir hal içindedir. Anne olan kutsaldır, dokunulmazdır gibi algılarımızın yanında, anne olmak istemeyen kadın bencildir, yapacak daha önemli işleri vardır düşüncesi ataerkil toplumda ve patriarkal düşünce içinde kadın için 'mahalle baskısı' yaratan bir değerdir. Anne olmayı tercih etmiş -yahut düşünmeden bu durumun içinde kendini bulan kadın- sonrasında da yine aynı rolü üzerinden puanlanmaya devam etmektedir. Örneğin 'ideal anne' olmak, 'fedakâr anne’ olmak, ‘çok çocuklu anne olmak, ‘çalışan anne' olmak... gibi örneklerini çoğaltabileceğimiz çeşitlilikleriyle 'annelik' kavramı kadının sosyal statüsünü, toplumsal yerini belirleyen en önemli rollerinden birisidir. Biyolojik annelik bir yana manevi yönden de 
edinilebilecek bir rol olan bu kavram toplumsal açıdan kadına artı değerler yükleyen bir duruş verir. Günümüzde etik açıdan toplumsal değerlere uygun düşmediği iddia edilen davranışları sergileyen popüler kişilerin bile 'annelik' rollerini kullanarak tüm saldırıları bertaraf ettiğini izleyebiliriz. O güne kadar yaptıkları hata kabul edilen ve toplumca dışlanan kadınların, ‘anneyim ben!' söylemi üzerinden tüm hataları görmezden gelinebilmektedir.

Annelik kadınlar için erkekler tarafından verilmiş bir ödev ve görev niteliğindedir. $\mathrm{Bu}$ konuyla ilgili yapılan çalışmalardan biri olan 1988 yılında DPT tarafından yirmi bin civarı hane halkı ile yapılan ankette "kadınların aile içindeki en önemli görevi" olarak ev işlerini yapmak, çocuklarını yetiştirmek, onları terbiye etmek, eşine ve çocuklarına manevi destek olmak, çocuklarına ve kocasına bakmak, çocuk doğurmak ve aile bütçesine katkıda bulunmak şeklinde sıralanmıştır (Aktaş, 1993;55). Anne olmak, ataerkil kültürde kadına atfedilmiş bir ödev, vazife niteliğindedir.

Peki günümüz anneleri nasıldır? Sağlıklı bir psikoloji ve biyoloji ile anne olmayı tercihen üzerine almış modern kadınlar da kendilerini farklı bir karmaşa noktasında bulabilmektedir. Alternatif annelik üzerine açılmış sosyal medya hesaplarının ve video kanallarının popülerliği göstermektedir ki günümüzün modern anneleri rollerini en iyi şekilde oynayabilmek adına araştıran, okuyan, en yeni bilimsel veriler eşliğinde çocuğunun bakımını düşünen kadınlardır. Alternatif yöntemler eşliğinde deneyerek ve araştırarak anneliğe yeni bir bakış açısı getirmişlerdir.

Annelik içgüdüsü bugün birçok bilim insanı tarafından tartışılmaktadır. Freud'a göre anne ve kızı arasında kurulan bir bağ mümkündür. Örneğin kızı doğum yapınca bir anne kasılmalar hissedebilir, sütünün geldiğine dair belirtiler hissedebilir ya da aniden âdet kanamaları başlayabilir.' (Schaffer, 2015;178). Emziren anneler bebeklerinin ağladığını duyunca memelerinden süt aktığını görürler, bu da kesinlikle bir şartlı reflekstir. (Drenth, s:57) $\mathrm{Bu}$ ve benzeri örneklerin çoğaltılması, anneliği öven cümlelerin, doğaüstü sayılabilecek 
bağlantılarının kurulması bir devlet politikası olarak çoğalmayı şart koşan ataerkil sistemlerde annelik mitini yaratan içgüdüsel tarafın beslenmesi olarak da görülebilir. Annelik içgüdüsü ile ilgili olarak Bruno Battelheim şunları söylemektedir:

"Hayatım boyunca, anneleri onlardan nefret ettiği için hayatları mahvolmuş çocuklarla çalıştım. [...] Bu, annelik içgüdüsünün olmadığının (elbette böyle bir içgüdü yoktur, eğer olsaydı benden destek alma ihtiyacı olanlar bu kadar kalabalık olmazdı) ve çocuklarını reddeden bir sürü anne olduğunun kanıtıdır." (Badinter 2011, 52).

Aydınlanma düşüncesi, ruhta cinsel ayrılığı reddetmiş, cinslerin eşitliğini ilan etmiş ve insanı burjuva erkeği ile eşitlemişti. Bu yaklaşım, onun kadına özgürlük ve eşitlik verme çabalarının bir ifadesiydi. Ne var ki burjuva toplumu kazançlarını (ve yerini) sağlamlaştırdığında ve geliştirici politik pozisyonundan geriye adım attığında, artık cinsler arasındaki eşitliğe gerek ve ihtiyaç kalmamıştı. Şimdi artık onun, kadının ve erkeğin toplumsal olarak eşitsizliği talebine temel olarak, cinsler arasında doğal bir fark olduğunu ileri süren bir teoriye ihtiyacı vardı. Bu yeni teori psikolojik kavramlarla derinleşirken, 'kadının onuru' gibi ince sözler, sadece erkeğin hizmetçisi olarak, kadının bağımlılığını sürdürmesi durumunun devamını sağlamaktan başka bir işe yaramıyordu (From, s:32). Bu bağlamda bakıldığında annelik, kadının politik olarak beklenen toplumsal cinsiyet rolünü cilalayan bir kavramdır.

Soru şu ki, annelik rolünü üzerine almak sanatçıyı ne kadar etkiler? Bu soruya cevap ararken 'kadın' olmanın sanatçı olmayı ne kadar etkilediğiyle başlamamız gerekir. İnsanoğlu tarım toplumuna geçiş yaptığından bu yana anne olsun ya da olmasın 'kadın' ataerkil toplumlarda arka planda kurgulanmıştır. Bu duruşu onu çocuk doğurmak ve bakmakla yükümlü kişi olarak sosyal hayattan alıkoymuştur. Sanayi toplumunun ihtiyacı olan işgücü için kadınlar tekrar çalışmaya çağırıldığında ise onlardan beklenen rollerde çalışma yaşamının yanında taşınması gereken yüklerin arasına katılmıştır. Bilim ve sanat alanlarında uzun yıllar yok sayılan kadın ancak son yüzyıl içinde kendini var etme mücadelesine girebilmiştir. Özellikle sanat alanı 
ele alındığında kadın uzun yıllar sanatın öznesi değil objesi olarak kabul edilmiş, Feminist hareket ile birlikte 'sanatçı' olarak müzelerde, galerilerde yer almayı başarabilmiştir. '1990’lı yıllarda Batı Sanat tarihinin belli başlı imgelerini kimlik olgusu üzerinden yeniden kurgulayan sanatçı Yasumasa Morimura, bir söyleşisinde şöyle diyor: 'Erkekler erkektir, kadınlar kadındır, babalar babadır, anneler annedir, Japonlar Japondur, Amerikalılar Amerikalıdır... İnsanların dahil edildikleri kategoriler, sürekli olarak dış dünya tarafindan dayatılır. Gene de tek tek her bireyin zihninde ve bedeninde, toplumun ona yüklediği ad, işlev ve konumun sınırlarını kat kat aşan unsurlar bulunur. Bunlar gri bölgelerdir. Ve günlük yaşamda genellikle su yüzüne çıkmayan bu gri bölgelere biçim kazandıran şey, sanattır.' (aktaran Antmen, s:11)

Kadın, kendisine özgürlük alanı da kazandıran sanat alanındaki yerini büyük mücadelelerle alabilmiştir. Bu noktada Guerilla Girls'ün yaptıklarını anmadan geçmemek gerekir. Kendisini sanat alanında gösterebilen kadın, tıpkı çalışma hayatındaki hemcinsleri gibi anne oluşuyla birlikte çalışma hayatının duraklaması ve hatta belki de sona erme tehlikesiyle baş başa kalır. Duygu zenginliği ile hareket gücü alan sanatçılar için bu yeni sıfatın onlara kattığı ivme ile daha üretken bir döneme geçiş yapan kadın sanatçılar çoğunlukta yer alır.

\section{'Anne?' Seramik Sergisi}

2019 yılı Nisan ayı başında Çanakkale Onsekiz Mart Üniversitesi Kadın Araştırmaları Merkezi Müdürü Prof. Dr. Ferah Özkök ile yapılan gayri resmi görüşmede Anneler Günü özelinde kadın kimliğinin annelik kavramı ile özdeşleşmesinin sorgulanması amacıyla bir sergi yapma fikri tartışılarak onaylandı. Bu fikir üzerine sergi konsepti oluşturuldu ve bir ekip kuruldu. ‘anneseramiksergisi @gmail.com’ adında bir elektronik posta adresi alındı ve bu adres üzerinden Türkiye'deki akademisyen kadın sanatçılara bir davet metni gönderildi. 


\section{'ANNE?' \\ Karma Seramik Sergisi \\ 24-30 Mayıs 2019}

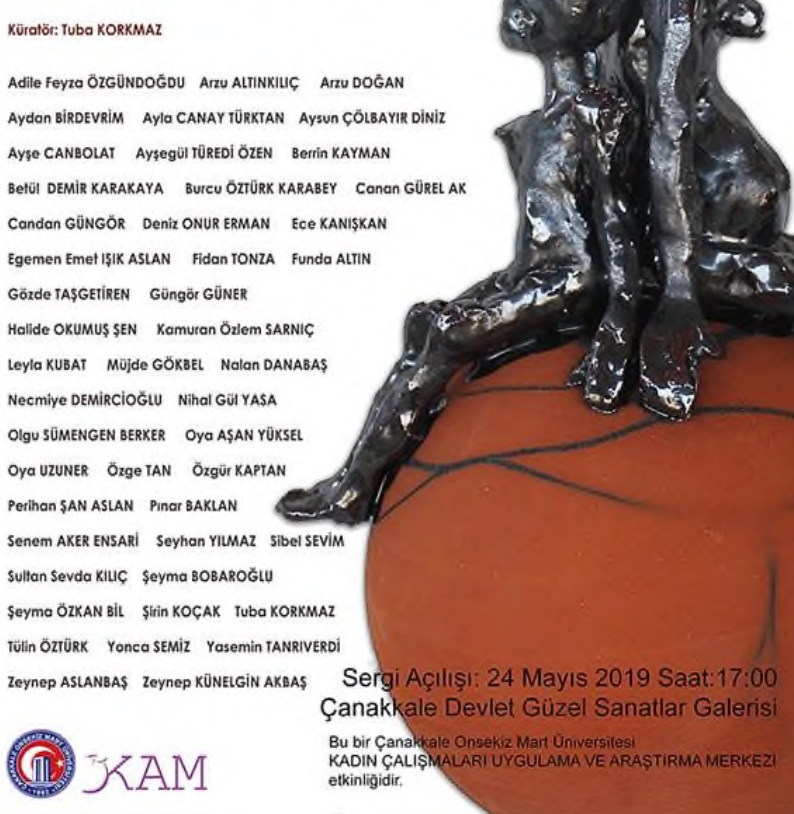

Fotograf 1: ‘Anne?' Seramik Sergisi Afişi

Davet metni şu şekilde idi:

'En aşina olduğumuz kelime; belki öğrendiklerimizin ilki: anne! İlk ilişki kurduğumuz öteki, ANNE...Kimdir ANNE? Yetersiz ve yaşamak için bir başkasının bakımına muhtaç halde iken, kendisinden ayrı bir varlık olduğumuzu tahayyül bile edemediğimiz, yaşam kaynă̆ımızdır ANNE. Kendinin farkına varma, benlik bilinci ilk ANNEden kopuşla mümkün olur. Dünyaya gerçek bir merhaba işte böyle başlar; "ben ANNEm değilmişim dediğimiz” anda. Arzusunun nesnesi olmak istediğimiz ilk öteki, hem ayrılarak kendimiz olmaya çalıştığımız hem de kendimizi onaylatmak için ilk ihtiyaç duyduğumuz kişidir ANNE.Yetişkin birer kadına dönüştügümüzde $O$ olmak isteyip istemediğimize karar verdiğimizde ya da olmak isteyip de olamadığımızda sorguladığımızdır. Doğurduğunu bırakıp gidene rağmen, teyze olarak yarısı, abla olarak üçte ikisi ve belki bir kadın olarak etrafımızdaki her insan yavrusuna ve hatta 
hayvanlara beslediğimiz tamlıkta bir duygudur ANNE.Babasından doğurduğuyla, tecavüzcüsünden olanla ANNE olanlar da var, maalesef...Ve bir de Cumartesileri oturan (!), Pazarları evi temiz çamaşır kokutan, şehit olan oğluna ya da kınası yakılırken kızına ă̆layan ya da Oedipus 'un aşkı... Doğuran ya da doğurmayan tüm kadınlar ANNEdir.Toprak gibi, içine koyduğunu büyüten ANNEyi, çamura şekil veren ellerin sahibi kadınlara soruyoruz, sizlere... ANNE NEDIR?'

Davete olumlu cevaplarla dönen ve bu sergiye katılmak isteyen kişilere birer katılım formu gönderildi. Gönderilen form sanatçının kısa özgeçmiş bilgilerini, sanatçının ve çalışmasının fotoğrafını, eser ya da konsept hakkında sanatçı görüşünü de içeren bilgilerin istendiği, aynı zamanda eser hakkında teknik bilgilerin ve sergilenme şeklinin de belirtildiği bir belge idi. Bu form üzerinden çalışmalar katalog için arşivlendi. Sanatçılara verilen adrese gönderilen eserler toparlandı ve sergi günü geldiğinde Çanakkale Devlet Güzel Sanatlar Galerisi'ne yerleştirildi. Açılış için sergi tarihinden yaklaşık bir hafta önce bastırılan afişler kentin ve üniversitenin çeşitli mekanlarına asıldı, davetiyeler şehrin önde gelenlerine ve sanatseverlere iletildi. Açılışı Çanakkale Belediye Başkanı Ülgür Gökhan ve eşi Hale Gökhan yaptı. Açılışa sergiye çalışmalarını gönderen sanatçılardan Eskişehir'den Ayşegül Türedi Özen, İstanbul'dan Aydan Birdevrim, Afyon'dan Canan Gürel Ak ve Konya'dan Egemen Emet Işık Aslan katıldılar. Sergi süresi sona erdiğinde çalışmalar kargo yoluyla veya elden sanatçılara geri gönderildi.

Sergiye Türkiye içinden toplam 47 kadın seramik sanatçı katılmıştır. Tüm katılımcıların yer aldığı bir katalog da açılış günü sergi salonunda dağıtıldı. Hazırlanan katalogda sanatçıların sıralaması alfabetik olarak yapıldı ve sanatçı fotoğrafı, özgeçmişi, eserin fotoğrafı ve eser hakkında sanatçı görüşü yer aldı. 


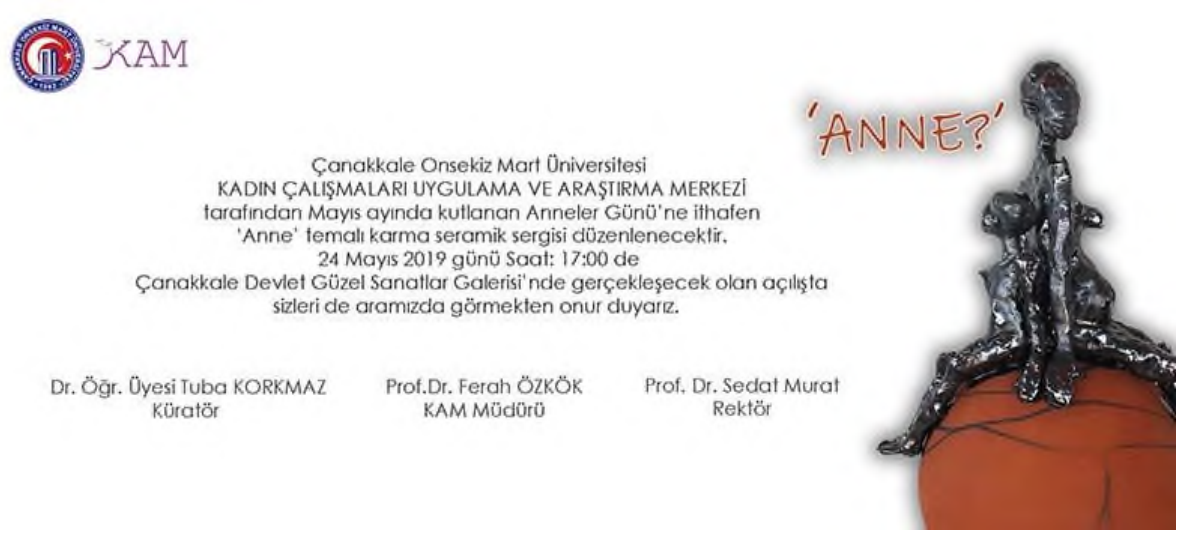

Fotoğraf 2: Sergi Davetiyesi

\section{Sergilenen Çalışmalar ve Sanatçıları}

Sergiye katılan 47 sanatçının çalışmalarında zaman sınırlaması yapılmadı. Kimi çalışmalar bu sergi için özel olarak yeni hazırlanmıştı, kimi sanatçılar ise geçmişte hazırlamış oldukları ve bu serginin konseptine uygun olan işleriyle sergiye iştirak etmişlerdi. Sergilenen çalışmalar arasında en eskisi 1960 yılında yapılmış olan Güngör Güner'in çalışması idi. 'Anne ve Çocuk' adlı çalışması kırmızı döküm çamuru ile yapılmış ve $1100{ }^{\circ} \mathrm{C}$ de pişirilmiş, $40 \mathrm{~cm}$ yüksekliğinde ve $10 \mathrm{~cm}$ eninde tasarlanmıştır. Güngör Güner' in kendi ifadesiyle eserin hikayesi şöyledir:

'Bizim öğrenciliğimizde henüz ne televizyon, nede bilgisayarlar vardı!' O nedenle daha çok kitap okuma şansımız oldu. Öğrenciliğimde okuduğum, Dostoyevski’nin EZİLENLER adlı romanında yer alan yoksulluk içinde ki anne ve çocuk figüründen çok etkilenmiştim. Aslında ikisinin gözyaşlarıyla dolan bir havuz çalışması yapmak istiyordum. O dönemde ki Avusturya 'lı konuk heykeltıraş hocamız Prof. Alfred Crepatz 'Gel ağlamasınlar sevgi ile birbirine baksınlar' dedi ve sonuçta bu çalışma ortaya çıktı.' (Anne? Seramik Sergisi Kataloğu, 2019;12). 


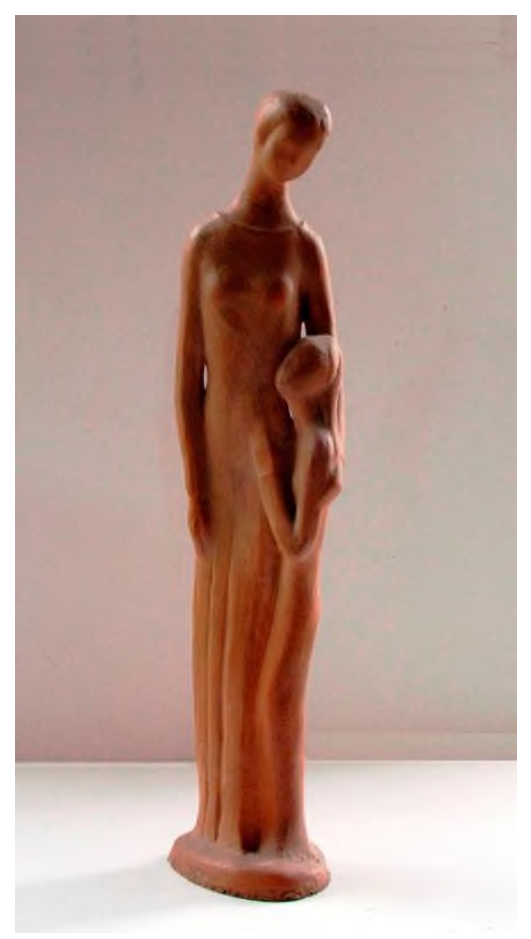

Fotoğraf 3: Güngör Güner, Anne ve Çocuk, 1960

Malzeme konusunda yapılan kısıtla bağlantılı olarak toprak-seramik ve annelik kavramı bağlamında çalışmalar üretmiş sanatçılardan biri olan Ayşegül Türedi Özen, Eskişehir-Sorkun köyü çömleklerinden yola çıkarak yaptığı triptik çalışmasının metninde de vurguladığı gibi 'Doğurmasa bile annelik güdüleri ile donanmış her kadın, bir annedir aslında... ' der ve ekler: 'Anne; sevgiyle, merhametle, sabırla canından can, kanından kan vererek erkek ya da dişi, kendi türünden bir can doğurandır. Doğurmasa bile annelik güdüleri ile donanmış her kadın, bir annedir aslında... Anne-Ana; Topraktır, Sudur, Havadır, Hayattır. Eskişehir'in Sorkun köyünde, yüzlerce yıldır nesilden nesile bilgisini, becerisini toprăğ şekillendirerek, pişirerek öğreten annelerin türküleri söylenir durur. Çömlekçilik mesleğini annesinden kızına, kızından torununa armağan eden Sorkun'unlu çömlekçi ANNELERIN TÜRKÜSÜ’ne seramik sanatıyla eşlik etmekten dolayı çok mutluyum, gururluyum. '(Anne? Seramik Sergisi Kataloğu, 2019;7). Müjde Gökbel'in çalışmasında seramiğin en temel formlarından olan çanak formu kadın formuna dönüştürülerek seramik malzeme ile ilişkilendirilmiştir. 
'Çanak, seramik sanatının en eski ve en bilindik formlarından biridir. Aslında çanak formu sanatçıyı sadece görünürdeki üç boyutlu hali ile değil, içinde boşluğun neden olduğu hacim ile de etkilemektedir. Boşluğun yarattığ iç hacim ile oynama arzusunun neticesi olarak "Içinde" serisi ortaya çıkmıştır. Serinin Anne konseptli çană̆ ise doğurganlı̆̆ı temsil etmektedir.' (Anne? Seramik Sergisi Kataloğu, 2019;13).

Pişmiş toprak malzeme Anadolu'daki tarih öncesi buluntular incelendiğinde kap-kacak formu kadar Ana-Tanrıça kültünün heykelcikleri ve idolleri için de kullanılmıştır. Bu bağlamdan yola çıkarak yapılmış eserlerden biri olan Sibel Sevim'in duvar tabağı örnek verilebilir. Bir diğer Ana-Tanrıça göndermesi olan çalışma Canan Gürel Ak’ın çalışmasıdır. Toprak ana inancının Yunan mitolojisindeki karşılığg olan Gaia 'ya ithafen yapılmış olan ‘Bugün Gaia Gözü Yaşı Bir Tanrıçadır’ isimli çalışmasıyla Özge Tan, mitolojik bir karakterin bugüne bakışını canlandırdığı eseri için şunları söylemektedir:

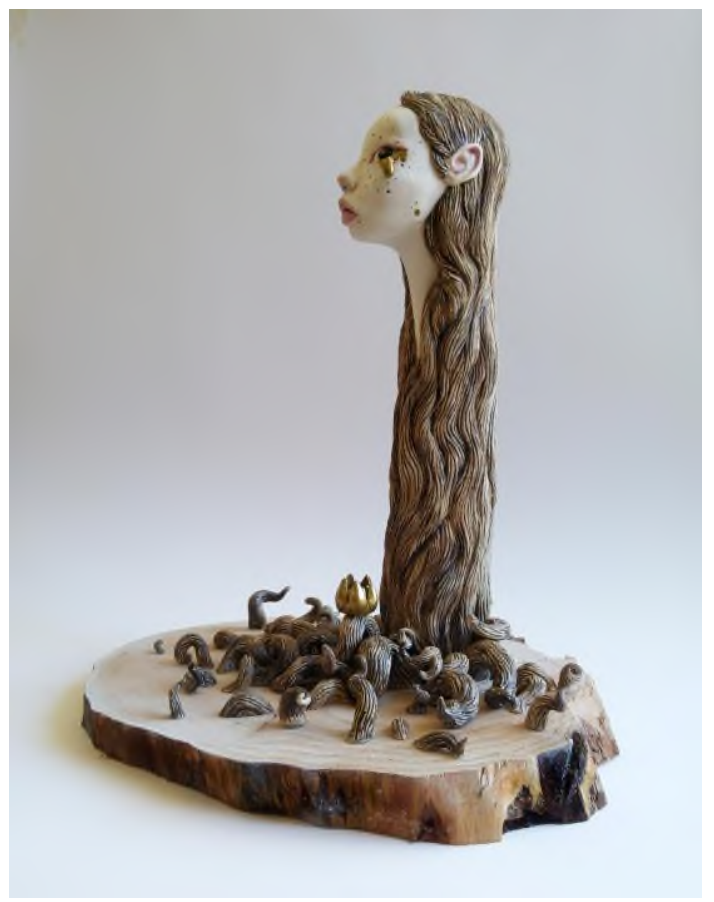

Fotoğraf 4: Özge Tan, Bugün Gaia Gözü Yaşlı Bir Tanrıçadır, 2019 
Özge Tan, Eser, antik inanış ve mitlerin neredeyse hepsinde 'bütün tanrl ve tanrıçalardan önce var olan ve onları kendinden doğurduğundan' söz edilen Doğa Ana, Toprak Tanrıçası ya da Yunan mitolojisindeki adıyla Gaia' nın, 'bugün kim bilir ne halde olduğu' sorusundan çıkışlı ve sanatçının bu soruya verdiği, Gaia' nın temsil ettiği hem kadına hem de doğaya ait değerlerin insan türü tarafindan incitilmiş ve incitilmeye devam edilmekte olduğu, bu yüzden de bugün Gaia' nın, olsa olsa gözü yaşlı bir tanrıça olacağı cevabı üzerine kuruludur (Anne? Seramik Sergisi Kataloğu, 2019;17).

Katılan sanatçılardan Berrin Kayman annelik kavramı üzerine yaptığı sorgulamada annelik ile ilgili görüşlerini kendi kaleminden şu şekilde dile getirmiştir:

'Kimdir ANNE.? Doğuran, besleyen, fedakarlık yapan, öğreten,...??? Kadın ve erkek milyonlarca yıldır erk peşinde koşarken, herşeyi tanımların ve kavramların içine sıkıştırmak öte yol alamadı. Kimdir ANNE...? Doğuran, besleyen, fedakarlık yapan, öğreten...??? Peki; Kucă̆ına alamadan kaybedenin adı ne? Eksik mi?' (Anne? Seramik Sergisi Kataloğu, 2019;7).

Egemen Emet Işı1k Aslan sergiye katıldığı çalışmasının açıklamasını şu şekilde yaparak ‘eksiklik’ söylemi üzerinde durmuştur:

“Anne” olduktan sonra eksik olmanın kabul edildiği, olmadı̆̆ın zaman diliminde ise eksik hissedildiği duygu durumunun adıdır. Görünmeyen ve görülmeyen emektir... cinsiyetsizdir... zamansızdır... mekânsızdır...tanrısaldır... (Anne? Seramik Sergisi Kataloğu, 2019;10).

Annelerine ithafen çalışmalarını gerçekleştirmiş olan sanatçılardan Şeyma Bobaroğlu, anne ve çocuk arasındaki ilk bağın -göbek bağının- kesilmesi ile çocuğun anneden ayrılışı ve ardından kurduğu yeni bağ ile -sevgi bağı- tekrar bir araya gelişi ifade etmiştir. Kaybettiği annesine yazdığı bir paragraf ile çalışmasının metnini oluşturmuştur. 


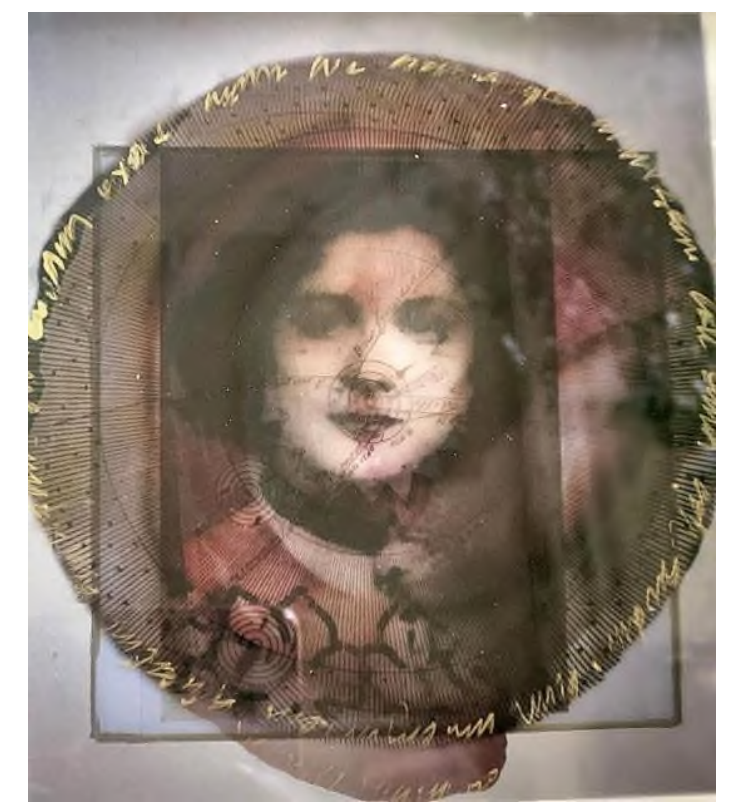

Fotoğraf 5: Şeyma Bobaroğlu, 2. Ahid çalışmasından ayrıntı, 2019

'Annem, sen girdiğin suretlerde ışık olup parlarken, ben senden devr aldı̆̆ım kanatları itina ile işlemeye ve seninle kurduğumuz o güzel bağı parlatmaya devam ediyorum.....' (Anne? Seramik Sergisi Kataloğu, 2019;21).

Pınar Baklan'da bu sergiye annesiyle kurduğu ilişki üzerinden çalışma üretmiş bir sanatçıdır. Anne ve çocuklarının deforme edilmiş seramik formlar ile temsil edildiği bu çalışmayı annesine yazdığı bir metin ile açıklamıştır.

Biz de çocuktuk, sen de. Kaldık bir başımıza... Vardı eş dost, ama yoklardı aslında. Anne, baba, kardeş, arkadaş, ögretmen sen oldun. Bir başına, dimdik savaş verirken narin, acılı kadın yüreğini, zarafetini ittin bir kenara. Geçti seneler, savrulmamaya çalışarak tutundun bize, hayata... Sana kulak vererek yetiştik, büyürken aldık şeklini. Sen, güçlü, hassas kadın, benim annem... Dönüp bak şimdi, seni dinleyerek şekillenen biz, aştık boyunu, toplandık çevrende, dinliyoruz yine...(Anne? Seramik Sergisi Kataloğu, 2019;18).

Leyla Kubat sergiye göndermiş olduğu ikili duvar seramiklerinde anneliğe övgüde bulunmuştur. Kızlarının dilinden kendi anneliğini taçlandırmış, anne gözünden de çocuğun bir 
anne için ifade ettiği değeri dile getirmiştir. Anne ve çocuk arasındaki bağın gücüne dikkat çeken bir diğer eser Ece Kanışkan'ın çalışmasıdır.

Kendi anneliklerinden yola çıkarak çalışmalarını üretmiş sanatçılar arasında Ayla Canay Türktan ve Deniz Onur Erman kendi hamilelikleri sırasında yapmış olduğu çalışmalarıyla sergiye katılmışlardır.

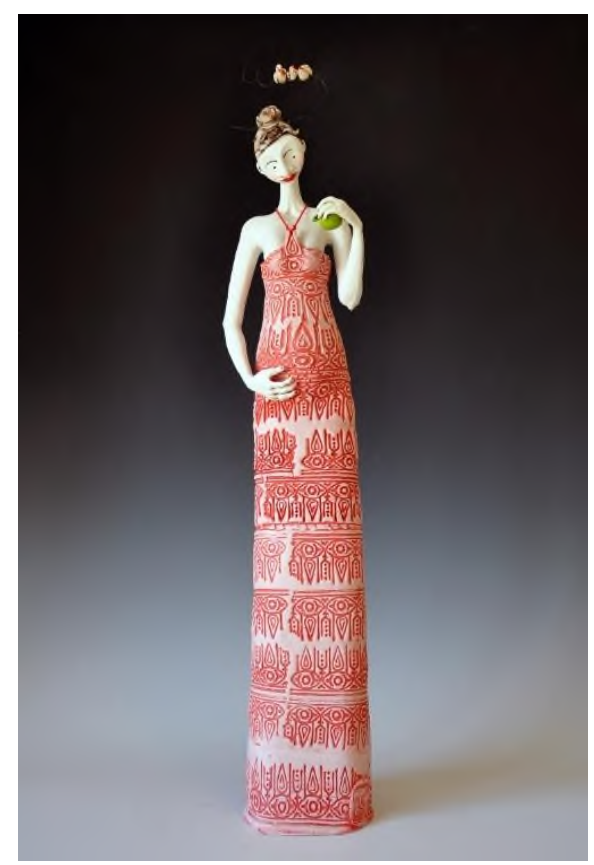

Fotoğraf 6: Deniz Onur Erman, Büyülü Bahçe-Elmall, 2017

Ayrıca sergiye çalışmalarıyla anlam veren diğer sanatçıların isimleri şu şekildedir: Adile Feyza ÖZGÜNDOĞDU, Arzu ALTINKILIÇ, Arzu DOĞAN, Aydan BİRDEVRİM, Aysun ÇÖLBAYIR DİNIZ, Ayşe CANBOLAT, Betül DEMİR KARAKAYA, Burcu ÖZTÜRK KARABEY, Candan GÜNGÖR, Fidan TONZA, Funda ALTIN, Gözde TAŞGETİREN, Halide OKUMUŞ ŞEN, Kamuran Özlem SARNIÇ, Nalan DANABAŞ, Necmiye DEMİRCİOĞLU, Nihal Gül YASA, Olgu SÜMENGEN BERKER, Oya AŞAN YÜKSEL, Oya UZUNER, Özge TAN, Özgür KAPTAN, Perihan ŞAN ASLAN, Senem AKER ENSARİ, Seyhan YILMAZ, Sultan Sevda KILIÇ, Şeyma ÖZKAN BİL, Şirin KOÇAK, Tuba KORKMAZ, Tülin ÖZTÜRK, Yonca SEMIZ, Yasemin TANRIVERDİ, Zeynep ASLANBAŞ, Zeynep KÜNELGIN AKBAŞ. 


\section{Sonuç}

Birleşmiş Milletler İyi Niyet Elçisi oyuncu Emma Watson Birleşmiş Milletler'de HeForShe adlı kampanya için yaptığı bir konuşmasında erkeklere seslenerek 'Cinsiyet eşitliği sizin de meseleniz.' Diyerek şöyle açıklamaktadır: 'Çünkü bugüne kadar, toplumda babamın daha az ebeveyn olarak sayıldığını gördüm. Çocukluğumda annem kadar onun da desteğine ihtiyaç duymuş olmama rağmen.' (Url-a) Bir çocuğun ruhsal ve bedensel gelişimine en çok etki eden kişi yani ‘bakıcı’ cinsiyetine bakılmaksızın ‘anne' olarak tanımlanır. Kadının üzerine bir yük gibi atılmış 'annelik' sıfatı tüm zorluklarından azade bir oluşla, olumlu ya da olumsuz bir kavram atfedilmeden tercihe bağlı bir duruş olarak kabul edilmelidir. Eğer böyle kabul edilirse o zaman bu kadın üzerinde bir yargılama aracı olmaktan kurtularak tüm özgürlüğü içinde barındıran bir kavram olacaktır.

Çanakkale Onsekiz Mart Üniversitesi Kadın Çalışmaları Uygulama ve Araştırma Merkezi etkinliği olarak seramik sanatçılarını bir araya getiren 'Anne? Seramik Sergisi' ni düzenleyerek sanatsal, kültürel ve sosyal etkileşimi sağlamak ve annelik kavramı üzerine düşündürmek amaçlanmış, hedefe ulaşılmıştır. Kadınlığın ve anneliğin yan yana anıldığı toplumda bir farkındalık yaratmak, bu kavramlar üzerine düşünerek kadınların omuzlarına bıraktıkları ağır yükleri anlayabilmek gerekliliği vurgulanmıştır. Bu metin sayesinde de plastik sanatlar alanında oluşturulmuş bir sorgulamanın kavramsal açıklaması, felsefi temelleri ve sonuçları kayıt altına alınmıştır.

\section{Kaynaklar}

İnceoğlu, Y. Kar, Altan. Kadın Ve Bedeni, Ayrıntı Yayınları, 2010

Butler, J. Cinsiyet Belası, Metis Yayınları, 2010

Antmen, A. Kimlikli Bedenler, Sel Yayıncılık, 2013

Drenth, J. Dünyanın Kökeni: Vajina, Agora Kitaplığı, 2008 
From, E. Anaerkil Toplum ve Kadın Hakları, ArıtanYayınevi, 1998

Paglia, C. Cinsel Kimlikler, Epos Yayınları, 2004

Aktaş, G. 'Feminist Söylemler Bağlamında Kadın Kimliği: Erkek Egemen Bir Toplumda Kadın Olmak’ Edebiyat Fakültesi Dergisi, Cilt 30-Sayı 1, Haziran, 2013

Sever, M. “Kadınlık, annelik, gönüllü çocuksuzluk: Elisabeth Badinter'den Kadınlık mı Annelik mi?, Tina Miller'dan Annelik Duygusu: Mitler ve deneyimler ve Corinne Maier'den No Kid üzerinden bir karşılaştırmalı okuma çalışması” Fe Dergi 7, no. 2 (2015), 72-86.

Emma Watson BM Konuşması: Url-a: https://www.youtube.com/watch?v=gkjW9PZBRfk 


\title{
LANDSCAPE AND GENDER IN TURKISH LITERATURE
}

Tülin URAL ${ }^{1}$

\begin{abstract}
The landscape consists an essential component of the literary narrative. It may be even argued that the novel itself is mainly an attempt to create an imaginary world, thus a new landscape. How the author asserts a claim of realism while drawing landscape through words, reflects the understanding of reality in the concerning literary realm. In addition, how different landscapes are described by particular authors or in specific periods, is a problematic related with the understanding of nature or more precisely with the tension between nature and civilization. Accordingly, as long as it's a claim on nature \& civilization tension, the landscapes of the fiction, have a strong gendered character, in almost every case.

In this presentation, I will examine the narratives of landscape in $19^{\text {th }}$ Century Turkish modern literature, in its relationship with gender, through a textual analysis of some representative examples. In other words, I will spectate and contemplate on some landscapes of literary world, from a feminist gaze, through a window provided by women studies.
\end{abstract}

Keywords: 19th Century Turkish Literature, Landscape, Gender

${ }^{1}$ Dr. Lect. Mimar Sinan Fine Arts University, Department of Art History, İstanbul tulinural@ yahoo.com; 


\section{TÜRK EDEBIYATINDA TOPLUMSAL CINSIYET VE MANZARA}

\section{$\ddot{O}_{z e t}$}

Manzara, edebi anlatının temel bir bileşenini oluşturur. Romanın kendisinin de esas olarak hayali bir dünya, yani yeni bir manzara yaratma çabası olduğu dahi söylenebilir. Yazarın kelimeler vasıtasıyla bir manzara çizerken nasıl bir gerçekçilik iddiası ortaya koyduğu, aynı zamanda, ilgili edebiyat alanında gerçekçiliğin nasıl anlaşıldı̆̆ını yansıtır. Ek olarak, farklı manzaraların tek tek yazarlarca ya da münferit dönemlerde nasıl tasvir edildiği, doğanın ya da daha doğru bir ifade ile doğa \& medeniyet geriliminin nasıl anlaşıldı̆̆ ile ilgili bir problematiktir. Buna göre, doğa \& medeniyet gerilimi üzerine bir iddia olduğu sürece, kurgu metinlerde karşımıza çıkan manzaralar, hemen her durumda, toplumsal cinsiyete ilişkin bir iddiayı da yansitırlar.

Bu sunumda, 19. yüzyıl modern Türk edebiyatında karşımıza çıkan manzara anlatılarını, bazı temsili örnekler üzerinden metinsel analiz yaparak, toplumsal cinsiyet ile ilişkisi içinde inceleyeceğim. Başka bir deyişle, edebi âlemin bazı manzaralarını kadın çalışmalarının mümkün kıldı̆̆g bir pencereden bakarak, feminist bir bakış açısıyla ele alacağım.

Anahtar Kelimeler: 19. Yüzyll Türk Edebiyatı, Manzara, Toplumsal Cinsiyet

\section{Manzara Neyi Gösterir?}

Meşhur romancımız Orhan Pamuk, Saf ve Düşünceli Romancl'da, bir roman okuduğumuzda zihnimizde ve ruhumuzda gerçekleşiveren sıradan mucizeyi anlatırken, uyku sırasında rüyalarımıza inanmamıza benzer şekilde okuduklarımıza inanmamızın sihrinden söz eder (Pamuk, 2011: 7-28). Romanı okurlar için keyifli kılan, işte tam da bu sihir, onun bize gerçek hayatmış gibi gelmesidir. Bizi saf okurlar yapan tam da budur. Ancak Pamuk bir yandan da aynı yazıda, yazdığının ya da okuduğunun kurgu olduğunun farkındaki düşünceli romancılardan ve okurlardan bahseder. Fakat ister saf ister düşünceli okur olalım, bir yandan da biliriz ki romanlar, dil dediğimiz mucizevi toplumsal uzlaşımın ürünüdür; 'gerçek bir hikâyeye' dayanmakta ise dahi, yine de hayal gücünün ve dilin süzgecinden geçmektedir yazilanlar. 
$\mathrm{Bu}$ bağlamda Pamuk, kendi okuma deneyimini, bir manzarayı hissetmek olarak tarif eder: Bu romanın hem de yeniden bir hayat, demek ki bir atmosfer yaratmasından kaynaklanan bir efekttir. Tam da okurun hayal gücünden geçerek, gene tıpkı rüyada olduğu gibi bazı resimler gelir roman okurken gözümüzün önüne. İște onların manzara resmi olarak belirdiği an, romanın dünyasına girdiğimiz andır: Bu resim huzurlu ya da fırtınalı olabilir; geniş, engin ve yüce ya da sıkıntıl1, sıkışık olabilir; ancak Pamuk'un sözleri ile bu, roman okurken, 'bütün dünyanın bambaşka bir 1şıktan yapıldığını' hissettiren mucizevi andır (Pamuk, 2011: 9).

Tam da içine kahramanların yerleşeceği (ya da bazen yerleşemeyeceği, ne yapsalar kendilerine bir yer bulamayacakları) ve olayların cereyan edeceği dünyanın kapılarını açmak ve bizi o atmosfere sokmak üzere birçok roman manzara tasvirleriyle açılır. Ve bu manzara tüm roman boyunca zihnimizin ardında asılı kalır. Ama romanda manzaranın işlevi genel bir atmosfer yaratmanın ötesindedir: Orhan Pamuk’a göre romanı kendisinden önceki diğer anlatım biçimlerinden, örneğin efsaneden farklılaştıran, derinlik duygusuna ve üç boyutlu bir efekte sahip olmasıdır. Hakiki bir dünya imiş, gerçek dünyanın bir yansıması imiş gibi algılanmasını tam da buna borçludur. Başka bir deyişle roman basbayağı bir perspektife yaslanır ve nasıl ki manzara resminde perspektif belli bir merkeze dayanıyorsa, roman da bunu, gizli bir merkeze, hayatın anlamına dair gizlenmiş bir söze sahip olabilmesi sayesinde başarır. Öyle ise manzara romanda sadece bir yan öğe değildir, romanın bizzat kendisi bir manzara gibi ele alınabilir

\footnotetext{
${ }^{1}$ Bu noktada Orhan Pamuk’un ressam olmayı hayal ederken dümeni son anda edebiyata kıran bir yazar olduğunu hatırlayalım. Dolayısıyla açık bir görsel duyum ile ve modern resmin aslında bir merkezi olduğunu, bu merkezi de asıl olarak perspektife borçlu olduğunu bilerek düşünmektedir Pamuk, öyle ise perspektifin yapabileceklerinden de haberdardır.
} 
Perspektifin, daha doğrusu geometrik perspektifin ${ }^{1}$; çoğunlukla dinsel bir hikâyenin arka planı olmaktan çıkıp doğanın müstakil bir temsili olarak manzara resminin, modern yaşamın başat anlatım biçimi olan romanın ve elbette koleksiyonerlik faaliyetlerinin ve sanat sevgisi fikrinin, sanatın yüce ve özerk bir alan olarak düşünülmesinin, bunların tamamının, 16. Yüzyılda, tam da modernliğin şafağında, eşzamanlı olarak Batı'da ortaya çıkmış olması bir tesadüf olamaz².

Tüm bunlar doğmakta olan burjuva toplumunun icadıdır. İşte modernliğin yeşerdiği bu tarihsel bağlam, manzara resmine bakarken bize kılavuzluk edebilecek üç önemli noktaya işaret eder: Doğaya ilişkin varsayımlarımızın kaydı olarak manzara; bununla bağlantılı içinde, bütünsellik anlayışımızın yansıması olarak manzara ve yine bu anlayışla ilişki içinde olmak üzere, gerçeklikle ilişkimizin ve buna içkin bir gerilimin temsili olarak manzara.

Kuşkusuz ki manzara resimleri, doğa ile insan arasındaki bağın arşividir. İnsan ne zaman doğaya Tanrı'nın yaratısı olarak bakmaktan çıkmıştır? Ne zaman kendisini doğanın bir parçası değil de doğanın efendisi, hatta sahibi olarak görmeye başlamıştır? ${ }^{3}$ Berger Görme Biçimleri’nde yağlıboya resmin içinde doğduğu tarihsel bağlama dikkat çeker ve roman gibi yüceltilmiş bir alan olan resim sanatını dünyamıza indirip, mülkiyet ile bağını açığa çıkarıverir. Bu noktada, her ikisi de 16. Yüzyılda yükselen manzara resmi ile -Berger özellikle değinmemiş

\footnotetext{
${ }^{1}$ Karatani Japon geleneksel dağ resimlerinde uzakta olanın yukarıya, yakında olanın aşağıya çizilmesi gibi belli perspektif yöntemleriniz zaten uygulanmakta olduğunu; yeni olanın geometrik perspektif olduğunu vurgular (Karatani, 2011:33)

${ }^{2}$ Manzara, sadece modernlikle bağlantılı değildir. Modernliğin oluşumuyla eş zamanlı gelişen milli devletin ve milli kimliğin kurulmasıyla da ilgilidir; zirâ manzara aynı zamanda milli uzamı da kurar; (Karatani, 2011: 42). Örneğin birer Anadolu Mona Lisa'sı olan kadınlarıyla Nuri İyem'in tabloları, içerdiği tüm coğrafî olasılıklara rağmen Türkiye'yi asıl bir bozkır olarak hayal etmemize katkıda bulunur. Pekâlâ manzaraların yönetmeni olarak anabileceğimiz Nuri Bilge Ceylan da 2008 Cannes Film festivalinde aldığı ödülü, muazzam bir ifade gücüyle, 'tutkuyla sevdiğim yalnız ve güzel ülkeme adıyorum' diyerek kabul ettiğinde aynı millî uzama referans vermekteydi aslında. Kezâ İngiliz ressamları da bıkmaksızın yaptıkları, çoğu fırtınalı deniz manzaralarıyla, üzerinde güneş batmayan imparatorluklarının denizlerin hakimi olduğunu hatırlatmaktaydılar.

${ }^{3}$ Tüm bu sorular eşliğinde, manzara resminin sergüzeştini bugün giderek yükselen ekolojik politik duyarlılık içinden okumak, heyecan verici sonuçlara gebe bir çalışma olabilir.
} 
de olsa- ölü doğa arasındaki bağlantı ilginçtir. Bu bağlamda manzara, ölü doğa resmi ile birçok açıdan benzerlikler taşır: Her ikisi de içinde insanın olmadığı (ya da manzarada bazen yer alsa dahi, ancak bir yan unsur olarak göründüğ̈̈) türlerdir ve her ikisi de ilk bakışta soyut bir fikri değil de ancak somut, görünür nesneleri resmederler ${ }^{1}$. Öte yandan manzara resmi gene de ölü doğadan iki açıdan ayrışır: İçindeki her şeye dokunamazsınız ve doğayı satın alamazsınız. Ama acaba öyle mi? Doğayı değilse bile, elbette tabloyu satın alabilirsiniz. Ve elbette manzara resmine konu olan toprağı da satın alabilirsiniz. Berger, özelde manzara, genelde de sanat sevgisi ve mülkiyet arasındaki ilişkiyi vurgulayan savını, Gainsborough'un 1750 tarihli Bay ve Bayan Andrews tablosuna dayandırır: Geride görünen manzara çiftin mülküdür (Berger, 1995: 105-107).

Tam da doğaya nasıl yaklaştığımızın kaydını tuttuğu içindir ki manzara resmi aynı zamanda doğa algımız üzerinden bütünlük anlayışımıza ilişkin önemli bir modern ikilemi de örnekler. Manzara, ister istemez çerçevelenmiştir. Ancak doğanın kendisi daha baştan bir bütünsellik arz eder; bir fikrin ötesinde, doğanın bütünselliğini neredeyse apaçık bir gerçeklik olarak sezeriz. Simmel de bu ikileme değinir: "Doğadan bir kesit' ifadesi kendi içinde çelişir. Doğanın kesiti olmaz. O, bütünün birliğidir ve oradan bir parça kesilmişse artık doğa olmaktan çıkar. Doğa, sadece sınırsız bir birlik içinde 'doğa' olabilir...Toprağın bir kısmını, onun üzerindekileri, manzara olarak seyretmek, doğadan koparılmış bir kesiti, kendi içinde bir bütünlük olarak seyretmekten başka bir şey değildir. Herhalde doğa kavramına bundan daha

\footnotetext{
1 18. Yüzyılda, resim sanatının kriterlerini belirlemeye muktedir temel kurumsal yapı olan Fransız akademisi manzarayı hiyerarşik olarak ölüdoğanın hemen üstüne, portrenin altına yerleştirerek değersiz bir tür sayıyordu. Akademiye göre hiyerarşinin en üstünde bir hikaye ve aksiyon içinde insan figürünü konu alan tablolar vardı. Gene de 18. Yüzyılın en varlıklı Fransız ressamı, akademiyi tiye almaktan çekinmeyen meşhur ölüdoğa ressamı Chardin'di. Gene bu dönemde, çıplak erkek figürle çalışmaları yasak olduğundan mecburen bu türlere yönelerek manzara ve ölüdoğa çalışan çok sayıda kadın ressam olduğunu da not düşmeliyiz; Liam McArdle, 2013: The Story of Still Life. BBC Belgeseli, , https://vimeo.com/84883341
} 
uzak bir şey yoktur” (Simmel, 2007 (1913): 21-22; tercümesi, Karatani, 2011: 35). Tam da bu yüzden manzara resmi daha baştan, bütünsel bir şeyi çerçevelediği için bir oksimorondur. Manzara türünde, doğanın büyüklügünü, görkemini bize hatırlatan, geniş, ulu ve yüce tabloların bu derece yaygın olması, belki de bu ikilemi alt etme çabasının sonucudur. Bu, romanın, hayatı, ister istemez bir bütünlük içinde anlam kazanacak hayatı, bir tek kesit içinden yansıtma iddiasında da karşımıza çıkan bir ikilemdir.

İyi ama çerçeve kimin bakış açısından konulmuştur, kimin bakış açısını yansıtır? Ressamın mı? Resme bakan gözün mü? Yoksa -varsa- resmin içindeki figürün mü? İşte bu, bizi, manzara ile ilgili belki de en modern ve asıl can alıcı soruya götürür. Manzara, 16. Yüzyılda doğayı olduğu gibi temsil etme iddiası ile, nesnel bir gözün yansıması olduğu savıyla ortaya çıkmıştır: Esasen geometrik perspektif de tam olarak bu iddiayı ortaya koyar. Oysa ki manzara resmi, hangi manzaranın (dağların mı, mülklerin mi, bozkırların mı? Fırtınalı denizlerin mi ya da sakin koyların mı?), nasıl (yüce mi, huzurlu mu, huzursuz edici mi? Aydınlık mı, karanlık mı?), hangi çerçeve içinden resmedildiğine dek, ister istemez öznel bir gözü yansıtır. Bu içkin gerilimi nedeniyledir ki müstakil manzara resmi, 16. Yüzyılda ortaya çıktığında, roman, perspektif ya da sanatla ilgili fikrimizde de yankı bulan, modern zamanın gerçeğe ilişkin algımızda yarattığı devrimsel bir dönüşümü yansıtır: Gerçeği kavrayabileceğimiz ve temsil edebileceğimiz yanılsamasıdır bu. Foucault'nun Kelimeler ve Şeyler'de işaret ettiği büyük epistemolojik dönüşümle, temsile dayanan epistemeye geçişle bağlantılıdır bu yeni icatlar (Michel Foucault, 2000). 


\section{Yüzyıl Osmanlı Romanının Manzaraları}

Manzara üzerine tüm bu soruların eşliğinde, onları hep aklımızda tutarak, Osmanlı’da modern bir tür olarak romanın doğduğu çağda manzaraların nasıl göründüğüne bakabiliriz artık. Elbette bu yolculukta asıl odak noktamız, manzarayı mekânın bir tür temsili olarak ele alıp, onun toplumsal cinsiyet ile bağlantısını anlamak olacak. Bu yolculukta, 19. yüzyılın, Osmanlı bağlamında, modern yaşamla birlikte, kadınlığa ve erkekliğe ilişkin anlamların, kadınlar ve erkekler arasındaki ilişkilere ilişkin fikirlerin yeniden sorgulandığı bir dönem olduğunu da hatırlamalıyız. Ancak bu sorgulamanın her durumda yeni anlamlar ve ilişki biçimleri önermediğini, hatta çoğu kez modernlikle birlikte geldiği vehmedilen (ve gerçeklikte aslında o kadar da hızlı esmeyen) bir değişim rüzgârı karşısındaki endişeleri ifade ettiğini de hatırlamalıyı.

$\mathrm{Bu}$ yüzyılda manzaraların, Batı romanı gibi Osmanlı romanında da önemli bir yeri olduğunu tespit ederek başlamalıyız işe ${ }^{1}$. Konu alacağımız metinlerden ilkini yazan Namık Kemal de Celaleddin Harzemşah adındaki tiyatro eserine yazdığı önsözde (Celal Mukaddimesi) eski hikâyelerimizi romanla karşılaştırarak eleştirmiş ve romanı oluşturan üç unsuru şöyle sıralamıştır: Olayın gerçekleşebilme imkânı; konunun ahlak, âdet, duygu ve ihtimallere dayandırılması ve tasvir (Namık Kemal, 2016). Tasvir derken kast ettiği alanda, manzaraların açık bir üstünlüğ̈̈ vardır.

Magosa'da sürgün günlerini geçiren Namık Kemal'in, ders kitaplarında ilk gerçekçi roman olarak anılan, ama gerçekçi mi romantik mi olduğu bir hayli tartışmalı olan (ki bizzat bu kategoriler de tartışmalıdır esasen), 1874 tarihli İntibah (Uyanış) romanı da bir manzara tasviri

\footnotetext{
${ }^{1}$ Oysa bugün romanda manzara hemen hemen tamamen geri çekilmiş durumdadır.
} 
ile açılır. Roman, Ali Bey adlı kahramanının neredeyse saçmalığa varan bir gaflet uykusundan, bir takıntıya dönüşmüş aldatılma korkusunun onu sürüklediği felaketlerden, çok ama çok geç uyanışının hikâyesidir. Tam da bu noktada bu anlatı, namus fikrinin savunucusu mudur, onu eleştirmekte midir belirsizdir aslında. Aynı belirsizlik kadın ve erkek kimliklerinin kurgulanışında da kendini gösterir: Romanın kötü kadını Mehpeyker'in onca günahı, hatta sonundaki yanlış cinayeti Ali Bey’e duyduğu tutku derecesindeki aşktan mı kaynaklanır, yoksa fahişe olduğundan mı, belirsizdir. Ali Bey namusuna düşkün bir adam mıdır, yoksa her şeye kapılıveren, öfkesini kontrol etmekten aciz bir yarı çocuk mudur? Bu da belirsizdir. Intibah, belirsizliklerin, havada asılı kalan soruların ve yanlış anlamaların romanı olur. Öyle ki her şeyi yanlış anlayan, kahramanlar mıdır, yoksa biz okurların, hatta yazarın mı aklı biraz karışmıştır, bu bile belirsiz kalır.

$\mathrm{Bu}$ yanlış anlamalar romanın merkezini oluşturan ve romana adını veren 'uyanış' fikrinde de kendini gösterir: Ali Bey’in uyanışı yanlışlarına, yanlış anlamalarına bir uyanış mıdır, yoksa cinsel bir uyanış mı kast edilir? Bu makaleye de ilham veren fikir, Babalar ve Oğullar'daki tek bir pasajdır aslında ve bu pasajı, Jale Parla da aynı soru ile açar. Parla’ya göre roman asıl bir cinsel uyanışın romanıdır; çünkü son derece keskin ve net yargılarla, bir ebeveyn sesiyle konuşan yazarının aslında kafası bir hayli karışıktır ve zihninin derinindeki cinsellik temas1, habire romana s1zar (Parla, 1993: 87).

Intibah bir tasvir ile açılır demiştik:

"Yaşlı dünyamızın taze bir sonbaharıdır, bahar günleri. İlkbahar geldiğinde toprağın ilkbaharın gelişiyle yeniden dirilmesi gerçeği ortaya çıkar. O kuru ağaçlar, mahşere ulaşan kemikler gibi yeniden canlanır. Öylesine canlanır ki, bu tazelik ağaçların gövdelerinde rahatça okunabilirdi, küçücük bir ot parçasının gelmesinde, evrenin her parçacı ğında yeni bir ruh ortaya çıkıyor 
sanılırdı. Kırların her tarafında belirmiş ruhsal bir zevk, canlanmış cismani bir sefa denilse, kesinlikle abartılmış olamaz.” (Namık Kemal, 1992: 19)

Güzel bir bahar manzarasıdır tasvir edilen. Yalnız şu da var: Ancak doğada gerçekleştiği sürece bu ruh ve cisim oyunu kabul edilebilir. Parla'nın da dikkat çektiği üzere hemen ardından 'yeşil' sıfatıyla kurulan söz oyunları, bize doğal olanın sınırını insanın aşmaması gerektiğini hatırlatır; yoksa insan cisme, bitkiye dönüşecektir:

"Yeşil, dünyamızda en sevilen renktir. Yeşilden daha güzel, başka bir renk olabilir mi? Ve bahar günlerinde yeryüzünün tamamı yeşile bürünür. (Kendilerini insan sanan, gerçekte ottan sadece istediklerinde istedikleri yere gidebilen, kısacası yalnızca yer değiştirme fark1 bulunan beyler de, karşılaştıkları hanımlara yeşillenmek için uğraşırlar.)" (Namık Kemal, 1992: 19)

Böylece, tam da bu manzara vasıtasıyla, keskin bir maneviyat/ruh/medeniyetcisim/doğa/beden/cinsiyet karşıtlığı içinde kurulan roman, doğayı da cismanî olana dahil eder ve insanı, ama bilhassa erkeği, ruhun ve medeniyetin hanesine yazar. O sınırları geçmek, erkeğe olsa olsa felaket getirecektir. Doğa ile cinsel uyanış arasında kurulan ilişki şu cesur satırlarda okunabilir:

“Divan ozanlarımızın şiirlerinde sık sık sözünü ettikleri "serv-i simin”in ne olduğunu anlamak, güzelliklerini görmek ve tadına varmak isteyenler, mehtabın durgun bir denize ya da göle yansımasını izlemelidirler ilkbaharda. Sanki baştan sona nur olan bir peri kızı, gümüş gibi olan vücudunu anadan doğma olarak, durgun suya bırakır, yavaş yavaş yüzmeye başlar. Ve ona değen her damla su bir anda nur kesilir.

Suların ortasında, düşlerimize, yine nurdan geniș bir sokak açılır. Bundan sonra, düşler evresinde istediğin yere gidebilirsin artık.” (Namık Kemal, 1992: 22-23) 
Öykü Terzioğlu'nun da tespit ettiği üzere, romanın kötü kadını Mehpeyker de doğal öğelerle anlatılır ve böylece sehvaniliği vurgulanır; güneşe, ama asıl dolunaya benzetilir. Taşkınlığı sürekli vurgulanan ve bana kalırsa Namık Kemal tarafından da ibret vermeye çalışırken basbayağı renkli, kıpır kıpır biçimde tasvir edilen etkin şehvaniliği de bu ikilemi güçlendirir (Terzioğlu, 2007: 15-16). Tanpınar'ın da dediği gibi “Namık Kemal'e göre evvela tabiatta iyi ve kötü beraberce mevcuttur ve insanoğlu iyi ile kötünün, güzelle çirkinin, ahenkli ile ahenksizin imkânlarına kendinde sahip olarak doğar” (Tanpınar, 2001: 429) İşte tüm bu doğa tasvirleri, tüm bu manzaralar aracılığı ile doğallaştırılmış kadın ve erkek kimliklerinin, kadınlar ve erkekler arasındaki ilişkilerin, doğanın hangi imkânlarına açıldığı ya da doğanın hangi tuzaklarına düştüğü de anlatılır.

Manzara, Eylül'de de cins kimliğini ve kadınlar ve erkekler arasında kaçgöçten arınmış modern ilişkilerin içerdiği tehlikeli olasılıkları anlatmanın en temel araçlarından biridir. 1900'de basılan Eylül, Intibah ile karş1laştırılamaz bir derinliğe sahiptir. Son derece basit bir olay öyküsü, derin ruh çözümlemeleri, bunlarla bağlanan uzun doğa tasvirleri ve evlilik, aşk, şehvanilik, kadınlık ve erkeklik gibi temalar üzerine çok boyutlu bir anlatımla örülür. Olay örgüsünü başlatan da aslında mekânla ilgili bir derttir: Süreyya, eşi Suad'la beraber, babasının tuttuğu bağ evinden uzaklaşıp, Boğaziçi’nde, kalabalıklar içinde yalnız kalabileceği bir köye kaçmak ister. Bu elbette genç bir adamın, babadan bağımsızlaşma isteğinin yansımasıdır. Tüm bu temel arzu, mekân boyutu üzerinden karşı1ık bulur.

Bu bağlamda Süreyya'nın halasının oğlu Necip ve Suad arasında yaşanacak aşk da hemen her zaman doğal mekânın, yani manzaraların tasviriyle iç içe geçerek gelişir. Örneğin 
Necip'in dengesiz, gerilimli ruhu, üçlünün Beykoz çayırında yaptığı gezi sırasında karşımıza çıkan şu betimlemede karşılık bulur:

"Ve oraya çıktıkları zaman rüzgarın sönmüş, denizin gümüş bir gevşeklikle bayılmış olduğunu gördüler; zeminin dalgaları dağıldıkça içeri doğru tepeler, gittikçe silsilenen bayırları, sonra dağları oluşturuyor ve her noktası tatl1, yeşil bir çimenle baştan başa örtülmüş görünüyordu. Oradan ta Hisar'a, Kanlıca’ya kadar görünüyor, ikisi arasında akan mavi suların dumanları içinde Boğaz'ın bükülerek, kıvranarak dolanan yolu fark ediliyordu. Güneş Tarabya'nın ötesinde, bir aynada görülüyormuş gibi (göz) kamaştıran ateş beyazıyla bir güneş değil, sınırsız, belli bir biçimi olmayan bir cehennem resmi gibi ufku bekliyordu. " (Mehmet Rauf, 2003: 98)

Romanın yasak aşkı itiraf edilmeden hemen önce de şehvanilikle gerilimin iç içe geçtiği şu firtına tasviri, biz okurları bu gayr-ı meşru aşkla gelebilecek felakete hazırlar:

“Fakat üstlerinde bir çatırtı ile birden dökülecek korkusu veren bu yığılmış dağlar gibi bulutların yeni duman dalgaları ve renkleriyle asılı duran halinde öyle öfkeli bir tehdit vardı ki bütün vadi, hatta üstünde mavi gökyüzü ile dalgalanan deniz bile ürkmüş, korku ve yürek çarpıntısıyla susuyor, sanki bekliyordu. Hissolunmaz, kuşkulu gök gürlemeleri geziniyordu; karartı gittikçe çoğalıyor, yayılıyor, manzara gittikçe korkutucu bir karanlığa, yavaş yavaş Anadolu'ya geçtikçe kaygısız mavilikleri karartan bir korkuya dönüşüyordu...ama yine bir kaygı titreyişiyle bekleyen insana bir tufan korkusu verirken, yalnızca bir yağmur beklemekten gelen zevkle haz duyuyor, bekliyorlardı.” (Mehmet Rauf, 2003: 207) 
Kaldı ki romanın en temel temalarından birini oluşturan ölümlülük de romana adını veren bir eylül manzarası içinden anlatılır. Bu manzara aynı zamanda romanın baş kadın kahramanı Suad'ın ruhunun bir görünümüdür:

Suad çınarların sarı, kuru düşen yapraklarının kapladığı yollarda yağmurlarla ıslanarak oluşturdukları çamura, bu çürümüş yapraklara bakarak "Işste!" diyordu...Evet, hepsi çürüyor, her şey...İnsanlar da çürümeyecek miydi?....Demek ki çürüyecekti, o da çürüyecekti! Böyle, hiçbir mutluluk gelmeden.” (Mehmet Rauf, 2003: 239).

Öyle ise Eylül huzurlu olmaktan çok, yüce ve tedirgin manzaraların kitabıdır. İçindeki doğa hiç de dostane değildir ve sık sık korku, tedirginlik ve hazzın karıştığı, dolayısıyla Namık Kemal'de olduğu gibi cinsellik imgelerini çağıran, ama bunu çok daha ince dengeler içinde yapan bir görünüme bürünür. Buradan devamla Eylül Simmel'in imkânsız dediği işe kalkışmaktadır, doğayı çerçevelerken onun bütüncül anlamına ulaşabileceğini varsayar. Kadınlar ve erkekler arasındaki ilişkilerin bütüncül anlamına, yani içkin gerilimine ulaşmanın metaforik yansıması da bu manzaralarda gizlenir.

Eylül'den hemen 2 yıl önce yazılan Araba Sevdası ise, tüm oyunculuğu, nüktedanlığı ile, Berna Moran'ın isabetle tespit ettiği üzere James Joyce'dan yıllar önce kullandığı bilinç akışı tekniğinin kıvraklığı içinden, Eylül'deki manzaralardan çok başka türlü, oyuncu ve parça parça bir Çamlıca manzarası ile açılır. Romanımızın kahramanının gözünden anlatılan bu manzara, Eylül'ün romantik imgelerinden bir hayli uzak, anlık, neredeyse spot bir deneyimin yansımasıdır ve bana kalırsa dildeki cesaretine koşut şekilde perspektifini de olduğu gibi açık etmekten çekinmez: 
‘ Üsküdar'dan Bağlarbaşı yoluyla Çamlıca'ya gidilirken Tophanelioğlu'ndaki dört yol ağzından yaklaşık bir yüz adım ileriye bakılırsa, o geniş şosenin sonunda çevresi bir buçuk arşın kadar yükseklikte duvar içine alınmış bir ağaçlık görülür. Bu ağaçlığa varıldığı gibi şose yol, sağ ve sol olmak üzere iki kola ayrılır. Duvarla çevrili olan ağaçlığın büyücek bir kapısı vardır ki, iki yolun tam birleştiği noktada bulunur..."

(Recaizade Mahmeu Ekrem, 2005: 25)

John Berger, Şeker Ahmet Paşa'nın bir resmi üzerine yazısında, ressamın, aslında kurallarına hakim olduğu klasik perspektifi bozarak ormana oduncunun gözüyle baktığını fark etmişti (Berger, 1979). Berger’e göre, pek az 19. Yüzyıl ressamı ya da yazarı Şeker Ahmet Paşa'nın yapabildiğini yapabilmiştir; çünkü modern bakış açısı ormanı ancak kendi dışındaki daha büyük bir dünya ile bağlantısı içinde, ancak önemli olayların mekânı olarak tasavvur edebilirdi ${ }^{1}$. Ressam ya da yazarla, orman arasında mesafe koyan bir bakış açısıydı bu ve Şeker Ahmet Paşa tam da bu bakışı sorunsallaştırıyordu.

Şeker Ahmet Paşa, ormanı kendi başına var olan bir yer olarak görüyor ve ormanın varlığı öylesine ağır basıyordu ki, Şeker Ahmet Paşa Paris’te öğrendiği gibi kendisiyle orman arasında olması gereken uzaklığı koruyamıyordu. Bu nedenledir ki Berger’e göre Şeker Ahmet Paşa'nın manzarası, Heidegger' de karşımıza çıkan düşünme tanımına yaklaşıyordu:

"Öyleyse düşünmek de uzaklığın yakınlığına gelmek demektir. Şeker Ahmet Paşa'nın resmi de "uzaklığın yakınına gelmek”le ilgili. Bu gerçeği bu ölçüde bir açıklıkla dile getiren

\footnotetext{
${ }^{1}$ Berger, aynı yazıda bu bakışın romandaki karşılığını şu sözlerle dile getiriyordu: ' Roman, Lukacs'ın Roman Kuramı'nda belirttiği gibi, ufkun ötesinde bulunan bir şeye duyulan özlemden doğmuştu: bir çeşit yurtsuzluk duygusunun sanat biçimiydi roman. Bu yurtsuzluk duygusuyla birlikte insanın daha önce tanımadığı bir seçenek özgürlüğü doğmuş oluyordu (romanların çoğu her şeyden önce bir seçim yapma sorunuyla ilgilidir).’; http://www.sanatatak.com/view/seker-ahmet-pasanin-bir-resmi-ustune-john-berger
} 
başka bir resim düşünemiyorum..."Uzaklığın yakınına gelme”de karşılıklı bir hareket var. Düşünce uzak olana yaklaşıyor, ama uzak olan da aynı zamanda düşünceye yaklaşıyor... Oduncu ile katırı ormanda ilerliyorlar. Oysa resim onları nerdeyse hareketsiz bir hale getiriyor. Sanki hiç kımıldamıyorlar. Kımıldayan bir şey varsa, o da orman - işin şaşırtıcı yanı da insanın bunu önceden farkına varmadan sezmesi. Orman bütün varlığı ile oduncunun ters doğrultusunda hareket ediyor, yani bize doğru ve sola doğru"; http://www.sanatatak.com/view/seker-ahmet-pasanin-bir-resmi-ustune-john-berger.

\section{Sonuç}

Bana kalırsa, 1898 tarihli Araba Sevdası'nın Çamlıca manzarasına bakışı ile Şeker Ahmet Paşa'nın gene yüzyıl sonunda ormana bakışı arasında önemli bir paralellik var: İlki kahramanının, ikincisi ise oduncunun gözünden bakıyor doğaya. Böylece her ikisi de modern perspektif ve bakış açısının getirdiği üçüncü gözün (büyük olayların, seyircinin, okurun gözünün) dışında bir açıdan, dış dünya ile bağlantılandırılmadan kendi başına var olabilen bir yer olarak görebiliyorlar mekânı: İçinde deneyimin, tüm bağlamlardan kopuk olarak yer alabileceği ve ‘uzaklığın yakınına gelen' bir bakış bu.

Sonuç niyetine bir de şunları söyleyebiliriz: İlki ibret verici olsun diye, ikincisi insan ruhunun derinliklerine inmek için, üçüncüsü ise modernliğin yarattığg yepyeni tecrübeyi yeni dilsel olanakları kullanarak ifade etmek üzere yazılmış bu üç 19. Yüzyıl anlatısı da toplumsal cinsiyeti modernlik tartışmalarının merkezine koyarken, bunu manzara tasvirleri aracılığıyla yapıyorlar. Kendi erekleri doğrultusunda, muhakkak ki farklı bakış açılarını yansıtarak yapıyorlar bunu. Ancak her koşulda bu anlatılardaki manzara, hiç de bir yan öğe ya da bir dolgudan ibaret değil, aksine romanın ana malzemesini oluşturan bir unsur. Tam da bu unsur, doğanın nasıl kavrandığını gösterirken, doğallaştırılmış bir toplumsal cinsiyet algısının da yansiticisı halini aliyor. 


\section{Kaynaklar}

Berger, J. (1979). Şeker Ahmet Paşa'nın Bir Resmi Üstüne. 30 Ekim 2019 tarihinde http://www.sanatatak.com/view/seker-ahmet-pasanin-bir-resmi-ustune-john-berger siitesinden erişilmiştir

Berger, J. (1995). Görme Biçimleri. İstanbul: Metis

Foucault, M. (2000). Kelimeler ve Şeyler. İstanbul: İmge Kitabevi

Karatani, K. (2011). Manzaranın Keşfi. Derinliğin Keşfi: Modern Japon Edebiyatının Kökenleri içinde (ss. 24-48). İstanbul: Metis

McArdle, L. (2013). The Story of Still Life. 30 Ekim 2019 tarihinde https://vimeo.com/84883341 siitesinden erişilmiştir

Mehmet Rauf (2003). Eylül. İstanbul: Bordo Siyah Yay. (1900)

Namık Kemal (1992). İntibah. İstanbul: Morpa (1874)

Namık Kemal (2016). Celaleddin Harzemşah. İstanbul: Kesit Yay. (1876)

Pamuk, O. (2011). Roman Okurken Kafamızda Neler Olup Biter? Saf ve Düşünceli Romancı içinde (ss. 7-28)

Parla, J. (1993). Babalar ve Oğullar. İstanbul: İletişim Yay.

Recaizade Mahmud Ekrem (2005). Araba Sevdası. İstanbul: Bordo Siyah Yay. (1898)

Simmel, G. (2007). The Philosophy of Landcape. Theory, Culture \& Society, 24 (7-8), 20-29 (1913)

Tanpınar, A. H. (2001). 19. Asır Türk Edebiyatı Tarihi. İstanbul: Çağlayan Yay.

Terzioğlu, Ö. (2007). İntibah'ta Kadın Bedeni ve Doğayla Erkek Zihni ve Medeniyetin Karşıtlı̆̆ 1 . Varlık, 2007/6-1197, 13-16 


\title{
SPACE AND GENDER-ORIENTED DISCOURSE ANALYSIS OF THE TAHSIN YÜCEL'S NOVEL "MUTFAK ÇIKMAZI"
}

\author{
Uğurcan TAŞDELEN ${ }^{1}$
}

\begin{abstract}
Gender can be defined as the integrity of determining limits of masculine and femine profiles in the society and the aforementioned profiles' effects on individuals. It is possible to determine how gender reflects on the Turkish society having a patriarchal structure and the factors resulting in individual vs society conflicts.Gender principles having the characteristics of unwritten laws by which limits of female and male's limits in social life can be easily observed are included in artistic texts emerging from the society and reflecting it.We can see that aforesaid subject is discussed in Mutfak Çıkmazl (1960) by Tahsin Yücel. By reviewing Mutfak Çıkmazı written approximately 60 years ago we will try to examine social principles within the Turkish society throughout the history, social gender roles and possible circumstances beyond said roles.A short summary of the novel Mutfak Çıkmazl will provide an overview of the masculine and feminine structure. The protagonist of the novel is Ilyas Divitoğlu. Ilyas Divitoğlu was the son of a noble and wealthy family. When his grandfather is judge died, his family wanted him to follow his grandfather. He was sent to Istanbul for his education and started to the Faculty of Law. His whole life changes when he falls in love with a girl named Emel in Istanbul. Ilyas, who has more than friendship with Emel, is disappointed and rejected by Emel on the day she expresses her feelings.Ilyas takes a decision that will be a turning point in his life when he is in a crisis and chats with a man he meets in the house of his close friend Murat. After that, he'il cook his own food. Murat thinks that his friend can get rid of his depression with this decision and gives him the necessary kitchen utensils. ilyas is from a noble family so he doesn't think it's appropriate to cook, but he believes that there is a way to cook for forgetting.Spending all day in the kitchen, Divitoğlu invests all the money in his books and kitchen becomes the center of life. His dreams, love, hopes, all his values change to cooking, and this adventure results in his being killed by his best friend. In this paper, examples of Ilyas Divitoğlu's life will be given and the place of men and women in Turkish society will be determined.
\end{abstract}

Keywords: Literature, Gender, Novel, Discourse Analysis, Mutfak Çıkmazı

1 MA, Communication and Media Studies Program, Eastern Mediterranean University, tasdelenugurcan@gmail.com 


\section{TAHSIN YÜCEL'İN MUTFAK ÇIKMAZI ROMANININ MEKÂN VE TOPLUMSAL CINSIYYET ODAKLI SÖYLEM ÇÖZÜMLEMESİ}

\section{$\ddot{O ̈ z e t}_{\text {zet }}$}

Toplumsal cinsiyet, toplum nezdinde eril ve dişil rollerin sınırlarının çizilmesi ve bireyler üzerinde bu rollerin getirmiş olduğu yaptırımların bütünü olarak tanımlanabilir. Ataerkil bir yapıya mensup olan Türk toplumunda toplumsal cinsiyet rollerinin hayattaki karşılıklarını gözlemleyebilmek ve birey-toplum çatışmasına yol açan unsurları tespit edebilmek mümkündür. Kadının ve erkeğin sosyal hayattaki sinırlılıklarının kolayca gözlemlenebilecĕgi yazısız kanunlar niteliğindeki toplumsal cinsiyet ilkeleri toplumun içinden doğan ve toplumu yansıtan sanatsal metinlere de girmiştir. Tahsin Yücel'in de "Mutfak Çıkmazl” (1960) adlı romanında bu konuyu işlediğini görmekteyiz. Yaklaşık altmış yıl önce yazılmış olan "Mutfak Çıkmazı" romanın inceleyerek Türk toplumunda geçmişten günümüze kadar gelmiş toplumsal ilkeleri, toplumsal cinsiyet rollerini ve bu rollerin ötesine geçildiğinde karşılaşılan durumu irdelemeye çalışacă̆ız.

Mutfak Çıkmazı romanı, soylu ve zengin bir ailenin oğlu olan ve gelecekte dedesi gibi Yargıtay üyesi olması hayal edilen İlyas Divitoğlu'nun, Hukuk eğitimi için geldiği İstanbul'da, âşık olduğu klz tarafindan reddedilince girdiği bunalım sonucu kendini mutfakta yemek yapmaya adaması üzerine kuruludur. Bunalımda olduğu dönemde, yakın arkadaşının evinde tanıştığı bir adamla sohbeti üzerine, önceleri kendini mutfăga yakıştıramasa da gerekli mutfak malzemelerini temin ederek yemek yapmaya başlar. Zamanla elindeki tüm parayı yemek kitaplarına yatırır ve mutfak hayatının merkezi haline gelir. Hayallerini, sevdasın $\imath$, umutlarını, tüm değerlerini yemek yapmakla değiştirir. Sonunda en yakın arkadaşı tarafından öldürülür. Bildiri, toplumsal rol değişiminin, mekân ve cinsiyet çatışmasının nasıl gerçekleştiğini ve bunun hem bireysel hem toplumsal yansımalarını sorgulamak üzere, romanı söylem çözümlemesine tâbi tutacaktır.

Anahtar Kelimeler: Toplumsal Cinsiyet, Edebiyat, Roman, Söylem Analizi,Mutfak Çıkmazı 


\section{Söylem Nedir? ${ }^{1}$}

Söylemi tanımlayabilmek için öncelikle ideoloji kavramını açıklamak gerekir. İdeoloji kavramı: İnsan ve toplumun (ya da toplumsal bir alt birimin) geliştirdiği, insan, toplum ve evrene ilişkin kapsamlı bilişsel ve ahlaksal inanç sistemlerinden biridir (Ergil,1983: 69). Gerçeklik, edebi metne taşınırken değiştirilmekte ve yazar tarafından yeniden üretilmektedir (Cengiz, 2015: 270). Yazar metni kurarken ideolojiye yaslanmakta ve ondan aldığg güçle eserini ortaya koymaktadır (Cengiz, 2015: 271). Edebiyatın temeli dil olduğu için dilde var olan toplumsal ideolojiler eserlere yansımaktadır. Bu bağlamda edebî ürünler ideolojiden bağımsız düşünülemez.

Latince kökenli “Discourse" kelimesi Türkçede "Söylem” olarak karşılık bulur ve "Bir şey bildirirken konuşanın ağzından çıkan sözlerin bütünü.” şeklinde tanımlanır (TDK). İktidar ile söylem arasındaki ilişkiyi inceleyen Michel Foucault ise söylemi; "amaç, geleneksel destekler, güç ilişkilerinin yeniden üretilmesi ve bunların ideolojik etkilerini inşa eden ifade sistemi” olarak tanımlar (Çelik ve Ekşi, 2008:113). Bu tanımdan da anlaşılacağı gibi söylem ideoloji ile iç içedir. Stuart Hall'a göre söylemin genel tanımı şu şekilde yapılabilir: "Dil vasıtasıyla görünürlük kazanan ve düzenlenen, hazır ve önceden kurulmuş 'tecrübe edişler' kümesi” (Coşar, 2014:22).

Toplumsal ilişkilerin, düzenin, nesnelerin, simgelerin, yeniden yapılandırılarak kullanılması söylemle ilgilidir ve toplum içinde yer alan söylemler bireylerin sözlerini doğrudan etkiler. Foucault, “Düşünce Sistemleri Tarihi Kürsüsü” başkanı iken 12 Nisan 1970'de yaptığ1 “Söylemin Düzeni” adlı açılış konuşmasında söylem hakkında şu ifadeleri kullanır:

\footnotetext{
${ }^{1}$ Bu bölümü hazırlarken, şu kaynaklardan yararlandık: Semran Cengiz, Edebiyat ve İdeoloji 15.09. 2015, s.266274.; Doğu Ergil, İdeoloji Üzerine Düşünceler, 1983, s.69.; Cevriye Demir Güneş, Michel Foucault'da Söylem ve İktidar, 2013, s.56.; Trevor Purvis ve Alan Hunt, Söylem, İdeoloji, Söylem, İdeoloji, Söylem İdeoloji, çev. Simten Coşar,2014, s.22.; Salih Özer, Söylem Çözümlemesi ve Rivayetlerin Anlaşılmasına Yönelik Katkıları, 2007, s.4142.; Yasin Şahin, Michel Foucault'da Söylem Analizi,2017, s. 121-125.; Yusuf Yüksel, İletişim Araştırma Metodları,2004, s.3-6.; Hilal Çelik, Halil Ekşi, Söylem Analizi, 2008, s.101-113.
} 
“Benim arkamda (çok önceden söze başlamış, söyleyeceğim şeyleri önceden söylemiş) bir sesin şöyle demesini isterdim: "sürdürmek gerek, ben sürdüremiyorum, sürdürmek gerek, sözcükler olduğu sürece onları söylemek gerek, beni buluncaya, beni söyleyinceye dek, onları söylemek gerek - tuhaf çaba, tuhaf hata, sürdürmek gerek, belki de çoktan oldu, belki de çoktan söylediler bana söyleyeceklerini, belki beni öykümün eşiğine dek, öyküme açılan kapının eşiğine dek taşıdılar, eğer kapı açılırsa şaşardım" (Güneş, 2013:21).

Günümüze değin söylenmiş ve söylenecek olan sözler, sosyal bir varlık olan insanın varoluşunun fizyolojik ispatıdır. Bireysel olan söz, toplumsal ve uzlaşımsal bir dilden doğar. Dil ise, sosyal yaşamı inşa eden en temel unsurdur. Toplum içinde ideolojileri besleyen söylem ise; toplumsal ve uzlaşımsal dilin ürünüdür. Dil olmadan söylemden söz edilemez ve böylelikle dil ile söylemi bir kâğıdın iki yüzü gibi nitelendirmek mümkündür.

Dil bireyden önce de vardır ve bireyden sonra da varlığını devam ettirir. Birey topluma ait bir dilin içine doğar ve toplumsal olan dille etkileşim içine girer. Söylemin ise dilin bireysel kullanımıyla varlığından söz edilir. Bir dil olmadan söylemden söz etmek olası değildir. Söylem sırasında gerekirse dile yeni anlamlar kazandırılır ve bir bağlam içerisinde yeniden üretilir.

Saussure'e göre dil ile düşünceyi birbirinden ayırt etmek olanaksızdır. (Çelik ve Ekşi, 2008:101). Dolayısıyla düşünce sistemi olarak adlandırdığımız ideoloji ise dilden ayrı düşünülemez. Sosyal dünyayı inşa eden dil yine meydana getirdiği sosyal dünya içerisinde yer alan ideolojiler tarafından kuşatılır ve bu karşılıklı etkileșim söylemin kendiliğinden oluşumuna zemin hazırlar. Toplum içinde kendini söz ile ortaya koyan birey bu sistemin dışında düşünülemez.

Dilin ve düşüncenin ürettiği söylemler bir amaç doğrultusunda belli bir kitleye hitap eder. $\mathrm{Bu}$ yüzden ne söylendiği ile birlikte söyleyenin niyeti ve söylenenlerin dinleyiciler/okuyucular üzerindeki etkisi de önem arz etmektedir. Gerçeklik, dillendirilirken bireylerin söylemleriyle bütünleşerek yeniden üretilmekte ve yeni bir boyut kazanarak sosyal 
hayatta yer edinmektedir. Dolayısıyla üretilen sözlü ya da yazılı metin içeriği haricinde başka bir alt metin taşımaktadır. İleti, gönderen tarafından kendi söylemlerini içeren kodlarla işlendiği için sözün bireysel kullanımında, dilde ve bireylerin üzerinde yarattığı etkiyi, sosyal hayatta bulduğu gücü gözlemleyebilmek mümkündür.

\section{Söylem Çözümlemesi Nedir?}

Söylem çözümlemesi, Bilim ve Sanat Terimleri Sözlüğünde, "Bir söylemin içine saklı biçimde bulunan ideolojik, hiyerarşik ve etik unsurların ortaya çıkarılarak söylemin temel unsurlarının belirginleştirilmesi amacına yönelik bir sosyal araştırma yöntemi, meta anlatı, yapı çözümü” şeklinde tanımlanır (http://sozluk.gov.tr/). Ancak söylem çözümlemesi için bugüne değin çeşitli tanımlamalar yapılmıştır.

Maingueneau'ya göre söylem çözümlemesi, sözceleme durumu ile belirli bir toplumsal uzamın birleşimi demek olan söylemi inceleyen bir bilim dalıdır (Günay, 2013:26).

Foucault' nun söylem üzerindeki görüşlerini temel alan söylem analizi, geleneksel düşünme ve yazma pratiklerinin kültürel yapı içinde politik ve ideolojik amaçlara nasıl hizmet ettiğini, benzer şekilde insanların düşünme biçimlerinin ve sosyal bir varlık olarak edenlerin nasıl sınırlandırdığına, kısıtlandığına yönelik açıklamalar getirmeyi amaç edinir (Özdemir, 2017:2).

Bir başka tanıma göre ise; söylem analizi, metinlerin onlara neden olan iletişim sürecinin analizine yönelik bir yöntemdir ve öncelikli amac1, metne yönelik daha derin bir anlama ve kavrama imkânı sağlamaktır (Özer, 2007:41).

Brown ve Yule ise; söylem çözümlemesini kullanılan dilin incelenmesi olarak tanımlamaktadır. Bu çözümleme, insan ilişkilerinin temelini oluşturan amaç ve işlevden bağımsız olarak yalın bir dilbilimsel biçimlerin tanımlanması olarak düşünülemez demektedirler (Yüksel, 2004:4). 
Hilal Çelik ve Halil Ekşi’ye göre; Söylem araştırmaları, semantik, fonoloji, sentaks, morfoloji ve pragmatik yaklaşımlarda görüldüğü gibi cümleyi temel alan dar kapsamlı dil analizi değildir. Tam tersine, dil kullanımının daha büyük bölümlerini sosyokültürel bağlam çerçevesinde ele alıp inceleyen bir yaklaşımdır (Çelik ve Ekşi, 2008:105).

Söylem çözümlemesinin amacı alt metni çözümlemek, metni daha derin ve geniş bir perspektifle anlamayı sağlamaktır. Metinde sözcüklerin ya da cümlelerin dilbilgisel anlamı bağlam içinde ifade edilen söylemsel anlamından farklı olur. Bu nedenle bir cümle ya da sözcük kendi anlamı dışında farklı anlamlar ifade edebilmekte ve anlam bağlama göre sinırlandırılabilmektedir.

Metinlerin dilin bireysel kullanımıyla oluşturulması, belirli bir söylem içerisinde ifade edildikleri anlamına gelir. Her metnin bilgi vericilik özelliği ve metnin ortaya çıkmasına neden olan amaçlılığı söz konusudur. Yazar, toplumsal olan dili amacı doğrultusunda kullanarak bireysel sözünü ortaya koyar ve toplum içerisinde var olan ideolojik sınırlılıklar içerisinde söz sahibi olur. Söylem çözümlemesi ise, metin aracılığıyla metnin altında yatan söylemi analiz etmektedir. Söylem çözümlemesi yaparken metin yazarının söylediklerinden yola çıkarak, yazarın aslında ne söylemek istediği ve söylemek istemediği, metinden hareketle gün yüzüne çıkartılır. Yazarın metni oluştururken seçtiği sözcükler ve bu sözcüklerin cümle içerisindeki yeri, sözcük tekrarları, eksiltili cümleler, konular arası geçişler, sözcüklerin bağlam içerisinde kazandığı anlamlar, yazarın türettiği sözcükler vb. birçok ölçüt göz önüne alınarak derin yapı çözümlenir.

Söylem çözümlemesi yapılırken içeriğin doğruluğu ya da yanlışlı̆̆ı, bilgilerin eksikliği ya da fazlalığı vb. üzerinde değil metnin vermek istediği mesajlar üzerinde durulur. Fonoloji, morfoloji, sentaks, semantik gibi dilbilgisel alanlarda yapılan çalışmalar metni yalnız çalışma alanının sınırlılıklarıyla ele alarak dar bir inceleme yapmaktadır. Oysa söylem çözümlemesi, tüm bu alanlarda dilbilgisel inceleme yapıldıktan sonra başlar. Yüzey yapıya sahip olan metin 
dilbilimsel yöntemlerle analiz edilerek derin yapıya ulaşmak amaçlanır ve metin çeşitli söylem çözümlemesi biçimleri doğrultusunda incelenir.

Foucault, söylem ile ilgili fikirlerini açıklarken dil ve toplumsal sınıflar arasında ilişki kurar. Ona göre, sözcükler anlamsal açıdan kullanıldıkları yere, kullanan bireylere ve bireylerin amaçlarına bağlı olarak açıklanır ve bu yüzden söylem, sosyaldir. Sosyal ortamlara göre kelimelerin anlamları değişeceği için söylem evrensel değildir. Ayrıca söylemler birbiriyle çatışabilir ve bir hiyerarşi içinde düzenlenmiş olabilir. Bu nedenle, söylem ve iktidar arasında kuvvetli bir ilişki söz konusudur ve söylem çözümlemesi yapılırken bu ilişki göz ard1 edilmemelidir. Foucault, söylemlerin politik ve ideolojik olarak bireylerin düşüncelerini bilinçli bir şekilde etkilediğine ve edenlerini sınırlandırdığına değinir. Söylem çözümlemesi yapılırken direkt bireylerin bilinçaltını hedef alan kodların metinden hareketle çıkartılarak, metnin yazılış amacı ortaya konulur.

Metnin yazılış amacının saklı olduğu kodlar anlambilim (semantik), sözcükbilim, metin dilbilimi gibi alanların yardımıyla analiz edilir. Kelimelerin temel anlamları ile bağlam içerisinde ifade ettiği anlamları, tekrar sıklığı, metin içi ve metin dışı gönderimleri, çağrışımları, cümle içerisindeki işlevleri vd. özellikleri değerlendirilir. Metnin kendi içerisindeki tutarlılığı, uygunluğu ve mesaj veren unsurları, metinsellik ölçütleri kapsamında irdelenerek tümce ötesi yapılara ulaşmaya çalışılır. Dolayısıyla söylem, tümcenin daha üst boyutundaki bir birimdir ve söylemi oluşturan içeriğin anlamı ile söylemin anlamı birbirinden farklıdır.

\section{Mekân - Cinsiyet Kodlamaları}

Ataerkil toplumlarda dış mekânlar erkek, iç mekânlar kadın için kodlanmıştır. Örneğin; kahvehaneler, kafeler, barlar, parklar, sokaklar vb. dış mekânlar erkek için kodlanırken; evler, odalar, mutfak, salonlar vb. kapalı içe dönük mekânlar kadın için kodlanır. Bir erkek, mesleki anlamda aşçılığı tercih ettiğinde ona saygı duyulur ve toplum içerisinde saygılı bir yer alır. 
Ancak bir avukatın ya da bir doktorun kendini eve kapatıp yemek yapması toplumsal cinsiyet bağlamında kabul edilemeyen bir durumdur. Böyle durumlarda kişi, toplum karşısında "Aşçı parçası" gibi sınıfsal ayrımlara yol açabilecek söylemlere maruz kalabilir.

Mekânların cinsiyet çizgileriyle sınırlandırılması, erkekleri ve kadınları bulundukları yere göre olumlu ya da olumsuz olarak etkileyebilmektedir. Örneğin; bir erkeğin kadın doğum polikliniğinde karısı ile beraber sıra beklemesi erkeğin çekingen tavırlar sergileyebilmesine yol açabilir. Aynı şekilde mekânlar cinsiyetler üzerinde yaptırımda doğurabilir. Örneğin; Kadınların kamusal alanlarda nasıl hareket edeceğine ilişkin görülmez kurallar mevcuttur; sigara içmek, sakız çiğnemek, yüksek sesle gülmek gibi (Küncü, 2018: 96).

Dilde zaman içinde kalıplaşan sözler deyim ve atasözlerini meydana getirmektedir. Toplum içerisinde kabul görmüş ve yaygınlaşmış bu sözlerde cinsiyet rollerinin çizdiği sınırlarla meydana getirilmiş bir takım deyim ve atasözleri de mevcuttur. Örneğin; "Çok gezen tavuk ayağında pis getirir." atasözünde "tavuk" ile kadın kastedilerek, kadının her yerde gezmesi laf olur mânâsıyla söylenmiş ve kadının mekânları sınırlandırılmıştır. Bir diğer örnekte ise "Yuvayı yapan dişi kuştur." Atasözünde "dişi kuş" ile kadın kastedilerek kadının evin yönetim, geçim, düzenini üstlendiği kastedilmiş aynı zamanda kadının mekânının ev olduğu üzerinde durulmuştur. Aynı şekilde, "erkek erkeğe" deyimiyle erkeklerin bulunduğu bir mekânda kadının yeri sınırlandırılmıştır.

\section{Mutfak Çıkmazı Romanının Söylem Açısından İncelenmesi}

\section{Mutfak Çıkmazı Romanının Kısa Özeti}

Mutfak Çıkmazı romanı, soylu ve zengin bir ailenin oğlu olan ve gelecekte dedesi gibi Yargıtay üyesi olması hayal edilen İlyas Divitoğlu'nun, Hukuk eğitimi için geldiği İstanbul'da, âşık olduğu kız tarafından reddedilince girdiği bunalım sonucu kendini mutfakta yemek yapmaya adaması üzerine kuruludur. Bunalımda olduğu dönemde, yakın arkadaşının evinde 
tanıştığı bir adamla sohbeti üzerine, önceleri kendini mutfağa yakıştıramasa da gerekli mutfak malzemelerini temin ederek yemek yapmaya başlar. Divitoğlu, erkek olarak mutfağa girdiği için mutfak alışverişi yaparken huzursuzluk hisseder ve utanç duyar. Ailesine yazdığ1 mektuplarda yemek yaptığından bahsetmez ve bir gün evini ziyarete gelen akrabası evdeki sofrayı görünce Divitoğlu nişanlandığını söyleyerek yalana başvurur. Yaşamını yemek için harcamaya başlayan Divitoğlu, zamanla elindeki tüm parayı yemek kitaplarına yatırır ve mutfak hayatının merkezi haline gelir. Hayallerini, sevdasını, umutlarını, tüm değerlerini yemek yapmakla değiştirir. Sonunda kendisini bir "aşçı parçası” şeklinde yargılayan en yakın arkadaşı Mustafa tarafindan öldürülür.

Mutfak Çıkmazı Romanında Mekân - Toplumsal Cinsiyet Çatışması ve Bunun Dile Yansımaları

Cümleyi kuran kategorik unsurların birbirlerine bağlanma şekilleri, bağlanma koşulları “İstem Dil Bilgisi” içinde incelenmektedir (Hirik, 2018: 126). Mutfak Çıkmazı romanında yaptı̆̆ımız "istem dilbilgisel inceleme" ile toplumsal cinsiyet kavram alanına giren kritik noktadaki söylemlerin metni nasıl yönlendirdiğini göstermeye çalıştık. Romanda çatışma alanlarının kahramanı çıkmaza sürüklediğini tespit ettik.

1) Kadının elinde bir kitap görürdü sık sık. Sarı kaplı bir kitaptı, bu kitaba bakarak yemek yapardı. Fena da yapmazd1. (s.45)

(Sarı rengin psikolojik çağrışımı; özgün düşünce ve merak uyandırmaktır. (http://www.kisiselgelisim.com/renklerin-psikolojisi-sari-renk-ve-sari-rengin-anlami/)

Kahramanın sarı renkli yemek kitabına olan ilgisi onun özgün yemekler yapmak amacıyla merak ettiği yeni tarifleri ifade eder ve bu kitabı bir kadından ister. Kadının yeri mutfaktır ve bir erkeğin bir kadından yemek kitabı istemesiyle yazar, bir çatışma alanı yaratarak toplumsal cinsiyet rollerine işaret eder ve roman toplumsal cinsiyet sınırlarının dışına çıkar). 
2) Başı dönüyordu İlyas'ın. Yüreğinde bir çarpıntı başlamıştı, bir aşk çarpıntısı. Hızla çeviriyordu sayfaları. (s.46)

(İlyas yemek kitabının sayfalarını aşkla ve heyecanla çevirir, yazar yemek yapmanın bir tutku haline döndügünü bu duygularla hissettirir. Bir kadının değil erkeğin yemek kitabı karşısında heyecanlanmasıyla toplum nezdinde toplumsal cinsiyet sınırlarının dışına çıkılır).

3) Sen her şeyi bana bırak. Göreceksin: yeni kızın eskisinden bin kat güzel olacak,” dedi, gene güldü kahkahayla, sonra birden kaşlarını çattı. "Ama kötü bir şey oldu, bir berbat yanlışlık," diye mırıldandı. (s.63)

(İlyas'la şaşırtıcı bir karşılaşma sırasında okuyucuyla bir araya getirilen Murat, şaşırtıcılık özelliğini koruyarak İlyas’a yeni bir kız arkadaşı bulacağını söyler. Yeni kızın eskisinden bin kat güzel olacak söylemiyle İlyas'a Emel'i unutturacağını İlyas'ın hayatını değiştirebileceğini düşünür).

4) İçini çekti. “Ben evlenmem,” diye söylendi. “Kadınları iyi bilirim: mutfaktan çıkmak bilmezler, her yemĕge karışırlar. Böyle şeylere gelemem, ben evlenmem...” (s.111) (İlyas, mutfă̆ı için sevdiği kadınla evlenme fikrine karşı çıkar. Evliliği yemekleriyle kendi arasına giren bir engel gibi görür. Yemeklerle arasındaki ilişki tüm kararlarını etkilemeye devam eder).

5) Bir lokanta mutfağı bile değildi, birkaç kuruş para bile getirmiyordu. Ama olan olmuştu bir kez: her şeyi bu mutfaktı işte, yaşamı bu mutfaktı! Yaşamını değiştirmek de istemiyordu. (s.141-142)

(İlyas, yaşamını yeni bir mutfağa adar ve yaşamını değiştirmek istemez. Tüm acılardan kurtulma yolunu yine mutfakta görmüş, mutfak sığındığı bir liman haline dönmüştür. İlyas pişmanlık hisseder fakat kişisel değildir. Pişmanlığı toplumsal yapı dolayısıyla hisseder. Toplumun ona karışması, onu bölmesi onu rahatsız eder). 
6) Yüzünü, çevresini, kılığını, önündeki önlüğü görünce, beyninden vurulmuşa döndü, yüzüne tükürdü. Mustafa, candan akrabası, sevgili çocukluk arkadaşı, "merhaba” bile demeden yüzüne tükürdü de İlyas hiç mi hiç kızmadı, alınmadı, gözleri yaşarmadı, karşılık vermeye de kalkmadı, boş boş bakmakla yetindi. Sonra önlügüyle yüzünü sildi, gülümsedi. (s.142) (En yakın arkadaşı Mustafa, yüzüne tükürdügünde İlyas’’n üzülmemesi ve önlüğüyle yüzünü silip gülümsemesi arkadaşını yaptığı davranıştan dolayı haksız görmediğine işarettir. Yüzüne tükürmek büyük bir hakaret olmasına rağmen İlyas, arkadaşının bu tepkisini bekliyormuş gibi davranır ve bu durumu hoş karşılar).

7) “Bir aşçı parçası mısın?"

\section{“Evet, bir aş̧̧ı parçasıyım.”}

Mustafa boynunu büktü gene. (s.143)

(İlyas, "Bir aşçı parçası mısın?” sorusuna evet yanıtını vererek yaşadığı hayatın itiraf etmesiyle arkadaşı Mustafa boynunu bükmüştür. Mustafa bu gerçeği öğrendiğinde canı yandığı için boynunu bükerek tepki verir).

Aynı doğrultuda Kavram alanı incelemesine göre yaptı̆̆ımız incelemede şu örnekler göze çarpmıştır:

- “Anlıyorum: kadın parmăğ ...” dedi. (s.93)

(“kadın parmağı” ifadesi bir kadının eli değdiği, bir erkeğin yapabileceği bir durumun olmadığı anlamları içerdiğinden “Toplumsal Cinsiyet” kavram alanını işaret eder).

- “Divitoğlu kasap dükkânında ne yapıyormuş, derler. Memlekete rezil olurum," (...)

(Örnekteki cümlede kasap dükkânında olduğunu duyulmasını istememesinin sebebi rezil olmaktır. Bunu bir erkek olarak kendine yakıştırmaz dolayısıyla "Toplumsal Cinsiyet" kavram alanını işaret eder).

- Öyle ya, erkekler ağlamazlardı o yerlerde, o yerlerde erkeklerin ă̆laması aytptı. (s.14) 
(“erkekler ağlamazlardı o yerlerde, o yerlerde erkeklerin ağlaması ayıptı.” ifadesinde erkeklere biçilen bir rol söz konusudur ve bu "Toplumsal Cinsiyet" kavram alanını işaret eder).

- Yemek pişiresin diye öteberi getiriyor sana, evinin erkeği gibi... (s.79)

- “(...) Yemek yapacak adam misın sen? Koca İlyas Divitoğlu yemek yapar mı? Yapmaz! (...) (s.60)

(Yukarıdaki örneklerde "evinin erkeği gibi”, “yemek yapacak adam mısın sen?” ifadeleriyle tercih edilen söylemle erkeklerin mutfakta ve evde iş yapmamalarını belirtir ve "Toplumsal Cinsiyet" kavram alanını işaret eder).

Yazar, kurduğu çatışmalarla toplumsal cinsiyet alanını şekillendirirken amacına yönelik ifadelere yer vermektedir. Bunları şu şekilde örnekleyebiliriz:

- Güldüm, yaa! Hem de çok güldüm. Yemek yapacak adam mısın sen? Koca İlyas Divitoğlu yemek yapar mı? Yapmaz! Şu ellere bir baksana: tutsa tutsa divit tutar, kâğıt tutar bu eller. Kap yıkamak, salata yapmak, soğan doğramak yakışmaz bu ellere. Ben bilmez miyim?.. Neyse, bunu bırakalım, şakayı bırak da söyle: bu arada neler yaptın?” (s.60)

- Öyle ya, erkekler ağlamazlardı o yerlerde, o yerlerde erkeklerin ă̆laması ayıptı. (s.14) Ayrıca romanda yazarın, eril söylemi kadın üzerinden nasıl şekillendirdiğine ve toplumsal cinsiyet alanını nasıl oluşturduğuna yönelik benzetme örneklerine rastlamaktayız:

- Kadın bedenlerini resimlerden tanıyan delikanlılara benziyordu: onlar gibi kuru ekmeğe sarıliyordu... (s.32)

(Yazar, Divitoğlu'nun açlığını betimler ve bu betimlemeyi yaparken "kadın bedenlerini resimlerden tanıyan delikanlılar” ifadesiyle Divitoğlu'nun çaresizliğini eril bir söylem üzerinden ortaya koyar).

- Murat erkek değil, güzel bir kımış, güzel kızla evlenmek istemiş de güzel kız hiç yanaşmamış, üstelik de alay etmiş gibi kızdı Divitoğlu. (s.44) 
(Murat'ın kızgınlığı betimlenirken “güzel bir kızı istemiş ama reddedilmiş, üstelik alay edilmiş gibi” ifadesiyle kızgınlığın ne kadar güçlü derecede olduğu eril bir söylem üzerinden şekillenir ve toplumsal cinsiyet alanına işaret eder).

\section{Değerlendirme ve Sonuç}

Disiplinler arası bir bilim dalı olan Söylem Çözümlemesi, dil çalışmalarında önemli bir yere sahip köklü bir alandır. Bu bağlamda Türk edebiyatının sosyal ve toplumsal eleştirileriyle ön planda olan yazarı Tahsin Yücel'in "Mutfak Çıkmazı romanını sosyal ve toplumsal eleştirilerini göz önünde bulundurarak, özellikle toplumsal cinsiyet rolleri çerçevesinde söylem çözümlemesi teknikleriyle inceledik.

Toplumsal cinsiyet rolleri, toplumda bireylere biçilen ve yaptırım gücü olan cinsiyet rolleridir. Kadın ve erkek toplumun karakteristik özellikleriyle şekillenmiş toplumsal cinsiyet alanına toplum tarafından itilir ve bu alanın dışına çıkan bireyler yine içinde bulunduğu toplum tarafından çeşitli tepkilere maruz kalır. "Mutfak Çıkmazı” romanı kadının yaşam alanı kabul edilen mutfak üzerine kurulu bir yapı üzerinden kaleme alınmıştır.

Yazar, romanlarda eril yapının toplum içindeki güçlü durumunu yansıtmak amacıyla bu sistemde varlığını sürdüren zihniyeti kahramanlara yansıtır. "Mutfak Çıkmazı" romanında Murat'ın “Bende evlenecek göz varmış gibi” ifadesi çapkınlığı, erkekliğin doğal bir parçası olarak göstermekte ve eril mekanizmayı kuvvetlendirmektedir.

“Mutfak Çıkmazı” romanının başkahramanı İlyas Divitoğlu, Anadolu’nun bir köyünden İstanbul'a okumaya gitmiştir. İlyas'ın yemek yapma arzusu ailesi ve akrabaları tarafından hayatının en büyük hatası gibi görülürken, İstanbul'daki çevresi onun yemek yapmaya başlamasıyla kendini daha iyi hissedeceğini düşündükleri için desteklerler. Örneğin; “Murat'1n ardından mutfağa girdi. Bir ufak tencere, birkaç eski tabak, iki çatal, iki kaşık, bir bıçak aldı. 
Kâğıtlara sarıp bağladılar. (s.28) ifadesiyle Divitoğlu'na en yakın arkadaşının "yemek yapma" konusunda destek olduğunu ve ona yardım ettiğini görürüz.

Bir taraftan İlyas, toplumsal cinsiyetin dışına çıkmaya çalışırken diğer taraftan çevresi toplumsal cinsiyetin içerisinde tutmaya çalışır. İlyas'ın kendi içsel yolculuğunda toplumsal cinsiyet rollerinin dışına çıkmaya yönelik eğilimler vardır ve buna doğru ilerler fakat çevresinde buna izin vermeyen insanlar vardır. Romanda bir insanın toplumsal cinsiyetinin, kendisi ve toplum tarafından nasıl bir çatışma alanı haline getirildiğini görürüz. Kişisel akış ve varoluş ile toplumsal akış ve varoluş çatışır. İlyas'ın kişisel akış ve varoluşu toplumsal cinsiyetin sınırlarını aşmaya başlar. Toplumsal akış ve varoluş onu olduğu yerde tutmaya çalışır. İlyas kasaptan et alırken rezil olacağını düşünürken aynı zamanda bir yemek kitabı karıştırırken heyecan duyabiliyor ve bu bir çatışmadır. Arkadaşı Murat, sana yeni bir kız bulacağım her şey güzel olacak diyerek İlyas'1 erkekliğini ispat etmesi gereken bir alanda tutmaya çalışırken, İlyas'1 içinde bulunduğu aşırılıktan kurtarmak niyetiyle kendisine evlenme teklifi eden Emel kendisine mutfakta karışılmasın diye İlyas tarafından reddeder.

Tahsin Yücel'in "Mutfak Çıkmazı” romanında alt metin ve üst metin arasındaki ilişki göz önünde bulundurularak yazarın, Türk toplumunda toplumsal cinsiyet rollerinin şehir ve köy yaşamındaki etkilerini yansıttığını görebilmekteyiz. Bu roman üzerinde uygulanan söylem çözümlemesi teknikleriyle elde ettiğimiz veriler, yazarın sosyolojik eleştirisini aydınlatmaya yardımcı olmaktadır.

\section{Kaynaklar}

Cengiz, S.. "Edebiyat ve İdeoloji”, Akademik Sosyal Araştırmalar Dergisi,15, Eylül 2015, 266274.

Çelik, H. ve Ekşi, H. “Söylem Analizi”, Marmara Üniversitesi Atatürk Eğitim Fakültesi Eğitim Bilimleri Bölümü, 2008, 101-113. 
Çiftçi, B. (2018), Renklerin Psikolojisi - Sart Renk ve Anlamı, http://www.kisiselgelisim.com/renklerin-psikolojisi-sari-renk-ve-sari-rengin-anlami/ Erişim Tarihi: (10 Ekim 2019)

Demir Güneş, C. "Michel Foucault 'da Söylem ve İktidar", Kayı Uludağ Üniversitesi Fen Edebiyat Fakültesi Felsefe Dergisi, 21, 2013, 56.

Ergil, Doğu. “İdeoloji Üzerine Düşünceler”, Ankara Üniversitesi SBF Dergisi, 38, 1983 -1, 69.

Günay, D. “Söylem Çözümlemesi”, İstanbul: Papatya Yayıncılık, 2013, 26.

Hirik, S. "Rol Kuramı ile Fiillerin Anlambilimsel Kategorilerinin İlişkisi: İyi ve Kötü Prens Öyküsü Örneği” Türkbilig, 2018,126.

Künkcü, E. “2000’li Yıllardaki Türk Romanlarında Toplumsal Cinsiyet Düzeni”, Karamanoğlu Mehmetbey Üniversitesi Sosyal Bilimler Enstitüsü, 2018, 96.

Özdemir, Ö. “Söylem Çözümlemesi ve Analiz Teknikleri Üzerine Genel Bir Araştırma”, Uşak Üniversitesi Halkla İlişkiler Bölümü, 1,2017, 2.

Özer, S. "Söylem Çözümlemesi ve Rivayetlerin Anlaşılmasına Yönelik Katkıları”, İslami Araştırmalar Dergisi, 1, 2007,41/42.

Purvis, T. \& Hunt A. “Söylem, İdeoloji, Söylem, İdeoloji, Söylem İdeoloji ...” çev.

Simten C. Moment Dergi, 2014, 1(1):22.

Şahin, Yasin. "Michel Foucault'da Söylem Analizi”, Sosyal ve Kültürel Araştırmalar Dergisi, $6,2017,121-125$.

Yücel, T. Mutfak Çıkmazı, İstanbul: Can Sanat Yayınları, 2016.

Yüksel, Y. “İetişim Araştırma Metodlarl”, Ankara Üniversitesi Sosyal Bilimler Enstitüsü Halkla İlişkiler ve Tanıtım Anabilim Dalı, 2004, 3-6. 


\title{
CONTRIBUTION OF EU LAW TO GENDER EQUALITY
}

\section{Ulaş GÜNDÜZLER ${ }^{1}$}

\begin{abstract}
Even though member states established European Union by concluding an international treaty, EU cannot be considered as an ordinary international organization, as it has been donated with the powers stemming from the sovereignty of member states. EU has the capacity to enact rules binding not only on member states but also on real and legal persons. In other words, EU law, beyond setting mutual rights and obligations among member states, provides individuals with rights which can be claimed before the national courts, therefore influences directly the economic, social and even cultural life in the member states. Lisbon Treaty, as the body of rules standing at the top of hierarchy of EU law, not only prohibits gender discrimination but also grants EU with competences to combat with it. Those competences allow EU both to take incentive measures to support member states actions and to harmonize member state laws in that matter. Case law of Court of Justice of European Union and the EU acts paved the way for the evolution of economic, cultural and social life of member states, by changing the perception of woman role from the carers of the family and children to the individuals to participate in the labour force in more fair and equal means.
\end{abstract}

Keywords: EU, Court of Justice of European Union, EU directives, Equality, Gender

\footnotetext{
${ }^{1}$ Asst.Prof.Dr. Eastern Mediterranean University, Faculty of Law ulas.gunduzler@emu.edu.tr;
} 


\section{AVRUPA BİRLİ̆İ HUKUKU'NUN TOPLUMSAL CINSIYYET EŞiTLİĞI’NE KATKISI}

\section{$\ddot{O} z e t$}

Avrupa Birliği, uluslararası antlaşma ile kurulmuş olmasina rağmen, üye devletlerin egemenliklerinden kaynaklanan yetkilerle donatılmış, böylelikle sadece üye devletler için değil, gerçek kişiler ve özel hukuk tüzel kişileri için de haklar ve yükümlülükler yaratacak olanaklara sahip olmuştur.

Diğer bir ifadeyle, Avrupa Birliği Hukuku, üye devletler arasinda karşllkkl hak ve yükümlülükler yaratan uluslararası hukuk kurallarından farklı olarak, kişilerin ulusal mahkemelerde ileri sürebileceği haklar vermekte, böylelikle, toplumsal, ekonomik ve hatta kültürel hayata etki etmektedir. Avrupa Birliği Hukuku içerisinde kurallar hiyerarşisinin en üstünde yer alan Lizbon Antlaşması, cinsiyete dayalı ayrımcıllğ̆ yasaklamanın ötesinde, Birliğe cinsiyete dayanan ayrmmcllkla mücadele bakımindan tasarrufta bulunma yetkisi de vermektedir. Birliğin tasarrufta bulunma yetkisi üye devletlerin bu alandaki çabalarını destekleyecek teşvik edici tedbirler alma yetkisi olarak ortaya çıkabileceği gibi, üye devletlerin hukuklarını uyumlaştırma yetkisi olarak da ortaya çıkmaktadır.

Adalet Divanı'nın toplumsal cinsiyet eşitliğine ilişskin içtihadı ve bunun ışığında yürürlüğe sokulmuş Birlik tasarrufları, kültürel ve toplumsal yapıyı evirerek, esas görevi aile ve çocuklara bakma olarak algllanan kadinların, ekonomik ve sosyal hayatta daha adil bir şekilde dâhil olmalarını sağlayıcı etkenler olmuşlardır.

Anahtar kelimeler: AB, Avrupa Birliği Adalet Divanı, AB direktifleri, Eşitlik. Toplumsal Cinsiyet

\section{Giriş}

Avrupa Birliği Komisyonu ve üye devletlerin uzmanlarından oluşan çalışma grubu tarafından hazırlanan "The Equal Quide on Gender Mainstreaming" başlıklı yayımda Toplumsal Cinsiyet Eşitliği kavram tanımlanmaktadır. "Cinsiyet" ve "Toplumsal Cinsiyet" kavramları bir birlerinden farklıdırlar. Söz konusu belgede, "Cinsiyet” (Sex) kavramı, kadın ve erkek arsında evrensel olarak geçerli biyolojik farklılıklar olarak tanımlamakta, "Toplumsam 
Cinsiyet" (Gender) kavramını ise kadına ve erkeğe yüklenen sosyal farklılıkları ve rolleri ifade etmek için kullanılmaktadır. Toplumsal Cinsiyet yani kadın ve erkeğe yüklenen roller, kültüre, etnik kökene, dini inanca, eğitime, sınıfa, ekonomik ve politik çevreye vs. göre farklılık gösteren, zamanla değişen, öğrenilmiş rollerdir. Daha basit bir ifadeyle, toplumun kadın ve erkekten beklediği, biyolojik farklılıklarına dayanamayan rollerdir. Söz konuş metin, bu iki kavram arasındaki farkı açıklamak bakımından örnek de vermektedir. Doğum yapmak, önceden biyolojik olarak belirlenmiş bir rol iken, çocuğun kim tarafından büyütüleceği toplumun belirlediği bir roldür. Belge, Toplumsal Cinsiyet Eşitliği kavramını ise, kadın ve erkeğin farklı davranış, ihtiyaç ve isteklerinin eşit şekilde değerlendirilmesi, böylelikle bu iki kategori arasındaki eşitsizliği pekiştirecek farklı sonuçların doğmasına izin vermeme olarak tanımlamaktadır. ("Equal Guide on Gender Mainstreaming", European Commission, 2004) O halde, Toplumsal Cinsiyet Eşitliğine Avrupa Birliği'nin katkısını anlayabilmek bakımından, öncelikle Avrupa Birliği’nin kurulmasından önceki dönemin ekonomik, sosyal ve kültürel çerçevesine kısaca bakmak gerekir.

Avrupa Birliğı’nin temellerinin atıldığı Avrupa Toplulukları (Avrupa Kömüre Çelik Topluluğu, Avrupa Ekonomik Topluluğu ve Avrupa Atom Enerjisi Topluluğu) 1950'li yıllarda, yani ikinci dünya savaşını takip eden on-on beş yıl içerisinde kurulmuşlardır. Bu dönemde Batı Avrupa'daki sosyal, siyasi ve hukuki yapının şekillenmesinde ikinci dünya savaşının getirdiği yıkımın etkisi oldukça fazladır. Bu dönemde sosyal, siyasi, ekonomik ve hukuki düzen, erkeklere çalışma ve eve ekmek getirme yükümlülüğü getirirken, kadınlara, çocuk doğurma ve yetiştirme yükümlülüğü getirmiştir. Zira, 2. Dünya Savaşında milyonlarca insanın ölümü, devletleri nüfuslarını yeniden toparlanmasını sağlayacak tedbirler almaya itmiştir. Kadınların nüfus artışını temin etmek üzere, doğurmak ve çocukları yetiştirme görevleri, ekonomik ve sosyal hayata erkekler kadar dahil olmalarını engellemiş, hatta devlet politikaları ve hukuk kuralları kadınların bu konuda önünü kesmiştir. Kadınlar ailevi yükümlülüklerini yerine 
getirirken, ancak yarı zamanlı ya da geçici işlerde çalışabilmişler, dolayısıyla eşlerinden bağımsız bir ekonomik kaynağa sahip olamamışlardır.( Manfredi, 2003, para. 5-6.)

Yapılan bir araştırma, Sovyetler Birliği’nin yıkılışına kadar, Orta Avrupa'da kadınların Batı Avrupa'daki kadınlara nazaran, ekonomik, sosyal ve siyasi hayata daha fazla katıldığını ortaya koymaktadır. Bu bölgede devletlerin çocuk bakımı için gerekli yapıyı oluşturdukları, çeşitli doğum yardımları yaptıkları ve hatta parlamentoda kadın kotası uyguladıkları bile görülmektedir. Ancak tüm bunlar, toplumsal cinsiyet eşitliğini temin etmek için değil, kadınların iş gücüne katılımını sağlamak için alınmış tedbirlerdir. Erkek egemen toplum düzeni sorgulanmadığından, işgücüne katıldıkları saatler dışında kadınlar evin ve ailenin bakımı sorumluluğunu da tek başına üstlenmişlerdir. Yani hem işgücüne katkı koyma hem de aileye bakma yükümlülüğünü, diğer bir ifadeyle çifte külfet üstlenmişlerdir. (Wiget, 2012: 13)

Toplumsal cinsiyet eşitliğinin yaygınlaşması bakımından küreselleşme büyük rol oynamıştır. Küreselleşme ulusların değerlerinin ve hukuk kurallarının bütünleşmesine, benzeşmesine sebebiyet vermektedir. Bu bağlamda, Feminist akımların Batı'da yaygınlaşması, erkek egemen ekonomik ve sosyal yapıyı statik hale getiren ulusal hukuk kurallarını erozyona uğratmaya başlamıştır. Bu noktada, Avrupa Birliği’nin Avrupa'daki Toplumsal Cinsiyet Eşitliği'ne sağladığı katkı, uluslararası düzeyde atılmış olan diğer tüm adımlardan çok daha görülebilirdir. Zira, Avrupa Birliğgi'ne üye olan devletler, egemenliklerini Avrupa Birliği lehine kısıtlamışlar ve Avrupa Birliği'ne, sadece kendilerini değil, vatandaşlarını da bağlayacak, vatandaşlarına hak ve yükümlülükler getirebilecek yetkiler vermişlerdir. Bu yetkiler, Birliğe üye devletlerin ekonomik ve sosyal yapılarına müdahale etme ve üye devletlerin hukuklarını uyumlaştırma olanağı vermektedir.

Birliğin tasarrufta bulunarak üye devletlerin hukuklarını uyumlaştırması, böylelikle Avrupa Birliği içerisinde hukuk birliği yaratmasına doktrinde pozitif bütünleşme denmektedir. Birlik Hukuku'nun ulusal hukukları ve böylelikle ulusal ekonomik-sosyal yapıyı etkilemesine 
olanak sağlayan diğer bir hukuki mekanizma da negatif bütünleşme olarak kabul edilen Birlik Hukuku'nun önceliği prensibidir. Birlik hukuku ile ulusal hukukun çatıştığ hallerde, ulusal mahkemeler Birlik Hukuku'nu uygulamak zorunda kalmaktadırlar.(İlkeye dipnot) Bu bağlamda Avrupa Birliği Adalet Divanı çok önemli bir rol oynamaktadır, zira Birlik Hukuku'nun yorumunu yapma konusunda Divan'ın yetkisi münhasırdır. Ulusal mahkemeler ve Divan arasında kurulan işbirliği mekanizması sayesinde, ulusal mahkemeler ulusal hukukların Birlik hukuku ile uyumlu olup olmadığı konusunda Divan'dan önkarar isteyebilmektedir. Toplumsal Cinsiyet Eşitliğinin Birlik içerisinde gelişmesinde Adalet Divanı katalizör rolü üstlenmiştir. Divan'ın, toplumsal cinsiyet eşitliğine ilişkin Birlik hukuku ile ilgili yaptığı yorumlar ve geliştirdiği prensipler birçok ulusal hukuk kuralının uygulanmasını durdurmuş, ortaya çıkacak kuralsızlık halini engellemek için de Birlik pozitif bütünleşme yöntemi ile yani çıkardığı direktifler ile ulusal hukukları uyumlaştırmaya başlamıştır. Bu durum, Birlik hukukuna toplumsal cinsiyet eşitliğini sağlamaya yönelik daha fazla kuralın eklenmesi için gerekli motivasyonu yaratmıştır.

Birlik hukukuna Toplumsal cinsiyet eşitliğine ilişkin olarak eklenen ilk hüküm, Avrupa Ekonomik Topluluğu Antlaşması'nın 119. maddesidir. İlgili hüküm, üye devletlere kadın ve erkeklerin eşit iş için eşit ücret almaları prensibini uygulamalarını emretmektedir. İlgili hüküm, ücreti tanımlarken ise, işçinin doğrudan ya da dolaylı olarak, yaptığı iş için işvereninden aldığ asgari haftalık, maaş veya nakdi ya da başka bir türdeki herhangi bir karşılık olarak tanımlamaktadır. Bu hüküm, aslında Fransa'nın baskısı ile antlaşmaya eklenmiştir. Zira Fransa, kendi hukukunda bulunan bu prensibin, AET'nin kurulması ile diğer devletlere nazaran kendi endüstrisinin rekabet etmesini zorlaştıracağını düşünmüştür. AET Antlaşması üye devletlerarasında bir ortak pazarın kurulmasını yani malların, kişilerin, hizmetlerin ve sermayenin serbestçe dolaşmasını öngörmüş ve üye devletlerin diğer üye devletlerden gelen üretim faktörlerine karşı korumacı tedbirler almasını yasaklamıştır. Bu ortamda, Fransa'da 
kadın işçilerin erkeklerle aynı ücreti alması ve fakat diğer üye devletlerde kadın işçilere daha az ücret ödenmesi, diğer üye devletlerdeki üretim maliyetlerini düşüreceğinden, Fransız üreticilerin rekabet etmesini zorlaştıracaktır. Kısacası, eşit işe eşit ücret prensibi aslında salt ekonomik maksatlarla Birlik hukukuna dahil edilmiştir. (Burri \& Prechal, 2008: 4) Bu hükmün formulasyonuna Uluslararası Çalışma Örgütü temsilcileri de katılmıştır. (dipnot) Ancak bu hükümün lafzından, Antlaşmanın esas itibarıyla üye devletlere yükümlülük yüklediği kanaati oluşmaktadır. Diğer bir ifadeyle bu hükmün etki doğurmasının üye devletlerin iç hukuklarında alacakları tedbirlere bağlı olduğu düşünülebilir. Nitekim bazı üye devletler, söz konusu hükmün uygulanmasını sağlamaya yönelik tasarrufları yürürlüğe koymaktan geçiş dönemi sonlanmış olsa da kaçınmışlardır. Buna karşın, üye devletlerin vatandaşları bu hükme dayanarak ulusal mahkemelerde davalar açmaya başlamışlar ve böylelikle Adalet Divanı, söz konusu hükmün kapsamını değerlendirme imkânı bulmuştur.

Bu davalar içerisinde Defrenne vs Sabena davasının büyük bir önemi vardır. Zira, bu davada, Adalet Divanı, öncelikle 119. maddenin yani eşit işe eşit ücret prensibinin, sadece ekonomik değil ayrıca sosyal amacının da olduğunun altını çizmiştir. Divan’a göre, 119. maddenin sosyal politika alanında değerlendirilmesi, Birliğin amaçlarından olan işçilerin çalışma koşullarının iyileştirilmesi ve yaşam koşullarının geliştirilmesi ihtiyacının bir gereğidir. Diğer bir ifadeyle eşit işe eşit ücret prensibi, Birliğin temel prensiplerinden biri olarak kabul edilmiştir. (Case 43/75, Defrenne vs Sabena, [1976], para.8-12) Bu davada karara bağlanan diğer ve en temel husus ise, üye devletlere yükümlülük getiren 119. maddeye, üye devletlerin uygulamaya yönelik hiçbir tasarrufu olmadan bireyler tarafından ulusal mahkemede dayanılıp dayanılmayacağıdır. Bayan Defrenne, özel bir hava yolu şirketinde hostes olarak çalışmış, Belçika kanunlarına istinaden 40 yaşına geldiği için görevini bırakmak zorunda kalmıştır. Bayan Defrenne özel hava yolu şirketine karşı dava açarak, erkek çalışanlar için öngörülen 
kurallardan daha az avantajlı kurallara tabi tutulduğunu ileri sürmüş, erken emekliye ayrıldığı için maaşları, emeklilik hakkını vs gibi konularda uğradığı zararı talep etmiştir.

Adalet Divanı nezdindeki sürece müdahil olan bazı üye devletler, söz konusu hükmün doğrudan etki doğurmadığını, yani üye devletlerin bu hükmü uygulamaya yönelik tasarrufta bulunmadıkları hallerde, ulusal mahkemede ileri sürülemeyeceğini iddia etmiştir. Diğer bir grup üye devlet ve Komisyon ise, hükmün devlete karş1 ileri sürülebileceğini ve fakat özel sektördeki işverenlere karşı ileri sürülemeyeceğini iddia etmiştir. Divan, bu iddiaları reddetmiş, 119. madde ile üye devletlere yükümlülük getirilirken bireylere de haklar verildiğine, bireylerin bu haklarını ulusal mahkemelerde ileri sürememesinin hükmün etkinliğini ortadan kaldıracağına, 119. maddenin emredici bir hüküm olduğuna ve sadece kamu sektöründe değil, özel sektörde kişiler arasında yapılan iş sözleşmelerine de uygulandığına karar vermiş, ulusal mahkemelerin bu hakkı özel işverenler karşı da koruması gerektiğine hükmetmiştir. (Case 43/75, Defrenne vs Sabena [1976], para.30-40)

Bu dava ile, 119. maddedeki "ücret” kavramının sadece aylık veya haftalık ücreti değil, yeri geldiğinde emeklilikle ilgili ödenekleri de kapsayabileceği ortaya çıkmıştır. (Burri, \& Prechal, 2008: 6-7) Diğer bir ifadeyle, AB'yi yaratan ve onun hukuk kurallarını temelde bir uluslararası antlaşmayla ortaya koyan egemen üye devletlerin rızaları hilafina 119. Maddenin kapsamı Divan kararıyla genişlemiştir.

Divan'ın, 119. Maddenin kapsamını genişleten diğer bir kararı da Jenkins v. Kingsgate kararıdır. Defrenne vs Sabena davasında, davacı Defrenne, ilgili mevzuat ya da uygulamanın kadın olma kriterine istinaden kendisini dezavantajlı duruma düşürdügünü iddia etmiştir. Yani, kadın ve erkeklere yapılan farklı muamele açıkça cinsiyet kriterine dayanmaktadır. Oysa Jenkins davasında uyuşmazlık, kadın veya erkek kriterini dikkate almayan ve fakat kadınların dezavantajlı duruma düşmesine sebebiyet veren bir işveren uygulamasıdır. Divan, bu kararında, Birlik hukukuna dolaylı ayrımcılık müessesini getirmiştir. 
Bayan Jenkins'in işvereni, tam zamanlı işçi statüsünün kazanılması için hem kadınlar hem de erkekler için 40 saat çalışma koşulu öngörmüştür. Tam zamanlı çalışan işçiler yarı zamanlı çalışan işçilere göre saat başı \%10 daha fazla ücret kazanmaktadır. Görünüşte hiçbir cinsiyet ayrımcılığı yapılmıyor olsa da, Jenkins yarı zamanlı çalışanların nerdeyse tamamının kadın olduğunu, bu sebeple söz konusu uygulamanın esasında cinsiyet ayrımcılığının yattığını ileri sürmüştür. ( Case 96/80 Jenkins v. Kingsgate [1981], para 6-7) Divan kararında, yarı zamanlı ve tam zamanlı çalışanlara cinsiyet ayrımı gözetmeden yapılan farklı muamelenin prensipte 119. maddeye aykırı olmayacağını, bir işverenin ekonomik gerekçelerle bu tip bir ayrım yapabileceğini belirttikten sonra, işverenin cinsiyete dayanan ayrımcılığı, farklı bir kriter kullanarak yapmasının 119. maddeye aykırı olacağını belirtmiştir. Buna göre ekonomik gerekçelerle meşrulaştırılamayan ve yarı zamanlı işçilerin çok büyük bir kısmının kadın olduğu bir ortamda, yapılan farklı ücretlendirmenin, aslında 119. maddedeki ayrımcılık yasağının kapsamına girebileceğine hükmetmiştir. Özellikle kadınların tam zamanlı çalışan statüsünü kazanmak için gerekli olan çalışma saatlerini doldurmalarının zor olmasının, işverenin cinsiyet kriteri dışındaki kriterleri kullanarak kadınlara yapılan ödemenin miktarını kısıtlamayı hedefleyebileceğine dikkat çekmiştir. Bu bağlamda Divan ulusal mahkemelerden, işverenin dolaylı olarak kadın işçilere ödenen ücreti düşürme niyeti olup olmadığını incelemelerini istemiştir. (Case 96/80 Jenkins v. Kingsgate [1981], para 9-15) O halde, aynı işi yapan farklı işçi kategorilerinden biri çoğunlukla ya da tamamen kadınlardan veya erkeklerden oluşuyor ve farklı muameleye tabi tutuluyorsa, ekonomik gerekçeler bu farklı muameleyi haklı göstermediği sürece dolaylı ayrımcılığın varlığından bahsedilebilmektedir.

Gerek doğrudan gerekse dolaylı ayrımcılık yasağı müessesesinin uygulanabilmesi için yapılan işin aynı olması gerektiği kanaati, Divan'ın daha sonra verdiği kararlarda ortadan kaldırılmıştır. Örneğin, bir işverenin çalıştırdığı konuşma terapistleri ile farklı antlaşma, çalıştırdığı eczacılarla farklı antlaşma yaptığı, çoğunluğunun kadın olduğu konuşma 
terapistlerine, çoğunluğunun erkek olduğu eczacılara nazaran daha az ücret ödediği bir durumun dahi, ekonomik şartların haklı göstermemesi halinde dolaylı ayrımcılık kapsamına girebileceğine karar vermiştir. Bu meseleye müdahil olan Alman hükümeti, konuşma terapisti ile eczacının yaptığı işin karşılaştırılamayacağını bu sebeple ayrımcılık olup olmadığının incelenmesine bile gerek olmadığını iddia etmiştir. (Suk, 2017: 1539-1540) Söz konusu davada, Divan, karşılaştırılan iki işin aynı olmasa da eşit değerde olması halinde, meselenin ayrımcılık kapsamında değerlendirilebileceğine karar vermiştir. (Case C-127/92, Enderby v. Frenchat Health Authority, [1993] para.16) Divan bu kararında, ayrıca dolaylı ayrımcılıktan mustarip olduğunu ileri süren kişinin, eşit değerdeki işlerden birinin çoğunluğunun kadınlar diğerinin de erkekler tarafından yapıldığını gösteren istatistiki veri sunduğu hallerde, ayrımcılık iddiasının ciddiye alınması gerektiğini, ayrımcılığın varlığına dair ispat külfetinin de yer değiştirebileceğini, yani işverenin objektif kritererin varlığına dayanarak ayrımcılığın olmadığını ispat etmek zorunda kalabileceğini belirtmiştir. (Case C-127/92, Enderby v. Frenchat Health Authority, [1993] para.16-28)

Kısacası, cinsiyete dayalı dolaylı ve doğrudan ayrımcılık bulgusu yapılabilmesi, esas itibarıyla karşılaştırılacak kişinin varlığını gerektirmektedir. Doğrudan ayrımcılık tespiti yapılabilmesi için, karşılaştırılacak olan kişinin, diğer cinsiyetten belirlenebilir bir kişi veya kişiler olması gerekir. Diğer bir ifadeyle doğrudan ayrımcılık bulgusuna, farazi bir kişi ile karşılaştırma yapılarak ulaşılamaz. Oysa dolaylı ayrımcılıkta, tamamen nötr olan bir kuralın cinsiyetlerden birine mensup olan kişilere göre, diğer cinsiyete mensup kişiler için daha dezavantajlı sonuçlar yarattığının tespiti halinde söz konusu olacaktır. $\mathrm{Bu}$ durum, karşılaştıracak spesifik bir kişinin varlığını gerektirmez. Aksine, nötr kuralın, bir cinsiyete mensup olanları diğerine mensup olanlara göre dezavantajlı duruma düşürdüğünün istatistiki veya başka veriler ile desteklenmesi yeterlidir. Divan, şikâyetçinin istatistiki veri sunmasının bir zorunluluk olmadığının altını da çizmiştir. Bir kişi, nötr kuralın belli bir cinsiyete mensup 
kişiler üzerinde daha fazla olumsuz etki yarattığını gösteriyorsa, örneğin kadınların iş piyasasına katılım şeklinin erkelerden farklı olduğunu ve bunun dezavantaj yarattığını gösteren veriler sunabiliyorsa, ayrımcılığa dair bir karine oluşacak, bu durumda işveren nötr kuralın ya da uygulamanın objektif kriterlere dayandığını ispat etme külfeti altına girecektir. (Herves, 2005:.312-313)

Birlik Hukuku’nun toplumsal cinsiyet eşitliği itibarıyla Adalet Divanı kararları katalizör rolü oynamış olsa da, Birliğin yürürlüğe soktuğu ve üye devlet hukuklarını uyumlaştırmaya yönelik direktiflerin de rolü oldukça büyüktür. Avrupa Topluluklarının günümüz Avrupa Birliğine evirilmesi süreci boyunca yürürlüğe koyulan çok sayıda direktif vardır. $\mathrm{Bu}$ direktiflerin bazıları 2006/54 sayılı direktifle tek bir metinde birleştirilmiştir. Bu çalışmada direktiflerin tamamına değinmek veya belli bir direktifin tüm unsurlarını detaylı olarak açıklamak hedeflenmemiştir. Direktiflere Adalet Divanı kararları 1şı̆̆ında değinilerek, toplumsal cinsiyet eşitliği bakımından üye devlet hukuklarının ve sosyal yaşamın nasıl değiştiğine işaret edilmeye çalış1lacaktır.

Bu bağlamda üzerinde ilk durulması gereken husus, direktiflerin uygulama alanı ve daha önce üzerinde durulan Antlaşma hükümlerinin koruma alanıdır. Daha önce açıklandığı üzere, Antlaşma hükümleri sadece bireyle devlet arasında değil, bireyle birey arasındaki uyuşmazlıklarda da uygulanabilirdir. Ancak direktifler, üye devletlerin iç hukuklarına aktarmaları gereken Birlik tasarruflarıdırlar. Bu sebeple, süresi içinde iç hukuka aktarılmazlarsa veya yanlış aktarılırlarsa, direktife dayanarak ulusal mahkemeye başvurulabilmesi için, meselenin prensip olarak devlet kaynaklı olması gerekir. "Her ne kadar devlet kaynaklı" kavramı Divan tarafından geniş yorumlansa da, (örneğin kamu hizmeti gören veya kamu gücü kullanabilen işyerleri bu kapsamda düşünülebilse de) özel sektörde faaliyet gösteren işverene karşı iç hukuka aktarılmamış veya yanlış aktarılmış direktife dayanılmaz. Ancak Divan, ulusal mahkemelere, özel sektörde faaliyet gösteren işverenlere karşı açılan davalarda, ulusal hukuku 
mümkün olduğunca direktife uygun yorumlama yükümlülüğü yüklemiştir. Bunun da mümkün olmadığı hallerde, toplumsal cinsiyet eşitliğine ilişkin direktiflerin iç hukuka aktarılması veya yanlış aktarılması nedeniyle özel sektörde çalışan işçinin uğradığı zararlar için devlete karşı tazminat davası açması mümkündür. Burada cinsiyete dayalı ayrımcılığg özel sektörde çalışan işveren yapmakta, fakat tazminatı devlet ödemektedir. $\mathrm{Bu}$ tazminat müessesesinin temel mantığı, devletin işçiyi koruyacak Birlik tasarrufunu iç hukuka aktarmayarak kusurlu davranması ve zarara sebebiyet vermesidir. Divan bu içtihadı ile Toplumsal cinsiyet eşitliğine ilişkin direktiflerin etkinliğini teminat altına almaktadır. (Herves, 2005:.319-320).

Birliğin, toplumsal cinsiyet eşitliğini sağlamaya yönelik çıkardığı direktiflerin ve Birlik hukukunun, esas itibarıyla ekonomik hayatı düzenlemeye yönelik olduğu, standart çalışma hayatını ilgilendirdiği, eşitsizliğin temel nedenlerini ortadan kaldıramadığ hayatın da erkek ihtiyaçlarına göre şekillendiği, Birlik hukukunun kadınların ihtiyaçlarını dikkate almadığg, evin ve çocukların bakımının esas itibarıyla kadının üzerinde olduğu algısını değiştirecek kurallar koyamadığı iddiaları doktrinde ileri sürülmektedir. (Walby, 2004: 6-7) Bu iddialar kısmen doğrudur. Zira AB, 2004 yılına kadar, işyeri dışında toplumsal cinsiyet eşitliğini temin etmeye yönelik hiçbir direktif yürürlüğe koymamıştır. Ancak 2004 yılında Birlik bir direktif çıkararak, mallara ve hizmetlere erşimi bakımından cinsiyet eşitliğini sağlamaya yönelik bir direktif çıkarmıştır. Bu direktif, işyeri dışında halka açık tesislere erişim, konut edinme, bankacılık sigortacılık hizmetlerinden yararlanma gibi sosyal boyuttaki haklardan yararlanma bakımından cinsiyet eşitliğini sağlayacak hükümler öngörmüştür. (Masselot, 2007:.153-154) Böylelikle iş hayatının bir parçası olmayan ama sosyal hayata dahil olmaya olanak sağlayan birçok mal ve hizmetten eşit şekilde yararlanılmasının yolu açılmıştır. Örneğin, sigorta şirketleri, kadınların daha uzun süre yaşadıklarını dikkate alarak, kadınlar için sigorta primlerini daha yüksek öngörürken, direktif bu eşitsizliğin ortadan kaldırılmasını sağlamıştır. 
Ekonomik ve iş hayatının ötesinde toplumsal cinsiyet eşitliğini sağlamaya yönelik olarak ana akımlaştırma (mainstreaming) prensibi de kabul edilmiştir. Yani birliğin yetkili olduğu tüm politika alanlarında, tasarrufta bulunulurken toplumsal cinsiyet eşitliğinin dikkate alınması gerekliliği kabul edilmiştir.

İş hayatında kadın erkek eşitliğini sağlamaya yönelik direktiflerin de, Adalet Divanı kararları 1şığında, toplumsal rollerin oluşmasına sebebiyet veren algıyı değiştirmeye başladıkları söylenebilir. Örneğin Tanja Kreil davasında, Divan, Çalışma Bakımından Eşitlik Direktifi'nin öngördüğü istisna hükümlerini dar yorumlamış ve kadının erkeklerden daha zayıf olduğu algısına istinaden belli meslekleri yapmaktan alı konmalarının Birlik Hukuku'na aykırı olduğuna karar vermiştir.

Söz konusu Direktif, işe girme, terfi, mesleki eğitim alma ve çalışma koşulları bakımından cinsiyete dayalı doğrudan ve dolaylı ayrımcılığı yasaklamakta fakat ayrımcılık yasağına istisnalar öngörmektedir. İstisnalardan biri, mesleki faaliyetin doğası veya yürütülmesi şekli bakımından işçinin cinsiyetinin belirleyici unsur teşkil ediyor olmasıdır. Diğer bir istisna ise, kadınların özellikle annelik ve hamilelik bakımından korunması gerekliliğidir. (Directive 76/207 EEC madde 2/2 ve 273) Tanja Kreil, Alman ordusunda silah bak1mı yapan mühendis olarak çalışmak istemiş, fakat bu başvurusu, Alman ordusunda silahlarla ilgili işlerin sadece erkekler tarafından yapılacağını öngören Anayasa hükmüne istinaden reddedilmiştir. Almanya, doğrudan ayrımcılık teşkil eden bu hükmü savunurken, ordu ve güvenliğin devletlerin egemenlik alanına girdiğini, bu sebeple direktifin ordu ile ilgili aktiviteler bakımından uygulanamayacağını iddia etmiş, ordu ile ilgili faaliyetlerin direktif kapsamına girdiği kabul edilse bile, direktifte öngörülen istisnalara dayanılabileceğini iddia etmiştir. ( Case C-285/98, Tanja Kreil v. Bundesrepublik Deutschland [2000], para. 12.) Divan, iç ve dış güvenlik konusunun üye devletlerin yetkisine girdiğini kabul etse de, orduda yürütülecek mesleki faaliyetlerin tamamen direktif kapsamı dışında kalamayacağına hükmetmiştir. (Case C-285/98, 
Tanja Kreil v. Bundesrepublik Deutschland [2000] para. 15-19). Divan, devletin güvenliği sağlamak bakımından belli mesleki faaliyetleri işin doğası gereği erkeklere hasretmesinin direktif kapsamında meşru kabul edilebileceğini, ancak kadınların ordudaki silahlarla ilgili mesleki faaliyetlerden tamamen dışlanmasının güvenliği sağlamak bakımından orantısız bir tedbir olduğuna karar vermiştir (Case C-285/98, Tanja Kreil v. Bundesrepublik Deutschland [2000] para. 23-39). Divan, Almanya'nın direktifin kadınların hamilelik ve annelik bakımından korunmasına dair istisna hükümlerine de dayanamayacağının altını çizmiştir. Bu meselede Divan, ilgili direktif hükmünün, kadınların erkelerden farklı biyolojik durumlarını ve çocukları ile olan özel ilişkilerini korumayı hedeflediğini belirtmiş, silahlarla ilgili faaliyetler bakımından kadınların erkeklerden daha fazla risk altında olmadığına dikkat çekerek Almanya'nın savunmasını reddetmiştir (Case C-285/98, Tanja Kreil v. Bundesrepublik Deutschland [2000] ECR I-00069 para. 30).

$\mathrm{Bu}$ karar, kadınların erkeklerden daha zayıf ve daha çok korunmaya muhtaç insanlar oldukları algısını ortadan kaldıracak bir etki doğuracaktır. Zira hamilelik ve annelik gibi kadınlara özgü biyolojik ve sosyal özellikler dışında kadınların erkeklerden daha zayıf olduğu algısı ile hareket edilmesinin mümkün olmadığına işaret edilmektedir. Bu sebeple kadınların daha zayıf olarak algılanması nedeniyle belli bir mesleki aktiviteden tamamen yoksun bırakılmaları mümkün görünmemektedir. İlgili direktifin, toplumsal cinsiyet eşitliğini sağlamak bakımından ataerkil zihniyeti yansıttığı, zira hamilelik ve annelik unsurlarına istinaden çocuk bakım yükünü esas itibarıyla kadına yüklediği ileri sürülebilir. Ancak bu iki durum, kadının biyolojik ve duygusal halinin korunmasına ilişkin bir hükümdür. Kaldı ki, Birlik çocuğa bakma yükünün sadece anne üzerinde değil, baba üzerinde de olduğunu ortaya koymak ve bu yönde toplumsal gelişimi sağlamak bakımından ebeveyn iznine ilişkin direktifi yürürlüğe koymuştur. Bu direktif, babanın da anne gibi çocuğa bakmak için işyerinden belli bir süreliğine izin almasına olanak sağlamaktadır. Diğer bir ifadeyle, Birlik ailevi yükümlülükler ile mesleki 
yükümlülükleri dengeleyecek şekilde bir düzen yaratma çabasındadır. Bir yandan kadının kendine özel doğasını korumaya çalışırken, diğer yandan kadının daha zayıf ve daha fazla korunmaya muhtaç olduğuna dair algıyı da kaldırmaya çalışmakta, toplumsal olarak belirlenmiş çocuğa bakma yükümlülügünü de ebeveynler arasında paylaştıracak hukuki düzenlemeler yapmaktadır. (Manfredi, 2003: para. 32-36) Diğer bir ifadeyle, Birlik sadece erkek zihniyetine göre şekillenmiş iş yaşamında eşitlik sağlamanın ötesine geçerek, aile hayatına etki edecek, kadınların içinde bulunduğu şartları da dikkate alan düzenlemeler de yapmıştır. (Walby, 2004:18-19.

\section{Sonuç}

Elbette, kadın ve erkeklere eşit hakların sağlanması, tek başına Toplumsal Cinsiyet Eşitliğini yaratmaya yetmeyecektir. Zira unutulmamalıdır ki, mevcut önyargılar, gelenekler ve edinilmiş toplumsal roller, belli hakların kadınlar tarafından erkekler kadar etkin şekilde kullanılmasını engelleyebilir. Birlik hukuku bu bağlamda, kadın ve erkekler arasındaki maddi eşitliğin diğer bir ifadeyle firsat eşitliğinin sağlanabilmesi bakımından pozitif ayrımcılığa da olanak sağlamaya başlamıştır. Nitekim gerek direktiflerde, gerekse 2009 yılında yürürlüğe giren Lizbon Antlaşması'nda, üye devletlere tam eşitlik sağlamak bakımından, belli bir meslek veya işte daha az temsil edilen cinsiyete mensup kişiler için pozitif ayrımcılık yapılmasına olanak sağlayacak düzenlemeler yapma yetkisi verilmiştir. (Avrupa Birliği’nin İşleyişine İlişkin Antlaşmanın 157/4 maddesi) Pozitif ayrımcılık, kadın ve erkeğe aynı muamele yapılması zorunluluğunun istisnası niteliğindedir. Yani pozitif ayrımcılığa olanak sağlayan bir hükmün bulunmaması halinde, belli bir cinsiyetin mensuplarına avantaj sağlayacak şekilde davranmak, prensip olarak eşit muamele kuralını ihlal etme anlamını taşıyacaktır. Fakat pozitif ayrımcı bir kurala Lizbon Antlaşması'nın veya direktiflerin olanak sağlaması, belli bir cinsiyetin 
mensuplarına ayrıcalık sağlayan her hukuk kuralını hukuka uygun da kılmamaktadır. Adalet Divanı pozitif ayrımcı uygulamaların geçerli olabilmesi için belli kıstaslar öngörmüştür.

Adalet Divanı, önüne gelen davalarda ( Örneğin Case C-409/95, Marschall v. Land Nordrhein-Westfallen, [1997]) temsiliyeti az olan cinsiyete mensup kişilerin otomatik ve mutlak olarak seçilmesini öngören ulusal tasarrufların, hukuka uygun pozitif ayrımcılık teşkil etmeyeceğinin altını çizmiştir. Temsiliyeti az olan cinsiyete mensup kişinin (kadın adayın) seçilebilmesine veya ona öncelik tanınmasına olanak sağlayan kuralın, hukuka uygun olarak kabul edilebilmesi için, öncelikle diğer cinsiyete mensup adayla (erkek adayla) eş değer düzeyde nitelikli olması gerekmektedir. Bu koşul, seçimi yapacak olan otoritenin objektif değerlendirme yapmasını da gerektirmektedir. Kadınlara öncelik verilmesini öngören ulusal hukuk kuralı, esas itibarıyla kadınların işe kabulü, terfi ettirilmesi konularında toplumsal önyargıları ortadan kaldırmak maksadıyla öngörülmüş olmalıdır. Divan, kararında, aile ve çocuğa bakım yükümlülükleri nedeniyle, kadınların mesleki görevlerini yerine getiremeyeceklerine dair toplumsal önyargıların bulunduğuna işaret ederek, öncelik sağlayan hukuk kuralının, kadınların işe kabul edilmesi veya yükseltilmesi açısından yaygın olan önyargıların yarattı̆̆ı fiili eşitsizliği ortadan kaldırmayı hedeflemesi gerektiğinin altını çizmiştir. (Örneğin Case C-409/95, Marschall v. Land Nordrhein-Westfallen, [1997] para 2931) Divan son olarak, erkek adayın bireysel niteliklerine istinaden kadınlara tanınan öncelik uygulanmasının durdurabilmesinin mümkün olması koşulunu aramaktadır. (Suk, 2017: 15411543)

Birlik Hukukunun üye devletlere pozitif ayrımcı olarak nitelendirilecek kuralları koymak bakımından yetki vermesinin ötesinde, kadın ve erkekler arasındaki fiili eşitsizlikleri ortadan kaldıracak pozitif ayrımcı düzenlemeleri Birlik de yapmaya çalışmaktadır. Bunun en iyi örneğin, AB Komisyonu'nun hazırladığı şirket yönetim kurullarında kadın kotası öngören 
direktif tasarısıdır. Söz konusu tasarı da Adalet Divanı tarafından geliştirilen prensiplere dayanmaktadir. (https://ec.europa.eu/newsroom/document.cfm?doc_id=46280)

Birlik Hukuku, görüleceği üzere, ekonomik hayata ilişkin düzenlemeler yaparak, sadece ekonomik değil, sosyal hayatı da etkilemiştir. Zira kadın ve erkek arasındaki eşitsizliği temeli olan toplumsal rolleri değiştirecek hukuki enstrümanları belli bir ölçüde sağlamıştır. Birliğin, toplumsal cinsiyet eşitliğini sağlamaya yönelik yetkilerinin ancak Birliğin yetki alanına giren konularda olduğu, ilgili yetki alanlarında ikincillik ilkesine uygun hareket etmek zorunda olduğu, yani düzenleme yapma konusunda üye devletlere öncelik vermek zorunda olduğu bir gerçektir. Ancak Birliğin anayasal nitelikteki metinlerinden olan Avrupa Birliği Antlaşması'nın 2. maddesi, Birliğe üye devletlerde kadın ve erkek eşitliğinin de güvence altına alınmasını gerektirmektedir. Aynı antlaşmanın 49. maddesi de ancak 2. maddede öngörülen değerleri koruyan ve geliştiren devletlerin Birliğe üye olacağını öngörmüştür. Yani Birliğe üye olan devletler ve aday devletler, sadece Birliğin yetkisine giren alanlarda değil, tüm politika alanlarında Toplumsal cinsiyet eşitliğini sağlamak zorundadırlar. Bu sebeple Birlik Hukuku, Birliğe üye olan veya olmak isteyen devletlerin de kendi kanunlarını yürürlüğe sokarken toplumsal cinsiyet eşitliğini dikkate almasını dolaylı olarak zorlamaktadır.

\section{Kaynaklar}

Herves Tamara K. (2005), Editorial, Thirty Years of EU Sex Equality Law: Looking Backwards, Looking Forwards", Maastricht Journal of European and Comparative Law, 12(4), p.307-325.

Manfredi, Simonetta (2003). The influence of European Sex Equality Law on the UK Legislation: a Challenge to the "male norm"? In: Nouvelles valeurs dans l'Angleterre d'aujourd'hui [electronic version]. Paris: Presses Sorbonne Nouvelle, 171-203. Retreaved 31 October 2019, from http://books.openedition.org/psn/4078

Masselot Annick March 2007), The State of Gender Equality Law in the European Union Law, European Law Journal, 13(2), p.152-168.

Suk Julie C. (2017), Equality After Brexit: Evaluating British Contributions to EU Antidiscrimination Law, Fordham International Law Journal, 40(5), p.1535-1552. 
Walby Silvia (Sring 2004), The European Union and Gender Equality: Emergent Varieties of Gender Regime, Social Politics: International Studies in Gender, State \& Society, 11(1), p.429.

Equal Guide on Gender Mainstreaming, European Commission (2004). retrieved 31 October 2019 from https://ec.europa.eu/employment_social/equal_consolidated/data/document/gendermain_en.pd $\mathrm{f}$

European Commission (July 2016), Gender Balance on Corporate Boards > Breaking Glass $\begin{array}{llll}\text { Ceiling, } & \text { Retrieved } & 31 & \text { October }\end{array}$ fromhttps://ec.europa.eu/newsroom/document.cfm?doc_id=46280

Burri Susanne \& Prechal Sacha (2008). EU Gender Equality Law, Euroepan Commision, Directorate-General for Employment, Social Affairs and Equal Opportunitities, Unit G.1

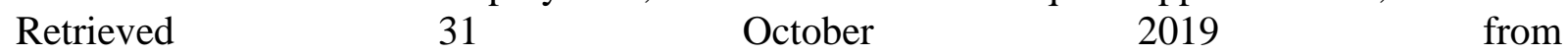
file://C:/Users/USER/Downloads/WEBEUGenderEqualityLawKE8008432ENC30Oct\%2020 08\%20(2)\%20(3).pdf

Wiget Verena (2012), Gender Equality in the European Union: A Farce? A case Study, on the European Union's influence in Central Europe. Retrieved 31 October 2019 from https://pdfs.semanticscholar.org/2812/e56c2c978093d9aa649c745d9823140521e5.pdf

Case 43/75, Defrenne vs Sabena, [1976] ECR 455.

Case 96/80 Jenkins v. Kingsgate [1981] ECR 911.

Case C-127/92, Enderby v. Frenchat Health Authority, [1993] ECR I-5566.

Case C-285/98, Tanja Kreil v. Bundesrepublik Deutschland [2000] ECR I-0006.

Case C-409/95, Marschall v. Land Nordrhein-Westfallen, [1997] ECR I-06363.

Council Directive 76/207/EEC of 9 February 1976 on the implementation of the principle of equal treatment for men and women as regards access to employment, vocational training and promotion, and working conditions

OJ L 39, 14.2.1976 


\title{
THE DEVELOPMENT OF ISLAMIST FEMINISM IN THE MIDDLE EAST: IRAN AND EGYPT CASES
}

\author{
Zeynep Banu DALAMAN ${ }^{1}$
}

\begin{abstract}
The issue of women is generally discussed in the context of modernization and social transformation in Islamic countries. After 1980, a reformed religious feminism developed among secular and well-educated Muslim women in cities of different societies. These pious women have maintained religion as an important element of their cultural and moral identity and have not quitted their own religious orientation. With the influence of modernism, they have evolved towards the idea of equality economically and feminist interpretations of the concepts of family life and gender in modern social life. The increasing immigration, cultural interaction and the development of mass media have been important in strengthening the Islamist feminist movement. In Muslim countries such as Egypt and Iran, there has been an increase in the level of consciousness by utilizing the opportunities provided by the mass media. These women, who have been torn between the old traditions and their new lives, found a way to get out of this dilemma. Amina Wadud, who conducted important studies on the Islamic feminist movement, divided this movement into two as Islamist feminism and Muslim feminism. Islamist feminists recognize that Islamic values put forward patriarchal patterns both in private and public life. Muslim feminists argue that misogyny and patriarchy in Islamic order are widespread and that dates back to the Jahiliyya Period. This paper's intention is to discuss Islamic feminism within the model developed by Wadud in Iran and Egypt.
\end{abstract}

Keywords: Islamist feminism, Muslim women, Iran, Egypt

1 PhD. C. Lect. Altınbaş University, Dircetor of Research Center on Gender and Women's Studies banu.dalaman@altinbas.edu.tr 


\section{ORTADOĞU'DA İSLAMİ FEMINIST HAREKETLER: MISIR VE İRAN ÖRNEKLERİ}

\section{$\ddot{O}_{z e t}$}

Kadın meselesi, genel olarak İslam ülkelerinde modernleşme ve toplumsal dönüşüm bağlamında tartışllmaktadır. 1980'den sonra ise farklı toplumlardaki Müslüman kadınlar arasında yeniden düzenlenmiş bir dini feminizm gelişmişstir. Bu hareketlenme ilk olarak şehirlerdeki laik ve eğitimli dindar kadınlar arasında belirmişstir. Bu Müslüman kadınlar kendi dini kimliklerini koruyarak İslam' k kültürel ve ahlaki kimliklerinin önemli bir unsuru olarak görmeye devam etmişlerdir. Bu kadınların fikirleri modernizmin etkisiyle günlük sosyal yaşamda sosyal ve politik eşitliğe, aile hayatı ve toplumsal cinsiyet kavramlarınin feminist yorumlarına doğru evirilmiş̧tir.

İslamcı feminist hareketin güçlenmesinde artan gö̧̧, kültürel etkileşim ve kitle iletişim araçlarının gelişimi önemli rol oynamıştır. Misır ve İran gibi Müslüman ülkelerde, kitle iletişiminin sağladı̆̆ı imkânlardan yararlanarak bilinç düzeyinde bir artış gerçeklemişstir. Dahası bu artışla birlikte eski gelenekler ile yeni modern yaşam seçeneği arasında sıkışan kadınlara yeni bir yol açılmıştır. İslami feminist hareket üzerine önemli çalışmalar yapan Amina Wadud, bu hareketi İslami feminizm ve Müslüman feminizmi olarak ikiye aylrmaktadır. İslami feministler Müslüman bir aile ve toplum hayatının patriarkal öğeleri öncelediğini kabul etmekle birlikte bunun kadınları aşağllayan, kadınları küçümseyen eşitsiz bir yaklaşım olmadığının da altını çizmektedir. Müslüman feministler ise Müslüman ülkelerde misojini ve patriyarkal düzeninin yaygın olduğunu ve bunun İslamiyet öncesi dönemde doğduğu fikrini savunmaktadır.

Bu çalışmanın amacı Wadud'un İran ve Misır gibi Müslüman ülkelerde geliştirdiği modeli irdelemektir.

Anahtar kelimeler: İslami feminizm, Müslüman kadınlar, Iran, Mısır

\section{Giriş}

İslami feminizm 1990'larda ortaya çıan bir kavram olarak feminist okumalarda ve aktvizmde yeni bir alan açmış; kadın hareketlerinde farklı feminizmler konusunun tartışıldığı 
ortama bir çeşitlilik katmıştır. Bu kavram "İslam” ve "feminizm” gibi iki çok önemli - ve birbiriyle tezat gibi görünen- kavramın birleşmesiyle ortaya çıktığından tartışmalara neden olmuştur. Özellikle ikinci dalganın katı feministleri bu iki kavramın bir arada olamayacağını düşünmektedir. Tunuslu avukat aktivist Neila Driss, İslam ve feminizmin birbiriyle çelişmekte olduğunu ve bu iki kavramın bir arada bulunmasının imkansız olduğunu ifade etmektedir:

“Feminizm ve İslamcılık bir arada olamaz yani islami feminizm diye bir şey olamaz. İki kavram bir biriyle çelişmektedir. Eğer bir kadın İslamcı ise erkeğe bağımlığı kabul ediyor ve onlar ne diyorsa kabul ediyor demektir. Bu kadınların feminizmin doğasında olan eşitlik, özgürlük gibi kavramlarla uzlaşması mümkün değildir. Uzlaştığını düşünenler süslü bir yalanın içindedirler.”"1 Türkiye'de ikinci dalga feminizmin önemli aktvistlerinden Tülin Tankut da benzer şekilde İslami feminizm kavramının benzer nedenlerle olamayacağını savunmaktadır. ${ }^{2}$ Buna karşılık İranlı İslami feminist Ziba Mir Hosseini ise feminizmin ortaya çıkardığg Batılı normların sonuna gelindiğini ve tek bir bakış açısıyla kadın hareketinin ileri bir noktaya gelemeyeceğini belirtmektedir:

"Müslüman dünyasında seküler feminizm, yirminci yüzyılın başlarında kadınların siyasete ve topluma girmesinin önünü açarak tarihsel rolünü yerine getirdi. Ama bu bakış açısının Müslüman olan biz feministlere bize verecek daha fazla bir şeyi yok.” (Mir-Hosseini 2006: 644).

Aynı bakış açısıyla Sara Ahmed de feminizmin Batı'dan doğuya aktarıldığı fikrini reddetmektedir. Dahası bu fikrin oryantist bakış açısının bir ürünü olduğunu ve bu fikrin nasıl geliştiğini bilmediğini ifade etmektedir (Ahmed, 2017: 16). Öte yandan kendi hikayesini anlatırken feminist olma hikayesinin Pakistanlı halaları üzerinden geliştiğini ifade etmektedir.

\footnotetext{
${ }^{1}$ Neila Driss ile görüşme, Mon Massir bloğu yazarı ve avukat, Tunus, 15 Ocak 2018

${ }^{2}$ Tülin Tankut ile görüşme, Kadın Eserleri Kütüphanesi ve Bilim Merkezi Vakfı Yönetim Kurulu Üyesi, İstanbul, 26 Nisan 2019
} 
Feminizmin kesişimsel bakış açısından yani feminizme farklı din ve etnik kökenlerden bakıldığında İslami feminizm de kendine bir alan açabildiği söylenebilmektedir.

\section{İslami Feminizm}

İslam coğrafyasında feminist hareketlerin çıkışı o dönem Osmanlı yani Türkiye, Mısır ve İran gibi ülkelerin önderliğinde Batı ile eş zamanlı olmuştur. Batı'da ilk dalga feminizm kadınların ezilen bir gruba ait olduklarının bilincine varmaları ile ortaya çıkmışken; İslam coğrafyasında ulus-devlet, milliyetçilik akımlarının ve modernleşme çabalarının bir parçası olmuştur. Batı coğrafyasında kadınların profili daha orta sınıf, işçi, çalışanlardan oluşurken, İslam coğrafyasındaki ilk kadın örgütlenmeleri üst tabaka ve eğitimli küçük gruplar tarafından ortaya atılmıştır. Bu dönem kadın hareketinin en büyük sınırlılığı halkı temsil eden kadınlarla ilişkinin neredeyse olmaması olmuştur. $\mathrm{Bu}$ durum, üst sınıf kadınları ilgilendirdiği düşüncesiyle kadın sorununun genelde detaylı bir şekilde tartışılmamasına yol açmıştır. Kadınlarla ilgili yasal değişimlerin gözle görülür sonuçlarını fark etmek için başka toplumsal değişimlerin yaşanması gerekmiştir (Graham-Brown, 2001). Bir başka sorun da halkın içinden gelen kadınlara dair arşiv, sözlü tarih çalışmasının yeterli olmaması olmuştur. O dönem kadınların aslında başka mücadeleleri olabileceği varsayımından yola çıkıldığında bu mücadeleler ile ilgili bilgiler telgraf, mektup, dilekçe gibi dökümanlar incelenerek döneme ait kadınların yaşadıkları sorunlara dair daha fazla bilgiye ulaşılabilecektir (Metinsoy: 2016). İlk dalga feminizmin 1800'lerin sonunda yaşandığı ABD, Fransa, Almanya, İngiltere gibi ülkelerde temel olarak eğitim hakkı, oy verme hakkı ve ücret eşitliği gibi doğal haklar savunulmuştur. Osmanlı'da çıkan ilk kadın hareketi irdelendiğinde de büyük ölçüde devletin himayesinde gelişmek zorunda kalmış ve kadın modernleşmenin merkezinde yer alan simgesel bir aktör olarak kalmıştır (Çaha,2010; 413). 
İslam coğrafyasında 1900’lerin başında özellikle Osmanlı, Mısır ve İran’da başlayan kadın örgütlenmeleri, Müslüman bir toplumda batılı etkilerle kadınların haklarını sorgulamaya başladıkları önemli bir hareket olmuştur. 19. yüzyıl sonlarına doğru Osmanlı İmparatorluğu, Mısır ve İran'da eğitimli kadınlar hareketlenmeye ve sorunlarını dile getirmeye başlamıştır. Ortadoğu'da başlayan ve erkeklerin de dahil olduğu kadınların sorunları tartışması, dünyada gerçekleşen kadın hareketlerine eş zamanlı olarak konuşulmaya başlanmıştır (Bora, 2010; 53). O dönem basılan kadın dergilerinin bu örgütlenmenin yankı bulmasında ve büyümesinde rolü büyük olmuştur. Sayısı kırka kadar ulaşan bu dergilerde kadınlar kendilerini birey olarak ifade etmekte, sorunlarını tartışmaktadır. Var olan İslami uygulamalara ve ataerkil toplumun kültürel kodlarına uygun yayınlara karşı bir şekilde muhalif kalarak haklarını aramışlardır.

Öte yandan İslam coğrafyasında kadın örgütlenmeleri 1990’lardan sonra yeniden hareket kazanmaya başlamıştır. Avrupa'da yaşanan ikinci dalga feminizmden de etkilenerek farklı bir boyut kazanmıştır. Birçok ülkede birinci dalga feminizm kadınların seçme ve seçilme haklarını kazanmalarından sonra sessizliğe gömülmüştür. Simone de Beauvoir 1949 yılında yazdığı İkinci Cins kitabında varoluşçu bir bakış açısıyla kadınların nasıl "öteki” durumuna geldiğini ortaya koymuştur. Kurtuluşun özel alandan kamusal alana çıkışta olduğunu ve tüm kadınların meslek sahibi olmaları gerektiğini ifade etmiştir (Beauvoir, 1949). İkinci dalga feminizmin teorik çerçevesinde kadınların gündelik sorunlarının ataerkil düzenden kaynaklandığı ve kadınların erkekler tarafından baskılandığı kürtaj, taciz, şiddet gibi konular ortaya çıkmıştır.

İslam coğrafyasında ikinci dalga feminizmin etkisi 1990'larda yani Batı'dan 15-20 yıl sonra ortaya çıkmıştır. Kimlik feminizminin ortaya çıkması ille ABD'de beliren siyahi feminizm gibi Müslüman ülkelerde de İslami feminizm olgusu tartışılmaya başlanmıştır. İslami feminizm kısaca birincil İslami kaynaklardan olan Kuran ve hadislerin kadınların hakları da göz önüne alınarak yeniden yorumlanması anlamına gelmektedir. Aslında daha eskilerde modern 
ulus-devlet inşası sürecinde de İslamiyet'in önemini vurgulayan kadınlar, özellikle Mısır'da mevcuttu. Örneğin Misırlı Labiba Ahmad (1870-1950) Arap milliyetçiliğiyle İslam'1 bağdaştırmaya çalışmış ve İslam'a feminist bir yorum getirmiştir (Bora, 2010; 58). Aynı şekilde İran'da İslam devriminin ardından kadınlar tefsir işine kalkışarak kendilerine yeni alanlar açmaya çalışmıştır. İslami feminizm Batı’da başlayan postmodern yaklaşımlardan ve varoluşçu felsefeden de etkilenmiştir. İkincil olarak etkilendikleri ve aktivist olmalarında önemli rol oynayan Müslüman düşünür Fazlul Rahman ve onun geliştirdiği modernist yaklaşım olmuştur (Çaha, 2010: 347).

Diğer taraftan İslam hukukuyla yönetilen ülkelerde erkek egemen bir yorum bulunmaktadır. Her türlü karar alma mekanizmasından da erkek sorumlu olmaktadır. Hadramut'lu kadınlar olayı, İslam'da kadının özgürlük adına giriştiği en önemli ayaklanma sayılmaktadır. Bazı Arap kaynakları, Yemen'in doğu bölgesinde yer alan Hadramut'da Hicretin on birinci yılında bu bölgede yaşayan bir kabileye mensup kadınların, peygamber Hz. Muhammed'in ölüm haberini aldıklarında sevindiklerini ve eğlenmeye başladıklarını bildirmektedir. Bu kadınların düşüncesine göre İslamiyet öncesi bu bölgede yaşayan kadınlar erkeklerle eşit ve özgür hareket eden, çalışan ve serbest giyinen bir kadın iken peygamber Muhammed sonrası bu özgürlük ve eşit haklar bitmiştir. Sevinmelerinin sebebi ise bu ölüm ile bu sistemin sona ereceğini düşünmeleri olmuştur. Ama olay söz konusu kadınların ve onları seyredenlerin öldürülmesi, öldüren kişilerin ise "fazilet örneği" olarak anılmasıyla son bulmuştur (Arsel, 1989: 467-471).

Dünyaca ünlü kadın aktivist Eva Ensler konuşmalarına "kadına olan baskı dünyanın her yerinde aynı” şeklinde başlamaktadır. Bunu eleştiren Somali asıllı Hollandalı kadın aktivist Aayan Hirshi Ali ${ }^{1}$ bloğunda paylaştığı videoda “Eva Ensler şeriat kurallarını ve bunun kadınlar

\footnotetext{
${ }^{1}$ AayanHirsi Ali Vakfi - AHA Foundation - New York, (çevrimiçi) http://www.theahafoundation.org
} 
üzerinde yarattığı baskı kültürünü bilmiyor” diyerek karşı çıkmaktadır. İslam hukuku yani şeriat ile yönetilen ülkelerde farklı yorumların olması faklı görüşlerin de doğmasına neden olmuştur. Fazlulrahman, Ali Şeriati, Mevdudi, Mutahharri gibi Müslüman düşünürlerin kadın ve aile olayına farklı yaklaşımları bulunmaktadır. Bazı ideologlar cinslerin tecritini ve birbirinden ayrılması gerektiğini, bunun için de kadınların örtünmesi gerektiğini savunurken, Fazlulrahman'a göre ise tecrit ve örtünme değil, iffetli ve namuslu olmak önemli olmaktadır (Sancar, 2016: 174). Ali Şeriati gibi ideologlara göre ise yeni İslam kimliğinin ve ideolojinin bayrağını kadının örtünmesi taşımaktadır. İslam'ın bayrağını taşıyacak ve sembol haline getirilecek Müslüman kadın ideal tipi Fatıma'dır. İslam ideolojisinin koruyucusu ve yayıcısı olarak etkin siyasi rol oynayacaktır. İdeal kadın moda giyimi, makyajı, süsü, mücevheri ile değil kişiliği ve yeteneği ile saygınlık kazanacaktır (Şeriati, 1986).

Genelde yapılan en büyük hata, Batılı feminist yaklaşımlarla İslam coğrafyasındaki kadın örgütlenmelerini anlamaya çalışmak olmuştur. $\mathrm{Bu}$ yaklaşım genelde Müslüman devletlerinde yaşayan kadınlara ilişkin çalışmalarda İslam'ın etkisi ve devletin rolü dikkate alınmaması durumunu doğurmaktadır (Kandiyoti, 1997). Buna ilaveten batılı feministler bu ülkelerde yaşayan kadınların deneyimlerini görmezden gelmektedir. Burada yaşayan kadınlar burkalarının arkasından bakan buğulu gözler olarak kayıtlara geçmekte, onların dertlerinin ve sıkıntılarının farklı olabileceği, sorunun burka değil de daha kadına özgü dertler olabileceği düşünülmemektedir. Burada tartışılması gereken İslam devletlerinde kadın hareketinin mücadelesini tarihte olmayan bir din ya da kültür olarak değil, kadınları birey olarak hareket planları bağlamında düşünmektir. Bu anlamda kadınların nasıl örgütlendikleri, hangi konuları dile getirdiklerini anlamaya çalışmak feminist kuramı daha açıklayıcı hale getirecektir.

Kadın konusu İslam ülkelerinde genellikle modernleşme ve toplumsal dönüşüm tartışmaları bağlamında ele alınmıştır. 1980 sonrasında yenilikçilik adı altında Müslüman kadınlar arasında bir dini feminizm gelişmiştir. Bu durum özellikle şehirlerde laik ve eğitimli dindar kadınlar 
arasında ortaya çıkmıştır. İslami kimliklerini korurlarken, din bu kadınlar için ahlaklarının ve geleneklerinin başat bir parçası olmaya devam etmiştir. Aydınlanma düşüncesinin getirdiği etkiyle de her alanda erkeklerle eşitlik ilkesi, gündelik aile hayatı ve toplumsal cinsiyet kavramlarının feminist yorumlarına doğru evirilmişlerdir. Globalleşmeyle birlikte artan göç; kültürel etkileşim, kitle iletişim araçlarındaki gelişme, İslamcı feminist hareketin güçlenmesinde önemli rol oynamıştır. Başta Mısır ve İran gibi Müslüman ülkelerde kadınların kitle iletişiminin de sağladığı imkanlardan istifade ile bilinç düzeylerinde artış sağlanmış, geleneksel örfler ile modern dünya arasında kalan bu kadınlar yaşadıkları çatışmadan bir kurtuluş yolu aramışlardır.

İslami feminist hareket üzerinde önemli çalışmalar yapan Amina Wadud bu hareketi İslami feministler ve Müslüman feministler olarak ikiye ayırmıştır (Yüce Tar, 2013: 80). İslami feministler Müslümanlığın günlük aile hayatının içinde kültürel kodlar doğrultusunda patriarkal kalıpları öne çıkardığını kabul etmektedir. Fakat bunun kadınları aşağılayan bir baskı unsuru olmadığının da altı çizilmektedir. Müslüman feministler ise Müslüman ülkelerde misojini ${ }^{1}$ ve patriarkal düzeninin yaygın olduğunu ve bunun İslamiyet öncesi dönemde doğduğu fikrini savunmaktadır. Kuran'da hiyerarşik olarak kategorilere ayrım bulunmaktadır ve gündelik toplum hayatı bu ayrıma göre düzenlenmelidir (Gürhan, 2011: 374). Bir hareket olarak tarihi çok eskilere dayanmaktaysa da -İslamcı Feminizm olarak da adlandırılan- "Müslüman Feminizm" deyimi ilk kez 1992 yılında Tahran'da Shahla Sherkat tarafından kurulan kadın dergisi Zanan'da kullanılmıştır (Kaya, 2018). Bu terimin Batı Avrupa toplumlarında kullanılması ise 2000'li yılların başına denk gelmektedir. İslami feministlere göre İslam dini, erkek egemen bir düşüncenin hâkimiyetinde erkekler tarafından düzenlenmiştir. Bu düşünceye karşı çıkan kadınlara göre İslam'ın kadınları dışlayan erkeklerden eşitsiz konuma sokan durum

\footnotetext{
${ }^{1}$ Kadın düşmanlığı
} 
ve analizlerden çıkarılarak özgür hale getirilmelidir (İngün, 2005: 109). Amina Wadud, “İslami feminist" kavramına alternatif "Müslüman feminist "adı altında başka bir tanım geliştirmiştir. Kadının her alanda eşit olduğu varsayımını güçlendirip geliştirmek yerine, Kuran'ın kadın meselesi üzerinden yeni bir bakış açısıyla yoruma açılması gerektiği fikrini savunmaktadır (Wadud, 1999). 1990 yılında yazdığı “Kuran ve Kadın: Kutsal Metnin Bir Kadın Bakış Açısıyla Yorumu" kitabı Kuran'ın bir kadın tarafından yorumlanmasıdır. Bu konuyla ilgili Kuran'da var olan "kadın sesini” ortaya çıkardığını, erkeklerin kendi lehlerine yaptıkları taraflı yorumları elediğini söylemektedir. Müslüman feministler, İslam dininin kadına kötü davranılan erkeklerin egemen olduğu toplumsal kültürde doğduğunu ve aslında Kuran’ın bu bozuk düzeni düzeltmek için geldiğini savunmaktadır. Kadınların kamusal alanda nasıl yer alacakları ve eşit duruşlarının nasıl sağlanacağına dair pratiklerin yeniden düzenlenmesini önerilmektedirler. Bu feminist perspektiften bakıldığında Kuran'ın ve hadislerin yeniden yorumlanması ve gözden geçirilmesi fikri ortaya çıkmaktadır. Bazı yazarlara göre ise bu düşüncedeki İslamcı feministler Kuran'ın yeniden yorumlanması vasıtasıyla şeriat hükümler ile çelişecek kararlar ortaya çıkarmış ve tüm şeriat kanunlarının uygulanışında ezber bozmuşlardır (Moghadam, 2002 1147). Kuran'ın kadın bakış açısıyla yeni bir okuma sonrası nasıl bir hukuk oluşturacağı ve Şeri hükümlerin nasıl uygulanacağı da ayrı bir tartışma konusu olmuştur (Tohidi, 2003). İslami feministlerin savundukları temel düşünceleri Kuran'ın bütün insanların eşit olduğu prensibine ${ }^{1}$ dayanmaktadır. İslami feministler, Kuran'da yer alan ve hadislerde örneklerinin olduğu eşitlik ilkesinin İslamiyet öncesi Arap ülkelerinde var olan erkek egemen düşünce ve uygulamalara uyarlandığını savunmaktadır. İslami feministlere göre kadın ve erkek arasındaki eşitsizlik Arap dünyasındaki kültürel patriarkal yapının eseridir. Bu nedenle de Kuran'ın bu bakış açısıyla yeni bir okuma yapılmasını ve yeniden yorumlanması gerektiğini savunmaktadırlar (Badran,2002).

\footnotetext{
${ }^{1}$ Hucurat suresi, Kuran 49. Sure 13.Ayet
} 
Wadud'un yaptığı bu modellemeyi Mısır ve İran üzerinde yapılacak kısa çaplı bir inceleme ile irdelemek mümkündür.

\section{Mısır'da Kadın Örgütlenmeleri}

İslami feminizm örgütlenmesinin ilk adımlarına Mısır'da rastlanmaktadır. “Kadının serbestleşmesi” anlamına gelen 1899 tarihli “Tahrir ül-Mer'e” ve 1900 tarihli “Al-Mar’a AlJedida" (Yeni Kadın) adlı çalışmalarıyla Kasım Emin kendinden sonraki çalışmalara kapı aralamıştır. Cahil, tembel ve eğitime ihtiyacı olduğunu düşündüğü Mısır kadının koşullarını dile getirmek için kaleme aldığı bu eserlerinde kadın düşmanı uygulamaları tartışmıştır. Kadının eve kapatılmasının ve ayarlanmış evliliklerin İslami olmadığını, sosyal reformun kadına da ulaşması gerektiğini, ulusun ilerleyememesinin nedeninin kadının geri kalmışlığı olduğunu savunmuştur. Kasım Emin çok eşliliğe karşı çıkarken kadının eğitiminin önemini de vurgulamıştır. Eğitimli kadın çocuklarını daha bilinçli yetiştireceği gibi kocasıyla ilişkilerini de daha sağlıklı düzenleyebilecektir. $\mathrm{Bu}$ görüşlerin aynı dönemde yaşamış ve pozitivizm etkisindeki Osmanlı Türk aydınları üzerinde de etkili olmuştur.

Kasım Emin, görüşlerine yöneltilen eleştirilere yanıt olarak "Yani Kadın" adlı eseri kaleme almış ve bu çalışmasında "doğal haklar" (Batıdaki liberal feminist harekete büyük oranda benzerlik göstermektedir) ve pozitivizmin etkisiyle "ilerleme" kavramını merkeze yerleştirerek dinle ilgisini azaltmış ve laik görüşlerini ortaya koymuştur.

Kasım Emin dışında Fars El-Shidjak 1855'te kadının eğitiminin önemini vurgulayan kitabı "Bacak Bacak Üstüne”yi yayımlamış, El-Tahtani de (1801-1871) kadının eğitilmesini ve kadının hukuksal durumunun iyileştirilmesini savunmuştur (Yüce Tar, 2013: 81). Mısır'daki bu tartışmalar daha sonraki tartışmaların da zeminini teşkil etmesi açısından önemlidir. $\mathrm{Bu}$ noktadan yola çıkıldığında Mısır'da kadın hareketinin 3 tane özelliği dikkat çekmektedir. Birincisi bu feminist hareketin kökleri yukarıda da değinildiği üzere Kuran'a dayanmaktadır. İkincisi Arap ve İslami örfi adetler ve gelenekler ile Avrupalı adetleri arasında kesin farklar 
ortaya çıkmaktadır. Üçüncüsü ise Mısır kadın hareketi aileyi toplumun bir parçası olarak ele almaktadır ve kadını birey olarak değil ailenin bir parçası olarak görmektedir. Mısır’ın bu karşı duruşunda yaşadığı uzun sömürge deneyimi ve oryantalist bakış açısına karşı duruşun da etkisi bulunmaktadır (Gürhan, 2011: 373).

Ghada Osman gibi araştırmacılar bu özellikleri dikkate alarak Müslüman kadınların batıdan farklı yeni bir feminist yaklaşım inşa ettiklerinin altını çizmektedir. Dünyada gelişen feminist ideolojinin etkisinde kalmış olsalar bile Müslüman kadınların farklı bir başlangıç noktasından hareket ettikleri görülmektedir (Güç, 2008: 660). Batıda dinle doğrudan çatışan ve dini, ataerkilliğin hem kaynağı hem de taşıyıcısı olarak görülen feministlerin aksine Müslüman feministler dinin temel varsayımlarının eleştirmekten kaçınmışlardır. Dahası söylemlerini dini argümanlarla meşrulaştırmaya çalışmışlardır. Peygamberin erkek oluşuyla ilgili herhangi bir eleştiriye girmekten özenle uzak durmuşlar ancak tarihi yorumu/geleneksel olanı kıyasıya eleştirmekten geri durmamışlardır (Gürhan, 2011: 374).

İslami feministlerin Kuran'ın korunmuşluğu konusunda en ufak tartışmaları bulunmamaktadır ancak erkeklerin üstün olduğunu işaret eden bazı ifadeleri o günün Arap toplumunun yapısının gerektirdiği bir zorunluluk çerçevesinde düşünmektedirler. Ayetlerin verdiği mesajların açık toplumsal hedefi üzerinde yoğunlaşılması gerektiğine inanılmıştır. Diğer önemli bir kaynak olan hadislerin geleneksel otoritelerin kıstaslarının dışında, akıl ve sağduyuyla eleştirilip topluma uyarlanması gerektiği savunulmuştur. Öte yandan İslami feministlere göre İslam dini erkek egemen zihniyetteki erkekler tarafından ablukaya alınmıştır. Mısır'da erkek yazarların kalemiyle can bulan feminist hareket, Batı düşüncesini anlayan üst sınıf kadınlar tarafından devam ettirilmiştir. Mısır'da kadın hareketinin başında “Mısır Feminist Birliğgi”(MFB) vardır. MFB'nin kurulmasında Huda Sharawi, Saiza Nabarawi ve Nabawiya Moussa başta olmak üzere 12 kadın önemli rol oynamışlardır. Huda Sharawi 1908'de "Cuma Konferansları" adı altında Mısır'da kadınların konuşma yapma geleneğini başlatmıştır. 
Sharawi, 1935'teki İstanbul Uluslararası Kadın Konferansı'nda başkan seçilmiştir. Sharawi aynı zamanda 1919'da Mısır'da Zaglul önderliğinde başlayan anti-emperyalist harekete kadınların katılmasını sağlamıştır. İslami feminist kadınların, hareketin dışında milliyetçi hareketlere katılımı yukarıda da değerlendirildiği üzere sömürgeci tecrübenin İslami feminist hareket içerisindeki yerini kanıtlamaktadır. Onun 1923’te kurduğu “Al İttihad Al-Nisa’i AlMısır” Mısır Feminist Birliği (MFB) ilk dernekleşen kadın hareketi olarak bilinmektedir.

MFB, kadın haklarını içeren bir program hazırlayarak kadının eğitimi, çok eşliliğin yasaklanması, evlenme yaşının 16'ya yükseltilmesi, boşanmanın yasal mahkemelerce yapılmasını oy hakkı, kadın-erkek eşitliğinin sağlanmasını istemiştir.

MFB'yi 1941'de Fatma Ni'mat Rashid tarafından kurulan ilk kadın partisi olan Ulusal Feminist Partisi (Al-Hizb Al-Nisa'i Al Vatani) takip etmiştir. Taleplerini sosyal ve ekonomik reformlar paketi ile kadına oy hakkı oluşturmaktadır. 1936'da Zeynep Ghazali tarafından “Müslüman Kadınlar Örgütü’nün talebi ise kadının ve ulusun özgürlüğü olmuştur. Doria Shafik 1948'de orta sınıf kadınlar ve sorularına çözüm bulmak için Bint El-Nil (Nil'in Kızı) derneğini kurmuştur. Kadına oy hakkı dahil tüm siyasi hakların sağlanmasını savunan ve okuma-yazma sorularını tartışan kampanyalar yürütmüştür.

Mısır'daki kadın hareketlerinde örgütlenmelerin yanı sıra çeşitli yayın organlarının da rolü olmuştur. İlk kadın dergisi “Genç Kız” (Al-Fatah) 1992'de İskenderiye'de Hind Nawfal tarafından çıkarılmıştır. Mısır'daki kadın dergilerinin pek çoğunun editörlüğü Kıpti kadınlar tarafından yürütülmüştür. Müslüman kadınlar da bu dönemde kadın dergilerinde boy göstermeye başlamıştır. Fatıma Rashid'in "Kadın İlerlemesi” (1908-1909), Sarah al Mühiyya'nın “Nil’in Kızı” 1913-1915 ve haftalık olarak çıkarılan “Erdem” 1910-22 arasında yayınlanmıştır. Balsam Abd-Al Malik'in “Mısırlı Kadın” 1920-39 arasında ve Kıpti ${ }^{1}$ Malaka

\footnotetext{
${ }^{1}$ Hristiyan Misırlılar
} 
Sa'd'ın "Latif Cinsi” adlı dergisi 1908-1925 arasında yayımlanan laik ulusçu çizgideki dergiler olarak yer almıştır.

\section{İran'da Kadın Örgütlenmeleri}

20. yüzyılın sonlarında İran İslam Cumhuriyeti hem İslam ülkelerindeki kadın hakları çabasının gidişatını hem de batıdaki feminist bilim insanlarını etkilemiştir. İran'daki tartışmalar 1980 ve 1990’lı y1llardaki ülkede yaşanan siyasal ve sosyal dönüşüm ekseninde şekillenmiştir. Tartışmaların başlangıcı 1980'ler olsa da asıl olarak tartışmaların yoğunlaşması 1990'larda yaşanmıştır. Kentli üst ve orta sınıfa ait kadınlar 1979'dan önce onlara sunulan yasal olanaklardan yararlanarak eğitim fırsatı elde etmişler ve evlilik ve çalışma hayatında çağdaş normları yakalarken, alt ve kırsal kesimde yaşayan kadınla ise bu olanaklardan yararlanamamışlardır. Kısacası İran'daki kadının statüsü var olan toplumsal yapıya bağlı olarak farklılaşma göstermiştir.

Mısır'da olduğu gibi İran'daki feminist hareketin doğuşu da 1900’lerin başına denk gelmiş ve yine erkek düşünürlerin öncülüğünde filizlenmiştir. Kadın haklarını destekleyen yenilikçi kanattan Mirza Malkom Khan 1890'da kaleme aldığı "Yasa" adlı eserinde siyasal fikrin arasında kadınların seçme ve seçilme hakkından bahsetmiştir. "Yüz Söylem" adlı çalışmasında kadının eğitiminin önemine dikkat çekmiş; buradan hareketle çocukların karakter kazanmasında nitelikli, eğitimli kadınların hayati bir rol oynadığını belirtmiştir. Öte yandan bu söylemlerin ardından Kermani, dönemin rejimi tarafından idam edilmiştir. 1874'de Tebriz'de doğan Prens Gholam Hussesin'ın oğlu Iraj Mirza ünlü bir şair ve siyasi aktivisttir. İranlı kadınların örtüsünü ülkenin geri kalmışlığının bir işareti olarak gördüğünü söylemiş ve açıkça eleştirmiştir. Başörtüsü ve/veya peçenin kadınlar için artık gereksiz olduğunu belirtmiş, şiirlerinde kadın bedenini örtülerinden çıkarmıştır. Rıza Pahlavi iktidara geldikten sonra suikaste kurban giden dönemin diğer bir ünlü siyasi şairi Mirzadeh Eshgi, "Üç Tablo veya 
Eshghi'nin İdeali" ve "Kara Kefen" eserlerinde İranlı kadınların hoş olmayan ve ezilen koşullarını ortaya koymuştur.

Feminist hareket İran'da başlangıç itibariyle tıpkı diğer İslam ülkelerinde olduğu gibi kadının serbestleşmesi ve toplumsal hayatta varlığının arttırılması için mücadele vermişken; İkinci Dünya Savaşı’ndan sonraki süreçte özellikle solcu-milliyetçi hareketin yok edilmesinden sonra kadının kamusal alana katılımının giderek azaldığı gözlemlenmiştir.

1850'de ise idam edilen İran'ın ilk kadın eylemcisi Fatıma, kadına eşit haklar verilmesinin yanında çok eşliliğinin yasaklanmasını istemiştir. Peçesiz olarak söylevler vermesinden dolayı din karşıtı olmakla suçlanmıştır. İran'ın ilk kadın milletvekili ve bakanı Farakhreo Parsha ise parlamentoda kadın ve aile yasaların iyileştirilmesi için çalışmış ve lise müfredatında cinsel eğitimin olmasını da savunmuştur. Devrimden sonra 1979'da rejimin idam ettiği ilk kadın olmuştur.

İslami feminist söylemin gelişiminde kadın grupları ile dergilerinin önemli bir rolü olmuştur. İran’daki "Peyam-e Hajar”, “Zanan” ve "Ferzaneh" “Journal of Women's Studies and Research" gibi dergiler Faneena Syedin başkanı olduğu feminist "Rahima Foundation" ve bu vakfın yayın organı "Swara Rahima” dergisi, Esma el Murabit önderliğindeki Fas merkezli “Sisters Arabic Forum” İslami bir perspektiften kadın haklarını desteklemektedir. 1910-1930 arası dönemde 20'den fazla süreli yayın kadın hareketinin ciddi bir ivme kazandığına işarettir. İran'da ilk kadın dergisi “Bilgi” 1910'da yayın hayatına başlamıştır. Ardından 1912’de “Olgunlaşmak” ve 1921 'de “Kadın Dünyası” çıkmaya başlamıştır. Bu dergilerde kadın eğitimi, kızlar için enstitüler, sağlıklı yaşam koşulları, hayat kadınlığına karşı mücadele, çocuk bakımı, ulusal bağımsızlık gibi konular ağırlıklı olarak işlenmiştir. Ortak payda olarak "toplum mühendisliği" noktasından hareket eden bu yazılarda kadının toplumun inşasındaki rolüne temas edilmektedir. 
Sıdıka Devletbali İran'ın yayınlanan üçüncü büyük kadın dergisi Zaban-e Zanan (Kadınların Kelimeleri) editörüdür. 1927'de Paris’te katıldığı uluslararası bir konferans akabinde kültürel ve sosyal aktivitelere başörtüsüz katılmaya başlamıştır. Bu derginin tarihsel önemi, kadın hakları için öncü konumda olması olmuştur. İran'da bir kadın tarafından oluşturulan ve yayınlanan ilk yayın olmuştur. Dahası kadınların yazdığı makalelerde kadın haklarına ilişkin soruları ele almış ve aynı zamanda başlığında Zan (Kadın) kelimesini kullanan ilk dergi olmuştur. Altıncı sayısından itibaren dergi, Arapça kelimeler yerine Farsça terimleri kullanmaya başlamış böylelikle de milliyetçilik vurgusuna dikkat çekmiştir.

Öte yandan 1979 'da İslam devrimi sonrasında İran'daki kadınların 1850'lerden beri zorlu mücadelelerle kazandıkları hakları iptal edilmiştir. "Baskı Dönemi” olarak adlandırılan bu dönemde pek çok yasa kabul edilmiştir. Kadınların yargıçlık yapması yasaklanmış, iş yerlerinde hicap giymeleri ve plaj ve spor müsabakalarında kadın ve erkeklerin ayrılması gerektiği yasalaştırılmıştır. Kadının ücretsiz doğum izni iptal edilmiş, çalışması kocasının iznine bağlanmıştır. Bu düzenlemeler kadının toplumsal alandan dışlanarak eve kapatılması anlamına gelmiş ve bir örgütlenme sürecini de beraberinde getirmiştir.

İslami feministler Kuran'ın kadınlara erkeklerin yanında tanımlayıcı rollerinden ayrı yasal vatandaşlık, çalışma hakkı gibi özgürlükler tanıdığını ileri sürmüşlerdir. Bu kapsamda ortaya çıkan örgütlenmelerin önemlilerinden biri 1979'da kurulan “İslam Devriminin Kadın Derneği” olmuştur. Hükümetin, İslami ayetleri çarpıtarak kadına baskı yapmalarını eleştiren dergi Batının kadın kavramını metalaştırıp cinsel objeye dönüştürdüğünü; devrimin de benzer bir şekilde İslam'ı kadın söz konusu olduğunda sadece örtünmekle eş değer hale getirdiğini savunmuştur.

Özellikle 1980’lerden sonra kadına yönelik baskıya paralel olarak kadın basınında bir hareketlenme görülmüştür. “Zanan”, “Kadın Bildirisi”, “Çağrı”, “Kadın Hakları”, "Hajar'ın Mesajı" bu dönemde seslerini duyurabilen dergiler arasında yer almıştır. Bu dergilerde devrim 
sonrasında "toplumun İslamileşmesiyle" cinsiyet ayrımcılığının daha da keskin hale geldiği noktasına ortak vurgu yapılmış ve kadının aile içindeki statüsü geliştirilmeye çalışılmıştır. Özellikle Afsaneh Najmabadi'nin başını çektiği bu jenerasyon İran'daki İslami feminist hareketi, dini ve laik feministleri aynı kadın sorunları başlığında bir araya getiren nadir bir hareket olarak tanıtmışlardır. Bununla ilintili olarak İranlı kadınların hareketi incelendiğinde, kadınların siyasal ve sosyal konumlarını geliştirme çabalarında seküler feminist hareket ile ortak paydaya sahip olduğu ilginç bir şekilde dikkat çekmektedir. Bu nedenle Najmabadi, Zanan'da kaleme aldığı yazılarında batılı feminist etkilere açık olduğunu duyurmuştur. Diğer taraftan da Zanan'daki diğer yazarların yazılarında Kuran'dan alıntılara rastlanmakta ve ana çizgi bu vasıtayla sürdürülmektedir. Bu noktadan hareketle Zanan, batılı seküler feminist hareket ile İslami feminist hareketin sentezlendiği bir saha haline gelmiştir (Yüce Tar, 2013: 83-87). Nitekim Zanan üzerinde detaylı araştırmalar yapan Mir-Hosseini de İran'daki İslami devriminin beklenmedik sonucu olarak ulusun toplumsal cinsiyet bilincinde sebep olduğu artışa işaret etmektedir. Aile hukuku, nafaka, çocuklar gibi konularda yaşanan anlaşmazlıklar yeni muhalefetin oluşmasına neden olmuştur. İran İslam Cumhuriyeti’nin kadınları yeni bir konumla taçlandıracağı konusunda yetersiz olması kadın örgütlerini harekete geçirmiş, İslami feminist bilinçlenmeyi artırmıştır. Shekart, Behrouzi, Groji, Sa’dizadeh gibi yazarlar kadınları yok sayan, onları özel alana koyan yasalara karşı çıkmışlardır (Güç, 2008: 661). Bu noktada uluslararası platformda yapılan İslami Feminizm Kongrelerinin işlevi hiç şüphesiz büyük olmuştur. Sırasıyla Ekim 2005, Kasım 2006 ve Ekim 2008'de gerçekleştirilen Uluslararası İslami Feminizm Kongre'leri önemli olmuştur. I. Kongre'de Kuran'ın eşit haklar temelinde ele alınması, bu bakış açısıyla okunması önerilmiş ve kadın hakları için cihat çağrısı yapılmıştır. II. Kongre'de Şeriat ve aile konusu tartışılmış, İslam ve toplumsal cinsiyet konusu üzerinde durulmuştur. Kongrenin sonuç metninde yer alan ifadede İslami feminizmin en karakteristik özelliğine temas edilmiştir. 
“İslami yasa olduğu ifade edilen düzenlemeler Allah’ın yasası değil; yüzlerce yıl önce kadınların erkeklerin malı olarak görüldüğü ve dinsel söylemlerin tamamen erkeklerin elinde olduğu toplumlarda insanlar tarafından oluşturulmuş yasalar olduğu...”

Bu kongrelere 20 ülkeden 400 katılımcının yer almasına rağmen Türkiye'den herhangi bir katılım olmaması dikkat çekici bir ayrıntı olarak yer almaktadır (Gürhan, 2011: 379, Yüce Tar, 2013: 87). 2010 y1lında düzenlenen 4. Kongrede ise Sufizm ve Feminizm arasındaki ilişki analiz edilmiş ve kadın hakları alanında çalışan İslami kadın kuruluşları uluslararası düzeye taşınmış böylelikle İslami feminizmin pekiştirilmesi istenmiştir.

İran'daki İslami feministler hem batılı hem de Müslüman seküler feministler, İslami feminist hareketi dikkatle takip etmişlerdir. Badran'a göre laik ve İslami feminist söylemler birbirinden tam olarak ayrıştırılamaz ve bu sebeple İslami feminizm araştırılırken dini ve seküler feminizm birbirine bağlı olduğu dikkatten kaçırılmamalıdır. Örneğin Wadud, kadını esas alan Kuran tefsirinde İslami düşünceyi değişmez bir temel olarak alıp klasik İslam metotları ile yeni sosyal bilim araçlarını bir arada kullanmıştır (Güç, 2008: 664).

Buna rağmen Batılı feminist hareket ile kıyaslandığında İslami feminist hareket teoride olduğu gibi pratikte de oldukça sınırlıdır. Mojab, teorik açıdan İslami feminizmi, liberalizm ve pozitivizmin kopyası olarak görmektedir. Liberalizm konusunda batıdan farkı evrensel formal eşitliği arzulamada yeterince arzulu ve hırslı olmaması olarak nitelendirilebilmektedir (Güç, 2008: 670). Oryantalist bakış açısıyla "Müslüman kadın” tanımlandığında Müslüman bir laik, dindar, feminist ayrımı yapılmaksızın bütün kadınlar referans alınmaktadır. Bu referans kültürel olarak sorunlu değildir fakat kadın kimliğinin inşasında dini merkez alan bir kadın ile laik bir yaşam tarzını tercih eden bir kadın arasındaki farkları anlatamamaktadır. Bu noktada iki grubu Ayşe Güç örneklendirmektedir: bu ayrıma göre "Nilüfer Göle, Fatima Mernissi, Nevval elSaadawi” gibi akademisyenler seküler Müslüman kadın; “Amina Wadud Muhsin, Aziza el- 
Hıbri, Asma Barlas, Hidayet Şefkatli Tuksal” gibi yazarlar ise İslami kadın grubunda yer almaktadır.

\section{Sonuç Yerine}

Farklı bir bakış açısıyla irdelendiğinde kadın hareketleri, kadın olarak cinsiyetlendirilmiş kimliklerini temel alarak kamuya açık iddialarda bulunmak için toplu davranan kadınlar olarak tanımlanabilmektedir. Kadın hareketlerinin feminist olması gerek şart olmamaktadır. Feminist hareketler, toplumsal hareketlerin bir alt kümesi olan kadın hareketlerinin bir alt kümesi içerisinde yer almaktadır. Genel olarak sosyal hareketler ve özellikle kadınların hareketleri hedefe yönelik olduğundan daha radikal olanlar geniş toplumsal dönüşümlere yönelik olsalar bile çoğu tanınma, katılım, temsil ve güçlendirme ihtiyacını ifade eden belirli yasal veya politika kaygılarına sahiptir. Bu anlamda İslami kadın hareketleri de bir kadın hareketi olarak değerlendirilmelidir. Dahası farklı feminizmlerin ve seslerin aynı hedefe doğru birlikte sağlıklı bir şekilde çalışacakları alanlar yaratılmalıdır. Kendini İslami feminist olarak tanımlayan kadınların sosyopolitik durumları, etkinlikleri ve içlerinde bulundukları ortamdan yola çıkarak farklı yaklaşımlar oluşmuştur. Mühim olan bu arayışlarda feminizmin uluslararası çalışmalarda tüm kadınlar için eşitliği ve adaleti güvence altına alma parolasıyla hareket etmesidir. Sara Ahmet'in de ifade ettiği şekliyle “feminizm kadınları için kolektif bir siyasal harekettir".

Bir günlüğüne, tüm kadınları ve erkekleri toplayarak toplumsal cinsiyete dayalı hiyerarşileri yeniden oluştursak, her şeyi tüm cinsiyet rollerini yeniden üretmeye kalksak, nasıl bir dünya ile karşı karşıya kalırız? \#MeToo, HeforShe gibi küresel toplumsal hareketler kadınlar için bir hareket alanı oluşturmakta ve erkekleri de toplumsal cinsiyet ayrımcılığının bir parçası haline getirmektedir. Bu noktada İslami feminist hareket de kendisini kadın hareketinin öznesi 
haline getirerek yeniden ürettikleri bir İslamcılık anlayışıyla yeni bir toplumsal cinsiyet modeli yaratmaya çalışmaktadırlar.

\section{Kaynaklar}

Ahmed, S. (2017) Living a Feminist Life, Duke University Press.

Arsel, İ. (1989) Şeriat ve Kadın, 4. bask1, İstanbul

Badran, M. (2002) Islamic Feminism-What's in a name? Al-Ahram Weekly Online, 17-23, Issue No. 569.

Beauvoir, S. D. (1949) Le deuxième sexe I: Les faits et les mythes. Paris: Editions Gallimard.

Bora, A. (2010) Hatırlananlar ve Unutulanlar: İslam Coğrafyasında Modernleşme ve Kadın Hareketleri. Türk Dünyası Sosyal Bilimler Dergisi, 53, 51-66.

Çaha, Ö. (2010) Sivil Kadın: Türkiye'de Kadın ve Sivil Toplum. Savaş Yayınları.

Graham-Brown, S. (2001) Women's activism in the Middle East: A historical perspective. Women and power in the Middle East, 23-33.

Güç, A. (2008) İslamcı Feminizm: Müslüman Kadınların Birey Olma Çabaları. Uludăg Üniversitesi İlahiyat Fakültesi Dergisi, 17(2), 649-673.

Gürhan, N. (2011) “Toplumsal Cinsiyet ve İslami Feminist Söylem”, Dipnot.

İngün, Ö. (2005) Feminizm ve İslam İlişkisi: ‘İslami Feminizm’ (Yayınlanmamış yüksek lisans tezi), Uludağ Üniversitesi: Bursa

Kandiyoti, D. (1997) Cariyeler, Bacılar, Yurttaşlar, Metis Yayınları: İstanbul

Kaya, B. (2018) https://www.haberpodium.ch/islam-ve-feminizm-musluman-kadin-olmak-vekadin-haklarini-savunmak-celiski-mi/, (çevrimiçi), 07-10-2019.

Metinsoy, E. M. (2016) Writing the History of Ordinary Ottoman Women during World War I. Aspasia, 10(1), 18-39.

Mir-Hosseini, Z. (1996) 'Women and Politics in Post-Khomeini Iran: Divorce, Veiling and Emerging Feminist Voices', in Haleh Afshar (ed.) Women and Politics in the Third World, London: Routledge; 149-69.

Mir-Hosseini, Z. (2006) 'Muslim Women's Quest for Equality: Between Islamic Law and Feminism', Critical Inquiry, 32: 629-45

Moghadam, V. M. (2002) "Islamic Feminism and Its Discontents: Toward A Resolution of The Debate", Signs, 27, 4 
Sancar, S. (2016) Din, Siyaset Ve Kadın: Iran Devrimi, Nika Yayınevi, Ankara

Şeriati, A. (1986) Fatima Fatimadır, (Çev.) F. Yalçnkaya, Dünya Yayınları

Tohidi, N. (2003) "Islamic Feminism": Perils and Promises." Middle Eastern Women on the move.

Wadud, A. (1999) Quran and Woman:Rereading the Sacred Text from a Woman's Perspective, New York: Oxford University Press.

Yüce Tar, Y. (2013) 2000'ler Türkiye'sinde Müslüman Kadının “Kadın Sorunu”, Ondokuz Mayıs Üniversitesi Sosyal Bilimler Enstitüsü, Yayınlanmamış Doktora Tezi, Samsun. 


\title{
RECOGNIZING THE DATING VIOLENCE: A SOCIOLOGICAL RESEARCH IN LAW SCHOOL

\author{
Zeynep Özlem ÜSKÜL ENGIN' ${ }^{1}$
}

\begin{abstract}
Dating violence, which has recently been subject to academic studies, is that one of the parties acts physical, sexual, psychological, social, economic and digital violence against the other in the relationship. Also the digital violence is important in terms of development of technology. Adolescents are subject to the dating violence, but they cannot recognize that because of the the situation that is normalized due to gender norms. The dating violence that experienced by adolescents has a negative impact on personality formation and future romantic relationships therefore they can encounter the same problems when they are adults. Hence, it is of great importance for the society to examine the forms of gender-based dating violence to reach the statistical data about how violence occurs.

In this respect, it was selected as the pilot region of Galatasaray University Faculty of Law considering the importance of personality formation in the university periods and the frequency of the flirtation relations. A variety of questions will be addressed to the first, second, third and fourth grade students which include criteria for determining awareness of gender norms and dating violence. Thus, from the first to the last grade, the effect of legal education on awareness of violence will be examined and the role of age and gender will be seen. Another aim of the study is to organize trainings and workshops for university students in order to get to know gender norms according to the results of the research in The Sexual Violence and Mobbing Departmant in Galatasaray University.

It is desirable that the study will provide an example to other educational institutions and to make these practices widespread.
\end{abstract}

Keywords: Dating Violence, Gender Norms, Sociological Research, Adolescent.

\footnotetext{
${ }^{1}$ Prof. Dr. Galatasaray University, Faculty of Law, zeynepuskul@ yahoo.com;
} 


\section{GALATASARAY ÜNIVERSITESİ HUKUK FAKÜLTESI ÖĞRENCILLERINE YÖNELİK FLÖRT ŞIDDETİ ALAN ARAŞTIRMASI}

\section{$\ddot{O} z e t$}

Akademik çalışmalara son zamanlarda konu olan flört şiddeti, ilişki içerisinde taraflardan birinin diğerine karşı fiziksel, cinsel, psikolojik, sosyal, ekonomik ve dijital şiddet içeren davranışlarda bulunmasıdır. Özellikle ergen kişiler arasında yaşanan bu şiddet biçiminin araştırılmasinda, teknolojinin gelişimi ile birlikte artan dijital şiddetin önemi büyüktür. Gençler, flört şiddetine uğramakta fakat bu durum toplumsal cinsiyet normlart sebebiyle normalleştiğinden şiddetin farkina varamamaktadırlar. Ergen kişilerin yaşadığı flört şiddeti, kişilik oluşumunu ve ileride yaşanacak romantik iliş̧kileri olumsuz yönde etkilemektedir. Dolaylsıyla yetişkin olduklarında da durum değişmemektedir. Bu sebeple, toplumsal cinsiyete dayalı flört şiddetinin biçimlerini incelemek, şiddetin nasıl yaşandı̆̆ına dair istatistiksel verilere ulaşmak üniversite içerisinde yaşanması muhtemel olayların önüne geçebilmek açısından büyük bir önem taşımaktadır.

Çalışmada bu doğrultuda, flört şiddetinin araştırlması için özellikle üniversite dönemlerinde kişilik oluşumunun önemi ve yaşanan flört ilişskilerini sıklğ̆ı göz önüne alınarak Galatasaray Üniversitesi Hukuk Fakültesi'ni pilot bölge olarak seçilmiştir. Birinci, ikinci, üçüncü ve dördüncü sinıf ögrrencilerine, toplumsal cinsiyet ve flört şiddeti farkindallğını tespit eden ölçütleri içeren çeşitli sorular yönlendirilecek, bu soruları yanttlamaları beklenecektir. Böylece birinci sinıftan son sinıfa kadar, görülen hukuki eğitiminin toplumsal cinsiyet ve flört şiddeti farkindalığına olan etkisi irdelenmiş olacak hem de yaşın ve cinsiyetin rolü görülmüs olacaktır. Ayrıca çalışmanin bir diğer amacı, araştırma sonucunda ulaşılan sonuçlara göre üniversite ögrencilerinin toplumsal cinsiyet ve flört şiddetini daha iyi tanımaları için üniversite bünyesinde kurulmuş olan ve her türlü tacize ve mobbinge karşı eğitimler düzenleyen Birim bünyesinde eğitim ve atölyeler düzenlemektir. Çalışmanın, diğer fakültelere de özellikle flört şiddeti araş̧trması için bir örnek teşkil etmesi düşünülmekte ve ileride onları da kapsayacak araştırmaların yapılması arzu edilmektedir.

Anahtar Kelimeler: Flört Şiddeti, Toplumsal Cinsiyet, Hukuk Sosyolojisi. 


\section{Giriş}

Bir süredir toplumsal cinsiyet çalışmaları akademik ilgi alanımda iken buna iki senedir bir idari görev de eklenince bir anlamda uygulamanın da içinde kendimi bulmuş oldum: Üniversitemizde iki sene önce Her Türlü Tacize ve Mobbinge Karşı Destek Birimi kuruldu ve ben de bu birimde başka sıfatı ile iki değerli hukukçu meslektaşım ve Personel Daire Başkanımızla birlikte çalışmaktayım. Birimimize yapılan başvuruları bir iş hukukçusu ve bir de ceza hukukçusu ile birlikte değerlendirmekteyiz.

Birime yapılan başvurularda 1srarlı takip, flört ilişkisi içerisinde tehdit, özel verilerin ifşası gibi şikayetler, mail adresinin hacklenmesiyle özel verilere ulaşma söz konusu olunca ve öğrencilerin flört şiddeti konusundaki hassasiyetlerini ve varsa deneyimlerini ölçmenin yerinde olacağı düşüncesiyle bu araştırma ortaya çıkmıştır.

Araştırma birinci sınıftan son sınıfa kadar hukuk fakültesi öğrencileri arasında, daha yüksek sayıda öğrenciye ulaşmak için final sınavı öncesinde yapılmıştır. Öğrencilere araştırmanın kapsamı ve amacı hakkında bilgi verilmiştir. Hukuk fakültesi öğrencileri arasında yapılmasının nedeni, pratik bir nedene dayanmaktadır: Galatasaray Üniversitesi Hukuk Fakültesi öğrenci sayısı az olan bir hukuk fakültesidir ve hoca öğrenci ilişkisi doğrudan sağlanabilmekte, öğrencilere kolayca ulaşma araştırmayı kolaylaştırmaktadır. ${ }^{1}$ Daha sonra zamanla bu alan araştırmasının tüm üniversite bünyesinde yapılması düşünülmektedir, bu anlamda bu bir pilot çalışmadır. Elde edilen veriler sonucunda da öğrencilere toplumsal cinsiyet eşitliği, flört şiddeti gibi konularda eğitimler düzenlenmesi planlanmaktadır. Bu eğitimler sonrasında araştırmanın tekrarlanması eğitimlerin ne denli etkili olduğu sonucuna varmamızı da kolaylaştıracaktır.

*Bu çalışma, 19.200.002 no’lu projenin Galatasaray Üniversitesi Bilimsel Araştırma Fonu tarafindan destelenmesiyle ortaya çıkmıştır. Yazar bu desteğinden ötürü Galatasaray Üniversitesi'ne minnettardır. ${ }^{1}$ Araştırma süresince benden desteğini esirgemeyen değerli araştırma görevlisi arkadaşlarım Göktürk Öcal ve Dolunay Çörek'e teşekkür ediyorum. 


\section{Flört Şiddeti}

Flört, Türkçe bir sözcük değildir, İngilizceden birçok dile geçmiştir ve kelime anlamına bakıldığında Türk Dil Kurumu’nun açıklamasında flörtün 'Karşı cinsen biriyle duygusal ilişki kurmak, çıkmak”, “Kadınla erkek arasındaki duygusal ilişki”, "Birbirine duygusal ilgi duyan kadın ve erkek" , "Siyasal bir parti, yabancı bir ülke vb.ne tam olarak bağlanmadan yaklaşma" olarak açıklandığı görülmektedir. Flörtü kadınla erkek arasındaki duygusal ilişki olarak sınırlamak devlet politikaları doğrultusunda bir olgu olsa da, pratikte lgbti bireylerini de kapsamaktadır. ${ }^{1}$ Dolayısıyla flört içinde cinsel yönelimi de barındıran bir duygusal ilişki olarak tanımlamak doğru olacaktır, çünkü TDK'nın belirttiği “kadınla erkek arasındaki duygusal ilişkiler" flörtten ibaret değildir, bu bir arkadaşlık, dostluk, kardeşlik ilişkisi de olabilir. Bu nedenle sözlü ve yazılı iletişimin yanı sıra beden dili ile bir kişinin diğerine karşı derin bir ilgiyi göstermek amacıyla yaptığı ve çok ciddi bir niyeti de içermeyen davranışları kapsamaktadır.

\section{Flört Şiddetinin Tanımı}

Toplumsal bir sorun olan şiddet "birey ya da bireylerin yaşam, özgürlük, irade, istek, hak, sağlık ve iyi hallerini tehdit eden ya da gelişmesini engelleyen fiziksel, psikolojik, sosyal, cinsel, ekonomik, siber ya da işaretler yardımı ile uygulanan aşağılama, yaralama, zarar verme, mahrum bırakma, yalnızlaştırma gibi kötü niyetli ve kasıtlı davranışların tümü” şeklinde tanımlanmaktadır ${ }^{2}$ (Özdere, 2017). Aslına bakılırsa bu davranışlar başka ilişkilerde de görülebilmektedir. Flört şiddetinin ayrıca kavramsallaştırılmasının nedeni, tarafların bu ilişkide

\footnotetext{
${ }^{1}$ Çörek, Dolunay; “Toplumsal Cinsiyet ve Flört Şiddeti”, Toplumsal Cinsiyet ve Hukuk, Ed.: Zeynep Özlem Üskül Engin, C.:I, Oniki Levha Yayınc1lık, İstanbul, 2019, s. 159-160.

2 Özdere, M. (2017). Öğretmenlere yönelik okul şiddeti. İstanbul: Cinius Yayınları.
} 
çocukluktan bu yana edindikleri toplumsal cinsiyet normlarını pratiğe dökmeleri, erkek şiddetin öznesi, kadın ise nesnesi olmayı belki de ilk defa duygusal bir ilişkide deneyimlemektedirler. ${ }^{1}$ "Flört” ve "şiddet" birlikte anılmaması gereken kavramlar olmasına karşın toplumsal cinsiyet konusunda gerçek bir eşitliğin sağlanmadığı, "hayır”ın bir red cevabı değil de bir nazlanma belirtisi ya da kabul edilemez bir cevap olarak algılandığı her halde sevgi ve ilgi ilişkisi olması beklenen flört, şiddetle birlikte anılabilmektedir. Aslına bakılırsa ülkemizde özellikle kadına karşı yönelen şiddet ciddi bir sorundur ve son y1llarda çok ciddi bir tırmanışa geçmiştir. Eril zihniyetin desteklenmesi, kadının bir birey olarak değil de aile ile birlikte ele alınması, mahkemelerde şiddet gösteren sırf erkeklerin takım elbise giymeleri ve saygılı tutumları nedeniyle sürekli cezalarında indirim almaları bu tırmanışı destekler görünmektedir. Oysa ki bu saygılı tutumun ilişki içerisinde tarafların birbirine göstermesi daha doğru olacaktır. Ancak toplumda artan şiddet vakalarının ergenlik dönemindeki ve ergenlik sonrası dönemde sıklıkla görülen flört ilişkilerine de etkisi olmaktadır. Flört ilişkisi içinde diğerini kontrol etme veya ona hükmetme amacıyla yapılan ve duygusal, fiziksel zararla sonuçlanan her türlü şiddet ergenlik döneminde ve sonrasında rastlanan önemli bir sorundur. ${ }^{2}$ Şiddete uğrayanların depresif davranışlar gösterdikleri, özellikle fiziksel ve cinsel şiddete maruz kalanların intihar düşüncesi ve girişiminin arttığı bilinmektedir. ${ }^{3}$ Bu nedenle, ilişkinin bir şiddet ilişkisine dönüşmemesi için gençlere toplumsal cinsiyet eşitliği konusunda eğitim verilmesi ve ciddi bir bilinçlendirme çalışmasının yapılması gerekmektedir. Bugüne kadar çok fazla üzerinde durulmayan bu konunun bir toplum sağlığı konusu çerçevesinde ele alınması yerinde olacaktır.

\footnotetext{
${ }^{1}$ Çörek, a.g.m., s. 165.

2 Üçcok Demir, Nagehan/ Irmak, Mustafa Yasin/ Murat, Duygu/ Perdahlı Fiş, Neşe; "Cinsel İstismara Uğrayan Ergen Adli Olgularda Flört İlişkisinde Şiddet Varlığı”, Anatolian Journal of Psychiatry 2016; 17(3): 245.(240247).

${ }^{3}$ Demir/ Irmak/ Murat/ Perdahlı Fiş, a.g.m., s. 245.
} 


\section{Flört Şiddetinin Nedenleri}

Flört ilişkisi tarafların birbirine ilgi duymalarının akabinde ilişki sırasında ortaya çıkan şiddeti hemen fark edebilmek çok kolay olmamaktadır. Tarafların birbirlerini çok tanımamaları ve bir tanıma sürecinde olmaları nedeniyle şiddetin özellikle psikolojik unsurlarının kullanılması halinde bu davranışa sevgi göstergesi denilmesi ya da anlamlandırılamaması söz konusu olabilmektedir. Taraflardan biri diğerinin ne giydiğine, kiminle görüştüğüne, nerede ve ne zaman bir mekanda olacağına karışması, durumunda, buna maruz kalan bireysel alanına karışılmasına set çekmezse, ilerleyen zamanda partnerinin daha fazla güç ve kontrol sağlamak için üzerindeki baskısını artıracağını ve psikolojik şiddetin, cinsel ve fiziksel şiddete dönüşebileceğini söylemek mümkündür.

$\mathrm{Bu}$ şiddetin nedeni ise, erkek ve kadın arasındaki cinsiyet rollerinin eşit bir biçimde toplumsal görünüme kavuşamamasıdır. Genellikle şiddet erkekten kadına yönelmektedir. Kadının şiddete başvurduğu anlar çoğunlukla ölmemek için öldürdüğü yani kendini savunduğu anlardır. Erkek baskın cins olduğuna inanmakta, kadının namusu erkeğin namusu sayılmakta, bu nedenle de kadının kontrol altında tutulması gereği üzerinde durulmaktadır. Eril zihniyetin devamını sağlayan kurumlar, bu inancın sürüp gitmesine destek olmaktadır.

Ailede şiddetin varlığı, çocuklukta kötü muameleye, şiddete uğramak, okul ve toplumda şiddete maruz kalmak gibi durumların, ilerde bireyin saldırgan ya da kurban olmasına neden olabileceği, Çocuklukta yaşanan kötü muamelenin, şiddete uğramanın ve yaşanan travmaların ilerde saldırgan davranışlara başvurma riskini arttırdığı düşünülmektedir. Çocuklukta şiddete uğramak, ihmal edilmek, kötü ebeveyn uygulamaları, sıkı disiplin gibi durumlar, ilerde bu kişilerin flört ilişkilerinde şiddete uğrama ya da başvurma olasılıklarını yükseltmektedir. Benzer şekilde aile içinde şiddetin varlığı, şiddete şahit olma, okul ve toplumda şiddete uğrama, flörtte şiddete uğrama veya başvurma ihtimalini etkileyen unsurlardandır. 


\section{Flört ŞiddetininTürleri}

Flört şiddeti, bitmiş ya da sürmekte olan heteroseksüel ya da homoseksüel ilişkilerde ortaya çıkabilmektedir. ${ }^{1}$ Flört şiddeti bir flört ilişkisinde fiziksel, cinsel, sözel taciz, tehdidi veya gizli gizli takip etmeyi tanımlamak için kullanılan bir terimdir ve ilişkinin başlangıcından birlikte yaşamaya kadar geçen süre içinde meydana gelen her türlü şiddet olayını bu kapsamda değerlendirilir: partnere fiziksel olarak acı vermek, çirkinleştirmek (saç kesmek, burun kesmek, yüze kezzap atmak vs.), yaralamak, öldürmek niyetiyle bilinçli olarak gerçekleştirilen, fiziksel güç kullanmak fiziksel şiddet görünümleridir. Bundan başka, silahla vurma, yumruklama, tokatlama, 1sırma, saç çekme, tekmeleme, dürtme, yakma, itme, çekme, boğma, bir şeyler atma, mala zarar verme gibi davranışlar şeklinde gözlemlenmektedir.

Şiddete başvurma ya da fiziki güç kullanma ile tehdit etme, sözel, dijital, yazılı taciz, kötü muamele gibi davranışlar ise psikolojik tacize girmektedir. Korku uyandıracak, kişinin kendisine olan güvenini ve saygısını zedeleyecek davranışlarda bulunma psikolojik şiddet olarak değerlendirilmektedir. Kişinin başkasının önünde küçük dürülmesi, karalanması, alay edilmesi, suçlanması, yıkıcı bir biçimde eleştirilmesi, sırlarının açıklanması buna örnek verilebilir.

Sosyal flört şiddeti ise, partnerin diğeri üzerinde sosyal ilişkilerini kısıtlayacak tarzda davranmasıdır. Taraflardan birinin sosyal ilişkilerinin kontrol altına alınması, sosyal çevresinden soyutlanmaya yol açacak şekilde görüşmelerine izin verilmemesi, başkalarına zaman ayrıldığında suçlamaya maruz kalması, sürekli başkalarıyla flört edip etmediğinin araştırılması, toplum önünde rezil etmekle tehdit etmesi sosyal şiddete örnek gösterilebilir.

Cinsel şiddet ise, partnerin cinsel birliktelik ya da yakınlık için zorlaması, cinsellik konusunda "hayır"1 kabul etmemesidir. Tecavüz girişimi, cinsel içerikli dedikodular yayma, röntgenleme,

\footnotetext{
${ }^{1}$ Bkz. morcati.org.tr (12. 8.2019).
} 
bunun yanında doğum kontrol yöntemlerini kabul etmemesi, cinsel birliktelik öncesi ya da sonrası küçümseyici ve kaba bir tutum izlemesi de cinsel şiddetin alanına girmektedir. Cinsel şiddetin en ağır hali tecavüzdür.

Dijital flört şiddeti son yıllarda ortaya çıkmış, teknolojinin kullanımıyla devreye girmiş bir şiddet türüdür. Partnerlerden biri tarafından teknolojik araçların diğerini kontrol etmek amacıyla kullanılması, bu araçlarla diğerini tehdit etmesi, sosyal medya hesaplarının şifrelerinin ele geçirilmesi ve bu hesapların kontrol edilmesi, resim ya da video göndermek için zorlaması, bu araçları izinsiz olarak karıştırması dijital şiddet olarak değerlendirilmektedir.

Israrlı takip, bitmiş ya da süren bir ilişkide partnerlerden birinin sürekli diğerini takip etmesidir. Takip davranışı diğerinde korku uyandırmakta, gözdağı vermekte ve kendini güvencesiz hissettirmektedir. Habersiz ziyaretler, beklenmedik karşılaşmaların sıklığı, davet edilmeden işyerine ya da okula gelinmesi, bitmiş bir ilişkide sürekli çiçek ya da hediye gönderilmesi, sürekli arkadaş ya da aile çevresinden haber alınmaya çalışılması ısrarlı takibin kapsamına girmektedir. Kişiyi tedirgin ve güvensiz hissettiren bu davranışlar da şiddetin bir görünümü olarak karşımıza çıkmaktadır. ${ }^{1}$

Ekonomik olarak taraflardan birinin diğerini sömürmesi, sürekli hesapları ödetmesi, kendisine hediye almak için zorlaması gibi durumlar ise ekonomik şiddete girmektedir.

Flört şiddeti üzerinde yapılan çalışmalarda, sorunun yaygın bir sorun olduğunu ortaya koymaktadır. Bu durumun fakültemizdeki görünümü ise aşağıda yapılan çalışmanın sonuçlarında aktarılacaktır.

\footnotetext{
${ }^{1}$ Bkz. morçati.org.tr (12.8.19)
} 


\section{Galatasaray Hukuk Fakültesi Öğrencilerinin Flört Şiddeti Karşısındaki Tutumu}

Türkiye'de flört şiddeti ile ilgili çalışmalar yenidir ve sayıda da çok olmadıkları gözlemlenmektedir. ${ }^{1}$ Ancak bu çalışmaların son yıllarda üniversitelerde açılan tacize karşı destek birimleri ya da komisyonları tarafından yapılarak yaygınlaştıracağı umut edilmektedir. $\mathrm{Bu}$ araştırma, Galatasaray Üniversitesi Hukuk Fakültesi öğrencileri arasında yapılmıştır. Araştırma birinci sınıftan dördüncü sınıfa kadar tüm sınıfları kapsayacak bir şekilde yapılmış, öğrencilere birer anket formu dağıtılarak, bu formun yanıtlanması istenmiştir.

Öğrencilerin yaşları 19 ile 36 arasındadır:

19 yaşında 22 öğrenci, 20 yaşında 32 öğrenci, 21 yaşında 35 öğrenci, 22 yaşında 46 öğrenci, 23 yaşında 24 öğrenci, 24 yaşında 4 öğrenci, 25 yaşında 2 öğrenci, 26 yaşında 1, 36 yaşında 1 öğrenci çalışmayı yanıtlamıştır. Toplamda 167 öğrenci katılmıştır.

Öğrencilere flört deneyimleri olup olmadığı sorulmuş ve flört deneyimi olanların flört ilişkisi içinde ya da ilişki sonrasında şiddete, tacize uğrayıp uğramadıkları anlaşılmaya çalışılmıştır. Ayrıca bu öğrencilerin hukuk öğrencileri olduğu da dikkate alınarak neyi şiddet görüp görmediklerini bu araştırma vasıtasıyla çıkarmak, eksik kalan varsa konuların tekrarı açısından da verimli olacaktır. Bunun dışında Üniversite bünyesinde yeni kurulmuş olan ve öğrenciler arasındaki taciz konularıyla da ilgilenen birimden haberdar olup olmadıkları da ortaya çıkarılacaktır. Bu şekilde tacize karşı destek vermeyi amaçlayan bu birimin öğrencilere daha yararlı bir tutum içinde olması hedeflenmektedir.

\footnotetext{
1 Yumuşak, Ahmet/ Şahin, Rukiye; "Flörtte Şiddete Yönelik Tutum Ölçeklerinin Güvenilirlik ve Geçerlik Çalışması" Elektronik ve Sosyal Bilimler Dergisi, C.:13, S.: 49, Bahar 2014, ss. 233-252. www.esosder.org (30. 9.19)
} 
Yapılan alan araştırmasına göre;

\section{Sinıfta}

25 kadın öğrencinin ve 14 erkek öğrencinin flört deneyimi olmuştur.

Bu sınıftan 5 kadın öğrenci sözlü tacize uğradığını belirtmiştir. Bunlardan 4ü yazılı, 5i sosyal medya aracılığıyla da tacize uğramıştır. Biri fiziksel tacize maruz kalmıştır. 1Biri psikolojik tacize maruz kalmıştır. İkisi ekonomik şiddete uğradığını belirtmiştir.

Flört deneyimi olan 24 kadın öğrenci tokat atmanın kesinlikle şiddet olduğu görüşündedir.1 kişi de biraz şiddet olduğunu düşünmektedir. 12 kadın öğrenci partnerini (sosyal anlamda) kontrol etmenin şiddet olduğu, 13ü olmadığ1 görüşündedir.

25 kadın öğrenci cinsellikle ısrarcı olmanın şiddet olduğunu düşünmektedir. Olumsuz cevap veren yoktur. Cinsellikte zor kullanmayı 25 kadın öğrenci şiddet olarak değerlendirmiştir. Aksi fikirde olan yoktur.25 kadın öğrenci bağırmayı şiddet olarak kabul etmiştir. 1 kadın öğrenci aksi fikirdedir. 25 kadın öğrenci flört ilişkisinde birinin diğerini herkesin içinde aşağılamasını şiddet olarak kabul etmiștir, aksi fikirde olan yoktur. 23 kadın öğrenci flört ilişkisinde birinin diğerine herkesin içinde sürekli kırıcı şakalar yapıyorsa bunu şiddet olarak kabul etmiştir, 2si aksi fikirdedir.

15 kadın öğrenci flört ilişkisinde birinin diğerine kendisiyle vakit geçirmesi için baskı yapıyorsa bunu şiddet olarak kabul etmiştir, 10u aksi fikirdedir. 25 kadın öğrenci flört ilişkisinde birinin diğerini fiziksel olarak zarar vermekle tehdit ediyorsa bunu şiddet olarak kabul etmiştir, aksi fikirde olan yoktur.

Öğrencilere bir flört ilişkisinde şiddet görmeleri halinde ilişkiyi kolaylıkla mı, biraz zorlanarak mı, bitireceklerini ya da bitirmekte çok zorlanıp zorlanmayacakları sorulmuştur. 20 kadın öğrenci şiddet görmeleri halinde ilişkilerini kolaylıkla bitirebileceklerini, 5i ise biraz zorlanacağını belirtmiştir. 6 kadın öğrenci flört ilişkisi bittikten sonra sözlü tacize uğradığını belirtmiştir, 19u uğramamıştır. 5 kadın öğrenci flört ilişkisi bittikten sonra yazılı tacize 
uğradığını belirtmiştir, 20si uğramamıştır. 6 kadın öğrenci flört ilişkisi bittikten sonra sosyal medya aracılığıyla tacize uğradığını belirtmiştir, 19u uğramamıştır. Hiçbir kadın öğrenci flört ilişkisi bittikten sonra fiziksel tacize uğramadığını belirtmiştir. 8 kadın öğrenci flört ilişkisi bittikten sonra psikolojik tacize uğradığını belirtmiştir, 17si uğramamıştır. Flört ilişkisi bittikten sonra ekonomik şiddete uğrayan kadın öğrenci yoktur.

Bir kişi tacize uğradığında şikayet etmiyorsa bu durumdan rahatsızlık duymadığından mı şikayet etmediği sorulmuştur ve 25 kadın öğrencinin hepsi aslında rahatsızlık duyduklarını belirtmiştir. Flört tacizine uğradığı takdirde nereye başvuracağını bilen kadın öğrenci sayısı 14tür, bilmeyen ise 11dir.

Flört tacizine uğradığı takdirde GSÜ'de nereye başvuracağını bilen kadın öğrenci sayısı sekizdir. Bilmeyen sayısı ise 10dur.

Birinci sınıfta sözlü, fiziksel ya da sosyal medya aracılığıyla, psikolojik tacize ya da ekonomik şiddete uğrayan erkek öğrenci yoktur.

Flört deneyimi olan 18 erkek öğrenci tokat atmanın kesinlikle şiddet olduğu, 5 öğrenci ise kiminle, nerede, ya da ne yaptığını kontrol etmenin ise şiddet olduğu görüşündedir. 13’ü ise kontrol etmenin şiddet olmadığını düşünmektedir. 15 erkek öğrenci cinsellikle 1srarcı olmanın şiddet olduğunu düşünmektedir. 2 öğrenci bu soruya olumsuz yanıt vermiştir. Cinsellikte zor kullanmayı 18 erkek öğrenci şiddet olarak değerlendirmiştir. Aksi fikirde olan yoktur. 16 erkek öğrenci bağırmayı şiddet olarak kabul etmiştir. 1 erkek öğrenci aksi fikirdedir. 17 erkek öğrenci flört ilişkisinde birinin diğerini herkesin içinde aşağılamasını şiddet olarak kabul etmiştir, biri aksi fikirdedir. 13 erkek öğrenci flört ilişkisinde birinin diğerine herkesin içinde sürekli kırıcı şakalar yapıyorsa bunu şiddet olarak kabul etmiştir, 5i aksi fikirdedir. 6 erkek öğrenci flört ilişkisinde birinin diğerine kendisiyle vakit geçirmesi için baskı yapıyorsa bunu şiddet olarak kabul etmiştir, 12si aksi fikirdedir. 17 erkek öğrenci flört ilişkisinde birinin diğerini fiziksel olarak zarar vermekle tehdit ediyorsa bunu şiddet olarak kabul etmiştir, li aksi fikirdedir. 
12 erkek öğrenci şiddet görmeleri halinde ilişkilerini kolaylıkla bitirebileceklerini, 6sı ise biraz zorlanacağını belirtmiştir. 2 erkek öğrenci flört ilişki bittikten sonra sözlü tacize uğradığını belirtmiştir, 16sı uğramamıştır. 2 erkek öğrenci flört ilişkisi bittikten sonra yazılı tacize uğradığını belirtmiştir, 16sı uğramamıştır. 14 erkek öğrenci flört ilişkisi bittikten sonra sosyal medya aracılığıyla tacize uğradığını belirtmiştir, 4ü uğramamıştır.

Hiçbir erkek öğrenci flört ilişkisi bittikten sonra fiziksel tacize uğramadığını belirtmiştir. 3 erkek öğrenci flört ilişkisi bittikten sonra psikolojik tacize uğradığını belirtmiştir, 14ü uğramamıştır. Ekonomik şiddete uğrayan erkek öğrenci yoktur.

Bir kişi tacize uğradığında şikayet etmiyorsa bu durumdan şikayet edip etmediği sorulmuştur ve 12 erkek öğrenci rahatsızlık olduğunu belirtmiştir, 1 erkek öğrenci rahatsızlık olmadığı düşüncesindedir. Flört tacizine uğradığı takdirde nereye başvuracağını bilen erkek öğrenci 7dir, bilmeyen ise 10dur. Flört tacizine uğradığg takdirde GSÜ’de nereye başvuracağını bilen erkek öğrenci sayısı 8dir. Bilmeyen sayısı ise 9dur. Bilgisayar ya da telefonun hacklenmesi yoluyla yapılan taciz bu sınıfta vuku bulmamıştır.

\section{Sinıfta}

15 kadın öğrenciden 1 kadın öğrenci tacize uğradığını belirtmiş, 4ü yazılı, 4ü sosyal medya aracılığıyla, 2'si bilgisayar ya da telefonun hacklenmesi yoluyla yapılan, $1 \mathrm{i}$ ise fiziksel tacize uğramıştır. 8 kadın öğrenci psikolojik tacize maruz kalmıştır. Tacize uğrayan bir kişi fiziksel tacize de uğramıştır.1 öğrenci ekonomik şiddete uğradığını belirtmiştir.

Flört deneyimi olan 15 kadın öğrenci tokat atmanın kesinlikle şiddet olduğu görüşündedir. 12 öğrenci kiminle, nerede, ya da ne yaptığını kontrol etmenin ise şiddet olduğu görüşündedir. 5'i ise kontrol etmenin şiddet olmadığını düşünmektedir. 17 kadın öğrenci cinsellikle ısrarcı olmanın şiddet olduğunu düşünmektedir. Olumsuz cevap veren yoktur. Cinsellikte zor kullanmayı 15 kadın öğrenci şiddet olarak değerlendirmiştir. 16 kadın öğrenci 
bağırmayı şiddet olarak kabul etmiştir. 1 kadın öğrenci aksi fikirdedir. 17 kadın öğrenci flört ilişkisinde birinin diğerini herkesin içinde aşağılamasını şiddet olarak kabul etmiştir, aksi fikirde olan yoktur. 15 kadın öğrenci flört ilişkisinde birinin diğerine herkesin içinde sürekli kırıcı şakalar yapıyorsa bunu şiddet olarak kabul etmiştir, 2si aksi fikirdedir. 8 kadın öğrenci flört ilişkisinde birinin diğerine kendisiyle vakit geçirmesi için baskı yapıyorsa bunu şiddet olarak kabul etmiştir, 9u aksi fikirdedir. 17 kadın öğrenci flört ilişkisinde birinin diğerini fiziksel olarak zarar vermekle tehdit ediyorsa bunu şiddet olarak kabul etmiştir, aksi fikirde olan yoktur. 11 kadın öğrenci şiddet görmeleri halinde ilişkilerini kolaylıkla bitirebileceklerini, 6sı ise biraz zorlanacağını belirtmiştir.

2 kadın öğrenci flört ilişki bittikten sonra sözlü tacize uğradığını belirtmiştir, 15i uğramamıştır. 2 kadın öğrenci flört ilişkisi bittikten sonra yazılı tacize uğradığını belirtmiştir, 15i uğramamıştır. 4 kadın öğrenci flört ilişkisi bittikten sonra sosyal medya aracılığıyla tacize uğradığını belirtmiştir, 13ü uğramamıştır.

Hiçbir kadın öğrenci flört ilişkisi bittikten sonra fiziksel tacize uğramamıştır. 3 kadın öğrenci flört ilişkisi bittikten sonra psikolojik tacize uğradığını belirtmiştir, 14ü uğramamıştır. Ekonomik şiddete uğrayan kadın öğrenci yoktur.

Bir kişi tacize uğradığında şikayet etmiyorsa bu durumdan şikayet edip etmediği sorulmuş ve 15 kadın öğrenci rahatsızlık olduğunu belirtmiştir, 2 kadın öğrenci rahatsızlık olmadığı düşüncesindedir. Flört tacizine uğradığı takdirde nereye başvuracağını bilen kadın öğrenci 7dir, bilmeyen ise 10dur. Flört tacizine uğradığı takdirde GSÜ'de nereye başvuracağını bilen kadın öğrenci sayısı 8dir. Bilmeyen sayısı ise 9dur.

2. Sınıfta 14 erkek öğrencinin flört deneyimi olmuştur, erkek öğrencilerden tacize uğradığını belirten yoktur. Bunun yanında yazılı tacize uğrayan da bulunmamaktadır. Ancak 1 erkek öğrenci sosyal medya aracılığıyla da tacize uğradığını belirtmiştir. Erkek öğrencilerden 
bilgisayar ya da telefonun hacklenmesi yoluyla taciz vuku bulmamıştır. 1i fiziksel tacize uğramıştır. 3'ü psikolojik tacize maruz kalmıştır.2si ekonomik şiddete uğradığını belirtmiştir.

10’u tokat atmanın kesinlikle şiddet olduğu görüşündedir, 2 kişi de biraz şiddet olduğunu düşünmektedir, 2 kişi de ne şiddettir ne de değildir demiştir. 3 öğrenci ise partnerinin kiminle, nerede, ya da ne yaptığını kontrol etmenin ise şiddet olduğu görüşündedir. 11'i ise kontrol etmenin şiddet olmadığını düşünmektedir. 14 erkek öğrenci cinsellikle ısrarcı olmanın şiddet olduğunu düşünmektedir, 3ü olmadığı düşüncesindedir. Cinsellikte zor kullanmayı 14 erkek öğrenci şiddet olarak değerlendirmiştir, aksi görüşte olan yoktur. 16 erkek öğrenci bağırmayı şiddet olarak kabul etmiştir. 1 erkek öğrenci aksi fikirdedir. 15 erkek öğrenci flört ilişkisinde birinin diğerini herkesin içinde aşağılamasını şiddet olarak kabul etmiş̧tir, 2 erkek öğrenci aksi fikirdedir. 10 erkek öğrenci flört ilişkisinde birinin diğerine herkesin içinde sürekli kırıcı şakalar yapıyorsa bunu şiddet olarak kabul etmiştir, 7si aksi fikirdedir. 4 erkek öğrenci flört ilişkisinde birinin diğerine kendisiyle vakit geçirmesi için baskı yapıyorsa bunu şiddet olarak kabul etmiştir, 13ü aksi fikirdedir. 17 erkek öğrenci flört ilişkisinde birinin diğerini fiziksel olarak zarar vermekle tehdit ediyorsa bunu şiddet olarak kabul etmiştir, aksi fikirde olan yoktur.

15 erkek öğrenci şiddet görmeleri halinde ilişkilerini kolaylıkla bitirebileceklerini, 2si ise biraz zorlanacağını belirtmiştir. 15 erkek öğrenci flört ilişki bittikten sonra sözlü tacize uğradığını belirtmiştir, 2si uğramamıştır. 2 erkek öğrenci flört ilişkisi bittikten sonra yazılı tacize uğradığını belirtmiştir, 14ü uğramamıştır. 4 erkek öğrenci flört ilişkisi bittikten sonra sosyal medya aracılığıyla tacize uğradığını belirtmiştir, 12si uğramamıştır. Hiçbir erkek öğrenci flört ilişkisi bittikten sonra fiziksel tacize uğramamıştır. 4 erkek öğrenci flört ilişkisi bittikten sonra psikolojik tacize uğradığını belirtmiştir, 12si uğramamıştır. Ekonomik şiddete uğrayan erkek öğrenci yoktur. 
Bir kişi tacize uğradığında şikayet etmiyorsa bu durumdan şikayet edip etmediği sorulduğunda tüm erkek öğrenciler rahatsızlık olduğunu belirtmiştir. Şikayet edilmemesi, rahatsızlık duyulmadığı anlamına gelmemektedir.

Flört tacizine uğradığı takdirde nereye başvuracağını bilen erkek öğrenci 6dır, bilmeyenlerin sayısı ise 11dir. Flört tacizine uğradığı takdirde GSÜ'de nereye başvuracağını bilen erkek öğrenci sayısı 9dur. Bilmeyen sayısı ise 8dir. Tacize uğramadım diyen erkek öğrencilerin sorular detaylandırılınca tacize uğradıklarını görmek ilginç bir sonuç olmuştur.

\section{Sinıfta}

Flört eden kadın öğrenci 19dur, bu sınıfta kadın öğrencilerin hepsi flört ilişkisini deneyimlemişlerdir.

Kadın öğrencilerden 3ü tacize uğradığını belirtmiştir, 1i yazılı tacize, 3’ü sosyal medya aracılığıyla, 2si fiziksel tacize uğramıştır. 3'ü psikolojik tacize maruz kalmıştır. Hiçbir kadın öğrenci ekonomik şiddete uğramamıştır.

16 kadın öğrenci tokat atmanın kesinlikle şiddet olduğunu düşünmektedir. Biri biraz şiddettir, 2si kesinlikle şiddet değildir demektedir. 4 öğrenci ise kiminle, nerede, ya da ne yaptığını kontrol etmenin ise şiddet olduğu görüşündedir, 11'i ise kontrol etmenin şiddet olmadığını düşünmektedir. 19 kadın öğrenci cinsellikle 1srarc1 olmanın şiddet olduğunu düşünmektedir, 1 kadın öğrenci aksi görüştedir. Cinsellikte zor kullanmayı 20 kadın öğrenci şiddet olarak değerlendirmiştir, aksi görüşte olan yoktur. 19 kadın öğrenci bağırmayı şiddet olarak kabul etmiştir. 1 kadın öğrenci aksi fikirdedir. 20 kadın öğrenci flört ilişkisinde birinin diğerini herkesin içinde aşağılamasını şiddet olarak kabul etmiştir, aksi fikirde olan yoktur. 16 kadın öğrenci flört ilişkisinde birinin diğerine herkesin içinde sürekli kırıcı şakalar yapıyorsa bunu şiddet olarak kabul etmiştir, 4ü aksi fikirdedir. 9 kadın öğrenci flört ilişkisinde birinin diğerine kendisiyle vakit geçirmesi için baskı yapıyorsa bunu şiddet olarak kabul etmiştir, 11 i 
aksi fikirdedir. 20 kadın öğrenci flört ilişkisinde birinin diğerini fiziksel olarak zarar vermekle tehdit ediyorsa bunu şiddet olarak kabul etmiştir, aksi fikirde olan yoktur.

15 kadın öğrenci şiddet görmeleri halinde ilişkilerini kolaylıkla bitirebileceklerini, 5i ise biraz zorlanacağını belirtmiştir. 17 kadın öğrenci flört ilişki bittikten sonra sözlü tacize uğradığını belirtmiştir, 1i uğramamıştır. 1 kadın öğrenci yazılı tacize uğradığını belirtmiştir, 18i uğramamıştır. 3 kadın öğrenci flört ilişkisi bittikten sonra sosyal medya aracılığıyla tacize uğradığını belirtmiştir, 16sı uğramamıştır. Hiçbir kadın öğrenci flört ilişkisi bittikten sonra fiziksel tacize uğramamıştır. 4 kadın öğrenci flört ilişkisi bittikten sonra psikolojik tacize uğradığını belirtmiştir, 15i uğramamıştır. Ekonomik şiddete uğrayan kadın öğrenci yoktur.

Bir kişi tacize uğradığında şikayet etmiyorsa bu durumdan şikayet edip etmediği sorulduğunda, şikayet edilmemesine karşın 20 kadın öğrenci rahatsızlık olduğunu belirtmiştir.

Flört tacizine uğradığı takdirde nereye başvuracağını bilen kadın öğrenci 17dir, bilmeyen ise 3tür. Flört tacizine uğradığı takdirde GSÜ'de nereye başvuracağını bilen kadın öğrenci sayıs1 8dur. Bilmeyen sayısı ise 12dir.

3. Sınıfta flört eden erkek öğrenci sayısı 15, tacize uğradığını belirten ise 2 kişidir. Yazılı tacize uğrayan 2erkek öğrenci sosyal medya aracılığıyla da tacize uğramıştır. 2si fiziksel tacize uğramıştır. 3’ü psikolojik tacize maruz kalmıştır. 2si ekonomik şiddete uğradığını belirtmiştir. 16 erkek öğrenci tokat atmanın kesinlikle şiddet olduğunu düşünmektedir. 1 erkek öğrenci tokat atmayı biraz şiddet olarak nitelemiştir. 1i ise kesinlikle şiddet değildir demektedir.6 öğrenci kiminle, nerede, ya da ne yaptığını kontrol etmenin ise şiddet olduğu görüşündedir. 12'si ise kontrol etmenin şiddet olmadığını düşünmektedir. 14 erkek öğrenci cinsellikle 1srarcı olmanın şiddet olduğunu düşünmektedir, 4ü ise aksi fikirdedir. Cinsellikte zor kullanmayı 18 erkek öğrenci şiddet olarak değerlendirmiştir. Aksi görüşte olan yoktur. 16 erkek öğrenci bağırmayı şiddet olarak kabul etmiştir. 2 erkek öğrenci aksi fikirdedir. 14 erkek öğrenci flört ilişkisinde birinin diğerini herkesin içinde aşağılamasını şiddet olarak kabul etmiştir, 4’ü aksi fikirdedir. 
14 erkek öğrenci flört ilişkisinde birinin diğerine herkesin içinde sürekli kırıcı şakalar yapıyorsa bunu şiddet olarak kabul etmiştir, 4ü aksi fikirdedir. 6 öğrenci flört ilişkisinde birinin diğerine kendisiyle vakit geçirmesi için baskı yapıyorsa bunu şiddet olarak kabul etmiştir, 12si aksi fikirdedir. 16 erkek öğrenci flört ilişkisinde birinin diğerini fiziksel olarak zarar vermekle tehdit ediyorsa bunu şiddet olarak kabul etmiştir, 2si aksi fikirdedir.

15 erkek öğrenci şiddet görmeleri halinde ilişkilerini kolaylıkla bitirebileceklerini, $3 \ddot{u}$ ise biraz zorlanacağını belirtmiştir. 15 erkek öğrenci flört ilişki bittikten sonra sözlü tacize uğradığını belirtmiştir, 4ü uğramamıştır. 4 erkek yazılı tacize uğradığını belirtmiştir, 14ü uğramamıştır. 14 erkek öğrenci sosyal medya aracılığıyla tacize uğradığını belirtmiştir, 11 uğramamıştır. 1 erkek öğrenci fiziksel tacize uğradığını belirtmiştir, 15i uğramamıştır. 3 erkek öğrenci flört ilişkisi bittikten sonra psikolojik tacize uğradığını belirtmiştir, 14ü uğramamıştır. Ekonomik şiddete uğrayan erkek öğrenci yoktur. Flört tacizine uğradığı takdirde nereye başvuracağını bilen erkek öğrenci 10dur, bilmeyen ise 8dir. Flört tacizine uğradığı takdirde GSÜ’de nereye başvuracağını bilen kadın öğrenci sayısı 3tür. Bilmeyen sayısı ise 15tir. Bilgisayar ya da telefonun hacklenmesi yoluyla yapılan taciz bu sınıfta vuku bulmamıştır.

\section{Sinifta}

Flört eden kadın öğrenci sayısı 34, tacize uğradığını belirten ise 8dir. Yazılı tacize uğrayan sekiz kadın öğrenci bulunmaktadır. 9 kadın öğrenci sosyal medya aracılığıyla da tacize uğramıştır. Tacize uğramadım diye düşünen bir kişi sosyal medya ile ilgili soruyu görünce, aslında tacize uğradığını düşünerek işaretlemiştir. 4'ü bilgisayar ya da telefonun hacklenmesi yoluyla yapılan tacize uğramıştır. 6sı fiziksel, 10’u psikolojik tacize maruz kalmıştır. 3ü ekonomik şiddete uğradığını belirtmiştir.

33 kadın öğrenci tokat atmanın kesinlikle şiddet olduğunu düşünmektedir. 3ü biraz şiddettir demekte, 1i ne şiddettir ne de değildir demektedir. 19 öğrenci ise kiminle, nerede, ya 
da ne yaptığını kontrol etmenin ise şiddet olduğu görüşündedir. 18'i ise kontrol etmenin şiddet olmadığını düşünmektedir. 36 kadın öğrenci cinsellikle ısrarcı olmanın şiddet olduğunu düşünmektedir, li aksi fikirdedir. 36 kadın öğrenci bağırmayı şiddet olarak kabul etmiştir. 1 kadın öğrenci aksi fikirdedir. 34 kadın öğrenci flört ilişkisinde birinin diğerini herkesin içinde aşağılamasını şiddet olarak kabul etmiştir, 1i aksi fikirdedir. 27 kadın öğrenci flört ilişkisinde birinin diğerine herkesin içinde sürekli kırıcı şakalar yapıyorsa bunu şiddet olarak kabul etmiştir, 6sı aksi fikirdedir. 23 kadın öğrenci flört ilişkisinde birinin diğerine kendisiyle vakit geçirmesi için baskı yapıyorsa bunu şiddet olarak kabul etmiştir, 14ü aksi fikirdedir. 36 kadın öğrenci flört ilişkisinde birinin diğerini fiziksel olarak zarar vermekle tehdit ediyorsa bunu şiddet olarak kabul etmiştir, 1i aksi fikirde olan yoktur.

27 kadın öğrenci şiddet görmeleri halinde ilişkilerini kolaylıkla bitirebileceklerini, $10 \mathrm{u}$ ise biraz zorlanacağını belirtmiştir. 23 kadın öğrenci flört ilişki bittikten sonra sözlü tacize uğradığını belirtmiştir, 9 u uğramamıştır. 9 kadın öğrenci flört ilişkisi bittikten sonra yazılı tacize uğradığını belirtmiştir, 26sı uğramamıştır. 10 kadın öğrenci flört ilişkisi bittikten sonra sosyal medya aracılığıyla tacize uğradığını belirtmiştir, 25i uğramamıştır. 3 kadın öğrenci flört ilişkisi bittikten sonra fiziksel tacize uğradığını belirtmiştir, 32si uğramamıştır. 13 kadın öğrenci flört ilişkisi bittikten sonra psikolojik tacize uğradığını belirtmiştir, 22si uğramamıştır. 2 kadın öğrenci flört ilişkisi bittikten sonra ekonomik tacize uğradığını belirtmiştir, 32si uğramamıştır.

Bir kişi tacize uğradığında şikayet etmiyorsa bu durumdan şikayet edip etmediği sorulduğunda 35 kadın öğrenci rahatsızlık olduğunu belirtmiştir, 2 kadın öğrenci rahatsızlık olmadığı düşüncesindedir. Flört tacizine uğradığı takdirde nereye başvuracağını bilen kadın öğrenci 24tür, bilmeyen ise 13 tür. Flört tacizine uğradığı takdirde GSÜ'de nereye başvuracağını bilen kadın öğrenci sayısı 13dir. Bilmeyen sayısı ise 24tür.

4. Sınıfta flört eden erkek öğrenci sayısı 20, tacize uğradığını belirten 2, yazılı tacize uğrayan 2dir. 4'ü sosyal medya aracılığıyla da tacize uğramıştır. Burada da erkek öğrencilerden 
2si tacize uğramadığını düşünmekte ancak sosyal medya aracılığıyla taciz edildiğini ifade etmektedir. 2'si Bilgisayar ya da telefonun hacklenmesi yoluyla yapılan tacize maruz kalmıştır. Fiziksel tacize uğrayan erkek öğrenci yoktur. 5’i psikolojik tacize maruz kalmıştır. 5’i ekonomik şiddete uğradığgnı belirtmiştir.

17 erkek öğrenci tokat atmanın kesinlikle şiddet olduğunu düşünmektedir. 1i ne şiddettir ne de değildir, 3ü kesinlikle şiddet değildir, 2si biraz şiddettir demektedir. 6 öğrenci ise kiminle, nerede, ya da ne yaptığını kontrol etmenin ise şiddet olduğu görüşündedir. 17'si ise kontrol etmenin şiddet olmadığını düşünmektedir. 16 erkek öğrenci cinsellikle ısrarcı olmanın şiddet olduğunu düşünmektedir, 7si aksi fikirdedir. Cinsellikte zor kullanmayı 19 erkek öğrenci şiddet olarak değerlendirmiştir, 4ü aksi fikirdedir. 21 erkek öğrenci bağırmayı şiddet olarak kabul etmiştir. 2 erkek öğrenci aksi fikirdedir. 19 erkek öğrenci flört ilişkisinde birinin diğerini herkesin içinde aşağılamasını şiddet olarak kabul etmiştir, 4'ü aksi fikirdedir. 20 erkek öğrenci flört ilişkisinde birinin diğerine herkesin içinde sürekli kırıcı şakalar yapıyorsa bunu şiddet olarak kabul etmiştir, 3ü aksi fikirdedir. 10 erkek öğrenci flört ilişkisinde birinin diğerine kendisiyle vakit geçirmesi için baskı yapıyorsa bunu şiddet olarak kabul etmiştir, 13ü aksi fikirdedir. 21 erkek öğrenci flört ilişkisinde birinin diğerini fiziksel olarak zarar vermekle tehdit ediyorsa bunu şiddet olarak kabul etmiştir, 2si aksi fikirdedir.16 erkek öğrenci şiddet görmeleri halinde ilişkilerini kolaylıkla bitirebileceklerini, 7si ise biraz, 1i ise çok zorlanacağını belirtmiştir.19 erkek öğrenci flört ilişki bittikten sonra sözlü tacize uğradığını belirtmiştir, 3ü uğramamıştır. 3'ü yazılı tacize, 18'i sosyal medya aracılığıyla tacize uğradığını belirtmiştir. Hiçbir erkek öğrenci flört ilişkisi bittikten sonra fiziksel tacize uğramamıştır. Buna karşın 4 erkek öğrenci flört ilişkisi bittikten sonra psikolojik, 2 erkek öğrenci flört ilişkisi bittikten sonra ekonomik tacize uğradığını belirtmiştir.Bir kişi tacize uğradığında şikayet etmiyorsa bu durumdan şikayet edip etmediği sorulduğunda 30 erkek öğrenci rahatsızlık olduğunu belirtmiştir, 2 erkek öğrenci rahatsızlık olmadığı düşüncesindedir.Flört tacizine uğradığ1 
takdirde nereye başvuracağını bilen erkek öğrenci 13tür, bilmeyen ise 9dur.Flört tacizine uğradığı takdirde GSÜ’de nereye başvuracağını bilen erkek öğrenci sayısı 2dir. Bilmeyen sayısı ise 20dir.

\section{Sonuç}

Türkiye'deki en yüksek puanla hukuk fakültesine öğrenci kabul eden Galatasaray Üniversitesi Hukuk Fakültesi öğrencileri arasında yapılan flört tacizi araştırmasının sonuçları aşağıdaki gibidir:

Her ne kadar dışarıdan bakıldığında parıltılı bir görünümü olsa da bu fakültede okuyan öğrenciler bu toplumun içinden gelmekte ve bazı toplumsal dinamikler üniversite ortamında da kendini tekrar etmektedir. Bu öğrencilere verilen ceza hukuku, insan hakları derslerinin bazı öğrenciler tarafından içselleştirilmediği tespiti yapılabilir. Toplumsal cinsiyet derslerinin 3. sınıfta seçimlik olması, banka hukukunun daha cazip görülmesi nedeniyle az öğrenci tarafından seçilmesine neden olmakta, bu dersi seçen öğrenciler de zaten konuya duyarlı olanlardan çıkmaktadır.

Öğrenciler arasında yapılan bu araştırmada kadın öğrencilerin erkek öğrencilerden daha fazla genel olarak tacize uğradığı saptanmıştır. Kadın öğrenciler erkek öğrencilere kıyasla daha fazla fiziksel şiddetle karşı karşıya kalmışlardır. Sözlü tacize uğrayan kadın öğrenciler aynı zamanda yazılı tacize de maruz kalmıştır, erkek öğrenciler de aynı şekilde sözlü ve yazılı tacize maruz kalmıştır ancak sosyal medya aracılığıyla yapılan taciz söz konusu olduğu olduğunda her 5 öğrenciden birinin tacize uğradığı görülmektedir. Psikolojik taciz her 5 kadın öğrenciden birinin başına gelmiştir. Ekonomik olarak ise, erkeklerin daha fazla mağdur olduklarını söylemek mümkündür. 
Neredeyse bütün öğrenciler tokat atmanın kesinlikle bir şiddet biçimi olduğunu düşünmektedir. Ancak 4. sınıfta okuyan ve şu anda mezun olup mesleğe adım atan 4 erkek öğrencinin tokat atmayı şiddet olarak kabul etmemesi dikkat çekicidir.

Flört ilişkisinde erkek öğrencilerin üçte ikisi partnerin kiminle, nerede, ya da ne yaptığını kontrol etmenin şiddet olmadığını düşünmektedir. Eril zihniyet kadını kontrol etmeyi doğal bulmakta, kadınlar öğrencilerin yarısı buna itiraz etmektedir.

Flört süresince sürekli bağırmanın şiddet olduğu yönünde kadın ve erkek öğrenciler arasında bir kanı vardır. Herkesin içinde aşağılanmak kadın öğrenciler için bir şiddet biçimi olarak değerlendirilirken, erkek öğrencilerin yüzde onbeşi farklı görüştedir. Herkes içinde yapılan kırıcı şakaların aşağılamadan farklı algılandığı tespit edilmiştir: aslında bir psikolojik şiddet türü olan bu kırıcı şakalar konusunda kadın öğrencilerin daha duyarlı oldukları görülmektedir.

Erkek öğrenciler, flört ilişkisi içinde partnerlerine kendileri ile birlikte olmaları yönünde bir baskı uygulamanın şiddet olmadığı kanısındadırlar. Her üç erkek öğrenciden ikisi bu yönde cevap vermiştir. Buna mukabil, kadın öğrencilerin kafası bu konuda karışık gibidir. Yarı yarıya bu baskıya boyun eğmektedirler.

Cinsellikte 1srarlı davranma karşısında kadın öğrenciler net bir tutum içindedirler: 1srarın şiddet olduğunu düşünmektedirler. Bu kadınların beden algısı açısından da sevindirici bir durumdur, hayır diyebilme özgürlüğü kadının erkeğin hizmetinde olmadığının kabullenilmesi açısından önemlidir. Erkek öğrencilerin yüzde 27sinin ise maalesef bunun şiddet olmadığı düşüncesinde olduğu saptanmıştır. Bu rakam her halükarda yüksek olmakla birlikte, hukuk öğrencileri açısından konuya bakıldığında, bu öğrencilerin daha sonra hakim olabilme ihtimali de göz önünde tutulursa daha da dikkat çekicidir. Toplumsal sınırlardan bahsedilen hukuk eğitiminin bireysel sınırlar söz konusu olduğu olduğunda öğrencilerin iç dünyasında çok fazla etki edemediği gibi bir veri elde etmiş olmak üzücüdür. 
İlişki sırasında şiddet görürse, kadın öğrencilerin 4te 3ü ilişkisini kolaylıkla bitirebileceğini, 4te biri ise biraz zorlanacağını belirtmiştir. Seçeneklerden biri olan "çok zorlanırım" 1 işaretleyen ise yoktur. Erkek öğrencilere gelince, 4te biri biraz zorlanacağını ifade etmiştir.

Flört ilişkisi bittikten sonra, kadın öğrencilerin yarısı sözlü tacize uğramıştır, erkek öğrencilerde bu oran 3te birdir. Yazılı tacize uğrama oranı bu süreçte oldukça düşüktür. Ama sosyal medya aracılığıyla tacize uğranıp uğranmadığı sorulunca oranlar artmaktadır. Yazılı taciz ile sosyal medya aracılığıyla taciz -bu yazılı olarak yapılmış olsa da- öğrenciler tarafından farklı algılanmaktadır.

4. sınıf öğrencilerinde flört ilişkisinin daha problematik olduğu söylenebilir: 3 kadın öğrenci fiziksel tacize maruz kalmıştır, diğer sınıflarda fiziksel şiddete uğrayan yoktur. Psikolojik şiddete de en çok 4. sınıfın kadın öğrencileri maruz kalmıştır. İlişki sonrası ekonomik şiddete uğranıp uğranmadığın sorusuna sadece 4. sınıf öğrencilerinden 2 kadın, 2 erkek öğrenci olumlu yanıt vermiştir.

Tacize uğrayan bir kişinin şikayet etmemesi halinde, bunun rahatsızlık olmadığına mı kanıt olduğu yoksa rahatsızlık duyulmasına karşın mı şikayet edilmediği sorusuna ise, ezici çoğunluk bu durumun bir rahatsızlık yarattığı ancak bir nedenden ötürü şikayet edilmediği görüşündedir.

Flört şiddetini nereye şikayet edeceğini bilen kadın öğrenci sayısı, kadın öğrenci sayısının 3te 2sidir. Erkek öğrencilerin yarısı ise bilmemektedir. Hukuk fakültesinde okuyan öğrencilerin mağdur olduklarında şikayet edecekleri merciyi bilmemeleri ilginçtir. Ayrıca kadın öğrencilerin daha bilinçli olmaları, şiddet konusunda daha fazla risk taşıdıkları gerçeğinden de kaynaklanabilir.

Galatasaray Üniversitesi'nde flört şiddetine maruz kalma halinde yine kadın öğrencilerin yarısı Üniversite bünyesinde nereye başvuracaklarını bilmekte, erkek öğrencilerin 
yarısından fazlası bilmemektedir. Her iki rakam da tacize karşı çalışmalar yapmaya başlamış bu birimin yeni olması nedeniyle çok fazla tanınır olmadığını göstermektedir. Bu rakamlar, tacize karşı etkin bir çalışma yapmak için Birim'in tanınırlığının artması gerekliliğini ortaya koymaktadır. Bunun dışında flört tacizine uğrama oranlarının azaltılması için öğrencilere toplumsal cinsiyet eşitliğinden, insan haklarından, bu konudaki ulusal ve uluslar arası düzenlemelerden bahsedilecek seminerler, eğitimler düzenlenmesi yerinde olacaktır. Mezunlarımızla gurur duyduğumuz bu gençler ülkenin önemli avukatlık bürolarında, diplomaside, yargıda çalışmaktadır. Eğer onların eğitimlerinde bir eksiklik varsa, sorumlularından biri de biz akademisyenlerizdir.

\section{Kaynaklar}

Çörek, D.; “Toplumsal Cinsiyet ve Flört Şiddeti”, Toplumsal Cinsiyet ve Hukuk, Ed.:

Üskül Engin, Z. Ö. C.:I, Oniki Levha Yayıncılık, İstanbul, 2019.

Üçok Demir, N./ Irmak, M. Y./ Murat, D./ Perdahlı Fiş, N.; “Cinsel İstismara Uğrayan Ergen Adli Olgularda Flört İlişkisinde Şiddet Varlığı”, Anatolian Journal of Psychiatry 2016; 17(3): 240-247.

Yumuşak, A. / Şahin, R.; "Flörtte Şiddete Yönelik Tutum Ölçeklerinin Güvenilirlik ve Geçerlik Çalışması", Elektronik ve Sosyal Bilimler Dergisi, C.:13, S.: 49, Bahar 2014, ss. 233-252. www.esosder.org (30.9.19) 


\title{
INDIRECT SEX DISCRIMINATION IN THE WORKING LIFE UNDER THE FRAMEWORK OF THE PRECEDENTS OF THE EUROPEAN COURT OF JUSTICE
}

\author{
Zübeyde AKSAY ${ }^{1}$
}

\begin{abstract}
Women have started to take more places in the working life depending upon the production and employment structure which have rapidly changed with industrialization. Even if legally all men and women have equal rights, in the working life it is apparent that women are not able to compete with men in an equal environment. It is seen both in national and international statistics that women remain at lower levels in terms of education, wages, employment rates and participation in the labor force compared to men in particular.For a long period of time in Europe social policies centering on gender equality are put in practice aiming to eliminate the gender-based discrimination along with race, ethnicity, religion, etc. based discriminatory practices. However, in some cases, gender discrimination cannot be directly noticed. A seemingly neutral application can have negative consequences for a party. The term called indirect discrimination was first used and defined in the Burden Of Proof In Cases Of Discrimination Based On sex Article 2 Paragraph 2.

The European Court of Justice (ECJ) has played a significant role in determining the concept with precedents on indirect gender discrimination. Even when we look at precedents of the ECJ, it can be observed that after the prior legal precedents, ECJ has changed its position. Furthermore, ECJ approaches the issue as eliminating not only indirect gender discrimination practices but also its additional effects.

The aim of this study is to give brief information about both direct and indirect sex discrimination and to discuss indirect gender discrimination in working life in the frame of the precedents of the ECJ.
\end{abstract}

Keywords: Indirect Sex Discrimination, Woman in Work, Precedents of the European Court of Justice, Gender Equality

\footnotetext{
${ }^{1}$ Lawyer, İzmir bar association, İzmir Turkey avzubeydeaksay@ hotmail.com
} 


\section{IŞS YAŞAMINDA GERÇEKLEŞEN DOLAYLI CINSIYYT AYRIMCILIĞININ AVRUPA BİRLİĞİ ADALET DIVANI İÇTIHHATLARINDAKİ GÖRÜNÜMÜ}

$\ddot{O}_{z e t}$

Sanayileşme ile değişen üretim ve istihdam yapısına bağlı olarak kadınlar çalışma hayatında daha fazla yer almaya başlamışlardır. Ancak kanun önünde tüm kadın ve erkekler eşit haklara sahip olsalar da iş yaşamında kadınların erkekler ile eşit bir ortamda mücadele edemedikleri görülmektedir. Kadınların özellikle erkeklere kıyasla ĕgitim, ücret, istihdam edilme ve işgücüne katılma hususlarında daha düşük seviyelerde kaldıkları ulusal ve uluslararası istatistiklerde görülmektedir.

Avrupa'da uzun süreden beri ırk, etnik köken, din v.b. temelli ayrımcı uygulamalar yanında cinsiyet temelli ayrımcılı̆̆ da ortadan kaldırmaya yönelik toplumsal cinsiyet eşitliğini merkeze alan sosyal politikalar uygulamaya konmaktadır. Ancak bazı durumlarda var olan cinsiyet ayrımcılı̆̆ı doğrudan fark edilemeyebilir. Görünüşte tarafsız görünen bir uygulama bir taraf için olumsuz sonuçlar doğurabilir. Dolaylı ayrımcılık olarak adlandırılan bu kavram ilk olarak 97/80 sayılı Cinsiyet Ayrımcılığı Davalarında İspat Yüküne İlişkin Yönerge”nin 2/2. maddesinde tanımlanmıştır. Buna göre, "tarafsız bir düzenleme, kriter veya usulün önemli ölçüde belirli bir cinsiyet grubunu mağdur etmesi ve bu düzenleme, kriter veya usulün uygun ve zorunlu olduğu ve cinsiyete dayalı haklı sebeplere dayandığının açıklanamaması halinde dolaylı ayrimcilı mevcuttur.",

Avrupa Birliği Adalet Divanı (ABAD), dolaylı cinsiyet ayrımcılı̆̆ına ilişkin içtihatları ile kavramın içeriğinin belirlenmesinde önemli rol oynamıştır. Hatta ABAD’ın içtihatlarındaki gelişime bakıldığında verdiği ilk kararlardan sonra görüş değiştirdiği ve dolaylı cinsiyet ayrımcılı̆̆ gerektiği yönünde bir görüşü de benimsediği gözlenmektedir.

Bu çalışmanın amacı doğrudan ve dolaylı cinsiyet ayrımcılı̆̆ ile ilgili olarak kısa bir bilgi verilerek, ABAD’n iç̧thatları üzerinden iş yaşamında karşılaşılan dolaylı cinsiyet ayrımcılı̆̆ tartışılacaktır.

Anahtar Kelimeler: Dolaylı Cinsiyet Ayrımcılı̆̆l, çalışma yaşamında kadın, Avrupa Birliği Adalet Divanı kararları, toplumsal cinsiyet eşitliği 


\section{Giriş}

Kadınların özel alandan kamusal alana çıkmalarının temelinde ekonomik kaygılar yatmaktadır. Özellikle sanayi devriminin, kadın işgücünün tarihsel gelişim sürecinde önemli bir dönüm noktası olduğu söylenebilir. Ancak kadının kamusal alanda kendine yer bulması dünya üzerindeki ülkelerin hukuk normlarını hazırlıksız yakalamış, her ne kadar birinci dalga feminizm ile başlayan ve ikinci dalgayla devam eden kadın hareketleri sonucunda kanun önünde tüm kadın ve erkekler görece eşit haklara sahip olsa da iş yaşamında eşitlik sağlanamamıştır. Öyle ki iş yaşamında kadınların erkekler ile eşit haklara sahip olmadıkları ve erkeklere kıyasla eğitim, ücret, istihdam edilme ve işgücüne katılma hususlarında daha düşük seviyelerde kaldıkları ulusal ve uluslararası istatistiklerde de görülmektedir.

Kadının iş yaşamına katılımıyla birlikte yaşanan ayrımcılığa yönelik olarak uluslararası hukuk, Avrupa Birliği (AB) Hukuku ve Türk Hukuku'nun yanında pek çok ulusal mevzuat cinsiyet, ırk, etnik köken ve benzeri nedenlerle ayrımcılığı yasaklamıştır. Bu kapsamda Avrupa'da cinsiyet temelli ayrımcılığı ortadan kaldırmaya yönelik toplumsal cinsiyet eşitliğini merkeze alan sosyal politikalar uygulanmaya başlanmıştır. Uygulanacak olan politikaların da cinsiyet ayrımcılığına yönelik hukuk normlarına uygun olarak geliştirilmesine dikkat etmek gerekmektedir. AB Hukuku çerçevesinde belirlenen ve ulusal hukuk sistemleri içerisinde uygulanması gereken hukuk normlarının tespitinde elbette ki Avrupa Birliği Adalet Divanı (ABAD) ve Avrupa Birliği İnsan Hakları Mahkemesi (AİHM) içtihatlarının önemi yadsınamaz.

$\mathrm{Bu}$ çalışmanın ilk bölümünde cinsiyete dayalı ayrımcılık yasağının uluslararası belgelerde yer alma sürecinden kısaca bahsedilerek doğrudan ve dolaylı ayrımcılık kavramlarına yer verilecektir. Çalışmanın ikinci bölümünde iş ilişkilerinde ayrımcılık yasağı ve eşit davranma ilkesine ilişkin $\mathrm{AB}$ direktifleri ile ABAD'ın dolaylı cinsiyet ayrımcılığına ilişkin bazı içtihatlarına yer verilerek Divan'ın konuya olan yaklaşımı değerlendirilecektir. 


\section{Cinsiyete Dayalı Ayrımcılık Yasağının Uluslararası Belgelerdeki Gelişimi}

Ayrımcılık, bir birey/birey grubunun sahip olduğu bazı özelliklerden dolayı, hak ve özgürlüklerden yararlanmada, haklı bir gerekçeye dayanmadan, başka birey/birey gruba karşı daha az lehte muamele görmesidir (Yücel, 2015:60). Birleşmiş Milletler (BM) Kadınlara Yönelik Her Türlü Ayrımcılığın Ortadan Kaldırılması Sözleşmesi (CEDAW) 1. maddesi uyarınca kadınlara karşı ayrımcılık “... siyasal, ekonomik, sosyal, kültürel, kişisel veya diğer alanlardaki kadın ve erkek eşitliğine dayanan insan haklarının ve temel özgürlüklerin, medeni durumları ne olursa olsun kadınlara tanınmasını, kadınların bu haklardan yararlanmalarını veya kullanmalarını engelleme veya hükümsüz kılma amacını taşıyan veya bu sonucu doğuran cinsiyete dayalı herhangi bir ayrım, dışlama veya kısıtlama... ”şeklinde tanımlanmıştır.

Uluslararası belgeler incelendiğinde cinsiyete dayalı ayrımdan ilk olarak 1945 tarihli BM Şartı'nda yer verildiği gözlenmektedir. Antlaşmanın 13. maddesinde “insan haklarının ve temel özgürlüklerin ... cinsiyet ... gibi farklılıklar gözetilmeden yerine getirilmesi” ifadesi yer almakta 55. ve 76. maddelerde ise "herkesin insan haklarına ve temel özgürlüklere ... cinsiyet, ırk, dil veya din ... gibi farklılıklar gözetilmeden” evrensel bir saygının sağlanması gerektiği belirtilmektedir.

1948 tarihinde ise cinsiyete dayalı ayrımcılık BM İnsan Hakları Bildirgesi’nde yasaklanmıştır. Bildirgenin 2. maddesi “Herkes ırk, renk, cinsiyet, dil, din, siyasal ya da başka türden kanaat, ulusal ya da toplumsal köken, mülkiyet, doğuş veya başka türden nedenler gibi herhangi bir ayrım gözetilmeksizin bu bildirgede belirtilen bütün hak ve özgürlüklere sahiptir” şeklinde düzenlenerek ayrımcılık yasağına yer verilmiştir.

Uluslararası Çalışma Örgütü (UÇÖ) Sözleşmelerinden 1951 tarihli eşit işe eşit ücret öngören 100 No’lu Eşit Ücret Sözleşmesi, 1958 tarihli 111 No'lu Ayrımcılık (İstihdam ve Meslek) Sözleşmesi ve 1962 tarihli 118 No’lu Eşit Muamele (Sosyal Güvenlik) Sözleşmesi doğrudan doğruya eşit muameleye ve ayrım yasağına ilişkindir (Bakırcı, 2012:26). 
1966 yılına gelindiğinde BM Ekonomik Sosyal ve Kültürel Haklar Sözleşmesi’nin 2. ve 3. maddeleri, sözleşmeyle düzenlenen hakların kullanılmasında cinsiyete dayalı ayrımcılığı yasaklamış ve bu haklardan yararlanmada kadın ve erkeklere eşit haklar tanımaktadır (Bakırcı, 2012:25). Sözleşme'nin “Sözleşmenin iç hukukta uygulanması ve ayrımcılık yasağı” başlıklı 2. maddesi 2. bendinde “Bu Sözleşmeye Taraf Devletler, bu Sözleşmede beyan edilen hakların ırk, renk, cinsiyet, dil, din, siyasal veya diğer bir fikir, ulusal veya toplumsal köken, mülkiyet, doğum gibi herhangi bir nedene göre ayrımcılık yapılmaksızın kullanılmasını güvence altına almayı taahhüt ederler”. ifadesi yer almaktadır. Sözleşme'nin “Cinsiyet eşitliği”" başlıklı 3. maddesi ise, “Bu Sözleşmeye Taraf Devletler, bu Sözleşmede yer alan bütün ekonomik, sosyal ve kültürel hakların kullanılmasında erkeklere ve kadınlara eşit haklar sağlamayı taahhüt eder.” şeklinde düzenlenmiştir.

Avrupa düzeyinde ayrımcılık yasağı ilk olarak 1950 yılında Avrupa İnsan Hakları Sözleşmesi'nde yer almıştır. AB Hukuku açısından bakıldığında ise Avrupa Birliği'nin kurucu antlaşması olan 1957 tarihli Avrupa Birliği Antlaşması'nın (ABA) 141. maddesinde (eski 119) istihdam ve meslekte kadın ve erkek eşitliğine ilk kez yer verildiği görülmektedir. İlgili maddeye göre "Her üye devlet, aynı veya aynı değerde işler için kadın ve erkek işçiler arasında ücret eşitliği uygulamasını să̆lar.”

Görüldüğü üzere ayrımcılık yasağı, AB Hukuku'nda ilk başlarda yalnızca kadın ve erkeklerde eşit işe eşit ücret ve vatandaşlık temelli olarak gündeme gelmiştir. Önceleri bu iki temelde ayrımcılığa yer verilmesi, ortak bir pazar inşa edilmesi yönünde bir araç olarak düşünülmüştür (Konuk, 2013; 1731) . Kadın ve erkek arasında eşit işe eşit ücret ilkesi bir temel hak olarak değil, ekonomik amaçla, adil bir rekabet ortamı için toplumsal bir gereklilik olarak görülmüştür (Gül ve Karan, 2011:72). Gerçekte kadın-erkek eşitliğine yönelik 141. maddenin ABA'da yer almasında Fransa etkili olmuştur. Fransa, kendi iç düzenlemelerinde kadın ve erkek çalışanlara eşit ücret ödenmesi ilkesine yer vermiş olduğundan bu ABA'da da yer alması için 
baskı yapmış ve bunu sağlamıştır. Fransa'nın bu tavrının gerçek nedeni, diğer üyeler karşısında işgücü maliyetleri bakımından rekabet eşitsizliği yaratacak bir durumun önüne geçmektir (Akpinar, 2015:12).

ABA'nın 141. maddesinin uygulamaya geçirilmesi amacıyla çeşitli konsey direktifleri düzenlenmiştir. Bu amaçla düzenlenen konsey direktifleri Tablo 1 de gösterilmiştir. Söz konusu konsey direktiflerinin açıklamaları Aydınöz'ün (2009) çalışmasından yararlanılarak özetlenmiştir. 
Tablo 1-ABA'nın 141. Maddesinin uygulamaya geçirilmesi amacıyla düzenlenen bazı Konsey Direktifleri

\begin{tabular}{|c|c|}
\hline $\begin{array}{l}\text { Kadın ve Erkek İşçiler Arasında Eşit } \\
\text { Ücret İlkesinin Uygulanmasına } \\
\text { Yönelik Üye Devlet Mevzuatının } \\
\text { Uyumlaştırılmasına } \\
\text { 75/117/CEE sayılı Konsey Direktifí }\end{array}$ & $\begin{array}{l}\text { Bu Direktif'in uygulama alanı, ücret bakımından } \\
\text { cinsiyet temeline dayalı ayrımcılık yasağı ile } \\
\text { sınırlıdır. }\end{array}$ \\
\hline $\begin{array}{l}\text { İşe Girişte, Formasyonda, Terfide ve } \\
\text { Çalışma Koşullarında Kadın ve } \\
\text { Errkeklere Eşit Davranma İlkesine } \\
\text { İlişkin 76/207/CEE sayılı Konsey } \\
\text { Direktifi }\end{array}$ & $\begin{array}{l}\text { 76/207/CEE sayılı direktif 2002 y1lında } \\
\text { 2002/73/CE sayılı Direktif ile değiştirilmiştir. Bu } \\
\text { değişikliğin amacı doğrudan-dolaylı ayrımcılık } \\
\text { tanımlarını ve bir ayrımcılık hali olarak taciz } \\
\text { kavramını Direktif'e eklemek olmuştur. }\end{array}$ \\
\hline $\begin{array}{l}\text { Sosyal Güvenlik Alanında Kadın ve } \\
\text { Erkeklere Eşit Davranma İlkesinin } \\
\text { Uygulanmasına İlişkin 79/7/CEE sayılı } \\
\text { Konsey Direktifi }\end{array}$ & $\begin{array}{l}\text { Direktif ile eşit davranma ilkesinin öncelikle } \\
\text { hastalık, malullük, yaşlılık, işsizlik, iş kazası ve } \\
\text { meslek hastalığı risklerine karşı koruma sağlayan } \\
\text { yasal sosyal güvenlik rejimlerinde uygulanması } \\
\text { öngörülmüştür. Topluluğun yasal sosyal güvenlik } \\
\text { rejimleri alanında ayrımcıllk yasağına ilişkin } \\
\text { düzenlemesi bu direktiften ibarettir. Doğrudan } \\
\text { ayrımcıllk-dolaylı ayrımcılık fark } \\
\text { belirtilmemiştir. }\end{array}$ \\
\hline $\begin{array}{l}\text { Mesleki Sosyal Güvenlik Rejimlerinde } \\
\text { Kadın ve Erkeklere Eşit Davranma } \\
\text { İlkesinin Uygulanmasına İlişkin } \\
\text { 86/378/CEE sayılı Konsey Direktifi }\end{array}$ & $\begin{array}{l}\text { Söz konusu Direktif, ABAD içtihadı ile ücret } \\
\text { kavramında meydana gelen değişiklikler sonucu } \\
\text { hukuk güvenliğinin sağlanması ve belirsizliğe } \\
\text { son verilmesi amacıyla 96/97/CE sayılı Konsey } \\
\text { Direktifi ile değiştirilmiştir. }\end{array}$ \\
\hline $\begin{array}{l}\text { Ebeveyn İznine İlişkin 96/34/CE sayılı } \\
\text { Konsey Direktifi }\end{array}$ & $\begin{array}{l}\text { Bu Direktifle sosyal taraflarca bağıtlanan } \\
\text { ebeveyn izni çerçeve anlaşması yürülüğe } \\
\text { konulmuştur. Direktif, işyeri sınırları dışına } \\
\text { yönelerek, ev içi işlerde kadınla birlikte erkeğin } \\
\text { de sorumluluk almasını sağlamaya dönük } \\
\text { düzenlemeler getirmektedir. Direktif ile birlikte } \\
\text { kadın çalışanlar yanında erkek çalışanlara da } \\
\text { doğum izni alma olanağı tanımaktadır (Akpınar, } \\
\text { 2005:19) }\end{array}$ \\
\hline $\begin{array}{l}\text { Kısmi Zamanlı Çalışmaya İlişskin } \\
\text { 97/81/CE sayılı Konsey Direktifi }\end{array}$ & $\begin{array}{l}\text { Kısmi zamanlı çalışanlara ayrımcı muamele } \\
\text { yasağı öngören Direktif'te ayrımcılık alanındaki } \\
\text { diğer direktiflerden farklı olarak doğrudan- } \\
\text { dolaylı ayrımcılık kavramlarına, bir ayrımcılık } \\
\text { hali olarak taciz kavramına ve ispat kurallarına } \\
\text { yer verilmemiştir. }\end{array}$ \\
\hline
\end{tabular}

(Aydınöz, 2009:165-173) 
Tablo 1-ABA'nın 141. Maddesinin uygulamaya geçirilmesi amacıyla düzenlenen bazı Konsey Direktifleri (Devam)

\begin{tabular}{|c|c|}
\hline $\begin{array}{l}\text { Cinsiyet Temeline Dayalı Ayrımcılık } \\
\text { Hallerinde İspat Yüküne İlişkin } \\
\text { 97/80/CE sayılı Konsey Direktifi }\end{array}$ & $\begin{array}{l}\text { AB Hukukunda, ayrımcılık yasağının esaslarının } \\
\text { belirlenmesinin yeterli olmadığı ve özellikle } \\
\text { ayrımcılığın ispatı sorununun etkili bir korumaya } \\
\text { engel teşkil ettiği kabul edilmiştir. İspat sorununa } \\
\text { çözüm getirmede ABAD öncülük etmiş ve ispat } \\
\text { yüküne ilişkin kuralları tersine çevirmeksizin ve } \\
\text { fakat davacı lehine yumuşatılmış ispat kulları ile } \\
\text { çözüm bulmuştur. ABAD içtihatlarıyla yerleşen bu } \\
\text { kurallar "Cinsiyet Temeline Dayalı Ayrımcılık } \\
\text { Hallerinde İspat Yüküne İlişkin 97/80/CE sayıll } \\
\text { Konsey Direktifi ile pozitif norm halini almıştır. }\end{array}$ \\
\hline $\begin{array}{l}\text { Eşit Davranma İlkesinin Irka ve } \\
\text { Etnik Kökenine Dayalı Ayrım } \\
\text { Yapılmaksızın } \\
\text { İlişkin Uygulanmasına } \\
\text { Direktifi }\end{array}$ & $\begin{array}{l}\text { Söz konusu direktif sadece iş ilişkisine ilişkin } \\
\text { olmayıp genel olarak 1rk ve etnik kökene dair } \\
\text { ayrımcılıkla mücadele amacına hizmet etmektedir. } \\
\text { Direktif, ayrımcılık konusundaki düzenlemelerin } \\
\text { çoğunluğuna paralel olarak doğrudan ayrımcılık- } \\
\text { dolaylı ayrımcılık kavramlarını tanımlamış ve taciz } \\
\text { kavramını da kapsamına almıştır. }\end{array}$ \\
\hline $\begin{array}{l}\text { Eşit Davranma İlkesine Genel Bir } \\
\text { Çerçeve Oluşturmasına İlişkin } \\
\text { 2000/78/CE sayılı Konsey Direktifi }\end{array}$ & $\begin{array}{l}\text { Direktif, özellikle kadınların aynı anda birçok farklı } \\
\text { konuda ayrımcılığa maruz kalması sebebiyle } \\
\text { çalışma ve istihdam alanında eşit davranma } \\
\text { ilkesinin uygulanmasının genel çerçevesini } \\
\text { belirlemek üzere düzenlenmiştir. Direktif, kurucu } \\
\text { anlaşmada anılan ilkelerin gereği olan ve fakat } \\
\text { direktiflerde yer almamış konuların } \\
\text { düzenlenmesini amaçlamaktadır. Din ve inanca, } \\
\text { cinsel eğilimlere, yaşa ve engelli olmaya dayalı } \\
\text { ayrımcılık hallerinin ilk defa direktif düzeyinde } \\
\text { düzenlenmesi bakımından da önemlidir. }\end{array}$ \\
\hline $\begin{array}{l}\text { İş ve İstihdam Alanında Kadın- } \\
\text { Erkek Arasında Fırsat Eşitliği ve } \\
\text { Eşit Davranma İlkelerine İlişkin } \\
\text { 2006/54/CE sayılı Konsey Direktifi }\end{array}$ & $\begin{array}{l}\text { Direktif, 75/117/CEE, 2002/73/CE, 97/80/CE, } \\
\text { 96/97/CE sayılı direktiflerin gözden geçirilmiş ve } \\
\text { birleştirilmiş halidir. Bu Direktif ile kadın-erkek } \\
\text { arasında cinsiyet temeline dayalı ayrımcılık } \\
\text { konusunda öngörülen kavramsal değişikliklerden } \\
\text { biri, ABAD kararlarıyla geliştirildiği üzere cinsiyet } \\
\text { temeline dayalı ayrımcılığın sadece iki farklı } \\
\text { cinsiyete dayalı halleri kapsamadığının ve fakat bir } \\
\text { kimsenin cinsiyetinin değişmesi haline dayanan } \\
\text { ayrımcı davranışın da cinsiyet temeline dayalı } \\
\text { ayrımcılık kavramı dahilinde değerlendirileceğinin } \\
\text { vurgulanmasıdır. }\end{array}$ \\
\hline
\end{tabular}

Aydınöz, 2009:165-173) 


\section{Cinsiyete Dayalı Ayrımcılık Türleri}

Ayrımcılık sınıflandırma bakımından doğrudan ayrımcılık, dolaylı ayrımcılık şeklinde ikiye ayrilmaktadır.

\section{Doğrudan Ayrımcılık}

Doğrudan ayrımcılık kısaca, ayrımcılığın yasaklandığı temellerden (cinsiyet, dil, ırk vs.) birine “doğrudan” dayalı olarak, bir kişi veya grubun haksız olarak farklı muameleye uğraması olarak tanımlanabilir (Karan, 2017:203). Cinsiyete dayalı doğrudan ayrımcılık, 2006/54/CE sayılı İstihdam Eşitliği Direktifi ile ise şöyle tanımlanmıştır: "Bir kişiye, başka bir kişiye göre cinsiyeti sebebiyle benzer durumlarda gösterilenden veya gösterilecek olandan daha az avantajlı şekilde davranılmasıdır. "Buna göre, cinsiyete dayalı olan ve karşılaştırılan cinse göre daha az avantajlı olan hareketler doğrudan ayrımcılıktır (Korkmaz ve Alp, 2016:531).

Doğrudan ayrımcılık özellikle işe almada, çalışma koşullarının uygulanmasında, ücretlendirmede, mesleki eğitim ve ilerlemede ve iş ilişsisinin sona ermesinde yaygın olarak ortaya çıkmaktadır (Kaya, 2010:107).

Örneğin aynı veya aynı değerde işler için farklı cinsiyetteki işçiler arasında eşit olmayan ücret belirlenmesi halinde cinsiyete dayalı doğrudan ayrımcılık söz konusu olmaktadır. Bu gibi durumlarda $\mathrm{ABAD}$ önüne gelen uyuşmazlıklarla birlikte ayrımcılı̆̆ın ispatı konusunda bir takım kriterler geliştirmiştir. Kadın ve erkek işçiler bakımından aynı veya eşit değerde işlerin varlığını ve aynı işyeri veya işletmedeki kadın ve erkek işçilerin farklı ücret aldığını ispat etmekle davacı işçi yükümlüdür (Aydınöz, 2009:176). Ancak ispat konusunda İstihdam Eşitliği Direktifinin 10. maddesinin 1. fikrası, "üye devletler, ulusal yarg1 sistemleri uyarınca, kendilerine eşit muamele ilkesinin uygulanmaması sebebiyle haksızlığa uğradığını düşünen kişiler bir mahkeme veya başka yetkili bir makam huzurunda, doğrudan veya dolaylı bir ayrımcılık bulunduğu varsayımı yaratabilecek olguları ortaya koyduğunda, eşit muamele 
ilkesine yönelik bir ihlal bulunmadığını ispatlama yükümlülüğünün karşı tarafa ait olmasını sağlayacak tedbirleri alacaktır.” şeklinde düzenlenmiştir. Söz konusu direktif hükmü, mağdura “ayrımcılık karinesi” çerçevesinde mahkemeye başvurabilme imkanı tanımakta ve ayrımcılık yapılmadığını kanıtlamak için ispat yükünü işverene yüklemektedir (Kaya, 2012:248).

Defrenne davasına konu olan olayda ise, Bayan Defrenne Belçika havayollarında hostes olarak görev yapmaktayken kendisine aynı işi yapan erkek meslektaşlarına ödenen orandan daha düşük bir ücret ödendiğini ve böylece kendisine ayrımcılık yapıldığını ileri sürerek tazminat talebinde bulunmuştur. Bayan Defrenne'nin iddiaları ABAD tarafından yerinde bulunmuş, ister kamu sektöründe olsun ister özel sektörde olsun aynı işi yapan bir erkek meslektaşından daha düşük ücret alınıyor olmasının 119. maddenin (yeni m.142) ihlali olduğu kararı verilmiş ve bu durumun doğrudan ayrımcılık olduğu tespit edilmiştir (Yavaşi, 2003:6566).

ABAD’ın doğrudan ayrımcılığa ilişkin pek çok kararı bulunmaktadır. Bu kararlardan biri ABAD'ın 2006 tarihli ve 294/04 sayılı Herrero kararıdır. Herrero kararında analık iznini kullanan kadın bu izin esnasında kendi işyerinde açılan sınavda idari asistan pozisyonuna atanmaya hak kazanmıştır. Fakat kıdem hesabında atama tarihi değil, analık izninin sona erdiği tarih temel alınmıştır. Divan, kadın çalışanın kıdeminin hesabında analık iznindeki sürenin dikkate alınmamasını doğrudan ayrımcılık olarak kabul etmiştir (Korkmaz ve Alp, 2016:532).

Kleist kararında, şirket iç hukuk kurallarının izni doğrultusunda emeklilik yaşına gelenlerin iş sözleşmesini feshetme kararı almıştır. Fakat Avusturya’da erkekler 65, kadınlar 60 yaşında emekli olabilmektedir. Kadın ve erkek çalışanlar için var olan yaş farkının ayrımcılık olup olmadığı ve iç hukukta var olan genç çalışanlara istihdam yaratma amacı taşıyan bu kuralın haklı neden olarak değerlendirilip değerlendirilemeyeceği sorusu Divan'a yöneltilmiştir (Korkmaz ve Alp, 2016:539). Burada Divan, bu iki grubun aynı çalışma şartlarına tabi olduklarını ve aynı şekilde sözleşmelerinin sona erdirildiği gerekçesiyle cinsiyete dayalı 
doğrudan bir ayrımcılık yapıldığı ve iç hukukta var olan genç çalışanlara istihdam yaratma amacı taşıyan bu kuralın da direktif hükümlerine aykırı olduğu kanaatine varmıştır (Korkmaz ve Alp, 2016:539).

Doğrudan ayrımcılığın tespiti, dolaylı ayrımcılığa göre daha kolaydır. Doğrudan ayrımcılığın ispat edilmesinde, aynı veya benzer durumda kişinin referans gösterilmesi gerekir (Yücel, 2015:73). Bir başka deyişle, karşılaştırma yapılan kadın ve erkeğin durumlarının benzer veya aynı, konumlarının eşit, karşılaştırılan konuların ise öz olarak aynı olması gerekir (Onaran Yüksel, 2000:101). Bu bazen mümkün olmayabilir. Karş1laştırılabilir öznenin gösterilememesi durumlarında varsayımsal olarak tespit edilmesi yoluna gidilecektir (Yücel, 2015:73). Kısacası bir uygulamanın doğrudan ayrımcılık unsuru içerip içermediğinin tespitinde somut olayın özellikleri göz önünde bulundurulur. Burada sorulması gereken, kişinin karşı cinsten olsaydı o işleme maruz kalıp kalmayacağıdır.

\section{Dolaylı Ayrımcilık}

Dolaylı ayrımcılık 2006/54/CE İstihdam Eşitliği Direktifinin 2. Maddesinde “Görünüşte tarafsız olan hükümler, kıstaslar ya da uygulamaların yasal olarak meşru bir amaca hizmet etmesi ve bu amaca ulaşmak için kullanılan araçların uygun ve gerekli olması durumu hariç bir cinsiyetteki kişileri diğer gruba karşı dezavantajlı duruma düşürmesi veya düşürme ihtimalidir." şeklinde tanımlanmıştır. Bir başka deyişle görünüşte tarafsız olan standartlar, bütün işçilere veya işçi adaylarına uygulanmasına rağmen, eşit durumda olmayan gruplara eşit muamele yapılması söz konusu gruplar üzerinde farklı sonuçlara yol açtığı hallerde dolaylı ayrımcılıktan söz edilir (Bakırcı, 2012:42).

Aslında bu tanımla birlikte Direktif önemli bir yenilik de getirmiştir. Şöyle ki; artık sadece olumsuz davranışın gerçekleştirilmesi ile değil aynı zamanda olma ihtimali olması durumunda da dolaylı ayrımcılıktan söz edilebilecektir. 
Gerçekte AB kapsamında yukarıda belirtilen Direktiflerden çok önce içtihat yoluyla dolaylı ayrımcılık, ayrımcılık yasağının bir parçası olarak kabul edilmiştir. ABAD’ın 1974 tarihli bir kararında vatandaşlık temelinde dolaylı ayrımcılık konusu ele alınmıştır. ABAD bundan sonraki dönemde ise özellikle cinsiyet temelli ayrımcılıkla ilgili olarak dolaylı ayrımcılık kavramına sıklıkla başvurmuştur (Karan, 2017:222-223).

ABAD’ın 1986 tarihli Bilka-Kaufhaus kararı önemli bir dönüm noktası olmuştur. ABAD'ın bu kararı ile dolaylı ayrımcılık kavramı bugünkü anlamına en yakın biçimi ile şekillenmiştir. Davada Almanya'da kısmi zamanlı çalışan kişilerin sosyal güvenlik sisteminden dışlanması uygulamasının erkek ve kadın kısmi zamanlı çalışanların her ikisini de dışladığı ve bu nedenle doğrudan bir ayrımcılık ortaya koymadığı ancak kısmi zamanlı çalışanların büyük çoğunluğunun kadınlar olduğu düşünüldüğünde erkek kısmi çalışanlara göre kadın kısmi çalışanlar için aleyhlerine etki doğurduğu ve bu durumun makul ve nesnel bir nedeninin bulunmadığı için ayrımcılık oluşturduğu belirtilmiştir (Karan, 2017:223). Olayda Bilka firması farklı muameleyi gözetme amacının, kısmi zamanlı çalışmayı caydırmak ve tam zamanlı çalışmayı özendirmek olduğunu, çünkü kısmi çalışanların akşam saatlerinde ve Cumartesi günlerinde çalışmaya karşı isteksiz olduklarını, bunun da yeterli personel bulundurmayı zorlaştırdığını iddia etmiştir (Yücel, 2015:174). Divan'a göre emeklilik sisteminden yapılan ödemeler ücret olarak görülmektedir. Divan Bilka-Kaufhaus kararında, "Cinsiyet ayrımcılığına dayanmadığı sürece araçların uygun ve zorunlu olması şartı ile daha az kısmi süreli çalışan istihdam etmeye yönelik politikalar haklı görülebilir. İlk görünüşte, kadın ve erkek arasında ayrımcılık yapılmadığı söylenebilir. İşyerinde kısmi süreli çalışanların önemli bir bölümünün kadın çalışan olmasına karşın, tam süreli çalışanların çoğunun erkek olması gözden uzak tutulmamalıdır. Dolayısıyla ilgili uygulama daha çok kadın çalışanlar üzerinde olumsuz etki yaratmaktadır. Netice itibariyle, görünüşten ziyade uygulamanın pratik sonuçlarına göre hüküm kurulması gerekir” şeklinde ifadelere yer vermiştir (Korkmaz ve Alp, 2016:533). 
ABAD, Jenkins kararında da İngiltere'de tam süreli çalışanlara nazaran kısmi süreli çalışanlara saat başına ödenen ücret miktarının \%10 daha az olmasının başlı başına bir ayrımcılık olmamakla birlikte kısmi süreli çalışanların büyük bir bölümünün kadın olması durumunda kadın ve erkek arasında eşit ücret prensibinin ihlali söz konusu olacağını belirtmiştir (Korkmaz ve Alp, 2016:533).

ABAD, Seymour-Smith ve Perez kararında ise İngiltere'de iş akdinin feshinde haksız fesih davasının açılabilme koşulu olarak en az iki yıl çalışma aranmasının kadınlara karşı dolaylı ayrımcılık olarak kabul etmiştir. ABAD bu kararını 1985 ve 1991 yılları arasında istatistiksel olarak daha az sayıda kadının kıdem tazminatından yararlanabildiğini, iki yıllık çalışma süresi kuralının kadınlar açısından dezavantaj yarattığını tespit etmiştir (ABAD, C167/97, 1999)

ABAD'ın, Stoeckel kararında İngiltere'de kadınların gece çalıştırılmalarının yasaklanması durumunu dolaylı ayrımcılık olarak kabul etmesi kafa karışıklığına yol açmıştır. Buna göre ABAD açıklamasında gece çalıştırılmayan kadınların gece çalışması karşılığında yapılan ek ödeme ve sağlanan diğer sosyal haklardan yararlanamamakta ve bu şekilde dolaylı bir ayrımcılığa maruz kaldığını belirtmiştir. Böylece bir yanda kadınların gece çalıştırılmalarını yasaklayan düzenlemeler, diğer yanda kadınların gece çalıştırılmalarının yasaklanmasını dolaylı ayrımcılık sayan düzenlemelerin bir arada varlığı uygulamada karmaşıklığa yol açmaktadır (Akpınar, 2015:4).

Yine Lakebeig kararında Divan, fazla çalışma ücretinin ister kısmi süreli ister tam süreli çalışma olsun ayda 3 saatten fazla yapılan çalışmalarda ödeneceğine ilişkin hükmü kadın erkek arasında eşit ücret ödenmesine ilişkin hükümlere aykırı bulmuştur. Çünkü tam süreli çalışanlar ayda 98 saat çalıştıklarından, 3 saat fazla çalışma ilave \%3 fazla çalışma gerektirirken kısmi süreli çalışanlar ise ayda 60 saat çalıştıklarından 3 saat fazla çalışma ilave $\% 5$ fazla çalışma 
gerektirmektedir. Yine kısmi süreli çalışanların çoğunlukla kadınlar olması durumunda kadın erkek arasında dolaylı bir ayrımcılık mevcut olacaktır (Korkmaz ve Alp, 2016:533-534).

Rinner-Kühn davasında ise yasa gereği tam zamanlı hizmet akdi ve kısmi süreli hizmet akdi ile (Alman mevzuatına göre haftada 10 saat veya daha az çalışan işçi olarak tanımlanır) çalışan işçilere hastalıkları süresince yapılan farklı oranlı ödemeleri dolaylı ayrımcılık olarak değerlendirip, yasadışı bulmuştur (Yavaşi, 2003:74).

ABAD’ın genel prensip olan “iş değerlendirme kriterleri objektif olmalıdır” prensibiyle çelişkili olarak Rummler davasında "kriterlerin objektif olması prensibinin, bir cinsiyetin lehine olan (dayanıklılık gibi) faktörlerin dikkate alınamayacağı anlamına gelmez.” demiştir (Yavaşi, 2003:76). Bahsi geçen davada Bayan Rummler, Almanya'daki baskı (matbaacılık) sanayiinde uygulanmakta olan ücret oranları sınıflandırmalarını dava konusu etmiştir. Bayan Rummler ambalajları paketleme olan işinin bu ücret sınıflandırmasında daha üst seviyeye konulmasını, çünkü, 20 kilogramdan daha ağır olan paketleri kaldırıp indirdiğini ve bunun bir kadın için ağır bir iș olduğunu iddia etmiștir (Yavaşi, 2003:76).

ABAD dayanıklılık ve fiziksel çaba dikkate alınarak işlerin sınıflandırılmasının aşağıdaki şartlarda Direktif’e aykırı olmadığı belirtmiştir. Şöyle ki, a) sistem bütün olarak cinsiyet ayrımını engellemelidir, b) kullanılan kriter objektif olmalıdır. ABAD ayrıca, uygulamada olan sistemin kriterinin her cinsiyetin sahip olduğu yeteneklerini göz önüne almak zorunda olduğunu ve kriterin yalnızca tek bir cinsiyetin yeteneklerine dayandırılmasının kabul edilebilir olmakla beraber "ayrımcılık yapma riski” ihtimali taşıdığını belirtmiştir (Yavaşi, 2003:76).

ABAD Smith kararında, bir işin değerinin diğer bir işin değerine eşit sayılabilmesi için, yapılan işlerin aynı işyerinde ve aynı zamanda yapılması zorunlu olmayacağını belirtmiştir. Adı geçen kararda farklı zamanlarda yapılan işlerin değerlerinin de karşılaştırabileceği değerlendirilmiştir. Depo müdürü olarak görev yapan Bayan Smith, kendisine selefi olan ve 
dört ay önce işten ayrılan erkek depo müdürüne ödenen ücretten haftada 10 Sterlin daha az ödenmesi üzerine açtığı davaya ilişkin olarak kararında, aynı işi farklı zamanlarda yapan iki kişinin ücretlerinin birbirinden cinsiyet ayrımına dayanmayan diğer faktörler nedeniyle faklı olabileceğini bu farklılığın sebebini belirlemenin ulusal mahkemelerin görevi olduğunu belirtmiştir. Kararın devamında şayet önceki depo müdürünün de kadın olası durumunda sorun olmayacağını, cinsiyetlerin farklı olması durumunda kararda geçen "cinsiyet ayrımına dayanmayan faktörler”in değerlendirilmesi, ücretlerin farklı olmasını gerektirecek haklı bir neden bulunamazsa zaman unsuru dikkate alınmadan cinsiyete dayılı dolaylı ayrımcılık olarak kabul edilmesi gerektiği belirtilmiştir (Yavaşi, 2003:76-77).

Danfoss davasına konu olan olayda ise, bir işyerinde kadın ve erkek ayrımı yapılmadan aynı toplu sözleşmeye taraf olan her iş grubu için asgari olarak ödenecek miktarın belirlenmiş olmasına karşın gösterilen performansa veya verimliliğe göre fazladan ödeme yapmanın mümkün olduğu kararı alınmıştır (Yavaşi, 2003:79). Divan doğrudan cinsiyete bağlı olmamakla birlikte, performansa dayalı olarak veya ödüllendirme amaçlı fazladan yapılan sosyal içerikli ödemelerin bir takım sübjektif kriterlere dayandırılması halinin dolaylı ayrımcılık olarak nitelendirilebileceğini ifade etmiştir. İlgili kararda konu olan olayda, işin icra edileceği mekân ve saatlere ilişkin esneklik kriterine göre ücrette artışa gidilmesinin, ev ve aile yaşantısına dair sorumlulukları gereği erkek işçilere göre daha az esnekliğe sahip olan kadın işçilerin aleyhine bir durum teşkil edebileceği belirtilmiştir (Konuk, 2013:1743).

ABAD Cornwall davasında erkek davacının cinsiyet değiştirip kadın olarak yaşamaya devam etmesi üzerine işine son verilmesine ilişkin olarak söz konusu olayda iki nedenle ayrımcılık olduğunu ortaya koymuştur. Birinci olarak Eşit Muamele Direktifi'nin Topluluğun temel taşlarından biri olduğunu, herkesin bu kapsamda cinsiyet ayrımı gözetilmeksizin tüm haklardan ve özgürlüklerden yararlanabileceğini belirtmiştir. İkinci olarak ise davacının önceki 
cinsiyetine nazaran daha kötü muameleye tabi tutulmuş olmasının ayrımcılığın cinsiyete dayalı olduğunu gösterdiğini ifade etmiştir (Yavaşi, 2003:88-89).

Doğrudan ayrımcılığın ispatı görece daha kolay olmasına karşın dolaylı ayrımcılıkta ispat o kadar kolay değildir. Öncelikle görünüşte tarafsız bir norm veya uygulamanın bir grup üzerinde orantısız olarak aleyhe sonuç doğurduğunun ortaya konulması gerekmektedir. Bu etki ortaya konulduktan sonra ispat yükü yer değiştirecek ve böyle bir durumun söz konusu olmadığının veya mevcut olmakla birlikte nesnel ve makul bir nedeni olduğunun ortaya konulması gerekecektir. Dolayısıyla bir grubun etkilenme derecesinin verilerle ortaya konması gerekmektedir (Karan, 2017:225).

Divan genel olarak kararlarında bir grubun diğerine oranla istatistiksel oranda daha düşük olarak temsil edilip edilmediğini incelemektedir. Ancak son dönemde belli bir davranışın grubun tümü üzerindeki etkilerini saptamakta karşılaşılan istatistiksel güçlükler Divan'1 ve Komisyonu istatistiklere dayanmayan bir dolaylı ayrımcılık anlayışına itmiştir. 2000 yılında kabul edilen yönergelerde, uygulama veya ölçütün bir cinse mensuplardan oluşan grubun önemli ölçüde yüksek oranda etkilenmesi ölçütü ve dolayısıyla istatistik yöntemi bir kenara bırakılmıştır. Artık dolaylı ayrımcılığın tespit edilebilmesi için tarafsız olarak görünen bir hüküm, ölçüt veya uygulamanın diğer kişilere nazaran belirli bir dine veya inanca mensup, belirli bir sakatlığı bulunan, belirli bir yaş veya cinsel tercihe sahip olan kişiler açısından özel bir aleyhte durum yaratabilecek nitelikte olmasının yeterli olacağını kabul etmiştir ( Doğan Yenisey, 2002:15)

\section{Sonuç}

Kadınların iş yaşamına katılımı ile birlikte cinsiyet ayrımcılığına maruz kalma alanları buna paralel olarak genişlemiştir. Doğrudan cinsiyet ayrımcılığının yanı sıra tespiti daha zor olan dolaylı cinsiyet ayrımcılığı kadın istihdamını olumsuz yönde etkilemektedir. Ayrımcılık 
yasağı ise çalışanların tamamının fursatlara eşit ve adil bir şekilde ulaşabilmeleri için düzenlenmiştir.

Kadınların yaşadığı bu olumsuzluk ile mücadelede hukuk normları önemli bir yer tutmaktadır. AB her ne kadar başlangıçta sadece ekonomik kaygılar güderek konuya yaklaşmış olsa da gün geçtikçe sorunun sosyal politika alanına da değinmeye başlamıştır. Ayrıca AB Hukukunun yeknesak bir hale gelmesinde ABAD'ın kararlarının takibi sadece uyuşmazlığın yaşandığı ülkeyi değil, tüm üye devletleri etkilemektedir. Öyle ki AB ye üye olmayan ülkelerin bile hukuk normlarının düzenlenmesinde söz konusu kararların örnek alınması ve ulusal hukuk normlarının düzenlenmesinde bu kararlara dikkat edilmesi kadınların maruz kaldıkları ayrımcı uygulamaların en aza indirilmesi sağlanacaktır.

\section{Kaynaklar}

Akpınar, T. (2015). AB İşü̈cü Piyasasında Cinsiyet Ayrımcılığının Boyutları ve Ortadan Kaldırmaya Yönelik Çabalar. Ankara Üniversitesi Sosyal Bilimler Fakültesi Dergisi, 60-4.

Aydınöz, G. (2009). Avrupa Birliği Direktifleri ve ATAD kararları Çerçevesinde Ayrımcılık Yasağı ve Ayrımcılığın İspatı. Çalışma ve Toplum Dergisi, C.I, No:44.

Bakırcı, K. (2012). Uluslararası Hukuk, AB ve ABD Hukuku ile Karşılaştırmalı İş Hukukunda Cinsiyet Ayrımcılı̆̆ Yasă̆ İlkesinin Ístisnaları ve Objektif Haklı Nedenler. Ankara:Seçkin.

Doğan Yenisey, K. (2002). Kadın-Erkek Eşitliği Bakımından Türk İş Hukuku'nun Avrupa Birliği Hukuku ile Olası Uyum Sorunları. Kamu-İs Sendikası, C:6, S:4.

Gül, İ.I., Karan, U. (2011). Ayrımcllık Yasağı Kavram, Hukuk, İzleme ve Belgeleme, İstanbul Bilgi Üniversitesi Yayınları, İstanbul.

Karan, U. (2017). Uluslararası İnsan Hakları Hukuku ve Anayasa Hukuku Işı̆̆ı̆nda Eşitlik İlkesi ve Ayrımcılık Yasă̆ı. Onikilevha Yayınları, İstanbul.

Kaya, G. (2010). Avrupa Birliği İş Hukuku'nda Cinsiyet Ayrımcılı̆̆ı(Doktora Tezi), Dokuz Eylül Üniversitesi Sosyal Bilimler Enstitüsü, İzmir.

Konuk, B. (2013). Avrupa Birliği Hukukunda Cinsiyet Ayrımcılığına İlişskin Temel Kavramların Değerlendirilmesi. Yaşar Üniversitesi Elektronik Dergisi, C.8.

Korkmaz, F., Alp, N.S. (2016). 2006/54/AT Sayılı Direktif ve Avrupa Adalet Divanı Kararları Işığında İstihdam ve Meslek Konularında Kadın ve Erkek Arasında Eşit Davranılması ve Fırsat 
Eşitliğinin Sağlanması, İstanbul Üniversitesi Hukuk Fakültesi Mecmuası, LXXIV Özel Sayı, Cilt:74.

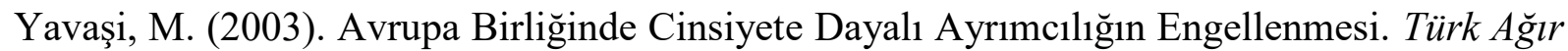
Sanayi ve Hizmet Sektörü Kamu İşverenleri Sendikası, Cilt: 18, Sayı:1.

Yücel, E. (2015). Avrupa İnsan Hakları Sözleşmesi ve Avrupa Birliği Direktiflerinde Ayrımcılık Yasağı Hukuku. Adam Akademi Sosyal Bilimler Dergisi, 6/1, 59-84.

Yücel, E. (2015). Avrupa Konseyi Belgelerinde, Avrupa Birliği ve Türk Hukukunda Ayrımcllı Yasă̆l ve Denetimi (Doktora Tezi). İstanbul Ticaret Üniversitesi Sosyal Bilimler Enstitüsü, İstanbul. 

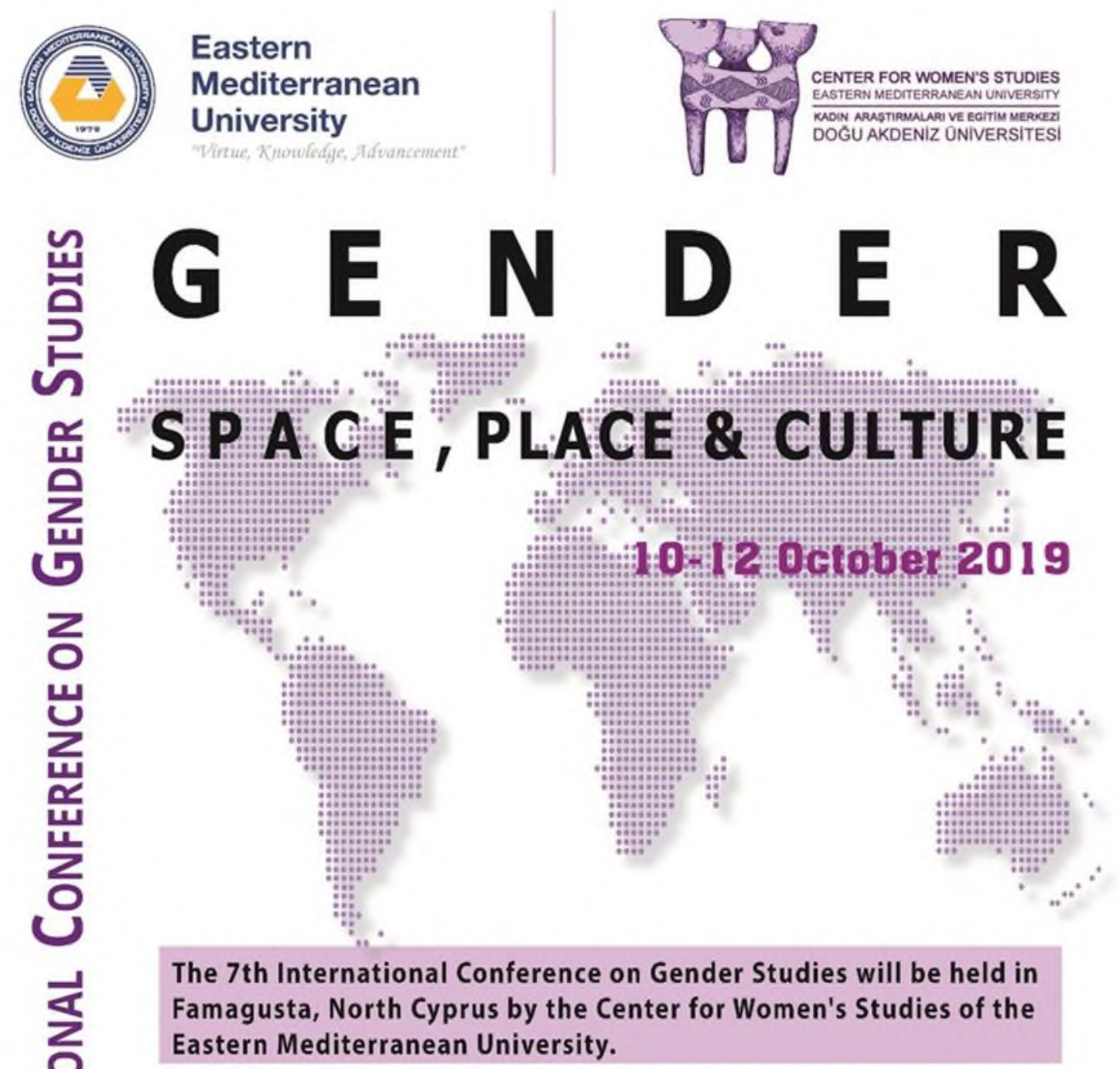

\section{The Deadline of Abstract Submission: 01 May 2019}

Please send your abstracts (not more than 250 words) through e-mail; gspc@emu.edu.tr

Conference Web Page:

5 N
Please do not hesitate to contact us if you require further information:

\section{IGU}

Commission on Gender and Geography

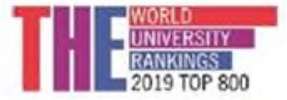

https: //gspc.emu.edu.tr/en

Center for Women's Studies

Eastern Mediterranean University

Famagusta - North Cyprus

(+90392) 6302269

cws-kaemgemu.edu.tr

http: $/$ /cws.emu.edu.ts/en

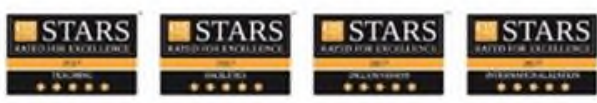




\section{CALL FOR PAPERS - BILDIRI ÇAĞRISI Eastern Mediterranean University - Center for Women's Studies 7th International Conference on Gender Studies Gender, Space, Place \& Culture}

The 7th International Conference on Gender Studies will be held in Famagusta, North Cyprus on 10-12 October 2019 by the Center for Women's Studies of the Eastern Mediterranean University. The goal of the conference is to provide a place for scholars, experts, professionals and activists with interdisciplinary backgrounds related to gender and space relations to exchange new ideas and latest researches. We seek to create a ground to examine relations between various disciplines such as urban planning, architecture, politics, gender and women's studies, anthropology, environmental studies, sociology, and history.

One of the earliest findings of feminist geographers is how gender relations varied and altered through space (Massey, 1994). Feminist academics and researchers who study on gender and space aim to examine and reveal the latent mutual constitution between gender discrimination and space segregation (Dias ve Blecha, 2008). Spatial relations are constitutive parts of social life; the spatial concepts and approaches developed by feminists would provide new insights and perspectives for various disciplines. So, looking at the mutual constitution between gender and space would also provide new ideas on the current changes in social sciences.

In North Cyprus and Turkey, although there is a limited number of studies entitled itself in the category of feminist geography, in recent years there is an increasing interest focusing and examining gender and space relations by various disciplines, such as gender and women's studies, political science, sociology, anthropology, history. Increasing numbers of articles and graduate degree dissertations, which based on peculiar field studies, display the specialty on gender space relations.

Researchers and activists at all stages of their careers are that are interested in presenting papers engage with discussions on current and emerging theoretical or methodological innovations on gender and space studies. We aim to promote intergenerational and intersectional dialogues among feminist scholars, researchers, and activists around the theme of practicing gender and space.

The conference will aim to explore, but not limited to, the following themes:

* Exploring Feminist Geographies: Theories, Methods, and Strategies

* Gender and the City: Feminist Analyses of Urban Space

* Gendered Spaces of the Public and Private: Negotiations and Boundaries

* Gender and Workplace: Spatial Analyses of Work

* Gender and Changing Meanings of Home

* Neoliberalism, Gender, Spaces of Power and Resistance

* Gender and New Geographies of Inequality: Gentrification, Urban Renewal, and Housing

* Gender, Development and Rural Geographies

* Geographies of Gender, Migration and Transnational Spaces

* Gendered Geographies of Displacement and Dislocation

* Gender, Place, and Memory

* Religion, Space and Place: Doing Feminist Geographies of Religion

* Emotional Geographies: Body, Sense, and Space

* Gender, Body, and Spaces of Disability

* Queer Spaces and Geographies of Sexualities 
* Spaces of Masculinities and Manhood

* Representations of Gendered Spaces in Literature and the Visual Arts

Submissions are subject to blind peer review at every stage. Papers without a gender perspective will be rejected. Abstracts and papers will be accessible to all participants on the conference website once the complete program is set. Due to the international nature of the conference, only abstracts written in English will be accepted for review.

Please send your abstracts (not more than 250 words) through e-mail; gspc@emu.edu.tr

\section{Conference Secretariat:}

Bilcan Bladanlı Korkmazel- cws-kaem@emu.edu.tr Eastern Mediterranean University - Center for Women's Studies

Jean-Jacques Rousseau str. Faculty of Business and Economics, Annex Building, BE159 Famagusta/North Cyprus (via Mersin 10 - Turkey)

Conference - mail: gspc@emu.edu.tr

Tel: +90 (392) 6302269

Fax: +90 (392) 3654038 


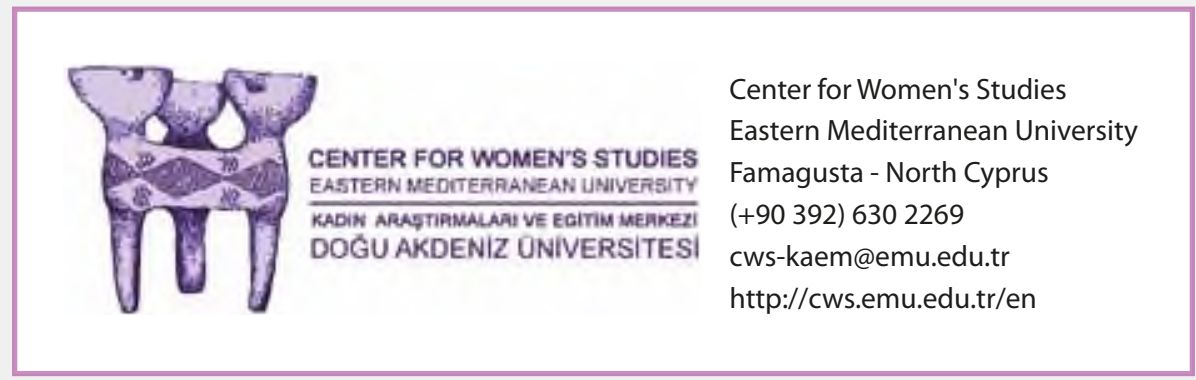

